
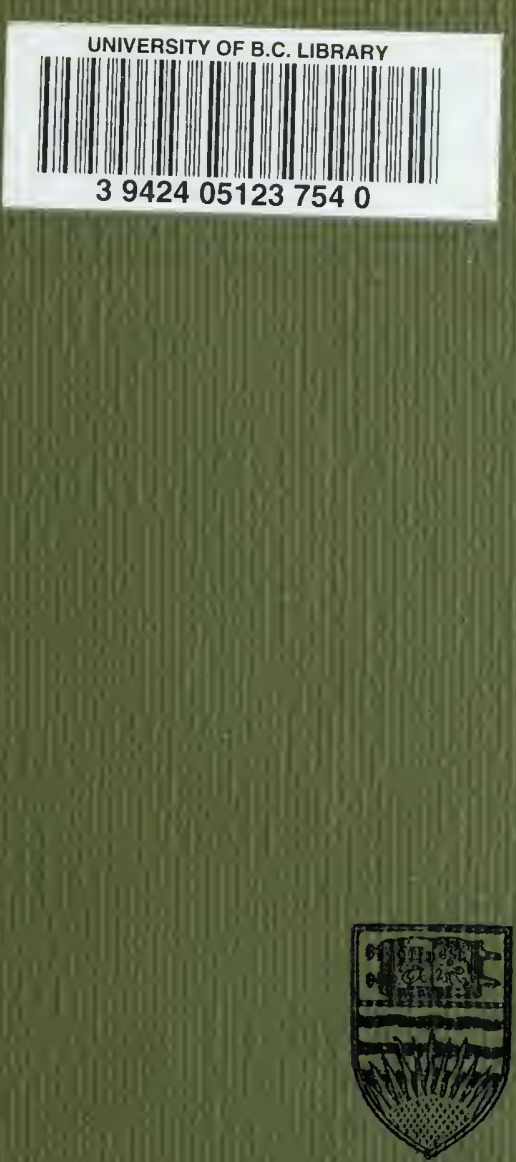

STONAGE ITHA

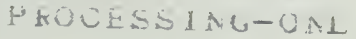

L. p $1-1 \cdot 1$ A

U.E.C. LIBRARY 
THE LIBRARY

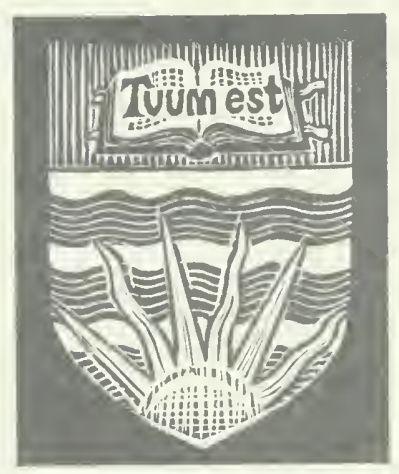

THE UNIVERSITY OF BRITISH COLUMBIA 
Digitized by the Internet Archive in 2010 with funding from University of British Columbia Library 



\section{CONGRÈS FORESTIER INTERIATIONAL}

Tenu à Paris du 16 au 20 Juin 1913

SOUS LA PRÉSIDENCE

de M. Henry DEFERT

Vice-Président du Touring-Club de France

Président de la Commission des Pelouses et Forêts 



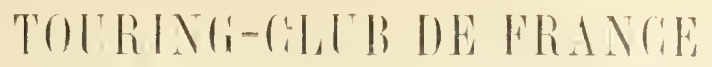

\section{ONGRES FORESTIER}

\section{INTERIITIOS.IL}

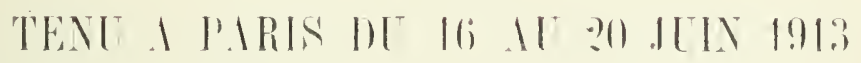

SOIE I.A PLESIIIXEE IIE

\section{IIENRY IDEEERT'}

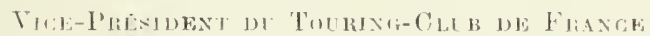

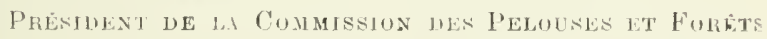

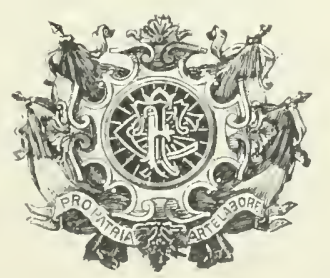

P.MIIS 



\section{COMITE D'HONNEUR}

\section{MII.}

\section{PRESIDENTS D'HONNEUR}

CLÉMENTEL, ministre de l'Agriculture.

KLOTZ, ministre de l'Intérieur et des Cultes.

LÉoN BÉRARD, sous-secrétaire d'État des Beaux-Arts.

MM.

\section{MEMBRES}

Émile LOUBET, président d'honneur de la Société Nationale d'Encouragement à l'Agriculture.

AUDEBRAND, président de l'Association Dauphinoise pour l'Aménagement des montagnes.

H. BARBIER, président de la Fédération des Syndicats du Commerce des bois et des industries qui s'y rattachent.

LÉoN BARBIER, vice-président de la Chambre Syndicale des Bois à ceuvrer.

BEAUQUIER, président de la Société pour la protection des Paysages de France.

BÉRARD, président de la Ligue du reboisement de l'Algérie.

M. BOUVET, président de la Société forestière de Franche-Comté et Belfort, membre de la Société Nationale d'Agriculture.

BRALLY, directeur de la Compagnie des Chargeurs réunis, membre du Comité de Tourisme colonial du Touring-Club.

CALVET, membre du Conseil de la Société Vationale d'Encouragement à l'Agriculture, président de la Société forestière française des Amis des Arbres, membre de la Commission des Pelouses et Forêts du Touring-Club.

GLAVEILLE, directeur des Chemins de fer de l'État.

Dr CRUVEILHIER, président du Groupe d'Etudes limousines.

DaL PIAZ, directeur de la Compagnie générale Transatlantique, membre du Comité de Tourisme colonial du Touring-Club.

P. DESCOMBES, président de l'Association centrale pour l'Aménagement des montagnes, membre de la Commission des Pelouses et Forêts du TouringClub.

Cı. GARIEL, inspecteur général des Ponts et Ghaussées, président de l'Académie de Médecine, membre du Conseil d'administration du Touring-Club. 
C. GIRERD, ancien sous-secrètaire d'État au Ministère de l'Agriculture et du Commerce, vice-président de la Société Nationale d'Encouragement à l'A griculture.

GOMOT, ancien ministre de l'Agriculture, président de la Société Nationale d'Encouragement à l'Agriculture.

F. GUILLAIN, ancien ministre des Colonies, membre du Conseil d'administration du Touring-Club.

Cr. GUYOT, ancien directeur de l'École nationale des Eaux et Forêts.

HÉBRARD DE VILLENEUVE, président de Section au Conseil d'État, président du Conseil d'administration de l'Office national du Tourisme.

LEDDET, conservateur des Eaux et Forêts en retraite.

Le GENDRE, président de la Société Botanique et d'Etudes scientifiques du Limousin.

LÉOPOLD MABILLEAU, directeur du Musée social.

P. MASSOT, président de la Société forestière provençale le "Chêne ".

MAURIS, directeur de la Compagnie des Chemins de fer de Paris à Lyon et à la Méditerranée, membre du Comité des Sites et Monuments pittoresques du Touring-Club.

MONGENOT, administrateur-vérificateur général des Eaxx et Forêts en retraite, membre de la Société Nationale d'Agriculture et de là Commission des Pelouses et Forêts du Touring-Club.

MOUGEOT, ancien ministre de l'Agriculture, membre du Conseil supérieur de l'Agriculture.

G. PINCHOT, ancien directeur général des Eaux et Forêts des Etats-Unis.

Émıe PLUCHET, ancien président de la Société Nationale d'Agriculture, président de la Société des Agriculteurs de France.

D. RECOPÉ, administrateur-vérificateur général honoraire des Eaux et Forêts, membre de la Commission des Pelouses et Forêts du Touring-Club.

DE ROQUEMAUREL, directenr de la Compagnie de Chemins de fer départementaux.

SARTIAUX, ingénieur en chef du service de l'Exploitation de la Compagnie du Chemin de fer du Nord, membre du Comité des Sites et Monuments pittoresques du Touring-Club.

SAUVAGE, président du Club-Alpin Français.

TATIN, président de la Société des Amis des Arbres et du reboisement des Alpes-Maritimes.

TISSERAND, membre de l'Académie des sciences, directeur honoraire de l'Agriculture, président de la Société Dendrologique de France.

VIGER, ancien ministre de l'Agriculture, membre du Conseil supérieur de l'Agriculture.

WEISS, directeur de la Compagnie des Chemins de fer de l'Est, membre du Comité des Sites et Monuments pittoresques du Touring-Clıb. 


\section{COMITE D'ORGANISATION}

\section{PRESIDENT D' HONNEUR}

M. L. DABAT, conseiller d'État, directeur général des Eaux et Forêts, membre de la Commission des Pelouses et Forêts du Touring-Club.

\section{PRESIDENT}

M. HENRY DEFERT, vice-président du Touring-Club, président de la Commission des Pelouses et Forêts.

\section{SECRETAIRE GENERAL}

M. GHAPLAIN, inspecteur des Eaux et Forêts, membre de la Commission des Pelouses et Forêts du Touring-Club.

\section{TRESORIER}

M. J. BERTHELOT, trésorier du Touring-Club.

\section{MM.}

\section{MEMBRES}

ALGAN, inspecteur des Eaux et Forêts en retraite, secrétaire général de la Société forestière de Franche-Comté et Belfort.

ANTONI, sous-directeur des Eaux et Forêts.

L. AUSCHER, membre du Conseil d'administration du Touring-Club, président du Comité de Tourisme en montagne.

BÉNARDEAU, inspecteur général des Eaux et Forêts.

BRIOT, conservateur des Eaux et Forêts en retraite, correspondant de la Société Nationale d'Agriculture.

F. CAQUET, propriétaire forestier, membre dı Conseil supérieur de l'Agriculture et du Conseil de la Société nationale d'Encouragement à l'Agriculture.

E. CARDOT, conservateur des Eaux et Forêts. chef du service des Améliorations pastorales, secrétaire général de la Société forestière française des Amis des Arbres, membre de la Commission des Pelouses et Forêts du Touring-Club.

CARRIER, inspecteur général des Améliorations agricoles. 
ED. CHAIX, prèsident de la Commission de Tourisme de l'Automobile-Club, membre du Conseil d'administration du Touring-Club, vice-président du Comité des Sites et Monument; pittoresques.

L. CHANCEREL, inspecteur des Eaux et Forêts.

A. CHANGEUR, secrétaire général de la Société pour la protection des Paysages de France.

ANDRÉ CHARGUERAUD, conseiller d'État, directeur des Routes, de la Navigation et des Mines au ministère des Travaux publics, membre du Comité des Sites et Monuments pittoresques du Touring-Club.

R. CLAUDE, président de la Section Lorraine des Amis des Arbres.

A. COLLIN, président de la Chambre syndicale du sciage et du travail mécanique des bois.

G. FAMECHON, inspecteur général de la Météorologie agricole, membre du Conseil d'administration du Touring-Club et de la Commission d'aménagement des Bois et Forêts des environs de Paris.

Gн. FLAHAULT, directeur de l'Institut de botanique de l'Université de Montpellier.

GARRIGOU-LAGRANGE, secrétaire général du Congrès permanent de l'Arbre et de l'Eau, secrétaire général du Comité des Sites et IIonuments pittoresques de la Haute-Vienne.

HICKEL, inspecteur des Eaux et Forêts, membre de la Société Nationale d'Agriculture, secrétaire général de la Société Dendrologique.

J. HOLLANDE, président de la Chambre syndicale des bois des Iles et d'ébénisterie, membre du Comité de Tourisme en montagne du Touring-Club.

HÜFFEL, sous-directeur et professeur d'Economie forestière à l'École Nationale des Eaux et Forêts, correspondant de la Société Nationale d'Agriculture.

JOLY DE SAILLY, inspecteur des Eaux et Forêts en retraite, membre de la Commission des Pelouses et Forêts du Touring-Club, délégué de l'Association centrale pour l'Aménagement des Montagnes.

A. KEIM, docteur ès lettres.

KUSS, conservateur des Eaux et Forêts, directeur des Forêts de l'Algérie.

LAFOSSE, inspecteur général des Eaux et Forêts.

DE LAGORSSE, secrétaire général de la Société Nationale d'encouragement à l'Agriculture, membre du Conseil supérieur de l'Agriculture.

LAPORTE, conservateur des Eaux et Forêts.

Vicomte DE LARNAGE, président du Syndicat forestier de Sologne.

L. LAVEUR, directeur de la Revue des Eaux et Forêts.

LECOQ, président de la Section d'Ausergne et du Plateau central des Amis des Arbres.

LINYER, président de la Loire navigable.

LORIEUX, ingénieur en chef des Ponts et Chaussées, directeur de l'Office National du Tourisme, membre du Comité de Tourisme en montagne du Touring-Club.

MAIRE, inspecteur des Eaux et Forêts en retraite.

MARINGER, conseiller d'État, directeur de l'administration départementale et communale au ministère de l'Intérieur, membre du Comité de Tourisme en montagne du Touring-Club.

A. MATHEY, conservateur des Eaux et Forêts, correspondant de la Société Nationale d'Agriculture. 
A. MATHIEU, syndic-président de la Communauté des marchands de bois at œuvrer, charpente, sciage et charronnage réunis.

R. MATHIS DE GRANDSEILLE, vice-président de la Section de Sylviculture de la Société des Agriculteurs de France.

Germain MAYER, directeur des Manufactures de l'État.

Comte J. DE NICOLAY, président du Syndicat des Propriétaires forestiers. de la Sarthe.

DE NUSSAC, secrétaire général du Groupe d'Études limousines.

PARDÉ, inspecteur des Eaux et Forêts.

PELLISSIER, inspecteur général des Améliorations agricoles.

Placine Peltereau, président du Syndicat général des cuirs et peaux de France.

P. PINGAULT, syndic-président de la Chambre syndicale des bois à brûler.

P. POUPINEL, président de la Chambre syndicale des bois de sciage et d'industrie.

Marquis de PRACOMTAL, propriétaire forestier.

Onésime RECLUS, membre du Comité des Sites et Monuments pittoresque du Touring-Club.

R. ROULLEAU, conservateur des Eaux et Forêts en retraite, secrêtaire général du Comité des Forêts.

Henry SAGNIER, membre de la Société Nationale d'Agriculture, rédacteur en chef du Journal d'Agriculture pratique.

THIBAULT, sous-directeur de l'Hydraulique agricole.

L. VIELLARD, correspondant de la Société Nationale d'Agriculture, viceprésident de Société Forestière de Franche-Comté et Belfort.

VILLAME, secrétaire de la Fédération des Syndicats du Commerce des bois et des industries qui s'y rattachent.

M. DE VILMORIN, membre de la Société Nationale d'Agriculture et de la Commission des Pelouses et Forêts du Touring-Club.

VIVIER, conservateur des Eaux et Forêts, Directeur de l'Ecole Nationale. des Eaux et Forèts.

WATIER, conservateur des Eaux et Forêts.

\section{SECRÉTAIRE ADMINISTRATIF}

M. A. UMBDENSTOCK, secrétaire de la Commission des Pelouses et Forêts du Touring-Club. 


\section{COMITE EXECUTIF}

PRÉSI DENT

M. Henty DEFERT ;

\section{VICE-PR ÉSI DENT}

M. ANTONI ;

\section{SECRÉTAIRE GÉNÉRAL}

M. CHAPLAIN;

\section{TRÉSORIER}

M. BERTHELOT ;

MEMBRES

MM. AUSCHER,

CARDOT,

CHAIX,

FAMECHON ;

SECRÉTAIRE

M. A. UMBDENSTOCK. 
INTERNATIONAL 1913

\section{DÉLEGUÉS DES PUISSANCES}

MM.

\section{RÉPUBLIQUE ARGENTINE}

Miguel F. CASARES, sous-secrétaire d'État au Ministère de l'Agriculture. Jul1o LLANOS, directeur général de l'Agriculture et de l'Élevage.

\section{Autriche :}

\section{AUTRICHE-HONGRIE}

M. Le Baron de HENNET, délégué permanent du Ministère I. R. autrichien de l'Agriculture.

Hongrie :

MM.

EUGÉn VADAS, conseiller ministériel, directeur des stations de recherches forestières.

Jules ROTH, inspecteur des Forêts, adjoint à la Station centrale des expériences forestières.

GERARD DE POTTERE, inspecteur au Service des Forêts domaniales et royales hongroises.

MM.

\section{BELGIQUE}

De SÉBILLE, membre du Conseil supérieur des Forêts du Royaume.

DIERCKX, membre du Conseil supérieur des Forêts du Royaume.

BLONDEAU, sous-inspecteur des Eaux et Forêts.

DUBOIS, sous-inspecteur des Eaux et Forêts.

MM.

\section{BRESIL}

Lucien Le COINTE, ingénieur agricole, directeur du Poste Zootechnique Fédéral, à Ribeirao Preto.

État de Parana :

MM.

FERREIRA GARDOSO.

Dr José Maria PINHINo LIMA.

J. EUGenio MARQUES, colonel.

\section{CHIU}

M. RAMON ELZO BAQUEDANO, ingénieur agronomo. 


\section{COLOMBIE}

M. Don José PABLO URIBE, conseiller commercial de la Légation Colombienne, à Paris.

\section{DANEMARK}

M. KRARUP, inspecteur des Forêts, chef de Bureau de la Direction des forêts d'Êtat.

\section{ESPAGNE}

M. Miguel Del CAMPO, professeur de sylviculture à l'Ecole forestière espagnole.

III.

\section{ÉQUATEUR}

E. DORN y DE ALZƯA, chargé d'affaires, à Paris.

PEDro VALDEZ, consul général, à Paris.

\section{ETATS-UNIS D'AMÉRIQUE}

M. WOLSEY, conservateur-adjoint des Forêts.

\section{GRANDE-BRETAGNE ET COLONIES}

Irlande et Union Sud-Africaine:

MM.

Arthur C. FORBES, inspecteur en chef des Forêts.

Augustin HENRY, professeur de sylviculture au Collège royal des sciences.

Écosse :

M. J. D. SUTHERLAND, administrateur attaché à la Direction de l'Agriculture.

Gouvernement du Commonwealth Australien:

M. P. GROOM, professeur au Collège impérial de Science et Technologie de Londres.

Gouvernement de Victoria. - Vouvelle-Galles du Sud. - Queensland. Tasmanie :

Honorable Peter Mic BRIDE, agent général du Gouvernement de Victoria, à Londres.

Gouvernement de l'A ustralie du Sud:

M. BEAUMONT-ARNOLD MOULDEN.

Gouvernement de l'Australie Occidentale :

Honorable Sir Newton MOORE, agent général de ce Gouvernement d Londres.

Gouvernement des Indes:

MM.

R. S. TROUP, Indian Forest Service.

A. CACCIA.

\section{GRÈCE}

M. ROMANOS, ministre plénipotentiaire à Paris. 


\section{HAITI}

M. le Dr NEMOURS AUGUSTE, ministre plénipotentiaire à Paris.

\section{HONDURAS}

M. DÉsıré PECTOR, consul général, à Paris.

\section{JAPON}

M. S. MIMURA, ingénieur forestier.

\section{LUXEMBOURG}

M. BADU, directeur des Ealix et Forèts du (irand-Juché de Luxembourg.

\section{MONACO}

Conte Justinien CLARY, président du Saint-Hubert-club de France.

\section{NORVĖGE}

M. SAXLUND, directeur général des Eaux et Forêts.

\section{PAYS-BAS}

M. Van DISSEL, inspecteur des Forêts de l'État.

\section{PORTUGAL}

MII.

Antonio MENDES D'ALMEIDA, ingénieur sylviculteur, chef de l'Intendance forestière.

JoAQuim FERREIRA BORGES, chef du Bureau des Forêts all Ministère des Travaux publics.

\section{ROUMANIE}

M. TANASSESCO, inspecteur général des Forêts, chef du Service dé Aménagements des Forêts au Ministère de l'Agriculture.

\section{RUSSIE}

M. KERN, conseiller d'État, vice-inspecteur dı Corps forestier. Membre du Conseil de l'Administration générale de l'Agriculture.

\section{SALVADOR}

M. GUERRERO, ministre plénipotentiaire à Paris.

MII.

\section{SUÈDE}

WAHLGREN, inspecteur des Forêts, chef intérimaire de l'Académie forestière du Royaume, à Stockholm.

De SCHULZENHEIM, chef de Section à l'Administration des Eaux et Forêts, secrétaire général par intérim.

URUGUAX

M. P. L. LOMBA, consul général, à Paris. 


\section{DELEGUES DES MINISTERES}

Ministère de l'Agriculture. - M. JEANNIN, chel-adjoint du Cabinet de M. le Ministre de l'Agriculture.

Ministère des Finances. - M. FÉRET du LONGBOIS, directeur du Contrôle des Administrations financières et de l'Ordonnancement.

M. TACHÉ, administrateur à la Direction générale de l'Enregistrement, des Domaines et du Timbre.

Ministère des Travaux publics. - M. LORIEUX, ingénieur en che des Ponts et Chaussées, directeur de l'Office National du Tourisme.

Ministère de l'Instruction publique : M. GAL, inspecteur général de l'Instruction publique.

Ministère des Colonies : M. CAPUS, délégué du Gouvernement général de l'Indo-Chine à l'Office Colonial.

Sous-Secrétariat d'Etat des Beaux-Arts. - M. BERR DE TURIQUE, inspecteur général des Monuments historiques. 


\section{MEMBRES}

MM.

ALAI, iaspecteur des Eaux et Forets, Sens.

ALloTTE (Alfred), inspecteur des Eaux et Forèts, Bayeux.

AlTMANN (Mme), 36, avenue du Ghemin-de-Fer, Rupil (Seine-et-Oise).

AliesR (Carlos de), \&2, Cours-la-Reine, Paris.

ANCELET (Gabriel-Paul), docteur en médecine, 104, rue de Rennes, Paris.

ANGIBOUT (Eugene), directeur de la sociétés du Charbon de Paris, 56, rue de Londres, Paris.

ANISSON DU PERRON (JACQUES-HENRI-JosEPH), propriétaire, château de Saint-Fargeau (Yonne).

ANTONESCO (PIErRE), directeur de l'École superieure de Sylviculture de Branesti (Roumanie).

ARAMON (Coute Gimlaume b'), agiculteur, 3't, rue de Chaillot, Paris.

ARANIO COSTA (Dr Antut r L. DE), membre de la Socicté nationale d'agriculture de Rio de Saneiro, 790, Aveaida Atlantica, Rio-de-Janeiro (Brésil).

APBOLIX (Madrice) attache de baoque, 15, rie de Naples, Paris.

AR\OLLD, inspecteur des Eanx et Forèts, 7, rue d'.lssas, Paris.

ArTUS (Gustave), syndic de la Chambre syndicale des Bois de sciage ct d'industrie, 26, rue Saint-Borart. Paris.

ASSOCIATION AMICALE DES INGENIEUKS DU SERVICE DES AMÉLIORATIONS ACRICOLES, 210, rue du Fäbourg-Sant-Martin, Paris, peprésentée par son président : 11. ROLLEY, ingẻnieur des Aneliorations agricoles.

ASSOCIATION - "JEDNOTA CESKYCH LESNIKU ZEMI KORUNY CiÉSkÉ ", représentée par : M. HOLUB (Axtonn), ingénieur forestiel, géomètre civil, à Plzèn (Pilsen), Bohême, président; M. SIMLI (KÁREL), professeur de l'École forestière à Jemnice (Moravie).

ASSOCIATION DU CULTE DE L'ARBRE, de Lisbonne, représentée par M. MENDEs W'ALMEIDA (Axtoxo), ingenieur sylviculter r, chef de l'Jitenda ice Forestière.

ASSOCIATION RURALE DE L'URUGUAY, représentee par II. RAMON

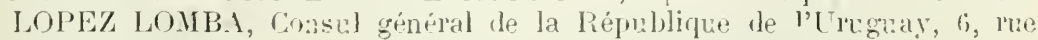
Villebois-Mareuil.

AST (Georges), entrepreneur de travaux publies, 13, rue Carpeaux, Paris. 
ASTIER DE la VIGERIE (Barox Raoul D'), 11, rue de Courcelles, Paris. AUBER DE PEYRELONGUE $\left(\mathrm{D}^{\prime}\right)$, inspecteur adjoint des Eaux et Forêts, 80 , rue de Varennes, Paris.

AUBERT (Charles), inspecteur adjoint des Eaux et Forêts, Alençon.

AUSCHER (Mme), Neuilly-sur-Seine (membre associé).

AUTIER (Alfred), Sainte-Menehould (Marne).

BACH (PALL), sylviculteur paysagiste, la Chapelle-en-Serval (Oise).

BACON DE LA TERGNE. Voir Société d'Agriculture du départemnent de la Gironde.

BAILLE, chef d'escadron au $7^{\mathrm{e}}$ chasseurs, Rouen.

BAILLY (Alphoxse-Louis), membre de la Chambre syndicale des Agents et commissiomnaires en bois d'industrie, 2, rue Charles-Nodier, Paris.

BAILLY ( $\left.\mathrm{U}^{\mathrm{e}}\right)$ (membre associé).

BAlieR (Hugue), Dean New-York State College Of Forestry at Syracuse University, Syracuse, New-York (U. S. A.).

BAKER (J. FrED), chargé de cours de sylviculture, au collège de Michigan U. S. A.

BANCHEREAU (JuLEs), sylviculteur, 6, quai Barentin, Orléans.

BARBEY (Auguste), expert forestier, Montcherand-sur-Orbe (Vaud), Suisse.

BARBEY (IIme) (membre associé).

BARBIER (Étieñe), 22, rue Carnot, Avallon (membre associé).

BARBIER (RENÉ), membre de la Communauté des Marchands de bois à cusver, 1'́, rue Cimarosa, Paris.

Barbudt (Comte Pierre de), à Pomnard (Còte-d'Or).

BARBIER dE LA SERRE (Louis-Gaston-ErNest), inspecteur adjoint des Eaux et Forêts, Amiens (Somme).

BAREEL (Luciex), avocat, bourgmestre de CaImpthout (province d'Anvers), 14, rue de la Vallée, Bruxelles.

BARP̣ET. Voir Comice agricole et viticole d'Auxerre.

BARRIO_ (GEORGES), ingénieur agronome, Tunis.

BARTHÉLEMY (Hexri), garde général des Eaux et Forêts, Saint-Laurentdu-Pont (Isère).

BAUBIET (HENRI), propriétaire sylviculteur, la Romagère jar saint-Gaultier (Indre).

BAUGHERY, sylviculteur, Crouy (Loir-et-Cher).

BAUGHET (Lours-NoEL), négociant en bois d'industrie, 41, rue Crozatier, Paris. BAUDOUX (Avgustix), industriel, 10, rue Saint-Pierre, Noyon (Oise).

BAZELAIRE de LEsSEUX (Gharles de), inspecteur des Eaux et Forêts, Bar-sur-Auje.

BEAU (Eugène), avoué honoraire, 9, rue des Saints-Pères, Paris.

BEAUCORPS (HENRI DE), propriétaire, Gy (Loir-et-Cher).

BECQUEY (Xatier-Laurent-Michel), garde général des Eaux et Forêts, Souk-Ahras (département de Constantine).

BÉLIAA (BArox MAURICE DE), propriétaire, château de Marèges par Liginiac: (Corrèze).

BELLET (HENRI), ingénieur civil, 35, quai Saint-Vincent, Lyon.

BeLLiard (Robert-Henri-Fernand), inspecteur des Eaux et Forêts, 49, rue Jeanne-d'Arc, Rouen. 
BELLIN (Lours), rentier, 28, boulevard Péreire, Paris.

BELOUIN, capitaine au 2 étranger, Oued-Ben-Kiffa, par Fez (Maroc).

BÉNARD (Jules), Régent de la Banque de France, 81, rue de Maubeuge, Paris.

BENEX (ALBERT), négociant en bois, 27, quai d'Ivry, Ivry.

BERAL (PAul-Joseph-MaUrice), inspecteur des Eaux et Forêts, Bagnèresde-Luchon (Haute-Garonne).

BERGER (PIERRE), procureur de la République, ancien député, Beauvais.

BERNARD (CLaudius), inspecteur des Eaux et Forêts, professeur de mathématiques appliquées à l'École nationale des Eaux et Forêts, Nancy.

BERNARD (Gharles), négociant en bois, Gray (Haute-Saône).

BERNHEIM (ÉmLe), propriétaire, 23, rue de l'Arcade, Paris.

BERNIER (LÉon), marchand de bois, secrétaire de la Chambre syndicale des Bois à brûler, 1, rue Lejemptel, Vincennes.

BERTHELIER, directeur des Services agricoles du département de la HauteSavoie, membre du Comité d'administration de la Société d'Agriculture, Annecy.

BERTHON (ÉTIENNE), inspecteur adjoint des Eaux et Forêts, Albertville.

BERTIN (ANDRÉ-JoSEPH), inspecteur adjoint des Eaux et Forêts, Royan. BERTIN (MIme) (membre associé).

BERTRAND (PAUL), conservateur des Eaux et Forèts, Rouen.

BÉTHERY DE LA BROSśs, conservateur des Eaux et Forèts, Tour's.

BEYRAND (AlfERD), docteur, 59, Grande-Rue, Enghien-les-Bains (Seine-etOise).

BÉZIER (Émile), inspecteur des Eaux et Forèts, Poitiers.

BILLEY, avoué, 25, rue de la République, Besançon.

BIZOT de FONTENY (Pierre), conservateur des Eaux et Forêts, Nìmes.

BLANC (Gaston-LÉon), 20, boulevard Magenta, Paris.

BLANCHET (MARIUS), commerce de bois et exploitations forestières, juge au Tribunal de commerce, 6, place Victor-Hugo, Grenoble.

BLEIN (Antonin-Joseph), Inspecteur-adjoint des Eaux et Forêts, Constantine).

BLET fils (EDMES), marchand de bois, ancien vice-président de la Chambre syndicale des Bois à œuvrer, 38, rue de Seine, Ivry-Port (Seine).

BLONDEL (EDouard), notaire honoraire, 32, rue Chabot-Charny, Dijon.

BLONDEL. Voir Comité du Commerce et de l'Industrie de l'Indo-Chine.

BLOT (JACQUES), propriétaire agriculteur, 9, rue Émile-Zola, Tours.

BOCQUET (Édound), syndic de la Chambre syndicale du Sciage et du Travail mécanique des bois, 215, rue Championnet, Paris.

BOCQLET (Mme Édouard) (membre associé).

BOITEUX (Augustin), 19, rue des Roses, Dijon.

BOIXO (PIERRE DE), inspecteur-adjoint des Eaux et Forêts, Toulouse.

BOMIIER (Charles), professeur à l'Université, membre du Conseil supérieur des Forèts, conservateur au Jardin Botanique de l'État, Bruxelles.

BOMIIER (Mme) (membre associé).

BONNEFOY (LUcien), professeur au lycée Bernard-Palissy, 51, boulevard Scaliger, Agen.

BONNEVAL (Conte Armand de), propriétaire, 30, rue Las-Cases, Paris. 
BONNICHON (Lous). Voir Chambre syndicale des Fabricants de parquet chêne.

BOPPE (JuLEs), inspecteur des Eaux et Forêts, Toul.

BORDET (Louis), industriel, à Froidrent, par Voulaines (Côte-d'Or).

BORY (PAUL), ingénieur, la Tuilière, Saint-Chamond.

BOUCHER DE LA BRUERE, surintendant de l'Instruction publique, palais législatif, Québec.

BOUCHERON (ALBERT), marchand de bois, vice-président de la Chambre syndicale des Bois de Sciage et d'Industrie, 11, quai d'Ivry, Ivry-sur-Seine.

BOUIN (Dr PALL), professeur à la Faculté de Médecine, 19, rue Israël-Sylvestre, Nancy.

BOUISSET (FERDiNAND), président honoraire du Syndicat d'Initiative de I'Aude, 39, boulevard de Strasbourg, Toulouse.

BOULANGER, inspecteur des Eaux et Forêts, Montbéliard.

BOULLENOIS (Marie-Robert DE), propriétaire, Senuc (Arilennzs:.

BOULOG_VE (EugèNE), négociant en bois, 13, rue de l'Église, au Vésinet (Seine-et-Oise).

BOURCY (Henri-Joseph), négociant en Bois, 5, rue Marbeau, Paris.

BOURCY (Mme) (membre associé).

BoURGolNG (Vicomte de), 24, quai de Béthune, Paris.

BOURGOUGNON (J.), ingénieur en chef des Ponts et Chaussées, 120, cours Lieutaud, Marseille.

BOUSQUET (ANDRÉ-Henri), directeur de la Société forestière d'Isolaccio et Serra, Pietrapola-les-Bains (Corse).

BOUVET (GEorges), docteur en droit, 20, rue d. Beauvau, Versailles.

BRETON (Louis), inspecteur des Eaux et Forêts, 3, rue Félix-Poulat, Grenoble.

BRETON BONIARD (Luciex), publiciste, villa Bonre-Espérance, Renancourt-lès-Amiers (Somme).

BRION (EMAXVEL), maire, secrétaire de la Chambre syndicale des Marchands de bois de la Seine-Inféricure et de l'Eure, Saint-Saë:is (Seine-Inférienre).

BRIOT (Augustin), proiesseur, 60 bis, avenue de Breteuil, Paris.

BROUSSAIS (IvAx), avocat à la Cour, 3, place de Rivoli, Paris.

BROLASAIs (Mme) (membre associé).

BROLSSE (EnyaxUEL). Voir Club touriste du Canigou.

BRUAND (LÉox-Louis-Josepll-Victor), conservateur des Eaux et Forêts en retraite, 11 bis, rue de la Planche, Paris.

BUFFAULT (Pierre), inspecteur des Eaux et Forêts, Périgueux.

BUISSOX (Fraxçois-Émite-Victor), conservateur des Eaux et Forêts, Pau.

BUNODIERE D'ESMALLEVILLE (MARQUIS DE LA), inspecteur des Eaux et Forets en retraite, Lyous-la-Forèt (Eure).

BURIN DEs ROZIERS, inspecteur adjoint des Eaux et Forêts, Moulins.

BUXAPEO ORIBE (FÉLIX), secrétaire honoraire de la Légation de l'Uruguay, 17, rue d'Astorg, Paris.

CABLA. inspecteur-arjoint des Eaux et Forêts, Bourmont (Haute-Marne). CACCIA (Mne), Oxford (Angleterre) (membre associé).

CAMUS (P^uL), propriétaire, 13, boulevard Péreire, Paris.

CAMUS (PAUL), inspecteur adjoint des Eaux et Forêts, Montargis. 
CANNON (DAvid), propriétaire aux Vaux, membre de la Société nationale $d^{\prime}$ Agriculture, la Ferté-Imbault (Loir-et-Cher).

CARBONNIER (HENRICK). Voir Société forestière suédoise.

CARDE (PAUL), ingénieur, 33, quai de Queyries, Bordeaux.

CAREZ (LÉon), 18, rue Hamelin, Paris.

CARRAZ (BEnjamin), château Miqui, près Saint-Claude.

CARRÉ (Étienne), négociant en bois, 128, rue de Paris, Clamart.

CAUBERT (Jules), propriétaire, 49, avenue Victor-Hugo, Paris.

CERISE (Baron Guillaume), président du Comité des Intérêts généraux de l'Assurance Incendie; directeur de la Compagnie d'assurances L'UnionIncendie, 9, place Vendôme, Paris.

CERQUEIPA MACHADO (JEAN MARIA), ingénieur forestier, Ponte da Barca (Portugal).

CHABRAND (ARMAND), ancien bâtonnier de l'Ordre des Avocats, président du Syndicat d'Initiative de Grenoble et du Dauphiné, 5, rue de la Liberté, Grenoble.

CHAMBEAU (Henri), inspecteur des Eaux et Forêts, Oloron.

GHAMBON (Gustave-Étinnne-Désiné), avoué honoraire, 2, rue Villaretde-Joyeuse, Paris.

CHAMBRE DE COMMERCE DE CARCASSONNE, représentée par M. NICO. LEAU (PAulin), Carcassonne.

CHAMBRE DE COMMERCE DE CHAMBÉRY.

CHAMBRE DE COMMERCE DE LYON, représentée par son président M. COIGNET.

CHAMBRE DE COMMERCE DE MELUN.

CHAMBRE DE COMMERCE DE NEVERS, représentée par M. VAG IE.

CHAMBRE DE COMMERGE D'ORLÉANS, représentée par M. LETURQUE.

CHAMBRE DE COMMERGE DE PARIS.

CHAMBRE DE COMMERCE DE ROUEN.

GHAMBRE SYNDICALE DES FABRICANTS DE PARQUET CHENE, 163, rue Saint-Honoré, Paris, représentée par M. BONNICHON (Lous), son vice-président.

CHAMBRE SYNDICALE DU COMMERGE DES BOIS DE LYON ET DE LA RÉGION, 72, rue Pierre-Corneille, Lyon.

CHANTREAU (Francis), secrétaire de la Chambre syndicale des Bois de sciage et d'industrie, négociant en bois, 24, rue Beccaria, Paris.

CHARPENAY (Georges), banquier, 26, rue du Lycée, Grenoble.

CHATELAIN (Louss), inspecteur des Eaux et Forêts, Laon.

CHATELET (JuLES), vice-président de la Communauté des Bois à aeuser, 72, quai de la Rapée, Paris.

CHATELET (André), 72, quai de Ia Rapée, Paris (membre associé).

CHAUDEY, inspecteur des Eaux et Forêts, Lons-le-Saunier.

CHAUMONNOT (HENRi), inspecteur-adjoint des Eaux et Forêts, Senlis.

CHEVALIER (PoL). Voir Syndicat d'initiative de Tourisme de Bar-le-Duc.

CHEVALLIER (Paymond). Voir Société d'Agriculture de Compiègne.

GLAUDE (Joseph-Fraņ̧̃os-René), ingénieur des Arts et Manufactures, 49, avenue de la Garenne, Nancy.

CLAUDOT, inspecteur des Eaux et Forêts, Mirecourt. 
CLERIONT (RAOu L DE), a vocat à la Cour d'appel, 10, r'ue de I'Université, Paris. Gloarec (Paul-Jean-Armand-Marie), membre du Comité de Tourisme Nautique du T. C. F., 28, rue de Ponthieu, Paris.

CLUB TOURiste DU CiNigou, rue de la Poste, Perpignan, représenté par M. BROUSSE (Eимaxuel), député.

COCHON (Jules-Françors), conservateur des Eaux et Forêts en retraite, 5, avenue du Comté-Vert, Chambéry.

CODORNIU (Rrcardo), inspecteur général de Montes, Madrid.

COGNAT (Françols), carbonisateur de bois, Saint-Rambert-d'Albon (Dròme). COGNAT (ALEXIS), (membre associé).

COIGNET. Voir Chambre de Commerce de Lyon.

COINCY (Henri DE), inspecteur adjoint des Ealix et Forêts, 7, rue d'Astorg, Toulouse.

COLIN (Ernest), agent de change, 6, rue Danton, Paris.

COLIN (Henry), Bulgnéville (Vosges).

COLMET D'AAGE. Voir Société des Agriculteurs de France.

COMBELÉRAN (GAston), secrétaire général du Syndica! d'Initiative de Carcassonne et de l'Aude, 15, rue de la Gare, Carcassonne.

COMIGE AGRIGOLE ET VITICOLE D'AUXERRE, représenté par son président, MI. BARREY, avocat.

COMICE AGRIGOLE DE PHILIPPEVILLE.

CONITÉ CENTRAL AGRIGOLE DE LA SOLOGNE, Lamotte-Beuvron (Loir-et-Cher), représenté par M. DENIZET, secrétaire-général.

COMITÉ DÉPARTEMENTAL DES SITES ET MONUMENTS PITTORESQUES DU PUY-DE-DOME, (T. C. F.), Clermont-Ferrand.

COMITÉ DU COMMERGE ET DE L'INDUSTRIE DE L'INDO-CHINE, 7, rue des Italiens, Paris, représenté par M. BLONDEL.

COMITÉ D'INITIATIVE DE DUNIERQUE ET MALO-LES-BAINS, 42 bis, rue de l'Église, Dunkerque.

COMMISSION DÉPARTEMENTALE DES SITES ET MONUMENTS NATURELS DE GARACTĖRE ARTISTIQUE des Basses-Pyrénées représentée par M. HOERTER, conseiller de Préfecture, Pau.

Comte (Ernest), industriel, Bar-sur-Aube.

CONTE (Jules-FÉlix), inspecteur des Eaux et Forêts, Rennes.

CONSTANT (Docteur), villa Marie-Louise, Viltel (Vosges).

CORMIER, directeur de la Société française de Tranchage des Bois, 16, pas. sage Charles-Dallery, Paris.

CORNEFERT, inspecteur des Eanx et Forêts, Saint-Dié.

CORNet (Charles-Françors), bois en gros, Sellières (Jura).

Costa ( $\mathrm{D}^{\mathrm{r}}$ Arthur), membre de la Société Nationale d'Agriculture de Rio de Janeiro, 50, rue des Mathurins, Paris.

COSTAZ, ingénieur agricole, membre du Comité d'Administration du Syndicat agricole de la Haute-Savoie, place aux Bois, Annecy.

COSTE (Gustave), président du Syndicat Forestier du Midi, 7, rue des FrèresMineurs, Nìmes.

COULET (PAUL), avocat à la Cour d'appel, 5, rue Greffulhe, Paris.

COUlon (Jean-Pierre-Maurice), garde général des Eaux et Forêts, Versailles. 
CREUZÉ de LESSER (EdouARD), propriétaire, 12, rue Volney, Paris.

CLIF (ÉMLE), inspecteur des Eaux et Forèts, attaché à la station de recherches et expériences de l'École nationale des Eaux et Forêts, 4\%, rre sigis. bert-Adam, Nancy.

CUSS IC (JosepH DE), conservateur des Eaux et Forêts, Amiens.

DAMONGEOT (ALFRED), géomètre forestier, 5, rue Millotet, Dijon.

DANLOUX-DUMESNILS (MARIE-PAUL-Roger), ingénieur civil, 15, rue d'Astorg', Paris.

DANNIN. Toir Société Trationale d'acclimatation de France.

Da RIOS, sous-inspecteur forestier, Salemo (Italie).

DECAUVILLE (Paul), ingénieur, ancien sénateur, à Port-Touteroye-Gouvieux (Oise).

DECENGI ÈVE FERRANDI ERE (JEAx-FÉLIX), 7, rue du Pré-aux-Cleres, Paris.

DEGROCK. Voir Société forestière prosençale de chêue.

DEDET (GAston), directeur des Mines de fer, à Wassy (Haute-Marne).

I)ELAHAYE, inspectenr-adjoint des Eanx et Forèts, docteur en droit, Les Sables-d'Olonne.

DELASSASSEIGNE (LÉON), ancien inspecteur des Eanx et Forêts, 9, rue du Réservoir, Bordeaux.

DELASSASSEIGXE (IIme) (membre associé).

DELAVAIVRE (HENRI), conservateur des Eaux et Forêts, directemr de l'École des Barres, Nogent-sur-V'ernisson (Loiret).

Del CAMPO (Francisco), ingénieur', 182, quai d'Auteuil, Paris.

DELICOURT (ÉmLE), négociant en bois, président du Syndicat des Marchands de bois de l'arrondissement de Compiègne. Compiègne.

DELPECH (Charles-Rayuond), président du Conseil d'Aministration du Syndicat Forestier de France, \&, rue de Lille, Paris.

DELPECH (JEAx), administrateur-délégué de l'Est Asiatique Frangais, 3, liue Vignon, Paris.

DELVILLE. Voil Touring-Club de Belgique.

DEMORLAINE, inspecteur des Eaux et Forêts, prolessenl a l'Institut national agronomique, Compiègne.

DENIZET. Voir Comité central agricole de la sologne.

DEROYE, conservateur des Eaux et Furèts, docteur en droit, Nancy.

DERQUE, agent forestier des Mamufactures des glaces et produits chimiques de Saint-Gobain, Cirey-sur-Vezonze (Aisne).

DESLINDRES, ministre plénipotentiaire, 28, quai du Loure, Paris. ।

DESPATYS (BARon), 4, rue Sainte-Sophie, Versailles.

DESWERT (Joseph), commerce de bois, 37 bis, rue de Montreuil, Paris.

DETHAN (GEorges), trésorier de la Société Nationale d'Encouragement à l'Agriculture, 16, r've Stanislas, Paris.

DÉTRICHÉ (Charles), horticulteur, 123, ronte des Ponts-de-Cé, Angers.

DEVARENNES (E.), inspecteur des Eaux et Forêts, 26, rue Charles-Nodier, Besançon.

boE, inspecteur des Eaux et Forêts, Épelna

DOLE, inspecteur adjoint des Eaux et Forèts, secrétaire de la Section d'Annecy de la Société Forestière française des Amis des Arbres, arenue de Chambéry, Annecy. 
DOMENGET (Lous), président du Club des Sports d'Hiver, 3 place Carnot, Aix-les-Bains.

DORIZON (Louss), vice-président de la Société Générale, 48, rue Ampère, Paris.

DOUET de GRAVILLE (Comte du), membre du Comitś de Tourisme Hippique du T. C. F., 85, avenue Victor-Hugo, Paris.

DUBoUrG (Henri), 28, rue Charles-Nodier, Besançon.

DUGAUP (Gaston-Roger), conservateur des Eaux et Forêts, chef du service forestier de l'Indo-Chine en congé, Lascours (Gard).

DUCHEMIN (RENÉ), ingénieur chimiste, secrétaire de l'Union syndicale des Usines de Carbonisation des Bois de France, 6, rue Chanoinesse, Paris.

DUCHIRON, secrétaire de la Chambre syndicale des Bois des Iles ct d'Ebénisterie, 14, passage Gatbois, Paris.

DUFAURE (Charles), propriétaire, 9, rue Jean-Gunjon, Paris.

DUFAY (JuLES), notaire, trésorier de la Société Forestière de Franche-Comté et Belfort, Baume-les-Dames (Doubs).

DUNESNIL, notaire lıonoraire, membre de la Commission des Pelouses et Forêts du T. C.F., 47, avenue de l'Alma, Paris.

DUPARG (Éห1LE), géomètre, vice-président de la Section d'Annecy de la Société Forestière française des Amis des Arbres, 10, rue Royale, Annecy.

DUPLAQUET (CharLes), conservateur des Eaux et Forèts, administrat ur du domaine de Chantilly (Oise).

DUPONT (Charles), 182, faubourg Saint-Honoré, Paris.

DUPONT (PAulin), régisseur, Bourg-Fidèle (Ardennes).

DUPRÉ LA TOUR (Lavrent), inspecteur des Eanx et Forêts, 2, rue Duplâa, Pau.

DUPUICH (PAUL), docteur en droit, avocat à la Cur d'appel, membre du Comité de Contentieux du Touring-Club, 20, rue Chauchat, Paris.

DUPUY (Charles). Voir Société Centrale des Architectes.

DURAND (EugèNe), conservateul des Eaux et Forêts en retraite, 6, rue du Che val-Blane, Montpellier.

DURAND (Alexande), Voir Syndicat d'initiative de Rambouillet.

DURAS-CHASTELLUX (Marquis De), 10, boulevard du Montparnasse, Paris.

DUVERGIER de HAURANNE (Edouard-Prosper-Emanuel), président de la Société d'Agrieulture du Cher, château d'Herry (Cher).

ECKLEY LECHMERE, docten' de l'Université de Paris, attaché an Laboratoire botanique du Collège Royal de sciences, South Kensington, Londres.

EGROT (AlFRED), administrateur de la Société Anonyme des Établissements Egrot, membre du Conseil supérieur de l'A griculture, 23, rue Mathis, Paris.

ELLIE (Joseph), garde général des Eaux et Forêts, Saint-Martin-Yésubie (Alpes-Maritimes).

EMERY, inspectenr des Eanx el Forèts, chef de Section à la hirection générale, 80 , rue de Varennes, Paris.

ENCAUSSE de LABATUT (Baron D’), 4, allée Saint-Étienne, Toulouse.

ESPEUILLES (Соnте D'), 5 bis, rue de Berri, Paris.

EVE (ALPhonse). Voir Union syndicale des marehands de bois de Seine-et-Oise.

EYMIEU (Мichel), Villa "la Terrasse ", rue de la Butte, Blois.

FABRE (L.), inspecteur des Eaux et Forêts en retraite, Dijon. 
FELTZ (PAUL), ancien notaire, Luxeuil (Haute-Saône).

FERNOW (B. E.), Dean Faculty of Forestry L'niversity of Toronto, member Commission of Consel'vation, Université de Toronto, Canada.

FERNOIV (Mme B.-E.) (membre associé).

FERRAND (Gharles), ingénienr en chef de la Narine en retraite, 48, rue de Grenelle, Paris.

FERREAUD (Mme (*.) (membre associé).

FERRASSE (PAư-F́mLE), négociant en bois, Courtenay (Loiret).

FERTRE (GEorges), négociant en bois, 103, rue de Charenton, Paris.

FLOURY, éditeur, 83, rue de la Victoire, Paris.

FOCQUET (Pierre), docteur en droit, notaire, sénateur, membre du Conseil supérieur des Forêts de Belgique, Romedenne-surice (Belgique).

FORDOXEL, Loiguyon (Meurthe-et-Moselle).

FORGET, conservateur des Eaux et Forêts, Bar-le-Duc.

FORTIER (EMMNUEL-Lous-Hoxoré), conservateur des Eaux et Forêts en retraite, $\mathbf{4 6}$, rue de Verneuil, Paris.

FORTUNET (JeAx-MArcel), inspectenr des Eanx et Forèts, Nevers.

FOURTIER-MARGUET, fabricant de placages, 21, rue des Charbonniers, Paris.

FOUSSE (PAuL), propriétaire, 4, square du Roule, Paris.

FREDERIC-MIOREAU (Luciex-PALL), ingénieur des Arts et Manufactures, 83 , avenue Malakoff, Paris.

FREDET (HENRI), industriel, 1 bis, boulevard des Italiens, Paris.

FRON (Louis-Albert), inspecteur des Eaux et Forêts, Besançon.

FRON (G.), maitre des Conférences à l'Institut national Agronomi(̨ue, 16, rue Claude-Bernard, Paris.

FRUCHARD (Gaston-Henri), ingénieul des Arts et Manufactures, 2, avenue Alphand, Paris.

GABIAT (CAmile), ancien député, conseiller général de la Haute-Vienne, maire de Saint-Sulpice-les-Feuilles (Haute-Vienne).

GABIAT (Mme) (membre associé).

GAIL (DE), ancien conservateur des Eaux et Forêts, 127, rue de Toul, à Nancy.

GAILLARD (Achille), industriel forestier, président de la Chambre de commerce, Béziers.

GALL (Hevry), administrateur-délégué de la Société d'Electro-Chimie, 2, rue Blanche, Paris.

GAGNEUR (DÉsIré), avoué, Dôle.

GAGNEUR (Mme) (nembre associé).

GALLICE (Georges), ingé.ieur, 1, riue Basse-de-la-Terrasse, Bellevue (Seineet-Oise).

GANTOIS, (Société des Etablissements Joseph), Saint-Dié (Vosges).

GARDE SAINT-ANGEL (Marquis ThibaUt DE LA), président du Syndicat Forestier de l'arrondissenent de Nontron, Saint-Angel par Nontron (Dordogine).

GARDIER, trésorier de la Section d'Annecy de la Société Forestière française des Amis des Arbres, Annecy.

GASSELIN, colonel, 13, rue de Paris, le Mans.

GAVOTY (RAymond), président de l'Union des Syndicats Agricoles des Alpes et de Provence, 30, rue de Lubeck, Paris. 
GAY (Albert), maire du Vigan, membre du Conseil général du Gard.

GAZEAU (Ernest), président du Syndicat Forestier de Touraine et départements limitrophes, 12, avenue Grammont, Tours.

GAZIN (Auguste), ancien inspecteur des Eaux et Forèts, administrateur des Forêts de la Maison d'Orléans, Arc-en-Barrois (Haute-Marne).

GEISSER (Alberto), 33 Via dell' Arsenale, Turin (Italie).

GELiN (Maurice-Alfred), inspecteur adjoint des Eaux et Forêts, Abbeville.

GEXEJU, conservateur des Eaux et Forèts, 6, rue Coëtlogon, Paris.

GERARD (VıстоR), inspecteur-adjoint des Eaix et Forèts, 33, quai Voltaire, Paris.

GERMAIN (LÉon), président du Tribunal civil, Yssingeaux (Haute-Loire). GIBERT, inspecteur des Eamx et Forèts en retraite, 9, rue Bassano, Paris. GILLES DEPERRI ÈRE (ÉmILE), conseiller d'arrondissement, président du Gomité départemental des Sites et Monuments pittoresques du T. C. F., 4, rue Talot, Angers.

GILLET (Gharles), conservateur des Eaux et Forêts en retraite, 5, avenue de la Pajaudière, Nantes.

GIRARD (J. M.), directeur des travaux de l'Association centrale pour l'Aménagement des Montagnes, 142, rue de Pessac, Bordeaux.

GIP.AUD (AvdrÉ), inspecteur adjoint des Eaux et Forêts, 80, rue de Varenne, Paris.

GIROD-GENET, inspecteur des Eaux et Forêts, Ajaccio.

GOdPioN (Alexandre-Henri), ingénienr des Ponts et Chaussées, 73, rue Crevier, Rouen.

GORODICHE (LÉon), docteur, 11, avenue d'Iéna, Paris.

GOL GET (GASTox), notaire honoraire, propriétaire, membre de la Commission des Pelouses et Forêts du Touring-Club, 74, rue Madame, Paris.

GOLILLY (PAUL), garde général des Eaux et Forêts, Ronen.

GOUREAU (Gustave), rentier, 3, avenue Desambrois, Nice.

GOUREAU (Hme) (membre associé).

GRAFFIN (Roger-Lours-MARIE), propriétaire forestier, château de Belval par Nonart (Ardennes).

GRAFFIN (Xavier), 6, rue Albert-Maignan, le Mans.

Grancey (Conte Gharles de), propriétaire, 17, rue Vernet, Paris.

GRAV1), Voir Société d'Agriculture du département de la Gironde.

GRAND D'ESNON (Gaston), domaine de Vaudepart, Payns (Aube).

GRANDJEAN (Charles), inspecteur des Eaux et Forèts, 232, boulevard de Caurdéran, Bordeaux.

GRANGER (André-Francis-Henri), inspecteur des Eaux et Forêts, Rambouillet.

Grangié (Pierre-Paul-Eugène), secrétaire général du Syndicat d'Initiative de Cahors et du Quercy, Cahors.

GRÉA (Pierre), propriétaire, Rotalier, par Vincelles (Jura).

GRIMAL, inspecteur des Eaux el Forêts, Chambéry.

GRISON (TIŕ́ODORE), ingénieur des Arts el Manufactures, 15 bis, rue do Sébastopol, Tours.

GRIVART DE IERSTRAT, conservateur des Eaux et Forêts, Moulins.

GUENYVEAU (Comte de), officier de cavalerie, 103, rue La Boëtie, Paris. 
GUÉRARD (Cinarles), professeur, Seattle (Wash.).

GUILLEMIN (AUguste), inspecteur d'assurances, 34, rue Ennest-Renan, Besançon.

GUILLOT (MAURICE), ingénieur agriculteur, Panissot Saint-Gaprais (Gironde). GUILLOU (HeNri), négociant en bois de sciage, 72, boulevard Barbès, Paris. GUINIER, inspecteur des Eaux et Forèts, professeur de botanique à l'École nationale des Eaux et Forêts, Nancy.

GUYOT (Joseph), ingénieur en chef des Ponts et Chaussés, Besançon.

GUYOT (RAOUL), marchand de bois, 180, rue Lafayette, Paris.

HATT, inspecteur adjoint des Eaux et Forêts, Épinal.

HENRIQUET, inspecteur des Eaux et Forêts, Sedan.

HENRY (JULES), architecte, 89, boulevard Exelmans, Paris.

HERRGOTT (PAUl-Marie), sous-préfet, Toul.

HERMANS (EDmond). Voir Ponts et Chaussées et Pépinière de l'Etat Belge. HIRSCH (PAUL), inspecteur des Eaux et Forêts, 18, rue de Labordère, Neuillysur-Seine.

HIRsciHAUER (Louss), garde général des Eaux et Forèts, Saulieu (Còted'Or').

HiVERT (Alfred), propriétaire, 8, rue Blanche, Paris.

HERTER. Voir Commission départementale des Sites et Monuments naturels de caractère artistique des Basses-Pyrénées.

HOLUB. Voir Association Jednota Ceokych Lesniku zemi Koruny Cèské.

HOREAU (RÉMx), directeur de la Société anonyme des Produits chimiques, Chimay (Belgique).

HUBAULT (Étienne), garde général des Eaux et Forêts, Chambéry (Savoie).

HUDAULT (ANdré-MArie-Joseph), garde général des Eaux et Forèts, Raon-l'Étape (Vosges).

HuET (Auguste), 5, rue Bara, Paris.

HUGUET (ANDRÉ), docteur en droit, 21, rue Gay-Lussac, Paris.

HULIN, inspecteur-adjoint des Eaux et Forêts, Grenoble.

HUMBERT et ROSSIGNOL, marchauds de bois, 62, rue de Cléry, Paris.

hURAUlt de VibRAYe (Marquis), propriétaire, 32, cours la Reine, Paris.

HURAULT DE VIBRAYE (Vicoute), général de brigade du cadre de réserve, 42 , avenue de la Bourdonnais, Paris.

HUSBERG (KARL-SigFRID), gouverneur de la province d'Affsborg, président de l'Association pour la protection des Forêts de l'Ouest de la Suède, Wenersborg (Suède).

HUTCHINS (DAvid-ERnEST), "chief Conservator of forests" en retraite, Medo House, Cobham, Kent (Angleterre).

HUYARD (RENÉ-Alcide), marchand de bois, président du Syndicat des Marchands de bois de l'Aube, Brienne-le-Clıâteau.

IMBART de LA TOUR (Conte). Voir Société des Agriculteurs de France.

IMBERT (IWAN), membre du Comité de Tourisme en Montagne du TouringClub, Ramonchamp (Vosges).

IRISH FORESTRY SOGIETY, représentée par M. le marquis MAC SWINEY DE MASHANAGLASS, 8, rue Edouard-Fournier, Paris, et par M. le capitaine R. F. LOMBARD, 9 Corrig Avenue, Kingstown, Co Dublin.

JAGERSCHMIDT, inspecteur-adjoint des Eaux et Forèts, Rambouillet. 
JANNIARD (Victor), gérant d'immeubles, 153, boulevard Malesherbes, Paris.

JANZÉ (Vicomte Édouard de), 9, place des Ternes, Paris.

JAUFFRET, inspecteur des Eaux et Forêts, Bar-sur-Seine.

JOBEZ (Henri), ingénieur civil des Mines, Pont-de-Poitte (Jura).

JOLAIN (ЈоSеPн), avocat, 3, rue des Saintes-Maries, Blois.

JOLLY, inspecteur des Eaux et Forêts, Troyes.

JOLY (HENrI), conservateur des Eaux et Forêts, Grenoble.

JOLYET, inspecteur des Eaux et Forèts, détaché à la Station de recherches et d'expériences de l'École nationale des Eaux et Forêts, Nancy.

JOUBERT (LÉon), garde général des Eaux et Forêts, Pont-Saint-Esprit (Gard).

JOUSSET, inspecteur-adjoint des Eaux et Forêts, rédacteur à la direction générale, 80, rue de Varenne, Paris.

KALKER (ANDré), 8, a venue des Ternes, Paris.

KIRWAN (Charles-Jean-Joseph De), inspecteur des Forêts en retraite, chalet Dalmassière, par Voiron (Isère).

KORN (HENRY), garde gẻnéral des Eaux et Forêts, Pithiviers.

KREITUANN (Lovis-Jules), garde général des Eaux et Forêts en disponibilité, 6, rue de l'Athénée, Genève.

LABORDERIE (JEAN), maire, Marnes (Seine-et-Oise).

LACOURTE (Jules-Alfred), conseiller du Commerce extérieur de la France, 8 , rue Euler, Paris.

LADAM (Ovide), inspecteur-adjoint des Eaux et Forêts, la Feuillie (S.-Inf.).

LAFARGUE (Sylvain-Elie-René), inspecteur-adjoint des Eaux et Forêts, 68 bis, Route Basse de Paris, Blois.

LAFOND (ANDRÉ), inspecteur des Eaux et Forêts, Limoges.

IaAHALSSOIS (Charles-Émile-Théodore), avocat, président des "Naturalistes Parisiens ", 2, rue de la Planche, Paris.

LALLEIAND (EugÈne). Voir Syndicat des propriétaires de Forêtts de chênesliège d'Algérie.

LANDANWERS COOPERATIVE FORESTRY SOCIETY OF SCOTLAND, 33, queen Street, Edimbourg, représentée par M. SCOTT-ELLIOT, son vice-président.

LAPORTE BISQUIT (ÉdouARD), maire de Jarnac (Charente).

LARNAUde (Ferdinand), professeur à la Faculté de droit de Paris, 92, boulevard Maillot, Neuilly-sur-Seine.

LARROQUETTE (ALBERT-JACQUES), professeur agrégé d'histoire au Lycée de Mont-de-Marsan.

LARTILLEY (HENRI), négociant en bois, Estravaux près Fresnes-SaintMamès (Haute-Saône).

LARUE (Pierre), ingénieur-agronome, 2, place du Chapitre, Saint-Dié.

LASCOLX (Antoine), ingénieur-agronome 15, rue de Grenelle, Paris.

LAVAL (ANDRÉ), exploitant de bois de pin, scieries mécaniques, 71, avenue d'Antin, Paris.

LAVAL (JEAs), propriétaire, Nohanent par Durtol, (Puy-de-Dôme).

LAYRE (BARoN DE), propriétaire, 8, rue de la Baume, Paris.

Le BEC (Dr Edouard), chirurgien de l'hôpital Saint-Joseph, 26, rue de Grenelle, Paris. 
Le BRECQ (RENÉ), propriétaire, Praslins, par Nogent-sur-Vernisson (Loiret). LECOQ (Jules). Voir Touring-Club de Belgique.

LECOQ (Mme), Bruxelles (membre associé).

LEDDET, conservateur des Eaux et Forèts, chef de bureau à la Direction générale, 80, rue de Varenne, Paris.

LEFÉBURE (AMÉDÉE-ALBERT), marchand de bois, 9, boulevard du Calvaire, Neufchâtel-en-Bray (Seine-Inférieure).

LEGRAND (Av.), 12, place Nationale, Gournay-en-Bray (Seine-Inférieure).

LEGUY (RENÉ), expert en immeubles, 18, rue d'Hauteville, le Mans.

LEGUY (Mme) (membre associé).

LEJOUR (Henri-Lous-Marie-Joseph), instituteur, Nogent-sur-Marne (Seine).

LEMAITRE (Lucies), administrateur délégué de la Société anonyme des Usines de Champlan et de la Société Corse pour le traitement des bois, Bastia.

Le MIRE (PAUL), château de Mirevent, par Pont-de-Poitte (Jura).

Le MIRE, 39, avenue de Breteuil, Paris (membre associé).

Le PĖRE (JAcQues), inspecteur des Eaux et Forêts, Bagnères-de-Bigorre (Hautes-Pyrénées).

LEROY-MOULIN (Jules), négociant, Ferrières, près Gournay-en-Bray (Se ine-In férieure).

LESCOUZ ÈrES (Gaston), industriel, Roquefort (Landes).

LESCOUZĖRES (Mme) (membre associé).

LESCURE (JeAN), propriétaire, Selongey (Côte d'Or).

LESSEUX (Coute DE), 95, boulevard Malesherbes, Paris.

LeSTRAnGe (Baron Hubert De), 92, avenue des Champs-Elysées, Paris.

Le TELLIER, conservateur des Eaux et Forêts en retraite, 33, rue Alphonsede-Neuville, Paris.

LETURQUE (PAUL). Voir Chambre de Commerce d'Orléans.

LIEVRE (ADRIEN), trésorier de la Chambre syndicale des Bois às sciage et d'industrie, 56, quai de la Rapée, Paris.

LIĖVRE (Hector), marchand de bois, 65, quai de la Gare, Paris.

LIÈVRE (PierRe), membre de la Chambre syndicale des bois de sicage et d'industrie, 56, quai de la Rapée, Paris.

LIGNOT (ANDRÉ), docteur en droit, maire de Nettancourt (Neuse).

LIGUE DU REBOISEMENT DE L'ALGÉRIE, 25, rue d'Isly, Alger.

LIGUE FRANGAISE POUR LA PROTECTION DES OISEAUX, 33, rue de Buffon, Paris, représentée par M. MICHAUD, garde général des Eaux et Forèts.

LILLO SANZ (José), ingénieur de Montes, 8, Almagro, Madrid.

LINNEAN SOCIETY, représentée par Sir Willia SCHLICH, 29, Banbury Road, Oxford (Angleterre).

LIPPEnS (RAymond), membre du Conseil supérieur des Forêts de Belgique, 23, rue de Flandre, Gand.

LIRMAN. Voir Ville de Paris.

LOMBaRd. (Capitaine). Voir Irish Forestry Society.

LONGUEVILLE (Édouard DE), inspecteur des Eaux et Forêts, 14, rue de Tournon, Paris. 
LORIN de REURE (JEAN), inspecteur adjoint des Eaux et Forêts, la Tronche (Isère).

LOTH (ANDRÉ), négociant et importateur de bois, 60, avenue Daumesnil, Paris.

LOUVEL (MI.-F.-C.), garde général des Eaux et Forêts, Tananarive.

LOUVET (Jean-Eugène), marchand de bois, 25, quai d'Austerlitz, Paris.

LOYEZ (GABRIEL), a vocat, Vesoul.

LUZARCHE D'AZAY (ALFRED), propriètaire forestier, 3, Square de Messine, Paris.

Mac SWINEY (Marquis). Voir Irish Forestry Society.

MADARIAGA Y CASADO (JUAN-ANGEL), ingénieur forestier, chef de la Division hydrologique forestière du Tajo, San Mateo, 11, Madrid.

MADELIN, inspecteur des Eaux et Forêts, docteur en droit, chef de section à la Direction générale, 80 , rue de Varenne, Paris.

MAIGE (HENRY), propriétaire, Montagnole-sur-Chambéry (Savoie).

MAIGE (Mme) (membre associé).

MAITRE, ingénieur des Mines, Morvillars, Territoire de Belfort.

MALEISSYE-MELUN (Conte DE), capitaine de cavalerie, 134, rue de Grenelle, Paris.

MALET (MARQUIS DE), colonel d'artillerie en retraite, propriétaire, 59, rue de Varenne, Paris.

MALET (RовеRT), négociant et propriétaire, 14, rue Jean-Jacques-Rousseau, Bordeaux.

MANDEL (Philippe), marchand de bois, 34, quai d'Ivry, Ivry-Port.

MANG]N, inspecteur-adjoint des Eaux et Forêts, Chantilly (Oise).

MARCEL (JulEs), conseiller du Commerce extérieur, négociant en bois de France et des colonies, 161, a venue Malakoff, Paris.

MARCHAL (Gharles-Francis), ancien député d'Alger, 34, rue Jouffroy, Paris.

MARCIGUEY, docteur en médecine, 92, avenue Victor-Hugo, Paris.

MARCILLAC (PAul), retraité, villa Pervenche, Montélimar.

MARGILLAC (Mme) (membre associé).

MARGAINE, inspecteur des Eaux et Forèts, vice-président de l'Union des Syndicats agricoles, horticoles et viticoles de la Marne, Sainte-Menehould.

MARTIN (ANDRÉ), agriculteur, la Tricherie (Vienne).

MARTIN (EDouard), inspecteur adjoint des Eaux et Forêts, 10, rue Daubigny, Paris.

MARTIN (JEAx), inspecteur-adjoint des Eaux et Forêts, 80, rue de Varenne, Paris,

MARTIN (PAUL), secrétaire général de la Section Lorraine de la Société Forestière française des Amis des Arbres, place de la République, Toul.

MASSE (Pierre), avocat à la Cour, 97, avenue Victor-Hugo, Paris.

MASSOT. Voir Société forestière provençale "Le Chêne ".

MASUREL-BARATTE (EDmond), président de la Société Industrielle, 63 bis, rue Nationale, Tourcoing.

MASUREL (Mme) (membre associé).

MATUSSI ÈRE (Lours), fabricant de papier, Fourneaux-Modane (Savoie).

MAZET (ALbert), propriétaire, Saint-Sulpice-le-Donzeil (Creuse). 
MENDES, inspecteur-adjoint des Eaux et Forèts, 31, rue Croix-Nivert, Paris. MENDES D'ALIIEIDA (Mme), Lisbonne (membre associé).

MENGET (PAul-Victor), propriétaire forestier et foncier, 16, rue Belzunce, Paris.

MENTQUE (Roвевт De), chef de division à la Compagnie le Soleil Incendie, 44, rue de Châteaudun, Paris.

MERMET, docteur, 5, rue du Puits-Salé, Lons-le-Saunier.

MERODE (Сомте Hermanx de), propriétaire, 28, rue Saint-Dominique, Paris.

MESSEY (Comte Gulllaume De), propriétaire, 1, rue Barbet-de-Jouy, Paris.

MICHAUD. Voir Ligue Française pour la protection des oiseaux.

MICHELEZ (PAUL), notaire, 50, a venue de Wagram, Paris.

MigUET (Charles), secrétaire de la Chambre syndicale des Bois des Iles, 50 , avenue Daumesnil, Paris.

MILGENT (Lous), Vaux, par Poligny (Jura).

Mille (Gharles), ingéaieur des Arts et Manufactures, 36, rue JulietteLamber, Paris.

MILLISCHER (Jules), inspecteur des Eaux et Forêts, Vesoul.

MONCHY (DE), inspecteur-adjoint des Eaux et Forêts, 5, square La TourMaubourg, Paris.

MONCHY (FerNaNd), négociant en bois, Albert (Somme).

MONNIN (Marcel-Louis), inspecteur adjoint des Eaux et Forêts, Dijon.

MONTAGU (Conte DE), château de Conches-les-Mines (Saòne-et-Loire).

MONTAGU (Mlle DE), 21, rue Pierre-Sauvage, Abbeville.

MONTGOLFIER (Charles-Antorne De), industriel, Mauvent (Ardèche).

MONTMORENGY-MIORR ÉS (HERVEY DE). Voil Syndicat des propriétaires de Forêts de chênes-liège d'Algérie.

MOREL (Jullex-Marc), ingénieur forestier, 10, avenue de la Raonde, Lausanne (Suisse).

MOREL-HERCULE. Voir Société nationale d'acclimatation de France.

MORINERIE (Armand-Arthur de La), président honoraire de la Clambre de commerce, 43, r'ue Libergier, Reims.

MORINERIE (Mme DE LA) (membre associé).

MOTARD (Eugène), villa "Mon Désir ", Cancade-Nice (Alpes-Marilimes).

MOTARD (ADOLPhe), Clion-sur-Indre (Indre) (membre associé).

MOTTE-SAINT-PIERRE (Bernard De la), propriétaire, château de Montpoupon (Indre-et-Loire).

MOUGIN, conservateur des Eaux et Forèts, Valence (Dròme).

MOUGIN (MARcel), 102, lue Erlanger, Paris.

MOYAT (Lucien), propriétaire, Château-Thierry (Aisne).

MURET (Lours), propriétaire sylviculteur, membre de la Commission des Pelouses et Forêts du Touring-Club, 4, place du Théâtre-Français, Paris.

MUteau (Henri), sous-directeur honoraire. au Ministère de la Guerre, 166, rue du Faubourg-Saint-Honoré, Paris.

NAZELle (Marquis Erhard-Henri de), ancien officier, clâteau de Guignicourt (Aisne).

NAVARRO de ANDRADE (Edmundo), chef du Service Forestier du Brésil Caixa 1322, Sao Paulo (Brésil). 
NEDERLANDSGHE HEIDEMAATSCHAPPI, Nieuwegracht, 94, Utrecht (Hollande), représenté par M. Van LONLHU YZEN, directeur.

NEGRE (HAX), inspecteur adjoint des Eaux et Forêts, Montpellier.

NICODĖME (AвEL), commissaire de la Marine, 20, rue Lafayette, Versailles (membre associé).

NICOLEAU (PAUlix). Voir Chambre de Commerce de Carcassonne.

NiCOLEAL (Lours), secrétaire général du Centre de tourisme de l'Aude et du Canigou, Quillan (Aude) (membre associé).

NOAILLES, pépiniériste, Laignes (Côte d'or).

NOEL (PALL-Hubert), inspecteur-adjoint des Eaux et Forêts, Longuyon (Meurthe-et-Moselle).

NORERO (HENRI), secrétaire général de la Société d'Horticulture, propriétaire, 1, rue des Cranges, Montmorency (Seine-et-Oise).

NOTTIN (Ernest), notaire, 23, rue Danjou, Paris.

NOUGUIER (Charles), propriétaire agriculteur, la Vallée, par Château• Renard (Loiret).

OFFICE NATIONAL DU TOURISIE, 1, avenue d'Iéna, Paris, représenté par M. LORIEUX (EDmoxp), ingéaieur en clef des Ponts et Chaussées, directeur.

ORLYe (Makie-Philibert D'), maire de Menthon, président de la Section d'Annecy de la Société Forestière française des Amis des Arbres, 10, rue Royale, Annecy.

ORMesSON (Comte Olvier d'), ambassadeur de France, ancien préfet, 7, rue Lamennais, Paris.

OTIX (PırRe). Voir Société de Crédit Foncier Rural de Roumanie.

OUVRÉ (ANDRÉ), président d'honneur de la Chambre syndicale des Bois à brûler, ancien député, Chancepoix (Seine-et-Marne).

PAGEOT (GAstov), propriétaire forestier, 205, faubourg Saint-Honoré. Paris.

PALlier (LÉox-Ernest-AxnRé), membre du Conseil supérieur de l'Agriculture, propriétaire forestier, viticulteur, 12, rue Court-le-Gébelin, Nîmes.

PALLOT (PAUL), notaire, 17, rue Guibal, Béziers.

PALLOT (Mlle Thérèse) (membre associé).

PARADIS (HENRI), administrateur de la Société d'Exploitations forestières et d'imprégnation des bois, 26, rue du Rocher, Paris.

PARENT (Henri), rentier, 14, avenue de la Grande-Armée, Paris.

PARENT (PAUL), négociant en bois, 37, quai de la Gare, Paris.

PASGAL (PAuL). Voir Union syndicale des Marchands de Bois de Seine-et-Oise.

PAYRET, Perpignan.

PEIFFER. Voir Syndicat d'initiatice de Compiègne.

PELET-HERMET, inspecteur-adjoint des Eaux et Forèts, en disponibilité, Genolhac (Gard).

PELletier de MARTRES (Auguste-Marie-Martial), 6, boulevard de Clichy, Paris.

PERRIN (Henri), inspecteur-adjoint des Eaux et Forêts, 37, aventie Duquesne, Paris.

PERROGHE (PAUL), maire d'Outines (Marne).

PETITCOLlot (Marie-Émile-André), garde général des Eaux et Forêts, Senones (Vosges). 
PETIT-JEAN, directeur du journal Bois et Charbons, 70, boulevard Beaumarchais, Paris.

PETITON SAINT-MARD (Comte), inspecteur général des Eaux et Forèts en retraite, 1, rue François Ier, Paris.

PHiLIPPE (Alice), 101, boulevard Carl Vogt, Genève.

PIERRAIN (Charles), négociant en bois, 36, rue Picpus, Paris.

PIERPONNE (Modeste), ingénieur, 17, avenue de Madrid, Neuilly-sur. Seine.

PIGOT (A.), ancien notaire, 15, rue Vavin, Paris.

PINGUET-GUINDON, horticulteur, 21, avenue du Mans, la Tranchée-Tours, PINTIAU (ERnest), inspecteur des Eaux et Forêts, Lyons-la-Forêt (Eure). PIOT (Roger), expert-forestier, 52, boulevard Malesherbes, Paris.

PLUMENAIL (Armand), président fondateur de la Société scolaire Forestière, Daglan (Dordogne).

PLUNKETT (Comte Georges), directeur du Musée National d'Irlande, avocat, 26, Upper Fitzwilliam Street, Dublin.

POISSON (AlBERT), maire de Rion, ancien conseiller général, château de Bellegarde, Rion-des-Landes.

POISSON (EugÈnE), secrétaire de la Chambre syndicale des Bois de sciage et d'industrie, 63, rue d'Allemagne, Paris.

POLAKO (IsAac), fabricant de tapis d'Orient, 125, rue du Ranelagh, Paris. POLAKO (Mme) (membre associé).

PONTS ET CHAUSSÉS ET PÉPINIÉRES DE L'ÉTAT BELGE (Anмnistration des), représentée par M. HERMANS (EDmond), conducteur des Ponts et Chaussées, Brée (Belgique).

POLPARD (Ernest), inspecteur des Eaux et Forêts, Angoulème.

POUPINEL (Gaston), propriétaire cultivateur, Mesnil-Saint-Arnoult (Seineet-Oise).

POUPINEL (PAul-HenR1), négociant en bois, 37, quai de la Gare, Paris.

POUSSARD (LF́on), inspecteur des Eaux et Forêts, 15, avenue de Compiègne, Senlis.

POUSSARD (Mme) (membre associé).

PRAL (RÉGIS), commerce de bois, Valence.

PRÉ DE SAINT-MAÜR (RENÉ DU), ancien président du Syndicat Forestier du Morvan, 53, avenue de Ségur, Paris.

PRETREL. Voir Société internationale des Amis des Arbres de Tunisie.

PROUTEAU (Raymond-Marie-Ferdinand), ingénieur des Arts et Manufactures, 153, rue de Rennes, Paris.

PRUD'HOMME (ANDRé), 32 bis, boulevard Haussmann, Paris.

PUTEAUX (AUGUSTE), vice-président de la Chambre syndicale du sciage et du travail mécanique des bois, 42, rue Dunois, Paris.

PUYO (Henri), notaire, 1, rue de Grassi, Bordeaux.

RABOUILLE, inspecteur-adjoint des Eaux et Forèts, Valenciennes (Nord). RACHET (GEORGEs), syndic de la Chambre syndicale des Bois de sciage et d'industrie, 32, avenue Philippe-Auguste, Paris.

RAISIN (Victor), directeur de la Compagnie Industrielle des Alcools de l'Ardèche, 48, boulevard Haussmann, Paris. 
RAVENEAU (Louis), secrétaire de Ia rédaction des Annales de Géographie, 76, rue d'Assas, Paris.

RAVERDEAU (HENRI), propriétaire pépiniériste, domaine de Faverolles par Romilly-sur-Seine (Aube).

REAULX (MARquis DE), 81, rue de Grenelle, Paris.

REGAL (JosÉ), ingénieur en chef du District forestier de Teruel (Espagne).

REIARD (PAUL), lieutenant-colonel du Génie, en retraite, ancien directeur du Parc aérostatique de Chalais-Meudon, président de la Société météoro-

logique de France, 11, rue Madame, Paris.

RENAULD (LÉOx). Voir Syndicat d'initiative du Viverais.

REVIERS (Viconte Richard DE), ancien officier, propriétaire, 50, rue Satory, Versailles.

REY, inspecteur du Service de la Météorologie agricole, 27, rue Vaneau, Paris. REYXARD. Voir Société forestière des Amis des Arbres (section d'Auvergne).

RICARD (EUGÈNE), négociant, propriétaire de forêts, Nebias par Quillan (Aude).

RICHOUX (EugÈNE), président d'honneur de la Chambre syndicale du Commerce des Bois de Lyon, 299, avenue de Saxe, Lyon.

RIDER (Willian), directeur du Journal du Commerce des Bois, 2't, cité Trévise, Paris.

RIGOIGNe (Marcel-Auguste), inspecteur des Eaux et Forêts, Vouziers (Ardennes).

RISACHER (Marie-Stanislas), inspecteur des Eaux et Forêts, Chalonsur-Saône.

RIVÉ (ANDré), garde gẻnéraI des Eaux et Forèts, Charolles (Saône-et-Loire).

RIZIER (ÉdolARD), membre du Bureau de la Chambre syndicale des Bois à brûler, 42, avenue de Breteuil, Paris.

ROCHÉ, garde général des Eaux et Forèts, Lapierre, par Brosses (Yonne).

ROCHE AYMON (Conte Raoul de La), château de Saint-Aignan-sur-Cher (Loir-et-Cher).

ROCHEQUAIRIE (Marquis Daniel De), château de Purnon par Verrue (Vienne).

ROËSER (PIERRE), ingénieur, Crécy-en-Brie (Seine-et-Marne).

ROLLEY. Voir Association amicale des ingénieurs du Service des Améliorations agricoles.

ROMILLAT (Maurice), attaché titulaire à la Chancellerie, 37, rue du Château, Asnières.

RONSERAY (Comte Arnold de), directeur de la Compagnie l'AigleIncendie, 4', rue de Châteaudun, Paris.

ROQUETTE-BUISSON (Comte DE), 9, rue du Quatre-Septembre, Tarbes.

Rotival (Georges), membre de la Communauté des Bois à ouorcr, 40, avenue Ledru-Rollin. Paris.

ROUCY (LOUIS DE), ancien conservateur des Eaux et Forêts, 6, rue des Huguenots, Épernay.

ROULARD (Henry), président honoraire du Syndicat des Bois de la Meuse Aulnois, par Essommes-sur-Marne (Aisne).

ROUSSEAU (Frédéric), 75, boulevard de Strasbourg, Paris.

ROUSSELET (Lovis), assureur conseil, 49, rue Berger, Paris. 
ROUSSELLE (Antoine), publiciste, 49, avenue Malakoff, Paris.

ROUSSELOT (Edouard), inspecteur des Eaux et Forêts en retraite, Noiron, par Pothières (Côte-d'Or).

ROUSSET (Avtonix), inspecteur des Eaux et Forêts en retraite, rue LibrePensée, l'Isle-sur-la-Sorgue (Vaucluse).

ROUVRAY (GEORGES DE), inspecteur des Eaux et Forêts, Clermont-Ferrand. ROUX, garde général des Eaux et Forêts, Villers-Cotterets (Aisre).

ROUX (FÉLIX-Sımox), garde général des Eaux et Forêts, Orgelet (Jura).

ROUI (MARIE). Voir Syndicat d'initiatjue de Rambouillet.

ROUZE (DE). Voir Syndicat forestier de l'arrondissement de Château-Thierry. ROY (ALEXANDRE), ancien inspecteur des Eaux et Forêts, Précy, par Livry (Nièvre).

ROY (Edouard), président du Syndicat des Fabricants d'Extraits tanniques et. tinctoriaux de France, 28, rue de Châteaudun, Paris.

ROYAL SCOTTISH ARBORICULTURAL SOCIETY, 19, Castle Street, Edinburgh (Ecosse).

ROZAN (LÉoNCE), ingénieur civil des Mines, 3'z, rue de l'Arsenal, Marseille. RUDAULT (Lours), inspecteur-adjoint des Eaux et Forêts, Compiègne.

SALABERRY (ComTESSE DE), (membre associé).

SAINTE-CLAIRE DEVILLE (Georges), conservateur des Eaux et Forệts en retraite, 92, rue Le Merchier, Amiens.

SAINTE-CLAIRE-DEVILLE. Voir Société entomologique de France.

SAINT-SEINE (Marquis de), 4, rue de Berri, Paris.

SALVAT (Ferdivaxd), président du Centre de Tourisme de l'Aude et du Canigou, Quillan (Aude).

SALVAT, inspecteur adjoint des Eaux et Forêts, 11, rue de la Sous-Intendance, Sant-Germain-en-Laye.

SARTIAUX (EUGÈne-Henri), ingénieur, maire de Saint-Gobain, 48, rue de Dunkerque, Paris.

SCHLICH (William). Voir Linneam Society.

SCHLICH (Mme), Oxford (Angleterre), (membre associè).

SCHLCESING 〈Henty-Edouard 〉, 38, avenue Niel, Paris.

SCHÆFFER, conservateur des Eaux et Forêts, Vesoul.

SCHOTSMANS (AUguSte), 9, boulevard Vauban, Lille.

SCOTT-ELIOT. Voir Landawners Cooperative Forestry Society.

SÉBASTIEN (PAul-Louis), membre de la Chambre syndicale des Bois de sciage et d'industrie, 7, rue Rataud, Paris.

SEGONZAC (Baron de). Voir Société des Agriculteurs de France.

SEGUIN (ADRIEN), négociant, rue aux Cordiers, Autun.

SEIGNETTE (ADRIEN), inspecteur général honoraire de l'Instruction publique, directeur du Journal des Instituteurs, 1, rue Dante, Paris.

SENARD, inspecteur des Eaux et Forêts, en retraite, Dôle (Jura).

SENART (Henri), avoué honoraire, 16, rue d'Abbeville, Paris.

SERRET (Antoine), professeur d'agriculture, Largentière.

SERVICE GEOLOGIQUE ET ÉCONOMIQUE DE LA CAROLINE DU NORD, DÉPARTEMENT DES FOR ÊTS, Chapel Hill N. C., représenté par M. SPRUNT HILL (JOH ).

SEURRE, inspecteur des Eaux et Forêts en retraite, Bourg. 
SIMAN. Voir Association Jednota Ceskych Lesniku zemi Koruny Cèské.

SIMON, ingénieur des Manufactures de l'État, chargé de la Direction de la Manufacture d'allumettes de Saintines (Oise).

SIMON (Mme RenÉE), 133, avenue Malakoff, Paris.

SIMON GROSDIDIER, Mauvages.

SINTUREL, inspecteur-adjoint des Eaux et Forêts, Fontainebleau.

SOCIÉTÉ D'AGRICÚLTURE, INDUSTRIE, SCIENCES, ARTS ET BELLES LETTRES DU DEPARTEMENT DE LA LOIRE, 27, rue SaintJean, Saint-Etienne.

SOGIÉTÉ D'AGRICULTURE DE COMPIĖGNE, représentée par son président, M. CHEVALLIER (RAYMOND).

SOCIÉTÉ D'AGRICULTURE DU DÉPARTEMENT DE LA GIRONDE, 7 , cours de l'Intendance, à Bordeaux, représentée par M. GRAND, président de la Section de Sylviculture, et II. Bacox de LA VERGNE.

SOCIETÉ DES AGRICULTEURS DE FRANCE, 8, rue d'Athènes. représentée par MM. COLMET D'AAGE, propriétaire; IMBART DE LA TOUR (Conte), docteur en droit); SEGONZAC (BARoN DE), propriétaire; VILLENEUVE-ESCLAPON (Cоите DE), propriétaire; VILLIERS-TERRAGE (BARON DE), secrétaire d'ambassade.

SOCIETÉ DES BUCHERONS DU GOUVERNEMENT D`AMOUR, Vladivostock (Russie).

SOGIÉTÉ CENTRALE D'AGRICULTURE DE L'AUDE, 6, rue Courtejaire, Carcassonne.

SOCIETÉ CENTRALE DES ARCHITECTES, 8, rue Danton, Paris, représentée par son vice-président, M. DUPUY (Charles), architecte du gouvernement.

SOCIÉTÉ CENTRALE FORESTIÈRE DE BELGIQUE, 3, rue de Louvain, Bruxelles, représentée par M. SÉBILLE (Albert-Louis DE), membre du Conseil supérieur des Forêts du Royaume de Belgique, vice-président de la Société.

SOCIÉTE DE CRÉDIT FONGIER RURAL DE ROUMANIE, à Bucarest, représentée par M. PETRE OTIN, ingénieur forestier.

SOCIÉTÉ ENTOMOLOGIQUE DE FRANCE, 28, rue Serpente, Paris, représentée par son président, M. SAINTE-CLAIRE-DEVILLE (J.), capitaine d'artillerie,

SOCIÉTÉ FORESTIÈRE ARGENTINE, 883, Victoria, Buenos-Aires, représentée par MM. THAYS (Сн.), directeur général des Promenades publiques et du Jardin botanique de Buenos-Aires; TOBAL (MiguelAxGEL), ingéaieur agronome.

SOGIÉTÉ FORESTIERE FRANÇAISE DES AMIS DES ARBRES (Section d'Auvergne et du Plateau Central), représentée par son secrétaire général M. REYNARD (J.), conservateur des Eaux et Forêts, en retraite, 9, rue Savaron, Clermont-Ferrand.

SOCIÉTÉ FORESTI ĖRE FRANÇAISE DES AMIS DES ARBRES (Section Lorraine à Nancy), représentée par so: secrétaire général, M. MARTIN (PAUL).

SOCIÉTÉ FORESTIÈRE PROVENÇALE "LE CHÊNE》, $3^{a}$ boulevard Dugonnier, Marseille, représentée par M. MASSOT (PIERRE), président; M. DECROCK (ÉLı), professeur de botanique à la Faculté des Sciences; II. BAUCHERY (A.), pépiniériste sylviculteur. 
SOCIETE FORESTIERE SUÉDOISE, à Stockholm, représentée par MM. IVAHLGREN (ANDERS-NiLs-Hexrick), chef de l'Académie Forestière de Suède; CARBONNIER (HExrick), inspecteur des forêts.

SOCIÉTÉ FORESTIÉRE SUÉDOISE, représentée par MM. WVAHLGREN (Axders-Nils-Henrik), chef de l'Académie Forestière de Suède ; CAPBONNIER (Henrick), inspecteur des forêts.

SOCIÉTÉ DE GÉOGRAPHIE DE LISBONNE, rıe Eugénio-Santos, Lisbonne. SOCIÉTÉ INTERNATIONALE DES AMIS DES ARBRES DE TUNISIE, hòtel des Sociétés françaises, Tunis, représentée par 11. PRETREL (Cu.), secrétaire général.

SOCIETE NATIONALE D’ACCLIMATATION DE FRANCE, 33, l'ue we Buffon, Paris; représentée par II. DANNIN, ingénieur cynégétique, II. MOREL HERCULE, propriétaire, 36, rue de Laborde, I'aris.

SOCIÉTÉ DES TOURISTES DU DAUPHINÉ, hôtel de la Gaisse d'Épargne, boulevard Edouard-Rey, Grenoble.

જOCIETE POUR LA PROTECTION DES FORETS DE LA NOLVELLA HAMPSHIRE, 6, Hancoch Irenue, Boston (Mass.), représentée par U. IVELSH (Herbert), artiste peintre.

SPRLNT HILL (JoH $)$ ). Voir Service géographique et économique de la Carolime du Nord.

STACY (Ralph.), banquier, president de The Pacific National Bank, Tacond, WTash, U. S. A.

STEINER (Louis), inspecteur des Eaux et Forêts, 31, rue Gambetta, Épinal. SUREAU, ingénienr agrieole, 51, rue des Eaux-Minérales, Forges les-Eaux. SYNDICAT D'INITIATIVE D'ARCACHON, 193, boulevard de Ia Plage, Arcachon, représenté par II. VALLEAU (DANıL), président.

SYNDICAT D'INITIATIVE DE COMPI ÈGNE, représenté par M. PEIFFER, conservateur des Eaux et Forêts

SYNDICAT D'INITIATIVE DE RAMBOUILLET, représenté par MM. ROUX (Marie), président, maire de Rambouillet, DURAND (ALEXANDre), propriétaire.

SYNDICAT D'INITIATIVE DE TOURISME DE BAR-LE-DUG, représenté par son président, M. CHEVALIER (PoL), avocat.

SYNDICAT D'INITIATIVE DE TOURISME DE VERSAILLES ET ENVIRONS, 39, rue Duplessis, Versailles.

SINDICAT D'INITIATIVE DU VIVARAIS, Vals-les-Bains (Areleche), représenté par II. RENALLI) (LÉox).

SYNDICAT FORESTIER DE L'ARRONDISSEMENT DE CHATEAU. THIERRY, représenté par MM. DE ROUZE et MOYAT.

SYNDICAT DES PROPRIETAIRES DE FORETS DE GHENES-LIEGE D’ALGÉRIE, 60, rue du Rocher, Paris, représenté par son président M. LALLEMAND (EugĖNE), et M. DE MONTMORENCY-MORR ÈS.

TALANSIER (JuLEs), maire de Montrodat, par Marvejols (Lozère).

TIL A NSIER (Mme) (membre associé).

TESSIER (Louis-Ferdinand), propriétaire forestier, Saint-Martin-de-laPlace (Maine-et-Loire).

TESSIER, conservateur des Eaux et Forêts, 13, rue Peyras, Toulouse.

THAYs. Voir Société jorestiere argentine. 
THÉLIN (RENÉ De), inspecteur général des Ponts et Chaussées et de l'Hydraulique agricole, 11, rue Michel-Ange, Paris.

THÉRON (АLвеRт), inspecteur des Eaux et Forêts, 57, rue de l'Université, Paris.

THEVIN (Fernand), éditeur, Saint-Germain-en-Laye (Seine-et-Oise).

THIÉBAULT (Jules), ancien receveur des Domaines, 65, rue de Metz, Nancy. THIL (André), inspecteur des Eaux et Forêts, en retraite, 27, rue de Fleurus Paris.

THIOLLIER (Joseph), inspecteur des Eaux et Forêts, 6, rue Louis-David, Paris.

THIOLLIER (Mme) (membre associé).

THIVEL (Georges), 24, rue Madeleine, Tarare (Rhône).

THOMAS (ÉmLE), marchand de bois, Les Islettes (Meuse).

TISSOT (ERnest), négociant en bois, Brazey-en-Plaine (Côte-d'Or).

TOBAL. Voir Société forestière argentine.

TORITCH. Voir Société des Bûcherons du gouvernement d'Amour.

TORTEL (PIERRE), propriétaire forestier, château de Ghapeau, par Montbeugny (Allier).

TOUGHALEAUME (René), château de Grandpré, par Lormes (Nièrre).

TOURING-GLUB ARGENTIN, à Buenos-Aires, représenté par M. TOBAL (MIGUEL-ANGEL), ingénieur agronome.

TOURING-CLUB DE BELGIQUE, 2, passage de la Bibliothèque, Bruxelles, représenté par MM. DELVILLE, inspecteur des Eaux et Forêts: LEGOQ (JULES), avocat près la Cour d'appel.

TOURING-CLUB ITALIEN, 14, via Monte-Napoleone, Milan, représenté par M. A. GEISSER,

TOURING-GLUB DES PAYS-BAS, 64, Laan Copeo v. Cattenburch, Gravenhague, représenté par M. VAX DE POLL, gentilhomme des Chasses de S. M. la Reine des Pays-Bas.

TOURRIOL (Henry), courtier en bois, 16, rue Taine, Paris.

TOURTEL (Jules), conservateur des Eaux et Forêts, à Nice.

TOYTOT (Albert DE), ancien conseiller général du Jura, Rainans (Jura).

TOYTOT (Auguste De), inspecteur de la Compagnie P.-L.-M., en retraite, Amange, par Rochefort (Jura).

TRIBOT-LASPIÉRE, ingénieur civil, 7, rue de Madrid, Paris.

TRIPIER (FÉLIX), 19, rue Marbeuf, Paris.

TRIPONEY (EugÈNE), maire de Glainans, par Clerval (Doubs).

TRUTAT (Henri-Jacques-Marie), inspecteur adjoint des Eaux et Forêts, Belley (Ain).

UNION SYNDICALE DES MARCHANDS DE BOIS DE SEINE-E'T-OISE, à Versailles, représentée par M. PASCAL (PAUL), vice-président; M. EVE (ALPHONSE), trésorier.

URVOY de PORTZAMPARG (Edmond-Françors), chef de bataillon en retralte, 7, rue de la Motte, Saint-Servan (Ille-et-Vilaine).

URVOY DE PORTZEIPARC (Mme) (membre associé).

VAGNE (Lours). Voir Chambre de Commerec de Nevers.

VAILlant (Jules), directeur de la revue Le Cuir, 54, rue de Bondy, Paris.

VALENTIN (Augustin), négociant, président du Syndicat des Exploitants de forêts du Var, Vidauban (Var). 
VALLEAU (DANIEL). Voir Syndicat d'initiative d'Arcachon.

VALLET (LÉon-Adolpine), osiériste, 52, quai de Seine, La Frette (Seineet-Oise).

VALLOT (Henri), ingénieur des Arts et Manufactures, 62 bis, rue Duplessis, Versailles.

VAx de POLL. Voir Touring-Club des Pays-Bas.

VAX DER VORST (PAUL), sous-inspecteur des Eaux et Forêts, 14, rue J.-Plateau, Gand.

VAN LONKHUIJZEN. Voir Nederlandsche IIeidemaatschappij.

VANTROYES (HENRI), inspecteur-adjoint des Eaux et Forêts, Laon.

VERLUISE (HENRI), négociant en bois, maire de Vincennes.

VERNET, inspecteur des Eaux et Forêts, Grenoble.

VERPILLIERE (Marquis Gharles de la), propriétaire, Lagnieu (Ain).

VESSIOT (PAUL), inspecteur des Eaux et Forêts, Langres.

VEYSSI ERE (DE), inspecteur-adjoint des Eaux et Forêts, 80 , rue de Varenne, Paris.

VEZIN (AlExANDre), directeur des Services agricoles de Loir-et-Cher, Blois.

VIBRAYE (Conte Paul de), 5, rue Saint-Dominique, Paris.

VIBRAYE (Louıs DE), propriétaire, 42, avenue du Trocadéro, Paris.

VICENTE (VAldivia), ingénieur agronome, 1, rue Racine, Paris.

VIDAL (Dr Léox-EmILE), secrétaire général de la Société Forestière des Maures, Hyères.

VIELHOMME (Émile), administrateur délégué de la Société Electro-Métallurgique française, Froges (Isère).

VIELHOMME (Henry), usine de la Saussaz, Saint-Michel-de-Maurienne (Savoie) (membre associé).

VIELMOMME (GharLes), usine de Largentière (Hautes-Alpes) (membre associé).

VIELLARD (Gharles-Henri), ingénieur des Arts et lanufactures, Forges de Morvillars (Territoire de Belfort).

VIGNON, Capitaine à l'École de cavalerie de Saumur.

VIGNON (Alfred), secrétaire d'ambassade, 8, lue Freycinet, Paris.

VIGLiON (Jules), La Chassagne, par Pont-de-Pany (Côte-d'Or').

VILLATTE DES PRUGNES (RoвERT), ingénieur agronome, 37, avenue d'Antin, Paris.

VILLE BAUGE (Marquis DE LA), 52, avenue Bosquet, Paris.

VILLEFRANGHE (Сомте DE), 19, rue Auguste-Vacquerie, Paris.

VILLEFRANGHE (Conte HENRI DE), ingénieur agronome, propriétaire, châtean de Villarceaux, par Bray-et-Lù (Seine-et-Oise).

VILLE DE LUXEMBOURG, représentée par M. WENGER (TONY), conseiller communal, délégué du T. C. F.

VILLE DE PARIS, usine municipale de Fabrication de Pavés de bois, représentée par M. LIRMAN, directeur.

VILLEMEREUIL (DE), 52 bis, boulevard Saint-Jacques, Pars.

VILLENEUVE (Vicomte Gharles de), Bussy-le-Grand (Côte-d'Or).

VILLENEUVE-ESGLAPON (ConTE DE). Voir Société des Agriculteurs de France.

VILLEPLE (EMIL), négociant en bois, Saint-t)uen-l'dumône (Seine-el-Oise). 
VILliers-TERRAGE (Barox de). Voir Société des Agriculteurs de France. VILMORIN (Philippe DE), membre de la Société Nationale d'Agriculture, 66, rue Boissière, Paris.

VIOLETTE, inspecteur des Eaux ef Forêts, Brignoles (Var).

VOELCLEL (EUGÈNE), négociant en bois, vice-président de la Chambre syndicale dés bois de sciage et d'industrie, 48, avenue Henri-Martin, Paris.

VOGELI (FÉLIX), inspecteur des Eaux et Forêts, Chambéry.

VOLMERANGE (RAYMoND), garde général des Eaux et Forêts, à Coulommier's.

VUILlAUME (Hent), \&, rue Totre-Dame, Arbois (Jura).

WEILL RAYNAL (Horace), ingénieur en chef des Ponts et Chaussées, 66, rue de la Chaussée-d'Antin, Paris.

WELSH (Herbert). Voir Société pour la protection des Forêts de la Touvelle IIampshire.

WENGER (ToNr). Voir Ville de Luxembourg.

WINKENWERDER, doyen du College of Forestry, à l'Universite de Washington.

ZEILleR (Charles Paul), ancien garde général des Eaux et Forêts, 47, rue Charles-Laffitte, Neuilly-sur-Seine.

ZURLINDEN (ALFRED), conservateur des Eaux et Forêts en retraite, 90, boulevard Raspail, Paris.

Z/I RLINDEN (Mme) (membre associé). 
INTERATIOXAL 191:;

\section{REGLEVENT}

Article Premer. - Un Congrès forestir international se tiendrat en 1913 à Paris, du 16 an 20 juin.

Ant. 2. - Ce Congrès a puur bul :

De réunir tous ceux qu'intéresse la forêt;

D'étudier les questions éeonomiques et teehniques qui s'y rattachent, y compris celles que soulève le tourisme, étroitement lié à la richesse des régions pittoresques;

D'étudier les réformes législatives ou administratives de nature ì assurer la conservation et l'amélioration des forêts, la restauration des montagnes dégradées et la mise en valeur des terres incultes;

De rechercher les améliorations à apporter par les particuliers dans la gestion de leurs bois et dans I'utilisation des produits des forêts.

Art. 3. - Le Congrès se compose de membres français et étrangers. Toute personne qui désire laire partie du Congrès loit un adresser la demande au Président du Comité d'organisation, au siège du TouringClub de France (65, avenue de la Grande-Armée, Paris), en indiquant la section dont elle désire suive plus particulièrement lis travaux,

La demande doit être accompagnée d'un mandat-poste de 20 franes, montint de la cotisation.

Les Sociétés, Syndieats et généralement toute association, peuvent faire partie du Congrès et y envoyer des délégués. La cotisation est due pour chaqque délégué.

Peuvent également participer au Congrès, à titre de membres associés, les personnes de la famille d'un membre du Congrès, moyennant le versement d'une cotisation dont le montant est fixé à 10 franes. 
Anт. 4. - Les membres inscrits au Congrès reçoivent une carte personnelle; ils ont droit :

10 A l'accès aux salles de çonférences et de réunion;

$2^{\circ}$ A l'envoi gratuit du compte rendu et des autres publications émanant du Congrès ;

$3^{0}$ Aux autres avantages qui seront ultérieurement indiqués : réceptions, excursions, facilités de transport, etc.

Les membres associés reçoivent également une carte qui leur permet. d'assister aux séances du Congrès, de prendre part aux réceptions et excursions, et de bénéficier des facilités de transport.

Les frais des excursions ne sont pas compris dans la cotisation, chaque membre ou associé ne paie que les frais des excursions auquelles il prend part.

Art. 5. - Les travaux du Congrès sont dirigés par le Comité exécutif.

Anт. 6. - Le Congrès se partage en einq sections, conformément au programme.

Arт. 7. - Les travaux de chaque section sont réglés par leur bureau d'après le programme. Les membres du bureau sont désignés par le Comité exécutif ; il pourra leur être adjoint des membres étrangers.

Arт. 8. - Les sujets d'étude inscrits au programme de chaque section feront l'objet de rapports qui seront discutés en séances de section.

Le Comité exécutif a tous pouvoirs pour accueillir ou rejeter toutes les demandes de communications qui lui seront adressées, sans qu'il soit tenu de faire connaître les motifs de son refus.

Les rapports devront être déposés au siège du Touring-Club de Franco avant le 15 avril 1913.

Arт. 9. - La publication des rapports sera faite en français. La langue française sera seule employée pour les communications verbales.

Toutefois, les délégués étrangers qui seraient dans l'impossibilité de s'exprimer en français, seront autorisés à employer leur langue nationale.

Dans ce dernier cas, les orateurs devront remettre au bureau de la section, dans les vingt-quatre heures, le résumé en français des paroles qu'ils auront prononcées.

Art. 10. - Les rapports, qqui devront ne constituer qu'un résumé sommaire des questions mises à l'étude, seront imprimés et distribués d'avance aux membres du Congrès. 
A l'égard des questions qui n'auraient pas été l'objet de rapports préalablement imprimés, le Secrétaire général du Congrès en préparera un résumé succinet qui sera lu avant la discussion.

Art. 11. - Le Comité exécutif fixera, d'accord avec les bureaux de section, l'ordre du jour de chaque séance.

Art. 12. - Les membres du Congrès ont seuls le droit de présenter des travaux et de prendre part aux discussions.

Les délégués des Gouvernements étrangers et des Administrations publiques jouissent des mêmes avantages.

Les associés n'out pas ce droit et ne reçoivent pas les publications du Congrès.

Les membres du Congrès qui désirent prendre part à la discussion ne pourront le faire qu'en section, ils devront en faire la demande et donner leur nom par écrit au Président de section.

Ils ne pourront intervenir plus de deux fois sur le même sujet et chacune de ces interventions ne pourra pas durer plus de 10 minutes.

Art. 13. - Les voux adoptés dans les diverses sections seront soumis i l'approbation du Congrès.

Art. 14. - Deux séances plénières st tiendront, l'une le jour de l'ouverture, l'autre le jour de la clòture.

Art. 15. - Pendant la tenue du Congrès, il ne pourra être introduii de modifications dans l'ordre des travaux que sur la proposition des présidents de section.

Arт. 16. - La direction des discussions appartiendra, dans chaque section, au Président et la police générale du Congrès appartiendra exclusivement à son Président.

Ant. 17. - Un compte rendu in extenso des travaux du Congrès sera publié par les soins du Touring-Club de France.

Le Comité exécutif pourra demander', et au besoin imposer aux auteurs des rapports et communications, des réductions ou suppressions; il pourra, s'il y a lieu, les opérer d'office afin de limiter l'étendue du rapport, général.

ArT. 18. - Tous les documents relatifs au Congrès doivent être adressés à M. le Secrétaire général du Congrès, au siège social du TouringClub de France, 65, avenue de la Grande-Armée, Paris. 


\title{
PROGRAMME DES TRAVAUX
}

\author{
PREUIERE SEOTION
}

TECIINIOSE FURESTIERE UL SYLVICULTURE

Enseignement sylvicole at Sylvo-Pastoral. - Eneouragements ot récompenses il la sylviculture. - Propagande cn faveur do l'arbre et de l'eau. - Sociétés seolaires forestièrs. - Fêtes de l'arbre.

Répartition des régétaux ligneux 'n France.

Les Forêts coloniales.

Allongement des rívolutions des taillis et taillis sous-futaie. - Diminution de la proporion des bois dre petite dimension. - Conversion des taillis of taillis sous-futair an lutair.

Amélioration des taillis í faible lendement situés en plaine ou en monlagne, par l'introduction dre résineux.

Les taillis d'acaria.

Le noyer. - Sa disparition. - Morens d'y remédier. - Nécessité de donner une nouvelle extension is sa culture.

Le châtaignier. - Sa disparition. - Novens d'y romédier. - Nécessitéde donner une nouvelle extension is sa culture.

Les engrais chimiques en Sylviculture.

Essences exotiques et natmalisies.

La capitalisation forestière.

La collaboration des forestiers an service de la métévrologie agricole.

\section{DEITIE.VESETTION}

\section{ECONOMIE ET IEGSLATUX FUIESTIERES}

Issuranees contre lineondie.

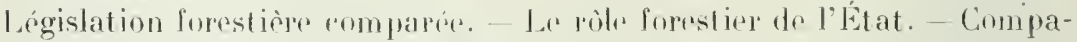
raison entre les dilfirents pays.

Établissement de forets dr protertion. 
Intervention de l'État dans la gestion des bois particuliers. - Législations diverses réglant cettr intervention.

L'impòt forestier.

Ligues. - Syndicats. - Caisses de crédil forestier.

Utilité de l'aequisition par l'État, les communes ou autres colletivités publiques, les établissements on assuciations d'utilité publique, de forêts ou terrains ì reboiser. - Nesures législatives, ardministratives ot financières ì prendre pour faciliter cettr aequisition.

Utilité pour les syndicats de propriétaires de créer un Office forestier international (Stations de recherches, d'expérienoes ot de renseigneinents).

Production forestière dans les diver's pays du globe.

Droits de douane.

Transport des boris.

\section{TROISIEIE SECTION}

TECHNOLOGIE RORESTIERE. - COMMERCE ET INDISTRIE DU BOIS.

Exploitation des bois.

Outillage.

Utilisation des bois. - Bois bruts, Chauflage, Charbon. - Étais de mines.

Utilisation dis menus bois par les nouveaux procédés chimiques et mécaniques.

Plantations des routes.

Poteaux télégraphiques.

Bois équarris. - Poutres, charpentes, traverses.

Subrentions industrielles.

Conservation des bois. - Procédés naturels, proefirlés artitieiets (enduits. injections, immersion, ignilugation).

Bois utilisés dans l'industrie des allumettes pour débitage ou la conlertion des boites.

Emplois diver's. - Fabrication du papier, laine de beis, sabotage, eerclage, bois courbé, bois plaqué, bois coloré artiticiellement.

Bois de seiage. - Outillage, débit, menuiserie, pavé.

Produits aecessoires. - Déchets du bois. - Utilisalion des sciures.

Bois de fente. - Bardeau, Merrain.

Ecoress. - Tanin. - Extraits Lanniques. - Liège.

L'industrie des résines. - La carbonisation des bois en vases clos.

\section{QU. THIEIE SECTIOX \\ GRIXUS TRATIYX FORESTERS}

Anciliorations pastorales. - Criation, restauration, entretien des pâturages. - Aménagement et réglementation des pâturages appartenant 
à des communes ou collectivités. - Afrouage pastoral. - Troupeaux transhumants. - La chèvre. - Le mouton.

Grands travaux. - Barrages. - Dérivations, canalisations. - Tunnels.

- Restauration des montagnes. - Lutte contre les torrents et les avalanches.

Petits travaux. - Fascinage. Clayonnage. Façonnage de lits. Enrochement. Drainage. Enherbement. Reboisement (semis et plantations. Essences). - Eessences à employer. - Graines. - Pépinières.

Tourbières. Marécages. - Leur assèchement et leur mise en valeur par leur reboisement. - Essences à employer. - Mode de plantation.

Les dunes. - Leur fixation. Leur reboisement. Défense contre la mer. -

Moyens d'action donnés par la législation actuelle. Mesures législatives à prendre.

Mliance de l'arbre et de l'eau. - Lutte contre les inondations.

\section{CINQUIE IE SECTION}

DE LA FORETT DANS LE DÉVELOPPEMENT DU TOURISME ET L'ÉDLCATION ESTHÉTIQTE DES PEUPLES

L'éducation forestière du public.

Beauté du pays par la forêt.

Beauté des routes. Plantations le lung des routes. Leurs arantages.

Choix des essences.

Jardins alpins. Arboretums.

Beauté des paysages. - Mesures prises dans les différents pays pour leur protection. Nouvelles mesures à prendre.

Beauté des cours d'eau (L'arbre sur la montagne, c'est l'eau dans la rivière).

Aménagements de forêts en vue du tourisme. - Création, amélioration des routes et chemins. Sentiers lorestiers.

Plaques. Poteaux. Signes indicateurs. - Abris. Bancs. Points de rue. Tables d'orientation, etc. - Livrets-guide ou plans des forêts à l'usage des touristes. Catalogue des arbres remarquables.

Parcs nationaux. - Réserves et séries artistiques. 
INTERNATIONAL 1913

\section{ORDRE DES TRAVAUX}

LUNDI 16 JUIN.

A 10 heures. - Séance d'ouverture du Congrès, sous la présidencede M. Clémentel, ministre de l'Agriculture.

$\left.\begin{array}{l}\text { de } 11 \text { h. à midi. } \\ \text { de } 2 \text { h. } \dot{a} 6 h \text {. }\end{array}\right\}$ Séances des Sections.

Mardi 17 , Merchedi 18 , Jeudi 19 Juin

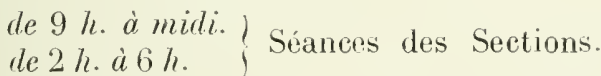

Vendredi 20 Juix

a 2 h. $1 \frac{1}{2}$. - Séance de. clòture sous la présidence de M. DABAT, Directeur général des Eaux et Forêts.

à 5 henres. - Réception à l'Hòtel de Ville de Paris.

SAMEOI 21 JUN

Excursion dans la forêt domaniale de Lyons.

DIMANCHE 22 JUN

à midi. - Banquet de elòture du Congrès.

à 7 h. 30 du soir. - Départ pour Grenoble et les Alpes-Dauphinoises. 


\section{SEANCES DU CONGRES}

Les séances du Congrès se sont tenters à l'Hòtel des Sortétés Savanter. 2s, rue Serpente et \&, rue Danton.

Le Secrétariat du Congres y a éte installé pendant sa durer. 
INTERTATIONAL 1913

\section{EXCURSIONS}

Les congressistes ont pris part à deux excursions : l'une, lo 21 juin, à Rouen et la forêt de Lyons, l'autre, du 23 au 28 juin, ì Grenoble et les Alpes Dauphinoises. 


\title{
COMPTES RENDUS DES SEANCES
}

\author{
SEATGE GÉTERAL DOOUERTTRE DU GONGRES
}

Le lundi, 16 juin 1913, les membres du Congrès Forestier International organisé par le Touring-Club de France se sont réunis à l'Itôtel des Sociétés Savantes sous la présidence de .I. Clémentel, Ministre de l'Igriculture.

\section{La séance est ourerte à 10 l. 15 minutes.}

M. Le Président. - La séance est ouverte. La parole est à M. Ballif, Président du Touring-Club de France.

M. Ballif. - Messienrs, aux termes de notre règlement. le Comité exécutif est chargé d'assurer les travanx du Congrès.

Le bureau de ce Comité est ainsi composé :

Président: M. Defert, Vice-Président du Touring-Club de France, Président de la Commission des Pelouses et Forêts.

Vice-Président : M. Antoxi, Sous-Directeur de l'Administration grénérale des Eaux et Forêts.

Secrétaire général : M. Chaplaix, Inspecteur des Eaux et Forêts.

Trésorier: M. Berthelot, Trésorier du Touring-Club de France.

Nous vous demandons de compléter ce bureau par l'adjonction, en qualité de Vice-Présidents, des représentant offieiels des États prenant part ì ce Congrès.

Nous pensons, Messieurs, que rous serez heureux de donner éc témoignage de gratitude aux personnalités distinguées qui viennent de si loin nous apporter leur préeieux concours (Assentiment). 
Le bureau se trouve donc composé ainsi que je viens de le dire, et il comprend, comme vice-présidents, les représentants officiels, par ordre alphabétique, de :

la République Argentine.

L'Empire d'Autriche-Hongrie.

Le Royaume de Belgreue.

Les États-Unis du BrésiL.

La République du Chici.

La République de Colonbie.

Le Royaume de Danemark.

La République de l'Équteur.

Le Royaume d'EsPagne.

Les États-Unis d'Amérique.

La Grande Bretagne et les Colonies

Le Royaume de Grèce.

La République de Haitı.

La République de Hondras.

L'Empire du JAPON.

Le Grand Duché de Luxemboura.

Le Royaume de la Norvìge.

Le Royaume des Pays-Bas.

La République du Portugal.

Le Royaume de Roumanie.

L'Empire de Russie.

La République du Salvador.

Le Royaume de la Suk̀ne.

La République Orientale de l'Urrguar.

La Principauté de Monaco.

Messieurs, tout à l'heure, Monsieur lo Ministre, avec sa haute autorité, avec cette élégance de parole dont il a le secret, vous parlera de cette passionnante question des forêts qui nous réunit aujourd'hui. Le Président du Touring-Club de France se gardera bien de s'aventurer dans cette voie. Il se bornera, prudemment, au rôle infiniment plus modeste et plus aisé d'un maître de maison qui souhaite la bienvenue à ses hôtes; et c'est de grand cœur, Messieurs, que je vous arlresse ces souhaits (Applaudissements).

Soyez done tous les bienvenus, en particulier vous, Messieurs les Étrangers, en notre doux pays de France, sur ce vieux sol gaulois qu'on ne saurait frapper du pied sans y éveiller l'écho de quelque haut fait, si plein de souvenirs historiques et artistiques, si pittoresque, si fertile enfin, qu'on a pu le dire " aimé des Dieux! "Vous y trouverez, Messieurs, cet accueil aimable et cordial que de tout temps la France a réservé aux étrangers.

Pour notre part, nous ferons en sorte que tous ici, Français et Étrangers, vous emportiez de votre séjour parmi nous un agréable et durable souvenir. 
Messieurs, au nom du Touring Club de France, j'ai à vous remercier de vous être rendus en si grant nombre ì notre appel, et, pour plusieurs, de si loin.

Nous devons des remerciements partieuliers aux divers États qui nous font l'honneur de prendre part à ce Congrès, et nous prions leurs très distingués délégués de vouloir bien être auprès de leurs gouvernements respectifs les interpretes de nos sentiments de gratitude.

Ce Congrès réunit 700 membres. Le Congrès de l'Exposition Universelle de 1900 en avait réuni 225. De tels chiffres sont éloquents et montrent le haut intérêt que soulèvent actuellement dans le monde entier les questions forestières. Votre savoir, votre expérience, votre amour du bien public sauront être à la hauteur de la tâche qui vous incombe, et jamais, on peut le clire, la cause de la forêt n'aura été remise en des mains plus (lignes, ni plus expertes (Applandissements).

Le tourisme profitera l'un des premiers de ros efforts. Ne puise-t-il pas sa raison d'être, en effet, dans la beauté de nos pays, et nos montagnes, nos vallées, nos rivières ne sont-elles pas d'autant plus belles que nos forêts sont plus prospères!

Je forme donc, en son nom, les vocux les plus ardents pour le succès de vos efforts. Non seulement ils serviront la cause du tourisme, mais aussi les intérêts économiques les plus importants pour l'avenir de nos pays; cn se plaçant à un point de vue plus élevé encore, on peut dire qu'ils sont appelés à servir la cause même de l'humanité. (Applandissements.)

Soyez-en fiers, Messieurs, et que l'espoir d'atteindre un tel but rous soutienne et vous inspire. Par avance tous les esprits éclairés, tous les cours généreux applaudissent à vos travaux (Applandissements).

\section{I. Clénentel, Ministre de l'Agriculture.}

\section{Messieurs,}

J'ai tenu à venir présider la séance d'ouverture de votre Congrès pour exprimer moi-même les remerciements du Gouvernement aux organisateur's de cette grande manifestation internationale.

Le metteur en scène de cette fête de l'arbre, la plus imposante qui se soil tenue jusqu'à ce jour, est le Touring-Club.

Je salue en lui, en ses dirigeants et spécialement en ses dévoués Président et Vice-Président, MM. Ballif et Defert, en tous ceux qu'ils ont su grouper autour d'eux pour la préparation de ce Congrès, de précieux collaborateurs du ministère dont j'ai la charge.

Avee leur sens profond des nécessités éronomiques et sociales, avec leur souei constant de l'embellissement de notre pays, ils exercent, depuis la fondation de leur puissante assoriation, leur action bienfaisante en faveur de l'épanouissement de notre richesse pastorate et forestière.

Les sarrifices quils consentent, leurs nobles efforts de propagande ont déjà porté des fruits aboudants. 
En tenant ces assises, ils ont voulu couronner me première ctape de leur oeuvre, ot prendre, dans la constatation des résultats obtenus, dans l'enseignement qui ya se dégager de la grande semaine forestière qui commence, des forees nouvelles, une nouvelle ardeur pour l'oruve de demain (Applaudissemenls).

Je vous félicite, Messienr's, d'aruir si nombreux, répondu à leur appel, d'être venus nous prêter le précientx concours de votre sympathie et de votre compétence.

Je salue tont spérialement les quarante-deux délégués accourus des quatre coins de l'Europe, d'Amérique, d'Asie, d'Océanie, au nom du Gouvernement de la République, au nom de la vieille France qu'ils vont, en travaillant dans la ruche qu'est cette Assemblér, en parcourant les paysages émouvants de nos Alpes dauphinoises, apprendre à mieux connaitre, c'est-à-dire ì mieux ainer (Applandissements).

Vous nous avez apporté, MM. les délégués étrangers, les dons de votre savoir et de votre expérience, vous emporterez dans vos pays respectifis la moisson de nos propres travaux et l'exemple de nos efforts.

lous emporterez surtout cettr conviction que la France hospitalière, malgré les ardeurs des compétitions économiques, en dépit des passions et des conflits de la politique, r'este fidèle à l'irléal de solidarité universellr qui s'exerce à la fois par la communauté des plus nobles idées, des plus purs sentiments de l'humanité et par les échanges nécessaires it la vie? et à la prospérité des nations (Applaudissements).

Cette solidarité internationale trouve l'un de ses champs d'action les plus vastes dans le culte de la forêt.

Le bois est une richesse mondiale.

Or, la production ligneuse de l'univers deviendra un jour, si l'on n'y prend garde, insullisante aux besoins sans cesse accrus de la consommation. Le péril grandit chaque jour.

Macbeth, à l'heure de sa mort, voyait une forêt hérissée et l'ormidable qui marchait et s'avançait vers lui. Nous la voyons, nous, qui recule, qui recule sans cesse (Applandissements).

Pendant des siècles, on a inconsidérément dévasté les dumaines ferestiers, on a poussé les exploitations sylvestres très au-delà du rendement régulipr. Beaucoup de pays d'Europe semblent menacés dès maintenant. d'une disette prochaine de bois d'ocuvre.

Si les nations privilégiées de l'Europe septentrionale et orientale et de l'Amérique du Nord, qui détiennent encore de grandes réserves forestières, ne s'attachaient pas à la défense de leurs trésors par l'application des règles de l'explritation rationnelle, si les pays déjà appauvris ne consacraient pas tous leurs clforts ì reconstituer ceux que l'imprévoyance ou l'ignorance a dilapidés, nous pourrions redouter pour' les générations prochaines unr crise mondiale d'autant plus grave qu'elle serait, sans renède, ot qu'elle rêtentirait sur l'avenir et la vie même de la planète.

"La France périra laute de bois ". I travers les siècles, ce cri d'alarme dr Colbert retentit douloureusement. Après les inondations de 1910, il ctait devenu danc notre pays conme un eri de détresse et de denil. 
Si nous assistions impassibles it l'aurre de destruetion, si nous ne nous efforcions pas à rétablir et à maintenir l'équilibre des forces de la nature, si nous laissions la terre se démuder lentement, mais súrement, si nous donnions raison à l'affirmation de Chateaubriand que "les forêts précèdent les peuples et que les déserts les suivent ", nous pourrions sans crainte de démenti élargir la triste prophétie de Colber't et aflirmer "que non seulement la France, mais le monde civilisé périra faute de bois ". (Applaudissements.)

Totre initiative, Messieur's, nous est une raison d'espérer que les calamités, que les causes de décadence et de ruine provenant de la disette de bois seront épargnés à l'humanité.

Aidés par vos gouvernements, vous arrêterez l'cuuvre de vandalisme qui devient un péril mondial et vous lui substituerez l'application des règles tutélaires qui sortiront plus préeises et plus impérieuses des travaux de votre Congrès.

Le Gouvernement que je représente iei donne l'assurance de sa collaboration active à l'ouvre qu'ont entreprise au Parlement les groupes de défense forestière, sur tous les points du territoire : le Touring-Club, les Sociétés d'Amis des arbres et leurs émules. (Applaudissements).

Nous savons que la France est parmi les nations qui ont le plus souffert du dépeuplement forestier.

Voilà plus de quatre sièeles que le grand poète de la Pléiade, dans son Élégie aux búcherons de la forêt de Gastine, s'éeriait:

"Écoute búcheron, arrête un peu le bras, Ce ne sont pas des bois que tu jettes à bas,

"Ne vois-tu pas le sang, lequel dégoutte à force,

"Des Nymphes qui vivaient dessous la rude écorce?"

Depuis lors, l'agonie de nos forêts, ces grandes victimes d'une civilisation mal comprise, a continué et c'est non le sang des Nymphes de Ronsard, mais le sang même de la France qui a conlé à chaque coup de hache. (Applaudissements.)

La plainte du peuple contre ces déprédations s'est affirmée avec véhémence lors de notre grande Révolution. Les cahiers retentissent des doléances de la France rurale sur les malheurs qui résultent de la dévastation des forêts.

Avec le siècle dernier, l'œuvre réparatrice a commencé.

Elle fut lente d'abord, incertaine, puis elle s'affirma avee la promulgation du code forestier, avee la eréation de l'Administration des eaux et forêts.

Elle se continua lentement encore, consacrant un nouvel et louable effort par notre programme de restauration des terrains en montagne r.t son commencement d'exécution.

Depuis que vous avez, Messieurs, entrepris votre croisade, les puuvoir's publics se sont orientés vers des solutions effieaces.

Je suis heureux de déposer sur le bureau de votre Congrès un acte 
législatif qui est d'hier, que nous derons saluer aree joie, ear il doit ourrir une ère nouvelle. C'est la loi Audiffred, qui vient d'être votée par les deux Chambres.

Elle permettra d'étendre à nombre de forêts les règles de la sylviculture trop souvent méconnues par leurs propriétaires, soit parce qu'ils n'en apercevaient pas le haut intérêt, soit parce que les conseils terhniques leur faisaient défaut.

Vos suggestions et vos conseils me seront précieux pour l'élaboration du règlement d'administration publique qui va en organiser l'application. (Applaudissements.)

Mais cette loi en appelle impérieusement une autre. C'est celle qui réalisera enfin la réforme de l'impòt qui pèse d'une manière inique sur lọ propriétaire forestier. (Applaudissements.)

Basé sur une classification cadastrale depuis longtemps vermoulue, il absorbe fréquemment la plus grande partie des revenus des bois, quani il ne les dépasse pas. (Applaudissements.)

L'œuvre d'équité fiscale que réclame la sylviculture est à réaliser sans délai. Je m’appliquerai pour ma part avec une volonté obstinée à obtenir cette réalisation .(A pplaudissements.)

Tout en aidant les collectivités et les particuliers à sauver ou it étendro leur domaine forestier, l'État, personne morale douée d'une existence séculaire, se doit d'élargir sans cesse son vaste patrimoine de bois et de forêts.

Nous sommes résolument entrés dans cette voie. J'espère obtenir bientòt du Parlement le vote du projet de loi que nous avons déposé pour sauver du feu et du fer le magnifique massif de la forêt d'Eu.

Je demande, d'autre part, à M. le Ministre des Finances, grand ami de la forêt, et qui j'espère m'entendra, de bien vouloir inserire au budget de 1914 un million destiné à l'achat par l'État, chaque année, des forêts particulières déboisées. Ces forêts sont presque sans valeur pour la vente? en raison du refus systématique que nous opposons aux demandes dr. défrichement. Acquises à peu de frais, livrées à l'intelligente initiative. d'une administration qui ne mérite que des éloges, elles représenteront. pour nos petits-neveux un accroissement considérable de la rirheses forestière de la France.

Ainsi, les fautes du passé nous servant d'enseignement, nous réparerons les erreurs commises par ceux de nos devanciers qui aliénèrent une partie du domaine national qui eût dú leur demeurer sacrée.

La forêt, vous le savez, Messieurs, n'est pas seulement une usine à bois.

Aider à la conservation des forêts, à leur extérieur, à la défense des moindres arbres, non seulement dans nos campagnes, mais autour de nos villes et de nos villages, ce n'est pas uniquement enrichir la France, e'est aussi l'assainir et c'est l'embellir.

C'est l'assainir par l'action qu'exerce la forêt sur le climat, sur la température, sur le régime des pluies.

L'arbre est le grand purificateur de l'atmosphère. 11 arrête et détruit 
les germes morbides. Il revivifie l'air par son incessante production d'oxygène et d'ozone.

11 transforme la lande marécageuse en une plaine productive, en disciplinant ses forees latentes. Il sert de filtre naturel aux eaux d'écoulement, il retient leurs impuretés, abritant dans le silence des vallées la naissance mystérieuse des sources.

Il régularise le débit du ruissean, de la rivière, du lleuve, il prévient le redoutable lléau de l'inondation, écarte son eortège de détresse et de misères. (Applandissements.)

Enfin. c'est embellir et parer notre pays que de lui conserver jalousement, là où il existe rneore, le manteau vert de ses forêts, de l'étendre à nouveau là où il fut déchiré par des mains impies. C'est dans le temple de la forêt que poètes ot peintres sont allés, dès les temps les plus reculés, puiser l'inspiration la plus pure.

N'avons-nous pas nous-même laissé fleurir nos rêves à l'abri des sousbois mélaneoliques, au détour des sentiers perdus dans le taillis, n'avonsnous pas senti descendre en nous la paix infinie et sereine de la nature sous le dôme silencieux des futaies séculaires?

Lussi, depuis quelques années, le Ministre de l'Agriculture, secondé par l'initiative d'hommes comme notre ami Beauquicr, aidé par vos associations, a-t-il entrepris do sauver en les classant les sites les plus pittoresques de nos forêts.

Une quarantaine de séries artistiques ont été eréées dans nos forêts domaniales et j'ai été heureux de donner très récemment ma signature au classement en série artistique d'une partie dı massif de la GrandeChartreuse. (Applandissements.)

Nous avons, d'autre part, prescrit de réserver dans toutes nos forêts les arbres remarquables, soit par la majesté de leur port, leurs dimensions exceptionnelles, soit par les souvenirs historiques ou légendaires qu'ils évoquent. N'est-ce pas un erime que d'abattre les beaux vieux arbres, que nous aimons conme de très vieux parents pour les lointains souvenirs qu'ils portent dans leurs bras alourdis?

Toutefois, la série artistique est et sera toujours un luxe. Elle constitue une réserve de beauté, mais elle diminuera d'autant le revenu de la forêt. 11 est done nécessaire, puisque l'État est un propriétaireq ui ne peut négliger aucune de ses ressources, d'établir les séries artistiques avec circonspection, en ménageant les susceptibilités du Trésor, en même temps que les intérêts de la main-d'ouvre, les besoins du commerce et de l'industrie. C'est pour qu'olle juge, documents en mains et suivant les ciconstances, de l'utilité de la création ou de l'extension des séries artistiques, que j’ai institué une Commission eomposée de membres du Touring-Club, de forestiers, de savants et d'artistes.

J'ai rffleuré, Messieurs, chemin faisant, quelques-unes des questions qui vont faire l'objet de nos travaux.

J'aurais aimé à deseendre avec vous dans le détail de votre vaste programme dont le résumé semble la table des matières d'une véritable eneyclopédie de l'art pastoral at forestier. 
de retarderais, en cérlant à mon désir, l'heure attrndue do ros études et de ros décisions.

Je m'arrête done et vous dis en terminant:

. Nettez-vous à l'ceuvre avee confiance, avec cette ardeur rélléchie qui inspirent tous ceux qui collaborent comme vous avee la nature maternelle.

Si vous ne parvenez pas à résoudre tous les problimes, vous proposerez du moins des solutions utiles, non seulement it notre pays, mais à tout le monde civilisé, pour qui, je le répète, la question de la forêt est ump question vitale.

Votre compétence, votre dévouement à l'intérêt général vous permettront de travailler avec sérénité ; votre foi en la nature, votre amour de la beauté vous.donneront la ferveur qui fait battre les jeunes cocurs 1.t monter les jeunes sèves; et quand votre tâche sera achevée, vous pourrez vous séparer, avec la certitude joyeuse d'avoir bien servi, non senlement notre beau pays de France, mais le genre humain tout entier.

\section{(.1 pplaudissements.)}

Je déclare ouvert le Congrès forestier international de 1913.

Jo cède la présidence à $\mathbf{M}$. Ballif.

11. Ballif. - Je donne la parole à M. Henry Defert, Président du Congrès.

11. Henry Defent. - Messieurs, on l'a dit bien souvenit: il y a des paroles qui sont des actes, et e'est le cas du magnifique et encourageant liscours ministériel que vous venez d'entendre. Je ne sache pas qu’il y. ait pour vous de meilleur stimulant pour vos travaux.

Mlais avant de vous rendre dans les differentes sections du Congrès, permettez-moi d'aborder très rapidement quelques questions d'ordre intérieur.

Commençons par le plaisir, je veux dire par les excursions. Pour l'excursion de Lyons-la-Forêt, le nombre des inserits doit, par suite des nicessités de transport, être limité à 140 excursionnistes.

In burean est installé it la porte de cette salle pour recevoir les insriptions.

(uant a l'excursion de Grenoble, le nombre des exeursiomistes doit Alr limité à 60 , à raison des difficultés de logement et de transport. Io même bureau recevra les inscriptions des amateurs.

Enfin, à l'issue de ce Congrès, après la séance de rloture de vendredi prochain, a 5 heures du soir, la Ville de Paris, le Conseil municipal et to P'réfet de la Seine font au Congrès les honneurs d'une réception. J'invite tous les membres ici présents à vouloir bien, à l'issue de la séance, donner leur nom de façon à nous permettre d'indiquer au Conseil municipal quelle sera l'importance de la réception dont il veut bien nous honorer.

En ce qui concerne le travail des sections, je prie MII. les Présidents de sections de vouloir bien veiller à ce qu'on s'écarte le moins possihlir de l'horaire dont vous avez tous reru un exemplaire, dr lacon a per- 
mettre à ceux des congressistes qui ne pourraient pas assister à toutes les séances de pouroir choisir à coup súr les jours et heures où seront examinées et diseutées les questions qui les intéressent plus particulièrement, et j'ajoute, dans cet ordre d'idées, que l'ensemble des sections va avoir à examiner à peu près 200 vœux. MMI. les Présidents de sections voudront bien tenir la main à ce que ce nombre ne soit pas dépassé; quant aux amendements, les sections ont toute latitude et toute liberté. mais il importe que le nombre déjà considérable de vocux reste renfermé dans les limites d'ailleur's très larges de nos propositions.

C'est ainsi que nous arriverons à la séance de clôture, et dans cette séance le Comité exécutif se réserve de rous faire deux propositions : la première, qui n'a rien d'original et qu'on retrouve dans tous les Congrès sera de faire un choix dans l'ensemble des voux émis par les sections en donnant la préférence à ceux qui présentent un caractère capital. un intérêt de premier ordre. Il importe au plus haut point, en effet, que. ces voux qui doivent servir de guide et de direction aux Pouvoirs publics. d'eneouragement à tous ceux que la question forestière intéresse, soient en quelque sorte hiérarchisés, et proposés pour les réalisations futures dans l'ordre qui leur revient naturellement d'après leur degré d'intérêt ou d'importance.

Le bureau de votre Comité exécutif fera ce travail qu'il proposera aux délibérations du Congrès à la séance de clôture, laquelle sera présidée par M. Dabat, Directeur général des Eaux et Forêts. Et en même temps que vous ratifierez ainsi l'ensemble des voux des sections, vous les classerez dans leur ordre de préférence.

Lautre proposition que le Comité se réserve de faire à votre séance plénière demande quelque réflexion, et si je vous en parle par arance, e'est que je crois utile de livrer la question à ros méditations.

Nous ertimons que ce Congrès, qui se présente comme une manifestation forestière des plus grandioses, ne doit pas être seulement l'couvre d'un jour, une manifestation éphémère, qu'il doit avoir un lendemain et même des surlendemains, et dans ce but nous envisageons la création d'une Ccommission permanente du Congrès, qui le prolongerait dans le temps et dans l'action (Applandissements), de façon à maintenir d'abord un contact entre toutes les personnalités qui ont pris part à ses travaux, et surtout un lien entre les différents intéressés au point de vue des initiatives à prendre, des efforts à tenter, des campagnes à engager pour arriver à la réalisation des voux que vous aurez exprimés. et faire faire ainsi un pas considérable à la question forestière. (Applan(lissements.)

Les applaudissements dont vous voulez bien honorer la proposition. me rassurent sur le sort que vous lui réservez; je rois qu'elle est appeléc ì recueillir une complète approbation.

Et maintenant, passons aux actes, c'est-à-dire dans les sections.

M. Bur.lfF - La séance générale est close.

la séance ust levée à 10 h. 55. 


\title{
PREMIERE SEGTION
}

\author{
TEGHNIQLE FORESTIERE OU SYLTIULTURE
}

\section{BUREAU}

Président :

r'ice-présidents :

Sccrétaires:

MII. Jousset, inspecteur-adjoint des Eaux ol Forêts, rédacteur à la Direction générale. DE VeYssière, inspecteur-adjoint des Eaux et Forêts.

Roux, garde-général des Eaux ef Forêts.

RAPPORTEURS : MM. A. Unвdenstock, secrétaire de la Commission des Pelouses et Forêts du Touring-Clul).

Ph. Gurner, inspecteur des Eaux et Forêt., professeur de botanique à l'Ecole nationale des Eaux et Forêts. 
11M. Hickel, inspecteur des Eaux et Forêts. maître des conférences de sylvicultur à l'Ecole nationale de Grignon.

SchæfFer, conservateur des Eaux et Forêts. Demorlare, inspecteur des Eaux el Forêt. professeur d'économie forestière c̀ l'Institut national agronomique.

Jolyet, inspecteur des Eaux et Forêts. détaché à la station de recherches et d'expériences de l'Ecole nationale des Eanx et Forêts.

Masar, inspecteur-adjoint des Eaux ef Forêts.

Francois Caquet, membre du Conseil supérieur de l'Agriculture.

R. Chaplain, inspecteur des Eaux ef Forêts. Ancien chargé de mission en Indo-Chine et aux Indes.

P. Rey, inspecteur du service de la métinrologie agricole. 


\section{SEANCE DU 16 JUIN 1913}

\section{(MATIN)}

\section{Présidence de M. Cyprien GIRERD, président de Section.}

La séance sit ouverte à 11 heures.

11. L P Pésnext. - Le premier rapport sur lequel vous ayez à statuer rst celui de 11 . Cimbdenstock, relatif à l'ENSEIGNEMENT SYLVICOLE ET SYLVO-PASTORAL, ¿ LA PROPAGANDE EX FAVEUR DE L'ARBRE ET In L'EAl, aux Sociétés scolatres forestières, aux Fètes de L'ARBRE, aUX ExCOIRAgEMENTS ET RÉCOMPENSES A LA SYLVICULTIRE.

La parole rst à II. Imbdenstock pour la lecture de son rapport.

M. Uмвоехsтоск. - "L'arbre est la joie de la terre ", a dit André Theuriet.

Facteur de richesse et de protection, facteur de beauté et d'harmonie, l'arbre constitue une parure incomparable, un des éléments essentiels d'un paysage. Il offre à la gent ailée, protectrice de nos cultures contre les insectes malfaisants, sa joie du printemps, son palais de verdure.

La forêt qui couronne les sommets, fait jaillir la source du rocher, protège le sol, tempère et revivifie l'atmosphère, constitue, par la diversité de ses aspects, par la majesté de ses grands arbres, la plus belle et la plus précieuse parure du sol.

Les forêts se placent donc au premier rang des éléments de beauté d'un pays; elles présentent de merveilleux spectacles qui font éclore les hautes pensées et les idées profondes.

Tous ceux qui ont le eulte du beau trouvent dans les harmonies de la forêt les plus grands enseignements.

Les peintres, les poètes. les littérateurs, vont chercher des inspirations sous l'ample éventail des feuilles chuchoteuses. Dans le silence mystérieux les futaies profondes, ils ont conçu, souvent, leurs ceuvres les plus hautes et puisé la poésie comme à sa sourco naturelle.

Dès que reviennent les beaux jours, chacun de nous, obéissant à un sentiment profond d'admiration des beautés de la nature, ne va-t-il pas, lorsque l'occasion lui permet de s'échapper de la ville tumultueuse, vers la forêt, parce qu'il aime le

Mystère des forêts ténébreuses et douces,

Où le silence dort sur le velours les mousses. 
Mais la forêt n'offre pas seulement l'agrément de son ombrage, elle ne doit pas être appréciée uniquement comme la parure de la terre, comme une simple charmeuse : elle a des rapports plus étroits avec la société humaine.

Elle est, des produits du sol, celui qui rend à l'homme les services les plus divers.

Agent essentiel de la vie à la surface de notre planète, la forêt doit être considérée comme une mère nourricière, et sa conservation, suivant le mot de Martignac, "est l'un des premiers éléments des sociétés".

On ne saurait donc trop proclamer le très grand intérêt qui s'attache à la conservation de la forêt, bienfaisante à la terre et intimement liée à l'existence de l'homme, à ses besoins matériels comme à .ses aspirations idéales.

Et cependant, sur notre sol, l'arbre est partout en danger. Les réserves de notre globe s'épuisent, de vieilles futaies sont livrées à la destruction, des coupes inconsidérées ont transformé des forêts en broussailles sans avenir, l'industrie pastorale est exercée sans ménagement et surtout avec inintelligence.

Pour un maigre profit immédiat, le particulier, comme le village, comme la ville, vendent leur richesse présente, leur richesse future, la vie même de leur descendance, en vendant la forêt que l'on abat et sur l'emplacement de laquelle s'étalera désormais la stérile horreur des espaces désertiques.

Les initiatives les plus généreuses se heurtent encore à des préjugés sans fondement. Nous citerons à ce sujet l'étrange aberration de deux communes à esprit véritablement rétrograde :

La première, Chalmazelles (Loire), a refusé un cadeau de 5.000 francs, offert moitié par l'Administration des Eaux et Forêts et par le 'TouringClub, pour transformer en pelouses 500 hectares de landes où de maigres troupeaux trouvent à peine de quoi ne pas mourir de faim.

La deuxième, Gijounet (Tarn), a préféré maintenir sa montagne dénudée plutôt que d'accepter un don de 1.000 francs de la Compagnie des chemins de fer départementaux du Tarn pour entreprendre le reboisement de ses vacants.

La ruine de certaines forêts privées provient surtout de ce que les propriétaires les exploitent sans méthode; les coupes sont faites au petit bonheur, parce que ces propriétaires ignorent les principes de la sylviculture et méconnaissent leur intérêt propre. Cependant, ces bois, soumis à un aménagement rationnel, verraient leur production augmenter dans une large mesure.

Nous ne devons pas rester impassibles devant cette situation.

Il faut apprendre aux enfants à aimer les arbres et à respecter le bien de la collectivité.

Il faut éclairer le peuple sur ses intérêts véritables plutôt que de le contraindre par des lois qu'il est si difficile de faire respecter.

Il faut, enfin, répandre parmi les populations rurales les notions les plus élémentaires de la sylviculture qui leur permettront d'élever, d'exploiter rationnellement des peuplements bien créés ou de transformer en pâturages productifs des friches stériles qui déshonorent un pays.

Cette ouvre contribuera puissamment à conjurer le péril national de la dépopulation des campagnes, en luttant contre l'exode des paysans vers la ville, question dont la gravité n'écliappe à personne et dont se 
préoccupent les pouvoirs publics. "Quand les petits villageois auront planté des arbres, ils resteront fidèles à la terre des ancêtres ", parce que l'arbre est un ami auquel on s'attache d'autant plus qu'on l'entoure chaque jour de soins assidus, on grandit côte à côte et les fleurs ou les fruits qu'il donne symbolisent les fruits de nos labeurs.

De toutes parts, on signale la mévente du bois de feu et une disette prochaine du bois d'œuvre. On concoit que l'État ne puisse, à lui seul, suffire à la production et, comme les besoins se sont accrus et ne cessent de s'accroître, il est de toute nécessité d'éclairer les propriétaires forestiers et de les orienter vers une modification du traitement de leurs bois, en leur démontrant que la privation momentanée de revenu qui peut résulter au début de la conversion de leurs maigres taillis en taillis sous futaie constituera pour eux "la plus belle des caisses d'épargne".

La diffusion de la science sylvicole mettrait, en outre, un frein aux défrichements intempestifs, comme aux exploitations inopportunes.

Or, l'enseignement forestier et sylvo-pastoral tient une place très restreinte dans les institutions françaises; il n'est pas exagéré de dire qu'il est presque exclusivement réservé aux forestiers de l'État.

En première ligne se place l'Institut national agronomique, véritable École polytechnique de l'Agriculture, dont l'École des Eaux et Forêts de Nancy est le complément indispensable : l'École d'application.

Il convient de citer également l'École d'enseignement technique et professionnel, l'École secondaire d'enseignement forestier professionnel, toutes deux installées au domaine des Barres-Vilmorin, et réservées aux employés de l'Etat.

L'Ecole nationale de Nancy admet à ses cours des auditeurs libres, français et étrangers, dont nombre de ces derniers tirent profit; les Français y sont rares (1). Nos compatriotes ignorent-ils cette institution? Ils trouveraient là un moyen de compléter leur éducation forestière et de devenir des propriétaires ou des intendants éclairés.

En 1906, au moment de la création de la Commission des Pelouses et Forêts du Touring-Club, nous appelions l'attention de nos collaborateurs sur l'émulation que ne manquerait pas de créer le titre d'ingénieur forestier donné aux élèves libres de l'École de Nancy qui, admis après concours à suivre les cours de cet établissement, en subiraient avec succès les examens de fin d'études. Nous nous sommes rencontré sur ce point en communion d'idées avec M. Delahaye, inspecteur-adjoint des Eaux et Forêts (2). Cette idée vaut d'être reprise, elle fera l'objet d'un vou que nous soumettrons à l'approbation du Congrès.

Dans plusieurs de ses Assemblées générales, en 1908, en 1909, et notamment dans celle du 10 février 1910, le Société Nationale d'Encouragement à l'A griculture formulait à ce sujet des vœux que nous ne saurions manquer de nous approprier en les renouvelant.

L'enseignement forestier, en honneur dans la plupart des Universités étrangères, n'a pas encore trouvé place dans les programmes des Univer-

(1) De 1830 à 1912, 423 élèves libres ont étó admis à suivre les cours de l’Ecole nationale des Eaux et Forêts; dans ce nombre, on compte 55 français seulement, soit $130 / 0$.

(2) Ch. Delahaye. Le Déboisement el le Régime des bois des particuliers (thèse). Niort, imprimerie Mercier, 1909. 
sités françaises. Toutefois, l'Université de Bordeaux, cédant aux instances de M. Descombes, président de l'Association centrale pour l'aménagement des montagnes, vient de créer un cours libre de sylvonomie (Economie et politique forestières).

L'auteur de ce néologisme fonde les meilleures espérances sur les résultats que donnera l'initiative prise par l'Université de Bordeaux.

Cependant, comme le disait Arago en 1836 : "Ce n'est pas avec de belles paroles qu'on fait du sucre de betterave, ce n'est pas avec des alexandrins qu'on extrait la soude du sel marin ". Nous pouvons ajouter : "Ce n'est pas avec une instruction purement classique que le sylviculteur pourra rendre sa forêt plus productive. Le meilleur moyen de faire aimer à un ouvrier son ouvrage, c'est de lui en faire comprendre les opérations principales et le profit. .

L'enseignement pratique s'impose donc comme une nécessité; un cours de sylviculture complété par des démonstrations donnerait des résultats plus satisfaisants, et c'est dans ce sens qu'il faudrait orienter les adjonctions à faire au programme des études.

Cette observation peut s'appliquer également aux Ecoles nationales d'Agriculture de Grignon, Montpellier et Rennes.

Nous sommes convaincu que le Congrès reconnaitra l'utilité d'introduire dans ces établissements, ouverts aux jeunes gens qui se destinent à l'enseignement et à la gestion des domaines ruraux, une part de pratique effective à la sylviculture. L'enseignement de la sylviculture, comme l'enseignement agricole, doit s'appliquer sur une expérimentation : c'est en mettant les phénomènes à observer sous les yeux des élèves qu'on fixe dans leur esprit les idées fondamentales sur lesquelles repose une science.

Dans les Ecoles pratiques d'Agriculture, lesquelles tiennent le milieu entre les écoles nationales d'agriculture et les fermes-écoles, l'enseignement de la sylviculture est l'exception. Sans surcharger le programme de ces écoles, il nous paraît que la sylviculture, avec démonstration, pourrait être le complément naturel du cours de sciences naturelles ou du cours d'arboriculture.

L'école primaire, considérée par les apologistes comme le point de départ d'une rénovation nationale, doit constituer un moyen puissant de généraliser l'enseignement sylvicole et sylvo-pastoral, en initiant les enfants de nos campagnes à ces connaissances, dans une mesure compatible avec la nature d'un enseignement du premier degré.

Un arrêté ministériel en date du 31 janvier 1897, relatif à l'examen du certificat d'études primaires, prévoit comme sanction de l'enseignement agricole une ou plusieurs questions choisies dans le programme du cours moyen. Pourquoi n'en serait-il pas de même pour la sylviculture? La note forestière s'ajouterait à celle d'écriture, de calcul, de rédaction. en prenant la même valeur que chacune d'elles.

C'est une mentalité nouvelle à créer chez les maîtres d'écoles ; mais, en s'imposant ce nouveau devoir, les instituteurs se créeront de nouveaux titres à la reconnaissance publique.

D'ailleurs, la circulaire du Ministre de l'Instruction publique, en date du 2 février 1906, dispose qu'il sera tenu compte, aux instituteurs et institutrices publics qui, tous les quatre ans, prennent part au concours institué pour récompenser ceux d'entre eux qui ont donné avec plus de zèle et de succès - d'une manière théorique et pratique - l'enseigne- 
ment agricole et horticole, des notions de sylviculture et d'améliorations pastorales qu'ils auront données à leurs élèves.

Malheureusement, les instituteurs ne sont pas préparés à eet enseignement.

C'est donc à l'École Normale, chargée de la formation de ces maitres, que l'Etat doit demander de remplir le rôle d'éducateur. Il ne s'agit pas de vouloir ériger les écoles normales en succursales de l'École Forestière, mais il nous parait indispensable de donner une plus grande extension aux programmes de ees écoles, en élaguant les sujets qui ne répondent pas à une réelle utilité. Un cour's devrait être consacré exclusivement à l'enseignement sylvicole ou sylvo-pastoral, selon les régions, dans la partie théorique comme dans les applications. Le personnel enseignant existe. Grâce à l'École de Nancy, les professeurs ne sont pas à former : ce sont les agents de l'Administration forestière, personnel d'élite et dévoué.

Les élèves-maîtres qui auraient fait preuve de sérieuses connaissances sylvicoles théoriques et pratiques pourraient recevoir un certificat de fin d'études normales portant la mention de sylviculture.

Dans quatorze écoles normales, la sylvieulture est effleurée accessoirement par le professeur de seiences et pendant les promenades. Dans douze autres écoles, les directeurs sont favorables à l'idée et se proposent d'organiser prochainement un cours. Dans deux écoles seulement, l'enseignement forestier est donné par un agent de l'Administration forestière, savoir : à Albertville, depuis 1878, et à Mireeourt, depuis 1881. Les programmes des cours de sylviculture de ces deux établissements pourraient servir de base pour l'enseignement général.

La première tentative faite en France pour créer un enseignement sylvicole et sylvo-pastoral semble remonter au Congrès de sylviculture de 1900. Mais le mouvement d'opinion s'est réellement manifesté en 1906, après la diffusion, par le Touring-Club de France, des Manuels de l'arbre et de l'eau dont cent mille exemplaires ont été distribués généreusement par lui dans les écoles. Un programme d'enseignement élaboré par sa Commission des Pelouses et Forêts a reçu un accueil ehaleureux de M. Bienvenu-Martin, ministre de l'Instruction publique, et M. Ruau, ministre de l'Agriculture. Deux circulaires, en dates des 2 février 1906 (Instruction publique) et 9 février 1906 (Agriculture), invitent les instituteurs à répandre l'enseignement sylvicole et sylvo-pastoral et les agents des Eaux et Forêts à provoquer la création de sociétés scolaires forestières.

L'Association centrale pour l'aménagement des montagnes a aussi contribué à cette propagande.

Des sociétés scolaires forestières se sont rapidement créées - on en compte aujour'd'hui près de quatre cents, - dont le Touring-Club s'est fait le prineipal pourvoyeur. Les instituteurs se sont dépensés largement et les jeunes écoliers se sont mis avec ardeur à l'ouvrage. Des fềtes de l'arbre ont été organisées; au début, simples manifestations pastorales et poétiques destinées à célébrer la verdure et la campagne, elles sont devenues par la suitc la consécration des travaux forestiers de l'année.

Ces tentatives ont-elles donné les résultats espérés par les promoteurs? Nous ne saurions nous prononcer ici. Nous devons toutefois constater que cent cinquante sociétés scolaires forestières seulement poursuivent leurs travaux; cela tient à ce que les sociélés scolaires manquent d'unité 
d'action, de direction générale; leur existence officielle administrative n'est pas reconnue. Souvent le départ de l'instituteur entraîne la faillite de l'œuvre et, d'autre part, l'intervention des forestiers et des instituteurs est restée absolument personnelle et volontaire.

Pour que l'enseignement prît corps et fût méthodique, il eùt fallu guider les maîtres et mettre à leur disposition un traité résumant les connaissances indispensables. C'est ce que, depuis deux ans, le Journal des Instituteurs s'efforce de faire en donnant chaque samedi, à ses trente mille lecteurs, une leçon de sylviculture. Leçon théorique, il est vrai, mais suffisante pour permettre à ceux qui veulent se rendre utiles de mettre en pratique les principes généraux $d u$ boisement décrits dans ce cours. Nous sommes heureux de cette circonstance qui nous permet de rendre ici hommage au directeur du Journal des Instituteurs, M. Seignette, inspecteur général honoraire de l'Enseignement. Nous associons à cet hommage le distingué secrétaire général de la Section d'Auvergne des Amis des arbres, M. le conservateur Reynard. Les instituteurs, qui dirigent les petites scolaires de la région, lisent avee fruit les conseils pratiques publiés chaque semaine par M. Reynard dans le Moniteur du Puyde-Dôme.

Enfin, les fêtes de l'arbre ne sont plus que des manifestations isolées, souvent symboliques, célébrées à grand renfort de discours et de chants plus ou moins sylvestres.

Dans cet ordre d'idées, il convient de signaler les initiatives prises dans divers pays et les résultats obtenus.

Depuis 1902, un décret royal institue, en Italie, la fête des arbres dans toutes les communes. Les enfants des écoles ont procédé à des plantations fort importantes en présence du roi et de la reine.

L'Autriche, la Hongrie, la Russie ont témoigné de leur intérêt pour ces manifestations.

En Espagne, l'Association des Amis de la fête de l'Arbre, fondée en 1898, a fait une propagande des plus actives; elle n'a pas été étrangère à la publication du déeret royal du 11 mars 1904, lequel institue la fête de l'Arbre dans tout le royaume. En 1913, 409 fêtes ont été célébrées avec le concours des gouverneur's de provinces.

Au Japon, la fête des Cerisiers est une fête nationale.

Aux Etats-Unis, sous le nom d'arbor-day, il s'est fondé, en 1872, une Association en vue de la reconstitution des forêts. Chaque année, l'arborday est célébré avee solennité : c'est une fête nationale statutairement établie par acte du Gouvernement. Cette mesure a eu pour conséquence d'augmenter de plusieur's millions d'hectares le domaine forestier de l'État.

Pourquoi, en France, n'aurions-nous pas notre fête de l'Arbre? Ce serait le prétexte d'une journée de joie saine, d'un contact réconfortant avec la nature. Planter des arbres, cela vaut certainement mieux que d'ériger des statues! "Quel plus beau monument, pour célébrer la gloire "d'un grand citoyen, qu'un arbre planté en son honneur par les mains "des enfants, heureux dans une fête patriotique " (LEsing).

Il est incontestable qu'au cours des cinquante dernières années, l'agrieulture a fait de sérieux progrès. Les Écoles d'agriculture, les Stations de recherches, les Sociétés d'agriculture, Coopératives, Comices, Syndi- 
cats, les Concours régionaux et nationaux, se sont multipliés lépandant autour d'eux cette science lumineuse qui chasse devant elle l'obscure routine; l'outillage s'est chaque jour perfectionné.

Seule, la sylviculture privée est restée stationnaire. Notre production ligneuse ne répond pas aux besoins de la consommation et la plupart des producteurs de bois ne font aucun effort pour satisfaire aux besoins nouveaux que réclame l'industrie; ils se confinent dans leurs métlodes antiques, vivant encore sous l'influence de ce vieux préjugé que "les arbres poussent tout seuls ", et, selon l'expression de M. Cyprien Girerd: "donnent des produits que l'on n'a qu'à cueillir quand on les croit mûrs, au risque souvent aussi de les cueillir quand ils sont encore verts ).

Pour remédier à cette incurie qui nuit aux intérêts privés autant qu'à l'intérêt général, il faut - nous venons de le voir, - par la vulgarisation de l'enseignement sylvicole, faire pénétrer dans l'esprit des producteurs qu'ils ont intérêt à modifier leurs aménagements en les rendant plus rationnels ; s'interdisant de mettre la cognée dans des arbres trop jeunes, sans, pour cela, attendre que la vieillesse les ait rendus impropres à toute exploitation; réglant l'leure des coupes suivant la maturité des arbres; réservant pour l'avenir un nombre d'ancêtres qui corresponde à la possibilité productive du sol; introduisant des essences nouvelles dans d'anciens massifs, comme dans des plantations récentes, d'après la nature du sol, le climat, l'altitude. C'est en vulgarisant les données de la science appliquée à l'agriculture et les méthodes nouvelles que les concours départementaux, régionaux et nationaux, par les rapports et la distribution de récompenses, ont puissamment contribué au merveilleux développement de l'agriculture française et à l'accroissement de sa productivité.

Il en sera de même pour la sylviculture si on lui fait dans les écoles, dans les expositions, les comices, la place qui lui revient.

Dans le budget de l'Agriculture, plusieurs millions figurent pour des encouragements divers (environ 10 millions). On chercherait en vain des primes à la sylviculture. Nous citons pour mémoire le chapitre relatif à la restauration et à la conservation des terrains en montagne, lequel comporte un paragraphe pour subventions aux particuliers; celui des améliorations pastorales et forestières, insuffisamment doté : 145000 francs.

Il importe aux besoins de la sylviculture de demander aux Pouvoirs publics d'accorder des primes, des subventions, aux améliorations apportées à la culture forestière, aux meilleurs procédés d'exploitation, au personnel qui aura coopéré avec zèle à ces travaux, ainsi qu'à l'exécution de reboisements et d'aménagements sylvo-pastoraux.

En résumé, il est de toute nécessité d'encourager la sylviculture, comme on encourage la grande et la petite culture, la sériciculture, la pisciculture, la culture du lin, du chanvre et la culture de l'olivier.

Il doit y avoir, en eflet, parité d'encouragement quand il s'agit de stimuler une œuvre qui a un objectif aussi impérieux que celui qui se rattaclıe à la prospérité d'une nation.

En conséquence, nous arons l'honneur de formuler les projets de v(eux suivants :

Que le diplôme d'INGÉnieur forestier soit décerné aux élèves libres de l'Ecole nationale des Eaux et Forêts de Nancy qui en seront jugés dignes; 
Que la mention Sylviculture soit portée sur le diplôme d'Ingénieur AGRICOLE délivré aux élèves des Ecoles nationales d'A griculture qui se seront particulièrement distingués dans cetle branche;

Que des notions les plus indispensables de sylviculture el d'aménagements sylvo-pastoranx soient données dans les Ecoles pratiques d'Agriculture et dans les fermes-écoles;

Que l'enseignement théorique et pratique de la sylviculture soit donné dans les écoles normales d'instituteurs, par un agent des Eaux et Forêts;

Que les éléments de cet enseignement soient inscrits dans les programmes des écoles primaires;

Que la mention Sylviculture soit portíe sur le certifical de fin d'éludes normales des maîtres qui en seront jugés dignes;

Qu'en général, l'enseignement ¿̀ tous les legrés comprenne l'étude sommaire et méthodique des notions les plus indispensables d'économie forestière et sylvo-pastorale;

Que les agents de l'Administration les Eanx et Forêts, les professenrs d'agriculture soient délégués, suivant un programme fixé annuellement, pour faire des conférences forestières et sylvo-pastorales de vulgarisation dans les écoles et partout où cette propagande pourrait être utile;

Qu'une entente s'établisse entre le ministère de l'Agriculture et celui de l'Instruction publique, afin que les Inspecteurs d'Académie et les Agents de l'Administration des Eaux et Forêts soient invités à aider, de toutes manières, la constitution de sociétés scolaires forestières, à en favoriser le plus possible le développement, à en assurer le bon fonctionnement et la pérennité, et propagent la FÊTE DE L'ARBRE;

Que les Pouvoirs publics instituent la Fête de L'Arbre;

Que les Associations touristiques, les Automobiles-Clubs, les Syndicats d'initiative, les Sociétés d'Agriculture, encouragent l'enseignement forestier et sylvo-pastoral, et concourent à l'organisation de Fêtes de l'Arbre;

Que, dans les concours nationaux ou généraux, le Ministre de l'Agricul. ture fasse à la sylviculture une place correspondant à son importance :

Par l'attribution de primes l'honneur anx meillenrs aménagements, à ceux qui auront le mieux tenu compte du climal, du sol, des essences. des besoins locaux;

Par la distribution de subventions, de récompenses, de prix aux meilleurs procédés d'exploitation des bois, à l'utilisation de leurs produits et sous-produits et à l'introduction d'essences nouvelles; en même temps qu'aux plantations dans les landes et autres terres incultes;

Par l'organisation de concours destinés à stimuler toutes les initiatives entre savants, industriels et producteurs pour la recherche de nouveaux produits et la construction des appareils propres à les extraire:

Par l'attribution de récompenses au personnel à gages qui se sera signalé dans les travanx forestiers ci-dessus et aura coopéré avec zèle à des travaux de reboisement ou d'améliorations pastorales. 
M. le Président. - Avant d'ouvrir la discussion sur les divers vœux, permettez-moi une observation d'ordre général. Ces vœux sont multiples ; mais ils procèdent tous d'une même idée sur laquelle il importe, je crois, que notre section se prononce. Cette idée est la suivante : il convient que la sylviculture soit traitée comme l'a été jusqu’à présent l'agriculture, e'est-à-dire qu'elle soit enseignée, soutenue, protégée comme l'agriculture n'a cessé de l'être depuis un siècle, ce qui a permis le grand développement que la production agricole a pris dans notre pays.

Je pose donc la question suivante: Y a-t-il lieu d'appliquer à la sylviculture les règles qui ont été appliquées à l'agriculture en ce qui concerne l'enseignement, les récompenses et les encouragements de toutes sortes?

C'est sur cette vue d'ensemble que j'appelle d'abord la section à se prononcer, avant d'entrer dans le détail des voeux.

M. de Lariag. - Je suis heureux, et je suis convaincu que nous le sommes tous, de voir que l'on songe à traiter la sylviculture comme l'agriculture au point de vue de l'enseignement et des encouragements. Mais permettez-moi de dire que nous souhaiterions, nous, forestiers, que la sylviculture fût mieux traitée que ne l'a été jusqu'ici l'agriculture, en particulier pour l'enseignement dans les écoles primaires.

Ce que nous devons demander, je crois, e'est un traitement plus favorable que celui dont bénéficie l'agriculture dans les écoles rurales. Mais tout de suite une distinction s'impose. Dans les régions comme celle de la Beauce, qui sont malheureusement dépourvues de bois, il n'y a pas lieu d'enseigner la sylviculture. Au contraire, dans les régions comme la mienne, où j'ai l'honneur d'être président d'un syndicat forestier qui groupe plusieurs départements voisins, il faut aux écoles rurales un programme d'enseignement sylvicole approprié à chaque région et assez détaillé.

11. UnвDExstock. - Nous sommes entièrement d'accord, puisque vous demandez plus que nous. Qui veut plus veut moins.

11. De Segoxzac. - Nous formulons donc deux desiderata:

$1^{\circ}$ Que l'on organise l'enseignement sylvicole dans les régions où il offre un intérêt;

$2^{\circ}$ Que l'on veuille bien traiter la sylviculture mieux que l'agriculture, laquelle, dans beaucoup de campagnes, n'a jamais été enseignée.

M. le Président. - Sur l'idée générale des voux formulés par M. le rapporteur, telle que je l'ai dégagée, personne ne demande plus la parole?...

Cette idée générale est approuvée par la section.

Je mets en délibération le premier voru proposé par M. le rapporteur, ainsi conçu : 
"Que e diplône d'ingénienr forestier soit décerné anx élèves libres de l'école nationale des Eunx et Forêts de Tancy qui en seront jugés dignes ".

M. Girot. - En ma qualité d'ancien directeur de l'école nationale de Naney, je désire appuyer très chaudement ce premier vou. Le titre d'ingénieur forestier n'est pas décerné actuellement aux élèves libres; mais l'enseignement leur est libéralement offert; le plus grand désir de ceux qui sont à la tête de cette école, - le mien quand j'avais l'honneur de la diriger, - c'est précisément d'étendre le plus possible l'enseignement forestier donné en faveur des élèves libres.

Mallieureusement, ce sont les candidats qui font délaut. Nous nous sommes évertués à faire connaitre dans toute la France les avantages que les fils de propriétaires et tous ceux qui se destinent à la carriẹre de régisseur forestier pourraient retirer de l'enseignement que donne l'école de Nancy. Ils y acquerraient les notions les plus élevées de la science forestière. Mais je dois constater que nos efforts n'ont pas abouti.

Sans doute il y a des exceptions : j'ai eu tout à l'heure le plaisir de voir quelques-uns de mes anciens élères qui, ayant suivi jusqu'au bout les cours de l'école nationale, ont bien voulu me dire qu'ils en gardaient un très bon souvenir. Mais je erois que leur cas est trop rare. Peut-être le titre que l'on propose d'accorder aux élèves remédieraitil dans une certaine mesure à l'état de choses que je signale. Mais ce qu'il faudrait avant tout, c'est de la publicité. Cette publicité, c'est à vous tous, Messieurs, qu'il appartient de la faire, chacun dans sa sphère. Vous pouvez dire autour de vous qu'à Nancy, l'enseignement sylvicole est distribué d'une manière aussi large que possible à tous ceux qui veulent bien venir le recevoir. L'école de Nancy ne demande qu'à rendre le plus de services possible. Je vois près de moi des membres du corps enseignant qui ne me démentiront certainement pas. Sans doute il en résulte pour eux un surcroit de charges et de peines, mais je suis persuadé qu'ils l'aceepteront volontiers, et qu'ils continueront à se dévouer comme ils l'ont tonjours fait à cette cuvre si belle. (Applau(dissements.)

J'ajoute qu'à Nancy - vous me direz peut-être que je prêehe pour mon saint; c'est vrai, mais puis-je done faire autre chose et n'est-il pas permis à un ancien directeur de notre école Nationale de dire ce qu'il en pense? - à Nancy, l'enseignement sylvicole est nécessairement meilleur que partout ailleurs.

Sans doute, on pourrait eréer un enseignement similaire dans les universités; mais il y manquerait toujours quelque chose. Ce qui manquera, c'est l'application praticque. Vous trouverez, pour faire des cours dans les universités, des professeurs capables de parler avee beaucoup de compétence des choses forestières. Nais ce qui fait la valeur particulière de l'enseignement rle l'école de Naney, c'est la proximité des forêts si diverses où l'application peut se faire et se fait journellement. 
C'est pourqui je erois qu'il est de l'intérêt des propriétaires et des futurs régis seur's de profiter de l'enseignement donné a l'école de Nancy. Il n'est peut-être pas saus intérêt de signaler que cet 'nseignement est absolument gratuit. Imaginez-vous que l'on nous en a fait un reproche? (Rires.) C'est en effet une idlée assez répandue que tout ce que l'on donne gratuitement ne vaut rien. (Touseaux rires.) Et à l'étranger surtout, on nous a dit: Faites donc payer vos cours, ne donnez votre enseignement que contre un bon prix; vous verrez que l'on y viendra.

Je donne cette indication à titre documentaire; mais je ne suis nullement partisan du sysième noureau qu'on nous suggère; je crois que nous pouvons continuer à nous montrer grands et généreux. Je rappelle le fait pour rous montrer avec quelle libéralite l'Arministration forestière agit à Nancy. Je vous demande à tous de voutoir bien faire connaître les avantages que l'on peut retirer de cutte organisation, unique en France, unique au monde, peut-être. (Applandissements.)

M. Désiré Pector. - On a parlé de la publicité à faire en faveur de l'école de Nancy; cette publicité pourrait être iaite aussi ì l'étranger. En ce qui me concerne, je me chargerais de faire connaitre cette école par des prospecius en langue copagnole, dans tous les pays qui nous environnent. Il y en a certainement ou l'on sera heureux de connaitre l'éeole de Naney et de profiter de son enseignement. ( 4 pprobation.)

M. Watier. - Pourquoi ne pas donner le même diplòme à tous les élèves de l'école de Nancy, sans distinetion d'élèves libres ou non libres?

M. Unbnenstock. - Je reconnais le bien fondé de cette observation. Cette mesure permettrait en effet aux élèves libres de l'école de Naney et aux "Agents des Eaux et Forêts " qui quittent l'Arministration, de faire état de leur titre d'ingénieur forestier. En conséquence, je propose de supprimer le mot "libres " dans le texte du vou.

M. Le Président. - Je mets aux roix le vocu ainsi modifié.

Le „„veu, ainsi morlifié, est adopté.

M. Le Président. - Le deuxième voeu est le suivant :

"Que la mention sylvicnlture soit portée sur le diplôme d'ingénieur agricole délivré anx élèves des écoles nationales d'ugriculture qui se seront particulièrement distingnés dans cette branche i.

M. Hı́кеL. - L'enseignement sylricole étani exactement le même à l'institut national agronomique que dans les écoles nationales d'agriculture, il conviendrait peut-être de demander que la mention sylviculture pút être ajoutée de méme sur le diplòme de l'institut agronomique.

M. Umbenstock. - Parfaitement. Le voeu serait done ainsi rédigé : 
"Qne la mention sylviculture soit portée sur les diplômes d'ingénieur ugronome et d'ingénieur agricole, délivrés anx élèves de l'Institut national agronomique et des Écoles nationales d'agriculture qui se seront particulièrement distingués dans cette branche».

Le voeu, ainsi modifié, est adopté.

M. le Rapporteur. - Troisième vœu :

"Que des notions les plus indispensables de sylviculture et d'aménagements sylvo-pastoranx soient données dans les écoles pratiques d'agriculture et dans les fermes-écoles ».

Adopté.

Quatrième rou :

"Que l'enseignement théorique et pratique de la sylviculture soit donné dans les écoles normales d'instituteurs, par un agent des Eanx et Forêts ».

1I. Watier. - Dans son rapport, M. le rapporteur s'est basé sur l'eriseignement qui est donné à Albertville. Albertville appartient à ma circonseription, l'agent forestier qui y fait le cours touche des émoluments. Il me semble qu'il serait bon d'ajouter au vœu que nous demandons au Parlement de vouloir bien voter les crédits nécessaires.

11. UMBDEхsтоск. - J'estime que nous n'avons pas à nous occuper de la question budgétaire que soulève notre voru.

M. DE LaRvige. - Je propose de modifier comme suit la rédaction du voeu : "... par un agent des Eanx et Forêts ou pour tout ingénieur agronome ou agricole ayant sur son diplôme la mention sylviculture ".

Le vœu, ainsi modifié, est adopté.

M. Le Rapporteur. - Cinquième rou :

"Que les éléments de cet enseignement soient inscrits dans les programines des écoles primaires $\%$.

MI. DE LAnxige. - Je demande que la formule du reeu soit précisée. On pourrait le rédiger dans les termes suivants:

"Que les éléments de cet enseignement, spécialisé selon les besoins de la région oì il est donné, soient inscrits dans les programmes des écoles primaires ".

Le vou, ainsi modifié, est adopté.

M. Le Rapporteur. - Sixième vou :

"Que la mention sylviculture soit portée sur le certificut de fin d'études normales des maîtres qui en seront jugés dignes". Adopté. 


\section{Septième rou :}

"Qu'en général l'enseignement à tous les degrés compremne l'étude sommaire et méthodique des notions les plus indispensables d'économie forestière et syloo-pastorale ".

Arlopté.

Huitiène vou :

"Qne les agents de l'administralion des Eanx et Forêts, les professentrs d'agriculture soient délégués, suivant un programme fixé annuellement pour faire des conférences forestières et sylvo-pastorales de vulgurisation dans les écoles et partout où cette propagande pourruit être utile".

M. DE Lipnage. - Je m'excuse de prendre à nouveau la parole. 11. le rapporteur propose d'émettre le vau que les agents de l'Administration des Eaux et Forêts, dont ou nous a dit qu'ils étaient surchargés par leurs propres fonctions, soient appelés encore à donner un enseignement complémentaire.

Je demande que le vœu soit rédigé de telle sorte que l'on puisse faire appel aux nembres des Sociétés sylvicoles de la région, et que la formule soit telle qu'elle ne semble pas exclure telle ou telle Société qui ne porterait pas le nom de syndicat. (Approbation.)

M. we Nicolay. - Je tiens à dire qu'il me parait très intéressant de faire appel à l'initiative privée pour l'enseignement sylvicole. Je crois que les organisations privées disposent de ressources susceptibles de donner à notre enseignement une grande force.

M. De Bazelare de Lesseux. - L'initiative privée est en effet une force appréciable; mais elle ne peut généralement plus rien quand on la soumet au contrôle administratif. Que les éléments privés restent indépendants! Ils travaillent, c'est parfait. Mais ne les mêlons pas à l'administration.

D'ailleurs quelle garantie offriraient-ils? La sylviculture est une science trop spéciale.

M. DE Nicolay. - La question posée par M. de Larnage découle d'une proposition antérieure, à savoir la spécialisation des enseignements sylvicoles. Les éléments privés peuvent intervenir d'une façon heureuse quand il s'agit d'une culture spécialisée, comme le gemmage, ou quand il s'agit ،'une culture locale, pineraies ou châtaigneraies, par exemple. Il est rertain que jamais un propriétaire ne pourra s'introduire dans des constrils d'études sylvicoles ayant une portée générale.

M. Lecoo. - Je ne suis pas un adversaire de l'initiative privie. Je suis le président d'un syndicat qui a fait des efforts couronnés de succès pour introduire l'enseignement sylvicole dans les écoles primaires. 
Je craindrais cependant que l'emploi de membres de syndicats comme professeurs n'entrainât certaines difficultés.

M. Le Présidext. - II. de Larnage demande qu'après les mots "les professenrs d'agriculture ", soient ajoutés les mots "et en général les

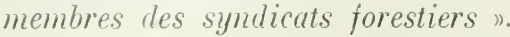

M. de Larvage. - Certaines Sociétés ne portent pas le nom de Syndicat; pour qu'elles ne soient pas exclues, on pourrait dire "et en général les membres des Sociétés sylvicoles ». (Assentiment.)

Le vou, ainsi modifié, est adopté.

M. le Rapportelr. -- Neuvième vou :

"Qu'une entente s'établisse entre le Ministère de l'A griculture et celni de l'Instruction publique, afun que les inspectenr's d'académie et les agents de l'administration des Eanx et Forêts soient invités à aider de toutes manières la constitution de Sociétés forestières, à en faroriser le plus possible le développement et la pérennité, et propagent la fête de l'Arbre ".

Adopté.

M. Umbdenstock étant appelé dans une autre Section, un Secrétaire continue la lecture des vœux

Dixième you :

"Que les Pouvoirs publics instituent la fête de l'Arbre ".

Plusievrs Congressistes. - Le voru parait inutile, puisque la fête existe déjà. (Assentiment.)

Le dixième roeu n'est pas adopté.

M. le Président. - Onzième voeu :

"Que les associations touristiques, les automobile-clubs, les syndicats d'initiative, les sociétés d'agriculture, encouragent l'enseignement forestier et sylvo-pastoral et concourent à l'organisation de fêtes de l'Arbre ».

M. DE Segoxzac. - Il faut supprimer le dernier membre de phrase, puisque le rou précédent n'a pas été adopté.

M. Le Président. - Il n'y a nullement contradiction entre le rejet du vou précédent et l'adoption de celui-ci, dans les termes où il est présenté. La formule adoptée n'engagte à rien.

M. de Segoxzac. - II ne faut pas que l'on fasse aux associations une obligation d'organiser ces fêtes. 
M. Roux. - On ne voit pas quelle autorité pourrait imposer une obligation de cette sorte aux associations touristiques.

Le onzième roeu est adopté.

Douzième voeu :

"Que, dans les concours nationanx ou généraux, le. Hinistre de l'Agriculture fasse d̀ la sylviculture une place correspondant à son importance ;

"Par l'attribution de primes d'honneur aux meilleurs aménagements, à ceux qui auront le mieux tenu compte du climat, du sol, des essences, des besoins locanx;

"Par la distribution de subventions, de récompense's, de prix, aux meilleurs procédés d'exploitation des bois, à l'utilisation de leurs produits et sous-produits et à l'introduction d'essences nouvelles, en même temps qu'aux plantations dans les landes et antres terres incultes;

"Par l'organisation de concours destinés à stimuler tontes les initiatives entre savants, industriels et producteurs pour la recherche de nouveaux produits et la construction des appureils propres à les extraire;

"Par l'attribution de récompenses au personnel à gages qui se sera signalé dans les travaux forestiers ci-dessus et aura coopéré avec zèle à des travanx de reboisement ou d'améliorutions pastorales $"$.

Le douzième vœu est adopté sans discussion.

La séance est levée à midi. 


\title{
SEANCE DU 16 JUIN 1913
}

\author{
(APRÈS-IIIDI)
}

\section{Présidence de M. Cyprien GIRERD, président de Section}

La séance est ouverte à 2 h. 15 .

M. Le Président. - L'ordre du jour appelle une communication de 11. Ricardo Codorniu sur la Fête de l'Arbre en Espagne. La parole est à M. le Secrétaire pour donner connaissance de cette communication.

M. Le Secrétarre, lisant:

\section{LA F ETTE DE L'ARBRE EN ESPAGNE}

Précédents et renseignements relatifs à sa célébration. - Fêtes en 1912.

La Fête de l'Arbre a d'honorables précédents en Espagne : en effet, en 1805, à Villanueva de la Sierra, localité de la province de Caceres, un prêtre décida de faire une plantation de peupliers, et, convaincu de la nécessité qu'il y avait à donner à ces entreprises le caractère d'une fète, non seulement pour éveiller les initiatives, mais encore pour faire naître l'idée du mérite et de l'utilité, il réunit la jeunesse, or ranise un banquet et un bal qui suivirent la plantation projetée.

En 1817, à Léon, on célébra une grande fête à l'occasion de la cléation du jardin de Saint-Francois; les dames elles-mêmes plantèrent des arbres en présence de toute la population, il y eut concert et feu d'artifice, distribution de pain aux pauvres, procession civique et bal de société.

Le Semanario Industrial mentionna, en 1840 , une autre fète, mais malheureusement il oublia de citer le nom de la localité où elle eut lieu. Il disait que dans le but de mettre un terme à l'hostilité des habitants envers l'Arbre, on se rendit en procession à un endroit où le prètre harangua la population et se mit à creuser de sa propre main des fossés, il fut secondé par tous les habitants. Huit jours plus tard on procéda à la plantation. "L'amour-propre et la vanité "des familles les incita à confier aux jeunes gens et aux enfants la garde d'un "certain nombre d'arbres ", dit le journal, et il ajoute: "Ies fils et les petits" fils de ceux qui assistèrent à cette inoubliable cérémonie, contemplent encore "la plantation avec estime et vénération.

On ne parlà plus de ces fêtes pendant plusieur's années, jusqu'au moment où le grand patriote Raphaël Puigy Valls, le très distingué ingénieur des Forèts, attristé par les malheurs rui ont frappé notre pays au cours des dernières aunées du siècle écoulé, pensa qu'il fallait le régénére r en faisant ainer l'arbre et en meltant la propagation de ce sentiment à la hauteur des exigences du climat et de l'orographie de la péninsule ibérique ; il considéra que le meilleur moyen d'y parvenir, útait d'instaurer la Fìte de l'Arbre. A cet effet, il 
commença par fonder à Barcelune, en 1898, la Société des Amis de la Fête de I'Arbre, qui, depuis 1900, publie de belles chroniques annuelles sur les Fêtes célébrées dans toute l'Espagne.

Le 11 mars 1904 , parut un décret royal conférant à la Fête un caractère officiel disposant que la direction supérieure de ce service ressortirait à l'Inspection des repeuplements forestiers et piscicoles, que l'on foumirait des semences, que l'on créerait des pépinières à l'effet de procurer gratuitement des plants à ceux qui voudraient célébrer ces fêtes, qu'on accorderait des prix pour les fètes qui antraient le mieux réussi, et que l'on récompenserait les maires, les médecins, les pharmaciens et les professeurs qui se seraient distingués le plus.

A cette fin, on a créé neuf pépinières, qui ont produit, en 1912, 487.185 plants, avec un budget de 30.000 pesetas. Chacun de ces plants a coûté en moyenne six centime. De plus, les pépinières forestières de l'Escurial et de Logroño ont donné respectivement 65.300 et 21.146 plants, de sorte que le total des plants que l'État a mis à la disposition des organisateurs de la Fête de l'Arbre, a été, pour 1912, de 573.631.

Persuadé que cette Fète, grâce à la distribution gratuite aux particuliers de plants et de semences, constitue le moyen le plus pratique de propagande forestière, on s'efforce de hi donner un caractère éducatif, èt, pour faciliter la réalisation de ce but, on publie, dans les bulletins officiels des différentes provinces, des circulaires au moyen desquelles l'Inspection de Repopulatior.s préconise la célébration de la Fête et fait connaître le nombre et l'espèce des plants qui existent dans les pépinières pour qu'on puisse en faire la demande. On distribue des brochures contenant la législation en vigurur, des conseils, des poésies, des maximes destinés à être lus au cours de la Fête ou pourant servir d'aide-mémoire à ceux qui doivent y prononcer des discours, on y fait figurer également les paroles et la musique de l'hymne à l'arbre.

Les Chroniques de la Fête et la propagande en tous sens, font que l'idée prend corps et se généralise, que chaque année on en célèbre un nombre pli:s considérable, à tel point que ce nombre, qui, jusqu'en 1911, n'avait pas dépassé 80 fêtes, a atteint, en 1913, le chiffre de 409 ; de plus, il résulte de renseigrements récents que ce nombre, qui s'accroît constamment, dépassera selon toute probabilité 450 .

Ces fêtes de l'Arbre contribuent à diminuer, sinon à faire disparaître complètement, les dommages causés aux arbres par les enfants et même par les hommes, à encourager beaucoup de propriétaires, qui, jusqu'alors n'y avaient pas songé, à faire des plantations. Grâce à elles, diverses localités ont été dotées de nouvelles promenades et de pares, des rues et des places ont été plantées d'arbres, et il en est résulté un goùt marqué pour la culture des espèces les plus recherchées ou les plus belles.

De notables exemples de sympathie pour la fête, ont été fournis par les gouverneurs actuels des provinces de Léon et de Grenade, MM. Bonito del Campo et José Corral y Latorre, rui ont été remarquablement secondés, respectivement, par les Ingénieurs des Forêts, MM. Eugenio Cuallart et José Almagro, l'ingénieul' des Forèts à Cuenca, M. Enrique de las Cuevas, le secrétaire de la Commission d'Instruction publique de Léou, M. Miguel Bravo, le professeur d'Agriculture de l'Institut de La Corogne, M. José-María Hernandez et bien d'autres.

Il est juste aussi de reconnaître les efforts qui ont été faits pour propager la Fête, en premier lieu par la Société espagnole des Amis de l'Arbre, au moyen d'une très active propagande dans son Bulletin, de la distribution gratuite de brochures et de cartes-postales, de la publication d'annonces, etc, et enfin de la célébration de la Fête à Getafe; grâce à cette cérémonie, on a commencé la repopulation du . Cerro de los Angeles n, point situé au centre de l'Espagne. L'Association des Amis de la Fête de l'Arbre à Barcelone a publié au cours de cette année la Chronique de la Fête de l'Arbre, en Espagne en 1910, beau volume de 132 pages, eomprenant de nombreuses photogravures. Nous devons 
signaler également la brochure intitulée : "La Fête de l'Arbre ", publié à Léon; cet ensemble de renseignements, de précédents et de pratiques en vue de sa célébration, est dû à la plume d'un enthousiaste de l'Arbre. Mentionnons aussi le Souvenir de la Fête de l'Arbre, célébrée au Séminaire concilaire de Madrid le 17 mai. La revue de l'enseignement primaile El Profesorado, organe de l'Association des Professeurs de la province de Grenade, a publié un numéro spécial, où se trourent décrites les quatre-vingt-douze fêtes célébrées en 1912 dans cette province, et le numéro spécial du Magisterio Conquense, consacré à la Fête célébrée à Cuenca.

Nous ne devons pas passer sous silence les deux vœux que j'ai eu l'honneur de formuler et qui ont été approuvés à l'unanimité par le cinquième Congrès International de Tourisme, célébré à Madrid au cours de ladite année :

$1^{0}$ Recommander aux administrations communales de défendre et de propager les arbres des routes, rues et promenades, en les considérant comme un ornement important; d'empêcher les tailles blâmables qu'on leur fait subir, et aussi de demander aux Gouvernements provinciaux, aux Municipalités et aux particuliers de propager les arbres forestiers et fruitiers, tant dans les campagnes que sur les versants des montagnes, ainsi que ceux qui se trouvent placés par groupes ou isolément dans les pâturages; de proposer que l'on coupe les vallées au moyen de "rideaux d'arbres, " dans le but de modérer pendant le jour les rapides courants d'air qui s'y produsent, et, de plus, que l'on généralise en rendant obligatoire pour toutes les administrations communales, la célébration de la Fète de l'Arbre, en lui donnant un caractère éducatif.

$2^{\circ}$ Recommander également qu'aux abords de toute localité ou agglomération, où ne se trouve pas de montagne, on réserve une certaine extension de terrain pour la cultule fol'estière, ceci à l'effet d'éveiller chez les habitants l'amour des arbres et de les doter d'un endroit susceptible d'élargir leur esprit ainsi que des moyens nécessaires à l'étude des sciences naturelles.

C'est tout ce que je crois devoir soumettre au Congrès pour qu'il se rende compte et du développement que la Fète de l'Arbre a acquis en Espagne et des résultats qui en découlent.

Je prie le Congrès de daigner adopter un vou tendant à recommander aux Gouvernements et aux forestiers de tous les pays de faire célébrer la Fète de l'Arbre dans toutes les localités et agglomérations, c'est un excellent moyen éducatif pour faite pénétrer dans les masses l'amour de l'arbre et de la montagne, qui assainissent, embellissent et enrichissent le pays.

M. Le Présidext. - La section donne acte à M. Ricardo Codorniu de la communication qu'il a faite.

L'ordre du jour appelle le rapport de M. Guinier sur la Répartition DES VÉGETATX LIGNETX EN France.

M. Guinier a la parole pour donner lecture de son rapport.

M. Ph. Guixier. - La sylviculture repose sur la connaissance de l'écologie des essences forestières, c'est-à-dire sur l'étude de leurs rapports avec le milieu dans lequel elles vivent. Ce n'est qu'à la condition de bien connaître les exigences, le tempérament des arbres que le forestier pourra agir sur la forêt, intervenir dans la lutte engagée entre les végétaux qui la constituent et modifier de la manière économiquement la plus profitable l'équilibre qui s'établit à chaque instant. Cette condition est non moins essentielle pour la pratique des boisements artificiels qui ne réussiront que si les essences plantées se trouvent dans le milieu qui leur convient.

La méthode tout naturellement employée pour déterminer les particularités écologiques d'une essence consiste à étudier les stations où 
l'espèce croît spontanément, à définir le plus strictement possible les conditions qui y règnent et à dégager en quelque sorte les facteurs communs à toutes ces stations. Le point de départ de l'étude est donc la connaissance de la répartition géographique de l'essence.

Mais, en outre, cette connaissance procure directement des indications précieuses et souvent plus sûres. Il faut remarquer que nos moyens d'investigation concernant les conditions de climat et de sol sont bien imparfaits pour apprécier les variations souvent très faibles qui agissent grandement sur les végétaux; les plantes, et en particulier les arbres, sont vis-à-vis du milieu des enregistreurs d'une extraordinaire sensibilité; au contraire, nos stations météorologiques sont trop peu nombreuses, nos méthodes d'analyse des sols insuffisamment perfectionnées : plus d'un facteur important peut nous échapper. C'est d'ailleur's une habitade ancienne que d'inverser le problème et de définir le milieu par l'existence d'une plante au lieu d'expliquer la présence de la plante en précisant les conditions du milieu; on dit couramment le climat de l'olivier, une terre $\dot{a}$ blé. La connaissance de la répartition géographique d'une essence, la constatation de la vigueur plus ou moins grande de son développement sur les divers points de son aire peuvent servir de guide pour le traitement des massifs existants ou la création de peuplements nouveaux. On est amené ainsi à délimiter la région où l'arbre trouve les conditions les plus favorables, son optimum; celles au contraire où il se trouve en état d'infériorité dans la lutte pour la vie. Cette notion de l'optimum, développée notamment par Mayr a une importance capitale en sylviculture : elle intervient pour expliquer des différences dans la rapidité de croissance, la facilité de régénération, la qualité du bois, et justifie de pratiques différentes dans la conduite des peuplements suivant les régions. Dans le cas de boisements artificiels, la connaissance de l'aire d'une essence suffira pour déterminer la possibilité de son introduction et ses chances de réussite dans un endroit donné.

L'étude de la répartition géographique est nécessaire pour nos principales essences; elle est souvent tout aussi utile pour des essences secondaires, même pour des arbustes ou des arbrisseaux. Il ne faut pas oublier que les divers végétaux qui constituent une forêt sont solidaires; ils se réunissent en associations parce qu'ils ont des besoins communs ; leurs aires géographiques présentent des parties communes sans que d'ailleurs leurs optima coinncident. Les végétaux ligneux d'importance secondaire servent de réactifs des conditions de milieu et leur présence renseigne sur la valeur de la station pour les grandes essences qui leur sont habituellement associées. L'existence dans une forêt du Sorbier des oiseleurs (Sorbus ancuparia L.) et de la Myrtille (Vaccinium Myrtillus L.), associés au sapin (Abies alba Mill) dans toute son aire, mais a yant une répartition plus large que lui, indique que ce résineux trouverait là des conditions suffisamment favorables. La présence de l'Aune vert (Alnus viridis $D C$ ) sur une montagne déboisée donne au forestier la certitude qu'il pourra y créer un peuplement de Mélèze (Larix decidua Mill.) ou d'Epicéa (Picea excelsa $L k$ ).

La connaissance de la répartition géographique des végétaux ligneux en général apparaît donc comme une nécessité, comme une condition des progrès de la sylviculture et de l'art du reboisement.

Il faut reconnaître que, actuellement, les données que nous possédons 
sur ce sujet sont bien loin d'être suffisantes. Il est singulier de constater même que, pour de grandes essences, il est parfois impossible de préciser leur répartition, et que des erreurs manifestes se trouvent constamment répétées. En France, au moyen des documents actuellement publiés, on ne peut décrire avee la précision désirable la répartition du Chêne Yeuse (Quercus Ilex L.) dans l'Ouest ni indiquer ses stations sur une carte.

Dans les travaux publiés, on néglige bien souvent de distinguer le Chêne Rouvre (Quercus sessiliflor'a Sm.) et le Chêne Pédonculé $(Q$. pedunculata Ehrh.), ces deux essences si différentes par leur's exigences. Dans les ouvrages les plus sérieux publiés à l'étranger jusque dans ces dernières années, on englobe dans l'aire naturelle de l'Epicea (Picea excelsa Lk.) le Mașsif central et les Pyrénées où cet arbre n'a jamais été spontané. A plus forte raison, l'incertitude la plus complète règne en ce qui concerne les essences moins répandues. L'Orme diffus (Ulmus effusa Willd) qui occupe quelques stations, surtout dans l'Est, passe inaperç ; dans les Pyrénées-Orientales, le Pin Laricio de Salzmann (Pinus Laricio Poir. var. Salzmanni Dun.) est resté ineonnu jusqu'à une époque récente; la découverte du Pin à crochets (Pinus montana Mill. ssp. uncinata Ram.) dans le Massif central est un fait presque d'actualité.

Quelles sont les raisons de cet état de choses? L'étude des arbres est à la fois du domaine de la botanique et de la sylviculture et il semblerait que de deux côtés on devrait s'y intéresser. En fait, il n'en est rien.

Les botanistes considèrent volontiers que l'étude des arbres constitue une branche spéciale, la dendrologie, qu'ils négligent. Les arlses offrent, il est vrai, plus d'une particularité qui en rend l'étude un peu compliquée, au moins matériellement; leurs rameaux sont souvent peu accessibles et il est difficile de s'en procurer des échantillons complets, avee fleurs et fruits, d'autant plus que la floraison a lieu chez beaucoup d'espèces, à une époque très précoce, avant le développement des feuilles, ce qui exige la récolte de rameaux à plusieurs moments de l'année sur le même arbre. Les botanistes collectionneurs, qui sont en majorité, reprochent aux végétaux ligneux d'être encombrants et de mal se prêter au classement en herbier. Si on consulte des herbiers même très complets, on est frappé de voir combien la flore ligneuse y est mal représentée. Dans les flores, les catalogues régionáux de plantes, on relève couramment des inexactitudes et des lacunes en ce qui eoneerne la répartition des arbres et arbustes. Dans des récits d'herborisations, il est courant de ne trouver aucune mention des arbres rencontrés et on peut citer des comptes rendus d'excursions botaniques en forêt où on ne dit pas de quelles essences se composent les forêts visitées. Des botanistes expérimentés, qui rougiraient de confondre deux espèces herbacées très voisines, arouent sans fausse honte qu'ils ne connaissent pas des arbres très répandus. Il y a des botanistes spécialistes, des dendrologues, mais le nombre en est restreint et de plus leur attention attirée par les innombrables espèces de végétaux ligneux exotiques cultivés dans les pares se concentre rarement sur les essences indigènes.

Le concours des botanistes se trouvant ainsi faire défaut en vertu d'un état d'esprit fâcheux, mais indéniable, il semble que l'on puisse compter sur les forestiers. Diverses raisons font que l'on ne trouve pas non plus de ce côté toutes les ressources que l'on pourrait attendre. Il y a bien des manières d'envisager la forêt. Le naturaliste la conçoit comme une 
réunion de végétaux dont.il étudie les caractères et le mode de vie, le sylviculteur concentre son attention sur les quelques essences principales et en détermine les conditions de croissance et de régénération ; l'aménagiste, se plaçant au point de vue économique, cherche à se rendre compte de l'accroissement, du volume et de la valeur des peuplements. On peut encore considérer la forêt au point de vue administratif, comme un domaine dont la gestion soulève une quantité de questions, construction te entretien de routes, questions de délimitation, de surveillance. Les forestiers, régisseurs du domaine boisé, se préoccupent avant tout de l'administrer et de le faire produire ; l'administration, l'aménagement, la sylvieulture purement pratique les absorbent et les empêchent de s'intéresser à d'autres questions, dont peut-être, jusqu'à présent, on n'a pas fait ressortir assez l'importance et les applications directes à la sylviculture. Assez nombreuses sont les études surtout historiques et économiques publiées par des forestiers sur les forêts qu'ils ont eu à gérer, infiniment plus rares sont les études où on se préoccupe aussi de la description même de la forêt, de l'étude des essences qui la composent, des conditions de leur développement. D'ailleurs on peut exprimer d'une manière générale le regret que les forestiers qui ont fait un long séjour dans une région, qui ont appris à la connaître et y ont réuni de nombreuses observations de tous ordres, ne publient pas plus souvent sous forme de notes ou de mémoires les résultats de leur expérience. Il se constituerait ainsi une collection de monographies des diverses régions forestières, qui serait une mine inépuisable de renseignements utiles, à tous égards, pour les progrès de l'art forestier. Il y a aussi une raison pour laquelle, malgré tout, les forestiers ne peuvent apporter qu'une contribution partielle à la connaissance de la répartition des végétaux ligneux : c'est qu'étant seulement chargés de la gestion des forêts soumises au régime forestier, ils sont très inégalement répartis en France. Ceux dont la circonscription restreinte comprend des forêts bien groupées ont l'occasion de parcourir presque tout le pays et peuvent le connaître parfaitement. On ne peut demander les mêmes renseignements à ceux dont l'activité est appelée à s'exercer dans des forêts réparties sur un ou plusieurs départements.

On peut s'expliquer ainsi que jusqu'à présent l'étude de la flore forestière, en France en particulier, et en Europe en général, ait été négligeee, en ce qui concerne notamment la répartition des espèces.

En France, les documents que nous possédons sur la répartition et d'une façon plus générale, sur l'écologie des végétaux ligneux sont peu nombreux. Ce sont des indications générales ou locales, parfois vagues ou incomplètes, éparses dans des ouvrages forestiers et dans diverses flores et eatalogues de plantes. Le seul ouvrage où ces indications sont réunies et condensées est la Flore forestière de Mathiell; cet auteur a essayé de caractériser chaque espèce au point de vue écologique et de définir sa répartition géographique. Ce sont les données rassemblées par Mathieu qui ont été reproduites avec des modifications de détail par les autres auteurs qui ont été amenés à traiter depuis la question en vue de ses applications à la sylviculture ou au reboisement. Mais ce ne sont là que des indications générales.

Dans la Statistique forestière publiée par l'Administration des Forêts en 1878, il existe cependant un document plus complet et plus détaillé. 
Mathieu, qui dirigeait le travail, a rassemblé les renseignements fournis par les agents forestiers sur la répartition en France de 36 espèces et a tracé pour 12 d'entre elles des cartes de distribution. Ce travail, très consciencieux, est pourtant complètement insuffisant. Son défaut fondamental vient de la conception purement administrative qui y a présidé : on a pris comme base la circonscription administrative, le département ou, plus fréquemment, le cantonnement forestier, et l'on n'a considéré que les forêts soumises au régime forestier. D'une façon générale, c'est une méthode inacceptable que de s'appuyer pour l'étude de faits naturels, sur des divisions administratives purement arbitraires. En particulier, le cantonnement est d'étendue très variable et ne peut être considéré comme homogène ; or, on donne pour la fréquence d'une essence dans un cantonnement un résultat moyen, en généralisant à toute la circonscription les faits consignés pour une ou deux localités. On ne łient aucun compte de la localisation des essences en fonction de l'altitude, du sol, des circonstances topographiques. Le procédé apparaît particulièrement choquant sur les cartes de distribution par cantonnement du Chêne Yeuse (Quercus Ilex L.), de l'Epicea (Picea excelsa Lk.), du Chêneliège (Quercus Suber L.). La grande inégalité de surface des cantonnements augmente encore l'imprécision de la documentation : la généralisation d'un fait dans les conditions précédentes a plus d'inconvénients pour un département que pour un seul canton. La considération exclusive des forêts soumises au régime forestier est une autre cause d'inexactitude; dans certains cas on a admis, pour établir la statistique, que les forêts particulières d'une région sont analogues aux forêts soumises au régime forestier, composées des mêmes essences, associées dans les mêmes proportions ; cette hypothèse, admissible dans les pays où les forêts particulières sont peu étendues et englobées dans les forêts domaniales on communales, conduit à de fortes erreurs dans les pays on les circonstances sont différentes. Enfin il est inévitable que dans un travail de la nature du précédent, dû à la collaboration d'un grand nombre de personnes, se glissent des erreurs provenant de malentendus ou d'oublis. On en a une prenve manifeste dans certaines lacunes figurant sur la carte de distribution des Chênes Rouvre et Pédonculé (Quercus sessiliflora Sm. et $Q$. pedunculata Ehrh.), lacunes correspondant à des régions où l'une au moins de ces essences est abondante.

On doit donc conclure que ni les données consignées par Mathieu et les auteurs qui l'ont suivi, ni les indications plus détaillées de la Statistique forestière, ne suffisent à nos besoins actuels. Elles constituent une première approximation, mais sont incomplètes, même pour nos grandes essences.

La nécessité de l'étude de la répartition des végétaux ligneux a été nettement énoncée, en 1894, par M. Flahault. Il a exposé à cette époque un projet de Carte botanique, forestière et agrieole de la France: il proposait d'emplacer sur une carte les groupements de végétaux, les associations végétales, occupant les diverses stations d'une région. Le but poursuivi est un peu différent de celui que l'on se propose en étudiant simplement la répartition des végétaux ligneux; on considère des ensembles et non plus des espèces isolées ; la carte est synthétique et non analytique. Mais, en fait, les essences forestières principales sont toujours les caractéristiques, les dominantes, de la plupart des associations régétales; l'étude de ces associations amène à l'étude de la distribution de ces essences. 
La méthode proposée, l'indication sur une carte des résultats constatés, est d'ailleurs le procédé le plus commode et le plus précis pour se rendre compte de la localisation des espèces et de ses causes. Au point de vue des applications à la sylviculture et à l'art du reboisement, l'auteur a montré comment une telle carte rendrait les services que nous demandons à une connaissance plus rigoureuse de l'écologie et de la répartition des arbres. M. Flahault a établi lui-même un certain nombre de feuilles de la carte de France projetée ; il a en outre, dans diverses publications, contribué à préciser les conditions de vie et la distribution de certaines de nos espèces ligneuses. Malheureusement les cartes établies ne concernent que la région méditerranéenne et quelques territoires attenants, et une seule a été publiée. Jusqu'à présent les efforts tentés dans d'autres régions par divers auteurs sont peu considérables.

A l'étranger', la situation est sensiblement la même qu'en France et le manque de renseignements certains sur la répartition des essences forestières a frappé tous les auteurs. Ce sont des forestiers qui ont pris l'initiative d'un mouvement en faveur d'une étude sérieuse de la question. En 1894, le premier Congrès des Stations de recherches forestières, réuni à Vienne, émettait, sur la proposition de M. Schuberg, un vœu dans ce sens. Les années suivantes, une commission, composée de forestiers allemands, autrichiens et suisses, déterminait la marche à suivre et élaborait un programme de recherches. La question fut de nouveau discutée au Congrès des Stations de recherches forestières à Zurich en 1900; on y décida de concentrer d'ahord les efforts sur quelques essences, les plus importantes, de réunir pour celles-ci des documents complets sur leur répartition naturelle et de reporter les résultats acquis sur des cartes. Le travail a été commencé et quelques résultats sont publiés. En Allemagne, la Station de recherches prussienne a publié des données complètes sur la distribution géographique dı Pin Sylvestre (Pinus Sylvestris L.), de l'Epicéa (Picea excelsa Lk.), du Sapin (Albies alba Mill.), dans l'Allemagne septentrionale et moyenne. En Suisse, une enquête a été organisée en 1902, dans chaque canton, par les soins de l'Inspection fédérale des forêts et de M. Schröter. Quelques résultats ont déjà été publiés.

Le moment est venu de se mettre à l'œuvre. Pour les progrès de la sylviculture, pour la réussite complète de l'œuvre du reboisement, il est nécessaire de remplacer les documents imparfaits que nous possédons sur la répartition de nos 'végétaux ligneux par des documents plus précis répondant mieux aux exigences modernes. Le travail à entreprendre est de longue haleine. C'est par une collaboration aussi large que possible des botanistes, des forestiers, de tous ceux de plus en plus nombreux qui s'intéressent à la forêt, que l'on pourra atteindre le but. L'attention étant tournée de ce côté, on rassemblera des clonnées, on provoquera dans certains cas des enquêtes locales. Ces résultats épars pourront être ensuite réunis en un travail d'ensemble, d'abord pour les essences les plus importantes, ensuite pour les essences secondaires, les arbustes et arbrisseaux. Ce travail de synthèse est du ressort d'une Station de recherches forestières; il est désirable de voir la Station de recherches annexée à l'École des Eaux et Forêts, en prendre l'initiative. 
Nous avons l'honneur de formuler le projet de vœu suivant:

Que l'attention des botanistes et des forestiers soit attirée sur l'étude des végétaux ligneux de la flore française en particulier, au point de vue de leur répartition géographique et de leurs relations avec les conditions de milieu.

Que les faits observés dans chaque région, quelle que soit leur importance, soient publiés sous forme de notes ou de mémoires; qu'il soit dressé le plus possible de cartes régionales indiquant la répartition des essences ou de préférence la répartition des associations qu'elles caractérisent, en s'inspirant des principes posés par M. Flahault.

Que des études d'ensemble soient organisées par la Station de recherches de l'Ecole des Eaux et Forêts avec le concours de tous les agents des Eaux et Forêts.

\section{(Applaudissements).}

M. HickeL. - 11 y a vraiment peu de chose à ajouter au rapport si bien défini que vient de nous présenter $\mathrm{M}$. Guinier.

Vous me permettez toutefois de souligner la portée pratique de l'exposé que vient de faire M. Guinier. Il ne s'agit pas évidemment d'essences rares, tellement clairsemées sur notre territoire que la plupart d'entre nous les ignorent, comme par exemple le quercus ilex réduit à une fraction des départements méridionaux, et qui cependant aurait une utilisation pratique, puisque c'est une essence à laquelle on a eu déjà recours pour les reboisements.

Mais à còté de cela, il se produit des confusions même pour des espèces courantes.

II. Guinier a fait allusion au chêne rouge et au chêne pédonculé, et a dit que nous ignorions leur répartition, ce qui est exact. Mais il y a mieux. Les forestiers ont un arbre qu'on appelle le chêne bâtard dans la Gironde, le chêne blanc dans certaines régions, le chêne noir dans d'autres régions : nous ignorons absolument toute la répartition de ce chêne, et cependant ce serait important à connaître, car c'est une espèce qui a des propriétés tout à fait particulières, qui s'adapte parfaitement aux terrains secs, calcaires, très ensoleillés : c'est donc une essence susceptible d'utilisations particulières très intéressantes dans certains cas déterminés.

En outre, elle n'atteint pas les dimensions et n'a pas les qualités technologiques du chêne rouge ni du chêne pédonculé. Lorsque nous achetons des chênes pour nos reboisements, les plus précis d'entre nous commandent du chêne ronge ou du chêne pédonculé. Mais on leur facture toujours du chêne commun, de façon à éviter le recours ultérieur, car les maisons de graines reçoivent toujours tardivement leurs approvisionnements, et lorsqu'elles les reçoivent, les caractères fugaces qui permettent de reconnaître les glands des différentes espèces de chênes ont disparu.

De même il est très difficile de reconnaitre les glands du chêne tauzin. 
Dans certaines régions du centre de la France, les agents ont reçu sous le nom de chêne commun du chêne tauzin, de sorte qu'à côté de chênes devant atteindre 30 à 35 mètres, ils pouvaient mettre des arbres qui ne dépassent presque jamais 15 mètres.

Je voulais simplement, par cet exemple concret, vous montrer l'importance tout à fait particulière que la connaissance exacte de la location des essences présente en pratique. (Applaudissements.)

M. le Présidext. - Nous remercions M. Hickel des renseignements extrêmement intéressants par lesquels il vient de confirmer les données de M. Guinier, dont nous ne pouvons qu'approuver le rapport.

Je vais mettre aux voix ses conclusions. Je ne crois pas qu'on puisse faire d'opposition au roeu de M. Guinier, que j'ai l'honneur de mettre aux voix.

Adopté.

L'ordre du jour appelle la communication de M. Durand : ConSIDÉRATION SUR LE DÉBOISEMENT.

La parole est à M. le Secrétaire pour en donner connaissance.

M. Le Seqrétaire. - M. Durand expose que le rendement des coupes de taillis sous futaie diminue chaque année dans les forêts des environs de Paris pour les causes suivantes :

10 Dégâts causés par les lapins dans les jeunes taillis

$2^{\circ}$ Anénagement trentenaire des coupes qui empêche le rejet du taillis dans de bonnes conditions.

$3^{\circ}$ Trop grand nombre de réserves et spécialement de baliveaux, ce qui est la ruine du taillis. (Murmures, protestations.)

$4^{\circ}$ Défaut de curage des fosses d'assainissement qui s'oppose à la croissance du taillis dans les bas fonds et les parties humides.

M. Le Présidext. - Je mets aux voix la proposition de donner à M. Durand acte de sa communication.

Adopté.

Nous avons maintenant à l'ordre du jour le rapport de M. Hickel sur les EsSExces EXotioues et caturalisées.

La parole est ì M. Hickel, pour la lecture de son rapport.

- M. HickeL. - Il semblerait, à première vue, que l'introduction d'essences forestières exotiques n'eût pas besoin d'être justifiée. Et cependant, chose assez singulière, alors qu'il ne viendrait certainement pas à l'idée de l'arboriculteur, de l'architecte paysagiste, de proscrire une espèce du jardin fruitier, du parc paysager ou du jardin d'agrément, par ce seul motif qu'elle est étrangère, un certain nombre de forestiers éminents, en France du moins, traitent, dans leurs écrits, des exotiques avec un souverain mépris, accompagné parfois, faut-il le dire, d'une documentation par trop insuflisante. Et pourtant, tel d'entre eux qui 
lance l'anathème sur l'emploi des exotiques en France est le premier à préconiser l'emploi, en Espagne, en Algérie, des Eucalyptus, des Casuarina, des Acacia.

Le principal argument de ces ennemis des exotiques peut se résumer en cette phrase de Boppe (1): "Si certains arbres exotiques semblent " naturalisés dans les parcs, c'est grâce aux soins constants dont ils sont " entourés et on les verrait bientôt disparaître des forêts où ces soins "leur feraient nécessairement défaut. On ne parviendrait à les y main" tenir qu'au moyen de sacrifices hors de proportion avec le but à " atteindre, et même, si quelques individus résistent, leur descendance " ne s'établira pas naturellement".

Emanant d'un maître comme Boppe, une semblable assertion mérite au moins une courte réfutation...

D'abord, la lutte pour l'existence n'existe-t-elle done pas entre nos différentes essences indigènes? Dans nos futaies feuillues mélangées, ne devons-nous pas, par exemple, intervenir à toutes les époques de l'existence des peuplements pour éviter que le hêtre ne supplante le chêne?

Quant à la descendance des arbres exotiques, il est facile de constater que, pour un très grand nombre d'entre eux, elle s'établit au contraire naturellement. Il suffit de citer, entre bien d'autres, le chêne rouge, qui glande presque tous les ans dans des régions où les glandées des chênes rouvres et pédonculés sont régulièrement espaccés de cinq, six, et même huit ans ! Il est superflu, je pense, d'insister sur ce point.

Sans doute, il ne s'agit pas de remplacer de parti pris par des peuplements d'exotiques nos magnifiques futaies de chênes du Centre et de l'Ouest, nos futaies de hêtres, nos sapinières ou nos pessières des Vosges et du Jura, ou nos pineraies à résine des landes de Gascogne.

Mais, à côté de ces joyaux de notre couronne forestière, combien de boisements ne sont composés que d'essences inférieures, combien de cas spéciaux ne rencontre-t-on pas où, du fait du sol, de la station, de cent autres circonstances, les essences indigènes ne donnent que des produits médiocres ou de réalisation trop lointaine?

Il y a done des raisons sérieuses qui militent en faveur de l'introduction des exotiques dans nos boisements, il y a des cas spéciaux où leur emploi mérite, à tout le moins, d'être pris en considération.

Cette introduction présente surtout de l'intérêt dans les régions où la flore forestière spontanée est pauvre en espèces, en espèces de grande taille tout au moins. Je n'entends naturellement ici point parler des régions où cette pauvreté résulte, soit de circonstances climatériques défarorables, soit de la nature du sol, qui leur impriment un caractère plus ou moins désertique et dont il serait, la plupart du temps, chimérique de poursuivre le boisement. Il ne s'agit que des régions où des vicissitudes de divers ordres ont, au cours des siècles, réduit la flore et l'ont amenée à son degré de pauvreté actuel... La répartition des espèces à la surface du globe, ne l'oublions pas, ne dépend pas uniquement du climat actuel...

C'est en particulier le cas pour l'Europe, dont la pauvreté en espèces et mêmr en genres est frappante, si on la compare, par exemple, aux régions à climat analogue de l'Asie orientale ou de l'Amérique du Nord.

(1) L. Boppe, Sylviculture, p. 81 . 
Ici, en introduisant des essences exotiques, nous ne faisons que rentrer dans notre bien, que réintroduire des espèces anciennement disparues de notre continent, que restaurer notre flore dans l'état où elle était, par exemple, avant que les périodes de glaciation successives en aient éliminé de nombreux éléments, et nous pouvons alors trouver, dans des pays à flore plus riche que le nôtre, des essences parfaitement susceptibles de s'acclimater chez nous.

Naturellement, abstraction faite du point de vue esthétique, notre choix ne devra porter que sur des essences dont les avantages sur les nôtres soient bien établis, au point de vue, par exemple : de la qualité du bois, de la production en volume, de la rectitude du fút, de la rapidité de croissance, de la frugalité, d'une endurance spéciale vis-à-vis de certains dangers (sécheresse, humidité excessive, gelées, dégâts des insectes, du gibier, des cryptogames, etc.). Pour chacun de ces objets, on peut citer déjà des espèces qui répondent au but poursuivi ; par exemple, le sapin de Douglas, pour la rapidité de sa croissance, sa production élevée à l'hectare, sa rectitude, la qualité de son bois, - le pin de Banks pour sa frugalité, etc., etc.

D'autres raisons d'ailleurs peuvent encore militer en faveur des introductions d'exotiques, par exemple le bon marché de leur graine, si important lorsqu'il s'agit de la création de boisements importants : c'est ainsi que le pin inaritime a littéralement conquis le monde. D'autres essences doivent leur faveur mondiale à des produits spéciaux ; c'est ainsi qu'on a cherché à acclimater le chêne-liège dans des régions parfois très lointaines, la Nouvelle-Zélande par exemple.

Mais la variété des climats est grande, même en Europe. L'expérience acquise sur un point est sans valeur sur un autre, et c'est pourquoi la lumière ne peut jaillir que de la comparaison minutieuse des résultats obtenus ici et là, de la collaboration intime des forestiers de tous les pays. Il n'en est guère qui ne puisse fournir quelque donnée intéressante, mais il faut bien le reconnaître, encore que les principaux résultats aient été portés à la connaissance de tout le monde forestier, leur groupement rationnel, par régions naturelles, reste en grande partie à faire...

Si nous cherchons à esquisser, à très grands traits, les caractéristiques des grandes régions naturelles de l'Europe, en examinant ce que, dans chacune d'elle, on peut attendre des exotiques, nous arrivons aux conclusions suivantes:

Dans l'Europe septentrionale, dans la péninsule scandinave, dans le Nord de la Russie, la flore est simple, les espèces peu nombreuses, comme d'ailleurs dans les régions similaires d'Asie ou de l'Amérique du Nord, et c'est jci qu'elle présente le moins de diversité d'un continent à l'autre. L'intérêt de l'introduction d'exotiques y est done en général moindre. Tout au plus peut-on signaler, comme source probable d'emprunts intéressants, l'Asie orientale, qui présente sans doute le maximum de richesse en espèces dans cette zone.

L'Europe centrale, c'est-à-dire la zone des feuillus, avee le pin sylvestre comme seul grand conifère spontané, offre déjà un champ beaucoup plus vaste aux essais : nombre d'essences nord-américaines, surtout celles de l'Ouest dont la flore est si riche en espèces de grande valeur, peuvent trouver ici leur emploi; la Chine, pauvre en forêts, mais riche en espèces, dont beaucoup sont encore inconnues de nos cultures, nous a déjà fourni une importante contribution; le Japon, dont la flore forestière est aussi 
d'une diversité infinie, nous a également doté de nombreuses et précieuses acquisitions; les merveilleuses forêts de Formose commencent à nous livrer leurs trésors; enfin, il n'est pas jusqu'aux régions tempérées de l'hémisphère boréal, comme le Chili, la Nouvelle-Zélande, qui ne puissent nous fournir un utile appoint.

Mais dans cette vaste zone, les eonditions se modifient notablement au fur et à mesure que l'on s'avance soit à l'Ouest, soit à l'Est... Vers l'Ouest, l'influence du Gulf-Stream apporte au climat de la Normandie, de la Bretagne, de l'Angleterre, et surtout de l'Irlande, des modifications qui font de ces régions, à flore spontanée très simple, le véritable paradis des exotiques.

Vers l'Est, au contraire, le elimat, continental, se fait de plus en plus rude, plus extrême. Le choix, ici, est notablement plus restreint, et aussi l'expérience acquise en matière d'exotiques, beaucoup moins profonde..

Par d'insensibles transitions, cette zone de l'Europe centrale se relie à la zone méditerranéenne. Ici tout change, nous sommes dans un autre monde végétal, le nombre des sources où puiser des aequisitions nouvelles s'accroit encore ; aux espèces chinoises, himalayennes, japonaises, nord-américaines, viennent s'ajouter les innombrables espèces australiennes ou sud-américaines, les encalyptus, les acacia, les casuarina, les arancaria, etc... Et la diversité, déjà grande, des espèces qu'on peut y cultiver, augmente encore si l'on considère la portion de cette zone que borde l'Atlantique, portion dont le climat présente des différences notables avee celui de la zone méditerranéenne proprement dite.

Enfin, les régions montagneuses de l'Europe centrale nécessitent une mention spéciale. Ici encore le champ est vaste, les sourees auxquelles on peut puiser sont nombreuses, mais il faut avouer que. sur ce point, les données précises sont encore rares, trop rares.

Ceci dit, qu'a-t-on fait? Comment résumer l'état général actuel de nos connaissances en matière d'introduction d'exotiques?

Durant l'antiquité, pendant le moyen âge surtout, on ne s'est guère occupé que d'introduire des arbres fruitiers, et il faut arriver au xvie siècle pour reneontrer, au sein de cette pléiade de botanistes éminents que furent les Dodoens, les Clusius, les de l'Obel, les Bauhin, un lomme qui fut le véritable précurseur en acclimatation, le véritable père de la dendrologie. C'est lui, en effet, c'est Pierre Belon, qui, le premier, dans ses Remonstrances, parle des espèces à apprivoiser dans les forêts de France. C'est lui encore qui, de retour de ses voyages à travers toute l'Europe et l'Orient, créait à Touvoie, près du Mans, le premier arboretum.

C'est encore au $\mathrm{xvI}^{\mathrm{e}}$ siècle que nous constatons les premières introductions d'espèces de provenances lointaines. Le premier sujet importé de Thuya du Canada (Th. occidentalis) fut, dit-on, offert à François Ier. Puis ce fut le marronnier d'Inde, et peut-être le févier...

Le $\mathrm{xvII}^{\mathrm{e}}$ siècle ne se signale que par un nombre assez restreint d'introductions nouvelles, mais quelques-unes sont de grande importance, comme le robinier, le cyprès chauve, le noyer noir, le ginkgo, le genévrier de Virginie, le liquidambar.

Au xvir siècle, le nombre des introductions est déjà plus grand et quelques espèces importées à cette époque ne tardent pas à se répandre largement, telles le pin Weymouth, le tsuga du Canada, le biota, l'ailante, le chêne rouge.

Mais e'est surtout la période qui englobe à la fois les dernières années 
du $\mathrm{xvIn}^{\mathrm{e}}$ siècle et le commencement du $\mathrm{x}_{\mathrm{x}} \mathrm{x}^{\mathrm{e}}$ qui est riche en acquisitions nouvelles. C'est qu'en effet, sans parler de Duhamel du Monceau et de Lemonnier, la seconde moitié du xvıı siècle voit naître d'éminents explorateurs qui, reprenant la tradition interrompue de Pierre Belon, contribuent puissamment à enrichir notre flore forestière. C'est simultanément : André Michaux (1746-1802) pour la France, Wangenheim (1747-1800) pour l'Allemagne.

Le premier explore la Perse, l'Amérique du Nord, dans le but exprès d'y rechercher les essences forestières susceptibles de s'acclimater en Europe, et meurt au cours d'un dernier voyage, à Nadagasear. Grâce à ses relations avec tous les savants de son époque, avec Duhamel du Monceau et Lemonnier en particulier, il répand largement le fruit de ses récoltes.

Le second explore l'Amérique du Nord et, dans un magistral ouvrage, décrit les espèces propres, selon lui, à enrichir les forêts allemandes.

En France, la tradition d'André Michaux est continuée par son fils, François André qui, par ses explorations, ses introductions et ses écrits demeurés célèbres, se montre le digne successeur de son père.

En France, en Allemagne, en Autriche, presque partout en Europe, on retrouve des plantations, des arbres, témoins encore vivants de cette qrande époque. Nombreux, en effet, étaient les disciples des Michaux et de Wangenheim; en France, ce furent les Vilmorin, les Ivoy, les Catros, les Delamare, les Adlanson, dont l'œuvre subsiste encore aux Barres, à Geneste, à Catros, à Harcourt, à Balsine, tandis que l'œuvre personnelle de Nichaux fils compte encore à Trianon de nombreux témoins.

Puis l'essor se ralentit, et bien que nos plantations d'agrément continuent à s'enrichir de nouvelles introductions de l'Himalaya, bien que dans la seconde moitié du xixe siècle l'Ouest de l'Amérique du Nord nous livre peu à peu ses incomparables trésors, grâce à des chercheurs comme David Douglas, Menzies, Lobb et tant d'autres, bien que le Japon à son tour s'ourre à nos investigations, le silence se fait, presque complet, sur la question de l'introduction des exotiques en forêt. Seuls, le robinier et, à un moindre degré, le pin Weymouth ont pris une large place dans nos boisements. Et c'est au point que telle essence d'introduction très ancienne, qui s'est affirmée comme apte à être cultivée avec succès dans presque toute l'Europe, et dont nous importons le bois en quantités considérables, n'est pour ainsi dire pas sortie des pares pour entrer dans la pratique forestière. C'est le cas, par exemple, du noyer noir, du tulipier et de bien d'autres.

Il appartenait aux hommes de la fin du xrxe siècle de reprendre la tradition des Belon, des Duhamel du Monceau, des Lemonnier, des Michaux, des IVangenheim, et cola avec d'autant plus de chances de succès qu'à la fin du siècle dernier le nombre des espèces exotiques cultivées en Europe s'était extraordinairement accru. Ce nombre même a d'ailleurs été parfois un obstacle : on a souvent, en effet, au cours de ces dernières années, publié d'interminables listes; des catalogues d'arboretums où sont réunies pêle-mêle des espèces rouées à ne jouer qu'un rôle purement ornemental à côté d'autres dignes d'entrer dans la composition de nos peuplements forestiers, ou bien, ce qui est aussi grave, des espèces spécialement adaptées à la montagne, à côté d'autres à confiner dans la plaine. De là, bien des incertitudes, bien des déceptions aussi. 
L'expérience aequise dans les pares, les arboretums, nous avait, pour la plupart des espèces, renseignés suffisamment sur la rusticité, et en partie sur les mérites des différentes espèces introduites. Il fallait franchir une nourelle étape, et aborder résolûment la culture, en forêt, des meilleures d'entre elles.

C'est à la Prusse que revient l'honneur de s'être engagée la première dans la roie des recherches méthodiques et d'avoir comnencé, dès 1881, l'exécution d'un plan de culture, dont les résultats ont été publiés en détail à la fin de chaque décennie.

Un peu plus tard, l'Autriche entrait à son tour dans cette voie et, par ses essais poursuivis à des altitudes relativement élevées, complétait heureusement l'expérience acquise en Prusse.

La Bavière, sous l'ardente impulsion du regretté Professeur Mayr procédait aussi à d'intéressants essais.

La Belgique, avec ses belles créations de Gronendael et de Tervueren, aux portes de Bruxelles, sous la direction d'hommes éminents comme MM. Bommer, Crahay et de Bocarmé, a fourni un important contingent d'olservations précieuses.

En Suisse, plusieurs forestiers se sont adonnés à l'étude pratique de la question.

En Angleterre, dans ce pays par excellence des beaux pares et des amateurs passionnés de beaux arbres, les essais ont été nombreux, et couronnés de succès avec un grand nombre d'espèces. Nul peut-être n'y a plus contribué, par la plume aussi bien que dans la pratique, que MM. Elwes et Henry.

Il est plus difficile de se rendre compte des résultats obtenus dans la région méditerranéenne, au moins en Europe, car les essais n'y ont pas toujours été poursuivis avec toute la méthode désirable. Des résultats très importants ont été cependant obtenus déjà en Italie, en Espagne, en Portugal et surtout en Algérie, qui montrent bien tout le parti qu'on y peut tirer des exotiques. Les circonstances, aussi bien celles résultant du climat que celles qui ont trait à la mentalité des populations peu ménagères des forêts, sont ici tellement spéciales que j'ai cru devoir préconiser, au Congrès international de Madrid (1911), une entente entre les diverses puissances méditerranéennes, aux fins d'étudier en commun les questions forestières propres à cette zone...

En France, aucun essai officiel n'a encore été tenté, en dehors de la création de l'arboretum des Barres et, plus récemment, de celui des environs de Naney. Mais, en revanche, de nombreux propriétaires de bois, de vaillants reboiseurs, ont fait aux exotiques une part souvent très large... Le sapin de Douglas, le mélèze du Japon, l'Abies grandis et le Pinus insignis dans l'Ouest, divers chênes américains, pour ne citer que les plus marquants, sont largement entrés dans la pratique.

La question de l'introduction des essences exotiques est, on le voit par l'exposé qui précède, pleinement entrée dans la pliase des réalisations, et, comme le disait excellemment un distingué forestier suisse, M. Barbey:

"Il n'est plus permis au sylviculteur de se désintéresser de ce problème "qui s'impose actuellement à lui aussi bien que celui de la protection des "forêts, de la sélection des graines, ou que celui de "utilisation des " engrais artificiels dans les pépinières ".

Mais les données acquises sont encore incomplètes, souvent sans lien entre rlles; elles sont surtout éparses en une foule d'écrits, de recueils 
périodiques où il n'est pas toujours aisé pour les non initiés de les retrouver.

Devrait-on poursuivre, pour coordonner les efforts, pour rassembler les documents sur cette question, la création d'un organe international spécial? Je ne le pense pas.

Il existe, en effet, au moins en Allemagne, en Autriche et en France, des sociétés mieux à même que toutes autres de renseigner leur's membres à cet égard, et dont le Bulletin est tout indiqué pour porter les résultats obtenus à la connaissance du public. Ce sont les sociétés dendrologiques, qui s'occupent des arbres et des arbustes au triple point de vue botanique, esthétique et forestier... Les trois sociétés, allemande, austrohongroise et française, sont d'ailleurs en relations étroites les unes avec les autres, chacune analysant et portant à la connaissance de ses membres 'les travaux des autres. Enfin, elles comptent dans tous les pays du globe des correspondants zélés qui leur servent de collecteurs... En fait, il existe entre elles une véritable fédération, et c'est à elles, croyons-nous, que doivent aller ceux qu'intéresse la question qui fait l'objet de ce rapport.

En conséquence, nous avons l'honneur de formuler les projets de vœux suivants :

I. Que l'introduction d'essences exotiques lans les plantations et les reboisements forestiers soit encoltragée:

Par des subventions en nature et en argent;

Par des récompenses et des primes distribuées dans les concours régionanx.

II. Que les parcs forestiers, dans lesquels auront été faites des pluntations de végétaux exotiques pouvant servir d'étude à l'emploi de ces essences dans les grands reboisements forestiers soient exonérés, pendant dix ou vingt ans, de tout impôt foncier, à la condition qu'ils seront ouverts aux professeurs d'agriculture, aux agents forestiers ou autres personnes officiellement accréditées en vue d'études dendrologiques, botaniques et forestières.

III. Que l'Etat entre dans la voie de la culture des essences exotiques.

Peut-être à ce mot " de la culture " pourrait-on substituer a des essais, ".

Plusieurs Congressistes. - Oui ! oui ! parfaitement !

M. Le Président. - Mettons "des essais".

M. IE LESSEUX. - Je demanderais à ajouter que les résultats des essais soient contrôlés avec ceux de l'Ecole Forestière, si on introduit des essences forestières.

M. Guinier. - Non seulement je n'y vois pas d'inconvénient, mais il existe à l'Ecole Forestière un champ d'études assez étendu pour l'emploi des essences exotiques. Je ne parle pas seulement de l'arboretum, qui est plutôt une collection, mais des surfaces consacrées à la culture d'un certain nombre d'essences choisies et de la création de petits 
massifs de ees essences qu'on pourra suivre et dont on pourra connaitre la loi d'accroissement. Done j'approuve cette adjonetion.

M. Le Président. - Personne n'a d'autres observations à présenter?

M. PARDE. - Je propose d'exonérer d'impôts les propriétaires de pares qui cultivent des essences exotiques, sous la eondition que ees parcs pourront être ouverts à ceux que la question intéresse.

M. Giılot. - Il ne faudrait pas néanmoins que la nouvelle législation augmentât les impòts sur les pares qui aroisinent les habitations. On va les classer en première catégorie, cela découragera les propriétaires de faire des plantations autour des habitations. Or ces plantations sont un exemple merveilleux au point de vue du reboisement; dans le Limousin notamment, on a fait des plantations, paree qu'on a eu sous les yeux des exemples de pares plantés autour des habitations. (Applandissements.)

M. TESsiER. - Je ne suis pas absolument de l'avis qu'on vient d'émettre; je crois que les expériences d'introduetion d'exotiques dans les parcs n'ont pas le grand intérêt forestier qu'on croit. Les pares sont généralement des terrains de bonne qualité; or, ee dont nous avons besoin, ce n'est pas d'expériences d'exotiques dans des terrains de qualité remarquable, nous avons besoin d'expériences faites dans le mílieu naturel de la forêt elle-même. Nous avons besoin aussi d'écarter avec grand soin les résultats extraordinaires de ces pares, qui, la plupart du temps, au lieu de nous guider, nous conduiraient à des erreurs par la généralisation des résultats obtenus sur un point local dans un terrain particulièrement favorable. (Signes d'approbation.)

M. HiCKEL. - Il n'en est peut-être pas toujours ainsi. Dans quelques eas, évidemment, comme l'a fort bien dit M. le Conservateur Tessier, ces pares sont installés dans des conditions tout à fait favorables, mais souvent on les fait dans l'endroit qu'on habite, et l'ancienne maison familiale ne se trouve pas toujours dans un terrain extrêmement favorable.

Prenez l'arboretum des Barres, il est loin d'être sur une zone fertile ; la région ou il est se compose de sable, d'argile silicieux et de terrain calcaire de la plus mauvaise qualité.

Quand il s'agit d'essences eultivées depuis longtemps; on n'a pas besoin de recourir aux pares, mais quand il s'agit d'essences d'introduction plus récente, il semble qu'on pourrait commencer par là, et qu'on gagnerait du temps à constater les résultats que ees essences ont donnés d'abord dans les parcs.

Evidemment, il ne faudrait pas tróp étendre les eonclusions, mais cela nous donnerait des indications premières, cela nous permettrait de constatrr que telle essence ne souffre pas trop de la gelée dans telle région, que tel sol développe sa eroissance, ct, chose importante, per- 
mettrait de voir si les graines transportées sur d'autres territoires peuvent germer.

En somme, comme on l'a dit pour le plan de culture en Allemagne, qui offre déjà 30 années d'expérience, on a commencé par ouvrir une vaste enquête sur les essences comprises dans le plan de culture; cette étude a porté surtout sur la tenue forestière des arbres situés dans des pares ou des plantations d'agrément.

Il y a deux phases à envisager : la phase des essais en parc, qui est le meilleur moyen de se rendre compte des conditions de l'arbre, puis les essais en forêt. Pour certaines espèces, nous avons dépassé la phase des essais en parcs, mais pour d'autres,"e'est la seule à prendre actuellement.

M. Gullot. - Il y a exotiques et exotiques. Le sapin pectiné cultivé dans un pare n'est pas une plantation exotique; cependant on taxera au maximum un pare où il y aura quelques pectinés.

11 faut aussi considérer l'influence de l'arbre sur le sol, quand vous aurez introduit des exotiques, ces arbres eux-mêmes aménageront le sol en vue de leur croissance. Broillard a dit : c'est l'arbre qui fait le sol, c'est le sol qui fait la forêt.

M. Le Président. - Messieurs, vous avez entendu les observations présentées; je vais mettre aux voix successivement les voux de M. Hickel:

" $1^{\circ}$ Que l'introduction d'essences exotiqnes dans les plantations et les reboisements forestiers soit encouragée :

"Par des subrentions en nature et en argent;

"Par des récompenses et des primes distribuées dans les concours régionanx $\%$.

Adopté.

"20 Que les parcs forestiers, dans lesquels anront été faites des plantations de végétanx exotiques pouvant servir d'étude à l'emploi de ces essences dans les grands reboisements forestiers soient exonérés, pendant 10 on 20 ans, de tont impôt foncier, à la condition qu'ils seront ouverts anx professeurs d'agriculture, aux agents forestiers on antres personnes officiellement accréditées en vue d'étndes dendrologiques, bolaniqnes et forestières ".

M. DE LESsetx. - Je voudrais qu'ils soient reconnus dans ce but, autrement tout le monde en fera.

M. Le Président. - Quelle modification proposez-vous?

M. DE LESSECx. - Je demande qu'ils soient reconnus par une Commission.

M. le Secrétalre. - Rédigez un voeu, apportez-nous un texte. 
M. Le Présinext. - C'est l'Administration des Contributions directes qui examinera cela et verra si les pares peuvent servir d'étude ou non; elle acceptera ou rejettera la demande en degrèvement. Voilà la solution. (Signes d'approbation.)

Que ceux qui sont d'avis d'adopter ce vœu lèvent la main.

Adopté.

$3^{\circ}$ Que l' Etat entre dans la voie des essais de culture des essences exotiques ».

Adopié.

M. Le Dr Alberto Gersser. - Auriez-yous la bonté de m'accorder quelques minutes?

M. Le Présidext. - Bien volontiers.

M. Le Dr Alberto Geisser. - Messieurs, c'est de la part du Touring-Cluq Italien que j'ai l'honneur de me présenter à rous.

Le Touring-Club d'Italie, dont je suis délégué, a été constitué en 1895, six ans après le vôtre; il compte actuellement près de 110.000 associés. Le TouringClub Italien a tenu à honneur de suirre le Touring-Club de France dans les diverses manifestations de son activité, que votre Ministre de l'Agriculture a si bien résumées ce matin : d'abord mieux faire connaître pour mieux faire aimer.

Notre Ministre de l'Instruction publique avait déjà, depuis 1902, introduit la Fète de l'Arbre dans les Ecoles Primaires. On est en train de faire dans notre pays différentes lois nouvelles à l'avantage de la sylviculture, mais la conviction s'est faite clez nous et a gagné les meilleurs esprits que tout cela aboutirait à peu si on ne gagnait pas l'opinion, - ce que l'on a appelé la conscience forestière des nations, - et le Touring-Club Italien, suivant le Touring-Club Français, s'est proposé de contribuer, dans la mesure de ses forces, à créer cette conscience qui manquait chez nous, car il semblerait que plus les peuples ont une civilisation ancienne, plus ils ont volé haut, moins ils s'inquiètent des bois et des montagıes qui sont cependant un élément essentiel de la civilisation. (Applaudissements.)

Le Touring-Club Italien a donc constitué une Commission de propagande précisément pour les paturages et la forêt, car nous qui avons une si vaste étendue d'arbres dans les Apennins, nous avons dì constater qu'il faut surtout surmonter les conflits qui existent entre les bergers et les forestiers.

Le Touring-Club a réussi à réunir dans ce but 200.000 francs.

Avec cette somme, on a résolu de créer des publications de propagande pour faciliter la formation de cette conscience nationale sur le problème forestier. Il ne fallait pas qu'elles soient trop techniques, mais bien illustrées et répandues à profusion, à bas prix, sur une raste échelle.

Iue premier volume a paru il y a deux ans, il a pour titre : "La Montagne,

le Bois et le Pâturage ", il a été tiré à 100.000 exemplaires.

Le deuxième volume a pour titre : "Le Bois contre le Torrent".

Le troisième, qui paraîtra cette année, est intitulé : "Les Richesses de la Nontagne $*$.

C'esi pour dimontrer aux habitants des montagnes qu'en exploitant de façon excessive les ressources des forêts et des pâturages, on arrive à les détruire. Car notre pays est de ceux qui souffrent le plus, dans certaines régions, du déboisement et de lexploitation excessive. (Applaudissements.)

Le q $^{\mathrm{e}}$ volume, qui paraitra l'année prochaine, aura pour titre: "La Houille blanche ". Vous n'êtes pas sans savoir quel rôle important l'eau joue pour les 
irrigations dans la Haute Italie et surtout pour le développenent de l'industrie électro-technique.

Je vous remercie, Messieur's, de votre bienveillant accueil et de l'attention que vous avez accordée à ma modeste communication, mais ce qui m'a appelé à Paris, c’était précisément le désir de rendre hommage au Touling-Club Français, qui a eu cette excellente idée de faire appel à toutes les nations; je fais des voux ardents pour que la France, celte fois encore, voie sortir de son initiative un mouvement qui réellement répourl à un besoin de la civilisation. (Applaudissements.)

M. Le Président. - Au nom de la Section, je crois être l'interprète du sentiment unanime de l'assistance en remerciant M. Io Délégué du Touring-Club Italien de la communication qu'il vient de nous faire.

Personne ici n'est étonné de voir sortir de la bouche d'un ltalien des appréciations aussi justes, aussi saines, aussi élevées des sentiments de son pays pour le nòtre. Entre la France et l'Italie, quoiqu'il advienne, il existe des liens de fraternité qui unissent les deux peuples ef les uniront à jamais.

La séance est levée à 3 h. 15 . 


\title{
SEANCE DU 17 JUIN 1913
}

\author{
(MATIN) \\ Présidence de M. CAQUET, vice-président de Section
}

La séance est ouverte à $9 \mathrm{~h}$. 1/2.

M. Le Présinext. - Y a-t-il des délégués étrangers? S'il y en avait, nous serions très heureux de les voir venir prendre place au bureau.

Nous allons prendre immédiatement le rapport de M. Schaeffer sur l'AMÉloration des taILlis a FAIBLE REXDEMEXT SITUÉS EX PLAIXE OI EN MONTAGNE, PAP L'IXTRODECTIOX DE RÉSINEIX.

M. Sch.effer. - Lorsque l'on compare les rendements en argent des forêts feuillues et des forêts résineuses, on est frappé de la grande supériorité qui se manifeste en faveur des secondes. Quelqu'élevé que soit le revenu d'une futaie de chênes on trouvera toujours une sapinière dont le rendement sera double. Si une chênaie plantureuse arrive exceptionnellement à rapporter 100 francs par hectare, il existe, d'autre part, des sapinières qui en produisent 200.

Cette supériorité du rendement des résineux a paru dans certains pays tellement évidente que l'on n'a pas hésité à susbtituer l'épicéa au chêne, même dans des régions où ce dernier était susceptible d'atteindre, comme réserve de taillis, les plus belles dimensions (Lorraine annexée, divers cantons suisses). Nous estimons qu'il y a là une exagération, car, en somme, rien ne prouve que le renchérissement du chêne, dont les réserves mondiales ne sont pas inépuisables, ne compensera pas un jour l'infériorité de son rendement. Mais si la transformation en futaies résineuses des forêts en bon sol est une opération contestable, toute hésitation disparait lorsqu'il s'agit de taillis médiocres. L'écart de rendement devient alors énorme, et il n'est pas rare de voir côte à côte des taillis rapportant péniblement 4 ou 5 franes par liectare et des sapinières qui en produisent 80 ou 100.

En montagne notamment, le taillis est un véritable non-sens économique : il n'a d'ailleurs, le plus souvent, qu'une origine récente.

Lorsqu'on parcourt les revues forestières de la fin du xvir $^{\mathrm{e}}$ siècle et du commencement $\mathrm{du} \mathrm{x}_{\mathrm{x}} \mathrm{x}^{\mathrm{e}}$, on constate que la grande préoccupation de l'époque était la crainte de manquer de charbon de bois pour l'industrie. C'est ce besoin de charbon qui a amené la destruction de nombreuses sapinières auxquelles succédèrent des broussailles que l'on baptisa taillis (1).

(1) Les archives de la Savoie le prouvent surabondamment. 
En v réinstallant les résineux, on ne fait donc que ramener les essences primitives et se conformer aux vues de la nature. Dans notre $\mathrm{xx}^{\mathrm{e}}$ siècle, que l'on a appelé l'âge du papier, la pâte de bois fait prime, et c'est peutêtré pour n'avoir pas compris assez tôt l'importance économique des résineux que la France est restée tributaire de l'étranger pour une matière de première nécessité. Il ne faut pas se dissimuler, en effet, qu'au XIx ${ }^{e}$ siècle les tendances n'étaient pas favorables à l'extension des résineux, en dehors surtout de leur zone naturelle, et ce fut presque une révélation lorsqu'en 1864, MM. Lanier et Mélard, au retour d'une mission en Belgique, attirèrent l'attention sur la mise en valeur des taillis de l'Ardenne par des plantations d'épicéa.

Depuis cette époque, il est vrai, la littérature forestière s'est enrichie de nombreuses publications faisant ressortir l'amélioration résultant de l'introduction des résineux dans les taillis. Au Congrès international de 1900 la question fut longuement discutée et elle aboutit à l'adoption du vou ci-après :

"Que l'introduction des résineux dans les taillis médiocres du premier plateau du Jura et stations analogues soit favorisée ".

On peut reprocher à ce vœu de manquer de généralité car, en dehors du premier plateau du Jura et des stations similaires, il ne manque pas de taillis médiocres situés en haute montagne, en coteau, voire même en plaine, que seule l'introduction des résineux peut transformer avantageusement au point de vue économique.

Tel qu'il a été émis, ce vœu n'a cependant pas été stérile et nous estimons qu'il serait opportun de le reproduire en lui donnant plus d'extension. Si, en effet, le desideratum de 1900 a eu l'heureux sort d'une graine tombant sur un sol bien préparé, si, grâce à l'impulsion énergique de la Société Forestière de Franche-Comté et de son distingué président, l'idée a germé et produit des fruits au centuple, il y a tout lieu d'espérer qu'une réédition amplifiée de ce vœu sera également féconde et aura la plus salutaire influence sur le rendement des forêts d'autres régions.

N'oublions pas cependant que les problèmes forestiers ne comportent pas de solution absolue et que l'introduction des résineux dans certains taillis a soulevé des objections que nous allons énumérer sommairement.

La première est relative au refroidissement du climat local ; elle n'est peut-être pas sans valeur. Linné déjà l'avait dit: "Abies frigoris comes et causa ». Il est fort possible qu'au printemps la présence d'un massif de sapins, retardant la fonte des neiges, abaisse la température de quelques dixièmes de degré, ce qui, dans certains cas, peut présenter des inconvénients. On y regardera donc à deux fois avant d'introduire des épicéas ou des sapins dans le voisinage immédiat des vignobles. Il est vrai que, d'autre part, les cimes aiguës des résineux constituent des paragrêles plus perfectionnés que les dômes arrondis des feuillus (1). C'est encore une considération.

On sait, par contre, que les angiospermes résistent mieux que les gymnospermes à l'intoxication par les émanations des usines. Autour de certaines villes industrielles de Saxe, on a dú revenir aux feuillus parce que les aiguilles persistantes de l'épicéa avaient trop à souffrír des dégâts de la fumée. En Maurienne, à proximité des usines d'aluminium, les peu-

(1) On admet généralement sur les bords du lac du Bourget que l'extension des résineux sur le massif de la Dent du Chat a réduit le nombre et l'importance de chutes de grêle. 
plements résineux sont détruits par les gaz délétères, tandis que les arbres dont les organes foliacés se renouvellent annuellement offrent plus de résistance. M. Nathey, enfin, affirme que dans certains cas l'introduction des résineux dans le taillis n'a pas plus d'effet pour l'amélioration du rendement qu'un cautère sur une jambe de bois.

Il est vrai que certaines stations sont tellement ingrates que les pins même y restent à l'état buissonnant, mais en définitive les circonstances qui entraînent la faillite des résineux sont très exceptionnelles et sur l'ensemble on peut dire qu'ils ont cause gagnéc.

Pour s'en convaincre, il suffit de parcourir les pays voisins du nôtre, et de voir les merveilleux résultats obtenus en Allemagne et en Suisse par la transformation en futaie résineuse des taillis de faible valeur. On peut aussi tout simplement lire les comptes rendus des Congrès forestiers qui se sont succédé dans l'Est de la France et l'on suivra ainsi la marche triomphale de l'idée. Communes et particuliers rivalisent de zèle pour infuser en quelque sorte à leurs forêts un sang nouveau en remplaçant les broussailles par de véritables arbres.

Pourquoi faut-il qu'à côté de ces populations prévoyantes et éclairées il s'en trouve d'autres qui, dédaigneuses des intérêts de l'avenir, non seulement ne cherchent pas à favoriser l'installation des résineux dans les taillis, mais réclament systématiquement l'extraction de ceux que la nature y a prodigués spontanément? Il n'y a pas de jour où l'Administration forestière ne soit obligée de lutter pour essayer de résister à ces dévastations presque sacrilèges. Et ne croyez pas que l'opposition manifestée par certaines communes à la transformation naturelle de leurs taillis en futaie résineuse soit basée sur une hostilité plus ou moins fondée à l'égard des épicéas et des sapins. C'est, au contraire, le plus souvent un excès d'amour qui les guide, c'est le désir de réaliser les résineux existants et d'en jouir immédiatement, sans seulement leur laisser le temps d'essaimer autour d'eux. Rien ne le démontre mieux que la réponse presque cynique qui me fut faite dans un conseil municipal, un jour que je m'efforçais de convaincre l'assemblée de l'intérêt que présentait pour les générations futures la conservation des résineux. Comme, à bout d'arguments, j'essayais de faire vibrer la fibre de l'amour paternel: "J'aime bien mes enfants, me fut-il répondu, mais j'aime encore mieux moi. "Tous les raisonnements échouent devant une pareille mentalité, car les plaidoyers sont vains devant le tribunal de l'égoïsme. Il ne reste done d'autre ressource que l'intervention de la loi. Les commissaires-députés en 1724 pour la réformation des bois et forêts de la province du Dauphiné l'avaient bien compris lorsqu'ils insérèrent dans leur règlement l'article suivant applicable aux bois taillis des communautés séculières :

"...Au cas que dans la coupe des dits taillis il se rencontre des sapins, suiffes (pin de montagne), sérantes (épicéa), mélèzes ou pins, ils sont laissés pour baliveaux par préférence à tous les autres bois. Faisons défense aux particuliers qui feront la coupe d'abattre aueuns sapins, suiffes, sérantes ou pins qui aient atteint la hauteur de douze pieds, quand même le nombre de baliveaux de seize par arpent serait rempli à peine de vingt livres d'amende pour chacun pied d'arbre abattu en contravention au présent article ".

Notre Code forestier actuel, bien que complété par l'ordonnance réglementaire, est muet sur la question des résineux dans les taillis et, en présence du silence de la loi, l'Administration est à peu près désarmée. 
En se basant sur ce que les résineux ne rejettent pas de souche on a pu prétendre, avec apparence de raison, que leur présence est incompatible avec le régime du taillis et, il faut bien le dire, certaines autorités administratives n'ont pas craint de donner leur appui à cette thèse.

C'est done au législateur qu'il faut s'adresser pour obtenir l'insertion dans le Code forestier d'un article analogue à celui des commissaires réformateurs du Dauphiné. La rédaction pourrait en être libellée comme suit :

"Dans les coupes de taillis, les résineux sont réservés en principe; "seront seuls exploités les sujets surannés, dépérissants ou surabondants, "martelés en délivrance par les agents forestiers".

La présence dans le Code de ces quelques lignes suffirait pour faire passer dans la classe des forêts productives des milliers d'hectares dont le revenu est dérisoire, et ce serait un titre d'honneur pour le Congrès que d'avoir provoqué une pareille amélioration.

Qu'on me permette, en terminant, d'effleurer le còté esthétique qui se trouve ici en parfaite harmonie avec l'intérêt économique.

Le Comité constitué par le Touring-Club de France pour la conservation des sites et monuments pittoresques de la Savoie a, dans sa séance du 6 avril 1906, émis sur ma proposition le vœu suivant:

"Attendu que la coupe rase est antiesthétique et que le maintien des résineux dans les taillis produit, au contraire, des effets très pittoresques, il est à désirer que les exploitations ne mettent jamais le sol complètement à nu et que spécialement les épicéas et les sapins soient scrupuleusement conservés ").

Ce vœu fut également adopté par le syndicat d'initiative de la Savoie e't M. le Préfet voulut bien l'insérer dans le Bulletin des actes administratifs.

Peut-être le Congrès jugera-t-jl opportun de lui donner encore plus de notoriété.

En conséquence, j'ai l'honneur de formuler le-projet de vœu suivant :

Que les résineux soient introduits dans la plus large mesure dans les taillis médiocres pour élever leur rendement, et que l'introduction en soit favorisée sur tous les points oi les feuillus ne sont pas susceptibles de fournir en quantité importante du bois d'œuvre de bonne qualité.

M. le Présidext. - La parole est à Mi. Cuif.

M. Crif. - Je désirerais que le Congrès adopte en premier lieu le voru tel qu'il est formulé par M. Schaefier et en second lieu celui de :

Favoriser par tous les moyens l'élaboration d'études ayant pour but de faire connaître anx propriétaires, en citant des exemples judiciensement choisis, les espèces les mieux approprices anx facteurs de la production et aux conditions économiques locales ".

M. Le Présinext. - J'adopte parfaitement votre veu, et cela d'autant plus que mon expérience personnelle me permet de faire la réflexion 
suivante : J'ai fait d'importantes plantations d'epiceas dans le centre de la France; or ces plantations ont complètement disparu il y a deux ans par suite de la grande séchesse de l'été de 1911. Cela montre qu'il faut donner des indications très précises aux planteurs des différentes régions de France, afin de leur éviter des aventures aussi pénibles que celle-là.

Nous allons commencer par le premier vœu qui se divise en deux: l'un se trouve dans le rapport de 11 . Schaeffer, l'autre a été lu par 11. Cuif. Je mets ce premier vou aux voix.

Le vou est adopté.

M. Le Présinext. - M. Schæffer a demandé qu'on adopte un troisième vœu. Je dois vous dire qu'au Comité du Congrès, ce vou a été examiné et nous avons compris que 11 . Schæffer voulait appliquer une règle fixe coercitive à l'égard de la propriété forestière privée, ce qui fait qu'il a été éliminé. S'il n'en est pas ainsi, je ne vois, je l'avoue, que des avantages à ce qu'il soit adopté.

11. SchefFER. - L'abus que je combats emporte des conséquences extrêmement graves; j'ai vu en Savoie des forêts dans lesquelles des résineux avaient été réservés depuis 50 ans; or, sous prétexte que ces forêts devaient être traitées en taillis, le préfet a obtenu la destruction de ces résineux!

11. Le Président. - En tous cas, le procès-verbal tiendra compte de votre déclaration et mentionnera que votre vœu ne s'applique qu'aux bois soumis au régime forestier.

11. SCHæfFER. - Voici la rédaction que je propose :

"Dans les coupes de taillis, les résineux sont réservés en principe; seront seules exploités les sujets surannés, dépérissants ou surabondants, martelés en déliorance par les agents forestiers".

11. Le Présinent. - II suffit d'ajouter à cette rédaction, après "Dans les coupes de taillis ", les mots: "soumis au régime forestier ".

S'il n'y a pas d'autre observation, je mets aux voix le troisième vocu de M. Sehaeffer modifié ainsi que je l'ai indiqué.

Le voen est arlopté.

11. Cypriex Girero prend la place de président de la réunion en remplacement de M. Caquet.

M. Le Président. - Je donne la parole à M. Mangin pour la lecture du rapport de $\mathrm{M}$. Demorlaine.

M. Mangix. - M. Demorlane m'a chargé de le représentel pour la lecture de son rapport sur l'ALIONGEMENT DES Rívolutioxs des 
TALLIS ET TAILLIS SOLS FUTAIE. - DIMINTION DE LA PROPORTION DES BOIS DE PETITE DIMENTION. - CONTERSION DES TAILLIS ET TAILLIS SOUS FL'TAIE EN FUTAIE.

Ripport on M. DenurLhie. - Une des causes principales de la disparition des massifs boisés par le défrichement, leur destruction plus lente par des coupes abusives ou des exploitations généralisées, est certainement la mévente des bois, notamment des bois de petites dimensions (bois de feu ou bois à écorcer), qui depuis dix ans augmente de jour en jour davantage.

Les bois particuliers constituent dans tous les pays la plus grande partie de la superficie générale boisée; il est donc d'une nécessité capitale, pour enrayer, dans l'intérêt général, les progrès de la déforestation, de trouver et d'indiquer aux propriétaires les moyens d'améliorer leur capital boisé, pour leur permettre d'en tirer un revenu suffisamment rémunérateur, les engageant à le conserver.

Ce serait, en effet, peine inutile, de prêclıer la conservation des bois, si l'on ne pouvait répondre victorieusement à cette observation, trop jus. tifiée, que les bois disparaissent faute d'emplois avantageux pour le producteur. Le problème à résoudre est identique à celui de la dépopulation : la natalité diminue par suite du coût de la vie, croissant de jour en jour, et du progrès du bien-être. Cette question sociale de la plus haute gravité, la dépopulation, sera résolue le jour où l'on aura pu trouver la possibilité de diminuer les charges et d'améliorer les ressources familiales.

De même pour la dé urestation : si l'on veut inciter les propriétaires particuliers à conserver leurs bois, il faut leur donner les moyens, aussi rapides que possible, d'améliorer le rendement de leurs massifs et leur permettre d'en écouler plus facilement les produits.

Est-ce là un problème insoluble? Nous ne le pensons pas. Les propriétaires forestiers doivent ne pas oublier qu'ils sont de véritables fabricants de bois, que toute industrie doit suivre attentivement les lois de variation de l'offre et de la demande, modifier en conséquence ses procédés de fabrication, sous peine de voir un jour cette industrie péricliter et même se réduire à néant. C'est ce phénomène qui s'est produit pour nos bois. Les progrès de la civilisation n'ont peut-être pas cu de répercussion plus grande que sur la propriété boisée : la culture forestière semble être l'antagoniste de la civilisation. C'est une vérité historique irréfutable.

L'âge d'exploitation des taillis n'a guère varié depuis bien tôt trois siècles, et cependant les menus bois n'ont plus qu'une utilisation très réduite, qui diminue de jour en jour, par suite de la diffusion presque générale, avec l'accroissement existant du r'éseau des voies ferrées, de la houille, du coke ou du pétrole pour les besoins du chauffage journalier.

Si l'on considère que la plus grande partie des forêts, dans tous les pays, est détenue par les particuliers, et qu'en France surtout, sur les 9.000.000 d'hectares qui constituent la superficie boisée, 6.000 .000 environ sont propriété privée, dont près de 4.500 .000 hectares traités en taillis simple. ou taillis sous futaie, il n'est pas étonnant que la mévente des produits, fournis par ce genre d'exploitation, ait entrainé la destruction même des forêts particulières françaises.

C'est, en effet, en France principalement que, drpuis une vingtaine d'années, l'on a constaté les funestes progrès de la déforestation, tandis qu'en Allemagne, où les forêts feuillues placées dans les mêmes conditions 
n'occupent que $32 \%$ de la surface boisée, dont $7 \%$ traitées er taillis simple et $5 \%$ en taillis sous futaie, les déboisements sont pour la plupart insignifiants. Il en est de même en Suisse, où les taillis occupent une proportion infime, à peine $10 \%$ de la superficie générale boisée.

On peut dire d'une façon certaine, d'après les données de l'histoire et de la répartition en Europe de la propriété forestière, que la déforestation tient certainement en grande partie à l'application aux forêts d'un régime qui, s'il n'est pas modifié dans ses conditions essentielles, ne permet plus aux propriétaires de tirer de leurs bois le parti qu'ils sont en droit d'en attendre.

Pour remédier à cette situation désastreuse, il est surtout indispensable de faire donner aux forêts des produits répondant aux besoins économiques de notre époque.

La conclusion des différents auteurs qui se sont occupés de la question est :

$1^{\circ}$ Que l'aménagement des taillis à longs termes est infiniment plus avantageux à l'approvisionnement en bois de toutes catégories que des aménagements fixés à des âges réduits ;

$2^{\circ}$ Que les particuliers, ne pouvant ou ne voulant pas, en général, différer leurs coupes jusqu'à 25,30 ou 40 ans, leurs bois sont moirs utiles à la consommation générale que les bois de l'État et ceux des communes, dont les coupes sont plus tardives.

Si donc tout le sol forestier passait dans le domaine des particuliers, on verrait inévitablement les produits en matière diminuer jusqu'au point de ne plus suffire à la consommation.

"Ces vérités, proclamées au début du $\mathrm{xIx}^{\mathrm{e}}$ siècle, démontrées par "l'expérience et le raisonnement, pourquoi, dit Baudrillard, sont-elles " aujourd'hui si peu appréciées? Sully, Colbert, Buffon, Duhamel, " n’oserait-on plus vous citer? Et cette postérité, que vous embrassiez "dans votre sage prévoyance, ne profitera-t-elle point de ros sages " avertissements? "

Combien ce cri d'alarme, poussé il y a plus de 150 ans, aurait dù depuis longtemps être entendu! Car actuellement, ce n'est plus seulement l'amélioration, l'accroissement du revenu de nos forêts, qui doit entrer en jeu, quand on parle de l'allongement des rérolutions de taillis, c'est la question d'existence des forêts elles-mêmes. Le propriétaire n'a plus qu'à choisir entre deux partis, ou laisser disparaître un bois, qui ne lui rapporte plus qu'un revenu insignifiant, ou transformer son aménagement de façon à lui permettre de fournir des produits rémunérateurs.

On comprend l'intérêt vital du problème que les gouvernements, les associations forestières ont le devoir d'essayer de résoudre pour enrayer la destruction forestière.

La question n'est d'ailleurs pas nouvelle; mais c'est seulement depuis une vingtaine d'années que, dans les divers pays où le régime du taillis est appliqué (France, Belgique, Allemagne et. Suisse), l'on a cherché à augmenter la révolution des taillis ou à procéder à leur conversion. Seules les forêts publiques ont le plus souvent subi ces heureuses transformations. Les propriétaires particuliers sont, pour la plupart, restés rebelles, à l'allongement de la révolution de leurs taillis, soit par' crainte d'interruption dans leurs revenus annuels, soit par ignorance de leurs véritables intérêts, soit encore et, surtout peut-être, par incurie.

Et cependant le résultat est certain. Le prix de vente du taillis à l'hec-

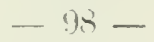


tarc augmente rigoureusement avec l'âge. Il suffit à tet égard de jeter les yeux sur les eonstatations faites dans une petite forêt du Doubs par II. E. Naire, inspecteur des Eaux et Forêts.

\begin{tabular}{|c|c|c|c|c|c|c|}
\hline $\begin{array}{l}\text { XéÉro } \\
\text { de la } \\
\text { ceupe }\end{array}$ & CONTEXANCE & $\begin{array}{l}\text { AXYEE } \\
\text { de la } \\
\text { vente }\end{array}$ & $\begin{array}{l}\text { Prix } \\
\text { de la } \\
\text { vente }\end{array}$ & $\begin{array}{l}\text { AGE } \\
\text { de la } \\
\text { conpe }\end{array}$ & $\begin{array}{c}\text { PRIX DE VENTE } \\
\vdots \\
\text { l'hoctare }\end{array}$ & $\begin{array}{l}160 \text { fr. } 37 \\
\text { placés à } 7 \% \\
\text { (intérêts } \\
\text { composés) } \\
\text { donneraient }\end{array}$ \\
\hline $\begin{array}{l}1 \ldots \ldots \ldots \\
2 \ldots \ldots \ldots \\
3 \ldots \ldots \ldots \\
i \ldots \ldots \ldots \\
5 \ldots \ldots \ldots\end{array}$ & $\begin{array}{l}11 \\
3,28 \\
2,96 \\
2,74 \\
3,01 \\
2,90\end{array}$ & $\begin{array}{l}1883 \\
1885 \\
1888 \\
1891 \\
1894\end{array}$ & $\begin{array}{l}1510^{\mathrm{lo}} \\
1790 \\
1990 \\
2390 \\
2750\end{array}$ & $\begin{array}{l}21^{\text {ans }} \\
23 \\
26 \\
29 \\
32\end{array}$ & $\begin{array}{c}\mathrm{fr} \\
460,37 \\
604,73 \\
726,28 \\
794,02 \\
948,28\end{array}$ & $\begin{array}{c}\mathrm{fr} \\
460,37 \\
527,08 \\
645,69 \\
791,00 \\
969,10\end{array}$ \\
\hline
\end{tabular}

De ce tableau il ressort clairement que l'accroissement de la valeur des bois, exploités à un âge supérieur à 20 ans, variant entre 20 et 30 ans, s'est fait au taux de $7 \%$, et ces résultats ont été atteints malgré la baisse annuelle, de plus en plus forte, de la valeur des bois de chauffage.

Convaincu de ces résultats, un préfet de la Haute-Marne, M. Boudier, dont le nom ne doit pas être oublié, réussissait en 1895 à persuader à un grand nombre de Conseils municipaux, ressortissant de son administr"dtion, d'allonger la révolution des taillis de leurs communes respectives et de la porter de 25 ans à 30 ans au moins et au dessus. Soixante-quinze communes répondirent à son appel, et l'aménagement de 45.000 hectares de taillis fut modifié dans le sens indiqué.

Exeollent exemple, dont la contagion aurait dû gagner les bois particuliers!

Si de la Haute-Marne nous passons dans le département de la Meurtheet-Moselle, aux environs de Naney, mêmes résultats. En 1876, époque à laquelle les prix des bois étaient arrivés au maximum, on constatait les résultats suivants sur des sols semblables à ceux de la Haute-Marne. A 20 ans les coupes de taillis se vendaient en moyenne 200 francs l'hectare et à 40 ans, 1.500 francs.

Frappé de ces exemples, en 1896, le Bulletin de la Société Forestière de Belgique, traitant la question de l'allongement de la révolution des taillis, calculait au taux de $3 \%$ la rente annuelle correspondant au revenu périodique de 55 francs d'un taillis exploité à 20 ans; elle était de 2 fr. 50 . Calculant de même la rente annuelle équivalant au revenu périodique de 400 francs en 40 ans, il obtenait 5 fr. 25 . La rente était done doublée par l'exploitation à 40 ans. Le calcul est exact. Mais les revenus de 60 et 400 franes sont des produits bruts. Si l'on envisage le produit net, e'est-àdiresil'on défalque les impòts annuels, les frais de gestion de toute nature, l'on roit que, dans le premier cas d'une.révolution de 20 ans, alors que les dépenses accessoires ne s'élèveraient qu'à $2 \mathrm{fr}$. 50 par heetare, ce quî est un minimum, le revenu net est nul, et dans le second, de 2 fr. 75. Ce n'est pas seulement la paurreté, c'est l'anéantissement de toute rente, qui, nde telles conditions, résulte de l'exploitation à 20 ans.

Ces quelques exemples, résultats d'expériences depuis longtemps contrôlées, peuvent se traduire sous forme des deux lois suirantes:

1o La valeur d'un taillis s'accroît comme le carré de l'âge. 
Cette loi que nul forestier n'ignore au pays qu'arrose la Saône et que le distingué forestier, M. Algan, a baptisée pour cette raison du nom de: - Loi Vesulienne s est peut-être beaucoup plus ancienne et aurait été formulée pour la première fois en 1834 par un forestier particulier de Dijon, M. Noirot. C'est dire que, d"puis près d'un siècle, elle a eu le temps d'être abondamment vérifiée.

II. Kornprobst, ancien inspecteur des Eaux et Forêts à Gray, a proposé de la compléter par un corollaire tout naturel:

$2^{\circ}$ La valeur de la coupe annuelle d'un taillis est proportionnelle à la révolution de la forêt traitée.

Or, la vérification de la loi, suivant la fertilité des sols, sous sa forme "vesulienne " ou "grayloise ", a montré que dans les cas, bien rares actuellement, où les bourrées et la charbonnette ont une valeur encore relativement élevée, la loi est:

Un peu supérieure ou égale à la réalité dans les bons sols;

Egale à la réalité dans les sols moyens;

Inférieure ù la réalité dans les sols médiocres on manvais.

Lorsque les menus bois sont sans valeur, et cist la condition presque générale à notre époque, la loi est toujours inférienr? ¿ la réalité surtout si le sol est de mauvaise qualité.

On peut done poser en principe que le rendement d'une coupe de taillis est plus que proportionnel à la révolution, surtout dans les mauvais terrains. C'est donc là une démonstration intéressante de l'avantage des longues révolutions de taillis.

Telle est la conclusion très intéressante à laquelle arrive $\mathrm{M}$. le Garde général des Eaux et Forêts Perrin, de Tesoul, rlans une récente étude publiée par le Bulletin de la Société forestière de Franche-Comté et Belfort.

Aussi, non seulement en France, comme nous l'avons vu plus haut pour les forêts communales soumises au régime forestier, mais dans les pays voisins, où le régime du taillis sous futaie présente, en raison du climat, une réelle importance, en Belgique, en Allemagne et en Suisse, les propriétaires forestiers, et surtont l'Etat, se sont préoccupés depuis 20 ans de l'allongement indispensable des révolutions de taillis.

Chez nos voisins les Belges, d'après les renseignements fournis par la Société Centrale Forestière de Belgique, la contenance des taillis sous futaie, qui ont vu leur révolution s'allonger, s'est élevée, pendant la période de 20 ans s'écoulant de 1885 à 190', au chiffre de 33.375 hectares, celle des taillis simples ayant subi la même transformation serait de 25.000 hectares. A cette contenance de 58.000 hect ares il est bon d'ajouter 3.000 hectares de taillis sous futaie convertis en FUTAIE PLEINE, 2.000 lesctares de taillis simples en TAILlis sous FUtAIE ou même futaie pleine.

En Allemagne, le taillis sous futaie a surtout une importance relative dans la partie ouest de l'Allemagne dı Sud (Bavière, Grand-Duché de Bade, Palatinat, Wurtemberg, Alsace-Lorraine), où il occupe $15 \%$ environ de la surface boisée. Or, sauf la Bavière, où la superficie oceupée par les massifs de taillis et de taillis sous futaie a légèrement augmenté en 20 ans, de 1883 à 1900, partout ailleurs le taillis sous futaie a été abandonné pour la conversion des forêts en futaies résineuses: pour l'ensemble de l'empire allemand si l'on constate, pour la période s'écoulant de 1.883 à 1900, une légère augmentation de 36.000 hectares de taillis simples, la superficie occupée par le taillis sous futaie a diminué de près de 200.000 hectares au profit res futaies résineuses, passées de 177.000 hectares à 
345.000 hectares pendant la même période. En 1900, pour une superficie totale boisée de 14 millions d'hectares, le taillis simple occupait en Allemagne une superficie de 950.000 hectares environ, soit $7 \%$, le taillis sons futaie 700.000 hectares, soit $5 \%$, et la futaie 11.000 .000 d'hectares, dont 2.500 .000 hectares pour les fenillus et 8.400 .000 hectares pour les résineux, soit respectivement $18 \%$ et $24 \%$ de la superficie générale boisée.

C'est donc dire également qu'en Allemagne, toutes réserves faites des conditions climatériques et locales, la tendance est également à la substitution des régimes à longues révolutions à ceux du taillis et du taillis sous futaie.

En Suisse, la situation est la même : si l'on remonte en arrière de 30 à 50 ans, on constate la disparition graduelle du régime du taillis. Le canton de Zurich, qui comportait, en 1880,37\% de la surface des forêts traitée de cette façon, n'en a plus que $26 \% \%$ en 1910. Dans le canton de Thurgovie, le taillis dans les forêts de l'État est passé de $15 \%$ en 1880 à $6 \%$ en 1910 , celui des communes de $60 \%$ à $34 \%$. Nême constatation pour le canton d'Argovie. Les causes de cette diminution résultent avant tout, dit M. Decoppet, professeur à l'Ecole Polytechnique de Zurich, de faits économiques et culturaux, de l'abandon de la pratique du furetage au pied du Jura et des Alpes dans les forêts, où le hêtre domine, et de la conversion des taillis simples par suite de l'abaissement du cours des bois de feu, des changements apportés aux installations de chauffage. Mais peut-être est-on allé trop loin dans cette voie, et, ajoute MI. Decoppet, si le mode de traitement a donné lieu à des mécomptes, ce n'est pas tant au traitement lui-même qu'il faut s'en prendre qu'à sa mauvaise application. Une amélioration des taillis est souvent possible, soit par un allongement des révolutions, soit par la réintroduction des bonnes essences et de soins culturaux appropriés.

Ainsi done, que l'on envisage la question au point de vue historique ou géographique, partout l'on aboutit à la même conclusion que l'allongement des révolutions de taillis et de taillis sous futaie s'impose, parce que C'EST UNE NÉGESSITÉ ABSOLUE AU POINT DE VUE ÉCONOMIQUE.

Il est nécessaire, néanmoins, de prouver que si les propriétaires se condamnent à l'allongement de la révolution de leurs taillis, qui ne peut se faire sans certains sacrifices pécuniaires importants, ils sont du moins certains de tirer de leurs forêts un revenu appréciable et rémunérateur.

Quels sont, en effet, les produits qu'un taillis de 30 ans, par exemple, car c'est là l'âge minimum auquel on doit tendre, pourra fournir :

$1^{\circ}$ Des bois de mine (étançons-rallonges);

$2^{\circ}$ Des bois de fente;

$3^{\circ}$ Des bois propres à la distillation;

$4^{\circ}$ Des bois de feu de grosses dimensions.

Nous laisserons de côté à dessein certains taillis d'essences particulières (châtaigneraies) qui, dans des conditions spéciales, peuvent donner, même exploités à un âge réduit, des prorluits appréciables. Ce n'est là qu'une exception très rare aujourd'hui.

Or, sans entrer dans le détail, il suffit d'interroger le commerce des bois pour savoir qu'actuellement seuls les bois de mine de fortes dimensions (étançons-rallonges) n'ont subi aucune dépréciation. Au contraire, par suite de l'abondance des exploitations, les potraux de petite dimension ne trouvent plus preneurs qu'à des prix relativement dérisoires. Les carreaux des mines en regorgent à peu près partout. Il est donc certain 
que seuls les taillis, exploités à un âge avancé, qui peuvent fournir des bois de mines de grandes dimensions, trouveront toujours une vente rémunératrice. La production houillère a une tendance à augmenter. La consommation en France, qui était, en 1902 , de 45.000 .000 da tonnes, s'est élevée, en 1901, à 60.000 .000 de tonnes, tandis que la production passait, dans le même laps de temps, de 30 millions à 39 millions de tonnes. En Angleterre, la situation est la même. En Belgique, les besoins industriels sont tels que ce pays, hier encore exportateur, est aujourd'hui dans l'obligation de recourir à l'étranger. L'Allemagne ne peut exporter sor charbon que lorsqu'elle a suffi aux demandes de plus en plus nombreuses de ses usines, et cette exportation tend actuellement à diminuer, ce qui prouve que la consommation intérieure augmente. De ce côté donc, aucun danger pour que la demande de bois, sous forme d'étais de mine, diminue de longtemps, car il est pour ainsi dire impossible, par suite de l'humidité et de la température des galeries, du prix de revien't et d'une foule de raisons techniques (élasticité, facilité de coupe et de transport du bois) de remplacer dans les mines ic bois par le fer. C'est donc un placement assuré pour de longues années. Alors même que pour certains pays (France, Belgique) la production dépasserait la consommation, un débouché certain leur est également assuré en Angleterre ct même en Allemagne.

Sous forme de bois de fente (bois à lattes ou piquets), les perches de taillis de fortes dimensions sont assurées de trouver également une utilisation certaine. En raison du développement toujours croissant de l'industrie du bâtiment, les bois à lattes sont, en général, fortement demandés, il en est de même des piquets. Sans doute la découverte du béton armé fait depuis quelques années une concurrence redoutable aux piquets de bois fendus, mais d'expériences récentes, faites en Allemagne, il résulte que, malgré sa durée plus longue, le pieu en béton revient, en dernière analyse, dans les travaux civils, 2 fois plus cher que le pieu en bois. D'ailleurs la stérilisation, le bétonnage des pieux dans leur partie souterraine, permet d'augmenter sensiblement leur durée. C'est donc là encore un débouché certainement possible.

Quant aux bois propres à la distillation ou à la pâte à papier, on est évidemment certain de les trouver en plus grande quantité, et surtout avec un rendement plus rémunérateur, dans les taillis âgés que dans les taillis exploités à une révolution réduite, car, sous un volume donné, la matière travaillée renferme une quantité plus grande de produits utiles (cellulose, alcool).

Enfin, ce sont surtout aujourd'hui les bois de feu rle faible dimension, qui sont presque inutilisés. Par contre, le bois de chauffage de fortes dimensions trouve encore relativement preneur, et il n'est pas téméraire de songer que la hausse croissante du charbon, due à de nombreuses causes économiques et sociales, forcera bientôt, dans les campagnes et mêrne dans les villes, à recourir de nouveau au hois pour le chauffage domestique. A cet effet, des appareils nouveaux devront être inventés, et ce seront alors surtout les bois de feu de fortes dimensions qui profiteront de ce retour au chauffage de nos pères.

A ces raisons, basées sur les conditions de la vie inoderne actuelle, il faut en ajouter une autre, celle de la facilité de la main-d'curre dans les taillis de fortes dimensions.

On sait combien aujourd'hui le recrutement de la main-d'œuvre 
búcheronne est un problème diflicile. C'est en fin de compte le propriétaire, qui paie le supplément de salaire dû à l'aceroissement du prix de revient de la main-d'œeuvre par suite de sa raréfaction croissante. Si done le coút de la main-d'œuvre, qui a augmenté depuis 10 ans d'un tiers environ, tend à s'aceroître encore, et c'est là une hypothèse qui n'a rien de chimérique, les différences entre le prix de vente des diverses catégories de bois augmenteront encore davantage.

Enfin, au point de vue même de l'exploitation, il n'est pas douteux que le jour où des procédés mécaniques seront inventés pour la coupe des bois, ces procédés seront rendus d'autant plus faciles que les peuplements seront plus clairs, facilitant le passage des machines, et par suite les vieux taillis seront d'autant plus recherchés par les exploitants.

Si maintenant, après avoir examiné la question au point de vue historique et économique, nous passons au côté cultural, nous ne voyons que des avantages à l'allongement de la révolution des taillis et surtout des taillis sous futaie.

On sait combien au début de leur croissance, et principalement sur les sols fertiles, les jeunes taillis sont eomposés d'essences diverses, dont un nombre relativement faible de bois de valeur. Ce n'est qu'au bout d'un certain nombre d'années que les essenees les plus longévives, en général les plus précieuses, arrivent à faire disparaitre celles de moindre valeur, les morts bois, et prendre le dessus. Il est done tout indiqué de laisser à la nature le temps de produire, dans nos elimats, cette sélection naturelle, dont profite l'enrichissement du taillis en essences préeieuses. Il ne faut pas oublier,comme on l'a dit souvent, que le régime du taillis est un régime contre nature, rendu nécessaire par la nécessité pour l'homme d'une jouissance rapide; il faut done laisser la nature reprendre une partie de ses droits.

Sans doute, il sera souvent nécessaire que la main de l'homme intervienne, à des intervalles plus ou moins répétés, pour faciliter cette sélection naturelle, aider la nature dans cette "lutte pour la vie" des essences précieuses. Ce sera l'œuvre des dégagements de semis se répétant tous les 5 ou 6 ans en général, pour favoriser la croissance des essences de lumière (ehêne, frêne), menacés par d'autres essences de moindre valeur, tels que le charme, les bois blanes (tremble, bouleau, ete.). Ce sera évidemment un surcroit de dépenses; mais les frais de cette opération, indispensable pour l'accroissement de la richesse des taillis en essences précieuses, ne dépassent guère encore aujourd'hui 3 francs par leetare. Dans les forêts de peu d'étendue, ils peuvent même être exécutés sans frais par le garde local.

Alors l'enrichissement du taillis s'en suivra forcément et le propriétaire pourra répondre victorieusement à cette hérésie légendaire, que le chêne disparaît, en allongeant les révolutions, parce que la terre n'en veut plus, ou qu'en laissant vieillir le taillis les bois s'éclaircissent et se dénudent sans profit aucun pour le vendeur.

Aux dégagements de semis succédera l'éclaircie portant sur les bois blancs ou les plus mauvais rejets, et le taillis s'élèvera en hauteur. Cet allongement des perches aura une influence culturale des plus heureuses: elle forcera les réserves à se développer également en hauteur; la longueur des fûts augmentera par suite d'un élagage naturel plus complet, d'où une plus grande proportion de bois d'œuvre à en espérer. De plus, moins fréquemment isolées, les réserves subiront plus rarement ces périodes de crises, dnes an découvert complet du sol et de la cime, et les perturbations 
de végétation, qui en résultent et leur sont parfois funestes, seront d'a tant moins répétées. Enfin pourquoi ne pas l'avouer, le propriétaire sera moins souvent tenté de faire tomber un arbre vigoureux, en pleine croissance, capable de vivre plusieurs lustres encore, s'il revient moins sou. vent sur le même point!

Les baliveaux eux-mêmes, fréquemment isolés par les dégagements et les éclaircies, seront plus vigoureux, plus solides, avec des cimes mieux équilibrées, et si le propriétaire a pris le soin de les préparer aux emplacements voulus, ils faciliteront le balivage de l'avenir, sans être à jamais perdus, couchés 'par le vent lors de la coupe du taillis, et permettront lenlèvement d'un plus grand nombre de réserves surâgées. Tout concourt done, au point de vue cultural, si la révolution est allongée, à l'amélioration de la réserve, qui, dans le régime mixte du taillis sous futaie, est fonction naturelle et obligatoire du régime appliqué au taillis. C'est lui qui dans ce mode de traitement de nos forêts est, comme l'a dit si justement M. le Professeur Boppe, ancien directeur de l'École de Nancy, l'agent de perpétuation de la forêt. On ne saurait l'oublier : améliorer l'une e'est améliorer l'autre et l'allongement des révolutions du taillis ne peut que profiter à la réserve elle-même.

Une nouvelle conclusion s'impose done encore: l'allongement des révolutions du taillis, indispensable pour des raisons économiques, est avantageux au point de vue cultural. Est-il maintenant facilement réalisable?

Tout dépendra surtout de la fertilité du sol et de l'essence prineipale cultivée.

On ne saurait prolonger la révolution au delà de l'âge où l'essence principale du taillis ne peut plus rejeter qu'imparfaitement. Si done, à cet âge, les perches de taillis sont incapables de donner des produits de valeur, suivant les exigenees économiques du moment ou de la région, c'est que le régime du taillis doit être abandonné et faire place à une conversion de la forêt en futaie; une substitution d'essences peut être envisagée également. De là l'idée de l'enrésinement des taillis dégradés en plaine et surtout en montagne lorsque les conditions orographiques ou climatériques doivent faire abandonner la culture des forêts en taillis.

En général, une étude attentive des conditions naturelles locales doit toujours précéder l'allongement de la révolution des taillis. Mais empressons-nous d'ajouter qu'à l'heure actuelle dans la plupart des forêts de plaine, traitées en taillis, la fertilité du sol est toujours suffisante pour permettre un allongement certain et avantageux de la révolution existante.

Comment déterminer la durée nouvelle de la révolution à fixer ?

Quel doit être l'âge choisi? Il dépendra, bien entendu, de la faculté des essences cultivées à rejeter. Il faut, en général, une grande expérience pour fixer d'une manière sûre la révolution convenable. D'après $M$. le Conservateur des Eaux et Forêts Mathey, dans sa belle étude sur les taillis sous futaie de la Haute-Saône, l'âge optimum serait celui où le taillis est arrivé à donner en bloc 200 stères à l'heetare, production variable bien entendu avec l'âge, suivant la fertilité du sol et permettant de fixer la révolution du taillis, selon les régions, entre 25 et 40 ans.

Peut-être ce eritériuin est-il par trop absolu ? Il est bon en tout cas de le signaler et de le connaître. Mais que les propriétaires n'oublient jamais qu'ils auront souvent intérêt à dépasser. l'âge qu'ils seraient tentés d'adopter, parce qu'instinctivement ils seront souvent portés de le fixer 
au-dessous de la vérité. Songeons à l'avenir, et n'oublions jamais que plus la durée de la révolution pourra être augmentée, plus nous sommes certains de fournir des produits variés, d'une vente plus rémunératrice. " Une révolution de 30 ans, a écrit le maître forestier Broilliard, n'est pas une très longue révolution de taillis sous futaie."

Quant à la méthode mệme à adopter pour l'allongement des révolutions de nos taillis, elle sera des plus simples, pour ainsi dire antomatique. Veut-on doubler la révolution? Il suffira de suspendre une coupe sur deux et à la fin de la période, anciennement choisie, la révolution se trouvera ainsi portée à un âge double ; ce sera évidemment une diminution momentanée de revenu sérieuse, que tous les propriétaires ne seront pas en état de supporter. On pourra également diviser chaque coupe ancienne en demi-coupe, et poursuivre l'exploitation annuelle par demi-coupes. Si par ce procédé on arrivait à un nombre de coupes supérieur an nombre d'années de la révolution choisie, on pourrait constituer une réserve d'un certain nombre de demi-coupes. Ce serait d'excellente administration : une forêt ayant plus de coupes que n'en comporte la durée de la révolution peut donner deux coupes par an, quand les prix sont élevés, et c'est fort avantageux pour le propriétaire; il domine la situation.

L'allongement des révolutions pourra toujours se faire suivant les deux principes suivants:

$1^{0}$ Soit porter sur une réduction de contenance, représentée par une fraction complémentaire du rapport entre le nombre d'années de la révolution ancienne et de la nouvelle; c'est le système que nous venons d'examiner.

20 Soit par une suspension de coupes, à intervalles d'autant plus grands que l'allongement nécessaire sera plus considérable par rapport à la révolution ancienne.

Ce dernier procédé oblige à supprimer pendant un certain temps tout revenu annuel, mais il n'a pas l'inconvénient, surtout pour les petites forêts, de réduire la contenance à des proportions souvent infimes, et d'éloigner par suite souvent les gros acquéreurs, qui peuvent payer in prix plus rémunérateur.

Et lorsque la forêt, traitée autrefois en taillis sous futaie ou en taillis simple, aura ainsi vu sa révolution s'allonger, sa conversion én futaie sera devenue d'autant plus facile, car toute opération de cette nature doit forcément subir, comme préliminaire, l'allongement des révolutions. La CONVERSion RADicale n'est guère possible. Elle est d'ailleurs toujour's fort coûteuse et aléatoire, car elle suppose l'essonchement et la régénération artificielle. Lors donc que la conversion de nos taillis en futaie sera rendue nécessaire, soit pour des raisons d'essence, de sol ou de climat, c'est par le vieillissement des taillis qu'il faudra d'abord commencer.

On peut abandonner le taillis à lui-même, le laisser vieillir et pratiquer à partir de 20 ou 30 ans, tous les 10 ans par exemple, des éclaircies portant sur les bois blancs, les mauvaises cépées, cxtraire les réserves au fur et à mesure de leur dépérissement, et procéder ainsi jusque vers 80 ans, vù le peuplement sera mùr pour la régénération naturelle. Celle-ci sera d'autant plus facile que les réserves seront d'autant plus nombreuses. et les bois moins disposés à rejeter de souches. Cette méthode qu'on peut appeler la MÉTHOde conservatrice est très simple; mais elle conduit à une diminution sensible de revenus pendant me période si longne rgue bien peu de propriétaires voudront s'y résoudre. 
Il est bien préférable d'allonger la révolution si celle-ci est trop courte et continuer les exploitations de taillis, en réservant le plus grand nombre d'arbres possible de belle venue. Alors, au bout de deux ou trois révolutions, les réserves multipliées formeront massif plein et le but sera atteint, la forêt passera successivement du taillis sous futaie à la futaie claire ou futaie sur taillis pour arriver à la futaie pleine bien constituée. C'est la MÉTHODE PROGRESSISTE, pour nous servir de l'expression très heureuse de M. le Conservateur des Eaux et Forêts Algan. Nos voisins les Suisses ont pu ainsi transformer, sur les contreforts du Jura, de vieux taillis en futaies riches et touffues; la réussite de la méthode employée fait honneur à leur clairvoyance forestière.

Si les circonstances de situation de sol et d'essence ne permettent pas la constitution d'une futaie aussi rapide et ne laissent entrevoir la conversion que dans un vague lointain, difficile à concilier avec la brièveté de notre existence, du moins le propriétaire aura fait œuvre utile, car les coupes de taillis, de plus en plus riches, auront acquis de plus en plus de valeur : le sol produira de moins en moins de bois de feu et une plus forte proportion de bois d'œurre et d'industrie.

Si enfin le sol est trop pauvre pour donner des réserves nombreuses facilitant la conversion, c'est alors que l'enrésinement s'impose : les plantations de pins sylvestres sur les sols secs, exposés au midi; le sapin, l'épicéa sur les terrains plus frais ou aux expositions moins chaudes. Ils faciliteront souvent le retour des bonnes essences feuillues, et pourront donner des produits de valeur, lors de la première exploitation en vue de la régénération. Mais l'examen de ce dernier point semble dépasser le cadre de notre étude.

Concluons, en disant que la conversion des taillis en futaie, toujours possible, surtout si le propriétaire, comme en Allemagne, vient constamment aider la nature par des opérations culturales appropriées (dégagements d'essences précieuses, semis, labours, hersages, etc), est une conséquence naturelle de l'allongement des révolutions de taillis, dont elle n'est que le couronnement. Il est donc grand temps pour les propriétaires d'aborder le problème sous sa première forme, de résoudre la première partie de l'équation, c'est-à-dire de songer d'abord à l'augmentation indispensable de la révolution de nos taillis, sans gaspiller toutes les forces vives de la plus grande partie du domaine forestier dans la production de menus bois sans valeur. C'est une nécessité économique inéluctable; autrement la propriété forestière est condamnée à une dépréciation assurée, devant entraîner sa ruine de plus en plus rapide.

Cette nécessité, nous proposons de la résumer sous la forme suivante:

\section{Le Congrès ixternatioxal Forestier, rélni à Paris en 1913.}

Considérant que la mévente des bois de faibles dimensions, et surtout des bois de feu, tend à s'accentuer de jour en jour davantage, entraînant la dépréciation du prix de vente des conpes de taillis et de taillis sous futaie exploitées à un âge trop faible;

Que cette dépréciation a pour conséquence lu disparition de nombreux massifs forestiers, souvent très ntiles dans l'intérêt général, par suite de défrichements ou de coupes exagérées, presque excusables pour des bois ne donnant plus qu'un rescnu insignifiant, sonvent insuffisant pour en compenser les charges. 
Considérant, par contre, qu'il résulte de l'examen du problème sous ses différentes formes, historique, économique et culturale, que l'allongement des révolutions de taillis et taillis sous futaie est tonjours avantageux, le revenu d'un bois augmentant plus que proportionnellement avec l'áge de son exploitation, et que c'est aujourd'hui une nécessité absolue, sanf de très rares exceptions, de tendre à l'augmentation de production des bois de fortes dimensions, dont les besoins modernes pourront toujours trouver l'utilisation certaine.

Considérant, en outre, que cet allongement des révolutions dans les taillis et taillis sous futaie est toujours nne opération facilement réalisable présentant des avantages culturaux certains et permettant, en cas de nécessité, la conversion même des taillis en futaie, dont elle n'est que la phase préliminaire obligatoire?

\section{ÉMET LE V̌EU:}

Que les propriétaires soient engugés par tous les moyens à prolonger l'âge d'exploitation de leur's taillis, assurés de compenser ainsi les sacrifices momentanés, résultant de l'opération, par une angmentation de revenu certaine et durable dans l'avenir;

Qu'à cet effet les gouvernements intéressés organisent des conférences faites par les forestiers de l'Etat, dans les régions forestières importantes, d'où les propriétaires particuliers puissent tirer toutes les explications nécessaires el intéressantes à l'opération proposée;

Qu'ils soient invités à profiter des avantages des lois cxistantes on projetées pour soumettre leurs forêts à la gestion des services publics, en vue de réaliser plus sûrement et plus rapidement, l'amélioration de leurs forêts dans le sens incliqué;

Qu'en raison enfin de l'intérêt général de la conservation et de l'amélioration des forêts, des primes, comme pour d'autres cultures, ì titre d'encouragement et de compensation de la perte de revenu momentanée, subie par les propriétaires intéressés, soient instituées par l'Etat en faveur des forêts améliorées par l'allongement indispensable de leurs révolutions successives.

M. Caquet. - Vous venez d'entendre la lecture du rapport de M. Demorlaine. Or, vous me permettrez de dire que ces explications ne paraissent pas bien neuves : elles ont été enseignées depuis plus de 40 ans à l'École forestière ! II semble qu'elles soient un résumé du cours que j'ai suivi, ainsi que beaucoup d'entre nous.

Vous nous postz un dilemme en nous disant : ou vous allez rester dans les errements actuels, c'est-à-dire garler vos courtes révolutions et vous ne tirerez de vos taillis aucun revenu, ou vous allongerez vos rérolutions et vous obtiendrez un revenu. Je ne rrois pas que ce dilemme soit exact. Il y a un moyen terme auquel j'arrive immédiatement pour ne pas éterniser la discussion. Il est bien certain que le bois provenant des taillis, charbonnette et lagots, ne trouve plus it se vendre. Cela tient neuf fois sur dix, soit à la mauvaise qualité du sol, soit à ce qu’il y a des populations búcheronnes qui réclament. qu'on coupe les taillis ì l'âge normal et qui vous eausent des tribulations

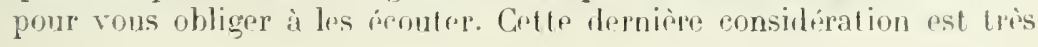


importante et M. Demorlaine ne l'envisage pas, paree qu'il est agent forestier. En outre, il est très facile de dire à un pauvre qu'on rencontre: je ne te donne pas deux sous tout de suite, mais dans huit jours, je te donnerai cinq franes! Il raudrait mieux donner immédiatement les deux sous que d'attendre huit jours pour donner les einq franes. Nous arons besoin de nos revenus, si petits soient-ils. Il faut donc chercher un mojen de se les procurer.

Je n'ai pas eu la prétention de vous le donner, ce moyen, dans mon. rapport sur l'utilisation chimique des bois, des forêts, mais je crois qu'il y a là une solution.

Je voudrais, à cette oceasion, soulever une question très intéressante. Dans le Nivernais, il existe une forêt soumise au régime forestier, c'est celle de Montambert. L'État y a dépensé des sommes énormes pour allonger les révolutions et, finalement il a été obligé de revenir à l'ancienne révolution, parce que les taillis ne comportaient pas la production à longue échéance. Cet exemple est typique. Je demanderai donc qu'une enquête soit faite pour prouver que, sur des terrains de mauvaise qualité, l'allongement des révolutions ne peut donner que des résultats médiocres et doit être déconseillée.

M. DE Larnage. - J'approuve d'une façon complète ce que M. Caquet vient de dire. Tous me permettrez d'apporter une observation à l'appui de sa thèse. D'une enquête ouverte par le Comité des forêts, association de propriétaires sylviculteurs de France qui a rendu déjà de très réels serrices, il résulte que $30 \%$ seulement des taillis étaient susceptibles de vieillissement. L'enquête a porté sur 15.000 hectares. En poussant une enquête de ce genre plus loin, rous verrez que la proportion tombera vite à $20 \%$.

Que ceux qui ont la bonne fortune de posséder des sols susceptibles de se prêter au vieillissement, en profitent; ils pourront de la sorte obtenir un rendement supérieur en recherchant le bois d'œurre. Mais laissez les propriétaires moins favorisés utiliser leur menu bois. Nous ferons une ocuvre des plus utiles en leur trourant les moyens de tirer parti de leur sol, au lieu d'aller leur prêcher des théories qui ne sont pas applicables.

M. Curf. - M. Caquet a fait allusion à l'École forestière en disant que le rapport de M. Demorlaine était l'expression de l'enseignement de cette école de Naney. C'était peut-être vrai à l'époque de M. Caquet, mais au nom de l'École, dont je fais partie depuis dix ans, je tiens a protester hautement contre cette opinion. L'École de Nancy ne prêche pas d'une façon absolue à l'heure actuelle l'allongement des révolutions. Elle cherche au contraire un autre système pour renir en aide aux particuliers, aussi bien qu'd̀ l'État et qu'aux communes en ce qui concerne les forêts traitées en taillis et en taillis sous futaie.

La communication que je rais rous lire est l'expression de ces idées. 
"La disette des bois d'ouvre se fera peut-être sentir avant cinquante ans ". Telle est la conclusion du remarquable rapport présenté au Congrés international de Sylviculture de 1900 par M. Mélard, inspecteur des Eaux et Forêts.

Comme remède, M. Mélard voulait :

$1^{\circ}$ Qu'on installât dans les plaines, sur les plateaux ou sur les montagnes de movenne élévation, soit des forèts de chêne, soit des sapinières ;

2o Qu'on arrêtât les destructions des forêts, soit par des mesures législatives strictement appliquées, soit en faisant comprendre aux propriétaires que leur intérêt bien entendu consiste à n'exploiter que la production de leurs forêts, et à en respecter le capital.

Si nous consultons les mercuriales des produits forestiers sur quelquesuns des principaux marchés de France, d'après la Revue des Eaux et Forêts, pour les amuées 1900 et $\mathbf{1 9 1 2}$, nous constatons les variations suivantes :

\section{Place de Paris :}

Chêne d'Autriche-Hongrie, premier choix, en sciage, le mètre cube....................... Fr. Chène d'Autriche-Hongrie, deuxième choix, en

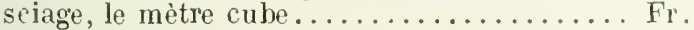

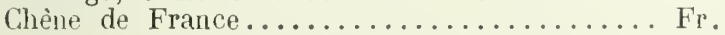

\section{Port de Clamecy (Vièore) :}

Charpente-chêne, le décistère au 1/6 déduit..... Fr. Bois d'cuvre-merrain, le millier de 2.600 pièces. Fr.

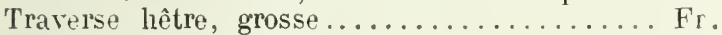

Ecorces, les 1.000 kilogrammes............ Fr. Charbons de bois, l'hècto..............Fr.

\section{Place de Villers-Cotterets :}

Charpente-chêne, bois équarris, le décistère... Fr. Bois ronds, grosseur moyenne, pour traverses de

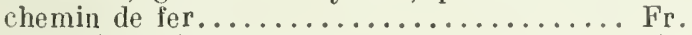
Petites dimensions, pour piquets d'entourage.. Fr. Bois de feu, chêne quartier.................. hêtre quartier................. Fr.

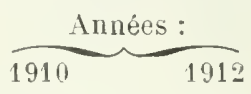

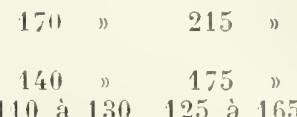

Diminution de ls proportion des bois de pelite dimension. Conversion des taillis et taillis sous fataie en futaie.

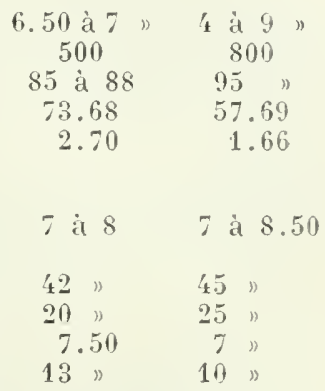

Des prix fortement croissants pour les bois-d'ceuvre, une dépréciation importante des bois de feu, des écorces et du charbon de bois, tels sont les faits mis en relief par les quelques chiffres rapprochés ci-dessus.

Les prévisions de M. Mélard paraissent donc se justifier, ainsi que les mesures préventives qu'il a cru devoir préconiser.

Mais si l'on considère que, d'une part, $80 \%$ des forèts particulières de France sont des taillis simples ou des taillis-sous-futaie, et, d'autre part, que ces régimes (1) domment toujours, à production égale, une proportion de bois d'œuvre très inférieure à celle obtenue avec le régime de la futaie (2), on

(1) Rappelons que le mot régime est synonyme de mode de régénération. - Dans la futaie, la dissémination naturelle des graines donne naissance à des peuplements formés de brins de semences. Dans le taillis, la reproduction par les axes rajeunit les peuplements au moyen de rejets de souches ou de drageons. Dans le taillis sous futaie, les deux modes de régénération se trouvent réunis sur la même surface et donnent lieu ainsi à des peuplements mixtes.

(2) D’après la statistique de 1878 , pour un mètre cube de matière ligneuse produite par hectare et par are, il y a :

\section{Forêts domıaniales et communales} Bois d'œuvre Bois de feu

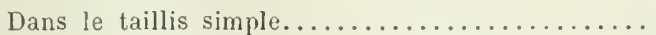

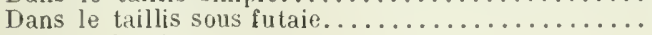

$\begin{array}{lll}0 \mathrm{mc} & 015 & 0 \mathrm{mc} 985 \\ 0 \mathrm{mc} 175 & 0 \mathrm{mc} 825 \\ 0 \mathrm{mc} & 465 & 0 \mathrm{mc} 535\end{array}$

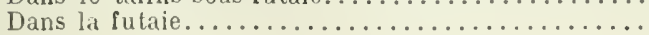

$0 \mathrm{mc} 465$

$\begin{array}{lll}0 & \mathrm{mc} & 825 \\ 0 & \mathrm{mc} & 535\end{array}$ 
admettra qu'il est de plus en plus dilficile de persuader aux propriétaires la nécessité de respecter exclusivement le capital de leurs for ts feullues.

Cette mesure conservatrice, ainsi limitée, est en effet, devenue insuffisante, Déjà, l’intérèt du présent commande, dans la plupart des cas, à tout propriétaire de forèts de renoncer à la production de bois de feu, qui ne réalise plus un placement arantageux du capital superficiel, cevendant peu élevé; cuélle impose.

L'avenirest au bois d'ceuvre, et, par suite, la gestion forestière doit sorienter progressivement vers le régime qui le fournit en plus grande abondance et de la meilleure qualité, c’est-à-dire, en général (1) vers la futaie. Or, chacun sait que cette dernière exige un capital superficiel supérieur à celui cque l'on observe lans les taillis sous futaie et à fortior $i$ dans les taillis simples. Le propriétaire le forêts feuillues devra donc, quel qu'il soit, se résondre à une augmentation lu capital engagé dans la superficie, augmentation qu'il ne réalisera qu'en coupant moins que la production, durant une période de transition dine durée proportionnelle à celle de la révolution de la futaie à créer.

La nécessité d'un changement de mode de régénération ou de régime étant établie pour les forêts traitées en taillis ou en taillis sous futaie, vers quelle forme de peuplement devront tendre les opérations de conversion, et comment seront conduites ces opérations? Telles sont les deux questions que nous allons examiner successivement.

La futaie pleine ou régulière, composée d'une suite ininterrompue de peuplements ayant mème àge chacun, présente certains avantages incontestables, qui la rendent recommandable. L'état uniforme sur de grands espares favorise une intervention efficace pour donner aux sujets d'élite les soins culturaux convenables, assure la mise en ordre des forèts, ainsi que le rapport soutenu, facilite les exploitations et l'exactitude dans la comptabilité et le contrôle.

Toutefois, cette forme n'est pas sans inconvénients, dont deux méritent particulièrement d'ètre signalés ici :

Difficilement applicable aux petites forèts, la futaie régulière est, en outre, de nature à compliquer à l'extrême, par suite d'une répartition inégale du capital superficiel, un partage successoral, auquel sont exposées les propriẹtés particulières.

Le second inconvénient, moins apparent an premier abord, mérite quelques développements. Il est d'ordre exclusivement cultural.

Les peuplements d'un seul àge, issus de graines, ne se créent jamais naturellement que sur des espaces restreints, à la suite d'accidents : météores, invasions d'insectes, etc. Hors ces cas exceptionnels, leur installation et leur maintien sur des étendues plus ou moins rastes, ne peurent ètre réalisés que gràce à une interrention incessante et sainement raisonnée du travail humain. Cette intervention doit être d'autant plus artive et plus continue que les facteurs de la production sont moins favorables à la régénération naturelle par la semence. Il peut mème arriver que ces facteurs viennent à opposer aux eforts du sylviculteur des obstacles, sinon insurmontables, du moins susceptibles de rendre très aléatoires les avantages d'un changement de régime.

Linfluence du sol et surtout du climat ressort nettement de l'histoire des conversions entreprises sur une grande échelle, vers le milieu du siècle dernier, dans les forèts domaniales. S'il serait injuste d'attribuer à une cause unique les nombreux insuccés de ces opérations, il faut reconnaitre cependant fque l'une dos principales erraur's commises a été nne extension trop large de l'ain

(1) Parmi les exceptions, nous signalerons le cas du département du Nord. Les forêts. y sont presque toutes feuillues et traitées en taillis-sous-futaie. Or, d'après la statistique de 18:8, elles ont produit, par hectare, en $1876,4 \mathrm{mc} 010$, dont $2 \mathrm{mc} 540$ de bois de service, contre 1 mc 4 \%0 de bois de feu. L'énorme quantité d'étais de mines réclamés par lindustrie houillère est la seule canse de cette relation. 
d'application de la futaie pleine, notamment en ce qui concerne les forêts de cliène des terrains frais et fertiles, sous les climats rudes du Nord-Est de la France. On a trop oublié alors que végétation et climat sont liés par des relations étroites de cause à effet.

Dans ces conditions, conseillel', d'une manière générale, aux propriétaires particulier's, la conversion de leur's forêts feuillues en futaie régulière, serait impludent, dangereux peut-être, en raison du découragement que pourrait entrainer une non-réussite, mème partielle.

Il est, val contre, dans le régime de la futaie, une forme de peuplement qui, tout en l'éunissant les principaux avantages de la futaie pleine, ne présente pas les inconvénients qui viennent d'être signalés.

Que l'on s'imagine les massifs de chaque âge formant, sur le terrain, non plus une suite ininterrompue, mais des groupes d'importance variable, répartis ça et là dans chaque parcelle de la forêt, sans qu'un emplacement leur ait été assigné d'avance, et l'on anra une idée exacte de cette forme à laquelle nous faisons allusion et que nous appelle rons futaie pleine par bouquets.

Supposons-là, pour un instant, réalisée; nous lui reconnaîtrons les avantages suivants :

10 Elle est applicable à tuutes les forêts, aux plus petites comme aux plus grandes;

20 Le capital étant réparti uniformément, le trouble dans l'anénagement est réduit au minimum, en cas de partage ou d'accident quelconque ;

$3^{\circ}$ La futale pleine par bouquets, se rapproche beaucoup de la forêt naturelle, telle qu'elle doit se présenter lorsque le peuplement est constitué exclusivement par uue essence de lumière, par le chène en particulier, qui ne peut comporter l'état jardiné ;

$4^{\circ}$ Les opérations répétées à de courts intervalles - 10 aus en moyenne permettent :

a) ie mettre à profit toutes les annèes de semences pour assurer la régẹne ération sous les vieux suje ts exploitables, isolés ou réunis par groupes;

b) de donner en mème temps aux peuplements en croissance les soins "ulturaux qu'ils réclament suivant leur état de développement, variable d'un şoupe d'âge au suivant ;

$5^{\circ}$ Le mélange des essences, toujours désirable au point de vue cultural et non sans avantages économicques, puisqu'il se prète à la production des bois d'curre les plus divers, peut être obtenu sans difficultés, par places ou compartiments, en mettant à profit les inégalités plus ou moins grandes dans la naturé du sol. Il n'en résulte aucun des inconvénients que présente le mélange intime - pied à pied - lorsque les essences associées sont de tempéraments opposés ou n'ont pas la mème activité de végétation;

$6^{\circ}$ Chaque essence peut être exploitée au moment le plus avantageux, si l'on sait faire choix d'une bonne néthode d'aménagement.

Voici, brièvement résumée, la néthode que nous préconisors.

10 Division de la forêt en coupons de 2 à 10 hectares chacun ;

$2^{\circ}$ Ail disut de chaque rotation d'une durée de 10 ans environ;

12) Dénombrement des arbres de 20 centimètres de diamètre et audessus, et évaluation de leur volume, en utilisant un tarif établi par escnce, s'il y a lieu, et relatif au bois d'cuvre exclusivement;

6) Calcul, par coupons, d'une possibilité par volume déterminée par ]'un les procédés habituels, après fixation de l'état normal qui parait con onir à la forèt ; cet état normal sera défini par le nombre des arbres de chaque catégorie de diamètre que devra renfermer l'hectare moyen, nomr qu'on puisse en tirer un revenu constant en arbres de la plus forte categorie ;

c) Etablissement d'un plan d'exploitation, en affectant un nombre entier de coupons à chaque anuée de la rotation. Pour cette affectation, on suivra l'ordic du numérotage des coupons et on les groupera de telle 
sorte que la somme de leurs contingents respectifs soit, autant que possible, voisine du chiffre de la possibilité de la forêt;

$3^{\circ}$ La coupe principale - ou recrutement de la possibilité en produits principaux parmi le matériel dénombré - sera accompagnée d'une coupe d'amélioration ayant pour but essentiel d'améliorer la jeune futaie en croissance, là où on la rencontrera, et d'assurer son recrutement. Par suite, cette coupé d'amélioration consistera en éclaircies prudentes et raisonnées des brins d'avenir et en dégagements des semis d'essences précieuses, de ceux de chêne et de frêne notamment, si le sol se prète à leur éducation.

Sans doute, la méthode exposée, qui assure l'ordre dans les exploitations, ne peut présenter la simplicité et la clarté d'une méthode exclusivement par contenance. Toutefois, il faut reconnaitre qu'elle procure, sur le taillis sous futaie, tel qu'ilest généralement pratiqué à l'heure actuelle, l'avantage incontestable de ne pas laisser la coupe indéterminée et par conséquent de s'opposer aux abus de jouissance.

Conversion d'nn taillis cous lintaie en futaie pleine parbouquets.
Cette conversion comporte la mise en application immédiate de toutes les opérations propres à la méthode et qui ont été énumérées précédemment, savoir: division de la forêt en coupons qui correspondront, en général, aux anciennes coupes de taillis sous futaie, inventaire du matériel, fixation de l'état normal et de la durée de la rotation, détermination d'une possibilité, à calculer avec d'autant plus de parcimonie que le coupon considéré sera moins riche en arbres de r'éserve, établissement d'un plan d'exploitation.

Tant que le volume normal à l'hectare, en bonnes essences, ne sera pas atteint, la coupe principale portera sur les arbres d'essences secondaires (bois blancs, charmes, etc.), ne devant entrer qu'à titre exceptionnel dans la constitution de la futaie future et, de préférence sur cenx de ces arbles devenus nuisibles à des brins d'avenir ayant crù sous leur couvert. Elle n'enlèvera, parmi les arbres des essences précieuses, que les sujets tarés ou trop dépérissants pour que l'on puisse en espérer de la semence, ainsi que les gros hètres, très branchus, à couvert bas, sous lesquels la régénération n'est pas possible.

Quant à la coupe d'amélioration, ì pratiquer toujours la mème année et dans la même enceinte que la coupe principale, elle pourra s'effectuer suivant deux modalités que nous allons décrire :

$1^{\text {er }}$ système. - La coupe d'amélioration consistera exclusivement en éclaircies des brins d'avenir et en dégagements des semis existants, ces opérations étant d'antant plus énergiques que brins ou semis seront d'une essence à tempérament plus robuste.

Accessoirement, à défaut de sujets de fran pied, il pourra ètre utile d'éclaircir ou de dégager les meilleurs montants de cépées provenant de jeunes souches.

En somme, dans ce système, pas de coupe systématique, pas de travaux non plus (semis ou plantations) susceptibles de ramener rapidement une essence précieuse sur des étendues plus ou moins vastes, dont elle a disparu sous l'influence du traitement antérieur, et où son éducation serait avantageuse au point de vue économique. Ce soin est abandonné entièrement à la inature qui s'en charge, il est vrai, mais avec une lenteur souvent regrettable.

2 e système. - Il remédie, dans la mesure du possible, à l'inconvéizient que nous venons. de signaler.

Lors du premier passage, sur les points où le couvert des réserves de l'ancien taillis sous futaie fera défaut, on formera, avec des perches de cépées, un massif complet, mais clair, susceptible de servir d'abri à des plantations ou à des semis artificiels, dont l'exécution aura lieu immédiatement après le passage de la coupe. Hormis ces perches de cépées, le taillis sera recépé complètement. Sous le couvert ménagé, les souches n'émettront que des rejets pen vigoureux, contre lesquels les semis naturels ou artificiels, et, a fortiori les plants mis en ter'e, lutteront sans peine pendant une dizaine d'amées, c'est-à-dire jusqu'au serond passage, oì des dégagements seront opérés. 
O. comprend aisément la supériorisé de ce second système, qui hâtera l'ouvre de la nature et réalisera la conversion daus le délai minimum.

Lopération dont il s'agit est évidemment semblahle à celle qui tend à convertir un taillis sous futaie en lutaie pleine par bouquets. La seule différence essentielle est que la conversion sera plus longue, en raison de l'absence de réselves qui, pour le taillis sous futaie, favorisent singulièrement un acheminement rapide vers l'état normal.

"La théorie la plus savante, a écrit de Perthuis, n'est yu'un simple jeu de l'esprit, lorsqu'elle n'est pas fondée sur des faits."

Convaincu que nous sommes, de la vérité de cette assertation, nous aurions hésité à préconiser la méthode de conversion qui vient d'être exposée, si elle n'avait déjà reçu la sanction.

Un examen particulierement aftentil et minutieux des résultats de son application dans trois res sćries d'études de la station de recherches et expériences de l'École Nationale des Eaux et Forèts, depuis 20 ans pour l'une

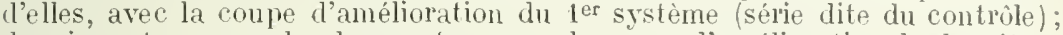
depuis sept ans pour'les deux autres, avec la coupe d'annélioration du deuxième système (séries de conversion en futaie claire), nous a permis de reconnaître sa parfaite efficacité.

En ce qui concerne la futaie pleine par bouquets, sa pratique séculaire dans des forèts particulières (1), au milieu desquelles nous arons passé notre jeunesse et dont l'attrait augmente sans cesse, pour nous, au fur et à mesure que nous pénétrons davantage les mysstères de la culture forestière, est la preuve irréfutable qu'elle n'est pas une conception imaginaire, mais un mode de traitement parfaitenent défni, qui, vu les avantages que nous hui avons reconmus, mériterait certainement une plus grande faveur que celle que lui ont témoignée jusqu'ici les sylviculteurs officiels.

M. Maxgix. - M. Demorlaine n'a pas voulu préconiser un allongement des révolutions obligatoire et applicable à toutes les forêts. Il a simplement indiqué un moyen propre, dans un grand nombre de cas, à favoriser l'amélioration de nos forêts. L'art des forestiers interviendra lorsqu'il s'agiua de discerner quel devra être l'allongement des révolutions, suivant les régions et s'il serait profitable l'user des motalités indiquées par M. Cuif.

La promière chose a faire dans les taillis, e'est d'utiliser le me nu bois. Au point de vue de l'utilisation économique, il y a des remèrles assez faciles que M. Demorlaine vous a indiqués. Vous choisirez la révolution qui vous parailra le plus favorable at vous pourrez, soit supprimer une coupe sur deux, soit réduir la superficie de cliaque coupe.

Il y a évidemment des mesures à prenclre pour permettre aux particuliers peu fortunés de supporter la réduclion de leur revenu et

(1) Les forêts particulières auxquelles nous faisuns allusion sont riveraines de la forêt domaniale de Signy-1'Abbaye (Ardennes). Le chêne, parfaitement à sa place vu la nature du sol (glaise oxfordienne recouverte d'une mince couche de limon des plateaux), et l'altitude (200 à 250 mètres), y est, en général, l'essence exclusive du peuplement dominant. Le sous-bois, toujours clair, mais suffisant pour maintenir le sol en excellent état, est formé par des morts-bois et par des rejets de chêne ou d'essences diverses. Son recépage à chaque passage de la coupe principale, qui revient tous les 10 à 15 ans, a pom* heureux résultat de dégager les semis de chêne qui se trouvent dans les vides créés par' l'enlèvement des bois exploitables, et de perpétuer ainsi la forme dı peuplement.

Comversion d'm Laillis simple en lutaie pleiue par bouquets. 
légrever momentanément d'impôt foncier les forêts en voie d'amélioration, et e'est ce que M. Demorlaine vous propose pour étayer sa thèse. Il rous indique done le moyen économique d'allonger les révolutions.

Quant à ce qui eoncerne la main d'œuvre, il est certain que tout progrès économique provoque une petite crise sociale. Dans toutes les régions, on aura du mal à lutter contre les habitudes des búcherons. Nais e'est un choc obligatoire, et, petit à petit, la main d'œuvre finira par s'adapter aux nouvelles révolutions. Je le crois du moins.

Par conséquent, je erois qu'on peut maintenir au moins le dernier rou de M. Demorlaine.

11. be LARxAGE. - Je puis vous assurer que les propriétaires forestiers ont fait des progrès énormes, en raison particulièrement de l'influence de l'École de Nancy. Ces propriétaires ont fait beaucoup pour les forêts. Comme président de syndicat forestier, je me permets de rous dire que tous les nembres de notre syndieat apportent le plus grand intérêt au bon entretien de leur's bois. Ils se préoccupent également d'une question sur laquelle vous serez sans doute de mon aris, c'est la stabilisation de la main d'œuvre, qui nous fait défaut. Or avee le régime préconisé, s'il était étendu à toute la France, ce serait la disparition de la main-d'ouvre búcheronne.

M. Maltre. - Je vouilrais dir un petit mot. Je ne veux pas parler de régions favorisées comme celles qu'a citées $\mathrm{M}$. de Larnage au point de vue de la vente du petit bois, mais de régions comme la Bourgogne et le Châtillonnais. Là, la charbonnette n'a plus aucune espèce de valeur : elle est même comptée au point de vue négatif ! Nous coupons done les taillis, non pas pour en faire de l'argent, mais parce que les acheteurs de futaie nous obligent à les enlever ; il n'y a que la futaie qui ait une valeur quelconque.

Étant donné cette situation, je me permets d'attirer l'attention sur un système préconisé et appliqué par M. Gazin, inspecteur des Forêts, et qui me parait fort heureux. On divise les filets de coupe en filets pairs et en filets impairs. Les filets pairs sont coupés comme aujourd'hui en taillis sous futaie; les filets impairs au contraire, sont réservés. On marque les futaies en délivrance qui sont bonnes à róaliser. De la sorte, sur près de la moitié de la surface le vieillissement des taillis est réalisé et c'est une économie. Si on veut avoir des arbles bien venant, on est bien obligé de laisser vieillir les taillis. Je Tous signale ce procédé qui me paraît assez ingénieux pour réaliser Ir vieillissement du taillis sans aucun sacrifice. Dans dix ans, on reviendra couper les filets impairs et on laissera les filets pairs.

MI. DE LESSEUX. - Je roudrais demander à M. Cuif quelle différence il y a entre la futaie pleine par bouquels et la futaie jardinée.

11. Cirf. - II reste luujour's dans l'esprit le mot originel. On ne peut 
pas aller dire à quelqu'un qu'il faut faire de la futaie jardinée de chêne, car il répondrait que e'est impossible, le chêne ne pouvant pas vive sous le couvert, même du chêne. J'ai done choisi le terme de futaie pleine par bouquets parce qu'il exprime bien la réalité.

N. Le Présidext. - $I 1$ faut ronclure.

M. Caquet. - Au point de vue cultural, M. Cuif vient de nous exposer une méthode qui est bien jeune pour avoir fait ses preuves et qu'il est difficile par conséquent de conseiller à des particuliers. Nons ne pouvons préconiser les expérimentations scientifiques de Nancy qui sont laites dans des lieux choisis. Ici nous cherchons un résultat décisif, pécuniaire et économique, c'est-à-dire définitif, alor's que ros expériences ne constituent que des données très restreintes.

M. Crif. - Permettez-moi de protester. J'ai cité les forêts particulières des Ardennes qui fournissent deux mètres cubes de bois d'œurre' par hectare et par an.

Je propose de rédiger ainsi le premier paragraphe.

Que les propriétaires soient engagés par tons les moyens, soit ¿ prolonger l'âge d'exploitation de leurs taillis, soit à entreprendre immédiutement la conversion de lenrs taillis on taillis sous futaie en futuie pleine par bouquets, mode de traitement parfaitement défini qui réduira un strict ininimun dans l'avenir la proportion des bois de petite dimension."

M. Le Présinext. - Je crois que M. de Larnage a une observation à présenter?

M. DE LARnage. - Je voutlais l'introduction de ces simples mots: "... quand les terruins s'y prêtent. " Ceci réserve toutes les autres solutions. Nous n'aurons pas l'air ainsi de poser des solutions inéJuetables.

M. Crif. - M. de Larnagre a raison, car on peut dire qu'il n'y a rien d'abselu en sylviculture.

M. DE Lanxage. - Je remercie M. Cuif de son alfirmation.

M. Rorx, secrétuire. - Je donne lecture du voru :

Que les propriétaires soient engagés par tous les moyens, soit à prolonger l'âge il'exploitation, soit à entreprendre immédiutement. la conversion de leurs tuillis ou taillis sous futaie en futaie pleine par bouquets, assurés de compenser ainsi les sacrifices momentanés résullant de l'opération, par une augmentution de revenu certaine et durable dans l'avenir;

"Qu'di cet effet, les gonvernements intéressés orgunisent des confé- 
rences failes par les forestiers de l'Etat dans les régions forestières importantes, d'où les propriétaires particnliers puissent tirer toutes les explications nécessaires et intéressantes à l'opération proposée;

"Qu'its soient invités à profiter des avantages des lois existantes ou projetées pour soumettre leurs foréts à la gestion des services publics, en s'ue de réaliser plus sûrement et plus rapidement l'amélioration de leurs forêts dans le sens indiqué;

"Qu'en raison enfin de l'intérét général de la conservation et de l'amélioration des forêts, des primes, comme pour d'autres cultures, ì titre d'enconragement et de compensation de la perte de revenu momentanée, subie par les propriétaires intéressés, soient institnées par l'Etat en faveur des forêts améliorées, soit par l'allongement indispensable de leurs révolutions successives, soit par leur conversion directe en futaie pleine par bouquets. "

M: le Président. - Je mets ce vou aux roix.

Le vœu ést adopté.

La parole est à M. Raverdeau pour une communication sur l'IxTROD ÜCTION DU PEUPLIER DANS LES TAILLIS.

11. Raverdeau. - J'ai l'honneur de rous soumettre les réflexions suivantes:

Puisqu'il est prouvé que, par suite de la main-d'ceuvre de plus en plus rare et coùteuse, de la mévente des menus bois, les propriétaires forestiers sont forcément appelés`à remplacer les taillis par les arbres de haute futaie qu'ils seront toujours assurés de vendre à des prix rémunérateurs, les besoins de bois de l'industrie allant toujours en augmentant, une très grave question se pose pour ces propriétaires, surtout pour ceux dont les bois renferment actuellement beaucoup de taillis et peu de gros arbres, comme c'est généralement le cas.

S'ils conservent les jeunes futaies de chênes, hêtres, charmes ou autres bois poussant très lentement pour en faire un jour de gros arbres, ils, ne peuvent émettre l'espoir de réaliser ces derniers eux-mèmes, l'espace de deux à trois générations d'hommes étant nécessaire pour que ces essences donnent des produits de valeur.

Voilà donc les propriétaires forestiers entièrement privés de revenus. Beaucoup renonceront à s'y résigner. Un remède existe heureusement à cela, du moins en ce qui concerne les bois situés en terrains frais. Il consiste à planter les bois en peupliers au fur et à mesure de l'exploitation des taillis. Pour cela, choisir de bon plants d'une essence connue et bien sélectionnée, déjà forts, âgés d'au moins trois ans afin qu'ils puissent dominer immédiatement le taillis qui ra repousser. Les plants à 5 mètres sur 5 , soit 400 plants à l'hectare. On pent ensuite laisser le taillis repousser en dessous, mais dans ce cas, le peuplier poussera moins vite, étant privé d'air.

Si l'our ne tient pas à conserver de taillis, il n'y a qu'à exterminer les jeunes pousses pendant la sève, les arracher des souches et ces dernières pourriront ensuite avec le temps.

Au cas où l'on tiendrait à garder du taillis tout en aérant les peupliers, il n'y a qu'à détruire les jeunes pousses de taillis se trouvant sur chaque ligne de peupliers sur une largeur de 3 mètres. Les lignes de peupliers étant à 5 mètres les unes des autres, il restera entre elles une bande de taillis de 2 mètres de largeur qui ne nuira mullement à la pousse des peupliers. 
J'ai commencé à appliquer depuis quelques années cette mélhrode dans mes propres bois et elle me donne un très bon résultat. Je suis persuadé qu'elle peut rendre d'excellents services à bon nombre de propriétaires.

Voici comment on peut exploiter un bois ainsi planté : .

A quinze ans, on abat le taillis qui pousse vite dans ce genre de terrain frais (étant d'ailleurs presque toujours composé d'essences à croissance rapide comme aulne, frène ou bouleau).

Le bois obtenu n'est pas très gros, mais suffisamment pour mériter d'être exploité.

On abat en mème temps une ligne de peupliers sur deux, puis un arbre sur deux dans les lignes restautes, soit 300 pieds représentant facilement une valeur de 3 francs pièce. Les petits penpliers de cette taille trouvent aujourd'hui très facilement preneur pour la fabrication de la pâte à papier ou la confection des planches à caisses d'emballages (pour faire de la barre à caisse). On a donc une réalisation de 2.400 francs.

Les peupliers restant se trouvent alors à 10 mètres sur 10 et ont tout l'espace voulu pour croîtue.

Quinze ans après, on coupe de nouveau le taillis, puis les peupliers restant : ceux-ci représentent une valenr de 40 à 45 francs pièce, au minimum.

Soit une réalisation d'au moins 4.000 francs.

L'hectare de bois aura done rapporté en l'espace de trente aus : 2.400 francs plus $\mathbf{4 . 0 0 0}$ franes, soit 6.400 francs, c'est-à-dire 213 francs par an, en ne tenaut aucun compte du taillis qui paiera les menus frais de garde et d'entretien.

Il me semble que cette opération qui peut être entreprise et réalisée par un homme mème âgé de quarante ans, est susceptible de tenter beaucoup de propriétaires à la veille de ne tirer aucun revenu de leur hois. D'autant que j'ai pris comme exemple les chiffres les plus faibles et que l'on peut obtenir facilement de beaucoup plus beaux résultats pour peu que l'on soigne ses plantations.

Le peuplier est le seul arbre que ceux qui le plantent peuvent espérer récolter eux-mêmes. Comme le prix de son bois atteint la moitié et même quelque fois les deux tiers de celui du cliêne et qu'il pousse quatre fois plus vite, il est facile de voir que le premier doit rapporter trois fois plus que le second.

Le peuplier convient tout particulièrement dans les terrains frais mais pousse bien dans les terrains mème humides, suffisamment remués.

C'est l'arbre de l'avenir. Sa consommation toujours croissante sera cause que ce bois va manquer un peu partout et que son prix déjà élevé montera encore. Son usage se répand de plus en plus et ses emplois sont multiples; de larges débouchés lui sont donc toujours assurés.

M. Le Président. - L'assemblée donne acte à M. Raverdeau de sa communication. La parole est à M. de Segonzac.

M. l. baron Je SEgoxzic. - Ia communication de M. Raverdeau est relative aux plantations de peupliers dans les terrains frais. J'ai tenté moi-même l'expérience. Les blanes de Hollande sont venus très bien et dans ce moment ils donnent des coupes régulières assęz bonnes. Les autres peupliers n'ont pas donné des résultats aussi bons. Les peuplier's parasols qui font si bien sur les routes, croissent régulièrement. Mlais il y a une certaine prudence à observer et e'est une question qui demande à être examinée avec beaucoup de circonspection. D'après mon expérience, e'est done le blane de Hollande qui donne les meilleurs résultats. Mais il y a des espèces qui meurent au bout de quinze à ringt ans et qui, par conséquent, ne peurént servir absolument à rien. Il faut done choisir son essence avec soin. 
M. BAtoocx. - J'appelle l'attention sur les maladies terribles qui attaquent les arbres. Il y a une sorte de gale qui attaque les pèpliers: il se forme de gros bourgeons qui arrivent à fendre l'arbre au bout de peu de temps. Je demande quelles sont les essences de peupliers qui sont réfractaires à cette maladie. C'est très important, car il r a des régions où l'on est obligé d'abattre des quantités de peupliers. ce qui "ntraine une grosse perte.

M. BARBEY. - L'insecte qui ravage le peuplier est bien connu. Ciest la saperte qui comprend deux espèces: la Saperde chagrinée (Saperda carcharias L.) dont les élytres sont jaunes tachetées de noir et la Saperde des peupliers (Saperda populea L.) très fréquente dans les trembles. Je crois qu'il n'y a pas de remède aux attaques de ces insectes, à part la destruction des larves. Il n'y a qu'un moyen, c'est l'incinération sur place. Dans les grands arbres sur lesquels on ne constate qu'une seule attaque de la grande Saperde chagrinée, on peut se contenter de la détruire au moyen d'un insecticide; mais dans les arbres atteints à l'infini, il n'y a pas de remède, sinon l'abatage de toutes les tiges infestées.

M. Le Présidext. - S'il n'y a pas d'autre observation, la discussion est close.

la séance est levée à 11 h. 20 . 


\section{SEANCE DU 18 JUIN 1913}

\section{(MATN)}

\section{Présidence de M. GAQUET, vice-président de Section}

La séance est ouverte à 9 h. 20 .

Y a-t-il dans la salle des délégués étrangers? S'ils veulent bien venir prendre place au bureau, nous serons heurenx de les accueillir.

I'ordre du jour appelle le rapport de M. Jolyet sur les taillis ¿l'aeacia. M. Jolyet n'étant pas dans la salle, je vous propose d'écouter d'abord la lecture d'une note sur l'acacia par M. Vadas, délègué de la Hongrie.

II. Vadas. - Messienrs, j'ai eu l'occasion de m'occupel en Hongrie de l'acacia d'une manière très complète; j'ai réuni mes études dans une monographie de l'acacia qui vient d'ètre publiée en français, et c'est pourquoi je vous demande la permission de vous présenter quelques brèves observations sur la ifuestion traitée.

Dans un climat où prospèrent les vignes et le chàlaignier, dans un solsablonneux et làche, qui n'est pas lumide, l'acacia peut s'élever en peuplement. La condition principale du succès de sa culture est de labourer au préalable le sol (culture agricole et sylviculture combinée), parce que le dóveloppement intensil des racines ne peut se faire que dans un sol labouré, qui soit le plus possible en contact avee l'air ; les tubereules des racines, qui recueillent l'azote atmospherique, se développent avee la plus grande abondance daus un tel sol, qui assure en même temps l'humidité nécessaire pour la croissance favorable de l'acacia.

La plantation se fait avec des plants d'un an, à l'espacement de deux mètres cn tous sens. Après la plantation, nous récépons à blanc étoc, et des drageons poussant ainsi, nous élevons les arbres à l'aide de l'émondage nécessaire. Actuellement le recépage se fait à 10 ou 20 centimètres au-dessus du sol, pour que la blessure soit la plus petite possible, car au lieu de la blessure, commence facilement la pourriture.

L’émondage est inévitable à l'àge de 2 ou 3 ans pour la formation de la couromne de l'arbre. C'est pourquoi j'estime que le recépage à 5 ans que $\mathbf{M}$. le Rapporteul" recommande, est superflu.

La révolution des taillis d'acacia peut être déterminée le plus avantageusement entro 25 et 30 ans au maximum.

Les jennes drageons, constitués en grande partie par de l'aubier, ne peuvent être utilises comme bois d'ceuvre ou comme échalas, comme l'indique M. Ie Rapportenr, car ce bois pourit vite et se rejette. Dans toutes les conditions. on ne rient employer comme bois d'œuvre que le bois nerveux, dont la durabilité estencore plus grande que celle du chêne.

Je dois mentionner encore l'exploitation de l'acacia en faveur de la régéné- 
ration des peuplements. Toutefois, il faut défricher le trou, couper les racines tout près du tronc et l'emplir la fosse. De cette façon, il pousse une quantité de drageons, parmi lesquels on choisit les plus forts.

Le robinier doit sa valeur à cinq propriétés éminentes :

$1^{\circ}$ Sa croissance rapide;

$2^{\circ}$ Son bois excellent;

$3^{\circ}$ Sa modération dans ses-exigences vis-à-vis du sol;

¿o son aptitude incroyablement vivace à rejeter de souche.

$5^{\circ}$ La large extension des racines.

En général, le robinier prouve que des espèces qui. dans leur pays d'origine, ne sont que des essences rares et obscures, ailleurs peuvent atteindre une valeur éminente pour tout le monde.

En Hongrie, le robinier a conquis tout le pays jusqu'aux montagnes moyennes. Dans la région des sables, il est la seule essence dominante, comme arbre de forêts, sul' des milliers d'hectares, et c'est pourquoi il est chez nous d'une importance extraordinaire sous le rapport forestier et économique.

'Pourvoyant l'Alfold d'un bois excellent, fixant le sable mouvant qui est absolument inutilisable et qui, transporté par le vent, couvre les territoires cultivés, le robinier procure encore au sol un rendement considérable. Il ramène la verdure sur les pentes dénudées des montagnes qui, déboisées pal' une mauraise exploitation, sont, non seulement improductives, mais exposent encore les pays bas arables aux conséquences nuisibles des averses. Il abrite l'homme et les troupeaux contre le soleil de la steppe, autrefois presrue sans arbre et jusqu'ici à climat extrèmement continental. Grâce à ces reboisements très étendus, ces steppes jouissent d"un climat plus favorable. Il augmente aussi, par sa richesse en miel, le bien-être des paysans et, de plus, le grand essor de la pomiculture et de la viticulture au coeur du pays est dù en grande partie au robinier, dont les qualités extraordinaires sont seules capables de fixer le sable mourant et de le rendre productif.

En finissant, messieurs, j'ai l'honneur de vous inviter à venir en Hongrie pour rous montrer, en nature, les résultats obtenus avec la culture de l'acacia, sur laquelle nous fournirons toujours des renseignements avec plaisir.

Mais j'aurai encore une prière ì formuler.

Ces jours passés, j'ai visité avee mes collègues, le vieil acacia du Jardin des Plantes, planté par Robin en 1636. Nous arons constaté avec plaisir qu'on a fait tous les efforts possibles pour conserver ce souvenir de la culture humaine. Cependant l'anneau en fer portant la tige de cet excellent acacia pénètre déjà dans l'écorce et affaiblit la croissance de l'arbre. C'est pourquoi je prie l'Administration du Congrès de demander qu'on prenne les dispositions nécessaires pour que cet arbre soit sauré encore, si Dieu le veut, pour un quatrième siècle! (Applaudissements).

M. le Présidext. - Nous remercions M. W délégué de la Hongrie d'avoir bien voulu nous faire une communication sur cet arbre si intéressant, qui a donné lieu à un rapport dont nous allons discuter les conclusions, et nous le félicitons de son travail.

Quant au vou, je crois qu'il ne trourera pas de contradicteurs : c'est une manifestation en faveur de la conservation d'un viril arbre it lacquelle nous ne pouvons que nous rallier tous. 
M. Mtxix. - Professeur au Muséum, je puis entretenir mes collègues de ce vou et d'une situation à laquelle il sera, je crois, facile de remédier. Nous avons demain une réunion, je me ferai un plaisir d'en parler.

M. Le Prénext. - Au nom de l'Assemblée, nous vous remereions de prendre cette initiative, qui donnera satislaction à M. Vadas et a nous tous.

II. Jolyet n'étant pas encore arrivé, je vous propose de lire son rapport sur les TiILLIS D'ACicias.

Rapport de M. JoLret. - Le Robinier, faux-acacia, Robinia psendoacaciı, Lin. est aujourd'hui cultivé dans toute la France et connu de tout le monde sous le nom d'acacia.

Peut-être, par égards pour J. Robin, qui l'introduisit dans notre payss en 1601, eût-il été convenable de lui réserver le nom de Robinier; mais aujourd'hui la dénomination d'acacia paraît avoir', comme l'arbré lui-même, conquis chez nous droit de cité.

L'acacia est originaire de régions des Etats-Unis dont les étés sont très chauds ; les taillis d'acacia, très intéressants pour la France, et spécialement pour les bassins de la Garonne et dı Rhône, pour la Hongrie, les puissances Balkaniques, le sud de la Russie, etc., le sont donc peutêtre moins pour des États situés plus près du pôle. Cependant ils paraissent être encore assez productifs en Allemagne. En Belgique, l'acacia donne de bons résultats sanf dans les stations élevées de l'Ardenne; les climats de montagne dont les étés ne sont pas assez chauds semblent bien lui être défavorables.

Et de fait, l'acacia s'est très vite naturalisé en France, où la rareté de ses semis naturels cst plutôt imputable à une compacité excessive du sol qu'à des conditions climatériques défectueuses; dans le sable meuble des dunes de Gascogne on voit des semis d'acacia. Toutefois, cette essence paraît avoir été dans notre pays largement utilisée à la consolidation de talus de routes ou de voies ferrées, mais moins souvent envisagée comme essence forestière productive.

Je signalerai cependant que P. Fliche n'a pas méconnu la valeur forestière de l'acacia; que le maitre Ch. Broilliard lui a fait une large place dans son étude des taillis considérés comme producteurs de bois d'œuvre ; qu'aujourd'lui les auteurs forestiers n'omettent pas de parler des taillis d'acacia; qu'enfin l'Association centrale pour l'aménagement des montagnes utilise l'acacia dans ses remarquables et si utiles travaux de restauration de nos grandes montagnes françaises. L'acacia, d'ailleurs, est ine des essences feuillues qui, dans les sables mouvants des dunes de Gascogne, sont parfois adjointes au pin maritime.

A l'étranger, je signalerai tout spécialement une étude de M. Vadas, qui montre le rôle utile de l'acacia en IIongrie et, si je ne me trompe, il existe aussi de très grands reboisements en acacia dans la plaine du Danube en Roumanic.

L'acacia nous offre les garanties les plus sérieuses quant à sa rusticité. linsticite del'acaL'hiver 1879-1880 l'a respecté même dans nos départements du cia. Nord-Est. 
Très exceptionnellement, dans certaines stations en sol mouilleux, quelques acacias ont pu être tués, mais des drageons ont toujours évolué et remplacé bien vite les sujets détruits.

Les gelées tardives n'endommagent pas ses jeunes pousses - très sensibles, mais dont l'évolution est très tardive, — aussi souvent que celles de plusieurs essences indigènes, comme le frêne et même le chêne.

Dans nos stations françaises de basse altitude, les pousses de l'année sont presque toujours suffisamment aoutées pour n'avoir rien à craindre des gelées précoces; mais, sous les climats de montagne, il peut en être autrement bien entendu; cela me confirme dans l'opinion qu'en France, sous $47^{\circ} L . N$, le taillis d'acacia n'est plus à sa place au-dessus de 500 mètres d'altitude.

L'expérience de l'été 1911 a montré que l'acacia est une des essences qui ont le moins à redonter les étés très chauds et très secs.

Enfin l'acacia compte peu d'ennemis très redoutables parmi les parasites animaux ou végétaux et, à tout le moins, en cas d'accịdent, les parties aériennes du végétal sont seules détruites et des drageons les remplacent spontanément.

A côté de cette grande rusticité, d'autres considérations me paraissent militer en faveur d'une plus large extension du robinier dans nos peuplements forestiers. Ce sont : l'abondance de ses drageons; sa valeur comme bois d'œuvre.

Abondance des trageous de l'acacia et ses consequences.

Valeurde l'acacia com me bois d'reuvie.
Les nombreux drageons de l'acacia assurent dans d'excellentes conditions la régénération naturelle des taillis de cette essence et aussi le reboisement spontané des vides qui peuvent exister dans le peuplement.

C'est à ces drageons également que l'on doit, à mon avis, de pouvoir cultiver avec avantage l'acacia sur les terrains superficiels des sols oolithiques pour pen que la roche du sous-sol soit fissurée: les drageons qui évoluent au-dessus des crevasses remplies de terre végétale I trouvent la profondeur qui leur est indispensable pour acquérir en peú de temps de belles dimensions.

La résistance du bois de l'acacia à la rupture, à la compression et à la pourriture est considérable.

Mais l'intérêt tout spécial de cette essence tient à ce fait qu'en raison de la minceur extrême de l'aubier, des perches de taillis de fort pet it calibre peuvent être utilisées comme bois d'œuvre. J'ajouterai que ce bois d'œuvre est surtout utile aux vignerons et aux cultivateurs (échalas, bois de pâture, piquets, rais pour les roues de voiture, etc.).

Dans ces conditions, il est permis d'admettre :

10 Qu'un reboisement en acacia donnera ì très brève échéance des produits qui seront utilisables comme bois d'œuvre et, par suite, d'une vente très facile et très rémunératrice. A mon avis, ces reboisenents en acacia plus faciles, moins dispendieux et moins exposés aux dégâts de la sécheresse, aux bris de neige et aux dommages des insectes ou des champignons que les reboisements en pin, seront aussi rémunérateurs que les reboisements en pin sylvestre et plus que ceux en pin noir, vu la difficulté avec laquelle on parvient à vendre le bois de ce dernier. Ils auront, en outre, sur les reboisements en pin l'avantage qu'une régénération naturelle succèdera toujours à l'exploitation. 
$2^{\circ}$ Que les reboisements en acacia une fois obtenus devront être traités en taillis simples réguliers.

Le taillis d'acacia présente un intérêt considérable dans les pays où la propriété est très morcelée : on peut créer un taillis d'acacia et l'exploiter d'une façon méthodique et très rémunératrice sur toute pièce de terre, si petite qu'elle soit.

En effet, à l'encontre de la plupart des essences forestières, l'acacia prospère tout aussi bien, sinon mieux, en bouquets de quelques ares d'étendue qu'en massifs de plusieurs hectares.

D'autre part, le bois d'œuvre qu'il fournit, approprié aux besoins locaux des cultivateurs et des vignerons, trouve acheteur quand il est offert en petite quantité dans d'aussi bonnes conditions que s'il formait un stock important.

Dans la Haute-Saône existent beaucoup de ces "buissons" qui jouent un ròle économique non négligeable, les uns, taillis spontanés de charme et d'érable champêtre, fournissant du bois de chauffage, les autres, taillis artificiels d'acacia, produisant du bois d'œuvre.

Le taillis d'acacia, d'autre part, n'est point très nuisible aux propriétés riveraines, en raison du couvert très léger de l'essence. Sarıs doute il présente l'inconvénient de ses drageons qui évoluent au milieu des terres cultivées du voisinage; mais je ne crois pas qu'il faille s'exagérer cet inconvénient, car, si la charrue retourne chaque année les terres en question, les drageons ne pourront se développer pendant plus d'une saison de végétation et le voisinage d'un drageon de cinq ou six mois d'âge ne peut porter aux cultures un préjudice bien sérieux. La pro. priété qu'ont les racines de l'acacia, comme celles des autres légumineuses, de fixer dans le sol l'azote atmosphérique doit enfin, en enrichissant les terres agricoles, être une large compensation aux légers ennuis dus à lá révolution des drageons.

On paraît craindre que l'acacia, exigeant la lumière d'une façon très impérieuse, ne puisse constituer des peuplements de taillis complets.

La vérité me paraît être ceei :

L'acacia peut former d'excellents taillis, mais à la condition que des éclaircies fréquentes assurent à la cime des perches un éclairemcnt suffisant. Il serait à souhaiter que l'on se déeidât à considérer l'acacia comme une essence forestière et à étudier les peuplements qu'il constitue au point de vue du nombre des tiges et de la surface terrière. Je n'ai pu trouver que fort peu de renseignements à ce sujet.

Un taillis d'acacia en terrain oolithique (à sous-sol fissuré) devrait être créé et traité de la façon suivante :

Plantation à l'espacement de $1 \mathrm{~m} .50$ en tous sens, soit 4.444 plants à l'hectare.

A cinq ans, recépage à blane étoc provoquant l'évolution de drageous dont un nombre suffisant apparaîtraient au-dessus des crevasses de la roche calcaire.

Adoption d'une révolution de 35 ans.

Eclaircies (certainement très rémunératrices) dans les peuplements de 15 ans et 25 ans.

L'exploitation des perehes de 35 ans serait accompagnée de celle de 
tous les drageons nés à la suite des éclaircies, car ils pourraient avoir souffert d'un éclairement insuffisant.

Futaie claired'acacia.

Emploi dn robinier pour la creation de forêts risineu. ses.
Lacacia de Decaisne.

On reproche aux taillis d'acacia qu'ils sont envahis peu à peu par des essences feuillues indigènes.

Sans doute, mais l'acacia aura cependant permis un boisement très économique du terrain et il restera pendant longtemps (surtout si l'on a soin d'opérer quelques dégagements en sa fareur) représenté par un nombre d'individus suffisant pour constituer une sorte de futaie très claire dominant un taillis de feuillus indigènes et fournissant un bois d'œuvre très apprécié.

Je possède, dans la Haute-Saône, des acacias que j'ai réservés comme baliveaux au-dessus d'un taillis d'autres essences et je n'ai pas remarqué qu'ils soient dégradés par des bris de branches au point qu'on puisse aroir des inquiétudes sur leur valeur dans l'avenir.

On peut du reste prévenir cette modification du taillis d'acacia en préparant, comme je l'explique ci-après, sa conversion en futaie résineuse.

Pour la mise en valeur des terres incultes dans les régions de plaines et de coteaux du Nord-Est, il est difficile de trouver un résinenx qui, acceptant les sols superficiels peu favorables au pin sylvestre et plus rémunérateur que le pin noir, résiste tout à la fois à des étés très chauds et très secs, et à des hivers exceptionnels comme celui de 1879-1880. Le seul qui me paraisse vraiment adapté à notre climat continental est le Donglas à fenillage glauque (Psendotsuga Donglasii, var. glauca).

Malheureusement le Douglas à feuillage glauque est d'une installation coûteuse et sa croissance n'est pas très rapide.

Les frais de boisement sont, au contraire, acceptables si l'on se contente de planter à l'hectare 280 Douglas en constituant un remplissage d'acacia,

Les produits fournis par ce dernier permettent d'attendre que les Douglas soient devenus exploitables et en même temps assez âgés pour ensemencer naturellement le terrain, qui sera dès lors occupé par un peuplement résineux. Les lacunes de ce peuplement résineux seront, du reste, remplies provisoirement par des drageons d'acacia.

MM. le comte Visart et Ch. Bommer appellent l'attention sur un hybride de $R$. Psendacacia et de $R$. Viscosa, connu sous les noms de $R$. Dubia Foucault, var. decaisneana et de $R$. decaisneana. hort. qui possèderait une croissance très vigoureuse et formerait " naturellement un tronc droit, élancé, non divisé, à cime régulière ".

Peut-être sa culture serait-elle avantageuse?

En conséquence des considérations qui précèdent, nous arons l'honneur de formuler le projet de vœu suivant:

Qu'il soit constitué des taillis d'acaciu comme mode économique de boisement, particulièrement sur les terrains de faible étendue.

M. DE SEgorzac. - Je crois qu'il faudrait ajouter "et des futaies". Je ne mettrais pas non plus "sur les terrains de faible étendue ", mais re "faible qualité ". Vous pouvez aussi bien en planter sur un terrain itrndu que sur un terrain de petites dimensions. 
M. Le Président. - Crovez-vous utile d'insister sur ce mot? Le plus souvent on fait des boismments sur des terrains de faible qualité, et d'autre part, l'acacia n'est pas si facile qu'on vent bien le dire pour le choix du terrain.

On vient de parler de Robin, et je ne voudrais pas trop me vieillir, mais je m'oreupe rlrpuis longtemps de la question et j'ai même publié en 18s:; un opuscule sur l'acacia. J'ai fait pas mal d'expériences et me suis rendu compte que c'est un arbre plus difficile qu'on le dit et qu'on l'écrit. J'ai ru des taillis d'acacia lonner des résultats merveilleux, mais dans des terrains qqui n'étaient pas maurais, et où la rulture agricole aurait donné des résultats non excellents, mais appréciables. Il faut done qu'on se détrompe à unt égard, ce n'est pas une cissence qui s'accommode de tous les sols. Si vous en mettez sur des terrains imperméables, sur des glaises compactes, vous n'aurez rien; sur des terrains mouillés, il pourrit; il est beancoup plus exclusif, sinon au point de vue chimirgue, tout au moins au point de vue physique, qu'on ne le dit.

Si donc vous voulez rélléchir à ce que je vous dis, je rous proposerai de ne pas insister sur ce mot.

M. HickEL. - Je confirme pleinement les observations que rient de faire notre président.

Eridemment, l'acacia est susceptible de croître dans des terrains pauvres, mais à condition qu'ils aient une certaine profondeur.

M. TADAs. - Comme je disais, un "sol lâche ».

M. Hickel. - Lor'squ'il croit sur un terrain pauvre et superficiel, c'est alors que les inconvénients se présentent au maximum. Lorsqu'il a un certain âge, les drageons se trourent cassés, tandis qu'au contraire quand il est sur des terrains paurres, mais en roches, comme toutes les essences, il dragenne an maximum. Sur un terrain superficiel, vous avez simultanément une foule le drageons de $2,3,4,5$ ans qui causent des épines, et rela devient extrêmement désagréable.

M. Delahaye. - A l'appui des indications qui viennent d'être fournies, je puis signaler que dans les dunes des còtes de la lendée, oì ne vient que le pin maritime, l'acacia donne d'excellents résultats. Mais il lui faut un terrain extrêmement meuble. Les plantations doivent être faites en potrts de un mètre cubr. l'ai v'u des plantations faites en potets de 50 centimètres de profondeur sur un mètre carré de surface, les arbres sont tous morts. Cr sol, drsable, a besoin lui-même d'être ameubli pour que la plantation réussisse. Mais alor l'acacia pousse admirablement. Dans les endroits mouilleux, on n'a aucun résultat. J'ai fait fair' quelques plantations dans l'emplacrment d'une ancienne carrière de sable : on y reconnait les particn mouilleuses ì la mort des sujets. 
II. LE l'Résu Ext. - C'est très intéressant.

11. L.hiE E. - Je demanderai au contraire que le not soit maintenu dans le voru. Hier, dans une autre section, j'ai parlé des difficultés du reboisement quand on n'a pas à sa disposition des terrains, vastes; or', l'acacia est l'essence qui convient le mieux pour les pays très morcelés.

Dans la Bourgogne, son emploi est classique sous forme de pieux.

Dans le sable vert, il pousse très bien; à côté du sol argileux qui appartient à l'étage inférieur au sable vert, dans l'aptien, il se couronne à 4 ou 5 mètres de hauteur. Donc, il ne peut pas servir à faire des rais de voiture, tandis que dans des sables roisins où on le coupe à l'âge de 16 ans, on estime que son rendement est plus intéressant que le chêne, à condition que la culture de la vigne marche bien dans le pays.

En ce qui concerne la Hongrie, les sols des steppes sont différents des sols de climat humide. J'ai étudié la question à propos du drei farming. Dans les sols des steppes, le climat étant sec,-la terre fine n'est pas entraînée par les eaux. Vous avez du diluvium dans le centre de la Hongrie, en Roumanie, en Russie, dans des sols très profonds. Donc la réussite de l'acacia dans ces régions n'est pas comparable à ce qu'elle peut être chez nous. Le climat et le sol ne sont pas les mêmes, les termes de comparaison n'existent pas.

En ce qui concerne la clòture de l'acacia en mélange dans un taillis, souvent un particulier plante de l'acacia en bordure et, au bout d'une trentaine d'années il arrive ceci :

L'acacia étant très exigeant comme sol, - j'insiste sur ce fait, épuise le sol au point de vue minéral, tout en l'enrichissant au point de vue azote. Ses drageons vont peupler à l'intérieur du bois; on trouve l'acacia dans le milieu du bois, et le vide se fait sur les bords.

Les botanistes disent : grâce à l'azote apporté par l'acacia, le sol est resté bon, mais la forêt n'est plus défendue, on a un vide pendant un certain temps; et si on est sur le bord d'une route, rxposé aux passants et aux animaux, ce vide se remplit difficilement. L'aeacia serait peut-être bon au milieu du bois, mais en bordure, e'est un inconvénient. On arrive à aroir de distance en distance un petit massif d'acacias, la coupe, n'est plus régulière.

M. Le Déléglé ne Pontugal. - Dans le Portugal, lacacia rient bien, mais nous n'arons pas de forêts d'acacias pour les raisons rxposées par M. le Président et M. Hickel : ses exigences souterraines sont très difficiles.

On peut dire que l'acacia rient sous tous les climats, mais je crois que cest dans le Midi qu'il peut donner les meilleurs résultats. Dans le Midi, on obtient un arbre très riche, qui donne 30 à $40 \%$, et e'est un acacia à grand rendement, qui vient très bien dans tous les sols. 
M. HickEL. - Ce sont des eas très différents suivant qqu'il est sur des territoires cultivables et dans les régions provençales. Dans toute la région du Sud-Ouest, il est possible de le faire remonter sur une zone dont je ne pourrais donner la largeur, mais qui va au moins jusqu'à Nantes. Évidemment, il peut réussir en quelques autres endroits du territoire, tels que l'extrémité de la presquille de la Manche, les côtes de Bretagne, mais je ne crois pas qu'il soit suceptible, en dehors de la Provence et de la Gironde, d'un emploi forestier.

M. Gullzot. - A l'appui de ce que rient de dire M. Larue, je signale que dans les landes de la Gironde, il y a des peuplements d'acacia, mais que bientôt ils se trouent au centre. Pour nous, l'acacia est une essence nomade, qui se déplace; d'ailleurs elle est goumande, puisque e'est une essence rivicole.

Au vou de M. Jolyet, je proposerais d'ajouter "à basse altitude " ou " $\dot{a}$ altitude modérée, dans un sol un pen frais et un pen substentiel ».

Ce sont les trois conditions nécessaires.

M. de Segonzac. - Nous ne sommes pas tout à fait d'accord; il y a de mon côté, dans l'Oise, des terrains très argileux où l'acacia rient d'une façon extraordinaire, il a une pousse dont on n'a aucune idée.

C'est un arbre qui, à mon avis, ne vit pas très longtemps; il vit indéfiniment si on veut, mais il est à peu près mort et n'est pas même bon pour l'industrie. 11 ne doit pas dépasser 40 ans pour être bon.

Comme je disais tout à l'heure, je ne suis pas d'accord avec l'honorable rapporteur qui demande de le cultiver en taillis. 11 est im possible de passer sans accidents dans les acacias quand ils sont jeunes, quand ils sont vieux, ce sont des futaies. 11 faut 15 ans pour avoir un arbre, e'est extrêmement difficile de les élever en taillis, il faut beaucoup de précautions pour éviter les accidents.

Il y a eu une époque où l'acacia était d'un bon rapport, c'était quand il fallait des pieux pour les vignes, mais on en demande moins. L'acacia était le premier des bois, pour les pieux, avec le châtaignier.

M. BAuchery. - On a oublié que l'acacia est une essence de bordure plutôt que de taillis.

Les plus beaux résultats obtenus avec l'acacia sont surtont dans les bordures; en dehors des pays Basques et des sables de la Loire, ou obtient diffieilement des massifs. Au contraire, dans les alluvions de l'Adour et même de la Loire, ces Messieurs ont pu remarquer combien l'acacia vient bien; je ne crois pas qu'une antre essence forestière donne un revenu semblable, mais il faut un sol profond et perméable.

Personnellement, je ne crois pas qu'en dehors le ces conditions, l'acacia soit une essence de taillis plein. 
M. DE Pottené. - Je voudrais confirmer les observations de M. le délégué du Portugal. Nous avons en Hongrie des qualités de sol très différentes, non seulement dans la steppe, mais partout. Dans la plaine, l'eau de la terre est à une profondeur de un demi mètre environ.

M. Moxix. - Je erois que tout le monde est d'aceord pour faire ressortir que la perméabilité du sol est la première condition pour que l'acacia ait une bonne croissance. On peut admettre que les bactéries de l'acacia ont besoin d'air pour vivre, en sorte que, dans ces taillis d'acacia qui disparaissent, si on arrivait à donner de l'air au sol, on donnerait de la vigueur aux acacias.

Du reste, la discussion s'est engagée sur la question de savoir s'il fallait boiser de grandes ou de petites étendues. Il est bon pour de grandes étendues, quand elles présentent les conditions d'aération qui lui sont indispensables, comme les sables de l'Adour, les sables d'Olonne; en Hongrie, il réussit sur de grandes étendues probableparce que le sol reste perméable. De même dans la Cùte d'Or, les vignerons plantent de l'acacia, qui pousse bien, dans des terrains autrefois cultivés en vignes.

J'ai remarqué qu'en particulier dans les terrains quí ont été fouillés pour l'extraction du minerai de fer, l'acacia pousse d'une façon remarquabte, M. Broillard parlait, dans ces conditions, d'un revenu de 4.000 franes à l'hectare; c'était erroné, car il s'agissait de deux hectares et demi, mais cela faisait encore 1.700 francs a l'hectare ; c'était déjà beau

Done, lorsque l'on a des terrains de grande étendue présentant cette perméabilité, on peut faire de grands massifs, mais la plupart du temps, ces conditions ne se présentent que pour des terrains peu étendus, des talus de routes, etc... 11 n'y a pas lieu de fixer la grandeur de la plantation, elle dépend de la nature du sol.

II. Hickel. - Je demanderai ì résumer ce qui a été dit par uno donnée générale que je m’excuse de ne pas avoir présentéc au début.

L'acacia est une essence continentale : c'est plutôt dans la partie centrale de l'Amérique que se rencontre l'acacia, et ceci explique peut-être les résultats heureux obtenus en Hongrie.

D'autre part, ce n'est pas ce qu'on pourrait appeler une essence sociable; dans son pays d'origine, on ne rencontre pas de massifs d'acacias. C'est aussi, comme on l'a dit, sur les riches alluvions de ces fleuves irrégulier's d'Amérique que se rencontrent les plus beaux acacias. C'est donr: unr essence disséminée, et vous savez commr? moi que ces essences disscimincées sont le plus souvent des essences exigeantes.

En même temps, e'est une essence essentiellement déconcertante. Comme elle exige des conditions de sol, de climat et de mélange 
très particulières, elle donne de bons résultats ici ot de maurais résultats là où manque un des facteurs. Pour l'acacia, la hauteur. réflète de façon étroite l'état du sol.

M. Le Pliésidext. - Pour terminer ce débat très intéressant, vous me permettrez d'ajouter quelques considérations qui ne me paparaissent pas avoir été envisagées par les personnes qui ont parlé de l'acacia.

Je tiendrais à vous signaler deux points prineipaux :

D'abord, une question qui a été largement envisagre, mais sur laquelle nous ne sommes par d'accord, e'est l'état plein.

Il y a des plantations d'acacias d'importance assez considérable, comme on a pu le constater dans différents concours institués pal de grandes sociétés agricoles, dont la Société des Igriculteurs de France. Je connais notamment dans la Nièvre, près de Decize. une plantation de 30 hectares dans un état de prospérité splendide. au bord de la Loire, dans des sables, mais dans des conditions remarrquables. Nais j'en connais d'autres ailleurs, en fort bonn? posture.

Voilà pour ce qui est ro l'état plein ou isolé de l'arbre.

En ce qui eoncerne le còté physique, il a été envisagé, mais persomne n'a parlé du còté chimique.

Personnellement, j'ai fait des expériences qui datent de plus d. 30 ans sur des plantations faites sur des places à fournaux, à la suite d'exploitations de taillis où on cuisait la charbonnette pour en fair. du charbon. Sur ces places i fourneaux, très imprégnées de polasse, j'ai planté des acacias, en même temps que j'en planiais aux alentours. Les plantations faites sur les places a fourneaux ont donné des résultats merveilleux au point de vue de la rapidité de la croissance, qui dépasse de beaucoup le taillis-chêne qui les entoure; mais sur les places à còté, dans le même terrain. lo résultat ítait tout différent.

Je n'ai pas fait analyser le sol des places à fourneaux, mais il n'est pas donteux qu'il contenait une quantité considérable de potasse que ne contenait pas le sol voisin. De là, selon moi. l'augmentation de cruissance constatée.

Ceri prouve qu'il serait sans doute intéressant d'essayer les engrais potassiques sur la plantation de l'acacia, étant donné cettr. prospérité que j'ai obtenue.

Un point qui me parait extrêmement important et qu'on a laissé de còté, e'est le còté économique.

M. Jolyet nous dit : plantez de l'acacia. Je m'en suis trop ocrupé pour ne pas abonder dans son sens, mais dans l'intérêt des planteurs, je dois vous mottre on garde contre un évènement économique de qrande importance : il s`agit des débouchés.

Les débouchés pour les bois de petite taill diminuent par le fait que la vigne n'on consumme plus guère, on la tend sur los fils de for. 
11. Maxgix. - Dans beaucoup de régions, on abandonne les fils de fer et on revient aux échalas; presque partout on renonce à ce système, quelque coúteux que soit le changement.

M. DE Lesseux. - Ce fait se produit dans 1'Aube : les vignerons constatent $20 \%$ de différence dans le rendement.

M. Le Président. - Cependant ì la suite de l'enquête dont je parlais tout à l'heure, comme suite au concours organisé par la Société des Agriculteurs de France, on s'est rendu compte que les débouchés étaient devenus difficiles pour des quantités importantes. Plusieurs de nos collègues s'en plaignaient amèrement et cherchaient comment vendre leurs acacias. Ils n'y sont pas parvenus, malgré les conseils et les indications qu'on leur a fournies. Donc les rlébouchés semblent. assez restreints. Ils sont peut-être suffisants, étant données les étendues que nous arons, mais si on les augmentait notablement, peut-être arriverait-on à une difficulté d'écoulement.

M. DE SEgoxzac. - Je propose d'ajouter " des tuillis el des futaies, particulièrement sur les terrains propices ». Je supprime : "sur les terruins de faible étendue $"$

11. I. Présinext. - Il n'y a qu'un moyen, cest de nous compter. Que ceux qui sont d'aris d'accepter l'amendement de M. de Sirgonzac lèvent la main.

- telopté.

Comme il a la priorité sur le vœu lui-même, le voeu se trouve supprimé. L'amendement est ainsi rédigé :

Qu'il soit constitué des tuillis ot des futaies d'acacia comme mode économique de boisement, parliculièrement sur les terrains propices. "

Ir domme la parole à M. Nangin pour la lecture de son rapport.

M. Mavar. - Le châtaignier, Castanea vnlgaris, Lam. (Castanea vesca, Gaertn.) appartient à la famille des Cupulifères, à laquelle d'ailleurs se rattachent plusieurs autres essences précicuses de nos forêts, le chêne, le hêtre, etc. Il est originaire de l'Europe méridionale où on le rencontre du Caucase au Portugal. L'Amérique du Nord en possède plusieurs espèces voisines, parmi lesquelles le Castanea pumila (Chincapin), arbre de moyenne grandeur à fruits très estimés, le Castanea dcntalı (Castanca vesca, var. Americana) à fruits excellents ét à bois de valeur. Le Japon renferme le Castanea vesca var. Japonica, dont on a distingué plusieurs variétés. Enfin en Chine on trouve le Castanea Sinensis, Spreng.

Le châtaignier est un arbre de première grandeur, ¿̀ végétation rapide. Il fructifie plus tôt (10 ou 15 ans) à l'état isolé que lorsqu'il crô̂t en massif ; c'est un arbre essentiellement silicicole : il exige pour végéter que la teneur du sol en clraux ne dépasse pas $4 \%$. Il préfère les sols profonds, 
frais, fertiles et dans de telles stations il forme des massifs de toute beauté, mais, et c'est ce qui le rend si précieux, il s'accommorle de situations moins favorables, sait se montrer, quand il le faut, aussi rustique que peu exigeant et, dans de telles conditions, constitue encore de beaux massifs, même sur des versants rocailleux et secs, à peine couverts d'une mince couche de terre régétale.

Le châtaignier repousse très bien de souche et fournit des cépéss vigoureuses, à rejets droits dont beaucoup à 25 ans peurent atteindre $0 \mathrm{~m} .20$ de diamètre. Cultivé à l'état isolé, il est plus trapu que lorsqu'il est élevé en massif, il se ramifie beaucoup, étale sa cime et fructifie abondamment.

Son bois a peu d'aubier et est analogue à celıi du chêne; c'est un excellent bois de fente : on en fait un merrain estimé, des échalas, des cercles de tonneaux, etc. Quand il provient d'arbres âgés de 50 à 70 ans. il est particulièrement riche en tannin et sert à la fabrication des extraits tanniques.

Le fruit dı châtaignier a été longtemps la base de l'alimentation des populations pauvres du centre de la France et de la Corse ; la châtaigne améliorée par la culture (sélection et greffage) est devenue le marron plus gros et plus fin qu'elle et dont les nombreuses variétés sont l'objet d'un commerce important.

Le châtaignier est done, par l'importance et le nombre des produits qu'il nous donne, une essence précieuse par excellence; là ne se borne pas son rôle : par son aptitude à garnir les pentes rocheuses à peine recouvertes d'une mince couche de terre, il y consolide le sol, le protège contre l'érosion des eaux et concourt à régulariser le débit des cours d'eau. Dans certaines vallées du Plateau Central où la disparition des anciennes châtaigneraies a provoqué la dégradation des versants que rien ne protégeait plus, l'exode des habitants, dont les conditions d'existence devenaient de jour en jour plus difficiles, s'est accru dans des proportions inquiétantes; la densité de la population a diminué de 60 à $70 \%$. Au moment où l'on parle tant de la dépopulation, qui donc viendra nier l'intérêt général qui s'attache à la conservation et à la propagation d'un tel arbre que l'on a si justement nommé "l'arbre à pain des Cévennes».

Cultivé pour son bois, le châtaignier constitue des taillis exploités généralement d'assez bonne heure (vers 12 à 15 ans).

Cultivés pour leurs fruits, les châtaigniers greffés sont plantés à une distance de 10 à 20 mètres les uns des autres, soit en massifs (ils constituent alors ce que l'on appelle les châtaigneraies), soit en bordure des champs. Il n'entre pas dans le cadre de cette étude de passer en revue les différentes et nombreuses variétés de châtaignes sélectionnées et de marrons obtenues par la greffe et adaptées à chaque station spéciale, il suffit de savoir que la production fruitière des châtaigneraies a atteint en 1910 une valeur de 20 millions environ.

On cultive le châtaignier en France, surtout dans les Pyrénées, les Cévennes, le Plateau Central, le Limousin et le Périgord ; mais on le rencontre un peu partout et même dans les Vosges. Il est abondant en Corse et en Algérie. La culture du châtaignier couvrait en 1882,356.000 hectares; elle subit, surtout depuis une vingtaine d'années, une crise qui restreint de jour en jour la superficie qu'elle occupe.

En effet, les progrès considérables réalisés depuis un demi-siècle dans sa al parntiou. 
l'industrie et l'agriculture, les transformations économiques incessantes ont modifié les conditions générales d'existence des populations rurales, les moyens de transport se sont multipliés et améliorés, les procédés de culture se sont perfectionnés, la main-d'œuvre s'est faitc plus chère et plus rare, les soins donnés aux châtaigneraies sont devenus plus coûteux et ont diminué, en même temps que l'on prenait l'habitude fâcheuse de ramasser les feuilles mortes pour en faire de la litière et de couper les jeunes branches garnies de feuilles pour nourrir les bestiaux. Les vieilles châtaigneraies délaissées, dépouillées, mutilées, ont périclité, donnant des récoltes de plus en plus faibles et ne valant parfois même plus le ramassage; elles ont peu à peu disparu pour faire place à des cultures plus rémunératrices.

Malheureusement, deux causes sont venues accélérer et aggraver cette disparition :

$1^{0}$ Le développement considérable qu'a pris depuis une vingtaine d'années la fabrication des extraits tanniques; cette industrie très florissante, pour laquelle la France tient encore le premier rang en Europe, a entraîné le déboisement de 60.000 hectares de châtaigneraies et en proroque encore annuellement l'exploitation de 1.400 hectares.

$2^{\circ}$ La maladie du châtaignier (maladie de l'encre ou du pied noir). Cette maladie est contagieuse, elle se propage comme une tache d'buile autour des foyers d'infection, dans les sols riches comme dans les sols pauvres, dans les châtaigneraies dépouillées ou non de leur couverture de feuilles mortes, elle attaque également les arbres jeunes ou vieux. Il importe de ne pas la confondre avec la maladie de l'étisie qui, elle, ne frappe que des arbres âgés et que l'on peut enrayer à l'aide de soins appropriés.

La maladie de l'encre n'a entrainé la disparition des châtaigneraies que sur une superficie de 4 à 5.000 hectares.

Dans les châtaigneraies saines, les propriétaires imprévoyants, éblouis par un gain immédiat, ont perdu de vue l'a venir et méconnu leurs intérêts; ils ont exploité à blanc étoc leurs belles châtaigneraies, les ont transformées en friches improductives pour alimenter les usines d'extraits ; dans les châtaigneraiess atteintes par la maladie de l'encre, les propriétaires, en présence d'un tel fléau, au lieu de songer: à purger et localiser les foyers d'infection, n'ont songé qu'à abattre les arbres encore sains, redoutant de les voir contaminés et dépréciés par la maladie, pour les vendre aux usines d'extraits.

Quoi qu'il en soit, la superficie cultivée en châtaignier a diminué de 60 à 70.000 hectares; cette diminution intéresse surtout une trentaine de départements. Dans vingt départements la disparition des châtaigneraies a eu un bon résultat et a provoqué une plus-value sensible de la valeur des terres, car il y a eu substitution d'une culture nouvelle, plus rémunératrice, à celle du châtaignier (par exemple : dans l'Ille-et-Vilaine, les deux Sèvres, la Haute-Vienne, la Dordogne). Dans ces départements il n'y a pas de crise du châtaignier.

Par contre, dans une dizaine de départements, la disparition du châtaignier a été désastreuse ; ce sont : l'Ardèche, la Corrèze, la Corse, le Gard, le Gers, le Lot, la Lozère, le Morbihan, les Hautes et BassesPyrénées. Les châtaigniers ont disparu de régions où le sol était impropre à toute autre culture plus rémunératrice, où les défrichements ont porté sur de si grandes étendues qu'il a été matériellement impossible de inettre 
"n valeur toutes les terres rendues libres, ou enfun les versants à jentro rapide et à sol instable ont été ravinés par les eaux.

C'est dans ces départements que se localise ce que l'on appelle "l a erise du châtaignier " .

On a beaucoup parlé et beaucoup écrit sur la erise du châtaignier : pratiquement, on n'a pour ainsi dire rien fait.

Arant d'examiner' les moyens de remédier à cette situation, souvenonsnous que la culture du châtaignier est actuellement subordonnée aux Moyalis a, re mitlier. factenrs suivants :

a) Diminution sensible de la consommation locale des châtaignes communes:

b) Insuffisance de production, en quanlité et en qualité, des marrons, (à Paris le commerce te la confiserie n'emploie plus que des marrons d'Italie) ;

c) Nécessité de favoriser le développenent de l'imdustrie des extrails tanniques, industrie essentiellement française lont les produits font prime sur les marchés étrangers;

d) Vécessité de la conservation et même de l'extension des châtaigneraies en vue de la consolidation des terrains en montagne, de la régularisation des cour's d'eau et de la mise en valeur de terrains absolument improductifs.

Les mesures proposées pour enraver la erise diffèreront suivant qu'il s'agit de régions non atteintes par la maladie de l'encre (soit environ 50.000 hectares) ou de régions contaminées (soit de 5 à 10.000 hectares).

En conséquenet, nous aroms l'bomnour de formuler les projets de voux suivants :

Pour les régions saines.

I. Que tous les terrains improductifs, inaptes à toule autre culture, soient remis en valeur par reconstitution de nouvelles châtaigneraies.

II. Que les châtaigneraies soient exploilées el entretenues par un jardinage judicieux ct des repeuplements en sujets greffés el soigneusement sélectionnés.

III. Qu'il soit créé des pépinières destinées à fonrnir des plants greffés dont la délivrance pourrait se faire ou gratuitement, ou à prix d'argent.

IV. Qu'il soit établi des primes à la replantation el, plus tard, aux châtaigneraies donnan les produits les meilleurs.

V. Que la loi dégrevant de toul impôt foncier, pendant 30 ans, les terruins remis en nature de bois soit étendue anx châtaigneraies nouvelles.

VI. Que la loi sur le défrichement des bois particuliers soit élendue aux châlaigneraies, partout oì les châtaigniers occupent des versants susceptibles de se dégrader, ou des régions dans lesquclles ils contribuent à régulariser le régime des eaux.

\section{Polir les régions contaminées.}

Le Congrès ne peut que conseiller aux propriétaires. en attendant le risultat des recherches entreprises, de remettre leurs terrains en nature 
de bois, pour préparer le sol en vue des futures reconstitutions de châtaigneraies.

Jo rous propose pour les régions saines, comme septième partie du viru :

VII. Mesures législatives analogues à celles des pays voisins, Italie, Suisse. Possibilité d'introduire dans la législation française, certaines dispositions par exemple de la loi italienne.

11. le Présidext. - Je vous prie de m'excuser, car je suis obligé de partir pour une autre réunion. Je cède la présidence à mon collègue et ami M. Émery, en attendant que notre Président, M. Girerd puisse venir.

La séance continue sous la présidence de M. ÉuERY.

M. Le Pŕésidext. - Avant de commencer la discussion sur les vœux de M. Mangin, on pourrait entendre les communications sur le même sujet. La première est celle de M. Pellequer, sur "Le Châtaignier en Lozère ". MI. le Secrétaire va vous en donner lecture.

M. LE SECrétAlRE. — Le châtaignier est intéressant à un double titre :

Pour son bois,

Pour ses fruits.

Autrefois le clıataignier était utilisé presque exclusivement pour ses fruit:; aujourd'hui, avec l'industrie des extraits tanniques, son bois est de plus en plus demandé.

La coupe des arbres est de plus en plus accélérée :

Par la diminution, depuis quelques années, de la récolte des fruits; Par l'augmentation du prix de la main-d'œuvre;

Par l'émigration vers les villes des paysans lozériens;

Par la maladie de l'encre.

REuÈDEs. - Réglementer les coupes dans les forèts de châtaignier's; exiger par exemple que les arbres exploités soient remplacés par de jeunes plants;

Reboisement en châtaigniers, par l'administration forestière, des terrains favorables ;

Allocation de primes ou dégrèvement d'impôts pour enconlı'ager les propriétaires qui créent on conservent des forêts de chàtaignier's;

Classement des plus beaux sites;

Encouragement à la substitution du châtaignier du Jayon au châtaignien! ordinaire. - L'Etat devrait établir des pépinières de jeunes plants et distribuer ces plants gratuitement ou à un faible prix.

Propager les notions de la taille du châtaiginier' ;

Développer, en en montrant l'utilité, la pratique de la limmure des châtaigne raies.

II. Le Présidext. - Nous allons entendre maintenant la communication de M. Marcillac, dont M. le Secrétaire va vous donner l'analyse.

M. LE secrétane. - M. Marcillac expose en quelques lignes que le hâtaignier est en roie de disparition. Tous les châtaignier's sont achetés par 
les industriels fabricants d'extraits tanniques. Il y a là un danger au point de vue national et au point de vue économique. En conséquence, M. Marcillac propose d'émettre le voeu suivant :

"Le Congrès émet le sæu : Qu'il soit fondé un prix d'un million à verser par l'Etat à l'insenteur, de quelque nationalité qu'il soit, du procédé fournissant autrement que par l'abatage et la distillation du châtaignier, les extraits recherchés pour le tannage.

M. LE Présidext. - Nous avons encore une troisième communication de M. Camus.

M. Gauus. - Meśsieurs, j'habite dans ure région contaminée, l'Ardèche. ou il y a une crise grave du châtagnier, pour les deux raisons qu'a données M. Mangin : la maladie de l'encre, qui sévit particulièrement dans l'arrondissement de Largentiere, et la fabrication des extraits tanniques.

En ce qui concerne la maladie, la thèse que je développe daus ma communication est bien connue et admise par tous les forestiers : le dernier mot de la science est de laisser le mélange des essences s'opérer au gré de la nature.

Il semble que du moment qu'on a oublié ce principe en créant de grandes étendues de châtaigniers, il est naturel que la maladie se développe.

J'ai remarqué que dans l'Ardèche, les régions contaminées sont d'une part des régions relativement chaides, et d'autre part des régions où les châtaigneraies ont la plus giande étendue.

Dans l'arrondissement de Tournon, il n'y a presque pas de maladies, parce que le climat est plus froid, les châtaigniers sont plus sépalés et entourés d'autres essences, de sorte que, à mon avis, il y a une influence due à ce voisinagé. En effet, quand on arrive à la limite d'un massif de châtaigniers, on remarque que la maladie de l'encre ne se produit pas, à cause du climat, et Iu voisinage d'autres espèces. Aussi lans les pays contaminés, on doit chercher le remède en plantant du pin, en mélangeant des essences résineuses avec les châtaigniers dans les vides déjà existants.

Dans la deuxieme partie de ma communication sur le châtaignier, je me place au point de rue de la consolidation des terrains en montagne. Dans les pays qui nous intéressent, le châtaigaier est utile pour son lruit, pour sa beauté, mais surtut pour la défense du sol.

Or, les extraits tanniques sont en train de développer nos châtaigneraies. Presque tous les propriétaires vendent leurs châtaigniers; dans quelque temps. il n'y aura plus de châtaigneraies.

Sommes-nous armés contre ces usines?

Les forestiers disent: Par la loi de 1859, concernant les terrains en montagnt au delà de 10 hectares, on peut empêcher le cléboisement. - Mais le châtaiginier n'est pas protégé, parce qu'il est considéré comme arble à fruit et non comme arbre de forêt.

Pour nous, la question capitale, avant de songer à reboiser, r'est de chercher à sauver ce qui reste : c'est la chose essentielle, et la plus facile.

Pour arriver à conserver ce qui reste, il faudrait tue la loi de 1859 puiss. s"appliquer aux châtaigneraies, que le châtaignier soit considéré comme arbré de forêt et que la loi de protection dont on parlail avant-hier à la deuxième Section soit applicable au châtaignier.

La loi proposée par M. David s'arrètait à l'altiturle de 800 mètres, je ne vois pas pourquoi, car il $\mathrm{y}$ a des terrains intéressants au-dessous de cette altitude.

Le projet déjosé par M. Chalamel à la Chambre il y a quelque temps, est plus large; il embrasse tous les terrains en pente et peut protéger les chataigniers.

En résumé, au sujet des voeux qui ont été émis, je demande au Congrès s'il veut bien les sérier par importance, mettre en tête les principaux et autant que possible, supprimer ceux qui seront considérés comme platoniques. Nous avons intérèt à émette le moins de voux possible. 
Il semble que le plus important ost celui qui chercherait à conserver les chàtaigheraies existantes. C'est celui qui porte le numéro VI, demandant rue la loi sur le défrichement des bois partieuliers soit étendue aux rhàtaigneraies. Je demande que le chàtaig lier soit considéré comme un arbre de forèt et que les lois futures sur les forêts de protection solent applicables aux rhitaigne raies.

E.rsuite je donnerais la préférence an cinquième ven :

(Me la loi dégresant de tout impot fomeier. pendant 30 ans. les terrains remis en unture de bois, soit étendue nux chataigneraies nouvelles."

1 ce sujet on a roté hier à la deuxieme section, un vou au sujet des impoits. (io vou est le suivant :

"Qu'il soit accordé des dégrérements temporaires pour les bois ruinrs par l'incendie, les maladies.

Il ý a intérèt à ce que les chàtaigajers snient englobés dans cp vien. Jr remande donc que le rinquieme rou snit ainsi conç :

"Que les dégrèsements et autres asantages aceordés aux terrains remis en nature de bois soient applicables nux chataigneraies nouselles.

Pour la question des pépinières, jo ne dirai qu'un simple mot.

Je n'ai pas compris pourquoi l' Idministration forestière lait payer une faible redevance aux particuliers pour les plants destines aux terrains contaminés.

Antrefois I'Administration forestière les aceordait gratuitement. linspecteur des Forêts prenait sur lui cette autorisation. suivant lesprit de la loi de 1882 qui est d'accorder des primes is rux qui reboisent.

Pour ma part, jai fait des demandes de châtaigniprs il y a un an 't demi, on m'a appliqué un petit tarif. C'est peu de chose, mais cela complique beancoup les demandes. surtout pour des paysans illettrés. d'autant plus qu'il faut envoyer les fonds à la caisse du départemeni. II me semble que pour le reboisement des terrains contaminés, les pépinières doivent distribuer gratuitemont les plants.

II. Maxgix. - Pour les terrains contaminés, il n'y a pas à s'oecuper des pépinières, puisqu'on ne peut pas replanter.

II. CAurs. - Dans l'Ardèche tout n'est pas contaminé; ainsi, dans l'arrondissement de Tournon, on pent replanter.

11. Mixgix. - l)ans certaines régions, on a constaté que la distribution gratuite donnait lieu à des abus, on a imposé une redrvanro très faible pour éviter ces abus.

11. Cums. - L'Arministration forestièr "st juge de savoir si alle doit ou non accueillir les demandes, mais j'estime qu'en tous cas, elte doit donner gratuitement les plants. C'est une économie pour clle quand les propriétaires plantent, car on sail re que coúte un reluiseinent.

La crise du châtaigniª a ite très grave en Italie; en Italie on a distribué jusrqu’̀ 300.000 plants gratuits pas an. Je ne vois pas pour- 
quoi on complique les choses pour une redevance aussi minime. In demande.

"Quili soit rréé des pépinières destinées à fournir des plants grefjés et d'untres essences à mélunger un châtuignier, dont la déliorance desrait se fuire gratnitement, en supprimant les formalités en vignenr.

11. Le Présinext. - En somme, rést une question de détails administratifs.

11. Cunts - Enfin, je demande que l'Administration forestière délivre, dans les pépinières, des mélanges aussi intéressants que possible pour répondre à l'idlée que j'exprimais.

Quant au varu No 1 , je le trouve platonique.

11. Hickel. - Les châtaigniers-bois peuvent bénéficier te la loi.

Quant aux châtaigniers-vergers, ce sont dés arbres épars sur un terrain débarrassé de la végétation parasite, arbres suflisamment éloignés les uns des autres, et je ne erris pas 'qu'on puisse considérer que les châtaigniers-vergers jouent un ròle au point de vur de la conservation du sol et au point de vue du régime des eaux.

1I. Ror, - Messieurs, parmi les facteurs importants qui militent en faveur de la replantation du châtaignier, M. Ie rapporteur Mangin atfirme la nécessité de favoriser le développement le l'industrie des extraits tanniques, industrie essentiellement française et dont les produits font prime sur les marehés itrangers.

Je dois dire que la menace de la raréfaction du châtaignier a déjà incité les intéressés a porter leurs efforts vers la même mesure.

Le Syndicat des Fabricants d'extraits tannants ot tinctoriaux de France qui, depuis cinq ans, groupe les quarante fabriques françaises d'extraits de châtaignier, s'honore de donner son concours aux pouvoirs publics et aux ouvres particulières pour le reboisement du pays en châtaigniers, conformément au programme qu'il s'est imposé en tête de ses statuts.

Il est done justr que re syndicat apporte ici sa modeste adhésion aux recux qui sont proposés par M. llangin, en même temps que sa gratilud an rapporteur pour l'hommage qu'il rend a l'industrie liancaise des extraits tanniques. (Applandissements.)

11. HE SEcovzac. - Nous ne nous ocrupons que des thataigneraies. Lic il y a deux choses is iviter.

la première. cest la maladie : il faut d'abord, arant de planter. etre certain que la maladie no viendra pas.

la deuxime, e'est qu'it est impossible de mettre des châtaigneraies dans tous les terrains improdnctifs. Laissez les propriétaires libres.

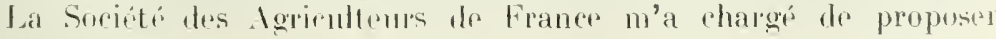
fre ren suivalu: 
"Que tous les terrains improductifs, dont le sol, le lien et le climut sont propices au châtaignier, soient remis en vuleur par la constitution de nouvelles châtaigneraies. "

Cela respecte la liberté de chacun, et invite les personnes dont le sol est convenable.

M. Le Présidext. - Ce n'esi qu'une nuance, lo róu de M. Mangin porte "inaptes à tonte antre culture ".

11. ne Segonzac. - C'est le mot "tous les terrains "qui nous a semblé exagéré.

I. Hirsch. - Je suis prêt à m'associer pleinement aux voeux de l'honorable rapporteur 11 . Mangin, sauf sur un point cependant : l'un des remèdes qu'il a indiqués, titre $c$, est la nécessité de favoriser le développement de l'industrie des extraits tanniques.

Il me semble qu'il y a une certaine contradiction entre ce que dit II. Mlangin et le remède qu'il propose.

En effet, l'une des causes principales pour lesquelles le châtaignier a disparu, c'est l'industrie des extraits tanniques. Si on la développe encore davantage, on fera disparaitre encore un peu plus de châtaigniers. Il convient done de ne pas favoriser le développenent de cette industrie, et justement en Italie, la législation est intervenue pour empêcher ce développement.

J'ajouterai même que le développement des industries tanniques est profondément préjudiciable à la forêt de chênes. L écorce de chênes rst de vente difficile en ce moment; d'ailleurs demain nous discuterons cette question à la troisième Section, où j'ai l'honneur d'être rapporteur, et je demanderai au Congrès de ne pas s'assorier à une phrase qui serait tout à fait en contradiction avec le viru que je présenterai à la troisième Sertion.

M. Mangrx. - Il semble en effet qu'il y ait une certain comtradiction entre la prospérité des châtaigneraies et l'industrie des extraits tanniques. Cela tient à ce que la question est mal posée et mal résolut.

En réalité, le châtaignier n'est bon pour l'extraction des extraits tanniques qu'à partir de 50 à 60 ans; plus jeune, il ne donne lien, j'en prends à témoin M. Roy, président du Syndicat des Extraits tanniques.

Ce que nous demandons, e'est done de constiturer des fhâtaigneraie's. Or, une châtaigneraic produit à partir de 15 ans, elle pent produire plus de $5 \%$, e'est donc un bon placement. Les arbres sont plantés en espacements de 10 à 12 mètres, au fur et à mestre que la châtaigneraie vieillit, vous entevez les arbres de 50 iो th0 ans, dont lo bois 'st déjà bon pour l'industrie des extraits, ceux qui restent développent leur cime et augmentent leur production. De soris qu’un propriétaire, it partir de 1.5 ans, tire parti du fruit, et à partir de tiflas, vend son 
bois aux usines. Je crois que du même coup, nous allons reconstituer une excellente production forestière et donner satisfaction à l'industrie des extraits tanniques. D'autant plus que le bois est rendu it un prix tellement élevé qu'il reste un bénéfice énorme une fois la plantation faite à nonveau.

$1 l$ y a done accord intime entre ces intérêts qui paraissent inconciliables.

La prospérité des extraits tanniques a un grave défaut, e'est de déprécier la vente des écor'es de chêne, nais nous n'y pouvons rien.

M. Hirsch. - Ah si !...

M. Mangin. - Laissez-moi terminer. L'industrie du tannage s'est modifiée d'une façon extraordinaire. Le rieux tannin a été abandonné; depuis vingt ans on tanne par des proeédés extrêmement variés, et ce qu'on cherche surtout, c'est it tanner rapidement. Si nos industriels n'employaient pas ces proeédés de tannage rapide, dans lesquels l'écorce de ehêne n'entre que pour une faible proportion, ils seraient distancés par les Amérieains, qui nous inondent de cuir à tellement bon marché qu'il y a une erise sur le cuir. Si l'industrie du cuir veut vive en Europe, il faut qu'elle suive la eoncurrence et tanne vite. Or, les seuls procédés de tannage rapide sont les extraits qui pénètrent peu à peu dans le cuir dans un temps relativement court, donnant un tannage suffisant, quoique mauvais relativement aux anciens procédés, pour permettre de faire eoncurrence aux cuirs américains.

Telle est la situation. En Hongrie, on fait beaucoup d'extraits tanniques; en Amérique, on s'adresse au québraeo, qui arrive en quantité au Havre; il y a une concurrence énorme pour tous ces extraits. Or s'il y avait ici des tanneurs, ils vous diraient que, parmi tous ces extraits, it en est un qu'on ne peut pas supprimer : c'est l'extrait de châtaignier.

L'extrait de châtaignier pallie les inconvénients de ces produits, il donne un mélange meilleur et il est employé dans la proportion de $1 / 5$ à $1 / 3$. S’il se produisait une modification des procédés de tannage, la vente de l'écorce de chêne pourrait reprendre, mais elle ne fournit pas assez de tannin pour les demandes de l'industrio du cuir. Si vous supprimiez en France les usines d'extraits, ce seraient les usines d'Italic qui feraient ces extraits, vous n'auriez pas pour cela reconstitué les châtaigneraies.

M. Le Président. - Je crois que nous sortons un peu de notre question en nous occupant des extraits tanniques.

11. Garrigor-Lagraxie. - Mis en cause par M. Mangin, je tiens à le remercier ainsi que $\mathbf{M}$. Roy de l'intérêt qu'ils nous ont témoigné.

C'est M. Gaillard qui a provoqué la reconstitution des châtaigneraies dans le Limousin ; nous avons déjà 500 à 600 hectares de reconstitués. 
Ce que je voudrais faire remarquer, rest que M. Mangin a dit qu'il y avait accord entre les interêt sles propriétaires de châtaigneraies it les fabrieants d'extraits lanniques. Il aurait mirux fait de dire que peut-être ree accord existera 111 jour.

Nous remons d'ourrir de nourelles lignes de tram ways; anssitot, jai vu res messienrs qui circulent pour la dévastation des bois, rar "ust noe veritable derastatation, rest ipourantable.

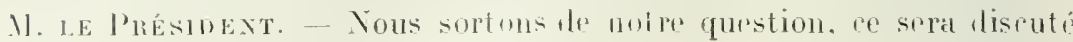
Ir main is la troisime sertion.

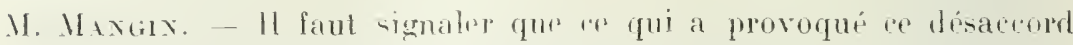

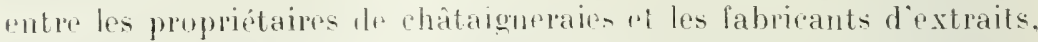
Cest que res demiers se divisent en denx catégories. Il y a les inclustriels sipieux, qui demandent a voir to marehé se slabiliser ret la production se faire normalement. Puis vous avez eu des spéculateurs, qui se sunt abatius sur une légion of ont fait des usines volantes ; ils ont ravagi fout un territuim, puis sont partis dans un. autre rigion.

11. Grollot. - On compe les châtaigniers pare qu'ils ont renilu tout ee quils pouvaient rendre.

Je suis proprietaire : a 40 ans un chataignier no vaut plus rien. (Exclumations).

Ex Coxgressiste. - 11 y en a de 800 ans, voyons!

11. Coste. - Comme Président de la Societe Centrale d'Igriculture du Gard, je rois des rxemptes lamentables dans te nord de notre departement.

Vous ne pouvez pas rous rendw rompte de l'impression pénible quion ressent en risitant ce pays : on eroirait que l'ennemi est passe par lir. Tout ust désert, les paysans sont partis dans les villes, les maisons s'effondrent et tombent en ruines.

Tous avons émis, à la Societé Centrale d'Igriculture du Gard, 1. même vou que la Société des Igriculteurs de France, reu tendant ¿̀ favoriser l'industrie de l'eropere de chêne, simplement on autorisant les tanneurs qui veutent tanner all chêne, à aroil une marque spé-

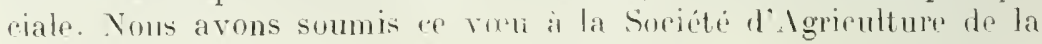
lozère qui, par letıre du 11 juin. m'inerit:

Atonsieur le I'résident,

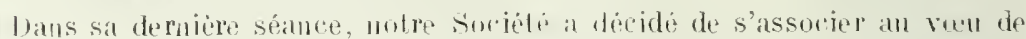
la siociété Centrale d'Agriculture du rard relatif a la mévente des écorees el a lit fatsification des ronirs.

Vous sommes heureux en meme temps d'avoir pur repondre, favorablencul a votre désir, atux diverses communications que vols ave\% bien vonlu mulc adresser ot de nous ètre joints à votre intialive qui intéresse notre rigion.

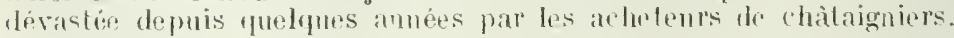

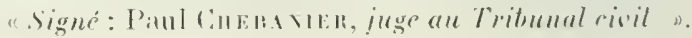


Voilà un témoignage des plus formels sur rettr dévastation.

Il ne me parait pas possible que le Congrès forestier déclare qu'il y a lieu de favoriser le développement de l'industrie tamnique.

M. Maxgrx. - Je voudrais que la question fút posée nettement. J'ai essayé de démontrer que l'entretien de bonnes châtaigneraies n'est pas incompatible avec l'existence des usines: ce qui est inaduissible, c'est que le propriétaire d'me châtaigneraio la ruine sans rien metre à la place.

Vous vous plaignez que vos rampagne's soient désertées, cest la faute de reux qui ont fait eela.

Vous avez le droit, en présence de "e manque de sonei du fonds commun qu'on laisse en friche, d'intervenir...

\section{Un CoxtiRestste. - Non!}

M. Maxgix. - ... el, par me loi, de dime anx propriétaires: lous ne défricherez qu'après autorisation, et cumme te code forestir l'indique, et non à blane étoc. Puis, quanıl vous voutrez détrichere, vous serez obligé de replanter.

Vous avez parlé des régions dévastérs ; en Corse, wi it y a ring usines, jai visité la plus aneienne, qui fonctionne depuis 30 ans et a draine tous les châtaigniers des environs. Jai été surpris de voir que tout le sol avoisinant cotte usine, était muvert de châtaigniers de 25 i 30 ans. On a bien abattu les châtaigneraies, mais on les a rrplantées. Done, ce ne sont pas les usines qu'il faut fermer, mais Ir procédé d'exploitation qui est délestable et qu'il faut modifier par une loi.

$\mathrm{Si}$, actuellement, vous trourez que, dans certains endroits on ravage, e'est que généralenment l'usine draine les châtaigniers des alentours, puis s'arrêtı, ì cause tu prix de transport, quand il faut aller trop loin. Mais s'il s'ourre une ligne de tram ways, les usinier's +n profitent.

D'ailleurs, j’ajoute que l'industrie des extraits tanniques est arrivée à son maximum; un certain nombre de petites usines joignent ì peine les deux bouts, il y en a qui disparaissent.

Or, pour celles-ci, que va-t-il arriver? Elles sont achetées par des spéculateurs qui, n'ayant pas à amortir le fonds de l'usine, aturont toute liberté. Ce sont ceux-là qui vont produire ces dévastations.

Done la question est urgente : il faut intervenir pour empêche' la destruction abusive des châtaigneraies par le propriétaire luimême et par les usiniers, qqui nr devront s'établir qu'après un" autorisation ministérielle.

M. Hirsch. - Je m'assorie aux vo'ux du rapporteur, notamment au septième varu, demandant que la loi italienne soit appliquá en France, rest-à-dire qu'on limite le nombre des usines d'exlrits tanniques. 
Je voterai des deux mains un rocu de ce genre, mais ne demandez pas qu'on favorise le développement de l'industrie des extraits tamniques.

M. Le Présidext. - Je ferai remarquer que la phrase de M. Mangin sur la nécessité de favoriser cette industrie, ne figure pas dans ses voux; nous pourons done laisser cette question de côté.

II. Gitllot. - Je roudrais signaler un fait très important. Vous narez pas besoin de défricher les châtaigneraies, il suffit de les recéper. Si on envisage ce procédé, c'est une grande partie de la solution. Elles se trouvent reboisées en châtaigniers, et vous pouvez reboiser en n'importe quelle autre essence, notamment en sapins pectinés.

C'est pourquoi je m'associe à la suppression du mot "tons " à l'article 1.

1I. Le Présidext. - Je mets aux voix la rédaction de M. de Segonzac:

10 "Que les terrains improductifs dont le sol, la région et le climat sont propres an châtaignier, soiemt remis en raleur par la reconstitution de nouvelles châtaigneraies."

11. Mixgrx. - Dans les régions où il n'y a pas beaucoup de châtaigniers, pourquoi les coupez-vous?

On a dit : e'est parce que cela ne rapporte rien.

Il y a des gens qui préfèrent couper leurs châtaigniers pour faire d'autres cultures forestières, notamment le pin maritime, et quelquefois, dans la région des hautes montagnes, il y a intérêt à supprimer le châtaignier et à établir la culture pastorale.

Je vous ai dit qu'il y a des départements où la culture du châtaignier a été remplacée par une autre culture; j'ai dit : là. il n'y a pas de crise, mais au contraire, plus-value des terrains. Nous ne nous occupons done que de quelques départements.

II. te Président. - fe mets aux voix le reu que je riens de lire. Adopté.

M. I. Présidext : Nous passons au deuxième vou :

"20 Que les châtaigneraies soient exploitées et entretenues par un jardinage judicienx et des repeuplements en sujets greffés et soigneusement sélectionnés ».

1I. Gilllot. - Je demande que ce rocu soit rectifié comme suit, parer qu'il y a des populations qui abusent :

"Que les châtaigneraies soient exploitées sans enlèvement des feuilles, qui constituent la converture morte, et entretenues par un jardinage judicieux, etc..." 
II. Le Présinext. - Je mets aux voix le denxième voeu.

Adopté.

Le troisième voeu dit :

$3^{0}$ "Qn'il soit créé des pépinières destinées à foumir des plants greffés dont la délivrance pourrait se faire ou gratuitement on à prix d'argent. ")

11. Cayus. - J'ai demandé tout it l'heure que le voru soit modifié comme suit :

"Qu'il soil créé des pépinières destinées à fournir des plants greffés et d'autres essences à mélanger an châtuignier, dont lu délivrance devrait se faire gratuitement, en supprimant les formalités en vigueur."

M. Maxar. - Je suis tellement imbu de conte idée que, lorsque je suis allé en Corse, où les châtaigniers sont délivrés gratuitement, on m'a dit que les reprises étaient rle $90 \%$. En Corse, l'accord est complet entre les propriétaires de châtaigneraies et les usiniers. Ivant on les recerait à coups de fourche; maintenant on est heureux de les voir parce que, l'an dernier, il a été distribué, tout près de Bastia, 12.000 plants de châtaigniers. On "n a replanté plusieurs et j'ai vu des régions où il n'y en avait pas et où on en plante maintenant parce qu'on sent la nécessité de le faire. Doit-on délivrer des châtaigniers gratuitement ou contre une faible redevance? Il s'agit là d'une question de doigté.

M. Garrigor-Lagratige. - J'ai été mis en cause; mais je dois dire que chez nous la question ne se pose pas: nous n'avons pas fourni de plants de ehâtaigniers. Toici comment on proeède : 99 fois sur 100, le paysan plante un saurageon et. an bout de deux ans, le greffe sur place. Ce qu'il faudrait, ce sont des porte-greffes pour pouvoir distribuer des greffes. II serait bon, je crois, d'introduire cette modification dans le veu. Nous sommes en train d'organiser un terrain à Limoges; mais ce qui manque le plus chez nous, ce sont les bonnes espèces de châtaignes.

M. Le Présidext. - On pourtait ajoute" : "...ou des porte-greffes"

M. C.nus. - On ferait mieux de donner les plants gratıitement plutòt que de distribuer des primes.

M. Garrgou-Lagraxide. - On peut laisser le vo'u tel qu'il est.

II. le Préstdext. - Nous laissons le voru tel qu'il est en ajoutant : "Quः il soit créé des pépinières ou des porte-grefjes, etc..." 
Je mets aux voix le voru ainsi modifié.

Adopté.

Nous arrivons maintenant à l'article 4. qui est ainsi conçu :

" $4^{\circ}$ Qn'il soil établi des primes à la replantation et, plus tard, unx châtaigneraies donnant les produits les meilleurs."

11. Garrigot-Lagraxge. - C'est la grosse affaire. Les petites satisfactions données ne suffisent pas pour encourager; il faut donner une prime ì la replantation.

11. Le Préshext. - Je mets cet article aux voix.

Idopté.

" $5^{\circ}$ Que la loi dégrevant de tont impôt foncier pendant 30 uns. les terrains remis en nuture de bois, soit étendue anx châtaigneraies nouvelles."

M. Garigor-Lagraxge. - Il y a une difficulté : éest que pendant 15 ans nous cultivons la châtaigneraie replantée.

11. Maxgrx. - Nous avons parlé ici des châtaigneraies au point de vur de la consolidation des terrains en montagne. Il y a certainement des versants dans le Plateau Central qui sont couverts de châtaigneraies, qu'on traite, moitié pour le fruit, moitié pour le bois. Par conséquent, il y a un mode de traitement qu'il faut favoriser.

II. le Présinext. - On pourrait ajouter: ".. lorsque ces châtaigneraies seraient nécessaires pour les peuplements de production."

11. C.ucs. - Je propose le veu suivant qui me paraît plus général :

"Que les dégrèvements et autres acantages accordés anx terrains remis en nuture de bois soient étendus anx châtaigneraies nouvelles.

Vous ne parlez que de la remise de l'impôt pendant 30 ans. J" demande que les autres avantages rotés soient aussi applicables aux châtaigneraies.

11. LE Présidext. - Je ne crois pas qu'i] y ait un inconvénient it demander cela.

11. Vixgry tils. - D'un manière générale, les châtaigneraies sont sommises at la loi forestière; mais il $y$ a des cas où l'administration n'admet pas notre interprétation.

II. Grobor. - Pour bien fixer la chose, il faudrait mettre : Chatuigneruies-cergers". 
INTERNATHONAL I!1:;

M. Le Presnext. - Voici le voou rectifié suivant les inlés qui onl éla émises :

"50 Qne la loi dégrésant de tout impôt foncier pendant 30 ans les terrains remis en nature de bois, soit étendue aux châtaigneraies nouvelles, lorsqu'elles sont nécessaires an maintien des terrains instables."

Adopté.

L.a séance est levée à 11 h. 3 . 


\title{
SEANCE DU 18 JUIN 1913
}

\author{
(APRÈS-MIDI) \\ Présidence de M. Cyprien GIRERD, président de Section
}

La séance est ouverte à 2 h. 20.

M. Le Président. - L'odre dı jour appelle la discussion du rapport de M. Mangin sur LE Noyer, SA DISPARITION, LES HOYExS D'Y REMÉdier, LA TÉCESSITÉ DE DOXNER UNE NOUVELLE EXTExSION A SA CULTLRE.

La parole est à M. Mangin pour la lecture de son rapport.

M. Maxgrx. - Le noyer, Juglans regia, Lin. appartient à la famille des Juglandées. Originaire de l'Asie tempérée, son importation est déjà ancienne; on peut le considérer aujourd'hui comme tout à fait naturalisé.

C'est un arbre de grande taille, assez rustique; la difficulté de son maintien au milieu de la végétation forestière en fait plutôt un arbre de culture qu'un arbre forestier proprement dit. Indifférent quant à la nature géologique du sol, il préfère néanmoins les terrains profonds, frais et substantiels : les versants pierreux des collines constituent sa station de prédilection. Son enracinement puissant rend sa transplantation difficile. Il commence à fructifier vers l'âge de quinze ans, mais les variétés greffées et sélectionnées produisent déjà des fruits dès la sixième année; la floraison précoce du noyer commun le rend sensible aux gelées tardives, ce qui a l'inconvénient grave de rendre irrégulière et aléatoire sa production fruitière; heureusement la sélection et le greffage ont diminué cet inconvénient.

Le bois du noyer est un des plus estimés, il sert à une foule d'usages, mais principalement en ébénisterie, en carrosserie et enfin en armurerie, car il est incomparable pour la fabrication des crosses de fusils (l'Allemagne même vient s'approvisionner en France pour son matériel de guerre).

Indépendamment de son bois, le noyer commun et surtout les variétés greffées et sélectionnées nous fournissent un fruit délicieux, la noix : noix sèches lorsqu'elles sont récoltées à maturité, cerneaux quand elles sont cueillies vertes encore, mais dès formation complète de l'amande. Les noix font l'objet d'un commerce d'exportation important, surtout avee l'Angleterre, les Etats-Unis, l'Allemagne, la Belgique, l'Algérie. La production moyenne annuelle a atteint de 1899 à 1908, 637.725 quintaux valant 20 millions.

Le noyer nous donne en outre quelques produits accessoires : 
Des noix on tire une huile comestible, fruitée, délicieuse quand elle est fraîche et extraite à froid, en tous cas, toujours propre à l'éclairage. L'écorce renferme de l'acide tannique, elle est employée en teinture, enfin l'enveloppe charnue du fruit, le brou, sert à faire une liqueur et principalement une teinture très employée en ébénisterie sous le nom de brou de noix.

Planté en vue de sa production ligneuse, le noyer aceepte des stations élevées ; mais, cultivé pour son fruit, il ne dépasse pas 600 à 700 mètres d'altitude : on plante alors les arbres à dix ou quinze mètres les uns des autres, soit en bordure des routes ou des champs, soit en massifs, ils constituent dans ce dernier eas les noyeraies si nombreuses et si belles dans quelques départements, en partieulier dans l'Isère.

On rencontre le noyer presque partout en France, mais l'aire dans laquelle il est le plus prospère et donne les meilleurs fruits est comprise entre le $44^{\circ}$ et le $47^{\circ}$ de latitude Nord. Malheureusement, à part quatre ou cinq départements, tels que l'Isère, la Corrèze, le Lot, la Dordogne, où la culture du noyer progresse, à part une douzaine de départements, tels que l'Aveyron, la Vienne et la Haute-Vienne, la Charente, les Deux-Sèvres, l'Indre-et-Loire, le Maine-et-Loire, la Nièvre, la Loire, le Puy-de-Dôme, l'Ardèche, la Drôme où elle se maintient juste, partout ailleurs elle diminue et l'on s'achemine plus ou moins rapidement, mais sûrement. vers la disparition du noyer de la plupart de nos départements français. C'est pourtant, par son tempérament, la valeur et le nombre des produits qu'il nous donne, un arbre de toute première importance, comme le châtaignier, l'olivier. Il faut en protéger et propager la culture, et porter un prompt remède à ce que l'on peut appeler comme pour le châtaignier : la crise du noyer.

Les causes de cette erise sont :

Le mauvais choix des variétés cultivées;

L'abandon trop fréquent de la pratique constante de la sélection;

La diminution des soins culturaux, (ehèreté de la main-d'œuvre) ;

La suppression presque complète de la restitution au sol des éléments nutritifs enlevés par les récoltes.

Dans de telles conditions, la production des noyers a constamment diminué en quantité comme en qualité : elle a cessé d'être rémunératrice. Aussi les cultivateurs, en présence de la hausse qui, depuis une vingtaine d'années, ne cesse de se faire sentir sur la valeur du bois de cet arbre (le renouvellement, l'augmentation, l'entretien des armements en Europe est un puissant facteur de cette hausse qui a plus que doublé le prix du mètre cube de bois de noyer), se sont-ils laissés entraîner par l'appât d'un gain immédiat. Méconnaissant leurs intérêts, ils ont sacrifié l'avenir et ont abattu leurs noyers pour les vendre, sans jamais les remplacer.

Pour justifier ces exploitations abusives et profondément regrettables, les cultivateurs ont prétexté : la lenteur de la mise à fruit du noyer, l'irrégularité de sa production fruitière, la fréquence de la carie de son bois (gaulage brutal et plaies non recouvertes d'un enduit protecteur), enfin ils l'ont accusé de nuire considérablement par son feuillage épais aux cultures intercalaires.

Certes, dans nombre de départements, ces eritiques sont justifiées, ce n'est pas la culture du noyer en elle-même qu'il faut ineriminer, 
mais bien l'ignorance, la négligence, l'impréroyance des cultivateurs. Rien ne leur serait plus facile que d'éviter les inconvénients qu'ils reprochent au noyer : simplement par la pratique de méthodes culturales appropriées et judicieuses.

Mojems din remirlier.

Par le choix de variétés greffées et soigneusement sélectionnées, à mise à fruit précoce, à florais on tardive, il leur serait possible d'attendre moins longtemps l'entrée en rapport de leurs noyers et de régulariser la production en diminuant le danger des gelées de printemps.

Par un apport régulier d'engrais et quelques facons culturales, ils amélioreraient le sol, lui restitueraient la quantité d'éléments nutritifs qui lui sont enlevés annuellement par la récolte et en augmenteraient sa richesse en principes fertilisants. La production des noix y gagnerait en quantité et en qualité.

Par un' taille raisonnér et des élagages bien compris, ils diminueraient l'épaisseur de la cime. l'amèneraient à prendre la forme en gobelet, si favorable à la libre circulation de l'air' et de la lumière. Les cultures intercalaires auraient moins à souffrir du couvert des noyers dont, d'autre part, la production fruitière serait sensiblement améliorée. Enfin ils obtiendraient des noyers à fût plus élevé et diminueraient la fréquence de la carie du bois par une pratique plus prudente du gaulage et l'habitude de recouvrir d'm enduit protecteur les plaies accidentelles ou culturales de l'arbre : la production ligneuse y gagnerait sensiblement.

Linsi comprise, la culture du noyer devient une source de richesse pour les populations rurales de nombreux départements et aucune des critiques qui ont été formulées contre elle ne subsiste.

Les mesures propres à enrayer la crise du noyer peuvent être formulées sous la forme de vocux que nous soumettons au Congrès.

Que des conférences destinées ì instruire nos cultivateurs, soient organisées.

Que des pépinières destinées à fournir gratuitement ou moyennant une redevance très faible, des plants de noyers greffés et soignensement sélectionnés, à tous ceux qui veulent effectuer des replantations, soient créées sous la direction des professeurs d'agriculture.

Qu'il soit établi des primes à la replantation des noyers.

Que la loi dégrevant de tout impôt foncier, pendant trente ans, les terrains remis en nature de bois, soit étendue aux noyeraies, $c^{*}$ est-à-dire aux noyers plantés en massits.

II. le Président. - Il n'existe pas de noyeraies en France.

11. MAxgr. - II y en a dans quelques départements et notamment dans l'Isère, mais presque toujours elles sont accompagnées d'une culture intercalaire, ce qui pourrait arrêter le législateur dans sa tendance de dégrèvenent d'impòt foncier. Il ne pourrait peut-être y aroir là qu'un dégrèvement partiel qui rentrerait dans la conception des primes, notamment pour la plantation du .Juglans nigra, ou noyer noir d'Amérique. Cet arbre fournit un bois d'excellente qualité qui, lans reptaines conditions, peut lutter avec le bois du noyer commun ot présenter même sur lui quelques arantages. 
M. DE SEgonaAC. - La question du noyer est très délicate : cest plutèt un arbre isolé qu'un arbre de grande lutaie; je signalerai in passant une particularité intéressante qui fait que cet arbre doit êtr. considéré comme d'un excellent rapport au point de vue de la chasse : c'est en effet le seul ou un des seuls que le gibier ne touche point. que ce gibier soit le cherreuil, le lapin ou le lièvre; sur ce point, je puis être tout à fait affirmatif : j'ai planté rhez moi des quantités de noyers, jamais le gibier ne les touche, même par temps de neige, c'esti-dire alors qu'il meurt de faim!

Pourquoi les noyers ont-ils en grande partie dispam elez nous? La première raison, à mon sens, il faut la trouver dans la gelée de I879.

La seconde raison, je la troure en ceci que, comme le châtaignier. c'est un arbre qui, pour une élévation de quatre mètres, présente au tronc un volume considérable qui le fait beaucoup rechercher, si bien qu'on le paye 250 francs le mètre cube.

En outre, le noyer est l'arbre le plus difticile du monde pour le greflage. Par conséquent, la plupart du temps on n'y procède pas, ar. il y a lì un aléa que je signale d'une facon tout à fait positive.

11 faut décider le paysan à planter le noyer auprès de lui, aux alentours de sa maison. Que surtout on n'aille pas lui faire faire des plantations an loin, dans la campagne ou les corbeanx lui mèveraicnt tout espoir de tirer profit de son fravail.

Dans le Midi, la question se présente sous un aspect un peu différent paree qu'il y a la question de l'huile à tirer du fruit, re qui pent être the source de revenus nouveaux. Il ne faut pas croire pourtant qu'il convient de remplir la France tout entière de noyers: je demandr que l'on procède comme pour les châtaignier's : qu'on fasse les plantations dans les pays où cette culture peut convenir at qu'on lasse - llltout des plantations de noyers isulés.

11. CAor et. - Je n'ai que deux mots à dire pour protestrer à l'égard t'une expression qui revient plusieurs fois, soit dans le rapport de II. Mangin, soit dans l'exposé qu'il nous a fait tout ì l'heure: pourquoi parle-t-il toujours d' exploitations abusives n? Laissez done un peu de liberté aux propriétaires! ils savent ce qu'ils ont il faire. fe protestr au nom de la liberte de la propriété dont je tiens a allirmer hantement le principe.

M. Maxgrx. - Et moi, je melère contre alle, d'une faşon non moins absolue.

M. Hickel. - It 11 ai rien it ajouter it ce qua dit M. de Segonzal sur les eauses de la disparition du noyer; jestime que l'une des prinei palrs est celle qu'il a signalée, tonchant la valeur élevée du bois df noyer; il n'est pas du tout étonnant que les cultivateurs n'hésitent pas rlevant les hauts prix qui leur sont ulferts; parmi les emplois très nombreux du noyer, il convient de signaler surtout l'usager qui 
en est fait dans l'ébénisterie ; et, actuellement par suite de cette disparition du noyer commun, du noyer français, les fabricants de meubles ont de plus en plus recours au noyer noir d'Amérique : la plupart des mobiliers du faubourg Saint-Antoine vendus pour du noyer frisé sont en noyer noir : c'est une preuve que ce bois a une valeur à peu près égale à celle du noyer indigène. Mais il est un autre emploi du noyer au sujet duquel je tiens à vous entretenir, parce que e'est un umploi qui se présente à intervalles périodiques et qui exige alors des quantités colossales de noyers : je veux parler de la fabrication des crosses de fusils : toutes les fois que l'on procède dans un pays, - en France ou ailleurs, - à la réfection de l'armement, on emploie des quantités énormes de noyers à l'exclusion de tous autres arbres. Je ne suis pas chasseur, mais j'ai manié le fusil de guerre comme vous tous, Messieurs, eh bien! je n’ai jamais trouvé une crosse de fusil qui ne fút pas en noyer. Et notez que cette fabrication, de par la forme même qui est donnée à la erosse, nécessite un déchet de $50 \%$. Lorsque l'Allemagne procède à la réfection de son armement, e'est en grande partie en France qu'elle vient s'approvisionner. Il convienIrait d'apporter un remède à cette situation.

On a parlé tout à l'heure du noyer noir et vous avez pu voir sur une table ici même un morceau de ce noyer, verni sur toutes ses faces, qu'on est venu vous présenter. Eh bien! il me semble que si l'on poussait à la culture en France du noyer noir, il pourrait suppléer utilement le noyer indigène pour l'industrie. Ce serait autant de gagné pour l'agriculture, ear la noix du noyer noir n'est pas comestible, en raison de l'épaisseur de son écorce et de la petitesse de son amande. D'un autre côté, le noyer noir présente des avantages sur le noyer indigène : il atteint des dimensions plus grandes, il croît aussi vite et donne un fût dénudé sur une grande longueur ; infiniment plus rustique, il résisterait aux rigueurs du climat du Nord ou re l'Est de la France.

Mlais en attendant que nous ayions constitué un stock de noyers noirs qui nous permettra de faire face à une réfection possible de notre armement - supposez, en effet, que demain, on substitue au fusil actuel à magasin, un fusil avec chargeur, voilà la porte ouverte à des destructions de noyers considérables - en attendant, dis-je, cette éventualité qui n'est peut-être pas lointaine, je propose qu'aux voeux qui sont présentés par M. Mangin on en 'ajoute un autre qui serait-libellé ainsi :

"Le Congrès émet le vœu que le Ministre de la Guerre fasse procéder dè à prèsent à des essuis à l'aide des différentes espèces indigènes et exoliques, de taçon à tronver un succédané du noyer réalisant les mêmes conditions. "

On sauverait ainsi une grande partie de nos noyers. Je ne erois pas que cela soit impossible. Evidemment, la plupart des bois des régions tropicales sont très denses, mais je crois qu'on pourrait trouver dans. 
nos possessions, motamment dans l'tfriques oroidentalı, Wr- bois ligers susceptibles do remplater le nover.

M. Caquet. - Je massocie pleinement aux paroles de M. Hickel : il y a là un remède qui tranche heureusement avec beaucoup d'autres voux qui n'ont pour but que d'appeler la répression à la rescousse; il nous offre un moyen ingénieux et pratique d'obvier à un ineonvénient sérieux : japplaudis, des deux mains, à sa proposition.

Je voudrais savoir, maintenant si on peut remédier anx inconvé. nients du couvert du noyer.

M. MANGin. - Le rapport répond exactement is cetle question.

M. Le Présinext. - Je mets aux voix les conelusions du rapport

Ces eonclusions sunt adoptées.

M. Le Présmext. - Voici maintenant le voru de M. Hiekrel :

"Que le Ministre de la Guerre fasse procéder, dès à présent, i des expériences de façon à trouver un succédané du noyer pour la fabrication des crosses de fusil. "

Adopté.

M. Le Présidext. - Lordre du jour appelle la diseussion du rapport de M. Caquet sur les Exgrais chmiQues EN Sylviculture.

M. Francois Ciquet. - Nous savons tous que, depuis trente ans environ, les engrais chimiques sont d'une application courante en agriculture. En sylviculture, il n'en est pas ainsi et nous en sommes encore à la période des essais, des tâtonnements et des incertitudes. Toutefois, cette question de l'application des engrais chimiques aux cultures forestières a préoccupé depuis longtemps déjà et à juste titre les hommes de progrès qui sont des fervents de la sylviculture intensive.

Depuis près de trente ans, nous nous sommes personnellement occupé de cette importante question, tant au point de vue pratique qu'áu point de vue théorique.

Dans la Presse quotidienne et périodique, nous avons consacré de nombreux artieles à la vulgarisation de cette question. Dès 1883, la "France Forestière ", que nous avons fondée, s'est préoccupée de l'application des engrais chimiques à la sylviculture.

Au Congrès international d'agriculture de Rome, en 1903, nous avons soulevé une discussion sur " l'emploi des engrais chimiques en sylviculture et cette intéressante question y a été l'objet d'un échange de vues consigné aux procès-verbaux des séances de la section de sylviculture. Au sein de différentes sociétés d'agriculture et particulièrement de la Société des agriculteurs de France, nous avons eu l'honneur de provoquer la mise à l'étude de ce sujet que nous croyons important pour l'avenir de la sylviculture mondiale; car, pourquoi la plus-value obtenue par l'emploi des engrais en agriculture ne serait-elle pas également obtenue par des applications judicieuses à la production forestière? 
Pour notre part et, en ce qui concerne au moins l'application des engrais aux jeunes plants, dans les pépinières, notre siège est fait et nous avons pu nous rendre compte, en particulier, de l'avantage réel qu'il y a à employer les engrais potassiques et phosphatés sur les terres destinées aux jeunes plants forestiers feuillus et résineux.

A l'égard de l'application des engrais chimiques dans les bois en croissance, aux taillis notamment, nos expériences personnelles ne reposent que sur le fait suivant.

Nous avons fait des plantations d'acacias de quelque importance sur les places à fourneaux de nos taillis en 1887 et 1888. Chaque place à fourneau présente une superficie maximum de 50 mètres carrés. L'engrais potassique qui se trouve dans les résidus de la fabrication du charbon a donné une vigueur exceptionnelle à la pousse de ces jeunes plants qui, très serrés et au nombre de quinze à vingt par place à fourneau, ont fourni un rendement net de 15 francs par place à fourneau au bout de 15 ans, chaque perche d'acacia ayant été vendue 0 fr. 80. Les plantations d'acacias faites à la même époque dans les vides des taillis sont loin d'avoir une semblable croissance. Ils n'ont pas plus de dimension en hauteur et en diamètre, au même âge que les tiges de chênes les plus voisines. Hâtons-nous de dire que les terrains sur lesquels nous avons opéré sont des argiles imperméables sur lesquels l'acacia prospère mal. Les acacias récépés, donnent une pousse plus vigoureuse que les brins plantés.

Une suralimentation qu'il serait très probablement fort utile de donner - à nos bois en général et à nos taillis tout spécialement, consisterait dans l'addition d'engrais phosphatés aux sols qui en manquent le plus ordinairement et desquels on les exporte à chaque coupe par la vente et l'enlèvement des produits ligneux : écorces et bois.

En général, les sols forestiers sont pauvres et tout particulièrement en acide phosphorique.

Un hectare de bois absorbe annuellement en principes minéraux divers les quantités suivantes: 185 kilos s'il s'agit du hêtre, 135 kilos s'il s'agit de l'cpicea et 46 kilos seulement pour une futaie de pins sylvestres. Les quantités de substances minérales qu'exigent les résineux sont donc sensiblement moins grandes que celles réclamées par les feuillus.

Si nous négligeons de tenir compte de la teneur d'acide phosphorique contenue dans les feuilles et les fruits qui ne sont pas exportés ordinairement et pourrissent sur le sol de la forêt, nous arrivons à calculer que, pour un hectare de bois planté en chênes, par excmple, il faut annuellement, pour le développement du bois et de l'écorce $1 \mathrm{~kg} 500$ d'acide phosphorique, 7 kilos de potasse et 27 kilos de chaux.

Dans un taillis d'une révolution de 18 ans, il conviendrait d'enrichir le sol végétal par l'importation d'un engrais composé contenant 18 fois an minimum ces richesses, utilisées annuellement pour la production du bois et de l'écorce qui doivent être exportés lors de la coupe. Mais 18 ans pour récupérer cette dépense qu'on peut chiffrer par 30 francs à l'hectare environ, c'est bien long; les besoins de la vie actuelle sont pressants et l'avenir n'est à personne! D'autre part, le crédit forestier n'existe pas; il n'est pas institué à l'instar du crédit agricole. Dès lors, à qui s'adresser pour obtenir la somme relativement importante que nécessiterait cette amélioration dont le résultat ne sera réalisé qu'à dix-huit ans de distance et en présence de la mévente des produits de nos taillis et des frais sans cesse croissants de la main-d'œuvre? C'est là une 
difficulté à l'emploi des engrais chimiques en forêt; mais cette difficulté est loin d'être insurmontable et pourra être levée quand il sera péremptoirement démontré par l'expérience que les engrais sont nécessaires à la prospérité des bois.

Aussi, donnerons-nous pour conclusions à ce court exposé, les vœux suivants que nous prions le Congrès forestier international de vouloir bien voter.

10 Que les Bulletins officiels et te renseignements agricoles des diverses nations sollicitent des expériences pratiqnes de la part des sylviculteurs; qu'ils recueillent et publient les observations communiquées et les résultats obtenus, afin que la Presse générale et spéciale puisse s'en inspirer pour la v'ulgarisution des procédés employés.

$2^{\circ}$ Oue les stations de recherches de France et de l'Etranger, les Administrations forestières, les Sociétés d'agriculture régionales et locales se livrent à des expériences pratiques d'engrais appliqués aux bois et forêts, qu'clles en reeneillent avee soin les résultats et les publient dans les bulletins dont elles disposent.

II. I) Lesserx. - Comme proprietaire forestier, j’ai appliqué la kainite à des reboisements depiceas. L'epirea abonde dans les terrains paurres, presque stériles: pour 700 des sujets, j'ai obtenu 35 of 40 centimètres d'accroissement : or, le terrain dont je vous parle est situé dans les Hautes losges et les arberes ont, en général, presque tous '́ m. 50 de hauteur. Nous avons gagné douze ans par l'apport de 250 kilos de kainite qui est un engrais potassique.

L'expérience date de 1899.

M. Cionet - C'est précisément pour " recoler n, - pour me servir d'un terme forestier, - des renseignements aussi intéressants que le vòtre, que j'ai jeté sur le papier res deux pages de mon rapport, proroquant ainsi une discussion sur une question qui parait tout it fait neuve, tout en étant vieille de trente ans pour un certain nombre te forestiers d'avant-garle.

11. Chaxcerel. - Jai déposé sur le bureau une communication sur le ròle du calcium dans la régétation forestière et son action sur les jeunes plants ligneux. Cette communicacion est dans l'esprit du rapport que nous discutons en ce moment.

M. Le Présidext. - Il va en être donné lecture.

Lim des secrétaires du hurean donne lecture de la communication -nivante :

LE ROLE DU CALCILY WAXS LA VÉGETATIUN FORESTIËR, SON ACTION SLR LES JEUNes phats higieli, par II. L. Chancerel, inspectenr des Eanx et Forèts, docteuren droit, en méilecine, is-steicuce.

si l'on dose les divers principes mineraux enfrant dans la composition d'un végétal ligneux, on comstato que le calcium est l'élément préunninant. 
* On peut donc en déduire a priori que ce corps est le plus important pour les régétaux forestiers.

"Cette conclusion a été confirmée pal" l'expérience.

- M. Chancerel a cultivé des végétaux ligneux variés :

10 E

20 En sol artificiel;

$3^{\circ}$ En terrain naturel.

"Ces divers milieux ont été arrosés de solutjons minérales diverses. Dans tous les cas, il a été constaté que les composés du calcium ont une action des plus puissantes sur la végétation des jeunes plants ligneux, l'évolution des rejets et la production des racines des boutures.

"Les autres composés (de potassiun, de sodium, d'amomnium, etc.) sont indifférents ou même parfois nuisibles si on les emploie à haute dose.

" D'autre part, au point de vue anatomique, les composés calciques produisent des vaisseaux plus larges, des cellules de parenchyne plus abondantes et plus épaisses; ils augmentent notablement le développement du cylindre central par rapport à léce a e tonnent aux éléments de la tige, de la racine, de la feuille, une liginification plus intense.

" Iu point de vue physiologique, ces composés farorisent l'assimilation chlorophylienne, la transpiration et la respiration des végétaux ligneux.

En résumé, les composés calciques, spécialement les phosphates et les sulfates sont les engrais forestiers par excellence, les stimulants de la végétafion ligneuse, des éléments de vitalité pour les jeunes plants. »

M. Chaxcerel. - Messieurs, les résultats qui riennent de rous être révélés par la communieation qui vous a été lue, ont été contròlés par la Faculté des sciences et ont fait l'objet d'une thèse de doctorat soutenue en 1909. Cette thèse rient à l'appui de ce que je disais : il y a urgence à continuer l'expérience. Je l'ai faite : une première fois en ean distillée, une seconde fois en sol artificiel et enfin sur le terrain même. J'ai obtenu presque constamment les mêmes résultats : excellence du calcium dans tous les cas, notamment du superphosphate de chaux.

Je me propose de suivre de nouvelles expériences sur le plus grand nombre d'essences possibles.

M. Le Président. - Nous remereions rivement M. Chancerel et de son intéressante rommunication et des explications complémentaires quil a bien voulu nous donner.

Avant de voter sur les roux du rapport de . M. Caquet, nous allons vous donner encore connaissance dune communication de M. Cuif

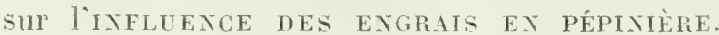

Liun des secrétaires donne lecture de la communication suivante :

II. Cuif, dans une communication des plus intéressantes, clonne les résultats d'expériences poursuivies depuis 1905 sur l'influence des engrais en pépinière forestière.

"Ces expériences ont porté sur l'épicéa, le pin sylvestre, le sapin pectiné, le pin noir d'Autriche, le frène, le chêne rouvre et le chêne pédonculé.

M. Cuif a étudié, non seulement l'influence des engrais sur les plants en pépinière, mais a en outre suivi, pendant quelques années, après leur transplantation en forêt, la façon clont se comportaient ces plants.

(II. Cuif termine le rósumé particulièrement instructif de ses expériences par cette conchusion : 
* Malgré quelques insuccès rencoutrés dans la pépinière de l’Étang-de-Brin, les premiers essais dont nous venons de rendre compte nous paraissent aussi encourageants que modestes.

"En les faisant connaitre à nos camarades forestiers, nous espérons leur communiquer un peu de notre foi dans l'efficacité des engrais chimiques en pépinière et les engager à aider la Station d'expériences de Nancy dans la poursuite de ses recherches sur une plus vaste échelle et dans des conditions aussi variées que possible. "

M. Le Président. - Voilà un nouvel appui pour la proposition de M. Caquet.

M. Chaxcerel. - Des expériences ont été entreprises par l'Administration forestière lans la forêt de Chinon : il serait intéressant que l'Administration communiquât les résultats qu'elle a obtenus et les méthodes qu'elle a suivies.

M. Le Présinext. - Tout ee qui vient d'être dit ne fait que eonfimer l'utilité des voux que nous avons à voter.

Il eonvient done, Messieurs, car nous ne sommes pas des théoriciens et nous nous intéressons aux choses pratiques, de manifester précisément maintenant notre sentiment en votant les voux.

Sur le premier, je crois que nous sommes tous d'accord.

Je le mets aux roix.

Le voeu $n^{\circ} 1$ est adopté sans modification.

M. Le Président. - l'our le voeu $n^{\circ}$ 2, vous avez manifesté. les uns et les autres, le désir d'y apporter des modifications; mais vous n'êtes pas d'accord sur une rédaction.

M. Guillot. - J'admets, avec M. Caquet, qu'il faut substituer In mot "centraliser " an mot "publier ", mais je demande que cett" centralisation se fasse à la station de recherches de Naucy, et non i l'Institut International de Rome.

M. Chancerel. - II fandrait que la station de Naney publiât son bulletin et fît ainsi connaître les résultats obtenus, car si ces résultats ne sont pas portés à la connaissance du public, nous émettons um vocu platonique.

M. Le Président. - Du moment que la station de recherches di. Nancy est invitée a publier ses renseignements, la direction de l'Éenl. lui en fournira les moyens.

M. Cagvet. - En somme, il y a un double voeu : le premier demande qu'on fasse des expériences, - il a été voté, - le deuxième, que l'on constate et que l'on publie : Eh bien! la station de Nancy, qui est une station de recherches fait des recherehes; de plus, elle constate les résultats obtenus par d'autres; entin alle les publiera. 
M. Le Présinext. - Mors. Mesiezurs, si nous sommes bien daccord. je mets anx roix le vou, dans les termes suirants, que rous venez de dégager :

"Que la station des recherches de Tuncy concentre les résnltats pratiques obtenus, soit à l'étranger, soit parmi les administration: forestières, les sociétés l'agriculture régionales et locales, par l'emploi d'engrais appliqués anx bois et forêts. et en f̣asse l'objet d'une publicution. "

Le velu mis aux voix est arlopte.

1I. ie Présinext. - La parole est ì M. Caquet.

M. Carzet. - Messieurs, hier, nous arons eu me discussion assez longue au sujet d'un procédé nouveau et très différent de l'ancien a appliquer anx taillis comme remède i la sitnation critiqu dans laquelle ils se trouvent. A la suite de cette discussion, plusieurs vopux ont été adoptés. Aujourd'hui. M. de Lesseux nous en apporte $n$ noureau qui pourrait servir de ronclusion aux débats d'hier. J'espèr. que vous ne verrez pas d'inconvénient it ce qu'on revienne ainsi els arrière. Voici ce dont il s’agit :

"Le Congrès émet le rou que l Administrution rentrale fusse immidiatement application, à tilre d'essui, duns les forêts domaniules traitées en taillis sous futaie de la méthode préconisée par l'Erol." forestière de Vancy sons le nom de futaie pleine par bounuets: as essais seraient tentés dans des forêts propices et des régions diverses et les résnltats du traitement seraient prodnits an prochain Congrés.

14. Chaxgerei. - Ciest là quelipe hos diexpellent.

11. Cincer. - Cela donne satisfaction à tout le monde. I la suite d. la diseussion d'hier entre M. Mangin et W. Cuif, chacun a sans dout conservé son opinion. L'un pense toujours que la longue révolntion doit être appliquée aux taillis: rt l'autre, au contraire, qu’il vandrait micux se lancer dans une roie differente. Si tous les auditeurs d'hier étaient présents, je suis certain qüils accepteraient le rou de: II. de lesseux qui est la conchusion de lexposi fait par. Yr. Cuif.

11. Chaxcerel. - Les expériences de Nancy se réduisent à la Lorraine.

11. be Lesserx. - Je roudrais qu'on les étende un peu partout. Actue]Iement, il n'y a qu'un essai qui ait été fait ; aussi il est diflicile de dir" aux propriétaires de forêts de faire de la futaie claire. Nous ne pourons pas assurer à ces propriétaires quils pourront gagner 60 franes par hectare et par an. Jo crois que la futair claire donne les meilleur: résultats, cest ma convietion prersonnelle. mais és une conviction : je n'en suis pas absolument síu. de voudrais done que l'Etat, dan= 
INTERNATIONAL 1913

ses énormes forêts domaniales, commence à constituer de petites séries dont nous pourrions donner les résultats au prochain Congrè̀s.

M. Caquet. - Il est bien évident que c'est à l'État qu'il appartient de faire ces expériences et non pas aux particuliers.

M. Le Président. - Je rais mettre aux voix le vou de M. de lesseux tel qu'il vient de vous être lu.

Le vou est adopté.

La séance est levép à 3 h. 25. 


\title{
SEANCE DU 19 JUIN 1913
}

\author{
(MATIN)
}

Présidence de M. EMERY, vice-président de Section

La séance est ouverte ì 9 h. 15.

M. Le Président. - Messieurs, l'ordre du jour appelle le rapport de

MM. Chaplain et A. UnbDenstock sur les Forêts coloniales.

La parole est à M. Chaplais pour la lecture du rapport.

M. Chaplain. - Le bois manque! Tel est le cri d'alarme poussé même à la tribune du Parlement.

La consommation ligneuse dépasse, en effet, la capacité des forêts, ce qui explique la hausse constante de ce produit de première nécessité.

Les pays producteurs de bois ont pris des mesures pour protéger, améliorer les forêts existantes et procéder à des travaux de reboisement, mais en attendant la reconstitution des forêts, l'accroissement de la consommation rendra fort difficile le rétablissement de l'équilibre rompu.

La France importe annuellement pour plus de 200 millions de francs de bois divers; on conçoit l'incomparable champ d'action que les colo. nies françaises peuvent offrir au commerce des bois.

Les colonies françaises possèdent, en effet, des forêts en situation d'approvisionner la Métropole en produits ligneux variés et précieux: bois de construction, d'ébénisterie, de pavage, ainsi que des essences propres à la fabrication de la pâte à papier.

Celles qui sont surtout à considérer à raison des intérêts forestiers sont :

$$
\begin{aligned}
& \text { La Guyane, } \\
& \text { Madagascar, } \\
& \text { L'Afrique-Occidentale, } \\
& \text { L'Indo-Chine. }
\end{aligned}
$$

D'autre part, l'Afrique du Nord fournit une quantité considérable de liège.

En Algérie, l'organisation du service forestier est le même qu'en France.

En Tunisie, les circonscriptions forestières ont à leur tête des agents métropolitains mis à la disposition du Gouvernement de la Régence.

Lorsque l'aménagement des forêts du Maghreb aura produit son effet, la production ira certainement croissant. 
Rien de ce qui touche à notre important domaine forestier colonial ne saurait nous laisser indifférents. Cependant, ces ressources d'avenir sont, dans certaines de leurs parties, vouées à la destruction, dans d'autres, livrées aux déprédations des indigènes à la recherche de nouveaux pâturages.

La forêt recule de plus en plus, faisant place à une brousse où ne naissent que des essencees sans valeur.

En Guyane, la déforestation n'a pas eneore accompli son œuvre néfaste. Le pays est couvert d'immenses futaies plusieurs fois séculaires renfermant plus de deux cents essences réunissant au premier degré les qualités recherchées dans les diverses industries du bois : menuiserie, ébénisterie, charronnage, constructions, etc. et offrant des produits secondaires variés et d'une importance primordiale : produits oléagineux, aromatiques, tinctoriaus et tannants, textiles et médicinaux. Ces forêts sont d'un luxe prodigieux de végétation dont il est difficile de se faire une idée sans avoir vu.

Le commerce d'exportation pourrait être fort important en Guyane. Malheureusement notre colonie est loin d'avoir atteint l'activité commerciale de la Guyane anglaise et de la Guyane hollandaise. Si l'industrie forestière n'y est pas florissante, cela tient, dit M. Voelckel, en grande partie à ce qu'il n'y a presque jamais, à la tête de l'entreprise, un homme compétent. Les exploitations sont engagées sans méthode et avec des capitaux insuffisants. Les difficultés d'exploitation exigent en effet un apport relativement considérable de capitaux, lesquels ne peuvent être fournis que par une société constituée sur des bases solides.

Par contre, à Madagascar, les forêts sont loin d'avoir la même importance : la déforestation a fait ici des progrès considérables.

La surface boisée de Madagascar varie entre 10 et 12 millions d'hectares; elle représente le einquième de la superficie de l'île.

4 millions d'hectares de forêts sont à peu près complètement ruinés par suite d'abus dans les exploitations et de défrichements ininterrompus.

4 autres millions d'hectares ne possèdent qu'un matériel très réduit de bois exploitables.

L'ạutre tiers de l'étendue forestière est constitué par des peuplements riches en essences les plus remarquables des régions intertropicales.

On rencontre à Madagasear d'immenses étendues dénudées et arides, notamment sur les hauts plateaux.

Parmi les causes de la dévastation des forêts, nous signalerons les incendies périodiques allumés par les populations pastorales. Le pâtre met le feu aux arbustes qui gênent l'extension de son pâturage; le feu gagne la forêt voisine peuplée d'arbres de valeur. Lambeau par lambeau, la forêt est détruite.

Le Gouvernement général a édicté des peines pour enrayer la destruction de la forêt malgache. Le Déeret du 10 février 1900, lequel comprend cent six articles, applique le régime forestier à la colonie; il réglemente l'exploitation, la répression des délits forestiers. Mais ce n'est pas tout que d'édicter des règlements, il faut être en mesure de les faire respecter. Or ces textes sont restés lettre morte ; les exploitations se font sans con- 
tròle ; pour détruire un hectare de forêt, il suffit d'acquitter une redevance annuelle de 10 centimes!

On conçoit que, dans de telles conditions, la dévastation ait fait des progrès considérables.

D’autre part, il n'existe pas de service forestier à Madagascar; la section première du titre II du Décret ci-dessus n'a pas reçu d'exécution. La gestion du domaine forestier est entre les mains de fonctionnaires coloniaux ; le service technique comprend un garde général qui a sous ses ordres des agents de police, des contremaîtres de culture, des commis des services civils, des gardes de milice.

La Commission chargée de l'organisation du régime forestier est composée de fonctionnaires du Gouvernement général, lesquels s'entendent peu aux choses forestières. D'autre part, trop absorbés par leurs occupations professionnelles ils risquent de traiter ces questions à l'envers de l'intérêt général.

L'Afrique Occidentale n'échappe pas au mouvement de régression sylrestre. I défaut d'agents forestiers, la surveillance et la constatation des délits est assurée par des agents coloniaux du cadre administratif. Les collectivités indigènes jouissent de droits d'usage dont ils abusent.

Pour satisfaire divers appétits, des étendues considérables ont été déboisées et le régime hydrologique s'en est ressenti : la navigation du lleuve Sénégal est devenue plus difficile; les terres de culture sont moins productives et les défrichements ont transformé certaines régions en véritables déserts d'où disparaissent peu à peu les cultures, les troupeaux et l'homme.

Cependant, il existe en Ifrique Occidentale française de vastes étendues de forêts, encore vierges, et dont il sera possible de tirer parti.

C'est ainsi que la Côle d'Ivoire est recouverte, sur les deux tiers de sa superficie, par une imposante forêt qu'on évalue à 12 millions d'hectares et dont l'étude botanique a été faite par M. Chevalier (1). On la cite comme une des plus puissantes qui soient au monde; elle est constituée par une futaie d'arbres géants et renferme des essences utilisables dans toutes les branches de l'industrie (industrie de luxe, chemins de fer, constructions navales, ete.).

En Indo-Chine, les forêts couvrent une notable partie du territoire, environ 25 millions d'hectares. Mais ici également l'arbre a des ennemis. D'après M. le conservateur Roger Ducamp, chef du service forestier de notre possession asiatique, le déboisement en Indo-Chine a pris des proportions inquiétantes contre lesquelles il est temps de réagir énergiquement.

L'anéantissement des forêts des vallées du Fleuve Rouge et du Mékong a rendu plus brutales les crues de ces cours d'eau et e'est à la même cause que l'on doit l'ensablement des vallées et des deltas. C'est également au déboisement du haut Tonkin et du Yunnan qu'il faut attribuer les inondations qui se produisent au Tonkin ainsi que la formation, dans le lit des cours d'eau de cette province de l'Union, de banes de sable, lesquels constituent un sérieux obstacle à la navigation.

(1) Les végétaux de l'Afrique Occidentale française. - A. Challamel, éditeur. 
Dans certaines régions, il y a lieu de procéder à des reboisements.

Dans d'autres, il suffirait d'aménager et de conserver les massifs existants.

Le relief montagneux de la péninsule et la pente accentuée de ses vallées, exigent que l'Indo-Chine conserve son patrimoine forestier.

Nous n'avons pas la prétention de vouloir maintenir à l'état de boisement permanent, soumis aux règles de la sylviculture moderne, les millions d'hectares occupés par les forêts coloniales.

Dans les régions agricoles, il n'y a aucun inconvénient à ce que des emprises soient faites sur le domaine forestier.

Mais il est nécessaire d'apporter au mal que nous venons de signaler les remèdes qui donneront de bons résultats en n'imposant aux pasteurs que le minimum de contrainte dans leurs coutumes.

Il convient donc de cadastrer les forêts coloniales, et de maintenir certaines parties en état de production.

Malgré leur immense étendue, ces forêts ne sont pas inépuisables et il se pourrait que des coupes sombres les anéantissent pour des siècles.

La question forestière coloniale est, on le voit, fort complexe, mais il nous paraît possible de la résoudre en partie.

Dès à présent il y a lieu, par des instructions écrites, de s'attacher à convaincre le personnel administratif colonial de l'intérêt que présente la conservation des forêts.

Par ce personnel ainsi convaincu, s'efforcer de faire comprendre aux populations, aux tribus, qu'elles seraient les premières vietimes de la ruine du pays par suite de la disparition des massifs boisés, comme elles seraient les premières à profiter de l'exploitation rationnelle desdits massifs.

Les forêts, on le sait, assurent aux pays qui savent les conserver, un régime climatérique convenable. Aux colonies plus que partout ailleurs, la conservation des forêts est l'élément principal de l'habitabilité : c'est donc, au premier chef, une question de salut public.

Au point de vue économique, les forêts ne jouent pas seulement un rôle important par suite de l'utilisation des produits qu'elles donnent. Comme toutes les beautés de la Nature, elles attirent les touristes; elles sont, par suite, une source de revenus pour les pays dont elles sont la parure appréciée des voyageurs. Protéger la forêt, c'est donc protéger la fortune d'un pays.

Il est nécessaire d'agir sans plus de délai : la peur du danger est le commencement de la sagesse. Il y va de l'avenir de nos possessions, et la France a le devoir de ne pas laisser détruire les forêts coloniales, mine vivante d'une valeur inestimable.

En conséquence des considérations qui précèdent, nous proposons au Congrès d'émettre les voux suivants :

I. Qu'il soit créé an Ministère des Colonies un burean spécial chargè :

a) Du contrôle supérieur du domaine forestier colonial;

b) De l'élaboration d'un programme d'action uniforme pour toutes les colonies, en ce qui concerne l'aménagement progressif des forêts dans chaque colonie, el la constitution de réserves forestières.

c) De centraliser les questions générales d'intérêt forestier concernant toutes les colonies. 
II. Qne le recrutement des Agents forestiers it destination des pays de protectorat et des colonies ait lieu, partiellement au moins, dans le cadre des agents de la métropole, et soit réglementé par décret pris d'accord entre les ministres intéressés (Agriculture, Affaires Ëtrangères, Colonies).

M. Chaplain. - Iu moment où notre pays commence à déplorel la légèreté avec laquelle on a procédé au déboisement sur biell des points, et s'ingénie à trouver un remède au terrible mal, il a paru nécessaire de jeter le cri d'alarme, en ce qui concerne les colonies françaises.

La plus coupable incurie, pour ne pas dire plus, a jusqu'ici, présidé à la gestion de l'immense domaine forestier dont l'étendue exacle reste presque partout inconnue.

L'accès difficile de la forêt, d'où la difliculté de tirer un parti immédiat et avantageux de ses produits, l'impossibilité pour les gourerneurs de trouver auprès d'eux les gens compétents pouvani organiser ces services très spéciaux, sont autant d'excuses à l'état actuel.

Ne perdons point de temps à chercher les fautes commises et les coupables!

Il est temps de réagir. C'est de la métropole que doit partir la direction générale à imprimer à notre organisation forestière coloniale. Sans enlever à chacune de nos colonies l'autonomie qui lui est indispensable, nous estimons que le rôle des forêis, tant au point de rue climatérique qu'économique, est assez important pour justifier un contrôle supérieur. (Approbation.)

M. Umbinenstock. - En conclusion é pour résumer les pensées qui ont inspiré notre communication, il s'agit d'élaborer un programme d'action forestière dans l'ensemble de nos colonies.

Certes, nous apprécions la difficulté de la îache, mais ce vaste programme n'est pas impossible à réaliser : il y a pour l'État-une neuvre sociale ì remplir.

- Les diverses parties du plan d'ensemble susceptible d'en faciliter l'exécution doivent avoir pour objectifs prineipaux :

La constitution d'un état civil des forêts coloniales, la délimitation et l'immatriculation de grandes réserves forestières, poursuivies parallèlement à la détermination des droits d'usage et de leur mode d'exercice, afin de prévenir les empiètements et les abus;

La mise en valeur, par une exploitation rationnelle, du domaine ainsi constitué ;

La réglementation et la surveillance des concessions;

La reconnaissance des terrains qui peuvent être défrichés sans nuire ¿̀ l'intérêt général;

S'il y a lieu, l'établissement de périmètres de reboisement.

Nos colonies ne paraissent pas toutes armées pour assurer l'exécution des prescriptions que nous venons d'énumérer ; celles-ci impliquent logiquement la création, dans chaque colonie, d'un service 
trehnique que, seuls, des forestiers sont en mesure de mettre en weuvre. Pour l'aider dans sa tâche, ce service devra s'attacher à l'éducation d'un corps de préposés indigènes et surlout ì intéresser aux choses de la forêt, par des mesures que nous n'arons pas à examiner iei, les chefs de village, lesquels pourraient être rendus responsables des atteintes portées au domaine forestier.

J'ajoute que, dans l'intérêt même de la forêt, il est indispensable d'intéresser les indigènes à la conservation des massifs dont ils sont voisins. Dans les exploitations, il y aura done lieu de faire une large place à la main-d'ouvre indigène locale.

Les mesures protectrices que nous réclamons correspondent à l'établissement d'un Code forestier approprié aux usages de chaque colonie. Exprimons le vou que ceux auxquels incombera ce soin tiennent compte des besoins et des coutumes de ehaque pays et se bornent à une règlementation courte et précise : les mesures les plus simples sont toujours les meilleures. (Applandissements.)

M. Roger Ducaup. - Je puis paraitre tout désigné pour parler des questions forestières coloniales, puisque j'ai eu l'lonneur d'être envoyé en Indo-Chine en 1900 pour y jeter les bases de l'organisation forestière.

J'évalue, en ce qui concerne l'Indo-Chine seulement, à un mininum de 25 millions d'hectares la surface boisée qu'il est possible de choisir parmi les meilleurs peuplements pour en faire la base d'un domaine forestier.

M. Chevalier, du Iluséum, qui a été en Afrique Equatoriale, avec lequel j’en ai parlé et qui a écrit de nombreuses études sur les forêts de ee pays, estime à des dizaines de millions les forêts qui existent et qui sont indispensables à ces pays.

Au point de vue international, il n'est pas sans intérêt de rappeler ce que tout le monte sait ici, a savoir l'intluence des grands massifs boisés qui agissent par grandes ragues mondiales, et règlent les elimats européens ou asiatiques : nous sommes, en Europe, sous la dépendance, non seulement de l'Océan Atlantique, mais des terres d'au delà. M. Dumas l'a établi dans un ouvrage qui mérite d'être signalé, et que je vous engage à lire.

Aux Indes anglaises, les Anglais ont fait à peu près tout ce qu'il est possible de faire. Lì, j’ai été fortement impressionné. 11 ne faut pas croire que l'Inde Anglaise, que nous royons mal sur les cartes, soit un pays de forêts; l'Inde Anglaise, après Bombay et Ceylan, m'est apparue comme un grand désert, mais les 30 millions d'hectares sur lesquels les Anglais ont mis la main sont aujourd'hui cadastrés, levés derrière des plaques ou des bornes, avee des chemins de ronde. En Indo-Chine, nous avons réussi, en douze ans, à mettre derrière des plaques et des bornes 600.000 hectares de forêts dont 54.000 liectares aujourd'hui sont aménagés et exploités.

Quel genre d'exploitation, faisons-nous là dedans? Une exploita- 
tion très simple, parce qu'il faut la faire avec un personnel qui, comme disait mon camarade Chaplain, est venu de n'importe où, dans lequel on voit un encadreur, un ancien gabier de la marine... Il n'est pas possible aux colonies, pas plus qu'à Jara ou au Japon, ou dans les Indes Anglaises, de faire garder la forêt par des Européens. Le climat s'y oppose. Il faut qu'elle soit gardée par des indigènes, et somme toute, c'est une chose heureuse, parce que cela permet de faire place à une partie de la population indigène et peut-être de lutter contre ce mauvais vouloir qu'ont les populations indigènes à supporter l'influence européenne.

Eh bien, j'estime que la France, qui possède un enseignement supérieur des forêts dont je ne parlerai pas - les membres étrangers y sont venus puiser des idées forestières, - qui s'est créé un empire colonial énorme, envié, qui renferme un domaine forestier remarquable, alors qu'elle achète pour près de 150 à 200 millions à l'étranger, se créant ainsi, comme dit M. Mélard, une dette vis-à-vis de l'étranger, doit être frappée de folie d'abandonner l'exploitation de ce domaine entre les mains de pâtissiers uu d'encadreurs de tableaux.

Nous avons là, en exigeant qu'on fasse aux agents forestiers la situation qu'ils méritent, des débouchés remarquables.

Voilà ce que je puis dire à ce sujet.

Il me serait peut-être difficile de dire pourquoi à Madagascar, à La Réunion, en Calédonie, rien encore n'a été fait.

\section{Caxion. - Et au Congo encore?}

II. Roger Ducaup. - Il arrive ce qui arrive aux Anglais dans les Indes Anglaises, ce qui arrive partout. C'est que les fonctionnaires de l'ordre administratif étant vice-rois dans leurs provinces, le jour où des techniciens de la Forêt, des techniciens des Ponts et Chaussées, des techniciens de l'Armée viemnent pour faire ourre utile dans leur province, les fonctionnaires d'ordre administratif, pour employer un mot vulgaire, ne veulent rien savoir. (Rires.)

Permettez-moi de vous raconter à ce sujet une petite anecdote.

Étant sous la tente aux Indes Anglaises avec le fils du colonel Pierson et 11. Guidot, tous deux anciens élèves de l'École Forestière, ces messieurs m'avaient demandé de m'expliquer en anglais, langue que je parle fort mal. Je leur racontais mes ennuis en Indo-Chine pour organiser le service forestier, et, comme je les voyais sourire, ¿t un moment je leur dis. "Ce n'est pas charitable de votre part de sourire de ma façon de parler anglais, puisque c'est vous qui m'avez demandé de m'exprimer en cette langue.

"- Mais, cher Monsieur, me dirent-ils, nous sourions, non pas parce que vous parlez mal l'anglais, mais parce que les difficultés dont vous parlez sont les mêmes pour nous; qu'il s'agisse de Madras, de Bombay ou du Centre, nous avons les mêmes difficultés avec ces Messieurs de l'Administration, qui ne peuvent sentir qu'on vienne 
leur montrer la façon de faire des choses qui n'ont pas encore été faites."

Ainsi on nous a reproché en Indw-Chine de mettre tout en réserves. Eh bien, déduction faite des superficies en culture en Indo-Chine, il reste 42 millions d'hectares, qui pourraient faire vivre 40 millions d'habitants agricoles : vous voyez que le reproche était dénué de tout fondement.

D'autant plus que les 25 millions d'hectares qu'il faut que nous prenions, nous ne les avons pas pris. Nous avons pris, en Cochin hine, au Cambodge, au Tonkin en Innam, 10.000 a 12.000 hectares. Chacune de ces divisions a un chef-lieu; à la tête sont des chefs dr division, qui sont des agents européens.

Si vous prenez les cartes du Service géographique de l'Armée en Indo-Chine, vous verrez que j'ai réussi à y faire porter les réserves forestières. Vous verrez que chacune est désignée par un numéro, ce qui dorne le détail de ces divisions. Nous en avons actuellement près de 600.000 hectares. Pour chacune de ces réserves, j’ai un plan d'aménagement, comme en France.

J'estime que vraiment il appartient à l'Administration des Eaux at Forêts de France de trouver un moyen d'inviter ou même de forcer le Ministère des Colonies, qui parait se désintéresser de la question, à aller de l'avant.

Nous avions réussi, en Indo-Chine, à être dix agents de France: aujourd'hui nous ne sommes plus que quatre; on désire que je parte et ne pas me remplacer, alors que vous voyez combien il y aurait de places et de travail pour des conservateurs.

Je n'ai rien à ajouter. (Appluulissements.)

Et vous voyez les sommes formidables que représentent ces forêts. Nous n'arons jamais coúté un centime; au contraire, après douze ans de direction, j'ai fait entrer à peu près 15 millions dans les caisses.

M. Le Président. - Personne n'a plus d'observations à présenter sur les vreux du rapport?

Je mets ces voux aux roix.

Adoptés.

M. Capus, délégné dn Ministre des Colonies. - Monsieur le Président, je vous demande à prendre la parole.

M. le Président. - La parole est à M. Capus.

M. C.ıpr's. - J'ai l'honneur d'être près de vous le délégué du Ministre des Colonies; je voudrais me faire d"une façon particulière et approfondie l'écho de vos délibérations et lui apporter le résultat de ros votes.

Nous devons également adresser à MII. Chaplain et Unbdenstock nos remereiements d'avoir porté cette question devant rous et de l'avoir soumise à vos délibérations. 
Je voudrais appuyer près du Ministre des Colonies la réalisation prompte et brève de ce vou.

Vous avez entendu M. Roger Ducamp, mon collaborateur, dont je ne puis trop vanter la collaboration et le dévouement dans le Service de l'Indo-Chine, et c'est avec étonnement que j'ai trouvé récemment dans la bouche d'un parlementaire la qualification d'embryonnaire appliquée à son œuvre. Non, ce n'est plus un embryon, M. Roger Ducamp a pu vous le dire.

Dans les autres colonies, il n'existe rien, tout est à faire, et il est inutile de dire devant vous que ce ne sont pas les corps administratifs qui peuvent remplacer le technicien, le forestier, qui a reçu son instruction à l'École des Barres ou à Naney. Le forestier local ne peut remplacer l'officier forestier qui a puisé ses connaissances dans la métropole; par conséquent vous avez eu parfaitement raison d'adopter les vœux qui vous ont été soumis.

Encore une fois, je vous demande pardon de mon intervention; elle n'a d'autre but que d'appuyer d'un souhait très vif la réalisation des vœux que vous avez votés, que je présenterai à M. le ministre des Colonies, non pas dans un avenir lointain, mais immédiatement, comme étant d'une réalisation urgente. Car les vœux que vous émettez dans les Congrès sont souvent des clous sur lesquels il est nécessaire de frapper longtemps pour les enfoncer; nous formons des souhaits pour qu'il n'en soit pas de même de celui-ci, et qu'il aboutisse dans un avenir prochain.

M. Le Présinext. - Je vous remercie de volre aimable intervention, et suis heureux que vous vouliez bien être notre interprète auprès de M. le Ministrè des Colonies pour lui faire part de nos désirs.

La parole est à $\mathrm{II}$. Rey, pour son rapporì sur la Collaboration DES FORESTIERS AU SERVICE DE LA MÉTÉOROLOGIE AGRICOLE.

M. Rey. - Le Service de la Météorologie agricole réiemment créé au Ministère de l'Agriculture, près la Direction générale des Eaux et Forêts, a pour objet essentiel de faire profiter l'agriculture des données de la météorologie.

Daris ce but, il se propose:

a) D'assurer, dans la mesure du possible, un service de prévision du temps et d'avertissements agricoles;

b) De contribuer à l'amélioration de la production agricole et d'étudier la protection rationnelle des cultures contre les intempéries.

c) D'étudier l'influence des phénomènes atmosphériques sur la végétation et l'action inverse de la végétation sur le climat.

C'est la dernière partie de ce programme, relative à l'étude de l'action du climat sur la végétation et de l'action réciproque de la végétation sur le climat, qui semble devoir intéresser plus directement les forestiers.

En effet, depuis longtemps déjà de nombreux forestiers accumulent des observations météorologiques et notent les principaux phénomènes de la végétation; mais, il faut bien le reconnaître, cette documentation 
est tout à fait insuffisante pour permettre d'entreprendre les travaux d'ensemble qu'il serait désirable d'effectuer.

Il convient donc de coordonner et de compléter le réseau des observatious, afin de pouvoir fournir aux spécialistes intéressés les éléments indispensables pour des études scientifiques générales, qui, sans aucun doute, seront susceptibles d'applications, tant au point de vue teclinique qu'au point de vue pratique, en permettant de définir et de spécialiser les terres de vocation agricole, forestière ou pastorale.

D’autre part, le Service de la météorologie agricole a pour mission de procéder à l'étude méthodiqque des intempéries, en vue de l'organisation rationnelle des travaux de défense contre les fléaux atmosphériques. Il doit également, en vue de la prévision rationnelle du temps, effectuer l'étude détaillée des types de temps locaux et régionaux en fonction des situations générales de l'atmosphère.

Pour rempli' cette lourde tâche, le nouveau Service devra disposer d'observations météorologiques effectuées avec la plus grande rigueur en un certain nombre de points judicieusement choisis sur l'ensemble du territoire. Le corps des forestiers constitue une pépinière inépuisable d'observateurs de premier ordre qui permettraient d'assurer, dans les meilleures conditions, l'ensemble des études dont il vient d'être question.

Il convient d'ajouter que si la collaboration des forestiers au Service de la météorologie agricole semble tout à fait compatible avec les attributions de ces agents, elle promet en outre d'être des plus fécondes on résultats.

Dans ces conditions, il conviendrait que le Congrès forestier émît le vœu:

Que, dans le plus bref délai possible, soit déterminé dans quelle mesure le service forestier et le service de la météorologie agricole doivent collaborer en one de l'intérêt général.

Vous savez, Messieurs, que le Ministre de l'Igriculture constitue un service de imétéorologie agricole, qui a pour objet de faire bénéficier les agriculteurs des données de la météorologie.

Pour arriver à ce but, le Ninistre doit constituer un certain nombre de stations, divisées en quatre catégories :

1o Les stations de recherches;

20 Les stations régionales;

30 Les stations d'avertissement agricoles:

to Les postes météorologiques agricoles.

Les státions de recherches doivent, comme leur nom l'indique, effectuer des recherehes en vue de travaux d'ordre technique et d'application pratique.

Les stations régionales de météorologie agricole devront étudier dans chacune des régions agricoles la prévision du temps avec des applications locales. Ces stations seront documentées sur l'état général de l'aimosphère par des télégrammes envoyés d'un bureau central à Paris, et elles auront à dresser les cartes du temps par région pour foumir aux intéressés des avis.

Elles auront à étudier ce qu'on peut appeler les types de végétation 
en fonction des types du temps. Elles auront à déterminer les moments favorables pour telle opération, par exemple pour l'application d'un traitement anti-cryptogamique, dire pour une année donnée, à quelle date l'application du traitement contre le mildiou a été le plus efficace.

Les postes météorologiques, qui constituent le quatrième échelon, seront eonfiés à des agents de nature variée, ils devront recueillir les renseignements qui serviront au contrôle technique des stations de recherches, des stations régionales ou des stations d'avertissement.

Eh bien, cette organisation est à l'état embryonnaire, il s'agit de la développer.

La météorologie forestière est une partie de la météorologie agricole, et rous savez que ces études ont été heureusement poursuivies à l'École de Nancy avee des moyens que j'oserai qualifier de rudimentaires, puisque les ressources mises à la disposition des ehefs de service étaient si modestes qu'ils n'ont jamais pu leur donner d'envergure.

Il s'agit de savoir si la météorologie forestière est une question complètement vidée; ou bien s'il y a lieu de l'organiser pour lui faire rendre les résultats qu'on est en droit d'en attendre. Je vois là une collaboration utile du service météorologique agricole avec le service forestier.

Lorsque les stations régionales de météorologie agricole auront formulé des avis et les auront établis, ce travail préparatoire qui consiste à étudier le type du temps d'une région étant fait, il faudra contròler ces avis. Eh bien, les stations régionales auront besoin d'avoir à leur disposition un certain nombre de postes dans lesquels se trouveront des agents modestes, instituteurs, cantonniers, qui auront pour mission d'envoyer aux stations régionales des relevés météorologiqués permettant à la station le contròle.

De sorte que l'ensemble du problème se présente.de la façon suivante: Le service de météorologie agricole peut rendre des services aux forestiers et, d'autre part, le service de météorologie agricole a besoin des forestiers, parce que ces agents constituent une pépinière inépuisable de bons observateurs. On peut trouver là des gens tout à fait dévoués, d'autant plus intéressés à fournir de bonnes observations qu'elles seront contròlées d'abord par les stations de recherehes, puis par les stations régionales et même par le bureau central de Paris.

J'estime ınême que s'il y a lieu de leur demander un travail supplémentaire, il y aura lieu de leur donner une petite rémunération.

Il ne s'agit pas non plus d'avoir la collaboration de tous les agents, mais de déterminer dans chaque région les points sur lesquels il faut des documents.

Je ne m'étends pas darantage sur ces données, je suis prêt à fournir toutes les explications complémentaires qui paraîtraient utiles, et s'il n'y a pas d'objection de votre part, je vous proposerai de voter le vo'u que j'ai eu l'honneur de vous présenter.

M. Caqcet. - Less observations faites par II. Rey sont certainement 
intéressantes et judicieuses, mais sans m'opposer personnellement au vœu, je crains que nous ne dépassions nos droits, et aussi que cette sorte d'intrusion de notre part dans les affaires du Ministre, ne soit vue d'un mauvais øeil.

M. Le Présinent. - Je comprends les scrupules de M. Caquet, mais je ne erois pas que le Ministre de l'Agriculture puisse voir d'un mauvais reil les renseignements qu'on lui donnera, au contraire.

M. Lecog. - J'applaudis d'autant plus à ce vo'u que j'ai l'honneur de faire partie de la Société Météorologique de France et que, dans quelques régions déjà, Jes agents forestiers nous rendent de grands services.

A titre d'indication, je serais heureux que la question de la grêle fút signalée à l'attention des observateurs forestiers, pour savoir si, dans les régions boisées, les ehutes de grêle sont moditiées et moins dévastatrices que dans d'autres régions.

M. REY. - Je me rallie à votre proposition qui est implicitement contenue dans mon reu et que j'ai laissée dans le vague pour permettre aux spéeialistes d'indiquer leurs desiderata.

M. Lecog. - La forêt est un véritable paragrêle.

M. Cuif. - Messieurs, je suis chargé du service de la météorologie furestière à l'école de Naney et les forestiers sont en grande majorité mes collaborateurs pour les observations météorologiques que je poursuis aux environs de Naney, en Meurthe-et-Moselle, dans les Vosges, dans la Meuse, et depuis peu dans le Doubs et le Jura.

Je fais aussi partie de la Commission météorologique de Meurtheet-Moselle et, de ce eôté, là, les résultats obtenus sont des plus douteux. Pourquoi? Parce qu'elle ne rémunère pas ees agents, elle leur donne une médaille au bout de dix ans (Rires).

M. Rey. - Nous sommes d'aceord avee M. Cuif.

11. le lieutenant-colonel Renaro. - Messieurs, je m'excuse de prendre la parole au milieu de vous et de faire partie de votre Congrès forestier. Mais je m'intéresse très vivement aux questions météorologiques; j’en ai le droit et le devoir, comme président de la Soeiété Météorologique de France.

I'autre part, j'appartiens par profession à une catégorie de gens qui s'intéressent de façon particulière à la météorologie et à la prévision du temps.

Sous ce rapport, la météorologie a actuellement une bien mauvaise presse, on dit souvent qu'elle prédit le temps de la veille.

Il n'en est pas de même dans tous les pays du monde. Aux ÉtatsUnis, le journal qui correspond à notre Bulletin du Bureau Central 
Météorologique, que personne ne lit en France, porte un autre nom; il s'appelle le Journal des Fermiers. Tous les fermiers le reçoivent et aucun ñ'entreprendrait une opération sans le consulter; dans ce pays on croit aux prévisions.

Est-ce à dire que les Américains sont plus forts que nous? Non, les méthodes sont les mêmes ; tout le monde est d'accord pour dire qu'il y a une prévision générale, création, développement ou rétrécissement de dépressions, et leur marche de l'Est à l'Ouest, ou en sens inverse, et une prévision régionale qui consiste à tirer de ees indications des renseignements pour tel ou tel pays.

Mais les Américains, ou au moins ceux de la partie la plus civilisée, sont dans une situation éminemment favorable, parce qu'ils sont à l'extrémité Est du continent, et comme les phénomènes météorolologiques se propagent généralement de l'Ouest à l'Est, ils sont avisés de la Californie et des Montagnes Rocheuses de ce qui va se passer. C'est pourquoi le Journal des Fermier's donne des prévisions si justes et qu'il a pour lui l'opinion publique, tandis que nous ne l'avons pas.

Evidemment nous serons toujours à l'ouest du continent ancien, nos observations seront toujours plus utiles pour l'Allemagne et. la Russie que ne peuvent l'être pour nous celles de ces pays. Néanmoins il y a moyen de tirer meilleur parti de notre situation.

La télégraphie sans fil peut nous être d'un grand secours. On nous annonce par les câbles qu'une dépression quitte l'Amérique et vient à nous. Que devient-elle pendant qu'elle traverse l'Océan? Nous ne le savons pas; elle peut disparaitre ou s'aggraver; elle peut arriver en Afrique ou en Espagne - c'est le temps sec pour nous - ou dans les îles Britanniques - c'est le brouillard et la pluie.

Donc il serait important de savoir ce que deviennnent ces dépressions, de savoir si elles nous arrivent par le nord ou par le sud.

Il y a quelques années, on a dit : Comme nous n'arons pas d'ìles au milieu de l'Atlantique, nous allons mettre des postes en Islande et aux Açores. Quand le baromètre baissait en Islande, on attendait la dépression par le Nord, c'est-à-dire le vent d'ouest; si c'était aux Açores que la baisse se prononçait, on attendait la dépression par le Sud.

Ces renseignements étaient vagues, mais ils étaient précieux. Pendant quinze ans ce service télégraphique a fonctionné dans tous les pays civilisés, sauf pour la France.

Pourguoi? Parce que la France, assez riche pour payer sa gloire, n'était pas assez riche pour payer les 5.000 franes par an nécessaires pour recevoir les dépêches d'Islande et des Açores. Maintenant nous les recevons; le Parlement s'est convaincu enfin de leur utilité.

Aujourd'hui, avec la télégraphie sans fil, on pourrait nous envoyer tous les jours une dépêche météorologique, on pourrait suivre les dépressions de l'Amérique jusqu'en France, ce qui donnerait des prévisions locales plus sérieuses.

Depuis quelques années il y a une race nouvelle d'hommes qui s'intéressent aux prévisions du temps. 
De tous temps il y a eu les agriculteurs et les marins ; maintenant il y a les aéronautes et les aviateurs, qui risquent, non seulement de retarder leurs voyages, mais qui risquent leur vie.

$\mathrm{Si}$ on avait pu, il y a quelques années, être averti de la marche des dépressions, on aurait pu probablement éviter quelques catastrophes, et payer 15.000 franes quelques vies humaines, e'eût été un bon placement.

Pourquoi l'aviation, après avoir marché d'une façon si remarquable, semble-t-elle tombée dans le marasme? Parce qu'elle est trop dangereuse. Les militaires continuent, mais les civils ne s'y lanceront que le jour où la sécurité sera assurée. Cela arrivera dans quelques années; les prévisions météorologiques seront suffisantes. Mais dès maintenant, il y a tout un peuple d'aéronautes et d'aviateurs qui désirent avoir les prévisions météorologiques à leur disposition, et déjà 24 heures d'avance, nous savons actuellement comment les choses vont se passer.

On n'est arrêté que par des difficultés administratives qui n'ont pas l'air très importantes: la question de savoir si un service doit être rattaché à tel ou tel Ministère... L'un appartient au Ministère de l'Instruction publique, on lui dit: Tâchez donc d'améliorer la prévision du temps. On nous répond: C'est un problème qui n'a pas d'intérêt pour nous, nous nous oceupons de la physique du globe.

La physique du globe, savez-vous ce que c'est? Cela consiste à réunir les indications des stations météorologiques, à les donner dans des tableaux qui arrivent quelques années plus tard et qui sont envoyés aux établissements publics; ceux-ci les mettent dans leurs bibliothèques, où personne ne les consulte.

J'aimerais mieux savoir s'il pleuvra demain.

Mais, peu à peu, la force des choses est intervenue: les aviateurs avaient un tel intérêt à savoir qu'ils ont forcé les portes du Bureau Central Météorologique, et actuellement, tous les aéronautes et les aviateurs consultent les prévisions du temps.

Quand Brindejone a entrepris son merveilleux voyage de Paris à Varsovie, il ne l'a fait qu'après avoir pris des renseignements au Bureau Météorologique.

Donc les aéronautes et les aviateurs ont le plus grand intérêt aux renseignements météorologiques, et comme ils jouissent de la faveur populaire, ils pourraient nous rendre le service de donner une bonne presse à la météorologie, et peut-être obtenir l'argent qui lui manque. Pourraient-ils même peut-être fournir les 15.000 franes nécessaires pour avoir la télégraphie sans fil.

Il nous a done semblé qu'il serait utile de réunir les efforts des uns et des autres pour une entente. Et cette entente a pris jour dans cette même salle, où avait lieu une réunion de la Société Météorologique de France. On a constitué une commission mixte dans laquelle sont représentés les principales sociétés aéronautiques, le Ministre de la Guerre, ainsi que le Bureau central Météorologique.

Or, de puis la constitution de cette société, j’ai appris que le Ministre 
de l'Agriculture était en train de constituer un service météorologique. J'ai demandé sa collaboration par la désignation de délégués dans cette Commission, afin de coordonner tous les efforts.

Si je me suis permis de prendre la parole aujourd'hui devant vous, r'est que j'ai pensé qu'il était bon que vous sachiez qu'en dehors des agriculteurs et des forestiers, il y a d'autres personnes qui s'intéressent à la météorologie et, en appuyant les veux de M. Rey, je puis vous assurer de l'appui moral et de la collaboration de tous les météorologistes et des aviateurs. (Appluudissements.)

M. Le Président. - Je mets aux roix le veu de M. Rey.

Adopté.

M. le Secrétaire donne lecture d’une communication très intéressante de M. Rousset, sur un Projet de dispositioxs légales et de POLICE POUR LA CONSERTATION DES BOIS CONTRE LES INCENDIES.

M. Le Président. - Je crois que nous n'arons qu'à donnel acte à M. Rousset de sa communication.

Nous passons à la communication de M. Cuif sur la Météorologie COMPARÉ, AGRICOLE ET FORESTIÈRE.

M. Curf. - Si nous connaissions, pour chacune de nos grandes essences, les conditions climatiques dans lesquelles elle vit, connaissant d'un autre côté les conditions climatiques l'un pars, nous pourrions savoir à quelle essence il faut s'adresser de préférence pour aboutir à un succès. Il y a eu des erreurs sans nombre commises dans l'introduction des essences; la plupart de ces trreurs tiennent à ce fait qu'on n'a pas tenu compte qu'on changeait l'essence de climat. Il est done essentiel de connaitre les conditions climatiques de nos grandes issences.

C'est pourquoi je vous propose ce veu :

"Que la météorologie forestière prenne un nouvel essor et s'attache notamment à déterminer les conditions climatiques de la zone naturelle des principales essences $\%$

Vous voyez que ce voul est international. Je propose que ces études soient poursuivies d'une taçon tout à fait générale. Car s'il y a des essences américaines qui peuvent être intéressantes pour nous, il fant savoir dans quelles conditions climatiques elles se trouve dans leur pays pour les introduire dans le nôtre avec plus de chances de succès. Il y a donc là un intérêt pratique très grand.

M. Le Présinent. - Nous remercions M. Cuif de sa communication. te mets aux roix le voeu de .II. Cuif.

Adopté.

La parole est à M. Monnin, pour sa communication : Li convars-

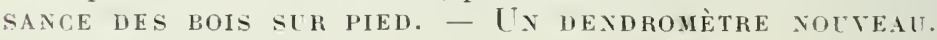

M. Monvix. - Le sujet est un peu spécial.

Le propriétaire forestier est soavent embarrassé quand il s'agit pour lui d'arheter ou de réaliser des plantations, de vendre une coupe. S'il lui est relativement facile d'établir les prix d'unités des diverses catégories de marchan- 
dises que fournit un peuplement, il éprouve des difficultés à connaitre le volume des tiges sur pied, et doit se fier au marchand de bois, an régisseur, ou bien adopter un tarif-ommibus dnquel il ignore la basede calcul ou l'opportunité Ie son application. Dans les perplements en croissance, il ignore l'accroissement des tiges, les modifications de leur forme, de leur manière d'être en concurrence avec les voisines.

Cette incertitude dans le cubage des arbres n'est-elle pas un obstacle à l'accès de la propriété lorestière pour ceux qui ament l'ordre, on simplement ont une légitime curiosité? C'est à ce point de vie que se place l'auteur de cette note pour vulgariser, en marge de la dendrométrie classique, des notions en partie noivelles sur le cubage des arbres sul pied et des peuplements ; aussi pour faire connaitre un dendrometre nouveau, donnant très simplement les hauteurs, les diamètres à tons niveaux, enfin les volumes pour lout niveau supposé médian.

Observations gévérales. - Rappelons d'abord que :

$1^{\circ}$ On n'a pas à cuber la tige entière d'un arbre juscqu'au bo:rgeon terminal, mais seulement la partie utilisable du tronc, de Iongueur $h$, variable avec la grosseur de la découpe au fin bout, laquelle est en movenne de $0 \mathrm{~m}$. 80 de tour pour le bois d'ouvre, $0 \mathrm{~m}$. 50 pomr la charpente résinense, $0 \mathrm{~m}$. 35 pour le potean télégraphique, 0 m. 25 poar le bois de mine, 0 m. 21 pour le bois de chauffage, 0 m. 06 pour la charbonnette. Theoriquement un arbre pourrait domner une série de hautenrs utiles, donc de volumes différents.

20 Commercialement, le volume grume d'un tronc, est égal au produit de sa hauteur par la surface de sa section à mi-hauteur, celle-ci étant calculée à

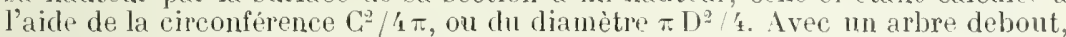
la dimension médiane est inaccessible ; on la déduit le la dimension à hauteur d'homme, D ou C, par une réduction de celle-ci. C'est lonc cette réduclion ou décroissance qui est à la base de toute estimation de bois sur pied. L'étude des lois de la décroissance n'a pas été faite; on se contente de quelques résultats expérimentaux, saus liaison les uns avec les autres. Nous en résumerons ci-après les dommées essentielles, que nous justifierons ailleurs, mais yui pourront ètre vérifiées par le lecteur, avec cette réserve toutefois que les lois mathématiques ne peuvent être que des moyennes, des indications forestières approchées.

$3^{\circ}$ Les volumes au $1 / 4$ sans déduction, all $1 / 6$, a $1 / 5$ déduits, correspondent à des bois équarris, dans lesquels le côté d'équarissage $q$ est égal au quart, soit de la circonférence médiane entière, soit de celle-ci préalablement diminuée de 1 6, 1/5. Le volume $q 2 \mathrm{H}$ est respectivement les $0,7854,0,5454,0,5027 \mathrm{du}$ volume grume. On pourra toujours passer de l'un à l'antre, et nous ne mentionnons ces cubages (spéciaux à la France) que pour mettre en garde contre les confusions intéressées du commerce des bois.

LA DÉcroissance. - La décroissance médiane des arbres pent s'exprimer:

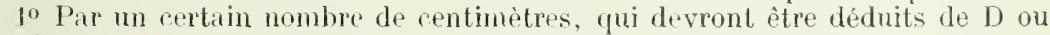
de C. pour obtenir $d$ ou $c$ à la hauteur envisagée; ce sera la décroissance par mètre de hateur; son étude ne se prète à ancune généralisation

$2^{\circ}$ Par une proportion selon laquelle levra ètre réduit D oll $\mathrm{C}$ pour obtenir d oir $c$ à mi-hautem. Cette proportion s'exprime souvent pour 100 unités, de I) ou de G, et s'énonce alors : decr. pour cent (\%), ou taux de la décroissance.

Cette dernière expression offre seule de l'intérèt: le taux $d$ de décroissance, pour toute hauteur utile, no descendant pas an-dessous de la moitié de la hauteur totale $H$ de la tige, peut s'exprimer par la formule générale $: d=\mathbf{K}(h-3)$, K étant une constante, pour le mème arbre, dite caractéristique, variable avec: $1^{\circ}$ la forme de l'arbre, notée par une certaine cote de défilement $F$ de la partie inférieure (dénudée de branches et par suite accessible aux regards ou anx mesures dendrométriques) dite fût; 20 la liauteur totale $H$ de l'arbre; et tel. que : $\mathrm{K}=\mathrm{F} / \mathrm{I}-3$.

I? ArBRE EN cas général. - I La forme des arbres a été rapprochée de celles des parabolö̈des de révolution, dont on a tiré la notion de coefficient de forme. 
Cette notion ne correspond à rien pour l'estimateur placé au pied de l'arbre. L’apprériation de la forme entière se fait par l'examen du fùt, et s'exprime par les locutions : arbre très bien filé, assez bien filé, mal filé ou en carotte. On dit aussi qu'un arbre est plus ou moins "plein de bois ».

Nous remplacerons ces expressions, fort arbitraires, par un chiffre, une cote F, telle que :

50 représente une forme conique.

30 (exactement 29,3 ) un paraboloïde ordinaire.

20 (exactement 20,6 ) un parabolö̈de cubique.

Ces cliffres n'ont rien d'arbitraire; ils représentent les taux de décroissance médiane des 3 types dendrométriques cités; ceux des types intermédiaires seront exprimés par des chiffres interpolés, de sorte que tout fût pourra comporter une cote prise entre 20 et 50, 35 étant une moyenne pour beaucoup d'arbres. Nous avons établi les concordances suivantes :

$\begin{array}{cccccccccc}\text { Coefficient } & & & & & & & & & \\ \text { de forme. } & 0.60 & 0.58 & 0.56 & 0.54 & 0.52 & 0.50 & 0.48 & 0.46 & 0.42 \\ \text { Cote F... } & 20.6 & 22.5 & 24.5 & 26 & 27.5 & 29.3 & 31 & 33 & 38 \\ \text { Coefficient } & 0.40 & 0.38 & 0.36 & 0.33 & & & & & \\ \text { Cote.... } & 41 & 44 & 47 & 50 & & & & & \end{array}$

A) Supposons que l'arbre puisse être noté par sa cote F, soit qu'on comnaisse son coefficient de forme, soit qu'on ait supputé directement, par une expérience acquise, son défilement. On calculera facilement la caractéristique $K$ par la relation $\mathrm{K}=\mathrm{F} / \mathrm{H}-3$.

B) Si l'arbre ne peut être coté, ou si sa hauteur est incertaine, l'instrumant de mesure doit intervenir ; nous donnons ci-après la description d'un dendromètre spécial.

A l'aide de celui-ci, on calculera directement le taux de décroissance: $d=\frac{\mathrm{D}-d}{\mathrm{D}}$ pour un diamètre médian $d$ situé à une hauteur $h$ comprise entre $1 / 2$ et $1 / 4$ de celle de la tige entière (celle du tronc correspondant est alors entre $\mathrm{H}$ et $\mathrm{H}_{2}$, cas dans lequel nous nous sommes placés au début). De la formule $d=K(h-3)$, on tirera $K=\frac{d}{h-3}$.

La caractéristique $\mathrm{K}$ ne sera prise qu'avec une décimale afin d'éviter une apparence de précision qu'elle ne comporte pas. En elle réside tout le secret de la décroissance des arbres, selon la hauteur utile envisagée - et aussi des peuplements. - mais sous réserve que cette hauteur soit au moins égale à la demi-hauteur de l'arbre; pour les formes coniques, cette réserve disparait.

Exemple : si un arbre de 20 mètres de haut est comparable à un paraboloïde cubique, sa cote de défilement est 20,6 , sa caractéristique 1,2 , la décroissance médiane du tronc découpé à 10 mètres est $1,2(10-3)=8,4$ ou $8 \%$; à 15 mètres : $1,2(15-3)=14,4$, ou $14 \%$; à 18 mètres : $1,2(18-3)=18 \%$.

Pour un cône, les chiffres seraient respectivement : $\mathrm{K}=5017=2,9 ; d=20 \%$, $35 \%, 52 \%$.

On remarquera que : $1^{0}$ la décroissance est, dans un mème arbrè, fouction de la hauteur $h$ diminuée de 3 mètres; dans des arbres de même forme, elle est, pour une même hauteur de tronc, inversement proportionnelle à la hauteur totale des arbres; $2^{\circ}$ elle est indépendante de la dimension de base, et son chiffre s'applique indifféremment à la circonférence ou au diamètre.

L'Arbre avec EMPATtement. - Il est des arbres qui ne sont filés qu'à partir d'un certain aiveau, au-dessous duquel ils présentent un empattement. Cette circonstance se traduit, dans l'expression de la décroissance, par une correction, dite taux d'empattement $\rho$ telle que $d=K(h-3)+\rho$.

harbre de futaie sur talllis, découpé en bois d'œuvre. Pour les réserves de taillis, et en particulier pour le chêne, il est difficile d'évaluer la 
hauteur totale de la tige, - de supputer le défilement d'un fùt souvent très court, - de comparer à un paraboloüde la tige en partie noueuse ou irrégulière.

Mais ici existe, pour une longueur de tronc correspondant à la découpe de .5 à 80 centimètres de tour, une relation entre $d$ et $h$, telle que $d / h=1$ à $11 / 2$, en moyenne 1,1. La formule précédente devient, quelle que soit la forme et la hauteur totale de l'arbre : $d=1,1 \mathrm{~h}$. On dira que 1,1 est la caractéristique spéciale à la découpe en bois d'ouvre des futaies sur taillis; elle varie d'ailleurs légèrement avec les régions et les essences. On pourra vérifier que le tronc de 5 mètres a $5 \%$ de décroissance; celui de 10 mètres $11 \%$; celui de 14 mètres $15 \%$

Le peuplement. - La réunion des arbres forme le peuplement, où les hauteurs, comme les formes, sont diverses. Néanmoins il se fait généralement une compensation sur le chiffre de la caractéristique, qui reste assez constante pour les divers arbres de peuplement; si elle n'est pas constante, elle est assez peu variable pour qu'on puisse admettre line moyenne, à augmenter ou à diminuer pour les grossenrs nu hauteurs extrèmes des arbres. Une telle caractéristique est beaucoup plus exacte que le coefficient moyen de forme, généralement admis pour le cubage des peuplements. Exemple : Dans un peuplement en croissance, les tiges dominantes ont une forme voisine du cône, ou tendent vers la paraboloüle ordinaire; mais les tiges dominées s'efforcent vers la lumiere, en portant tout leur accroissement vers le haut de la tige, et tendent vers le paraholoöde cubique. Les coefficients de formes varient dans des limites considérables; la moyenne est trop incertaine. Au contraire, avec les caractéristiques, le cliffre 4 correspondra aux arbres cotés 20 pour 8 mètres de lianteur totale, 28 pour 10 mètres; 36 pour 12 mètres; 38 pour lí mètres. Les décroissances en découleront de suite pour toutes hauteurs.

Il est injuste, comme on le fait dans certaines estimations de peuplement, en particulier de résineux, d'attribuer à tontes les tiges une décroissance uniforme, d'ailleurs arbitraire ou tirée d'expériences faites sans discernement des facteurs qui interviennent. Si l'uniformité existe, c'est généralement dans la caractéristique.

Celle-ci peut s'estimer directement dans an peuplement qui renfernie des arbres, non exceptionnels, de i mètre de tour à hauteur d'homme : on cherchera à évaluer, sur cet arbre de 1 mètre, l'angle entre les deux profils dı fût, - angle qui est aussi une expression du "filé " de l'arbre; à cliaque $1010^{\text {" }}$ correspond 1 unité de la caractéristique. Ainsi $4^{0} 40^{\circ}$ correspond à 4.

\section{NOUVEAU DENDROMÈTRE}

I cette occasion, pour ces cubages d'arbres, j'avais l'intention de présenter au Congrès un dendromètre nouveau. L'Administration a bien voulu l'exposer à l'Exposition de Gand, et il ne m'en reste qu'un exemplaire assez rudimentaire. Ce dendromètre domme les hauteurs, les diamètres à to:s les niveaux et permet de lire directement les cubes avec ume précision assez grande, il m’a donné tomjours de bous résultats.

J'ai profité de l'occasion pour vous le faire connaitre, m'excusant de vous dire : "Prenez mon ours ". I'aurais plaisir à ce qu'il intéressât certains membres du Congrès, et, si plusieurs d'entre vous voulaient le faire construire, il serait intéressant qu'on puisse le construire en série.

M. LE l'Résidext. - La parole 'st à M. Massot, pour une communication tendant à diminur les risques d'incendie des bois, présentée par la Société Forestière provençale "Le Chêne ".

M. Massot. - Je suis persuadé que, daus ce Congrès, toutes les mesures ont été envisagées pour mettre les arbres, les forèts et les bois, à l'abri de l'incendie ou pour le combattre. 
Je viens, au nom de la Société forestière Provençale "Le Cliêne ", vous proposer un vœu qui a pour but d'augmenter les chances de protection.

On ne voit pas bien la Provence sans pins et sans soleil!

Mais si nol's ne pouvons rien sur la nature, il est de notre devoir de nous employer à diminuer les inconvénients qu'elle nous procure, par une meilleure arlaptation des règles d'existence des populations provençales.

Notre action est encore trop récente pour que nous puissions faire appel à la statistique pour en mesurer les résultats. Un fait est certain : c'est l'attention publique éveillée sur la question, qui a motivé, de la part des Pouvoirs publics, le rappel des prescriptions légales dont le but est de réduire le nombre des incendies et, de la part des institutions privées, (sociétés excursionnistes et sportives, notamment), l'ouvertire d'une campagne contre les incendies dus à l'imprudence, au moyen de conférences spéciales à leurs membres associés. C'est une véritable éducation nouvelle qui commence, vigoureuse et prometteuse d'une splendide moisson.

A còté des mesures de prłudence sus-visées, se place la question de l'aménagement des bois. Celle-ci, stagnante aux environs de Marseille, où il reste beaucoup à faire, a fait de grands progrès parmi les propriétaires des vastes forêts des Vaures et de l'Estérel, où il n'est pas rare de rencontrer, disposés méthodiquement, les tranchées-parafeu et les sentiers protecteurs qui viendront, si c'est nécessaire, opposer leur nudité à l'envahissement du fléau dévastateur et réussiront à le localiser, réduisant ainsi ses effets désastreux. Les sous-bois sont aussi, dans cette région, mieux aménagés et converablement nettoyẻs.

La généralisation de cette méthode salutaire se fera par la persuasion et par l'exemple.

Mais il existe des errements condamnables qui devraient disparaître de notre civilisation.

Nous visons, ici, la partie des réjouissances publiques ou privées qui consiste à lancer dans les airs, au gré du vent ou de la brise, des fusées luminetises ou des ballons en papier, ou de toute autre composition, gonflés à l'air chaud et maintenus à la pression convenable au moyen d'une éponge imbibée d'alcool et enflammée au moment du lancement.

Si, au point de vue privé, le préjudice résultant de ces pratiques abominables peut être réparé en invoquant les articles 1382 et suivants de notre Code civil, il n'en subsiste pas moins que la preuve de la responsabilité est fort difficile à établir et que celui qui est lésé hésite presque toujours à la démontrer pour n'avoir pas, all préalable, à vaincre de trop nombreuses difficultés.

Que faire devant cette situation lamentable, car là, la persuasion et l'exemple sont inefficaces?

Après y avoir mùrement réfléchi, il nous paraît que, seule, l'intervention de l'État, sous forme de prohibitions desdits amusements, peut apporter le remède appropriẻ au mal que nous déplorons.

C'est pourquoi nous soumettons au Congrès Forestier International le projet de vou dont la teneur siit :

"Le Congrès Forestier International, organisé par le Touring-Club de France, et réuni à Paris du 16 au 20 juin 1913, justement ému des dangers que font courir aux bois certaines réjouissances publiques ou privées, telles que le lancement de FUSÉES ou de BALLONS PORTEURS D'ESSENCE ENFLAMMÉE, émet le veu que ce genre d'amusements soit prohibé par la loi et constitue un délit punissable comme tel.

M. LecoQ. - Certainement il y a du vraj dans ce que dit l'orateur: cependant une cause plus fréquente des incendies en forêt, ce sont les fumeurs et surtout les allumettes-tisons; le feu ayant commencé, couve et éclate une demi-heure après.

Une chose aussi qui n'est pas assez sévèrement réprimée, c'est 
l'habitude qu'ont les bergers, les bergères et les gamins de faire du feu près des peuplements.

M. MichaidD. - Je voudrais vous signaler le fait suivant :

Après les malheurs qui ont frappé la forêt de Fontainebleau, j'ai fait l'expérience qui consiste à faire brúler du papier avec du verre blanc. Je l'ai faite à Moulins, et le papier a fort bien brûlé, il a mis deux minutes à prendre, puis il a complètement brúlé. Je crois qu'on peut apporter un remèdle en surveillant les promeneurs.

M. Marcillac. - En qualité d'ancien aérostier amateur, je viens appuyer le voeu de M. Massot, car j'ai constaté les mêmes inconvénients que lui.

$1 l$ serait à souhaiter que les maires un peu mieux instruits comprennent qu'ils ne doivent pas autoriser le lancement de montgolfières.

D'ailleurs les mesures qu'on demande existent : il y a des règlements de police, il n'y a qu'à appliquer la loi.

Quant à ce que vient de dire M. Michaud, j'ai fait la même expérience. Les culots de bouteille en verre blanc forment lentille, et j'ai vu des incendies produits par cette cause.

Mais nous pouvons nous borner à demander l'application des règlements existants. Ainsi, contrairement aux règlements forestiers, j'ai vu des feux de charbonniers à 20 ou 25 mètres de la forêt, alors qu'ils doivent être à 200 mètres au moins. Cela, e'est visible. Eh bien, personne n'intervenait. 11 y avait à quelques hectomètres des gardesforestiers ayant toute qualité pour les interdire.

M. Le Président. - Alors nous rédigeons le voeu dans ce sens :

Le Congrès appelle l'attention des pouvoirs publics sur la néces. sité d'interdire l'emploi des montgolfières dans les fêtes publiques à cause des dungers qu'elles présentent pour les incendies de forêts. "

Alopté.

Nous passons à la communication de M. Girard: Les I Xeenifes EX FORÊTS.

M. Descoubes. - M. Girard n'a pas pu venir; je vais, si vous le voulez bien, résumer sa communication.

Jusqu'à ces dernières années, aucune étude spéciale n'avait été faite sur les incendies de forêts dont il n'existait aucune technique.

On se bornait à une prévention incomplète, et, lor'sque le feu venait à éclater, on le combattait par des méthodes différentes suivant les régions, inais toutes empiriques et plus souvent très dangerenses. La découverte de l'action réelle de l'eau, même en petite quantité, sur ces sortes de feux par M. Denigès, et la création de corps spéciaux de sapeurs-pompiers, nous ont conduits à la recherche d'une technique des incendies de forêts uniquement basée sur l'expérience des nombreuses extinctions allxquelles nous avons assisté. Le raisonne- 
ment et la pratique nous ont permis d'établir cette technique, exposée dans notre ouvrage: Les Incendies de Forêts, et que nous allons condenser en quelques lignes.

La défense contre l'incendie peut se résumer à trois choses : prévoir le feu, le prévenir et s'assurer de moyens pour le combattre.

11 importe d'attacher une très grande importance à la prévention. Elle est à l'incendie ce que l'hygiène est à la maladie.

La prévention consiste à sectionner la forêt en blocs séparés, au inoyen d'allées très larges (de 15 à 50 mètres) formant pare-feu, et chaque bloc en îlots à l'aide de passages de 3 mètres. Dans les régions montagneuses, la forêt peut être coupée par des pâturages et le boisement en damier doit ètre conseillé.

L'eau devant constituer l'unique agent d'extinction, il importe de préparer, à l'avance, l'utilisation des points d'eau naturels, d'en créer d'artificiels (puits, citernes, dépôts d'eau), et même de prévoir des transports d'eau.

Il faut nécessairement surveiller la forêt aux époques critiques, en la laisant parcourir par des rondes, ou mieux encore, en plaçant des vigies au sommet de belvédères dominant les bois, pylônes qui doivent être des sémaphores. avertisseurs, permettant de donner l'alarme dès l'apparition de la moindre funiée.

Le service de secours, organisé autant que possible par une permanence, comprend un corps de sapeurs-pompiers dont le personnel, entraîné et exercé, doit être en majorité recruté parmi les ouvriers travaillant habituellement er: forêt: L'absolue nécessité de corps de sapeurs,pompiers communaux a été reconnile.

Le matériel comprend des arrosoirs, des seaux, des pompes à main, des tonnes-pompes attelées, des outils de déblai et de destruction. On peut y adjoindre, en plaine, des tracteurs-automobiles de réquisition et des motopompes alimentaires.

Le matériel est appelé à varier selon les régions : en plaine, le matériel attelé ou automobile convient parfaitement; en montagne, les pompes à main (modèles Nos 1 et 2) scnt appelées à le remplacer, tandis qu'en terrain plat, et transportées par les sapeurs-cyclistes, elles concourent à l'attaque avec lui.

En principe, les appareils de secours les plus simples sont les plus pratiques et ils doivent être limités exclusivement à ceux que nous venons de citer. Nous ferons remarquer toutefois que la pompe à main, en asage du reste dans la plupart des corps de sapeur's-pompiers et notamment au régiment de Paris, rend des services inappréciables. Elle est à conseiller partout, car c'est uniquement sur elle qu'il faudra bien souvent compter dans les endroits difficiles.

Comment doit-on attaquer un feu en forèt? Si l'incendie ne présente qu'un foyer relativement peu étendu et si le fea n'a pas encore pris une direction de marche, la tactique consiste à l'entourer et à le serrer de plus en plus près en avançant constamment, tout en ne perdant jamais de vue les points susceptibles d'être directement menacés.

Dans le cas d'un grand feu, d'un feu venant de loin. c'est sur les flanes que doivent se porter les efforts, de facon toujours à resserrer progressivement l'incendit et à parrenir à atteindr la tête du feu. L'attaque du front n'est possible que lorsque les flanes sont déjà tenus.

Une attaque de fell en forèt demande des chefs énergiques, capables de se faire obéir de leurs sapeurs qu'ils doivent pousser en avant malgré la chaleur et la fumée, car il improrte d'aller très vite en abattant les flammes afin d'éviter les retours que pomrait provoquer une saute subite de rent. Les lances sont munies d'ajutages à jel unique droit et d'ajutages à jets multiples.

Le jour où toutes les communes forestières seront organisées, il n y aura plus à redouter les grands incendies tels qu'on en a trop souvent rus, car les secours arriveront toujours arant que le feu n'ait pris un développement considérable. C'est dans cette voie d'organisation qu'il serait du deroir des Pouvoirs publics, pensons-nous, de diriger les communes, et nous estimons que toutes les forèts peurent être défendues, du moins en France, par les 
INTERNATIONAL 1913

moyens que nous indiquons, lesquels n'ont cessé de donnel à lllac les meilleurs réstats et que nous nous efforçons tous les jours de perfectionner encore.

On ne saurait consacrer trop d'efforts à la protection des forêts contre l'incendie : les dépenses nécessitées par la prévention et le service de secours sont bien peu importantes, comparées aux pertes énormes que peuvent subir les propriétaires en quelques heures et les conséquences du feu sont encore plus graves, car l'incendie entraîne une diminution de la richesse nationale et est une cause de dépopulation des communes sinistrées.

M. Le Président. - Nous donnons acte à M. Girard de la communication qui vient de nous être faite.

La séance est levée à 11 heures. 


\title{
SEANCE DU 19 JUIN 1913
}

\author{
(APRÈS-MIDI)
}

\section{Présidence de M. EMERY, vice-président de Section}

La séance est ouverte à 2 li. 10 .

11. Le Présinext. - L'ordre du jour appelle la discussion du rapport de 11. Caquet sur la Capitalisation forestière.

La parole est à M. CAQIET pour la lecture de son rapport.

1I. Caquet. - La crise des menus bois est générale et connue de tous. Elle sévit, en France plus que partout ailleurs, pour de nombreuses raisons que vous connaissez aussi bien que nous-mêmes et au développement desquelles nous ne nous attarderons pas. Le grand et l'unique remède qui a été offert aux propriétaires de taillis, sous forme de conseil désintéressé, consiste dans ces mots : Laissez vieillir vos taillis et vos surtaillis.

"Les conseilleurs ne sont pas les payeurs ", dit un vieux proverbe, et les propriétaires de taillis actuellement dénués de tous revenus nets et dont les bois occupent en France les deux tiers de la surface forestière totale, en savent malheureusement quelque chose. En suivant ce facile conseil de laisser vieillir le taillis, on n'arrive qu'à titre très exceptionnel, à trouver dans l'exploitation de ces bois à 25 ans (âge qu'on doit considérer comme un maximum pour assurer la bonne régénération des souches), des rejets susceptibles de fournir des étais de mines, c'est-à-dire des bois d'industrie de la plus petite dimension.

Sans développer plus longuement les nombreuses raisons techniques qui s'opposent à l'allongement des révolutions de taillis et que rous connaissez tous, nous arriverons aussitôt à l'exposé des raisons dirimantes qui empêchent le propriétaire de taillis sous futaie, de conduire ses arbres réservés au delà d'un certain âge : de quatre-vingts ans environ, dans les meilleurs taillis.

Et pour établir cette démonstration qui a besoin d'être faite ici et renouvelée en présence des conseils cités plus haut et reproduits, sans discernement dans la presse à des milliers d'exemplaires, il nous suffira d'établir la comparaison entre le produit en argent de l'arbre aux différents âges de sa croissance, avec celui qu'on aurait obtenu en plaçant à intérêts, l'argent provenant de sa vente lors de la première coupe, supposée rase.

Nous adopterons pour ce calcul le taux normal de $4 \%$. Et, comme les brins réservés de l'âge du taillis sont des sujets de choir, sélectionnés dans 
l'ensemble de toutes les perches, nous les estimerons 0 fr. 75 pièce, comme cela est d'usage dans le centre de la France, au moins, région de taillis de chênes.

Nous prendrons pour type le chêne, dont l'augmentation de valeur en vieillissant s'accroit progressivement et plus vite que celle de toute autre essence. Ce qui sera vrai pour le chêne sera donc et à plus forte raison vrai pour les autres essences, résineuses et feuillues.

Nous supposerons l'aménagement du taillis établi à 16 et à 20 ans. C'est en effet, entre ces deux âges extrêmes qu'a lieu la base de l'aménagement habituel en France, au moins pour les bois particuliers. Nous supposerons qu'il s'agit d'un taillis de chênes, placé dans des conditions moyennes de qualité de sol, d'altitude et de climat et nous appliquerons la moyenne des très nombreuses mensurations que nous avons faites en vue de cette étude, les comparant à celles de nos exploitations personnelles depuis l'année 1880 et à celles qui nous ont été aimablement fournies par plusieur's sylviculteurs distingués auxquels nous adressons ici, un remerciement public.

Ces mensurations prises à 1 mètre du sol, nous ont donné les résultats suivants dans les taillis de 20 ans :

Pour le baliveau de l'âge, $0 \mathrm{~m} .284$ de tour sur écorce, soit $0 \mathrm{~m} .09$ de diamètre sur écorce et à peine $0 \mathrm{~m}$. 08 sous écorce.

Nous avons fixé son prix, -d'après l'usage du centre de la France, à $0 \mathrm{fr} .75$.

Les balivettes, soit les arbres de 40 ans ou âgés de deux révolutions, mesurent en moyenne $0 \mathrm{~m}$. 58 de tour, soit $0 \mathrm{~m} .18$ de diamètre sur écorce ou $0 \mathrm{~m} .165$ sous écorce. Cette balivette a $5 \mathrm{~m} .50$ utilisables en étais de $0 \mathrm{~m} .14$ à $0 \mathrm{~m} .09$ au petit bout. Or, ces étais, du prix de $0 \mathrm{fr}$. 25 ou 0 fr. 35 le mètre courant, rendus en gare ou sur canal et reçus par les Agents de la mine ou leurs préposés, subissent en frais de façon, de transport moyen au lieu de livraison, d'intérêts d'avances aux ouvriers et autres menus frais, $0 \mathrm{fr}$. 075 par mètre, défalcation faite du très minime bénéfice résultant de l'écorçage de ces perches et du menu bois fourni par la cîme. C'est done un prix net de 0 fr. 175 par mètre pour les étais de $0 \mathrm{~m} .09$ et de $0 \mathrm{fr} .275$ pour les étais de $0 \mathrm{~m}$. 14. Les types de $0 \mathrm{~m} .09$ et de $0 \mathrm{~m} .14$ de diamètre formant les deux types principaux d'étais de longueurs variées, auxquels peuvent se ramener tous les autres. Cette balivette type, peut fournir $2 \mathrm{~m}$. 50 d'étais à $0 \mathrm{~m}$. 14 au petit bout et 3 mètres d'étais à $0 \mathrm{~m} .09$; e'est done un rendement net de $1 \mathrm{fr} .11$ pour le propriétaire exploitant. Il faut défalquer de ce prix l'intérêt composé à $4 \%$ de 0 fr. 75 , prix dı baliveau conservé. Cet intérêt étant de 1 franc, ce serait done un gain définitif de 0 fr. 11, si l'on ne tient pas compte de la valeur de la cépée de remplacement.

Pour la cadette ou arbre de trois âges, nous avons une cireonférence moyenne de $0 \mathrm{~m} .869$ ou un diamètre moyen de $0 \mathrm{~m}$. 25 sous écorce. Ce chêne fournira une traverse de chemin de fer dans la bille du pied (de $2 \mathrm{~m} .80$ ) et 2 traverses vicinales dans le restant de la longueur, estimée en moyenne à $6 \mathrm{~m} .50$ au total. Défalcation faite du prix de façon qui est de 1 franc par traverse ordinaire et 0 fr. 50 par traverse vicinale, des frais de transport du parterre de la coupe au lieu de réception, gare de fer ou de canal, des avances faites à l'ouvrier, du r'cfus lors de la réception des dites traverses, refus dont le montant n'est pas inférieur à $5 \%$, ctc., nous arrivons au rendement net qui suit pour le produit de la cadelle : 
Façon de la traverse de joint..................... 1. "

Transport au lieu de réception..................... 0.60

Perte par refus de l'administration à la réception de la mar-

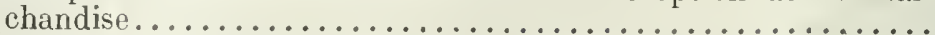

(Étant mentionné ici que la traverse rebutée est prise pour moitié de son prix normal.)

Intérêts des avances du façonnage de la traverse, à l'époque du

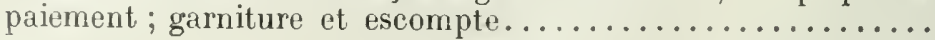

Total...... $\overline{\underline{1.80}}$

néfice net qu'elle nous laissera.

La traverse vicinale étant vendue $1 \mathrm{fr}$. 30 et les frais étant de moitié que ci-dessus, soit de 0 fr. 90 ; c'est donc un bénéfice de 0 fr. 40 qu'elle. nous laissera.

La valeur encaissée pour la cadette sera donc de :

2 fr. $30+2$ fr. +0 fr. $90+$ un demi-stère de chauffage produit par le cimier qui, a 7 francs la corde de 2 st 33 donnera, défalcation faite de la façon, un boni de 0 fr. 75 .

Soit au total : 5 fr. $95=2$ fr. $30+2$ fr. +0 fr. $90+0$ fr. 75 .

Mais si, de cette somme, on défalque : 10 l'intérêt perdu pendant 20 ans sur 1 fr. 11 , prix net de la balivette ; $2^{\circ}$ le déficit en sous-bois, par suite de la cépée absente, la balance ne laisse que quelques centimes en faveur de la végétation de la cadette.

Conservons done encore sur pied cet arbre de trois âges, pendant la nouvelle révolution de 20 ans.

Le chêne de 4 âges du taillis aménagé à 20 ans, appelé moderne dans l'usage du centre, ou ancien dans le langage purement administratif, a $1 \mathrm{~m} .362$ de tour ou $0 \mathrm{~m} .43$ de diamètre et 7 mètres de long, utilisable en bois d'œuvre. Au milieu de sa longueur, ce chêne a $0 \mathrm{~m}$. 38 do diamètre et mesure, au $1 / 5$ déduit, $0^{\text {m3 } 323}$ qui, à 50 francs le mètre cube, font $16 \mathrm{fr} .17$ auxquels il y a lieu d'ajouter un stère de bois de chauffage produit par le cimier; dans les conditions ci-dessus, c'est donc $1 \mathrm{fr} .50$ net à ajouter au total. $17 \mathrm{fr} .67$ représentent le profit net de cet arbre. Toutefois, il y a lieu de défalquer, comme ci-dessus, l'intérêt à $4 \%$ de $4 \mathrm{fr} .85$, pendant 20 ans, que nous aurions perçu si nous avions réalisé la cadette, augmenté du déficit ou sous-bois. Et le calcul nous force à conclure que nous avons intérêt à ne pas pousser plus loin l'expérience; car si nous maintenons cette moderne sur pied jusqu'à 100 ans, nous sommes en perte et sans faire plus complet calcul, nous nous en remettons à celui qu'a établi notre regretté maître, Ch. Broilliard, ancien professeur de sylviculture à l'Ecole nationale des Eaux et Forêts, qui ne fut pas seulement un écrivain forestier distingué, mais encore un bon praticien.

Dans son livre sur le "Traitement des Bois en France ", Ch. Broilliard nous dit (page 171 et suivantes et particulièrement par le tableau figurant à la page 173) “qu'iln'y a pas intérêt à conserver l'arbre de 100 ans, car la balance de la plus-value qu'il a acquise sur l'arbre de 80 ans, par rapport à l'intérêt de l'argent réalisé par le placement de la valeur de l'arbre de 60 ans, n'est pas en faveur de la végétation forestière. "La capitalisation forestière cesse done en moyenne à cet âge d'être avantageuse 
pour le chêne et à plus forte raison ne le serait-elle plus pour toute autre essence dont l'accroissement du revenu net annuel n'est pas aussi rapide.

Nous avons présenté les calculs ci-dessus quelque peu différents de ceux offerts au publie par certains auteurs qui ont eu surtout en vue de riches taillis de l'Etat ou des Communes qu'ils administrent. Nos calculs diffèrent aussi quelque peu de ceux de notre maitre Ch. Broilliard qui adoptait dans son ouvrage de 1894, le taux de $3 \%$ alors qu'aujourd'hui, c'est-à-dire 25 ans après, le loyer de l'argent a augmenté et qu'on doit le porter à $4 \%$ pour être véridique. Pour ces diverses raisons, et aussi parce qu'en maintes contrées de France, nos chênes ont subi de rudes atteintes du chef des coræbus bifaciatus, de l'oïdium et de l'excessive gelée de 1879-80 ainsi que des séeheresses anormales de 1893 et de 1911 et la rapidité de leur croissance s'en est gravement ressentie.

La plupart des ouvrages forestiers qui traitent la question de capi talisation forestière n'ont pu tenir compte de ces données.

Nous avons dû en faire état et c'est pourquoi nous sommes arrivés à fixer à 80 ans et non à 100 ans, à 4 révolutions de 20 ans et non à 5 , l'âge de l'exploitabilité des chênes réservés de nos taillis. Ce que nous venons de dire du taillis aménagé à 20 ans est vrai à fortiori pour le taillis aménagé à 16 ans, comme cela a lieu dans une notable partie des bois français; ear au lieu de 4 âgès, le chêne de 80 ans aura cinq âges du taillis, il aura été réservé une fois de plus et son allongement ainsi que sa croissance, loin d'avoir été favorisés par cette méthode, auront été singulièrement gênés par cette augmentation de coupes successives. Toutes choses égales d'ailleurs, dans un même taillis aménagé à 16 ans, la valeur des arbres réservés de 80 ans sera moins grande que dans le taillis aménagé à 20 ans. Notre démonstration appliquée au chêne de 80 ans dans les taillis aménagés à 20 ans est donc d'autant plus vraie dans les taillis aménagés à 16 ans.

Comme on ne saurait demander au propriétaire de bois de faire abandon de son intérêt particulier, c'est à 80 ans au plus tard qu'il devra couper ses réserves chênes. Et malgré que le prix du mètre cube de chêne augmente avec une prodigieuse rapidité suivant l'âge du sujet, la capitalisation-forestière est vite obligée de céder le pas à l'accroissement beaucoup plus prodigieux encore de la capitalisation-argent.

Dans eette lutte, la victoire quelque peu indécise dans les premières décades entre la végétation forestière et les intérêts accumulés, ne tarde pas à se dessiner nettement en faveur de ces derniers et si, par exemple, nous supposons un chêne de 2 siècles et d'un volume de $2^{\text {m3 }} 500$ au cinquième déduit (ou $5^{\mathrm{e}}$ en grume), valant 100 francs le mètre ou 250 franes, il ne pourra plus 'soutenir la comparaison avec la capitalisation de 0 fr. 75 du baliveau qui, an bout de 200 ans, aura dépassé le prix de 1.000 francs, sans compter la perte des recrûs qui ne peuvent être d'ailleurs évalués que par l'expérience et l'appréciation des rendements des taillis couverts, comparés aux taillis découverts. "T Tè̀s faible sous un tremble, dit Ch. Broïllard, cette perte est notable sous un balivean-chêne qui anéantit une cépée ", et nous ajouterons que sous un ehêne de 200 ans, cette perte équivaut au déboisement de trois ares environ de taillis.

Nous dirons encore que, cette victoire de la capitalisation-argent sur la capitalisation-forestière est d'autant plus éelatante sur les bois de chêne que ceux-ci augmentent progressivement dè valeur avec l'âge, à telle enseigne que : 
$1^{0}$ Dans le taillis de 20 ans, le mètre cube plein de brins de chêne au cinquième déduit, vaut au plus 1 franc, alors qu'à 40 ans, il vaut 10 à 12 francs; à 60 ans, 25 francs ; à 80 ou 100 ans, 50 francs et à 200 ans, il vaut 100 francs et plus, parfois 200 .

On a vu vendre 200 francs et même 300 francs, le mètre cube au cinquième, des chênes exceptionnels en longueur et diamètre, en accroissements réguliers et en bois sans nœuds et sans aucune tare, de nos belles forêts de France, de Tronçay et Moladier, dans le département de l'Allier, de Bellème et Bercé, etc. Même à ces prix très exceptionnels, si l'on faisait la comparaison, étant donné leur grand âge, entre la capitalisation forestière et la capitalisation des intérêts, celle-ci l'emporterait de cent coudées et d'autant plus que l'on devrait tenir compte de ce que ces arbres sont des exceptions notoires, à côté de tant d'autres sujets du même âge qui, blessés par le passage de charriots, dans leur jeunesse, atteints de quelque carie ou noueux, gelés, lunés ou roulés, dans le cours de leur végétation, n’ont été vendus qu’à des prix très inférieurs, quand ils n'ont pas dû être simplement débités en bois de chauffage.

Malgré les études faites par divers auteurs sur la croissance des arbres et quoique nous ayons personnellement étudié très consciencieusement ce sujet et fait de très nombreuses mensurations sur les arbres feuillus et les chênes notamment, nous croyons que la question de l'accroissement de nos différéntes essences d'arbres forestiers peut et doit encore faire l'objet d'expériences complémentaires pour être mise définitivement au point. Pour qu'il ne subsiste aucun doute sur cette supériorité que, jusqu'à preuve du contraire, nous considérons comme écrasante, de la capitalisation-argent sur la capitalisation-forestière, au bout de quelques décades à peine, nous proposons au Congrès forestier international d'émettre le rou suivant:

Que les administrations forestières de France el de l'étranger soient invitées à procoquer tous les renseignements des sylviculteurs mondiunx sur la croissunce des urbres forestiers;

Que les Bulletins officiels et de renseignements agricoles des diverses nations soient invités à les centraliser et à les publier, afin d'éclairer définitivement l'opinion publique égarée par les écrits d'anteurs qui, au lieu de prendre pour bases des données scientifiques ou expérimentales, se sont laissés gnider par des tendances personnelles ou une imagination trop facile.

M. Descombes. - Je me rallie entièrement aux vơux de M. Caquet qui est un ancien forestier, travailleur infatigable. Les voux qu'il propose sont rationnels et judicieux et ils devraient avoir reçu satisfaction depuis cinquante ans et plus.

Lorsque les travailleurs ont des recherches à effectuer, ils n'ont à leur disposition aucune publication officielle et ne trouvent que des renseignements épars, car la bibliothèque forestière n'est pas considérable.

Le capital qu'on met en reboisement est décuplé en moins de cinquante ans, ce qui fait un revenu remarquable de près de $6_{\%}^{\circ}$, car il faut tenir compte des intérêts composés. Ce résultat, qu'on m'a quelquefois reproché, je le maintiens, mais à une condition: 
c'est du revenu brut que je parle, du revenu du bois lui-même; si l'impòt vient prendre la moitié, les deux tiers ou les trois quarts de ce revenu, ou même ce revenu tout entier, ou une fois et demie ou une fois trois quarts, ce revenu, comme M. Gouget l'a montré ces jours derniers à la troisième section et comme il l'avait montré aux Agriculteurs de France et dans diverses publications, le revenu net diffère alors considérablement.

Il est désirable, il est indispensable que les administrations forestières mettent à la disposition du public des renseignements circonstanciés, précis, sur la croissance des arbres, sur l'avenir clu'on peut en espérer.

11. Le Président. - S'il n'y a pas d'autre observation, je rais mettre aux roix les voux tels qu'ils ont été rédigés par $M$. Caquei.

Arlopté.

11. Le Président. - Nous passons à une communication dé M. Marchal sur la SAUVEgarde des forets CONTRE L'INCENDIE PAR DES PLANTATIONS IGNIFUGES.

M. Marchal. - Il n'y a pas de question d'un intérêt plus universel, je pourrai dire plus mondial, que celle des incendies de forêts. On croit trop facilement que ce sont des questions locales, méridionales. Ceux qui ont yu un incendie dazs les Maures on l'Estérel - qu'on appelle les pays du feu, et qui sont malheurzusement bien dénommés - croient que c'est un fléau local, régional. D'au tres soat disposés à le croire régional aussi dans les Landes et dans quelques régions où les résineux dominent. C'est à cette occasion que je renourelle la constatation que le président M. Descombes a faite tout à l'heure, sur l'insuffisance des renseignements : il n'y a pas de livres, il n'y a pas de détails. Permettez-moi, à mon grand âge, de l'affirmer, j'en ai la preuve ici, j'ai fait le relevé de toutes les publications qui ont été faites dans la Resue des Eaux et Forêts actuelle et dans la revue qui l'a précédée - et elle est encore plus ancienne que moi, puisqu'elle date de 1842 - au sujet des incendies de forèts. C'est une admirable collection, rien n'est plus intéressant, rien n'est plus vivant; j'y ai trouvé la description la plus complète et la plus pariaite qui puisse ètre faite. Quatre-vingt-dix-neuf fois sur cent les études sonl faites par des professionnels des Maures, de l'Estérel, des Landes, quelquefois, rarement, de l'Algérie et de quelques autres régions; jy ai trouvé le relevé, fait par un vé.érable fonctionnaire, délégué du ministère de l’Intérienr, sur la période des incendies qui ont désolé l'Amérique et roilà tout. Jamais je n'ai vu nulle part un aperçu collectif qui puisse nous donner une idée d'ensemble des maux universels et prodigieux dont j'ai eu, non pas la certitude mathématique, mais la conscience, en parcourant les quelques listes que le hasard a mises sous mes yeux, outre celles que j'ai pu composer moi-mème par un moyen qui est à la portéz de tout le monde. C'est ainsi que j’ai relevé, dans trois jouraaux de Paris, les iacendies qui ont été sigaalés depuis quelques années dàns les Maures, l'Estérel et les La idos. Quelque fois aussi, les dépèches en signalent én Bretagıe, dars la Creuse, en Angleterre, en Allemagne. Cinquante, cent, deux-cents hectares à la fois sont détruits par un incendie qui éclate d'une faço.I terrible et inattendue. Il faut avoir découpé ces dépèches reçues quotidiennement dars les journeaux pour s'en rendre compte.

C'est dans les mêmes conditions qu'il y a deux ans, j'ai relevé dans l'édition parisienne du Vew-Vork Heruld, des résumés de journaux de New-York, 
avec quelques gravures à l'appui, où l'on cite les milliers d'hectares yui ont été détruits, les villes qui ont disparu, les trains qui ont été areètés, les régiments qui n'ont pu arriver an secolirs des malheureux, les familles entières anéanties, et comme rest en Amérique que ces choses se passent et qu'on y est précis, on résume les pertes par un chiffre. Ce chiflıe, évalué d'une façon moderate, - je me rappelle ce mot - fixe les pertes à cent millions de dollars pour trois semaines environ d'incendie. Cinq cents millions de franes, un demi-milliard! Je n'i, siste pas. Ce n'est pas moi qui ai inventé ce renseignement, je vous ai dit où je t'ai puisé (Applaudissements).

Ces indications sur lesquelles je re veux pas m’étendre davantage, vous donnent un aperçu de la proportion phénoménale, mondiale, universelle de ce fléau que nous n'avons pas assez apprécié!

En France, certes, - on l'a dit et répété sourent et on a raison - le service forestier a fait des choses quion n'a fait mulle part aillenrs, et on ne saurait trop proclamer ses mérites, mais on n'a pas fait d'étude générale. I telle enseigne, qre dans re pays, oi la statistique surabonde, on n'a pas fait de statistiques, d'incendies de forêts, sauf dẹuis cinq ans.

Dans ces cinq années, on a constaté qu'il y a annuellement, dans les forèts de l'État et les forèts privées, des pertes estimées deux millions et demi, trois millions et mème jusqu à cinq millions. Cela commence à comptel ! Je n’insis ta pas sur ces chiffres, je rous prie simplement de retenir leur caractèrénorme, auquel jaj ajouté quelques indications universelles qui rous montrent que ce péril grandit tous les jours

Nolis avous entendu res jours-ci d'excellents rapports où il était question de l'extension des forêts et notamment de l'extension facile des résireux. C'est la vérité, ils viennent très bien, exigent peu de travaux, peu de difficultés, et produisent rapidement, mais ils brîlent très facilement, de sorte quen augmentant les forêts de résineux, on angmente aussi dans des proportions tout à fait inaltendues et incommensurees, permettez-moi ce mot nouveau, le da ger des incendies.

Commrent naissent les incendies?

Oi) oublie trop qu'un des plus grands inslruments des incendies, c'est le chemin de fer. Nous ponrrions, sans critiquer personne, appeler collectivement toutes les compragnies de chemins de fer les "compagnies incendiaires".

Le rôle de la fordre est bien mesquin à coté de ces grandes coupables.

Mais le feu, quelle qu'en soit la cause, se propage par la ronverture.

Tous ceux qui ont vécu dans les régions d'Orient savent qu'il y a des végétaux dont la combustion est telle qu'elle s'oppose à l'incinération. à l'iuflammation, c'est le cas de plantes dont je rais vons parler. et notamment du cactlis et d'un certai nombre de plantes grasses. M. Grandot, le savant auteur, est arrivé à constater par l'analyse, que le cactus contenait jusqu'à 9/4 o d'eau. Il n'y a aucume espece d’industre, si helie qu'elle soit, qui soit arrivée à créer une honteille jdéale qui rontiemne un telle quantité de contenu en proportion du co. tenant. C'est vraiment un instrument idéal au point de vue de l'extinction.

Outre qu'elle est fraîche, cetle plante a une valeur alimentaire considérable.

L'objection princioale est que cette plante est une plante des pays chauds. Mais la nature et nos praticiens, nossimples jardiniers, même, sans aller jusqu'à nos savants, ont fait des choses beauroup plus fortes : la youka, plante qui remplit nos squares el los jardins mème dans les pays du Norl est une plante des mays chands : il a suffi de quelques années d'application par les marchands qui les ont vendues, oum les acclimater. 11 serait donc très facile de créer des espèces pal voie d'hybridation.

Le fait certain, constaté, est rue dans les régions hautes, non habitées des Apennins, on a trowié des ractus.

Je re cite ftu'a titre supplémentaire une autre plante grasse. le nesembrianthenum acinaciforme, ainsi nommé parce que sa feuille a la forme d'me lame de sabre. 
L'intérèt de cette plante réside en ce que, aussitôt qu'elle pousse, des radicelles, des racines adventives pénètrent dans le sol; c'est une plante superficielle qui couvre tout le sol et son ininflammabilité la rend très précieuse.

Au Muséum, il y a également des variétés de cédum, qui viennent des liautes montagnes du Tyrol et du Japon; elles peuveut être multipliées.

Plus près de nous, poulquoi ne nous adressons-nous pas au lierre vulgaire; on ne se l'imagine pas, parce que tous les traités officiels déclarent que le lierre est un parasite dangereux qu'il faut détruire. Voilà quinze ou vingt ans que je l'étudie et que je le soumets à des expériences.

La nature du lierre, contrairement à ce qu'on croit, n'est pas d'enrouler l'arbre ; c'est par erreur qu'on l'appelle edera helica; il n'a pas de forme hélicoïdale, il monte tout droit, mais pas avec des racines qui sucent, comme le déclarent habituellement des auteurs mal informés. Ce sont des crampillons qui n'atteignent pas la surface. On croit qu'il abîme les mur's; c'est une erreur. Dans des pays où l'esprit pratique est plus développé qu'en France, comme l'A igleterre et l'Amérique, on n'a jamais pensé cela. Les cottages les plus riches d'Angleterre et les grandes usines d'Amérique en sont converts depuis le sol jusqu'au sommet, parce que le lierre entrefient la liaicheur du mur et le préserve du soleil et de l'attaque directe de la pluie; il le préserve aussi des insectes, car les insectes ne mangent pas le lierre. Par contre, j'ai vu daus des pares où on avait oublié du lierre depuis ring ans, les bestianx manger le lierre plutôt que l'herbe des environs. La derıière paysanne de France sait rela et lorsqu'il n'y a plus de fourrage uulle part ou qu'il coute cher, on donne du lierre aux vaches polir les nourrir. Un savant, II. Isidore Pierie, a fait cette analyse et a trouvé que le lierre équivant au fourage le plus parlait. Un seul homme en a parlé, c'est M. Vilmorin, à la société des Igriculteurs de France, i) y a deux ans environ.

Voici un exemple de ce que peut donner le lierre; rous pouvez voin en certain point du parc Monceau un rideau de lierre au-dessous d'un bouquet considérable de maronniers. Le maromier donne des feuilles abondantes qui sèchent et recouvrent rapidement le sol; la grande feuille de marronnier après ètre tombée, sèche, se ratative et passe entre les feuilles de lierre qui, elles, restent fraîches et vertes toute l'année. Le lierié étalé, érigé en espalier, n'aurait pas les qualités que je vous indique : les feuilles qui se fanent sur un espalier s'aperçoivent et, lorsqu'elles sont fanées, elles tombent et sèchent. Or, dans les squares, et mème au Bois de Boulog e, rous se voyez jamais de fenilles de lierre mortes; il semble que cette plaite ne doive jamais mourir; c'est une erreur, mais aussitòt que les feuilles meurent, passent au second plan, des feuilles fraiches, prennent le dessus et recouvrent entièrement la partie fanée, la laissant ainsi à l'ombre et à la lrâ̂cheur.

Et je vous répète que le lierre a une valeur alimentaire de premier ordre, excepté toutefois pour les insectes qui ne s'y mettent pas, pour la raison bien simple qu'il y a une balistique du lierre couché : chaque feuille de lierre est dressée sur un pédoncule qui forme pivot; la feuille reste horizontale, très fréquemment proche d'une autre, de façon à former coquille, comme la coquille d'une carapace; comme tout est mobile, aussitòt qu'un insecte, une graine, une feuille morte tombe, il y a m espace vide dais lequel tombe l'insecte. En douze ans, j'ai vu en tout, deux petits escargots sur le lierre; ils n'y sont pas restés longtemps.

Les indications que je viens de vous donner vous montrent la valeur agricole, alimentaire et surtout défensive de certaines plantes. Les véritables maîtres de la doctrine forestière déclarent qu'ils défendent la forèt à cause de son ròle providentiel - j'ai vu ce mut écrit dans notre siècle - je le veux bien, et je ne prétends pas revendiquer pour les plantations dont je vous parle un rôle providentiel. Je m'occupe simplement de leur' rôle pratique,

Je voudrais que les expériences que j’ai faites fussenl imitées par les services de l'État, dans quelques-uns de ses domaines. Cos expériences peuvent ètre commenrées immédiatement dans le Midi et même étendues à quelques l'égions 
du centre de la France et, probablement, dans peu de temps, dans les régions du Nord.

M. LE Présinext. - Je suis convaincu que l'Administration des forêts ne demandera pas mieux que de tenter des expériences, surtout dans la région de la Provence, des Maures et de l'Estérel, par des plantations de cactus; ces expériences pourront amener des résultats utiles et intéressants.

M. Marchal. - Des expériences ont déjà été commencées en Algérie. Lll vou a été présenté par la Ligue de reboisement de l'Algérie en 1880 ou 1881. Le gonverneur général Cambon, qui a été frappé, comme l'était tout Algérien, de l'ininflammabilité matérielle évidente d'un certain nombre de plantes comme le cactus, a demandé qu'on en fit l'expérience. Mais on les a faites de telle façon qu'elles n'ont pas réussi du tout.

M. DEscombes. - Je puis d'ailleurs donner à M. Marchal l'assurance que les expériences qu'il demande ont déjà été faites. L'Association pour les montagnes, qui occupe dans les Pyrénées plusieurs milliers d'hectares tans lesquels elle réconcilie le montagnard avee l'arbre, a crée un type de lierre. On a fait un reboisement de 60 hectares dans la vallée, ce sont des résineux qu'on a mis et on les a garnis d'un iype de lierre planté depuis deux ans. Les expériences ont done déjà commencé.

11. LE Président. - Je donne acte à M. Marchal de sa communication et puisque nous sommes en matière d'incendie, je donne la parole à 11. de Montmorency-Morrès, qui a une courte communication à faire.

M. DE Montyorency-Morrès. - Je suis administrateur dı Syndicat général des propriétaires forestiers d'Algérie, où nous avons réuni 150.000 lıectares. Nous avons souffert beaucoup tlincendies pendant des années. Ces incendies sont dus à deux causes, les unes accidentelles, les autres volontaires. Les incendies accidentels ont été de peu d'importance : ils portent sur 50, 100 ou 200 hectares, c'est relativement pen de chose. Les ineendies volontaires, au contraire, on t porté sur des étendues considérables. Les incendies accidentels s'éteignent facilement, car les Arabes sont habiles et nous avons les moyens à notre disposition. Mais les incendies volontaires ne peuvent s'éteindre aussi facilement, car, dès qu'on réussit à en enrayer un, il y en a immédiatement d'autres qui s'allument. Les pouvoirs publics ont des moyens de réprimer ces incendies, c'est de poursuirre les incendiaires. Je sais bien que c'est assez difficile, mais on peut y arriver, et on obtiendrait de bons résultats en les punissant très sévèrement. La question est importante pour nous, car, en 1871 , ces incendies nous ont coùté près de 20.000 hectares; en 1881, nouveaux incendies considérables.

Je vous demande donc la permission de soumettre un vœu tendant à demander que les pouvoirs publics cherchent les auteurs des incendies volontaires et réprime de la façon la plus énergique.

M. Rotx, secrétaire. - Voici la teneur du veú :

"Considérunt les dommuges considérables qui résultent pour les 
propriétaires forestiers en général el pour les propriétaires forestiers d'Algérie en particulier, des incendies dus à la malveillance, le Congrès des Propriëtaires forestiers émet le vœu que les pouvoirs publics recherchent activement les antents responsables des incendies et lenr appliquent duns toute leur rigueur, les sanctions prévues par la loi. "

Adopté.

M. Le Présidext. - Je donne la parole à M. Narcillac, auteur d'une communication sUr : (TNE DISPARITION QUI COMHENCE. - LE MURIER.

M. Marcillac. - Le mûrier, qui avait été prodigieusement développé par Olivier de Serres, est en train de disparaître. Il y a à cela diverses causes. La principale est que le paysan $y$ voit de l'argent réalisable immédiatement. Quand on lui dit: "Vous faites une sottise, vous avez là une espèce de rente que vous pouvez toucher chaque année ", il répond : "Cela fait du bois, il y a de l'argent à toucher, mes fils feront comme moi, ils se débrouilleront. " Il est inutile de chercher à discuter avec lui, mieux vaudrait travailler le roc, Il faut donc se substitıer à lui, puisqu'on ne peut lui faire entendre raison, et il s'agit de savoir s'il y a quelque chose à faire. Voici les raisons que les modérés, les sages, nous opposent; ils disent : "les primes qui étaient très óle rées, - elles allaient jusqu'à 5 francs, - étant tombées à 20 ou 30 sous, nous ne trourons pas notre compte á faire l'élevage du cocon, nous n'avons donc pas intérèt à conserver le mùrier. "Tout autour de ces propriétaires de cocon, il y avait de nombreuses usines de soie : depuis l'Isère jusqu'au bas de la Dròme, c’était en quelque sorte semé de tissages; toutes ces usines ront disparaître si la matière première fait défaut. Les industriels de la région ont eu l'idée de combattre le mal et de le prévenir dans une certaine mesure en cherchant en Chine et au Japon les ressources nécessaires en matières premières. Seulement, ils ont constaté que les métiers chargés de soie irançaise donnent des fils d'une résistance parfaite et qu'au contraire les métier's chargés de soie de Chine donnent des mécomptes, au point qu'une ouvrière qui mènerait par exemple quarante broches avec de la soie francaise, n'en mèue rait que quinze avec de la soie de Chine. Cela tient à l'importation et à l'emballage. Il y aurait peut-ètre lieu pour les grands fabricants, de rechercher si l'on ne pourrait pas tronver un système d'emballage tel que la soie de Chine arrive bonne en France.

M. le Présinent. - Votre communication porte surtout sur la disparition dı múrier.

M. Marcillac. - On ne trouve pas, parait-il, dans le múrier de France, la matière à papier. Il y a un múrier japonais qui pourrait être rapidement introduit chez nous et qui mené à bien donne de bons résultats en tant que base du papier. Si done nos grands fabricants de papier voyaient dans le múrier quelque chose d'avantageux, le paysan. sachant qu'il va pouvoir vendre sa feuille de múrier, le recultiverait. Il y a là une crise forestière et une crise de soierie, les deux se tiennent, lorsqu'on combat l'une, on combat l'autre. C'est pourquoi je rous demande de vouloir bien adopter le vou suivant :

"Considérant que la destruction active des mûriers pourruit être enrayée sinon arrêtée par l'emploi des feuilles ou de l'écorce des branches: de ces arbres dans la fabrication du papier, le Congrès émet le sou que 
l'Administration. fasse rechercher anprès des principaux fabricants s'il n'y aurait pas lien d'employer les produits du mûrier concuremment uvec la fibre de bois et les chiffons. "

Adopté.

M. Le Président. - Il nous reste pour terminer notre ordre du jour, une communication de M. Michaud sur L'OISEAU ET LA FORÊT:

II. Michaud. - Avant de clòturer nos travaux, permettez-moi de prendre la parole en faveur d'un auxiliaire des plus précieux et des plus indispensables de la forêt, je veux parler de l'oiseau.

Il est grand temps, je pense, qu'on s'occupe de l'oiseau et qu'on arrète la guerre d'extermination dirigée contre lui. Après trente ans d'observation sérierse, je dis, en connaissance de cause, que tous les oiseaux sont utiles : l'oiseau est utile à la forèt pour la défendre et la forêt est utile à l'oiseau pour l'abriter. Je rais dire quelques mots sur les oiseaux insectivores.

$\mathrm{O}_{n}$ ne peut se faire une idée des massacres qui se pratiquent dans certaines régions de la France. Les oiseaux insectivores sont massacrés sans merci.

J'ai vu un individu prendre, au moyen de "pantes ", jusqu'à mille oiseaux par jour, des insectivores ou carnivores: J'ai vu, les larmes aux yeux, je puis le dire, des pinsons, des rouge-gorges, des fauvettes, tout espèces d'oiseaux les plus précieux massacrés sans merci.

Il serait grand temps que les pouvoirs publics supprimassent ces abus et ces massacres.

Je voudirais aussi vous dire deux mots sur deux oiseaux qui sont en voie de disparition. La buse est l'oisean exécré de beaucoup de chasseurs, de ceux surtont qui ne la con zaissent pas. Je puis vous assurer que la buse est un oiseau excessivement utile. La première fois que j'ai rencontré un nid de buses dans la Gironde, il y avait, je crois, près du nid, onze rats, des lézards, un écureuil, des vipères et, ce qui m’a étonné le plus, un renard d'eau fraîchement tué. La buse peut détruire, sans exagération, de 80 à 100 mulots par journée; on a quelquefois parlé de 500 , mais c'est une exagération. En tout cas, un couple de buses peut facilement détruire 150 mulots par jour, sans compter les reptiles, car on dirait que la buse a été créée pour tuer les reptiles, et Dieu sait s'il y en a dans la Gironde.

L'antre oiseau dont je veux vous parler, vous le connaissez tous, mais il se fait rare, c'est le grand duc.

Cet oiseau dévore une quantité innombrable de vipères, d'écurenils et de rats. Et vous savez que le rat est le pire ennemi des oiseaux; il en détruit de toute espèce et il y a ici des congressistes qui mont dit que, depuis des années, ils sont empestés par des rats, si je puis ainsi m'exprimer.

Je vous demanderai donc de vouloir bien adopter les trois voux que j'ai l'honneur de vous présenter, et qui sont les suivants :

"10 Que dans l'enseignement sylvicole, des leçons soient faites sur le rôle réciproque de la forêt et de l'oiseau l'un envers l'autre, l'oiseau protégeant la forêt contre l'insecte, la forèt offrrant refuge ct abri à l'oiseau. "

" $2^{\circ} Q u^{\prime} \dot{a}$ la fêtc de l'arbre soit adjointe une fête de l'oiseau. "

" $3^{\circ}$ Que dans les réserves nationales et pares nationaux, des mesures soient prises pour la multiplication et la protection des oiseaux utiles ou des espèces rares et en voie de disparition. "

II. Villatte des Prignes. - L'année dernière, une commission temporaire, nommée par MI. Pams, alors ministre de l'Agriculture, s'est 
réunie en vue de faire la classification des oiseaux. Il y avait bien eu, en 1902, un Congrès général où on a classé une certaine partie des oiseaux, ceux qui intéressaient lous les pays, mais il en restait un certain nombre qui n’étaient pas classés. Lans cette commission temporaire se trouraient des ornithologistes de tous les coins de la France, comme M. Xavier Raspail, M. Labodenne, etc. Cetie commission a établi une classification absolument complète; elle n'a ienu que trois séances, mais les personnes qui étaient là étaient compétentes et on apporté des faits, conme le prince d'Arenberg, par exemple, qui, depuis des années, a fait des études très complètes sur la crécerel et qui en a apporté les résultats à la Commission.

Nous avons fait à la suite de cela une classification excessivement sévère et très peu l'oiseaux ont íté déclarés nuisibles, comme le petit geai, parce que c'était incontestable; on ne peut pas signaler un seul bienfait de cet oiseau qui ne commet que des dégàts. Le Ministère de l'Agriculture possède deux rapports de M. Menegaud, du Muséum, sur les traraux de cette Commission. Ces deux rapports dorment dans des cartons, paree que le Midi s'est soulevé comme un seul homme quand il a su que nous arions protégé tous les petits oiseaux d'une façon invariable. Nous nous sommes dit en effet que si nous faisions quelques exceptions, ce serait la mort de tous, et s'il y en a qui peuvent commettre quelques petits dégâts, ces dégâts sont probablement rachetés par des arantages considérables. Le Micli s'est done levé et a fait intervenir ses députés, de sorte que les rapports ne sont pas publiés parce que leur publication gênerait cette région.

Je propose donc que nous émettions un vou par lequel nous demanderons la production de ces rapports, et nous exprimerons le désir qu'on tienne compte de leurs eonclusions.

Je puis vous donner un exemple des raisons qu'on invoque pour la destruction des oiseaux : pour l'étourneau, la commission avait été unanime à déclarer qu'il était un oiseau utile. Cet oiseau commei quelques dégats, il mange bien quelques grappes de raisins au moment de la vendange, mais ces dégâts sont très largement compensés par les services qu'il rend. Vous ne pourriez jamais deviner pour quelle raison la destruction de l'étourneau a été autorisée par le Ministère de l'Agriculture. Parce qu'on l'a accusé de propager la fièvre aphteuse."(Exclamations et rires.) Des gens avaieni envoyé des parlementaires pour se plaindre au Ninistère que l'étourneau propageail la fièvre aphteuse, et c'est ainsi qu'on en a autorisé la destruction. Ce fait est au rapport. Dans ces conditions-là, on pourrait déclarer que la fauvette, le rossignol et tous les oiseaux qui émigrent en Égypte, en Turquie, dans des régions où le choléra, règne à l'état endémique ainsi que la peste, sont des propagateurs du choléra et de la peste, et la destruction de tous ces oiseaux devrait être autorisée.

Je vous demande done de vouloir bien ajouter aux voeux de II. Michaud, celui par lerquel nous demanderons que le rapport de la Commission temporaire instituée au Ministère de l'Agriculture soit 
publié dans le plus bref délai, et qu’on en tienne compte pour empêcher la destruction des petits oiseaux.

Je ne suis pas tout à fait de l'aris de M. Michaud sur le grandduc : e'est le seul oiseau nocturne que nous avons déclaré nuisible. Pour le chat-huant, on a bien cité quelques méfaits dont ils étaient les auteurs, mais on a trouvé qu'après tout ce n'était pas absolument prouvé, et qu'en tout cas, ces méfaits étaient largement compensés par la destruction d'un grand nombre de mulots ou de rats et nous n'avons pas voulu mettre le chat-huant hors la loi.

II. DE SEgoxzac. - J'approuve entièrement deux des voux présentés par M. Michaud, mais je demande qu'on ne vote pas celui qui est relatif à la fête de l'oiseau parce que nous ne nous sommes pas associés à la fête de l'arbre. Je ne vois done pas l'utilité de ce vœu. La question importante pour nous est d'émettre un veu en faveur de la conservation de tous les oiseaux utiles sous toutes les formes, comme, vient de l'expliquer M. Villatte.

11. Villate oes Prugnes. - Pour donner satisfaction à M. le Président, nous pourrions rédiger le vou en remerciant le Ministre d'avoir pris l'initiative de terminer la classification complète des oiseaux, et en émettant le voeu que les rapports de la Commission soient mis à exécution.

11. Le Présinent. - Ayez l'obligeance de remettre une rédaction au bureau.

Je soumets à votre approbation les voux de M. Michaud :

"10 Que dans l'enseignement sylvicole des leçons soient faites sur le rôle réciproque des forêts et de l'oiseun l'un envers l'autre, l'oisean protégeant la forêt contre l'insecte, la forêt offrant refuge et abri à l'oisean."

Adopté.

"20 Qu'à la fête de l'arbre soit adjointe une fête de l'oiseau. " Repoussé.

" $3^{\circ}$ Qune, dans les réserves forestières et parcs nationanx, des mesures soient prises pour la multiplication et la protection des oiseanx utiles ou des espèces rares et en voie de disparition. "

Alopté.

" 'o Le Congrès remercie . I. le .Ministre de l'Agriculture de l'henreuse initiative qu'il a prise en nommant une Commission pour la classification des oiseaux en espèces utiles et nuisibles et émet le rou que le résultat des travanx de cette Commission soit porté le plus promptement possible à la connaissance du public.

M. le Présinent. - Ne vous parait-il pas utile d'émettre le rou 
qu'une classification définitive soit adoptée; ce serait plus complet et plus net que de demander simplement cqu' on communique au public le résultat des travaux d'une Commission.

M. Roux. - Nous pourrions demander une classification basée sur ces travaux.

M. Villatte des Prigres. - Voici le texte du ven tel que je vous le propose :

"Remercie 1\%. le Winistre de I'Agriculture de l'heureuse initiative qu'il a prise en nommant une Commission pour la classification des oiseaux en espéces utiles et nuisibles et émet le vœu qu une classification basée sur les travaux de la Commission soit établie le plus tót possible. "

Adopté.

La séance est levée à 4 heures. 



\title{
DEUXIEME SEGTION
}

\author{
EGONOMIE ET LÉGINLATION FORESTIERES
}

\section{BUREAU :}

Président: $\quad$ M. Vivier, conservateur des Eaux et Forèts; directeur de l'École nationale des Eaux et Forêts.

Vice-présidents : MM. Bouvet, président de la Société foresticire de Franche-Comté et Belfort.

F. Deroye, conservateur des Eaux et Forêts, docteur en droit.

Secrétaires : MM. DE Movcuy, inspecteur-adjoint des Eaux et Forêts.

Delahaye, inspecteur-adjoint des Eaux et et Forêts, docteur en droit.

Perrin, inspecteur-adjoint des Eaux et Forêts.

RAPPORTEURS: MM.F. DERoye, conservateur des Eaux et Forêts, docteur en droit.

G. HuFFEL, sous-directeur et professeur d'Economie forestière à l'Ecole nationale des Eaux et Forêts.

Ch. Guyot, ancien directeur de l'École nationale des Eaux et Forêts.

R. Roulleau, conservateur des Eaux et Forêts en retraite, secrétaire général du Comité des Forêts. 
RAPPORTEURS: MM. ArNotld, inspecteur des Eaux et Forêts.

Margarie, inspecteur des Eaux et Forêts, vice-président de l'Union des Syndicats agricoles, horticoles et riticoles de la Marne.

Vivier, conservateur des Eaux et Forêts, directeur de l'École nationale des Eaux et Forêts.

Comte de Nicoldy, président du Syndicat des propriétaires forestiers de la Sarthe.

MADELIx, inspecteur des Eaux et Forèts, docteur en droit. chef de section à la Direction générale.

Villame, secrétaire de la Fédération des Syndicats du commerce des bois de France et des industries qui $s^{\prime} y$ rattachent. 


\section{SEANCE DU 16 JUIN 1913}

\section{(MATIN)}

\section{Présidence de M. VIVIER, président de Section}

Lat réance est ouverte it 11 h. 5.

11. ef Présidext. - Avant d'ourrir les travaux de la deuxième section du Congrès forestier, je me permettrai de renouveler les souhaits de bienvenue qu'adressaient tout à l'heure, aux membres étrangers, M. I Ministre de l'Agriculture et M. le président du Touring-Club. Nour serous très hemreux de recevoir les idées qu'ils voudront bien nous donner au sujet de la manière dont on comprend, à l'étranger, lequestions d'économir? et de législation forestières, et j'espère qu', de leur côté, ils troureront utilité et profit à nos délibérations.

J'adresse le salut le plus cordial à tous ceux des congressistes qui veulent bien préférer notre réunion - au programme un peu austère à des sections plus attrayantes. Ils comprennent toute l'importance des questions qui vont se traiter ici et qui peuvent avoir des réperassions considérables au point de vue de l'avenir de la propriéti forestière.

Tous, Messieurs, qui que vous soyez, propriétaires forestiers, techniciens des diverses eatégories, fonctionnaires, vous êtes à mêm. d'apporter une utile contribution à nos discussions dont l'animation probable n'exclura pas, j'en suis convaincu d'avance, la plus parfaite courtoisie. Vous pouvez être assurés que le bureau s'efforcera, dans la mesure du possible, de diriger et d'éclairer vos délibérations th j'espère que, d'une collaboration commune, naitra une ourre utile it féconde (Applaulissements).

J. donne la parole à notre vice-président, M. Deroye, pour la locture de son rapport sur les Assurances contre L'INCExIIE.

II. F. Deroye. - L'assurance des forêts contre l'incendie préoceupe depuis de longues années les propriétaires forestiers en France, mais n'est pas ou que fort peu pratiquée.

La plupart des Compagnies à primes fixes ont un même tarif et des clauses semblables. Le premier est prohibitif ; les secondes sont absolnment défavorables aux assurés. Quant aux Compagnies d'assurances mutuelles pour risques de l'espèce, on bien elles n'ont pu arriver à se 
constituer, ou bien elles fonctionnent avec les mêmes errements que les Compagnies à primes fixes.

M. Fernand David, ancien Ministre de l'Agriculture; déclare, dans un de ses remarquables rapports sur le budget de l'Agriculture, que le risque d'incendie en forêt est eonsidérable et qu'on ne saurait lui opposer un système d'assurances, tant que les Compagnies seront inaccessibles et les Mutuelles impraticables. Il préconise donc la formation d'associations syndicales, conformément à la Loi du 13 décembre 1902, pour réaliser la défense préventive qui est, à son avis, la seule pratique en la circonstance. Cette défense aurait pour but de réduire au minimum la part du feu par des aménagements dont nous trouvons de précieux exemples en Provence et dans les Landes. M. Fernand David ajoute qu'il semblerait très justifié de faire participer ces travaux aux subrentions accordées par l'Etat pour les améliorations agricoles.

Se plaçant à un point de vue similaire, M. Louée, d'une part, MM. de Liocourt et Pardé, d'autre part, ont étudié les bases de Syndicats forestiers pour l'administration et l'exploitation rationnelle des bois particuliers, comme aussi pour la réduetion des risques d'incendie.

Un infatigable travailleur, M. Paul Descombes, président de l'Association centrale pour l'aménagement des montagnes, demande qu'une loi autorise l'assurance par l'Etat des forêts contre l'incendic, en faisant remarquer que cette solution complèterait de la plus heureuse façon les lois tendant à favoriser le reboisement.

En Allemagne, afin d'encourager les entreprises d'assurances privées à assurer le risque d'incendie des forêts, l'office impérial d'assurance a publié un modèle de contrat pour la garantie de ce risque. Ce modèle détermine les droits et les obligations des parties au moment de la conclusion du contrat, durant son exécution et après le sinistre. Alors qu'en 1900 il n'existait en Allemagne qu'une seule société d'assurances contre l'incendie couvrant les risques forestiers, actuellement de nombreuses sociétés privées et plusieurs instituts publics provincianx d'assurances s'en occupent.

Nous pensons que les associations syndicales préconisées par M. le Ministre Fernand David et par MM. de Liocourt, Pardé et Louée pourraient en même temps être constituées en Sociétés ou Caisses d'assurances mutuelles agricoles, conformément à la Loi du 4 juillet 1900, et cette solution pourrait, dans bien des cas, rendre de réels services.

Il n'en est pas encore de même de l'assurance par l'État. La commission de réorganisation du service forestier qui a fonctionné en 1912 ne l'a pas envisagée dans ses études relatives aux bois particuliers. Ce procédé soulève la grave question de l'immixtion de l'État dans le domaine des assurances-incendie et donnerait très vraisemblablement lieu à des protestations de la part des Compagnies.

Nous en revenons done à demander pour le moment la garantie des forêts contre l'incendie à des Compagnies ou à des Caisses d'assurances, comme en Allemagne. Cette solution admise par la Société française des Amis des Arbres, par la Société forestière de Franche-Comté et Belfort, par de nombreux forestiers et publicistes, semble maintenant assez étudiée pour pouvoir être réalisée.

Une statistique très complète des incendies dans les forêts soumises 
et non soumises au régime forestier est établie depuis 1908 par l'Administration des Eaux et Forêts. Les résultats en seront d'un grand secours pour la mise au point définitive de la question.

Il convient, pour commencer, d'arrêter les principes rationnels et équitables qui devront être proposés aux Compagnies pour l'établissement des contrats d'assurances et le règlement des sinistres.

N'oublions pas, en effet, que si d'un eôté les propriétaires persistent, à juste raison d'ailleur's, à ne pas s'assurer, de l'autre côté les Compagnies d'assurances attendent pour modifier leurs conditions qu'il leur soit présenté une étude sérieuse de la question. En même temps les Caisses d'assurances mutuelles agricoles de la Loi du 4 juillet 1900 trouveront dans cețte étude les renseignements nécessaires pour leur adaptation à l'assurance forestière.

Nous allons donc examiner pour les différents points de l'assurance comment opèrent les Compagnies et ce que nous sommes d'avis de leur proposer :

SYstème ACTUEL. - Les Compagnies n'assurent en principe que les forêts feuillues (taillis et taillis sous futaie) ne contenant pas plus de 1/10

(objet de l’assuralle. de résineux en mélange. Elles acceptent parfois l'assurance des plantations résineuses, à condition qu'elles soient âgées de plus de dix ans, et dans le Nord et le Centre de la France seulement.

Elles font des difficultés pour assurer l'ensouchement.

Elles refusent d'assurer l'ensemencement.

Elles ignorent complètement la couverture morte.

Système Proposé. - Les Compagnies devront assurer :

Dans les forêts feuillues:

10 Le taillis,

20 Les réserves,

30 L'ensouchement,

$4^{0}$ La couverture morte.

Dans les plantations résineuses :

$1^{\circ}$ Les plantations,

$2^{\circ}$ L'ensemencement,

$3^{\circ}$ La couverture morte.

Srstème actuel. - Les Compagnies ne donnent de règles qu'en ce qui concerne les taillis et ces règles sont basées sur des principes compliqués, incomplets et erronés. Il n'est jamais question de l'estimation des réserves non plus que de celle du capitảl relatif à l'ensouchement et à la couverture morte. Enfin l'application des susdites règles aux plantations résineuses est totalement impossible.

\section{SYsTÈme Proposé. - Il conviendra d'évaluer le capital à assurer :}

$1^{\circ}$ Pour le taillis : En calculant la valeur des coupes des différents âges par la méthode des annuités ;

$2^{\circ}$ Pour les réserves : En classant les arbres par eatégories d'après leurs dimensions et en déterminant pour chaque catégorie la valeur de l'arbre moyen et la moyenne du nombre de pieds à l'hectare ; 
$3^{\circ}$ Pour l'ensouchement: Par la somme nécessaire pour reconstituer par voie de plantation l'état boisé supposé complètement détruit ;

$4^{\circ}$ Pour la couverture morle: Par la somme nécessaire pour réeupérer, au moyen d'engrais appropriés, la quantité de matière fertilisante que renferme cette couverture ;

jo Pour les plantations résineuses : De façon à rembourser au proprié taire le montant de ses frais de plantation et de ses pertes d'intérêts sur la valeur du sol et les frais de plantation. La somme à rembourser augmentant chaque année, il faudra ealculer séparément le capital à assurer pour chacune des années de la police;

$6^{\circ}$ Pour l'ensemencement : Comme s'il provenait d'un boisement artifieiel, en tenant compte de sa densité et de son âge.

l'rime d'assurinceannuelle.

Ialcui du dommage ell ca rincendie.
Systìme ACtuel. - Pour les taillis et taillis sous futaie, les Compagnies demandent en général une prime de $0 \mathrm{fr}$. $75 \%$.

Pour les plantations résineuses, les tarifs varient suivant les âgres, entre 1 et $10 \mathrm{fr}$. pour 1.000 francs de capital assuré ou bien entre $0,09 \%$ et $4 \%$ de la valeur à l'hectare, réglée d'avance par la police.

SystèMe proposé. - $1^{\circ}$ Une prime, établie par région, fixe pour les feuillus et variable suivant l'âge pour les plantations résinəuses ;

$2^{\circ}$ Une augmentation de cette prime d'un ou plusieurs dixièmes, proportionnellement aux risques supplémentaires qui pourraient exister (proximité des voies ferrées ou d'habitations. Carbonisation des produits. Absence de tranchées, etc.).

Système ictúel. - Les Compagnies évaluent le dommage en cas d'incendie :

Pour le taillis: Par une simple proportion établie en fonetion de son âge réel et de la valeur qu'il aurait à l'âge usuel de la coupe; puis elles diminuent la somme trouvée d'un eseompte de $4 \%$ pour autant d'années qu'il reste à courir jusqu'à cet âge usuel de la coupe. Enfin elles retranchent le sauvetage.

Pour les réserves: Par la valeur de ces réserves à leur âge moyen d'exploitation, valeur diminuée de la dépréciation qu'elles présenteront à cette époque du fait de l'incendie et ensuite escomptée à $4 \%$ par an pour autant d'années qu'il reste à courir jusqu'à cet âge moyen d'exploitation.

Pour l'ensouchement : Par la somme nécessaire pour mettre deux plants nouveaux par souche détruite.

Lapplication de ees règles aux plantations résineuses est impossible rt les Compagnies n'en indiquent point d'autres.

Système proposé. - $1^{0}$ Le taillis incendié devra être estimé à son âge réel, ealeulé d'après la méthode des annuités, sans aucun escomple, déduction faite ensuite du sauvetage;

20 Les réserves brùlées seront évaluées individuellement à leur valeur d'assurance par catégorie, dédıction faite ensuite dı sauvetage ;

$3^{\circ}$ Le dommage eausé à l'ensouchement sera calculé à l'hectare comme l'a été le capital assuré pour cet ensouchement ;

$4^{0}$ Le dommage eausé à la couverture morte sera calculé à l'hectare comme l'a été le eapital assuré pour cette couverture ; 
$5^{\circ}$ Les plantations résineuses détruites seront évaluées de la même façon qu'elles l'ont été pour la recherche du capital à assurer ;

$6^{\circ}$ Le dommage causé à l'ensemencement sera calculé à l'hectare comme l'a été le capital assuré pour' cet ensemencement.

En conséquence, nous avons l'honneur de formuler lo projet de voen suivant :

Que des procédés rationnels et équitables, basés sur les principes et les méthodes admis d'une façon générale en matière de sylviculture et d'aménagement soient adoptés pour l'assurance des forêts et des plantations contre l'incendie.

Qu'en ce qui concerne spécialement les forêts françaises, ces principes et ces méthodes, ainsi que des modèles d'assurance et de règlement de sinistre, soient transmis anx Compagnies d'assurances on anx Unions de ces Compagnies par les syndicats de propriétaires forestiers ou par les fédérations d. ces syndicats en vue d'établir nne entente sirr de telles bases.

M. Descoubes. - Je nai pas l'intention de combattre le reeu propose. mais je tiendrais à dommer quelques explications.

Je: me permets tout d'abord de déposer sur le bureau un fascicult do sylvonomie (Économie et Politique forestières) dans lequel rette question se trouve développée.

Il y a déjà un grand nombre il'années que les sociétés forestières. spécialement la société forestière de Franche-Comté, sont en pourparparlers arec les compagnies d'assurances pour faciliter l'assurance des forêts contre l'incendie. Cette question a me importance très considérable, en ce sens que la forèt, tant qu'elle ne peut pas ètre? pratiquement assurée, ne constitue 'pas un gage suffisant pour permettre au propriétaire d'emprunter, pour les arances dont il a besein. Étant donnó que nous n'arons pas encore de cródit forestier, il faudrait au moins que les propriétaires de forèts puissent avoir les autres systèmes de crédit qui sont dans le domaine public.

Si les forêts pouvaient être assurées contre l'incendie, si la loi nonvelle dont $M$. le Ministre nous amoncait le vote tout à l'heure entrait en vigneur, les forêts représentant un matériel ligneux garanti contre la destruction deviendraient un imneuble susceptible d'être hypothéqué comme les autres et ainsi disparaitrait un ćlément d'infiriorité qui affecte actuellement la forêt comme propriété.

Nalheureusement, la plupart des compagnies d'assurances ont fort peu répondu à l'appel qui leur a été adressé dans ce sens. L'A ssociation centrale pour l'aménagement des monlagnes a mtrepris à ce sujet une enquête qui a révélé qu'une seule compagnie, l' Lrbaine, semble être mentée dans cette voie. Le directeur de son agence de Bordeanx a pu. gràce aux renseignements statistigues du service forestier, établir une irhelle de primes qui ont permis l'assurer quelques milliers d'hertares We pineraies dans la Gironde et les Landes. Il pourrait faire un travail analogue pour d'autres regions s'il etait pourve des documents nicessaires: 
L'assurance par les compagnies semble cependant limitée aux régions de forêts riches, et le problème se trouve ramené à l'assurance des forêts paurres. Or, ce sont les forêts pauvres qu'il fandrait protéger, étant donné les services qu'elles rendent, au point de rue climatérique et au point de vue hydrologique.

L'Étal reste, pour ces forêts paures, le seul assureur pratique. Le rapport indique qu'il n y a guère de chance d'aboutir. C'est très possible. M. Drimot, un forestier belge, a établi, au Congrès de Bruxelles, rles projets d'assurances mutuelles en Belgique, et il arrive à cettr conclusion qu'il faudrait que l'État fournisse au moins un fonds de garantie important. Dans les Pays-Bas, plus arancés, la question a été résolue en partie, mais les compagnies ont failli sombrer il y a quelques années à la suite de sinistres considérables, et la Société du Reboisement des Pays-Bas conclut qu'il faudrait le concours de l'Etat aux assurances mutuelles.

Reste à savoir maintenant sur quelles bases il convient de fonder des mutuelles, des mutualités ou des coopératires largement aidées par l'État. Les mutuelles pourraient être aidées, soit directement par l'État, soit par les Caisses de Crédit agricole qui ont la garantit' de la Banque de France; nous pensons que l'Administration pourra effectuer, à l'aide de ses statistiques, les travaux préparatoires indispensables.

Je ne propose pas d'apporter de modification au rou, mais j’indique seulement la voie dans laquelle il me parait nécessaire de rechereher la solution.

M. Deroye. - Pour ce qui est de la question du crédit forestier, je rappelle que le rapport de M. Margaine sera discuté le mercredi 18 juin. Mais la question de l'assurance par l'État soulève celle du monopole des assurances et pourrait provoquer des protestations des rompagnies. J'ajoute que la Commission de réorganisation du service forestier, qui a étudié également les améliorations à apporter au régime des bois particulier's, n`a pas envisagé les mesures à prendre au sujet des incendies de forêts.

Reste donc la participation des assurances mutuelles. Je ne crois pas que nous ayons donné un avis défavorable à cette participation, puisque notre rapport rous indique que les associations syndicales préconisées par M. le Vinistre Frenand David pourraient itre en inême temps constituées en sociétés ou caisses d'assurances mutuelles agricoles, conformément à la Loi du 4 juillet 1900 et que cette solution pourrait, dans bien des cas, rendre de réels services.

Nais la mutualité n'est pas, à nos yeux, une solution unique ni une solution immédiate; nous nous servons de ce qui existe : les compagnies d'assurances, quitte à recourir à la mutualité agricole lorsque nous pourrons le faire. Les deux combinaisons peurent s'allier et se soutenir l'une l'autre.

En n'excluant pas la mutualité et le crédit agrieole, nous donnons 
done satisfaction à M. Descombes qui a d'ailleurs décłaré accepter, en principe, notre rou.

II. le Dr ViD aL. - Je ne saurais trop appuyer la motion de M. Descombes. L:État a intérèt, non seulement à la conservation des forêts, mais à leur préservation. Plus une forêt est en ben état. plus elle se vend eher et plus les droits d'enregistrement sont élevés.

M. de Sébille. - Il n’y a pas de question qui préoceupe davantage les différentes sociétés forestières et même le Conseil supérieur des Forèts, que celle de l'assurance contre les incendies. Mais je reux rous signaler spécialement une soeiété mutuelle qui existe en Norvège depuis plusieurs années et qui rend des services considérables. La mutualité n’a done pas fait faillite, comme parait le penser. M. Deroye, lorsqu'il déclare que notre seule ressource est celle des sociétís d'assurances.

Nous pensons, en Belgique, que lorsque l'État comprendra sa mission, au lieu de donner aux sociétés de mutualité subsides et subventions, il s'assurera lui-même contre l'incendie. Vous savez que. dans la plupart des cas, il est déjà son propre assureur, mais je crois qu'il finira par s'assurer lui-même. Comme il possède la moitié ou les trois quarts des propriétés boisées du pays, une mutuelle qui compterait dans son sein le Gouvernement et qui assurerait tous ses bois. serait eertaine de vivre...

D'un autre eôté, l'État pourrait permettre à ses agents de faire partie du comité de direction de cette soeiété ; il aurait alors la certitude que les deniers publies ne seraient pas dilapidés.

Je me range aux conclusions présentées par M. Deroye en faisant remarquer eependant qu'il strait utile d'ouvrir la porte un peu plus large aux mutualités.

M. Robert de Mextque. - Le rapport de M. Deroye m’a intéressé tout partieulièrement en ma qualité de presque forestier. Jo suis assureur et propriétaire de forêts. Je erois donc que, dans la question, je ne fais preuve d'aucune partialité.

M. Deroye, bien qu'il reconnaisse les compagnies d'assurances comme particulièrement qualifiées pour assurer les bois et les forêts. a formulé contre des compagnies quelques critiques.

Sans entrer dans les questions de létail, je fais simplement observer que le règlement à la feuille, qui peut paraitre extraordinaire à dus forestiers et qui comporte une déduction d'escompte, revient très sensiblement au mème que le mode de règlement proposé par 11 . Deroye. J'ai fait à ee sujet des études comparées et j'ai pu constater qur les assurés des eompagnies à primes fixes ne sont nullement lésés par les règlements effectués par les assurances. D'autre part, la valeur assuréc. est sensiblement égale dans les calculs très simples dont se servent les compagnies et lans le système que propose le rapporteur.

La plus grosse critique qu'adresse 11 . Deroye aux compagnies 
l'assurances, e'est l'élévation des primes d'une part, et d'autre part, les maigres avantages accordés aux assurés. Sur ces deux points, je ne mois pas les critiques justifines.

Si les primes étaient très élovées et les avantages minimes, les compagnies réaliseraient des béućfices énormes. (r), il n'en est rien. Je nai les résultats d'exploitation que pour deux compagnies qui ne passent pas pour travailler plus mal que d'autres. Dans les soixante dernières années. l'une d'elle a perdu $9 \%$ 'de ses primes et l'autre $16 \%$. Si on augmentait les avantages accordis anx assurés et si on diminuait les primes, les compagnies ne pouraient plus vive. Il y a done autpe chose.

Pent-être y a-t-il dans le projet Deroye des points à itudier : réduction dans certains cas ou. all "ontraire, majoration lorsque la lorêt est dans un pays plus exposi au feu ou quielle est dans le roisinage d'usines, ou encore qu elle ist traverser par une voie ferrie. Les compagnies itudieraient certainement are. plaisir les donneses du ministère de l'Agriculture.

M. Rousselet. - Je prends la parole au double point de vue de propriétaire forestier et l'assureur.

Pourquoi les compagnies d'assurances ont-elles pertu une si gross? partie de leurs primes? Cest parer que la loi des glands nombres n'a pas joué suffisamment: ést parer que lo nombre des risques n était pas assez grand (l'assuranc" no est que le jeu de la loi des grands $110 \mathrm{mbres})$.

La question me parait done devoir être résolue par la mutualití, mais avec la collaboration de l'État, nom sous forme de primes. mais sous forme de cotisation payée par l'ítat pour l'assurance de ses forèts. L'État payant une cotisation proportiomelle à l'importance de se's forêts, cettri cotisation sorait forcément blevie. The là. pour les mutuelles, la possibilité de vivre et de faire face a un excreice désastreux au bout rle de quelques années, puisquayant un portefeuille de primes, elles auraient la capacité demprunter : on pourrait faire fond sur rette cotisation de l'etat.

Le remboursement des sinistres des forêts de l'État compensant, dans une certaine mesure, sa cotisation, les pertes seraient róduites au minimum et d'autre part, la sociéte anrait une position plus assise et trouverait la possibilité de recruter de nombreux adhérents, non seulement parmi les particuliers, mais aussi parmi les départements et les communes.

Je conclus donc an maintien de la première partie du veen th M. Deroye, mais pour la seconde partir, je désirerais qu'on insistat sur l'avantage que présenterait la rémion d'une commission qui serait chargée de l'étude d'un projet complet ret définitif, aver proposition de tarifs, etc...

M. Le Présidext. - Le bureau a écouté aree beancoup d'intiprit les 
orateurs exposer leurs idées. Au moment do voter, il y a deux points quil ne laut pas perdre de vue.

Tout d'abord, il est certains détails dans lesquels le Congrès ne peut pas entrer. Il ne peut rester que dans des lignes générales. Les observations très intéressantes qui ont été présentres, notamment au sujet de la défense des compagnies d'assurances, trouveront leur place dans les pourparlers d'entente avẹ les syndicats de propriétaires menacés par le feu.

D'un autre côté, il faut ètre pratique. 11 est ricilent qu'il est impossible de eréer une commission spéciale pour "hacune des questions examinées par le Congrès.

En second lieu, il serait dangereux de smulever un principe qui ne vise pas seulement les forèts, celui de savir si l'État doit ou ne doit pas être son propre assureur.

L'État a son opinion à point de vue, je reconnais que, suivant la constitution des États et l'importance do leurs immeubles, les solutions peuvent ne pas ètre les mêmes partout. Je ne crois pas que le principe de l" État son propre assureur" puisse ètre vrai dans le monde entier. Mais notre ministère des Finances a posé ce principe et il serait peut-être dangereux de l'attaquer.

Ma mission est de répondre à la pensée exprimée par la plupart des orateurs, tout en restant lans les limites de la pratique.

Je propose, pour rester le plus pratique possible, de faire le moins de bouleversements possible, ot, pour donner satisfaction à M. Descombes et à d'autres de nos collègues, je demande qu'on ajoute à la dernière partie du vou de .M. Deroye la phrase suivante:

"...Sans préjulice, purtout oì les circonstances le permettront, du développement des assurances mutuelles bénéficiant de tous les avantages que l'État peut accorder ì la mutualitè ».

Cette rédaction remet an lumière le principe de mutualité que tout le monde a défendu ici, et, d'autre part, reste dans le droit commun. Or, moins nous demanderons de mesures d'exception, plus nous aurons chance d'aboutir, à mon avis.

Nous pourrions ajouter in fine:

\section{"...Qne l'État accorde ou accordera aux mutualistes ».}

Il est très possible, en eflet que l'État n ait pas dit son dernier mot à ve sujet.

Ce texte réserve l'avenir et permet d'étudier des questions délicates et importantes, tout en donnant satisfaction au désir essentiel exprimé par les orateurs, au point de vue de la mutualité.

M. ve SébILle. - Je me rallie à l'amendement qui vient d'être proposé. M. le Dr Vin.lL. - Cette modification me donne également satisfaction. 
M. Deroye. - L’instiution d’une Commission, pour la réalisation des vœux que nous allons émettre, me paraît avoir été traitée déjà par M. Defert tout à l'heure, lorsqu'il a annoncé à l'Assemblée Générale la constitution d'une commission permanente "dans le temps et dans l'action ». Ce sont les termes mêmes qu'il a employés (Très bien! Très bien!)

M. Roulleau. - Dans la seconde partie de son vœu, M. Deroye a invité les syndicats de propriétaires à s'occuper pratiquement de la question de l'assurance contre l'incendic. Or, des démarches ont été faites par le comité des Forêts, qui s'est lié à une société très puissante, l'Union des Intérêts économiques.

M. Le Président. - Vous voyez, Messieurs, que déjà le vœu a un commencement de réalisation, ee qui est la meilleure preuve de son intérêt pratique.

Voici le texte que nous proposons à votre vote :

"Que des procédés rationnels et équitables basés sur les principes ct les méthodes admis d'nne façon générale en matière de sylvicntture et d'aménagement soient aidoptés pour l'assurance des forêts et des plantations contre l'incendie;

"Qu'en ce qui concerne spécialement les forêts françaises, ces primcipes et ces méthodes, ainsi que des modèles d'assurance et de règlement. de sinistre, soient transmis aux compagnies d'assurances ou aиx unions de ces compagnies par les syndicats de propriétaires forestiers ou par les fédérations de ces syndicats, en vue d'établir une entente sur de telles bases, sans préjndice - partont oì les circonstances le le permettront - du développement des assurances mutuelles bénéficiont de tous les asantages que l'Etat aceorde ou accordera anx mutualités".

Le texte du vou, mis aux voix, est adopté.

M. Le Président. - M. le Dr Vidal, d'Hyères, nous a adressé une communication qui se rattache à la question des incendies dans les Maures et l'Estérel.

Je prie l'un de Mul. les Secrétaires de vouloir bien donner lecture de l'observation essentielle qui a été faite au sujet de ce travail.

M. Le Secrétaire. - Le mémoire de M. Vidal, dont l'original etait annexé à la pétition présentée en 1881 à la Chambre des députés par des électeur's du département du Var, avait bour but de modifier la Loi du 6 juillet 1870, concernant la région des Maures et de l'Estérel.

Ce mémoire ne parait plus avoir aucun intérêt actuel, la Loi du 6 juillet 1870 ayant été remplacée par celle du 19 août 1893, actuellement en vigueur.

M. Le Présinent. - La situation au point de vue législatif s 'est modifice, d'abord par le vote de la nouvelle loi de 1893, et ensuite par me 
proposition nouvelle qui est actuellement en discussion. Le nouveau projet a été voté par la Chambre et est actuellement soumis au Sénat. Les Conseils généraux, tout en ne considérant pas ce projet comme la perfection, insistent (dans leur désir d'arriver à un résultat effectif) pour que le Sénat adopte le plus tôt possible le projet, parce qu'il constitue certainement un progrès.

Sous bénéfice de ces observations, je dome la parole à M. le Lr Vidal.

II le Dr E. VIDAL. - Nous profitons de la situation qui nous est offerte par ce Congrès pour faire entendre de nouveau les justes revendications des habitants de la région des Maures et pour prier nos collègues de vouloir bien renouveler le rou suivant:

"Le titre IV de la Loi forestière dn 6 juillet 18j0 desrait être modifié dans le sens suivant:

"10 Qu'il soit ouvert, au Ministère de l'Agriculture, un crédit divisé en plusieurs exercices et suffisant pour la consiruction, à bref délai, et pour l'entretien d'un réseau de chemins de protection et d'exploitation forestière dans la région des Maures et de l'Estérel.

"20 Que la construction et l'entretien de ce réseau soient dirigés par les agents de l'administration des foréts dont la compétence spéciale en pareille occurence est une garantie de la bonne et économique exécution des trasaux ".

La seule forêt domaniale de la contrée, le Don de Bormes, est bien desstrvie et elle ne brûle pas, alors qu'autour d'elle les incendies se multiplient.

" $3^{\circ}$ Le Congrès considérant que dans la région" des Maures les poies de communication sont notoirement insuffisantes. "

Émet le voul :

"Qu'il soit mis, à bref délai, un terme à cette situation dont on ne trouve pas un autre exemple sur tout le territoire frangais."

Il ne nous est point permis toutefois d'oublier que nous avons été conviés à ce Congrès par la grande société du Touring-Club de France qui a de tout tenps protégé l'ouverture et l'entretien des voies nouvelles destinées à mettre en relief les différents points de notre territoire qui méritent d'être visités par les touristes de tous les pays. C'est à ce point de vue particulier que nous devons ncus placer pour signaler à l'attention du conseil d'administration de cette association et à celle de tous les voyageurs, un des points les plus admirables de la côte d'Azur, qui serait aussi l'un des plus fréquenté s'il existait un chemin plus convenable pour l'aborder.

Nous voulons parler de la partie du littoral située entre le Lavandou et la plage de Cogolin. Une ronte a bien été tracée autrefois tout le long de la côte et elle était charmante; mais elle est actuellement tellement délabrée que les robustes chariots qui transportent les produits de la forêt, ne peuvent euxmême y circuler qu'en surmontant les phıs grandes difficultés.

En conséquence, ne pensez-vous pas, Jlessieurs, que le Congrès pourrait émettre le vou que le Touring-Club veuille bien prendresous sa puissante protection cette partie du littoral français et inscrire dès aujourd'hui sa visite dans les programmes des excursions qu'il recommande aux visiteur's de la Côte d'Azur? (Applaudissements.)

J'ajoute qu'il conviendrait d'appeler en même temps l'attention de l'Adıninistration des furêts et de l'Administration des Ponts et Chaussées sur l'urgence qu'il y a à créer et à entretenir des chemins forestiers. 
M. Le Président. - Il n est pas douteux que les congressistes portent le plus vif intérêt à tous les points de vue, au massif des Maures. Mais il n'échappera pas à nos collègues que le Congrès ne peut pas descendre clans de trop petits détails. Le mesure que réclame M. IN Dr Vidal, tout le monde la désire, l'Administration forestière aussi: mais la première condition pour agir, c'est que la fameuse loi soit rotée.

Je crois done, Messieurs, que je répondrai à vos intentions et en même temps au désir de M. le Dr Vidal en déclarant que l'attention des Administrations des forêts et des Ponts et Chaussées devra ètre appelée, en même temps que celle du Touring-Club de France. sur les incendies de la région des Maures, si ruineux pour les population: qui l'habitent, et sur les remèdes qu'on pent y apporter.

11. le Dr Vidal. - Je vous remercie, jai completesatisfaction.

La séance est levée à midi. 


\title{
SEANCE DU 16 JUIN 1913
}

\author{
(APRÈS-MIDI)
}

\section{Présidence de MI. VIVIER, président de Section}

La siance est ouverte à 2 h. $1 / 2$.

II. Le Préshext. - Liordre du jour appelle la discussion du rapport de H. Huffel, sur la législation forestière comparée, le róll: Forestier DE L'ÉTAT. - Comparalson ENTRE les DIfFérextPAYS.

La parole est à M. 11 uffel pour la lecture de son rapport.

1I. G, HufFEL. - L'État, dans nos sociétés modernes, est cette personnalité morale qui, représentant la collectivité des citoyens, porte la charge de leurs intérêts collectifs. Il lui appartient d'intervenir dans toutes les circonstances où l'utilité publique est intéressée. La conservation et l'exploitation des forêts présentent à un degré éminent et à différents points de vue, un véritable intérêt public, et c'est ainsi qu'il existe pour l'État un rôle forestier à remplir.

Les forêts présentent deux genres d'utilité bien distincts :

Elles peuvent être une source de revenus pour leur propriétaire par les produits matériels : bois, écorces, résines, etc., qu'il est possible d'en extraire.

Elles peuvent encore être utiles :

$1^{\circ}$ Comme forêts de protection, par suite de leur influence sur le régime des eaux sauvages et souterraines, sur les érosions, les dégâts des avalanches ;

$2^{\circ}$ Elles sont utiles à la défense, à la salubrité et à l'ornement des régions où elles croissent.

L'État a-t-il à s'oceuper des forêts au point de vue de leur rendement?

Parmi les produits très variés de la forêt, les bois d'œuvre de forte dimension, et plus spécialement les gros chênes, constituent une matière première par excellence, qui n'a pas de succédané pour une foule d'emplois, et dont la consommation ne saurait pas plus se passer qu'elle ne se passerait de coton ou dı papier, par exemple. La demande de ces bois ne cesse de s'aceroître dans tous les pays civilisés et la production va en diminuant. Beaucoup d'économistes croient, et sans doute avec raison, que dès à présent la consommation mondiale dépasse la production, qu'elle est alimentée aux dépens clu capital producteur des forêts et que nous allons au devant d'une pénurie certaine de bois d'œurre. 
Les gros bois d'œuvre ne peuvent s'obtenir qu'en immobilisant dans les forêts un capital énorme. Pour pouvoir couper annuellement un mètre cube de gros chêne il faut en entretenir cinquante mètres cubes semblables, ou davantage, dans la forêt, sans compter les autres capitaux à engager dans l'exploitation. Cette situation résulte immédiatement et nécessairement de la lenteur avec laquelle se forme ce genre de produits qui met 150 ou 200 ans à mûrir. La conséquence en est que l'ensemble des capitaux employés à produire de gros bois d'œuvre ne peut être rémunéré qu'à un taux très faible : son revenu est à peine de 1 à 2 pour 100 par an, et souvent encore inférieur. La production de gros bois ne saurait donc convenir, en général, à des propriétaires particuliers. Ceux-ci ont organisé et organisent de plus en plus leurs forêts en vue d'autres productions : menus bois d'œuvre, bois de feu, écorces, résines.

La production des gros bois est d'intérêt public. Elle est onéreuse pour celui qui l'entreprend. Il en résulte évidemment qu'elle incombe à l'État. Un des aspects du rôle forestier de l'État est d'assurer l'alimen. tation du pays en bois de fortes dimensions.

En France, la loi s'est toujours efforcée d'orienter les forêts de l'État vers la production des gros bois. Les ordonnances forestières de l'ancien régime renferment de nombreuses dispositions en ce sens et l'ordonnance encore en vigueur de 1827 ordonne de les aménager en vue de "l'éducation des futaies "(1). Malheureusement l'étendue de la partie de nos forêts domaniales qui est susceptible de produire des gros bois est beaucoup trop faible et représente moins du dixième de l'étendue boisée totale du pays.

Il y aurait lieu de l'augmenter par l'acquisition de forêts particulières et aussi par l'application d'une méthode d'aménagement nouvelle qui permettrait d'obtenir un meilleur rendement en bois d'œuvre que le traitement en taillis sous futaie, qui reste suivisur près du tiers des forêts de l'Etat français. Les tentatives de conversion en futaie pleine des taillis sous futaie peuplés de chêne, croissant en terrains frais et fertiles, mais sous un climat rude dans le Nord-Est de la France ont donné lieu à beaucoup de mécomptes. Il serait désirable d'y essayer le traitement en FUTAIE CLAIRE, qui assurerait un grand progrès, sans aucun risque ni difficulté (2).

Beaucoup de forêts, en région de montagne, ou bien sur les rivages de la mer (dunes de sables mouvants) sont avant tout des forêts de protection. Elles défendent le sol contre l'érosion par les eaux ou le vent, ralentissent l'écoulement des eaux et facilitent leur infiltration, elles arrêtent le vent et les avalanches, etc., etc. Ces forêts de protection ne sont, le plus souvent, susceptibles que d'un revenu très faible ou même nul. Elles ne peuvent en tout cas remplir leur rôle si éminemment utile que si la considération de leur revenu est entièrement subordonnée à leur rôle de protection.

De pareilles forêts, dont la conservation est d'intérêt public, et dont le détenteur ne peut jouir librement, doivent nécessairement faire partie du domaine de l'État. En réalité, ces forêts sont très généralement, en France, la propriété de communes ou, quelquefois, de particuliers.

Les forêts de protection communales sont, sans doute, soumises au régime forestier, gérées par des agents de l'État, ce qui assure leur conser-

(1) Article 68 de l'ordonnance du 1 er août 1827.

(2) Voir pour la définition de la FUTAIE Claire Economie forestière, par G. Huffel, professeur à l’École nationale des Eaux et Forêts, $1^{\text {re }}$ édition, $3^{\circ}$ volume, pages 450 et 454 . Paris, Laveur, éditeur 1907. 
vation. Mais celle-ci entraîne de la part des communes propriétares des sacrifices qu'il parait peu équitables de faire supporter à quelques communes dans l'intérêt général du pays. Il est vrai que l'on s'efforce d'indemniser indirectement les communes propriétaires de forêts de protection des restrictions inı posées à leur jouissance dans l'intérêt général (1). Il serait préférable d'incorporer au domaine public tout ce qui doit être aménagé au point de vue cle l'intérêt collectif de la nation, tout ce qui possède franchement le caractère d'une forêt de protection. Cela pourrait se faire d'autant plus facilement, sans grandes dépenses, que le revenu en argent de ces forêts est très faible et souvent presque nul.

Les forêts ont à jouer un rôle important pour l'ornement du pays. Celles qui sont situées auprès des grandes villes devraient être aménagées avec le souci de l'agrément des touristes, en vue d'y attirer le public. Quel service plus grand les forêts pourraient-elles rendre à notre pays que de développer le goút de la marche en plein air, des distractions saines que l'homme du peuple prend en famille lorsqu'il va passer au bois ses heures de liberté? Qui ne se réjouirait de voir les ouvriers des usines ou de la mine passer le dimanche en forêt plutôt que dans ces locaux où ils prennent trop souvent leur récréation en empoisonnant à la fois leur corps et leur esprit? Nous voudrions trouver partout, et spécialement dans le voisinage des villes, dans les plus beaux lieux de nos bois, auprès des sources, des rochers ou des vieux arbres, des sentiers commodes, des banes, des tables, des abris au lieu de ces elôtures ou de ces inscriptions reproduisant les articles les plus menacants de nos codes qu'on y voit trop fréquemment.

Comme conclusion aux observations ci-dessus, nous proposons au Congrès les trois voux ci-après:

I. Qu'il soit institué un fonds spécial, alimenté soit par une allocation budgétaire spéciale, soit plutôt par le prélèvement annucl de $2 \%$ par exemple sur le revenu des forêts de l'Êtat, à l'effet d'acquérir à l'amiable, pour les incorporer au domaine public, des forêts particulières susceptibles de produire des bois de fortes dimensions et qui seraient aménagées en vue de cette production.

II. Qu'il soit établi un inventaire général des forêts croissant sur le territoire français qui présentent le caractère de forêts de protection. Que l'État soit autorisé à acquérir ces forêts, à l'amiable ou par voic d'expropriation, dans ce dernier cas en payant aux propriétaires une somme égale à trente fois le revenu net annuel moyen des dix dernières années, établi après expertise. Une partie des fonds affectés à la "restauration et à la conservation des terrains en monlagne ", en exécution de la loi du 4 asril 1882, pourraient recevoir cette destination.

III. Que des cantons bien choisis des forêts de l'État, dans le voisinage des grandes villes, en des points pittoresques et facilement accessibles, soient distraits du cadre des aménagements ordinaires et traités spécialement au

(1) Lo décret du 11 juillet 1882 dispose, dans son article 22, que dans les communes où l'Etat aura entrepris des travaux en vue de la correction des torrents dangerenx, les préposés forestiers chargés de la surveillance de ces travaux assurecont en même temps, sans aucun frais pour les communes, la surveillance des forêts communales du territoire. 
point de vue de l'ornement, et disposés pour l'agrément des promeneurs et des touristes.

1I. Le Président. - Deux d'entre ces vœux se rapportent à des sujets voisins de ceux traités dans d'autres rapports.

Nous pourrions, je pense, en renvoyer l'étude au moment de la discussion de ces rapports. Il ne nous resterait plus à discuter en ee moment que le dernier des voux de M. Huffel.

11 en est ainsi décidé.

Voici, Messieurs, le troisième vœu de MI. Huffel :

"Qne des cantons bien choisis des forêts de l'État, dans le voisinage des grandes villes, en des points pittoresques et facilement accessibles, soient distraits du cadre des aménagements ordinaires et traités spéciale. ment au point de 'ue de l'ornement, et disposés pour l'agrément des promeneurs et des touristes."

Ce vou de M. Huffel ne fait, si jose dire, double emploi avec aucun autre rocu qui nous soit soumis; il répond évidemment à l'une des préoccupations du moment.

Je me permettrai d'y faire, cependant, une petite critique, qui n'est que la confirmation des paroles prononcées ce matin par M. le Ministre de l'Agriculture. Il est certes fort bien de faire des forêts d'ornement. Mais il ne faut pas oublier que les forêts sont faites surtout pour être exploitées, et que leur còté financier et économique ne doit pas être dédaigné. Les séries artistiques ont beaucoup de chances d'être constituées avec ce que nous appelons, nous autres forestiers, les premières affectations de futaie. et la mise hors aménagement d'un de ces cantons pent ainsi représenter un assez gros sacrifice finaneier. Sans m'opposer an voeu de MI. Huffel, je proposerai d'y apporter l'addition suivante : "Partout oì les circonstances économiques ne s'y opposent pas ». Peut-être pourrait-on dire même : "économiqnes et financières ". Pourtant, si l'on vend du bois, ce n'est pas seulement pour mettre de l'argent dans les eaisses de l'Etat, c'est surtout pour pourvoir aux besoins de la eonsommation.

Jappelle en outre votre attention sur le membre de phrase : "... dans le voisinage des grandes villes ", qui est très important.

11. Gurot. - J'abonde dans votre sens. Nous sommes tous partisans de la beauté des paysages. Comme le faisait remarquer ce matin 11. Clémentel, il est dur de porter la hache sur de vieux arbres. Notre cour saigne, romme celui de honsard, lorsque nous le faisons. Ciest entendu. Je suis partisan des réserves. Mais, pour arriver à un résultat pratique, il faut les limiter. Ces réserves dites artistiques doivent plutôt ètre multipliées sur de petits espaces, qu'être itendues à un petit nombre de grandes étendues.

11. Le Prísinent. - Je mets donc aux voix le vou no 3 te $\mathbf{M}$. Huffel, avee une double addition : 
$1^{\circ}$ Après le mot "cantons", ajouter "ou parcelles".

$2^{\circ}$ A la fin, ajouter : "Partout où les circonstances économiques ne s'y opposeront pas ».

Il n'y a pas d'opposition?...

Le vœu ainsi modifié est adopté.

11. Delahaxe. - Bien que le vou $n^{\circ} \mathrm{l}$ ait été renvoyé à une séance ultérieure, il serait intéressant de fixer dès aujourd'lui un point qui dominera les discussions de notre section et qui sst relatif à la disette de bois d'œurre. C'est une grave question et qui préoccupe à juste titre l'opinion publique.

La disette des bois d'œuvre revêt-elle une acuití suffisante pour qu'on puisse considérer la question eomme d'intérêt public, au sens strictement juridique du mot. Si le bois l'œuvle est devenu si rare quil faille, pour satisfaire aux besoins de la Société, se préoccuper d'en produire conte que coǹte, peut-ètre pourrait-il y avoir là une raison pour l'État, un motif d'ingérence dans la gestion des propriétés particulières boisées.

II. Le Présunent. - Le rapport de M. Madelin répond à vos jréoccupations. Si l'on 'nvisage la production mondiale, II. Madelin estime que le danger n'est pas encore imminent. Hais tans quelle mesure pourra-t-on faire venir les bois étrangers?

II. Delahaye. - J'aurais roulu savoir si lintervention de létat pourrait trouver motif à se justifier.

M. le Présinent. - Ciest une question d'appréciation individuelle. Le prix de certains bois d'ouvre, comme le chène, augmente beancoup.

V. Blanchereiv. - II n'y a pas disette de bois d'ourte.

II. Descombes. - Les craintes émises reposent sur une base sérieuse, mais je ne crois pas qu'on en soit enteore à attenter à la liberté des propriétaires de forêts. La crise des forèts date de loin. Le progrès de: la civilisation, lemploi de la vapeur, de lélectrieité, le travail indus. triel, ont développé la consommation du bois d'œuvre et déprécié les bois de feu. C'est une transformation reonomique grave, qui a d'abord passë inaperçue, parce qu'elle s'est faite insensiblement. Mais il faut remédier aux phénomènes économiques, non par des lois d'exception, mais par des mesures économiques. Du moment que le bois de feu ne se vend plus et que? le bois d'œuvre augmente de prix, il faut que les producteurs produisent re qui se rend bien et cessent de produire ce qui ne se rend plus.

M. le Présinent. - Je me pernets de vous faire remarquel que la question pourra être traité dans son amplrur quand nous discuterons 
le rapport de MII. Guyot et Roulleau sur l'Intervention de l'État dans la gestions des bois particuliers.

La parole est à M. Ch. Guyot pour la lecture de son rapport sur l'Établissevent de Forêts de protectiox.

M. Ch. Guyot. - L'établissement de forêts de protection comporte un ensemble de mesures préventives tendant à empêcher la disparition de massifs boisés dont la conservation intéresse certaines parties du territoire. Il en résulte une intervention de l'État, réglementant très étroitement la jouissance des particuliers propriétaires de ces forêts.

Il s'agit donc de servitudes d'intérêt public, dérogatoires au droit commun, qui ne peuvent être établies qu'en cas d'absolue nécessité, et en assurant aux propriétaires auxquels ces servitudes s'appliquent des compensations équitables pour les restrictions de jouissance qui leur sont imposées.

Le droit commun en cette matière, c'est la législation du défrichement. Il est interdit, en principe, de supprimer l'état boisé d'un immeuble, à moins que ce changement puisse être considéré par l'autorité compétente comme sans influence pour les intérêts généraux du pays. Tout propriétaire qui défriche, nonobstant une opposition administrative, est passible d'une peine sévère et peut être obligé à reboiser à ses frais. Cette servitude générale d'utilité publique, dont on n'a pas d'analogue pour les autres sortes de propriétés, s'applique aux forêts sans aucune indemnité.

On pourrait penser a priori que les propriétaires forestiers sont ainsi suffisamment grevés, qu'on ne doit pas leur imposer de servitudes plus lourdes et que l'interdiction de défricher satisfait entièrement l'intérêr public dont la sauvegarde justifie l'intervention administrative. Nous estimons, en effet, que toute intervention de l'Etat dans la gestion des forêts de particuliers doịt être écartée, comme entraînant des conséquences exorbitantes du droit commun, et que la règle, pour les forêts comme pour les autres immeubles, doit être le respect des intérêts privés.

Mais à toute règle il est des exceptions. Il faut seulement que ces exceptions soient justifiées et qu'elles ne s'appliquent qu'au cas d'absolue nécessité. Ce sont ces conditions dont nous devons démontrer l'existence pour permettre l'introduction d'une législation spéciale aux forêts de protection.

Quelque rigoureuse que puisse être la législation générale sur le défrichement, elle présente néanmoins une lacune, résultant de la nature de ses dispositions; ce sont uniquement des dispositions répressives, des pénalités qui s'appliquent à un fait consommé, à une destruction déjà entièrement réalisée. Or, il se peut que, dans certains cas, cette destruction soit irrémédiable, que le mal causé par la disparition de la forêt ne puisse plus être réparé. D'où la nécessité de mesures préventives, tendant à empêcher le mal d'être commis et par conséquent permettant à l'Administration d'intervenir avant qu'il ne soit irréparable.

Ces cas se présentent surtout dans les régions de hautes montagnes, et aussi dans celles des dunes. En montagne principalement, la destruction d'une forêt, même de peu d'étendue, peut avoir pour effet la désagrégation du sol, des éboulements ou des glissements sur les pentes, la formation ou l'amplification soudaine du phénomène torrentiel. Toute 
la terre, jusqu'au roc sous-jacent, entrainée par les eaux, avec l'anéantissement des habitations et des cultures inférieures, la formation subite de couloirs d'avalanches, telles peuvent être les conséquences d'un défrichement intempestif, ou même d'une exploitation forestière imprudente. Et alors, on aura beau punir l'auteur de ce désastre, sa peine ne remédiera pas au mal désormais irréparable, et la reconstitution de la forêt lui serait vainement imposée, car ce travail est pour longtemps devenu impossible. Tandis que si l'on avait pu intervenir à temps, empêcher l'exploitation abusive, le pâturage exagéré, par le simple effet de ces mesures préventives, la catastrophe eût été évitée, la région que protégeait la forêt eût été sauvegardée.

L'influence souveraine des massifs forestiers pour la protection du sol dans les pays de hautes montagnes a été de tout temps reconnue, en France aussi bien que dans les autres États. Dans nos Alpes notamment, il existait avant 1789 bon nombre de règlements locaux ordonnant le maintien des défens, et assurant ainsi, sous des peines sévères, l'existence de ces bois sacrés indispensables pour la sécurité des populations alpestres, ainsi protégées contre les dangers de leur sol instable et de leur climat rigoureux (1). De ces anciens règlements, qui prohibaient toute exploitation nuisible, tout acte même'de jouissance, il ne reste plus que le souvenir : ils ont disparu dans l'excès d'uniformité qui caractérise notre législation du $\mathrm{xIx}^{\mathrm{e}}$ siècle; il faudrait les rétablir. Chose étrange : l'importance de la forêt en montagne est parfaitement reconnue; l'État s'impose de lourds sacrifices pour créer des périmètres de reboisement destinés à empêcher la formation des torrents, et il assiste impuissant à la ruine de ce qui subsiste encore de ces défens qu'une simple réglementation pourrait conserver. Ni dans la Loi de 1882 sur la restauration des montagnes, ni dans les autres actes législatifs concernant les forêts. on ne s'est inquiété de rétablir cette notion essentielle de la forêt de protection, qui devrait être à la base de toute législation forestière.

Il nous faut maintenant recourir aux pays étrangers pour trouver des modèles de textes législatifs dont nous puissions introduire dans notre code des équivalents. Du moins, ces modèles ne manquent pas; nous n'avons qu'à choisir', car la plupart des pays d'Europe nous offrent à ce sujet une législation aussi complète que variée. On peut dire que la France seule s'est refusée jusqu'à ce jour à entrer dans une voie qui lui était pourtant si naturellement indiquée. Nous ne pouvons analyser ici toutes ces lois étrangères (2); leur caractère commun est, comme nous l'avons exprimé ci-dessus, d'imposer aux propriétaires de forêts placées dans certaines conditions déterminées des. restrictions de jouissance pouvant aller jusqu'à l'abstention complète, dans un but d'utilité publique. Ces lois comportent d'ailleurs des différences assez profondes quant aux forêts susceptibles d'être soumises à cette servitude et quant aux effets de la soumission. La législation suisse est celle qui paraît de nature à être le plus facilement adaptée à notre législation française : mais encore ne doit-elle pas être copiée servilement : ce qui est d'une

(1) Voir notamment HufFer, Economie forestière, tome $1^{\text {er }}$ (1re édition), p. 131 et suir

(2) Voir à ce sujet J. Madelin, Les restrictions légales au droit de propriété privée, en France, en Allemagne, en Autriche, en Hongrie et en Suisse (Paris, 1905), spécialemen pour la Suisse, 1. 187 et suiv.

Voir anssi la loi forestiere italienne du 20 juin 1877 , publiée en français par B. DI IA Grye, Revue des Eaux et Forêts, 1877, p. 391 et suiv. 
application facile dans un pays tel que la Suisse, dont la plus grande partie du territoire est en haute montagne, et dont la population se soumet docilement à des mesures restrictives en vue de la protection du sol, pourrait paraître intolérable s'il s'agissait de la France, déshabituée d'une réglementation aussi sévère, et qui n'a qu'une partie relativement minime de son territoire exposée aux dangers qu'il s'agit de conjurer.

Notre conviction intime est que la servitude des forêts de protection n'a de chances d'être acceptée en France qu'aux conditions suivantes : son application doit être très exceptionnelle et ne doit pas être étendue pour des motifs autres que la défense des hautes montagnes et des dunes; ensuite, cette charge fort lourde ne doit être imposée aux propriétaires que moyennant des avantages équivalents, sous forme d'exemptions d'impôts, de surveillance gratuite, de subventions pour travaux d'entretien, etc.; enfin le propriétaire, s'il estime intolérable la situation qui lui est ainsi créée, doit pouvoir en sortir en requérant l'expropriation.

Ce serait une illusion de croire qu'en étendant indéfiniment l'action administrative en vue de l'application d'une loi sur les forêts de protection, on arriverait à des résultats meilleurs pour l'intérêt public : on risquerait fatalement ainsi d'aboutir à une faillite complète et à l'impossibilité absolue de mettre en pratique des mesures aussi impopulaires. Déjà l'on a pu voir avec quelle difficulté l'Administration arrive à se servir de la réglementation des pâturages communaux, mise à sa disposition par la Loi de 1882; il s'agit pourtant d'une intervention beaucoup moins grave, dont les résultats eussent pu être excellents si le nombre des communes réglementées était quelque peu considérable; mais on a reculé devant l'hostilité des populations, et c'est à peine si l'on a tenté dans 300 communes un semblant de réglementation absolument insuffisant. Combien plus énergique serait la résistance s'il s'agissait d'appliquer à tous les propriétaires forestiers de France les limitations de jouissance beaucoup plus sérieuses qui caractérisent les forêts de protection!

Nous insistons sur ce point parce que, dans une intention d'ailleurs très louable, la Chambre des députés a été saisie, par l'un de nos représentants les plus dévoués à la cause forestière, d'un projet qui permet de classer au nombre des forêts de protection, non seulement les forêts de montagne et des dunes, mais encore toutes celles au sujet desquelles l'opposition au défrichement pourrait être formulée par l'Administration (1). Ce serait donner à la législation nouvelle une ampleur qu'elle ne comporte pas; si l'on veut réussir, il faut limiter étroitement cette application, sauf alors à prendre toutes les mesures nécessaires pour assurer le maintien de la forêt : non seulement interdiction de couper les gros arbres, mais défense de toute exploitation, de toute fouille ou extraction, de toute introduction du bétail, sauf autorisation expresse de l'Administration.

En revanche, la plus stricte équité commande de garantir au propriétaire grevé des compensations telles qu'il puisse accepter la dure situation qui lui est ainsi faite dans l'intérêt public. De ce que la prohibition de défricher est imposée sans indemnité, il ne faut pas conclure que le propriétaire forestier doit se soumettre gratuitement à toutes les aggrava-

(1) Proposition de loi de M. Fernand David, 1907. Voir au 1er appendice ci-dessous le texte de cette proposition, et un autre texte que nous serions d'avis de lui substituer. 
tions qu'il plaira au législateur de lui faire subir. A défaut des principes juridiques, l'idée de solidarité elle-même, dont on se prévaut si fréquemment à notre époque, s'oppose à ce que l'intérêt particulier soit ainsi indéfiniment sacrifié.

C'est dans ce sens que nous serions heureux de voir aboutir, au Parlement français, la généreuse initiative prise en 1907 par M. Fernand David. Nous croyons aussi que, pour réaliser pratiquement cette introduction de la forêt de protection dans notre législation forestière, il serait préférable de la présenter seule, dégagée de toutes autres innovations qui peuvent être excellentes, mais dont la discussion pourrait faire ajourner longtemps encore une réforme nécessaire, susceptible d'être ainsi plus facilement admise (1).

- Nous avons envisagé la question des forêts de protection en nous plaçant surtout au point de vue des intérêts français. Hais cette question comporte une application qui n'est certes pas restreinte à la limite de nos frontières : elle se pose dans tous les pays et par conséquent, elle est de celles qui peuvent faire l'objet d'une résolution de principe de la part du Congrès forestier international, résolution qui sera de nature à être invoqué toutes les fois qu'il s'agira de eréer ou de modifier, dans un État quelconque, une législation des forêts de protection.

C'est dans ce but que nous avons l'honneur de proposer au Congrès un projet de vœu libellé comme il suit :

\section{"LE Coxgrès,}

Considérant que la conservation des forêts existant dans les régions élevées et dans les dunes nécessite des mesures exreptionnelles, et que la législation répressive du défrichement ne suffit pus ponr assurer le maintien de ces forêts,

Est d'avis qu'une législation spéciule des forêts do protection est soule capable de présenir les dangers yni résultent de lenr disparition, législation préventive qui doit tenir compte de la situation économique et re l'organisution administrative des divers pays, étant entendu tontefois que les servitudes qui en résultent pour les propriétaires fórestiers doivent être compensées par des usantages équivulents, tels que subventions et exemptions d'impôt.

Proposition de loi ayant pour but de mettre fun au déboisement du sol de la France, présentée par M. Fernand David, député (Chambre des députés, session de $1907, n^{0} 843$. Annexe au procès-verbal de la séance du 15 mars 1907).

Nous transcrivons seulement les parties de cette proposition qui concernent les forêts de protection.

"Art. 3. - Les forêts de la France sont classées en forêts protectrices et en forêts ordinaires.

"Art. 6. - Sont déclarées protectrices toutes les forêts situées en

(1) Tel serait, notamment, l'inconvénient d'une très intéressante proposition de Loi sur la protection des forêts, préparée par le groupe forestier de la Chambre des députés, et qui doit être incessamment présentée à cette Chambre; elle contient, outre la matière des forêts de protection d'autres dispositions se référant à des préoccupations plus ou moins différentes. Voir, au $2^{\mathrm{e}}$ appendice ci-dessous, le texte de cette proposition, avec les observations qu'elle nous suggère, relativement aux forêts de protection. 
montagne à une altitude supérieure à 800 mètres, ainsi que les parcelles boisées qui les continuent sans interruption dans la zone inféricure.

"Art. 7. - Pourront également être déclarées protectrices par décret, soit d'office, soit sur la demande des intéressés, toutes les forêts situées dans la zone inférieure à 800 mètres et dont la conservation sera reconnue nécessaire : $1^{\circ}$ au maintien du sol sur les pentes; $2^{\circ}$ à la défense du sol contre les érosions et les envahissements des fleuves, rivières ou torrents; $3^{\circ}$ à l'existence des sources et cours d'eau ; $4^{\circ}$ à la protection des dunes et des côtes contre les érosions de la mer et l'envahissement des sables; $5^{\circ}$ à la défense du territoire dans la partie de la zone frontière qui sera déterminée par un règlement d'administration publique ; $6^{\circ}$ à la salubrité publique ; $7^{\circ}$ au maintien des conditions économiques existantes, relatives aux besoins des populations bûcheronnes ct industrielles qui vivent de l'exploitation régulière de la forêt.

"Art. 8. - Dans les forêts protectrices de montagnes, est considérée comme défrichement et par suite interdite la coupe à blanc estoc ou coupe rase, même partielle, sauf pour les bois-taillis. Dans toutes celles de ces mêmes forêts qui ne sont point soumises au régime forestier, la coupe ou l'enlèvement des arbres de moins de quatre décimètres de tour est interdite. Toutefois, les opérations culturales portant sur les arbres de cette catégorie pourront avoir lieu avec l'autorisation et sous le contrôle des agents forestiers.

"Art. 9. - Dans les forêts protectrices de plaines, le décret déclaratif détermine, pour chaque cas particulier, les coupes et opérations abusives qui seront interdites comme étant de nature à détruire, suspendre, affaiblir ou compromettre le rôle protecteur ou bicnfaisant de la forêt.

"Art. 10. - Toute contravention aux dispositions qui précèdent sera punie, selon les cas, des peines portées au titre XII du Code forestier ou de celles indiquées par l'article 221 du même Code. Les infractions à la présente loi seront constatées et poursuivies par les préposés et agents forestiers, conformément aux dispositions du titre XI du Code forestier.

"Art. 11. - Les communes, collectivités ou particuliers, propriétaires des fonds situés au-dessous des forêts protectrices, ou qui vivent de leur exploitation régulière, pourront, en outre, exercer toutes les actions ou réparations des dommages résultant de coupes illicites ou de leurs conséquences. Ces actions se prescrivent par un délai de vingt ans."

A cette proposition de M. F. David, nous serions d'avis de substituer les dispositions suivantes :

"Article premier. - Peuvent être classées comme forêts de protection les forêts dont le maintien est reconnu nécessaire : $1^{0}$ au maintien des terres sur les montagnes ou sur les pentes, et à la protection contre les avalanches; $2^{\circ}$ à la défense du sol contre les érosions de la mer ou des cours d'eau et à l'envahissement des sables.

"Art. 2. - Des décrets après enquête, rendus sur la proposition du Ministre de l'Agriculture, déterminent les forêts qui sont classées comme forêts de protection. Les formes de l'enquête sont fixées dans un règlement d'administration publique.

" Art. 3. - Les forêts de protection appartenant à des particuliers sont soumises à un régime forestier spécial. Elles sont surveillées par- 
les agents et préposés de l'État. Aucune coupe ou enlèvement de bois ne peut y être pratiqué, aucune fouille ou extraction de matériaux ne peut y être effectuée sans l'autorisation expresse de l'Administration des Eaux et Forêts. L'introduction de toute espèce de bétail y est entièrement prohibée, quel que soit l'âge des peuplements, sauf pareillement un règlement imposé par la même Administration. Toutes les contraventions à ces règles de jouissance commises par le propriétaire sont considérées comme des délits forestiers commis dans la forêt d'autrui; ils seront poursuivis par les agents de l'Administration des Eaux et Forêts et punis en conséquence.

"Art. 4. - Les forêts de protection appartenant à des communes, sections de commune ou établissements publics, sont toujours soumises au régime forestier communal, sans que l'exception fondée sur l'impossibilité d'anénagement ou d'exploitation régulière puisse, dans aucun cas, être opposée à cette soumission.

"Art. 5. - Les forêts de protection, quel qu'en soit le propriétaire, sont exemptes de tout impôt foncier et de tous centimes additionnels, départementaux ou communaux. Il est pourvu gratuitement, par les préposés de l'État, à la surveillance des dites forêts. Des travaux de reconstitution ou d'amélioration desdites forêts actuellement ruinées pourront être exécutés, sur la demande des propriétaires, par les agents forestiers de l'État, et, dans ce cas, il sera accordé par l'Administration, pour l'exécution desdits travaux, des subventions équivalentes au moins à la moitié de la dépense totale.

"Art. 6. - Tout propriétaire de forêts de protection peut réclamer l'expropriation de ces forêts par l'État. Il est alors procédé à cette expropriation dans les conditions de la Loi du 3 mai $1841 \%$.

Le groupe forestier de la Chambre des députés, que préside M. Chalamel, a dû déposer, au commencement du mois de mai 1913, une proposition de Loi sur la protection des forêts, dont le texte suit:

"Article premier. - Peuvent être classées comme forêts d'utilité publique les forêts, bois, prés-bois et pâturages boisés, quels qu'en soient les propriétaires, dont la conservation est reconnue nécessaire : 10 au maintien des terres sur les montagnes ou sur les pentes; $2^{\circ}$ à la défense du sol contre les érosions et les envahissements des fleuves, rivières ou torrents ; 3o à l'existence ou à la salubrité des sources et des cours d'eau ; $4^{0}$ à la protection contre les écarts considérables dans le régime des eaux; $5^{\circ}$ à la protection contre les avalanches et les chutes de glace ; $6^{0}$ à la protection des dunes et des côtes contre les érosions de la mer et l'envahissement des sables ; 70 à la défense du territoire ; $\$^{0}$ à la salubrité publique; 90 à la protection contre les influences climatologiques nuisibles.

"Art. 2. - Le classement doit s'opérer de façon à embrasser des zones dites de protection ayant, autant que possible, des limites naturelles et à l'intérieur desquelles les forêts, bois, prés-bois, seront considérés comme forêts d'utilité publique. Le périmètre de chaque zone est fixé après enquête par une loi spéciale. Les formes de l'enquête seront déterminées dans un règlement d'administration publique.

"Art. 3. - Les dispositions exceptionnelles de l'article 224 du Code forestier ne sont pas applicables aux forêts d'utilité publique. 
"Art. 4. - Les forêts d'utilité publique appartenant à des communes, sections de commune ou établissements publics sont toujours soumises au régime forestier, sans que l'exception fondée sur l'impossibilité d'aménagement ou d'exploitation régulière puisse, dans aucun cas, être opposée à cette soumission.

"Art. 5. - Aucun particulier ne peut user du droit d'exploiter les bois lui appartenant et situés dans la zone de protection, qu'après avoir fait une demande spéciale à la Conservation des Eaux èt Forêts au moins deux mois à l'avance. La demande doit contenir élection de domicile dans la commune de la situation des bois et indiquer la nature et la quotité de l'exploitation. Le Conservateur des Eaux et Forêts devra, dans le délai de deux mois, donner l'autorisation d'exploiter, en prescrivant les conditions et précautions jugées nécessaires pour permettre aux forêts, bois, prés-bois et pâturages boisés, de jouer le ròle pour lequel ils ont été classés d'utilité publique. Passé le délai de deux mois, si le Conservateur des Eaux et Forêts n'avait pas répondu, le propriétaire aurait le droit d'exploiter ses bois dans les conditions indiquées par lui dans la demande. En cas de réclamation du propriétaire des bois, l'affaire sera portée devant le tribunal civil de la situation des lieux, et instruite comme il est dit en matière de droit d'enregistrement, par les Lois du 22 frimaire an VII et du 27 ventôse an IX. Dans le cas où le propriétaire subirait ainsi une diminution de revenus, il aurait droit à une indemnité, fixée, si nécessaire, à dire d'experts et suivant des règles à déterminer par un règlement d'administration publique pour chaque zone envisagée.

"Art. 6. - Toutes les exploitations effectuées contrairement à l'article précédent seront considérées comme des délits forestiers et punis comme tels. Les infractions seront constatées et poursuivies par l'Administration des Eaux et Forêts.

“Art. 7. - Les forêts d'utilité publique appartenant à des particuliers seront, lorsque ceux-ci le demanderont, et pour une période d'au moins dix années, gérées par l'Administration des. Eaux et Forêts dans les formes et à des conditions analogues à celles en vigueur pour les forêts communales ou d'établissements publics. Elles pourront être délimitées et bornées suivant les règles prévues pour les forêts soumises au régime forestier. Elles seront gratifiées, de préférence à tous autres terrains boisés ou à reboiser, situés en dehors des périmètres de restauration de la Loi du 4 avril 1882, de subventions de l'État, pour délimitations, bornages, repeuplements, clôtures, chemins, réunions parcellaires et suppression d'enclares et de servitudes. Les forêts d'utilité publique seraient exonérées de tout impôt, taxe ou contribution revenant à l'État, à l'exception toutefois des frais de gestion par l'Administration des Eaux et Forêts, s'il y a lieu.

"Art. S. - Les forêts de protection non classées d'utilité publique demeureront soumises aux dispositions du titre XV du Code forestier contre le défrichement.

" Art. 9. - L'article 221 du Code forestier est complété comme suit : L'exercice du parcours après exploitation, recépage ou incendie, qui aurait pour conséquence d'entraîner la destruction de tout ou partie de la forêt dans lequel il sera pratiqué, sera, après avertissement préalable notifié au propriétaire de ladite forêt, assimilé à un défrichement et puni comme tel. 
"Art. 10. - La présente loi est applicable à la France, à l'Algérie et aux Colonies. »

Observations. - On voit que cette proposition contient des dispositions très diverses et que ses auteurs ont cherché à réunir dans un texte unique tous les projets de lois forestières éclos dans le cours des dernières années. D'une part, en effet, il y est question des forêts de protection (appelées ici forêts d'utilité publique); d'autre part, de la réglementation de jouissance des particuliers, de la soumission facultative au régime forestier, du défrichement indirect, etc.

Pour nous borner à ce qui concerne les forêts de protection, nous constatons que cette proposition, non seulement s'inspire, avec certaines différences toutefois, de celle de M. F. David, mais qu'elle se montre encore plus large, s'il est possible dans l'énumération des conditions qui peuvent motiver le classement. Nous lui adressons donc les mêmes objections que nous avons précédemment formulées. Mais d'autre part, les avantages promis ou offerts aux propriétaires dans l'article 7 sont conformes au principe que nous avons énoncé, savoir que toute restriction de jouissance doit avoir pour compensation des indemnités accordées au propriétaire de la forêt grevée pour des motifs d'utilité publique.

Nous aurons encore, à d'autres égards, à apprécier cette proposition de loi dans le rapport que nous devons présenter, en collaboration avec M. Roulleau, sur l'Intervention de l'État dans la gestion des bois particuliers.

\section{(Applandissements).}

M. Le Président. - Vos applaudissements sont la juste récompense de l'intéressant rapport de M. le Directeur Guyot, en qui nous saluons tous le maitre incontesté du droit forestier.

M. Desconbes. - Les forêts de protection sont indispensables, et il faut que leur existence puisse ètre protégée de la destruction par les troupeaux. La question pastorale est malheureusement la contrepartie de la question forestière. Sans empiŕter sur les travaux de la section qui s'occupe des travaux en montagne, on peut dire que la conservation de la forêt est pratiquement impossible partont où le bétail manque d'herbages.

M. Marchal. - Hélas! que de pays le savent!

M. Desconbes. - C'est done à l'amélioration pastorale qu'on doit demander la conservation de ces forèts nécessaires d'ailleurs à cettr industrie pastorale, qui l'ignore. Cependant, dans les régions où opère l'Association centrale pour l'aménagement des montagnes et où elle a constitué des pâturages communaux, les nouveaux reboisements ont déjà suscité des sources.

De là, Messieurs, la nécessité de secon der les institutions désintéressées qui transforment les montagnards en amis des arbres. Il faut que la forêt devienne l'auxiliaire dì montagnard, dont elle ressuscitera les sources ; elle augmentera la fertilité de ses pàturages. On a quelquefoi mérlit des sociétés désintéressées. Pourtant, nous avons l'exemple. 
du Danemark, où l'Association désintéressée de la reforestation des Landes du Danemark a reboisé plus de 40.000 hectares, a augmenté la pluviosité, et est arrivé à ce résultat que les cantons qu'elle a reboisés sont maintenant les plus fertiles et ceux où le rendement de l'impòt augmente le plus rapidement.

L'État est toujours disposé à diminuer ses dépenses. Mais quelques millions employés en reboisements se traduiraient par des dizaines et des centaines de millions de plus values d'impôts. L'État danois a donné un exemple remarquable. La société de reboisement dont je parle a touché en 1868, l'année de sa fondation, une subvention de 1.400 franes ! Mais, l'État doublant l'apport des initiatives, la subvention atteint maintenant 690.000 franes. Gràce à eet appui de l'État, cette société désintéressée, à quatre couronnes par an de cotisation, a produit une révolution bienfaisante et un enrichissement du pays. Ciest un exemple à suivre.

M. Le Président. - Les observations qui ont plus spécialement trait aux améliorations pastorales sont plutòt du ressort de la quatrième section.

Ce qui est à retenir des intéressantes observations de M. Descombes, notamment au sujet du Danemark, concorde avec les conclusions de M. Guyot. Il s agit de faire un pas de plus dans la voie de la protection des forêts par l'État.

Les conclusions de M. Guyot, très modérées, ont cet avantage, qu’il a signalé lui-mème, de ne pas toucher à la liberté du Parlement. Les lignes générales de M. Guyot permettront au législateur de se monvoir facilement.

Le projet du groupe forestier, que préside M. Challamel, présente un avantage sur celui de M. Fernand David; il se rapproche plus des conclusions de M. Guyot.

Sans doute, on peut faire interrenir dans la question des forêts de protection des préoccupations économiques, mais c’est un détail, ce n'est plus l'idée-mère.

Je constate que vous ètes d'accord sur le principe : pour délimiter' les forêts de protection, il faut s'en tenir à ce que je pourrais appeler les préoceupations de sécurité générale. La formule de M. Guyot et celle du groupe ne sont point inconeiliables.

Une Vorx. - Au contraire!

Un Congressiste. - Pour les forêts de plaine, que fera-t-on?

M. Le Présinent. - C'est une autre question. Elle sera discutée surtout demain. Demain matin, nous aurons à discuter une grosse question ; ce soir, ce n'est qu'une esearmouche.

LE MèMe Congressiste. - En plaine, on ruine des forêts iggalement. 
M. Le Président. - La question est tout à fait différente.

M. Imbart de la Tour. - Je tiens à faire une réserve de principe. Je suis d'accord avee M. Guyot sur la question des terrains en montagne. Pourtant je voudrais faire remarquer que si le considérant parle des terrains en montagne, le texte même du vou n'y fait pas allusion. II serait nécessaire de faire une distinction au point de vue de la question d'expropriation. Nous sommes d'accord en appliquant la restriction nécessitée par les terrains spéciaux, mais comme notre intention est marquée simptement dans le considérant et non pas dans le dispositif, il serait bon de faire une petite restriction pour maintenir les droits des propriétaires à l'égard de l'expropriation. Nous pouvons faire des réserves pour cette question d'expropriation tout en donnant satisfaction aux justes réclamations de M. Guyot pour la question des terrains en montagne, mais nous devons rejeter à présent l'expropriation d'une façon générale, si elle est imposée arbitrairement aux propriétaires forestiers, déjà si épronvés.

M. Le Président. - Cette observation se rapporte au deuxième rou de M. Huffel.

Il ressort déjà des observations de $\mathrm{M}$. Guyot que ce vo̊u devrait disparaître devant celui de M. Guyot, car on pent lui reprocher de soulever cette question de l'expropriation avec une trop grande précision.

N'oublions pas qu'aujourd'hui l'État est déjà armé du droit d'expropriation de la Loi de 1882. Il y a un projet de M. Fernand David, qui élargit, d’une façon assez limitée, ce droit d'expropriation. mais toujours pour les terrains de montagne. Les droits de l'Etat, en matière, de protection, sont cléjà très étendus. Ce qu'il y a de grave dans le vou de M. Huffel, c'est de fixer, d'avance, et d'une façon exorbitante, la base de l'indemnité.

Je vois bien la pensée à laquelle a obéi M. Huffel en fixant son chiffre. Il s'est souvenu de cet arrêt du jury d'expropriation des Pyrénées-Orientales qui voulait faire payer 4.000 franes l'hectare des terrains qui en valaient deux ou trois cents. Heureusement qu'on a trouvé à cet arrêt un vice de forme, ce qui a permis à l'Administration de le faire casser par la Cour de cassation et de renvoyer la cause devant le jury de l'Ariège, qui a accordé 300 franes pour l'heetare.

De tels faits sont de nature à effrayer les fonctionnaires des forêts, et c'est cela qui a inspiré notro collègue dans la rédaction de son vœu. Mais il serait dangereux d'entrer aussi gravement dans la voie des dérogations. Les précédents, d'ailleurs, sont bien moins graves. M. Guyot pourrait vous dire, qu'en ce qui concerne l'occupation du sol par les exploitants de mines, les bases d'indemnité sont fixées par la loi, mais, si ma mémoire est fidèle, il ne s'agit que du double du revenu.

M. Deroxe. - Ce soni des cas tont particuliers. 
11. Le Présidext. - Oui, et même dans ces cas, on a oru deroir donner aux propriétaires un gros avantage, au moins en apparence.

Le vou de M. Huffel me paraît dangereux.

11. I) Nrcolay. - En outre, les dispositions ront à l'encontre du but proposé. Lorsqu un propriétaire aura exploité à fond sa forêt et vendra à l'État une propriété depréeiée, si la base du prix est fixée sur l'exploitation moyenne des dix demières années, l'État achètera très cher. Dans le cas contraire, il achètera à un prix dérisoire.

II. Le Présidext. - Ces observations sont d'une justesse évidente.

II. Chalanel. - Vous avez bien voulu rappeler, Monsieur Guyot, que j'avais déposé une proposition de loi sur la matière. Je suis tout à fait d'accord avec vous. Si notre proposition, qui a été signée par un grand nombre de nos collègues, est plus restrictive que celle de II. Guyot, ça été par tactique parlementaire.

11. Girot. - Je remercie M. Chalamel des bons sentiments qu’il a exprimés à un camarade de la cause forestière.

Toutes les transactions restent possibles. Ce que je roudrais faire trancher par cette assemblée, c'est la question de principe. Ce principe. est que la forêt de' protection ne doit pas ètre indéfiniment extensible, et qu'on ne doit pas pouvoir employer des motifs quelconques pour elasser comme forêt de protection un massif déterminé.

J'ai cité en appendice les raisons par lesquelles M. Fernand David prétend pouroir justifier le elassement. Elles me paraissent beaucoup trop étendues. Je n'ai rien à dire en ce qui concerne le maintien du sol sur les pentes ou la défense du sol contre les érosions. Mais il n’en est pas de même pour l'existence des sources et cour's d'eau. Est-ce que toutes les forêts, qu'elles soient de plaine ou de montagne, ne sont pas utiles aux cours deau? Une telle disposition permettrait d'étendre indéfiniment, sur tout le territoire, le principe des forêts de protection. Ce serait excessif (Applaudissements).

La salubrité générale! Est-ce que toutes les forêts ne sont pas nécessaires à la salubrité générale? Le maintien des conditions économiques existantes! Mais vous ne pouvez toucher au moindre boqueteau sans modifier dans une certaine mesure les conditions économiques du village roisin. La protection contre les influences climatologiques nuisibles! Oui, sans doute, la forêt peut jouer ici un rôle utile, mais cela ne vise pas seulement la forêt de montagne.

de n'insiste pas, parce que je vois que nous sommes tous d'accord.

M. Ciralanel. - Il faut limiter le plus possible les forêts de protection, et les borner à quelques grands massifs qu'il importe vraiment de conserver.

Malheureusement nous devons tenir compte de l'opinion d'un très grand nombre de nos collègues, qui pourraient se rallier à la mentalité 
qui a inspiré la proposition de M. Dumont et qui nous échapperaient. Nous espérons cependant les amener progressivement aux idées que vous exprimez si justement.

M. DE Nicolay. - Les explications de M. Chalamel sont tout à fait intéressantes. Elles montrent les difficultés qu'on rencontre à soutenir notre thèse. C'est une raison de plus pour émettre des voux formels qui soient l'expression du désir que nous avons de ne voir appliquer des restrictions au droit de propriété que dans des conditions déterminées. Si les exigences parlementaires amènent à étendre la zone protégée, nous pouvons espérer que nos intérêts seront défendus avec succès. Dans tous les cas, nous devons rester strictement attachés au texte proposé par M. Guyot et demander que la zone de protection sarrête aux terrains de montagne et aux dunes.

M. Le Président. - D'accord avec M. de Nicolay, j'estime que le Congrès doit manifester nettement ses tendances. Nais il ne faudrait pas en arriver à discuter des modalités de détail, comme la question de savoir si le propriétaire, quand la servitude lui sera trop lourde, aura le droit de demander l'expropriation. Ce qui me parait surtout important, e'est d'indiquer que la servitude devra apporter avoc, elle des compensations.

M. Delahaye. - Si l'État doit donner au propriétaire des compensations équivalentes aux restrictions qu'il lui impose, il semble que le propriétaire n'aurait jamais à souffrir. D'autre part, il arriverait un moment où les compensations couteraient peut-être plus cher que l'expropriation, à laquelle l'État serait ainsi amené par la force même des choses.

M. Le Président. - Ne perdons pas de vue ce principe que la zone de protection doit être restreinte aux pays de montagnes et aux dunes. Il serait bon de répéter ces mots dans le texte même du rou. On limiterait ainsi nettement nos demandes et l'on éviterait bien des inconvénients.

Quant à discuter les modalités, ce serait entrer dans le détail de questions délicates et de nature à soulever des contestations.

Le rejet du vœu de $\mathrm{M}$. Huffel, que je mettrai tout à l'heure aux voix, sera la manifestation très nette des intentions de la section de ne pas admettre l'extension du droit d'expropriation.

M. Denoye. - Quand on parle de droits, on oublie en général de parler de devoirs. Nous discutons pour le moment les droits qu'auraient les propriétaires forestiers aux récompenses et aux avantages, mais nous ne savons pas du tout quels seront leurs devoirs, quel sera le texte instituant les forêts de protection, à quelles obligations il soumettra les propriétaires. Il conviendrait done de rester dans les termes généraux du vou de M. Guyot. 
M. de Nicolay.. - Parfaitement. Mais pourquoi n'ajouterions-nous pas, après les subventions et exemptions d'impôts. "et même expropriation sur la demande des propriétaires ॥? (Très bien! Très bien !)

M. Le Présidext. - M. de Nicolay nous donne là peut-être le germe d'une solution.

Quant à l'observation de M. Deroye, elle est très juste : on ne peut définir les droits d’une façon précise, puisque les charges ne sont pas définies.

Je vous propose la formule suivante; "Tels que subventions et exemptions d'impôts et, au besoin, faculté pour les propriétaires de requérir l'expropriation" (Très bien! Très bien! Applaudissements).

Ces mots conservent un caractère indicatif, et laissent toute liberté au Parlement.

M. Chalamel. - Ciest parfait.

M. Le Présidext. - Alors, Messieurs, pour déblayer le terrain, je vais vous proposer d'une façon ferme de rejeter le second rœu de M. Huffel.

M. Descombes. - De le disjoindre.

M. Le Président. - Le rejet présente une importance. Il importe que le Congrès se prononce formellement.

Le second vou de M. Huffel, mis aux voix, est rejeté.

Un Congressiste. - Dans le vœu de M. Guyot, après les mots "Est d'asis qu' une légistation spéciale des forêts de protection ", ne pourrait-on ajouter: "dans les régions ci-dessus définies".

Ux autre Coxgressiste. - Pourquoi ne pas ajouter la phrase ellemême: "dans les régions élevées et clans les dunes »? Ainsi il n'y aurait aucun inconvénient à ce que le rœu fût détaché de son considérant, ce qui arrive quelquefois.

M. Le Présidext - Les esprits les moins curieux auraient tendance à rechercher trois lignes plus haut ce que signifient ces mots : "ci-dessus définies ", mais, comme le fait remarquer M. le Rapporteur : expleta non nocent.

M. VIDAL. - Tout cela est très bien, mais nous sommes bien loin du milieu de la France. Je voudrais qu'on indique d'un mot qu'on tient à généraliser la question dans toutes les parties de la France.

M. Le Présidbat. - Il y a des montagnes et des régions élevées dans toutes les régions de France.

M. Chalanel. - Le Parlement généralisera.

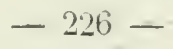


M. Le Président. - Notre texte s’applique à toute la France.

M. Cinlamel. - Nous demandons une loi particulière pour chaque cas. Si nous restreignons le nombre des cas, nous arriverons à empêcher une extension excessive.

M. Arvould. - Il serait plus logique d'écrire "exemptions d'impôts et subventions" au lieu d" "subventions et exemptions d'impôts ".

M. Le Président. - Votre observation est très juste.

M. Guyot. - Je ne m’oppose pas à cette modification (Très bien! Très bien!)

M. Le Président. - Desgedifférentes modifications proposées, il résulte que le texte serait ainsi amendé :

"Est d'avis qu'une législation spéciule des forêts de protection, dans les régions élevées et dans les dunes, est senle capuble de prévenir les dangers qui résultent de leur disparition, législation prés'entive qui doit tenir compte de la situation économique et de l'organisation administrative des divers pays, étant entendu toutefois que les servitudes qui en résultent pour les propriétaires forestiers doicent être compensées par des avantages équivalents, tels que exemptions d impôts, subventions et, au besoin, faculté pour les propriétaires intéressés de requérir l'expropriation ".

Je mets aux roix le vou ainsi modifié.

Le vœu est adopté à l'unanimité.

La séance est levée à $3 \mathrm{~h}$. 35 . 


\title{
SEANCE DU 17 JUIN 1913
}

\author{
(MATIN) \\ Présidence de M. VIVIER, président de Section
}

La séance est ouverte à 9 h. 25.

M. le Président. - Avant d'aborder l'ordre du jour, je tiens à bien inviter nos collègues étrangers à prendre paṛt à nos discussions.

lls ne s'étonneront pas que, dans un Congrès de législation où la majorité des membres sont des Français, où l'on traite des questions d'un intérêt palpitant pour la France, on se place surtout au point de vue français. En matière législative, cela se comprend puisqu'il s'agit de questions concrètes, susceptibles d'applications pratiques, et il n'est pas douteux que le point de vue forcément national domine. Mais, indépendamment de l'intérêt que MM. les délégués étrangers pourront trouver, au point de vue de la législation comparée, à nos délibérations, nous aussi, nous pouvons avoir grand in térêt à entendre leurs observations.

Nous serons, par conséquent, très heureux si, dans les discussions qui pourront aroir lieu, nos collègues étrangers veulent bien nous prêter le concours de leur compétence et des notions spéciales qu'ils peuvent tirer de leur législation nationale.

Ceci dit, j’arrive à l'ordre du jour, qui appelle la discussion du rapport de MM. Guyot et Roulleau.

Je donne la parole à M. Roulleau pour la lecture du rapport sur l'INTERVENTION DE L'ÉTAT DANS LA GESTION DES BOIS PARTICULIERS.

- Léglslations diverses réglant cette intervention.

11. Roulleau. - L'État doit-il intervenir dans la gestion des bois de particuliers? Pour quels motifs, dans quelle mesure et à quelles conditions? Telles sont les questions fort graves et d'une pressante actualité que nous nous proposons de traiter dans le présent rapport.

Nous devons faire à cet égard une distinction fondamentale entre la conservation et la gestion des forêts privées. Il est généralement admis que la conservation des forêts importe à l'intérêt public, et qu'il appartient à l'État de veiller à ce que "l'aire forestière ne soit point diminuée ". Tel est le but de la législation du défrichement, dont nous n'entendons pas nous inquiéter ici. On admet également que, dans des cas exceptionnels, 
lorsqu'il s'agit de prérenir ou de combattre un danger qui menace gravement certains points du territoire, l'intervention de l'État peut se manifester par des inesures de préservation et de régénération, qui sont l'objet de la législation des terrains en montagne et des dunes; ce sujet se relie à celui des forêts de protection, dont il a été traité dans un autre rapport, et sur lequel nous ne reviendrons pas, pour le moment du moins.

Nous entendons parler ici des forêts privées auxquelles ne s'applique point la législation spéciale des terrains en montagne et des dunes. Elles constituent de beaucoup la plus forte partie des six millions et demi d'hectares boisés qui appartiennent en France aux particuliers. Sauf le défrichement qui leur est défendu, ces propriétaires seront-ils libres d'administrer comme ils l'entendent, ou bien devrons-nous admettre que leur gestion pourra être contrôlée, que l'État pourra intervenir, en leur imposant une sorte de tutelle, à laquelle ils seront nécessairement assujettis?

Cette tutelle serait à coup súr une inesure bien extraordinaire, difficile à concilier avec la notion moderne de la propriété privée. Elle nous ramènerait au droit féodal et monarchique, alors que le seigneur ou le souverain, se considérant comme un père de famille chargé de veiller sur la fortune de ses sujets présumés incapables, s'arrogeait le droit de réglementer, de tracer des règles de conduite, pour redresser leurs erreurs de gestion et empêcher la dilapidation de leur patrimoine. Mais ce droit ancien n'existe plus; depuis longtemps il est aboli, et les citoyens français sont déclarés maîtres de leur personne et de leurs biens. La théorie de "l'abus du droit" que l'on invoque parfois pour justifier l'extension des pouvoirs de l'État, est incompatible avec la notion moderne de la propriété; et pour trouver des exemples de son application aux forêts, il faut aller chercher dans la législation des peuples dont la constitution politique et sociale est très différente de la nòtre. Cette théorie nous conduit en effet à admettre la Forsthoheit des anciennes législations allemandes, dont on trouve encore des traces en Wurtemberg par exemple, ou encore en Hongrie et dans certains cantons suisses, mais qui, même dans ces pays, tend à être abandonnéc en faveur d'un système plus libéral et plus conforme aux idées modernes. De ce que, dans les siècles lointains, la forêt appartenait à tout le monde, et que l'État pouvait alors y réglementer souverainement la jouissance commune, on ne saurait conclure qu'il doit en être de même aujourd'hui, dans des pays où la propriété forestière, depuis très longtemps assise, doit jouir des mêmes garanties que toutes les autres propriétés privées.

Sans doute, pour justifier l'intervention de l'État dans la gestion des particuliers, on invoque l'utilité publique des forêts et l'intérêt pour la nation de veiller à ce que les détenteurs de forêts leur appliquent un judicieux traitement. Mais ce motif est insuffisant. S'il était admis pour la forêt, pourquoi ne pas l'étendre aux autres natures d'immeubles? Il importe également à l'intérêt public que les terres arables produisent le plus de céréales possible, que les vignes donnent du vin de la meilleure qualité, que les bestiaux élevés dans les pâturages soient des races les meilleures pour la précocité et la fécondité. Ira-t-on cependant jusqu'd souffrir que les agents de l'État viennent imposer l'emploi de certaines semences et de certains engrais, obliger à planter certains cépages, défendent d'élever certaines races ou exigent de nourrir à l'hectare un certain nombre de têtes de bétail? Nos agriculteurs ne manqueraient 
pas de répondre qu'ils savent ce que leur commandent leurs intérêts, et que l'État n'a point à se mêler de leurs affaires.

Pourquoi alors ce qui paraît, à juste titre, exorbitant pour les propriétaires agricoles serait-il admissible pour les propriétaires de forêts privées? On objectera la nature spéciale de la propriété forestière. Sans doute c'est un argument qui est à bon droit employé pour expliquer la soumission au régime forestier des forêts communales; là, il est vrai tandis que pour les autres parties du domaine de la commune, le Conseil municipal administre sous le simple contrôle du Préfet, pour la forêt communale, la commune est en tutelle et la gestion est confiée à une Administration de l'État. Cette anomalie s'explique parce qu'il s'agit d'une jouissance de tous les habitants, auxquels le frein de l'intérêt personnel fait défaut, et qui conduit, plus facilement pour la forêt que pour d'autres biens, à des ruines irréparables; il importe que la génération actuelle ne puisse pas, au préjudice des générations futures, dissiper une richesse qui ne se reforme que très lentement. Mais il n'en est plus ainsi pour la propriété privée; là, le propriétaire qui serait tenté d'abuser, subirait directement les conséquences de sa mauvaise gestion; son intérêt personnel le force à être bon administrateur. C'est ce qu'on remarque dans les pays de montagne, par exemple, si l'on compare le pâturage communal, ruiné par la jouissance commune, et les pâturages privés. L'argument tiré de la nature spéciale de la forêt n'a donc rien à faire ici.

De ce que la prospérité de la forêt privée importe à l'intérêt public, nous ne devons donc pas déduire que l'Etat a le droit d'intervenir dans sa gestion. Une telle intervention ne serait autre chose que l'application d'une théorie socialiste conduisant à la nationalisation de la propriété forestière ; et une fois cette nationalisation admise, nous ne voyons pas pourquoi elle ne serait pas étendue à toutes les autres parties du sol national. Est-ce le résultat que l'on voudrait obtenir?

L'exemple des législations étrangères serait un mauvais argument pour entrainer leur imitation dans un pays tel que la France. Sans doute, dans les pays allemands, en Autriche-IHongrie, et enfin en Suisse, la législation antorise une intervention, qui peut s'étendre fort loin, de l'État dans la gestion des bois particuliers (1). Nais l'application de telles mesures est généralement laissée à des autorités locales, mieux placées que l'Etat pour concilier avec l'intérêt public les habitudes et les besoins des propriétaires. Ensuite, ce n'est pas tout que d'édicter des lois; il faut voir comment elles sont acceptées et quel effet produit leur application; or, à cet égard nous croyons bien que ces textes coercitifs ne sont guère mis en pratique et que leurs résultats sont assez médiocres. Ce n'est pas la peine alors de violer les principes de notre législation française pour essayer d'acclimater chez nous des mesures que supportent diflicilement les nations voisines, mieux façonnées que nous cependant pour admettre la réglementation et l'ingérence de l'État.

En résumé, nous croyons pouvoir conclure qu'en France, l'État doit se borner à gérer les forêts dont il est propriétaire, et celles des personnes morales placées sous sa tutelle; $\mathrm{et} \mathrm{s'il} \mathrm{veut} \mathrm{se} \mathrm{rendre} \mathrm{maître} \mathrm{d'autres} \mathrm{forêts}$

(1) Pour l'analyse de ces législations étrangères, voir notamment J. Madelin, Les Restrictions légales au droit de proprićté forestière privée (Paris, Rousseau, 1905. Spécia. lement: Chapitre IX, Empire Allemand; Chapitre X, Autriche; Chapitre XI, Hongrie; Chapitre XIII, Suisse. 
pour les traiter comme il l'entend, il n'a qu'à les acquérir par les moyens du droit commun.

Jusqu'à une époque très voisine de nous, on n'avait jamais eu l'idée d'étendre chez les particuliers l'intervention de l'État; notre Code forestier ne contient aucune trace de telles prétentions. Nais nous devons reconnaitre que, depuis quelques années, une campagne très vive a été entreprise, surtout dans le monde parlementaire, pour recruter des partisans en faveur d'une' ingérence plus complète de l'État dans la gestion des forêts privées. Et, bien que les diverses tentatives imaginées pour limiter les droits des particuliers, n'aient pas abouti jusqu'à ce jour, il est intéressant de considérer sous quelles formes elles se sont produites, d'autant plus que pour certaines d'entre elles, les promoteurs de ces innorations paraissent agir dans les meilleures intentions et sans se douter, peut-être, des conséquences que peuvent avoir les mesures qu'ils proposent sous le prétexte de l'intérêt public.

L'entreprise la plus grave et la plus brutale qui ait été formulée contre le droit des propriétaires est celle du projet de Loi du 20 février 1908 "sur les défrichements et exploitations des bois particuliers ". Les auteurs de ce projet étaient parfaitement conscients de l'énormité juridique et économique qu'ils voulaient commettre, en insérant dans un nouvel article 223 du Code forestier leur famenx système dit " des cinq possibilités ». Il s'agissait de défendre au propriétaire de couper dans sa forêt une quantité de matériel présumée susceptible d'appauviir le peuplement, et au cas où cette quantité aurait été dépassée, le propriétaire coupable du nouveau délit de "déforestation "était puni comme s'il avait défriché sans autorisation. C'était mettre tous les propriétaires de France à la discrétion de l'autorité administrative, les priver de l'un des avantages les plus précieux de la propriété forestière, celui de réaliser au moment opportun et le plus avantageux, le matériel mis en épargne par des économies volontaires; enfin la sanction était exorbitante et hors de proportion avec la nature de l'infraction. Aussi ce projet de loi souleva$\mathrm{t}$-il, dans tout le monde forestier, les plus violentes réeriminations. En vain, pour répondre à l'une des critiques adressées au nouvel article 223, consistant dans la difficulté de s'entendre sur la possibilité de la plupart des forêts, le projet fût-il modifié, et les " cinq possibilités " remplacées par le "dixième du matériel existant ", plus facile à vérifier sur place. Cette atténuation ne supprimait pas le vice originel du projet qui, en outre de la question de principe, entrainait une administration de l'État à une ingérence absolument différente do ses fonctions habituelles et contraire à ses traditions. Au reste, ce projet de 1908 paraît abandonné, et il est peu probable que personne essaie de le faire revivre.

Mlais tout péril n'est pas écarté ; le danger résultant de l'immixtion de l'État dans la gestion des forêts privées réapparait, sous une forme moins directe peut-être, tout anssi réelle cependant, que lel ait été ou non le but des auteurs de deux propositions de loi qui, au premier abord, ne paraissent pas s'appliquer à notre sujet : proposition Fernand David, du 15 mars 1907, sur les forêts de protection, et proposition Chalamel, mai 1913, sur les forêts l'utilité publique. Dans le rapport consacré aux forêts de protection, on a pu voir que l'introduction en France de ces forêts est parfaitement admissible, pourvu que l'application du système soit modérée et restreinte aux cas de dangers imminents, tels que ceux qui se présentent dans les hautes montagnes et les dunes. 
Mais les deux propositions de loi précitées vont infiniment plus loin, et, c'est en cela que, d'une manière détournéc, elles constituent, pour la propriété forestière privée, une menace presqu'aussi grave que le projet du 20 février 1908.

Quels sont, en effet, les motifs pour lesquels, sous prétexte de protection ou d'utilité publique, les forêts privées seraient soumises à l'ingérence administrative, à l'arbitraire de l'Etat? Ce sont, non seulement tous les motifs qui peuvent être invoqués pour une opposition au défrichement, mais d'autres encore, tellement vagues, qu'en se fondant sur les uns ou sur les autres, il serait possible d'y comprendre toutes les forêts françaises.

Ainsi, dans le projet Fernand David, article 7, peuvent être déclarées forêts protectrices, par décret, celles dont la conservation est reconnue nécessaire... $3^{\circ}$ à l'existence des sources et cours d'eau... $6^{\circ}$ à la salubrité publique: $7^{\circ}$ au maintien des conditions économiques existantes, relatives aux besoins des populations bûcheronnes et industrielles qui rivent de l'exploitation régulière de la forêt. Pour l'un ou l'autre de ces motifs, il est facile de prétendre qu'une forêt quelconque doit être rangée parmi les forêts protectrices.

De même, dans le projet Chalamel, article 1er, peuvent être classées comme forêts d'utilité publique celles reconnues nécessaires... $3^{\circ}$ à l'ex istence ou à la salubrité des sources et cours d'eau; $4^{\circ}$ à la protection contre les écarts considérables dans le régime des eaux; $8^{\circ}$ à la salubrité publique; 90 à la protection contre les influences climatologiques nuisibles.

N'est-il pas évident que pour toutes les forêts existantes, l'une ou l'autre de ces raisons peut être donnée pour justifier le classement d'utilité publique?

Et quels vont être alors les effets de ces classements?

D'après la proposition David, article 9, c'est un régime spécial qui sera imposé à chaque forêt, sous le contrôle des agents forestiers, consistant dans la défense de se livrer à toute opération de nature "à détruire, suspendre, affaiblir ou compromettre le rôle protecteur ou bienfaisant de la forêt ". C'est le propriétaire livré, pieds et poings liés, à l'arbitraire administratif.

De même, d'après la proposition Chalamel, article 5, défense pour le propriétaire de faire une exploitation quelconque dans sa forêt sans demande préalable et autorisation spéciale. Quelles que soient ensuite les atténuations et les garanties promises, peu importe ; ainsi la proposition Chalamel veut une loi spéciale après enquête; elle entend que l'utilité publique sera déclaréz non pour une forêt déterminée mais pour une zone naturelle, le tout sauf recours devant un tribunal civil, etc.

11 n'en est pas moins vrai que, si l'une ou l'autre de ces propositions était adoptée, tous les propriétaires de France auraient désormais suspendue sur leurs têtes cette épée de Damoclès : sous prétexte de protection ou d'utilité publique, l'État pourrait venir leur imposer des règles de jouissance, empêcher toute réalisation de matériel, se substituer à eux pour l'entière gestion de leurs forêts.

Vainement nous dira-t-on que l'application de telles lois serait exceptionnelle. S'il doit en être ainsi, pourquoi leur donner une extension aussi considérable, inquiéter tout le monde, déprécier la propriété forestière à un moment où elle a le plus besoin d'être encouragée? Que le veulent 
ou non les auteurs de ces propositions, tant qu'elles n'auront pas été étroiment limitées à des cas pour lesquels le danger imminent, la nécessité publique, ne peuvent être contestés, elles sont infiniment redoutables pour la propriété forestière privée, et tons les propriétaires doivent s'unir pour s'opposer à leur adoption.

Mais si nous croyons devoir ainsi repousser énergiquement toutes les mesures coercitives tendant à une ingérence de l'État dans la gestion des forêts privées, ce n'est pas que nous méconnaissions les services, l'aide et le secours bénévoles que ces forêts sont en droit d'attendre des pouvoirs publics. Ces services sont nombreux et importants, et la propriété forestière privée en a un pressant besoin, dans la crise intense qu'elle traverse en ce moment : crise économique surtout, provenant de l'avilissement de certaines marchandises, chauffage, charbons, écorces, qui constituent la production à peu près exclusive des bois particuliers, sans compter les fléaux, tels que des maladies cryptogamiques, qui sont venus aggraver cette crise dans beaucoup de contrées. On dit aux particuliers qu'ils doivent transformer leurs modes d'exploitation, allonger les révolutions de leurs taillis, faire produire à leurs forêts des bois d'industrie ; mais cette transformation sera longue, et avant qu'elle soit opérée les particuliers devront subir une énorme diminution de leurs revenus. C'est dans une situation aussi précaire qu'ils doivent pouvoir tous compter sur le secours de l'État. Vainement prétendra-t-on qu'il ne s'agit en somme que d'une aristocratie de riches particuliers détenteurs de vastes domaines, qui peuvent se donner le luxe d'une propriété onéreuse; ce serait une grave erreur de croire que les forêts particulières sont réunies partout par grandes masses en un petit nombre de mains ; pour la majeure partie, ces forêts sont très divisées, et le nombre des propriétaires particuliers est infiniment plus considérable qu'on ne le croit généralement (1). A tous ces détentrurs de la forêt privée, quelque minime ou importante que soit leur propriété, l'Etat doit aide et assistance, suivant le principe de l'égalité.

Comment se manifestera cette sollicitude de l'État, en vue de remédier à la crise de la propriété forestière privée? Les moyens sont nombreux; nous allons énumérer les principaux.

D'abord et surtout, la forêt doit obtenir un allègement des impôts qui l'accablent. Cet allègement des impòts qui absorbent la plus grande partie, parfois même la totalité du revenu, serait la mesure la plus efficace pour encourager les propriétaires, arrêter la dépréciation de la forêt, prévenir la réalisation du matériel, cette " déforestation " que l'on reproche si vivement à ceux que la nécessité seule a le plus souvent conduits à l'exploitation prématurée des arbres do futaie. En quoi et sous quelle forme pourront être accordés les dégrèvements d'impôts en faveur de la propriété forestière, nous n'arons pas à l'indiquer ici ; disons seulement qu'on se contente de réclamer, pour la forêt, l'égalité des charges fiscales, et non un privilège, dans la mesure de la valeur actuelle, si considérablement diminuée, de cette propriété.

Après la question fiscale, de beaucoup la plus importante et la plus urgente, d'autres encore appellent la sollicitude des pouroirs publics. Ainsi, l'intervention facultative des agents et préposés de l'État, venant

(1) Ainsi, dans la région de l'Est, il se chiffre en moyenne par 10.000 au moins dans chaque département. Dans le Centre, la moyenne est de 20.000, parfois de 25.000 . 
coopérer, sur la demande des propriétaires, à la gestion des forêts privées. On a proposé à ce sujet une soumission pure et simple de ces forêts au régime forestier; nous doutons que les propriétaires consentent à abdiquer ainsi complètement leurs droits, à se mettre en tutelle, alors même qu'ils auraient une entière confiance dans le savoir et l'expérience de leurs tuteurs. Mais à défaut de cette soumission complète, nous demandons, comme l'écrivait dèjà l'un de nous en 1908 (1), que les propriétaires soient autorisés à s'entendre avec ceux des forestiers de la région dont ils apprécient la capacité, et qui pourraient se charger de certains travaux de gestion, tels que balivages, estimations, aménagements, repeuplements. Que l'État continue à permettre, plus largement encore qu'aujourd'hui, à ses gardes d'assurer la surveillance des bois particuliers; qu'il consente de plus à exercer les poursuites contre les délinquants et à requérir l'application de la loi pénale : ce seront des services très appréciés qu'il peut rendre facilement aux propriétaires, sans les obliger à se désintéresser complètement de la gestion de leurs forêts.

L'État devrait aussi faire une part plus considérable à la propriété forestière dans les encouragements de toutes sortes qu'il pratique aux autres propriétés rurales. Il faudrait que le principe des subventions en nature, sous forme de fournitures de graines ou de plants, fut plus largement appliqué aux forêts, non seulement dans les pays de montagnes mais aussi pour le repeuplement des vides et le reboisement des forêts de plaine; que le nouveau service des améliorations agricoles se mit à la disposition des propriétaires forestiers pour des travaux tels que la création de chemins de vidange, si nécessaire au transport des produits ; il faudrait que dans tons les Comices, dans toutes les Sociétés subventionnées par le Ministère de l'Agriculture la forêt reçût, sous forme de prix de concours, des encouragements au moins égaux à ceux des autres exploitations agricoles. 11 n'est pas besoin dinsister beaucoup sur ce chapitre: la simple équité vent que la propriété forestière, si importante au point de vue de l'intérêt public, soit placée au rang qu'elle doit justement occuper, toutes les fois qu'il s'agit de participer aux libéralités du budget de l'État.

Nous arons exprimś le désir que les particuliers puissent avoir recours aux agents et préposés de l'État. Les services que peut leur rendre ce personnel d'élite seraient encore plus grands si l'Administration prenait le soin d'orienter davantage l'activité de ce personnel vers les applications commerciales, tout en lui conservant la valeur technique dont il est suffisamment pourvu. Il fut un temps où les agents forestiers semblaient dédaigner cette fonction pourtant essentielle de tirer des produits de la forêt le maximum de profits possible et s'absorbaient par trop dans les théories d'aménagement et de possibilité. Nous savons que ce temps n'est plus; cependant existe-t-il encore beaucoup d'agents qui comprennent la nécessité de la science pratique du "marchand de bois ", et qui consentent à s'en servir? A l'inverse, le particulier ne voit trop souvent que le rendement pécuniaire, auquel il est tenté de sacrifier l'avenir, l'amélioration du matériel futur. Il faut que, dès les bancs de l'École d'application, les agents et les préposés de l'État soient bien imbus de cette nécessité de la science commerciale, de la recherche des débouchés et des

(1) Bulletin de l'Office forestier du Centre et de l'Ouest, tome $1^{\mathrm{er}}, \mathrm{p} .331$ et s., férrier 1909. Dans le même sens: Resue des Eaux et Forêts, no du 15 mars 1913: "A propos de la loi sur la conservation des forêts privées 
besoins des industries de la région, et qu'ils s'appliquent à obtenir, par la confection des marchandises les mieux appropriées aux situations locales, le rendement pécuniaire le plus élevé. Alors seulement les particuliers pourront trouver auprès d'eux tout ce qui est essentiel pour la gestion de leurs forêts : la science théorique et le profit immédiat.

Nous voudrions aussi que l'Administration consentît à communiquer plus facilement aux propriétaires tous les renseignements statistiques et commerciaux que lui fournissent ses agents, et qui ne sont pas toujours utilisés comme ils pourraient l'être. Il serait nécessaire d'instituer à cet effet, à l'Administration centrale des Eaux et Forêts, un office de renseignements ouvert à tous les intéressés, et auquel pourraient recourir les organes qui se donnent pour mission l'étude et la défense des intérêts forestiers privés : les Syndicats de propriétaires et le Comité des forêts. Mouvement des importations et exportations, résultats des ventes, prix des transports et de la main-d'ouvre, tout ce qui peut instruire les vendeurs, leur permettre d'établir le cours régional des produits de la forêt et de traiter en parfaite connaissance de cause avec les acheteurs, se trouverait ainsi à la disposition des propriétaires et de leurs représentants.

L'État peut aussi aider puissamment, pendant la période critique que nous traversons, à enrayer la dépréciation des marchandises que le particulier ne peut pas écouler avantageusement : bois de chauffage, charbons et écorces. Non qu'il suffise pour cela de décréter le relèvement des cours ; mais par beaucoup de moyens indirects, l'État peut arriver à ce résultat si désirable pour la propriété privée. Ainsi, il faut réagir contre l'emploi exclusif de la houille et du coke pour le chauffage, au détriment du combustible ligneux, plus agréable et plus sain. Dans ce but, il est urgent d'étudier des procédés permettant le chauffage central par le bois et le charbon de bois, l'emploi du charbon et des agglomérés de charbon de bois dans les appareils à feu continu, son utilisation pour la production de la force motrice. Déjà le Comité des forêts a pu intéresser à cette étude plusieurs de nos constructeurs les plus réputés; mais qu'en même temps l'État n'hésite pas à instituer et à subventionner largement les expériences nécessaires! Il peut encore agir efficacement sur les Compagnies de chemins de fer, et tout au moins accorder sur les voies ferrées de son réseau le même tarif de transport pour la calorie de bois que pour la calorie de houille; hâter aussi l'amélioration des voies navigables les plus aptes au transport de cette marchandise encombrante qu'est la matière ligneuse, et enfin appliquer les lois récentes sur les fraudes, lorsque ces fraudes, comme celles pratiquées sur certains cuirs notamment, nuisent aux débouchés d'un des produits les plus précieux de nos taillis, l'écorce. Au nom de la propriété privée, nous réclamons énergiquement à ce sujet des garanties immédiates et formelles .

De plus, il est nécessaire, surtout pendant cette période de transformation actuelle des forêts privées, que l'Etat mette à la disposition des propriétaires, par le crédit collectif à long terme, ou toute autre combinaison analogue, et au taux le plus réduit possible, les sommes dont ils ont besoin pour les travaux de conservation et d'amélioration des forêts existantes, et pour la création par le reboisement des forêts nouvelles. Nous voyions tout récemment publié un projet consistant à consentir aux sociétés qui s'occupent de la construction d'habitations à bon marché des fonds au taux de $21 / 2 \%$. Pourquoi un bénéfice analogue ne serait-il 
pas consenti en faveur de la propriété forestière, dont les besoins actuels sont si considérables? Pour la réalisation pratique de ce projet, les intermédiaires sont tout trourés : le Comité des forêts à Paris, les Syndicats de propriétaires dans les départements, fonctionnant dans les conditions de la Loi de 1884, seraient tout désignés pour recevoir les avances de l'État et les distribuer à leurs adhérents, grands, moyens ou petits propriétaires, petits surtout. dans la proportion de leurs besoins.

Pour conclure, nous demandons instamment que rien ne soit changé au régime de liberté dont jouit actuellement la forêt privée. Ce n'est pas à ce régime qu'il faut imputer la ruine, trop souvent exagérée d'ailleurs des forêts françaises. On a prétendu que "la liberté forestière, pratiquée de 1791 à 1827 , nous coúte un effort qui ne sera pas terminé avant 1950 et qui nous impose une dépense de plus de 200 millions pour rétablir à peu près l'ét at de choses existant avant la Révolution ". Cette assertion, bien que produite au cours d'une discussion relative aux mesures fiscales et à la gestion des forêts, ne vise que le défrichement, et même au sujet du défrichement, rappelons que l'ancien régime, loin de l'interdire, le conseillait parfois et le considérait comme un progrès (1). Ce n'est done pas le régime de liberté datant de la Révolution qu'il faut incriminer, et a fortiori ne doit-on pas davantage attribuer à la liberté dont nous jouissons les "déforestations " dont on se plaint depuis peu de temps. alors que cette liberté date de plus de 120 ans. Ainsi que nous l'avons affirmé, c'est l'impôt, annuel ou successoral, qu'il faut surtout incriminer.

Dès lors, nous nous croyons bien fondés à vous prier, Messieurs, d'approuver les idées développées dans ce rapport, en votant les résolutions suivantes :

\section{Le Coxgrès :}

Considérant que les droits de jouissance et de disposition des propriétaires forestiers sont aussi respectables que ceux des propriétaires de tous autres immeubles; que ces propriétaires doivent avoir la liberté de jouir de leurs forêts comme ils l'entendent, sans être soumis à une intervention alministrative; qu'une telle intervention ne pent se justifier qu'en cas de danger public, et non sous le simple prétexte d'utilité publique;

Est d'avis :

Que, sous réserve des mesures de conservation qui penvent être prise's contre le défrichement et pour la protection des terrains en montagne et des dunes, les particuliers soient libres d'asseoir lans leurs forêts telles coupes qu'ils jugent convenables, de réaliser quand ils l'estiment opporlun le matériel sur pied résultant de leurs économies, sans étre astreints à aucune déclaration ni autorisation préalable;

Mais attendu que, dans la crise économique intense que subit en ce moment la propriété forestière privée, l'État a le devoir de venir en aide aux particuliers détenteurs de forêts, qui sont pour la plupart de petits propriétaires, suivant les principes de l'égalité et de la solidarité sociale.

(1) A la suite de la Déclaration Royale de 1766, dit M. le Professeur Huffel (Economic forestière, tome $1^{\mathrm{er}} 1^{\mathrm{re}}$ édition, p. 188), un rapport adressé au roi par lo ministre des finances évalue à 359.282 arpents la contenance défrichée depuis quatre ans, de 1:66 a 1770 . 


\section{Le Congrès est D'Avis :}

Que la sollicitude de l'État peut se manifester très efficacement, sans aucune mesure coercitive, notamment: par des modérations d'impôts; par la faculté donnée aux particuliers d'utiliser le personnel de l'Administration des Eaux et Forêts, qu'il convient d'orienter en vue des services commercianx qu'il peut rendre, an moins autant que dans le sens des applications techniques; par des mesures à prendre pour arrêter la dépréciation de certains produits ligneux (bois de chauffage, charbons de bois, écorces); par des institutions de crédit facilitant anx particuliers la création on la reconstitution de leurs forêts.

\section{Le Présinent. - La parole est à M. Jauffret.}

M. Jauffret. - Messieurs, je désirerais présenter quelques observations qui se rapportent à des faits dont je suis actuellement le témoin dans divers départements, notamment dans l'Yonne, dans la Còte-d'Or, dans la Haute-Marne et dans l'Aube.

Il s'agit de la gestion, - si c'en est rraiment une — de ces propriétaires qui s'inspirent du traitement subi par la poule aux oeufs d'or: Ils s'acharnent à mettre, si jose dire, les entrailles de leurs forêts à nu. Je vous eiterai particulièrement trois massifs de l'Aube. Sur plus de 300 hectares aux flanes de coteaux à pentes abruptes, des taillis sous futaie de végétation médiocre, mais jusqu'à présent sagement aménagés, sont en roie de disparition complète. Dans quelques mois, il ne restera rien, pas un arbre, pas mème un baliveau. On retourne jusque dans les jeunes coupes pour réaliser les moindres réserves en piétinant le taillis. Chaque jour je constate l'extension de la plaie sur le coteau et je ne puis voir ce spectacle sans m'en indigner. Je viens même d'être saisi officiellement d'une plainte de municipalité qui gémit de voir disparaitre en un jour la forêt séculaire, et avee elle son abri, son gagne-pain. La population réclame à grands eris l'intervention des Pouvoirs publies; elle aceuse l'Administration forestière d'indifférence, voire même d'incapacité. Cependant, il n'y a pas défrichement et l'Administration est désarmée. J'avoue que j’ai demandé officiellement que le Conseil ggénéral émette un rou pour que le Parlement interdise sans tarder des actes d'une telle-barbarie, dignes des nomades de l'Asie centrale.

J'estime qu'aucune excuse ne saurait justifier de tels faits. Il y a là un abus manifeste, un gaspillage évident, qui entraînent l'encombrement du marché en produits secondaires; la dépréciation complète du bois de chauffage et de la charbonnette, l'affolement de la maind'œuvre, le tout au plus grand détriment des propriétaires qui exploitent en bons pères de famille.

Nais il y a plus; le sol aride du coteau, lor'squ'il va se trouver complètement dénudé, perdra toute fertilité. Le moindre orage entrainera tout l'humus à la rivière, la Seine; bien que la région ne soit pas dans la zone des montagnes, elle subira, toutes proportions gardées, un dommage analogue. Ia forêt disparue ne renaitra jamais; le fonds 
va être vendu à vil prix. Quelque homme de paille plus ou moins solvable l'achètera; bientôt les impôts ne pourront même plus être recouvrés (Protestations).

Est-il admissible, je vous le demande, Messieurs, de laisser un particulier jeter ainsi et sans motif plausible, par simple spéculation, la désolation dans toute une contrée.

On dit que le propriétaire doit être aussi libre de son bois que d'une vigne ou d'un champ de céréales. Mais il suffit de quelques années pour qu'une vigne rapporte et un champ de céréales peut s'improviser. On n'improvise pas une forêt et le propriétaire, lorsqu'il ruine un massif, ne songe pas qu'il détruit ce qu'il est incapable de remplacer. Il réalise en un jour, non seulement ses économies antérieures, mais celles de plusieurs générations.

Autrefois, personne n'aurait eu l'idée de procéder à des exploitations généralisées sur d’immenses étendues; les débouchés ne l'auraient pas permis, non plus que les moyens de transport. Actuellement, on a réussi à mobilișer la forêt; la tentation devient trop forte, on y succombe; mais c'est un beau jour sans lendemain.

A une époque, le taux de boisement de la France était assez élevé pour permettre les défrichements; cet heureux temps n'est plus, on l'a constaté et on a cru remédier au mal en interdisant le défrichement. La mesure a d'abord suffi, parce qu'au siècle dernier, on n'avait intérêt à défricher que les terrains fertiles pour les livrer à la culture et non pas, je le répète, pour effectuer des exploitations généralisées. Il n’en va plus ainsi. Défricher?... Pourquoi faire?... Non. Il suffit de réaliser tous les produits de valeur et d'abandonner ensuite la brousse et le caillou. Ce procédé est pire que le défrichement, car il ne met à la place de la forêt que le néant.

Puisque la loi se trouve tournée, puisqu'au défrichement démodé succède la déforestation plus funeste encore, il faut parer au nouvean danger ; il faut reprendre la pensée du législateur antérieur, la compléter et l'accommoder aux circonstances présentes.

Je ne pense pas qu'en une telle occurrence le Congrès puisse conseiller le statu quo; ce serait la mort de la forêt en certaines régions. Et vraiment, il y a un intérêt plus sacré que tous les autres, il y a une obligation plus forte que tous les droits. Un bien de première nécessité qu'aucune force liumaine n'est capable de reconstitucr dans un délai utile ne peut être abandonné au caprice d'un homme. Cependant l'État ne suffirait pas à racheter toutes les forêts et, pút-il le faire, que son intervention serait trop tardive si elle se bornait à l'acquisition de massifs ruinés. Ce serait dans un avenir prochain le désert en France.

Mais il n'est pas si diffrile de sauregarder les forêts existantes et je ne crois pas qu'il soit besoin de moyens de coercition bien sévères.

Pourquoi ne pas chercher une disposition très simple, très libérale, s'appliquant à la généralité des forêts de France et permettant aux propriétaires de retirer, le cas échéant, de leurs forêts, le maximum des ressources sans entrainer leur destruction? 
Serait-il impossible de classer les forêts en grandes catégories sans distinction de régions, mais d'après leur état actuel?

La première catégorie comprendrait les taillis simples pour lesquels toute liberté serait laissée aux proprićtaires à l'exclusion du défrichement.

La deuxième catégorie comprendrait les taillis sous futaie. Les coupes pourraient ètre toutes réalisées, sauf application d'une disposition inspirée de l'ordonnance réglementaire : réserve d'un nombre minimum de baliveaux à l'hectare, de modernes et d'anciens.

Le troisième catégorie comprendrait les futaies feuillues et les peuplements résineux. Leur exploitation serait soumise â l'exécution de travaux de repeuplement devant assurer la reconstitution du massif.

Enfin, comme dans la législation sur le défrichement, les massifs de faible étendue et les plantations nouvelles pendant un délai à déterminer, seraient exonérés de toute surveillance et de toute intervention.

La continuité de l'état boisé serait ainsi garantie. Le propriétaire. resterait libre d'user et de disposer de son bien ; sa jouissance ne serait pas réduite à celle d'un usufruitier. Sa propriété serait simplement grevée d'une servitude asséz peu génante (Protestations).

L'intérêt général ne peut être sauvegardé qu'au prix de sacrifices particuliers et il a existé de tous temps des servitudes légales contre lesquelles personne ne songe à protester. Ce serait d'ailleurs le cas de demander une modération d'impôts à titre de compensation; l'oceasion est précisément bonne en ce moment où les propriétaires forestiers ont tant besoin d'un dégrèvement; leurs revendications n'en pourraient ètre que mieux acceptées. Donnant domnant.

Qu'une telle servitude déprécie la propriété forestière, cela n'est guère à craindre. Toutes les forêts étant soumises au même régime, il est à prévoir qu'on prendrait vite l'habitude de la disposition nouvelle et que les transactions n'en seraient pas troublées.

Au surplus, il existe en ce moment un courant dopinion en faveur de l'intervention de l'État dans la gestion des bois particuliers. Ne serait-il pas imprudent de n'en pas tenir compte? Ne vaudrait-il pas mieux essayer d'endiguer et de diriger le flot que les spéculateurs ont soulevé? Je propose done de toute la force que je puis, et dans l'intérêt le plus élevé, celui de la conservation de notre sol boisé, de notre richesse nationale, de celle que les siècles seuls ont pu nous léguer, qu'il suffit d’un jour pour nous arracher, je propose à vos suffrages, le vou suivant :

\section{LE Congrès,}

" Considérant que la déforestation de la France se poursuit dans bon nombre de bois particuliers, de manière à compromettre les intérêts vitaux du pays, tant au point de sue économique que sous le rapport de la sécurité et de l'hygiène publics; 
"Considérant d'autre part qu'il est juste de n'apporter, à l'exercice intégral du droit de propriété que la restriction strictement imposée par l'intérêt général;

\section{ÉMET LE VEU :}

"Que les textes législatifs relatifs à la protection des forêts laissent aux propriétaires particuliers toute liberté d'exploitation sous réserve de l'obligation d'assurer la reproduction des massifs par les mêmes moyens et dans le même temps qu'ils se sont constitués depuis leur dernière réalisation, sous des conditions à déterminer par un Règlement d'administration publique».

En somme, je voudrais assurer la continuité des massifs forestiers et je roudrais que le néant ne succède pas à la forêt.

1I. Morat. - Je voudrais m'élever, moi aussi, de toutes mes forces, contre les paroles que vous venez d'entendre et je dirai tout d'abord que, selon moi, la question a dévié.

Il ne s'agit pas de savoir si on a trop coupé, mais de rechercher les moyens d'éviter qu'à l'avenir on ne coupe trop. Or', hier, il en a déjà été parlé et 11 . Rachet avait présenté un rou demandant que tous les bois particuliers soient soumis au régime forestier et dirigés par' l'Administration, non pas facultativement, mais obligatoirement. Je m’empresse de dire que ce vœu n'a recueilli que la voix de M. Rachet et celle de son voisin.

Cette proposition de soumission de tous les bois au régime forestier est tentante en ce sens que c'est le moyen radical d'empêcher la déforestation, mais l'ingérence de l'Administration forestière dans les bois des particuliers aurait plus d'inconvénients que d'avantages.

Le gros inconvénient, l'inconvénient capital, à mon sens, serait de porter une atteinte extrêmement grave aux principes mêmes de la propriété et à la base même de notre droit français.

Sans vouloir remonter au déluge et faire ici un cours de droit romain, je rappellerai que ce droit de propriété se compose du jus utendi, droit d'user de la ehose, et du jus abutendi, droit d'en abuser...

M. JAUfFret. - Droit d'en disposer....

M. Mочат. - Le jus abutendi est la caractéristique même du droit de propriété, tandis que le jus utendi se retrouve dans le droit de l'usufruitier et ailleurs, dans les locations par exemple. Par contre, le jus abutendi est le fondement du droit de propriété et si vous voulez introduire l'ingérence de l'Administration forestière dans les bois particuliers, le propriétaire n'ayant plus le droit d'abuser n'a plus la propriété.

A mon avis, le seul moyen d'enrayer' le défrichement et le déboisement, c'est de donner aux propriétaires un revenu suffisant leur permettant de vivre du produit de leurs bois, par exemple une diminution d'impôts. Certes, les propriétaires de bois reulent, comme tout le 
monde, payer l'impôt, mais dans des' proportions raisonnables. Je suis de ceux-là, je n'ai d'ailleurs pas à me plaindre — je ne le dis qu'à mi-voix - ear je ne paie que $50 \%$ des revenus de mes bois, j'en connais qui paient beaucoup plus... (Rires.)

M. Guгот. - Je suis désolé d'avoir à prendre la parole contre la proposition de mon excellent camarade et ancien élève $M$. Jauffret, mais je ne puis le moins du monde accepter ses conclusions.

Qu il le veuille ou non, M. Jauffret adopte les idées de M. Dumont, et ce qu'il vient de nous dire me rappelle une séance mémorable, que nous avons eue à l'Administration forestière, lorsqu'il s'est agi de faire des propositions pour la réforme du Code forestier.

Je me rappelle que, m'étant permis de faire observer à M. Dumont que le droit de propriété, tel que nous l'entendons, se compose de deux éléments : le droit de jouir et le droit de disposer, non pas d'abuser, car e'est à tort qu'on a fait cette traduction par trop littérale du mot abutendi, qui veut dire disposer, - M. Dumont, avee l'éloquence fougueuse qui lui est coutumière, me répondit qu'on ne remontait plus aujourd'hui au droit romain, que les prineipes de la solidarité sociale avaient aboli tout cela.

A la suite de cette séance, on accepta son projet des einq possibilités.

M. Jauffret voudrait nous ramener à quelque chose d'analogue. Voulez-vous, Messieurs, de cette loi des einq possibilités?...

Nombreuses volx. - Non !... Non !...

M. Guyot. - Voulez-vous, un jour ou l'autre, être limités dans vos exploitations?... Voulez-vous que l'Administration forestière - que je respecte et aime beaucoup - soit autorisée à venir chez vous pour limiter vos coupes et vous dire : "Vous ne couperez pas ceci?"

C'est à cela que revient la proposition de M. Jauffret.

Je comprends parfaitement la nécessité de l'utilité publique et je suis ému, comme notre collègue, de la déforestation lorsqu'elle sa produit; mais, nous l'avons déjà répété, la faute n'en est pas aux propriétaires. Donnez-leur un intérêt quelconque à conserver leurs bois en bon état et ils n'iront pas, de gaité de cœur, gàcher leurs immeubles, supprimer la végétation ligneuse et mettre leurs forêts à néant.

11. Jauffret nous disait ceci : dans l'intérêt publie, la forêt privée de ses arbres ne rendra plus le service qu'on est en droit d'attendre d'elle.

11 faut distinguer. Si nous parlons des services économiques, je comprends très bien. La production en bois d'œuvre se rétablira seulement dans un temps assez éloigné, mais, à tous les autres points de vue, climatologique, ou régime des pluies et des eaux, du moment où le sol est couvert, soit par une végétation riche telle que de gros arbres, ou par une végétation pauvre comme un taillis simple, la situation doit ètre absolument la même. 
Par conséquent, si nous nous inspirons de ces intérêts généraux très considérables, de l'intérêt public, je ne vois pas que vous puissiez vous en armer pour obliger le propriétaire à conserver sur son sol une superficie forestière plus ou moins riche. Je crois, pour ma part, que ce que nous avons admis dans la précédente séance est un maximum que nous ne pouvons permettre à l'État de dépasser.

Abandonner les forêts de protection, les forêts de montagnes, c'est un maximum à concéder, et l'intervention de l'État en plaine pour limiter les exploitations forestières me paraîtrait exorbitante (Très bien, très bien!)

Je comprends très bien l'idée de M. Jauffret. Je ne demande pas, dit-il, quelque chose d'extraordinaire, mais simplement le maintien du statu quo...

M. Jauffret. - Non. Mème pas le stutu quo.

M. Gurot. - Je disais à MI. Dumont: "Je suis père de famille, j'ai aceumulé depuis 20 ou 40 ans des réserves sur mon immeuble; je voudrais en extraire, retirer de cette caisse d'épargne, le capital dont j'ai besoin à un moment donné et vous voudriez m'en empêcher?

"Oui, me répondait-il, je vous en empêcherai, vous n'en arez pas le droit..."

Eh bien! Messieurs, je crois avoir ce droit (Applaudissements), et de toutes nos forces, nous devons conserver aux propriétaires forestiers ces deux éléments de la propriété : le droit d'user et le droit de disposer. (Applandissements).

M. de SÉbille. - Après avoir lu le remarquable rapport de MM. Guyot et Roulleau, le premier sentiment que j'éprouve est le besoin de les féliciter d'un travail aussi bien conçu, qui soutient les idées d'indépendance et de liberté qui nous sont chères.

Nous sommes absolument les adversaires de l'interventionnisme et je ne vois pas pourquoi les propriétaires de bois seraient devenus des incapables, des mineurs et auraient besoin de tuteurs.

A tout prix, nous désirons conserver la liberté qui nous tient tant à coeur et je félicite ces Messieurs, dans un pays où l'interventionnisme a l'air de prendre des proportions considérables, d'avoir eu le courage de défendre la liberté. (Applandissements.)

M. du Pré De Samp-Maur. - Je tiens à donner iei un petit renseignement que beaucoup d'entre vous connaissent déjà.

Il y a quelques années, une propriété de 4.000 hectares environ, située dans le Morvan, a été vendue plusieurs fois de suite ou a changé de propriétaire par voie de succession, mais, chaque fois, avec une diminution considérable de valeur.

Il arriva qu un des propriétaires, qui ne redontait pas les opérations un peu hasardeuses, voyant que cette forêt ne lui rapportait mème 
pas 5 francs à l'hectare alors que l'impôt lui en coùtait 5, a vendu toute la superficie.

Bien entendu, cette décision un peu radicale a peiné tous les amateurs, mais on ne pouvait lui interdire cette rente.

A-t-il loué le sol pour le pacage comme on l'a prétendu?

Si oui, je vous le demande, qui pouvait l'empêcher de le faire? En vertu de quelle disposition aurait-on pu le lui interdire?

M. le Présidext. - En cas de défrichement direct, on peut réclamer.

M. Du Pré de Saint-Matr. - Pouvait-on le forcer à avoir 15 gardes?

M. le Président. - L'État n'entre pas dans ces détails, mais, par le seul fait qu’après exploitation il y avait abus de pâturage, le délit de défrichement indirect pouvait être invoqué d'après la législation en vigueur.

Le propriétaire est responsable, non seulement de ce qu'il fait, mais encore de ce qu'il laisse faire.

M. du Pré de Saint-Maur. - Faudra-t-il admettre que les propriétaires doivent se soumettre à tous les règlements administratifs sans pouvoir tirer un sou de leurs forêts?

Et vous crovez qu'il pourra encore se vendre un hectare de bois dans ces conditions... que la propriété ne diminuera pas ipso facto de valeur, au point d'être réduite à rien?

M. Jauffret. - Dans certains pays, on respecte la forêt.

M. le l'résinent. - Je retiens l'observation qu'en France, le fait de laisser pâturer après l'exploitation est trop souvent impuni. Il y a là une question de défrichement indirect, mais ce n'est pas le moment de la traiter, ni dr r'estreindre la législation du défrichement. C'est, certes, une servitude très lourde, elle est acceptée et personne, je crois. ne voudrait y toucher.

M. B.XchereAL - - On peut citer les forêts anéanties, et il y en a dans la région de l'Aube, par exemple, mais on ne met jamais en parallèle les territoires reboisés; on veut interdire de couper quoi que ce soit tout en engrageant à reboiser.

Veut-on faire de la France un massif forestier immense? C'est cependant ce à quoi on arrivera si on veut ainsi reboiser.

On oublie qu'il a y quelques années, l’Administration forestière a fait une enquête dont les chiffres exacts n'ont pas été publiés, mais (qui a démontré rư il y avait 600.000 hectares environ de surface boisée rl plus qu'il y a 40 ans. On ne peut done pas parler de déforestation en France. et nous voudrions bien avoir les chiffres exacts de cette statistique dont nous ne connaissons que les conclusions.

Pourquoi roudrait-on nous mettre en tutelle et nous donner une 
méthode forestière! Les agents de l'Administration emploieraient chez nous la méthode en vigueur dans les forêts domaniales qui, bien entendu, est excellente. mais qui n'est pas la seule bonne. Nous n'aurons plus la possibilité de faire des expériences qui cependant sont utiles, émanant de l’initiative privée.

Les pays étrangers qui ont des forèts aussi bien tenues que les nòtres, emploient d’autres méthodes et ne s'en trouvent quelquefois pas plus mal. N’adoptons pas une méthode unique qui serait la ruine de nos forêts.

On nous demande de reconstituer les massifs tels qu'ils étaient auparavant, mais nous savons tous que ce n'est pas toujours possible quand un massif a disparu. Que pourons-nous faire après un incendie détruisant un vieux massif de chênes? Il faudra, pendant un sièıle, un siècle et demi et même plus, y introduire d'autres essences, le pin ou le sapin, par exemple. Ce ne sera done pas l'ancien massif dans son état primitif.

C'est pourquoi, Messieurs, je m'associe à la proposition de M. Roulleau et je demande la plus grande liberté pour les propriétaires.

M. Laroquette, - Je citerai un fait personnel et local rui s'est passé dans le département des Landes.

A Solférino existait un domaine impérial de 6.000 hectares, acquis par Napoléon III en 1857 et transformé par lui en une très belle forèt d'exploitation.

En 1905, l'ex-impératrice Eugénie l’a vendu à des marchands do bois qui ont abattu 500.000 pins, si bien que de ce magnifique domaine que Napoléon avait conquis à la sylviculture, il ne reste absolument rien depuis 1911.

Le département s'est ému, l'affaire a eu son écho au Parlement où on a dit que les Landes redevenaient ce qu'elles étaient autrefois : un désert, et on a réclamé l'intervention de l'État pour empècher cette dévastation abusive.

Mais cet ancien domaine impérial ne restera pas longtemps lande rase. Il a eu la bonne fortune, il y a deux ans, d'être acheté par Ime Vve Schneider qui, grâce aux capitaux considérables dont olle dispose, y fait exécuter des travaux d'aménagement et des plantations, si bien qu'il y a lieu d'espérer que, d'ici quinze ans, la forêt sera recoustituée.

11. Banchereau. - Grâce à la liberté.

M. Laroquette. - Je me demande, si Mme Schneider ne s'était pas trouvée là, avec sa grosse fortune, ce qu’il serait advenu de ce domaine.

Un Congressiste. - C'est un autre capitaliste qui l'aurait acheté.

M. LARoQueTte. - Il serait plutôt resté à l'état de lande rase et c'eût été dommage. Déjà la population de Solférino avait dù imigrer en 
partie; les fossés d'écoulement, non 'entretenus, transformaient la lande en un maréeage, c'est-à-dire en un foyer pestilentiel.

En résumé, le erois que l'intervention de l'État n'est pas absolument indispensable pour obliger les particuliers à reboiser.

Dans notre département, la question ne se pose pas; le projet des cinq possibilités a été repoussé par toute la représentation landaise qui voit nos propriétaires reboiser au fur et à mesure qu'ils coupent; il n'y a donc rien à craindre chez nous.

M. Tanassesco. - Les questions diseutées iei sont très importantes, mais je constate qu'on les traite surtout au point de rue français.

En Roumanie, le taux de boisement était, il y a 60 ans, de $60 \%$, et, ces dernières amnées, il n'était plus que de $16 \%$, ce qui a déterminé le Gouvernement à prendre des mesures un peu coercitives contre les propriétaires particuliers, surtout contre la propriété indivise des paysans qui englobe eliez nous 600.000 hectares environ.

Une loi votée il y a trois ans a classé les forêts en forêts de protection, où le droit d'intervenir est donné à l'État. Elles sont en montagnes et l'État ne s'occupe pas des forèts de collines ou de plaines où les propriétaires forestiers sont à eôté des proprićtaires fonciers. Je vous demanderai, si vous adoptez un vœu sur la question et puisque nous sommes en Congrès international, de ne pas adopter un rou visant exclusivement la France, mais tous les autres pays, afin que vocu n'empiète pas sur ce qui se fait ailleurs.

M. le Président. - Nous avons été très intéressés par cette communication, mais je vous ferai remarquer que vous arez déjà satisfaction.

Hier, la question des forêts de protection a été résolue dans le sens que vous désirez. Vous nous dites que vous avez aussi des forêt. de protection et nous sommes très heureux de l'apprendre, car il s'agit d'un pays neuf où les expériences sont plus faciles et plus intéressantes. Le vou adopté hier en faveur de la constitution de forêts de protection dans les régions élevées et dans les dunes est en parfaite concordance avee la législation roumaine.

Quel que soit le vou adopté dans un iustant, il ne portera pas préjudice à celui émis hier.

M. Carbonner. - Je n'avais pas l'intention de prendre part à la discussion, mais jo dois dire qu'en suède, nous avons une loi qui concerne les forêts appartenant aux particuliers et que les congressistes désirent peut-être eonnaitre. J'en ai préparé un résumé que voici :

\footnotetext{
Résumé DE LA LoI DU 2'́ JULLet 1903, Relative A L'ENTRETIEN DES FORETS APPARTENANT A DES PARTICULIERS EN SUÈDE.
}

Article premer. - Il est interdit d'exploiter les forèts appartenant aux particuliers de telle façon que la régénération naturelle en soit compromise. Celui qui se sera rendu coupable de pareils faits sera tenu de prendre les mesures 
nécesaires pour assuler le reborsement. Si le juopriétaire d'une forêt a cédé à une tierce personne le droit d'exploitation de celle-ci, et si cette personne se rend coupable de faits analogues à ceux montionnés ci-dessus, le propriétaire, de la forêt sera solidairement responsable de la réparation des torts commis; toutefois, le propriétaire, en ce cas, aura le droit de réclamer au coupable le lemboursement dis sommes déboursées par lui de ce fait. La surveillance de l'exécution des présentes dispositions appartient à une administration pour la protection des forêts, désignée à cet eflet dans chaque province où la présente loi est applicable, aux employés, et inspecteurs ccmmis à ces fonctions par la dite administration, de même qu'aux commissions désignées par les communes dans un but analogue.

Art. 2. - Dans le cas où ladite administration - soit qu'elle ait été saisie de l'affaire par un avis lormel, soit pour toute autre raison - aurait lieu de présumer qu'une forêt est exploitée d"une façon contraile aux dispositions de l'article premier, elle devra en référer à l'autorité gouvernementale pour qu'il soit procédé à une enquête. L'autorité en question désignera à cet effet un agent forestier, lequel, assisté de deux prud'lommes impartiaux désignés par lui parmi les membres des commissions locales chargées de faire le partage légal des terres ou remplissant les fonctions d'arbitres dans les opérations d'arpentage, se rendra sur les lieux aux fins de procéder à une inspection. Cette opératicn terminée, l'agent forestier dressera un rapport, qui devra être transmis à l'Administration, et où devront se treuver consignées les mesures nécessaires en vue du reboisement du ou des terrains dont il s'agit. Au cas où les inspecteurs ainsi désignés ne seraient pas daccord sur les mesures à prendre leurs opinions divergentes devront ètre portées à la connaissance de l'Administration.

En conséquence du dit rapport, l’Administration aura à dresser une convention concernant des mesures nécessaires en vue du reboisement. Dans le cas où cela ne réussirait pas, où les mesures prescrites ne seraient pas exécutées en temps, des poursuites auraient lieu.

L'exploitation peut être complètement ou partiellement interdite jusqu'à ce que les mesures de reboisement soient exécutées. Cette interdiction sera annulée si une caution est fournie, par laquelle lexécution des mesures de reboisement est garantie.

\section{RéSUMÉ DE L'URdoÑATCE ROYALE DU 24 JUILlet 1903, RELATIVE AUX ADMIXISTRATIONS FORESTIERES LOCALES EN SUÈDE.}

Article preyier. - Les administrations your la protection des forêts, dont chaque province doit être dotée, seront composées de trois membres parfaitement au courant des affaires forestières et désignés dans l'ordre suivant pour une durée de trois ans, savoir : le premier, président, sera choisi par le gouvernement, le second, par le Conseil général, et le troisième par le Comité administratif de la Société d'économie rurale de la province.

Les suppléants, en nombre égal à celui des membres ordinaires, seroni désignés pour une même durée et de la même façon que ceux-ci.

Art. 2. - Toute administration forestière locale devra attacher à son service un aide forestier compétent.

ArT. 4. - Les administrations forestieres locales auront pour but :

a) D'améliorer l'économie forestière - pour les forèts appartenant à des particuliers - en répandant les connaissances utiles en matière de sylviculture, en favorisant cette culture. soit par la voie de crédits, soit par des travaux pratiques; en tenant à la disposition des intéressés, des graines et des plants d'arbres forestiers, et en urenant, d'une façon générale, toutes dispositions utiles en rue de l'amélioration de l'économie forestière de la région.

b) D'exercer une surveillance et prendre les mesures incombant aux admi- 
nistrations forestières, aux termes de la loi relative à l'entretien des forêts appartenant à des particuliers; les administrations forestières seront tenues, en outre, de fournir tous renseignements demandés, relativement aux mesures prises par elles dans un but analogue, de mème qu'en ce qui concerne les sanctions prises sur leur demande par les tribunaux ou par les sur-exécuteurs, en exécution des dispositions de la loi précitée;

c) De gérer les fonds provenant des taxes perçues pour l'entretien des forêts ou versées pour toute autre raison à la caisse destinée à subvenir aux besoins de la sylviculture ;

d) De faire choix d'un aide compétent (voir ci-dessus, article 2) et assurer son traitement au moyen des fonds confiés à leur gestion ; nommer, s'il y a lieu, un secrétaire et, de plus, tous employés compétents et tous inspecteurs nécessaires ; donner toute instruction opportune à l'usage du personnel ainsi désigné ;

Dans le cas oì le propriétaire ou l'usufruitier d'une forêt désirerait un aidé compétent pour l'entretien de sa forêt ou simplement des instructions relatives à l'exploitation de celle-ci ou bier concernant les mesures à prendre quant su terrain nouvellement déboisé, l'intéressé devra adresser à cet effet une demande écrite à l'administration forestière compétente, laquelle désignera à son tour un expert pour fouruir à l'intéressé tous renseignements utiles.

Il appartiendra aux administrations forestières locales de prescrire les conditions dans lesquelles les particuliers possédant des forêts, pourront obtenir l'assistance des employés et inspecteur's engagés par elles; l'assistance en question pourra, s'il y a lieu, être donnée gratuitemrent.

Les administrations forestières locales devront se conformer, dans l'exercicé de leurs fonctions, au règlement qui aura été édicté à leur intention et sur leurs propositions par le gouverne $m$ nt après avis préalable du Conseil général compétent et du Comité administratif de la Société d'économie rurale de la région.

Arт. 5. - Dans les communes qui en feront la demande, il pourra être procédé - aux fins de venir en aide aux administrations forestières locales dans l'exercice des fonctions leur incombant aux ter'mes de l'article 4 ci-dessus alinéas $a$ ) et $b$ ) - à la nomination d'une Commission composée de trois personnes désignées pour une durée de trois ans, l'une par' l'administration forestière compétente et les deux autres par l'assemblée communale, dans les conditions stipulées pour le choix des arbitres en matière de partage des terres.

M. Moyat. - Je formulerai simplement trois observations et je répondrai à deux arguments invoqués.

La première observation, c'est qu'il ne faut pas faire dévier la question, car il s'agit simplement de savoir comment on empêchera demain de couper autant que par le passé.

Deuxième observation : en ce qui concerne la Roumanie, je crois que la loi dont il a été parlé est une loi restrietire, non pas de la propriété particulièse, mais de ce qu'on appelle la propriété d'indivision.

Tanassesco. - Non, il s'agit de la propriété particulière des forêts de montagnes et de collines.

M. Moyat. - Quant à la loi suédoise, nous l'arons en France, e'est la loi sur le défrichement, mais ce n'est pas là la question, puisque nous parlons de l'ingérence de l'Administration forestière dans les propriépriétés particulières.

Enfin, il n'a pas été répondu à deux arguments extrêmement forts, invoqués par M. Jauffret. Il nous a dit qu'en France, nous admettons 
beaucoup datteintes au droit de propriété, notamment l'expropriation pour cause d'utilité publique, les servitudes, etc...

C'est exact, mais il faut tenir compte de ce fait qu'il n'en est aucune qui, du moins à l'origine, n'ait été compensée par une juste et préalable indemnité.

Le second argument qu'il a invoqué c’est que, la loi s`appliquant à toutes les propriétés forestières, aucune ne sera dépréciée. Évidemment, elle ne sera pas dépréciée par rapport à sa voisine, mais ‘ comparée aux autres propriétés, elle sera en état d'infériorité, notamment auprès des terres en culture. La valeur d'un bois ne sera pas proportionnellement inférieure à celle d'un bois voisin, mais elle sera beaucoup moindre que les terrains de labour ou les pâturages roisins.

M. Margaine. - Arant que le Congrès faşse à la proposition de M. Jauffret un sort qu'elle ne mérite pas, je voudrais dire un mot à propos du jus abutendi dont on a parlé.

Il semble qu'au point de vue des propriétés forestières, le jus abutendi a déjà été sérieusement restreint sous l'ancien régime par l'interdiction de défricher. Au lieu de "défrichements", nous voudrions voir mettre dans la loi " déforestation ". M. Jauffret ne demande rien de plus.

Nous ne venons pas prendre les forêts des particuliers, nous leur disons simplement: "Vous voulez un petit avantage en ce qui concerne l'impòt forestier; vous demandez une exonération; elı bien ! acceptez une tutelle légère \%.

11. P. Desconbes. - La lutte est évidemment entre l'intérêt général et lintérêt privé des propriétaires, mais il y a intérêt à faire la conciliation.

Si on chargeait l'État de reboiser les forêts, l'intérêt public serait sauvegardé, mais il s'agit de ne pas limiter le droit de propriété et, surtout, de ne pas le supprimer.

L'Association Centrale pour l'aménagement des montagnes a étudié l'orientation des capitaux ver's le reboisement et la loi déposée en 1907 a abouti ces jours derniers. Or. M. le Ministre de l'Agriculture demandait hier au Congrès international sa collaboration pour l'application de cette loi et la préparation du règlement d'administration publique.

Actuellement, les propriétaires de bois qui n'habitent pas leurs propriétés et sont embarrassés pour les administrer eux-mêmes, n’ont personne à qui s’adresser pour une gestion sage et raisonnable.

A l'avenir, ils pourront s'adresser à l'État, mais personne ne les y obligera, ils le fecont s'ils le croient convenable. De même, si ces propriétaires trouvent que leurs forêts sont onéreuses, gènantes pour eux, ils pourront s'en débarrasser en trouvant comme acheteurs les propriétaires impérissables : Compaguies d'assurances, Caisses d'épargne, Mutualités, etc., qui possèdent plusieurs milliards et pourronts orienter vers la propriété boisée s ils y trouvent arantage. 
Il y a intérèt à ce que cette tutelle volontaire soit, dans l'intérêt de la collectivité, le plus simple possible, qu'elle donne le moins de sujétions possibles aux propriétaires, à ce qu'elle puisse s'étendre, et ainsi on aura une nouvelle eatégorie de propriétés.

La forêt privée sera divisée en deux eatégories; d'abord la forêt privée, administrée en tout ou partie par l'État, suivant les prescriptions du règlement d'administration publique; ce sera une propriété protégée donnant des garanties de conservation et qui a droit à un traitement de faveur justifié par ces garanties de conservation. Puis, la propriété forestière libre, qui réclame le droit commun, c'est-à-rlire demande à n'être pas plus imposée que l'ensemble de la propriété foncière.

Puisque le Ministre a bien voulu inviter le Congrès à l'aider dans la préparation du règlement d'administration publique, je proposerai au Congrès d'ajouter, au vou préparé par MM. Guyot et Roulleau, la phrase suivante :

"Qu'en ce qui concerne en France l'application de la loi Audiffred, il appartient au règlement d'administration publique de définir le minimum de sujétions permettant aux propriétaires de forêts protégées de profiter du traitement de faseur qui pourra correspondre à leurs garanties de conservation".

M. Le Présinent. - La loi Audiffred prévoit plusieurs modalitís. Le contrat est à débattre entre le propriétaire et l'État.

11. Descombes. - Dans chaque cas, oui, mais le règlement dadministration publique devra fixer un régime des forêts protégées, tel qu'il puisse être invoqué par les lois suivantes quand on demanclera, par exemple, l’immunité des droits d'enregistrement...

M. Le Présinent. - Un décret ne suffit pas ; chaque fois qu'on parle d’immunité d'impôt, il faut une nouvelle loi.

II. Descombes. - Il faudrait fixer ce régime de telle façon que les lois suivantes puissent s'y reporter.

1I. Coste. - La mesure proposée par M. Jauffret deviendrait bientôt odieuse parce qu'elle serait nécessairement arbitraire. En France, on n'observe la loi que dans la mesure où l'état de l'opinion locale le permet.

Vous parliez tout à l'heure de la loi contre le défrichement. Or, dans plus de vingt départements du Midi, il n'y a peut-être pas un seul propriétaire qui connaisse et respecte cette loi. On défriche continuellement et, chaque fois qu'on fait une coupe, on fait sauter la souche, "le piquet ", comme on dit, en termes de métier, de façon à transformer la forêt en pâturage qui rapporte davantage.

Faites une nouvelle loi, si vous le voulez, on n'en tiendra pas compte. 
On l'appliquera peut-être à quelques propriétaires isolés contre lesquels l'opinion publique s'ameutera... (Applaudissements), on leur dressera procès-verbal, mais royez alors l'état de conscience du juge auquel les propriétaires poursuivis diront : "Comment pouvez-vous nous condamner alors que dans 10,20 départements, on ne respecte pas cette loi \%.

Une loi nouvelle serait inapplicable et odieuse.

M. Le Président. - Si la loi est d'une application difficile, il faut en comprendre la principale raison : cest que le personnel des gardesforestiers est très inégalement réparti. Or, il ne faut pas se faire d'illusion, e'est sur lui seul qu'on peut compter pour empêcher le défrichement.

Je sais bien que la loi ordonne aux maires de le constater, mais je n'étonnerai personne en disant qu'on ne peut pas faire fond sur eux. Il y a bien des eas particuliers et des maires qui verbalisent, mais n'approfondissons pas...

On ne peut que déplorer cet état de choses et on pourrait sans doute y remédier, mais cela ne tient pas à un arbitraire quelconque de la part de l'administration.

M. Imbart de la Tour. - Nous sommes d'accord sur l'étendue de la déforestation et je vois à cela trois causes principales.

Tout d'abord, il y a la question de l'impôt, et c'est tellement rrai que ce sont les grands domaines forestiers qui disparaissent. C'est à l'État à prendre des mesures pour atténuer le régime fiscal dont nous souffrons; ce n'est pas une faveur que nous demandons, c'est la justice.

Une autre cause de cette situation, e'est la question des bûcherons. Il arrive en bien des pays que le prix de façon est double de la valeur du bois. Dans la Nièvre, notamment, c'est constant; il appartient encore à l'État d'intervenir et de faire respecter la liberté du travail en permettant à tous les bùcherons de travailler librement.

En troisième lieu, il y a la question des débouchés et je n'y vois pas de solution. Il n'y a pas grand chose à faire en ce qui concerne le bois de consommation.

M. de Nicolay. - On a parlé de lutte entre l’intérêt général et l'intérêt privé. Je proteste énergiquement contre cette idée et je crois, au contraire, qu'il s'agit de s'expliquer sur la façon dont doit se comprendre lintérèt général.

Il pourrait être avantageux, au point de vue forestier, que l'État soit propriétaire d'un très large domaine et beaucoup de roux ont été présentés en ce sens au Congrès, mais je crois aussi que nous arrivons à cette heure, qui peut être déclarée bien heureuse, où l'État aura intérèt à ce que la propriété privée se développe et soit eonservée.

Or, la cause de la crise actuelle est celle-ci : c'est que la propriété 
forestière souffre, pour un grand nombre de raisons déjà énumérées, sur lesquelles je ne reriendrai pas. A ce mal, quel remède propose-t-on? Une limitation clu droit de propriété, c’est-à-dire un mal de plus! (Applaudissements).

Le résultat de cette limitation serait fatalement d'abaisser encore le prix des propriétés forestières déjà si avili (Applaudissements).

Le prix de la propriété forestière est avili dans le sens du revenu et j'estime que cest rendre le plus maurais sprvice à la cause forestière que d'en diminuer encore la valeur.

M. Laroquette vous a montré l'exemple d'un gros eapitaliste reconstituant une forêt gràce à une méthode culturale raisonnée, de façon à récolter, dans 50 ou 60 ans, ce qu'il aura semé. Croyez-vous que si on était venu lui dire : "Vous allez semer, mais vous ne récolterez pas ", croyez-rous, dis-je, que ce capitaliste aurait acheté cette propriété?... (Applaudissements).

La seule solution à la crise dont nous souffrons, est la liberté des propriétaires (lifs applundissements).

II. Grand. - Comme représentant de la section de sylviculture de la Société d'Agriculture de la Gironde et comme représentant du Syndicat de la Gironde et des Landes, je puis dire que jai derrière moi les 800.000 hectares de pins du Sud-Ouest et cest pourquoi je viens apporter ici la protestation énergique de tout ce pays contre toute immixtion de l'État dans les forèts particulières.

Mais il me semble que la question est mal posée et qu'elle est trop générale. On disait tout à l'heure : la propriété forestière souffre. Oui, il y a des propriétés forestières qui souffrent, mais il y en a - c'est peut-être la minorité - qui ne souffrent pas et la propriété forestière landaise est de celles-là, elle n'a pas busoin d'être protégée, elle se protège toute seule et, chaque fois qu’on a proposé à nos propriétaires de venir les aider et leur montrer à gérer leurs domaines, cela a été pour eux une stupéfaction profonde.

Mettre les propriétaires forestiers en tutelle n'est pas possible et il n'en est nul besoin (Applandissements).

La question ne doit pas se poser ainsi. Il faut dire que, si dans cretains cas l'intérêt général est assez gravement compromis pour qu'on astreigne les propriétaires à subir, dans une certaine mesure, l'inmixtion de l'État, il faurra bien spécifier ces cas et ne pas généraliser, car e'est inutile dans bien des régions.

M. LE P'résident. - Votre préoccupation très légitime a reçu satisfaction par le vote d'hier instituant des forèts de protection. Ces forêts sont donc, maintenant, hors de cause.

M. Graxd. - Alors, je retire en que jai dit.

M. Le Présinext. - Vos obsrrvations sont très intéressantes el nous 
ne regrettons qu'une chose, c'est que tous les propriétaires ne puissent pas dire de leur région ce que vous dites de la vôtre.

M. de Sébille. - Une loi existe en Danemark depuis 1905, qui laisse toute liberté aux propriétaires, mais interdit aux aequéreurs de forêts de couper les hautes futaies avant 10 ans, je crois, après l'acquisition.

Il était intéressant de le rappeler ici; cette loi protège les forêts contre les bandes noires qui exploitent la France et la Belgique.

11. Le Présinent. - Si une pareille loi existait en France, il serait facile rle la tourner. Dans bien des cas, le propriétaire ne veut pas détruire lui-même sa forêt, il le fait par l'intermédiaire d'un mandataire.

On ne peut raisonner d'une façon absolue d'après ce qui se passe rlans les autres pays. La Belgique est beaucoup plus proche de la France, à tous les points de vue, que le Danemark dont les conditions climatologiques, l'état social et politique, sont différents des nôtres. Il n'y a même pas de grandes étendues comme en Suède, on ne peut donc pas en tirer argument pour parler de la France.

M. de Sébille. - Le Congrès de Gand a, la semaine dernière, été saisi d'un roeu analogue, mais ne l'a pas admis.

M. le Président. — Connaitriez-vous la loi danoise, Monsieur le délégué de la Suède?

M. Cirboxicier. - Très peu; je sais simplement quon ne peut couper dans les quelques années qui suivent l'acquisition.

11. Di Pré de Sannt-Maur. - J'ai vu quelque chose en Hongrie qui est moins rigoureux.

Il y a de superbes forêts aménagées à cent ans. Quand on les exploite, on laisse des porte-graines à certaines distances, de façon à assurer le renouvellement du taillis.

M. DE SAlly. - Il serait bon de ne pas invoquer, en faveur de l'immixtion de l'État, cet argument qu'il faut un siècle et plus pour aroir des bois de futaie.

$\mathrm{Si}$, de ce fait qu'il faut un siècle pour reconstituer une futaie, on en déduit que l'État doit intervenir pour limiter l'exploitation, il faudrait aller beaucoup plus loin et déclarer qu'il interviendra aussi, par exemple, dans les mines. Voilà une mine capable de fournir du charbon pendant 70 ans, jamais l'idée n'est venue à l'État de déclarer au propriétaire qu'il allait restreindre l'extraction, de façon à faire durer la mine pendant 200 ans. Et cependaut, la forêt se reconstitue d'ellemême, alors que la mine s'épuise.

M. Bouvet. - Je demande la parole, car je crois qu'il y a encore quelques mots à dire. 
Le mal existe; il y a beaucoup de déforestation. J'habite le Jura et j'y ai vu raser les grandes forêts du pays. Elles existent bien encore, mais au lieu d'être riches en futaies, et d'avoir beaucoup d'arbres, il n'y en a plus que l'apparence. On a coupé tous les bons arbres et. on a laissé tous les mauvais, e’est-à-dire des balivaux sans valeur, de façon à tromper l'œil des amateurs. Quelqu'un de peu expérimenté croirait que rien n'est changé dans la forêt, mais il n’en est pas ainsi,

Je crois que nous sommes tous d'aceord pour ériter la déforestation et pour demander que les forêts particulières soient très riches. On peut y arriver do deux façons différentes : par la coercition ou par le régime de liberté.

La coercition, e'est l'intervention de l'État, et vous savez où elle nous mène, e'est au socialisme d'État. Nous n'avons que trop de propension aujourd'hui à nous acheminer sur cette pente glissante, c'est un mal terrible qui nous amènera au niveau de la Turquie (Applandissements).

Je n'en parlerais donc pas s'il n'y avait un danger à craindre. Ce danger est constitué par le Parlement qui est beaucoup trop favorable à l'intervention de l'État. Les parlementaires ont derrière eux le commerce des bois, non pas les spéculateurs, mais le vrai commerce des bois et les populations qui ont intérêt à avoir des coupes régulières et non pas ces soubresauts qui jettent la perturbation dans le pays.

Voilà ce qui donne de la force au Parlement et fait que les parlementaires voudraient l'intervention de l'État et même voudraient vous exproprier sans indemnité (Protestations).

M. Challamel. - Je proteste; ce n'est pas du tout la mentalité qui règne au Parlement et nous sommes une majorité qui n'approuvons pas du tout cette théorie.

M. Borvet. - Alors, vous êtes d'avis que, s'il y a intervention de l'État et diminution de la liberté des propriétaires, il doit y avoir de larges compensations?

M. Cirallanel. - C'est lopinion émise par ceux qui sont le plus partisans de l'intervention de l'État.

M. Bouver. - Il est donc entendu que si le Parlement croit devoir entrer dans cette voie, il y aura pour les propriétaires une compensation telle...

M. Challamel. - Qu'ils y trouveront peut-être leur avantage.

M. Bouvet. - Je considère maintenant le régime de la liberté et je dis que l'État devrait vous donner des avantages sans vous imposer d'obligations. 
Ceci rous paraît peut-être paradoxal, mais c'est la vérité ; il devrait notamment vous accorder des remises dimpôts.

On parle beaucoup des forêts protégées, il n'y en a qu'une qui ne le soit pas, c'est la propriété forestière privée. Tos forêts sont livrées au pillage, aucune loi ne vous défend et je soutiens que c'est dans un régime de liberté que le Parlement devrait trouver la combinaison qui permettra aux particuliers, par le jeu même des lois économiques, d'avoir intérêt à conserver leurs forêts et à les enrichir (Applaudissements).

M. Delahaye. - Dans son rapport, M. Roulleau semble insinuer que ce n'est que depuis quelques années que l'État a songé à intervenir dans la gestion des bois particuliers. Or, l'ordonnance de 1669 et les nombreux arrêts qui ont suivi, comportent au contraire une ingérence exorbitante de l'État, une quasi expropriation.

M. Banchereat, - Pas en ce qui concerne les forêts particulières.

M. le Président. - Mais si, c’est un fait historique, qui n'est pas contestable.

M. Delahaye. - On imposait par exemple de réserver 16 ou 20 baliveaux suivant les coupes pendant 20 ou 40 ans.

En ce qui concerne les restrictions à apporter aux droits des particuliers. il y a une distinction à faire entre : to le maintien de l'état boisé et $2^{\circ}$ la nature de la production ligneuse.

En ce rui concerne la nature de la production ligneuse, il faudrait que la disette de bois d'œurre devint une calamité publique imminente pour que l'État ait le droit d'intervenir dans la production des catégories.

Reste alors la question du maintien de l'état boisé nécessaire pour les différentes raisons exposées au code forestier qui préroit simplement l'existence de la végétation ligneuse, quelle que soit la production, quel que soit l'âge.

Actuellement, la législation sur le défrichement et la jurisprudence qui est venu la corroborer donnent, semble-t-il, des armes suffisantes pour assurer l'intérêt général, mais dans cette question, il y a un point qui n'a pas encore été traité.

Je voudrais qu'on n`interdise aucun droit de jouissance sans compensation, car l'interdiction de défricher est une limitation du droit de propriété. Telle propriété dont on exige actuellement le maintien en nature de bois rapporterait darantage en culture agricole. Si done l'État prive le propriétaire forestier d"une jouissance, il lui doit une compensation.

Je demande qu'on ajoute aux roux proposés que, toutes les fois que l'État empêchera le défrichement d'une forêt. il donne une indemnité, une juste rémunération de la priration imposée au propriétaire.

Je vous citerai un exemple : me personne arait défriché en délit, 
il s'agissait de 24 hectares, elle était done passible de 12.000 francs d'amende, mais une transaction à 1.200 franes fut accordée. Or, avec la seule plus-value du revenu agricole de la première année, les 1.200 francs demandés ont pu être payés.

Ux Congressiste. - Mais on a dù reboiser, la loi l'impose.

M. Delahaye. - Pas du tout, c'est le Ministre seul qui a facultativement le droit d'imposer le reboisement.

Le Même Congressiste. - Et il ne l'a pas fait, c'est fantastique!

M. Delahaye. - C'est possible, mais c'est ainsi. Pour conclure, je demande qu'aucun défrichement ne soit interdit sans qu'il soit accordé une compensation pécuniaire au propriétaire.

M. Le Président. - La question est grave et c'est peut-être aller bien loin, car en demandant trop on risque de ne rien obtenir du tout.

Messieurs les propriétaires étaient d'accord, je crois, pour mettre hors de cause la queśtion du défrichement; il est peut-être sage de s'en tenir là, parce que, si on va plus loin, ce sera dangereux.

M. Grгот. - Nous sommes parfaitement d'accord et je ne dirai qu'un mot à ce sujet, ne voulant pas abuser de votre complaisance.

Je ne crois pas qu'il importe de demander dès maintenant une indemnité pour la servitude de défrichement et, si on ne la demande pas d'une façon directe, je me réfère à la seconde partie de notre projet pour que l'État veuille bien nous accorder, d'une manière bénévole, les avantages que nous réclamons et qui ont été énumérés d'une façon sommaire dans le libellé de notre vou, mais auxquels, évidemment, on peut ajouter bien des choses.

Je ne suis pas le moins du monde ennemi d'une certaine ingérence de l'État; il ne faut pas croire que je suis sur ce point plus intransigeant que d'autres. J'accepterai même - je dois le dire — et les Parlementaires le savent, une définition plus exacte des défrichements indirects. Je crois qu'il ne faudra pas laisser cela dans le domaine de la jurisprudence et qu’il serait bon de l'asseoir sur un texte précis du code forestier.

Cela pourrait être fait; mais puisque nous consentons à fortifier ainsi l'action de l'État dans une certaine mesure, qu'il nous dome en échange les avantages que nous réclamons dans la seconde partie du vœu.

Ces avantages - et je ne parle pas de l'impôt - nous en causerons plus tard, je les ai indiqués d'une façon énonciative, et l'un d'eux, je ne puis m'empècher de le répéter, est relatif à la répression des délits.

La loi de 1906, imposée malgré l'Administration forestière, malgré les vœux des propriétaires forestiers, ne nous défend pas contre les délinquants. Nous avions une réglementation suffisante dans les 
articles répressifs du Code forestier, on est venu protester et déclarer que les coupables étaient très souvent dignes de pitié, qu'il fallait diminuer la répression. En effet, on a réduit les peines dans des proportions considérables : on a diminué les amendes et, chose plus grave, supprimé toutes les peines d'emprisonnement en matière forestière.

Or, parmi les délinquants, s il y en a qui sont dignes de pitié, beaucoup sont les pires vagabonds. Ce sont eux qui mettent nos forêts au pillage, d'autant mieux que nous n'avons plus de moyens d'action à leur égard.

Le secours le plus efficace que pourrait nous donner l'État serait de rétablir la prison. Peu nous importe qu'on relève le chiffre des amendes, mais ce que nous réclamons, e'est la possibilité de punir de prison des vagabonds insolvables qui sont des délinquants d'habitude.

Je me résume : je vous demande d'envisager la question dans l'ordre d'idées où nous nous sommes placés ce matin et de voter les propositions qui vous sont faites. Nous ne sommes pas intransigeants, mais nous voulons être maîtres chez nous (Applaudissements).

M. Le Président. - Je erois répondre à la pensée de plusieurs de nos collègues en vous proposant d'apporter au texte du vou les modifications suivantes :

$1^{0}$ Nous demandons que la sollieitude de l'État s'exerce "notamment par une répression plus efficace des délits, par des modérations d'impôts, etc..."

$2^{\circ} \mathrm{On}$ pourrait à la suite du vou de MII. Guyot et Roulleau, ajouter : "qu'en France, la loi Audiffred soit appliquée dans un esprit de bienreillante collaboration entre l'administration forestière et les propriétaires particuliers ".

Le vou peut s'appliquer à tous les pays, mais on pourrait y ajouter ce membre de phrase s'appliquant spéeialement à la France. M. le Ministre nous ayant demandé une indieation, nous la lui donnons.

M. du Pré de Saint-Maur. - Parlez aussi des moyens de transport.

M. Le Président. - Nous traiterons la question jeudi prochain.

Je mets aux roix le vou ainsi complété.

Un Congressiste. - Mettez que l'État doit manifester sa sollicitude par une législation particulière.

M. Jauffret. - M. Guyot parlait de la déforestation, on pourrait le mentionner.

Il s'est déelaré favorable à une définition du défriehement indireet.

M. le Présinent. - Le défrichement est interdit, la législation existe.

M. Jaltaret. - Cela m'aurait permis de voter pour le vou, je vais être obligé de voter contre. 
1. LE Présnext. - Je crois répondre à la pensée générale en disant que les propriétaires forestims renoncent à soulever la question de lindemnitó.

N'insistons pas sur ce point, sanis quoi la question de M. Delahaye se pose ígalement.

II. Giгот. - Je n’insiste pas du tout.

M. Le l'résinext. - Je mets anx roix le voeu présenté par MIM. Guyot et Roullean tel qu'il vient dêtre complété.

Le vou ainsi modifié est adopté à l'unanimité moins denx voix. La séance est levée à 11 h. 10. 


\title{
SEANCE DU 17 JUIN 1913
}

\author{
(APRÈS-MIIDI)
}

\section{Présidence de M. VIVIER, président de Section}

La séance est ourerte à 2 h. 35 .

M. Le Présidext. - Messieurs, nous avons à aborder cet après-midi la très importante question de l'impôt forestier.

Afin de procéder par ordre, M. Arnould lira son rapport; les secrétaires de la séance donneront ensuite lecture des trois communications écrites présentées sur la question; enfin je donnerai la parole à ceux d'entre vous qui auraient des observations à présenter.

La parole est à M. Arnould pour la lecture de son rapport sur l'IMPÒT FORESTIER.

Exagération de l'impôt sill le forits.

II. Ariould. - Quelle doit être la base de l'impôt sur les forêts pour que le revenu forestier ne soit pas plus imposé que les autres revenus de même nature?

Cette question si importante pour la conservation des forêts n'a attiré l'attention des forestiers qu'à la fin du xix'e siècle et n'a été réellement étudiée qu'au $\mathrm{xx}^{\mathrm{e}}$ siècle. Les premières études sont celles de Baur (1875), puis Judeich, en Allemagne; Puton (1882), Arnould (1895), en France; Riebal et Hufnagel (1895), en Autriche. En ce siècle, la question fut traitée en Allemagne par Endres, Graner, Wimmenauer, Urich et Weber, notamment au Congrès forestier d'Eisenach, en 1904; en France, par Broilliard, Arnould et Roulleau, surtout depuis 1908. Je ne cite que les principaux auteurs.

En France, l'exagération effrayante de l'impôt sur les forêts, constatée officiellement par les ministres des Finances et de l'Agriculture, et la réforme fiscale à l'étude, lui ont, depuis 1908, donné une grande actualité et une acuité singulière. Cette exagération de l'impôt sur les forêts a pour cause première le principe - aujourd'hui eondamné - du système fiscal français de l'an VII (1799) qui impose la propriété foncière non bâtie d'après un revenu cadastral, fixe et immuable depuis plus de cent ans.

Le revenu des forêts a été évalué à l'époque de la confection du cadastre : pour les forêts feuillues, d'après le revenu net que donnait la forêt supposée traitée en taillis simple, e'était le prix de la coupe divisé par l'âge ; pour les forêts résineuses, d'après le revenu net réel.

Mais depuis un siècle, le rendement en argent des taillis simples a considérablement diminué; d'une part, les frais d'exploitation, les frais 
de garde et d'entretien, qui sont en raison du taux des salaires, augmentaient sans cesse; d'autre part, les produits du taillis perdaient de leur valeur. La charbonnette, produit principal du taillis, valait en 1810 8 francs au moins le stère sur pied, elle se vend aujourd'hui moins de 1 frane. Les écorces, autre produit du taillis très recherché autrefois, sont aujourd'hui d'un placement difficile. Par suite de ces faits économiques, le revenu cadastral immuable des forêts feuillues se trouve supérieur de huit fois environ au revenu que donnerait une nouvelle évaluation faite avec la même méthode.

Le principal de l'impôt foncier, la part de l'État, était et est restée modérée, 4 à $5 \%$ du revenu cadistral. Mais les budgets des départements et des communes sont alimentés par des centimes qui s'ajoutent au principal de l'impôt. Ces centimes, en nombre restreint au début, ont augmenté avec les besoins des collectivités, conséquences du développement économique. En 1910, le nombre des centimes additionnels à l'impôt sur la propriété foncière non bâtie était en moyenne, pour l'ensemble de la France, de 12 centimes généraux, 72 centimes départementaux et 62 centimes communaux, soit au total 146 centimes, auxquels s'ajoutent, dans nombre de communes, 20 centimes pour la taxe vicinale. Le taux de l'impôt a, par suite, augmenté dans la proportion de 1 à 2 1/2 en moyenne ; dans quelques départements, le nombre des centimes atteint 250. le taux de l'impôt est passé de 1 à 3 1/2.

Pour les forêts feuillues, imposées sur un revenu huit fois plus fort que celui qui devrait leur être attribué, l'impôt atteint $8 \times 4 \times 2,5=80 \%$ en moyenne, et jusqu'à $8 \times 4 \times 3,5=112 \%$ de ce revenu.

Il résulte de ce fait que pour les taillis simples, l'impôt absorbe la presque totalité et même la totalité du revenu ; que pour les taillis sous futaie, selon que le revenu de la futaie est égal au revenu du taillis ou est le double de ce dernier, l'impôt est, en moyenne, de $40 \%$ ou de $27 \%$ du revenu.

Pour les forêts résineuses, comme la plus-value que le développement des voies de communication a donné aux bois a contrebalancé, souvent avantageusement, l'augmentation des frais d'exploitation et des frais annuels, le revenu actuel est en général supérieur au revenu cadastral, mais les pays de montagne étant moins riches que ceux de la plaine, le nombre des centimes additionnels y est plus élevé. L'impôt pèse moins lourdement sur les forêts résineuses de montagne que sur les autres forêts, mais n'en est pas moins encore excessif.

Pour tirer quelques ressources de leurs forêts, les propriétaires sont réduits soit à couper plus que la possibilité, à abattre les futaies, préparant ainsi la ruine des forêts, soit à exploiter la superficie et à se débarrasser du fonds à vil prix.

Une réforme du mode d'évaluation du revenu forestier est indispensable pour mettre fin à ces injustices, pour conjurer ce danger.

La question est complexe; la solution exige des connaissances assez étendues en économie forestière et en science fiscale. Trop souvent, les forestiers n'ayant que les premières et les agents des finances ne possédant que les secondes, n'envisagent qu'un côté différent de la question. Ce serait un grand pas fait vers la solution, si ce Congrès, où des représentants du Ministère des Finances siègent à côté des forestiers, arrivait à préparer entre les deux parties une collaboration loyale, étroite et fructueuse. 
Pour aboutir il importe de bien préciser la question, de mettre en évidence les lois de la formation du revenu des forêts et d'en déduire les conséquences au point de vue de l'impòt.

Si une simplification pratique paraissait nécessaire pour faciliter la perception de l'impôt, il serait facile pour chaque cas particulier de chercher et de trouver, d'un commun accord, une disposition transactionnelle satisfaisante pour les deux parties.

i.tude de lat $101^{*}$ mation dil $\mathrm{rr}$ vemuloresticer.

Que l'impôt porte sur le capital ou sur le revenu, son assiette exige une discrimination précise entre le capital, instrument de production, et le produit ou revenu. Cette discrimination est particulièrement nécessaire lorsqu'il s'agit des forêts.

Si la forêt, comme les autres productions agricoles, est le résultat d'une culture, c'est une culture qui ne ressemble à aucune autre. Elle en diffère notamment en ce que la plante cultivée, l'arbre, le bois, ne produit pas de récoltes annuelles. Le revenu forestier n'est perçu que quand les bois sont assez gros pour avoir une valeur marchande, et qu'on puisse les couper économiquement. D'autre part, à la différence de la récolte des autres cultures, la valeur des bois augmente progressivement d'année en année. Le propriétaire a done intérêt : en principe, à exploiter des bois aussi gros que possible; en fait, à ne pas exploiter des bois trop jeunes, de trop faible dimension; dans ce but, pour ne pas différer indéfiniment la perception de ses revenus, il est conduit à laisser sur pied un matériel permettant d'exploiter annuellement des taillis de vingt ans ou des futaies de soixante ans, par exemple. Ce matériel, véritable capital d'exploitation, est uni si intimement au revenu qu'il est impossible de déterminer ce qui, lans le bois sur pied, appartient à l'un ou à l'autre. Seule, l'exploitation, la coupe, permet de séparer le revenu du capital, et encore à la condition qu'elle soit normale, c'est-à-dire conforme au plan adopté, qu'elle porte uniquement sur la production annuelle du sol et qu'elle laisse le capital d'exploitation constitué, comme il l'était à la coupe précédente.

Cette situation particulière aux forêts rend obscure la théorie du revenu annuel des bois et forêts qui n'a été exposée d'une façon suffisamment précise qu'en ces dernières années.

Aujourd'hui, forestiers et économistes sont d'accord, du moins dans l'école française, sur la nécessité de distinguer dans le revenu forestier deux ́́léments: le revenu du sol, d'une part, et, d'autre part, le revenu de l'épargne, du capital-bois des forestiers ou, suivant une expression quelque peu impropre mais plus claire pour le public, de la futaie.

Ces deux éléments du revenu forestier existent nécessairement, quoique sous des formes dill'érentes, qu'il s'agisse d'un taillis simple, d'un taillis sous futaic ou d'une futaie, qu'il s'agisse d'une forêt exploitée en une seule fois ou d'une forêt aménagée ou, selon l'expression du Code civil, d'une forêt en coupes réglées. Dans tous les cas, le revenu foresticr apparaît, pour une très large part, comme le fait d'une ouvre de prévoyance et d'épargne et non comme le produit du sol, ainsi qu'on l'a cru longtemps.

Faisons la démonstration pour le cas le moins complexe, celui du taillis simple exploité en une scule fois.

On aperçoit dans la coupe, à l'âge de l'exploitation économique (vingt ans par oxemple, un premier élément constitué par les pousses annuelles, 
fait direct de la puissance productive du sol ensouché, au nombre de vingt, toujours les mêmes, toujours égales. Concurremment avec cet élément, en est intervenu un sccond : le concours apporté par chacune des pousses précédentes. En ne recueillant pas son revenu, le propriétaire permet aux pousses annuelles accumulées de travailler, avec la terre comme support, pendant l'année suivante, à la fin de laquelle le produit représente non seulement la pousse de l'année (la contribution toujours égale du sol), mais encore le travail du matériel-bois, que l'on peut considérer par l'analyse comme un facteur indépendant. Le produit auquel ce travail a abouti et qu'il est impossible d'évaluer en fait s'ajoute au produit du sol ensouché. Cette cuvre d'épargne et de prévoyance se manifeste dès la seconde feuille : c'est à ce moment que se constitue le capitalbois économique, qui n'est autre que le matériel-bois technique. Ce matérielbois, produit de la nature, conservé et vivifié par l'épargne, servant à la production de richesses nouvelles, est bien un capital au sens où l'entendent les économistes.

Il est par suite possible d'assimiler l'accroissement de valeur d'un bois aux accroissements de valeur d'un capital placé à intérêts composés, bien qu'à la rigueur il n'y ait pas dans les coupes de bois aux différents âges cette régularité mathématique. On peut assimiler la valeur d'une coupe de tailiis de vingt ans à une somme formée par l'accumulation à intérêts composés de vingt annuités fixes. L'annuité correspond à la valeur de la puissance productive du sol, et les intérêts composés expriment le concours apporté à cette puissance productive par l'élément grossissement successif du matériel-bois.

Le rcvenu annuel d'un bois traité en taillis simple, exploité en une seule fois, est représenté par l'annıité qui, versée pendant un nombre d'années correspondant à la révolution, reproduirait une somme égale à la valeur de la coupe, au moment de l'exploitation. Cette annuité, correspondant à la valeur de la pousse annuelle, donne la mesure de la puissance productive du sol ensouché : c'est le revenu foncier.

Le raisonnement serait le même pour toute forêt constituée par un peuplement d'âge uniforme exploité en une seule fois. Dans le cas du taillis sous futaie ou de la futaie jardinée, apparaît un nouvel élément, la valeur des réserves, représentant une épargne consolidée, un capital d'exploitation qui reste constant pour une exploitation donnée. Cet élément augmente le revenu annuel de la forêt, mais non le revenu foncier. D'autre part, l'aménagement permet, avec différentes modalités et en principe par une économie judiciense sur les revenus antérieurs, d'obtenir, au lieu d'une coupe unique, des coupes réglées revenant à intervalles plus rapprochés que l'âge de l'exploitation, et même des coupes annuelles. Le revenu de la forêt est par suite augmenté; cette augmentation du revenu n'est pas le produit du sol, elle provient du capital engagé dans l'exploitation en vue d'une culture intensive, de l'épargne constituée par des économies successives et représentée par la valeur des coupes en croissance. Ce n'est pas un revenu foncier.

Le capital constitué par l'épargne n'est pas incorporé au sol, il peut, au contraire, en être séparé à tout moment, il peut, il doit parfois être réduit ou supprimé par une coupe intensive ou une coupe à blanc. Le temps, condition essentielle pour sa constitution, n'est pas nécessaire pour sa réalisation.

En résumé, quels que soient le mode de traitement, l'âge de l'exploi- 
tation et l'aménagement des coupes, le revenu total d'une forêt, la rente de la forêt, se compose de deux éléments :

10 Le revenu du sol;

$2^{\circ}$ Le revenu de l'épargne ou du capital d'exploitation accumulé dans les réserves et dans les coupes en croissance, que l'on peut appeler la futaie.

Il faut se garder de confondre la rente ou revenu total de la forêt avec le rendement ou produit des coupes. Ce dernier peut être supérieur ou inférieur au revenu, selon qu'on réalise une partie du capital accumulé ou que l'on augmente ce capital, opérations qui ont pour conséquence la diminution ou l'augmentation du revenu à la fin de la révolution, dont cette opération marque le début. La réalisation peut d'ailleurs être imposée par force majeure (ouragan, verglas, insectes).

Le revenu annuel total ou rente de la forét est l'annuité reproduisant la valeur de la coupe normale dans le nombre d'années compris entre deux coupes successives - les coupes étant supposées revenir périodique ment; - si la forêt est exploitée en coupes annuelles, la rente de la forêt est égale à la valeur de la coupe normale.

Le revenu du sol est égal à l'annuité reproduisant la valeur de la coupe d'un peuplement uniforme, constitué des essences de la forêt, exploité à l'âge minimum auquel il peut fournir des produits de valeur marchande dans la région.

Le revenu de l'épargne est la différence entre le revenu total et le revenu du sol.

L'impôt sur les forêts doit tenir compte des lois de la formation du revenu forestier; ce fait doit intervenir pour la détermination de l'assiette de l'impôt, qu'il s'agisse d'impôt sur le revenu, d'impôt sur les revenus, d'impôt sur le capital ou d'impôt sur la plus-value ou enrichissement.

La méconnaissance de ce principe explique la diversité des méthodes préconisées en France pour le calcul de l'impôt forestier.

La première en date est le revenu cadastral de la loi de frimaire an VII, qui ne voulait imposer que le revenu du sol, mais qui aboutissait à imposer les forêts feuillues sur ce revenu augmenté de celui provenant de l'aménagement en taillis simple, et les forêts résineuses, sur le revenu total des coupes annuelles.

Le revenu dit effectif de l'instruction des Finances de 1908, ou revenu moyen arithmétique, - du moins selon l'interprétation que l'Administration a faite primitivement de son texte - impose les forêts sur le revenu total résultant de l'aménagement en coupes annuelles.

Le revenu effectif, selon une interprétation plus récente de l'Administration, plus conforme au sens littéral, et confirmée à la Chambre par le Ministre des Finances, le 25 février 1913, s'obtient en divisant le prix du taillis, d'une part, et le prix de la futaie, d'autre part, par l'âge respectif des bois et en additionnant les deux quotients. Pour le taillis simple et pour la futaie pure, c'est le revenu moyen arithmétique; pour le taillis sous futaie, c'est le revenu moyen arithmétique du taillis augmenté du quart ou du cinquième du revenu moyen de la futaie.

Le revenu dit théorique de la même instruction est évalué différemment selon la nature des forêts : pour les forêts feuillues, c'est le revenu cadastral; pour les forêts résineuses, c'est le revenu obtenu par comparaison avec les sols roisins. 
Le revenu escompté, proposé par un groupe parlementaire, est le revenu total des forêts supposées exploitées en une seule fois. Le grave défaut de ces méthodes est de ne faire aucune distinction entre les deux éléments du revenu des forêts, d'évaluer le revenu total, plus ou moins empiriquement, et de l'imposer à la contribution foncière, sans pouvoir prévoir les conséquences au point de vue de la juste répartition de l'impôt.

La méthode proposée en 1912 par la sous-commission sénatoriale de l'impôt forestier fait une évaluation distincte des deux éléments du revenu des forêts, mais sans se préoccuper du revenu total.

A toutes ces méthodes, on reproche de ne faire aucune différence entre le revenu des forêts exploitées en coupes annuelles et les revenus des forêts exploitées en coupes non annuelles, même en une seule fois, à quatre-vingts ans et plus pour les futaies.

Pour parer à cet inconvénient, on a préconisé l'impôt sur la coupe. Cette solution, logique lorsqu'il s'agit d'un impôt sur le revenu, serait difficilement conciliable avec les principes du système fiscal français. D'ailleurs, cet impôt devrait être perçu non sur le produit de la coupe, mais sur le revenu. Les réalisations de capital, l'excédent sur la possibilité ne devraient pas être atteintes par l'impôt qui,au contraire, devrait porter sur la part du revenu qui serait économisée. Il faudrait déterminer la valeur de la coupe normale et, comme conséquence, exiger du propriétaire une déclaration d'intention d'exploiter et lui imposer une vérification de ses balivages et de ses récolements. L'impòt sur la coupe comporterait un contrôle étroit de l'Etat sur la gestion des forêts particulières et prendrait fatalement un caractère vexatoire et inquisitorial qui suffit à le faire repousser.

L'application des principes rationnels évite tous les inconvénients, qui viennent d'être signalés.

Que les exploitations reviennent ou non chaque année, le revenu du sol est le même pour une forêt donnée, seul le revenu de l'épargne et par suite le revenu total varie. On objecte la complication du calcul des annuités : il n'est pas impossible d'y remédier, au cas où l'impôt est réel et a pour base non le revenu exact d'une forêt déterminée, mais le revenu que peut donner une forêt moyenne soumise à l'exploitation et à l'aménagement usuellement adoptés dans la région pour les forêts similaires. Dans ce cas, au calcul des annuités, il sera toujours possible de substituer des coefficients simples et peu nombreux, qui, convenablement choisis et appliqués au revenu moyen arithmétique, donneront le revenu annuel avec une approximation de 10 à $12 \%$, bien suffisante en pratique.

Il serait trop long de donner la démonstration mathématique de ce fait, elle nécessite des calculs que chacun peut faire, s'il le désire. Il suffil d'en retenir les résultats.

Pour une forêt donnée, exploitée en coupes périodiques revenant au moins tous les dix ans, la différence entre le revenu total évalué par la moyenne arithmétique et le revenu évalué par les annuités, à des taux compris entre 2 ét $3 \%$, n'excède pas $12 \%$. Par suite, pour toutes les forêts pouvant être exploitées au moins en coupes décennales, on peut. sans erreur sensible admettre que les coupes sont annuelles et considérer le revenu total comme égal au quotient du prix de la coupe par l'âge de l'exploitation. Seules seraient à considérer comme ne pouvant être exploitées en coupes annuelles, les forêts de trop faible contenance pour être 
divisées en coupes revenant tous les dix ans. On peut admettre que les bois de moins de dix hectares sont dans ee cas.

Le revenu d'une forêt exploitée tous les vingt, vingt-cinq ou trente ans, calculé par les annuités à 2,5\% d'une part, et celui d'une forêt exploitée tous les vingt-cinq, trente et quarante ans, calculé par les annuités à $3 \%$, d'autre part, ne diffèrent que de $10 \%$ au plus des deux tiers du revenu moyen. On peut, en conséquence, prendre pour revenu total des taillis de moins de dix hectares, les deux tiers du revenu moyen annuel, et pour revenu du sol les deux tiers du revenu moyen du peuplement donnant le revenu foncier.

Pour une forêt exploitée tous les soixante, quatre-vingts ou cent ans, l'annuité calculée selon le cas à 3 , à 2,5 ou $2 \%$ est sensiblement égale au tiers du revenu moyen arithmétique. Cette proportion peut être admise pour l'évaluation du revenu total des futaies de moins de dix hectares. Deux coefficients suffiraient en pratique :

Celui de $2 / 3$ pour le revenu foncier et pour le revenu total des taillis de moins de dix hectares;

Celui de $1 / 3$ pour le revenu total des futaies de moins de dix hectares.

Sans doute à la limite extrême, une différence d'un are dans la contenance de deux forêts suffirait pour fa re considérer l'une comme pouvant être exploitée en coupes annuelles et l'autre comme ne pouvant donner qu'une seule coupe; pour augmenter le revenu de moitié s'il s'agit de taillis, pour le tripler' s'il s'agit de futaie. Mais c'est la conséquence fatale du système des moyennes.

Malgré eette imperfection, cette solution suffisamment approchée et équitable domnerait pour le revenu du sol une évaluation très voisine de la réalité et serait, pour les propriétaires de forêts, bien préférable aux méthodès proposées jusqu'ici, si on exclut eelle des annuités; elle aurait le grand avantage de permettre de ne pas taxer proportionnellement les petits bois plus que les grandes forêts.

Application des principes dans tèmes d'inpôt
I. Impôt unique sur le revenu. - C'est le revenu total de la forêt qui doit être assujetti à l'impôt. Il n'y a, parsuite, aucune différence à établir entre le revenu du sol et le revenu de l'épargne; mais l'ıмpôt Dortr porter sur LE PRODUit dE LA COUPE NORMALE, c'est-à-dire sur le produit de l'exploitation, diminué de la valeur du capital d'exploitation réalisé, ou augmenté de la valeur de l'épargne constituée.

II. Impôt sur les revenus. Impôt cédulaire. - Le revenu imposable est toujours le revenu déterminé par la valeur de la coupe normale. Si le taux de l' mpôt est le même pour les revenus des diverses cédules, comme dans l'income-tax anglais, on revient au cas précédent. Si le taux varie selon la catégorie des revenus, l'équité exige qu'il soit fait une distinction entre le revenu du sol et le revenu de l'épargne. Le revenu du sol est imposable au taux des revenus fonciers. Quant à l'épargne, à la futaie, il importe, dans l'intérêt économique, national et même mondial, d'en assurer la constitution et la conservation, ee qui n'est possible qu'à la condition que le revenu des capitaux employés aux placements forestiers, ou revenu de la futaie, ne soit pas plus imposé que le revenu des capitaux employés dans le commeree ou l'industrie. Dans le cas contraire, les propriétaires auraient un intérêt évident ì raser leurs futaies pour en employer le prix en placements dont le revenu serait moins impasé. 
Si pour un motif de convenancè fiscale, un Etat prétend n'imposer le revenu forestier que dans une seule cédule, celle de la contribution foncière par exemple, il faut que l'impôt total, en principal et en accessoires s'il en existe, grevant dans ce cas le revenu de la futaie, ne soit pas supérieur soit à l'impôt sur les revenus du commerce et de l'industrie, soit à l'impôt sur les bénéfices agricoles. L'un ou l'autre de ces impôts est, en effet, le seul que doit, en équité, en droit et en logique, le revenu de la futaie. Ce point est particulièrement important dans le système fiscal français où l'impôt foncier sert de base aux taxes locales, centimes départementaux et communaux, taxe vicinale et taxe de main-morte.

III. Impôt sur le capital. - Dans ee système fiscal, le capital forestier à imposer se déduit généralement du revenu. C'est le cas pour l'impôt français des successions.

Le revenu qui sert à évaluer le capital doit être calculé non d'après le rendement moyen des dernières coupes effectuées, mais d'après le produit que donnerait la coupe normale, correspondant à l'état actuel de la forêt. Le revenu à capitaliser est égal au rendement moyen des coupes, diminué de la valeur du capital réalisé, ou augmenté de la valeur du capital épargné dans chaque coupe.

Pour les forêts exploitées en coupes annuelles, le capital est le quotient de la rente de la forêt par le taü des placements forestiers; pour les forêts en coupes non annuelles, c'est le capital générateur du revenu périodique total ou le quotient du revenu total annuel par le taux.

Lorsqu'il s'agit de l'assiette d'un impôt annuel sur le capital, cet impôt doit frapper exclusivement le capital qui produit le revenu, sans porter, au cas d'exploitation périodique, sur les revenus produits mais non recueillis, sur la valeur de la coupe en croissance.

Si, au contraire, comme dans l'impôt français des successions, l'impôt doit atteiridre le capital existant à un moment déterminé, il est nécessaire, pour avoir la valeur vénale actuelle de la forêt exploitée en coupes non annuelles, d'ajouter au capital générateur du revenu la valeur des coupes en croissance.

IV. Impôt sur la plus-salue. - La plus-value pour les forêts peut provenir d'une élévation du cours des bois se maintenant depuis un temps assez long pour être considérée comme définitive, ou d'une augmentation du capital d'exploitation. On ne doit pas considérer comme enrichissement, ou plus-value des forêts à exploitation non annuelle, les revenus dont la pereeption est différée et qui restent dans les coupes en croissance en attendant l'époque de leur réalisation.

V. Impôts de mutation. - Ces impòts sont perçus lors de la transmission de la propriété. Nous avons parlé de l'impôt successoral, à propos de l'impôt sur le capital, il convient de rappeler cependant qu'il est équitable et logique de déduire du revenu à capitaliser la part du revenu absorbé annuellement par l'impôt. Reste à examiner l'impôt sur les transmissions entre vifs. En France, notamment, les droits de mutation entre vifs à titre onéreux ont un taux qui varie selon la nature mobilière ou immobilière de l'objet vendu : 2 1/2 \% pour les meubles; $7 \%$ pour les immeubles. Le sol des forêts est incontestablement immeuble; quant à la superficie, il faut distinguer: les arbres vendus avec le sol'sont considérés comme immeubles ; mais s'ils sont destinés à être prochainement séparés du sol, s'ils sont vendus pour être abattus, ils sont réputés meubles. En cas de vente d'une forêt, le marchand de 
bois, qui achète la superficie pour l'abattre, paye 2,50\% sur la valeur des bois (1), le propriétaire qui achète la forêt pour continuer l'exploitation forestière paye $7 \%$ sur la valeur des mêmes bois. Cette situation met le forestier dans une infériorité manifeste en face du marchand de bois, elle a pour conséquence les exploitations intensives, le déboisement.

Pour assurer la conservation des forêts, il est nécessaire de distinguer dans le prix de vente des forêts la valeur du sol et celle de la superficie, fruit de l'épargne et de la prévoyance. La valeur de la superficie qui s'obtient par la capitalisation du revenu de l'épargne, augmentée de la valeur des coupes en croissance, devrait être taxée au taux du droit des ventes mobilières et même au taux du droit de transmission des valeurs mobilières.

Les propriétaires impérissables : État, départements, communes, établissements publies ou reconnus d'utilité publique, sont tout désignés pour assurer la conservation des forêts. Leur pérennité met celles qu'ils possèdent à l'abri d'un partage toujours funeste, ou d'une licitation plus dangereuse encore, elle leur facilite les sacrifices qu'exigent l'allongement des révolutions et l'éducation de la futaie, assurés qu'ils sont de tirer un avantage de cette conversion. L'intérêt public commande done de faciliter à cette eatégorie de propriétaires l'acquisition de forêts, surtout en montagne. Il serait désirable, à cet effet, de les exonérer des droits d'enregistrement et de n'imposer les achats de forêts qu'ils font que d'un droit fixe de 1 frane, taux payé par l'Etat, en matière d'expropriation pour cause d'utilité publique. Cette mesure aurait encore l'avantage de,permettre aux personnes morales du droit administratif, autres que l'Etat, d'entrer utilement en coneurrence avee les exploitants et même avec les particuliers, pour l'acquisition de forêts, ce qu'elles ne peuvent faire actuellement : le revenu net qu'elles tirent de leurs forêts est, en effet, inférieur à celui qu'en tirerait un particulier, puisqu'elles payent, en plus que celui-ci, l'impôt de main-morte égal aux 0,875 (2) du principal de l'impôt foncier; par suite, elles ne peuvent offrir qu'un prix moindre à moins de se contenter d'un taux de capitalisation inférieur, les deux solutions les mettent dans une situation désavantageuse.

\section{VEUX RELATIFS A L'IMPÔT FONGIER}

I. Que, dans tont système fiscal, la base d'évaluation du revenu forestier soit le produit net de la coupe normale correspondant all plan d'exploitation adopté : usuellement dans la région, si l'impôt est réel ; par le propriétaire, si l'impôt est personnel.

II. Que le Revenu total annuel des forêts soit évalué : pour les forêts en coupes annuelles, comme le quotient du prix de la coupe normale par l'âge de l'exploitation; pour les forêts à exploitation discontinue, comme l'annuité reproduisant la valeur de la coupe normale dans le nombre d'années compris entre deux coupes successives, les coupes étant supposées régulièrement réparties sur la durée de la révolution.

(1) Le projet de loi de finances de l'exeicice 1913, voté par la Chambre, porte ce taux de 2 à $5 \%$, selon la valeur des bois vendus; au-dessus de 100.000 francs, le taux de $5 \%$ serait applicable.

(2) L'article 2 de la loi de finances de l'exercice 1913, roté par la Chambre des députés, élève cet impôt de $50 \%$ et le porte à $131.25 \%$ du principal de l'impot foncier. 
III. Que, excepté au cas d'un impôt unique sur le revenu, l'évaluation du revenu imposable des bois et forêts soit faite d'après les principes suivants:

Le revenu des bois et forêts est formé de deux éléments : 10 le revenu du sol; 20 le revenu de l'épargne accumulée dans les arbres de futaie et les coupes en croissance.

LE REVEXU DU SOL est égal à l'annaité reproduisant la valeur de la coupe d'un peuplement (taillis, semis ou plantation) exploité à l'âge minimum auquel il peut fournir des produits de valeur marchande dans la région.

LE REVENU DE L'ÉPARGNE est la différence entre le revenu total et le revenu dil sol.

IV. Que, dans aucun cas, le revenu de l'épargne ne supporte un impôt total supérieur à celui auquel sont assujettis les revenus du commerce et de l'industrie.

Qu'en France, notamment, ce revenu ne soit pas assujetti à la contribution foncière ou que, dans le cas contraire, il ne soit frappé en principal que d'une laxe réduite en sorte que l'impôt total sur ce revenu (principal, centimes et taxe vicinale) ne soit pas supérieur à l'impôt sur les bénéfices du commerce et de l'industrie, sinon à l'impôt sur les bénéfices agricoles.

V. Que, dans l'impôt sur la plus-value ou l'enrichissement, ne soient pas considérés comme un accroissement de valeur des forêts à coupes non annuelles, les revenus dont la perception est différée et qui restent accumulés dans les coupes en croissance en attendant l'époque de leur réalisation.

VשUX RELATIFS AUX IMPÒTS DE MUTATION ET AUX EXEMPTIONS D'IMPÔTS INTÉRESSANT SPÉCIALEMENT LA LÉGISLATION FRANÇAISE

I. Que, pour l'impôt sur les successions, l'évaluation des forêts en capital soit basée non sur le rendement moyen des dernières exploitations, mais sur le revenu total annuel que peut donner la forêt dans l'état où elle se trouve à l'ouverture de la succession.

II. Que, dans les ventes de forêts en fonds et superficie, la valeur du fonds soit senle imposée anx droits sur les ventes immobilières, la valeur de la superficie étant imposée aux droits de transmission des valeurs mobilières ou au plus anx droits sur les ventes mobilières.

III. Qu'au cas d'acquisition de forêts par les départements, les communes et les établissements publics ou d'utilité publique, il ne soit perçu pour l'enregistrement qu'un droit fixe de 1 franc.

IV. Que la taxe de main-morte sur les bois et forêts acquis par les établissements publics ou d'utilité publique ne soit pas supérieure à celle frappant les biens des communes et des établissements publics de bienfaisance ou d'assistance.

V. Que les terrains reboisés ou nouvellement boisés soient exonérés de tout impôt:

Pendant trente ans pour ceux situés sur les sommets et les versants des montagnes, sur les dunes, dans les landes et les terrains marécagenx;

Pendant vingt ans pour tous les autres terrains.

VI. Qu'il soit accordé des dégrèvements temporaires pour les bois ruinés par des invasions d'insectes ou des maladies cryptogamiques, dont la recons- 
titution par semis ou plantations aura été reconnue indispensable au maintien de l'état boisé.

Des applaudissements nourris saluent la lecture des vocus jrésentés par M. Arnould.

M. LE Prísident. - Les applaudissements par lesquels rous renez de saluer la lecture du rapport de M. Armould et des voeux qui le telminent, sont, Messieurs, la juste récompense: de l'intelligegee et de ] ardeur avec laquelle, depuis de longues années, notre collègue s'occupe de la ruestion si intéressante, si aride et si ingrate de limpôt forestier.

Lordre du jour appelle maintenant la lecture d'une communication

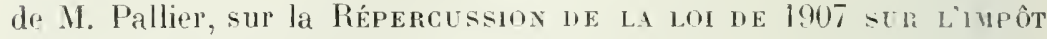
bes Bors. Je prierai l'un des secrétaires de la séance de nous flu donner lecture.

II. Pallier expose que le dégrèvement de la propriété non bìtie que vise la Loi du 31 décembre 1907 , se traduit en réalité par un accrois iement d'innôts. Il cite comme exemple 105 hectares de bois sitnés dans larronlisenent d'Alais (Gard).

Cette augmentation d'impôts, réalisée par les agents de l'administration des Finances, est contraire à l'esprit de la loi, et se produit à un moment où les coupes se vemdent de plus en plus mal.

Conchusion : L'impôt sur la forèt ne doit ètre qu'un droit fixe sur les produits forestiers au moment de lenr exploitation ; le taux doit en eitre sulfitamment réduit pour attirer les capitaux et fąvoriser te reboisement.

M. Gouget. - Ce que jai à vous dire est en quelque sorle une suite au rapport de M. Imould. J'en ai deduit aussi des conelusions au point de vue du droit du proprictaire.

Veuillez m'excuser de prendre la parole après le rapport si sayant et si complet de l'honorable M. Arnould qui, depuis 1895, lutte avec autant de ténacité, d'énergie et de courage que d'intelligence et de competence, pour une application plus juste de notre systeme flscal! Qu'il me soit done permis ici de profiter de la circonstance pour rendre hommage à son labeur el lui témoigner la recomnaissance de tous los propriétaires forestiers.

A la question de limpôt est líe indissolublement celle du droit de propriété, et c'est à ce propos que j'ai cru devoir vous soumnttre quelques observations en m’appuyant sur les principes dr notre droit. sur l'opinion de tous les économistes et jurisconsultes et sur la loi elle-même.

L'impòt, aujourd lui, est, pour la plus grande partie de la fortume forestière française, la négation du droit de propricté.

Et cependant, que voyons-nous dans toutes les ronstitutions?

Laffirmation constante de ce droit de propriété el sa défense contre toute oppression.

Depuis 1789 jusqu'à nos jours, ce grand princijes a ete constamment proclame; en voici les principaux textes: 
Constitution du 17 septembre 1791, article 17 :

"La propriété étant un droit inviolable et sacre", nul ne peut en ètre "privé, si ce n’est lorsque la nécessité publique lexige évidrmment "et sous la condition d'une juste et probable indemnité ".

Dans la déclaration des Droits de l'Homme du 8 juin 1793 et larte constitutionnel du 2't du même mois, il est dit : "Que le droit de "propriaté est celui qui appartient à tout citoyen de jouir et de đlis"poser à son gré de ses biens, de ses resemus, tlu fruit de son travail "et de son industrie ".

La résistance à l'oppression est la conséquence des autres droits de l'homme, et le Gouvernement ne peut violer les droits du peuple.

La Constitution garantit à tous les Français, l'Egalité, la Liberté, la Propristé.

C'est sur le maintien des propriétés que reposent la culture de la terre, toutes les productions et tout lordre social (Constitution du 17 aoùt 1795).

Au surplus, tous ces mêmes principes sont renourelés dans toutes les lois ćtablies jusqu à ce jour.

Ainsi done, ce droit de propriété, proclamé depuis plus 1te 120 ans, inviolable et sacré, est en partie détruit; par quoi? par des lois qui, sans l'abroger ouvertement, le minent et l'amniluilent petit à petit.

Il s’agit de savoir si ces lois sont bien ce qu’a voulu et prévu le législateur et si l'interpretation qu'on leur donne si facilement est bien juridique.

Pour ma part, je ne le crois pas. Aussi ai-je roulu profiter de ce grand congrès, dù à l'heureuse initiative du Touring-Chub de France, pour faire valoir les motifs de ma conviction.

Toutes les contributions doivent être reparties également entre les citoyens, en proportion de leurs facultés.

Aux termes de l'article 59 de la Loi du 23 août 1815, les francais sont égaux devant la loi pour la contribution aux impôts et aux charges publiques; ils contribuent indistinctement, daris la proportion de leur fortune, aux charges de l'État (1 oi du 24 aonit 1830).

L'Egalité de proportion dans l'impôt est done de droit.

$\mathrm{Si}$, de l'article 37 de la Loi du 25 septembre 1807, il résulte que les bases du revenu imposé sur les propriétés non bàties sont intangibles, et que le droit de se pourvoir en réduetion n'est plus admissible, nous pouvons et nous devons opposer l'article 9 de l'ordonnance du 3 octobre 1821, lont l'interprétation, fournie par l'article 10 du règlement de cette ordonnance, est ainsi formulee :

"Les propriétaires sont arlmis à réclamer à toute époque lorsque la diminution qu'ils éprouvent provient de canses postérieures ot étrangères au classement, telles rue : démolitions, incendles, eessions de terrains à la roie publique, disparition lu fonds, mfin, perte du revenu dans quelqne propriété dont la suleur justement ésuluér dans le prinripe unra été détériorée par suite dévénements imprésus ct indé- 
pendants de la volonté du propriétaire et, ajoute Dalloz, par suite de ('ariations dans le commerce ».

Eh bien! Messieurs, je rous le demande, nos bois, taillis simples et sous futaies, ne se trourent-ils pas dans le cas préru par cette Loi du 3 septembre 1821, postérieure à celle de 1807? Les législateurs ne se sont-ils paș rendu compte, 14 ans après, qu'il était inadmissible qu'on pùt demander un impôt à une propriété qui ne produit plus suffisamment pour l'aequitter?

N'ont-ils pas voulu corriger la règle par trop absolue et injuste de l'intangibilité du revenu imposable et rentrer dans le principe de l'inviolabilité du droit de propriété?

Le simple raisonnement porte à le croire.

- Que deviendrait, du reste, ee droit de propriété si, par l'impôt, on absorbait le revenu? Ce qui se produit actuellement pour les boistaillis peut très bien s'étendre à toute la fortune immobilière française, et alors!

Sans vouloir m'étendre trop longuement sur cette question que jai traitée à la Société des Agrieulteurs de France, le 16 févi ier 1912, je vous ferai remarquer que les causes de la diminution et de la disparition de nos revenus sont bien postérieures et étrangères au classement de nos propriétés et indépendantes de la volonté des déteniteurs des forêts; que ces causes ont détérioré (c'est-à-dire ôté la valeur), changé, modifié et même anéanti le revenu de nos bois, et que, si elles sont dues au progrès, elles n'en subsistent pas moins pour la perte de nos taillis; tous, vous les connaissez ces eauses, et je crois inutile de vous les signaler à nouveau; dans tous les eas, nos produits ne trouvant plus que très difficilement leur écoulement, les débouchés se restreignent de plus en plus et, au fur et à mesure de la baisse des revenus, les frais d'exploitation, de transport, les impôts et les autres charges anciennes et récentes, créces par les lois sociales, augmentent dans des proportions telles que la forêt n'est plus une richesse, mais une charge dont on ne peut plus se débarrasser.

En frappant nos bois d'impôts toujour's croissants, on absorbe le capital ou plutòt on détruit sa valeur! Et alors on impose quoi? La misère!

Or, à l'intangibilité des bases absolument fausses de l’impòt, j'oppose :

to Linviolabilité constamment consacrée du droit de propriété;

$2^{\circ}$ L'Ordonnaner du 3 octobre 1821 et son règlement;

$3^{\circ}$ Et l'opinion de tous les économistes qui ont traité cette grave question et dont voici quelques extraits :

"L'impòt, dit Ricaldo, est la portion du produit de la terre et de l'industrie qu'on met a la disposition du Gouvernement. ”

Suirant Jean-Baptiste Say, "cest seulement une portion des biens des particuliers que le Gourernement consarre à satisfaire les besoins du corps social ».

L'impòt est légitime et juste en principe, mais il a une limite, c'est seulement la part de l'État dans les résultats de la production, et eette 
part (toujours et partout le mot : part et portion) doit être proportionnelle à ces résultats, elle doit augmenter et déervître avec elle.

Les charges, dont les peuples souffrent, sont réputées saines et justes, dit un député aux États généraux du Dauphiné; " mais elles sont, dans l'État, ce que sont les voiles dans un vaisseau pour le conduire et non pour le charger et le submerger. Elles doivent done suivre en principe, dans leur marche, la richesse nationale, progresser et décroitre avee elle; alors la fortune publique n'en souffre pas ».

Je termine ces quelques citations par une des maximes d'Idam Smith; "Les sujets d un État doivent contribuer au soutien du Gouvernement, ehaeun le plus possible en proportion de ses facultés, e'est-à-dire en proportion du resenu dont il jouit sous la protection de l'État. La taxe ou portion d'impôt doit être certaine et non arbitraire $"$.

Toutes ces opinions et ces maximes ont été eonstamment reproduites, admises et suivies dans tous les pays constitutionnels; la France doit-elle done faire exception?

Tous les éeonomistes ont toujours regardé comme illégitime l'impòt que l'on ne peut payer qu'en attaquant le capital.

Ce capital, pour nos bois taillis, ah! il est joli!

Dans certaines contrées de la France, on ne peut plus l'estimer; les transmissions à titre onéreux ne sont plus possibles que pour des sols portant de la futaie; les autres, mème offertes gratuitement, on les refuse; j'ai là sous les yeux des extraits de contrats régulier's et authentiques où l'on a passé les immeubles à des miséreux pour échapper à l’impôt.

Je me dispenserai de vons énumérer à nouveau les nombreux exemples où l'impôt dépasse le revenu ; je l'ai déjà fait, je me bornerai seulement à eiter celui qui me concerne personnellement : propriétaire d'une forêt de 575 hectares, aménagée à 23 ans par des coupes annuelles de 25 heetares, j'ai vendu celle du présent exereice sur le pied de 116 franes l'heetare, ce qui représente un prix total de 2.900 francs pour la contenance prévue par l'aménagement régulier; eh bien! l'impôt qui, pour 1912, s'élevait à 3.321 fr. 38, atteint pour 1913 : 3.576 fr. 25 , soit encore une augmentation de $256 \mathrm{fr}$. 87 et un revenu inférieur de $676 \mathrm{fr}$. 25 à la charge à acquitter eet te année.

Après cela, que faire? Raser les quelques futaies encore existantes; eh bien non, je n'ai pas youlu le faire, parce que je eonserve le ferme espoir quine situation aussi injuste que lamentable doit prendre fin, que les Pouvoir's publics, suffisamment éclairés aujourd'hui, n'hésiteront pas à la changer, que nos réclamations en détaxe no seront plus rejetées et que la jurisprudence consacrera la légitimité de nos droits de propriété, forte qu'elle sera en s'appuyant sur tous les principes du droit, sur les lois que je viens de rappeler rapidement et sur la pénurie de nos revenus de taillis.

Cet espoir, aujourd'hui presque une assurance, après les paroles prononcées hier par M. le Ministre de l'Agriculture, je le place surtout 
en rous tous. Messieurs, en cette haute et bienfaisante association du Touring-Club de France qui a pris en main arre ardeur, la défense, la conservation et l'amélioration d" nos bois.

Nous aimons tous la forèt; clte est nécessaire, indispensable à lexistence des peuples; elle nous préserve des calamités; elle étend ses bienfaits sur toute la nature; elle charme la vue, poétise la pensén et le cour; elle nous donne la santé et même la vie, il faut qu'elle prospère ; il fant qu'clle donne à celui qui la détient des revenus, c'està-dire cette jouissance que proclament tontes les lois, principe essentiel du droit de propriété, et non des charges qui la détruisent et la ruinent.

Confiant dans la justice et l'équité des Pouvoirs publies, dans la haute compétence de notre distinguée et savante Administration forestière, dans le dévourment inlassable du Touring-Club de France et dans tous nos efforts réunis, je répète : "Réduisez l'impôt. Et ałors. je crie de tout coeur :

Tire la forêt!

Permettez-moi maintenant de rous lire quelqu's renseignements recueillis au bureau de l'Enregistrement de Verzy (Mlarne) et chez le percepteur de ce même canton :

Ventes sous-seing privé :

II. Rémy Fresnet (Alexandre) de Verzy, a vendu le 27 janvier 1908, à Peyre (J.-Baptiste), marchand ambulant à T'royes, pour le prix te 15 franes, déclarés payés complant :

[o 0 l. 22 a. 30 c. de bois, lieu dit le Grand Corizeux, sur Verzenay.

zo 0 h. 22 a. 09 e., lien dit le Corizeux-sur-Verzenay.

Payre est inconnu du percepteur et les impots ne sonl pas recourrés.

La veuve Renois-Pithois, de Verzenay, vend le 12 janvier 1912, à Lecompcre (Émile), de Cormontreuil, 2 h. 48 a. 20 c. de bois sur Verzenay, pour 15 francs.

Antoine (Donalieu), de Verzenay, mendiant et insolvable, achète le 15 féviler 1901 pour 20 franes, 2 h. 09 a. de bois, sur Verzenay, et le $1^{\text {er }}$ décembre 1902 , $1 \mathrm{~h} .01 \mathrm{a}$. de bois sur Mailly-Champagne, ponr 25 francs. Les prix de vente n'ont, parait-il, jamais été payés.

Ferré Trucharl (Guslave) à Verzenay, insolvable, a acheté les parcelles de bois ci-apres :

\begin{tabular}{|c|c|c|c|c|c|c|}
\hline $110 \mathrm{~V}$. & $\begin{array}{l}191 \\
-\end{array}$ & 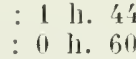 & StII & Terzenay & pou & 1 \\
\hline- & - & : 1 h. 2' & . & - & - & 5 \\
\hline mars & - & $: 0 \mathrm{~h} .57$ & & Mailly & - & 5 \\
\hline
\end{tabular}

Les faits de ce genre sont, paraît-il, nombreux, tant à Mailly qu'à Ver'zenay, canton de Verzy (Marne). En général, les parcelles sont vendues 1 ou 2 frames. "ui no sont pas pavés; tous les frais restent a la charge du vendeur qui veille de près à ce que la mutation de propriété soit laile. Le receveur de l'knregis. trement ne peut pas attarpuer les parties pour dissimulatio $n$ de prix de vente. car il sait que ces parcelles n'onl réellement aucume valeur, par suite des impoits à payer.

Les adjudications publiques donnenl, du reste, des résultats analogios

30 octobre 1910, adjudication par Me Labilte notaire à Verzy : 1 h. 20 a. de bois au Grand Corizeux, territoire de Verzenay, ventu 1 franc à M. Gustave Ferré, de Verzenar. Le mème jour, M. Ferré a achefé au mène lieu, 0 h. 55 a. de bois pour 1 l'rane, par-devant Me Ferté, notaire à Beaumont-sur-Vesles. 25 mars 1906 : II Labitte vend par adjudication, t h. à M. Patis-Cavel, de Verzenay, $\mathrm{l}$ h. de bois sur Verzenay, lieu dif le Planl. 
M. ie Présinent. — Vous avez employé dans votre discours, à diverses r"prises, une expression qui peut avoir une grande importance. L. document de 1821 est-il une ordonnarce ou une loi?

M. Govget. - Ciest une ordonnance royale.

M. I.e Président. - Justement! Il y a là un point faible; d'un còtí, nous avons la Loi de 1807 et de l'autre, nous avons une simple ordonnance royale! Ceci, tout simplement pour faire remarquer. comme le disent dailleurs ros conclusiors, que ce serait téméraire de faire fonds sur lopposition de cette ordonnance avec la loi. En definitive, lans l'étude de cette question, et si nous voulons une amélionation de la situation, nous sommes obligés de tabler uniquement sur une modification complète de la situation actuelle. Cela ne touche en rien à vos conclusions. Ce que je veux dire, eest qu'il serait imprudent le compter sui l'état actuel de la législation pour en tirer avantage, parce que la réponse que je vous fais, le fise vous la ferait immédiatement.

M. Covget. - Parfaitement!

1 la Socióté des Agricultenrs, on ma demandé, à la suite de ce "apport, de prier le Congrès de vouloir bien renouveler le vou qu" la Société des Agriculteurs avait émis le 19 février 1912. Je ne sais si jai bien le droit de rappeler ici ce vœu?...(Voix nombreuses: Oni! Oni !) Puisque vous le voulez bien, je vais rous le lire:

"Considérant que limpôt foncier sur les forêts, principalement sur les bois taillis, est anjourd'hui hors de proportion avee leur's revenus qui il absorbe même dans certains cas;

"Que la proportion contributive de cet impôt dépasse tonte quotité présule;

"Que la diminution du resenu des bois est due à des causes indépendantes de la volonté des propriétuires;

"One cenx-ci, soumis ì des charges écrasantes, sont dans limpossibilité de conserver et d'améliorer l'état boisé de leurs propriétés;

"Que les forêts, par l'interdiction de défrichement et l'obligation de garder contre le paturage, ne pencent foumir un antre revenu compensuteur ;

"Qne la crise quielles subissent est devenue un état permanent et que rien n'en fait présoir la fin;

"Qne l'allègement qui pourrait résulter de la Loi du 31 décembre 1907 pour lévalnation du revenu net des propriétés non bâties n'est pas encore certain et que, dans tous les cas, l'application peut en être fort èloignée ;

"La Socióté des Agriculteurs de France est d'avis qu il y a lieu, dès maintenant, de confirmer ou d'admettre le principe de la réduction de limpôt, par rapport aux resenus forestiers uctucls dûment justiflés ou à défunt de justifications et en cas de contestations, d'en déterminer l'importance par une expertise contradictoire." 
Ciest un rou d'attente. La plupart d'entre nous constatent que l'évaluation a été fort mal faite. Pour arriver à une révision complète, il faudrait que la révision fùt faite dans d'autres conditions. Mais cette vision nouvelle, si elle était accordée, pourrait nous mener pendant trois, quatre, cinq ans, peut-être plus, avant que les impôts fussent diminués. Or, si d’ici là, nous restons dans cette situation, moi, le premier, je commence à faire argent de mes bois, au moins pour payer les impòts. Ce vœu a pour but d'arriver tout de suite à une réduction de limpòt qui sera une détaxe, comme cela a eu lieu pour la vigne, je crois, pour des produits qui n'existent plus.

M. Le Président. - Le bureau prend note de ce vœu, mais si vous voulez bien, nous le remettrons à la fin $\mathrm{d}$ з la discussion, pour ne pas interrompre celle-ci.

M. Gouget. - Ciest entendu.

M. Delahaye. - On a parlé, en matière d'impòt sur les forèts, de l'évaluation du revenu. C'est la base des impòts. Or, il est intéressant de savoir comment cette évaluation est faite. Le contrôleur des contributions, assisté de classificateur's choisis, vous savez comment, procède à cette opération. Or, la propriété forestière a le malheur d'apparaitre comme une propriété riche et on est toujours porté à la taxer un peu lourdement. Il n'y a aucun contròle, et le malheureux propriétaire, une fois l'évaluation faite - c'est d'ailleurs ce qui s'est passé lors de l'évaluation de la propriété non bâtie - n'a qu'un recours illusoire. Il a la charge de la preuve, à l'inverse de ce qui se passe en matière d'enregistrement, et cette preuve est fort diffleile à faire.

Il s'agit done de chercher à obtenir pour les rontribuables forestiers des garanties, et il semble que l'État, de son côté, aurait des garanties suffisantes, en faisant intervenir, dans toutes ces exvaluations et les litiges qui peuvent en résulter, un agent de son service, un agent forestier.

L'agent forestier n'est pas un homme à tendances fiscales ; par conséquent, je ne crois pas que les propriétaires aient à craindre d'exagérations de sa part. Il agira en toute conscience et impartialité.

Je vous demanderai done d'insérer dans le roeu que, dans toutes les évaluations de propriétés forestières et dans les litiges qui les concernent, les agents forestiers de l'État soient appelés, obligatoirement, à donner leur aris.

M. Le Président. - Je vois tout de suite une objection : il faudrait augmenter considérablement le nombre des agents forestiers.

M. Delahaye. - C'est évident, et les indemniser de ce travail suppléinentaire.

II. LE Prísident. - C'est tout de suite une transformation considérable 
de l'administration. Or, comme le faisait remarquer M. Gouget, nous avons à solutionner une question urgente. Je me permets done de signaler en passant, que, peut-ètre, dans les solutions à envisager, il faut avoir grand soin de tenir compte de la facilité de ces solutions, et d'éviter de trop préciser, ce qui amènerait toute une série de difficultés.

M. Delahaye. - On pour rait envisager tout au moins le cas des litiges et des réelamations.

M. Le Présidext. - Al ! ça, c'est autre chose!

M. de Sébille. - Messieurs, la question qui vous préoceupe aujourd'hui fait l'objet en Belgique, également, de la plus grande sollicitude.

En 1897, le Gouvernement se proposait de modifier la base de l'impôt. Emotion générale! Parce qu'on sait bien que si on modifie un impôt, e'est toujours pour l'augmenter! (Rires.)

L'inpôi foncier sur les bois a dans presque tous les pays des bases injustes, il est partout exagéré ei particulièrement en France, car je constate, Messieurs, que tous vous vous en plaignez.

Chargé par la Société centrale Forestière et la Sociéiécentrale d'Agriculture de Belgique de rechereher les modifications qui seraient utiles à apporter à notre législation pour soulager les propriétés foncières boisées, j'ai fait un rapport qui a en l'approhation des plus liautes autorités. Je vous demande la permission de le résumer.

J'ai constaté les profondes modificaiions apportées à la loi du 3 frimaire an VII et spécialement par le prince sourerain des PaysBas, à cause de son arrêté du 30 septembre 1811́, qui avait à cette ćpoque la plénitude du pouvoir législatif, qu’il a conservée jusqu’a la promulgation de la loi fondamentale, en août 1815.

Les instructions qui existaient sur le Cadastre en 181'́ n'ont jamais été abrogées en Belgique; il en résulte que les articles 111 à 120 de la loi du 3 frimaire an VII sont sans application en cas de révision générale.

1)'où des complications, puisque les lois anciennes reprennent leur empire après la révision; de sorte que les elassements en bois, ierres vaines et vagues ou en friches subissent des modifications injustifiables.

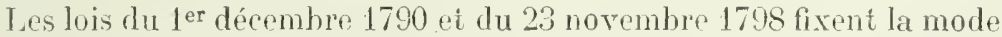
d'évaluation des bois sur la base des annuités des révolutions, s'il s'agit de taillis en coupe réglée. Mais s'il s'agit des bois de sapins, ils doivent être estimés d'après leur produit réel, c'est-à-dire sans déduction des frais de premier établissement, d'entretien et de gardiennage.

Les bois de haute futaie font l'ohjet de classifications séparées suivant (fu'elle est pure on en mélange.

Il résulte de l'exposé que j'ai fait des lo is sur le cadastre, que dans l'esprit du législateur, la base de la cotisation des bris fenillus est caleulée d'après la valeur du taillis croissant dans la région. Le taillis est divisé en plusiemrs rlasses (fui servent de base à son évaluation pour les bois à feuilles caduques; si sa révolution est de 10, 15,20 ou 25 ans, le produit 
de sa vente, dédurion faite des frais de garde, d'entretien of de refertplement provos a l'art. 305. doit-être livise par 10, 15, 20 on 25, d'après

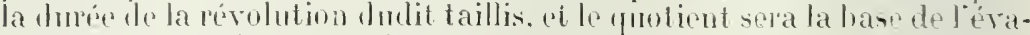

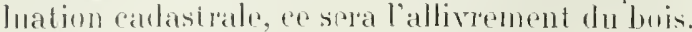

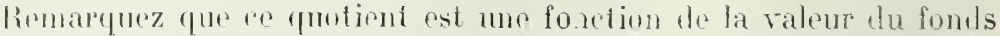

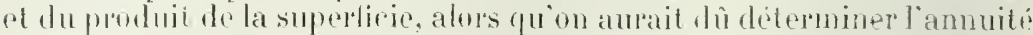

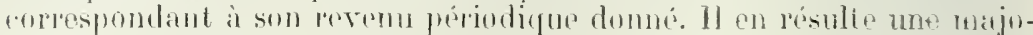

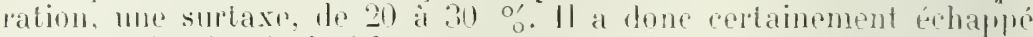

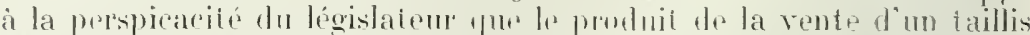

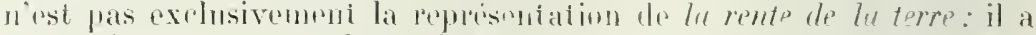

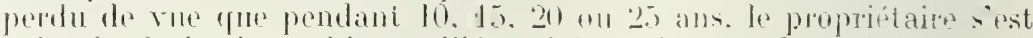

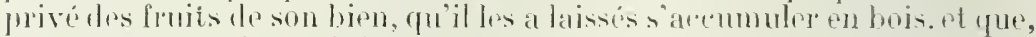
par consífuent, le produii que le lise alteint est mon seulement la peute

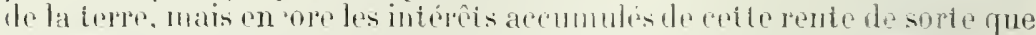

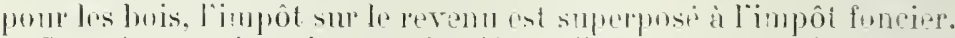

Cefle inmoration n'est pas justifice; colle est en onntradiotion formelle aver l'esprit de l'époque ot avee les basesétablics pour les terrescult ivées, olle rst illegale; aussi espéroms-nous qu'olle ra disparaitre défnitionment le nos lois.

Si mom passons maintenant des bois fenillus amx bois rénemex, nous

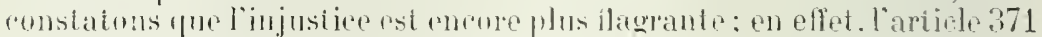

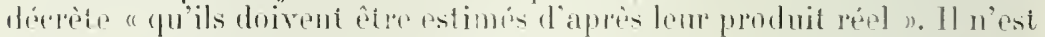

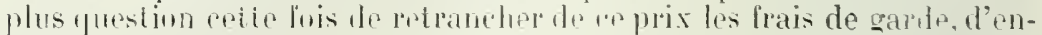

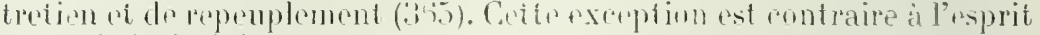
géméral de la loi.

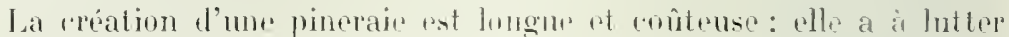
rontre la nature du sol, le elimat, le fer, les inseetes, et lorsque l'pxploitation on est laite, on ne peut janais compter sur le repeuplenent naturel : il faut enterer les souches. laisser son terain en jachere pentant phusiem's années arant de le replanter, de sorte que les bases sm" lesefuclles limpôt est calenlé sont inexactes. On a done prélevé, jusequ'a présent. un impôt beancoup trop filéré sur tous les bois en général; ; rette majoration pour les pineraies atteint de 40 a $50 \%$ o.

Dans lis developpements quil a lumues au Sénat, le 2 te décembre 1897, le Comvernement, expliefuant la loj bulgétaire du 30 décembru 1896, a ronfirmé rue les nourelles érahations seront établies d'apris la valene locative actuelle des propriétés.

Or, les bois ne sent, ne general. pas mis en location pour lo produit

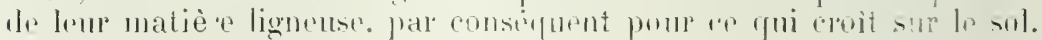

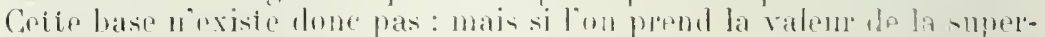

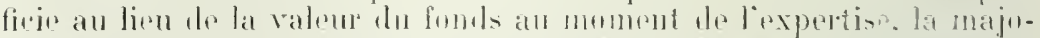

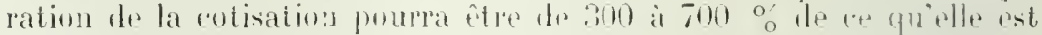
actuellement; ancum bois ne pumrail sujpontor un pureil impôt, il serait inique ot inegal.

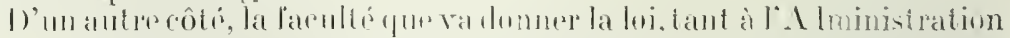

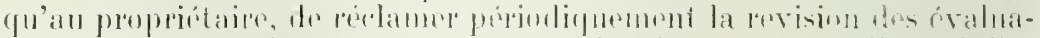

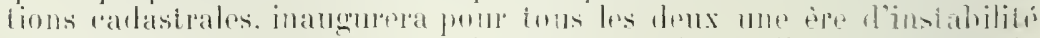

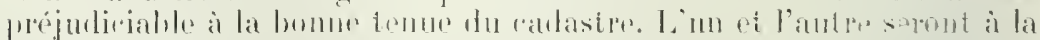

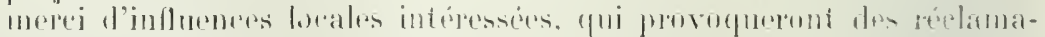

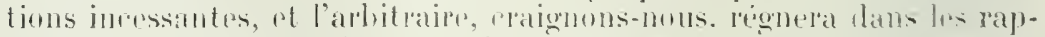

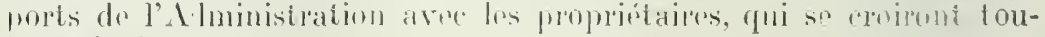
jours lisests. 
Pour iviter toutes ces difficultés et dommer au fise comme anx pro. priétaires le plus de garanties possible pour l'évaluation exacie de la cotisation des propriétés boistes, il est indispensalıle que l'on choisisse parmi les experts un homme compétent, agréé par eux. Cetir mesure d'équité s'impose pour éviter le retour des erreur's que nous venons de signaler.

Le principe de l'immutabilité des cotes foncières est très disenté. Il a ses partisans, comme sas détracteurs; cependant, en ce qui concerne les bois, la plupart y trouvent de sérieux avantagrs. En effet, on est unanime à constaier que la valeur d'un bois change tous les jours, de sorte que elaque fois qu'me expertise d'un terrain boisé sera faite, il lui sera attribué, avee raison, une valeur diflérente; quand l'exploitation en sera terminée, la valeur de la superficie sera profondément modifiée: aịnsi, pour les pineraies, par exemple, elle deviend a nulle et, qui plus est, le reboisem nt du terrain entrainera des frais considérables, car il faudra enlever les souches, etc. Ces variations de valeur provorquent des réclamations continuelles, au grand préjudice de tous.

Il est done nécessaire de maintenir l'immutabilité de l'impót, tout au moins pendant une certaine période, sans tenir coinp te des variation, qui peuvent atteindre sur le fmarché la valeur de quelques produits forestiers.

Je conclus en proposant de demander au Couvernement que l"inpôt foncier soit exclusivemsnt établi, pour les terres boisées aussi bien que pour les terres cultivées, sur le revenu net du sol ou sur la valem du fonds de terre, en y comprenant de part et d'autre les améliorations incorporées dans le sol, et cela sans privilège ni exemption d'a'tcune espèce et sans préoccupation de l'essence cultivée, ni même dı traitement adopté.

Pour les terres cultivées, l'A Iministration prend pour base la valeur locaive, elle n'a pas à s'inquiéter des assolements, ni de la valeur dos récoltes qu'on leur fera porter : pourquoi voudrait-clle alors s'immiser dans les aménagements ou les essences des bris qu'on cultivera?

La valeur du fonds de terre doit seule, à notre aris, la prénecuper; c'est la base la moins variable de la propriéts.

Cette base présente le second avartage de pouvoir être généralistén pour ioutes les ierres sans exception; elle est à la portée de tout le monde, elle peut done être facilement discutée.

Pour toutes ces raisons j'estime, M sssieurs, que l'annuité que rous préennisez pour hase de l'impôt n'est pas justifiée, et d'autani monins, que vous modifiez, à votre détriment, l'mnité de taxation exisiante; en effet, pour les terres cultivées, vous aeceptez la valeur vénale des clamps sans ienir compte des p'o luits que vous leur faites porter.

Vous réctanez la justice pour cet impôi, vous ne pouvez la tromper que dans la seule base indiscutable qui est la valeur du fonds de terre.

Je erois que daus ces conclusions, il y en a beaucoup qui se rapprochent de celles qui ont ité ćnises par M. Arnould.

M. Le Président. - Cette communication nous dimontre quil u'y a pas que la France où la question de l'impòt forestier soit à l'ordre du jour et qu'il y a, évidemment, à déterminer les bases de l impòt 
un peu partout d'une manière plus rationnelle que cela n'a été fait jusqu'ici.

M. Coste. - Il ne me paraît pas du tout désirable que dans les litiges — et ils seront nombreux - qui viendront à propos de la révision de l'évaluation de la propriété foncière, l'expertise soit, d'une façon obligatoire, confiée à des agents de l'Administration des forêts. Je crois qu'il serait de beaucoup préférable de laisser toute liberté aux juges chargés de trancher les litiges. Ils prendront les experts où ils roudront.

Ce n'est pas que je me méfie des lumières ni de l'impartialité des agents des forêts, mais je connais la mentalité des plaideur's; elle est souvent déplorable. Tous ceux qui peuvent aroir été mêlés à des affaires judiciaires vous diront que le plaideur qui perd son procès est facilement porté à la suspicion, et si l'expert de l'Administration fait une évaluation qui ne lui plait pas, le plaideur sera volontiers tenté de dire - à tort, je n'en doute pas - mais il le dira tout de même, qu'il y a eu entente entre l'Administration des Forêts et celle des Finances.

Il y a eu une situation analogue, que je dois rappeler, en matière d'expertise concernant les travaux publies.

Là aussi, on avait décidé qu'en manière d'expertises pour dommages, la tierce expertise serait obligatoirement confiée à l'ingénieur en chef des Ponts et Chaussées.

L'intervention de ce haut fonctionnaire n’a pas désarmé les soupçons. Il y a eu des plaintes, des réeriminations, et, depuis un certain nombre d'années, cette disposition a disparu. (Assentiment.)

Eh bien! je crois qu'une intervention analogue aurait un grand inconvénient en matière forestière, d'autant plus que la loi Audiffred prétend établir - ce qui est très souhaitable, - une collaboration de tous les jours entre l'Administration des forêts et les propriétaires forestiers.

Je suis persuadé que cette collaboration, souhaitable à tous points de rue, risquera d'être troublée, si tous les jours, à propos de litiges, d'évaluations, le propriétaire est en présence de l'expert, agent de l'Administration des forêts.

Je rous demande de vous prononcer contre la proposition faite à cet égard.

M. Chatcerel. - Liarticle, complété par les conelusions de M. Gouget, qui demande l'expertise - et dans le's termes mêmes oì il la demande - me parait être, en l'état actuel des choses, la seule solution possible.

M. Michel Taxassesco. - Nessieur's, la question est fort importante puisqu'il s'agit de ee que le fonds forestier et le bois sont imposés. Il est évident que chaeun des congressistes désire que la solution à laquelle s'arrêtera le Congrès donne satisfaction à Lous. 
En Roumanie, l'impòt forestier est basé sur le même système que limpôt agricole, c’est-à-dire que le propriétaire paye lor'sque la forêt est coupée. Il paye $6 \%$, dine part, pour l'Etat et $8 \%$ (cela varie avec les régions) pour les dixièmes communaux, départementaux. etc...

Cette question me parait être ainsi résolue d une manière équitable, surtout pour le propriétaire, puisqu'it n’est pas obligé; comme en France, de payer à l'État un impòt sans avoir rien touché auparavant (Applandissements). Le propriétaire paie quand il réalise. Dans les exploitations agricoles, on touche chaque année le revenu de son sol, tandis que dans la forêt, ce n'est pas la même chose; on tonche quand le massif est mis en exploitation. En France, on paye chaque année, puisque l'impôt est annuel. En Rounanie, on paye par périodes. La base est le contrat entre les parties. s'il existe. si c'est le propriétaire qui exploite le bois, naturellement les agents du fisc en font une estimation. Si cette évaluation ne satisfait pas le propriétaire, il a le droit de la contester et l'affaire peut être jugée par la Commission d'appel avec droit de recours en cassation.

Par conséquent, ohez nous, le propriétaire ne paye à l'État un impôt annucl que pendant le temps qu'il réalise la coupe ou la forèt qu'il exploite, c'est-à-dire que si le contrat stipule par exemple sept annéés pour l'exploitation, l'impôt est dirisé en sept parties, et le propriétaire paye annuellement pendant ce temps, un septième de l'impôt calculé sur la valeur de la coupe. L'impôt n'existe que pour la coupe, c'est-à-dire que pour ce qu'on touche et non pas sur une estimation, comme en France.

M. Le Prf́sident. - Votre communication est des plus intéressantes, mon cher collègue, et je rous en remercie au nom de la Commission. Il est toujours du plus haut intérêt d'avoir des vues sur ce qui se passe à l'étranger.

M. Arnot ld. - Je voudrais bien préciser et prier M. Tanassesco de notis dire si, en Roumanie, on a l'impôt sur le revenu ou l'impôt foncier?

M. Taxassesco. - On a l'impôt sur le revenu.

11. Le Présidext. - En delor's des forêts, par exemple, pour les propriétés aguricoles, existe-t-il un impòt foncier ou bien un impôt sur le revenu?

11. Tanassesco. - C Cest toujour's sur le revenu qu'est basé l'impôt si le terrain est pris à bail, sinon, daprès une expertise du fise et dans les mêmes conditions que je rous ai exposées pour la forêt.

M. Le Présinent. - C'est un principe profondément diffèrent du nôtre. Nous notons ce point particulier qui n'enlève aucunement soll intérêt à rotre communication.

M. de Barbut. - Jajouterai seulement quelques mots aux communi- 
cations si intéressantes de M. Gouget et de M. le délégué de Roumanie. Il s'agit d'un cas qui, comme pour M. Gouget, m'est personnel, d'une forèt qui se trouve. non en Roumanie, mais dans l'Yonne... mallıeureusement.

Dans cet te forèt. à partir de 1909. la crise. lue à la baisse des produits linnenx. scorce, charbonnette et bois de chauffage, s'accélère du fait Ap la dipopulation loeale. Plus de consommateurs de bois de chauffage plus de bùcherons, pius de charretiers, pius de marchands de bois.

En 1910. la coupe ne peut se vendre: en 1911, elle trouve acquéreur à 2.400 franes a u lieu de 8.805 . En 1912 aussi, pas de rente.

lème ne vendant pas, il faut payer les impôts.

Cos impòts, toujours croissants, 4 fr. 40 en 1901. 5 fi. 17 en 1909, (i) fr. 59 en 1913, dépassent le rendement actuel, $6 \mathrm{fr}$. 40, et se maintiennent définitivement au-dessus des rendements futurs qui suivront nécessairement les rendements antérieurs décroissants.

II est maintenant rigoureusement certain que jamais les prix des coupes ne pourront payer les impòts.

Que: faire de cette terre qui donnait autrefois beaucoup de revenu et payait peu d'impòts, alors quelle aurait pu en paycr davantage (le systeme roumain a du bon) et qui maintenant ne donnant plus de revenu doit payei beaucoup d'impôts?

La-eule solution est relle qui a été employér et que cit ait M. Gouget: la mort te la forèt. la coupe à blanc et la vente du sol à un insolvable.

si nous examinons maintenant quelles sont les parts respectives di: l'Etat, du département, de la commune, dans l'impòt frappant la mème forêt, nous trouvons qu'alors que l'État seul touche $19 \%$, le département touehe $33 \%$. la commune, $48 \%$.

La part de l'Etat, comme le constatait If. Arnould est donc bien modirée par rapport au reste, et un allègement de cette seule part donnerait un résultat très incomplet.

Dans recas particulier. la grosse responsabilité in rombe à la commune qui, prodigne des deniers d'autrui, fait payer par les proprićtaires de la forèt, située à 5 ou 6 kilomètres, des frais énormes dont ils ne profitent aucunement et qui sont contraires aux intérêts de la forêt ellemême .

11. Descoubes. - Messieurs, la question qui rous est soumise est une dos plus importantes au point de rue du maintim de nos forèts, mais elle est aussi infiniment compliquée. Nous nous trourons en effet en prisence l'une lígislation fiscale qui n'est pas encore faite; on hésite à morlifier une législation qui approche de sa fin et on ne sait pas 'ncore comment prendre une législation qui n'est pas encore faite, carsi l’impôt sur le revenu a déjà fait l'objet du vote de la Chambre dans ses grandes lignes en ce qui concerne l'Etat, on ne sait pas du tout comment il agira vis-à-vis des ressources départementales et communales. Par conséqueıt, on est absolument dans le rague au point de rue de l'impòt fiutur. 
L'impôt actuel, celui qu'on considère comme passé, repose sur la Loi de frimaire an VII qui était extrêmement bien intentionnée, et il est extraordinaire de roir comme une loi bien intentionnée a prokluit des résultats déplorables. Cette loi, en affet, prévoyait que l'on n'imposait pas plus les futaies que les taillis. Dans l'application, il y a eu du flottement; il s'est trouvé que cette loi a été faussée par une série de considérations diverses, par des eauses ginnirales et par des causes particulieres.

Dans le cours d'économie professé à la Faculté des Sciences de Bordeaux, l'hiver dernier, les causes gínérales d'aggravation de cet impôt bien intentionné ont eté réduités à trois. Il y a d'ahord le fait que cet impôt est augmenté. En effet, les budgets des départements et des communes sont alimentés par des centimes qui s'ajoutent au principal de l'impôt. Les quatre vieilles contributions directes ont la charge de ces centimes départementaux et communaux, pt cette charge est assez considérable; elle représente en moyenne, pour lrs forèts, $186 \%$, e'est-à-dire qu'elle triple presque l'impòt prévu pour l'Etat.

D'autre part, on a assimilé la proprićté forestière à la propriété agraire; on a considéré son revenu annuel. Or, les forêts n'ont pas de revenu anmuel, elles n'ont qu'un revenu périodique, et par cha même que le revenu est périodique, il y a un revenu apparent qui est très supérieur a revenu réel. Quand une forêt donne une coupe de $2.500 \mathrm{fr}$., a bout de 25 ans, vous ne pouvez pas dire qu'elle rapporte 100 franes par an. Par conséquent, l'impôt forestier se trouve méconnu dans sa périodicité et augmenté dú tiers.

Enfin, on considère le revenu forestier comme un revenu foncier. Un rapport très remarquable qui a été fait à la Société nationale d'agriculture au printemps 1910 a très bien combattu ce préjugi du earactère foncier de la propriété forestière. La propriété forestièrr a une partie funcière: son sol, mais elle a une partie immobilière: les arbres. Le code civil considère que les arbres qui sont immubiliers quand ils sont au sol, deviennent mobilier's quand ils ont été abattus, et l'on arrive à une série de complications. Il n'en est pas moins rrai que, comme règ le générale, la propriété forestière comprend au muins pour les trois quarts, un bien qui est immobilier; si done on lui fait payer l'impôt mobilier, on la surcharge abominablement, et en movenne, la valeur des forêts se trouve augmentée de $20 \%$ par la confusion entre mobilier et inmobilier.

Quand on additionne ces aggravations successives, on arrive ainsi à constater que l'impôt foncier se trouve quintuplé.

M. Le Présinent. - Ce que vous dites en ce moment, M. Arnould l'a exposé dans son rapport; je vous demanderai done de rous limiter autant que possible.

M. Descoubes. - Je disais done que l'impôt foncier se trour ainsi quintuplé par des méconnaissances dans l'application de la loi. 
Quant à l'impòt de transmission, M. Gouget nous a montré ce qu'il avait d'excessif:

Il y a là une transformation de la fiscalité des forèts que, heureusement. M. le Ministre nous a promis détudier, de concert avec M. le Ministre des Finances.

Il y aurait encore d'autres atténuations à obtenir, et, puisque nous avons parlé ce matin des forêts protégées, ne pourrait-on assimiler les forêts protégées aux forêts domaniales, en supprimant le principal de l'impòt. Ce serait un petit sacrifice que pourrait faire l'Etat.

M. Larroquette. - Dans le rapport si complet de M. Arnould, j’ai relevé une partie concernant l'exploitation en Gascogne des forèts de pins maritimes.

A la séance de ce matin, je vous ai signalé le cas du déboisement intense dans l'ancien domaine impérial, suivi fort heureusement du repeuplement. Je voudrais maintenant vous dire, que, depuis la Loi du 19 juin 1857, il y a 500.000 hectares en Gascogne, qui, actuellement, sont couverts de très belles forêts de pins. Or, la législation fiscale les a, fort heureusement pour les propriétaires et les communes, épargnés. En effet, un hectare de pins qui, actuellement, rapporte de 30 à 60 franes par an, paie quelques centimes d'impôts seulement. Naturellement, les propriétaires ne demandent 'qu'une chose, c'est que cette situation dure le plus longtemps possible.!

Or, le prix de la propriété forestière a augmenté de $60 \%$ à $70 \%$, tandis que le prix de la propriété agraire a diminué de $30 \%$. Les agriculteurs trouvent donc que, véritablement, les charges fiscales ne sont pas proportionnées.

L’impôt sur le revenu va mettre bon ordre à cela, et je troure que c'est parfaitement juste, en corrigeant ainsi les inégalités du cadastre. Mais si les propriétaires, avec la plus-value que leur donne leurs arbres et la résine, acceptent, il y a toutefois opposition entre la conception des propriétaires et celle des contributions directes qui considère les coupes rases comme un revenu annuel. Les exploitants disent : non, ce n'est pas une exploitation ordinaire, cela n'a rien de commun avec les exploitations de bois en montagne, et ils disent: nous voulons bien payer à l'impôt, nous faisons des sacrifices, seulement, répartissons l'impôt de telle façon que les coupes rases ne soient pas considérées comme un revenu annuel.

La ques tion est actuellement discutée dans la région; elle a provoqué au début une certaine émotion, mais je crois qu'on arrivera à s'entendre avec de la bonne volonté de part et d'autre.

Je puis citer comme document les vœux émis au Congrès tenu pour la première fois à Bordeaux, en 1909, et dans lequel cette question de l'impôt sur le revenu appliqué aux forêts de Gascogne a été examiné. Ces roux correspondent à ceux qui terminent le rapport de M. Arnoult. Je crois donc qu'il n'y aurait qu'une simple addition à faire en ce 
qui concerne les forêts landaises, parce que ce sont des forêts soumises à une exploitation différente et tout à fait spéciale.

Voiei ces veux :

"Les propriétaires et résiniers représentant les 800.000 hectares de fulaies résinières du Sud-Onest de lu France, réunis en Congrès à Bordeaux, le 3 juin 1910, protestent énergiquement contre le système d'ésaluation adoplé pour le revenu des pins dans l'application de la Loi du 31 décembre 1907, par l'Administration des contributions indirectes.

"Déclarent que ce régime eśt absolument contraire à la Loi, qui ne frappe le revenu foncier que sur la salcur locative, c'est-à-dire sur la rente directe du sol et estiment que seul le système des annnilés peut être appliqué dans le calcul du rev'enu du pin.

"Ils demandent en outre que les semis des pelits plunts de pins soient exonérés d'impôts jusqu'ci l'âge de 30 ans.

"Que des remises et modérations d'impôts puissent être accordées au cas de baisse importante dans la valeur des produits du sol.

"Que l'évaluatiôn du revenu des pins puisse être modifié en cour's de période décennale sur décluration de conpe rase faite par le propriétaire.

M. Le Président. - Étant donné que nous sommes obligés de rester sur le terrain des généralités, je crois que les vœux du Congrès répondent mieux à ees généralités.

M. Roulleau. - Messieurs, il a semblé tout à l'heure que quelques orateurs étaient partisans de I'impôt sur les coupes. En théorie, je me rallierais bien volontiers à cet impòt sur les coupes qui est en effet l'impôt idéal payé au moment où vous touchez.

La méthode des annuités que M. Arnould a mise en évidenee et a établie d'une façon très savante ne découle, en prineipe, exclusivement que de l'impòt sur la coupe ; l'annuité n'a été établie que pour annualiser un revenu que l'on touche périodiquement, e'est-à-dire à la coupe, mais je voudrais vous faire toucher du doigt l'iniquité en pratique de l'impôt sur la coupe, dans un pays de vieille civilisation comme le nôtre, où des systèmes réguliers d'impôt fonctionnent depuis de très longues années. Prenons, si vous le voulez bien, pour concréter ma pensée, une pineraie âgée de 50 ans ; elle va venir en exploitation dans deux ans ; elle a 48 ans. Pendant 48 ans, j'ai payé l'impôt annuel. A 50 ans arrive l'impôt sur le revenu qui vient d'être décrété à la coupe, et on me. fait payer l'impôt à la coupe. Non seulement tout ce que j'aurai payé depuis le commencement n'entrera pas en ligne de compte, mais je payerai en bloc l'impôt à la coupe, c'est-à-dire que je paierai une seconde fois. Il y a là une injustice absolument flagrante sur laquelle je me permets d'attirer votre attention.

Il y en a une seeonde. La Loi de frimaire an VII a exempté d'une façon formelle la futaie feuillue ; la futaie feuillue ne paie pas d'impôts, 
même aujourd hui, autre que celui du taillis simple qui en oceuperait la place; c'est inserit dans le Recueil méthodique en toutes lettres. Eh bien! sur la foi de ce qui a été inscrit dans le Recueil méthodique, moi, proprićtaire - et il y a beancoup plus de propriétaires de ce genpe que vous ne le supposez - j'ai écononisé, j'ai multiplié la réserve, j’ai créé une forêt riche. Croyez-vous que si j'avais su qu'à un moment donné jaaurais à payer l'impôt sur la coupe, j'aurais constitué cette épargne? Jamais !

Nuus nous trourons par conséqquent en présence d'une double injustice et je vous demande d'émettre le vocu que l'impôt sur la coupe ne soit pas adopté (Applaudissements).

M. In Nicoliy. - J'ajouterai quelques mots à ce que vient de dire 1f. Roulleau, à savoir qu'il faut chercher à aboutir à des solutions prochaines. En l'espèce, tous les budgets, non seulement le budget de l'État, mais les burlgets communaux sont intéressés d'une façon très spéciale à ces déterminations foncières; l'impòt de la coupe jetterait dans la détermination des budgets communaux un bouleversement que ceux-ci sont incapables de subir, notamment dans les régions où les domaines boisés représentent une très grande partie de la surface de la commune. Par conséquent, il semble qu'il ne soit pas possible au Congrès d'entrer dans une voie qui ne semble absolument pas réalisable d'une façon pratique, car elle soulèverait de la part des intéressés - en l'espèce, les administrateurs des communes, - des protestations, de sorte quil ne faut pas nous mettre dans cette situation pénible de demanter une chose que nous serions obligés de repousser comme administrateurs de communes.

II. DE L.IRXAge. - Je voudrais répondre un mot à notre collègue de la Gascogne.

Nous avons des résineux en massifs très importants dans le centre et dans l'ouest de la France, qui font du gemmage et dont les intérêts sont intimement liés à ceux du sud-ouest. MI. Roulleau, très justement, a pris comme exemple, une coupe de pins idéale; il a répondu a l'objection que je voulais faire au point de vue de votre système. En ce qui me concerne personnellement, je me rallie done d'une façon complète, pour les pineraies, au vou d'ordre général émis par II. Arnould.

Quant à ce qui concerne les évaluations pour les pineraies, c'est un point très spécial, sur lequel on aura l'oceasion de revenir dans la discussion et que nous étudierons d'une façon plus serrée. Pour le moment, qu'il me suffise de dire que nous sommes tous d'aceord, au point de vue des éclaircies, pour dire que la perception si admirablement organisée en Roumanie est impossible à faire, étant donnés nos systèmes d'éclaircies en ce qui concerne les pineraies.

Lx Coxglessiste. - Je crois qu'il y a une question qui domine : e'est celle de l’avilissement général des produits forestiers et qui est la 
"auk do la crise que nous subissons tous. A l'heure acturlle, je ne vois yu'un remète: c'est la révision du cadastre.

II. GoEciet. - Évidemment, la révision du cadlastre serait itéale, mais we termandera 25 a 30 ans. Si nous attendons juscfur-lì, et si nous teron payer les mêmes impòts, il n'est pas possible de continuer dans ees conditions. Le but de mon recu, est de demander, en attendant la révision du cadastre, un dégrèvement qur l'on peut baser it raison dim tant pour cent sur le revenu qui existe aetuellement.

11. Le Préghext. - La révision de la base de l'impôt foucir peut se faire de différentes façons, ot sans révision du carlastre, par une nouvelle assiette de limpòt; les deux choses ne sont pas conplètement liess.

En tous eas, nois avous d'abord à examiner les verux du rapporteur qui ont une portée générale ot je dirai, internationale. Dans la premièr partie, nous arons à roter sur ce que jappellerai l'impòt idcial, la faron lont on doit asseoir l'impòt. Remarfuez que vous ne ferez pas senlement une ouvre théorique, puisque le Parlement, précisé ment en ce moment, examine cette question. Par conséfuent, ce vote, tout en ayant une portée internationale théorique, aura néanmoins me repereussion immédiate on France.

J'aurai ensuite à vous proposer le texte d'un vou complémentaire qui répondra à la préorcupation de .II. Gouget, et a toutes les vòtres, Mrsieur's, car il y a un fait certain, c'est que la question do l'impòt forestier est extrêmement urgente. La "guillotine sèche " que nous a montrés tout à lheure notre confrère, prouve que, indépendamment de la snlution générale qu prépare le Parlement, il peut y avoir deo remedes plus rapides à appliquer. C'est ce que je me propose de vous montrer tout a l'heure, quand nous aurons termine les cinq premines voux.

Le promier veru (pui verus est soum is est le suivant:

Io Que, dans tom systeme fiseal, la base d'évaluation du revent forestier soil te produil net de la conpe normale correspondanl an plan dexploilation adoplé : nsmellement dans la région, si l'impôt est réel; pur le propriétuire, si l'impồt est personnel. "

M. TE SÉBHLL. - Je roudrais apporter à ce voru une petite morlifiration; ne pourrait-rin pas lo présenter comme ceci :

Qne dans tont système fiscral, la base d'éraluation dn revenn jurestier soit étublie, on sur la sulen foncière des termins boisés, on sur lent revenn net."

M. Ironelo. - Nous arrivons iei encore i distinguer un revenu foneicr at un revenu net. On distingue lont de suite les deux catégories de

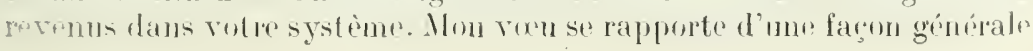


au revenu net de la forêt quel qu'il soit; nous verrons plus tard ce que nous roulons appeler le revenu net du sol et le revenu d'épargne.

M. DE SÉbille. - L'observation qu'on faisait au sujet des pineraies prourr combien il serait plus rationnel de prendre pour base l'impôt foncier, au lieu de l'annuité. Vous réclamez, Messieurs, d'être mis sur le même pied que l'Agriculture et vous vous empressez de choisir une base différente.

M. Arvortd. - Elle prendra place au second vœu.

M. Le Président - Je crois que ce premier vœu a une portée extrêmement générale; il prévoit tous les ș̣stèmes possibles de taxation. Je le mets aux voix.

Adopté à l'unanimité.

"20 Que le revenu total annuel des forêts soit évalué : pour les forêts en coupes annuelles, comme le quotient du prix de la coupe normale par l'âge de l'exploitation; pour les forêts à exploitation discontinue. comme l'annuité reproduisant la valeur de la coupe normale dans le nombre d'années compris entre deux coupes successives, les coupes étant supposées régulièrement réparties sur la durée de la révolution."

M. Hirsch. - Je ne rois pas très bien l'avantage de faire cette distinction entre les forêts à exploitation continue et à exploitation discontinue. Lorsque nous avons une forêt à exploitation continue, nous pouvons vendre du jour au lendemain, par portions, et en faire une exploitation discontinue; il s'en suit que la façon d'évaluer le revenu total variera suivant que la propriété passera entre plus ou moins de mains et changera de nature pour passer d'exploitation continue à exploitation discontinue. Il me semble qu'il y aurait lieu de ne faire qu'une seule catégorie; toutes les forêts sont à exploitation discontinue.

M. Le Présidext. - Théoriquement, vous avez peut-être raison, mais je vous ferai remarquer qu'il y a un avantage de forme; c'est plus simple et plus pratique : nous réduisons l'application des annuités générales. Remarquez que nous nous adressons au fond aux administrations fiscales et par conséquent, plus nous adopterons une solution simple et se rapprochant, sans rien compromettre des intérêts que vous défendez, de leur propre intérêt et de leur propre idée, plus nous aurons chance de triompher.

M. Descoubes. - Il est érident que nous cherchons des solutions simples, mais si nous n'apportons pas des solutions exactes, nous serons dans le faux. Nous ne pouvons pas distinguer la forêt aménagée de la forêt ă exploitation discontinue, et nous ne pourons pas mettre le Ministre des Finances et le législateur dans une situation fausse. 
Evidemment, il est compliqué de dire que, pour une forêt qui rapporte 1.000 franes par an, son revenu net n'est que de 870 francs; elle rapporte en réalité 1.000 franes, mais pour les rapporter, le propriétaire a fait des frais d'aménagement, il a sacrifié de son revenu pendant plusieurs années, il s'est interdit de spéculer sur les bois, n'a pas pu profiter de la hausse si elle s'est produite. Il est obligé d'exploiter sa parcelle, et si, ensuite, les bois sont bon marché, tant pis pour lui. Il ne faut done pas qu'on lui fasse payer les sacrifices qu'il a faits dans l'intérêt général, car une forêt aménagée rend plus de services hydrologiquement qu'une forêt qui serait rasée.

M. Le Président. - En somme, vous vous ralliez à l'opinion de M. Hirsch.

M. ArvoùlD. - Il ne faut pas oublier que nous devons tenir compte de la question des annuités, qui a une très grosse importance, notamment en Allemagne. Dans beaucoup d'États d'Allemagne, il y a une différence complète entre les deux exploitations annuelles et diseontinues. Pourquoi ne pas en tenir compte dans le vœu; d'ailleurs, en quoi cela gêne-t-il. La forêt est aménagée ou ne l'est pas; si elle est aménagée, il y a un revenu annuel; si elle ne l'est pas, le revenu est périodique. On appliquera par conséquent le système des annuités.

M. Hirsch nous parle du partage de la propriété forestière ; il est évident qu'en cas de succession, cela peut se produire, mais ce n'est pas à nous à régler cette question, c'est au moment de la transmission de la propriété.

M. Hirsch. - Je suppose que nous ayons une forêt aménagée; on va établir l'imposition pour cette forêt aménagée; elle change de mains et rentre dans la seconde eatégorie. Nous allons être obligés d'employer le second mode, d'où une nouvelle évaluation. Ceci me semble une complication du système de fiscalité. Il serait beaucoup plus simple de n'avoir qu'un seul système de fiscalité.

M. Le Président. - Théoriquement, votre thèse n'est pas contestable, mais je me permets, pour justifier mon observation, de vous dire ceci : quand il s'agit d'une première évaluation, il est évident que si le mode du quotient arithmétique, si cher aux administrations financières, s'applique d'une façon courante, et que le fonctionnaire n'ait à appliquer les annuités que dans un nombre de cas assez restreint, ce sera pour lui un grand soulagement. Je erois donc que, sur ce point, nous pouvons dire qu'il y a simplification.

Ceci dit, nous sommes en présence de deux vœux; le vœu intégral du rapporteur et celui de M. Descombes qui supprime toute la partie relative aux coupes annuelles.

M. Hinsch. - Je demanderai la division.

M. L. Barbier. - Je vois dans la deuxième partie du vœu qui nous 
est présenté, qu'il ést question de la coupe annuelle ot de l'annuité. Je crois qu'il serait bon de provoquer quelques explications sur re quotient de la coupe annuelle et l'annuité. Vous parlez d'une part do la coupe annuelle et rous réclamez d'autre part l'annuité. Il serait peut-être utile de rhoisir l'un de ces deux modes.

II. Arrolid. - bans les forêts en coupes annuelles, e'est la coupe qüil faut envisager. On díduit d'une part le revenu du sol domé par l'annuité et le reste esi le produit de l'úpargne.

M. ne Nicular. - Je crois qu'il y a dans l'ensemble des voux préserités par M. le Rapporteur un enchaînement, et, si nous rompons tet enchainement en supprimant une maille, nous risquons de détruire l'harmonie de l'ensemble.

II. Le Présidext. - Evirlemment, c'est un risque, mais il inporte eu Congrès de déciler s’il y a liesu de le courir.

M. L. Barbier. - J'ai peut-être mal compris M. le Rapporteur : rais s'il a envisagé que le mot annuité peut s'appliquer à la première partio du vru, je rous conseillerai de répéter le mot, parce que cest le? désir qui semble être lans notre esprit, mais il y aura peut-être di.s gens qui feront comme moi, qui ne vous comprendront pas.

M. le Présinext. - Si, vous comprenez bien. Votre propusition fat conforme, au fond, à celle de MMI. Hirsch et Descombes.

Le rote que vous allez émettre a une certaine gravití, paree qu'iz y a dans l'assemblée des idées divergentes. Les uns, et c'rst l'avi- lu rapporteur, veulent faire une distinction entre le revenu total te revenu annuel.

11 s'agit en co moment du revenu total. Dans le revenu total, In: rapporteur a cru devoir faire une distinction entre les forêts en exploitation annuelle et les forêts en exploitation discontinue, et il a jrévu une base un peu rifférente, suivant les cas. Tandis que. V. Hirsch II. Descombes et M. le sénateur Barbier, paraissent désirer que, dans tous les cas, ce soit l'annuité qui suit la base do l'évaluation du revenu total.

Au fond, l'observation de it. Barbier ne fait que s'associer à r.iles de III. Hirsch et Descombes.

V. Hırscre - Je demande à ajouter un sinple mot : cest que la di-tinetion faite en la circonstance n'est pas très favorable aux exploitations en coupes annuelles, et, par conséquent, aux aménagements.

(Jr, dans l'instruction ministérielle du 31 dérembre 1908, il pot dit en première ligne que, dans l'évaluation des propriétés non bâtip-, wn ne tiendra pas compte des revenus, les bénélices agrieoles provinant des engrais, les semenees, el do tous les travaux augnentant la vitene dr la propriété. 
Je ne rois pas pourquoi en matière forestière, on tiendrait compte de cette augmentation de valeur que, par le travail du propriétaire, on a donné à la propriété.

Nous avons là deux façons te traiter les forêts. Le Sénat a proposí de traiter les forêts au moyen des annuités. Le terrain est excellent. Je demande qu'on s'y tienne!

11. Le Présidextr. - Alors, ee rou perd son earactère international et devient tout à fait national.

M. L. Barbier. - Je crois qu'il serait, en effet, bon d'envisager un peu les modalités que le Sénat a cru devoir suirre sur les indications des intéressés.

En ce qui concerne le quotient, je demande à insister pour bien vous montrer que vous allez apporter demain une modification i ce que rous demandez aujourd'hui au point de rue de la valeur des coupes.

Sur ce premier point, on a envisagé que, dans le futur, il n'y aurait que les quatre cinquièmes de la valeur qui compteraient. Peut-être fautil en faire état.

Pour le quotient, je me permets de rous conseiller de faire ressortir l'intérêt qu'il y a à ne pas laisser le fisc tabler sur une raleur annuelle qui va se calculer sur 18 années par exemple. En comptant ainsi sur 18 années, pendant lesquelles vous allez payer sans tenir compte de l'annuité, vous allez simplement du simple au double. Quand rous avez une annuité calculée sur 18 années, vous payez une somme qui est un peu plus de la moitié de ce que rous payreriez si vous payiez tous les ans.

Vous arez droit a l'amortissement des sommes que rous payez tous les ans.

Voyez-rous un inconvénient à faire ressortir ce que j’ai demandé, c'est-à-dire une atténuation de re que vous payez par arance, alor's que vous ne profiterez de vos coupes qu'au bout de vos 18 ans? (Applundissements).

11. Le Présinext. - Remarquez que le texte du vou vous donne satisfaction.

11. Arvucto. - Il est absolument évident que dans les forêts "n enupes annuelles, le revenu est supérieur à celui qu'atteint une forêt en une stule fois. Si vous ne parlez pas de cette différence, on vous dra : rous dissimulez!

M. Hirsch. - Jans la culture, e'est la même chose : l'engrais ul la semence ne complent pas.

II. L. BARBiER. - Quand l'éraluation nouvelle sera faite, on va rommencer par évaluer les coupes avec l'âge qu'elles ont, étant donnér la encentrín. 
C'est là-dessus qu'il faut commencer par tabler. Il n'est pas encore artmis qu'on prenne pour base la valeur réelle de la vente de la coupe. lous l'envisagez, mais l'administration est en présence de coupes très variables. 11 y a eu des coupes qui ont été faites l'année dernière, qui avaient 17 ou 18 ans. Le texte que rous enrisagez permet au fise de considérer qu'il peut faire payer tous les ans pour une coupe te 18 ans suivant le chiffre réalisé par la coupe. C'est une petite précaution que je vous engage à prendre.

M. DE SÉbille. - Pourquoi complique-t-on cette affaire d'une façon aussi extraordinaire? Tout à l'heure, tout le monde était d'aceord pour traiter la sylviculture comme l'agriculture. Si vous traitez l'impôt foncier comme l'impôt sur les bois, nous payerons tous les ans.

11. De Barbiat : - Il y a deux termes dans le vou : le quotient du prix de la coupe normale et la valeur de la coupe normale.

Comment établira-t-on ce prix et cette raleur? Sera-ce en se basant sur le montant des ventes faites?

11. L. Barbier. - On pourrait modifier un peu la rédaction; il y a us principe que vous devez faire admettre; fest l'annuité.

11. Borvet. - Nous sommes d'aceord, nous désirons l'annuité; la formule de II. le sénateur Barbier est parfaite. Je vous demanderai simplement si vous pourrez faire admettre par le Parlement ceci : Vous avez une forêt qui vous rapporte 20.000 franes, si vous la coupez tous les vingt ans. Si vous voulez calculer ce que cette forêt aménagée rapporterait pour un an, rous trouverez un chiffre qui sera, par exemple, do 600 ou de 900 francs. Alors, on rous dira : vous ne nous ferez jamais croire que votre revenu nist pas de 1.000 franes (Protestations et dénégations).

11. L. BAnвıR. - Vous 'nvisagerez comme moi que l'État fera ce calcul sur les coupes qu'on fera. Mais l’État peut dire que votre forêt est aménagée et que les coupes n'ayant pas la même valeur, il faut calculer sur la valeur intégrale de la forêt. lous ne pouvez qu'espérer que ce soit la coupe annuclle qui serve de base, mais je rous invite à ne pas rous abriter terrière ceite espérance. Que l'annuité soit la base dévos ealculs! ()u'est-ce qu'il un coúte l'ajouter cette phrase? Exeusez-moi d'insister, mais c'est l'éraluation aree l'annuité comme base qui ust le pirot de toutr ceite question.

M. Huscul - M. Bonvet fait valoir romme objoction qu'on ne poura pas comprondre qu'un' forêt qui rapporto 1.000 franes par an ne puisse pas être inposice pour plus dr 600 franes.

Je réponds: pour arriver à avoir $n$ mevenu de 1.000 franes par an, jai été obligé d'aliéner mon fonds, mes rerenus, pendant un temps déterminé jai payé l'impôt of on ${ }^{2}$ minn a pas tenu compte. On en 
tient compte à l'agriculture : j'ai bien le droit qu'on m'en tienne compte.

Au surplus, ce n'est pas au Congrès forestier à présenter des solutions qui sont favorables au fise. Je crains que le fisc ne s'empare de cette première solution et ne dise : nous ne voulons pas de la seconde!

Nous devons tabler sur celle qui répond justement à l'idée forestière, c'est-à-dire l'idée de l'annuité. Nous ne devons pas en sortir. Voilà un terrain ferme, nous devons le conservir pour toutes les forêts, quelles qu'elles soient! (Applaudissements).

II. Vessiot, - Ne craignez-rous pas que le fisc, en voyant cette objection, ne vienne vous dire : prurquoi n'aménagez-vous pas vos forêts?

M. Govget. - Je me rallie à la transaction de M. le sénateur Barbier.

M. Bouvet vient nous dire: je coupe tous les ans, j'encaisse le revenu tous les ans, re n'est pas comme celui qui touche ses revenus tous les vingt ans!

Mais voilà une forêt qui a 20 hectares. Je meurs te cette forêt est partagée entre mes quatre enfants. Celui qui va avoir la dernière eoupe ne va pas arvir la mime somme à payer, et celıi qui a la première ne bénéficiera pas du syatèmp des annuités.

II. Le Présinext. - Je erois que nous sommes suffisamment éelairés. Il s'agit maintenant de roter. Le vote est important. Nous sommes en présence de deux systèmes. J'appelle votre attention sur la gravité de la question. Le texte de $\mathrm{M}$. le Rapporteur fait une concession aux idées chères aux finances et aux contributions directes. Au contraire, la proposition de MII. Hirsch, Descombes et Barbier maintient, intangible, le principe forestier de l'annuité. Tous allez voter sur l'un ou l'autre de ces deux systèmes.

M. L. Barbier. - Pardon! J'admets très bien la division de M. Ie rapporteur, mais je demande cette adjonction de l'annuité í l'origine du varu.

11. Le Présinezt. - Mais cette adjonetion ne se peut pas. Si rous mettez d'abord que l'évaluation doit être faite d'après les annuités, forcément, cela s'appliquera dans tous les cas. Or, vous ne pouvez pas mettre après que, dans les cas de coupes annuelles, on appliquera, au lieu de l'annuité, le quotient arithmétique : ce serait une contradiction!

M. L. Btreter. - si je mappelais le fise, je pourrais accepter la formule pour le prix de la coupe normale, et pour le reste des coupes, j'appliquerais peut-être des droits différents, mais je vous ferais payer tout de même. Prenez garde! Le fise est très fort ! Héfiez-vous!

M. Le Présidext. - Ciest pour cela que je considère qu'il faut roter le vou tel que vous le proposez avec MM. Hirsch of Descombers, dr supprimer le quotient alithmétique et le mettre simplement : 
"Que le revenu lotal anmuel des forêts soit éoalué comme l'annuité reproduisant la "aleur de la conpe normale dans le nombre d'aniées compris entre denx coupes successives, les coupes élunt supposées régulièrement répurties sur la durée de la révolution."

C'est la formule qui vous donne satisfaction.

Je commence donc par mettre aux voix le vou de M. le Rappoiteur.

Le veru ne réunit que 3 voix.

Je mets aux voix maintenant le vou de MII. Hirsch, Deseombes et Barbier.

Le vou est adopte.

Nous passons au troisième rœu.

Je conis que or texte donne satisfaction it tous les intérêts. Je le mets aux voix.

Niopté.

Nous passons all veru no $n^{\circ}$.

17. Husch. - Nous n'avons pas besoin d'aller au-devant des désirs du fisc. La Loi de brumaire an VII prévoit que l'épargne ne supporte aucun impot. Pourquoi ne nous en tenons-nous pas à cette loi de brumaire an $1 / 1$ qui ne dit rien pour l'obligation de défricher? C. serait ume juste compensation et une manière de favoriser l'exploitation des gros arbres que de supprimer tous les impots fonciers sur les arbres. II me semble que ce serait justice.

C'est la thès que nous sommes en droit el que nous avons le deroir de soutenir.

M. LE Présibexr. - II ne faut pas perdre de vne le còtr pratique des choses. Si vous allez trop lom, vous risquez - et j'attire votre attention sur ce point - qu'on traite la question contre vous.

II. le Rapporteur a obéi éridemment à une préoccupation, celle d'aller an-devant des discussions à intervenir et des menaces qui se produisent et il a voulu dire : du moins, qu'on ne nous applique pas telle ou telle chose!

Je me permets justement de demander à M. Barbier, qui est intervenu dans la discussion du deuxième voeu au point de vue des idées parlementaires, s'il serait bien opportun de se montrer intraitable et intransigeant sur cettr question.

II. L. BAnвter. - L'esprit général qui animr l'Adninistration, c'est la protection des futaies. Il y a un certain nombre de formules qui sont en ce moment un pru en l'air, qu'il est difficile d'énoncer ; mais il y a une formule qui semble prendre jour un pen, qui aurait pour but de frapper d'mne façon assez ćlevée celui qui ferait des coupes blanches, c'est-a-dire la coupe dos futaies an même temps que la coupe de branches. 
Je ne peux pas vous indiquer une formule et vous le comprenez, mais la vérité, e'est que voila le but que l'on veut atteindre.

En te qui concerne re quatriène veru, voulez-vous me permettre de vous dire qu'il est très platonique, parce qu'il n'y a pas de base de comparaison quand vous dites : "anquel soml assujettis les revenus du commerce el de l'industrie."

Ces revenus du commerce et do l'industrir sont lo bénéfice résultant du travail absolu, tandis que vous, vous êtes soumis au temps. Vous n'avez qu'à regarder pousser vos arbres. Il est done difficile d'appliquer un voru concu sous cette forne pour dire : vous assujetirez notre rovenu dans la même proportion que celui du commeree et de l'industrie! Que vous le souhaitiez d'une façon générale, e’est birn, mais c'est tout ce que rous pouvez faire.

11. Le Présinext. - Ce voru a un! allur assez générale. Le premier paragraphe est même international.

II. L. Barbikr. - Dans ]e second alinéa, vous dites que ce revenu ne soit pas assujetti, ete... En ce qui concerno les bénétices agrieoles, je ne demande s'il n’est pas possible de faire là une assimilation. Vous incitez l'Administration à envisager l'appliration de l'impòt sur les bénéfices agricoles, quand, en réalité, il semblerait y avoir en l'air une bienveillance particulière pour l'agriculture et une tentance ¿t ne pas faire payer les bénéfices agricules.

M. Irxoted. - Nous demandons alors à ne rien payer nous-mêmes

M. L. Barbier. - Voulez-vous me permettre de vous dire que la il y a un travail à faire, travail ayant un but supérieur a la valeur de la forêt que vous possédez. En réalité, vous n avez pas la même situation que l'agriculture qui a beaucoup de travail et de dépenses à faire.

Jo crois que si vous voulez manifester le désir que les dépenses de limpòt soient semblables pour tout le monde, sous la forme où vous l'indiquez, ce sera une manifestation platonique. C'est un désir, mais un désir dont l'application est reconnue, à l'avance, impossible.

M. LE Présinext. - Alors, voulez-vous me permettre de vous suggérer une transaction. Sans entrer dans le détail du commerce et de l'industrie qui, comme le dit M. Barbier, peuvent soulever des difficultés, mettons simplement : que les revemus de l'épargne supportent les contributions les plus morlérées que la législation de chaque pays permettra.

C'est un va'u très simple, mais qui laisse le jeu libre.

Plistetrs Volx. - Supprinez le vocu!

II. Le Président. - Non, paree qu'il faut marquer notre pensée qui 'st qu'on ne laxe pas, si possible, dans les proportions où cela a licu actuellement, et ensuite marquer notre intérêt pour les revenus Wr. l'épargne. 
M. L. Barbier. - On pourrait mettre: "Que l'impôt ne soit pas supérieur unx impóts perçus sur toutes les sources de revenns».

II. Le Président. - Oui, mais cela laisse de còté la fameuse distinction entre les revenus du sol et les revenus de l'épargne.

H. Hirsci. - Je demande qu'on émette un rou demandant que les revenus de l'épargne ne supportent aucun impòt. On a besoin d'arbres, tout le pays en a besoin; il faut encourager la culture des arbres, donner des subventions. Ce sera là une manière d'encourager les arbres de croissance et de futaie (Approbation générale).

II. Pelletier de Martres. - I la troisième section, ce matin, nous arons roté un roeu absolument conforme à ce que demande M. Hirsch.

II. Leroy. - Je demande qu'on adopte un voru demandant que le revenu de l'épargne ne supporte en aucun cas l'impòt foncier ni les impòts ou taxes assimilées. Cette rédaction réserve la question. Elle ne ferme pas la porte, mais elle ne l'ourre pas non plus.

11. L. Barbier. - Envisagez-vous l'impòt d'État ou l'impòt communal seulement?

II. Leroy. - Je dis l'impôt foncier, d'une façon générale, et j’ajoute les taxes assimilées.

II. Le Présidext. - Je mets aux voix la rédaction de 11 . Leroy, telle qu'il vient de vous la présenter.

Adoptée.

Nous passons au rou 5. Personne ne demande la parole? Je le mets aux voix.

Adopté.

C'est ici que je me permets de suggérer un vou spécial à la France et qui répondrait à la pensée très sage de 11 . Gouget.

Il est évident que la révision do l'impôt n'est pas encore faite. Le Sénat s'en orcupe, mais je crois qu'il y a beaucoup de chances - j'en appelle à M. Barbier - pour que l'œuvre du Sénat fasse encore retour a la Chambre. Par conséquent, le résultat n'est pas encore acquis.

Or, tout le monde nous a cité des faits criants, et m'inspirant de la pensée de II. Gouget, je proposerai le texte suivant, qui a l'avantage de ne pas entrer dans trop de détails et qui se base déjà en partie sur la réglementation déjà existante.

"Qn'en France, le dégrèvement de la propriété non bâtie soit voté le plus vile possible jar le Parlement, mais qu'en utlentant les propriélaires particuliers soient almis légalement à bénéficier immédiatement des dispositions de l'Ordonnance dn 3 octubre L'21. " 
Ce vreu tendrait à faire insérer, par exemple, dans une loi de finanees. en tont cas, par une disposition législative très simple, cette application de l'Ordonnance royale de 1821 dont nous parlait M. Gouget et qui permettrait d'obtenir immédiatement des dégrèvements dans les cas intéressants.

M. De Nicolar. - Je m'excuse de prolonger ce débat, mais nous sommes dans un domaine qui ne connait pas encore la réalisation. Nous ne devons pas oublier que les travaux législatifs, comme le disait M. Barbier, sont entrés dans cette voie des réalisations, et nous devons d'autant moins l'oublier que nous arons ici un des hommes qui ont le plus contribué à faire voter un texte qui est le seul qui ait donné aux propriétaires la satisfaction qu'ils demandent ; j’ai nommé M. le sénateur Barbier, dont l'activité et le dévouement ont été remarquables ( Vifs applaudissements).

Je me demande si, au moment où le Congrès discute ceite question de l'impòt forestier, il ne doit pas avoir une pensée pour le travail qui est en ce moment pendant devant le Sénat, lequel travail, si je m'en souviens bien, comporte justement le principe que vous avez émis aujourd hui, à savoir la séparation des revenus, le caleul des annuités et un dégrèvement de l'épargne représenté par les futaies et les arbres en eroissance.

Je n'ai malheureusement pas ici la formule sur les lèvres, mais peut-être y aurait-il intérêt, en outre des formules que nous renons d'arrêter et qui ne sont en aucune opposition avec celles qui ont été soutenues par H. Barbier, notamment devant le Sénat, à souhaiter, par exemple, que dans la nouvelle évaluation qui va se faire incessamment, si l'amendement qui s'est appelé l'amendement Renard, pendant quelque temps, devient un texte de la loi de linances, pour la mise en pratique de cet amendement, on s'inspire des dispositions qui, jusqu'à présent, ont été émises devant la Commission sénatoriale de l'impòt sur le revenu.

Je me permets, non pas de donner une solution, mais plutòt, et M. le sérateur Barbier in'en excusera, de solliciter son intervention. (A pplandissements.)

11. L. Barbier. - La question de l'impòt sur le revenu, lorsque l'amendement a été présenté, avait pour but de procéder au dégrèvement de l'impôt foncier en retrourant la contre-partie dans l'impòt sur les valeurs mobilières françaises ei ctrangères. Vous vous rappelez que l'origine de l'inpôt sur le revenu a été précisément la nécessité de dégrever l'impôt foncier.

A còté de l'amendement Renard, il y a eu l'amendement Malry ayant pour but le dégrèvement de la cote mobilière et de l'impòt des portes et fenêtres.

Je tiens ì téclarer que la Commission du Sénat serait prête, si on le voulait, à faire to dégrèvement de l'impò foncier non bâti en trouvant 
la contre-partie dans les valuurs mobilières françaises et étrangères. et en s'en tenant là, pour cette bonne raison que le dégrèvement ayant une répercussion sur les centimes additionnels, cette répercussion peut être solutionnée en autorisant les rommunes et les départements ¿ augmenter le nombre de ces centimes d'une façon équiralente au dégrèsement de l'impòt foncier qui disparaitrait. Il y aurait là un dégrèvement d'origine assez important en ec qui concerne le principal, mais si vous voulez souder à cela la suppression de la personnelle mobilière ct des portes et fenêtres pour en faire limpòt général sur le revenu, c'est toute la loi ( $\mathrm{T}$ on, non). En effet, par cette suppression, rous supprimez le principal d'une contribution qui entraine la suppression des centimes correspondants. centimes qui s'élèvent à 315.000.000. Par conséquent, vous allez être dans l’obligation, avant de résoudr la question et de la proposer même sous cette forme, de demander i la Chambre de voter le projet de loi sur la iransformation et la modification des centimes communaux et départementaux qui est resté latent a la Chambre, en attendant que le Sénat se prononce sur la réforme d'ensemble.

Messieurs, vous attendrez un certain nombre d'années cette réforme si on soude les différents éléments que je vous indique pour constituer l'impôt sur le revenu. Il y a done intérêt à ce que vous réclamiez d'urgence que l'application de la loi d'origine, ayant pour but le dégrèvement de l'impòt foncier, ait lieu dès maintenant, puisqu'on in a les moyens et qu'on tronve sa contre-partic financière; sinon, en soudant cette réforme à l'amendement Malry, e'est l'ajournement certain à un certain nombre d'années dont je ne voudrais même pas me permettre de rous fixer la limite (Rires).

Si nous réclamons seulement le légrèvement de l'impòt foncier, on peut faire très vite, et si je dis qu'on peut faire, e'est parce que le Ministre des Finances, ees jours derniers, a déclaré que le recensemenit de la propriété non bâtie était terminé, et que dans quelques jour's, une quinzaine au plus, la Commission du Sénat allait être saisie des rísultats. Par conséquent, nous aurons là ce que nous pouvons appeler les bases des projets d'évaluation faits par le Ministre des Finances.

Nous avons demandé rlans les arrondissements les opérations de recensement qui ont été faites; on prétent qu'elles sont assez mal faites (Très mal, très mal). Je veux croir qu'on a fait son possible pour bien faire, mais, d'après les règlements antérieurs, il y aurait. it l'heure actnelle, preseription pour pouvoir formuler des réclamations sur ces évaluations.

Je puis vous déclarer dès maintenant que vous pouvez avoir sur te point une sécurité, parce qu'il y aura un délai assez long accordé, lorsque la loi le permettra, pour permettre à chacun de formuler de nouvelles déclarations.

En résumé, nous demandons que cette réforme soit faite d'urgence. puisqu'elle est prête et qu'on ne sourde rien dessus.

Messieurs, associez-vous it nous, et je rpois que vous nous anr'z 
donné une Porce plus grande, pour ohtenir le résultat désiré depuis si longtemps.

1I. be Nicolty. - Je remercie beaueoup M. Ir Sénateur de m'avoir fait l'honneur de lépondre a la question que jai posée, mais je lui demanderai un petit complément dexplieations. La nouvelle évalualion de la propriété non bâtie va-telle ourrir d’ici peu un recours d’vant l'autorité judiciane pour protester contre les craluations que nous estimons excessives?

Ce recours, une fois ouvert, va comporter une nouvelle évaluation, s'il est fait droit ì nos réclamations, évaluation faite en prenant pour base de nouveaux principes. Nous venons d'en énnttre un iei mêne. I défaut de celui-ci, j’aurais aimó qur l’on prenne comme principe, par exemple, celui qui a étr émis jusqu'i présent par la Commission sénatoriale de l'impót sur le revenu.

M. L. B.двier. - C'est la Loi de 1907 qui a établi la base du recensement de la propriété non bâtie; or, il n'appartient à persomne, tant que rette loi ne sera pas motifice, de prévoir d'autres bases pour les évaluations. Nous sommes done dans l'ubligation, pour respecter la loi, de nous baser sur le principe de la Loi de 1907, mais vous aurez toujours la ressource, si l'évaluation rous semble mal faite, le pouvoir formuler des réclamations et demander qu'il soit fait me nouvelle appréciation.

M. DE LARXAge. - Je crois qu'en ce qui concerne les ovaluations de 1907 , il faut nous en tenir à un strirt règtement; il faut essayer de tirer de l'application des modes de revision qui nous sont ouverts le maximum de ce que nous pouvons obtenir. Or, nous pourons obtenir, aver le mote actuel, de régler les rérlamations individuelles de ceux dont la contribution a été un pu trop fortement taxée, dans les délais fixés par la Loi de 1907. Mais en dehors de cela, il y a le droit des rollectivités.

Devant le groupe agricole du Sénat, javais l'honneur avee le président du Comité des forêts, M. de Nicolay comme délégué de la Sociéti. de's Agriculteurs de France, de demander au groupe de vouloir bien appuyer ce droit des collectivités, égal ì celui des particuliers, d'après la Loi dr 1907. Or, elle est muette sur "e point. Je demanderai done au Congrès de formuler à cet égard le voru, que dans la revision, telle qu'elle nous est ouverte par la Loi do 1907, les propriétaires forestiers $\therefore$ volent appliquer les méthodes qui ont fíe rreomnues par l'Administration des forêts elle-même comme les plus propres à donner satisfaction à nos intérêts, c'test-ḋ-dire, en premier lieu, la distinction du rapital, lu revenu et de lépargne. En second liru, demandons que les colleretivités aient lo wême druit que les individus, e'est-à-dire solent arlmises ì réclamer dans les mêmes formes et dálais que ceux-ei, itant domnó qu'on a omis leur ròle dans la Loi de 1907.

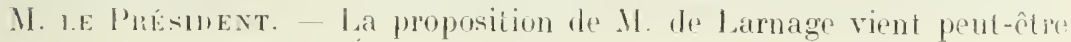


compliquer la question, et je me permettrai de modifier le vou dans le sens qu'indiquait M. Barbier, pour dire qu'en France le dégrèvemeni de la propriété non bâtie soit voté le plus tòt possible par le Parlement, mais qu'en attendant, les propriétaires forestiers soient admis à bénéficier immédiatement des dispositions de l'Ordonnance de 1821 .

Cette première partie donne aux sénateurs l'arme dont ils ont besoin, et le second paragraphe donne satisfaction aux besoins immédiats, parce qu'il sera plus facile de fairc insérer dans une loi de finances une disposition comme celle-là, que de faire voter pour un dégrèviment immédiat, en raison des complications soulerées au Parlement et que II. le Sénateur Barbier nous exposait tout à l'heure.

Je mets donc ce vœu aux voix.

\section{iropté.}

M. DE Nicolay. - $11 \mathrm{~m}$ `a été reproché de faire une opposition illégal», mais je n'avais pas la prétention de parler lu passé. Nous arons ici la prétention - et nous y avons été autorisés par de hautes autorités - à inspirer la législation de l'avenir.

Ma proposition avait seulemeni pour but, itant donné que les Pouvoirs publics sont décidés à faire quelque chose pour la forèt, qu'ils sont décidés - la promesse nous en a été donnée - à obtenir", spécialement sur la question forestière, quelque chose en matièrt: d'impòt forestier, ma proposition, dis-je, avait seulement pour but et tendait simplement à ce que les dispositions soient prises en temps utile pour qu'il soit fait droit aux réclamations qui ront naitre, sur la base de l'impôt tel que nous venons de le fixer et tel que la Commission sénatoriale de l'impôt sur le revenu en a déjà tracé la direction. J'arais done pour but, non pas de parler de l'état ancien, mais de prépares. l'état nouveau vers lequel nous aspirons le plus promptement possible.

II. Le Président. - Je crois que les vreux du Congrès répondent it votre désir. Nous demandons déjà le vote rapide du dégrèvement de l’impôt foncier non bâti; il ne faut peut-être pas demander trop de modifications législatives, et dans ces conditions, je ne sais si un rote spécial entraînant une modification législative nourelle ne viendrait pas, précisément, compliqurr l'aruve du Sénai.

II. le Sénatrur, n'êtes-rous pas dt' cel avis?

Ne trouvez-vous pas que les membres du Parlement, defenseurs drs intérêts forestiers, sont, théoriquement et pratiquement, suffisamment armés, et qu'il serait plutòt gênant pour rux d'avoir à se prononerr sur une demande tendant à moditier législativement la Loi de 1907. Je me permets de poser la question sans la résourlre.

11. L. Barbier. - Vous ne pouvez pas préparer lin texte, pas plus qur nous d'ailleurs. Je rends un hommage particulies it l' Idministration des Forêts et au Ministre de l'Igriculture pour le ancour's qu ils 
nous ont accordé pour l'étude de cette question. Je vous demande de vous joindre à moi en cette necasion. (Assentiment.)

Je sonhaite que nous trouvions la même bienveillance auprès du Ministre des Finances, parce que e'est là le còté intéressant, - le côté financier. Le côté fisc est l'objet de nos pins grandes préoceupations.

Je crois, Messieurs, que ce que vous avez voté est suffisant et représente bien ce que peut faire un congrès forestier. Il est imutile de compliquer les demandes formulées; il pourrait y en avoir de contradictoires; elles se compliqueraient les unes les autres. Je vondrais pouvoir répondre en face d'une proposition très nette.

M. Le Président. - Le Parlement nous parait suffisamment armé. Je passe, Messieurs, à l'adoption des reux dont je rous redomne lecture :

$1^{\circ}$ Que pour l'impôt sur les successions, l'évaluation des forêts en capital soit basée, non sur le rendement moyen des dernières exploitutions, mais sur le revenu total annuel que peut donner la forêt duns l'élat où elle se trouve à l'ouserture de la succession."

Je mets ce rou anx roix.

Adopté.

Je passe au second vou :

$2^{\circ}$ "Que duns les ventes de forêts en fonds et superficie, la valeu du fonds soit senle imposée aux droits sur les ventes immobilières, lu valeur de la superfieie étant imposée unx droits de transmission des valeurs mobilières on an plus anx droits sur les rentes mobilières. "

İx Congressiste. - Cela existe déjà...

11. Le Présidext. - Non! C'est pour cette raison que, lorsque la forêt est à vendre, le propriétaire qui voudrait l'acheter pour la conserver se trouverait en infériorité vis-à-vis du marchand de bois.

M. L. Barbier. - En matière de rente de forêts, il faut distinguer deux genres de forêts : celle qui est une propriété de jouissance, où les arbres ne sont pas abaltus...

11. Le Présinext. - Je vois, M. Barbier, ce que vous voulez dire. (in On pourrait ajouter au voeu ces mots: "Lex pures et les jardins exceptés"?

Ux Congressiste. - C'est la mort de tous les pares.

1I. i.e Présinext. - Non, car ils resteront soumis au régime actuel

M. de LARxitit. - Les pares sont classés tlans une catégorie spéciale.

M. Le Présidext. - Oui, seulement, nou noús oceupons ici de droits de mutation et non pas d'impôt direet. 
Jusqu'a ce moment on pourrait dire que la législation des contributions directes ne les connait pas.

On pourrait, je le répète, modifier légèrement le vou en mettant : "les pares et jardins exceptés".

fr Coxgressiste. - Le mot "forêt "implique naturellement l'exelusion des jardins et pares.

M. Le Présibext. - Il peut s'établir une confusion.

Ux aUtre coxgressiste. - On n'a qu'à mettre "foréts exploitées"

II. LE Préstrext. - Cela pourrait domnep lieu à de grosses disenssions. de mets anx voix te vou ainsi molifie:

"20 Que dans les rentes de forêts en fonds el superficie, parcs et jardins exceptés. la valent dn fonds soil senle imposée anx droits sur les ventes immobilières la valenr de la superficie étant imposée anx. droits de transmission des valeurs mobilières on an plus anx droits sur les rentes mobilières."

Le vou est adoptr.

Je donne lecture du troisième veru :

"30 Qn'an cas d'acquisition de forêts par les départements, les rommunes at les étublissements publics on d'utilité publique, il ne soit perçu pour l'enregistrement qu' un droil fixe de un frane. "

II. Grazix. - Jo demande quion clargisse le sens du texte: "ainsi qu ponr les soriétés ciriles qui pourraient se constimer en vue de l'acquisition et de la possession de forêts al du reboisement des terrains vagues. "

11. Le PuÉsidext. - Ces sociétés existent déja et ce que vous demandez sera peut-être difficile ì faire arlmottre. Le voru de II. Amoulıl contient les mots : "publies on utilité publique "; e'est ce qui nous facilitera le succès auprès du Parlement. Le jour où vous étendrez ce droit que nous réclamons ì de simples sociótés civiles, j’ai bien peur que ce jour-li le veu soit comdamni. Les finanees sont très intransigeantes là-dessus.

11. Gazns. - Il y aurait cependant lieu d'encourager ces sociétés civiles. Elles supportent l'impòt foncier comme les propriétaires particuliers : l'impôt de constitution de soriété; l'impòt de main-morte. Elles sont romplètement décurragées. 11 ne s'rn constitur plus, précisément i) cause de tontes ces charges qui les rerasent.

les forêts seraient mieux placées notre les mains dr sociétés que dans celles des particuliers.

11. L.e PBísment. - Dans fe fond, en serait tris hemeux. Mais ne risquerions-nous pas do faire conplitement repousser notrieren? 
11. Leror. - La question est très délicate. Je proposerais simplement l'exmítion du droit d'enregistrement.

M. Le Présunext. - On pourrait ajouter : "Soipm exemplés duns l" plus large mesure possible?

Ux Coxanessiste. - Il serait bon de faire mention de cos societés qui sont fort utiles.

11. Le Président. - Nous ne le contesteroms pas. de vous propose de distraire ce ra'u et de le discuter demain.

11. L. B.rbier. - Ce n'est pas au moment wù l'titat a besoin de tant d'argent qu'il faut demander des avantages particuliers, nou seulement pour les départements, les communes, mais les etablissements publies.

1). Le Présidext, - Je vous propose de disjoindre ce varu qui strád discuté demain lorsque nous étudierons la question de lacquisition par les collectivités.

L'assemblée se rallie ì cette manièr de voir.

1). LE Présidext. - Nous passons an rinquiène voru :

Que les terrains reboisès on nownellement boisés soient exonérés de tout impôt;

Pendant trente ans pour cenx sitnés sur les sommets et les rersants des montugnes, sur les dumes, duns les lumdes of les: terrains maricugeux;

Pendant wingt ans pour tous les antres terrains "

11. Banchereat. - Je roudrais que l'on tienne ronte des terrains reboisés. Nous avuns ubtenu que les terrains peboisés, c'est-à-tlime ayant été autrefois en forêt, déboisés, ot remis de nourrau en forêt, suient exonérés de l'impôt pendant trente ars. C'est une nouvelle faveur que nous arons obtenue il y a très peu de temps. Je crois qu'il est interessant de ne pas comprendre les résineux dans les exonérations et d'admetre qu'une forêt de résineus qui, au bout de 60 nu 70 ans, aurait étó coupée et reboisér, ne soit pas considérée comme un terrain reboisé.

Iais lorsqu'un propriétaire achète un terrain qui a été boisé autrefois, dans lequel on a fait une opération malkeureuse de defrichement et de mise an culture, comme cela est arrivé trop souvent autour ilu perimetre domanial, il faudrait que Ir propristaire puisse jonir do l'pxonération.

M. he Présinent. - Votre observation est juste.

V. BAXCHEREAC. - Je me suis trouve dans des cireonstances semblables. 
Les terrains araient été achetés par l'Administration domaniale en 'm 1835. Mon père les a vant mis en culture a demandé l'exonération pendant trente ans : elle lui a étérefusée : on lui a dit qu'il s'agissait de terrains aỹant été boisés. Le fisc a été intraitable. Depuis, l'exonération a été obtenue. Je voudrais que l'on établit une ristinetion justement pour éviter ces erreurs.

Lx Congresstste - La jurisprudence sera maintenue, il n'y a pas de doute.

11. le Président. - Je crois qu'il est préférable de maintenir le lexte de Mi. Arnould. Je crois qu'il donnera satisfaction à tout le monde.

ii. Pelletier de Marties. - Il y y a pas de législation qui dépasse trente ans, c'est pour cela que nous demandons qu'on en fasse une.

M. L. Barbier. - La loi actuelle, si j’ai bonne mémoire, exonère pendant trente ans les semis, et plantations. Ce sont les termes mêmes...

M. Le Présinext. - En effet.

11. Rothleil - 11 me semble que ce texte donne toute satisfaction a II. Barbier puisque e'est la Commission sénatoriale de l'impòt sur le revenu elle-même qui a fixé ce- texte-là. Il est conforme à celui de 11. Arnould.

II. L. Barbier. - Je vous demande d'ajouter les mots "semis et plantations".

11. Pelletier de Martres. - Pourquoi ne pas mette "terrains incultes?"

Ux Coxgressiste. - Ne pourrait-on pas ajouter " Même en cas de role de l'impót sur le revenu? "

11. ie Présidext. - Je crois qu'il vaut mieux ne pas en parler.

Le même Coxgressiste. - Nous n'aurons pas le dégrèrement alor's, puisque l'impòt sera global?

11. L. Barbier. - On ne peut pas apporter une exception à une loi qui n'existe pas encore.

11. LE Présinent. - Je mets aux voix le voru du rapporteur en ajoutant après les mots "ou nouvellement boisés", les mots "par semis et plantations \%.

Lir vou est adoptr.

Messieurs, je donne lecture du sixième et dernier voeu : 
INTERNATIONAL 1913

"Qu'il soit accordé des dégrèrements temporaires pour les bois ruinés par des invasions d'insectes on des maladies cryptogamiques dont la reconstitution par semis ou. plantutions aur élé reconnue indispentable an maintien de l'état boisé."

Un Congressiste. - Ne conviendrait-il pas de prévoir la destruction par incendie?

M. LE Présidext. - Certainement. Nous ajouterons donc le mot "des incendies " entre les mots "par " et "des invasions".

Je mets aux voix le vou ainsi modifié.

Le vou est adopté.

La séance est levée à 5 h. 30 . 


\title{
SEANCE DU 18 JUIN 1913
}

\author{
(MATIN) \\ Présidence de IM. VIVIER, président de Section
}

La séance est ouverte à 9 h. 35 .

II. Le Présnext. - Lorlde du jour appelle la discussion du rapport de M. Margaine, sur les Ligtes, sYdDICATS ET CAISSES DE CRÉdT FORESTIER.

La parole est a M. Margaine pour la lecture de son rapport.

II. Margaixe. - Le rapporteur compte sur la bienveillante indulgence des lecteurs pour excuser les lacunes inhérentes à un travail aussi court sur un sujet aussi vaste.

II doit remercier les nombreux correspondants qui ont bien voulu répondre à l'appel du Touring-Club et tout particulièrement, pour les pays étrangers, MM. Anstruttier pour l'Angleterre, Campbell pour le Canada, Pillichody et Barbey pour la Suisse, Krarup pour le Danemark, Saxlund pour la Norvège, les départements des forêts pour l'Autriche et les Etats-Unis ainsi que l'Association centrale des syndicats agricoles de Darmstadt pour l'Allemagne.

Sommuile d'HI essia sh1 lorgallisilion ricoII $0 \mathrm{miq}$ i 11 e du monds lores: liar.

Terminologie adoptée. - L'instinct d'entr'aide qui existe chez tous les hommes se manifeste, dans les groupements qu'ils établissent entre eux, suivant leur profession, sous deux formes nettement différentes :

$1^{0}$ Ils peuvent s'unir dans un but d'intérêt uniquement général, désintéressé, sous les formes de "Sociétés académiques ", "Sociétés d'études ", "Associations pour la défense des intérêts généraux du pays", etc. : groupements scientifiques.

20 Ils peuvent s'unir dans un but d'intérêt particulier: groupements économiques.

1. Ce hut peut être relativement général lorsqu'il s'agit pour le groupement formé de défendre les intérêts généraux de la profession de ses membres, sans s'occuper de leurs intérêts, à eux, pris isolément. C'est ce que nous appellerons le mouvement syndicaliste et nous désignerons ces groupements sous le nom de syndicals.

B. Ce but peut être de défendre les intérêts particuliers de chacun des membres du groupement par la coopérution ou la mutualité.

a) Dans la coopération, les hommes groupent leurs capitaux, leurs biens mobiliers et immobiliers ou leur travail dans un intérêt spéculatif.

Nous n"étudierons que les groupements des biens et les groupements 
du travail que l'on désigne plus généralement sous le nom de "coopératives " et nous n'entendrons même par "coopération" que l'association des biens et du travail à l'exclusion des groupements de capitaux.

b) Nous entendrons par mutualilé, le groupement des hommes dans le but de se venir en aide les uns aux autres sans idée de bénéfice immédiat.

Ces organisations sont permanentes (Sociétés) ou temporaires (Congrès); nationales ou internationales.

a) Sociétés nationales. - Les questions forestières sont à l'ordre du jour dans tous les pays civilisés ayant des forêts. Dans tous, les sociétés savantes les étudient; dans tous, des sociétés savantes spéciales se sont formées pour les examiner.

Certaines sociétés étudient toutes ces questions en général, réunissent des congrès nationaux, font des excursions scientifiques et publient des mémoires dans des bulletins périodiques (1).

D'autres poursuivent des buts plus nettement déterminés : elles cherchent à provoquer le reboisement dans le pays (2), ou à empêcher le déboisement des montagnes (3), à défendre les forêts en tant que sites naturels (4), a étudier les essences ligneuses et en propager l'emploi (5).

Certaines sociétés à but général poursuivent en même temps des buts spéciaux. Certaines sociétés forestières patronnent le reboisement des terres incultes, la diffusion de l'instruction forestière dans l'enseignement primaire.

b) Congrès nationaux. - Dans tous les pays, les congrès agricoles s'occupent souvent des questions forestières. En dehors des congrès des sociétés savantes, il se tient dans beaucoup de pays des congrès spéciaux de sylviculture.

c) Sociétés internationales. - Il existe même une société internationale d'études forestières : "l'Association internationale des Stations de recherches forestières "fondée en 1874 sur l'initiative du docteur Wittmack, conservateur du musée agricole de Berlin.

d) Congrès internationaux. - Beaucoup de congrès internationaux d'agriculture ont étudié certaines questions forestières. Le Congrès de Vienne (1907), dans sa VIII ${ }^{\mathrm{e}}$ section a discuté les rapports de MM. Pardé et Péronna sur la coopération forestière; il a demandé l'établissement d'une revue internationale forestière et établi une commission internationale pour l'étude d'un système uniforme de statistique de la production et du commerce du bois. Le Congrès de Madrid en 1911 a étudié le reboisement. Celui de Gand (1913), comprend une section de sylviculture.

A Paris, en 1900, s'est tenu un Congrès international de sylvicuture. Il n'y a pas été question de coopération forestière.

(1) Société forestière de Franche-Comté, en France; Société des Forestiers suisses; Sociétéforestière norvégienne "Norsk Strogele Kal) "; Association forestière du Canada ; Société d'Ingénieurs forestiers du Canada; Association forestière américaine; Société des Forestiers allemands et Société des Forestiers mecklembourgeois; Société forestière centrale de Belgique; Société forestière de Saint-Pétersbourg; Société nationale de Hongrie; Société forestière danoise, etc.

(2) Société des Amis des Arbres en France, en Espagne; Congrès de l'Arbre et de l'Eau.

(3) Association pour l'aménagement des montagnes en France, en Algérie; Société Pro Montibus et Sylvis, en Italie.

(4) Commission des Pelouses et Forêts du T. C. F., en France; Association pour la conservation des richesses naturelles, aux Etats-Unis.

(5) Sociétés denclrologiques française, allemande, société royale d'arboriculture anglaise et écossaise. 
Groupemenis économiques.

Les syndicats forestiers. - Les syndicats, avons-nous dit, sont des associations fondées par des gens ayant une profession déterminée, dans le but de défendre les intérêts généraux de leur profession. Les syndicats doivent donc se classer et s'étudier d'après la profession de ceux qui les composent: marchands de bois, agents et préposés forestiers, propriétaires forestiers, ouvriers bûcherons.

a) Syndicats de marchands de bois. - Le commerce de bois dans la plupart des pays est fortement organisé, mais ce genre d'organisation ne rentre pas dans le cadre de notre étude.

b) Syndicats d'agents forestiers. - Dans nombre de pays également, les agents ou préposés forestiers de l'Etat (1) ou des particuliers, les ingénieurs forestiers, etc., se sont unis pour la défense de leurs intérêts. Ces syndicats sont formés d'une catégorie trop spéciale de personnes et sont souvent dans une dépendance trop étroite des pouvoirs centraux pour avoir une véritable influence dans le mouvement économique forestier.

c) Syndicats de propriétaires forestiers. - L'esprit généralement particulariste du propriétaire, surtout du propriétaire forestier, dans tous les pays, fait que celui-ci entre plus volontiers dans l'organisation syndicale que dans l'organisation coopératiste, et encore faut-il que quelqu'un mette le mouvement en train. En France, le mouvement a pris une extension apparente assez considérable sous l'impulsion de "l'Office forestier du Centre et de l'Ouest ", fondé en 1908 par un homme de grande compétence forestière, M. Roulleau. Le mouvement a été favorisé par la diminution du revenu de la propriété boisée à la suite de l'effondrement des cours des bois de chauffage, de l'augmentation du prix de la main-d'œuvre, de l'accroissement des charges fiscales coïncidant avec une taxation maladroite des droits successoraux. Les propriétaires qui n'ont pas réalisé leurs forêts, ont fondé en beaucoup d'endroits des syndicats (2) dont le but est surtout, en ce moment, de combattre la législation fiscale forestière. Mais le nombre de ces syndicats ne doit pas faire illusion sur le nombre de leurs membres, qui est très restreint (1500 environ?); aussi la force de ces syndicats est-elle limitée, parce qu'ils n'ont pas pu ou pas su grouper les masses des petits propriétaires forestiers, et que le syndicat est l'arme des masses. La richesse de leurs membres aide à la prospérité des coopératives; le syndicat lui ne puise la vie que dans le nombre de ses adhérents. Conscients de leur faiblesse, les syndicats forestiers français se sont fédérés en un "Comité des forêts" qui est à la fois une union de syndicats et un syndicat à rayon très étendu. Il est fondé depuis trop peu de temps pour qu'on puisse constater les résultats de son action. Ses dirigeants semblent vouloir s'adresser plus directement qu'il n'a été fait jusqu'ici aux nombreux petits propriétaires forestiers. Personnellement, nous pensons que cette organisation très utile, ne trouvera, si elle reste sur le terrain uniquement syn-

(1) En France : Société des Agents forestiers, qui est aussi une société de secours et de prêts; Association des Agents forestiers, qui est un véritable syndicat de défense professionnelle, comme l'Association des préposés forcstiers. Au Canada : Société des ingénieurs forestiers.

(2) Syndicats de Saint-Bonnet-le-Château, d'Eure-et-Loir, des Cótes-du-Nord, de Ia Mayenne, de la Sarthe, de Touraine, du Berri, de Maine-et-Loire, de l'Aisne, du Nord, de la Marne, de Château-Thierry, de la Haule-Marne, de l'Ain, de Lorraine, du Nivernais. 
dical, que difficilement les ressources qui lui sont nécessaires pour jouer le rôle économique auquel elle aspire.

Il existe aussi à l'étranger des syndicats ayant une aetion législative. En Autriche la "Société Centrale pour la protection des intérêts agricoles et forestiers, à l'oceasion des traités de commerce ", a une action politique très nette et très active (1).

Mais l'action des syndicats peut s'exereer dans d'autres sens Il y en a qui se sont fondés, en France, pour lutter contre l'organisation syndicale ouvrière, comme le syndicat des propriétaires forestiers de la Nièvre (spécialement section de Decize), d'autres, pour lutter contre l'organisation syndicale des marchands de bois. Lorsque ces syndicats procèdent à des ventes en commun ou à des exploitations directes, ils prennent une allure nettement coopérative et doivent être considérés comme coopératives.

d) Syndicats ouvriers. - Il existe, en France, deux régions où ont pris naissance et se sont implantées des organisations syndicales ouvrières. Elles ont d'ailleurs dans chaque contrée, des allures assez différentes. 1. Syndicats ouvriers du centre. - Les syndicats ouvriers du Centre sont de véritables syndicats dont l'action se poursuit sur le terrain des salaires et des lois et sur le terrain politique. lls sont unis en une "Fédération nationale des syndicats de bûcherons ", affiliée à la Confédération générale du travail (Congrès de Bourges 1902) et formant l'Union fédérative terrienne, avec la Fédération agricole du Midi, la Fédération nationale horticole et la Fédération agricole du Nord. L'organe officiel de cette union est le Travailleur de la Terre.

Le mouvément est né à la suite de dépréciations de salaires telles que beaucoup de bûcherons n'arrivaient pas à gagner plus de $0 \mathrm{fr}$. 75 par jour; il a réussi à arrêter la chute des salaires et même à les faire remonter à un taux plus normal. Le congrès des syndicats bûcherons du LurcyLurcy (1912), accompagné d'une réunion d'ouvriers agricoles, s'est cantonné sur le terrain des revendications professionnelles, mais le IXe congrès de leur fédération nationale a affirmé par certaines résolutions le rôle qu'il entend jouer dans la lutte des classes.

2. Syndicats ouvriers des Landes. - Dans les Landes, les gemmeurs se sont syndiqués. Le mouvement a pris naissance en 1905 à Lit et Mixe, il a eu moins d'homogénéité que dans le Centre. Une Fédération des des différents syndicats s'est formée, mais beaucoup se tiennent à l'écart pour des raisons le plus souvent d'ordre politique. L'action des syndicats est restée cependant uniquement professionnelle et elle a abouti à un sérieux relèvement des salaires; elle tend aujourd'hui à des buts nettement coopératifs. Au VIIe de leurs congrès (Castets 1912), les gemmeurs. ont demandé à l'administration forestière " de passer directement avec leurs associations des contrats collectifs pour l'extraction de la gemme à des conditions déterminées à l'avance ". Ce vou a été examiné par une commission d'étude nommée par le ministre de l'Agriculture et qui s'est réunie à Labouheyre. L'obtention de la mise en régie directe des forêts de l'Etat est un grand succès pour ces syndicats et aura dans le monde du travail un grand retentissement.

En résumé, ces syndicats ouvriers français n’ont pas grande homogénéité: ils n'ont pas grande influence syndicale n'ayaut pu grouper

(1) Bulletin des Institutions écon. et soc. de l'Institut intern. de Rome, 1911, nº 6, p. 35. 
un grand ensemble de travailleurs. Ils sentent que leur véritable force leur viendra par la coopération et ils l'avouent. Leurs dirigeants d’ailleurs les poussent dans cette voie.

En Danemark également, les ouvriers bùcherons sont souvent organisés en syndicats professionnels.

I. conpriation Iorestiere.

lielations entre l'auprivulture et in sivioulture.

Pimperation en agyriculturo.

L'organisation des sociétés et des syndicats forestiers est actuellement chose faite dans la plupart des pays. Un Congrès ne peut guère que constater ce qui a été fait.

Par contre, dans le domaine de la coopération et de la mutualité, tout est à construire et il semble du rôle d'un congrès international, qui réunit les plus éminentes compétences en matière forestière, d'appeler' l'attention du législateur sur l'intérêt de ces questions et d'indiquer aux intéressés les voies à suivre.

Nous allons donc sommairement exposer que, bien que les relations entre l'agriculture et la sylviculture soient profondes, le grand mouvement coopératiste qui vient de s'épanouir dans les campagnes, n'a pas eu de répercussion dans le monde forestier. Nous verrons que si la forêt se prête admirablement à l'exploitation communiste ou collective et que si la coopérative forestière présente de nombreux avantages, il n'en est pas moins certain que le mouvement coopératiste est encore en germe. Nous chercherons à montrer pourquoi il en est ainsi ; nous exposerons où en est actuellement cette organisation et quelles sont les différentes formes de coopératives que l'on peut fonder. Enfin nous examinerons comment on pourrait développer le mouvement coopératiste dans le monde forestier et sous quelle forme il convient de fonder les coopératives forestières.

Nous rappellerons simplement que des liens étroits unissent l'agriculture et la sylviculture sur le terrain économique. Nombre d'auteurs ont étudié le rôle des communaux, des bois communaux et des forêts en général sur la vie économique des campagnes. Aussi est-il logique d'examiner rapidement où en est une question dans un des milieux avant de l'étudier dans l'autre.

Or dans tous les pays civilisés, ce mouvement coopératif a pris une expansion excessivement considérable. Les bases de cette organisation coopérative agricole sont maintenant nettement assises et de nombreux congrès nationaux et internationaux en ont consacré les méthodes.

La pierre fondamentale de l'édifice est le Syndicat communal. Celui-ci étudie tout d'abord la vie économique du milieu où il a éclos, puis il se lance dans la coopération d'achat et de vente, parfois de transformation des produits, presque jamais d'exploitation du sol. Il crée la banque coopérative qui lui est indispensahe au moyen des caisses locales de crédit mutuel à responsabilité limitée ou illimitée. Et le voilà amené à la Mutualité : mutualité des risques d'incendie, mutualité des risques de mortalité des bestiaux, mutualité des risques d'accidents, de maladies, d'infirmités, de vieillesse, etc. ete. Le tout organisé en coopératives et en caisses locales, annexes et filiales du syndicat, mais indépendantes de lui en général.

Toutes ces petites organisations locales, communales autant que possible, s'unissent pour avoir une véritable force ; les syndieats fondent des 
unions, les caisses de crédit font des eaisses régionales, les mutuelles se fédèrent en caisses de réassurance. Toutes ces organisations du 2 e degré s'unissent parfois au $3^{\mathrm{e}}$ degré.

A côté de ces organisations à bases locales, il existe des caisses et syndicats à grand rayon; mais, outre que souvent ces groupements se fractionnent en "seetions ", il semble admis, par les congrès, qu'ils n'ont pas l'action économique et sociale des autres à base restreinte.

La forêt a sur les autres biens des eauses d'infériorité nais eelles-ei disparaissent avec l'exploitation eolleetive. Cette exploitation est le mode rêvé pour la forêt (1).

La gestion de celle-ci par les particuliers en amène généralement la ruine à cause du moreellement, suite inévitable des suceessions ou des ventes; à cause de la rupture des aménagements, des frais généraux, de la diffieulté de vendre les coupes petites et dispersées et enfin de la facilité et de la rapidité de réalisation qui earactérisent le bien forestier et qui n'ont d'égales que la difficulté et la lenteur de sa reconstitution (2).

La constitution de coopératives forestières semble done devoir se rrantages qui présenter à l'esprit de tous.

Elles ont pour avantages primordiaux :

10 d'empêcher le morcellement et d'obvier à ses inconvénients : impossibilité d'établir un plan d'exploitation pour un revenu annuel et soutenu qu'on ne peut réaliser que pour une forêt suffisamment vaste (3).

$2^{\circ}$ de permettre de grandes éeonomies dans l'administration, la surveillance, le bornage du massif.

$3^{\circ}$ de permettre une vente plus rémunératrice des eoupes.

$4^{\circ}$ de donner une meilleure location di droit de chasse.

$5^{\circ}$ de permettre la gestion par un agent eompétent et par suite d'entraîner la constitution d'un personnel compétent.

$6^{\circ}$ de donner la possibilité de transformer le eapital immobilier en actions mobilières faeilitant les transaetions (' 4 ).

$7^{\circ}$ de diminuer les risques provenant d'incendie, de eoups de vents, d'invasion d'insectes, de pénurie de main-d'œuvre, d'accidents du travail, de faillite de marehands de bois; tous ces risques se répartissant sur lous, affectent moins la part de chacun.

So de faeiliter le reboisement.

(1) C'est tellement exact que dans les pays les plus civilisés on trouve encore des traces d'exploitation absolument communiste de la forêt. Dans les Ardennes françaises, nous trouvons des communes où les habitants vont, tous les ans, dans la coupe communale, couper eux-mêmes les arbres de leur part affouagère et rapportent le bois chez eux, sans intermédiaire d'un adjudicataire, comme dans la plupart des coupes affouagères. Cf. dans le même ordre d'idée VANDERvelde, Exode rura!, p. 59. E. REClus, La Terre ef l'homme, tome VI.

(2) Cf́. Gerdil, La coopération appliquée alux forêts. De Cavaye, Bulletin de la Soeiété forestière de Belgique, avril 1903. Lotí: : La propriété forestière est par excellence la propriété des personnes qui ne meurent pas (Bulletin de la Société forestière de Franche. Comté et Belfort, avril 1903.

(3) G. MADELix, Restrictions légales au droit de propriété forestière privée en France, en Allemagne, etc., 1905.

(i) DE LiocouRT, Avantages descooperatives forestières (Bulletin de la Société forestiòre de Franche-Comté et Belfort 1906). De tous ces avantages résulte pour la forêt coopérative un rapport non seulement soutenu, mais progressif. 
vifférencesentri les cooperatives agricole. et les coopé ratives forestieres.

(H) bacles qui pu lavent la formation de rogejératives Iorestières.

f'lassification

Malgré tous leurs avantages les coopératives forestières n'ont pas suivi le mouvement de progression des coopératives agricoles', qui est très net, même quand on le ramène à ses véritables limites. C'est qu'il existe entre ces deux coopératives des différences fondamentales. Tout d'abord à l'inverse de la coopérative agricole, la véritable coopérative forestière a pour base un territoire (en l'espèce une forêt) à exploiter en commun. Or ce genre d'exploitation n'est pas dans les mœurs du propriétaire terrien ou du cultivateur actuels (1). Le coopératiste forestier doit apporter sa forêt à la coopérative et son.droit de propriété se trouve restreint. Et alors que la coopérative agricole cherche à améliorer de suite la situation économique de ses membres, la coopérative forestière s'occupe surtout de restaurer la forêt coopérative, au détriment apparent parfois des intérêts immédiats des coopératistes.

A côté des raisons qui résultent de la répugnance qu'ont les propriétaires forestiers à se dessaisir d'une partie même minime de leurs droits. de propriété, il existe bien d'autres causes qui font obstacle à l'expansion des coopératives forestières.

a) Ces coopératives sont surtout utiles aux petits propriétaires. Ceux-ci suivent souvent l'impulsion et l'exemple qui leur sont donnés par les grands propriétaires et exploitants. Or, si le grand propriétaire agricole a tendance à favoriser la formation des coopératives agricoles pour ses avantages propres et pour fixer dans le pays les petits propriétaires dont il a besoin, le grand propriétaire forestier ne se prêtera qu'à la formation de coopératives forestières tout à fait limitées, peu utiles au petit propriétaire. Le grand propriétaire possède une forêt aménagée formant un tout et il croit, à tort, n'avoir besoin de personne.

b) De plus, et cette raison est plus grave, la législation des différents pays ne se prête pas en général à la constitution de coopératives forestières. Il en est ainsi en France, où le crédit agricole n'est pas adapté aux nécessités de la coopération forestière, et en Allemagne, où cependant certains états (Prusse), ont cherché à faire naître des coopératives forestières.

c) Cette attitude expectante des gouvernements s'est traduite par un manque d'aide et d'encouragement de la part de l'Etat, cause très efficiente de la stagnation de la coopération forestière.

Les coopératives forestières peuvent se distinguer, comme les syndicats, d'après les éléments qui les composent, en coopératives de propriétaires ou patronales et coopératives ouvrières.

A. Coopératives de propriètaires. - Ce sont des unions de propriétaires en vue de l'exécution en commun de certaines opérations forestières sur un ensemble déterminé de parcelles.

Ces coopératives, si on se place au PoINT DE VUE DE LEUR FoncTIONNEMENT effectif, peuvent se diriser en coopératives de propriétés et en coopératives de gestion.

a) Dans les coopératives de propriétés, il est constitué une forêt commune, indivisible, gérée comme un tout suivant une place déterminée.

b) Dans les coopératives de gestion, chaque propriétaire reste en possession de sa parcelle boisée, on ne met en commun que la gestion.

(1) Dr Exones, Handbuch der Forstpolitik, Berlin 1905. 
Les coopératives de gestion se subdivisent en coopératives restreintes ou limitées lorsqu'elles ne visent qu'une partie des opérations dont est susceptible la gestion des forêts depuis la simple garderie par un garde commun jusqu'à la gestion totale (celle-ci non comprise); et en coopératives complètes ou véritables coopératives où l'utilisation se fait en commun suivant un plan d'exploitation général, en compte commun. Les dépenses et les charges sont, dans ces coopératives, supportées dans la limite des engagements pris et les recettes correspondantes partagées, le tout au prorata du capital forestier engagé par chacun.

Les coopératives de propriétaires peuvent encore être classées StIVANT LE MODE DE LEUR FORMATION.

On distingue :

a) les coopératives libres c'est-à-dire celies où les membres entrent librement, sans être l'objet d'aucune contrainte légale.

b) Les coopératives forcées ou à entrée obligatoire où une majorité peut, après l'accomplissement de certaines formalités, forcer une minorité à adhérer à la coopérative (associations syndicales autorisées françaises).

c) Les coopératives administratives formées administrativement sans consultation des intéressés.

B. Coopératives ouvrières. - Ces coopératives sont excessivement peu nombreuses. Là encore, les habitudes des ouvriers, les mœurs générales et la législation des différents pays ont opposé des obstacles puissants à la formation de ces coopératives. 11 en existe en France, mais leur action ne s'étend encore que dans un rayon des plus restreints.

En France, on en est pour ainsi dire à la période d'étude : les solutions préconisées sont nombreuses et diverses. Gerdil recommande les sociétés de reboisement des terres incultes sous forme de sociétés civiles anonymes à capital variable; De Liocourt et Pardé conseillent la coopérative de propriété: Louée préconise la formation de coopératives limitées de garderie; Triquéra opine pour les associations syndicales autorisées. MII. Descombes et Cardot aussi conseillent la formation de coopératives.

Ces appels n'ont été que faiblement entendus. La Société civile du Contrôle a des allures coopératives, mais est une société capitaliste en ce sens qu'elle s'est formée pour acheter une forêt qui n'appartenait à aucun des membres. Le syndicat forestier de Mignovillard est une coopérative limitée de garderie. Le syndicat de Sologne n'est qu'un timide essai de vente de produits en commun (bois de boulange).

Comme essais. d'exploitation directe, il n'y a aussi que des ébauches tentées par: les syndicats forestiers du Centre fondés par M. de Montsaulin dans le Cher, le syndicat des propriétaires forestiers du Nivernais présidé par M. de Montrichard et le syndicat des bûcherons fondé à Parigny-le-Vaux (Nièvre) par M. de Berthier-Bizy (1). Comme coopératives d'annexes des forêts, citons les coopératives résinifères des

(1) Bulletin des Institutions économiques et sociales de l'Institut agricole de Rome, 31 mars 1911, n 3. Voir aussi Société nationale d'agriculture de France, séance du 8 décembre 1909 , á propos de la participation aux bénéfices en matière d'exploitation forestière dans la Société de Villebois-Mareuil. 
Landes et de la Gironde (1) et le syndicat de reboisement de Tortebesse (2) (Puy-de-Dôme).

Il existe en France des associations forestières de défense contre l'incendie. Elles se sont constituées, soit sous la forme syndicale (Onesse-Laherie, Pessac, Barp, etc.) en Gironde, en Charente et dans les Landes, soit sous la forme d'associations syndicales (Petit-SaintGervais). Le régime juridique adopté par ces associations entrave leur complet développement, car ce sont de véritables coopératives dont le but est de combattre matériellement les incendies (3).

En Allemagne, il n'existe que 4 coopératives considérées comme véritables par les auteurs allemands; les autres, assez nombreuses, sont soit des associations syndicales, soit des corporations, soit des coopératives annexes de l'exploitation forestière. Ces dernières existent en assez grand nombre (coopérative d'abatage de bois de la Basse Hesse et Waldeck, coopératives pour l'utilisation de la fraise des bois, scieries coopératives, ete.) (4).

En Autriche, il existe aussi des coopératives forestières limitées it l'achat en gros de semences, d'instruments, de machines, ou à la construction de routes forestières, ete. L'État incite les petits propriétaires a se réunir en coopératives locales (5) qui se fédéreraient. Les associations forestières prònent également ce mouvement, et en Bohême s'est fondé un conseil de sylvirulture (6). Il existe également une coopérative avec caisse de crédit mutuel et une société pour l'exploitation de la r'ésine. Les caisses de crédit à responsabilité illimitée dont il existe pluto 7.000 en Autriche, accordent des prêts aux propriétaires forestiers (i).

En Angleterre, deux sociétés ont été récemment constituées : les sociétén forestières coopératives des propriétaires anglais et écossais. Elles se sont jusqu'ici limitées à l'achat en commun de graines et de plants.

Au Canada et aux Etats-Unis les propriétaires de forêts se groupent en coopératives pour défendre les forêts contre les incendies (Société de protection des forêts de la vallée de Saint-Mlaurice au Canada).

A $и$ Danemark, la vente des coupes sur pied a cessé depuis longtemps. Tout le bois des forêts est coupé au compte des cantonnements (districts) et est vendu directement aux scieries et aux autres consommateurs.

L'Italie a modifié son Code forestier et sa loi du 2 juin 1910 prévoit la formation de coopératives (associations syndicales) pour le reboisement des terrains en montagne.

En Suisse, il y a également des coopératives (Association des communes bourgeoises, communes mixtes et de l'Administration forestière de l'Etat des 15 arrondissements du canton de Berne. Organisation analogue du

(1) TARDY, La coopération dans l'Agriculture française. Rapport présenté au premier congrès international des Associations agricoles, Bruxelles 1910. Il existe également un Syndicat de défense des produits résineux de la Gironde, à Bordeaux, sur lequel nous n'avons pas de renseignements.

(2) P. Descomes, La Défense forestière et pastorale, page 228.

(3) Bulletin des Institutions économiques et sociales de Institut International agricol? de Rome, mars 1913.

(4) K.UI. No 4, 28 février 1913, de la Deutsche landwirtchaflliche Genossenschaftspresse.

(5) Bulletin des Institutions économiques et sociales de l'Institut International d'agriculture de Rome, tome II, pagres 11 et 12

(6) Bulletin des Institutions économiques et sociales de linstitut International dagri. culture de Rome, tome III (juillet 1912).

(7) Renseignements du Département des forêts. 
Val de Travers. Société forestière Pfannenstiel à Meilen et la Société forestière d'Hérisau, sorte de Société du Contrôle), mais dans ce pays, l'Etat, excessivement décentralisé, supplée lui-même à l'action des coopératives : il s'est fait mutualiste.

En Rommanie, il existait au 31 décembre 1911, 119 coopératives pour l'exploitation des forêts, ayant un capital souscrit de 1.158.330 lei. Elles groupent $6.67 \mathrm{~T}$ membres se répartissant en 5.958 cultivateurs, I's commercants, 105 unvriers, 167 fonctionnaires, 32 propriétaires, 110 prêtres, 157 instituteurs. Le rapital social versé est de 770.220 lei. Elles ont versé en dividendes, 82.082 lei pour 1911; les frais d'administration se sont élevés à 14.546 lei. Leur encaisse est de 210.55 T lei, elles possèdent un matériel de bois pour 278.350 lei. On voit que leur situation est prospère.

1] existe encore dans ce pays. :) coopératives pour le merrein au rapital souscrit de 16.436 lei et au capital versé de 10.578 , elles ont donné 1.27s lei de dividende. Elles comprennent 131 membres. Lrux sont composées de commerçants, une de eultivateurs (Coopérative l'Lnirea à Baia).

Enfin il existe une coopérative, forestière celle de Foltisti, fondée en 1908, au capital souscrit de 9.092 lei, au capital versé de 25.930 lei et ayant distribué 2.660 lei de dividende. Elle groupe 71 membres dont 5.5 cultivateurs (1).

En Vorvège, les propriétaires de forêts ont formé diverses associations (plus de 50 en 10 ans), ayant pour but la vente en commun. Toutes res sociétés sont réunies èn une union "Norsk Skogeierforband ". II existe, dans ce pays, une soriété mutuelle contre l'incendie des forêts, créée in 1911. La somme souscrite jusqu'à ce jour se monte à 70.000.000. L.a prime est de I 1/4\% $\%$.

Le reboisement des landes, bruyères, terres incultes se prête bien à la formation de coopératives. En Allemagne, il a entrainé la formation de coopératives obligatoires à la suite de la loi du 6 juillet 1875. Au Danemark et en Hollande, existent dans ce but deux sociétés des bruyères, celle du Danemark fondée en 1866 et celle de Hollande en 1888(2). En France, existent dans ce but, à allures plus ou moins coopératistes : l'CEuvre forestière du Limousin, le Syndicat forestier de l'arrondissement de Nontron et la société provençale "Le Chêne ". Ces deux dernières étant plutôt des sociétés de propagande.

Donc les coopératives ne rendent pas les services qu'on pourrait en attendre et il faut étudier comment on pourrait en développer le nombre et par là en faire connaître les bienfaits.

Il faut pour cela faire l'éducation coopératiste des générations actuelles. vieilles et jeunes, et adapter la législation des pays à cette organisation.

On y arrivera par:

10 La propagande faite par les sociétés savantes et les syndicats, ces

(1) Compte rendu des opérations de la Caisse centrale des banques populaires, rummuniqué jar M. Tanessesco, Inspecteur général des Forêts, délégué de la Ronmanie -tu Congrès international. Cette caisse dépend du Ministère des Finances qui a mis, yar son intermédiaire, 30 millions à la disposition des paysans.

(2) Rapport VIII, 6, 1, au Congrès international des Associations agricoles de Bruxelles 1910. Cette sorte de coopérative se rapproche plutôt des sociétés d'encouragement. Cf. aussi, Société culticatrice des Landes de Danemark (de Forenede Bogtrykkeripr) Aarhuz, 1913. 
derniers subventionnant et guidant les premières coopératives après avoir aidé et même provoqué leur éclosion.

$2^{\circ}$ Une action analogue, plus active encore si possible, parce que pluś efficace, par les administrations, surtout les administrations forestières, apportant l'aide et les subventions de l'Etat.

3o Une instruction et une éducation coopératistes données aux enfants des campagnes.

$4^{\circ}$ La collahoration des organisations agricoles existant dans les pays ou dans le voisinage des pays forestiers. Coopératives agricoles et coopératives forestières ont les mêmes intérêts et les mêmes tendances; elles doivent se prêter mútuellement main-forte et les secondes doivent profiter de l'expérience acquise par les premières. Il faudra songer à eréer des eaisses locales du crédit forestier ou à adapter le crédit agricole aux besoins forestiers.

$5^{\circ}$ L'institution d'une commission internationale étudiant les questions internationales intéressant les coopératives, cette mesure étant le prélude de la création d'un office forestier international dont l'opportunité sera exposée aux membres de ce Congrès. Cet office coordonnera, suivant les indications données par le Congrès, les efforts faits jusqu'ici d'une façon trop dispersée et trop disparate en vue du développement de la coopération forestière.

La Yutualite forestiere.

Presque rien n'existe ni ne semble en projet en ce domaine dans le monde forestier. Signalons dans certains pays (France, Etats-Unis, Suisse) des mutualités entre agents et préposés forestiers pour les frais de maladie. Citons les mutuelles scolaires forestières fondées en France pour éveiller chez l'enfant à la fois l'amour de la forêt et l'esprit de mutualité. - Cependant les champs d'action qui s'ouvrent de ce côté aux initiatives sont vastes et sont de trois sortes: le crédit mutuel, les risques d'incendie et les risques d'accidents du travail.

$1^{\circ}$ Caisses de crédit forestier. - Une des causes fondamentales qui entravent en France l'essor de la coopération forestière est qu'elle ne possède pas l'organisme financier qui lui est indispensable. Les agriculteurs ont organisé le crédit mutuel agricole en caisses locales et en caisses régionales qui leur assurent :

10 Le crédit individuel à court terme (loi du 5 novembre 1894, modifiée par les lois des 20 juillet 1901, 14 janvier 1908, 18 février et 19 mars 1910);

20 Le crédit individuel à long terme (loi du 19 mars 1910).

Ces caisses donnent également aux coopératives agricoles le crédit à court terme et le crédit à long terme (loi du 26 décembre 1910). Mais les modalités de ce crédit agricole, ne lui permettent pas de s'adapter aux besoins des coopératives forestières. Celles restreintes, de vente des coupes ou d'utilisation des produits, peuvent faire usage du crédit à court terme (limite maximum des effets : 9 mois) mais les coopératives de gestion, de véritable exploitation et de reboisement, sc heurtent, pour le crédit à long terme qui leur est indispensable, à l'obligation légale (article 6 du décret du 26 aoút 1907) du remboursement de la dette, d'année en année par des amortissements successifs. Il faudrait done en France obtenir une législation spéciale pemettant la création de caisses de crédit forestier qui, moyennant certaines garanties spéciales à déterminer, pourraient différer le rembourscment de la dette jusqu'à la fin 
de la durée du prêt. Cette durée devrait aussi pouvoir être supérieure à 25 ans.

D'ailleurs, les coopératives agricoles semblent élever certaines difficultés à l'admission des coopératives forestières aux bénéfices des avances de l'Etat. Les associations agricoles ont donné trop de preuves de leur compréhension du rôle économique de la forêt pour persévérer dans cette voie.

$2^{\circ}$ Caisses d'assurances mutuelles. - Seule la mutualité permettra aux propriétaires de se couvrir effectivement et à un taux raisonnable contre les risques d'incendie; de même que, seule, elle permettra aux coopératives d'exploitation l'assurance de leurs ouvriers.

En France, la mutualité agricole est en train d'échafauder l'assurance mutuelle locale contre l'incendie et, là où elle a essayé, elle a très bien réussi. Elle songe déjà, et sera amenée prochainement, à bâtir l'assurance mutuelle contre les risques du travail. Les forestiers auront tout intérêt à coopérer à ce mouvement et à s'unir aux cultivateurs dans tous les centres où la forêt existe à côté des champs

Au Danemark, les propriétaires sont tenus d'assurer leurs ouvriers; ils le font à la "Caisse d'assurance mutuelle des patrons " à Copenhague.

Syndicalisme ou coopération. - Nous devons admirer les efforts, la c'onclusions. ténacité et l'abnégation de ceux qui ont édifié l'édifice que nous venons d'examiner rapidement et les remercier de l'œuvre accomplie. Mais il nous semble que le rôle d'un congrès est d'indiquer aux hommes de bonne volonté la meilleure voie du progrès afin de leur permettre de coordonner leurs efforts et d'arriver à un même but. Deux voies semblent s'ouvrir pour l'organisation économique du monde forestier : le syndicalisme et la coopération.

La voie du syndicalisme est plus large, plus spacieuse ; ceux qui s'y . engagent aliénent moins leur liberté; mais ils ne se rapproclient pas vite du but qui est de construire une organisation solide et prospère. C'est que le syndicalisme ne tend pas à changer les facteurs économiques actuels : il apporte à un membre d'une corporation la force de tous les autres membres réunis dans la lutte économique : il rend par conséquent celle-ci d'autant plus vive et plus intense. Il prend parsuite une allure de combat à grands eris, puisqu'il agit surtout par propagande et c'est ce que sent confusément la foule dans l'esprit de laquelle syndicat éveille idée de bataille. Nos syndicats forestiers français n'ont pas pu échapper à cette destinée : ils luttent contre le fisc, contre le Parlement, contre d'autres syndicats (leurs statuts l'indiquent, leurs brochures de propagande l'avouent) et après bien des efforts, bien du travail, leurs dirigeants n'ont-ils pas la sensation qu'ils ont peu obtenu et que l'organisation qu'ils ont construite est peu solide?

Si elle est benoîte d'allures, au fond, la coopération est au point de vue économique beaucoup plus révolutionnaire que le syndicalisme: elle cherche à adopter des méthodes nouvelles et à bouleverser les facteurs économiques actuels. Elle s'attaque aux habitudes des gens, à leur particularisme quand elle leur conseille de mettre leurs biens en commun; elle menace les intérôts d'autrui quand elle veut supprimer des intermédiaires. Il lui faut done vaincre la routine des uns et la résistance désespérée des autres. Nais si elle n'avance que pas à pas, le sillon qu'elle. trace est profond et l'œuvre bâtie se trouve assise sur des bases solides. 
Qu'on n'objecte pas contre cette thèse, l'exemple des syndicats agricoles français. Le nom ne doit là pas faire illusion sur la chose. Tous les syndicats agricoles franȩais sont devenus des coopératives. Ils ne fonctionnent comme syndicats que lors de leurs congrès annuels, manifestations de leurs unions, là où ils sont en nombre ; mais dans la pratique journalière, ils sont tous devenus coopératives : coopératives d'achat d'engrais, coopératives d'utilisation d'instruments, coopératives de laiterie, etc., ete.; et là où ils n'ont pu bâtir de coopérative, ils ont disparu. Les modifications qu'il a fallu apporter à la législation, les discussions relatives à la jurisprudence ont montré récemment que la désignation de syndicat ne correspond plus à l'organisme existant.

Les progrès réalisés dans leur organisation économique par les agriculteurs tiennent donc à ce que leurs syndicats, sans abandonner complètement leur rôle syndical, ne l'ont considéré que comme secondaire et sont entrés résolument dans la voie coopérative. Ils y ont trouvé le succès parce que seule la coopération rend les organisations financièrement solides : "pas d'affaires, pas d'argent ".

Nous pensons que dans l'organisation économique forestière, la phase syndicale ne doit être que préparatoire, qu'il sera bon de la franchir le plus tôt possible et que cette organisation économique, comme l'indique le remarquable rapport de l'association forestière autrichienne au XXIVe Congrès forestier autrichien, n'entrera dans la véritable voie du progrès que lorsque les syndicats forestiers et les forestiers adopteront résoluInent la méthode de la coopération : coopératives limitées tout d'abord, tendant de plus en plus à la coopérative complète. Et la sylviculture devra profiter des expériences faites par l'agriculture et en adopter les procédés : coopératives locales assez restreintes pour ne pas disperser leur effort, assez étendues pour être fortes mais puisant surtout leur force dans la fédération: fédérations progressives, provinciales, puis nationales, le tout couronné par une fédération internationale.

Si les syndicats forestiers essayent de remplir ce programme, s'ils réussissent à réaliser cet idéal, ils auront bien mérité de la cause forestièré et leurs débuts difficiles n'auront été que l'aube d'une journée radieuse.

Si les éminents congressistes veulent bien adopter les vues qui semblent résulter du rapport soumis à leur examen et les conclusions qui précèdent, ils pourraient envisager l'utilité du vœu suivant:

\section{Le Congrès forestier international,}

Rendant justice aux efforts faits par les syndicalistes de tous les pays, les engage à diriger, autant que possible, leur aetion vers la formation de coopératives,

Préconise la formation de coopératives de propriétés, complètes, it circonscription restreinte et unies par des fédérations,

Souhaite que les associations agrieoles aident de leur expérience et de leur pouvoir à la formation de coopératives forestières et de caisses de crédit forestier et émet le vœu :

Que les législations des différents pays soient adaptées à la formation de coopératives forestières et que les Etats favorisent celles-ci par des subvertions, par des exemptions d'impôts graduées, par l'aide de leurs agents forestiers et par la création de caisses de crédit mutuel forestier. 
Je m'appuierai sur l'expérience aequise dans le domaine do l'agriculture pour conseiller la formation de coopératives plutòt que de syndicats dans le monde forestier. La transformation du mouvement syndicaliste agricole est un fait reconnu par tous. Tout dernièrement, M. Zolla, l'économiste connu, écrivait : "Interdire aux syndicats agricoles de faire des achats et des ventes pour le compte le leurs membres, e'est en rendre l'action presque stérile et l'unité quasi nulle.,

11. Dubier, dans son excellent rapport sur la question de la législation syndicale, écrit :

"Par la force naturelle des choses, en majorité, les syndirats agricoles ont été érigés en coopératives."

Malgré toutes ces considérations et malgré la conviction profonde que seule, la coopération ouvrira des voies nouvelles et fécondes au mouvement économique ouvrier, je n'oserais pas demander à votre Congrès d'émettre un voeu dans ce sens, si je n'étais pas soutenu dans mon opinion, d'abord par les campagnes menées par des forestiers comme MII. Pardé, Liocourt, Cardot, Huffel, Louée, Descombes, ete, et ensuite par les conclusions d'un remarquable rapport de l'Association forestière autrichienne au vingt-quatrième Congrès forestier du 26 mars 1912. Ce rapport arait trait à l'organisation économique des sylviculteurs. Jo vous demande la permission de rous en riter in extenso les passages suivants :

"C'est le devoir des sylviculteurs de fonder un grand nombre de coopératives. Le mouvement à opérer dlans ce sens, devrait être analogue à celui qui s’est fait pour la coopération agricole. On devrait d'abord fonder un réseau de coopératives locales, pour les grouper ensuite en organisations centrales, province par province. Ces organisations se rattacheraient ì leur tour à un seul organisme ayant tout le territoire comme sphère d'action et constituant le dernier échelon de la coopération forestière."

Et le Congrès concluait :

"10 L'organisation économique des sylviculteurs présente une nécessité urgente ; les petits propriétaires ont besoin de se réunir en coopératives de rente, d'après les principes précités.

" $2^{\circ}$ On recommande aux assoriations forestières de favoriser efficacement l'institution de telles cooperatives tocales et d'organiser les fédérations provinciales correspondantes; les dites associations devraient s'ardresser, directement ou par l'intermédiaire des organisations agricoles, aux autorités compétentes, en vue d'obtenir les moyens nécessaires pour entreprendre l'ocuvre de propagande et d'organisation a l'aide d'experts en matière forestière ot de maitres forestiers ambulants $)$.

Enfin, le Congrès priait le Ministre de l'Agriculture d'aceorder aux associations forestières des subventions destinées à la fondation de coopératives forestières dr rente et permettant, "n général, de favoriser l'essor de la coopération dans la sphère forestière.

Iessieurs, au moment de vous demander le vote du roeu que jai 
proposé, je tiens essentiellement à spécifier que le vote de ce vou ne saurait en aucune mesure impliquer une désapprobation de l'effort et du travail fourni par les hommes de bonne volonté qui ont jusqu'ici pratiqué la voie syndicale. Ils ont fait ce qu'ils ont pu au milieu de grandes difficultés. Remercions-les de l'ouvre accomplie, rendons justice à leur persévérance et à leur labeur. Mais, après les avoir vus bien faire, demandons leur de faire mieux encore. Et, pour cela, donnons leur les armes nécessaires.

C'est pour ces raisons, Messieurs, que je vous demande de voter le roeu qui termine mon rapport.

Je crois qu'on pourrait facilement obtenir des satisfactions dans le domaine de l'impòt forestier, pour les coopératives. Si l'on n'obtient pas de réductions d'impôt, on peut avoir de larges subrentions, grâce au crédit mutuel (Applandissements).

11. Le Président. - Vos applaudissements sont un remerciement ì II. Margaine pour cette trés intéressante communication, qu'il a faite aver une véritable ardeur d'apôtre.

Au tribut de reconnaissance qu'il a apporté aux forestiers étrangers qui ont bien voulu lui fournir des renseignements, je tiens à joindre les remerciements du bureau. Je prie ceux de nos collègues étrangers, présents dans cette salle, de prendre d'abord pour eux et de transmettre ensuite à leurs confrères les remerciements de $\mathrm{M}$. le rapporteur et de toute la section pour leur amabilité à nous renseigner.

II. DE LIRXiGE. - Je voudrais relever une phrase du rapport imprimé qui a certainement dépassé la pensée de M. Margaine. Il a écrit : "Il n'y a plus de syndicats, it n'y a que des coopératives."

l'ourtant, si nous regardons du còté de l'agriculture, qui fut initiatrice en cette matière, nous rencontrons l'Union centrale des agriculteurs de France, qui groupe 1.800 syndicats et plus de 1.200 .000 membres. C'est dire que les syndicats existent toujours. A còté cle ces syndicats, combien y a-t-il de coopératives? C'est la contrepartie nécessaire, je me hâte de le dire, c’est un còté, un accessoire très important du syndicalisme que la vente directe des produits fabriqués par les syndiqués, s'il s'agit de coopération forestière surtout. A l'heure actuelle, on peut dire que la coopération intervieudrait dans le syndicat comme une nécessité inélurtable, en présence de la erise des bois. C'est vous dire que nous sommes loin d'être opposés à cette forme heureuse de l'action syndicaliste.

Mais ce n'en est pas moins, je tiens à le dire, une forme accessoire. En effet, le ròle du syndicat n'est pas simplement commercial, c'est un rôle moral aussi, c'est un ròle de défense des intérêts économiques généraux, et si nous avons ronquis en France bien des libertés, c'est grâce à l'effort syndicaliste. Il ne faut pas l'oublier, à l'heure oì l'on vient nous dire : "Insistons, avant tout, pour qu'on vienne en aids aux associations coopératives $\%$. 
Je suis done partisan d'une formule moins absolue (approbation). Disons que nous souhaitons que les législations des différents pays soient adaptées à la formation des syndicats et des coopératives daus le domaine forestier. Nous ne pouvons souhaiter qu'une chose, nous, forestiers, e'est de voir la même bonne fortune arriver à l'action forestière qu'à l'action des syndicats agricoles proprement dits. Nous souhaiterions certes que l'action des syndirats ou des coopératives, an matière forestière, puisse acquérir rette puissance d'expansion, grâce à laquelle la coopération centrale de l'Union des syndicats d'agriculteurs de France arrive à fournir une cquantité considérable de graines et de semences à ses syndiqués, tout en laissant ehacun des organismes syndicaux affiliés, chacune des cellules originelles indispensables à la base, si l'on veut procéder logiquement et aller de la partie vers le tout, tout en les laissant libres, dis-je, de se fournir ou non à la coopérative.

Telle est la première observation que je désirais faire. Je me permettrai d'en présenter une seconde, d'ordre peut-être accessoire, mais que je dois au groupement que j'ai l'honneur de représenter.

Je voudrais voir une date dans le rapport; j'y voudrais voir la date de la fondation du premier syndicat forestier en France. J'ai l'honneur d'en être le président, je n'ajouterai pas autre chose en ce qui me concerne, et je ne serais pas intervenu, si ju n'avais tenu d̀ rendre hommage aux efforts de mes collaborateurs à tous les degrés. Très modeste comme nombre de membres et comme chifire d'actions, le Syndieat de Sologne a été fondé en 1905.

Il y en avait déjà un en fondation à cette époque; M. Thivel me fait un signe comme pour revendirquer l'antériorité. Mais j'envisage l'action effective, organisée, sur le double terrain syndicaliste et coopératif.

H. Thivel. - Nous n'avons pas fait de coopérative, naais nous avons vendu en commun.

M. DE LARXAge. - Notre syndicat est le premier a avoir fonctionné sous cette forme et à avoir eu une coopérative : il y a, aux Chantiers d'Irry, des bois de Sologne qui vont directement à la boulange sans passer par l'intermédiaire. Dire que c'est très fructueux pour les propriétaires, je ne le dirai pas, parce que nous avons voulu simplement, jusqu“ à présent, parr à certaines éventualités.

Nous sommes encore jeunes, mais il est intéressant de voir que, comme dans le domaine agricole, nous avons commencé par la petitscellule syndicale avant d'arriver à construire sur des cellules, agglomérées en unions, un syndicat qui s'appelle aujourd'lrui Comité des Forêts. Avant d'en arriver là, nous avons voulu, dans les différentes régions forestières de France, nous baser sur le mouvement syndical, c'est-à-dire sur l'union des propriétaires sur le terrain de la défense des intérêts économiques, of nous commençons maintenant à passer dans le domaine de l'action par la création d'urganes coopératifs. 
La fusion de ces deux formes, syndicat et roopérative, présenterait un très grand danger. J'ai eu l'honneur, en 188'. d'être l'un des fondateurs du premier syndicat agricole de France, celui des Agriculteurs de l'Est, qui compte aujourd'hui plus de 10.000 membres. Au début, nous avons voulu faire de la coopération, et nous avons reconnu qu il ftait dangereux de faire participer ì une couvre pour ainsi dire commerciale tous nos syndiqués sans exception. Nous leur laissons maintenant la liberté d'user ou de ne pas user de l'organe à caractère commerrial créé à còté du syndicat. Ils ont leur indépendance complète. llais c'est un défant de responsabilité pour ceux qui n'en usent pas. C'est pourquoi nous avons voulu bien séparer la gestion commerciale, qui peut quelquefois entrainer des aléas et mener au-delà de la pensée des fondateurs. Nous avons voulu que le rôle moral de notre syndicat fut sauvegardé et restât intact au-dessus dı toute idée d'ordre matériel et commercial. C'est une sage façon de procéder.

En ne liant pas les deux questions, en disant que la forme syndicale pt la forme coopérative sont de nature à rendre les plus grands services au monde forestier. nous aurons accompli notre véritable devoir de Congrès international, qui consiste surtout à appeler l'attention du monde forestier tout entier sur la nécessité de l'action indépendante de chacun des deux organismes dont nous venons de parler.

13. Gt yot. - Si j’ai tout à theure demandé à répondre à Ml. Margaine, r'était pour présenter, sous une forme moins élégante certainement, les mêmes observations que $\mathbf{~ I}$. de Larnage.

lous me permettrez done de dire, Monsieur le Rapporteur, que le ròle des syndicats forestiers n'est pas nul ou terminé. Je crois au contraire, comme l'a dit si éloquemment II. de Larnage, que nous ne faisons qu'entrer dans cette voie, en matière forestière, et qu'il importu d'une façon extrêmement urgente de comstituer et de grouper ces cellules initiales dont il rient de parler.

Lorsque nous aurons couvert le territoire français d'un réseau de syndicats forestiers, nous aurons donnć conseience de leurs droits aux propriétaires de forêts, petits et grands, et nous leur aurons procuré un moyen de revendiquer, devant les Ponvoirs publies, ce qu'ils croient nécessaire à leurs intérêts.

II. Nargaine me permetira de lui thire qu'il rabaisse un peu trop le ròle des syndicats forestiers, dans son rapport. Il est tout à fait nécessaire, au contraire, de constituer ces syndicats. Les renseignements de II. Margaine lui ont été foumis par des personnes insuffisamment renseignées. Il croit que nos syndicats forestiers sont composés d'un petit nombre de personnes. Nous groupons au contraire un nombre très respectable déjà de petits propriétaires et, pour ma part, jaai déja avere moi, dans le syndicat des propriétaires forestiers de la région lorraine, $11 n$ petit bataillon qui eommence à empter : nous sommes en effet plusieurs runtaines, re qui n'est pas mal, n'est-ce pas? 
M. DE Larvage. - Individuellement, chacun de nos syndicats est au moins aussi nombreux que la Société de Franche-Comté dont je puis parler, puisque j'en suis membre.

M. Guyot. - Nous débutons, il faut nous laisser nous développer. Quant à dire que c'est seulement parce qu'ils ont eu conscience de leut infériorité, de leur inutilité, pour ainsi dire, que les syndicats forestiers se sont groupés au sein des Comités des Forêts, cela est exagéré, mais les deux genres d'associations n'en sont pas moins nécessaires. Il faut d'abord un groupement local et, au-dessus des groupements locaux, un organe qui les représente tous et qui est le Comité des Forêts.

Je crois que l'on ne doit pas repousser la forme syndicale, qui peut avoir ses avantages et qui, même au point de vue forestier, peut être utilisée avec profit. Il faut, autant que possible, en maintenir l'application et constituer des syndicats, qui ne font pas double emploi, j'en suis certain, avec le Comité des Forêts. (Applandissements.)

M. Margane. - Je me suis mal exprimé, et, peut-être mes paroles ont-elles en effet dépassé ma pensée. Je ne prétends pas que les syndicats $n^{\prime}$ ont pas d'action, au contraire. Je crois avoir dit, dans mon rapport que toujours la phase syndicale a précédé la phase coopérative. Je voulais simplement indiquer que lorsque le syndicat est formé, lorsqu'il a su grouper le monde économique, il doit créer une coopérative, sans quoi il n'a pas de force. Le syndicat est la forme primitive du groupement économique mutualiste : il n'en est pas l'épanouissement définitif et final.

J'ai dit que le Comité des Forêts était une institution utile, mais j'ai ajouté qu'il ne puiserait sa force que dans la constitution des coopératives qui s'y affilieraient.

Un peu plus loin, j'ai dit que les coopératives étaient les filiales et les annexes de nos syndicats. Mais je crois devoir dire aux syndicalistes : si vous vous en tenez à votre organisation, vous mourrez; vous n'avez qu'un moyen de prospérer, e'est la coopération.

Il n'est pas besoin de changer la législation d'aucun État pour fonder des syndicats; toutes les législations sont adaptées aux syndicats. Mais, pour la coopération forestière, nous avons besoin qu'on change les différentes législations et qu'on les adapte aux besoms de nos coopératives.

Ce n'est pas jeter le discrédit sur les syndicats que de leur dire : "Lorsque vous voudrez aller plus loin, vous ne pourrez pas le faire, parce que la loi telle qu'elle est ne vous le permettra pas. lous ne pourrez pas eréer de caisses de erédit; vous ne pourrez pas profiter du crédit agricole, parce que la loi ne vous permettra pas de profiter des avances de l'État ».

Demander l'arlaptation de la législation à de nouveaux besoins, ce n'est nullement rabaisser ce qui a été fait par les fondateurs des syndicats. 
M. Descombes. - J'ai écouté avec beaucoup d'attention le remarquable rapport de M. Margaine. Je suis absolument de son avis sur la nécessité de développer les coopératives forestières et d'aider leur fonctionnement par une amélioration de la législation en leur faveur.

Les syndicats de propriétaires forestiers doivent évidemment bénéficier des encouragements à accorder sous forme de crédit forestier, mais ces institutions ne paraissent pas répondre à tous les besoins.

Il y a des cas où l'intervention de ces groupements serait inefficace. Les communes de montagne, par exemple, qui ont à réparer des dégradations, à améliorer leurs pâturages, à faire du reboisement, ont tout d'abord la ressource des travaux facultatifs, pour lesquels il faut généralement apporter la moitié des fonds nécessaires. Elles ont une autre ressource, dont elles usent quelquefois, et qui consiste à laisser le terrain se dégrader jusqu'à la fin pour que l'État l'achète et le répare à ses frais, mais alor's c'est la désertion de la montagne. Il y a donc intérêt à ce que les communes montagnardes pauvres puissent faire la moitié de la dépense pour restaurer leurs territoires par des travaux faculicatifs.

Le banquier ordinaire des communes, e'est actuellement le Crédit Foncier. Or, il esi forcé, par la loi, d'exiger des communes le paiement d'un intérêt dès la première année de l'emprunt. Une commune pauvre de montagne a besoin de 10.000 francs; elle les emprunte au Crédit Foncier à $3 \mathrm{fr}$. 60 ou $3 \mathrm{fr} .85 \%$. Si son centime est de 10 francs seulement, il lui iaut s'imposer de 45 centimes extraordinaires; si son centime n'est que de 5 francs, il lui faut voter 90 centimes extraordinaires.

Cela est impossible pour des communes paurres. Elles ne peuvent restaurer leurs terrains qui arrivent à la dégradation complète, ce qui amène l'expatriation des habitants, leur transport en Algérie ou ailleurs, la dépopulation.

Ni la mutualité, ni le syndicat, ni la coopérative ne peuvent résoudre de pareils cas. Il faut autre chose. 11 suffirait d'élargir les méthodes de prêt du Crédit Foncier, et d'autoriser par une loi cet établissement à faire des prêts à intérêt différé. Ce mode de prêt pourrait être également autorisé au profit des syndicats et des coopératives, en fixant, bien entendu, ceriaines garanties.

C'est une question compliquée; il y a plusieurs années que l'Association centrale pour l'aménagement des montagnes s'en occupe. Le Crédit Foncier, le ministère des Finances et celui de l'Agriculture n'ont pas encore réussi à se mettre d'aceord sur ce point. C'est un mode de crédit qu'il serait bon de développer.

La récente déclaration ministérielle du 24 janvier 1912 parlait du crédit au petit et au moyen commerce, à la petite et à la moyenne industrie, du crédit ouvrier, du crédit maritime : il ne faudrait pas oublier le crédit forestier.

Ce crédit forestier peut être réalisé sous plusieurs formes : les coopératives et les syndicats pourraient profiter d'une partie du 
fonds de 110.000 .000 , bien que les agriculteurs à rícolte annuelle n'entendent nullement en laisser distraire la plus petite part pour les forestiers. D'ailleurs la loi, qui n'en permet que difficilement l'emploi pour l'agriculture, le rend impossible pour la sylviculture, parce que les délais de remboursement sont beaucoup trop courts.

Il faudrait done réformer la loi du crédit agricole. Il faudrait chercher aussi à utiliser les prêts du Crédit Foncier, qui a été fondé spécialement en vue des prêts à long terme, à l'aide de l'émission autorisée par l'État d'obligations à lots. Cette grande institution doit être adaptée aux nécessités forestières. Il sera d'ailleurs nécessaire de prévoir des crédits considérables, car la solution du problème forestier peut nécessiter plus d'un milliard.

M. le Présinent. - Je comprends très bien re que vous proposez...

M. Desconbes. - Nous pourrions émettre le vau que l'on favorise les syndicats, les coopératives, et les institutions de erédit foncier.

M. Scott Elliot. - Püdonnez-moi, Messieur's, si je m'exprime difficilement ; c'est la première fois qu'il m'arrive de parler français en public (Parlez! Parlez!)

J'ai assumé la grande responsabilité de fonder en Erosse une association de propriétaires de bois en vue de tirer un meilleur parti de leur's propriétés forestières. L'expérience était très difficile, car une association de propriétaires n'est pas une association de commercants. Nous avons eu beaucoup de mal à surmonter les difficultés, mais les bénéfices que nous avons tirés de notre association ont été extraordinaires. Maintenant, tous les propriétaires affiliés peuvent acheter au meilleur marché possible tout ce qui leur est utile pour la forêt, non seulement les semences et les plants, comme le disait M. Margaine, dans sun rapport, mais encore les outils. Nais la plus grande utilité de cette société consiste dans la vente des bois et des produits secondaires. Sur tous les lieux de vente de bois, la société est représentée.

Une société de ce genre pourrait être, je pense, en France, de la plus grande utilité. Je ne connais pas les conditions économiques en France, mais c'est sans doute Loujours la même chose : un petil propriétaire qui reut vendre ou acheter, est toujours dans une situation moins bonne qu'un grand propriétaire (murques d'approbation). La vente, par une société de ce genre, avantage beaucoup les petits propriétaires. Les grands propriétaires aux-mêmes y trouvent aussi leur profit. En Écosse, il y a des produits secondaires, comme les petites branclies de bouleau, par exemple, qu'on a laissé perdre jusqu'à présent. Mlaintenant, il y a un assez grand marché pour ce produit dans les grandes villes. On n'en savait rien auparavant dans notre région,

En Écosse, je suis d'avis qu'il est meilleur dans cette industrie de ne pas aller à l'État du tout, d'avoir confiane dans les soeiétés con- 
duites par les propriétaires eux-mêmes, et de ne rien demander du tout à l'État (Très bien! très bien! et applaudissements).

11. Le Président. - Nous remercions M. Scott Elliot de sa très intéressante communication. C'est une contribution très instructive à l'étude de la coopération, puisqu'en définitive, l'association dont il vient de nous signaler l'existence, est une forme des coopératives dont on vient de parler.

11. De Lariage. - M. Descombes a proposé un amendement qui me parait très dangereux. La Loi de 188 ' me parait suffisamment élastique, de même que la loi sur les coopératives en refonte devant le Parlement, pour lui donner tout apaisement et se plier aux besoins de l'organisation très spéciale qu'il demande.

Je propose de nous en tenir à la formule qui a été proposée tout à l'heure, mais, auparavant, M. Margaine me permettra de lui iaire une dernière objection : je voudrais qu'il consentît à modifier deux phrases de son très beau rapport.

11 a représenté les syndicats comme une arme de combat. Le syndieat, a-t-il dit, prend une allure de combat à grands cris... La foule, dans l'esprit de laquelle Srvorcat éveille idée de bataille. Nos syndicats forestiers français n'ont pas pu échapper à cette destinée: ils luttent contre le fisc, contre le parlement, contre d'autres syndicats..."

Permettez-moi, Monsieur Mlargaine, de vous dire que nous sommes avant tout des facteurs de paix sociale (Très bien! Très bien!) Nous sommes avant tout les défenseurs de gens dont les intérêts ne sont pas nécessairement opposés aux nôtres, puisque ce sont pour nous des collaborateurs indispensables (Applaudissements).

Je voudrais donc voir disparaitre du rapport, avant son adoption par le Congrès, cette phrase où M. Mlargaine a certainement vu sa plume courir plus vite que son esprit et devancer son cocur.

Je demande en outre à nos collègues de rester sur le terrain des généralités, mais d'insérer clans le texte du voeu ce mot de syndicat qui nous est cher à beaucoup d'entre nous.

On nous disait tout à l'heure qu'en Ecosse, a vec beaucoup d'intelligence et d'activité, les propriétaires se réunissaient et faisaient, dès le début de leur syndicalisme, de la coopération sans le savoir. En somme, ils ont débuté comme nous tous, syndicats marchant vers la coopération. Nous en avons fait sous une forme légale, puisque la Loi de 1884 nous y autorisait, mais nous en avons fait à côté, et cela est inévitable, indispensable, et c'est même toléré par la loi. II ne faudrait pas qu'on puisse croire qu'en achetant des outils, des plantes, des semences, nous allons contre la loi. Du tout, nous allons vers la coopération jusqu'au moment où nous devenons coopérative de vente; alors, l'organisation commerciale nous est indispensable.

Pour me résumer, je demande de bien vouloir formuler ainsi le voril : 
"... Préconise la formation de syndicats et de coopératives... ". Cette simple adjonction donnerait satisfaction aux désirs des syndicalistes.

M. Thivel. - Voulez-vous me permettre une simple observation pour montrer le ròle économique des syndicats?

Je représente le Syndicat du Centre. Il est déjà ancien ; c'est surtout un groupement de gros propriétaires. Nous avons résolu la question économique pour les ventes en commun où nous avons obtenu des résultats merveilleux. Nous avons vendu nos coupes à des marchands de bois à des prix successivement supérieurs de 10, 20 et $25 \%$ aux estimations des propriétaires. Le syndicat peut done, dans ces conditions, avoir un rôle économique important.

11 peut aussi jouer un rôle très intéressant vis-à-ris des syndicats ouvriers. Dans le Centre, les syndicats ouvriers se sont dressés contre nous, propriétaires forestiers. Nous avons été obligés de mettre l'ordre dans nos coupes, certainement contre notre gré.

Mais nous avons obtenu des marchands de bois qu'ils acceptent des prix très rémunérateurs pour l'ourrier, et il leur est interdit, sous peine d'amende, de payer aux ouvriers des salaires inférieurs à ceux que nous avons fixés. Le marchand de bois ne pourrait pas payer un ouvrier au-dessous du tarif, même si l'ouvrier le demandait.

Nous avons apaisé ainsi un immense territoire, car maintenant les ouvriers reconnaissent notre justice et sont les premiers à venir à nous. Je ne dis pas que cela n'a pas désorganisé leurs syndicats affiliés à l'organisation que vous savez, mais les bons syndicats sont restés, parce qu'ils ont su comprendre ce que nous avons fait. (Applaudissements.)

De petits propriétaires n'auraient peut-être pas pu agir ainsi. II n'en est pas moins vrai que, dans l'affaire, le syndicat a joué un rôle économique. Rien ne nous empêchera de créer à côté une coopérative, et surtout cette caisse de crédit agricole qui nous permettrait de différer nos coupes pour obtenir un plus grand rendement. Mais cela, c'est en dehors du syndicat, et c'est à ses chefs de surveiller cette affaire.

M. Le Président. - Nous vous remercions de cette contribution à l'étude de l'action syndicale. Yous nous avez beaucoup intéressés par la constatation des bons effets de cette action.

$11 \mathrm{y}$ a quelque chose à retenir des observations de 11 . Descombes sur la question du crédit forestier. Le Crédit Foncier pent avoir à jouer son rôle. On pourrait remplacer les mots "cuisses de crédit mutuel forestier ", par ceux-ci : "organisation du crédit forestier" (Très bien! Très bien!)

M. Giyot. - Un de nos confrères, M. Gazin, voudrait voir mentionner les sociétés civiles de propriétaires forestiers, car c'est une forme de coopréation.

M. Margane. - Je les considère comme des coopératives. 
11. Le Présidext. - Il n'y a pas de doute sur ce point. Mais il faut rester dans les généralités.

M. Guyot. - Le Congrès est bien d'avis de faire rentrer dans les coopératives de propriétaires les sociétés civiles que préconise M. Gazin.

M. Cazix. - Nous avons créé dans le Jura une société pour l'exploitation des forêts. Nous payons l'impôt foncier, le droit de main-morte, et aussi l'impòt sur le revenu de nos coupes, sur le dividende de nos actions. Cela fait par conséquent double emploi.

M. Le Présidext. - Le veu vous donne toute satisfaction, puisqu'il parle pour les coopératives forestières, des exemptions d'impôt graduées.

M. Margaixe. - La Société du Contrôle, à laquelle fait allusion M. Gazin, a été classée dans le rapport parmi les coopératives.

M. Banchereau. - Vous l'avez citée avee une restriction.

II. Margarxe. - Parce que ses membres n'ont pas mis en commun des terrains possédés par eux, mais ont an contraire mis leur argent en commun pour acheter un bois. J'ai dit que cela arait une allure de suciété capitaliste et que ce n'était pas tout à fait de la coopération.

M. Baxchereat. - Il serait bon de citer ce genre de sociétés dans le voeu.

M. DE LARNAGE. - II n'y a pas de donte au point de rue légal.

M. Le Président. - C'est toujours là me ceuvre commme, une coopération. L'œurre commune existe en l'espece; il n'y a pas d'inquiétude à avoir.

M. Gazix. - Dans tous les cas, il est injuste de payer l'impòt foncier, et de payer encore l'impòt sur le revenu de la coupe.

1I. Le Présinext. - Les observations insérées au procès-verbal serviraient, le cas échéant, i éclairer la portée du vote.

M. Margane. - Je citerai encore l'(Eurre forestière du Limousin, qui avait demandé à laire ume communication, ce que nous navons pu lui accorder, à cause du manque de temps. Cette société rentre dans cette catégorie de groupements en vue de l'achat en commun des bois, que nous avons classés dans les coopératives.

Nous avons tenu à dire: "Ce sont des coopératives ", parce que, pour certains auteurs, les roopératives forestières nesont que lessociétés qui metlent en commun des biens fonds.

M. LE Présidext. - Je donne une nouvelle lecture du vau, amendé à la suite de la discussion qui vient de se produire : 
Le Congrès forestier international :

"Rendant justice aux efforts faits par les syndicalistes de tous les pays, les engage à continupr à développer leur action syndicale, "Préconise, d'autre part, la formation de coopératives de propriétés, complètes, à circonscription restreintes et unies par des fédérations,

"Souhaite que les associations agricoles aident de leur expérience et de leur pouvoir à la formation de coopératives forestières et de caisses de crédit forestier et émet le vou:

"Que les législutions des différents pays soient adaptées à la formation de syndicats forestiers et de coopératives forestières, et que les Etats favorisent celles-ci par des subventions, par des exemptions d'impôts graduées, par l'aide de leurs agents forestiers et par l'organisution dn crédit forestier."

Le roeu, mis aux voix, est adopté.

M. Bouvet remplace M. Vivier au fauteuil de la présidence.

M. Le Présidext. - La parole est à M. Vivier pour la lecture de son rapport sur l'Utilité de L'ACQUiSITION PAR L'ÉTAT, LES CONMUNES OU AUTRES COLlEćtivités PUBLIQUES, LES ÉtABLISSEMEATS OU ASSOClatioxs D'Utilité PUblique, DE Forêts ot terraiNs a reboiser. - Mesures législatives, admisistratives et fixaxcières a PRENDRE POUR FACILITER CETTE ACRIISITION.

M. Vivier. - La propriété forestière présente, au point de vue économique, ce caractère fondamental que, sur unn point donné, elle ne peut jamais fournir un revenu annuel. Tandis qu'en agriculture, la règle générale est de tirer chaque année un produit du sol, et que ce principe comporte de moins en moins d'exception, par suite de la restriction progressive des jachères, une parcelle boisée, quelle qu'elle soit, n'est exploitable qu'un certain nombre d'années après l'époque à laquelle son peuplement a été créé ou régénéré. Le temps pendant lequel le propriétaire devra laisser le peuplement sur pied sera très variable, il pourra être réduit à sept ou huit ans comme dans certains taillis de châtaigniers, ou dépasser largement le siècle, notamment pour les futaies de chêne: en tout cas, le revenu sera périodique et non annuel. Ce n'est pas que le sol, avec l'aide de l'atmosphère ne "produise » chaque année, pour le bois comme pour toute autre culture; mais, pour être réalisables, ces produits doivent s'accumuler sur place pendant une période plus ou moins longue : c'est ce que l'on définit en disant que le sol forestier est un capital qui fonctionne à intérêts composés.

Sans doute, quand l'immeuble en nature de bois offre une étendue suffisante, le propriétaire peut arriver à obten ir un revenu annuel, si on suppose que son bien comprend la série des âges depuis le semis ou le recru jusqu'au terme d'exploitabilité; mais le principe que nous venons de poser n'en reste pas moins vrai pour chaque surface occupée par des 
sujets de même âge (1), et le résultat n'a pu être atteint que par une organisation des exploitations, adaptée spécialement à la propriété en cause, telle qu'elle était constituée au moment où ce règlement a été fait, c'est-àdire par un aménagement.

De ces considérations, il ressort déjà que le bois s'accommode mal de la propriété privée, qu'il s'agisse soit du reboisement d'un terrain nu, soit de la conservation et de l'exploitation régulière et continue d'une forêt existante. Un particulier hésite à engager des fonds importants dans une entreprise de reboisement, car, dans la plupart des cas, il sait qu'ilne vivra pas assez longtemps pour recueillir, par la coupe principale, le bénéfice essentiel de l'opé ation. S'il possède une forêt existante, il sera souvent incité, par les besoins de la vie, à réaliser ses bois dès qu'ils auront une valeur marchande appréciable; on ne peut lui demander d'ailleurs de leur laisser atteindre tout le développement nécessaire pour donner les produits les plus avantageux à la société. Mais surtout chaque décès de propriétaire risque de provoquer une véritable crise dans l'existence de la forêt apartenant aux particuliers.

En effet, s'il y a plusieurs héritiers, il y aura fréquemment partage ; et cette opération, qui exigera une expertise longue et coûteuse, entraînera, suivant l'importance du bois à partager, ou un morcellement excessif rendant l'exploitation difficile et désavantageuse et conduisant à l'abandon et à la ruine, ou (à moins d'une conformation exceptionnellement favorable du massif et de ses divisions) un bouleversement complet de l'aménagement. Or, ces troubles, s'ils se renouvellent à des intervalles un peu rapprochés, sont évidemment incompatibles avec une bonne gestion. Non seulement ils empêchent toute amélioration, mais ils sont l'occasion d'abus de jouissance et de réalisations prématurées. Pour échapper au partage, les héritiers vendront; mais sur ce terrain, en raison notamment du jeu bien connu des droits d'enregistrement (2), les amateurs de forêts sont en état d'infériorité par rapport aux spéculateurs marchands de bois, qui pourront bien être empêchés par la loi sur les défrichements de transformer la nature de la propriété, mais qui, par l'enlèvement de tous les bois de quelque valeur, compromettront pour longtemps l'avenir.

Sous l'ancien régime où, du reste, la proportion de forêts appartenant à des propriétaires impérissables (roi, communes, hospices, communautés religieuses) était considérable. la situation était sensiblement différente parce que beaucoup de grands massifs particuliers se transmettaient par droit d'aînesse; mais notre législation moderne sur les héritages entraîne, au point de vue forestier, les inconvénients que nous venons de signaler, et il semble que de plus en plus les bois privés se trouvent dans des condition désavantageuses, car leurs propriétaires sont évidemment portés à traiter leurs forêts suivant le mode qui exigera la moindre accumulation de capital sur pied et permettra les réalisations les plus fréquentes, c'est-àdire pour une grande partie de la France suivant le régime du taillis à révolution relativement courte. Or, à l'heure actuelle, par suite de la

(1) On peut toujours, au moins par la pensée, décomposer un bois en fractions de même âge, certaines fractions pouvant être composées de parcelles très petites disséminées dans toutle massif, comme dans les taillis sous futaie et les futaies jardinées.

(2) On sait que si une forêt est vendue fonds et superficie, le tout paie un droit de mutation de $7 \%$ : si on vend, en même temps que le sol, une coupe comprenant tout ce qu'il y a de réalisable dans la superficie, la valeur de celle-ci devenue abien meuble „ne rapporte qu'une taxe de $2 \frac{1 / 2}{2}$, le fonds seul supportant les $7 \%$. 
dépréciation croissante des bois de feu et des écorees, la valeur de ees taillis baisse, leur utilité disparaît; ce sont de plus en plus des bois d'œuvre dont la consommation a besoin, et le développement de la production de ces bois suppose, dans les taillis, une augmentation et un vieillissement des réserves ou une élévation de la révolution, ou même une conversion en futaie, e'est-à-dire, sous une forme ou sous une autre, des économies considérables qu'il est bien difficile d'attendre de particuliers. Ces améliorations, comme aussi le traitement de futaies existantes ou la mise en valeur de terrains nus par le reboisement, demandent, d'ailleurs un esprit de suite, et un sens de la conservation et de l'économie incompatibles avec les fréquentes mutations des propriétés privées et même, dans bien des cas, avec les vicissitudes d'une existence humaine.

Pour parer à ces inconvénients, de très bons esprits ont songé à la formation de sociétés forestières constituées par des propriétaires de bois qui réuniraient leurs immeubles de manière à en former une forêt soumise à un aménagement et à une gestion uniques. Les droits originaires, étant transformés en des parts de société, pourraient faire l'objet de ventes ou de successions san que le sort de la forêt fût troublé ou compromis en quelque manière.

L'idée est assurément séduisante, mais, quoique lancée il y a plus de dix ans, elle ne semble pas avoir fait pratiquement de progrès notables : au fond, elle revient à une véritable aliénation par les propriétaires de leurs bois au profit de la société, et sa généralisation parait répugner au caractère du propriétaire foncier français; eelui-ci quand il voudra se défaire de son bous, le vendra pour un prix en argent qu'il utilisera à son gré ; autrement, il préfèrera garder son immeuble pour lui que "le mettre en actions ". Ce n'est pas à dire que dans certaines régions, et dans des cas déterminés, le système ne puiss ’ trouver son application et rendre de réels services ; on ne saurait, croyons-nous, y voir le remède à la disparition et à la dégradation progressive des bois particuliers.

A l'égard du reboisement, on ne peut faire appel aux sociétés privées pour les travaux qui ont en vue l'intérêt public (notamment la restauration et conservation des terrains en montagne) et présentent le plus sonvent un caractère onéreux; quant aux opérations qui ont principalement pour but une mise en valeur de terrains, elles constituent une spéculation ì trop long terme et demandent une confiance trop grande dans les chefs de l'entreprise pour qu'il soit facile d'organiser des sociétés en vue de leur exécution. Ces sociétés se formeront d'autant moins aisément qu'en tout état de cause les bénéfices du reboisement sont très limités, et qu'ici l'appât du gain ne paraîtrait pas suffisant pour engager les capitalistes à passer sur les retards de réalisation et les aléas de gestion. On doit souhaiter la formation et le succès de sociétés de ce genre, mais il est permis de penser que leur rôle sera très restreint.

On peut donc conclure de cet exposé qu'à l'inverse de ce qui se passe pour les domaines agricoles, l'avenir de la propriété boisée et du reboisement n'est pas assuré entre les mains des particuliers et que, par suite, c'est entre les mains des propriétaires impérissables que les bois sont le mieux placés. Il va sans dire que, dans cette étude, nous arons surtout en vue la France; mais, avec des différences de degré suivant le caractère, l'organisation sociale ou le régime foncier de chaque nation, et léserve faite des périodes de mise en exploitation de grands massifs dans les pays 
neufs, la conclusion peut trouver, croyons-nous, son application générale dans le monde entier.

En fait, sur les 9.850 .000 hectares de forêts de France, les propriétaires impérissables ne possèdent à l'heure actuelle que 3.400.000 hectares, le surplus (environ 6 millions $1 / 2$ ) appartenant à des particuliers. D'autre part, sans vouloir ramener le sol français à l'état où il était au temps de la conquête romaine, nous considérons comme acquis (la démonstration serait en dehors de notre sujet et nous entrainerait beaucoup trop loin) que le taux de boisement de notre pays ( $25 \%$ environ) est insuffisant, et que, tant au point de vue des avantages immatériels (maintien des terres sur les pentes, régularisation du climat et du régime des eaux, salubrité, etc.), qu'au point de vue des besoins de la consommation en produits ligneux, il reste à exécuter un important programme de reboisement portant, bien entendu, sur des terres incultes ou convenant mieux, pour des motifs divers, à la culture forestière qu'à toute autre espèce de culture.

Dans ees conditions, il est conforme à l'intérêt général que les propriétaires impérissables, c'est-à-dire les collectivités publiques, puissent acquérir des forêts existantes et des terrains à reboiser. Nous allons examiner maintenant les différentes eatégories de collectivités et le rôle qui parait revenir à chacune d'elles dans ces acquisitions.

La première et la plus importante de ces personnes morales est l'État: ce dernier est évidemment seul qualifié pour prendre la charge soit des forêts qui jouent un rôle de pure protection, sans fournir de revenu net appréciable, soit des entreprises de reboisement effectuées dans un intérêt principalement "immatériel ", et où le bénéfice futur est absolument aléatoire ou, en, tout cas, hors de proportion avec les dépenses engagées. En outre, l'État, en raison des ressourees considérables de son budget général de recettes, est actuellement le seul propriétaire qui ne soit pas incité à réaliser un peuplement, quand il a déjà une certaine valeur marehande, sans avoir atteint cependant l'âge où il peut donner les produits les plus utiles à la consommation. C'est donc lui qui est le plus qualifié pour élever les vieilles futaies (notamment celles oì le chêne est l'essence dominante), ou même des taillis sous futaie très riches en réserve. Ft, comme les bois d'œuvre de forte dimension restent les plus utiles et les plus reclicrchés, l'étendue actuelle des forêts domaniales productives (environ 950.000 heetares) est éridemment insuffisante et doit être augmentée, alors surtout que l'épuisement de beaucoup de forêts étrangères peut rendre dans l'avenir les importations moins abondantes et plus coúteuses. Il serait d'ailleurs excessif, à notre avis, de tendre à fajre de l'État l'unique propriétaire de forêts, on aboutirait ainsi, en effet, à la destruction de toute initiative et de toute activité en dehors de celles du pouvoir central, et ce système ne paraît pas moins funeste en matière forestière qu'en d'autres matières.

Les communes et les établissements publies proprement dits (principalement les hospices) possèdent déjà un patrimoine forestier important (2.200.000 hectares) qui est à conserver aussi bien dans l'intérêt des propriétaires que dans l'intérêt général, car il donne, sans diffieulté de gestion pour les municipalités ou les commissions administratives (lorsque conformément à la règle il est soumis au régine forestier), un revenu généralement sûr qui, moyennant adaptation du traitement à l'évolution économique, est susceptible d'augmenter de plus en plus dans l'avenir. Les communes doivent également être ineitées à reboiser une 
grande partie de leurs terrains incultes et de leurs vacants ce qui n'est pas inconciliable avec le maintien et l'améliorat on de leur domaine pastoral); d'autre part, des legs de forêts sont consentis parfois en leur faveur ou au profit des établissements publics, et ce fait, qui depuis trente ans a été relativement. fréquent, est, évidemment favorable aux intérêts forestiers. Mais d'une manière générale, nous ne croyons pas qu'on puisse beaucoup compter sur ces catégories de propriétaires pour des acquisitions à titre onéreux de forêts ou de terrains à reboiser. Les communes et étałlissements publics ne font guère d'économies; et, surtout pour les premières, les ressources disponibles trouveront, presque tonjours, un emploi d'un intérêt plus urgent qu'un achat de forêt, le champ des améliorations réalisables dans une commune pour les adductions d'eau, la voirie, les écoles, les égouts, les promenades, etc., étant presque indéfini. Dans certains cas, cependant, une ville pourra réaliser une opération utile à tous points de vue en achetant un bois situé à sa portée, parce que ce dernier convenablement aménagé constituera, en même temps qu'un bien productif de revenu, une sorte de parc agréable et salubre pour les habitants. En outre, comme il est reconnu que la propriété agricole convient généralement mal aux collectivités, il est à souhaiter que peu à peu les communes et établissements publics échangent les domaines qu'ils possèdent contre des bois, soit directement, soit par le moyen d'une vente et d'un achat. Nous allons même jusqu'à penser que, lorsqu'une occasion avantageuse d'acquisition de forêt se présente, les communes et établissements publics qui détiennent des valeurs mobilières importantes feraient une bonne opération en vendant une partie de celles-ci pour acheter l'immeuble boisé (1): outre que les titres, même les meilleurs, n'offrent jamais pour un propriétaire impérissable une sécurité aussi grande qu'un fonds de terre, le revenu qu'ils donnent garde une valeur nominale qui, même si elle n'est pas réduite par suite de conversions ou de remboursements suivis de remplois, subit avec le temps la dépréciation correspondant à la diminution de puissance d'achat du numéraire, tandis qu'un bien donnant des produits en nature comme le bois, n'offre pas cet inconvénient. On objectera sans doute que certaines communes propriétaires de taillis à charbonnette et à écorce ont subi au $\mathrm{XIX}^{\mathrm{e}}$ siècle des pertes considérables de revenu; mais ces cas sont heureusement en petit nombre; du reste, le plus souvent, il est possible, dans une période de temps relativement courte pour un propriétaire impérissable, de revenir à un bon rendement en changeant le mode de traitement de la forêt.

Les départements ne semblent appelés à jouer qu'un rôle accessoire au point de vue forestier. Actuellement l'étendue des forêts départementales est presque insignifiante; et, comme les Conseils généraux se trouvent dans une situation très analogue à celle des Conseils municipaux, en ce qui concerne l'absorption des disponibilités budgétaires par des dépenses d'un intérêt urgent, ils n'auront guère l'occasion de se porter acquéreurs de forêts et encore moins de terrains à reboiser. Il pourra y avoir cependant certaines exceptions, dans des départements riches, pour des forêts intéressant, à des titres divers, un assez grand nombre de communes.

Par contre, il est toute une catégorie de collectivités que leur nature même doit amener à devenir propriétaires d'une partie importante du

(1) Grâce à la soumission au régime forestier, les bois acquis peuven t se trouver très éloignés du siège de la commune ou de l'établissement propriétaire. 
domaine forestier de la France; nous voulons parler de toutes ces caisses d'épargne, caisses de retraites, sociétés de secours mutuels, etc., que leur fonctionnement oblige à conserver et faire fructifier des capitaux déposés ou à capitaliser des versements périodiques. Jusqu'à ces derniers temps la tendance des pouvoirs publics a été d'imposer à toutes ces associations le placement de leurs fonds en valeurs mobilières de premier ordre; et, à l'heure actuelle, les exceptions autorisées sont encore bien restreintes et visent surtout des propriétés bâties. Ce système, étant donné l'extension de plus en plus grande des groupements de capitaux dont nous parlons, n'est pas sans offrir quelques dangers en accumulant des sommes énormes en placements purement mobiliers, spécialement en rentes sur l'État français: si, à un moment donné, se produisaient de très graves complications extérieures ou intérieures, on comprend quelle effroyable crise en résulterait pour l'avoir de toutes ces collectivités. D’autre part, la propriété boisée offre au moins autant de sécurité que l'immeuble bâti. Il serait donc aussi prudent, au point de vue général, qu'avantageux, au point de vue forestier, de dériver vers les achats de forêts ou de terrains à reboiser une certaine fraction de capitaux de ces sociétés, étant entendu qu'à l'égard des caisses d'épargne, le prélèvement ne porterait que sur la fortune personnelle de ces établissements. L'acquisition de forêts existantes conviendrait principalement aux sociétés qui ont à répartir annuellement des sommes à peu près équivalentes; l'achat de terrains nus et leur boisement constitueraient une excellente opération pour les groupements qui ont à capitaliser des versements pendant un assez grand nombre d'années pour servir plus tard, sous une forme ou sous urie autre, des allocations en argent aux ayants droit. La soumission au régime forestier des immeubles ainsi acquis supprimerait pour les propriétaires toutes les difficultés d'administration, en même temps qu'elle assurerait à la gestion les meilleures garanties d'intégrité et de compétence. Il semble que les grandes compagnies d'assurances qui possèdent actuellement tant de maisons pourraient également entrer dans la voie des acquisitions de forêts. Enfin, toutes les associations déclarées d'utilité publique, et, par là même, offrant généralement des garanties de long avenir, pourraient, avec les mêmes avantages que les établissements publics, devenir propriétaires de forêts, et employer de cette manière une portion de leur avoir qui est souvent considérable.

Même en admettant que chacune des collectivités en discussion n'employât ainsi qu'une faible part de ses capitaux, de manière à se garantir contre les effets de variations éventuelles dans le revenu des bois, une œuvre importante n'en serait pas moins susceptible d'être réalisée au point de vue de la conservation et de l'amélioration du domaine forestier du pays.

Il reste à examiner les mesures légales, administratives ou financières à prendre pour faciliter la réalisation des acquisitions dont les considérations exposées ei-dessus ont fait ressortir l'utilité. A notre avis, il serait excessif de recourir à des moyens coercitifs et, notamment, à l'expropriation : appliqué à toute une catégorie d'immeubles qui occupe plus de 6.000.000 d'hectares en France, ce procédé porterait une grave atteinte au principe de la propriété privée, sa mise en pratique risquerait d'être, suivant le cas, défavorable aux particuliers ou ruineuse pour les collectivités publiques. Nous ne sommes même pas partisan d'un droit de préemption pour l'Etat : outre qu'il pourrait donner lieu à des fraudes au détri- 
ment du Trésor, toute entrave qui pèserait sur la propriété boísée commencerait par déprécier celle-ci, de sorte que le résultat immédiat serait plutôt nuisible aux intérêts forestiers. Le passage des bois et forêts des mains des particuliers entre celles des propriétaires impérissables doit être, selon nous, une opération de très longue haleine, susceptible même de ne pas s'achever d'une manière absolue, ce n'est qu'à la condition de se réaliser peu à peu, suivant les occasions, que cette transmission pourra s'effectuer sans crise économique et sans dépenses excessives. La dégradation des forêts particulières étant, dans l'ensemble, lente et progressive, le remède semble pouvoir présenter les mêmes caractères, et c'est en excluant la contrainte légale que nous allons poursuirre notre étude.

En ce qui concerne les acquisitions par l'État, il est à remarquel' qu'actuellement l'administration forestière ne peut acheter, en dehors des régions de montagnes, des terrains nus ou boisés qu'en vue de l'amélioration des forêts domaniales proprement dites; et comme, d'autre part, il n'est prévu pour cet objet qu'un crédit insignifiant, l'État ne peut ainsi incorporer à son domaine que quelques parcelles enclavées dans ses massifs ou situées en bordure. Pour que l'Administration des Eaux et Forêts pût entrer dans la voie indiquée plus haut, il serait indispensable que chaque année elle disposât sur son budget d'une allocation assez importante (1.000.000 fr. par exemple) pour acquisition de forêts particulières, avec faculté de payer par annuités dans une période n'excédant pas dix ans. Une semblable mesure donnerait déjà, semble-t-il, d'excellents résultats. Elle serait cependant insuffisante lorsque l'occasion se présenterait pour l'État de se rendre propriétaire de certains grands massifs offrant un intérêt considérahle, mais d'une valeur trop élevée pour être facilement payés sur le crédit annuel dont l'ourerture vient d'être envisagée. Il serait nécessaire que les ministères de l'Agriculture et des Finances pûssent, en dehors des limites de ce crédit, conclure des contrats d'acquisition de forêts sous condition suspensive, lesdits contrats ne devant devenir défin it ifs que par un vote du Parlement qui accorderait, en même temps, une allocation spéciale pour le paiement. Cette a!location extraordinaire pourrait être couverte par des ressources extraordinaires: nous ne sommes pas partisan du système d'emprunt au Crédit Foncier qui a trou vé de distingués défenseurs. Le Trésor dispose, en effet, d'un crédit assez ample pour ne pas avoir besoin de recourir à l'intermédiaire d'une Société semi-privée. Au cas où le système d'emprunts directs amortissables (gagés au moins pour la plus grande part par les revenus des immeubles à acquérir) soulèverait de trop grandes objections de la part du Ministère des Finances, nous croyons qu'on pourrait résoudre la difficulté, soit en obtenant de la Caisse des Dépôts et Consignations une avance remboursable, soit en faisant réaliser l'opération, non plus directement par l'État, mais par la Caisse nationale des retraites dont l'encaisse a pris un si grand développement par l'application de la loi sur les retraites ouvrières et paysannes, et qui est habilitée à acquérir des bois ou des terrains à boiser par l'article 15 de la loi du 5 avril 1910. Nous ajouterons que, bien que destinée surtout à favoriser la régularisation du régime des eaux, la loi Fernand David, adoptéc par la Chambre des Députés le $1^{e_{r}}$ août 1910 et actuellement soumise au Sénat, aurait pour effet immédiat d'étendre l'importance des acquisitions de terrains à boiser par l'Etat.

Pour faciliter aux communes et établissements publics l'achat de 
forêts, une disposition législative pourrait supprimer ou tout au moins réduire, dans une forte proportion, les droits d'enregistrement à percevoir en pareil cas d'après le droit commun. Il est à souhaiter, d'autre part, que les décrets autorisant l'aceeptation de legs de forêts par les communes et établissements publics n'imposent la vente de ces immeubles que lorsque cette condition résultera de la volonté formelle du testateur. Enfin, des instructions pourront être utilement adressées aux Préfets par le Ministre de l'Intérieur pour les inviter à ne pas entraver sans motif grave, et même à encourager, avec le discernement voulu mais aussi avec un bienveillant intérêt, les Conseils municipaux et Commissions administratives qui roudraient vendre des valeurs mobilières ou des domaines agricoles pour acheter des bois dans des conditions avantageuses.

A l'égard des sociétés diverses, on ne peut que souhaiter le vote rapide de la loi Audiffred autorisant les caisses d'épargne à placer en forêts ou en terrains à boiser $1 / 10^{e}$ de leur fortune personnelle, complétant le $2^{\text {e }}$ paragraphe de l'article 11 de la loi du $1^{\text {er }}$ juillet 1901 par une clause qui autorise les sociétés déclarées d'utilité publique à acquérir des bois, forêts ou terrains à reboiser, et soumettant au régime forestier les immeubles de cette nature, lorsqu'ils appartiennent à des associations reconnues d'utilité publique ou à des sociétés de secours mutuels approuvées. L'article 20 de la loi du ler avril 1898 permet à ces dernières sociétés d'aequérir des immeubles (de toute nature) jusqu'à concurrence des $3 / 4$ de leur avoir ; au contraire, l'article 15 de la loi du 5 avril 1910 limite au $1 / 400$ la fraction de capital que les caisses de retraites auront le droit d'affecter à des achats de bois et de terrains à reboiser. Cette proportion est bien faible, il semble qu'elle pourrait sans inconvénient être portée immédiatement à $1 / 100$, en attendant que l'expérience permette d'apprécier si elle ne serait pas utilement susceptib]e d'une nouvelle augmentation.

En conséquence, nous avons l'honneur de soumettre à la Section d'économie et législation forestière du Congrès forestier les vœux suivants :

1. Que la Chambre des Députés adopte sans retard la loi Audifjred telle qu'elle a été volée par le Sénat;

II. Que le Sénat mette le plus tôt possible en discussion le projet de loi "Fernand David " portant modification de la loi du 5 avril 1S82;

III. Qu'à l'avenir un crédit soit inscrit chaque année an budgct des Eaux et Forêts pour acquisition, sur l'ensemble du territoire, de forêts payables par annuités;

IV. Ou'à l'égard des massifs d'une valeur trop grande pour être achetés à l'aide du crédit ci-dessus mentionné, les Ministères de l'Agriculture el des Finances soient antorisés à conclure des contrats d'acquisilion sous la condition suspensive de la ratification parlementaire, et qu'en cas d'insuffisance des disponibilités budgétaires, le paiement en soit assuré par un eimprunt amortissable, ou par une avance de fonds de la Caisse des Dépôts et Consignations;

Subsidiairement, qu'an cas où les raisons financières ne permettraient 
pas un de ces deux modes de réalisation des achats de grands massifs, que les Ministères de l'Agriculture et des Finances aient le droit de saisir des projets la Caisse des Dépôts et Consignations chargée de la gestion de la Caisse nationale de retraites, en vie de l'application de l'article 15 (\$ 4) de la loi du 5 avril 1910;

V. Que les droits de mutation à titre onéreux soient réduits en cas d'acquisition de forêts par des communes ou établissements publics, et même, s'il est possible, par les associations reconnues d'utilité publique: Caisses d'épargne, Caisses de retraites et Sociétés de secours mutuels approuvées;

VI. Que les décrets autorisant les communes ou établissements publics à accepter des legs de propriétés forestières n'imposent l'obligation de vendre ces immeubles qu'en cas de volonté formelle du testateur;

VII. Que le Ninistre de l'Intérieur invite les Préfets à favoriser les opérations qui consisteraient pour les communes et établissements publics à transformer, dans DES CONDITIONS AVANTAGEUSES, en placements forestiers, leurs valeurs mobilières et leurs domaines agricoles;

VIII. Que le paragraphe 4 de l'article 15 de la loi du 5 auril 1910 soit modifié par l'élévation à 1/100 de la portion de l'avoir que les Caisses de retraites pourront employer en achat de bois et de terrains à boiser.

Nous croyons devoir ajouter d'ailleurs que plusieurs des dispositions proposées ne pourront produire d'effet que si les Administrateurs ou gérants des collectivités habilitées à posséder des immeubles, prêtent un concours actif à leur application.

Le mouvement d'opinion que va produire le Congrès forestier international contribuera, il faut l'espérer, à amener ce résultat, car, dans la question qui nous a occupé comme dans bien d'autres, c'est le cas de répéter le vieil adage "quid leges sine moribus".

Le programme qui marait élé tracé, vous l'avez vu par la lecture de mon rapport, m’a obligé de m'éloigner un peu du caractère international de ce congrès.

Je n'avais, en effet, pas seulement été chargé d'étudier la question in ubstructo, mais je devais aussi rechercher les mesures administratives et financières à prendre pour faciliter les acquisitions de forêts par l'État ou autres collectivités publiques. Sur ce terrain, j'étais obligé dle rester à peu près exclusivement dans le domaine national. Du moment où il fallait entrer dans le détail des mesures administratives, législatives, je ne pouvais guère que me limiter à la France. Autrement, il aurait fallu étudier toutes les législations étrangères; je n'en avais pas le loisir. II y aurait d'ailleurs une certaine présomption, pour un Français, à proposer des mesures administratives et législatives aux pays étrangers. Cela me permet de m'excuser vis-à-vis de mes collègues étrangers de ce que mon étude a un raractère plus particulièrement national. En tout cas, la partie générale peut s'appliquer, je crois, à toutes les nations indistinctement.

La propriété forestière présente un caractère dont M. Arnould vous 
a entretenus hier, et auquel il faut toujours revenir, parce qu'il est fondamental : la forêt ne donne pas de récoltes annuelles, et il faut, à còté du capital lui-même, constituer un capital-bois.

En conséquence, un propriétaire, s'il veut obtenir un rendement annuel, est obligé d'aménager sa forêt, c'est-à-dire de l'organiser, au prix de certains sacrifices, pour qu'on puisse réaliser des coupes annuelles.

Un autre caractère très net, c'est que ce capital bois aura une valeur marchande appréciable longtemps avant qu'il ait atteint son maximum de valeur financière et surtout de valeur économique. C'est en somme une tentation perpétuelle pour le propriétaire.

De ces deux caractères essentiels, nous pouvons déjà déduire cette conclusion que la forêt ne convient pas tout à fait aux propriétés privées.

A chaque décès, la forêt est exposée aux partages, c'est-à-dire à la rupture de l'aménagement avec toutes ses conséquences, morcellement, etc. En cas de partage d'ailleurs, par suite du jeu des droits d'enregistrement dont nous parlait 11. Arnould, c'est le spéculateur qui se troure dans une situation privilégiée par rapport à l'exploitant, de sorte qu'il y a bien des chances pour que vente signifie déforestation...

Plus nous allons, plus les difficultés sont grandes pour la réalisation des forêts.

Les produits les plus facilement réalisables à court terme, les taillis ont de moins en moins de valeur. Les besoins de la vie augmentent, les pays deviennent de plus en plus riches, il faut produire et les propriétaires ne sont plus incités à reboiser, ear il faut un trop long temps pour aroir une futaie.

Sous l'ancien régime - je dis cela au point de rue historique - il y avait des atténuations assez grandes, indépendamment des grandes quantités de forêts appartenant aux propriétaires impérissables; à còté des forêts royales considérables, il y avait des forêts communales comme aujourd'hui et surtout les forêts des communautés écclésiastiques qui représentaient un capital énorme.

Comme forêts privées, il y arait des forêts seigneuriales qui pouvaient se transmettre dans certaines conditions suivant une législation spéciale et échapper à beaucoup d'impôts.

Aujourd'hui - e'est une simple constatation que je fais - le régime successoral en vigueur est plus défavorable à la forêt privée.

Par conséquent, plus nous allons, plus les forêts se trouvent exposées à certains llangers entre les mains des propriétaires particuliers.

On a proposé un remède : e'est l'association. Je suis loin de nier les bienfaits de l'association, mais les opinions peuvent différer et je crois qu'il serait téméraire d'y voir un remède final et définitif aux périls qui menacent la propriété forestière.

11. Nargaine a signalé avec beaucoup de raison, dans son rapport et ce n'est pas vous, syndicalistes et coopératistes qui me contre- 
direz - qu'il y a eu en France, jusqu'à ces derniers temps, des difficulcultés à réaliser l'association, la coopération et, surtout, à faire inettre? en commun les biens-fonds. Tous réaliserez peut-être plus facilement l'opération dont parlait M. Gazin, e'est-à-dire l'association pour laachat et l'entretien des terrains, mais pour mettre les propriétés en commun, on se heurtera à des résistances.

Ajoutez que ces sociétés privées très intéressantes, dont le développement est souhaitable, n'ont peut-être pas les garanties d'avenir des collectivités publiques. Elles sont forcément composées de personnes agissant dans un intérêt privé et soumises à des causes de dissolution qui, évidemment, agissent beaucoup moins sur les communes ou les établissements publies ou même les associations déclarées d'utilité publique. De telle sorte, Messieurs, que tout en rendant pleine justice aux associations de ce genre, tout en souhaitant leur développement, je crois qu'il est prudent de n'y pas voir le remède définitif aux dangers qui menacent la propriété forestière.

Si nous parlons de la question du reboisement, là encore, Messieurs, laetion privée parait limitée. Quand il s'agit de grands travaux de restauration en montagnes, il faut évidemment ne pas s'adresser aux personnes privées et quand il s'agit de reboisement tout simplement, étant donné les aléas de ces travaux, l'attente très longue nécessaire pour récolter, on aura peut-être du mal à orienter les capitaux privés de ce côté.

Bref, je crois qu'on peut conclure, à l'inverse de ce qui se passe pour la propriété agricole, que la propriété forestière est mieux placée entre les mains de propriétaires impérissables qu'entre celles de propriétaires particuliers. Ceci dit, sans vouloir le inoins du monde enlever aux propriétaires forestiers leurs mérites, surtout à ceux qui luttent pour remédier à cette situation.

11 y a différentes collectivités publiques. W'abord, l'État qui, en matière forestière, a un grand rôle à jouer. Quand il s'agit des périmètres de restauration des terrains en montagne, personne ne lui conteste ce ròle, de même quand il s'agit de forêts de pure protection qui donnent un revenu insignifiant et sont là presque uniquement pour jouer un ròle de sécurité publique. Il est, sinon seul, du moins le mieux qualifié pour la production du gros bois d'ouvre.

Les petits bois perdent de leur valeur de plus en plus pendant que les gros bois en acquièrent de jour en jour; ces derniers étaient déjà très importants du temps de Colbert pour la marine, ils lo sont aujourd'hui pour d'autres besoins. Il faut done procluire du gros bois et c'est l'État, avec son gros budget - ce 'qui fait qu'il n'a pas la tentation et il l'a moins aujourd'hui qu'il y' a un siècl', de chereher quelques millions dans des coupes extraordinaires - c'est l'Etat, dis-je, qui, avec sa garantie de perpétuité supérieure à celle de tous les autres, est le plus qualifié pour la production du bois d'ceuvre.

Remarquez que l'État ne possède act uellement que 950.000 liectares de forêts productives, en délalquant les périmètres de reboisement. 
C'est un chiffre relativement restreint qu'on peut augmenter dans une large mesure, sans inconvénient.

Je me hâte d'ajouter que je ne suis pas partisan du rachat de toutes les forêts. Si le monopole de l'État en 'matière économique a de gros inconvénients, je crois que la main-mise de l'État sur les forêts étoufferait toute initiative en matière forestière, romprait l'équilibre économique et serait un précédent dangereux dans le sens de la nationalisation du sol.

L'État doit done augmenter son domaine, mais cette extension a des limites et il y a d'autres propriétaires impérissables qui ont un rôle à jouer.

Il y a d'abord les départements. On en a beaucoup parlé, mais je n'ai pas grande confiance en eux. Incidemment, un département riche pourra acheter une forêt qui intéresse quelques communes, mais ce sera l'exception. Les budgets départementaux ne sont pas étendus outre mesure et les lépenses départementales grossissent comme toutes les dépenses locales; il y aura done d'autres emplois plus pressants à faire des fonds départementaux.

Les communes et les établissements publics ont 3.200.000 hectares de forêts qu'il faut leur conserver avec grand soin.

Les communes ont aussi des reboisements à faire dans leurs terrains vagues, ce qui n'empêche pas d'améliorer le régime pastoral, car il faut bien garder la mesure entre les deux régimes. Les communes auront beaucoup de terrains à boiser avant de nuire aux intérêts pastoraux de leurs administrés.

Les communes feront quelques acquisitions à titre gratuit; j'en ai vu plusieurs exemples au cours de ma carrière et le cas n'est pas rare. Les legs de forêts faits aux communes ont été relativement assez fréquents au cours des trente dernières années et, naturellement, elles ne peuvent que gagner à ces acquisitions.

Mais elles en font excessivement peu à titre onéreux. Sauf quelques exceptions pour des forêts aux portes de villes riches que celles-ci achètent pour, en même temps qu'une source de revenus, y trouver un lieu de promenade, sauf ces quelques exceptions, je ne rois pas comment les communes qui ont tant à dépenser pour les travaux de voierie, les écoles, l'alimentation en eau, etc., pourraient faire l'acquisition de forêts.

Mais il y a toute une catégorie de collectivités qui, au contraire, auraient, à molı sens, grand intérêt à entrer dans la voie de l'acquisition forestière.

Ce sont, pour rester sur le terrain des collectivités publiques, toutes ces Caisses d'épargne, ces Caisses de retraite, de secours mutuels approurées qui entassent et entasseront encoré plus des sommes énormes.

Jusqu'à ces derniers temps, la tendance des financiers et du Ministre des Finances qui exerce une tutelle sur ces Sociétés étaient de les obliger à employer uniquement leurs fonds en valeurs mobilières de 
premier ordre. J'ajoute que, depuis la Loi de 1898, cette règle s'est un peu relâchée et que la loi Audiffred accentue encore le relachement dans une assez large mesure.

Cependant, l'idée générale des financiers est de se défier des placements forestiers.

Je comprends, Messieurs, que certains placements offrent des risques, mais le placement en immeubles, aujourd'hui accepté pour toutes ces sociétés et que les compagnies d'assurances pratiquent sur une large échelle, a bien ses risques lui aussi : risques de non-loeation, d'incendie, de démolition, etc...

De même, il y a eu des exemples, à propos des communaux dont on parlait tout à l'heure, de baisses de revenus et d'aléas dus à la dépréciation des écorces et des bois de feu, mais il ne faut pas en exagérer l'importance. Les propriétaires qui ont perdu quelque chose, ont été peu nombreux et un propriétaire impérissable, qui a tout le temps devant lui, pent modifier le traitement de sa forêt de façon à l'adapter aux conditions économiques et à en améliorer le rendement.

La propriété agricole ne convient pas très bien aux propriétaires impérissables; c'est ce qui a amené jadis, contre les biens de mainmorte, des idées très vivaces encore aujourd'hui. La propriété forestière a sur les placements mobiliers cette supériorité que ces derniers suivent la dépréciation du numéraire, tandis que le produit de la forêt, abstraction faite de variations relatives, ne se modifie pas sensiblement.

Prenez une commune au moyen-âge, - remarquez que certaines ont 800 ou 900 ans d'existence - il y a des exemples de commune s'étant constitué une rente au xrve siècle de 50 ou 100 livres. Cette rente aujourd'hui, quand elle la paie, est toújours de 100 franes, mais la forêt qui a été aliénée moyennant cette rente, rapporte deux, trois, quatre ou cinq mille francs.

Les collectivités qui ont l'avenir devant elles doivent done se méfier moins de la propriété forestière que des autres, d'autant plus que la loi Audiffred sur la soumission faeultative au régime forestier donne à ces collectivités toute garantie et toute facilité pour la gestion de leurs forêts.

Remarquez qu'il ne s'agit point de demander à ces Caisses ou Compagnies de placer tous leurs fonds en forêts; n'exagérons pas, ear on compromet n'importe quelle cause par l'exagération. Mais supposons qu'elles emploient une partie, même modeste, de leurs apports, à des placements forestiers, et voyez quel résultat immédiat, au point de vue de la conservation des propriétés forestières!

Ces propriétés entre les mains de Sociétés publiques ou d'utilité publique, même dirigées par des partieuliers, formeront le contrepoids à la propriété domaniale pure et maintiendront l'émulation et l'initiative.

Telles sont, Messieurs, les différentes considérations que je me permets de vous soumettre à ce sujet. Il reste à examiner les mesures à prendre pour faciliter ces acquisitions. 
Je tiens à dire tout de suite que, à mon sens, il faut se placer sur le terrain du droit commun. Je n'ai pas besoin d'ajouter que je ne porte pas atteinte au Alroit d'expropriation tel que le définit la Loi de 18.2 pour la restauration des terrains en montagnes. Je parle des forêts en général et, abstraction faite de quelques cas exceptionnels, je considère que l'on doit laisser le libre jeu de l'offre et de la demande.

Le passage des forêts entre les mains des propriétaires impérissables doit être une opération de très longue haleine. C'est à cette seule condition qu'on le réalisera sans grosse dépense et sans erise économique. Peut-être cette opération ne s'achèrera-t-elle jamais; elle se fera au fur et à mesure des oceasions et lles besoins, sur le terrain de la liberté et du droit commun.

C'est dans cet esprit que j'ai rédigé un eertain nombre de voux dont je vais vous donner lecture :

Le premier vou ne sera pas celui imprimé dans mon rapport, la loi ayaut été votée depuis l'impression, je l'ai modifié ainsi :

¿ $1^{\circ}$ Qule le règlement d'alministrution publique concernant l'exécution de la Loi Audiffred soit établi et publié dans le plus bref délai.

"20 Que le Sénat mette le plus tôt possible en discussion le projet de loi "Fernand David" portant modification de la Loi du 5 asril 1882.

" $3^{\circ}$ Qu'à l'avenir un crédit soit inscrit chaque année au budget des Eanx et Forêts pour acquisition, sur l'ensemble du territoire, de forêts payables par annuités."

Cette proposition a déjà reçu un commencement d'exécution : 11. le Ministre nous en a parlé, mais il est bon de soumettre ce vou au Parlement.

Pour justifier le quatrième veu, je dirai qu'un crédit de un million ouvert au budget peut ne pas pourvoir à tous les besoins. L'État peut se trourer en présence d'un projet d'acquisition d'un grand massif, et eomme ce sont les grands massifs les plus intéressants, il ne faut pas qu'on soit obligé de se laisser pousser par l'opinion et de venir demander un crédit noureau. S'il en était ainsi, l'affaire serait onéreuse et c'est pourquoi j'ai proposé ce veru en m'exeusant d'entrer dans des détails, ce qui est contraire aux prineipes du Congrès :

" 40 Qu'à l'égard des massifs d'une valeur trop grande pour être achetés ci l'aide du crédit ci-dessns mentionné, les ministres de l'Agriculture et des Finances soient antorisés à conclure des contrats d'acquisition sous la condition suspensive de la ratification parlementaire et qu'en cas d'insuffisunce des disponibilités bulgétaires, le paiement en soit assuré par un emprunt amortissable on par une avance de fonds de la Caisse des Dépôts et Consignations;

"Subsidiairement, qu' an cas où les raisons financières ne permettraient pas un de ces deux modes de réulisation des achats de grands massifs, que les I/inistères de l'Agriculture et des Finances aient le droit de saisir des projets la Caisse des Dépôts et Consignations chargée 
de la gestion de la Caisse Nationale de Retraites, en vue de lapplication de l'urticle 15 (\$ 4) de la Loi du 7 arril $1910 \%$.

Il y a un grand projet - mon ami Cardot le connait - qui serait exécuté grâce à un emprunt fait au Crédit Foncier par l'État. II me semble que l'État est assez riche et a assez de erédit pour emprunter lui-même et qu'il n'a rien à gagner à s'achresser à une société semiprivée, qui, forcément, prendra son bénéfice.

L'État a la Caisse des Dépôts et Consignations et M. Guyot n'ignore pas l'application très intéressante prévue par la Loi de 1882.

" $5^{\circ}$ Que les droits de mutation à titre onéreux soient réduits en cus d'acquisition de forêts par des communes on établissements publics et même, s'il est possible, par les associutions reconnues d'utitité publique : Caisses d'épargne, Caisses de retruites et Sociétés de Seconrs mutuels approus'ées."

C'est le vou de M. Arnould, un peu élargi, mais, au lieu de demander l'exemption complète, je rérlame surtout des atténuations.

$6^{\circ}$ Que les décrets autorisant les communes et établissements publics à accepter des legs de propriétés forestières n'imposent l'obligation de vendre ces immeubles qu'en cas de volonté formelle du lestateur."

La tendance du Conseil d'État à obliger la vente est déplorable.

"7o Que le Ministre de l'Intérieur invite les Préfets à furoriser les opérations qui consisteraient pour les communes et étublissements publics à transformer DANS IIES CONDITIONS AVAXTAELSES en placements forestiers leurs valeurs mobilières et lenr's domuines ugricoles \%.

Je souligne les mots : "conditions aruntugeuses", car il ne s'agit pas de transformer le tout sans discernement.

" 80 Que le paragraphe 4 de l'article 15 de la Loi dn 5 asril 1910 soit modifié par l'élévation à un centième de la portion de l'avoir que les caisses de retraites pourront employer en achat de bois et de terrains ¿i boiser."

Un centième, c'est un début.

Enfin, il est un autre voeu qui ne demande pas à etre formulé. Je demande qu'on modifie la mentalité de toutes les personnes appelées à gérer ces Caisses et Sociétés, car si une transformation ne s'opère pas en eux, jamais la loi ne sera appliquée.

Nessieurs, vous appartenez à tous les points de la France, vous avez tous, de par vos situations, de l'influence dans le pays ; je vous prie d'en user pour arriver à motifier cette mentalité, car c'est indispensable pour assurer le succès de la cause forestière que nous dófendons tous (V'ifs upplandissements). 
1. Guyot. - Messieurs, rous applaudissez eomme moi le magistral rapport fait par 11. le conservateur Vivier. Nul mieux que lui n'aurait pu exposer en termes excellents le rôle forestier de l'Élat et des propriétaires impérissables. .

M. Vivier, avee sa discrétion coutumière, a su limiter le rôle de l'État et montrer que son rôle essentiel consiste à donner à notre industrie nationale les bois de fortes dimensions que, seul, il peut fournir. Il faut done qu'il y ait des forêts domaniales nombreuses, plus nombreuses qu'elles ne le sont.

Mais M. Vivier, très sagement, a fait cette restriction qu'il fallait augmenter ce domaine progressivement. Nous sommes tout à fait d'accord à ce sujet.

Ensuite, MI. le rapporteur a indiqué l'intérêt qu'il y avait, pour les propriétaires impérissables, à posséder des forêts. Peut-être a-t-il insisté un peu trop sur les inconvénients des propriétés forestières pour les particuliers. C'est vrai pour les petits particuliers, mais je crois que les inconvénients sont moindres qu'il ne le croit. D'ailleurs, je n'msiste pas, il n'est pas question de faire passer entre les mains de propriétaires impérissables la totalité des six millions d'hectares de forêts françaises, une grande partie resteront toujours la propriété te particuliers.

Je suis absolument stupéfait d'apprendre que certains décrets autorisant l'acceptatio i de legs de forêts par les communes, imposent la vente immédiate...

11. Vivier. - Cela est arrivé.

11. Gurot. - C'est inadmissible.

11. VIVIER. - C'est un reste de cet état d'esprit que je signalais à propos des biens de main-morte. On considère que, les communes étant mineures, le placement le meilleur qu'elles puissent faire est la rente sur l'État.

11. Givot. - Il faut réagir contru cette idée.

M. Vivier. - J'ai vu le fait se produire pour la forêt de Carlarache; l'intention du testatenr n'était pas formelle.

11. Guyot. - Il fani que cette mentalité administrative soit modifiée. Exiger que les propriétaires impérissalbes n'aient que du $3 \%$, e’est insensé au point de vue économique.

En ce qui concerne les forêts eommunales, je vous signalerai une particularité spéciale à ma région, mais assez intéressante.

Vous connaissez l'arrondissement de Briey, en Meurthe-et-Moselle. 11 est actuellement soumis à une transformation tout à fait extraordinaire, les exploitations minières y prennent une telle extension que tont en est boulerersé. C'est certainement un grand avantage au 
point de vue métallurgique, mais au point de vue social, au point de vue des propriétaires et des populations autochtones, c'est déplorable.

A cette occasion, on achète aux communes, directement ou par expropriation, dès forêts que l'on paie très largement. Certaines ont été vendues 10.000 francs l'hectare. Mais l'Administration oblige toujours les communes - et je l'en félicite - à remployer une partie' plus ou moins considérable de cette somme en acquisitions nouvelles de forêts.

Nous devons demander que cette pratique ádministrative soit continuée.

M. Vivier. - Si je n'en ai pas parlé, c'est que cette pratique est passée dans les habitudes administratives.

M. Guyot. - C'est tout à votre honneur et il était bon d'en parler iei. Je suis également d'accord avec vous sur la nécessité de modifier la mentalité des dirigeants des sociétés qui sont opposés aux acquisitions de forêts. Je puis vous en donner un exemple typique qui s'est passé dans ma localité où fonctionne très bien une Caisse d'Épargne.

Cette Caisse est riche et pourrait bénéficier de la loi Audiffred. Quand j'en ai causé avec les directeurs, j'ai été repoussé avec énergie : "Comment! mais jamais nous n'accepterons chose pareille!"

Il nous faut done montrer à ces collectivités les grands avantages qu'elles retireraient de ces acquisitions. M. Vivier en a fait une démonstration tellement frappante que je n'y reviendrai pas, j'émettrai simplement le regret que la loi Audiffred se soit montrée si timide en fixant au dixième de leur revenu la part susceptible d'être consacrée par les Caisses d'épargne aux achats forestiers. En définitive, il s'agit des fonds libres, cela ne peut pas compremettre les intérêts des déposants.

Qu'est-ce qu'un dixième pour les Caisses d'épargne, on aurait dû être plus généreux.

M. Vivier. - Je crois qu'il est prudent, pour le moment, de se contenter de ce dixième, car e'est le point qui a failli faire échouer la loi devant le Sénat. Le Conseil supérieur des Caisses d'épargne hésitait beaucoup également et il faudrait bien se garder de réclamer davantage.

Contentons-nous de cela et soyez bien certains que si l'utilisation de cette faculté donne de bons résultats, les administrateur's de Caisses d'épargne seront les premiers à demander l'augmentation de cette somme minime.

M. Gurot. - L'énumération qui figure au paragraphe 5 du vou esi très complète, mais je voudrais y voir mentionner les sociétés civiles de propriétaices destinées à acquérir des forêts.

M. Vivier. - Très volontiers. Remarquez que je demande une réduction que le législateur pourra graduer comme il lui plaira. 
M. Banchereat. - Il est bien entendu que ces Sociétés civiles ne sont pas obligatoirement soumises au régime forestier.

M. Vivier. - Les deux choses sont tout à fait distinctes.

M. Banchereau. - Ainsi la Société du Contròle, qui a pour but un aménagement spécial, ne peut pas être soumise au régime forestier.

M. Vivier. - Elle pourra profiter de la loi Audiffred qui prévoit des soumissions partielles au régime forestier. Ce n'est plus comme autrefois où ce régime formait un bloc; la loi Audiffred permet de rompre ce bloc.

M. Guyot. - La soumission obligatoire ne s'applique qu'aux communes, aux établissements publies, e'est-à-dire à des groupements faisant partie de l'organisation publique.

M. Vivier. - Et à des collectivités déterminées.

M. Le Présidext. - M. Blondeau nous a fait parvenir une communication dont je prie M. le Secrétaire de bien vouloir nous donner lecture.

M. DElahaye. - Voici cette communication.

UTILITÉ DE L'ACQUISITION PAR L'ÉTAT, LES COMMUNES OU AUTRES COLLECTIVITÉs PliblQUES, LES ÉtABLISSEMENTS OU ASSOCIATIONS D'UtILITÉ PUBlique, DE FOrêts ou de terraixs a reboIser. - Mesures législa-

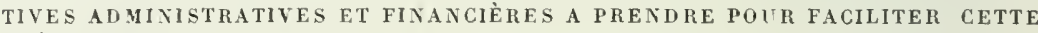
OPÉRATION.

La forèt doit être conservée; c'est une nécessité admise par tous les forestiers qui connaissent les maux des peuples qui ont laissé détruire les leurs et les difficultés de rétablir l'état boisé. Son rôle bienfaisant touche aux intérêts les plus divers des collectivités, il est inutile de le démontrer ici.

Pourtant, il semble que l'existence même de la forêt n'ait jamais été menacée autant qu'aujourd'hui.

I. - Dans tous les pars, sous mille formes, la consommation de bois prend une extension de plus en plus grande, au fur et à mesure des progrès de la civilisation, de la recherche de bien être, de confort, de luxe; la belle prospérité de l'industrie pendant ces dernières années, la formidable extension qu'à acquise ou yu'attend l'outillage public, chemins de fer, canaux, ponts, etc., ont provoqué avec une consommation croissante de bois, la destruction de maintes forèts.

Rares sont les pays qui, dans une forme ou l'autre n'importent annuellement du bois pour des sommes considérables et il n'en est rraisemblablement pas un seul qui, pour'satisfaire à des demandes toujour's renouvelées, n'entame ses réserves forestières, véritables richesses naturelles accumulées pendant les siècles précédents. L’insuffisance de la production du bois d'œuvre dans le monde a d'ailleurs été nise en lumière par un réputé forestier français, M. Mélard, et il est à craindre que ses prévisions se réalisent de façon toute prématurée.

De lì, faut-ił donc conclure que les forèts doivent disparáitre tôt ou tard? On hésite à répondre par l'atlimative quoique les craintes actuelles paraissent devoir dans l'avenir s'aggraver encore, si, ce qui ne semble pas douteux, la consommation de bois continue à s'accroître et à dépasser la production. 
Il est permis de dire et de répéter que, dans l'intérêt de la forêt elle-même, il est d'ceuvre méritoire d'étendre encore et de faciliter le marché mondial de la matière ligneuse, de perfectionner au plus tôt les méthodes de conservation les bois mis en ceuvre, de rechercher de nouvelles utilisations de la matière ligneuse déjà usée (papier, bois d'emballage, etc.), et enfin, d'étudier les movens de remplacer le bois dans certains de ses emplois.

1I. - Le régime successora], l'impôt souvent excessif, parfois vexant, de la propriété forestière, ont été la cause du démantèlement, de l'appauvrissement de beaucoup de domaines particuliers. La liquidation de successions, le paiement des droits de mutation, des nécessités urgentes du propriétaire ou de ses héritiers, ont souvent provoqué la réduction de bois bien achalandés à l'état de simples ébauches forestières.

Qu'ils'agisse de massifs de petite, moyenne ou grande étendue, il est certain que l'appropriation particulière des forêts que possédaient sous l'ancien régime social, les souverains, les seigneurs et les communautés, n'a guère abouti ‘fu'à appauvrir ces domaines en arbres, en gros arbres surtout, qu'à abaisser et le nombre d'arbres et leur' grosseur moyenne, à affaiblir leur utilité de l'ensembile : peu de gardes, de bùcherons diront que telle forèt est mieux garnie aujourl'hui (fu'autrefois; presque tous les gens de la forèt, et les marchands de bois surtout, affirmeront que le plus grand nombre des bois de leur région s'éclaircissent d'année en année.

Il n’est plus le temps où les forèts étaieut bien garnies; les gros arbres étaient l'une des manilestations du luxe, l'apanage obligé ou désiré de certains noms et familles, le complément indispensable du claâteau ou de la "terre ". Tout cela s'est écroulé ou s'écroulera sous le coup de nécessités diverses, de partages aux décès, de besoins sans cesse grandissants des propriétaires successifs de forèts qui s'émiettent.

Il n'est pas hasardé de prévoir à brève échéance pour ces raisons et surtout pour celle que nous donnerons tantìt, la faillite de la propriété particulière constituée en futaie et en taillis sous futaie.

III. - Faisons observer ici que, malgré les réalisations extraordinaires consenties en ces dernières années sur une étendue considérable de massifs particılier's, les prix unitaires des bois n'en ont pas moins haussé et qu'ils ont pour le moment encore une tendance à s'affermir davantage.

Nous avons dit précédemment que la consommation de bois augmente chaque année dans des proportions considérables, qu'elle est en partie le fait de la proṕriété générale de l'industrie; celle-ci agit d'une autre façon, dans un sens convergent, pour augmenter encore les dangers de l'existence de la forèt privée

11 n'est un secret pour personne anjourd'lni que la rémunération des capitaux engagés dans le commerce et l'industrie est meilleure que celle de l'argent placé en fonds publics, de pleine sécurité pourtant, et malgré les immunités dont certains d'entre eux sont entourés; les fonds placés en forèt donnent un intérêt encore moindre que ces derniers.

Quoique l'on fasse, cette infériorité du taux de placement des fonds forestiers subsistera parce que la production ligneuse est essentiellement lente, parce que l'utilité ne se crée en forêt qu'au bout d'un nombre d'années plus ou moins grand, que les valeurs ne s'y engendrent que par la superposition de nombreux cernes anmuels, qu'elles sont le fruit de l'épargne et du temps.

Tandis que l'industrie et le commerce peuvent généralement, au gré de leurs dirigeants, augmenter l'une et l'autre leur fabrication et leur chiffre d'alfaires et abaisser souvent leur prix de revient, le sylviculteur n'a guère d'action sur une production dont les éléments sont le sol, le climat et les peuplements. llest cantonné dans les sols les moins bons, souvent les plus ingrats et dont l'amélioration est impossible ou trop coûteuse. Le climat est chose intangible. Il n'est guère que sur les peuplements qu'il puisse agir par un choix judicieux des essences d'installation, de reconstitution on de regarnissage, par des soins 
pariiculiers au cours de la croissance, par des éclaircies bien faites qui peuvent pourtant, au delà d'une limite donnée, porter atteinte à la forme des arbres et à la qualité de leur bois; l'ensemble de ces mesures ne peut corriger que dans une mesure peu appréciable la lenteur de la production ligneuse, de la formation des raleurs en forêt.

Dans notre civilisation industrielle, les capitaux disponibles vont donc moins à la forêt qu'aux affaires et celles-ci les délogeront de celles-là. La destruction des futaies est donc due, tant à la rémunération insuffisante des capitaux forestiers qu'aux bénéfices plus grauds des entreprises industrielles, qu'à la capitalisation des fonds d'État à un taux plus élevé, plus rapproché du loyer de l'argent à l'industrie et au commerce.

Il importe de noter que la réalisation des capitaux forestiers est singulièrement excitée par des marclıands d'immeubles, spéculateurs avides, doublés ou non, de banquiers et d'exploitants, - les uns et les autres ne commettant en cela aucun acte répréhensible en soi - qui ont organisé tout un système d'informations sur la situation de fortune des détenteurs des immeubles fores. tiers.

La perspective d'une rente en bloc vite conclue, du prix soldé en une fois et non atteint par le fisc en ce qui concerne les valeurs des bois sur pied, la possibilité du remploi immédiat des fonds à de plus fructueuses opérations, la crainte, la hantise, d'une revision des charges fiscales qu'on ne diminue jamais, le manque fréquent de connaissances dans la gestion et la culture forestières, décident la plupart du temps le propriétaire à réaliser la vente du patrimoine looisé lentement accumulé et sagement ménagé par des ancêtres moins hardis, si pas plus prudents.

Les marchands d'immeubles recherchent naturellement les forêts les plus riches en arbres, abattent ceux-ci dans le moindre temps possible, rendent, en bloc ou en détail, le fonds dégarni ou à peu près et passent au plus tôt à d'autres "opérations". Des faits récents montrent qu'ils peuvent atteindre les domaines les plus grands, certains qu'ils sont de vendre à chers deniers tous les bois qu'ils y pourront réaliser.

Ainsi que nous le disions tantôt - et nous ajouterons qu'elle est organisée presque administrativement - c'est la destruction intégrale, à brève échéance, des propriétés particulières, des forêts peuplées de chênes, de hêtres, d'essences feuillues plus spécialement; elle laisse derrière elle des surfaces livrées à la production de taillis dont la dépréciation est générale; elle prive du travail habituel, bûcherons et voituriers, du bénéfice des transactions anmelles, industriels et commerçants de la région, du pittoresque de la forêt, amateurs du beau et amants de la nature; elle menace les vallées d'inondations désastreuses, les cultures, des gelées printanières, la région tout entière d'extrêmes inconnus de température.

Ces opérations sont toujours l'objet de la réprobation générale, ce dont les dévastateurs n'ont guère cure, soyons en certains.

Dans les lignes qui précèdent, nous croyous avoir montré que le danger que court la forêt particulière tient plutôt de la prospérité générale, des immobilisations énormes d'argent dans les installations d'intérêt public, plus que des rharges fiscales et des dispositions de nos lois civiles.

Il est plus qu'imminent, il est actuel, il est général, chez les nations occidentales surtout, qui aspirent à un outillage complet et il est très grave ; il est lié à l'avenir du loyer de l'argent au sujet duquel on ne peut guère émettre que res probabilités.

Nous avons exposé notre pensée avec la franchise que donne une conscience claire du danger ; elle résume ce que pensent ou disent les propriétaires de bois en général, les mandataires communaux non exceptés. La question est exclusive, assurément, de toute poésie, de toute sentimentalité; elle est matérielle au premier chef et il est peut-être bon de le dire sans ambages, elle est du domaine des closes abstraites de la finance.

IV. - La diffusion des sciences sylvicoles, une connaissance plus détaillée 
de l'art de bien traiter les bois, corrigerait à n'en pas douter, bien des erreurs actuelles dans la gestion des propriétés forestières en général. Toutefois, ainsi que nous avolls déjà eu l'honneur de l'exposer', elles ne peuvent guère aboutir qu'à améliorer la culture par' un choix plus judicieux des essences; il en résultera le plus souvent des substitutions aux essences feuillues des espèces résineuses qui, hors de leur station naturelle, ne sont guère aptes à assurer la permanence de l'état boisé.

V. - La soumission volontaire des bois particuliers au régime forestier, moyennant rémunération des services de gestion et de surveillance, sans ancune espèce de compensation, ne parait devoir jamais recevoir que des applications fort restreintes; s'il peut en résulter des avantages pour la propriété elle-mème, le détenteur hésitera souvent à déléguer la gestion de son bien à un service. public dont les unités sont nécessairement de valeur fort diverse.

VI. - L'atténuation de l'impòt foncier', des droits de succession, de mutation, fiscaux en général, est à désirer assurément, mais il ne pourra ğuère, dans les bois de haute futaie, alléger les charges de la propriété dans une mesure qui puisse quelque peu relever le taux de placement des fonds.

VII. - Le principe en est admis partout, l'État, impérissable, chargé dans notre civilitation de la sanvegarde de l'intérèt général, doit rester et devenir propriétaire de bois. Il est mauvais industriel, il est médiocre conmerçant, mais pour laconner ses valeurs, la forêt bien constituée n'a guère besvin du concours de l'homme qui doit surtout viser à ne pas excédel' la possibilité dans les récoltes annuelles, que représentent les coupes ordinaires, de facon à conserver tout au moins l'homogénéité clans le temps et dans l'espace, de la richesce qui lui est confiée.

Mais, les forêts les plus intéressantes sunt les plus riches et les plus chères. Pour les domanialiser en les achetant, l'État doit débourser des sommes considérables qu'il trouve dans l'emprunt conclu à chers deniers auprès du public. Pour lui, comme pour chacun, l'argent est côteux et la forêt ne lui procule qu'un revenu restreint, inférieur au loyer des emprunts qu'il fait pour' en solder le prix. Il faut donc que l'État admette que la différence entre le taux de l'emprunt et le taux de placement en forêt, représente la part de l'intérèt général qu'il doit sauvegarder.

Ce raisonnement s'applique également à l'acquisition que l'on se croirait en droit de recomnander aux provinces et communes dont la situation financière laisse souvent, d'ailleurs, à désirer. Il peut s'étendre encol'e à des proje ts récenment présentés et tendants à autoriser les associations reconnues d'utilité publique, les sociétés de secours mutuels approuvées et les caisses d'épargnes à posséder des bois.

Si le placement n'est pas avantageux, si l'opération n'est pas fructueuse, il ne laut guère attendre de ces organismes qu'ils acliètent, des forèts qui seraient mises du jour au lendemain dans la gestion d'un service public.

Autre chose en est de leur permettre l'acquisition de terrains à boiser; la croissance rapide des essences résineuses, le plus souvent employées dans les nonveaux bois, donne à cette spéculation un caractère avantageux pour une période donnée tout au moins.

V1II. - Les restrictions ılans la jouissance, la régle mentation des délivrances, leur limitation, lég'ale me nt, officielle ment déterminée, sont des mesures extrêmes que la liberté de nos institutions répugnera toujours à faire admettre: le charbonnier est maître chez lui!

IX. - Nous en revenons au caractère abstrait du problème; il ne peut avoil qu'une solution par nos temps de matérialisme et de mercantilisme. Qui veut la fin doit vouloir les moyens et pour tue nos successeurs et nous-mimes n'ayons pas ì regretter amèrement les conséquences de l'épuisement de la propriété boisée particulière, la plus étendue dans beaucoup de pays, il importe 
au plus haut point que les gouvernements se décident à prendre des mesures effectives, adéquates.

Les états ont garanti autrefois un minimum d'intérèt aux porteurs d'obligations des compagnies de chemins de fer chargées de la construction et de l'exploitation des voies ferrées, industrie dont le caractère d'utilité publique est unanimement reconnue (1).

Pourquoi les mêmes États, l’econnaissant l'incapacité du particulier à posséder des bois de futaie, les plus utiles aux divers doints de vue climatérique, hydrologique, économique et social, ne détermineraient-ils les forêts ou groupes de forêts dont la conservation est désirable, nécessaire, au point de vue général?

Te seraient envisagées que les forêts réunissant certaines conditions de sol, de situation, de configuration, ayant, à elles seules ou en groupe, une étendue minimum de too hectares, par exemple, et comportant, en arbres feuillus, un volume total équiralant à $40^{\mathrm{m}: t}$ de bois d'œuvre au moins à l'hectare, par exemple.

L'inventaire serait dressé, et la valeur marchande de l'immeuble fixée de commun accord par le service forestier et le propriétaire.

LiÉtat garantirait à celui-ci un minimum d'intérêt annuel à un taux à convenir, des valeurs ainsi déterminées, assure rait dès la conclusion du contrat, la surveillance et la gestion du bien, ferait les ventes d'arbres à son profit. Il aurait à couvrir chaque année par la création de nouvelles ressources - la matière des réclames qui profanent trop nos paysages serait peut-être bonne à taxer dans ce but - la différence entre le revenu brut de la forêt d'une part, la rente à servir au propriétaire, les dépenses diverses de gestion d'impôts, de travaux, etc., d'autre part.

L'État ou une institution par lui déléguée se chargerait de faire les opérations de prèts hypothécaires, et autres, et se rembourserait en déduction du compte d"intérêts.

Aux prix unitaires de l'inventaire, augmenté en ce qui concerne la futaie d'un tantième à fixer et à limiter à la conclusion du contrat, et déduction faite de ses créances éventuelles, l'État pourrait à tout moment réaliser l'achat, le propriétaire ou ses ayant-droits, conclure la vente effective de l'immeuble à l'État, mais à l'État seul.

11 s'agit, somme toute, d'une vente à terme dont nous n'avons fait qu'esquisser les conditions. Le projet a l'avantage de respecter la liberté des propriétaires qui sont maîtres de demander ou de négliger la garantie domaniale, et il est permis de supposer que nombre d'entre eux chercheraient à meubler leurs bois, de brins, de jeune futaie, de façon à pouvoir se réserver, pour eux ou pour leurs héritiers et si le besoin s'en présente, le bénéfice du minimum d'intérêt.

La domanialisation serait progressive ; elle aurait lieu plus ou moins vite selon les disponibilités de l'état et les prélérences des propriétaires, mais. entre temps, la production normale et la conservation de la forêt seraient garanties. Entreprise de cette façon, elle paraît devoir être moins onéreuse que l'expropriation et que l'achat au comptant de domaines au sujet desquels l’autorité est parfois la dernière à connaìtre les intentions des propriétaires.

M. DelailaYe. - Voiei également le résumé d'une autre communication faite par M. Georges Marlio :

(1) La loi belge du 24 juin 1885 sur les chemins de fer vicinaux stipule dans son article 10 :

Le Gouvernement est autorisé à garantir envers les tiers, aux conditions à déterminer par lui, l'intérêt et l'amortissement des obligations émises par la société nationale en représentation des annuités dues par les communes, les provinces el l'État.

Les engarements de l'État. comme garant d'obligations, ne peuvent dépasser les sommes fixées par la loi. 
Pour les forèts des particuliers, crise grave résultant :

10 D'une législation du défrichement insuffisante;

$2^{\circ}$ De la production de bois de qualité inférieure et comme conséquence de la mévente des produits;

$3^{\circ}$ De l'exagération de l'impôt;

Remèdes à cette situation :

$1^{0}$ Nouvelle législation du défrichement.

$2^{\circ}$ Dégrèvement des forèts.

$3^{\circ}$ Production de bois d'ouvre au lieu de bois de feu, commandée d'ailleurs par des nécessités économiques.

L'égoïsme de l'individu se refusant à accepter de nouveaux modes de traitement qui allongeraient les révolutions à l'effet de prorluire du bois d'ceuvre, seules les personnes morales publiques et privées, ont toutes qualités pour devenir propriétaires de l'ensemble des forêts françaises.

Pour remédier à la situation défavorable faite à la forèt rrançaise par le rẻgime de la propriété individuelle, émet le veeu que les personnes morales publiques se substituent comme propriétaires à l'individu.

Hí Le Présinext. - La parole est à M. Blondeau.

M. Bloxbeat. - Je n’ai rien inventé, je me suis inspiré de ce fait que, depuis 70 ou 80 ans que les chemins de fer existent, l'État garantit aux obligataires des Compagnies un intérêt minimum afin d'assurer le trafic des lignes reconnues d'intérêt public.

La conservation des forêts n'est-elle pas aussi intéressante et ne pourrait-on pas aussi nous garantir un minimum de revenu? On ferait l'inventaire des propriétés forestières et le service forestier prendrait la gestion de ces biens; on déterminerait le taux de revenu après entente entre les propriétaires et l'État.

La convention passée entre eux sêrait aussi longue que la vie du propriétaire qui pourrait demander à l'État de réaliser la vente : ce serait donc une vente différée et à terme. Ainsi la conservation des forêts serait assurée et les propriétés forestières pourraient s'accroître. Je crois qu'il y a là une formule nouvelle.

M. Vivier. - Je répondrai quelques mots à l'honorable orateur.

Son idée est originale, mais j'y ferai quelques objections. La première, c'est qu'on ne peut assimiler les propriétaires de forêts aux obligataires des Compagnies de chemins de fer. Dans beaucoup de pays, les lignes ferrées sont gérées par des Compagnies qui sont des concessionnaires de l'Etat, qui sont liées à lui par des conventions. On ne peut les considérer comme des personnes privées, elles ont la charge d'un service public, sous certaines conditions, et ceci est tellement rrai, qu'à l'expiration des concessions, les lignes reviennent à l'État.

L'État laissant certaines charges aux Compagnies, leur assure des avantages, et ainsi on ne déroge pas du tout au régime de la propriété privée.

Au contraire, l'application de ce système à la propriété forestière constituerait un précédent qui pourrait être dangereux, car il y a beaucoup d'agriculteurs partisans de ce système et, à ce sujet, je vous raconterai une histoire qui s'est passée quand j'étais garde-général. 
Un de mes gardes communaux, petit propriétaire de vingt et quelques hectares, car leur métier ne leur permettait pas de vivre, causait avec un autre propriétaire et lui disait que le seul remède à la crise agricole - on était en 1885 - était l'assurance par l'État d'un minimum de revenu aux propriét aires agricoles.

Si nous introduisons ce principe en ce qui concerne les forêts, vous rerriez done une foule de petits propriétaires agricoles demander le bénéfice de cette disposition. Ce serait un précédent qui nous conduirait à la nationalisation du sol, sous une forme ou sous une autre.

Quelque séduisante que soit votre idée, je ne la crois pas réalisable. D'ailleurs, elle est en contradiction avec les voux adoptés hier matin par cette section qui sont tous défavorables à l'intervention de l'État dans la gestion des bois particuliers.

M. Girero. - Je m'excuse d'intervenir dans cette discussion, mais j'ai un devoir à remplir en vous soumettant les observations que le rapport de M. Vivier m'a suggérées, tant à sa lecture qu'à son audition.

Du rapport de M. Vivier, il résulte nettement que les six millions d'hectares de forêts appartenant à des particuliers sont sans arenir... (Protestations). Je vous demande pardon, c'est ce qui se dégage de ce rapport.

On ne pourra jamais y faire de futaies ni de réserves sérieuses, on n'aura jamais que des taillis médiocres qui continueront à ne pas se vendre. Il faut donc en prendre son parti, dit M. Vivier, ces bois particuliers sont sans avenir... (Touvelles protestations).

Eh bien! admettez que ce soit simplement un raisonnement et rous allez voir les conclusions qu'il faut en déduire.

La conclusion - et M. Tivier la dégage très bien - c'est que la conservation des forêts en France ne peut être assurée que si elles forment en quelque sorte l'apanage des propriétaires impérissables, État, départements, communes, établissements publics, etc...

Mais s'il en est ainsi, que restera-t-il aux propriétaires privés. Les propriétaires privés sont reconnus impuissants à faire-des réserves, leur intérêt, dit-on, s'y oppose, ils ne peurent donner à leurs bois une valeur réelle, ils les laissent à l'état de taillis plus ou moins produetifs, par conséquent, on n'aura jamais de gros bois, ni de bois d'ourre, et, comme les taillis sont condamnés à n'avoir aucune valeur tant qu'on n'aura pas trouvé le moyen de tirer un parti, mécaniquement ou chimiquement, de leurs bois, les forêts particulières sont condamnées à disparaître un jour ou l'autre.

Je suis au ilésespoir de trouver l'éminent ancien directeur de l'Ecole de Nancy parmi les partisans de cette tliéorie et de l'entendre dire que l'État doit acheter les propriétés boisées de France.

L'Etat a 900.000 hectares, ce n'est pas assez, dites-rous, il lui en faut davantage, il faut qu'il achète toutes les propriétés forestic̀res qui deviendront disponibles (Protestations).

M. Le Président. - Pas toutes. 
11. Girerd. - Où vous arrêterez-vous dans cette voie, et pourquoí voulez-vous que ce soit l'État qui achète ainsi? Parce que, dites-vous, ses ressources sont innombrables, inépuisables mêmes. Non, elles ne sont pas inépuisables et ce sont les contribuables qui les constituent. Vous allez done demander des centimes additionnels nouveaux ou un impôt direct ou indirect pour pouvoir acheter des forêts. Ce n'est pas possible.

Les ressources de l'État sont faites pour subvenir aux intérêts publics. Envisagerez-vous l'acquisition des forêts comme un service public? A cet égard, je rous prie de distinguer deux choses : les forêts en plaines et les forêts en montagnes.

Si vous considérez les forêts en montagnes - et j'y ajoute même les terrains en montagnes - nous sommes d'accord, c'est bien un service public, un intérêt public de premier ordre que d'assurer la conservation de terres qui, en cas d'inondations, produisent des désastres épouvantables. Si vous voulez, à cet égard, inviter les Pouvoirs publics à prendre les mesures nécessaires à l'acquisition de ces terrains en montagnes, je serai avec vous.

Mais pour les terrains en plaine, l'intérêt n'est plus le même et, par conséquent, il faut laisser le champ libre à la propriété privée; rien ne justifie, en ce qui concerne les forêts de plaine, l'emploi des deniers des contribuables.

C'est tout ce que je voulais dire, considérant qu'il était de mon devoir de vieillard d'attirer sur ce point votre attention (Applaudissements).

M. Le Présidext. - Les paroles prononcées par M. Girerd, ancien directeur général des Eaux et Forêts, revêtent par sa bouche une grande importance, mais je crois qu'il a vu les choses un peu en noir.

M. Tivier s'expliquera; mais je suis sûr qu'il n'a pas voulu condamner les forêts privées qui joueront toujours un grand rôle. Il a simplement indiqué la supériorité, à certains points de vue, des forêts possédées par des propriétaires impérissables.

Quand à ce crédit de un million cqu'il demande pour permettre l'acquisition de forêts le plus souvent ruinées, il existe dans tous les autres pays; la France seule, jusqu'ici ne peut pas acheter de forêts et laisse échapper de belles occasions, laissant en friches des forêts qui ne trouvent pas d'acquéreurs.

Il ne s'agit done nullement de faire concurrence aux particuliers. L'État n'achèterait que quand les particuliers ne le feraient pas. Remarquez d'ailleurs que M. Tivier n'a parłé de l'État qu'incidemment et que son roeu rise surtout lachat des forêts par les collectivités.

M. Girerd. - Pour lesquelles il n'y a pas d'objection à faire.

M. Le Président. - La question de l'État est tout à fait accessoire dans son rapport. 
M. Girerd. - Les eommunes n'achèteront pas beaucoup, car les conseillers municipaux, qui doivent faire face aux besoins publics, seraient honnis par leurs concitoyens s'ils employaient les ressources communales à l'acquisition de forêts.

Les départements eux-mêmes n'achèteront guère, tandis que les établissements publies, caisses d'épargne et autres le pourront à àmerveille.

Je ne combats que les acquisitions faites par l'État, car j'estime que les ressources des contribuables ne doivent pas recevoir une pareille destination.

Vous dites qu'il ne s'agit que d'un million. C'est peu pour le budget de l'État français, mais ce qui m'effraie, c'est le principe. S'il ne s'agissait que d'inserire cette somme au budget afin de permettre à un Ministre; à un moment donné, d'acheter une forêt ruinée qui pourra se reconstituer, je ne m'y opposerais pas, mais j'ai peur que vous ne soyiez entraînés plus loin.

D'ailleurs, voici ce qui se passe. On constate que telle forêt est menacée, qu'elle est malade. Vite un docteur se présente : il faut que l'État l'achète pour la sauver. L'acquisition est faite, puis on décourre que le docteur s'est trompé de diagnostic, que la forêt n'était nullement malade, mais elle reste achetée.

C'est bien ainsi que la question s'est posée il y a quelques années à propos de la forêt de Marchenoir : forêt ruinée, perdue, disait-on, c'était un véritable désastre. Heureusement, l'État n'a pas voulu acheter cette forêt parce qu'il n'avait pas votre crédit d'un million et, à la réflexion, à l'étude, on a découvert que ce qui s'était passé là était absolument normal, que la forêt n'était pas malade ni menacée de maladie. Elle passait simplement entre les mains d'un ancien agent forestier très compétent qui ne l'achetait pas pour la ruiner mais pour la cultiver, pour en faire un placement, pour l'exploiter normalement, car l'exploitation d'une forêt est une culture, et pour faire courre utile très avantageuse pour son propriétaire.

Cet exemple pourra se reproduire. Il se trouvera toujours des forêts qu'on croira menacées et qu'on voudra acheter, après quoi, on s'apercevra que les eraintes étaient chimériques. Pourquoi donc ne pas laisser faire les particuliers qui exploiteront tout aussi normalement of pourront peut-être fournir à l'Etat et aux Compagnies de chemins de fer ces traverses dont le besoin est de plus en plus grand, et qu'on fait venir de l'étranger en les payant très cher.

Si l'exploitation de certaines forêts devait nous permettre de trouver chez nous ces traverses, ce ne serait plus un désastre, mais une utilisation très bonne, et c'est pourquoi je considère comme dangereux l'ouverture d'un crédit de un million au budget de l'État.

11. Vivier. - Nous sommes d'accord sur les acquisitions faites par les collectivités publiques, mais M. Girerd se sépare de moi en ce qui concerne les acquisitions à faire par l'État. Ml. Girerd a exagéré ce que j'ai dit à ce sujet, car j'ai limité ce ròle. 
Il n'admet pas le ròle de l'État, comme service public, dans les forêts de plaine. Si j'exagérais, comme il l'a fait pour moi, ce qu'il a dit, je prétendrais qu'il veut l'aliénation des forêts de plaine par l'État.

Cependant l'État a son ròle à jouer, même dans les forêts de plaine, pour les gros bois et, étant donnée la limitation que j'ai eu soin d'introduire, je n'exagère rien en proposant l'inscription d'm crédit d'un million pour l'acquisition des forêts. C'est peu sur un budget de quatre milliards et nous ne ferons que suivre l'exemple des pays étrangers (Applaudissements).

11. Taxassesco. - La Roumanie est plus avancée que la France à cet égard en ce qui concerne l'acquisition des forêts par l'État et les établissements publies.

Depuis 1908 fonctionne la Caisse rurale roumaine au rapital de 10.000.000 souscrit par les particuliers à l'aide d'actions de 500 francs qui, actuellement, en valent 1.600 , tellement la caisse est bien organisée.

Cette Caisse rurale, qui est pour ainsi dire garantie par l'État, a pour but d'acheter des propriétés particulières. Elle les divise en propriétés forestières et en propriétés rurales agricoles; la partie agricole est vendue aux paysans par lots de 5 hectares et même plus, et la propriété forestière est rendue à l'État après estimation faite par les agents forestiers et acceptér par la caisse rurale.

En cinq ans, l'État roumain a aclueté pour près de 5.000 .000 france de forêts.

En 1910, une nouvelle caisse a été fondée ou plutòt, c'rst l'ancienne direction des forêts qui s'est transformée en administration spéciale appelée "Caisse des Forêts ", toujours lans le but d'acheter des forêts aux particulier's qui n'en voulaient plus, pour une raison ou pour une autre. Quand l'Etat en trouve une à rendre près de son domaine ou dans des conditions avantageuses, il lineorpore et ainsi les diftirultés d'exploitation sont beaucoup amoindries.

Cette Caisse des Forêts est alimentée par un fond d'État do 7 millions et par un prélèvement de $10 \%$ sur le revenu des forêts de l’État, ainsi que par le revenu de la rente des petites proprítés de l'État, c'est-à-dire des biens qui se rendent par ci par là.

Vous voyez, Messieurs, que la Roumanie est allée beaucoup plus loin que la France dans cette voie, et que la crainte xprimée par M. Girerd n'est pas de nature à inquiéter personne. Bonc je suis d'aris d'admettre le voru tel qu'il est proposí par notre excellent président (Applaudissements).

M. Le Présinext. - Nous remercions notre collègue roumain de ses renseignements si précis qui nous prouvent qu'en adoptant le reeu de M. Vivier, nous n'innovons pas, que nous marchons, an contraire. dans des sentiers battus. 
M. Descombes. - Je remercie d'abord le rapporteur de son commentaire de la Loi Audiffred que I'Association pour l'aménagement des montagnes réclamait depuis 1905 .

La loi portait d'abord les quatre centièmes, mais la Chambre a voté le dixième de l'aroir. Nous pourrions peut-être demander que la Loi de 1910 soit modifiée en ce sens, ce serait d'accord avec le vote de la Chambre. Cependant, je me rallie aux propositions de M. Vivier.

M. le Présidext. - Nous passons au vote. M. Girerd maintient-il sa demande relative au rou $n^{\circ} 3$ ?

M. Girerd. - J'en demande la suppression.

M. Le Présidext. - Je vais donc laisser de côté, pour le moment, le vœu $n^{\circ} 3$ et je mets aux voix les sept autres vœux, étant entendu que le texte du vou no 1 est modifié ainsi que M. Vivier l'a indiqué et qu'au vœu no 5 nous ajoutons, à la suite des différentes associations énumérées : "Et les sociétés constituées en vue du reboisement ou de l'acquisition des forêts n.

L'ensemble des sept rœux est adopté.

M. Le Président. - Je mets aux voix séparément le vœu $n^{\circ} 3$, dont M. Girerd demande la suppression.

Le vou no 3 est adopté.

La séance est levée à $11 \mathrm{~h} .35$. 


\title{
SEANCE DU 18 JUIN 1913
}

\author{
(APRÈS-MIDI) \\ Présidence de M. VIVIER, président de Section
}

La séance est ouverte à 2 h. 40 .

M. Le Président. - La parole est à M. le comte de Nicolay pour la lecture de son rapport sur l'UTILITÉ POUR LES SYNDICATS DE PROPRIÉtAIRES DE GRÉER UN OFFIGE FORESTIER INTERNATIONAL.

M. le Comte de Nicolar. - La forêt semble être restée en marge des progrès que la science a fait réaliser à l'agriculture depuis un demi-siècle. Il a paru suffisant pour protéger la forêt d'entraver les défrichements encore si intenses sur certaines parties du globe et cependant l'on s’aperçoit déjà que des mesures nouvelles sont devenues nécessaires.

L'industrie réclame toujours avec plus d'avidité du bois à ouvrer et la quantité en diminue sans cesse, du moins dans nos forêts françaises.

Les difficultés de transport ont souvent contrarié les échanges commerciaux avec les pays grands producteurs, d'où il est résulté dans certains de ces pays un véritable gaspillage de leurs richesses en bois. Les transformations des conditions de l'existence moderne ont avili de façon inquiétante les produits de nos taillis indigènes. Il en découle une sorte de déséquilibre très nuisible à l'avenir des forêts et qui pourrait avoir un jour son contre-coup sur l'économie de beaucoup de pays européens.

Tous les problèmes soulevés par ces considérations donnent matière à des études profondes qu'il serait du plus haut intérêt d'entreprendre. Mais la tâche est colossale. La longue périodicité des récoltes fournies par les essences ligneuses rend l'expérimentation difficile et exige dans l'effort une continuité qui dépasse plusieurs générations humaines. Les expériences pour être efficaces doivent donc être assurées de toutes les garanties de longue durée. A cette condition seule, pourront être suffisamment définies les lois qui régissent le développement et l'accroissement des essences, l'influence des méthodes culturales, la répercussion des forêts sur les phénomènes météorologiques de l'atmosphère.

Ces données solidement établies guideront les propriétaires périssables et impérissables dans les traitements à appliquer à leurs forêts, elles dicteront aux Etats, aux législateurs et aux Administrations les mesures propres à assurer la pérennité de la forêt tout en respectant les droits de la propriété.

De pareils travaux effectués le plus souvent par l'initiative privée ne 
donneront la plénitude des résultats qu'on en peut attendre que s'ils sont dirigés, poursuivis, stimulés par un être impérissable, je veux dire par l'Etat. C'est ce qui fut compris et organisé par les différents États au point de vue agricole lors de la création de l'Institut international de Rome. II fut bien prévu que les questions forestières ne seraient pas exclues du cycle de ses travaux, mais jamais il n'a été donné de suite à cette faculté et le problème est, à la vérité, si vaste et si complexe que l'on ne voit ni la nécessité, ni même l'avantage de le fondre dans le domaine des questions agricoles.

L'utilité de cette organisation internationale n'en apparaît pas moins réelle. Son programme à première vue est considérable.

Il consistera tout d'abord à établir des statistiques, bases indispensables de tout travail sérieux : statistiques sur la surface boisée en plaine et en montagne des différents pays, sur l'étendue et la composition des massifs, sur leurs rendements, sur la répartition des essences.

Puis viennent les conditions d'exploitation de ces massifs avec le relevé des voies de communication, des centres d'utilisation des produits façonnés, des facilités de transport, des exigences de la main-d'œuvre.

Les statistiques devront alors révéler les fluctuations que subit la forêt, son enrichissement ou son appauvrissement, ses disponibilités, son rendement... Il s'ensuivra des considérations sur le développement, l'acclimatement, la croissance des essences, sur leurs exigences et les maux dont elles souffrent.

Il faudra étudier les fléaux qui menacent les forêts, fléaux qui ont le plus souvent un caractère international et qu'il faut combattre par des mesures internationales.

Telles sont les maladies dues aux insectes ou aux cryptogames comme ce blanc de chêne qui fait des ravages irréparables.

Les incendies peuvent trouver dans un réseau d'assurances un palliatif aux destructions qu'ils occasionnent. L'impôt si pesant pour la propriété boisée trouverait un certain allègement dans une manière de péréquation internationale. La législation forestière toute entière aurait des effets autrement plus efficaces si des accords s'établissaient entre les différents Etats producteurs et consommateurs.

Les stations d'expérience doivent faire l'objet d'une préoccupation spéciale.

L'expérimentation en matière forestière est très difficile, nous l'avons déjà dit. L'expérience commencée par un observateur sera rarement terminée par lui.

L'étude synchronique de peuplements d'âges différents s'impose donc. Un travail lent et patient peut préparer l'avenir, mais les expériences actuelles utiliseront le plus souvent les matériaux préparés, souvent au hasard, par les générations précédentes. Il s'agit donc moins de mener en un point donné une expérience de longue haleine, que de profiter, à notre époque, de tous les champs d'expérience existants, naturels ou artificiels, de transformer en champs d'expérience toutes les forêts où des constatations pourront être faites. Au lieu du cadre étroit d'une administration, e'est au contraire l'imprévu de l'initiative individuelle qui suscitera les remarques les plus utiles. Pour saisir ces observations, pour en contrôler l'importance et les utiliser, un organisme central s'impose, institution internationale ayant des ramifications, des offices de renseignements, des correspondants dans tous les centres forestiers. 
Au siège, des laboratoires poursuivront les recherches; dans les forêts, l'agent comme le simple particulier', consigneront le résultat de leurs observations.

Enfin un service spécial créera une bibliographie forestière; de nombreuses publications fournissent une documentation intéressante que le public ignore, à laquelle il est incapable de s'adresser lor'squ'il en a besoin. Il faudra les classer et en rendre la recherche facile.

Déjà se sont constituées des Sociétés pour le reboisement des landes ou des montagnes; un exemple des plus caractéristique existe en Danemark, il sera précieux de faire connaître les procédés employés, les errements dans lesquels on est tombé, les résultats obtenus. Tous ces faits guideront les instigateurs de nouvelles entreprises.

Aux services d'ordre scientifique nous ajouterons des services commerciaux.

Seul un organisme du genre que nous indiquons pourra établir une mercuriale des bois sur pied, abattus, équarris, signaler les besoins ou les offres de telle ou telle région, faire entrevoir un débouché nouveau... autant de renseignements qu'utiliseront les intérêts particuliers.

Les questions douanières, les tarifs de transport, de fret gagneront à être étudiés par des commissions internationales, non pas de ces commissions intermittentes se réunissant tous les 3 ou 4 ans, mais par un organisme permanent susceptible de poursuivre la réalisation des solutions adoptées. Enfin il y a de vieux usages qui paralysent les échanges dont il faudrait atténuer l'effet, des pratiques nouvelles à instaurer, comme l'unification des mesures de cubage... Il y a des utilisations industrielles à faire connaître, des inventeurs, des chimistes à encourager.

La tâche est immense, et l'on conçoit que seull'État, avec les ressources dont il dispose, avec les sources d'information qu'il peut utiliser, soit susceptible de mener à bien cette entreprise.

Les rapports des agents forestiers sont déjà par eux-mêmes une documentation de la plus haute importance. Ces renseignements pourraient être complétés par les Associations sylvicoles et notamment par ces Syndicats de marchands de bois, de propriétaires forestiers qui vivent de la vie forestière journalière.

La simple inspection du programme que nous avons tenté d'élaborer indique quel appui trouveraient dans cet Office les Syndicats de propriétaires et notamment ce Comité des Forêts, de création récente, qui cherche à diriger les efforts épars et à centraliser les renseignements acquis. Son champ d'action s'élargirait aussitôt, et de l'appui tutélaire d'un c rganisme ainsi constitué il tirerait une sûreté de jugement profitable à tous les intérêts forestiers.

Le Touring-Club ne saurait manquer de préconiser une pareille institution. Il se verra appuyé dans sa demande par toutes les associations forestières. C'est à la France qu'il appartient de prendre une telle initiative. Sa situation géographique lui crée une sorte de devoir spécial de provo. quer la création d'un Office forestier international. Faisant un premier effort pour le doter et lui assurer un local digne du but qu'il se propose, elle invitera les nations forestières d'Europe et d'Amérique à contribuer à son fonctionnement. L'autonomie dont jouirait cet Office rendrait plus naturelle la collaboration des États intéressés et plus effectif leur contrôle. Ils ne manqueraient pas d'y voir un auxiliaire puissant du développement 
de la richesse forestière. Aussi croyons-nous devoir résumer ces considérations dans le rœu suivant:'

\section{LE Coxgrès ÉMET LE vœU :'}

Que le Gouvernement de la République Française prenne l'initiative de la création à Paris d'un Office forestier international autonome, dont l'emplacement serait fourni par la France et dont le budget serait alimenté par lés contributions de tous les Etats intéressés.

Le rapport qui m'a été confié a pour titre : "Ltilité pour les syndicats de propriétaires de créer un Office forestier international (stations de recherches, d'expériences et de renseignements).

C'est à dessein que je répète ce titre pour bien expliquer le terrain sur lequel je me suis placé. Il s'agit de saroir dans quelle mesure un Office forestier international peut être utile aux syndicats de propriétaires forestiers. Nous n'avons pas cherché à préciser une organisation future, nous avons cherché seulement à lancer une idée, laissant à d'autres le soin de préciser de quelle façon elle était réalisable.

La forêt actuellement souffre ; c'est ce qui résulte de tous les exposés qui ont été faits ici. Partout, il se crée des groupements ayant pour objet de lutter contre l'état actuel. Parmi ces groupements, je me permets de penser que les groupements de propriétaires sont actuellement de ceux qui sont les plus intéressants, puisque la plus grande partie du sol boisé en France est entre les mains de propriétaires périssables. Or, les propriétaires, quoi qu'on dise, sont souvent des hommes de bonne volonté et éminemment désireux de défendre, en même temps que leurs intérêts particuliers, l'intérêt général, mais il faut reconnaître que, dans bien des cas, ils ont beaucoup de peine à concilier ces deux intérêts.

Nous arons exposé déjà longuement dans quelle mesure l'État peut intervenir, soit sous la forme de réduction d'impôts, soit saus la forme d'autres aides pour faciliter la tâche des propriétaires.

J'ai voulu envisager cette fois comment, au point de vue technique, l'État peut aider les propriétaires.

L'État a des ressources d'argent et d'hommes considérables; par ces ressources, il peut accumuler des renseignements de tous ordres; ces renseignements sont d'un intérêt capital, mais jusqu'ici le seul qui en profite, c'est l'État lui-même. Or, il me semble qu'il y aurait un intérêt d'ordre général à ce que les particulicrs puissent profiter dans une certaine mesure de tous les efforts considérables faits de toute part par les agents de l'État.

D’où la nécessité de créer un organisme spécial.

Comment créer cet organisme? C'est ici, éridemment, que toutes les initiatives peuvent se donner libre cours. Nous arons cependant un exemple de ce qui s'est fait, au point de vue agricole, avec I'Institut international de Rome, dont les publications, trop rarement lues, 
sont des documents de la plus haute importance au point de vue de toute la culture, d'une façon générale.

Ne pourrait-on pas faire, au point de vue forestier, quelque chose d'identique? L'Institut de Rome a bien prévu en effet dans ses statuts qu'il pourrait avoir une section sylvicole, mais les études que comporte cette branche de l'agriculture sont si complexes et si vastes qu'elles semblent bien pouvoir donner matière à une organisation spéciale, (Très bien! Très bien!) d'autant plus qu'il existe ici un facteur noureau, et ce facteur, c'est l'expérimentation. Or, pour pouvoir mener à bien les expériences très longues que comporte la culture forestière, il y a, il me semble, une question de toute première importance : c'est de se trouver dans une région où ces expériences puissent être poursuivies. Je ne veux pas, dans un Congrès international, vanter exclusivement les avantages que présente à ce point de vue notre propre pays, mais je crois que par la variété de la production forestière qu'on y rencontre, par les essences extrêmement variées qui poussent du nord au sud, la France est tout indiquée pour prendre en l'espèce une initiative à laquelle, je crois, beaucoup d'Etats applaudiront.

Cette initiative comporte une collaboration, et alors, je vois un Institut autonome dirigé par les intéressés, e'est-à-dire d'une part par l'Administration des Eaux et Forêts, d'autre part par les groupements de producteurs et d'intermédiaires, je veux dire les propriétaires et les marchands de bois ; puis je vois également dans cet Institut la collaboration des représentants des mêmes groupements dans les pays étrangers.

Vous voyez dès lors quel peut être le programme. Ce programme comporte tout d'abord de la statistique. Toute espèce de travail commence par la statistique. II s'agit de savoir quelle est la production boisée, il s'agit ensuite de savoir quelles sont les exigences des différentes sortes de consommation. Il y a ensuite à faire connaitre les travaux qui ont été faits sur ces questions. Il existe partout, dans de très nombreuses revues, des articles excessivement intéressants et extrêmement circonstanciés, mais qui, étant donné qu'ils sont très spéciaux, sont, j'oserai presque dire, perdus dans la masse des publications où ils paraissent.

Eh bien! il y aurait un intérêt colossal à ce que tous ces articles fassent l'objet d'une bibliographie. Vous savez le mal que nous autres propriétaires, qui ne sommes pas très initiés à ces questions, avons, lorsque nous voulons étudier une question spéciale intéressant un point déterminé; nous ne savons pas où le trouver, et cependant il existe toujours, car depuis que les forestiers travaillent, il y a un monde de renseignements qui ont été foumis. Ces renseignements, on ne les connaît pas. Même celui qui les suit peut les découvrir le jour où ils paraissent, mais quelque temps après ne peut déjà plus les retrouver.

Je crois donc qu'une bibliographie qui consisterait simplement à permettre aux chercheurs de savoir qu'il y a 10 ou 15 ans, un homme 
compétent, un liomme du métier a fait un article sur telle question, serait à elle seule susceptible de fournir des renseignements de la plus haute importance.

En dehors de cette question de simple bibliographie se place la question de l'expérimentation. On a dit tous ces jours-ci, et à juste titre, que l'idéal pour la propriété, ce serait d'être entre les mains de propriétaires impérissables. C'est important au point de vue de la conservation des forêts, mais c'est peut-être tout aussi important au point de vue de la direction donnée aux expériences, paree qu il est évident que l'expérimentation forestière dépasse de beaucoup la génération humaine, et qu'on peut toujours craindre qu'un changement de propriétaire n'annihile des efforts qui ont été longuement múris.

D'autre part, si nous voulons avoir une expérimentation qui nous rende service à l'heure actuelle, nous ne pouvons pas commencer aujourd'hui des expériences à prolonger indéfiniment; nous sommes donc amenés à souhaiter qu’en matière de forêts on remplace cette expérimentation suivie par une expérimentation, je dirai, synchronique, à savoir que l'on profite à l'heure actuelle des éléments qui nous ont été fournis par les années précédentes et qui sont susceptibles de donner des renseignements. Mais, pour ee faire, il faut des hommes beaucoup plus compétents que ne le sont des propriétaịres, et je crois que l'expérimentation peut être conduite d'une façon tout aussi intéressante en s'adressant aux bois partieuliers qu'en s'adressant aux bois de l'État, je dirai presque, plus intéressante, parce que si les bois de l'État ont toujours été bien adıninistrés, il n'en est pas de même des bois particuliers, et dès lors, en comparant une bonne administration et les résultats fournis par une mauvaise, on peut en tirer une règle.

J'ai entendu dire à beaucoup de forestiers de l'État qu'ils ignoraient complètement les forêts particulières; or, je crois que l'État a un double rôle : son rôle personnel de propriétaire, mais surtout ce ròle essentiel qui est un ròle tutélaire, à savoir d'aider, de liriger, de guider.

Eh bien, pour pouroir guider d'une façon utile, il faut aroir tout en mains; il faut pouroir suivre des expériences partout où il y a matière à étude; ceci peut faire l'objet de cet organisme central auquel je faisais allısion qui, faisant appel à tous les concours, groupant toutes les bonnes rolóntés, cherchant des sujets d'étude partout où il yen a, ayant sa vie propre, car je le considère comme autonome, mais ayant aussi les avantages d'un budget élastique, grâce aux contributions des différents États, ayant également à sa disposition les ressources d'hommes que peuvent seules donner des administrations compétentes, est susceptible de donner aux propriétaires, et notamunent a ces propriétaires qui maintenant éprouvent le besoin de se grouper, et qui, par conséquent sont plus susceptibles de profiter des leçons que vous leur donnerez, une impulsion nouvelle qui pourra p’ut-être concilier dans une large inesure les dégâts que l'on reconnait 
partout dans le domaine boisé, partieulièrement en France (1pplandissements).

Je me permettrai, Messieurs, de vous lire le veu qui termine mon rapport ;

Le Congrès émet le voru :

"Que le gouvernement de la Képnblique frunçaise prenne l'initiative de la création à Paris d'un office forestier international antonome dont l'emplacement serait fourni par la France, et dont le budget sersit alimenté par les contributions de tons les États intéressés."

M. Le Présidext. - Je remereie 11. de Nicolay de l'intéressante eommunication qu'il vient de nous faire et dont le mérite est do traiter un sujet tout à fait nouveau. C'est une question à l'ordre du jour et qui, pour nous, a le plus vif intérêt.

11. Parué. - Je crois que l'organe que demande M. de Nicolay existe déjà en partie au point de vue international. 11 y a en effet une Association internationale des stations de recherches qui tient des rongrès et qui a l'intention - car elle a pris cette décision à son dernier congrès de publier un bulletin, afin de faire connaitre toutes les données de l'expérimentation et de donner tous les renseignements bibliographiques. Cela a été déeidé au Congrès de Bruxelles. Peut-être y aurait-il à améliorer cet organisme, mais enfin, il existe et il existe au point de vue international.

M. Curf. - Je dirai même que la France n'a adhéré que tout récemment, bien qu'elle ait été l'instigatrice de cette Association internationale; pour des raisons que j'ignore, la France n'a jamais été représentée dans ces congrès internationaux. A Bruxelles, il y a eu un représentant officiel, mais l'Arlministration n'a envoyé aucun de ses délégués

M. LE Président. - Cette association a-t-elle un organisme permanent? Où est son siège?

II Parué. - 11 varie à chaque Congrès; le président est choisi rlans la Puissance wù doit avoir lieu le Congrès suivant.

II. Gryot. - Je ne crois pas que l'organisme dont parle nos collègues puisse remplacer celui que désire eréer M. Nicolay. Je connais parfaitetement l'Union des stations de recherches, nous en avons parle bien souvent à l'École forestière, il a même été rquestion plusieur's fois que le Congrès se tienne a Nancy, mais ee n'est pas un établissement permanent, il voyage de còté et d'autre; il n'a done pas la stabilité qui est absolument nécessaire à l'établissement que nous voulons créer. Nous voulons que tous les propriétaires, les propriétaires français comme les autres, puissent savoir où s'adresser, puissent avoir un organe permanent où ils trouveront ce qu'il leur faut connaître. 
Où iront-ils chercher cet organe voyageur qui tantòt est en Belgique, tantòt en Bavière ou ailleurs? Je ne pense pas, quel que soit l'intérêt que présente cette union, qu'elle puisse faire double emploi avec l'organe permanent que nous voudrions créer, car, je l'avoue sincèrement, je suis absolument d'avis que cet'te création s'impose et s'impose pour un pays comme la France.

Nous avons laissé échapper, et je le regrette profondément pour mon pays, la eréation de l'Office international d'agriculture qui a été créé en Italie parce que nous n'en avons pas voulu. Il importe donc de revendiquer ici au moins une partie de cet héritage qui devait nous appartenir. Je dis qu'il devait nous appartenir, parce que l'Italie certainement a un très grand intérêt au point de vue de l'agriculture ; l'agriculture y est extrêmement variee, mais la sylviculture n'y est certainement pas aussi développée qu'en France. Notre pays, par la variété de son climat, par la variété de ses essences, est placé précisément à l'endroit nécessaire pour centraliser tous les efforts, toutes les cultures, tous les travaux. Voilà pourquoi il me semble que ce serait en France plutôt qu'ailleur's que cet organe international devrait être créé.

Quant aux différents éléments que l'Office international devrait comprendre, je me rallie parfaitement à l'énumération qu'en a faite M. de Nicolay, notamment en ce qui concerne les renseignements du commerce mondial. Ce sont des renseignements qu'il faut savoir trouver, que les propriétaires particuliers ont besoin de connaître et de chercher à un endroit déterminé. De plus, la bibliographie est une chose capitale, elle ne peut pas non plus se promener d'endroit en endroit; il faut qu'elle soit située dans un local où chacun pourra venir la consulter.

Je me souviens que lors de l'Exposition de 1889, j'étais jeune agent à Nancy, et l'on m'a chargé de préparer, avec d'autres, une bibliographie forestière. Nous avons envoyé des circulaires partout, dans tout l'Univers, il nous est arrivé un grand nombre de fiches, j'en ai préparé des volumes énormes, puis, cela a été trouvé tellement considérable qu'on nous a dit ensuite qu'on n'avait pas d'argent pour l'imprimer.

Ce qu'il faut, c'est une continuité d'efforts, il ne faut pas que ce soit un agent passager qui soit clıargé de réunir les documents nécessaires ; il faut que ce soit un Office permanent, qui ne meure pas et qui continue à accumuler documents et idées.

Je crois - et M. Pardé voudra bien me permettre d'insister là-dessus - que tout en adhérant dans la mesure du possible à l'Union des stations de recherches forestières, nous devons créer l'institution préconisée par M. Nicolay, qui ne fera pas double emploi, et j'engage vivement le Congrès à prendre une résolution dans ce sens ( $A$ pplalldissements).

M. Pardé. - Je vois très bien les avantages que nous autres, Français, 
avons à la création à Paris d'un Office de renseignements forestiers, mais nous sommes dans un Congrès international, il faut un organisme international. Peut-être y a-t-il des améliorations à apporter à ce qui existe déjà, mais pourquoi ne pas en profiter?

M. Le Présidext. - Je crois que nous pouvons très bien nous entendre. Il y a différentes manières d'en profiter. Ce qui m'a frappé précisément dans ce que vient de dire M. Nicolay, et après lui M. Guyot, c'est que l'organisme dont vous parlez, cette association très intéressante que nous vous remercions de nous avoir fait connaître d'une façon plus précise, est essentiellement une Association de stations de recherches. Or, l'Institut international dont parle M. Nicolay comprend deux éléments aussi importants l'un que l'autre : l'expérimentation, sans doute destinée à indiquer aux propriétaires la meilleure manière de production, mais aussi la question commerciale, la question des débouchés, qui est d'une importance énorme. Or, les stations de recherches, d'une manière générale, s'occupent plutôt d'expérimentation, de science forestière que de commerce. Par conséquent, l'Office international a une portée plus vaste que l'Association dont vous parlez.

En second lieu, cette Association, par le seul fait qu'elle se déplace, qu'elle constitue un bureau valable pour une période donnée, manque évidenment un peu du caractère de permanence qu'on peut souhaiter pour un établissement de ce genre et qu'on a créé en matière agricole par l'lnstitut international de Rome.

Je crois que l'association des deux, peut très bien se faire; il ne me paraît pas douteux que le jour où l'on créerait cet Office forestier international autonome, un de ses premiers soins serait de se mettre en relations avec cette Association qui serait susceptible de lui apporter une contribution très importante, mais simplement une contribution, et qui alors, pourrait continuer à opérer dans la liberté de ses mouvements, de ses statuts particuliers, avec cette mobilité relative - je dis relative pour indiquer qu'il y a un lien - pendant que l'Office forestier international, tout en profitant de l'expérience acquise par cette Association, de tous ses travaux passés et présents, s'occuperait également de toute la partie commerciale, et possèderait une permanence absolue, un siège fixe, un personnel stable où tous les intéressés pourraient avoir les renseignements dont ils auraient besoin.

Je crois done qu'il n'y a pas contradiction entre les deux choses, et qu'au contraire l'Association dont vous parlez serait le premier appui sur lequel l'Office forestier international aurait à compter. Voilà les deux avantages que j'y vois : compléter d'une part et fixer de l'autre (Applaudissements).

M. Pardé. - J'applaudis de tout cocur à la création en France d'un Office de renseignements forestiers, seulement je crains, que par leur multiplication, ces organismes ne se nuisent. 
Si je suis bien renseigné, je crois que, précisément, la création de l'Institut agricole a nui beaucoup au Congrès d'agriculture ; beaucoup de nations européennes n'ont pas pris part au Congrès de Gand. Je ne sais pas si c'est exact, mais on m'a dit que c'était à la suite de la création de l'Institut.

Quant à la création en France d'un Institut forestier, je n'y vois que des avantages.

M. Margaixe. - Je voudrais appuyer le vou de M. de Nicolay, à propos de l'Institut international de Rome.

Cet institut a un grand inconvénient pour les particuliers; c'est qu'il est une institution d'État; ce qui fait que les particuliers ne peurent correspondre avec lui que par l'intermédiaire de leurs gouvernements.

M. le Présinext. - Je crois que son insuffisance au point de vur lorestier est reconnue par tout le monde. Cette institution a un mérite, mais je crois qu'au point de vue forestier elle est insuffisante.

M. Margaine. - L'Office que nous voulons créer, sera directement en contact avec nous, propriétaires.

M. Le Présinext. - Le voru que M. de Nicolay a joint à son rapport contient ces mots Office international autonome. Vous avez suffisamment montré par ce mot autonome que ce que vous demandiez n'était pas purement et simplement un service administratif. Ce mot répond suffisamment à votre rou.

Entre votre vou et l'exécution, il pourrait y avoir des modalités. Messieurs, vous qui êtes des forestiers de tous les pays, qui arez à faire connaitre librement vos intentions, vous montrez par le mot autonome que vous entendez éviter ce qui, d'après l'exposé de M. Margaine, aurait été un des écueils.

M. Makgaine. - L'institut de Rome ne connait que les gouvernements.

M. Le Présidext. - Le mot autonome montre que vous avez l'intention de le rendre le moins possible officiel et administratif.

M. DE Larxage. - Je ne puis qu'appuyer d'une façon très énergique le vou présenté par M. de Nicolay.

Je demanderai done s'il ne serait pas opportun de compléter le voeu en spécifiant que l'Office forestier comprenne dans ses représentants - nous, Français, nous ne pouvons parler quau nom de notre pays en dehors des membres de nos services forestiers, des membres de toutes les grandes sociétés. ou syndicats s'orcupant des questions forestières.

11. Le Président. - En ce qui concerne la première proposition de 11. de Larnage, il faudra faire de larges appels; mais il serait excessif de spécifier préciséinent les noms des groupements qui seraient repré- 
sentés a l'office international. On prut en oublier, de sorte que je vous proposerai, pour répondre à la pensée de M. de Larnagen, de mettre dans le vou de M. de Nicolay : "d'm office internationul antonome, faisunt uppel à tous les concours... .. C.la montrupait birn que la pensée du Congrès est qur, dans l'organisation de joffiere, personne ne soit oublié. Mais il n'st pas possible d'entrer tans ler détail d'une énumération.

M. le baron de Hexset - Messieurs, je suis ici en qualité de délégué du ministère autrichien de l'Igrieulture. de ne suis pas chargé par mon gouvernement de prendre la parole, ni de faire des propositions dans un sens quelconque. Mon ròle est d'écouter, le eomprendre et de rapporter ensuite à mes mantants ere que jaurai appris.

Je dirai - au titre de simple congressiste et de proprietaire - que j'approure pleinement la création d'un institut international.

Je troure que les propositions formulées par lorateur qui mª précédé sont un peu trop compliquérs.

Vous vous rappelez tous, Messirurs, quelles rliffeultés a soulevée la création de l'Institut de Rome: A re moment - en 1905, si je ne me trompe - cest l'Autriche qui a demandé qu'il fút composé des Associations agricoles. L'Autriche est restée en minorité parce que tous les autres gouremements ont roulu créer un institut gonverne. mental.

Je crains qu'il en soit de même actuellement. Il serait nuisible de trop préciser.

MI. Parué. - Pour préciser lo caractère international du voru, jr demande qu'on fasse appel aux Parlements de tous les pays.

M. LE PrésIDExT. - Le mot internutionul et l'Pxpression tons les concours, que nous venons de proposer d'ajouter au vou, laisse supposer qu'il s'agit du concours de tous ceux qui ont m intérêt queleconque à la création de cet Office, en tant que nation ou en tant qüindividus. II faut ête aussi simple que possible.

11. le comte dr Nicolir. - M. Ir Président ma fait tout fa l'heure l'honneur de me dire que lo veu que j'étais chargé de vous tradnire était une idée neure. Je dirai que c'est simplement une idén qui nest pas múre, qui a besuin d'une plus longue discussion et d'une etude plıs attentive qua pu êtro cellr aboutissant à présenter un rapport de quatre pages.

Aussisommes-nous volontairement restés lans des termes généraux, peut-être excessifs, mais assurément prudents.

II. Je président me propose d'ajouter quelques mots an vou que j'ai présenté, et qui seront une petite spécification supplementaire aux termes rlans lesquels j'étais resté. Le Congrès aurait un intérêt général à se reporter au nouveau texte qu'il a proposé. 
M. DE SÉbille. - J'appuie énergiquement la proposition de créer "Un Office forestier international ", j'en reconnais l'inéluctable nécessité, surtout en présence de ce qui vient de se passer à Gand. La cinquième section de ce congrès, que j'avais l'honneur de présider, rappelant le vote émis au Congrès de Paris de 1900, proposa de nouveau de modifier le titre du Congrès et de l'appeler dorénavant Congrès International d'Agriculture et de Sylviculture, faisant valoir que beaucoup de forestiers ignoraient que les congrès d'agriculture traitaient des questions de sylviculture, en montrant qu'à Gand même, il n'y avait qu'une trentaine de personnes suivant nos discussions; beaucoup de mes compatriotes ne se doutaient même pas que l'on discutait des questions qui les intéressaient, la publicité sur ce point ayant été très peu efficace.

Cette motion fut repoussée par les dirigeants du Congrès, s'appuyant pour ce faire sur des arguments plutòt spécieux, montrant une fois de plus que l'on tenait la sylviculture comme la Cendrillon de la famille.

L'importance et la valeur des intérêts que nous défendons ne nous permettent pas d'accepter cette situation d'infériorité; aussi est-ce arec enthousiasme que je rois surgir la proposition que nous présente le comité organisateur et je souhaite vivement qu’elle soit rotée par l'assemblée.

M. Le Présidext. - Sous le bénéfice de ces observations, je mets aux voix le vau de M. de Nicolay qui est ainsi conçu :

"Que le gonsernement de la République française prenne l'initiative de la création à Paris d'un Office forestier international, faisant appel à tous les concours, dont l'emplacement serait fourni par la France et dont le budget seruit alimenté pur les contributions de tous les États intéressés. "

Ce rou est adopté.

La parole est donnée à M. Delahaye, secrétaire, pour la lecture du résumé de la communication de M. Cuif sur les Statiors DE RECHERCHES FORESTIÈRES.

M. Delahaye. - Dans un rapport à l'appui duquel il produit un long projet d'organisation de la station de recherches et d'expériences annexée à l'École nationale des Eaux et Forêts, M. Cuif, inspecteur des Eaux et Forêts et directeur de cette station, propose :

10 D'en spécialiser le personncl qui comprendrait: l'inspecteur directeur et un ou deux chefs de cantonnement comme auxiliaires :

$2^{\circ}$ De doter largement en traitement, crédits, matériel et personnel, cette station de recherches.

$3^{\circ}$ In: la placer sous la haute surveillance et le patronage d'un comité composé du directeur de l'École forestière, de trois professeurs 
de cette école, de trois conservateurs du service actif, d'un propriétaire particulier et d'un marchand de bois.

L'objet qu'il poursuit est d'établir, dit-il, une organisation suffisante pouvant imprimer en tous temps et en tous lieux une impulsion unique à des forces éparses.

11. Le Président. - La parole est à MI. Cuif pour faire l'exposé général de sa communication.

M. Gurf. - Messieurs, des visites réitérées des stations expérimentales de recherclies appliquées à la sylviculture, organisées par les divers pays de l'Allemagne, "j'ai rapporté la conviction, écrivait Grandeau en 1879, que cet exemple de vrait être suivi par l'Administration lrançaise pour le plus grand profit de la seience et de la pratique forestières».

Un arrèté du Ministre de l'Agriculture en date du 27 février 1882 exauça ce vou, en instituant une station de recherches auprès de l'École forestière de Nancy.

Dans un rapport adressé le 15 octobre 1912, à II. le Directeur général des Eaux et Forèts, sur'sa demande, j'ai donné un résumé de l'historique de cette station, ainsi qu'un exposé des réformes urgentes qu'il conviendrait, selon moi, d'apporter à son organisation et à son fonctionnement, pour la mettre à même de rendre tous les services que l'on est en droit d'attendre d'une institution de ce genre.

Il est hors de doute, en effet, que la station de Nancy est restée, depuis trente ans, à l'état d'embryon. Tout lui a manqué pour lui permettre de prendre un essor digne des neuf millions d'hectares boisés que l'on rencontre en France : personnel, crédits, organe spécial de publications, etc..

Le résultat de cette déplorable infériorité est, sinon une stagnation complète des sciences forestières dans notre pays, du moins une influence souvent nélaste exercée sur elle par des publications étrangères. Onvrons un traité récent de sylviculture ou d'économie forestière écrit en langue française, nous y trourons des théories appuyées pour ainsi dire exclusivement sur des faits constatés chez nos voisins de l'Est. N'est-ce pas là un fait regrettable contre lequel il importe de réagir avec d'autant plus d'activité qu'il faudra des années, parfois même des siècles, pour réparer les désastres causés par de nouveaux venus, nullement adaptés à notre esprit national et surtout à nos conditions de productions forestières.

En mettant à l'ordre du jour cette question des recherches forestières, les organisateurs du Congrès international ont donc été sage ment inspirés.

Ce qu'il faut, en la circonstance, c'est une organisation suffisante qui puisse impriner, en tout temps et en tout lieu, une impulsion unique à des forces éparses.

N'oublions pas qu'il a fallu renoncer, en Prusse, aux stations secondaires pour centraliser à Ebersvalde la conduite des recherches.

N'oublions pas que, non seulement les stations des divers pays de l'Allemagne ont reconnu la nécessité de se constituer en association pour assurer, dit l'article premier des statuts, le succès de l'expérimentation, en adoptant des plans d'exécution uniformes, mais qu'il parut bientôt utile d'aller plus loin encore dans cette voie, en réunissant dans une Association internationale toutes les stations de recherches des différents pays forestiers.

X'est-il pas beaucoup plus sage, dans ces conditions, de grouper immédiatement, en France, tous les efforts, au lieu d'admettre une dispersion, source fatale de médiocrité, probablement d'insuccès.

Ce groupement, le projet de réformes que j’ai déposé, tendra à le réaliser. Il aura pour objet la création d'une institution solide, entrainant avec elle l'unité de direction, l'unité de méthode et l'esprit de suite, c'est-à-dire le maintien des traditions en dépit des cliangements de personnel qu'il est impossible 
"'eviter. Lne institution de ce genre est absolument indispensable au succès de l'entreprise.

I'ai donc l'honneur de vous proposer le reu suivant:

"Que l'Administration des Eaux et Forêts poursuive dans le plus bref délai, sans attendre la réforme de l'enseignement qui doit être entreprise prochainement, une organisation rationnelte de l'expérimentation forestière en France.") (Applaudissements.)

11. GrYot, - J'espère que l'Administration saura comprendre le devoir qui lui incombe, et, sans ent er dans les détails de M. Cuif, je me borne a demander qu'au phus vite a station de Nancy soit organisée à l'égal des stations étrangères $\left(A_{H_{i}}\right.$ landissements).

II. LE PrÉslnext. - Je tiens à dire que l'Administration forestière n'a pas attendu aujourd'hui pour porter sa pensée sur les stations de recherches et je vous propose de remplacer le vocu de M. Cuif par relui-ci qui est plus général.

"Que duns tous les pays, spécialement en France, l'amélioration et le développement des stations de recherches soient l'objet de la sollicitude particulière de l'Administralion forestière."

Adopté.

La séance est levée à 4 heures 


\title{
SEANCE DU 19 JUIN 1913
}

\author{
(MATIN) \\ il \\ Présidence de M. VIVIER, płésident de Section
}

La séance est ouverte à 9 h. 15 .

M. LE Présinext. - La parole est à M. Madelin pour donner lecture do

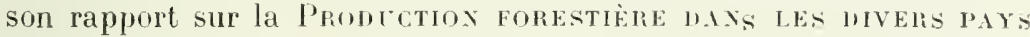
DU GLOBE.

M. MADELIX. - Nous nous proposons dans ce rapport, non pas, comme son titre tendrait à le faire croire, de rechercher la valeur de l'ensemble des produits forestiers dans le monde, mais beaucoup plus modestement de grouper les éléments statistiques et les divers renseignements qu'il est actuellement possible de réunir en vue de se rendre compte de la situation forestière des divers continents.

Pour parvenir à ce résultat et pour présenter, avec quelque clartí, les documents recueillis, nous avons adopté la division suirante :

10 Superficie occupée par les forêts;

$2 \circ$ Production en matière dans différents pays;

$3^{\circ}$ Besoins actuels de la consommation.

Lorsque Mélard publia, en 1900, son fameux rapport sur "l'lnsuffisance de la production des bois d'œuvre dans le monde ", il chercha à se rendre compte de la place occupée par les peuplements forestiers sur le globe terrestre; il réunit des chiffres, mais les trouvant incomplets et insuflisants, il renonça à les livrer au public. Il voulut bien, quelques mois avant sa mort, nous remettre ses notes, avec la pensée qu'elles nous serviraient un jour. Elles sont l'élément de base de ce travail. Nous avons cherché, par une enquête poursuivie un peu partout, et pour laquelle nous avons trouvé d'empressés concours, à compléter les doeuments dont il disposait. Ce sont les résultats de cette consultation que nous reproduisons ci-après. Toutefois, nous faisons les plus expresses réserves sur beaucoup de ces chiffres.

Il est évident, en effet, que la précision est impossible pour les trois raisons suivantes :

$1^{\circ}$ Dans les pays éloignés des centres civilisés, la contenance des forêts sur d'immenses espaces n'a pu être établie. On se contente de larges àpeu-près. Les gouvernements de ces pays ignorent eux-mêmes l'étendue 
de leurs territoires boisés et, par conséquent, n'ont rien publié d'officiel à ce sujet.

$2^{\circ}$ Il est très difficile de s'entendre sur la question de savoir ce qui doit ou non, être considéré comme forêt. Parfois de vastes landes au milieu desquelles apparaissent épars de rares échantillons ligneux, ou des espaces ravagés par les incendies et non repeuplés, ou des pâturages, ou même d'immenses étangs, des lacs, etc., ont été compris dans les surfaces forestières.

$3^{\circ}$ Enfin dans tous les pays, même fussent-ils très civilisés, la forêt est en perpétuel mouvement de ra-et-vient : défrichements d'une part, reboisements de l'autre. Il n'est pas de jour où l'aire forestière puisse être considérée comme fixée.

Ces observations préliminaires étaient nécessaires pour donner au tableau qui va suivre l'excuse de contenir des chiffres certainement contestables, mais qui ont été cherchés le plus près possible de la vérité.

Enfin, pour permettre à la critique de s'exercer utilement, nous arons cru devoir indiquer les sources auxquelles les renseignements donnés ont été puisés.

\section{Superficie boisée des différents pays du globe (en hectares)}

\section{EUROPE}

France..................

Bavière.............

Saxe (royaume de)....

Prusse.............

Wurtemberg.........

Autres pays allemands.

Alsace-Lorraine.......

Autriche............

Hongrie............

Bosnie-Herzégovine...
9.886.700 Statistique établie en 1912 parl'Administration des Eaux et Forêts.

2.466.553 D’après le Forst und Jagd-Kalender, année 1913, du Dr Neumeister.

384.540 D'après le Forst und Jagd-Kalender, année 1913, du Dr Neumeister.

8.270.133 D'après le Forst und Jagd-Kalender, année 1913, du Dr Neumeister.

600.415 D'après le Forst und Jagd-Kalender, année 1913, du Dr Neumeister.

1.838.144 D'après le Forst und Jagd-Kalender, année 1913, du Dr Neumeister.

439.832 D’après le Forst und Jagd-Kalender, année 1913, du Dr Neumeister.

9.778.000 Dont 7.306.000 pour l'Autriche occidentale et 2.472.000 pour la Galicie et la Bukovine. - Aperçus statistiques de G. Sundbärg, Stockholm, 1908.

9.056.000 Aper'çus statistiques de G. Sundbärg, Stockholm, 1908.

2.275.000 Aperçus statistiques de G. Sundbarg, Stockholm, 1908.

D'après la notice publiée à l'occasion de l'Exposition universelle de 1900 , la contenance serait de 2.709.000 hectares.

A reporter...... 44.995 .317 
Report

Grande-Bretagne.....

Belgique...........

Bulgarie...........

Danemark..........

Espagne ...........

Grèce (lles comprises) . .

Italie...........

Luxembourg. ........

Norvège...........

Pays-Bas. ..........

Portugal..........

Roumanie..........

Russie d'Europe...... 1
44.995 .317

1.226.300 D'après M. Schlich, professeur à Cooper's Hill (Revue des Eaux et Forêts, 1906, page 461). La statistique publiée en 1908 par le département d'Agriculture d'Angleterre indiquait comme contenance 2.782.000 acres, ce qui revient à 1.125 .800 hectares. Le chiffre donné par M. Robinson, au Congrès de Gand, est de 1.120.700 hectares.

534.917 Statistique dressée par le service forestier belge en 1905.

2.590.000 Aperçusstatistiques de G. Sundbärg, Stockholm, 1908.

327.268 D'après les rapports de 1907 , publiés par le Journal du commerce des bois.

8.483.000 Chiffres de M. Schlich, professeur à Cooper's Hill, adopté par nous parce qu'il est intermédiaire entre celui de la statistique agricole de $1892: 6.488 .000$ et celui donné par M. l'inspecteur Vanutberghe : 10.600.000 (Résue des Eaux et Forêts, 1908, page 533).

830.000 Chiffres de 1893, donnés par le ministre des Finances à Athènes. D'après l'article : Ueber Griechenlands Walder, dans la Revue Centralblatt für das gesamte Forstwesen, avril 1912, page 195 , le chiffre de la contenance serait de 2 millions d'acres ou 809.000 hectares.

4.156.000 D'après les aperçus statistiques internationaux de G. Sundbärg, Stockholm, 1908. — L'annuaire statistique italien de 1898 portait: 4.093.000 hectares.

83.400 Revision du cadastre en 1898 (Revue des Eaux et Forêts, 1903, page 697).

6.897.800 D'après M. l'Inspecteur-adjoint Perrin (Revue des Eaux et Forêts, 1910, page 263). La surface réllement boisée est de 6.637 .900 hectares. - D'après M. l'Inspecteur Mührwold, la contenance serait de 6.818 .000 hectares (Resue des Eaux et Forêts, 15 février 1900).

260.222 Notes sur l'agriculture de la Hollande par Rabaté (Bulletin de la Société d'Encouragement pour l'Industrie nationale, $\mathrm{n}^{\circ}$ de décem. bre 1912).

1.621.589 Excursion forestière en Portugal par Pardé, chiffres empruntés au rapport présenté à l'Exposition de Rio-de-Janeiro par le gouvernement portugais et rédigé par M. J. Ferreira Borges.

2.755.726 Statistique publiée par le gouvernement rou. main en 1907.

196.530.000 Dont 2.740.000 pour la Pologne. Le chiffre cicontre est extrait des aperçus statistiques de Sundbärg, Stockholm, 1908. D'après certains autres renseignements, il parait plus près do la vérité que celui donné en 1900 par la notico sur les forêts de la Russie, 164.968.000 hec. tares. 
Report.......... 271.291.539

Finlande........ 17.000.000 Aperçus statistiques de Sundbărg, Stockholrn, 1908. La notice ci-dessus citée donnait 20.430 .000 hectares.

Serbie................

1.517.000 Revue des Eaux et Forêts, 1906, pag? 334, D'après les aperçus statistiques de sundbärs, la contenance serait de $\mathbf{1 . 5 0 0 . 0 0 0 ~ h e c t a r e s ; ~}$ d'après M. Schlich : 967.200 hectares; d'aprèz Bouquet de la Grye : 2.090.000 hectares. Le chiffre intermédiaire a été choisi.

Suède $\ldots \ldots \ldots \ldots \ldots$. 21.210.100 Aperçus statistiques de Sundbărg, Stockhølm, 1908. Il y a toutlieu de croire que M. Gustare Sundbärg a donné pour son pays le renseignement très exact. Cependant, une publication officielle faite en 1900: La Suede, son peuple et son industrie mentionnait le chiffre de $1897: 19.591 .000$ hectares.

Suisse ...........

Turquie d'Europe et Crète............

2500.000 Chiffre douteux d'après M. Schlicl. La conte. nance totale des forêts de l'empire ture (Asie et Europe) est de 8.800 .300 hectares (avant le démembrement de 1913). Rapport du ministre des mines et forêts cité par l'article: Waldbestände und der IIolzhandel in ter Türkei (Continental Holzeitung, juin 1912. pages 221,222 ).

TOtAl POUR L'EUROPE. $\overline{314.468 .539}$

\section{AFR IQUE}

Algérie..........

Tunisie...........

Maroc............. Cote d'Ivoire .........

Dahomey .......... Autres pays de l'Afrique Occidentale française Afrique équatoriale Irançaise (Gabon, Moyen - Congo, Oubanghi-Chari, Tchad).
2.816.000 M. Guyot, Commentaire de la loi forestière algérienne du 21 février 1903, page \%, d'après l'Exposé de la situation générale de l'Algśrie en 1903.

878.000 Dont 808.000 hectares domaniaux, 198.000 au $\mathrm{N}$. de la Medjerdah, 610.000 au S. (Renseignements fournis par M. Bastien, Directeur dos forêts de la Régence.)

1.500.000 Chiffre forcément approximatif.

6.000.000 D'après le commandant Gros, chargé d'une mission en Afrique. Il est vraisemblable que ce chiffre qui représente un taux de boisement de $20 \%$ est plutôt faible. La Revue des Eaux et Forêts, 1912, page 751, donnait ly chiffre de 12.000 .000 d'hectares.

1.122.000 Chiffres forcément approximatifs.

\subsection{0 .000}

id.

50.000.000 Chiffres représentant un taux de boisement $\mathrm{d}$ t $30 \%$ environ.

A reporter....... $\overline{\mathbf{1 1 7 . 3 1 6 . 0 0 0}}$ 
Report...........

Madagascar...........

Autres pays de protectorat et possessions françaises en Afrique (Mayotte et Comores, la Réunion, Somalie, etc., etc...)........

Congo belge..........

Abyssinie..........

Le Cap et Natal.......

Transvaal ..........

Kameroun allemand et Est-Africain allemand..

Egypte et Soudan..... Tripolitaine. ......... Autres pays d'Afrique..

Total de l'Afrique . 229.314.200

\section{Canada :}

Colombie anglaise..... Maritoba, Alberta, Saskatchawan et territoires du Nord-Ouest. Ontario............ Québec............. Nouveau-Brunswick... Ile du Prince-Édouard .

Nouvelle-Écosse......

États-Unis

Alaska

Cuba

Mexique

A reporter.

$\overline{392.042 .200}$

47.600 .000
9.000.000 Revue des Eaux et Forêts, 1912, page 696 .

7.060.000 Chifre représentant un taux de boisement de $10 \%$

6.000.000 Chiffre établisur le taux de boisement de $12 \%$ 209.800 Rapport de M. D.-F. Hutchins a l'Association du Sud-Africain pour l'avancement des Sciences, 1903 (Forestry Quaterly, vol. X, no 4 de 1912, p. 721).

8.400 Rerue des Eaux et Forêts, p. 600, 1906, d'après M. Hutchins.

8.380.000 Forests and Forestry in the German Colonies, par 11. Fernow, dans Forestry Quaterly, vol. X. $n^{\circ} 4$ de 1912 , page 633 .

2.800.000 Chiffre forcément approximatif.

1.000 .000 id.

30.000 .000 Chiffre établisur le taux de boisement de $10 \%$

\section{MNERIQUE}

20.235.000 Chiffes extraits du volume intitulé : Le Canada et la France, publié en 1911 par la Chambre de commerce française de Montréal, page 254. Ce sont vraisemblablement les chifres des forêts régulièrement cadastrés et utilisables. Le totaldesforêts du Canadaes très supériemr. D'après le même volume il est cinq fois plus grand que le total des forêts des Indes $(63 \mathrm{mil}$. lions d'hectares). La contenance totale des forêts du Canada doit être portée, en effet, à 315 millious d'hectares.

2.044.700 Forest Conditions Nova Scotia, par B.-E. Fernow (Commission of Conservation Canada).

202.300.000 500 millions d'acres d'après lesstatistiques publiées par le gouvernement d-s États-Unis.

\$3.300.000 D'après les statistiques publices pal' le gouvernement des États. Unis.

2.000.000 Chiffre doutenx. Le seul chiffre certain est : forêts domaniales, 779.760 hectares.

8.000.000 Chifre foumi par M. l'Inspecteur des eaux et. forêts Lapie, doctenr ès-sciences, qui a été chargé d'une mission en Amérique. 
Report...........392.042.200

Antilles .......... $\mathbf{1 7 . 2 5 0 . 0 0 0 ~ D ' a p r e ̀ s ~ l e s ~ s t a t i s t i q u e s ~ p u b l i e ́ e s ~ p a r ~ l e ~ g o u v e r - ~}$ nement des Etats.Unis.

Brésil............. 124.000.000 D'après le taux de boisement présumé $15 \%$.

Venezuela......... 5.500 .000 D'après M. Lapie qui estime le taux de boisement supérieur à $50 \%$.

République Argentine.. $\quad 36.800 .000$ D'après M. Lapie qui estime le taux de boise. ment à $13 \%$.

Paraguay ......... 20.000.000 Chiffre fourni par M. Lapie, 12.000 .000 d̀ l'Est de Rio-Paraguay et 8.000 .000 dans le Chaco.

Panama..............

République Domini-

caine.............

Chili ...............

Guyane française ......

Autres pays de l'Amérique du Sud. ..... 25.000000 Chiffre forcément approximatif.

TOTAL POURL'AMÉRIQUE 646.752 .200

ASIE

Chine.......... 48.300.000 Chiffre très douteux. Certaines régions de l'Ouest chinois sont encore très peuplées de forêts (Revue des Eaux et Forêts, année 1910, page 347 ). Il semble possible d'estimer à $12 \%$ le taux de boisement de la Chine.

Corée...............

3.300.000 Chiffre établi en admettant le taux de boise. ment de $15 \%$.

Japon .......... 22.750.000 Revue des Eaux et Forêts, 1906, page 438.

Slam ............ 14.000.000 Chiffre établi en admettant le taux de boise. ment de $20 \%$.

Indo-Chine française... 25.000.000 D'après M. Ducamp, chef du service forestier de l'Indo-Cline, dans son article: La Forêt, richesse coloniale. M. Ducamp parait admettre que ces 25 millions ne constituent qu'une partie de la forêt lndo-Chinoise.

Russie d'Asie ....... 136.546.800 Bulletin de statistique et législation comparée, Revue des Eaux et Forêts, 1903, page 55. D'après la statistique du gouvernement des Etats-Unis, 1912, la contenance serait de 141.000 .000 d'hectares.

Indes anglaises....... 62.843.000 D'après M. Pearson; Forest economic products Bulletin Economique de l'Indo-Chine, novembre-décembre 1912, page 809.

Beloutchistan....... 53.000 Renseignements fournis par le gouverneur anglais du Beloutchistan.

Chypre.......... 180.000 Schlich's manual of Forestry (Resue des Eaux et Forêts, 1906, page 454).

Ceylan.......... 2.730.000 Iême source, page 453 .

A reporter........ $\overline{315.702 .800}$ 
INTERNATIONAL 1913

Report......... 315.702 .800

Perse.......... 14.000.000 Chiffre établi en supposant le taux de boise. ment de $8 \%$, d'après des renseignements qui nous ont été envoyés par la Légation de France à Téhéran.

Turquie d'Asie....... $\quad 6.300 .300$ Chiffre déduit de celui qui a été donné plus haut relativement à l'ensemble des forêts do l'empire turc.

Autres pays d'Asie.... 50.000.000 Chiffre forcément approximatif.

TOTAL POUR L'AsiE.... $\overline{386.003 .100}$

Australie :

Queensland....

Victorle-Galles du Sud.

Victoria..............

Australie du Sud.....

Australie de l'Ouest....

Tasmanie ...........

Nouvelle-Zólande.....

Iles Philippines.... . .

Java

Nouvelle-Guinée allemande. ...........

Autres pays de l'Océanie ............. 20.000.000 Chiffre approximatif.

Tot.de l'Australasie. $\overline{94.430 .000}$

\begin{tabular}{|c|c|}
\hline Europe......... & 314.468 .500 \\
\hline Afri & 229.314 .200 \\
\hline Amérique..... . & 646.752 .200 \\
\hline Asie........... . & 386.003 .100 \\
\hline Australasie. & 94.430 .000 \\
\hline Total général. & \\
\hline
\end{tabular}

Les données sont sur ce point encore plus incertaines que pour les prowlution ars contenances. Toutefois certains résultats ont paru intéressants à consigner.

France. - D'après la statistique de 1912, la production annuelle des 9.886.700 hectares de forêts françaises serait de 23.503.711 mètres cubes, tant gros bois que menus bois, soit en moyenne 2 me 38 par hectare et par an.

\section{Récapitulation}

16.180.000 Die Wälder Australiens, dans Zeitschrift für Forstund Jagdwesen, octobre 1912, pages 637 par Schlich's etci tés dans la Reoue des Eaux et Forêts, 1906, page 449, sauf pour la NouvelleGalles du Sud, à laquelle M. Schlich's donnait 8.000 .000 d'hectares de forêts. forest of the Philippines, par le Dr H.-NWhitf ord, Bulletin n⿳10. Bureau of Forestry, Départment of Interior Philippine Islands 1911. Erance à Batavia (Revue des 1906, page 29) M. Fernow : Forest and Forestry in the German Colonies (Forestry Quaterly, vol, X, n०4, 1912, page 632).

(1) ripts pll miaticres. 
L'Etat est propriétaire de 1.199.439 hectares, rapportant 2.798.600 mètres cubes. Pour établir la production annuelle, il convient de déduire 200.000 hectares environ improductifs : dunes, terrains de montagne, etc. La production annuelle serait ainsi très voisine de 3 mètres cubes. Elle dépasserait certainement ce chiffre si l'Administration, guidée par une pensée d'avenir, ne s'attachait pas à ménager ses forêts, de telle sorte qu'une partie du revenu s'incorpore au capital-bois. Les forêts des communes et des établissements publics soumises au régime forestier, 1.948.632 hectares, rendent 4.639 .032 mètres eubes, soit 2 mc 38 .

D’après une statistique établie en 1905 par la Direction générale des Eaux et Forêts, la valeur totale des forêts domaniales en fonds et superficie serait de.......................... 1.413.055.169 La valeur des autres forêts du régime forestier ....... 1.470.113.664 Enfin, en estimant les forêts particulières à 350 franes en

moyenne à l'hectare, elles vaudraient ensemble ..... 2. 2.358.500.000 Ou pour la valeur entière de la forêt française ...... Fr. $\overline{5.241 .668 .833}$

Suisse. - M. le Professeur Decoppet, de l'École polytechnique de Zurich, estime ainsi qu'il suit la production des forêts suisses :

Forêts des

Cantons .... 41.590 hectares produisant

Communes.. 653.700

Particuliers. 254.710

Totaux... $\overline{950.000}$

-

175.500 mc. soit par hectare 4,08

$\begin{array}{lll}1.703 .000 & - & 2,60\end{array}$ $\begin{array}{r}421.500 \quad-\quad 1,65 \\ \hline\end{array}$

$\overline{2.300 .000}$

2,42

Allemagne. - Les renseignements suivants sont puisés dans l'articlo de M. le Professeur Hüffel, de l'École forestière de Nancy : "Le mouvement forestier à l'étranger "(Revue des Eaux et Forêts, annéc 1911, page 552).

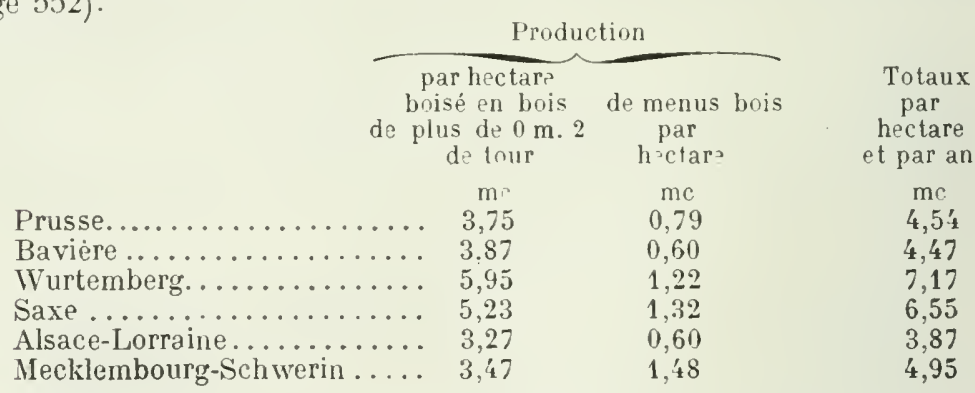

A première vue, on pourrait être surpris de la production singulièrement plus forte à l'hectare que fait ressortir la comparaison entre la France et l'Allemagne. Cet écart tient principalement à ce que les futaies résineuses, très productives, sont proportionnellement beaucoup plus considérables dans le deuxième pays que dans le premier. D'après la statistique de 1898, les peuplements résineux occupent en France 14,9\% de la surface totale des forêts. Il n'en est pas de même en Allemagne. Pour ne citer qu'un chiffre, il existe en Prusse 5.713.498 hectares de forêts résineuses pour 2.556 .636 hectares de forêts feuillues.

Graxde-Bretagne. - D'après la statistique publiée en Angleterre 
et qui concerne l'année 1908 , les peuplements résineux couvrent $27 \%$ de la superficie totale des forêts. Pour l'Écosse, cette proportion s'élève à $55 \%$.

Le revenu annuel moyen par acre serait de $7 \mathrm{fr}$. 18, soit pour l'hectare 17 fr. 74. En admettant le prix moyen du mètre cube de toutes catégories à 10 francs (sur la coupe), ce revenu représente $1 \mathrm{~m} 77$ à l'hectare et par an.

Russie. - La Direction générale de l'Organisation agraire et de l'Agriculture a publié, en 1907, un rapport sur "Les richesses forestières de la Russie ». Il y est mentionné que les forêts domaniales occupant 93 millions de terres boisées utilisables ont produit, en 1905, 110.300.000 mètres cubes de bois, soit 1,1 mètre cube par hectare. Le devis pour les bois domaniaux du Caucase était de 10.700.000 mètres cubes, ce qui constituait pour 3.400 .000 hectares une production de 3,1 mètres cubes; mais on n'a trouvé l'écoulement que de $12,1 \%$ de la quantité prévue, c'est-à-dire 0 mc 4 par hectare.

L'auteur de ce rapport constate que l'État russe ne tire pas de ses forêts la moitié du matériel qu'elles peuvent donner, eu égard à leur force productive et à l'état actuel de leurs peuplements.

Canada. - C'est la province de Québec qui est actuellement, au Canada, la plus riche en forêts. On estime à 2 milliards $1 / 2$ de francs la valeur des bois sur pied dans ses forêts. La moyenne annuelle des bois exploités de la province s'établit à environ 640 millions de pieds (1) $(18.120 .000 \mathrm{mc})$ représentant 50 millions de francs. Les forêts de la Colombie anglaise produisent 830 millions de pieds (plus de 23 millions de mètres cubes) représentant une valeur supérieure à 62 inillions de francs. Dans la province d'Ontario 1 milliard $1 / 2$ de pieds représentant plus de 150 millions de francs. Dans la Nouvelle-Écosse, le bois coupé en 1910 avait une valeur de plus de 10 millions de franes. Mais dans le Nouveau-Brunswick on estime que les richesses forestières ont besoin d'être ménagées. D'autre part, il est signalé que l'Ile du Prince Edouard, autrefois très boisée produit aujourd'hui à peine assez de bois pour suffire à ses besoins.

Des quelques aperçus qui précèdent, il paraît possible de conclure qu'en admettant, dans un avenir certainement très lointain, les forêts du monde entier aménagées et régulièrement exploitées, le revenu moyen pourrait varier entre 2 mètres cubes et 3 à l'hectare et par an ce qui représente 3 à 5 milliards de mètres cubes; cette production serait très supérieure aux besoins actuels de la consommation, la population entière du globle étant de 1 milliard 744 millions d'hommes.

Sur la consommation du bois d'curre, tout à été dit par llélard, dans le remarquable travail produit par lui, au moment de l'Exposition universelle de 1900. Il prévoyait que les besoins de tous les pays iraient indéfiniment en augmentant. 11 nous a paru curieux de rechercher si ses pronostics étaient vérifiés, dans l'espace des treize années dernières.

les limites de ce travail ne permettent pas de poursuivre sur ce point une très complète enquête. Nous avons limité nos recherches à quatre pays, nettement importateurs, la France, la Grande-Bretagne. la Bel-

(1) Le metre cube vaut 35,31658 pieds cubes (Annuaire du Bureau des longitudes). 
gique et l'Italie. La situation comparative est indiquée dans les quatre tableaux suivants, où ne figurent que les bois d'œuvre, à l'exception des menus bois, du chauffage et du charbon.

FRANCE. - ChIFFRES COMPARATIFS DER MMPORTATIONS ET EXPORTATIOTS en metres cubes)

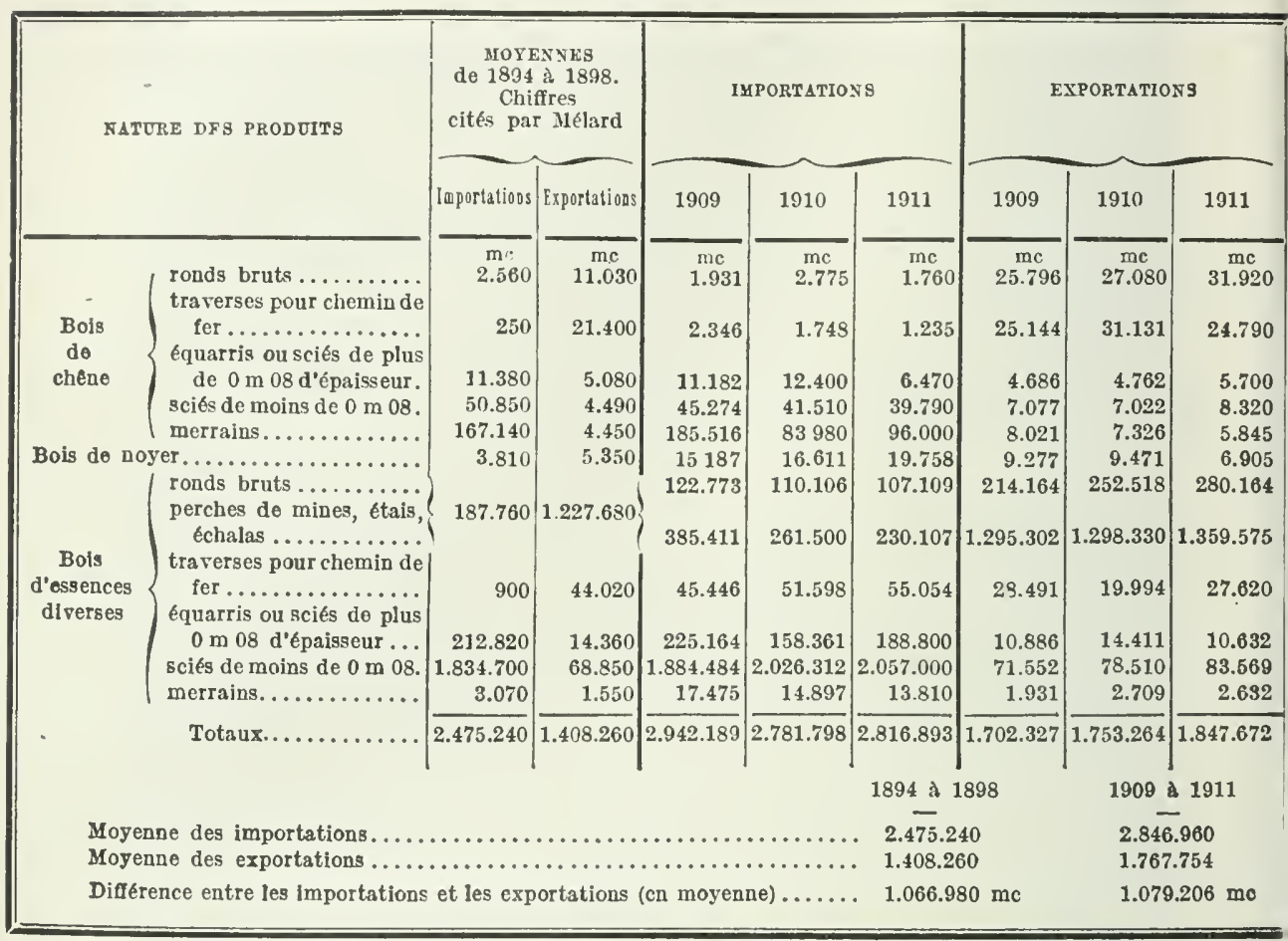

ITALIE. - CHIFFRES COMPARATIES (quantités en tonnes de 1.000 kilogrammes)

\begin{tabular}{|c|c|c|c|c|c|c|c|c|}
\hline \multirow[b]{2}{*}{ NATURE DES PRODUITS } & \multicolumn{4}{|c|}{ IMPORTATIONS } & \multicolumn{4}{|c|}{ EXPORTATIONS } \\
\hline & $\begin{array}{r}\text { Chi } \\
\text { cites pai } \\
1888\end{array}$ & $\underbrace{\text { Mes }}_{1898}$ & 1908 & 1911 & $\begin{array}{r}\text { Chi } \\
\text { cités p? } \\
1888\end{array}$ & $\underbrace{\text { Mélard }}_{1898}$ & 1908 & 1911 \\
\hline $\begin{array}{l}\text { Bols brut on simplement dégross] a la } \\
\text { hache......................... } \\
\text { Bois équarri, bois débite dans le sens } \\
\text { de la longueur, sciages. . . . . . . } \\
\text { A utres bois communs............. }\end{array}$ & $\begin{array}{r}70.175 \\
385.173 \\
18.335\end{array}$ & $\begin{array}{r}54.094 \\
431.854 \\
2.012\end{array}$ & $\begin{array}{r}117.493 \\
1.185 .869 \\
1.710\end{array}$ & \begin{tabular}{|r|}
168.724 \\
\\
1.317 .841 \\
2.381
\end{tabular} & $\begin{array}{l}12.702 \\
27.521 \\
22.582\end{array}$ & $\begin{array}{r}4.316 \\
44.510 \\
18.936\end{array}$ & $\begin{array}{r}6.771 \\
22.598 \\
2.609\end{array}$ & $\begin{array}{r}3.656 \\
11.801 \\
2.127\end{array}$ \\
\hline Totaux.............. & 479.683 & 487.960 & 1.305 .072 & 1.488 .946 & 62.805 & 67.762 & 31.978 & 17.584 \\
\hline
\end{tabular}


pour ces produits dont la consommation a progressé manifestement dans ces treize ou quatorze dernières années.

D'ailleurs. les pays exportateurs ont envoyé hors de leurs frontières de plus en plus de bois, ainsi qu'il ressort du tableau suivant emprunté à la statistique de Gustave Sundbärg :

Exportation DU BOIS NOY OUVRE DES PRIXCIPAUX PATS EXPORTATEURS

(Faleurs en milliers de francs)

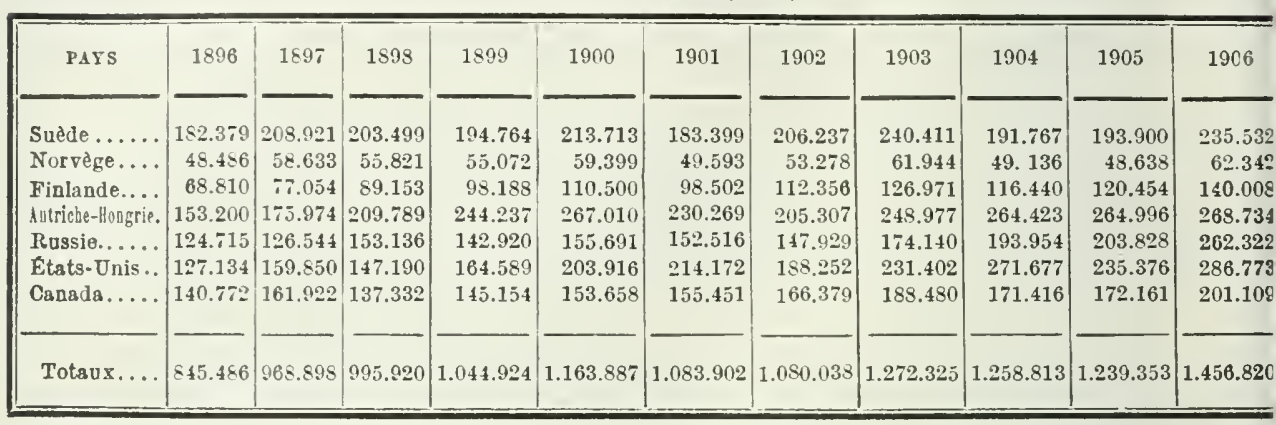

L'essor donné à l'industrie du papier, grâce à la multiplication des livres, des prospectus, des journaux, des revues, etc., produit un effet direct sur la consommation du bois destiné à la fabrication de la pâte, qui augmente dans des proportions considérables.

Voici quelques chiffres indiquant cette progression:

IMPORTATIONS EN FRANCE

(tonnes métriques)

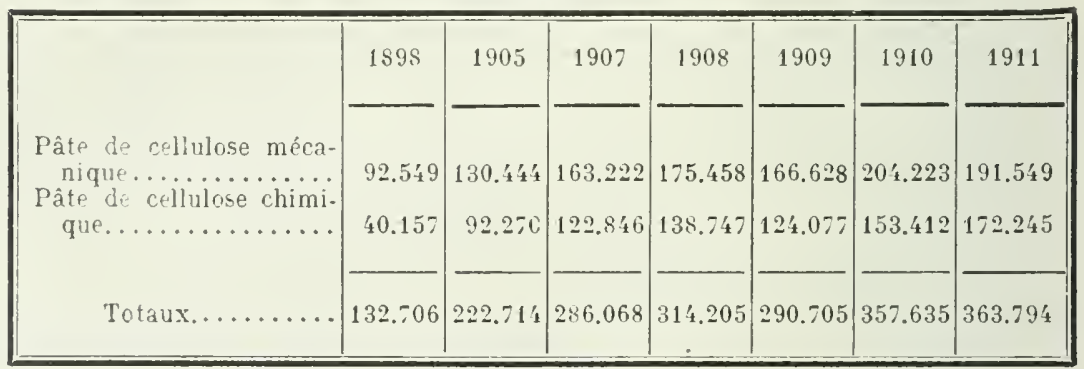

IMPORTATIONS EN GRANDE-BRETAGNE

(mesures en tonnes anglaises: 1016 k. 048)

\begin{tabular}{|c|c|c|c|c|c|}
\hline & 1907 & 1908 & 1909 & 1910 & 1911 \\
\hline $\begin{array}{l}\text { Pâte de cellulose mécanique. } \\
\text { Pâte de cellulose chimique.. } \\
\text { Autres matières pour la fa- } \\
\text { brication du papier...... }\end{array}$ & $\begin{array}{l}393.103 \\
293.255 \\
222.561\end{array}$ & $\begin{array}{l}443.911 \\
315.951 \\
208.510\end{array}$ & $\begin{array}{l}445.950 \\
315.174 \\
215.299\end{array}$ & $\begin{array}{l}503.037 \\
370.715 \\
211.790\end{array}$ & $\begin{array}{l}428.59: \\
370.806 \\
222.509\end{array}$ \\
\hline Totaux .......... & 908.919 & 968.372 & 976.423 & $1.085 .5 \div 2$ & 1.021 .909 \\
\hline
\end{tabular}


IMPORTATIONS EN ITALIE

(tonnes métriques)

\begin{tabular}{|r|c|c|c|c|c|}
\hline & 1907 & 1908 & 1909 & 1910 & 1911 \\
\hline Pátes de celluluse......... & 57.561 & 61.663 & 66.011 & 71.835 & 79.671 \\
\hline
\end{tabular}

La Belgique a importé, en 1911,136.887 tonnes et exporté 43.216 tonnes de pâtes à papier. La même année l'Allemagne, pays produeteur en a importé, 62.452 tonnes et exporté 171.679 tonnes.

Aux États-Unis, le nombre des fabriques de papier était de 163 en 1900 et de 161 seulement en 1905 , mais grâce aux améliorations apportées à la machinerie des usines, la production des États-Unis, durant cette période de einq ans, avait augmenté de près de $50 \%$, ainsi que le révèlent les chiffres suivants :

$\begin{array}{lccc} & & 1900 & \$ 905 \\ \text { Production de pulpe (en tonnes)... } & 1.536 .431 & 2.664 .753 \\ \text { Production de papier } & - & 2.782 .219 & \$ .857 .903\end{array}$

Il se eonsomme aux États-Unis 5.000 tonnes par jour de pulpe de bois, soit plus de 1.800 .000 tonnes par an (1).

En France, d'après le très intéressant rapport produit au Congrès International d'Agrieulture de Gand par 11 . l'Inspeeteur général des Eaux et Forêts Lafosse, qui a bien voulu nous le communiquer, la production du papier était de 180.497 tonnes en 1886 ; elle atteignait 365.000 tonnes en 1890, 450.000 en 1900. Elle est aujourd'hui de 867.000 tonnes(2).

Nous avons eu la curiosité de rechercher quel est, dans ce total, la part de nos grands journaux quotidiens. Avec la plus entière bonne grâce, leurs directeurs ont bien voulu nous renseigner :

Le Petit Parisien consomme de 60 à 85 tonnes par jour, soit

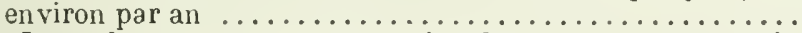

Le Journal accuse une consommation de 2.500 tonnes par mois. Il entre dans la composition du papier de ce journal environ $15 \%$ de matières autres que le bois. Cette déduction faite, sa consommation annuelle serait de...................

Le Matin absorberait tous les jours de 53 à 55 tonnes, soit

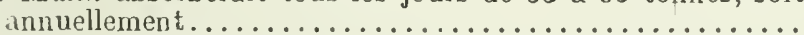
Le Petit Journal accuse une consommation annuelle de.........

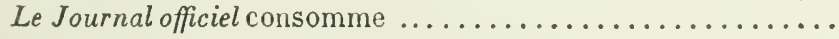
Ces cinq journaux ensemble consomment............ $\overline{86.550}$ tonnes

Soit sensiblement le $1 / 10$ de la production française.

Que représentent en bois ces 86.550 tonnes de papier? M. Janot, directeur de la Papeterie de la Seine (qui fournit entièrement le papier du Petit Parisien), a bien voulu nous donner sur les questions de fabrication

(1) Le Canada et la France, volume déjà cité.

(2) Il existe des fabriques de papier dans 70 départements. Viennent en tête: Seinefi-nise, production journalière :3/' tonnes; Isère, 31 't tonnes; Seine, 2for tonnes, etr. 
des explications très intéressantes que les limites déjà trop étendues de ce rapport nous empêchent de répéter; il estime qu'on peut compter, sans erreur sensible, que 100 kilogrammes de pâte donnent 100 kilogrammes de papier. Quant à la quantité de bois nécessaire pour donner une tonne de pâte, les chiffres varient énormément, suivant les pays et les usines, ce qui s'explique par l'âge, la dimension et la nature du bois mis en ocurre.

M. Janot estime cependant qu'on peut prendre comme moyenne, en Scandinavie, les chiffres suivants :

Pour la pâte mécanique, 3 mètres cubes et demi de bois de sapin pour 1.000 kilogrammes de pâte sèche ;

Pour la pâte chimique au bisulfite, 7 mètres cubes et demi de bois de sapin pour 1.000 kilogrammes de pâte sèche.

M. l'Inspecteur général Lafosse admet qu'en moyenne il faut employer 5 mètres cubes de bois pour obtenir une tonne de papier. Les journaux énumérés plus haut absorberaient annuellement 433.000 mètres cubes de bois, ce qui représente le revenu (à 3 mètres cubes par hectare et par an) de 145.000 hectares de forêts, c'est-à-dire environ huit fois la contenance de la forêt de Fontainebleau.

La production dans le monde des pâtes à papier de toutes sortes se chiffrait ainsi en 1910 (1) :

Production en Europe ............Tonnes. 3.783.732

Production hors d'Europe ............ 3.181.588

Total. ........Tonnes. $\overline{6.965 .320}$

Ce qui représente 30 à 35 millions (2) de mètres cubes de bois.

Evidemment, ce chiffre parait redoutable, mais il faut bien se dire, d'une part, que les bois employés à la fabrication du papier ne sont pas de ceux dont le grossissement est le plus désirable ; les essences employées n'appartiennent pas aux catégories feuillues précieuses; d'autre part, les bois pouvant, pour la fabrication du papier, être exploités fort jeunes (des peuplements résineux sont utilisables dès 12 ans), les renouvellements de récoltes s'opèreront très facilement. Si la pénurie se fait sentir, et elle est déjà sensible (3), la hausse des prix aura donc pour conséquence une production nouvelle qui peut être rapidement obtenue. Enfin, le remplacement du bois par d'autres produits sera un jour ou l'autre la résultante de la hausse ; jusqu'ici, le bois est encore à un prix assez bas pour ne pas inciter à l'emploi des succédanés. Vienne une raréfaction de la matière ligneuse, les procédés économiques seront trouvés pour la fabrication au moyen d'autres végétaux.

La situation est beaucoup moins rassurante pour le bois d'œuvre. En 1900, Mélard a poussé un cri d'alarme dont l'écho a été retentissant. A-t-il exagéré les craintes à avoir? D'aucuns le prétendent. Ce qui n'est pas niable, c'est que les ressources en vieux bois que recèlent les forêts éloignées des centres de civilisation ne sont pas actuellement disponibles

(1) D'après M. Franz Krawany, directeur de la Papeterie Union de Vienne, article publié dans l'International Papier Statistik.

(2) Chiffre approximatif puisqu'il entre d'autres matières que le bois dans la compo. sition de certaines pâtes.

(3) Depuis 1912, le cours des pâtes mécaniques, stationnaire jusque-là a subi uu augmentation de 2 francs par 100 kilogrammes, sur celuides pâtes chimiques, soit 5 francs pour le même poids (Excelsior, numéro du 11 mai 1913, sous la signature de Jean Barsac). 
pour les deux raisons suirantes : insuffisance des moyens d'exploitation et de vidange, frais élevés des transports. Avant qu'il y ait amélioration de ce côté, il faut s'attendre à une hausse constante des futaies. Cette hausse est indispensable pour provoquer la mise en valeur des forêts situées hors d'Europe, par des aménagements étudiés, par la création de larges roies de desserte et de moyens économiques de transport jusqu'à la mer. Une crise grave se produira certainement à un moment donné. Elle affectera notamment le chêne qui sera plus demandé qu'offert. La lenteur de la croissance des bois précieux ne permettra de parer à cette crise que si, dès maintenant, les gouvernements mettent tout en œuvre pour encourager leur production. Il serait hors du sujet de ce rapport d'indiquer les meyens multiples, et souvent préconisés, destinés à obtenir ce résultat.

Nous avons cherché seulement, en présentant la situation actuelle des forêts du monde entier, à faire ressortir combien eḷle est mal connue, et l'intérêt puissant qui s'attacherait à ce qu'il fût procédé, dans tous les pays du monde, à un inventaire détaillé des richesses forestières qu'ils contiennent. Sachant avec une précision au moins approchée le capital qu'elles représentent, peut-être pourrait-on mieux régulariser leurs exploitations, de façon à ne livrer au commerce que le revenu annuel en matière. Ce souhait n'a, pour le moment, que la valeur d'une utopie ; il n'y a pas cependant de raison qui s'oppose à ce que, la civilisation aidant, les forêts du monde entier soient un jour, comme les forêts soumises au régime forestier du Centre et de l'Ouest de l'Europe, exploitées avec méthode et régularité.

Comme conclusion de ce travail, nous demanderons que le Congrès international émette un vœu, qui d'ailleurs a été voté à peu près dans la même forme en 1900 :

Qu'une entente internationale intervienne pour publier les statistiques résumées faisant connaître, dans chaque pays, l'étendue des forêts exploitables, leurs richesses, leur capacité de production et, d'une façon générale, les ressources qu'elles sont susceptibles de fournir au commerce du monde entier.

1I. Madelix. - Sur le sujet que je traite dans ce rapport, nous avons reçu une communication dont je vous demande la permission de dire un mot. Cette communication a été envoyée au Congrès par les États-Unis. Ce que j'ai entre les mains est une traduction qui a été faite par les soins du bureau du Congrès et qui n'est pas signée. Je ne sais si le rapport lui-même l'était.

Je ne vous donnerai point lecture intégrale de ce document, pour épargner vos instants, mais il contient, sur la superficie des forêts aux Etats-Unis, quelques renseignements intéressants que je vais très rapidement résumer.

La superficie totale est, d'après ce rapport, de 545 inillions d'acres. Ce chiffre est un peu supérieur à celui que j'indicuais, dans mon rapport (500 millions d'acres). C'est en général un chiffre approchant que l'on donne pour la contenance des forêts des États-Unis. En 
fait, je me ligure qu'on n'en sait rien: (fuand il s'agit de pareilles étentues, il est facile de faire une erreur de 15 ou 20 millions d'acres.

Le taux de boisement est de $29^{\circ} \%$, cr qui parait un peu élevé.

11. Gryot. - Oh oui! Ce taux est vrai pour les Montagnes-Rocheuses. Mais toute la praire de l'Ouest n'est nullement boisée, et elle constitne à peu près le tiers de la superficie totale.

M. MAnELIx. - Les forêts nationales représentent 18,5\%; les forêts départementales (celles des Etats), $0,5 \%$, les forêts privées, ainsi que les forêts publiques non réservées, $81^{\circ} \%$.

165 millions d'acres appartiennent au gouvernement fédéral.

Le rapport s'étend ensuite longuement sur les trois sources de profits et d'exploitation, le bois, te pâturage et les forces hydrauliques. Pour les bois, on compte à jeu près 2 milliards 800 millions de mètres cubes de forêts vierges, dont une grande partie est inaccessible. Je me permets de trouver que le renseignement a bien des chances d'être inexart, puisque les furêts sont inaccessibles.

L’année dernière, pnriron 2 millions de mètres cubes ont été amenagés et mis en rente. De plus, 500.000 mètres cubes étaient donnés aux colons pour le chauffage et l'exploitation de leurs fermes. La quantité d'arbres abattus n'est que de 7 \%o du produit des forêts nationales.

Les pâturages tiennent une large part de ces forêts qui sont aménagèes. Le rapport traite encore des questions de sylviculture et de la manière dont sont aménagés les réserves, ainsi que des travaux d'exploration exécutés. Il s'occupe ensuite de questions de dendrologie, et il termine enfin en citant les travaux des stations de recherches citablies aux Etats-lnis.

Ce travail est très documenté, très intéressant, et je regrette que sa longurur ne me permette pas de le lire entièrement.

de vous demande ígalement la permission de faire mention spéciale d'une communication qui nous parrient d'un ami très lointain. Cirst un Russe, M. Moustafiz, de l'Administration de l'agriculture et les domaines de l'État, a Tachkent, dlans le Turkestan russe. Sun travail, consiclirable, est écrit en russe, et il a éte traduit pour le congrès par .1. Muller, représentant l'Mlliance française ì Tachkent.

Nous trourons dans ce document des renseignements très interestants sur le's forêts du Turkestan qu'il divise en forêts de montagne. forêts dr rives basses des rivières, et strppes. Le Turkestan russe a un taux de brisement moyen de $11,3 \%$, ce qui parait assez rraisemblable.

Je dois signaler au Congrès qu'à la suite de l'adoption, hier, d’un

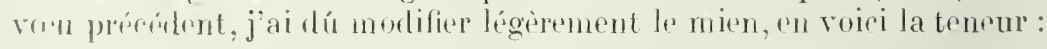

Qne lof Ofire forestier international, dont la création a élé demandée pur un s'xu précédent, püblie les statistiques résumées faisunt conmuitre. dans chuque pays, l'étendue des forêts exploitables, leurs 
richesses, leur capacité de production, et, d'une façon générale, les ressources qu'elles sont susceptibles de fournir au commerce du monde entier."

II. Le Présinext. - Messieurs, nous remercions M. Madelin de son travail si documenté. M. Madelin fait là une ceuvre extrêmement utile et dont on ne peut que le féliciter.

Je mets aux voix le voeu modifié ainsi qu'il l'a indiqué.

Le rou de M. Madelin ainsi modifié, est adopté.

Lordre du jour appelle la diseussion du rapport de M. Villame sur les Drorts DE norixe et la parole est ì II. Villame pour la lecture de son rapport.

M. Villame. - Nous voudrions, dans ce Rapport, que nous ferons aussi suecinet que possible, passer en revue les différents produits forestiers pour lesquels nos groupements eorporatifs ont demándé des modifications au tarif aetuel des douanes.

Déjà, en 1908-1910, lors de la révision de la loi douanière de 1892 , nos syndicats se sont efforeés d'obtenir des relèvements justifiés par la erise que traverse depuis quelques années l'exploitation des forêts nationales. Nos tentatives n'ont pas eu, il faut bien le dire, le suecès que nous escomptions, et, bien loin d'obtenir satisfaetion, nous dûmes nous estimer heureux d obtenir le maintien du statu quo et de nous défendre contre les abaissements des tarifs qui étaient proposés par eertains députés, et qui auraient eu pour résultat d'aggraver eneore les conditions d'infériorité dans lesquelles le commerce des bois doit lutter eontre la eoneurrence étrangère.

Certes, en pareille matière, il faut se garder des exagérations. Il faut tenir compte, dans une large mesure, des situations aequises également respectables et des habitudes du commeree et aussi d'autres intérêts parfois divergents. Mais, ceei dit, nous ne saurions trop énergiquement affirmer que la forêt française a besoin d'être protégée et que nous ne devons négliger aueun moyen pour venir en aide à un commerce pour lequel les pouvoirs publies sont loin d'avoir toute la sollieitude qu'on serait en droit d'en attendre.

Le eommerce des bois de France, estimant avec raisòn que nos forêts lois de mines. regorgent de petits bois aptes à l'usage de bois de mines, demande logiquement que "les perehes, étançons, éehalas bruts, de plus de $1 \mathrm{~m} .10$ de longueur et de circonférence atteignant au maximum $0 \mathrm{~m}$. 60 au gros bout, soient taxés à raison de 0 fr. 65 les 100 kilogrammes, au tarif minimum » (au lieu de 0 fr. 30 au tarif minimum aetuel).

Mais, dira-t-on, ne peut-on craindre des représailles de la part des États étrangers? Nous ne redoutons pas ce danger.

Quels sont, en effet, les marchés étrangers qui s’approvisionnent de bois en France? Ceux d'Angleterre et de Belgique qui trouvent ehez nous des bois à meilleur compte que dans le Nord. D'ailleurs, on sait que les États du Nord, comme la Norvège, ont interdit depuis 1905, la coupe des jeunes arbres. Ne sunt-ce pas là justement des bois de mines? Si nous 
en demandons moins, on en coupera moins, et les États septentrionaux qui prennent des mesures contre l'exploitation prématurée de leurs forêts ne pourront que s'en réjonir. Donc, point de représailles de ce côté. Et, quant à l'Angleterre, si elle vient chercher dans les Landes les bois qui lui font défant, c'est qu'elle y trouve son compte et que nos bois ont des qualités qui lui conviennent mieux que ceux du Nord. Croit-on vraiment qu'il y ait quelques représailles à craindre de ce côté?

Pour la répercussion que cette élévation des droits pourrait avoir sur les mines du Nord, elle se traduirait par une augmentation d'un centime environ par tonne de charbon extrait, dont la valeur est au moins de 16 franes sur le carreau de la mine. Les mines du Nord, dont la prospérité est si grande, ne pourraient-elles supporter sans murmurer cette insignifiante augmentation?

Mais, dira-t-on encore, les forêts de France ne sont-elles pas trop éloignées de la région du Nord, pour contribuer utilement à l'approvisionnement des mines! Cette objection ne nous paraît pas très convaincante, car on sait que la Belgique fait des achats jusque dans le Plateau Central, et, d'autre part, notre réseau de navigation intérieure est très bien organisé pour desservir à souhait le bassin du Nord. Et si l'on veut bien approfondir, on reconnaitra que la question de la protection des bois de mines est solidaire de la prospérité de la batellerie qui trouvera dans le transport des bois, à destination du Nord, un frêt de retour des plus importants et un aliment appréeiable pour son activité.

Les quinze mille communes de France, propriétaires de misérables taillis que la mévente des petits bois a cruellement atteintes dans leur revenu, demandent instamment qu'on protège d'une manière efficace les bois de mines.

Le tableau suivant montre la quantité considérable de bois de mines importés en France, à destination des houillères du Nord bien entendu. On remarquera l'énorme augmentation survenue depuis 1900 :

\begin{tabular}{|c|c|c|c|c|c|}
\hline En $1900 \ldots$ & 36.670 & tonnes & En $1907 \ldots$ & 126.770 & toline: \\
\hline $1901 \ldots$ & 59.060 & - & $-1908 .$. & 211.655 & - \\
\hline$-1902 \ldots$ & 81.130 & 一 & $-1909 \ldots$ & 215.830 & - \\
\hline$-1903 \ldots$ & 124.870 & - & $-1910 \ldots$ & 146.440 & - \\
\hline $1904 \ldots$ & 175.190 & - & -1911... & 128.860 & 一 \\
\hline$-1905 \ldots$ & 87.556 & - & $-1912 \ldots$ & 135.580 & - \\
\hline$-1906 \ldots$ & 80.750 & - & & & \\
\hline
\end{tabular}

Sciages dechêne. La valeur des sciages de chêne est pour les qualités communes double de celle des sciages de sapin et pour les qualités supérieures débitées en faible épaisseur, quatre fois plus élevée: si donc, on veut arrêter l'exode de nos beaux chênes vers l'Allenagne, il faudrait, en bonne logique, doubler les droits d'entrée sur les sciages épais de chêne et quadrupler ces inêmes droits sur les sciages minces.

Mais le commerce des bois de France sait faire la part des situations de fait et des justes nécessités. Et, pour assurer au chêne de notre pays, sans rival eomme qualité et comme durée, la place qui doit lui revenir sur notre marché, il demande simplement, ce qu'il n'a pu obtenir ne 1910 : le classement à part des sciages de chêne et un droit d'entrée de : 
Pour les bois sciés ou équarris de $0,080 \mathrm{~m} / \mathrm{m}$ d'épaisseur et au-dessus :

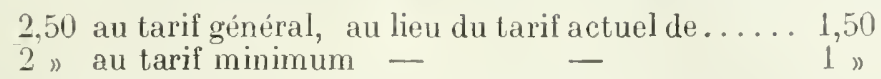

Pour les bois sciés de $0,035 \mathrm{~m} / \mathrm{m}$ et inférieurs à $0,080 \mathrm{~m} / \mathrm{m}$ :

2,75 au tarif général, au lieu du tarif actuel de .... 1,75

2 2 au tarif minimum - _ 1,25

Pour les bois sciés de 0,035 ${ }_{\mathrm{m}}^{\mathrm{m}}$ d'épaisseur et au-dessous:

4 » au tarif général, au lieu du tarif actuel de.... 2,50

2,50 au tarif minimum - $\quad$ - $\quad 1,75$

Les premiers droits s'appliquent à des marchandises qui valent au minimum 120 franes le mètre cube, les seconds à des marchandises qui valent au minimum 240 francs le mètre cube, et le troisième à des marchandises qui atteignent souvent 400 francs le mètre cube.

La Fédération du commerce des bois a demandé aussi que le droit de liais injectés. douane sur les bois injectés à leur entrée en France fût majoré de 5 franes par 100 kilogrammes.

Le marché français est envahi par les poteaux injectés en Allemagne et en Suisse, qui sont avantagés par le bon marché de la matière première, de la main-d'œuvre et aussi des transports dans leurs pays.

Il est nécessaire de défendre notre production et le taux qui est réclamé nous paraît justifié, non pas même pour secourir nos nationaux, mais pour égaliser leurs moyens avec ceux de leurs concurrents étrangers.

M. Farjon, député du Pas-de-Calais a, dans la précédente législature, Dou velles de déposé une proposition de loi ayant pour objet de faire accorder le bénéfice de l'admission temporaire aux douvelles de sapin étrangères, destinées à la fabrication des barils d'emballage.

Cette proposition n'a pạs manqué de soulever les protestations des producteurs français de bois résineux, notamment de la région des Landes, et, la Fédération du commerce des bois de France, au cours de l'Assemblée générale de 1910, émit le vœu que la proposition de loi Farjon ne fût pas adoptée par les Chambres et que si le droit de douane sur la douvelle étrangère en sapin n'était pas augmenté, le statu quo tout au moins fùt obtenu.

Conformément au désir de la Fédération, la proposition de loi Farjon ne vit jamais le jour et, à l'expiration de la législature, elle devint caduque.

M. Farjon n'ayant pas été réélu en 1910, on pouvait supposer que sa proposition de loi resterait à jamais enfouie dans les cartons parlementaires, mais M. Loth, également député du Pas-de-Calais, a repris à son compte et déposé à noureau sur le bureau de la Chamlre cette proposition.

Les raisons qui militaient contre la proposition Farjon n'ont rien perdu de leur force. En laissant de côté les fraudes que fasorise presque toujours l'admission temporaire, il est évident que, si cette faculté peut ne pas présenter de gros inconvénients quand il s'agit des prodıits non fabriqués en France, quoique prétende l'auteur de la proposition, il n'en va pas de même de l'admission temporaire de produits étrangers venant, comme la 
douvelle de sapin, concurrencer les produits français d'usage et de qualité analogues. Aussi, le commerce des bois est-il résolument opposé à l'admission temporaire des bois à douvelles, comme il le serait à l'admission des planches, des madriers et des bois de charpente, parce que tous ces produits sont fabriqués également en France et que l'industrie nationale est déjà assez attaquée par la concurrence étrangère, sans qu'il soit besoin de faciliter encore cette concurrence.

Ce fut avec une douloureuse surprise que le commerce des bois apprit, lors de la revision générale du tarif des douanes, en 1910, que la Commission des douanes, sur l'initiative de son rapporteur, M. Bouctot, désireux sans doute de favoriser le mouvement des ports de la Manche et de la mer du Nord, région dont il était le représentant, — proposait une diminution du droit qui frappe les planches de 25,27 et 30 millimètres d'épaisseur à leur entrée en France, non seulement pour la planche sapin, mais pour toutes les essences.

D'après le tarif actuel, les bois équarris ou sciés de 80 millimètres et au-dessus payent, par 100 kilogrammes, 1 fr. 50 au tarif général et un franc au tarif minimum.

Les bois équarris ou sciés, d'une épaisseur inférieure à 80 millimètres et supérieure à 35 millimètres, payent 1 fr. 75 au tarif général et 1 fr. 25 au tarif minimum.

Les bois sciés, de 35 millimètres d'épaisseur et all-dessuus, paient 2 fr. 50 au tarif général et 1 fr. 75 au tarif minimum.

Au tarif minimum, la planche paie 1 fr. 75 de droits par 100 kilogrammes; le rapporteur proposait de la mettre dans la catégorie des sciages payant seulement 1 fr. 25. C'était done une réduction de 0 fr. 50 par 100 kilos, soit 2 fr. 50 par mètre cube fabriqué.

Sous une apparence inoffensive, cette proposition entrainait, en raison du déchet infligé à la propriété forestière, une perte d'environ 2 francs par mètre cube sur pied. Elle menaçait, en outre, l'élément principal de notre industrie du bois: la planche, cet article courant, base de fabrication des scieries, qui, sans elle, ne sauraient comment necuper leurs ouvriers d'une faron continue, si elles n'avaient pas cet article qui peut être fabriqué. d'arance, par grandes quantités.

Il n'est pas douteux, d'autre part, que l'étranger qui déjà nous envoie des quantités de planches profiterait d'un abaissement des droits pour' augmenter la production de cet article et pour nous inonder au point de fermer entièrement le débouché à la production nationale, et, de l'encombrement, résulterait l'enlisement des prix.

Et nous ne parlons pas de l'injustice choquante qu'il y avait à frapper d'un même droit de 1 fr. 75 par 100 kilogrammes, des feuillets de chêne, de 15 millimètres d'épaisseur valant 400 francs le mètre cube et des planches de sapin de 27 millimètres d'épaisseur valant 60 franes le mètre cube.

Ce projet provoqua dans toute la France un mouvement de protestation unanime.

Une opposition vigoureuse eńt raison de la menace de M. Bouctot et les anciens droits, grâce à l'intervention de M. Fleurent, alors député de Saint-Dié, furent maintenus par la Commission des douanes.

M. Bouctot cherchait à légitimer la mesure qu’il proposait par l'intérêt đqui s'attache à réduire le prix des logements ouviers : Or, dans une 
maison ouvrière de 3.000 francs, on peut admettre qu'il entre bien 200 mètres car'és de planches de 27 millimètres pour la construction, ce qui fait une économie de 10 à 15 franes, soit les 5 millièmes du montant total de l'entreprise.

Il faut noter ici une demande très légitime, présentée par la Chambre de Commerce du Jura, en vue de la eréation d'une classification nouvelle pour les sciages inférieurs à 11 millimètres d'épaisseur dont la valeur intrinsèque est incomparablement supérieure. Cette nécessité est d'autant plus grande que les pièces sont coupées de longueur pour être assemblées et que, dans la catégorie nouvelle rentreraient les véritables bois façonnés.

M. Pasqual, député du Nord, a déposé en mars 1911, sur le bureau de Bois rontrentala Chambre une proposition de loi tendant à frapper d'un droit de douane les bois contreplaqués à leur entrée en France.

On sait que les bois contreplaqués sont des feuilles de bois de faible épaisseur déroulées en grande surface et collées ensuite ensemble; on obtient ainsi le maximum de rendement des bois.

Ces bois contreplaqués sont employés pour les meubles, les chaises, les lambris, et comme ils sont obtenus en grande surface, ils font une économie de main-d'œuvre. Les ébénistes, fabricants de chaises, menuisiers, en font usage. Ces bois sont importés par milliers de tonnes en France chaque année d'Allemagne, de Russie, d'Autriche. Cette impor' tation augmente tous les jours. Or, il existe en France des usines qui ne peuvent prospérer à cause de cette concurrence étrangère, et, cependant, grâce aux bois de nos colonies, comme l'okoumé, le tulipier et autres essences, grâce aux essences telles que l'aulne, le hêtre, le bouleau, qui se trouvent en abondance dans nos forêts de l'Etat et des particuliers, ces usines pourraient s'alimenter sans faire appel à l'étranger.

Tels sont les motifs qui ont déterminé M. Pasqual à présenter sa proposition de loi.

La proposition elle-même tend à ce que les droits de douane qui frappent actuellement les marchandises groupées sous le nº 601 de notre tarif douanier, soient augmentés dans les proportions suivantes:

\begin{tabular}{|c|c|c|c|}
\hline Marchandises & Droit actuel & Droit proposé & \\
\hline Panneaux...... & 12 fr. 50 & 40 francs & par tonne \\
\hline Fonds des sièges.... & $18 川$ & 45 & de \\
\hline Autres............ & $12 "$ & 30 & 100 kilogs. \\
\hline
\end{tabular}

Ces nouveaux tarifs seraient encore très modérés. Les bois dont il s'agit sont, en effet, relativement légers. Les panneaux de 3 millimètres pèsent 1.700 grammes par mètre carré en moyenne : ceux de 4 millimètres de 2.500 à 2.900 grammes et ceux de 5 millimètres de 2.800 à 3.300 grammes. Le droit par mètre carré serait done très faible.

Presque toutes les chambres syndicales du commerce et de l'industrie en bois ont demandé le vote de la proposition Pasqual. Il semble donc que la Chambre des Députés n'ait plus qu'à adopter sans tarder davantage une proposition de loi qui est déposée depuis plus de deux ans, et au sujet de laquelle le commerce intéressé a émis un avis unanimement favorable, sauf, toutefois, quelques intermédiaires, agents de maisons étrangères.

Le commerce des bois est loin de préconiser une protection à outrance verraius. 
et de demander une augmentation générale de tous les bois étrangers entrant en France. Aussi, en ce qui concerne le merrain, n'avons-nous jamais sollicité aucun relèvement qui ferait renchérir la futaille et élèverait encore les frais des viticulteurs, bien que le prix de la main-d'œuvre ait considérablement augmenté, et que le prix du merrain n'ait pas été relevé dans les mêmes proportions.

Dernièrement, la Chambre de Commerce de Bordeaux a présenté une demande tendant à l'admission temporaire des merrains, en vue du sciage pour leur réexportation.

Certains pays d'Europe, de même que nos colonies, ne sont pas encore outillés pour scier les merrains : et il y aurait intérêt à ce que ces pays s'adressent à nous pour la fabrication de la tonnellerie. Le trafic et la main-d'œuvre de nos ports ne peuvent que ressentir de bienfaisants effets de cette mesure. La facilité réclamée pour le sciage et le façonnage de ces bois en France permettrait au commerce d'exportation du bois et de la tonnellerie de lutter contré la concurrence étrangère et procurerait aussi un frêt important à la marine marchande, telles sont les considérations que fait valoir la Chambre de Commerce de Bordeaux à l'appui de sa demande.

Le commerce des bois s'associerait volontiers à cette demande, s'il n’avait la crainte justifiée, de voir cette admission temporaire favoriser outre mesure la fraude, ainsi que nous l'avons expliqué précédemment, au sujet de l'admission temporaire des douvelles de sapin.

La futaille étrangère est frappée d'un droit inférieur, de beaucoup, aux droits élémentaires sur les merrains et cercles ; la tonnellerie entre même en franchise comme emballage dans nombre de cas. Ce fait constitue une faveur destructive de toute protection, à tel point que, si la tonnellerie française lutte souvent avec avantage sur les marchés mondiaux, elle se voit menacée, sur nos propres marchés, qui restent ouverts aussi bien par des tarifs de pénétration pour les transports économiques, que par des droits d'entrée insuffisants. Il y a là une anomalie que nous signalons tout spécialement à l'attention des pouvoirs publics.

La Fédération des syndicats du commerce des bois de France a demandé que le droit de donane sur les charbons de bois soit porté de 1 franc les 100 kilogrammes, tarif minimum, droit actuel à 2 francs. Cette proposition a pour but de conserver l'emploi de milliers de stères de menus bois en France. Utilisés jadis à la lois par l'industrie et la consommation ménagère, les charbons de bois eurent longtemps un débouché suffisant et rémunérateur. Il n'en est plus ainsi aujourd'hui, malheureusement. La consommation de ce produit est en diminution con tinue. L'utilisation toujours croissante de la houille et du gaz lui a été des plus funestes et, dans les grands centres, l'abaissement du prix dı gaz lui a porté un coup mortel.

Cette situation est entièrement préjudiciable à la forêt française. C'est une cause de plus pour favoriser le déboisement. De plus, des milliers d'ouvriers charbonniers qui vivaient pendant la moitié de l'année, du travail si sain de la forêt, sont obligés de quitter les campagnes déjà trop désertées pour aller chercher, dans les villes, l'occupation que nos bois ne peuvent plus leur fournir.

L'augmentation des droits de donanes que nous demandons sur les 
charbons de bois aurait pour résultat de venir en aide à l'exploitation de nos taillis déjà si précaire. Il s'agit de conserver l'emploi de deux millions de stères de menus bois. La main-d'oeuvre qui s'y applique, façon de bois, carbonisation, transport, peut être évaluée à dix ou quinze millions par an. Elle doit être conservée à l'onvrier français. Le charbon de bois est un produit exclusivement national. En outre, on facilitera la création d'usines d̀ distiller le bois en France. Un large débouché sera créé ainsi pour nos charbons de bois dans les départements peu boisés du midi qu'envahissent en ce moment les charbons étrangers, moins chers, à cause du bon marché de la main-d'œuvre italienne, mais de qualité médiocre.

Dans le même ordre d'idées, il convient de signaler les démarches Méthylène. faites par l'Union syndicale des usines de carbonisation des bois de France, en vue d'obtenir un relèvement des tarils à l'entrée en France du méthylène étranger qui vient concurrencer chez nous les produits de notre pays et avilir les prix.

Le méthylène paie, à l'entrée en France, 13 francs les 100 kilogrammes sur le net, lorsqu'il renferme moins de $20 \%$ d'acétone, 15 francs les 100 kilogrammes lorsqu'il renferme plus de $20 \%$ d'acétone. Il paie, d'autre part, sur le net, 25 franes en Allemagne, 96 franes en Autriche, 300 franes en Belgique, et 37 fr. 50 en Italie.

Il résulte clairement de cette comparaison que, dans tous les principaux pay's d'Europe, sauf l'Angleterre, où règne le libre échange, le méthylène est protégé plus qu'en France.

D'autre part, les cours du méthylène oscillant entre 78 francs et 82 francs, l'élévation des droits de douane qu'on demande à porter de 13 et 15 franes, à 25 francs, aurait pour résultat de porter le prix de vente du méthylène régie à 82 francs, plus 13 francs, total : 95 francs. Or, ce relèvement des cour's du, méthylène ne saurait entraver en rien l'ossor de la consommation de l'alcool dénaturé, puisque, depuis 1902, le coût du dénaturant est remboursé au dénatureur, à raison de 9 francs par hectolitre d'alcool, puis soumis à la dénaturation et que cette ristourne de 9 francs a été calculée en prenant pour prix de vente du inéthylène, le cours de 104 franes l'hectolitre.

Il reste donc, une marge suffisante entre 95 francs et 104 francs, pour que la demande des carbonisateurs puisse être accucillie favorablement.

Bois de Quebracho en bûches. - On sait que le bois de Quebracho destiné à la fabrication d'extraits tanniques nous arrive principalement de la République Argentine; il entre chez nous librement, en franchise de tous droits de douane, alors que ses extraits concrets et liquides, acquittent respectivement les taxes suivantes, aux 100 kilogrammes:

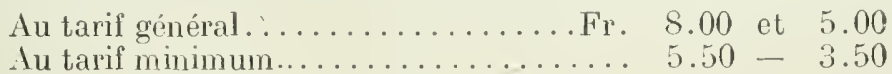

Depuis une quinzaine d'années, l'emploi du bois de Québracho a pris en France une grande extension et supplante en partic l'emploi de l'écorce de ehêne, au grand détriment des intérêts de nos propriétaires de taillis. Ce bois coute moins cher que le chêne, mais aussi il est acquis maintenant que son tannin donne un cuir beaucoup moins bon que celui du chêne. 
Des expériences faites par des experts ont démontré, en effet, que le cuir, tanné avec des extraits n'est pas suffisamment souple, est trop perméable se prête difficilement aux réparations et donne aux chaussures en moyenne un poids de 450 grammes supérieur à celui des chaussures faites de cuir tanné à l'écorce de chêne pure.

(Le tarif douanier allemand du $1^{\text {er mars }} 1906$ frappe le quebracho, d'un droit de 8 fr. 75 au tarif général et de 2 fr. 50 au tarif conventionnel (aux 100 kilogrammes). Ces droits ont été établis sur la réclamation des propriétaires forestiers de l'empire).

Nous demandons, en conséquence, qu'il soit établi, dans le plus bref délai, un droit sur l'entrée du bois de quebracho en France.

Conclusion. - Une double conclusion se dégage, suivant nous, de la brève étude que nous venons de faire.

D'abord, comment se fait-il que les intérêts du commerce des bois soient pour ainsi dire ignorés par les administrations publiques?

Cela s'explique très facilement, du moins en partie: Il n'y a personne pour renseigner le gouvernement! Le commerce des bois de France ne compte aucun représentant, ni au Comité consultatif des arts et manufactures, ni à la Commission permanente des valeurs en douane, à part un ou deux négociants en bois de Paris qui, évidemment, peuvent être compétents en ce qui concerne la vente des bois d'importation et des bois d'œuvre, mais qui connaissent peut-être moins bien les intérêts des exploitants de forêts, lesquels constituent la très grosse majorité de notre corporation.

En serond lieu, à l'heure où l'État semble vouloir s’intéresser it l'ouvre de préservation de la propriété forestière, il n'est aucun de ceux que la question touche qui ne puisse avoir à coeur de lui accorder son concours : le contribuable français, en supportant l'effort considérable. presøue au-dessus de ses forces, qui va lui être demandé: les exportateurs étrangers en acceptant les tarifs rationnels, nous venons de le voir, qui vont leur être imposés. Les bénéfices énormes réalisés depuis quelques années par l'étranger, offriront d'ailleurs à ces derniers une large consolation.

A la question de protection du bois français, restant en France pour être mis en ouvre par des mains françaises, est lié le développement de nos scieries, de notre outillage, de nos ateliers de construction; à la question de protection du bois français, est lié l'avenir de nos forêts et conséquemment aussi celui de nos finances.

En terminant, qu'il nous soit permis de faire remarquer que la France, tout en laissant ses portes ouvertes aux produits de ses concurrents, a le devoir de défendre ses richesses nationales et de mettre les producteurs français en situation de lutter à armes égales avec l'étranger.

Pour conclure, nous avons l'honneur de proposerau Congrès l'adoption des roux suivants :

$1^{\circ}$ Que lors de la prochaine revision des tarifs douaniers, il soit fait droit aux demandes du commerce des bois français, dans le sens de leur protection;

$2^{\circ}$ Que la proposition de loi de $\mathrm{M}$. Loth député du Pas-de-Calais, tendant à l'admission temporaire des douvelles de sapin, soit rejetée; 
$3^{\circ}$ Que, d'une manière générale, les admissions temporaires des bois ne soient pas accordées, parce qu'elles favorisent la fraudo;

$4^{\circ}$ Que la proposition de loi déposée par M. Pasqual, député du Nord, tendant à augmenter les droits de douane sur les bois contreplaqués, soit adoptée le plus tôt possible;

$5^{\circ} Q u^{\prime} i l$ soit établi un droit sur l'entrée du bois de quebracho en France:

$6^{\circ}$ Que les marchands de bois exploitants de France soient réprésentés, savoir :

a) A $u$ Comité consultatif des arts et manufactures;

b) A la Commission permanente des valeurs en douane.

1I. Hulcaxne. - Monsieur Villame, je suis non pas importateur étranger, puisque je suis Français, mais importateur de bois étrangers. Or, avant qu'aucune discussion commence, je dois vous dire que si je parlais au nom des importateurs de bois etrangers. j’affirmerais que nous ne demandons qu'une chose : droits de douane aussi forts que vous voudrez...

II. Liflaye. - Nous sommes alors d'accord?

M. Hollaxie. - Attendez! je vais mexpliquer.

La France ne peut pas fournir la quantité de bois dont elle a besoin. Plus il y aura de droits de douane, plus les marchands de bois étrangers gagneront d'argent, car ils prendront leur bénéfice sur le droit de douane compris, de même que les exploitants de forêts prennent leur bénéfice, non seulement sur le prix d'achat de la coupe, maís sur les frais d'exploitation.

Nous sommes ici pour défendre les intérêts de la forêt. Or, faites attention que nous souffrons d'une insuffisance de bois. Il est fort probable - les chiffres seront officiels seulement le 7 juillet - qu'en 1912, il aura été importé 1.821.317 tomnes de bois étrangers, payant comme bois communs des droits de douane.

Dans cette discussion, je demande qu'on ne s'embarrasse pas de l'intérêt des marchands de bois étrangers, car plus il y aura de droits de douane, plus sera élevé le bénéfice des importateurs de bois exotiques ou étrangers; on a besoin de leurs bois, et quant aux droits, rela leur est complètement ígal.

M. Le Présinext. - II ne faut pas opposer les intérêts personnels les uns aux autres.

Ce qui se dira des intérêts de la forêt française pourra se dire des intérêts des forêts de tous les pays.

Nous nous plaçons au point de vue des intérêts généraux de la forêt française, et toute question personnelle doit être écartée.

II. V'efckel. - L'honorablr rapporteur, II. Villame, a présenté un rapport dans tequel il dit que la forêt française a besoin d'être protégée. 
En cela il est d'accord avec tous les congressistes, qui se sont réunis afin d'examiner les moyens à employer pour conserver à notre pays les forêts actuellement existantes et pour tâcher, si possible, d'augmenter les surfaces forestières de France. Mais l'honorable M. Villame a, me semble-t-il, wne conception toute particulière de la protection de nos forêts. Jusqu'à présent, je m’étais imaginé que le meilleur moyen de conserver nos forêts françaises, c'était de chercher à n'y abattre que l'équivalent de l'accroissement annuel. C'est le còté difficile, car la consommation annuelle du bois en France, dépasse de plus de rleux millions de mètres cubes la production forestière de notre pays et il faut nécessairement faire appel aux bois étrangers, si l'on ne veut pas, chaque année, entamer fortement le capital ligneux.

Si la thèse du rapporteur était acceptée, qu'adriendrait-il? Nos forêts françaises, déjà si appauvries, seraient exploitées d'une façon encore plus intensive, et dans peu d'années, nous aboutirions à la déforestation complète.

J'exploite actuellement, avec un associé, une forêt en France et nous y avons une scierie mécanique. Une augmentation des droits de douane sur les sciages de chêne étrangers nous ferait réaliser un très beau bénéfice par la plus-value et des arbres sur pied et des marchandises sciées. Mais, Messieurs, j'étudie la question des droits de douane sur les bois depuis 30 ans, et ma conscience m 'oblige à vous déclarer et à crier bien haut qu'une augmentation des droits de douane sur les bois, quels qu'ils soient, hâterait la déforestation de nos forêts, ce qui serait un désastre, car nous aurions chaque année des inondations peut-être plus terribles qu'en 1910. (Dénégations.)

J'ajouterai que déjà, en 1903, l'Union des Marchands de bois de France, dont M. Villame faisait partie, avait pétitionné sans succès pour demander les mêmes augmentations de droits de douane que ceux réclamés aujourd'hui, et que cette demande arait été énergiquement combattue par le distingué conservateur des Eaux et Forêts, MI. Adrien Melard.

En 1910, au moment de la rérision du tarif douanier, une nouvelle tentative avait été faite par les mêmes personnes. Cette tentative n'a pas eu d'écho au Parlement, M. Villame le reconnait dans son rapport.

Aujourd'hui vous êtes saisis d'une semblable demande. J'espère que, comme l'a fait le Parlement en 1903 et en 1910, vous rejetterez toute proposition d'augmentation des droits sur les bois, et je propose, en conséquence, de ne pas prendre en considératiọn lo ronu proposé sous le no l par II. Villame.

Pour conserver les forêts de France. supprimez les impòts qui écrasent les propriétaires de forêts. Facilitez les transports intérieurs, aussi bien par voies ferrées que par la voie lluviate. (Obligez le cabotage français à réduire ses prix qui sont exorbitants, of vous atteindrez votre but; mais ne parlez pas d'une augmentation des droits de dnuane, vous iriez à l'encontre de ce que vous cherchez. 
Messieurs, je n'ai pas cité de chiffres, mais je pourrais reprendro pied à pied toutes les propositions par lesquelles M. Villame demande des augmentations.

J'ai mieux aimé rester dans la généralité et parler d'une façon générale sur l'ensemble de la forêt française, qui n'a pas besoin, pour être protégée, de l'augmentation des droits de douane.

M. Villaste. - Nous n'avons jamais pensé empêcher l'importation des bois étrangers; mais nous demandons que notre production nationale, que nous avons à défendre, soit protégée. Je répète que nous ne domandons pas de droits prohibitifs, mais simplement des droits compensateurs.

M. Le Président. - Messieurs, les observations de l'honorable M. Volckel m'ont inspiré un texte que je viens de soumettre à M. le rapporteur, et qui peut-être, répondra à la pensée de tous.

Nous avons besoin que les bois étrangers viennent compléter nos ressources, cela n'est pas douteux; d'autre part, nous avons également besoin que nos forêts soient protégées et encouragées et que leurs produits soient rémunérateurs. Si une propriété n'est pas rémunératrice, elle est complètement délaissée, c'est l'abandon et la ruine.

On pourrait peut-être donner satisfaction à ce qu'il $\mathrm{y}$ a de légitime dans les observations de $\mathbf{H}$. Voelckel, en complétant le premier vou par cette addition: "Sans que les droits de donane sur les bois prennent un curactère prohibitif $"$.

M. Hollaxie. - Nous sommes ici pour défendre les intérêts des commerçants en bois, mais il ne faut pas que nous soyons une petite république dans la grande. Nous avons des concurrents, je ne parle pas dans notre commerce, nıais dans un commerce voisin, celui de la fabrication des meubles. Depuis une ringtaine d'années, toute l'exportation des meubles, vers la République-Argentine spécialement, au lieu de provenir de France, est envoyée d'ltalie ou de Belgique. It faut aussi prendre les intérêts des fabricants de meubles français. car ce sont nos clients : le jour où ils ne fabriqueront plus, ils ne vendront plus de bois.

II faudrait done dire: "et que les droits de douane ne soient pas prohibitifs pour les consommateurs de bois, pour le commerce destiné it l'exportation."

M. Le Présidext. - Ce point de rue rentre dans la formule que jai proposée. Il vaut mieux s'en tenir aux formules générales qui englobent le plus d'intérêts possible. C'est pour tout le monde que nous demandons d'éviter les droits prohibitifs.

II. Valchel. - Je demande la suppression pure et simple du premier rou. 
11. Villame a parle des importations de bois de mine. Or, en 1911 , it en a été exporté 761.000 tonnes contre une importation te 128.000 tonnes. Il y a done un exeédent d'exportations de 632.000 tonnes. 11 faut ('ncourager l'exportation de eet article, que nous produisons, et ne pas mettre un droit sur les potraux de mine, dont nous avons un excédent de production. Ce n'est pas moi, marchand de bois, nais ar sont les forestiers qui nous disent quen France, depuis un siète, on a aménagé les forêts en rue de la production de taillis et de petit bois, alors qu'il faudrait maintenant des bois de grosses dimensions.

1I. Girot. - Ce n'est ni comme Directeur ni comme profosseur qü j'interviens. C'est eomme reprísentant du sỵdicat de's propriétaires forestiers de la région lorraine. Depuis une vingtaine d'années, dans cette région, s'est produit un mouvement remarquable. $11 \mathrm{y}$ avait beaucoup de terres en friche, délaissies par l'agrieulture, et lion a engagé de tous côtés les propriétaires à laire des reboisements. Cres boisements ont été faits généralement rn pin sylvestre ou in pin noir. Je puis les évaluer à des eentaines de mille hectares, dans toute cette région. Les propriétaires sont arrivés au moment où ils p'uvent tirer un profit de leurs forêts. Ils attendaient aver beaucoup d"impatience et d'anxiété ce moment. Leurs pins sont exploitables maintenant, et ils n'ont pas le moyen d'arriver à une rémunération, si ce n'est de les vendre pour en faire des titais de mine ou de la pâte ¿ papier.

Or, cette année-ci, et l'année dernière, dans la région dont je parle - je ne généralise pas - les prix des etais de mine ne sont pas rémunérateurs pour les proprietaires: d'antre part, on ne demande plus du tout de bois pour la pâte ì papier. Je n'examine pas les raisons de ces faits, je ne rrois pas les eonnaitre suffisamment pour les indiquer, je vous les signale simplement. Si nos proprictaires, d'ici à quelqum temps, ne peuvent tirer parti des pins arrives ì l'âge d'exploitation, jo vous déclare que ce monrement si intiressant de reboisement d'une partie idu territoire français sera arrêté brusquement, et cu'il nous sera impossible de recommeneer un mouvement que nous avions lait naitre avec tant de peine, it y a vingt ou vingt-cinc ans.

Par quel moyen arriverons-nous ì donner satisfaction à ces proprifilaires. Comme vous, je ne erois pas qu'il faille ctablir des droits prohibitils, mais c'ost à la deuxième section tu congrès à roir si peut-être des droits modérés ne pourraient pas leur donner satisfaction dans une certaine mesure.

de suis ineompétent sur pe point, je l'avour. Nais je rous demande de prendre en considération cette situation très digne d’intérêt at l'exaniner une question qui pent aroir une très grande répereussion sur le reboisement du territoire lrancais.

11. SÉBASTEN. - On vient dr nous dire que, dans la rigion lorrainr, les bois n'étaient plus rxploites ef que l'on manquait la vonte dres 
bois pour la pâte à papier ou pour les itais de mine. Est-ce que M. le rapporteur pourrait nous dire ce que vaut actuellement le bois pour étais de mine en France, et ce qu'il vaut pris à l'étranger? Ce serait intéressant à savoir.

M. Villame. - On a calculé que l'augmentation du droit de douane...

M. Sébastiex. - Je parle du prix de revient.

11. Gurot. - Cela dépend des catégories.

II. Villane. - Il vaut, selon les catégories, de 20 à 30 francs (grand maximum) le mètre cube réel, rendu sur to carreau de la mine.

M. Sébastien. - Et les bois etrangers?

M. Villane. - Sensiblement les mêmes prix.

M. SÉbastifx. - th ! e’est intéressant à savoir !

M. Villane. - Les producteurs français ne peuvent pas augmenter leurs prix de vente, parce qu'ils sont concurrencés par l'importation étrangère et, d'une facon d'autant plus dangereuse que nous ne pouvons pas prévoir cette importation. La preuve en est donnée par les statistiques douanières. D'une année sur l'autre, on trouve facilement 50,60, 80.000 tonnes de différence et quand on jette ainsi sur le marché français un tel supplément d'importations, nous avons de justes motifs de craindre que cela gêne notre production nationale.

Le droit de douane appliqué actuellement, au tarif minimum, est de 0 fr. 30. Nous avons demandé en 1910, sans pouvoir l'obtenir, qu il fut porté à $0 \mathrm{fr}$. 65. J'avais calculé, et mes calculs ont été publiés et n'ont jamais été démentis ni contredits, que cette augmentation sur les bois de mine aurait amené une augmentation d'un centime sur le prix de revient de la tonne de charbon. Est-ce bien la peine de jeter d'aussi hauts cris pour une telle augmentation?

M. Sébastiex. - Vous n'avez nullement répondu à ma question. Pour demander une augmentation du droit de douane, il faudrait arriver i prowver que le produit étranger coúte meilleur marché que le produit français. Or, vous ne faites nullement wette preuve.

M. Villane. - Mais les producteurs français sont concurrencés.

M. Sébastiex. - Vous ne citez aucun chiffre. Nous ]e sommes tous, concurrencés!

M. Irlane. - Si une mine est sollicitée par deux vendeur's, l'un français, l'autre étranger, et si le producteur étranger fait, ce qui est le cas, des prix inférieurs... 
11. Sébastiex. - Quels sont ces prix?

M. Villane. - Ils varient sensiblement entre 2, 3 ou 4 francs le mètre cube, en moins.

11. Sébastiex. - 11 faut mettre le doigt sur la plaie. Si les bois de mine Irancais coútent 20 francs - je prends un chiffre quelconque - et les bois de mine étrangers 18 franes, il faut effectivement faire tout ce que lon pourra pour éviter cette différence. Il ne faut pas mettre des droits prohibitifs, mais il laut établir un droit qui forcera les étrangers à vendre au même prix que les producteurs français : ın augmentera done le droit de 2 franes.

Ilais si les poteaux de mine français valent 20 franes et les poteaux étrangers 22 francs sur le carreau de la mine française, vous n'arez pas besoin de droit de douane.

M. Vrllaye. - Y a-t-il dans la salle des négociants en bois de mines?...

II. LE l'RésIDEXT. - Totre argumentation ne résoudrait pas complètement la question.

M. Gryot. - Je sais que les propriétaires se plaignent beaucoup de re qu'on ne leur donne, pour des bois de pin âgés de 30 ans, que 6 franco environ le stère, soit 8 franes par mètre cube.

Ux Coxgressiste. - Est-ce le stère de mine?

II. Guyot. - Ils estiment que ces prix sont insuffisants et je suin de leur avis.

11. Le Présidext. - L'hypothèse dont on parlait tout à l'heure ne ste réalisera jamais. Quand les poteaux de mines coúteront 22 franc: à l'étranger, les producteurs français; au lieu de vendre les leur20 francs, les augmenteront de 2 francs.

1I. Sébastiex. - C'est là la question. Les poteaux de mines renant di. l'étranger valent plus que les bois de mines français.

II. Le Présidext. - L'équilibre se rétablira toujours d'une manière générale.

11. DU P'Ré DE SAINT-Mlarli. - C'est contraire à l'intérêt des propriitaires. Ils prétendent que la quantité de poteaux de mines exportéc augmente chaque année et il est vraisemblable que le trafic continurra de la même façon, attendu que, dans les pays scandinaves, on a $m$ iundroit à la sortie afin que le travail se fasse dans le lieu de production.

Vous savez bien qu'il ne vient jamais, du Canada, un ctai de mines ; ils ront tous au défibrage dans le même payss. 
Le's marchands de bois du Haut-Nivernais vous répondront de la même façon que les demandes de l'Angleterre, de la Belgique, ront en augmentant, ainsi que celles de nos mines du nord, car les résinenx leur arrivent plus rher des pays scandinaves.

Au congrès de Rouen, il y a quelques années, j'ai vu arriver en peu de temps trois bateaux de 1.400 tonnes chargés de bois tant qu'ils en pouvaient tenir. Les bateliers m'ont dit qu'ils allaient à Swansea, à Cardiff, et quand je leur demandais ee qu'ils allaient exporter, ils me répondaient : "Mais rien du tout, nous remplissons nos caisses d'eau et nous partons. "

Si nous avions eu là des étais de mines, croyez-vous done que nons n'aurions pas trouvé un débouché facile en Angleterre? Evidemment, et je crois que les étais de mines sont un objet d'exportation dont nous pourrions tirer des revenus.

M. Guyot. - Les bénéfices sont minces.

\section{Sébastiex. - Voyez les statistiques.}

M. In Pré de Sarnt-Macr. - Cela a encore un autre intérêt. Dans le Nivernais, il se passe quelque chose de bien intéressant au puint de vue économique.

Chacun sait que les bois de chauffage ne comptent guère. Cin certain nombre de marchands de bois se sont entendus avec les mines du nord et avec les petits bateliers qui viennent apporter le charbon du nord et remportent nos étais de mines. C'est très pratique, pour $6 \mathrm{fr}$. 50 à Anzin et 7 francs à Charleroi, ils transportent nos bois, choses que ne font ni les chemins de fer, ni les autres modes de transport. lls annoncent aux marchands de bois qu'ils passeront tel jour ; ils déchargent leur charbon, chargent les bois et s'en vont.

Des amis de M. Villame pourraient lui fournir des renseignements très préeieux à cet égard.

II. VELCKEL. - Voici ce que dit M. Mélard à ce sujet :

"Les bois de $0 \mathrm{~m}$. 60 et au-dessous se composent en majeure partie de bois de mines (perches et étançons). Sommes-nous vraiment, en ce qui concerne ces produits, en présence t'un afflux de marchandises étrangères dont il faille se défendre par des mesures énergiques? 11 n'en est rien. La production française de bois de mines est tellement supérieure à nos besoins que nous en exportons chaque année une quantité considérable et que tous nos efforts doivent consister, non à leur fermer nos frontières, mais à leur ouvrir largement les marchés étrangers et à éviter soigneusement toute mesure pouvant servir de prétexte à représailles ».

M. Grand. - Si ce renseignement peut être utile, je dirai que, dans les bois du Sud-Onest, des Landes et de la Gironde, nous faisons une 
exportation considérable de poteaux de mines. C'est un des emplois les plus importants des pins de la région.

Ces poteaux de mines se vendent entre 11 et 12 francs les 1.000 kilogrammes et ce prix est, considéré comme suffisamment rémunérateur.

J'ajouterai qu'il est exi sivement rare qu'on les rende pour la France; la grande majori sont exportés.

M. Væugkel. - On en exporte 570.000 tonnes.

M. Hollaxde. - Eh bien, supposez qu'on mette un droit, même pas prohibitif, mais simplement protecteur à l'exportation des bois de mines. Immédiatement, l'Ingleterre mettra les mêmes droits sur nos bois de mines ou autres.

Croyez-vous done que les propriétaires forestiers des Landes accepteront avec plaisir qu'on mette un droit chez nous sachant que l'Angleterre fera de même?

II. Graxid - Ils ne l'accepteront pas avee plaisir; mais rien ne prouve que l'Angleterre nous répondrait du tac au tac.

M. Hollaxde. - Quand on parle d'instituer un droit de ce genre, il faut prévoir les conséquences.

II. Graxd. - Si l'Angleterre établissait ce droit, elle supporterait pentêtre à elle seule les conséquences.

M. Delanaye. - Dans les dunes de la Charente-Inférieure et de la Vendée, les pins maritimes servent à faire des poteaux enverés presque tous en Angleterre.

Or, en Vendée, nous vendons le stère de pins mariłimes, bois de leu, 8 franes et le pin maritime exporté comme pc zux se rend 25 franes et plus.

II. VELCKei. - 11 est estimé 28 franes pour l'exportation.

M. de Sébille. - Jaai demandé la parole pour dégager quelque peu ma responsabilité.

Nous traitons une question particulière à la France et ji ne voudrais pas qu'on puisse dire que, représentant de la Belgique, j'i i appuyé des droits protecteurs. Nous sommes tous libres-échangiste et, quoique nous ayons a souffrir pas mal de l'importation des $l$ is etrangers. puisque nous en importons actuellement pour près de 200 millions, nous estimons que les droits protecteurs n'ont jamais sauvé la situation, quelle quelle soit (Applaudissements).

M. Le Présinext. - Nous sommes très heureux de cette déclaration ; nous avons intérêt à savoir ce qui se passe à l'étranger. 
A mon sens, le débat a quelque peu dévié et si nous voulons examiner successivement chaque marchandise, nous n'en sortirons pas. Ce quil faut savoir, c’est le sens général dans lequel le Congrès désire s'orienter. Il s’agit forcément de a France et, après avoir pris connaissance avec intérêt de ce qui fait ailleurs, nous avons à choisir entre une orientation protectir iste ou libre-échangiste.

C'est dans ce sens que nous allons ? ir à nous prononcer.

1I. Voelckel demande la suppression du premier voru présenté par 11. Villame et qui est ainsi conçu :

"To Que, lors de la prochaine révision des tarifs douaniers, il soit fait woil aux demundes du commerce des bois français, dans le sens de leur protection."

Je mets aux voix ce vou.

Le roeu est repoussé par 18 voix contre 14.

La question étant très grave et le vote restant acquis, je pense qu'il serait bon de faire venir la question en séance plénière. Nous venons d'exprimer, sous une forme négative, l'opinion de la Section, mais je voudrais la voir ém ise sous une forme positive.

11. Viefckel. - Je demande simplement qu'on ne touche pas aux tarifs douaniers actuels. La forêt française est suffisamment protégée et la proposition de .I. Villame serait la déforestation complète.

11. Risix. - Javoue qu'après avoir entendu les différents orateurs qui ont pis la parole, je ne puis pas me faire une opinion précise. Ils n'ont apporté, dans ce débat, aucun argument probant me permettant de me pro: neer dans un sens ou dans l'autre. Dans ces conditions, le seul vor. a émettre serait, à mon avis, de renvoyer la question à l'étude, soi d'accord avec l'Administration des douanes, soit avec les Fédérations.

11. DU PRÉ de ṠINT-MAIR. - Il est bien difficile d'avoir ié quelque chose re irécis. La solution doit varier avec toutes les espèces de bois dont il essquestion.

11. Gravil. Parfaitement. Il y a des bois que nous exportons, d'autres que nous iportons, on ne peut leur appliquer la même mesure.

II. Le Présiont. - lous avez rejeté l'orientation dans le sens proteeteur...

II. Holdavine. - P'ardon, nous n'avons rien rejeté du tout.

Nous demandons le maintien du statu quo. Ne retournez pas en arrière. 
11. Velckel. - J'ai demandé le rejet du vou de M. Villame. Ma proposition a été adoptée, il n'y a plus à y revenir.

11. Le Présidext. - Evidemment, mais il serait bon que le Congrès soit saisi de la question. Or, il ne le sera pas, en séance plénière, si nous nous bornons à exprimer notre opinion en supprimant le vou de iI. Villame. Je demande done à M. Voelckel de formuler sa proposition dans un sens positif afin que nous ayons un texte précis portant qu'aucune modification ne doit être apportée aux droits de douane actuels.

11. Gгуот. - Je formule cette proposition.

II. Hollande. - Alors vous allez revenir sur le vote acquis?... Je proteste contre cette manière de faire et je vais me retirer (Protestations).

M. Le Présidext. - Pas du tout, nous confirmons notre premier vote, mais de telle façon que la séance plénière du Congrès soit saisie d'un texte précis.

Il n'y a là rien de désobligeant pour personne, e'est tout simplement une question de rédaction et je sais que vous êtes tout le premier à désirer qu'il n'y ait pas de vote de surprise.

M. Vefckel. - Il n'y a pas eu de vole de surprise.

M. Le Président. - M. Guyot reprend la proposition tendant à demander qu'il ne soit apporté aucune modification aux droits de douanes actuellement en vigueur sur les bois.

M. Graxio. - Ce vou n'a pas la même signification.

M. du Pré de Salnt-Maur. - Est-ce bien utile de voter cette nouvelle proposition? Pendant combien de temps en sera-t-il ainsi? Au contraire, en admettant la proposition de M. Vorlckel, nous n'envisageons pas la question qui reste entière.

II. Le P'résidextr. - Le gros inlérêt, à mon sens, est de saisir le Congrès, en séance plénière.

11. V'TELKEL. - Tous les voux émis dans nos séances reviendront done au Congrès?...

M. Le Présinext. - Parfaitement, mais si nous adoptons simplement votre proposition, la question des douanes ne viendra pas en séance plénière.

11. Botvet. - La question nous passionne et à juste titre.

Les droits de douane datent de 1882, je crois; c’est M. Méline qui a fait voter l'ensemble des luis protectrices, disons mieux, com- 
pensatrices, sur tous les produits agricoles et les droits sur les bois. Je m'en souviens d'autant mieux que j'ai pris une large part, aves. la Société forestière de Franche-Comté, à cette discussion et qu'aree II. Viette, notre compatriote, nous arons fait établir ces droits.

M. Vazckel. - En 1891.

II. Bouvet. - Peut-être. Nous arons voulu avoir des droits ad palorem, c'est-à-dire non prohibitifs et non exorbitants, mais seulement conpensateurs.

Nous sommes tous d'accord, je l'espère, sur ce point, que nos produits français soient sur le pied d'égalité avec les produits étrangers, e'est-à-dire que ces derniers supportent les mêmes frais et les mêmes charges que les nòtres.

Étant donné l'origine de ces droits, nous devons manifester notre intention ou qu'on a mal agi en 1891, ou qu'on pourrait faire mieur, ou que nous désirons le statn quo.

Le statu quo serait un minimum; je serais plutòt partisan d'une légère augmentation, suivant les circonstances et suivant les produits; en tout cas, il ne faut pas revenir en arrière.

La proposition de M. Guyot peut, à la rigueur, nous donner satisfaction, je l'approuve comme un minimum et surtout parce que ce n'est pas un recul.

M. Véckel. - Nous ne voulons pas revenir en arrière.

M. Le Présidext. - Alors vous devez vous rallier à la proposition de 11. Guyot.

M. VELCKEL. - Je demande le maintien du stafu quo et la suppression du vou de M. Villame.

M. Le Présmext. - Remarquez que si nous ne nous prononçons pas autrement, on pourra augmenter ou diminuer les droits, tandis que II. Guyot demande qu'il n'y ait aucune modification, ni dans un sens ni dans l'autre.

Je suis saisi d'un roeu ferme de M. Guyot présenté en section au moment de la discussion, e'est-à-dire dans des conditions parfaitement régulières.

Je mets aux voix le vou présenté par. M. Guyot tendant à ce qu'ancune modification ne soit apportée anx droits actuellement en vigneur sur les bois.

M. Vefckel. - Je demande à mes amis de voter avec moi ce von.

Le vou de M. Guyot est adopté.

M. Le Présinext. - Nous allons examiner le second vou du rapport de M. Villame : 
"20 Qne la proposition de Loi de II. Loth député du Pas-de-Calais, tendant à l'admission temporaire des douvelles de sapin, soit rejetée ”.

M. Sébastien. - Dans son rapport, M. Villame a parlé de la fraude, je voudrais bien quelques explications à ce sujet. Qu'entendez-vous par là?...

11. Villame. - J'ai emprunté cette formule à l'administration des douanes, je l'ai trouvée dans un rapport. Quand il s'agit d'admission temporaire, on envisage toujours la possibilité de la fraude.

11. Sébustiex. - Vous devez cependant connaitre l'administration des douanes.

11. Yilline. - Je ne suspecte personne, mais vous savez bien que, même à l'octroi de Paris, il faut une surveillance active. On peut citer des faits.

On entre une certaine quantité de bois en admission temporaire et on en ressort une moindre quantité à la faveur de déclarations inexactes.

11. Sébastiex. - C'est très grave ce que vous dites là.

11. Velckel. - Vous accusez les eommereants en bois d'être des fraudeurs.

M. Villane. - C'est la douane, re n'est pas moi.

11. VéckEL. - Ce sont des fonctionnaires qui le prétendent.

11. Villame. - Et nous nous rangeons à leur avis (Protestations).

11. Le Présinext. - Tout le monde sait bien que, dans tous les corps de métier, il y a des personnalités de caractères différents. Il n'y a done. pas de déshonneur pour les commerçants en bois à admettre que certains systèmes peuvent favoriser la fraude. Les commerçants sérieux et honnêtes doivent ctre les premiers à rocunnaitre qu'il y a des possibilités de fraude, ce qui n'entache en rien l'honorabilité de la corporation, mais oblige a prendre certaines précautions quand il s'agit de légiférer.

II. SÉbastiex. - Vous dites, dans votre rapport, au sujet des merrains;

"Le commerce des hois s'associerait volontiers a cette demande, s'il n'avait la rainte justifié de voir cette admission temporaire favoriser outre mesure la fraude, ainsi que nous l'avons expliqué préédemment, au sujet de ladmission temporaire des douvelles de sapins $m$.

Où en avez-vous parlé?...

M. Vildame. - Voyez page quatre de mon rapport. 
11. Sébastiex. - En effet, je lis : "En laissant de còté les fraudes que favorise presque toujours l'admission temporaire ».

Ce n'est pas une explication.

M. Villaye. - C'est un fait. Nous n'ineriminons personne. M. Voelckel sait bien que l'Administration des douanes serait disposée à accepter, mais qu'elle prend toutes les précautions nécessaires contre la fraude possible. Nous nous rangeons à son avis.

M. Hollaxpe. - On pourra demander le rejet de la proposition de Loi' de 11. Loth, mais il faudrait plutòt réclamer des mesures spéciales prises en vue d'éviter la fraude.

1I. le Présinext. - Ce n'est pas toujours facile. Dans les questions de police de ce genre, il y a bien des mesures, bien des interdictions à ordonner pour éviter la fraude.

11. Giу⿰т. - Je comprends la suseeptibilité de l'honorable corporation des marchands de bois. Il pourrait être très désobligeant pour elle de roir insérer, dans un va'u rendu publie, de pareilles insinuations.

II. Le Présinext. - Les considérants du rapport n'engagent que lo rédacteur, je l'ai déjà dit hier. Le vote ne porte que sur les dispositils du voeu.

M. Sébastiex. - Quelles sont les fraudes que redoute M. Villame?...

M. Borvet. - Rappelez-vous que nous venons de demander le maintien du statu quo.

11. Sébastiex. - Nous demandons aussi le statu quo pour les entrées.

M. Vielckel. - Pour les marehandises consommées en France.

11. Hollaxie. - Il faut considérer la chose à un point de vue très élevé.

Vous savez que la France n'a malheurensement pas de moyens de navigation suffisants. Les flottes marchandes ćtrangères s'accroissent et envahissent nos ports et nous subissons constamment des augmentations de frêt, de droit de quais, ot de nouvelles difficultés d'embarquement qui n'existent pas ailleurs au même degré.

Or, nous avons la chance d'être un pays forestier et de pouvoir vendre à l'étranger beaueoup de nos bois, alors que la Belgique est un pays de transit pour l'Allemagne.

11 serait intéressant pour nous de pouvoir recevoir dans nos ports de grandes quantités de bois, de les y entreposer et de faire la réexpódition sans avoir à payer de droits de donane.

Mllez à Invers, a Rotterdam, vous y verrez entinuellement arriver des bois, non pour le pays lui-même, mais pour les réexpéditions. Il 
y a des bois qui viennent d'Allemagne à Anvers ou à Rotterdam pour aller en Suisse. Craignez-vous done de faire gagner quelques franes à nos Compagnies maritimes qui transporteraient les bois admis temporairement en France?...

M. Le Président. - Tous venez de défendre, avee beaucoup de talent - et je vous en félicite - l'admission temporaire et Je système des ports franes.

C'est une grosse question qui peut être envisagée à différents points de rue : ou en rue de la suppression de cette introduction, à cause des difficultés de la surveillance, ou en vue de donner satisfaction à ce grand commerce international dont vous parlez.

Le Congrès doit se prononcer par son vote.

M. VELíkEL. - Je demande la supprëssion des voux 2 et 3.

M. Le Présinext. - Je mets aux roix le rou No 2 présenté par M. Villame.

Ce rocu est rejeté par IS voix contre 12.

M. le Présinest. - Le voru no 3 est ainsi conçu :

" $3^{\circ}$ Que, d'une manière générale. les admissions temporaires des bois ne soient pas accordées, parce que favorisant la fraude".

II. Guгoт. - Je demande la suppression des derniers mots: "Parce que favorisant la fraude $\%$.

M. Le Présidext. - Le rejet du róu no 2 n’implique pas celui du troisième. Il traite la question "d'une manière générale ".

11. Velckel. - Il est beaucoup plus grave que le précédent.

M. Sébastiex. - Avez-rous une raison, Monsieur le rapporteur, pour supprimer l'admission temporaire?

II. Villane. - J'ai discuté avec des fonctionnaires des douanes et nous sommes tombés d'accord que l'admission temporaire est très dangereuse, paree qu'elle favorise la fraude (Protestations).

11. Sébastiex. - Ce n'est pas une raison suffisante. Retirez vous-même ce vou.

M. Hollaxue. - Je suis membre de la Commission permanente des valeurs en douane. Je comnais beaucoup de vérificateurs des douanes qui drelarent eux-mêmes qu'ils ue connaissent rien aux bois. Que voulez-rous, il faudrait qu'ils s'y connaissent en tout, ce n'est pas possible; si on ne leur apportait pas de marehandises, ils seraient beaucuup. plus heureux et ne se tromperaient pas. 
M. Vezckel. - M. Villame prétend que la France a suffisamment de hois; c'est inexact.

M. Villane. - Je n'ai jamais prétendu que la France produisait suffisamment de bois.

II. VELCKEL. - J'en prends acte bien volontiers.

II. Sébastifex. - Enfin, nous direz-rous pourquoi vous repoussez l'admission temporaire?

1I. Villaie. - Parce que - pour prendre un exemple - on peut tentrer, je suppose, 8.000 mètres cubes à la faveur de l'admission temporaire, c'est-à-dire sans payer de droits, et qu'il est facile d'en faire sortir 10.000 mètres cubes.

M. Sébastiex. - Vous arez une piètre idée des importateurs et des exportateurs.

II. VazchęL. - Le directeur des douanes lui-même protesterait s'il vous entendait.

II. Villane. - Le fait est connu, on peut frauder partout, à l'octroi comme à la douane.

II. Sébastiex. - J'affirme que jamais nous ne fraudons ainsi, mes collègues sont là pour le dire.

M. Hollaye. - lous venez de dire qu'on pouvait sortir moins de bois qu'on n'en arait fait admettre temporairement.

Voulez-rous me permettre de vous expliquer ce qui se passe. Lorsque le bois arrive dans un port, s'il est vendu au mètre cube, la douane ou l'octroi font passer tous les camions en bascule et font payer les droits sur le certificat de pesage. S'il est vendu au poids, le certificat d'octroi ne suffit pas, la douane exige que les bois passent une fois de plus en bascule.

Lorsqu'on sort le bois, on repasse en bascule et non sur une bascule queleonque, sur celle de l'octroi du Havre, par exemple. Vous pouvez, it ce sujet, rous renseigner auprès de . I. Morgand, adjoint au maire du Havre, ou de M. Couvert, à la Chambre de Commerce.

11 est done impossible de frauder à la douane, d'autant plus que l'Administration exige la production du connaissement qui porte ou le nombre de mètres cubes ou le nombre de billes ou le poids.

La fraude est donc impossible pour tous les bois, quels qu'ils soient.

11. Graxd. - Ce vou présente-t-il un grant intérêt pour le fise ou pour les particuliers?

II. VøLCKEL. - L'admission tomporaire consiste à mettre en entrepòt, 
dans les ports de mer, des boïs qui vont ensuite dans les pays étrangers. Cela ne fait aucun tort aux bois français et cela n'a aucun rapport avec la protection.

Je demande la suppression du roru $n^{\circ} 3$.

M. Le Présidext. - Je mets aux voix le vou no 3 dont 11 . Voelekel vous demande, le rejet.

Le rou $n^{\circ} 3$ est rejeté at une grande majorité.

M. Le Président. - Le rơu no 4 est ainsi conçu :

" 4º Que la proposition de loi déposée par . IT. Pasqual, député du Nord, tendant a augmenter les droits de donane sur les bois contreplaqués, soit adoptée le plus tót possible ».

M. Hollaxbe. - On a prétendu, demièrement, que les bois contreplaqués ne devaient pas être imposés parce que ce sont des produits naturels et non des produits fabriqués.

Je voudrais donc voir ajouter à ce ro'u une indication portant qu' toute pièce composée de trois ussences différentes ou non, collées aver. de la colle, est bien un produit manufacturé et non naturel.

M. SÉbastiex. - C'est tellement évident qu“il est inutile de rien ajouter au veru.

M. Le Président. - En effet: je mets aux voix le vou no4.

Le vou $n^{\circ}$ \& est adopté.

M. Le Présinent. -- Le veeu no jest le suivant :

" $5^{\circ}$ Qu'il soit établi un droit sur l'entrée du bois de quebracho en France ".

II. Vezckel. - Nous arons demandé que les droits actuels ne soient pas modifiés.

M. Le Présinext. - Oui, mais vous venez d'apporter une premièrét dérogation à cette règle.

M. Velckel. - Cela ne figure pas au tarif.

M. Villaye. - Selon le cas, vous votez done des droits protecteurs.

Je vous félieite d'aroir admis l'augmentation des droits de douane sur les bois contreplaqués.

M. Sébastiex. - P’arce qüil ý a fabricalion.

M. Le Prísinext. - Votre ra'u gínéral n'implique pas qu'on ne puisere 
admettre des dérogations pour un bois aussi spécial que le quebracho, qui est très important.

1I. Siegfrien. - Il y a là des intérêts extrêmement sérieux qu'il ne faut pas sacrifier. Nous n'avons pas voulu lair de particularités, c'est pourquoi l'assistance s'est décidée dans un sens général en votant la proposition de .I. Guyot.

1I. Geyot. - Si nous pouvions suire la discussion qui a probablement lieu ce matin, au-dessous de nous, dans une autre section, vous verriez l'importance du'quebracho pour la tannerie française.

Il est probable que nos collègues déelareront que l'emploi du quebracho dans la tannerie est fâcheux et regrettable. Il serait bon d'empêcher qu'il concurrencie nos écorces françaises et les produits tannants provenant des bois français.

1I. Sébıstiex. - Je ne connais pas très bien la question, mais je crois savoir qu'il existe, du còté de Honfleur ou de Harileur, des usines qui reçoivent le quebracho pour en extraire les matières tanniques.

Le quebracho ne paie pas de droits de donane, mais les matières tanniques en paient un.

11. GLyot. - Parfaitement.

II. Sébistiex. - Si vous imposez le quebracho, ne croyez-vous pas que ce soit la fermeture de ces usines françaises?

11. Gi yot. - Ce ne serait pas un grand mal.

11. Sébastiex. - Vous avez pourtant là une main-d ocurre française.

II. Guyot. - Je parle au point de vue de la production.

II. Sébastiex. - Et est-ce qu'ainsi vous empêcherez les extraits tanniques d'entrer en France?...

II. Gryot. - Je rectifie mon interruption : je veux dire que la fabrication des cuirs au moyen des extraits tanniques étant très défectueuse, la fermeture de ces usines ne nuirait pas à l'industrie du cuir.

11. Sébastiex. - C'est possible, mais elles rlisparaitront quand même.

11. Le Présinext. - II faut mettre en balance tous les intérêts. Ces usines sont intéressantes, mais il s'agit de savoir si l'intérêt très respectable de quelques usiniers - en très petit nombre - doit primes celui des propriétaires de taillis ou d'écorces qui sont innombrables.

Ux Coxgressiste. - Et nous sommes dans un Congrès forestier, ne l'oublions pas. 
1I. Sébastiex. - Ces usines ne produisent des extraits tamiques qu'en très petite quantité ; on en importe de grandes quantités, si bien que la fermeture des usines n'empêcherait nullement l'introduction des extraits en France. Par contre, vous auriez supprimé une main-d'œuvre française.

II. Villaue. - J'estime que ces usines sont suffisamment protégées par les droits très élevés qui pèsent sur les extraits du quebracho à leur entrée en France.

Cette industrie est très prospère puisque, d'après les statistiques, il est entré en France, en 1905, 16 millions de kilogrammes de quebracho et qu'en 1913, il en est entré 32 millions.

II. Sébastien. - Mais le droit sur le quebracho empêchera-t-il les extraits de pénétrer en France?

1I. Siegraied. - C'est aux tanneurs à se prononcer. Nous n'avons pas à nous occuper de cette question. Occupons-nous des intérêts des bois français.

M. Hollaxie. - Renvoyons le vou à la troisième commission.

M. le Président. - Elle ne s'occupe pas des droits de douane. Je mets aux voix le vou no 5 tel qu'il est proposé par M. Villame.

Le vou $n^{\circ} 5$ est adopté par. 16 voix contre 13 .

Voici le texte du $6^{\mathrm{e}}$ vœu :

"60 Que les marchands de bois exploitants de France soient représentés, savoir :

"a) A u Comité consultatif des arts et manufactures;

"b) 1 la Commission permanente des valeurs en douane».

II. Guуoт. - Je demande qu'on fasse une petite place aux représentants des propriétaires forestiers français.

11. Hollande. - Au sujet de ce vœu, je vous rappellerai ce qui se passe à la Commission des valeurs en douane. Elle n'a pas à donner d'avis au point de rue des droits de douane; elle comprend des personnes compétentes pour aider l'Administration et faire des statistiques.

MI. Daubrée représente les perches et les étançons, M. Voelckel les chênes et les bois de sapin; moi, les bois exoliques. On nous demande de fixer la valeur à l'importation des bois étrangers et de voir, avec l'Administration, si les quantités importées sont exactes.

M. Guyot. - Je ne voudrais pas qu'on puisse croire à l'exclusion des propriétaires forestiers qui sont intéressés dans la question el qui comptent, parmi eux, des persomnes compétentes. 
M. Hollande. - Je n'y vois aucun inconvénient, mais je demande qu'on mette, dans le vœu "le commerce en général".

11. Le Président. - Si on n'a pas mis "le commerce", e'est qu'on a tenu compte de ce fait que l'autre partie du commerce était déjà représentée.

M. Sébastien. - Pour donner satisfaction à M. Guyot, je propose la rédaction suivante : "Qne les marchands de bois et les propriétaires forestiers... etc.». Je ne parle pas des exploitants, car M. Volckel, qui est de la Commission, est exploitant.

M. Le Président. - Le but initial de ce vou est, tout en respectant les situations acquises par le commerce proprement dit, de compléter cette représentation par l'intervention des marchands de bois exploitants.

M. SÉ Bastiex. - J'ajouterais même : "... soient lurgement représentés... n

M. Le Présidext. - Nous concilir rions tout le monde en mettant : "Les marchands de bois des diverses catégories".

M. Véckel. - Le rapporteur a l'air de croire, d'après sa motion, que les exploitants sont sacrifiés et ne sont pas représentés.

M. Y'illame. - C'était bien ainsi jusqu'à présent.

II. Verchel. - M. Daubrée est de la Commission.

M. Le Président. - Il n'est pas exploitant.

M. Vechkel. - Si quelqu'un défend la forêt, e'est bien lui, directeur des Forêts.

M. Le Président. - Ce n'est pas la même chose ; il est là au point de vue administratif.

11. Vergkel. - Eh bien mettez "les marchands de bois français...", - les exploitants sont compris là-dedans - "soient largement représentés, etc. ", mais ajoutez-y : "... et au Comité consultatif des chemins de fer $\%$.

11. Le Président. - Il en sera question quand nous traiterons la question des transports. M. Villame en a fait l'objet d'un vœu spécial.

11. Sébastien. - Pourquoi ne pas l'introduire ici.

M. Le Présinext. - Parce que ce comité consultatif n'a qu'une relation bien lointaine avec la question des douanes.

M. Vectiel. - Cela facilite les transactions. 
M. Raisix.- Tous parlez de la représentation des commerçants en bois, mais il faut une formule générale les englobant tous. Ainsi, je représente une nouvelle catégorie de commerçants puisque nous sommes les seuls acheteurs de sciures dont l'utilisation est toute récente. Je voudrais que nous puissions rentrer dans la formule que vous allez adopter.

1I. Gurot. - lous avez raison.

M. Le Président.

Je crois que nous pourrions rédiger ainsi le vocu $n^{\circ} 6$ :

"Que les propriétaires forestiers et les négociants appartenant anx différentes catégories du commerce des bois et prodnits accessoires des forêts..."

Cela engloberait le commerce de la sciure, de la résine, etc...

II. Verchel. - J'insiste pour qu'il soit question ici du Comité eonsultatif des chemins de fer, car, ce soir, dans un autre rapport, la signification de ce roeu ne sera plus la même.

Ux Congressiste. - Je vous propose une formule plus courte et plus simple :

"Que les propriétaires forestiers et les négociants en bois et antres produits forestiers..."

M. Le Président. - Je crois que la nottre est plus rompréliensiblr, quoique plus longue.

Je mets aux roix le texte suivant :

"60 Que les négociants appartenant an commerce des bois et produits accessoires des forêts et les propriétaires forestiers soient largement représentés, savoir :

"a) An Comité consnltatif des Arts et I/annfactures;

"b) A la Commission permanente des valeurs en donane".

Ce rocu est adopté.

M. Le Présinext. - Il ne nous reste plus à examiner que la question des transports.

M. Rassix. - Je demande la parole pour traiter une question douanièr intéressante pour les départements de l'Ain, de la Saroie et de la Haute-Savoie, e'est-i-dire pour la zone frontière.

Il existe là près de 350 scieries qui ne peuvent, en aucune façon, utiliser leur sciure de bois et la jettent à la rivière à cause du droit de douane de 2 franes qui la frappe par 1.000 kilogrammes.

Comme cette sciure se vend habituellement 5,6 ou 7 francs la tonne, vous royez que ce droit de douane est de près de $50^{\circ}{ }_{0}$ de la valeur dr la marchandise. Elle ne peut done pas notrer en France. 
Ne pourrions-nous pas demander avec ces exploitants des scieries la suppression de ce droit? Ce serait d'autant plus juste qu'on a promis aux populations annexées, en 1860, d'exempter les produits du sol de toute taxe.

L'Administration, je le sais, prétend que la sciure est un produit fabriqué. Cependant, les planches qui sont, elles aussi, des produits fabriqués, ne paient rien à leur entrée en France. C'est une anomalie qu'il conviendrait de faire disparaitre.

M. LE Présidext. - Nous avons adopté ce principe de ne pas traiter les questions par trop spéciales. Vous nous soumettez une question locale très intéressante, je le sais, pour toute cette zone franche que je connais bien, ayant eu des attaches avec la Haute-Savoie.

Mais, demander à un Congrès forestier international d'intervenir dans ce débat est impossible et je crois me faire l'interprète de mes collègues en disant que, le cas échéant, nous ferons, chacun dans la mesure de nos moyens, ce que nous pourrons pour nous intéresser a cette question, mais que nous ne pouvons faire émettre un vou par le Congrès international (Assentiment).

M. Villane. - Je crois que nous pourrions traiter de suite la question des transports. Nous sonımes, j'espère, tous d'accord à ce sujet.

M. Le Présidext. - Alors, nous abordons la question du Traxsport DES BoIs.

La parole est à .II. Villame pour la lecture de son rapport.

M. Villame. - Les transports par navigation intérieure ont pris, en France, depuis une trentaine d'années une importance que l'on est loin de soupçonner dans le public. Alors qu'en 1880, le tonnage ramené an parcours d'un kilomètre sur les fleuves, rivières et canaux atteignait à peine 2.007.000.000 tonnes, en 1911, ce tomnage s'est élevé à 5.767 .000 .000 tonnes, soit $185 \%$ d'augmentation, la longueur du réseau navigable restant à peu près stationnaire (10.940 kil. en 1879 et 11.440 kil. en 1911).

Pendant ce même temps, le tonnage kilométrique des grands réseaux de chemin de fer passait de 8.999 millions de tonnes kilométriques, à 23.178 millions, soit une augmentation de $157 \%$, la longueur des réseaux s'étant accrue de $120 \%$.

Ces chiffres font bien voir que la navigation intérieure est un mode de transport qui est loin d'être en décadence, comme certains esprits un peu trop prévenus voudraient nous le faire croire et qu'il ne convient pas de la traiter en chose négligeable.

Aussi assistons-nous avec beaucoup d'intérêt à cette renaissance des transports par eau et au mouvement d'opinion qui tend à les arracher à la situation désavantageuse où la concurrence des puissants chemins de fer les avait fait déchoir. Le Ministère des travaux publics, à qui cet abandon était surtout imputable, semble lui-même vouloir entrer dans une voie nouvelle, soit en préconisant l'établissement de nouvelles artères destinées à compléter ou à étendre notre réseau actuel de navigation, soit en prenant l'initiative de dispositions et prescriptions ayant pour 
but d'améliorer l'exploitation des fleures, rivières et canaux, aujourd'hui encore si défectueuse.

Dans un travail récent, publié par la Chambre syndicale des houillères de France, M. Grüner évaluait à 25 \% l'abaissement du prix de revient immédiatement possible sur les voies navigables de France avec des procédés d'exploitation un peu plus modernes.

Par les facilités de tous genres qu'elles offrent, les voies navigables constituent, pour le transport des bois en particulier, un mode de transport des moins onéreux et des plus commodes.

Les inconvénients : lenteur du voyage et dépréciation de la marchandise, sont peut-être moins préjudiciables pour le bois que pour tout autre commerce. Aussi il n'y a rien de surprenant à ce que les transports de bois atteignent annuellement un nombre considérable de tonnes sur les fleuves, rivières et canaux et prennent leur part de l'augmentation générale du tonnage des voies navigables que nous constations plus haut.

En 1881, le tonnage des bois s'était élevé à 186.651 .431 tonnes pour les bois à brûler et bois de service. Le tonnage des bois flottés, pendant cette même année, était de 57.647.394 tonnes.

En 1911, dernière année pour laquelle la statistique officielle ait été publiée, ces chiffres ont été les suivants :

Bois à brûler et bois de service : 299.318 .085 tonnes.

Quant au flottage, qui est un procédé abandonné dans presque toutes les régions - à part dans le Morvan pour les bois à brûler — le tonnage s'en est abaissé à 5.493.929 tonnes (tonnage, nous le répétons, ramené an parcours d'un kilomètre).

Le tableau suivant indiquera d'ailleurs exactement le tonnage des bois et charbons de bois transportés par voie d'eau :

\begin{tabular}{|c|c|c|}
\hline EMBARQUEMENT & SUR LES VOIES DE & NAVIGATION INTÉRIEURE. \\
\hline & $\begin{array}{l}\text { BOIS ET CHARBON } \\
\text { DE BOIS }\end{array}$ & $\begin{array}{c}\text { TOUTES } \\
\text { LES MARCHANDISES }\end{array}$ \\
\hline - & tonnes & tonnes \\
\hline 1908. & 1.907 .188 & 34.225 .139 \\
\hline 1909. & 1.898 .725 & 35.624 .223 \\
\hline 1910. & 1.642 .496 & 34.623 .791 \\
\hline 1911. & 1.840 .397 & 38.117 .641 \\
\hline
\end{tabular}

Transports par Dans diverses assemblées, congrès et autres réunions, la Fédération des voie ferrée. Syndicats du Commerce des bois de France a fait entendre ses doléances à l'égard du traitement que subissent, de la part des Compagnies de chemins de fer, les produits forestiers français.

C'est aujourd'hui, en ce Congrès forestier international, organisé par le Touring Club de France que nous allons, de nouveau, exposer les revendications de notre commerce.

$\Lambda$ l'encontre de ce qui se passe avec la batellerie ou tout autre entrepreneur de transport, avec lesquels les prix peuvent être débattus, les tarifs de chemins de fer sont imposés et rigides, tout en étant, très hypothétiquement, le résultat de la loi de l'offre et de la demande.

Le contrat est considéré comme synallagmatique, alors, que les intéressés, c'est-à-dire les commerçants eux-mêmes ne sont pas consultés et 
ne peuvent ainsi formuler les observations qu'ils auraient à présenter pour ou contre des dispositions à appliquer à tel ou tel transport les concernant.

Cependant le trafie des bois et de ses dérivés est un appoint très appréciable pour les voies ferrées françaises, puisqu'il leur procure une recette annuelle que nous évaluons à environ 100 millions de francs (1).

Que les bois soient bruts, ébauchés ou ouvrés : de la tarification qui les affecte, résultera incontestablement un développement plus ou moins grand de leur trafic.

Les administrations des chemins de fer ont pour principe de faire supporter aux marchandises toutes les charges qui leur paraissent les plus compatibles avec leurs propres intérêts, sauf à voir parfois leurs recettes diminuer du fait d'un abaissement ou d'un déplacement de courant résultant simplement de prohibition introduite, par elles-mêmes. dans leurs propres tarifs.

Les compagnies de chemins de fer ont des tarifs qui constituent la loi des parties, mais avec cette circonstance tout particulièrement aggravante que les intéressés, qui ignorent le plus souvent les propositions des réseaux, ne sont nullement consultés à leur sujet, ou du moins, le sont bien peu.

Le service du contrôle, il est vrai, fait tout son possible pour maintenir un juste équilibre entre les divers points concurrents, mais n'ayant pas toujours les moyens de pénétrer dans le tréfonds de la question, il recourt au tableau des valeurs de marchandises de la statistique des douanes; il risque ainsi d'être fort mal renseigné.

Ce service ne peut donc opérer que par voie de comparaison des tarifs entre eux, eu égard aux distances respectives qu'il y a lieu de considérer, abstraction faite de la valeur rigoureusement intrinsèque des marchandises qui, si elles étaient reprises aujourd hui dans de nouveaux cahiers de charges, ne seraient plus classées, dans bien des cas, comme elles l'ont été au début des concessions.

Ceci nous conduit à parler, en ce qui nous intéresse, du Comité consultatif des chemins de fer et de la représentation de nos intérêts dans cette assemblée.

Les études du Comité consultatif des chemins de fer, faites avec le plus grand soin, peuvent avoir parfois pour résultat, de conduire les réseaux, par voie de réserves, à introduire des modifications fort utiles pour le commerce. Mais il ne peut pas en être ainsi lorsque, par exemple, en dehors des questions d'équilibre économique, la tarification blesse la marchandise dans sa valeur intrinsèque, car, comme nous venons de le dire, les tableaux des valeurs en douane des marchandises ne répondent pas d'une façon absolue à la valeur réelle marchande en cours.

C'est pourquoi la Fédération des Syndicats du commerce des bois de France va porter ses efforts en vue d'obtenir sa représentation dans la section permanente du Comité consultatif des chemins de fer. Il y a lieu d'estimer, d'ores et déjà, que cette représentation de nos intérêts aura, dans l'avenir, les plus heureux effets pour la sauvegarde du commerce et de l'industrie des bois de France.

(1) Le total des recettes encaissées par les compagnies de chemins de fer français pour les marchandises transportées par petite vitesse, est annuellement d'environ 980 millions de francs. 
Nous aimons à croire qu'en cette occurrence, le Touring-Club de France ne négligera rien pour seconder les efforts de notre Fédération et nous l'en remercions.

Les critiques qui ont été faites de la tarification des chemins de fer, qu'il s'agisse de tarifs intérieurs ou de tarifs communs à deux ou plusieurs réseaux, sont encore loin d'être épuisées. Il y aurait long à dire à cet égard.

Nous nous contenterons ici de quelques faits saillants di tilre d'exemples.

Tarification comparée entre les réseaux. - Pour montrer tout l'in térêt que présente la question, nous nous bornerons à vous soumettre le tableau suivant faisant connaître les prix des transports à la tonne qu'ont à acquitter sur les réseaux Est, Orléans et P. L. M., les trois principaux produits de nos forêts : bois de construction, bois à brûler et charbons de bois.

Bois à brûler.

\begin{tabular}{|c|c|c|c|c|}
\hline & & Est & Orléans & P. L. M \\
\hline 100 kilomètres & $\ldots \ldots$ Fr. & 5.15 & 5.65 & $4 川$ \\
\hline 00 . & $\ldots \ldots \ldots \ldots$ & 7.40 & 8.15 & 5.50 \\
\hline - & $\ldots \ldots \ldots$ & 9.40 & 10,65 & \\
\hline - & $\ldots \ldots$ & 11.40 & 13.15 & 8.50 \\
\hline 500 & $\ldots$ & 13.40 & 15.60 & $10 \%$ \\
\hline
\end{tabular}

Charbons de bois.

\begin{tabular}{|c|c|c|c|c|}
\hline & & Est & Orléans & P. L. M. \\
\hline 50 kilomètres & $\ldots \ldots$ Fr. & $4 "$ & & $4 n$ \\
\hline - & $\ldots \ldots \ldots$ & $8 \%$ & $10 "$ & $7 n$ \\
\hline 200 & $\ldots \ldots \ldots \ldots$ & $12 \%$ & $15 »$ & $.13 »$ \\
\hline - & $\ldots \ldots \ldots$ & $16 "$ & $18 "$ & $15{ }^{\prime \prime}$ \\
\hline - & $\ldots \ldots \ldots$ & $20 "$ & $21 "$ & $17 \%$ \\
\hline 500 & $\ldots \ldots \ldots \ldots$ & $24 »$ & $24 \pi$ & $19 »$ \\
\hline
\end{tabular}

Bois de construction.

\begin{tabular}{|c|c|c|c|c|c|}
\hline & & & Est & Orléans & P. L. M \\
\hline 50 & nètres & $\therefore \ldots$ Fr. & 2.75 & $4 "$ & $3 \%$ \\
\hline 100 & - & $\ldots \ldots \ldots$ & 4.75 & 6.50 & \\
\hline 200 & - & $\ldots \ldots \ldots$ & $7 \%$ & 10.50 & 8.50 \\
\hline 30 & - & $\ldots \ldots$ & $9 "$ & 13,50 & $12 "$ \\
\hline 40 & - & $\ldots \ldots \ldots$ & $11 "$ & 15.50 & $15 »$ \\
\hline 50 & - & $\ldots \ldots \ldots$ & $13 "$ & 17.50 & 18 \\
\hline
\end{tabular}

L'examen des tarifs spéciaux PY des divers réseaux - transport des bois à brûler et charbons de bois - présente des différences par trop sensibles d'un réseau à un autre, étant donné surtout que le prix marchand des bois à brûler par exemple, peut être considéré comme étant le même à peu près partout.

Supposons deux transports sur Paris, partant, l'un d'Angoulême $(449 \mathrm{~km}$.) et l'autre de Saint-Laurent-du-Jura $(451 \mathrm{~km}$.$) points que$ l'on peut considérer comme également distants de Paris. 
Les réseaux d'Orléans et de 1. L. M. admettent tous deux la condition de chargement minimum de 5.000 kilugrammes: les prix étant sur l'Orléans de $14 \mathrm{fr} .10$ et sur le P.-L.-Il. de 9 fr. 25, la movenne kilométrique ressort respectivement à $0 \mathrm{fr}$. 031 et à $0 \mathrm{fr} .02$, là valeur en forêt étant sensiblement la même de part et d'autre.

A l'égard des deux combustibles bois et houille. la différence de traitement est frappante.

Le bois à lorùler paie d'Ingoulême à Paris 1 '́ fr. 10 par tonne el par wagon do 5.000 kilugrammes ou $0 \mathrm{fr} .031$ comme prix moyen kilométrique.

Pour un parcours quelque peu supérieur $(472 \mathrm{~km})$ de Champagnacles-Mines à Paris, la houille ne paie que $9 \mathrm{fr} .20$ ou $0 \mathrm{fr} .0199$ comme prix moyen kilométrique.

La différence est vraiment trop grande et sans raison.

Charbons de bois. - Les charhons de bois sont rendus le plus ordinairement à Paris sous la forme de sac de 60 kilogrammes qui est payé (en gare Paris) 4 fr. 50, ce qui le ramène à 75 francs la tonne, alors que la houille pour le chauffage domestique est évaluée (tonjours gare Paris) 4 ' franes les 1.000 kilogrammes.

Prenons pour termes de comparaison des houilles du Nord, à destina tion de la gare de La Chapelle et des charbons do bois en provenance du réseau P. L. M. ayant effectué un parcours identique ì celui de la houille soit 210 kilomètres. La houille paie $6 \mathrm{fr}$. 30 et le charbon de bois $13 \mathrm{fr}$. 20 la tonne, e'est-à-dire les prix moyens kilométriques respectifs de $0 \mathrm{fr} .03$ et de $0 \mathrm{fr}$. 062. N'est-ce pas là le moyen d" paralyser l'industrie du charbon de bois qui, dans bien des cas, malgré la différence de valeur calorifique, pourrait rendre d'aussi hons services à l'industrie que la houille elle-même (1).

Constatons, en passant, que nos revendications sont basées surtout sur ceci, que la production houillère est protégée, quelle que soit sa provenance, nationale ou étrangère, et que nous demandons que l'on assure aux produits des forêts de France, un traitement qui ne puisse pas les placer dans des conditions moins favorables.

Des exemples semblables seraient nombreux à citer, mais nous craindrions de lasser votre bienveillante attention.

Bois pour les mines. - Le prix de transport des bois pour les mines est, dans bien des cas, assez sensiblement le même que celıi des bois à brüler, il est fixé par le tarif P. V. no 9 ,

Le tarif spécial P. V. nº 9 , présente des anumalies un peu surprenantes que nous allons éturlier.

La Sologne arant demandé à éeunler ses bois résineux, susceptibles d'un excellent emploi pour les mines, des accords sont intervenus à son sujet entre les divers réseaux intéressés et la lecture du Cliaix (petite vitesse) nous montre quatre tarifications dissemblables, selon que les transports seront dirigés dans tel ou tel sens.

Le chapitre premier de ce tarif vise les relations entre tous les grands réseaux et les Ceintures (c'est l'ancien régime).

(1) D'après l'aide-mémoire de Claudel. lit valeur calorifique moyenne de la houille est de 9.200 ; celle du charbon de bois de 6.950. Leur rapport est de $1,3237$. 
Le nouveau régime se retrouve dans le chapitre 4, relations entre les Ceintures, l'Est, le Nord et le P.-L.-M. ; le chapitre 35, paragraphe 8: relations Orléans, P.-L.-M. ; enfin le chapitre 40 : relations Ceintures, Nord, Orléans, Ouest, P.-L.-M.

Ces différents chapitres comportent les barêmes suivants:

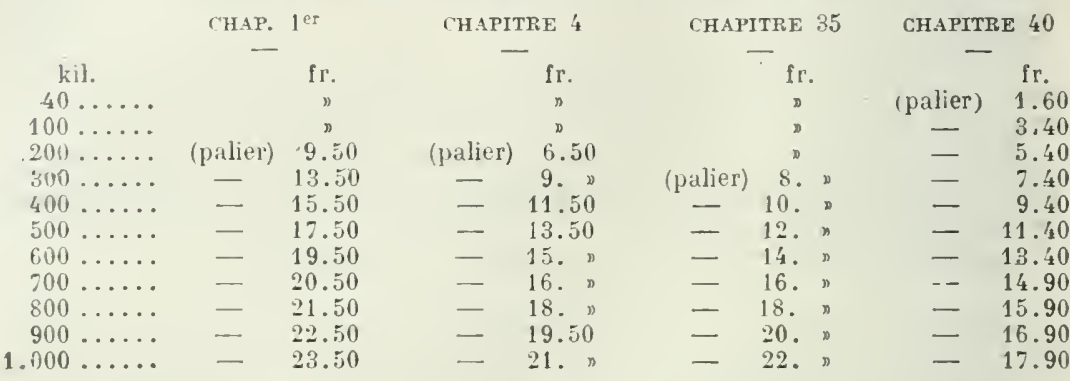

Il suit de là que la Sologne qui a demandé pour ses bois résineux un régime de protection, a obtenu un régime de faveur ressemblant d'assez près à un traité particulier.

Permettez-nous de nous étendre un peu sur le jeu de ces divers barèmes.

Le chapitre premier ne demeure applicable, que lorsqu'il s'agit de transports de ou pour le réseau du Midi et de l'Etat (ancien réseau).

Le chapitre 4 ne peut servir que pour les relations de ou par le réseau de l'Est.

Le chapitre 35, Orléans, P.-L.-M., devrait disparaitre parce qu'il est avantageusement remplacé par les prix du chapitre 40 auquel participent, comme au chapitre 35 , les réseaux d Orléans et de P.-L.-M. par un traitement meilleur pour les mines du Nord et du Pas-de-Calais.

D'où cette conclusion : pourquoi ne pas demander au réseau de l'Est de participer aux conditions du chapitre 40 , ce qui conduirait à la suppression du chapitre 4 dont les prix feraient place à ceux du chapitre 40.

Les transports des bois pour les mines seraient ainsi traités d'une façon uniforme, quelles que soient les provenances et les destinations, par les réseaux de l'Est, d'Orléans, de l'Ouest, de P.-L.-M. et les Ceintures de Paris. Libre aux réseaux de l'Etat et du Midi de se confiner dans les conditions prévues au chapitre premier.

Notre démonstration a pour but de faire ressortir le prix moyen kilométrique prévu à chacun des chapitres que nous a vons signalés. Ce prix moven est à 500 kilomètres par exemple, d'après : le chapitre Ier, $0 \mathrm{fr}$. 0.35 , le chapitre 4, $0 \mathrm{fr}$. 026, le chapitre $35,0 \mathrm{fr} .024$ et le chapitre 40, $0 \mathrm{fr} .0228$.

Pourquoi ces traitements divers?

Cet exemple, qui pourrait être corroboré par un grand nombre d'autres (1), corduit à dire qu'il appartient aux Compagnies de revoir leur tarification; de la réduire en la refondant, de manière telle que la

(1) a) Sur le réseau de l'Est, il n'est fait aucune distinction, pour le transport, entre les différentes espèces et qualités des boís: le bois de charbonnette d'une valeur de 10 francs les 1.000 kilos sur wagon, étant assimilé aux feuillets de chêne d'une valeur d'environ 250 francs le mètre cube.

b) Un sac de charbon de bois, vendu gare départ, un prix moyen de 3 fr. 40 , pour arriver en gare à Paris, supporte un transport par fer moyen, de i fr. 10 , soit $33 \%$ de sa valeur; n'est-ce pas véritoblement plus qu'excessif? 
valeur du transport, quelle que puisse être sa direction, soit ramenée partout à la plus juste mesure.

En effet, les Compagnies ont admis une table générale par séries de marchandises; elles se sont mises d'accord pour grouper les marchandises en des catégories représentées par la classification des tarifs spéciaux.

Ne conviendrait-il pas qu'elles s'entendissent aussi en vue de l'unification des bases de leurs barêmes, de manière à arriver à une tarification unique pour une même marchandise transportée sur notre territoire?

Wagon complet. - Minimum de tonnage.

Les tarifs spéciaux prévoient le plus généralement la condition du chargement par wagon complet, avee un minimum de tonnage exprimé.

Dans certains cas, comme par exemple, un chargement de bois pour les mines, il n'est pas toujours possible d'arriver à placer 5.000 kilos.

Il n'est pas toujours possible non plus de charger 8.000 kilogrammes de bois à défibrer sur un seul wagon (minimum de poids exigé sur presque toutes les compagnies).

Enfin, il n'est pas toujours possible, pour un expéditeur, de remplir ees conditions, non que la marchandise soit en quantité insuffisante, mais parce que la capacité du wagon ne permet pas de placer 5.000 kilogrammes.

Il semblerait équitable, dans ces conditions, que le wagon ne soit taxé que pour le poids réel qu'il comporte, ru'il soit isclé ou qu'il entre dans la composition d'une rame, lorsque le tonnage total répond à la condition exprimée au tarif.

C'est ainsi par exemple que si 3 wagons de petit modèle sont nécessaires pour envoyer 10 tonnes, alors que 2 wagons devraient suffire, le prix par wagon complet est appliqué, non sur le poids de 10.000 kilogrammes, mais sur l'utilisation des 3 véhicules comptés chacun comme chargés à 5.000 , soit pour les trois, 15.000 kilogrammes.

Il y a là quelque chose de choquant dont ne devraient pas suuffrir les expéditeurs et dont les Compagnies qui fournissent un matériel insuffisant ne devraient pas profiter.

Fourniture de matériel. - Il serait à désirer que la fourniture du matériel soit l'objet, de la part des compagnies, d'une attention plus particulière, et qu'elles se conforment d'une manière plus rigoureuse, aux prescriptions des tarifs dont elles ont, elles-mêmes, rédigé les termes.

Il est aussi très regrettable que le matériel demandé pour une date précise par les expéditeurs ne soit pas mis à leur disposition au jour fixé.

Il résulte de la non observation de cette clause, des diffieultés et souvent des frais qui ne peuvent être récupérés par eeux qui les subissent. Par contre, si un expéditeur retarde d'un jour le chargement ou la libération du matériel, il doit, conformément aux conditions d'application dẹs tarifs, subir la pénalité qui y est édietée.

Lettre d'avis. - Un autre point, très important, e'est la lettre d'avis. Son envoi, a dit la Cour de cassation dans divers arrêts, n'est pas obligatoire; elle ne doit servir que pour marquer le jour à partir duquel doit. courir le magasinage. A défaut de son envoi, la marchandise est réputée. remise, les délais expirés. 
Il y a là un double inconvénient : celui pour la Compagnie de conserver une marchandise sans nécusité at ainsi d'encumbrer inutilement ses quais; le second, celui d'ohliger le destinataire à des déplacements toujour's desagréables, parfois onéreux.

Quand elles croient leurs responsabilités engagées, les Compagnies usent de la lettre d'aris sans ménagements; dans los autres cas, elles semblent seen désintéresser.

Obliger les Compagnies à correspondre arec leur clientèle (comme de simples commerçants) par la lettre d'aris, est certainement demander au personnel un travail supplémentaire; mais qu'est ce léger surcroît de besogne. d'ailleurs rapidè à effectuer, à còté des avantages à en attendre?

Il semble done que loobligation de l'onvoi de la lettre d'a vis s'imposecomme mesure d'ordre général en vue du bon fonctionnement des relations obligées du public arec les Compagnies.

Bâchuge. - Lu flot d'encre qui a déjà coulé à l'oceasion de cette question, nous ne viendrons rien ajonter. Mais nous pouvons, cependant, ćmettre lavis snivant : il n’est pas nécessaire de légiférer sur une question de bon sens. Ou la marchandise peut voyager sans être protégée contre les circonstances atmosphériques, ou elie ne le peut pas; ou elle peut être abritée dius un wagon enurert, si elle doit être abritée, ou elle ne le peut pas, quelle quen soit la cause. C'est dans ce dernier cas que le bâchage devient obligatoire, sa conservation ne pouvant être assurée que par ce seul moven.

11 nous paraît pn conséquence inutile et oiseux de chercher par des considérations d'spèce, à limiter, à telle ou telle catégorie de transport, le bénéfice du bâchag̣..

Four terminer, il nous parait indispensable de présenter quelques considérations plus générales, sur la taxation des marchandises en prenant ponr base leur valeur commerciale réelle.

Tout dabord, nous admettrons très volontiers que les marchandises subissent, selon les moments, des hansses on des baisses, que ne pent pas suive la tarification des chemins de fer.

Ce que l'on peut cependant considérer comme certain, c'est que la moyenne dir res fluctuations n'a pas pour effet direct de modifier d'une façon très sonsible le cours ordinairł moyen, qui lui, an contraire, en ce qui conceme nus produits lorestiers, a à souffrir de la concurrence qu'exerce en France l'importation des produits étrangers.

Le commerce des bois français subit la loi inéluctable de la tarification de nos réseaux, dont il ne peut pas s’affranchir sous peine de déchoir complètement, mais eula nro prouve pas, d'une façon incontestable, la justesse et la précision dr cette tarification.

M. Heurteau, ancion directeur de la Compagnie d'Orléans, considérait comme une règle économique alssolue, en matière de transport, de faire payer à la marchandise tout ee qu'elle pouvait payer; nous sommes de son a vis.

Mais, pour que l'application de ce principe suit une réalité, encore fant-il que la taxation soit bien en rapport avec la valeur de la marchandise, en tenant compte aussi dr la situation géographique. Les Compagnı ies ne devraient pas considérer d'une façon absolument rigoureuse la part dr transport reffectué par chacunr d'rlle, mais l'ensemble du 
transportsur le territoire français, et aussi l'utilité que présente la marchaudise, quant aux besoins généraux de la consommation.

Il faut se somvenir encore de cet autre principe, que le transport est un prix mort qui ne touche en rien la valeur intrinsèque de la marchandise, mais peut contribuer à son inertie.

Liexamen des phénomènes commerciaux, tout au moins en ce qui concerne notre Fédération, nous conduit à penser que la tarification actuelle des marchandises demanderait à être l'objet d'une révision permottant de classer les produits pxploités d'une manière plus adéquate, et reci conduirait à une application plus juste du prix de transport auquel les Compagnies pourraient prétendre, sans augmenter inutilement le prix de consommation.

Ce serait évidemment un travail de longue haleine, mais nous estimons que le résultat à en attendre tout en contribuant à la richesse des Compagnies aiderait puissamment au développement du commerce et de lindustrie des bois. 11 entrainerait une simplification rationnelle des tarifs, en rendant, en même temps, la lecture ei l'application desdits tarifs plus faciles.

A ces considérations générales se rattache la question des marchandises qui, transportées à l'état brut, font retour an transport après transformation.

Ciest ainsi que les bois en grume reviennent au transport transformés pn planclies, plateaux, madrier's, douelles, parquets, ete.; que les bois à défibrer sont rechargés comne fibres di: bois; que les bois destinés à la trituration se représentent comme papier et qur les bois destinés à la distillation sont remis an chemin de fer sous forme d'acides pyroligneux on leurs dérivés, et ensuite comme charbon do bois.

Il y a intérêt à ce que les matières prumières soient l'objet d'un traitement en rapport non seulement avec leur propre transport, mais eneore arec celui qui leur sera réserví après transformation.

Les bois en grume sont de beaucoup les plus intéressants, et pour d'ux raisons: la première, e'est qu'ils présentent des masses d'un poids très appréciable, sans aucun risque pour le transporteur sous leur pre mière forme; la seconde, c'est qu'après main-d'ouvre par l'industrie, ils seront encore frappés de tarifs rémunérateurs par les Compagnies sous leurs formes rliverses.

Il conviendrait, en conséquenee, d'appliquer aux bois en grume la taxation la plus faible possible, en tenant compte do leur valeur commerciale.

Telles sont les quelques ennsidérations générales que nous avions à présenter au Congrès.

Le sujet, on le voit, est encore loin d'être épuisé et nous n'avons pas eu la prétention de vous développer, en quelques pages, une question aussi vaste, aussi délicate que culle du transport des produits de nos forêts.

Nous croyons cependant avoir atteint un but : celui d'attirer volre attention sur des questions vitales pour notre industrie forestière.

Il a élé fait quelque chose, nous le reconnaissons, mais nous devons bien nous pénétrer qu'il reste encure beaucoup ì faire.

Si l'on veut que l'exploitation devienne productive, il faut que celte exploitation soit secondée dans l'éroulement lis sis pinduits. 
Les tarifs de chemin de fer sont un de ces éléments qui peuvent puissamment aider au développement des produits forestiers comme, au contraire, ils peuvent réduire ce déreloppement en paralysant l'écoulement normal.

Pour conclure, nous avons l'honneur de proposer au Congrès forestier l'adoption des vœux suivants :

I. Que les tarifs des chemins de fer soient révisés.

II. Que le commerce des bois soit représenté largement à la section permanente du comité consultatif des chemins de fer.

M. Le Présinext. - MM. Chancerel et P. Leturque nous ont adressé deux communications relatives à l'unification des transports. Leurs conclusions sont conformes à celles de M. Villame.

M. du Pré de Sarst-Maur. - Le syndicat forestier du Morran, le Syndicat du Commerce des bois et des industries qui s'y rattachent, et de nombreuses collectivités du Centre et de l'Ouest de la France, se sont mis d'aceord, depuis un certain nombre d'années sur la formule suivante: mener nos produits à l'industrie et rapprocher le plus possible l'industrie de nos bois.

Voilà qui résume notre manière de faire et nos efforts pendant plus de cinq ans.

Nous voudrions mener nos produits aux débouchés actuels, arec les facilités dont jouit le frêt de retour, et nous roudrions instituer dans le centre de la France, entre le canal laiéral à la Loire, le canal du Nivernais et le canal de Bourgogne, une zone où tous les produits, toutes les industries se rapportant aux bois, pourraient trouver d'énormes arantages.

Toudriez-rous approuver cette formule comme remède au inal dont souffre les forêts? Elle a été approurée à l'unanimité par les intéressés dans bien des départements; les représentants dı commerce des bois, réunis ici en ce moment, peuvent vous le dire.

11. Le Présidext. - Le rapport et les vocux de .II. Villame vous donnent, je crois, toute satisfaction.

M. Villane, - J'en ai parlé rlans le rapport.

1I. Le Prêsinext. - Toici le premier rou proposé par M. Villame :

" $1^{\circ}$ Qne les tarifs des chemins de fer soient révisés dans le sens fuvoruble à la production et un commerce des bois de France".

M. Holdaxde - Ajoutez "et des colonies "parce que lrs bois exotiques paient un tarif spécial beaucoup plus élevé. La région de Burdeaux ot do Marseille réclane un noureau tarif pour ces bois exotiques.

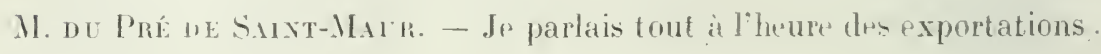


l'étais en Angleterre. Voyez quelle facilité pour nous, Nivernais, si nous arions des communications aisées avee Bordeaux, alors qu'aujourd'hui les bateaux the $38 \mathrm{~m}$. 50, ne peuvent arriver chez nous.

M. Le Présidext. - Chaque contrée a son point de vie spécial. Restons dans les généralités.

M. Raisin. - Demandez d'urgence cette révision sans quoi nous attendrons deux ou trois ans comme d'habitude. Nous apportons assez de millions aux Compagnies pour qu'elles nous donment rapidement satisfaction.

D'ailleurs, il est bon rqu'on dise ici que le commerex des bois en général est extrêmement mécontent des rhemins de fer. C'est le drvoir du Congrès d'appeler l'attention sur ce fait. Nous sommes des travailleurs consciencieux; si nous étions des travailleurs conscients, nous aurions déjà mis en demeur les Compagnies do nous donner satisfaction.

M. Le Présinext. - Nous pouvons ajouter le mot "d'urgence ", car votre obserration est très sage.

Je mets aux voix le veru ainsi modifié :

" 10 Que les tarifs des chemins de fer soient révisés d"urgence dans le sens furorable à la protuction et an commerce des bois de France et des rolonies".

Ce voun est adopté.

Le second roru est ainsi ronçu :

"20 Que le commerce des bois soit représenté largement à la section permanente du comité consultatif des chemins de fer".

Coŕnme pour le roun relatif aux douanes, nous pourrions le rédiger ainsi :

"Que les propriétuires forestiers et le commerce des bois et produits accessoires dè la forêt soient largement représentés... etc... ).

Je mets aux roix le voeu ainsi modifié.

Le voru est adopté.

L'ordre du jour de notre section étant épuisé, il ne me reste plus, Messieurs, qu'à vous remereier de l'attention soutenue que vous avez apportée à nos séances et ì dérlarer clos les travaux de la druxième section.

La séance est levép à 11 heures. 



\title{
TROISIENE SECTION
}

\author{
TEGINOLOGIE FORESTIERE - GMMURRE ET INDUSTRIE \\ DII BOIN
}

\section{BUREAU}

Présilent :

M. Paul Potpinel, prisident de la Chambre syndicale des bois de Sciage et dindustrie, vice-prósident du Syndicat général du Commerce et de l'Judustrie.

Vice-présidents : MII. Honoré Barbier, président de la Fédération des Syndicats du Commerce des Bois de France et des industries qui s"y rattachent.

P. Pincaler, syndis-président de la Chambre syndicale des Bois ì bruler.

A. MAthes, président de la Communanté des Marchands de bois a courer.

J. Hollande, prísident de la Chambre syndicule des Bois des iles ot d'Ebénisterie.

1. Cousix, prísident de la Chambre syndicale du Sciage et dll Trasuil mérminge des bois.

Mabelix, inspecteur des Eaux et Forîts, doeteur en droit, ehef desection a la Direction générale.

Secrétaires:

MII. L. SÉbasten, membre de la Chambre symbicale des bois de Sriage et d'Industrie. 
E. Porsorox, secrétaire de la Chambre syndicule des bois de Sciuge et d' Indnstrie,

Giratd, inspecteur-adjoint des Eaux et Forêts.

RAPPORTEURS : $1 \mathrm{M}$. RAchet, syndic de la Chambre syndicale des Bois de Sciage et d' Industrie.

Pierre Lièvre, membre de la Chambre syndicale des Bois de Sciage et dindustrie.

Edouard Rizier, membre du bureau de la Chambre syndicale des Bois à brîler.

Caquet, membre du Conseil supérieur de l'Agriculture.

Gustave Antws, syndic de la Chambre syndicale des Bois de Sciage et d Industrie.

Pelletier de Martres.

Georges Rotival, membre de la Communauté des marchands de Bois à Deurrer; président de section au Tribunal de Commerce de la Seine.

Paul Coulet, avocat à la Cout ditppel de Paris, avocat-conseil de la Chambre syndicale des Bois de Sciage et d'Industrie.

René Barbier, membre de la Commmanté des marchands de Bois à enurer.

Srmox, ingénieur des Manufactures de l'État, chargé de la Direction de la Nanufacture d'allumettes de Saintines.

MARCEL, membre de la Chambre syndicale des agents et commissionnaires en bois dindustrie. Conseiller du commerce extérieur de la France.

Prtealx, vice-président de la Chambre syndicale du Sciage et du Trasail mécanique des Bois.

BOCQuet, syndic: de la Chambre syndicale dn Sciage et iln Travail mécaniqne des Bois.

Hirsch, inspecteur des Eaux et Forêts.

Dчснемл, secrétaire général de l'Union syndicale des usines de carbonisation des bois de France. 
SEANCE DL 16 JUIN 1913

\begin{abstract}
(MATIN)
$(\operatorname{MATIN)}$

Présidence de M. POUPINEL, président de Section
\end{abstract}

La séance est ouverte à 11 heures.

M. Le Présinent. - Messieurs, arant daborder la discussion des rapports, je rous rappelle qque ceux d'entre rous qui auraient des observations à présenter, non seulement sur les conclusions, mais encore sur la rédaction même de ces rapports, peuvent demander et obtenir la parole.

L'ordre du jour appelant la discussion sur le rapport de l'Explortation Des Bois de .1. Rachet, je donne à M. Rachet la parole pour la lecture de son rapport.

M. Rachet. - L'exploitation des bois dans les forêts domaniales comme dans les forêts privées, s'est complètement transformée depuis un demi-siècle.

A côté du bùcheron qui abattait les arbres, on voyait autrefois dans les coupes de nombreux travailleurs de métiers divers : les scieurs de long qui, sur le parterre de ces coupes, transformaient les arbres en plateaux, en frises, etc.; les fabricants de cercles pour tonneaux; les fabricants de sabots, d'articles de boissellerie, de jougs, d'attelles; les charbonniers.

La forêt était un vaste atelier. Les plus belles pièces de chêne étaient choisies pour la marine de l'État. Le marchand de bois adjudicataire était tenu de les façonner en charpente. Ces belles pièces étaient conduites, à des distances parfois assez grandes, jusqu'au bord des cours d'eau qu'elles descendaient ensuité jusqu'à leur embouchure pour arriver' enfin sur les chantiers de construction de la Marine.

Mais le bois disparut de la construction des navires de guerre et aussi de la construction des bateaux de la marine marchande. Le travail forestier subit une première atteinte. Il restait pourtant au scieur de long le débit considérable des traverses de chemins de fer et de bois nécessaire à la construction du matériel roulant. Dans le rapide développement des voies ferrées en France il y eut de l'occupation pour le pénible travail du scieur de long jusqu'au moment où les scies mécaniques, scies eirculaires, scies alternatives et scies à ruban, apparurent pour revolutionner le travail en forêt.

Les scieries mécaniques étant devenues les indispensables auxiliaires 
des marehands de bois exploitants, la forêt se vide de ses travailieurs. Le seieur de long disparait; les boisselier's, tourneurs, tonneliers vont s'établir auprès des scieries méeaniques et deviennent leurs auxiliaires.

Le charbonnier quitte à son tour la forêt. Les usines de distillation du bois obtiennent par la carbonisation en vase elos de riches produits dérivés de l'acide acétique du pyroligneux. Le charbon de bois n'est plus qu'un sous-produit de ces usines.

L'exploitation des bois est alors complètement changée. Le bûcheron reste seul dans la coupe.

Et le travail même de cet isolé ne tardo pas à se modifier. Il est resté pour abattre du bois de feu et des grumes. Les bois en grumes sont enlevés tels quels par des roituriers qui les transportent aux gares ou aux scieries mécaniques. D'autre part, la valeur du bois de chauffage diminue en raison même de la transformation du confort intérieur; toutes les constructions nourelles, dans les grandes villes, se font avec chauffage central. En conséquence, on réserve le moins possible de bois pour le chauffage et ce qui ne pourra être mis en grumes sera employé comme rondins de choix pour diverses industries de formes, roules, bois tournés, etc.

Si la forêt est maintenant moins peuplés qu autrefois de travailleurs, .lle n'en fournit pas moins son bois au commerce et à l'industrie et d'une façon même beaucoup plus intensive que jadis. L'exploitation de la forêt ne peut se faire qu'à l'aide des chemins qui y sont créés. Il n'y avait autrefois à enlever de la coupe que des bois travaillés en sciages, sabots, cercles, boissellerie, charbon ; ces transports étaient relativement légers et peu encombrants. L'exploitation actuelle nécessite des transports beaucoup plus lourds et plus difficiles.

Au fur et à mesure que la transformation s'est effectuée dans l'exploitation de la forêt, l'Administration a dù augmenter le nombre des routes forestières et améliorer celles qui existaient.

Il reste encore pourtant beaucoup à faire en ce qui concerne les chemins pour faciliter les transports et le commerce des bois désire vivement que les améliorations nécessaires soient apportées le plus tòt possible. Quand le réseau des routes forestières sera suffisamment déreloppé et que ces routes seront en bon état, on pourra alors remplacer la traction animale par la traction mécanique et en mème temps un énorme progrès sera réalisé dans l'exploitation des bois.

Le besoin de ces améliorations des chemins et routes n'est du reste nullement contesté et personne n'a jamais douté qu'en l'absence de chemirs appropriés l'exploitation rationnelle de la forêt est complètement impossible. On n'ignore pas non plus comment il laudrait procéder pour obtenir' une exploitation rationnelle de la forêt en ce qui concerne les coupes à y effectuer et la fréquence de ces coupes. Mais entre la théorie et les mesures d'application, il y a place pour les graves questions financières.

S'il est admis indiscutablement que des coupes périodiques sont nécessaires pour aérer et assainir la forêt, pour permettre aux sujets plus jeunes de grandir et de se développer normalement, on est forcé par contre de constater que les règles admises sont loin d'ètre suivies. Le déboisement sans méthode est trop généralement pratiqué dans les forêts particulières, les règles logiques de reboisement ne sont pas observées; l'appauvrissement de nos richesses forestieres est un mal depuis longtemps dénoncé sans qu'on ait pu lui trouver le rénede.

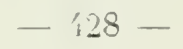


C'est qu'il y a encore ici une question fnanciere qui prime tous les arguments de logique.

Ainsi que l'a dit excellemment l'économiste Armand Mossé dan-une. étude récente sur cette grave question, le propriétaire d'aujourd'hui, à l'encontre du seigneur foncier d'autrefois, est incapable de conserver un capital immobilisé ou insuffisamment fructueux et il est pressé de monnayer la richesse improductive. Aussi, comprenant son intérêt immédiat, est-il tenté d'abuser de la forêt, par la réalisation hátive des produits et même par la destruction du capital-bois; en tout cas, préférant accroître son revenu plutôt que son capital, il n'hésitera pas à choisir le mode d'exploitation en taillis, à adopter des révolutions courtes qui lui procurent un revenu supérieur. Non pas que la forêt ainsi exploitée lui donne plus de bois par unité de superficie, mais parce que la qualité du bois, elle-même, augmente avec l'âge des arbres; le bois de vingt ans, par exemple, la charbonnette, ne vaut guère que 4 francs le mètre cube, tandis que le bois de 25 ans, le rondin, vaut 8 francs le mètre cube. Au surplus, et en se référant en cela aux observations de l'économiste Cauwes, on peut dire que l'exploitation en futaie, qui correspond par rapport aux coupes de taillis à ce qu'est l'agriculture intensive par rapport à la culture extensive, ne lui eût apporté qu'ua revenu moindre. Un hectare de 500 francs qui produit un revenu de 400 francs en 20 ans, soit au moins $2,04 \%$ ne donnerait en 150 ans - par exemple - que 8.000 francs de revenu, soit un taux de placement de $1,90 \%$ seulement.

Il résulte donc de ces observations que l'exploitation forestière n'est pas un placement rémunérateur et qu'il ne faut pas se laisser influencer par cette assurance qu'une forêt de chênes double de valeur en cent ans. Le cent pour cent ainsi obtenu ne représente, en défnitive, que $1 \%$ par an. Ces considérations expliquent le déboisement des forêts particulières et il est difficile de faire autrement que de le constater sans pouvoir intervenir légalement contre les droits inhérents à la propriété. En présence pourtant de l'appauvrissement national et des répercussions climatériques qu'occasionne le déboisement; en considération aussi de l'affront causé à la nature et à sa beauté par les farouches déboisements auxquels nous assistons, il est de toute évidence que le législateur devra prendre des mesures préservatrices; mais qu'il ne le pourra qu'en tenant compte des droits imprescriptibles de la propriété.

Dans les forêts soumises au régime forestier (État, communes, établissements publics), le danger de déboisement et de dénudation n'existe plus. L'administration procède à l'organisation des coupes avec le plus grand soin et elle surveille minutieusement les aḅatages, vidanges, charrois et déblaiements. Mais la forêt gérée par l'État ne représente que le tiers du domaine forestier français. Sur 9 millions d'hectares environ, il y a plus de 6 millions d'hectares de forêts appartenant à des partıculiers. Il faudrait pouvoir imposer à ces particuliers le régime forestier avec toutes ses sévères prescriptions.

On a parlé de nationalisation de ces forêts privées. Le remède serait énergique et absolu, puisqu'il ne s'agirait rien moins que d'expropriation. Mais on se heurte immédiatement à une valeur à payer qui représenterait plusieurs milliards.

Le budget de l'État, déjà si élevé et si lourd pour le contribuable ne peut permettre d'envisager l'expropriation. A défaut de cette solution, 
l'État devra s'arrêter au rôle de protecteur qui est de son droit et même de son deroir.

Il joue déjà ce rôle de protecteur par des encouragements et des subventions, mais dans la mesure de ses moyens budgétaires qui sont de peu au regard des réelles nécessités. On trouve dans notre budget pour 1911 une somme de 3.500 .000 francs pour restauration et conservation des terrains en montagne; 1.250 .000 pour amélioration et entretien des forêts et dunes, pêche et pisciculture, subvention pour les améliorations pastorales et forestières; les dépenses de personnel des agents des eaux et forêts dans les départements dépassent 2.500 .000 francs; le personnel des préposés dans les départements.coûte 3.270.000 francs; la contribution de l'État pour le traitement des préposés forestiers communaux atteint près de 200.000 francs ; d'autres frais d'enseignement, d'aménagement, d'exploitation, de matériel, portent au total les crédits rotés annuellement à environ 15 millions de francs, dont 5 millions s'appliquent à des dépenses d'intérêt général (reboisement, pêche, gestion communale, etc.) et 10 millions à la gestion proprement dite du domaine de l'État. Dans ce même budget de 1911, on voit dans les tableaux des revenus du domaine de l'État les produits des forêts portés en recettes pour une 'somme évaluée à 33.515.200 francs. Le bénéfice industriel ressort donc à 24 millions de francs, ce qui, pour un domaine d'État évalué à un milliard et demi donne un rendement de $1,60 \%$. Cet exemple vient à l'appui des déclarations des économistes que nous avons cités, lesquels démontrent, quand les rendements des particuliers sont forcés par l'exploitation irrationnelle, des taux d'environ $2 \%$.

La nécessité d'avoir des forêts s'imposant pour le fonctionnement régulier et normal des pluies et des cours d'eaux, c'est-à-dire pour le bien-être général de la nation, l'État devra compter toutes les données du problème actuel pour les changer. Ces données sont : le taux de rendement trop minime des terrains boisés, l'exagération des taxes ou impôts qui les grèrent, les réalisations trop incertaines ou trop lointaines. Toutes ces causes provoquent des cessions et des ventes où se manifeste l'avidité des gens d'affaires. Au sujet des impòts qui pèsent sur les forêts, les pouvoirs publics sont, depuis longtemps, saisis du régime profondément injuste qui en résulte. La presse compétente et les divers Congrès agricoles ont montré par de nombreux exemples, que beaucoup de particuliers et de communes payaient une taxe supérieure au revenu de leurs bois. La diminution de l'impôt foncier sur les bois et forêts s'impose dans le plus bref délai par la réforme de cette loi surannée du 3 frimaire an VII qui les régit encore. Le remède qui a été proposé et qui serait seul capable d'apporter l'allègement nécessaire, résiderait dans l'application à ces bois et forêts du nouveau régime de la propriété non-bâtie.

Si l'on ne veut pas que, dans un temps trop prochain, la lande déserte fasse place aux terrains boisés que possèdent les particuliers, il faudra intéresser ces particuliers à la conservation de leurs forêts.

D’autre part, quand cette diminution de charges sera obtenue, l'État pevit vouloir et ordonner, au nom de l'intérêt public, que le régime forestier sera observé dans les forêts particulières. Les agents forestiers règleraient l'aménagement des forêts privées, règleraient l'assiette des coupes, le balivage des réserves. Mais, en échange de cette atteinte à la liberté, qui ne doit pas entraver dans ses droits un propriétaire do 
bois plutôt que toutautre propriétaire d'objet ou de bien quelconque, l'Etat apporterait, pour le bien public, comme il l'apporte déjà pour les chemins de fer, le dessèchement des marais, etc, une garantie minima d'intérêts auxdits propriétaires ainsi que la possibilité pour ces propriétaires d'obtenir des a vances sur les recettes ou d'hypothéquer leurs biens. Cette garantie d'intérêts ne jouera plus, du reste, lorsque lés bois auront atteint le prix rémunérateur. Une caisse de crédit forestier, fonctionnant sous le contrôle de l'Etat, serait chargée de toutes ces opérations. Une émission publique pourrait en faire le Capital en actions qui seraient gagées sur un bien certain. Par cette caisse autonome, l'État qui la subventionnerait, se rendrait acquéreur des forêts ou parcelles boisées que leurs possesseurs auraient à réaliser.

Qu'on ne dise pas que l'État s'engagerait ainsi dans une aventure dont il ne pourrait percevoir les limites. Le bois est un produit nécessaire et qui se vend; s'il ne se vend pas à un prix rémunérateur actuellement, c'est que des ventes hâtives ou forcées et les trafics sans scrupules de certains marchands de biens ont amené la dilapidation et, dans certains cas, provoqué une offre plus considérable que la demande.

La production de l'ensemble des forêts de France en gros bois a été estimée par M. Mélard, à 6 millions de mètres cubes.

D’après ce savant économiste, notre pays a besoin d'une fourniture supplémentaire de 3 millions de mètres cubes comme le révèlent les statistiques douanières.

La France ne produit donc actuellement que les deux tiers de sa consommation annuelle en gros bois. Elle pourrait, de l'avis de forestiers, produire bien davantage, si les forêts des particuliers au lieu de donner en surabondance des bois de feu et de charbon, étaient acheminées vers le traitement en futaie appliqué dans les forêts du domaine national.

Il faut donc en France faire appel à la protection du Code forestier et à tout un ensemble de règles tutélaires dans l'intérêt supérieur de la nation.

C'est cet intérêt qui doit être invoqué pour lutter contre le déboisement, pour obtenir l'exploitation rationnelle du bois. Et cette protection, alliée à la généralisation dans les forêts privées des règlements du code forestier, contrebalancée dans ses sévérités et dans son atteinte à la liberté par des avantages tels que ceux procurés par le Crédit forestier; toute cette sage protection, préservatrice des intempéries et des inondations, est la seule qui soit de nature à rendre à la France la beauté des sites, la régularité des pluies et des cours d'eau et les profits légitimes que mérite la culture forestière, non seulement pour elle-même, mais encore dans l'intérêt public.

Si ces arguments et conclusions devaient rencontrer auprès du Congrès l'approbation que votre troisième section croit si désirable, pour amener la réforme de l'exploitation du Bois en France, les considérants et les voux ci-après seraient présentés.

\section{Le Coxgrès Forestier international :}

Considérant que le mode intensif d'exploitation des bois en France, dans les forêts particulières, a provoqué des désordres dans le fonctionnement des pluies et des cours d'eaux et qu'il importe, dans l'intérêt 
de la Nation, de rétablir ce fonctionmement régulier et normal, et, en même temps, de rendre aux sites leur beauté qui est un des éléments de richesse du pays tout entier;

Considérant que l'élération exagérée de l'impòt foncier sur les bois et forêts des particuliers et des communes, provoque des exploitations sans rendement suffisant et quelquefois avec perte;

Considérant qu'on ne peut, sans porter atteinte à la liberté, entraver dans leurs droits, les propriétaires de bois plutôt que tout autre propriétaire d'objet ou de bien quelconque et qu'on ne peut, en conséquence, astreindre sans compensation, ces propriétaires aux règles de déboisement normal du régime forestier;

Considérant, toutefois, qu'à défaut de l'expropriation générale pour cause d'utilité publique, laquelle se heurte à une impossibilité financière, l'État peut établir une expropriation partielle des droits des propriétaires forestiers, à condition que les propriétaires n'en éprouvent pas de préjudice ;

Considérant que la garantie minima d'intérêts accordée par l'État, pourrait constituer une compensation suffisante à l'obligation pour les propriétaires de se soumettre aux règles du Code forestier ;

Considérant, d'autre part, que la création d'une Caisse de Crédit forestier pourrait donner auxdits propriétaires toutes facilités pour emprunter, hypothéquer ou vendre et que par cette Caisse, l'Etat pourrait se rendre acquéreur de parcelles boisées;

Considérant enfin que la préservation de la culture forestière est devenue d'un intérêt supérieur pour la France et que les Pouvoirs Publics doivent rechercher au plus tôt les mesures efficaces de protection ;

ÉNET LE VEU :

Que les forêts particulières en France soient astreintes anx règles du Code forestier avec garantie par l'État d'un minimum d'intérêts pour les propriétaires;

Qu'nne Caisse de Crédit forestier, subventionnée par lÉtat, soil créée pour régler celle garantie ainsi que pour consentir des prêts, avances et hypothèques aux propriétaires, acheter des propriétés forestières;

Que l'impôt foncier que les forêts particulières ont à acquitter, soit diminué par la réforme de la Loi dı 3 frimaire an VII on par l'application du nonvean régime de la propriété non-bâtie.

M. Le Président. - Le vou de M. Rachet comporte trois paragraphes. Si vous le voulez bien, Messieurs, pour faciliter la discussion, nous l'ouvrirons successivement sur chacun d'eux. (Assentimem.)

L. paragraphe premier est ainsi conçu :

"One les foréts particulières en France soient astreintes anx règles du Corle forestier avec garantie par l'État d"un minimum d'intêrêts pour les propriétaires..." 
M. Caquet. - Je suis obligá, comme dépgur de la Société Nationale d'Encouragenent à l'Agrieulture, de combattre eette partie du vou, comme contraire à la libertó du propriétaire. Les propriétaires tirent parti de leurs bois le mieux qu'ils prurent. Je tiens à protester contre lexistence des déboisemerts dont parle le rapporteur. Si les propriétaires forestiers ont quelque peu díforesté. ils n'ont pas déboisé. La preuve en a été surabondamment faite par l'enquête très loyale, très sincère et très sérieuse menée par la Société des Agriculteurs de France. Dailleurs, par définition, le propriétaire a le droit d'user et d'abuser, nti et abuti, et la soumission des propriétés forestières au régime forestier, implique par le paragraphe premier du voeu, serait une atteinte à la liberté qu'on duit à la propriété forestière, comme à toute autro, ainsi que vous l'avez leconnu vous-même. D’autre part, un pareil régime entrainerait pour l'État des cliarges que vons n’avez pas calculées, mais qui seraient si grandes que jo me refuse à les envisager.

M. Hrsce. - Je massocio aux dictarations de M. Caquet. Ladoption du paragraphe premier du vou qui nous est sommis amènerait um déboisement immédiat des propriétés forestières particulières. Les propriétaires se diraient : Nous allons raser nos forèts, puis nous demanderons la garantie de l'État. (Ioncements divers. Applaudissements sur divers bancs.)

M. Raciet, rapporteur. - Jamais de la vie.

M. Revé Barbier. - Iu nom du commeree dro bois. je massogere de MII. Caquet et Hirsch pour demander le rejet du paragraphe premier du vou de M. Rachet.

Le propriétaire a le droit d'user et d'abuser. A-t-il abusi? Je n'en sais rien. En tout eas, il n’a jamais déboisé. Le mot "déboisement " a étr pris dans deux sens; il n’en a qu'un, celui auquel M. Caquet a fait allusion. Une forèt coupée à blane nest pas me forèt déboisép (.1 pplaudissements.)

11. LE Préstuexte - Ceeux de mes collègues qui ont suivi les travaux préparatoires de la $3 e$ section savent re qui s est passé pour la rédaction de ce vou dans les conclusions de II. Rachet. On s'est préocupé de rechercher les moyens d'empecher les coupes trop importantes de bois dont tout le monde se plaint. Vous avez entendu, a la séance inangurale du Congrès, un écho de ces plaintes. Cette partie du voen a ité maintenue pour provoquer, si faire se pourait, l'indication de solutions pratiques. Car, si tont le monte se plaint qu’on déboise à outranés, personne n'a indiqué de remèrle rapable denrayer ce déboisement.

M. Baxchereal. - On ne devait plus parter, en France, de téboisements a outrance, car la presse est aujourd hui faite que si peut-être 
certaines forêts ont été déboisées, certains buis coupés. les terrains. boisés orcupent une surface beaucoup plus étendue que jadis.

Ce que lon constate, cest que la nature du hois a changé. Les bois durs, les plantations de chènes et de sapins dans les Vosges ont tendance à diminuer ; par contre, les plantations en autres espèces résineuses, en pins, en epiceas, angmentent d'importance.

Je m`ilève done contre le mot "déboisement " si fréquemment employé et je ne vois pas pourquoi les propriétaires forestiers seraient soumis à l'ingérence de l'État dans leurs forèts.

11. Artis. - Ne pourrait-on trouver un moyen terme et demander que l'État crée une caisse de crédit forestier qui permettrait aux propriétaires de se soumettre facultatirement au régime forestier?

I. Hı́sсн. - C'est l'objet du deuxième paragraphe du roeu de M. Rachet.

II. Artus. - La sommission au régime forestier doit, bien entendu, rester facultative et non devenir une obligation pour les propriétaires forestiers.

1]. Prat. - Il y a un article de loi qui autorise cette soumission facultative.

M. Hrascul. - En effet, une loi toute récente, roté il y a quelques jours, autorise les propriétaires de bois et forêts à les soumettre au régime forestier. Un décret doit prochainement paraître à ce sujet. Nous n'avons donc pas à nous occuper de cette question.

1I. Artis. Je ne connaissais pas cette loi.

11. Prat. - 11 y a deux manières de prérenir le dóboisement.

Le prenier, II. Clémentel l'a indiqué lui-même : faire en sorte que l'impôt ne soit pas supérieur à nos revenus forestiers. Nous pourrions émettre un vou en ce sens.

Le second, - qui pourrait également faire l'objet d"un rou, consisterait à employer partie des cotisations versées en vertu de la loi sur les retraites ouvrières et paysannes, non pas à l'achat de rentes sur l'État, mais à l'achat de terrains qui seraient un jour garnis de forêts, dont les revenus assureraient le paiement des retraites.

11. Frox. - II. Hirsch a fait tout à l'heure allusion à la loi Audiffred. Je dois faire remarquer qu'il y a une différence entre cette loi et le vou présenté par 11 . Rachet. La loi Audiffred n'r crablit qu'une faculté pour le propriétaire forestier. Dans le vou, au contraire, il s'agit d'une soumission obligatoire au régime forest ier, astreinte qui serait beacoup plus grave encore pour les particuliers que pour les communes ellesmêmes.

Le paragraphe premier du rou, mis aux voix, n’est pas adopté.

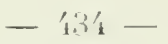


M. Le Président. - Nous passons au paragraphe 2. J'en rappelle les terines :

"Qu'une caisse de crédit forestier, subventionnée par l'Étut, soit créée pour régler cette garantie ainsi que pour consentir des prêts, avances et hypothèques aux propriétaires, acheter des propriétés forestières... "

Après une courte discussion à laquelle prement part MM. Rachet, Caquet et Moya, le paragraphe 2 du vou est retiré par le rapporteur.

M. Le Président. - Nous passons au paragraphe 3. J'en donne lecture:

"Que l’impôt foncier que les forêts particulières ont à acquitter soit diminué par la réforme de la Loi dn 3 frimaire an VII ou par l'applicution du nouveau régime de la propriété non bâtie ».

Après une courte discussion à laquelle premnent part MN. Caquet et Fron, le vou présenté par 11 . le rapporteur est mis aux roix, et adopté.

M. le Président. - La parole est à M. Pierre Lièvre pour la lecture de son rapport sur l'Outillage.

M. Pierre Lièvre. - Les machines, engins, outils, instruments que outils d'abatage. l'on emploie pour l'exploitation forestière, se partagent en deux catégories principales.

D'une part, ceux qui servent à l'abatage des bois sur pied.

D'autre part, ceux qui servent à la manutention et au transport des bois abattus.

C'est très succinctement que nous allons les passer en revue, car ces deux sortes d'instruments sont d'un emploi si répandu que la plupart d'entre eux se trouvent parfaitement connus, de ceux-là même qui sont étrangers aux questions spéciales auxquelles ils se rapportent.

Le mode d'abatage le plus répandu est l'abatage à la main. On sait qu'il se pratique de deux façons différentes, à la cognée ou à la hache, et au passe-partout.

Ces deux sortes d'outils (1) sont d'un emploi très simple et, pourrait- 'n dire, universel.

Les haches et les cognées sont des outils de même famiille. La hache est plus légère ; elle présente un fer plus trapu et plus ramassé. La cognée est plus lourde, plus mordante et sa tête aplatie peut servir de masse.

La hache convient spécialement pour l'exploitation du taillis et des réserves feuillues. Elle donne une coupe favorable à la conservation de la souche et à la production des surjets. La cognée, au contraire, creuse les souches qui se décomposent promptement sous l'action de la pluie. Elle doit être employée clans les futaies résineuses et feuillues, où la reproduction se fait par semis.

Comme tous les instruments dont l'antiquité est très grande et qui ont

(1) Cf. A. Mathey, Traité d'exploitation commerciale des bois, tome ${ }^{\mathrm{er}}$, pages $274 \mathrm{ets}$.

Au cours de ce travail, nous avonsfait de fréruen ts emprunts à ce remarquable ouvrage.

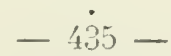


été successivement perfectionnés par l'expérience humàine, la lıache ni la cognée n'ont pas une forme fixe. On les voit au contraire varier non seu. lement d'un pays à un autre, mais encore de campagne à campagne.

Leurs variations ne se rapportent d'ailleurs jamais qu'à un détail, qui se modifie d'un type à l'autre,c'est le profil ou le dessin du fer ou de son tranchant. Toutefois il faut noter que, d'une façon constante dans les différents modèles, le tranchant n'a pas une forme symétrique par rapport à une perpendiculaire au manche.

tu contraire, sa partie supérieure, qui est celle qui travaille le plus, présente une saillie plus accentuée, qui permet de remédier plus aisément à son usure.

Les passe-partout sont une sorte de scie à main. Leur largeur de lame est d'une vingtaine de centimètres, leur longueur varie de $1 \mathrm{~m} .20$ à $2 \mathrm{~m} .40$. Toutefois il faut remarquer que la longueur de $2 \mathrm{~m}$. 40, se rapportant à des arbres qui dépassent de beaucoup la moyenne, est exceptionnelle ellemême. La consommation française, par exemple, ne demande guère que trois ou quatre de ces instruments de longueur extraordinaire, dans une année.

La lame porte à ses deux extrémités des douilles qui reçoivent des poignées en bois, placées de façon à se trouver à angle droit avec le dos de la lame.

La lame a plus de largeur au milieu qu'aux extrémités, parce que ce sont les dents centrales qui s'usent le plus rapidement.

Le profil des dents est essentiellement rariable. Mais il est néanmoins toujours symétrique pour que l'outil puisse travailler dans les deux sens. Il faut qu'elles soient suffisamment espacées pour que les sciures puissent se loger dans leur interralle.

Les scies américaines ont apporté un perfectionnement au passe-partout classique. Leur innovation a été de juxtaposer des dents de différents profils, qui ont chacune une destination différente.

L'inconvénient du passe-partout classique était que la sciure et le copeau se logeant entre les dents symétriques toujours semblables, une partie de la force employée pour manier l'instrument s'usait à pousser ce déchet.

Le problème à résoudre était dlonc d'ériter cette déperdition d'effort, afin de rendre le travail plus efficace.

Pour y parvenir, le passe-partout américain divise le travail entre les deux catégories de dents. Les unes, dents sciantes, coupent le bois; les autres, dents dégorgeantes. n'ont d'autre office que de pousser devant elles le copeau qui se trouve logé dans la gorge qui les sépare du groupe de dents sciantes. De cette façon les dents sciantes qui suivent la dent dégorgeante n'ont pas à faire d'autre travail que leur travail d'attaque du bois.

Dans la même catégorie d'outils que le passe-partout il faut ranger la tronconneuse à main. Cet instrument dont nous parlons à cette place, it cause de sa similitude arec celui que nous renons de décrire, mais qui ne pourrait pas en général être rangé parmi les outils de l'abatage, est une sorte de puissante égohine destinée à être manmurrée par un seul ouvrier, pour tronçonner un arbre de petit diamètre.

Elle se compose d'une lame triangulaire. comme celle de l'égohine. Cette lame doit avoir la mème rigidité qur celle du passo-partout. et elle a la même denture que lui.

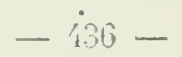


Elle peut notamment profiter de la denture prefectionnée du passe. partout américain.

Elle est munie de deux poignées situées toutes deux du même côté de la grande base de la lame. L'une de ces poignées est placée dans le prolongement du dos de la lame; l'autre lui est perpendieulaire. Elles font toutes deux leur effort au même endroit, et ne sont placées là que pour permettre à l'ouvrier de manier cet instrument à deux mains.

Sur le parterre de la coupe, les opérations de manutention que l'on ontils de manupeut avoir à faire sont les suivantes:

Rouler un arbre dans le sens du développement de sa circonférence;

Le tirer dans le sens de sa longueur;

L'élever afin d'opérer son chargement.

On peut dire, d'une manière un peu trop théorique peut-ètr, que les opérations de la première catégorie sont faites au moyen d'outils de la famille du levier, que les secondes sont faites au moven d'appareils de roulage, et les dernières au moyen d'appareils de levage. Il va sans diro que, dans la pratique, de pareilles séparations entre les moyens ne s'observent point, mais au contraire que bien souvent tous les moyens dont on peut disposer concourent à une seule opération.

Les appareils de la famille du levier sont :

$1^{\circ}$ Des leviers perfectionnés, tels que la sappie tyrolienne qui se compose d'un fer courbe et aigu, dont la forme continu le manche courbe auquel il est fixé ; l'anspect qui n'est autre chose qu'un levier muni à sa pointe d'une forte garniture en métal.

2 Des outils ou la force du levier se trouve servir et accrue par une partie métallique, généralement articulée, destinée à saisir l'arbre ì mancuvrer.

Les appareils de cette dernière sorte sont très nombreux comme il arrive chaque fois que l'on peut mettre en pratique un principe tres simple.

On peut prendre conme type de cette série l'appareils un instrument établi de la façon suivante:

Un bras de levier d'une longueur de 2 mètres environ est muni à sa partie inférieure d'une garniture d'acier terminée en pointe aiguë, de façon à ce que l'appareil puisse piquer fortement le bois.

A une dizaine de centimètres de cette extrémité inférieure sst fixée une sorte de puissante griffe qui est, soit de forme courbe, soit coudée à angle droit.

L'arbre est saisi et maintenu entre l'extrémité métalliqum du levier et la pointe du croehet. On agit alors sur le bras du levier de façon à déplacer dans le sens voulu la pièce à manceuver; deux ouvriers faisant effort sur cet appareil peuvent lui faire déployer une force de 3.000 kilogs.

Un autre type de la même série d'appareils est constitué par une très forte griffe d'acier munie d'un anneau d'assez grand diamètre pour que l'on puisse y introduire un levier. La partie du levier qui est engagée dans l'anneau forme avec la pointe de la griffe un mécanisme analogue à celui dont est muni l'outil que nous avons décrit précédemment et qui se manie de facon semblable.

Les appareils de roulage sont d'abord des roules eux-mêmes. Cé sont des pièces de bois rond que l'on dispose sous un arbre préalablement soulevé à l'aide d'un cric et sur lesquelles on fait glisser le bois à déplacer. 
Perfectionnant le roule, on en a fait un appareil mobile dans une armature fixe. 11 y est maintenu par une sorte d'essieu. L'ensemble de l'appareil repose sur une plate-forme légère qui n'a pas d'épaisseur appréciable et qui est composée d'un châssis métallique.

L'arantage de cet appareil est double :

to Il assure un roulement meilleur que le simple roule;

2. L'appareil étant fixe, toute la force employée est utilisée pour l'avancement de l'arbre, et il ne s'en perd point pour déplacer le roule lui-même.

D'autre part, cet appareil peut aroir une seconde destination. On peut s'en servir en le retournant, comme d'une roue mobile que l'on installerait en dessous de la pièce à manier. Dans ce cas, on n'actionne plụs la pièce sur l'appareil. L'avancement se fait comme si la pièce était chargée sur un chariot rudimentaire.

Quand les conditions du terrain le permettent on peut, au lieu de se servir de ces instruments de roulage, procéder au tirage des bois. On emploie alors soit des chaînes, soit de forts câbles que l'on fixe à l'arbre par le moyen d'un coin enfoncé dans la section d'abatage, ou de griffes qui viennent emprisonner le fút.

On se sert en Allemagne, pour faciliter ce tirage, de glissières en bois. La glissière est une sorte de brancard sur l'arrière duquel on fait reposer et on fixe l'une des extrémités de l'arbre à déplacer. Puis on y attelle un cheval ou un mulet.

Comme appareil de levage on n'emploie dans les coupes que le cric. Cet appareil est trop généralement connu pour que nous entreprenions de le décrire. Chacun sait qu'il se compose d'une crémaillère et d'un système d'engrenages. C'est un instrument très pratique parce qu'il est très maniable alors qu'il atteint une force considérable et l'on sait qu'il peut . arriver à déployer une force de 10.000 liilogrammes.

A la suite de ces diverses opérations, on procédait autrefois, et jusque dans un passé qui n'est pas très éloigné, au débit sur place d'une partie des bois abattus.

Ce travail était alors exécuté au moyen de la scie de long, employée à bras d'hommes.

La scie de long fut, jusqu'à l'apparition de la scie mécanique, le seul mode de débiter les bois en sciages de toutes épaisseurs et de toutes dimensions. De même que pour le passe-partout, il faut deux hommes pour manier la scie de long. Nlais le débit devant être accompli dans le sens de la longueur de la pièce, il est nécessaire de la disposer d'une façon particulière. La pièce ayant été préalablement équarrie à la hache sur une de ses faces, est disposée sur des chantiers de hauteurs inégales qui lui ménagent une certaine inclinaison, tout en l'établissant à peu près à liauteur d'épaulement. Les scieurs se placent l'un sur la pièce et l'autre en dessous, et ils pratiquent leur sciage suivant un trait tracé au cordeau sur la pièce. Cette méthode de travail est presque entièrement délaissée aujourd'hui. Sa lenteur l'a forcée à disparaitre dès l'apparition des procédés rnécaniques.

Birn que le sciage de long soit, pour ainsi dire, complètement abandonné, certaines opérations de débit sont actuellement exécutées dans le voisinage des coupes et dans les centres d'exploitation.

Tout d'abord, quand il s'agit d'une exploitation considérable de bois dur, il peut être intéressant d'établir, sur les lieux mêmes ou dans leur 
roisinage immédiat, une scierie mécanique queleonque et l'étude de son matériel et de son outillage ne rentre pas dans le cadre de notre rapport.

En second lieu, quand il s'agit d'exploitation de bois blane, il est non pas préférable, mais indispensable d'établir une seierie rolante.

La seierie volante est une création originale et curieuse. Une seierie volante typique sera installée sur un espace découvert, à proximité des coupes, non loin d'un canal, d'une gare, en un mot d'une voie d'évacuation des produits débités.

On établit l'outillage à l'intérieur d'un hangar démontable que l'on dresse sur les lieux; la foree est fournie par une locomobile qui actionne les diverses machines. Les machines nécessaires au travail que l'on reut exécuter sont les suivantes:

Tout d'abord un bane d'équarrissage sur lequel les bois tronçonnés en morceaux de longueurs déterminées sont passés une première fois. Les dosses sont enlevées de façon à ce que lis pièces présentent des faces qui rendent plus aisé leur passage aux outils suivants.

Les pièces, une fois équarries, passent d'abord à un second outil où elles sont débitées en planehes suivant l'épaisseur désirée. Au troisième outil, les planches sont tirées de large.

Pour ces trois opérations on emploie des scies circulaires, qui ne diffèrent entre elles que par leur puissance. On comprend, en effet, naturellement qu'il faut des banes de résistanees diverses et des seies de diamètre et de force variés pour supporter ou pour attaquer la tronce brute qu'ilfaut équarrir ou le feuillet débité qu'il s'agit de déligner. En outre de ce groupe essentiel de trois outils principaux, la locomobile peut encore aetionner des machines seeondaires destinées à l'affütage et aux autres besoins de l'usine, la force utilisée dans l'ensemble de l'installation étant d'environ 25 à 30 elevaux. Les bois au sortir de la scie sont empilés sur le terrain qui dépend de la scierie. Ils y demeurent, après même que lit scierie a été s'installer ailleurs, jusqu'à ce qu'ils aient atteint un degré de sécheresse qui en permette l'emploi.

La scierie reste montée sur un même ehantier pendant un temps que détermine seule l'importance de l'exploitation. Il peut être utile d'établir une scierie pour un mois. On n'en voit guère demeurer au même endroit plus de six à sept mois.

Tout le personnel ouvrier qui est nécessaire à leur fonetionnement se groupe autour des seieries mobiles. Il se déplace par caravanes, et s'établit sur les lieux mêmes dans des baraquements provisoires que l'on construit dans les dépendances de la seierie.

On comprend facilement les avantages que l'usage de ces seieries mobiles a procuré à eeux qui les ont utilisées. Leur emploi a permis de réaliser de sérieuses économies sur les transports qui se sont trourés réduits et facilités. Le transport des déchets s'est trouvé évité.

La multiplicité de pareils établissements évite à l'industriel l'encombrement qui ne manquerait pas de se produire chez lui s'il ne disposait que d'nne seule usine eentrale dans laquelle il devrait faire venir tous les bois qu'il doit débiter. C'est encore un avantage pour lui que la possibilité de laisser les bois qu'il a débités sécher sur l'emplacement de la seierie. Il peut ainsi ne faire rentrer chez lui les bois dont íl a besoin qu'au fur et à mesure de ses nécessités, sans être obligé d'avoir chez lui à un moment la totalité de son stock. 
L'imploi toujours plus généralisé de la scierie mobile est done un progrès très sensible réalisé dans la voie de l'introduction du mécanisme dans les industries forestières.

Est-ce une voie où l'on puisse espérer voir se réaliser bientôt des progrès appréciables? Il est à craindre que non. Toutes les opérations qui se font sur le parterre de la coupe sont difficilement remplaçables par des opérations mécaniques, tant par leur nature particulière que par les conditions dans lesquelles elles s'exécutent. Outre que les transports de force sont actuellement encore malaisés en forêt, le sol de la coupe, inégal, accilenté, coupé de mille obstacles divers, ne se prête pas volontier's à l'établissement ni au déplacement d'une machine de quelque poids.

En dépit de ces conditions défavarables, on a vu établir une machine à abattre la futaie qui mériterait de retenir notre attention si sa réalisation apportait une solution réellement pratique. Ce n'est pas le cas. La création de la machine à abattre semble plutôt une solution théorique. Quoi qu'il en soit, on se plaît à constater que le problème, ayant été posé a été résolu d'une façon quelconque, et il est permis d'espérer que des perfectionnements successifs permettront quelque jour d'atteindre un résultat plus satisfaisant.

Avant de quitter les questions qui se rapportent au travail forestier mécanique, signalons ici une lacune de l'outillage mécanique. Il n'existe pas do machine à aluattre le taillis et l'étude d'une machine qui aurait cette destination est une question actuclement à l'ordre du jour.

La Société des Agriculteurs de France a même créé un prix de 3.000 francs qui sera décerné en 1915 à l'inventeur de la meilleure machine à exploiter le taillis feuillu. Outre les qualités de solidité, d'économie, de qualité de travail, qui seules peuvent permettre à une machine de se substituer à la main-d'ouvre courante, on exigera de cette machine qu'elle ne compromette pas la repousse naturelle du taillis.

Jodes de trausport.
Ayant examiné dans les pages précédentes l'outillage nécessaire à l'abatage et à la manutention des bois, il nous reste à examiner les modes de transport destinés tant à la vidange des coupes qu'à la conduite des bois vers une destination nouvelle.

Sans examiner s'il est tout à fait légitime de ranger les engins de transpurt dans l'outillage (ce qui pourrait ètre discuté), nous allons en passer une revue très rapide.

Nous en avons déjà vu un, le plus élémentaire, quand nous avons décrit la manutention par le moyen des roules. On comprend, en effet, que les roules peuvent servir, non seulement à déplacer de peu un arbre sur le parterre de la coupe, mais encore à le mener à quelque distance de son point d'abatage, et dans certains cas favorables, jusqu'au chemin de ridange lui-même.

Nous devons voir maintenant les transports par véhicules attelés et les cssais de véhicules automobiles.

A propos des véhicules attelés, nous allons remarquer une particularité que nous avons eu déjà l'occasion de signaler et qui contribue à donner aux industries forestières l'un de leurs caractères, plus pittoresque à rrai dire que pratique.

Nous roulons parler de la très grande ancienneté, de l'antiquité pourrait-on dire, de leur matériel. Il est bien connu que l'agriculture a longuement tardé à renouveler les formes de ses antiques instruments et ì leur 
substituer des machines, mais il est bien certain que e'est le travail forestier qui doit être le dernier à s'engager dans cette voie. Nous en arons indiqué brièvement les raisons quand nous avons décrit la machine à abattre, nous ne les répéterons pas iei.

Le transport des longues pièces se fait au moyen de diables ou de fardiers, et c'est à ces véhicules que nous pensons quand nous parlons de l'ancienneté du matériel forestier.

Le diable se compose d'un train de bautes roues; on suspend la pièce à transporter sous l'essieu au moyen d'une chaîne ou, dans un modèle plus récent, au moyen de deux griffes mobiles, qui serrent automatiquement la pièce à la façon d'une pince.

On ramène la charge au moyen d'une flèche de $2 \mathrm{~m}$. 50 à $3 \mathrm{~m}$. 50 de longueur. L'arbre reste suspendu en équilibre, et on attelle un cheral au diable, en se servant d'un palonnier mobile que l'on fixe à la pointe de la flèche ou que l'on cramponne à l'extrémité de l'arbre s'il dépasse la tlèche. Quand il s'agit de transporter des pièces de grandes dimensions on peut y employer deux diables, disposés l'un derrière l'autre de façon à former en quelque sorte un seul véhicule à quatre roues. On a alors une voiture qui présente les facilités de chargement que procure le diable ot notamment la commodité d'avoir la charge suspendue sous les essieux, tout en ayant la stabilité et la longue portée de la voiture à quatre roues.

Le fardier est construit sur les mêmes principes que le diable, mais est plus puissant. Il est en outre in uni d'une limonière fixe, ee qui facilite l'attelage des chevaux. Le diablr et le fardier sont des véhieules à deux roues. On emploie aussi des camions à quatre roues. Certains d'entre eux offrent la particularité de pouvoir's'allonger ou se raccoureir à la demande les pièces que l'on veut transporter. Il y en a d'autres dont on peut démonter les roues du côté où l'on charge, ee qui favorise la mise en voiture souvent difficultueuse.

Les transports automobiles sont destinés à être utilisés dans l'industrie forestière. Mais leur emploi sera foreément limité; on ne pourra jamais songer à les employer sur le lieu d'abatage. Leur service ne pent commencer qu'avec une route praticable pour eux et il faudra toujours amener au moyen de roules ou de fardier's les bois à l'endroit où on pourra les charger utilement sur un camion automobile.

A partir de ce moment, l'automobile reprend son avantage; mode de transport rapide et régulier, il est destiné au service à distance, soit pour conduire les bois à la gare la plus proche afin d'être expédiés, soit pour alimenter une scierie.

En Auvergne, en Bourgogne, dans la forêt de Fontainebleau, des roitures de diverses marques sont très heureurement utilisées.

Rendant des serviees analogues à ceux que l'on pourrait attendre de l'emploi généralisé de l'automobile, les installations Deeauville de wagonnets sur rails sont très heurcusement employées dans la moyenne exploitation, et les services qu'elles rendent sont très appréeiables.

Nous avons ainsi terminé la revue rapide des moyens de transports employés sur le terrain même de l'exploitation. Nous n'avons pas abordé les questions que proposent les transports à longue distance qui s'opèrent en montagne par le schlittage ou le téléférage, sur cours d'eau par le flottage, craignant de donner à cet exposé déjà étendu des proportions exces sives, et considérant, d'autre part, que les questions de transport, si elles se rattachent aux questions de l'outillage, n’en font pas réellement partie. 
Nous voulons cependant indiquer que dans certaines exploitations américaines les procédés de téléférage tels que nous les royons employés parfois dans les Alpes suisses et dans certaines parties de l'Autriche ont reçu une extension et une ampleur tout à fait dignes de remarque.

Des installations de câbles sont faites entre des points éloignés, d'altitudes sensiblement différentes, que ne relient entre eux aucun chemin praticable, et qui peuvent même être séparés par toutes sortes d'obstacles', tels que ravins ou cours d'eau. Un chariot sous lequel on suspend les grumes à transporter glisse sur le câble, emmenant avec lui sa charge par cette voie aérienne.

La vapeur et l'électricité mettent en ouvre les divers éléments de ces installations.

Ce moyen de transport, qui est pratique quand on manque de chenins, ou que l'on n'en pourrait établir qu'à grands frais, ne peut convenir que lorsque l'on a exploité des parties boisées d'une très grande étendue.

Il ne serait pas avantageusement employé dans le cas d'exploitations disséminées et de petites contenances. Il pourrait être heureusement pratiqué en Algérie.

Tous avons ainsi terminé l'examen de l'état actuel de l'outillage forestier et, au moment de le conclure en formulant quelque vou, nous ne sommes pas sans éprouver un certain embarras.

$\mathrm{Si}$, d'une part, nous avons suffisamment confiance dans l'industrie humaine pour être assurés de l'amélioration continue du matériel dont nous disposons, d'autre part, nous ne voyons pas actuellement de problème précis à lui proposer.

Dans le domaine du gros outillage, nous ferions volontiers notre le voeu de la Société d'Agriculture, de voir établie une machine à abattre le taillis, si nous avions l'assurance qu'elle puisse être d'une utilisation plus réellement pratique que la machine à abattre la futaie.

Le petit outillage de manutention et d'abatage nous paraît très pratique et très bien adapté à ses fins.

\section{LE Congrès ÉMET Le veu :}

I. Que dans le domaine du gros ontillage il soit établi une machine à abattre le taillis, d'une utilisation réellement pratique.

II. Que les transformations du petit ontillage de manutention et d'abatage se produisent en s'inspirant des progrès déjà réalisés, antant en France qu'à l'étranger, et en tenant compte des améliorations obtenues par le perfectionnement du matériel servant aux grandes exploitutions.

III. Que l'emploi des transports automobiles soit favorisé de tontes manières, notamment par l'amélioration des chemins forestiers an point de vue de leur solidité.

M. Le Présidext. - Personne ne demande la paroles sur ce rapport?

Le veu, mis aux voix, est arlopté.

la síances u-t levés à midi. 


\title{
SEANCE DU 16 JUIN 1913
}

\author{
(APRÈS-MIDI)
}

\section{Présidence de M. POUPINEL, président de Section}

La séance est ouverte à 2 h. 45 .

M. Le Président. - La parole est à M. Edouard Rizier pour la lecture de son rapport sur l'Utilisation des Bors, Bois brtets, Chalffage, Charbon, Etais de mines.

M. Édouard Rizier. - La nature, en faisant surgir à la surface du sol ces immenses et magnifiques forêts qui font la joie et l'admiration du touriste, a fait à l'homme un de ses dons les plus riches et les plus précieux.

En effet, la forêt qui concourt si puissamment à la beauté de nos paysages, et qui durant les longs jours d'été nous protège avec tant de sollicitude contre les ardeurs excessives du soleil, est indispensable à l'existence même de l'homme, non seulement à cause des produits qu'elle lui fournit, mais encore en raison de son action bienfaisante sur les éléments; en effet, chacun connaît l'influence considérable qu'elle exerce sur le climat dont elle diminue la sécheresse, et personne n'ignore qu'elle est le grand modérateur des vents, dont elle calme les violences dévastatrices, comme elle est le régulateur indispensable à l'établissement rationnel du régime des eaux.

La forêt est en outre une réserve inépuisable, puisqu'elle se reconstitue. constamment, d'une matière première, le bois, dont l'homme ne saurait se . passer.

Bien que le génie humain, en arrachant aux enirailles de la terre la houille et certains métaux ait réussi, par l'emploi de ceux-ci, à remplacer le bois dans un grand nombre de ses applications, il n'en est pas moins établi, qu'à notre époque de houille noire et de houille blanche, la consommation du bois considéré dans ses emplois industriels tend à s'accroitre de jour en jour Nos belles forêts de France sont, en l'état actuel, dans l'impossibilité absolue de répondre aux besoins de la consommation nationale; depuis longtemps déjà, nous faisons appel à la production étrangère, mais celle-ci n'est pas inépuisable, et si nous n'y prenons garde, si nous n'apportons pas de sages méthodes à la conservation et à l'exploitation de nos forêts, si nous ne procédons pas dès maintenant à un reboisement rationnel et intelligent des terres actuellement incultes, bientôt arrivera le jour, peut-être peu éloigné, où il nous sera impossible 
de trouver à l'étranger, même à prix d'or, les bois indispensables à nos diverses industries. Ulilisation des
lois.

Le bois, à quelque essence qu'il appartienne, trouve son utilisation à l'infini, dans les industries les plus diverses. Il ne nous appartient pas d'étudier toutes les questions touchant l'emploi du bois, en général; des plumes plus autorisées que la nôtre les traiteront, chacune en ce qui la concerne, au point de vue de ses applications industrielles, et nous ne nous occuperons ici que de son utilisation en tant que chauffage, charbon et étais de mines.

Bois bruts (Chaufjuge). - La question des bois de chauffage est intimement liée à celle des taillis dont la situation lamentable effraie, à juste titre, les propriétaires forestiers et émeut les pouvoirs publics, mais nous ne nous occuperons pas de cette importante question qui doit être traitée par une autre section.

Il est de toute évidence que, eomme combustible, le bois, depuis un quart de siècle, joue un rôle de plus en plus effacé, et que s'il jouit encore de quelque faveur en provinee, surtout dans les pays situés à proximité de forêts, il a dans les villes, et plus particulièrement à Paris, été remplacé en grande partie par la houille ou les produits de sa distillation, le coke et le gaz, et il n'est pas douteux que ces terribles coneurrents lui ont porté des coups dont il ne se relèvera jamais.

Los bois de chauffage proprement dits peuvent être divisés en deux grandes catégories bien distinctes: les bois d'essences dures ou bois durs et les bois d'essences tendres ou bois blanes.

Bois durs - Les bois durs, et plus particulièrement, les chênes, les charmes et les hêtres, que leur âge, leurs dimensions ou leur qualité rendent impropres à des usages industriels, sont utilisés comme combustible, soit pour le chauffage domestique, soit encore pour le chauffage de certains fours industriels, mais, comme nous venons de le dire, leur emploi comme combustible tend à se faire de plus en plus lare.

La statistique nous apprend, en effet, que la consommation parisienne qui, en bois dur, était de 423.000 stères en 1886 , est passée à 255.000 stères en 1896, pour tomber à 198.000 stères en 1910, soit une diminution de plus de $53 \%$ en 25 ans. Il est infiniment probable que dans une vingtaine d'années la consommation du bois dur à Paris sera presque insignifiante.

On sait que ces bois sont en général coupés, pour les exploitations situées dans toute l'étendue du bassin de la Seine, à la longueur de $1 \mathrm{~m} .14$, et que leur grosseur varie généralement entre 6 et 20 centimètres de diamètre.

Ces bois qui ont été coupés à l'époque où la sève est inactive, proviennent de taillis de 20 à 30 ans ou de jeune futaie, demi-futaie ou haute lutaie, dont les produits n'ont pu être utilisés par l'industrie.

Les bois de chauffage se divisent en bois neufs et en bois flottés.

Les bois neufs sont ceux qui, par voie de terre ou voie de fer, oni élé transportés directement à un port ou à une gare d'embarquement pour être chargés sur wagon ou bateau.

Les bois flottés sont ceux qui ont été jetés à bûches perdues, dans des rivières ou ruisseanx, et recueillis, à l'aide d'un barrage, en un point déterminé. 
Ce moyen économique de transport qui, pendant plus de trois siècles, a joué un rôle considérable dans l'approvisionnement de la capitale, est dû à un marchand de bois de Paris, Jean Rouvet, qui l'imagina en 1549 .

Jean Rouvet inventa, non seulement le flottage à bûches perdues sur les cours d'eau non navigables, mais c'est encóre à lui que l'on doit la création de ces trains de bois que nous avons connus dans notre enfance et que de hardis et vaillants nautonniers conduisaient à destination, en leur faisant descendre lentement, mais sûrement et économiquement, le cours des rivières; pour ce faire, ils les dirigeaient à l'aide de longues perches qu'ils plongeaient jusqu'au fond du lit des cours d'eau. Ce dernier procédé a été complètement abandonné pour le transport des bois de chauffage, depuis trente-cinq ans environ, en raison de l'intensité de la navigation à vapeur; quant au flottage à bûches perdues, il n'est plus guère en usage que sur deux rivières du Morvan, la Cure et l'Yonne; les bois jetés dans la Cure ou dans ses affluents sont recueillis à Vermenton, ceux jetés dans l'Yonne sont arrêtés à Clamecy et à Coulanges-sur-Yonne, et de là, après séchage sur ces ports, acheminés sur leur destination définitive, à l'aide de bateaux.

A propos de ports, il nous paraît indispensable de leur consacrer quelques lignes, en raison des relations étroites qui existent entre les exploitations forestières et le commerce des bois.

On sait que la loi a frappé de servitude, en faveur du commerce des bois, toutes les propriétés à l'état de prés ou labours situées sur les bords d'une rivière ou d'un canal, et que, moyennant une indemnité fixée par décret, tout exploitant ou négociant peut déposer des bois à brûler ou d'industrie sur les rives des voies navigables; c'est ce qui explique le nombre relativement important de ports fixes et accidentels que l'on rencontre un peu partout, et notamment dans le bassin de la Seine.

Cette faveur accordée au commerce des bois, et par suite à tous les consommateurs, puisqu'en diminuant les frais de transport elle permet d'obtenir un prix de revient moins élevé, remonte aux temps les plus reculés; on en trouve trace, en effet, dans une ordonnance édictée sous Philippe-Auguste, en novembre 1219, et l'ordonnance du 23 décembre 1672 n'est que la condensation et la codification de celles des 2 novembre 1582 et 28 juin 1656 sur la matière. L'ordonnance de 1672 a été elle-même confirmée et complétée par la loi du 28 juillet 1824 et par le décret du 21 a out 1852, toujours en vigueur. Nous aurions désiré dire quelques mots du service des ports qui, depuis la création en février 1644 des commissaires contrôleurs-jurés-mouleurs, (qui n'étaient autres que nos gardes. ports d'aujourd'hui), a rendu de si importants services au commerce et à l'exploitation des bois, mais les limites étroites qui nous sont fixées pour la rédaction de ce rapport ne nous permettent pas d'aborder ce sujet. Cependant, nous croirions manquer à un devoir d'équité si, en passant, nous ne rendions un légitime hommage au zèle et au dévouement de ces excellents agents des ports qui président, avec la plus grande impartialité et la plus parfaite loyauté à l'exécution littérale du décret de 1852 , et, fonctionnaires de l'Etat, non salariés par lui, ont résolu ce problème, insoluble a priori, d'être à la fois les collaborateurs des vendeurs et des acheteurs en même temps que lcurs arbitres.

Malgré les services que rendent les gardes-ports, un petit nombre de négociants, désirant s'affranchir de leur contrôle et s'exonérer des 
modestes rétributions qui leur sont dues, demandent à grands cris leur suppression.

Nous ne sommes pas de cet avis; nous pensons au contraire, avec la très grande majorité des membres du commerce des bois, que si le service des ports n'existait pas, il faudrait le créer; nous allons même plus loin, nous émettons le vou que, dans le cas où des bois seraient livrables dans une gare, on fasse appel, chaque fois que cela serait possible, au concours du garde-port. Son intervention donnerait en effet une sécurité absolue aux parties contractantes, puisqu'elle les assurerait que la marchandise serait livrée et reçue suivant les prescriptions du décret de'1852. Cette mesure, en assurant la loyauté des transactions, les faciliterait et éviterait bien des froissements et des procès.

Cet hommage rendu au mérite et à la valeur des agents des ports, nous revenons à la question du bois de chauffage.

Il est à remarquer que le hêtre destiné au chauffage est toujours fendu dans les quatre mois qui suivent son abatage; cela tient à ce que, par sa nature même, il "s'échauffe " rapidement, c'est-à-dire que, sous l'actior de la fermentation putride il commence à se pourrir.

Nous croyons devoir faire remarquer, dans l'intérêt des négociants et des exploitants, que trop souvent ceux-ci négligent de faire fendre le hêtre en temps voulu; il en résulte d'abord que la fente s'opère plus difficilement, et qu'ensuite le bois a subi un commencement d'altération qui nuit considérablement à sa qualité.

Le charme, d'une certaine grosseur, est sonvent sujet aux mêmes inconvénients; c'est pourquoi, dans les exploitations forestières, on prend quelquefois soin de le faire fendre lorsqu'il atteint ou dépasse la grosseur de 14 centimètres de diamètre.

Mais cette mesure n'est prise qu'exceptionnellement et devrait se généraliser. Il serait, pensons-nous, de l'intérêt bien compris des exploitants de l'appliquer, puisque, d'une part, ils livreraient des produits absolument sains et exempts de tous reproches, et que, d'autre part, ils trouveraient, par le foisonnement de la marchandise, une compensation largement suffisante aux frais occasionnés par ce travail.

Un des bois les plus appréciés pour le chauffage domestique et industriel est, sans contredit, le chêne pelard, qui est ainsi nommé parce qu'il a été " pelé ", ou plus exactement dépouillé deson écorce, laquelle une fois moulue sert au tannage des cuirs. Chacun sait en effet que le tan, indispensable jusqu'en ces dernières années à la préparation des peaux, n'est autre que de l'écorce de chêne. L'opération de l'écorçage se fait au'. moment où la sève est la plus active, c'est-à-dire au mois de mai ; à cette époque, en effet, le liquide nourricier, en circulant abondamment entre le bois et l'écorce, permet d'enlever l'épiderme de l'arbre avec une extrême facilité. Le "pelard "n'est pas seulement un bois de chauffage parfait, il fait encore d'excellents étais de mines et du charbon de qualité supérieure.

Bois blancs. - Par opposition à "bois durs" on donne le nom de bois tendres ou bois blancs à tous ceux qui offrent peu de consistance, qu'ils : soient blanes, teintés ou résineux, comme le tremble, le bouleau. le sapin; ces bois ne sont employés conme combustibles que dans les indus. tries qui exigent un feu clair, notamment dans la boulangerie et les fabriques de porcelaine. 
Si la consommation du bois dur a baissé dans les proportions fantas. tiques que nous avons indiquées plus haut, celle du bois blanc a diminué d'une manière beaucoup moins sensible.

C'est ainsi que Paris, qui consommait annuellement 360.000 stères de bois blancs en 1886 , ne réduisait sa consommation qu'à 331.000 stères en 1896 et qu'en 1910, 287.000 stères lui étaient encore nécessaires. C'est donc une diminution de $14 \%$ seulement qu'il y a lieu d'enregistrer pour une période de 25 années.

Comme pour le bois dur, cette diminution dans la consommation des bois blancs est due au remplacement du bois par le charbon dans le chauffage des fours de boulangerie et de diverses industries, mais il faut reconnaitre cependant que cette transformation est loin de se généraliser et qu'elle ne s'opère que très lentement. Nous devons, d'ailleurs, inciter et encourager l'industrie boulangère à n'employer que le bois exclusivement pour la cuisson du pain, car il est incontestable, et chacun a pu en faire la constatation par lui-même, que le pain cuit au bois est infiniment plus délicat au goùt et plus savoureux que celui qui a été cuit dans des fours chauffés au charbon, au coke ou au gaz.

Parmi les bois blanes destinés au chauffage il en est un, le pin, qui peut rendre les plus grands services pour le reboisement de certains terrains sablonneux ou rocheux, que leur infertilité rend impropres à toute autre culture.

Pour le pin, en effet, point n'est besoin de terre abondante et féconde, un sol sablonneux ou pierreux lui suffit ; c'est lui que l'on voit s'accrocher au flanc des montagnes et jusque sur les rochers les moins couverts de terre; c'est lui qui, sous le nom de pin maritime, garnit les dunes de sable qui bordent la mer, empêche leur envahissement et fertilise des terrains arides et sans valeur, permettant après son exploitation de les utiliser en culture.

Enfin, c'est grâce à lui que notre département des Landes, qui n'était qu'un désert, a connu le bien-être et la prospérité, que la Sologne et la Sarthe ont été assainies et sont devenues des régions riches après avoir été de très pauvres pays.

Nous venons de voir que la consommation ars bois de chauffage a baissé dans des proportions fantastiques et que cette situation, en provoquant la mévente des bois de moulée, a eu pour conséquence directe d'abaisser considérablement la valeur vénale des coupes de taillis.

Nous savons d'autre part que les bois d'industrie sont tellement en faveur à notre époque, que la production nationale ne répond plus aux besoins de notre consommation.

Il s'agit donc de ramener, autant que faire se peut, l'équilibre entre les deux éléments de la production forestière. Produisons donc plus de futaies et moins de taillis. Mais ceci est une œuvre de longue haleine qui mérite d'être grandement encouragée dans l'intérêt supérieur du pays.

Nous pensons donc que pour obtenir ce résultat désirable qui serait, dans l'avenir, un des facteurs de la prospérité nationale, il faudrait que l'État fit des réserves de plus en plus grandes dans le domaine forestier qu'il administre, et que les particuliers, sans les priver du revenu légitime de leurs propriétés, auquel ils ont droit, fussent invités à conserver des sujets d'avenir en plus grand nombre qu'ils ne le font aujourd'hui (la proportion par hectare pomrrait être fixée suivant les possibilités). Pour 
indemniser ces propriétaires du sacrifice qu'ils consentiraient, puisque ce faisant, ils travailleraient pour l'avenir, l'État leur ferait remise totale ou particlle des impôts qui pèsent si lourdement sur la propriété forestière.

Charbon de bois. - Le charbon de bois, dont l'usage remonte à la plus haute antiquité, a joué, au cours des siècles, un rôle considérable. C'était en effet un combustible domestique particulièrement recherché, et son concours était absolument indispensable à l'alimentation des forges, des fonderies.et de toute l'industrie en général.

Mais que les temps sont changés! Aujourd'hui, la houille et le coke, son dérivé, ont complètement remplacé le charbon de bois dans l'industrie, et le gaz, le pétrole, les alcools dénaturés, voire même l'électricité, lui ont ravi, surtout dans les villes, la plus grande partie de sa clientèle bourgeoise.

En effet, si pour prendre un exemple, nous choisissons Paris, nous constatons que la consommation de la capitale qui, en 1886, était de 4.716.000 hectolitres, est passée, en 1896, à 3.288 .000 hectolitres pour tomber, en 1910, à 1.321.000 hectolitres, soit, en 25 ans, une diminution dans la consommation de près de $72 \%$.

Nous venons d'indiquer brièvement les principales causes de la défaveur, à Paris, du charbon de bois; mais il en est une autre qui a précipité sa chute, c'est son prix de revient élevé, en raison du tarif exorbitant des droits d'octroi. Nous savons, en effet, que les droits à l'entrée de Paris sont de 1 fr. 35 par sac de 2 hectogr. 20, soit environ 25 francs par 1.000 kilogrammes, alors que la louille ne paie que $7 \mathrm{fr} .20$ et que le gaz est exonéré de tout droit, puisque le charbon de terre qui sert à sa fabrication entre en franchise; il y a là une inégalité de traitement qui ne s'explique pas, et le Conseil municipal de Paris serait bien inspiré, pensonsnous, en réduisant notablement ces droits exagérés ; ce n'est d'ailleurs pas un bien gros sacrifice que nous lui demandons de faire, puisque si la diminution de consommation continue à s'accentuer dans les proportions que nous venons d'indiquer, le jour n'est pas éloigné où la matière imposable aura presque entièrement disparu.

Peut-on espérer, dans l'avenir, pour le charbon de bois, une reprise de sa consommation industrielle et domestique?

A moins de s'adresser à l'étranger où il y a peut-être des débouchés à découvrir, nous ne croyons pas, qu'en l'état actuel de la science, un nouvel essor puisse être envisagé, mais nous pensons qu'il y aurait lieu d'encourager les chercheurs à trouver des procédés scientifiques qui permissent de l'employer industriellement.

Nous ne pouvons actucllement que constater qu'il y a pléthore de charbon de bois, et que par suite de la mévente de ce produit il y a avilis. sement non seulement du prix de la charbonnette, dont les frais de façon sont souvent plus élevés que le prix de vente, mais encore du taillis en général.

La formule serait done: produire moins de charbonnette.

Pour ce faire, deux moyens se présentent à notre esprit, mais ces deux moyens devraient être employés simultanément.

Le premier consiste à ne pas carboniser les bois au-dessous de 0,025 de diamètre au petit bout; il est en effet reconnu que non seulement ces bois ne produisent que du charbon peu estimé du consommateur, mais que par sucroît ce charbon déprécie, dans des proportions importantes, 
celui avec lequel il se trouve mélangé. De cette élimination qui ne serait pas une perte pour lo marchand de bois exploitant, puisqu'il vendrait sa charbonnette ou son charbon de bois à un prix plus élevé, résulterait, estime-t-on, une diminution de 20 à $25 \%$ dans la production; les ramilles pourraient être abandonnées aux ouvriers ou brûlées sur place.

Le deuxième moyen est relatif à l'aménagement des coupes et demande quelques explications.

Nous avons dit combien jadis était prospère la situation du commerce des charbons de bois; il en fallait des quantités considérables pour la consommation domestique et il était un élément tellement nécessaire à la prospérité industrielle, que nombre d'usines et de fonderies s'étaient installées dans les grands centres forestiers, notamment dans les régions de l'Est, de la Côte-d'Or, de la Haute-Marne, du Centre, etc., pour obtenir en aböndance et à meilleur compte ce produit indispensable à leur activité.

Que se passa-t-il alors?

Tout simplement ceci : c'est que les coupes furent aménagées de façon à produire beaucoup de charbonnettes, c'est ainsi que l'on fut amené à couper les bois entre 20 et 25 ans.

Or, malgré la diminution colossale qui s'est produite dans la consommation du charbon de bois, les propriétaires forestiers qui, escomptant leur revenu annuel, avaient divisé leur bien en 20 ou 25 parts, ne crurent pas devoir, pour un grand nombre, changer quoi que ce fût à leurs habitudes, et c'est pour cette raison qu'on a continuè à produire beaucoup plus de charbonnettes qu'on en pouvait utiliser.

Nous pensons, nous, qu'on réduirait très sensiblement la production de la charbonnette en augmentant la durée des aménagements des coupes et nous croyons que cette manière de procéder serait d'un meilleur rapport pour le propriétaire.

A I'appui de notre thèse, nous allons donner un exemple.

Supposons le cas d'un taillis sous futaie, dans un terrain de qualité moyenne.

Coupé à 25 ans, le rendement à l'hectare sera d'environ 130 stères qui se décomposeront en 100 stères de charbonnette et 30 stères de moulée.

Ce même taillis, coupé à 35 ans seulement, donnerait un rendement d'environ 160 stères à l'hectare dont 90 stères de charbonnette et 70 stères de moulée.

Nous ne pouvons pas préconiser cet aménagement pour tous les terrains, mais nous pensons qu'il pourrait être mis en pratique dans la plupart des cas.

De plus si l'on porte l'aménagement du taillis de 35 à 40 ans, non seulement la proportion de moulée augmentera au détriment de la charbonnette, mais encore il sera possible de tirer de ce gros taillis certains bois d'industrie très demandés, notamment des manches de pelle qui sont d'un placement très rémunérateur, des étais 'de mine et bien d'autres produits.

Nous savons bien que notre proposition aurait à vaincre une grosse résistance de la part des communes et des particuliers, car ceux-ci se résoudront difficilement à une diminution de revenu immédiat, même avec la perspective certaine de récupérer amplement plus tard les fruits de ce sacrifice momentané.

Nous n'ignorons pas en effet que la plupart tablent sur des revenus 
immiédiats et ne se soucient pas d'entretenir une propriété coûteuse pour leurs héritiers; mais nous pensons que pour leur permettre d'entretenir leur bien sans bourse délier, ces propriétaires pourraient se contenter de ne faire que des demi-coupes, jusqu'à ce que le cycle du nouvel aménagegement soit terminé.

De plus, l'État pourrait les dédommager par des remises partielles ou totales d'impôts.

Nous émettons aussi le vœu que les distillateurs de bois en vases clos ne chargent leurs cornues qu'avec de la charbonnette exclusivement. Și ce vœu était réalisé ce serait autant de charbonnette utilisée ; on nous objectera que la consommation de la charbonnette se ferait en remplacement de la moulée et que ce n'est pas le moyen d'utiliser ce produit d jà délaissé, e'est vrai, mais nous pensons que, surtout avec le nouvel aménagement des coupes, tel que nous le préconisons, ce produit trouverait son emploi industriellement, notamment dans les mines où sa grosseur lui permettrait d'être converti en étais.

Nous savons que, comme combustible, les produits de la forêt ont été remplacés en grande partie par ceux de la mine, mais juste retour des choses d'ici-bas, la mine a besoin pour son exploitation du précieux concours de la forêt, et celle-là doit payer à celle-ci un tribut considérable sous forme d'achats de bois de mines de toute nature.

La France, dont l'exploitation houillère est très restreinte, puisqu'elle ne produit que 50 à $55 \%$ environ de sa consommation, extrait annuellement des entrailles de la terre environ 35 millions de tonnes de houille; or, M. Pelletier de Martres, dans son remarquable rapport sur les poteaux télégraphiques, indique ineidemment que la mine consomme environ 1 franc de bois par tonne de houille extraite; cette constatation équivaut donc à dire que les houillères françaises doivent acheter du bois pour 35 millions de franes environ; si nous estimons le prix du mètre cube à 25 francs, rendı à la mine, nous voyons, par déduction, que la consommation nationale est d'environ 1.400 .000 mètres cubes; sur cette quantité, les statistiques nous révèlent qu'il est importé, notamment de Russie, environ 15 à 20.000 mètres cubes, mais, que, par contre, nous exportons pour l'Allemagne, l'Angleterre et la Belgique une quantité au moins dix fois plus élevée. Cette exportation qui pourrait être développée, jointe à la consommation nationale ouvrent donc à notre exploitation forestière un débouché considérable.

Il y a deux sortes d'étais de mines, les étais de bois dur et ceux de bois tendre; les premiers entrent dans la consommation des houillères pour le quart et les seeonds pour les trois autres quarts.

La consommation des bois tendres tend à augmenter en raison de l'obligation où se trourent les mines de remblayer. Pour ce faire, il ne leur paraît donc pas nécessaire d'employer du bois dur, c'est-à-dire plus résistant, dont le prix d'achat est beaucoup plus élevé; l'expérience a d'ailleurs démontré qu'à un certain degré de profondeur et à une température à peu près sensiblement la même, les bois tendres offrent une durée presque équivalente à celle des bois durs.

Les bois durs sont surtout utilisés en tant que hanoches et lattis et les bois tendres comme étayage; mais, il est à remarquer que fort heureusement beaucoup de mines préfèrent le bois dur. 11 serait à désirer que cet usage se généralisât, car si les propriétaires de résineux avaient moins $d$ ? 
débouchés de ce côté, ils seraient poussés à faire de la futaie qui, en ces essences, a une grosse valeur dès l'âge de 45 à 50 ans, alors qu'en matière de feuillus, il faut attendre au moins 120 ans'pour obtenir le même résultat.

Les mines emploient des bois de toutes longueurs et de toutes dimensions, depuis les petits bois, appelés " queue » de $1 \mathrm{~m}$. 20 de longueur sur 12 à 18 centimètres de circonférence, jusqu'aux " étais " de 3 mètres de longueur sur 55 à 60 centimètres de circonférence, en passant par les " rallonges" qui ont $2 \mathrm{~m} .50$ de longueur et 18 à 26 centimètres de circonférence.

Nous pensons que les vendeurs de bois de mines devraient inciter les houillères à acheter les perches dans toute ləur longueur. Les mines pourraient débiter elles-mêmes, à leurs dimensions et au fur et à mesure de leurs besoins, les bois qui leur sont nécessaires; cette façon de procéder faciliterait l'exploitation des marchands de bois, qui ont maintenant la main-d'œuvre de plus en plus difficultueuse.

Ce système est d'ailleurs adopté déjà par un certain nombre de mines.

Des dimensions que nous venons d'indiquer, il résulte, qu'en feuillus, le produit d'une coupe de 35 ans pourrait être presque entièrement utilisé par les mines, puisque la vente aux houillères des bois des dimensions précitées enlèverait toute la moulée droite et une partie de la charbonnette; c'est donc dire que l'utilisation des bois pour l'usage des mines peut venir en aide de la façon la plus efficace à la crise du taillis, mais nous répétons ce que nous avons déjà dit à propos du charbon de bois, pour que les résultats soient intéressants, il faut cesser de couper les taillis entre 20 et 25 ans, et porter la durée des aménagements des coupes à 35 et 40 ans.

\section{LE Congrès Émet Les VEuX CI-APrès :}

BoIs DE ChaUfFage. - Que l'État soit invité à faire le plus de réserves possible, de façon à produire, dans un avenir encore lointain, plus de futaies et moins de taillis.

Qu'on encourage les particuliers à faire les mêmes réserves, en les indemnisant de leur sacrifice, an moyen de la suppression totale ou partielle des impôts qui grèvent la propriété forestière.

Que l'État incite les particuliers et les communes à constituer des massifs de futaies partout oì la qualité du sol le permet; pour ce faire, non seulement ces massifs seraient, comme les plantations et les semis, exonérés d'impôts pendant trente ans, mais encore des primes pourraient leur être attribués.

Que l'État, sans s'occuper des nécessités budgétaires, augmente la durée de ses aménagements et encourage les particuliers et les communes à suivre son cxemple.

Que la législation facilite l'accession à la propriété forestière de propriétaires dits "impérissables "qui, semls, ont intérêt à l'aménagement de coupes de longue durée.

Que de très sérieux encouragements soient accordés anx chercheurs pour les amener à trouver l'utilisation industrielle du petit bois, notamment pour la fabrication de la pâte à papier. 
Que l'industrie boulangère soit incitée à utiliser le bois pour la cuisson du pain.

Que certains canaux soient améliorés, notamment que les travaux commencés depuis de nombreuses années sur le canal dn Vivernais, qui dessert une région essentiellement forestière, soient poussés activement de façon à permettre le passage des bateanx de 38 mètres, ce qui diminuerait notablement les frais de transport.

Que le service des ports, si économique pour le commerce des bois, soit maintenu dans son intégralité, et étendu, autant que faire se pourra, aux gares situées dans les limites des cantonnements des gardes-ports.

Que, d'une manière générale, les marchands de bois exploitants fassent fendre toutes les bîches de charme dont la grosseur atteint vul dépasse 14 centimètres de diamètre.

Charbon de bors. - Quc la durée des aménagements des coupes soit augmentée et portée, chaque fois que la qualité du sol le permettra, a 35 ou 40 ans.

Que les bois destinés à la carbonisation aient au moins $0 \mathrm{~m} .025$ de diamètre au petit bout.

Que les distillateurs de bois en vases clos soient invités à n'utiliser que la charbonnette exclusivement.

Que la Ville de Paris abaisse sensiblement les droits d'octroi qu'elle perçoit actuellement sur le charbon de bois, et qu'elle mette ces droits en harmonie avec ceux auxquels sont taxés les autres combustibles.

Que de très réels encouragements soient accordés aux chercheurs, soit par voie de concours, soit par tout autre moyen, pour les amener à trouver des procédés scientifiques permettant l'emploi industriel. du charbon de bois.

Que des tarifs spéciaux soient accordés au transport du charbon de bois destiné à l'exportation.

Étais De mines. - Que la durée des aménagements des coupcs soit, chaque fois que la qualité du sol le permettra, portée à 35 et 40 ans.

Que les houilleres de France fassent un usage de plus on plus grand des bois d'essence dure.

Que les bois de mines destinés à l'exportation joulssent d'un régime de faveur particulièrement réduit pour les transports à longlue distance.

Que les houillères prennent livraison des bois de mines en perches ayant toute la longueur de l'arbre.

M. Le Président - Le rapport de M. Rizier a une certaine importance. Les voux constituent un ensemble intéressant dont je vais vous donner lecture; vous aurez à vous prononcer sur chacun des alinéas.

Personne ne dernante la parole au point de vie général du rapport?

S'il en est ainsi, je vais prendre les voux les uns après les autres et les soumettre à votre approbation. 
11. Rizier conclut : au point de vue des bois de chauffage :

"Que l'État soit invité à fuire le plus de réserves possibles, de façon à produire, daus un avenir encore lointuin, plus de futaies at moins de taillis."

Je crois que nous sommes tous dacord sur ce point.

Adopté à l'umanimité.

"Qu'on encourage les particuliers ì fuire les mêmes réser'es, en les indemnisant de leur sucrifice, an moyen de la suppression totale ou partielle des impôts qui grèsent la propriété forestière. "

M. Tortel. - Je ne combats pas ce vœu, car ne serait éridemment notre intérêt, mais les bùcherons, la population ourrière qui travaille tlans les bois, lorsquils verront ce dégrèvement complet, vont avoir un état d'esprit nouveau; ils sont rléjà assez animés contre les propriétaires. Je demanderai donc qu'au lien de la suppresion des impôts on classe les bois au tarif des terres les moins productives.

M. Le Présidento - Il faut demander le plus pour obtenir le moins; e'est un peu l'esprit dlu voeu.

M. Caquet. - Je demande qu'on maintienne intégralement ce vou qui me parait très bien libellé, car je crains que M. Tortel ne se fasse illusion à l'égard des ouvriers. Leur travail est très respectable indubitablement, mais il y a une chose très respectable aussi : c'est qu'une propriété qui ne rapporte rien ne doit rien payer. Je demande done que le mot suppression totale soit maintenu dans le vœu.

M. Le Présinext. - Nous paraissons d'aceord pour maintenir le paragraphe tel quil est libellé?

Adopté à la majorité.

"Que lEtat incite les particuliers et les communes à constituer des massifs de futaies partout où la qualité du sol le permet; pour ce faire, non seulement ces massifs seraient, comme les plantations ot les semis, exonérés d'impôts pendunt trente ans, mais encore des primes pourraient leur être attribuées."

Adopté à l'unanimité.

"Que lÉtut, sans s'occuper des nécessités budgétaires, angmente. la durée de ses ménagements et encourage les particuliers ot les rommunes à suivre son exemple. \#.

Adopté à l'unanimití. 
"Qne la législation facilite l'accession ì la propriété forestière de propriétuires dits "impérissables ", qui, seuls, ont intérêt à l'aménagement de coupes de longue durée ".

Adopté à l'unanimité.

"Que de très sérieux encouragements soient accordés aux chercheurs pour les amener à trouver l'utilisation industrielle du petit bois, notamment pour la fabrication de la pâte à papier ».

11. Duснандх. - Je demande la suppression des derniers mots : Notamment pour la fabrication de la pâte à papier ».

En effet, pour les bois durs, on se heurte à des difficultés techniques insurmontables; ne présentons pas des choses qui ne sont pas susceptibles d'aboutir à un succès et restons dans les propositions générales.

11. Le Préstnext. - Nous supprimons done les mots " notamment pour la fabrication de la pate à papier".

Arlopte a 1 unanimiti.

"Qne l'industrie bonlangère soit incitée à ntiliser le bois ponr la cuisson du pain ".

Adopté à l'unanimití.

"Que certuins canaux soient umétiorés, notamment que les tracanx. commencés depuis le nombreuses années sur le canal du Nivernais, qui dessert une région essentiellement forestière, soient poussés activement de façon i permettre le passage des bateanx de 38 mètres. ce qui diminueruit notablement les frais de transport".

11. Ciguet. - Je demande la parole, non pas pour combattre ce rou, tant s'en fant, mais pour le souligner, car il est très important.

M. Le Présidext. - Le ministre des Travaux publies n’a-t-il pas écrit dernièrement un* lettre officielle pour téclarer qu'il se préoccupait beaucoup de cette question et qu'il allait faire le nécessaire?

M. Ciquet. - Les efforts róunis du Conseil génóral de la Nièvre. de la Chambre de commerce et des Chambres syndicales, nont abouti, après 12 ans d'efforts, quà obtenir une demi-douzaine d’écluses transformées, sur 36.

M. Le Préstonent. - Le ministre des Travaus Publies, M. Thierry, vient d'icripe une lettre officielle dans laquells il disait que la question du "anal du Nivernais l'interessait beaucoup et allait aboutir.

A1. Cinget - Lispérols-le !

Le ven mis anx voix est adoptón a lomanimite. 
M. Le Présillext.

"Que le service des ports, si économique pour le conmerce des bois, soit maintenu dans son intégralité, et étendu, antant que faire se pourra, anx gares situées dans les limites des cantonnements des gardes-ports \%.

Arloptí à 1 unanimitó.

"Que d'une manière générale, les murchands de bois exploitants fassent fendre toutes les buches de charme dont la grosseur atteint ou dépasse 1/4 centimètres de diamètre $n$.

M. le Secrétalre. Cost un bon conseil.

M. Le Président. - Ciest peut-être un peu spécial, mais cela ne gène personne.

Adopté à l'unanimité.

M. Le Présinext. - Nous passons à la question du charbon de bois.

"One la durée des aménagements des coupes soit angmentée et portée, chaque fois que la qualité du sol le permettra, a 35 on 40 ans $)$

II. CiQvet. - Hl semble qu’il y ait là plus qu une invitation. Je ne vois pas très bien quello est lintention de l'auteur; si c'est simplement un conseil, jesuis diaccord avec lui, mais si c'est une mise en demeure, je men sćpare, trourant que la formule laisse à désirer.

M. Dechemix. - Nous pourrions mettre:

"Qne les proprictuires forestiers soient invités à augmenter la durée des aménagements des coupes et ì la porter chaque fois que la qualité du sol le permettre à 35 on 40 ans $).$

II. Ciquet. - Je me rallie à cette proposition.

Le vou ainsi morlifié est adopté à l'unanimité.

II. Le P'résidext.

"One les bois destines à la carbonisation aient an moins $0 \mathrm{~m} .025$ de diametre an petit bout".

Lus reprósentants de la arbonisation ont-ils des observations à prisenter?

11. Dechemin. - Incunt, au entrairp.

M. Caquet. - Ce sont les limension quon mous demamde.

Le roeu est adoptó à l'unanimiti. 
M. LE P'RÉ-IUENT.

"Que les distillateurs de bois en s'uses rlos soient invités à n"utiliser que la charbonnette exclusivement".

11. Drсfevix. - Ciest un veu absolument platonique et dont je demande la suppression.

11. Le Présid ext. - Voyez-rous un intérêt spécial à supprimer ce rœu? Sinon nous pourrions le laisser subsister.

Le rou est adopté à l'unanimité.

A1. Le Présinext.

"One la Ville de Puris abuisse sensiblement les droits doctroi qu'elle perçoit actuellement sur le charbon de bois. et qu' elle mette ces droits en harmonie avec cenx anxquels sont tuxés les antres combustibles ".

Le voeu est adopté à l'unanimité.

11. Le Présinent.

"Que de très réels encouragements soient accordés anx chercheurs, soit par voie de concours, soit par tout autre moyen, pour les amener à trouser des procédés scientifiques permettant l'emploi industriel du churbon de bois".

Le rœu est adopté à l'unanimité.

Le Présinent.

"Que des turifs spéciaux soient uccordés au transport du charbon de bois destiné à lexportation".

Adopté à l'unanimité.

"Qne la durée des aménagements des conpes soit. chaque lois que la qualité du sol le, permettra, portée ì 35 et 40 ans m.

Adopté à l'unanimité.

"Que les honillères de Frunce fussent un nsage de plus en plus grand des bois dessence dure $\%$.

Suit une discussion jassez vive, à laquelle prennent part M. Lescasar, Hollande, Sćbastien, Caquet, Rachet.

M. Dцспемл. - Je crois "qu'inviter les houillères de France "serait peut-être priferable, bien que platonique, car elles ont commencé à prendre des étais de bois dur, et cela peut-ètre. pour amener à composition les fournissenrs des Landes. Je crois savoir en effet que, lorsque les houillères trouvent que les prix des étais do mines de provenance

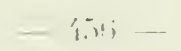


des Landes sont trop ilevies, elles viement lans le Morvan chereher des étais, de manière à faire le vide momentanément. Je pense donc que leur demander ou ne pas leur demander de prender des bois durs revient au même (Protestations).

M. Le Président. - Je mets aux roix le veu.

A la.majorité le voen est repoussé.

"Que les bois de mines destinés à lexportation jonissent d’un régime de faseur particulièrement réduit pour les transports à longue distance ".

Adopté à l'unanimití.

M. Le Présinext. - Lil de nos collègues propose de remplacer ree rou par le suivani:

"Que les houilleres prennent livraison des bois de mines en perches ayant tonte la longueur de l'arbre.

"Qne les Compagnies de chemins de fer soient invitées it ne fuire aucune distinction, pour ce qui est du transport des bois de mines, entre cenx ayum moins de $5 \mathrm{~m}$. 40, qui soyagent à la série $E$ et ceux ayant plus de $5 \mathrm{~m}$. 40, qui voyagent à la sixième série, et à les faire. voyager, suns distinction de longnent, à la série E. "

Ce vou serait mienx placé à la Commission qui soecupe des transports. Je rous demande toutefois si vous acceptez la rédaction proposée.

Le roeu est adopté.

M. Le Présinent. - La parole est à VI. Caquet, pour la lecture de son rapport sur l'UTHLISATION WES MEXUS BOIS PAR LES NOLVEATY PROCÉDÉS CHIMIQUES ET MÉCANIQTES.

11. Caquet. - Jusqu'à ce jour, l'exploitation des forêts est restée ce qu'elle était il y a des sièeles. Les progrès accomplis sont presque nuls en matière sylvicole, et les instruments dont se servaient nos aneêtres pour abattre et débiter les hois sur pied, c'est-à-dire la cognée et la scie à main, sont les seuls que nous utilisions encore aujourd'hui pour l'exploitation des taillis, dont les produits ne se vendent plus.

Nos futaies feuillues et nos résineux en général se vendent bien, leurs propriétaires n'éprouvant pas de difficultés dans les débouchés qui les concernent.

La surface forestière exploitée actuellement en taillis occupe, en France, près de einq millions et demi d'heetares, dont quatre millions appartiennent aux particuliers; le reste, soit un million et demi, est la propriété de l'État, des communes et des établissements publics.

Nous exploitons chaque année, en France, 300.000 hectares de bois taillis, en chiffres ronds, produisant environ 10 millions de tonnes de bois 
à charbon, qui ne foumissent qu'un rendement net de 0 fr. 20 par stère, à peine.

D'autre part, le produit moyen d'une coupe àgée de 17 à 20 ans est environ à l'hectare de 3.000 fagots, pesant unitairement 6 à 7 kilogrammes en moyenne; c'est donc par hectare exploité 20 tonnes de fagots ou, pour notre production totale annuelle en France, 6 millions de tonnes, dont moitié au moins pourrissent sur le parterre des coupes, faute de débouchés et d'utilisation, l'autre moitié étant vendue à perte par le propriétaire, et au-dessous des prix de façon payés aux ouvriers.

Comment tirer parti de ces fagots et de ces bois à charbon dont la vente est devenue impossible?

On a répondu qu'il fallait cesser d'en produire, et qu'il était plus avantageux de laisser vieillir et re pousser à la production des bois d'œuvre et de travail qui sont plus faciles à vendre, actuellement, à des prix rémunérateurs.

Si, dans certains cas exceptionnels, le propriétaire forestier, disposant par ailleurs de revenus suffisants, peut laisser vieillir ses coupes, ainsi que nous l'avons nous-mêmes recommandé, nous savons que le plus ordinairement ce remède est illusoire, les besoins individuels quotidiens étant sans cesse grandissants. D'ailleurs, il y aura toujours, quel que soit l'âge des coupes exploitées, une notable quantité de bois à charbon et de fagots dont il faut trouver l'utilisation avantageuse. Le problème à résoudre présente done deux facteurs distincts : bois à charbon et de chauffage, d'une part; fagots de l'autre.

Le chauffage au bois n'existe plus dans nos villes, et il nous paraît superflu d'appeler ici la statistique à notre aide pour montrer la décroissance stupéfiante de la consommation dı bois à brûler et du charbon: à Paris notamment, les bois de chauffage et les charbons, ainsi que les fagots, ne se vendent plus; il faut chercher d'autres utilisations dont ils seront la matière première. C'est la chimie et la mécanique qui nous en fourniront les moyens.

La mécanique à déjà prouvé quelles merveilles elle peut accomplir dans les usines fixées pour le travail des bois de toute sorte, mais elle n'a pas encore fonctionné économiquement dans nos taillis, où elle est appelée à détacher les rejets de la souche et à les sectionner en longueurs, aussi courtes que l'industrie l'exigera. Par ailleurs, la chimie nous réserv' certainement des découvertes sensationnelles, dans l'étude des extraits qu'il est possible de tirer du bois, et de la sciure de bois, qui se chiffr" annuellement en France par une production de 800.000 tonnes. Ce produit, que l'on peut ranger dans la eatégorie des menus bois, a trouvè récemment son emploi dans la fabrication de l'alcool éthylique, tel qu'il est extrait de la betterave, des pommes de terre et autres tibercules, et du vin lui-même.

Cet alcool obtenu au laboratoire, il y a une quinzaine d'années, par le docteur Alexandre Classen, d'Aix-la-Chapelle, est actuellement fabriqué industriellement par la Compagnie industrielle des alcools de l'Ardèche, à Saint-Marcel-d'Ardèche.

Jusqu'à ce jour, il n'a été traité à cette usine que des sciures de bois résineux. La cellulose est saccharifiée par un ensemble de procédés qui constituent l'ingénieuse invention du prolesseur Classen, et sans entrer dans le détail des manutentions subies par la matière première et des réactions chimiques auxquelles elle est soumise, nous vous dirons que la 
saccharification des sciures de résineux traitées a donné, d'après les indications qui nous ont été fournies, $10 \%$ en poids d'alcool éthylique et $3 \%$ de méthylène.

Il nous paraît nécessaire d'insister de façon toute spéciale sur cette découverte et sur les graves conséquences qu'elle peut avoir dans l'avenir, en présence de l'épuisement des ressources mondiales en pétrole, dont nous sommes importateurs. Comme nous sommes tributaires intégralement de l'étranger pour ce produit, qui est le pain actuel de notre industrie automobile et de notre motoculture naissante, il y a un intérêt supérieur à remplacer ce carburant étranger, dont les gisements sont chaque jour de moins en moins riches en essence, par un nouveau carburant à renouvellement naturel et suffisant pour les besoins de plus en plus importants des moteur's à explosion. Nous croyons fermement que l'alcool éthylique tiré de nos menus bois résondra la crise qu'ils subissent actuellement en permettant le développement considérable de la motoculture.

$\mathrm{Au}$ résultat industriel si intéressant, quoique incomplet au point de vue qui nous occupe, réalisé à Saint-Marcel-d'Ardèche, il faut ajouter l'obtention d'acétates et de résidus employés à la fabrication des briquettes agglomérées et des comprimés qui, mélangés à certaines matières, donnent des produits extrêmement curieux, mais qui ne sont pas encore entrés définitivement dans le domaine de l'industrie courante, en France au moins, tout en laissant l'horizon ouvert aux plus légitimes espoirs.

L'alcool éthylique obtenu est d'une pureté remarquable, sans odeur, et supérieur aux alcools de grains les mieux raffinés. Les sciures, achetées actuellement $7 \mathrm{fr}$. 50 la tonne, subissent des frais de transport égaux, de sorte que la tonne de sciure revient à 15 francs. Traitée à l'usine, elle donne 1 hectolitre d'alcool, 30 litres de méthylène et, en plus, des produits accessoires qui, actuellement, remboursent la Compagnie de tous les frais d'achat, de manutention et de traitement, les alcools éthylique et méthylène, restant comme bénéfice absolument net de l'opération.

N'est-ce pas là un grand pas franchi dans la voie de la solution du pro. blème que nous désirons résondre complètement ? Assurément; mais il reste encore beaucoup à faire.

En effet, seule, la sciure des résineux a été utilisée, et pour mener à bien le résultat définitif s'appliquant aux bois durs et particulièrement au chêne (les résineux et les bois blanes étant en pleine prospérité avec des débouchés intéressants et avantageux), il faudrait soumettre charbonnette et fagots à deux opérations distinctes. L'une, mécanique, relativement facile; l'autre, chimique, plus laborieuse, car la saccharification des glucoses ne peut, dans l'état actuel des connaissances et de la pratique des laboratoires, être faite en présence de l'acide tannique, assez abondant dans les menues branches de chêne pour opposer un obstacle à cette opération nécessaire, mais peut-être pas assez abondant pour donner naissance à une industrie extractive fructueuse, au moins en ce qui concerne le bois lui-même. Ajoutons que la saccharification des matières amylacées a pu récemment être faite en présence de certains acides, ce qui nous permet d'espérer que, quoique plus actif, l'acide tannique sera lui-même bientôt vaincu par les efforts de nos savants, et re jour-là tous les menus bois, réduits en pulpe, pourront sans doute être traités chimiqueinent comme le sont actuellement les sciures de sapins à l'usine de Saint-Marcel-d'Ardèche. 
Nous attendons ce bienfaisant résultat de la chimie française, sans pouvoir espérer, pour l'instant, l'application de la distillation en vase clos sur le parterre même de nos coupes. C'est cependant l'une des questions les plus importantes au point de vue de l'avenir de nos forêts et en particulier de nos taillis.

La carbonisation par le procédé dit "en vase clos " comporte des appareils qui ne sont pas en général transportables et sont fixés à demeure. Les usines fixes exigent un matériel considérable et la question est de savoir s'il ne serait pas possible de diminuer de beaucoup l'importance de ce matériel pour fabriquer des pyroligneux et des acétates par usines portatives.

Il y a en Allemagne, aux environs de la forêt Noire, dans le Wurtemberg, la Bavière et le Harz, des usines volantes de carbonisation des petits hois en vase elos qui domment, paraît-il, des bénéfices très appréciables.

Dans le Jutland, en Suède et en Norvège, cette industrie est très prospère, et a pris une extension considérable. C'est donc dans ces régions qu'il faut aller constater les progrès industriels accomplis, pour les mettre ensuite en pratique chez nous, en leur faisant subir des améliorations.

On concoit aisément l'économie considérable qui résulterait de la carbonisation en vase clos, en forêt même, par la suppression du transport à l'usine fixe des bois à distiller, les acétates et les pyroligneux obtenus étant seuls expédiés pour subir un raffinage spécial, qui ne peut être fait qu'au moyen d'appareils compliqués impossibles à transporter sur chariots.

Le charbon de cornue, restant au lieu même de la distillation, pourrait être vendu sur place ou plutôt serait employé à la fabrication du gaz pauvre sur le parterre même des coupes.

On a objecté qu'il fallait de très grandes quantités d'eau pour cette distillation en vase clos, comme si, dans la plupart des cas, les cours d'eau et les étangs faisaient défaut dans nos forêts de France. Nous croyons que les efforts de nos techniciens, chimistes et ingénieurs, unis dans un but coinmun, nous donneront la solution désirée de cet important problème des usines volantes de carbonisation en vase clos.

En attendant, ết sans nous tourner du côté de l'Etat-Providence, faisons appel à l'initiative privée des propriétaires de bois réunis, syndiqués en vue de la recherche de cette solution qui, si elle importe au bien public, sera éminemment favorable aux intérêts des exploitants.

Notre communication actuelle n'aurait-elle pour résultat que de faire éclore cette initiative désirable que nous nous féliciterions de vous l'avoir faite.

Dans cette communication, nous n'avons pas voulu nous arrêter un seul instant aux sentiers battus, et désirant économiser votre temps si précieux nous avons concentré tous nos efforts à donner de l'inédit. C'est dans cet esprit que nous vous dirons quelques mots d'une découverte de laboratoire, relative au "bois fondu".

Au premier abord, fondre du bois parait ehose impossible. Il n'en est rien pourtant et bien que le bois soit éminemment inflammable, il fond à une température relativement basse, mais dans des conditions très précises et seulement quand il est absolument soustrait au contact de l'oxygène, de façon à rendre impossible sa combustion. Cela se comprend, du reste, quand on se souvient de la constitution du bois. Débarrassé au moyen de l'alcool, par exemple, de ses éléinents immédia- 
tement solubles, il donne à l'analyse des acides organiques, de l'eau, des essences huileuses, des silicates, des sulfates, des phosphates, des chlorures et des hydrocarbonates de chaux, de potasse, de soude et de magnésie; de l'acide carbonique, de l'hydrogène carboné.

Partant de ces données, on a étudié, dès 1895, le problème de la fusion des bois et, après un an de recherches, on a pu produire un échantillon de bois fondu. Ces essais ont été repris, et actuellement il existe toute une technique opératoire sur laquelle noıs ne nous étendrons pas qui permet d'obtenir ce curieux produit doué de qualités qui lui assurent un véritable avenir industriel. Il est d'un grain très fin, susceptible d'acquérir un très beau poli, très dur et très résistant à l'usure. Il prend facilement l'encre typographique et supporte des lavages répétés à la potasse, au carbonate de soude et à la térébenthine.

Versé dans des moule- à l'état liquide, il se prend en masse par refroidissement tout en épousant toutes les sinuosités de la surface mise en contact avec lui. On a pu faire ainsi des objets de formes très variées, notamment fabriquer des caractères mobiles pour l'impression, surtout les caractères de grandes dimensions employés "pour les affiches.

On peut ajouter au bois destiné à être fondu des substances antiseptiques, particulièrement du bichlorure de mercure, qui en assurent la conservation pour ainsi dire indéfinie, et le soustraient à l'action des insectes destructeurs. C'est là un avantage considérable, qui ne peut qu'augmenter la valeur du bois fondu.

Il nous a paru intéressant de mettre sous vos yeux cet exemple curieux d'utilisation chimique nouvelle $d u$ bois pour vous montrer à quelles nombreuses, importantes et utiles transformations, grâce à la science et à la chimie principalement, peuvent donner lieu ces menus bois, actuellement sans valeur, et qui seront peut-être appelés, pensons-nous, à enrichir, dans un avenir que nous ne pouvons préciser, ceux-là qui les possèdent actuellement.

Après avoir esquissé à grands traits le rôle que la chimie aura à remplir dans l'étude plus approfondie des produits à extraire des essences si variées de nos bois, il nous sera permis de passer rapidement en revue les moyens que la mécanique peut mettre à notre disposition pour tirer parti de nos menus bois: charbonnette et fagots.

Comment transformer cette matière onéreuse qu'est le fagot en produit avantageux et de bon rendement? Nous pensons que la solution n'est pas impossible par le découpage mécanique, au moyen d'un hache-bois, de ces fagots en bûchettes de petites longueurs.

Ces menus bois broyés ou coupés en petites longueurs pourront servir à la fabrication des braisettes, par le procédé " des meules" ou à la fabrication du gaz pauvre par le gazogène système fixe du genre "Riché" ou système mobile du genre "Caze" ou tout autre analogue, amélioré et mis au point, ce qui permettrait ensuite le transport de la force obtenue à la ferme voisine par câble ayant au plus douze à quinze cents mètres de long. Cette force motrice serait très précieuse dans les régions où il n'existe pas de chutes d'eau et où la houille est chère.

L'utilisation du gaz pauvre se répand, en effet, de plus en plus, et il est à présumer que, dans un avenir rapproché, il aura détrôné partiellement la vapeur. La raison de cette faveur croissante du gaz paurre réside dans le meilleur rendement des moteurs ruu'il actionne. 
Ceux-ci, en effet, à puissance égale font une consommation de combustible deux fois moindre que les moteurs à vapeur.

D'après les expériences "faites sur deux installations de même force, l'une à gaz pauvre, l'autre à vapeur, l'économie réalisée avec la première atteignait $53 \%$.

II y aurait donc une excellente utilisation des menus bois pour la fabrication du gaz, ce qui permettrait de se procurer ce gaz partout, à la campagne comme à la ville, dans les plus petits villages, dans les usines isolées, de même que dans les châteaux et dans les fermes du voisinage immédiat des forêts. La gazéification des bois est appelée à rendre de multiples services, tant à l'industrie qu'à l'agriculture; mais sa mise au point n'est pas définitive et elle sollicite encore les travaux des chercheurs.

Les appareils à production $\mathrm{du}$ gaz peuvent du reste utiliser tous les bois, rondins ou bourrées, mais à la condition absolue que ces menus bois soient tout d'abord débités par le broyeur ou le hache-bois, en bûchettes de très courte longueur. Ces broyeurs, ces hache-bois, ces scies circulaires et à ruban placées sur chariots mobiles seront actionnés par le gaz pauvre, de telle sorte que la force produite par une partie des menus bois servira à mettre en valeur l'autre partie elle-même. De ces bois à charbons et de ces fagots, il sera possible de tirer tout d'abord l'écorce par le procédé mécanique de la vapeur, expérimenté il y a plus de trente ans, et qui, depuis cette époque, n'a fait aucun progrès, faute d'étude consciencieuse. Il serait cependant fort intéressant de remplacer, dans la mesure du possible, par ces écorces complémentaires qui ne sont pas, il est vrai, d'une grande richesse en tannin, les extraits de châtaigniers dont l'exploitation intensive a ruiné en partie nos châtaigneraies du centre de la France et de la Corse principalement.

Depuis plus de vingt-cinq ans, l'industrie a tenté l'écorçage à la vapeur, qui serait un des principaux desiderata de la propriété forestière, principalement à l'égard des écorces de fagots contenant moins de matières tannantes et d'une valeur inférieure aux écorces normales actuellement exploitées.

La tentative, qui n'a échoué que par suite de l'excédent des frais sur la valeur des produits, peut être utilement reprise, le problème mieux étudié peut être résolu, pensons-nous, dans le sens de l'écorçage mécanique des chênes en temps de sève. La conséquence de cette mise au point serait la solution de cet autre grave problème : les châtaigniers de France. Les matières tannantes produites dans notre pays dépassant alors certainement nos besoins nous permettraient, en conservant les châtaigniers restants, de faire en outre de l'exportation des produits tanni(ques, que nous importons actuellement.

Nous ne saurions assez insister sur l'intérêt que présente cette question du tannage des cuirs par l'écorce de chêne qui touche si étroitement à la fois à la mévente de nos bois taillis, au renchérissement de la maind'œuvre et à la prospérité d'une de nos plus importantes industries nationales: la tannerie battue en brèche et discréditée par l'emploi des sels de chrome chaque jour plus envahissants, au grand détriment de la souplesse et de la qualité des cuirs traités par l'écorce de chêne. Il faut à tout prix que nous obtenions des écorces à bon marché et seule la machine à écorcer, mise au point, nous permettra de résoudre cet important problème, déjà en bonne voie de solution, car il appert très nettement des résultats acquis sur cet écorçage à la vapeur, que les éçorces obtenues 
par ce procédé, abandonné par raison économique, avaient une qualité presque égale à colle des écorees recueillies en temps de sève, et une égale teneur en tanin. Mais dans cette voie il reste encore, pensons-nous, un grand pas à faire pour solutionner le problème.

Ce pas peut el doit être fait dans le sens de l'écorçage mécanique et économique sur le parterre des coupes mêmes. Le problème déjà en bonne voie n'est ni insoluble ni utopiste, et la machine à écorcer le bois, mise au point, aurait en outre pour conséquence l'enrichissement du pays en améliorant sensiblement la situation des propriétaires de taillis qui, actuellement ont pour la plupart cessé d'écorcer.

Peut-être serait-il également possible, au moyen de broyeurs établis sur chariots, transportés sur le parterre des coupes et actionnés par l'usine à gaz pauvre de transformer en fibres ou copeanx d'emballage certains menus bois de nos forêts.

Nous estimons également que ces menus bois, hachés ou broyés, pourraient donner naissance à la fabrication sur place de briquettes pour chauffage, grâce à un mélange à petites doses de produits agglutinants appropriés. Il pourrait également être fait des briques légères destinées à la construction et dont les avantages apparaissent immédiatement, ne serait-ce qu'à l'égard de leur légèreté, de leur imperméablité et de leur inconductibilité.

Mais ces briques spéciales ne seront d'une vente courante et facile qu'en raison de leur bon marché. C'est sur ce terrain économique que le problème doit être posé et résolu.

Ces diverses transformations pourraient avorr lieu dans de petites usines fixes ou démontables même, placées au voisinage des grands massifs forestiers, à l'instar des petits établissements industriels de carbonisation des bois en vase clos et qui ont été établis au voisinage de Reims et dans le département du Cher notamment. Quelques-unes de ces usines ne consomment que 25 stères de bois par jour et sont cependant très prospères.

Une des utilisations intéressantes des fagots coupés th bois courts consiste dans la fabrication des margotins, qui sont des produits d'usage courant et de facile débouché.

Tout le monde connaît la fabrication des margotins liés à la main; le prix de revient en est trop élevé pour rendre cette fabrication lucrative et intéressante ; mais il est facile d'imaginer une lieuse mécanique plus compliquée assurément que la moissonneuse-lieuse dont se sert l'agriculture. Cette lieuse mécanique agricole ne nous donne-t-elle pas le principe mêrne d'après lequel pourrait être établie la lieuse forestière pour cotrets de toutes dimensions?

On sait que le commerce des margotins occupe une place tròs importante dans l'ensemble du commerce des bois en général et pourrait devenir prospère et lucratif par l'emploi de la lieuse mécanique appliquée en forêt.

()utre, cette utilisation ingénieuse des menus bois, d'un diamètre supérieur à $0 \mathrm{~m} 02$ et correspondant au talon des bourrées et fagots, tels qu'ils sont composés dans lc Centre de la France, dans nos taillis de chênes, charmes et autres essences mélangées, il serait possible de trouver un autrc débouché fort avantageux aux produits sans aucune valeur de plus faible dimension, grâce à unc industric toute nouvclle puisqu'elle ne date que de 1893. 
Nous voulons parler de la paille-bois pour alimentation du bétail qui fut l'objet d'expériences concluantes faites en forêt de Sénart par notre vénéré maître M. L. Grandeau qui a donné, avec la clarté lumineuse caractérisant tous ses écrits, les détails les plus précis sur cette intéressante question dans un petit livre édité par la Librairie agricole de la Maison rustique et auquel nous renvoyons nos lecteurs. Cet ouvrage a pour titre: Instruction pratique sur la ramille alimentaire. Il fut publié après la disette de fourrage de l'année 1903.

Toutes ces transformations intéressantes et avantageuses des menus bois pourraient être obtenues, sur le parterre même de la coupe, par la force si économique du gaz pauvre.

L'installation de petites usines fixes ou volantes de gaz pauvre sur le parterre de nos coupes, dans les pays boisés, aurait pour conséquence, outre la vente de la force motrice qui augmenterait sensiblement le revenu du propriétaire forestier, la création de très utiles petites industries de toute sorte dans nos villages, non loin des bois, et partant fourniraient un moyen efficace de combattre l'exode de nos paysans vers les villes et de ramener peut-être aux champs certains d'entre eux qui ne les ont quittés que parce qu'ils n'y trouvaient plus à s'y employer.

Si l'ensemble des machines et des moyens mécaniques d'exploitation forestière, auxquels nous avons fait plus haut allusion, pouvait être réalisé, ce serait, de l'avis des meilleurs spécialistes, une régénération certaine de nos taillis de France; car la plus-value qui en résulterait ne saurait être estimée à moins de 30 francs par hectare, ce qui représenterait, pour l'ensemble de notre domaine forestier français et colonial, une somme énorme, sans compter qu'il serait possible d'appliquer de la même façon ces procédés aux autres forêts mondiales. Pour la forêt mondiale, encore mal connue dans ses ressources, il ne nous est pas possible de chiffrer cette plus-value qui dépasserait certainement ce que l'imagination la plus fertile pourrait rêver. Nous nous bornerons à exprimer ici que, pour notre domaine forestier français, grand de $9 \mathrm{mil}$ lions d'hectares, ce serait une augmentation de revenu net de plus de deux cent soixante-dix millions, représentant un capital de sept milliards environ.

Les décharges ou degrèvements d'impôts, actuellement demandés pour la forêt et que nous trouvons amplement justifiés ne sauraient qu'appauvrir l'État, l'application des moyens que nous préconisons ne peut que l'enrichir. Aussi, pour atteindre ce but, proposons-nous à votre approbation les vœux suivants :

I. Que l'État fasse faire à la station forestière spéciale de Nancy el dans tous les établissements scientifiques dont il dispose des recherches scientifiques sur la meilleure utilisation chimique et mécanique des menus bois.

II. Qu'il accorde de larges subventions à toutes les initiatives privées: syndicats, sociétés et savants qui se livreront à des travaux sérieux sur cette question.

III. Qu'il fonde un prix d'une importante valeitr pour récompenser les savants ou les inventeurs qui auront trouvé une ou plusieurs solutions économiquement pratiques de cet important problème de l'utilisation chimique et mécanique des menus bois. 
Suivant ainsi l'exemple donné par une République du Nouveau Monde, le Chili, qui, pour un but exclusivement national et non mondial, comme celui que nous envisageons, a voté une loi accordant une prime de 12 millions et demi de francs $(500.000 £)$ à l'inventeur qui trouvera le procédé pour extraire complètement le nitrate contenu dans le caliche, produit brut des salpêtrières du Chili.

M. Le Président. - Messieurs, avez-vous des ohservations à présenter au sujet du rapport de M. Caquet.

M. Rassix. - Dans son rapport, II. Caquet a visé le procedé du Dr Alexandre Classen, d Aix-la-Chapelle. 11 est juste, pour la science française, de reconnaitre que le procédé originaire du traitement de la cellulose en vue de la fabrication de la gluciose et, par suite, des alcools, appartient à un savant français, M. Nraconneau. M. Caquet n’ignore certainement pas ce dritail, mais il semblerait, llaprès les termes du rapport, que e'sst uniquement M. Classen qui a créé lo traitement de la cellulose, alors que cest un savant français qui en a eu la première idée. (Applaudissements.)

M. he l'résinext. - Nous ne pouvons que nous en glorifier.

11. Cinget. - Jesuis très heureux de l'addition que veut bien faire notre collègue à mon rapport.

Je crois quen outre de Mí. Draconneau, il y a eu un de nes collègues, décédé il y a quelques années, qui a, lui aussi, participé à ces travaux et à qui il serait bon de rendre justice. Cest II. Arachquen, et ses travaux n'ont pas été sans aider M. le I) Classen. J'associe donr le nom de M. Irachquen à celui qui vient d'être indiqué.

M. Le Président. - Le procès-verbal en fera foi, pour le plus grand honneur de la France.

Le vœu 1 de M. Caquet est ainsi conçu :

"Que l'État fasse faire à la station forestière spéciale de Nuncy et dans tous les établissements scientifiques dont il dispose, des recherches scientifiques sur la meilleure utilisation chimique et mécanique des menus bois \%.

Personne ne demandant la parole, le vou, mis aux voix, ust adopté.

M. Le Présinent. - Le vou 2 est ainsi libellé :

"Qu'il accorde de larges subventions à tontes les initiatives privées: syndicats, sociétés et savants qui se livreront it des travaux sérien.x. sur cette question.

Adopté à l'unanimité.

M. Le Président. - Nous passons an roul 3. 
"Quil fonde un prix d'une importunte saleur pour récompenser les savunts ou les inventeurs qui auront trouvé une ou plusienrs solntions économiquement pratiques de cet important problème de lutilisation chimique et mécanique des menus bois".

M. Sébastien. - Est-ce que crum ne se confond pas avec les deux prícédents:

II. Cieret. - Non, cest, en quelque sorte, une explication complémentaire des deux premiers.

M. Sébastien. - Je crois que vous allezeffrayer un peu le gourernement. si vous lui demandez de fonder des prix d'une importante valenr!

M. Cielet. - Loin de chercher à l'effrayer. jai eu, au contraire, la pensée de le rassurer, en montrant qu un petite république fonde un prix d'un chiffre énorme, alors que nous ne trouvons pas quelques dizaines de mille franes pour fonder nu prix qui, peut être, ponrrait déterminer des inventeur's à chercher une solution qui intéress? six millions dhectares de taillis et les propriétaires de ces six million d'hectares!

I. le baron ne Ségoxzac. - J'appuie complètement la manière dr voir de M. Caquet.

M. Dechems. - Je rois. pour ma part, que ces roeux ne font pas double emploi. D'abord, il nest pas suflisant que l'État cherche dans ses corps constitués, parce que, phus il y a de rerveaux qui travaillent un question, plus on a de chances de la roir aboutir. Autre point : la subvention est une somme courante qui permet au savant de continuer ses travaux. Le prix, cest la récompense du savant qui aboutit. Tou: pouvez avoir dix ou quinze savants qui recevront des subventions. sans arriver à un résultat. 11 est juste que celui qui arrive au but ait, en dehors de la subvention qui lui a permis de faire ses travaux, un prix qui est sa récompense directe. (Approbution générale.)

Le vœu est arloptí.

La séance est levée à ? h. 45. 


\section{SEANCE DU 17 JL'IN 1913}

\section{(MATIN)}

\section{Présidence de IM. POUPINEL, président de Section}

La séance est ouverte à 9 h. 30.

M. Le Présinext. - L'ordre du jour appelle la discussion du rapport de M. Gustave Artus sur les Plintations des roetes.

M. Gustave Artus. - Le voyageur qui circule sur nos grandes et belles routes de Franee est frappé par la disparition progressive de ces arbres magnifiques qui faisaient, il y a quelques années encore, l'admiration de tous.

Nous n'avons pas, dans cette courte étude, à nous inquiéter des moyens à employer pour améliorer l'entretien de nos routes; nous nous contenterons seulement de plaider de notre mieux en faveur de l'amélioration et de la conservation de l'importante partie de notre domaine forestier constituée par les arbres qui les bordent.

Il nous paraît presque superflu d'insister sur le côté artistique rempli par les plantations; quoi de plus laid et de plus monotone qu'une route dénudée! En se plaçant donc à ce seul point de vue. il est déjà permis de conclure, au nom de l'intérêt général, à la plantation et à la conservation de ces arbres d'alignement qui, depuis des siècles. ont si puissamment contribué à maintenir la réputation de beauté de nos voies françaises.

Si l'on se place au point de vue tourisme, on arrive aux mêmes conclusions, car l'arbre de bordure est, pour le touriste, un véritable ami. L'été, il étend sur lui sa puissante ramure et forme, au-dessus de sa tête, une voûte de verdure qui le garantit des ardents rayons du soleil ; l'hiver, il le guide à travers la plaine, lorsque celle-ci est recouverte d'un blanc manteau de neige.

Alors, pourquoi cette exploitation intense? Pourquoi cette dévastation qui appauvrit et enlaidit notre pays? C'est que les arbres de route ont des ennemis contre lesquels il est nécessaire de les protéger; il y a bien les insectes et les rongeurs, mais il y a surtout pour lui un adversaire beaucoup plus redoutable : je veux parler de l'homme

L'arbre, en effet, n'a pas d'adversaire plus acharné que le riverain dont il borde le ehamp, et il est facile de remarquer que c'est dans les plaines où la culture est la plus intense et la plus riche que les arbres sont le moins nombreux. C'est que l'ombre projetée sur les champs et l'envahissement du sous-sol par les racines sont des plus préjudiciables au rende- 
ment cultural ; aussi dès qu'un arbre se trouve en bordure d'un champ, le cultivateur de ce champ emploie tous ses efforts à le faire disparaître, méprisant l'intérêt général et ne voyant que son intérêt particulier.

Et pourtant, si les arbres de routes causent à la culture une légère perte, combien de fois cette perte n'est-elle pas compensée! Si le préjudice causé est si grand, pourquoi le cultivateur donne-t-il toujours sa préférence aux terres situées le long des routes ?

C'est qu'aujourd'hui les chemins empierrés sont indispensables à la culture; ils facilitent les gros charrois et économisent animaux et matériel; ils permettent, par suite, de cultiver industriellement les terres qui les avoisinent et cela pour le plus grand profit du détenteur de ces terres. Le cultivataur est done mal fondé à venir se plaindre du déficit produit dan son rendement cultural par le voisinage des arbres et à vouloir s'affranchir de la servitude que doivent supporter les terres qui bordent les routes dont il se sẹt et dont nous payons tous l'établissement et le bon entretien.

Sans hésitation aucune, faisons done passer l'intérêt général avant l'intérêt particulier; n'écoutons pas les plaintes mal fondées des riverains et conservons à nos routes la parure qui fait leur beauté.

Pour arriver à ce résultat, il serait à souhaiter que la vente des arbres de routes et des canaux soit soumise à une sévère règlementation et ne puisse être ordonnée par l'Administration qu'au moment seulement où l'arbre le demande de lui-même, c'est-à-dire lorscu'il cesse de croître pour commencer à dépérir. Cette façon d'opérer conduirait à conserver nos peupliers de route un laps de temps variant entre 40 à 50 années, et cela pour le plus grand profit de l'Administration qui, livrant à l'industrie des pièces de fortes dimensions, en obtiendrait au mètre cube un prix fort élevé.

Du choix de l'essence à planter. - Une fois l'arbre abattu, il faut le remplacer; l'essence à choisir doit être subordonnée à la nature du sol.

L'expérience prouve d'une façon péremptoire que l'arbre qui convient le mieux à la majorité de nos terres est le peuplier. Cette essence a sur toutes les autres une quantité d'avantages qui devraient la faire choisir d'une façon absolue, sauf toutefois pour les terres reconnues totalement impropres à sa bonne venue.

Le peuplier est notre arbre national ; c'est lui qui pousse le plus vite. Dans un terrain moyen, 25 années suffisent pour obtenir un arbre cubant de 1 mètre cube à 1 mètre cube $1 / 2$, pouvant être utilisé industriellement.

De toutes les essences, on peut affirmer, sans crainte d'être démenti, que c'est la seule qui puisse donner un pareil résultat; de plus, depuis une dizaine d'années, son emploi se généralisant, son prix n'a cessé de croître progressivement

Aussi ce n'est pas sans un prodigieux étonnement que, depuiz quelques années, on voit l'Administration, abandonnant nos superbes plantations de peupliers, les remplacer par d'autres, faites en arbres fruitiers souvent malingres et rabougris. Dans cette façon d'opérer, on retrouve l'influence néfaste des riverains qui, ne pouvant prétendre à empêcher le reboisement de nos routes, se contentent d'im poser à l'Administ ration une essence qui donne des arbres de faible hauteur, projetant par cela même peu d'ombre el leur causant un minimum de préjudice.

Au point de vue budgétaire, une telle pratique donne des résultats déplorables, l'arbre fruitier planté le long des routes donnant un revenu 
absolument nul. Une enquête personnelle portant sur une plantation de poiriers faite il y a dix-huit ans sur une route de 2 kil. 600 de longueur, dans le département de l'Aisne m'a donné les résultats suivants : l'entretien et la taille des arbres sont confiés à un jardinier payé annuellement 25 francs; la plupart des fruits sont dérobés par les passants avant leur maturité, et ce qui reste produit seulement une vingtaine de francs; le rapport d'une pareille plantation est donc absolument nul.

Si la même route avait été plantée en peupliers à raison de dix pieds à l'hectomètre, on aurait obtenu une plantation de 520 arbres produisant annuellement 520 franes, soit, au bout de 18 années, 9.360 francs, somme qui pourrait être employée utilement à l'entretien de la route.

Aussi, dans ce département, l'Administration, complètement édifiée sur les résultats à attendre des plantations d'arbres fruitiers, est-elle décidée à revenir exclusivement aux plantations de peupliers et cela. pour le plus grand bien du contribuable et du touriste.

Il résulte de cette courte étude que les voux que l'on peut formuler relativement aux plantations le long des routes sont les suivants :

Que l'Etat, les départements et les communes plantent indistinctement toutes les routes de France en essences appropriées à la nature du sol, à l'exclusion des arbres fruitiers.

Que les arbres de route ne soient abatus que le plus tard possible, c'està-dire senlement au moment où ils commencent à dépérir.

M. Le Président. - Aroz-rous, Mesieurs, des observations à présenter à propos de ce vou?

1I. Pral. - Dans les Cévemes et daus dlautres régions montagnenses, on parcourt des pays fimmenses sur des routes absolument sanombrages. Il suffirait, je crois, de pen de chose pour rendre ces rontes très agréables : il s’agirait simplement d'acheter quelques mètres dr. terrain en bordure et de les boiser; là, le terrain na pour ain $i$ dir aucune valeur, au lieu de le payer comme à Paris 1.000 francs le mètre carré, on peut le payer 100 francs l'hectare.

De même qu'il y a des commissions départementales qui ont classé les sites et monuments, de même on pourrait classer les router intéressantes au point de rue touristique. Je demanderais que sur to bord de ces routes il y ait une largent de 20 mètres au plus qui ne levrait pas être dépassée, plantée d'arbres, et alors, quand on passerait sur les routes de France, au lieu d'avoir un soleil écrasant qui rons enlève tout agrément, on trourerait une véritable petite forèt qui se déroulerait sous les pas. Je crois que la drpense ne serait pas consiclérable.

Dans rhaque région de la France, it y a des membres du TouringClul, ceserait à eux à signaler les routes intéressaules au point de vur touristique et à en provoquer le classement.

M. LE P'résident. - Ce que rous demandez, si jo comprents bien, cont qu'on puisse avoir à coté de la route elle-mène, unr bande de terrain 
boisée; mais, éest surtout au propriétaire du terrain lui-même à s'en occuper. Je crois que votre proposition pourrait faire l'objet d un roeu spécial, mais qu elle ne se rattache pas d'une façon directe à celui dont nous nous occupons.

M. Pral. - Il me semble que les choses sont du mème ordre, puisque nous cherchons à rendre les routes de France agréables.

M. Le Présinext. - Je demande à la section de voter le vou de M. G. Artus tel qu il est, afin de ne pas être en contradiction avec celui qui a été voté hier à la première section (Assentiment).

Adopté.

M. le Président. - Voulez-rous avoir l'obligeance, Monsieur Pral, de présenter votre proposition sous la forme d'un vou spécial, que nous voterons comme arjonction à celui-ci ?

M. Prat. - C'est entendu.

M. Gazead déclare à la section qu'il est l'auteur d’un projet de machine à abattre les taillis dont il ne peut pas divulguer les moyens d'exécution.

Cette déclaration est prise en considération.

M. Pral. - Voici le voeu que je désirais présenter tout à l'heure :

"Le Congrès émet le r'ou que, de méme quil existe des commissions qui, dans chaqne département, ont fait le classement des sites et monuments, des commissions, composées de membres de bonne volonté du Touring-Club de France signalent, dans les pays montagneux, les chemins présentunt un intérêt touristique, et que ces chemins ne puissent pas être déboisés sur une longueur de cinquante mètres environ; si ces chemins sont bordés par des terrains appartenant à des particuliers, cette bande de terrain serait achetée dans le cas où les vendeurs accepteraient le prix habituel d'achat de l'État."

Après consultation des membres présents, ce voru est renvoyé à la cinquième section.

II. Le Présinent. - Nous arrivons à la discussion du rapport de II. Pelletier de Martres sur la question des Poteatx télégriPHOUES.

La parole est à M. Pelletier de Martres.

II. Pílietier de Martres. - Grâce aux découvertes modernes, le progrès procède aujourd'hui à pas de géant.

La facilité et la rapidité des communications, par la suppression des distances, ont permis aux lommes d'échanger aisément leurs produits el leurs idées; elles ont donné aux savants de l'univers entier la possibilité de se transmettre, sans retard, leurs découvertes, de vivre 
dans une communion constante de pensées; un un mot, elles ont, tout en le grandissant, rapetissé le globe et, dans une certaine mesmre, ter1dent à l'unifier, jusqu'au moment oi ce même progrès le divisera pentêtre en le bouleversant étrangerment.

En attendant, nous le voyons déja modifier profondément la façon d'être et de vivre des peuples, préparant ainsi l'évolution complète des lois économiques futures et mondiales.

Pour entrer immédiatement dans le sujet qui nous oceupe, sans nous arrêter à de plus amples généralités, on peut constater que la valeur d'un eertain nombre de produits forestiers a été singulièrenent abaissée, tandis que celle de certains autres a été considérahlement augmentée, par suite d'un emploi intensif, inattendu et de leur rareté.

Si, par exemple, les taillis, d'où l'on tire les charbons, bois de feu et écorces pour la tannerie, ont vu leur valeur diminuer jusqu'a tomber, dans quelques régions, au-dessous même du chiffre dẹ l'impôt dont il sont grevés, d'autre part, les résineux qui n'étaient gouère utilisés, il y a quelques années, qu'en chauffage, étais de mine, pâte à papier, et bois de construction, ont vu leur prix s'augmenter dans des proportions sensibles; l'industrie en tire actuellement des emplois multiples et de plus en plus importants...

Parmi les découvertes les plus sensationnelles du sircle dernior, a éte celle de l'électricité et surtout de sess applications.

Qu'est-ce que l'électricité?

Nul ne saurait la définir, même approximativenent, car la nature des choses semble devoir rester toujour's inconnaissable aux hommes dont ia science doit se borner it pnregistrer les rapports de cus choses entre elles.

Par contre, nous en connaissons déja, avee les moyens de production, certains effets, nous avons pu les clomestiquer et les faire servir à nos usages; il est à présumer que d'autres utilisations nous apparaîtront quelque jour, mais d'ores et déjà, pour s'en tenir anx résultats acquis, nous voici obligés de trouver, à bref délai, un moyen pratique autant qu'économique de transporter cette nouvelle force qui s'est imposée anx nécessités di l'existence, à tel point qu'elle semble ètre devenue indispensable.

Dans cet ordre l'idées, "st venu, en premier lieu, le polaau télégraphique ou mât de transmission électrique. Son emploi n'a pas tardé à s'accroitre dans des proportions énormes, en raison d'une consommation tout à fait imprévue.

La télégraphie sans fil n'étant jusqu'à présent appliquéte qu'aux grandes distances, les câbles souterrains, par suite de dérivations, ruptures, difficultés de réparation, de surveillance, de leur cherté de pose et d'entretien, n'ayant guère domné que des inécomptes, en dehor's des villes organisées pour les recevoir, fore demeure, jusqu'au jour d'une solution pratique en ce qui les concerne, de s'en tenir, pour un temps indéterminé, au mât de transmission que l'usage comme l'uxpérience unt amené les consommateurs à prélérer en matière ligneuse.

Or, il faut bien l'avouer, dès aujourd'hui, nous devons envisager la date assez rapprochée où la France ne suffira plus, elle-même, aux besoins toujours croissants des utilisations télégraphiques et électriques. Il convient done de rechercher, sans plus tarder, les moyens pratiques de résoudre le problème dont la solution s'impose à notre attention. 
Déjà et tour à tour, le fer, le ciment armé, ont été utilisés pour, sinon remplacer le bois, du moins venir à son secours.

Examinons rapidement les nécessités qui nous pressent.

Actuellement, on peut calculer que les Postes et Télégraphes, les Chemins de fer, de nombreuses compagnies ou sociétés ont mis en terre, pour leurs besoins, plus de huit millions de poteaux.

D'ici peu, avec le renforcement des lignes existantes, en raison d'un trafic de plus en plus intensif, lorsque toutes les communes de France auront été reliées par fil à leur chef-lieu de canton, lorsque les sociétés électriques auront atteint le développement qu'elles permettent, c'est-àdire d'ici trois ou quatre ans, ce chiffre dépassera dix millions.

La France sera-t-elle en mesure, non seulement de pourvoir aux nécessités présentes et futures, mais encore à l'entretien de ce nombre formidable?

Il est permis d'en douter, si les errements actuels devaient se protlonger.

La durée moyenne des poteaux en bois a été calculée par les Postes et Télégraphes. Cette administration l'évalue environ à treize ou quatorze ans, e'est-à-dire qu'il faut songer à remplacer annuellement sept et demi à huit pour cent des poteaux complantés. Cette moyenne peut paraître élevée, mais il ne faut point oublier que si nos poteaux, préparés au système Boucherie, système qui a fait ses preuves, sont susceptibles, en certains cas et suivant la nature des terrains dans lesquels ils ont été placés, de durer cinquante ans, en d'autres endroits, ils atteignent une bien moindre longévité. Certains de ces terrains sont d'une nocivité telle que les poteaux résistent au maximum de six à douze mois.

Faut-il ajouter que le coefficient de remplacement tendra encore à augmenter, par suite des mises en terre trop hâtives auxquelles l'administration s'est vue contrainte de procéder, faute d'approvisionnements suffisants et des demandes, pour nos nouvelles conquêtes.

Depuis longtemps déjà, l'on a recherché les moyens pratiques de prolonger leur durée. De multiples procédés ou métlodes ont été préconisés successivement; nous allons les examiner aussi brièvement que possible.

D'abord le fer: on a cherché à l'utiliser en barres simples, en barres en T ou double $\mathrm{T}$ et même en $\mathrm{U}$; puis, la fonte creuse et cylindrique. L'expérience a démontré que la résistance et la durée de ces poteaux était inférieure à celle qu'on leur supposait, que leur entretien était fort coûteux et qu'enfin, si l'on tenait compte de leur prix d'achat qui est environ trois fois plus élevé que celui du poteau en bois, de puissance à répondre aux mêmes emplois, ils présentaient d'assez sérieux désavantages.

Le ciment armé est venu, en dernier lieu, et, depuis 5 ou 6 ans, nous le voyons mis en ouvre par des compagnies électriques, pour la transmission de leur énergie. Ce procédé n’a pas encore subi l'épreuve du temps; nous ne pouvons en dire, présentement, qu'un mot : c'est qu'il est d'un prix coûtant au moins 6 ou 7 fois plus élevé que le vulgaire poteau de bois.

D'autres méthodes ont encore été indiquées, mais elles ont reçu jusqu'à présent si peu d'applications qu'il est inutile d'en parler.

Dans ees conditions, et au simple point de vue de l'économie, les poteaux en bois sembleraient donc devoir continuer à jouir de la faveur 
qu'ils possèdent depuis longtemps si, nous le répétons, nous ne nous trouvions à la veille de voir notre pays en manquer.

Il faut bien le dire, l'époque $n^{7} e s t$ plus où la France pouvait espérer compter sur ses forêts pour arriver à satisfaire tous ses besoins.

Sans parler de la consommation de plus en plus importante de la pâte à papier, sans nous appesantir plus qu'il ne convient sur les demandes toujours grandissantes de l'industrie, en général, voici que les houillères ont progressé à leur tour, et l'extraction de la houille s'est accrue depuis quelques années dans des proportions considérables. On a calculé que chaque tonne de houille extraite demandait environ 1 franc de bois, et, aujourd'hui cette extraction dépasse en France 38 millions de tonnes annuellement.

La recherche des bois de mine est devenue des plus actives tant en France qu'à l'étranger', qui vient même s'approvisionner en partie chez nous, et les propriétaires ont d'autant mieux accueilli les offres qu'elles répondaient à un désir de réalisation plus rapide, d'un revenu destiné, dans les résineux, à être perçu à longue échéance.

Point n'est besoin, en effet, d'attendre 50 ou 60 ans pour jouir de ces plantations; dès l'âge de 20 à 25 ans, les résineux sont déjà susceptibles de fournir des bois de mine; aussi, beaucoup de propriétaires se sont-ils enıpressés d'exploiter, mangeant leur blé en herbe, s'il nous est permis If nous expliquer de la sorte.

Le niveau de la production s'est donc trouvé ainsi notablement abaissé.

Certes, les forêts domaniales et communales contiennent encore des réserves abondantes, mais il faudrait, pour que la consommation puisse en profiter, créer une organisation nouvelle, et que les ministères intéressés, arrivant à ne plus se considérer comme des frères ennemis, se donnent mutuellement la main, en vue de l'intérêt général.

Enfin, il convient de concentrer nos efforts dans la recherche et l'utilisation des meilleurs procédés destinés à prolonger la durée des poteaux en bois.

De nombreuses méthodes d'asepsie et de préservation ont été indiquées et nous avons relevé, à l'Office des brevets, près de trois cents inventions tendant à ce but.

Un certain nombre d'entre elles ont été éprouvées; d'autres, hélas ! n'ont jamais vu le jour. Peut-être étaient-elles excellentes, c'est avec un regret, la seule consolation que l'on puisse donner en passant aux inventeurs malheureux dont la formule a constitué l'idéal qu'ils n'ont jamais pu réaliser.

Pour nous en tenir aux réalités présentes, disons que quatre procédés ont eu, jusqu'ici, la faveur des différentes administrations et du publie.

10 Le procédé du docteur Boucherie, dont nous avons dit un mot plus haut. Ce procédé utilisé depuis bientôt 60 ans, et qqui consiste à injecter des arbres frais avec une dissolution de sulfate de cuivre à $1 \%$, a donné les meilleurs résultats, à condition de laisser les poteaux s'assimiler le sulfate, avant de les employer, ce qui demande une année.

La France utilise presque exclusivement ce procédé, la Belgique ef la Suisse quelque peu. L'injection du sulfate de cuivre, en cylindre clos, par vide et pression, pour poteaux secs, a pris quelque importance ces temps derniers et permet d'utiliser des bois importés de Russie, Suède et Norwège; toutefois, les brins ainsi préparés ne doivent pas non plus être mis en œuvre avant 10 ou 12 mois, après la date de leur prépara- 
tion. L'inconvénient de ces méthodes est de nécessiter' l'assez gros approvisionnements.

$2^{\circ}$ Le procédé Kyan, qui consiste à tremper le poteau sec dans une dissolution de bichlorure de mercure : on l'utilise en Suisse, en Allemagne et en ltalie.

Nous n'en parlerons pas, afin de ne pas en dire du mal.

$3^{\circ}$ Le réosotage, d'après le procédé Rupping, que l'on emploie dans toute l'Europe, à l'exception de la France.

C'est un excellent procédé, probablement même le meilleur connu, mais il a l'inconvénient de présenter les poteaux sous un aspect inesthétique et funéraire, il les rend d'un maniement désagréable aux ouvriers dont il brûle la peau et salit les vêtements, de sorte qu'il jouit d'une mauvaise presse près de ces derniers; et ne doit-on pas aujourd'hui compter sérieusement avec la main d'ocuvre, surtout en France?

$4^{\circ}$ Signalons aussi, parmi les essais faits, ces dernières années, par les Postes et Télégraphes, l'emploi d'un nouveau produit connu sous le nom d'injectol.

Nous avons sous les yeux le rapport de M. Massin, Ingénieur en chef des P. T. T., à la Conférence internationale des techniciens des Administrations des télégraphes et téléphones de l'Europe, ce rapport est des phus concluants, relativement à la valeur de ce produit nouveau

D’après sos données, sur l'ensemble des poteaux traités à l'injectol et mis à l'épreuve, il ressort mathématiquement que la prolongation de leur durée est au moins 6 ou 7 fois plus grande que colle de tous les témons plantés au même moment dans des terrains septiques et mycélés les plus dévorants.

$5^{\circ}$ Il convient, en dernier lieu, de noter l'introduction sur le marclié de certaines essences coloniales : palétuvier, quebraclıo et autres, signalées comme imputrescibles dans leur pays d'origine.

Que conclure de tout ce qui précède?

La nécessité impérieuse d'augmenter notre production comme notre réserve, de rechercher les meilleurs moyens de préservation contre la pourriture et d'en conseiller l'utilisation, enfin de tourner nos regards vers les régions productrices eneore inexploitées.

Peut être n'y a-t-il dans toutes ces considérations que des palliatifs insuffisants, mais s'il est difficile de guérir entièrement et rapidement certains malades le devoir est du moins de les prolonger, cette prolongation pouvant parfois permettre d'entrevoir la guérison. Peut-être le progrès dont nous avons parlé au début de ce rapport nous apportera-t-il le remède au mal qu'il a causé?

En tout cas, il convient de suivre attentivement sa marche et de profiter des enseignements qu'il nous apporte tous les jours.

Travaillons et luttons : "Labor improbus omnia vincit " (Un travail acharné vient à bout de toutes les difficultés).

Que ce vieil adage reste notre devise ; conservons-la fidèlement et sachons la mettre en pratique sans faiblesse ni défaillance : elle maintiendra nos énergies en nous empêchant de désespérer jamais de la réussite et de l'avenir.

C'est d'ailleurs pour nous, Français, un devoir impérieux, car ne l'oublions pas, en cetle ouvre comme en beaucoup d'autres, il s'agit non senlement du bien de notre pays, mais encore de l'intérêt général de 
la civilisation à la tête de laquelle la France doit toujours tenir à honneur d'être placée.

\section{Le Congrès Émet le veu :}

I. Que les terrains incultes les plus susceptibles de reboisement soient plantés en résineux, avec exonération d'impôts pour les propriétaires, au-delà même des 30 ans préous par la loi, à charge d'observer certains règlements d'aménagement, adéquats aux plantations, rédigés par l'État, en vue d'ainener ces plantations à 50 ou 60 ans d'âge.

II. Que, dans les coupes de forêts communales ou domaniales, les pins susceptibles de faire des poteaux télégraphiques soient marqués en réserve par les agents de l'État, soit pour faire l'objet d'une réadjudication aux fabriques de poteanx télégraphiques, soit pour ĉtre traités par l'État ou la commune en vue de leur emploi direct.

III. Que des produits antiseptiques ayant fait leurs preuves, dans le genre de l'injectol, soient utilisés à l'effet d'angmenter le coefficient. de résistance et de durée des bois soumis à leur traitement.

IV. Qu'une impulsion vigoureuse et pratique à tous égards soit donnée à l'importation de nos essences coloniales qui peuvent, en maticire de poteanx télégraphiques comme en bien d'autres, parer au déficit menaçant de la production nationale.

M. Le Présinent. - Quelqu'un demande-t-il la parole sur le paragraphe premier?

M. H. Barbier. - Je propose d'adresser nos lélicitalions au rapporteur, sous le bénéfice de la précision suivante : qu'entendez-vous par : "Observation de certains règlements d'aménagement, adéquats anx plantations, rédigés par l'État»?

M. Pelletier de Martres. - Vous demandez une modification à la loi qui exonère d'impôt pendant trente ans les plantations de résineux, vous devez bien d'un autre còté donner quelque chose à l'État. L'État lui-même vous demandera certaines choses, vous posera des conditions, re sont des conditions à discuter avec l'État lui-même.

M. H. BArbier. - Dans ces conditions, je propose à l'assemblée l'arloption de la première partie clu vœu, sans indiquer à l'État ce qu'il a à faire comme corrélation entre le dégrèvement et les charges à apporter à la propriété; nous n'avous rien à lui indiquer au point de vue de la rédaction de ses règlements d’aménagement.

M. Pelletier ne Martres. - Je n'y vois aucun inconvénient.

M. Le Prísinent. - Nors, vous retirez à la rédartion du vou les mots: "A charge dobserver certains règlements d'aménagement, adéquats unx plantutions, rédigés par l'Etat, en rue d'amener ces plantations à 50 on (i) uns di tist n? 
M. Pelletier de Martres. - Je me range à la proposition de M. Barbier.

11. Le Préstexte - Mors, le vou serait ainsi rédigé :

"Que les terrains incultes les plus susceptibles de reboisement soient plantés en résineux, avec exonérution d'impôts pour les propriétuires, an delì même des 30 ans présus par la loi. .)

1I. Gustave Artes. - Pourquoi ne pas mettre que "tous les terrains incultes susceptibles de reboisement soient pluntés "Pourquoi "en résineux $n$ ?

M. Pelletier de Martres. - D’abord, il s'agit de poteaux télégraphiques.

M. Gustave Artus. - J'ai un terrain inculte qui est susceptible d'être planté en autre chose qu'en résinenx, exemptez-moi d'impôts. Le résinenx va être un privilège.

M. Le Président. - C'est un peu exact.

11. Gustave Artis. - J'ai un marécage que je ne plante pas : je trouve que les impôts sont trop élevés; lonnez-moi l'autorisation de le planter en autre chose qu'en résineux. Vous voulez protéger les terrains incultes, eh bien! protégez-les pour toutes les plantations.

M. Pelletien de Martres. - J'une façon générale, les terrains incultes sont plus susceptibles d'ètre plantís d'abord en essences résineuses qu'en n’importe quelle autre essence. Prenez les dunes de l'Océan, prenez les inontagnes, c'est partout du résineux qui est planté. Il y a évidemment des exceptions à rette règle, mais je n'ai traité que la question des poteaux télégraphiques, ils sont généralement en résineux; je ne me snis oceupé que de cette question, je n`ai pas envisagé les questions à còté.

M. H. Bırbier. - Lobservation de M. Artus est très fondée, mais je crois que le rapporteur a surtout envisagé les terrains absolument. pauvres et qu'il n’a pas pensé aux terrains à peupliers, qui sont susceptibles de domer de gros revenus à rendement rapide.

Je crois anssi quion peut très bien domner satisfaction à M. Artus, at je ne perise pas que M. Pelletier de Martres s'y oppose.

M. Gustave Artus. - Ciest pour faciliter le reboisement.

M. Le Présinext. - Nous allons alors voter définitivement sur la rídaction suivante :

"Le. Congrès émet le v'ru que les terrains incultes les ptus susceptibles 
de reboisement soient plantés, arec exonération d'impôts pour les propriétaires au-delì même des 30 ans prévus par la loi $n$.

Adopté.

Nous passons à la seconde partie du voen, qui est ainsi conçne:

"Que dans les coupes de forêts communales ou domaniales. les pins susceptibles de faire des poteaux télégraphiques soient marqués en réserve par les agents de l'État, soit pour faire l'objet d'une réadjudication aux fabriques de poteanx télégraphiques, soit pour être traité par l'État ou la commnne en sue de leur emploi direet."

M. Brion. - Je crois qu'il est inutile de faire entrer l'Administration dans l'exploitation forestière, et je ne partage pas l'idre de M. Polletier de Martres, parce que je trouve que clire à l'Administration de venir marquer les poteaux télégraphiques en rue d'en faire plus tard nne réadjudication, c'est paralyser les commerces locaux. Je pense? qu’il ne faudrait pas mettre cet alinéa, qu'il faudrait laisser les adjudications se faire comme elles se font, et ne pas faire entrer du tont l'État dans l'exploitation. Je demande tout simplenent que les adjudications et les exploitations contiunent à se faire comme elles se font.

M. Le Présidext. - Alor's, vous demandez la suppression de cette partie dı vœu?

M. Brion. - Parfaitement.

M. Pelletier de Martres. - La question nest point nenve en matière de réserve par l'État : autrefois l'État ayant besoin de bois pour sa marine, avait le soin de passer dans chaque coupe en délivrance et de faire ses réserves. Il est très juste que l'État ayant besoin de bois, commence par se servir lui-même. Or, à cette cpoque-là, personne ne faisait d'objection sous prétexte que cela pouvait nuire à l'adjudication des coupes, les bois se vendaient très bien, et je suis persuadé qu'ils se vendraient pareillement malgré la réserve que l'État pourrait faire.

Permettez-moi de prendre quelques comparaisons. Il y a des chantiers d'injection aux alentours des grandes forêts de l'État, plantées en résineux. La forêt de Lorris, par exemple, délivre au commeree des bois annuellement 200.000 pieds de pin; ces 200.000 pieds de pin, qu'il m'est arrivé personnellement d'expertiser, auraient ité susceptibles de fournir une moyenne oscillant entre 30 et 50.000 poteaux télégraphiques. Un chantier de préparation se trouve en plein centre forestier, à Lorris. Eh bien! les industriels qui l'exploitent ont le plus grand mal à obtenir de 4 à 5.000 poteaux télégraphiques annuellement.

Fontainebleau se trouve dans les mêmes conditions. A Fontainebleaı, on pourrait trouver annuellement dans les forèts de l'État, 25, $30 \mathrm{et}$, 
certaine- annérs, jusqu’à 40.000 poteaux. Le chantier de Fontainebleau - car il y en a un également - en produit à peine 6 à 7.000 .

Si je rentre dans la région fortunée de 11 . Brion, je me trouve en fare de la forêt de Rouen, oủ annuellement - je l'ai visitée moimême, je suis done bien sûr de ce que je dis - on pourrait également faire de 30 à 40.000 poteaux télégraphiques. Le chantier dé Sotteville - car il y en a toujours un à proximité d'une forêt - en donne 8, 10, quelquefois 12.000 .

Pourquoi tout cela? Je ne sais. Messieurs, si rous avez pris connaissance de mon rapport, mais il y est dit dans un coin que l'ennemi des poteaux télégraphiques, rest le marchand de bois de mines. Le marchand de bois de mines ne tient pas à rendre les poteaux télégraphiques que le hasard de l'arljudication met en sa possession. Pourquoi? Parce qu'il prétend que le poteau télégraphique étant le plus beau de ses bois, on prive son lot d'une valeur marchande, en lui prenant des bois dont les mines sont extrêmement friandes.

Je ne vois donc pas d'autre moyen de parer au grand déficit des poteaux télégraphiques, déficit qui s'accentuera de plus pour des raisons que je pourrais vous donner, que d'arriver à cette méthode, c'est-à-dire que l'État marque chaque année les bois, comme autrefois les chênes de la marine, pour les mettre en réserve, quitte, je le répète, à faire une réadjudication après. J'ai fait à ce sujet un petit calcul qui, bien entendu, ne peut être que très vagne, mais je crois néanmoins que l'État retirera de la sorte tant dans le Centre que dans l'Est, l'Ouest et le Midi, au moins 3 ou 400.000 poteaux télégraphriques. S'il ne fait pas cela, je me demande comment il arrivera à satisfaire ses besoins. Je ne crois pas, d'autre part, que cette réserve gêne beaucoup les adjudications; on achètera la coupe grevée de ces réserves pour ce quelle vaudra; les marchands de bois, qui sont tous de hons spéculateurs, évidemment ne les estimeront pas du tout, ce qui sera beaucoup plus simple, et les coupes seront payées le prix qu'elles valent. Je rois, en un mot, que tout le monde recevra satisfaction et que cela ne portera préjudice à personne.

M. H. Barbier. - Je regrette d'être en résaccord absolu avec l'lionorable M. Pelletier de Martres. Il n'y a aucune assimilation à faire entre lexemple qu'il a pris de l'ancien bois de marine et les poteaux télégraphiques. Je suis extrêmement surpris de lui pntendre dire que le commerce des bois préfère laisser en hois de mines 60 ou $80 \%$ des poteaux télégraphiques...

11. Pelletier ne Martres. - C"est exact, cependant.

M. H. Barb1er. - Alors, rous jetez sur lo commerre dos bois un discrédit qui revient à dire reri : le commercer abandonne ce qui raut cher. pour faire desa matière première un produit avili : car. cumparativement au prix du poteau télegraphique, le poteau de mines n'est rraiment

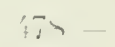


qưun résidu - jemploie le terme en le forçant, mais cest cela. Les adjudications qui viennent d'avoir lieu hier et avant-hier, et dont personne mieux que II. Pelletier n'est informé, en sont la démonstration la plus íclatante; le prix des poteaux télégraphiques s'est affirmé en laausse. A qui dira-t-on que le marchand de bois, serré de très près par son estimation et ses frais généraux, va laisser, dans l'aubier ou dans le bois de mines, du bois destiné à faire du feuillet?

1 aucun prix il ne faut demander que l'État vienne mettre sa mainmise, par l'exploitation directe, sur nos forêts; à aucun prix il ne faut faire un compartiment de faveur à nos amis les fabricants de poteaux tilégraphiques, en retirant de la forèt cette crême bien blanche pour la leur apporter dans une baratte bien fraiche. Voila pourquoi je moppose de tontes mes fores à l'arloption lu vocu.

M. Briox. - Dans notre région, tous les poteaux qui sont rlans les roupes partent en poteaux télégraphiques. Dans la région de Rouen, depuis einq ans, il $n^{\circ} \mathrm{y}$ a pas un poteau qui soit allé dans les mines. Du moment oì on a bien payí les poteaux tílógraphiques, tont le monde en a fait.

M. Le Présinent. - L'esprit qui a guidé M. Pelletier de Nartres, c’est certainement la préoccupation de roir, dans un temps déterminé. le poteau tálégraphique devenir trop rare.

M. Pral. - Nos colonies françaises sont très riches en poteaux télégraphiques, malleureusement l'État fait preuve, à cet égard, d'une incurie extraordinaire. Nous avons offert à l'Etat de lui faire cadeau gratuitement de poteaux en palétuvier pour faire des essais, il n’a pas mème vonlu les essayer. 11 faut donc croire qu'il a suffisamment de poteaux en France. Dans la région de Konakry, il y a du bois pour des centaines et des milliers l'annéps : au fur à mesure qu'on les rase, les bois repoussent. J'ai ité dépositaire d'une maison qui a offert à l'État de lui donner des poteaux en palétuvier pour faire des essais, il a refusé.

II. Madelin. - On ne rous a pas donné de motif?

M. Pelletier ne Mirtares. - II y a un motif qui a été donné; le palituvier a un très gros inconvénient : lorsqu'il est troué, il se fend, et on le trone pour mettre les supports des fils. Mais, cest un inconvénient aucpel on peut remidier.

11. Le Présidext. - Si vous ronlez, Messieurs, nous allons revenir à notre roen; quelqu'un demande-t-il uncore la parole?

M. Pelletier he Martres. - M. Brion dit que apuis quatre ou cinq ans à Rouen, tous les hois sunceptibles d'ètre transformés en poteanx toligraphiques se vendent aisinent. Jo ne reux pas insister. Malheu- 
reusement, ailleurs il n'en est point ainsi ; jai également la conviction que si on n’agit pas de la. façon que j’indique on ne trouvera bientòt plus de poteaux telégraphiques en quantité suffisante.

Sur l'intervention de .1. H. Barbier. M. Pelletier de Martres consent à retirer son rou car, dit-il, ce rou était surtout une indication pour les pouvoirs publics et ils en ont déjà été saisis.

1I. le Présidext. - La troisième partie du rou est ainsi rédigée :

Que des produits antiseptiques, ayant fait leurs preuces, dans le genre de l'injectol, soient utilisés à l'effet d'angmenter le coefficient de résistance et de durée des bois'soumis à leur traitement".

Ce paragraphe est adopté arec, sur intervention de .II. Duchemin, suppression des mots "dans le genre de l'injectol".

II. Le Présidext. - Nous passons au paragraphe 4:

Qu' une impulsion vigonrense et pratique à tous égards soit donnée al l'importation de nos essences coloniales qui penvent, en matière de poteaux télégraphiques comme en bien d'antres, purer au déficit menaçant de la production nationale ».

11. RAL. - Nous achetons en Allemagne des poteaux télégraphiques qui roútent très cher et qui viennent dela Forêt Noire, alors que nous arons lans nos colonies des auantités de bois formidables qui feraient très bien et qu'on laisse sur place.

11. Pelletier de Mirtres. - Je puis rous dire que mon rapport a été fait un peu en collaboration avec certaine personnalité du Gourernement. Je peux même ajouter que la question du palétuvier a été itudiée et qu'on va lui donner une solution favorable.

Il est certain que toute la còte occidentale d'Afrique, depuis la Guinée jusqu'au bout du Congo, est peuplée d’admirables paléturiers en quantité considérable, et que, dans cette quantité-là on trouvera ine réserve de potraux télégraphiques très súre.

Le paragraphe 4 du vóeu est adopté.

11. he Présidext. - Nous arrivons à la discussion du rapport de 11. Georges Rotival sur les Bors Équaris, poltres, charpextes, TR.AVERSES.

11. Georges Rotival. - En France les essences de bois qui subissent la façon de l'équarissage sont en général celles de chêne, de châtaignier et de sapin.

On peut les diviser en deux catégories, savoir :

$1^{0}$ Bois équarris à la hache.

$2^{\circ}$ Bois équarris à la scie.

Les produits de chacune de ces deux catégories ayant des destinations particulières et faisant l'objet de branches différentes du commerce 
des bois, nous les étudierons successivement et avec le plus de brièveté possible, les termes de ce rapport devant être nécessairement limités à des considérations générales.

De temps immémorial dans nos forêts et particulièrement dans celles liois iquarris : situées dans le bassin de la Seine et de ses affluents et sous-affluents, parmi lesquels nous citerons la Marne, l'Aisne, l'Yonne, l'Aube, le Morin, etc., etc., on a équarri sur place, dans les coupes, les chênes et quelques rares châtaigniers destinés à la charpente et à la construction.

Ce procédé avait plusieurs a vantages :

D'abord il débarrassait les arbres de leur écorce et d'une bonne partie de leur aubier, en conséquence d'un poids mort qui constituait des parties inutilisables, ensuite les pièces une fois équarries étaient d'une manutention beaucoup plus facile, principalement en ce qui concerne le transport à travers les forêts sur des chemins souvent peu praticables et aussi en ce qui conceme l'arrimage dans les chargements et sur les chantiers.

En outre, bon nombre d'entre elles, à une époque déjà lointaine de nous, devant être expédiées à de longues distances au moyen du flottage, leur formation en radeaux était grandement facilitée par cette premièrc façon.

Enfin, dans ce travail de l'équarrissage, la cognée de l'ouvrier suivait les courbes de l'arbre; de sorte que les fibres du bois n'étaient pas sectionnées et conservaient ainsi toute leur élasticité, par suite toute leur force de résistance.

Ce genre de marchandise était ct est encore employé presque uniquement par les entrepreneurs de charpente et de travaux publics, qui les font entrer dans leurs constructions et travaux, soit à l'état brut lorsqu'il s'agit de pièces de faibles dimensions destinées notamment à l'édification des hangars, planchers, pans de bois, etc., soit à l'état de pièces débitées à des mesures spéciales on en marches d'escalier lorsqu'il s'agit de pièces de fortes dimensions.

A notre époque, la plupart des chênes sont enlevés des coupes à l'état de grumes et prennent directement le chemin des nombreuses scieries répandues un peu sur tous les points de notre territoire; d'un autre côté, l'emploi du fer remplace de plus en plus dans les constructions celui du bois ; il est résulté de ces faits que le commerce des bois de charpente en chêne équarri proprement dit a tout à fait déchu de la splendeur qu'il a connue sous les générations qui nous ont précédés.

Il ne se fait plus aujourd'hui pour ce genre de marchandises qu'un faible mouvement d'affaires et en parler n'a plus qu'un intérêt pour ainsi dire rétrospectif. Nous nous bornerons donc à leur sujet à ces courtes explications.

Les observations qui viennent d'être faites pour la charpente de chêne équarrie à la hache s'appliquent éga lement à la charpente desa pin équa rrie suivant le même procédé.

$\mathrm{Si}$, pendant des siècles, on a vu circuler sur nos rivières et sur nos canaux en même tcmps que ces longs trains composés de coupons de bois de chêne, des radeaux dits "éclusées de sapins " provenant principalement des régions du Jura, il ne restera plus bientôt que le souvenir de ce spectacle.

Comme les chênes, les sapins aussitôt abattus, prennent le chemin des 
scieries où les outils mécaniques se chargent de les débiter ou de les équarrir.

Nous ne royons done plus arriver qu'en petite quantité ces magnifiques pièces de longueurs et de dimensions prodigieuses qui ne sont plus maintenant employées que pour servir au débit de pièces de dimensions extraordinaires ou dans des travaux tout à fait spéciaux.

Il se fait cependant encore actuellement une assez grande consommation de poutres de sapin équarries à la hache pour l'établissement des monte-charge servant à l'élévation des matériaux entrant dans la construction des bâtiments. Pour cet emploi, il est nécessaire de disposer de très longues pièces ayant conservé toute leur force de résistance et toute leur élasticité, qualité que, pour des motifs exposés plus haut, leur laisse l'équarrissage à la hache.

On se sert aussi, dans l'industrie du bâtiment, d'une assez grande quantité de sapins de petites dimensions également équarris à la hache . et qui sont vendus dans le commerce sous le nom de poutrelles.

Bois équarris it la scie.

Poutres et charpentes. - Les bois équarris à la scie sont en grande partie destinés à la constrúction; ils comprennent :

$1^{0}$ Les pièces en chêne et en sapin sciées sur commande à des dimensions déterminées.

$2^{\circ}$ Les poutres en sapin désignées dans le commerce sous le nom de quatre faces et provenant d'arbres simplement équarris sur les quatre côtés et conservant les dimensions maximum que comporte la grosseur de l'arbre.

Ainsi qu'il a été dit plus haut, de nombreuses scieries sont réparties sur tous les points de notre territoire et plus particulièrement dans les régions forestières.

Ces usines débitent de préférence les arbres provenant des forêts situées dans leur région. Aussi les produits forestiers à l'état brut sont-ils de moins en moins expédiés vers les centres de consommation; ils sont la plupart du temps transportés dans les scieries du voisinage où ils sont façonnés à la demande de la clientèle ou débités suivant les échantillons en usage dans le commerce.

Grâce à cet état de choses, les consommateurs ont la commodité de s'approvisionner de bois aux dimensions qui leur sont nécessaires et d'éviter ainsi les inconvénients qu'il y aurait pour eux à acheter des bois en grumes qu'ils devraient ensuite faire scier à leurs besoins, courant ainsi les risques des vices cachés, des erreurs de débits, des manutentions répétées, etc.

Ainsi, en raison du développement considérable de l'industrie du bâtiment et des travaux publics entrepris un peu partout, le commerce des bois de charpente équarris à la scie donne lieu actuellement à des affaires considérables.

Les pièces toutes préparées arrivent directement sur les lieux de consommation où il n'y a plus qu'à les assembler.

Ce mode de procéder est devenu général et il est inutile d'insister sur les avantages qu'en retirent les industriels.

Quant aux poutres dites "quatre faces », l'emploi de ce genre de marchandise se répand de plus en plus.

C'est surtout dans les Vosges et dans le Jura que le commerce de bo is s'approvisionne de ces poutres. Les importations de Bosnie qui avaient 
pris une certaine importance se font de plus en plus rares actuellement, en raison du prix élevé qui est demandé.

Ces pièces, dont nos chantiers français possèdent toujours des stocks importants, sont vendues telles qu'elles sont expédiées des lieux de production aux consommateurs qui les font débiter ensuite à leurs dimensions ou les emploient suivant leurs besoins.

Nous ne parlerons que pour mémoire des nombreuses pièces de bois de chêne, sapin ou autres essences, qui sont équarries et façonnées sur place, sur tous les points du territoire, pour les besoins locaux.

Traverses. - Il nous reste à parler maintenant des traverses.

Comme chacun le sait, cette sorte de marchandise est uniquement employée pour la construction des voies ferrées.

II suffit de considérer le développement extraordinaire des chemins de fer depuis un certain nombre d'années pour se rendre compte de l'énormité de la quantité de traverses qui a été absorbée pour fournir à la consommation de nos grandes compagnies de chemins de fer. 11 convient aussi d'observer que ces pièces de bois noyées dans le ballast et exposées à toutes les intempéries n'ont qu'une durée relativement courte. Celles en bois de chêne peurent durer de 14 à 15 ans. Tant donc pour le remplacement. de celles usées que pour l'établissement de voies nourelles il y a à faire chaque année des fournitures qui représentent un très gros chiffre d'affaires.

Trois essences de bois servent à la confection des traverses de chemins de fer : ce sont les essences de chêne, de hêtre et de sapin, plus spécialement de pin des Landes.

Le chêne seul peut être employé à l'état de nature; le hêtre et le pin doivent être injectés; sans cette précaution, en raison de leur disposition à pourrir rapidement, ils ne pourraient résister que peu de temps à l'humidité du sol. Grâce à cette préparation, les traverses en hêtre peuvent résister pendant plus de 20 ans.

Bien que la consommation des traverses soit naturellement irrégulière, on peut fixer cependant approximativement le nombre de celles employées annuellement par nos cinq grandes compagnies d̀ 1.500 .000 pour le chêne, à 2.000 .000 pour le hêtre et à 500.000 pour le pin.

Il faudrait ajouter à ces chiffres ceux représentant le nombre des traverses destinées à la construction des voies étroites et des tramways ; mais il serait difficile d'indiquer ces chiffres, même approximativement, les travaux exécutés pour ces voies de communication variant d'année en année, dans des proportions extrêmement importantes.

Nous n'entrerons pas dans l'indication, ni dans le détail des prix et des dimensions de ces diverses sortes de traverses, cela nous entraînerait dans des développements qui dépasseraient les limites de cette brève étude.

Les marchés de fournitures de traverses à nos grandes Compagnies de chemins de fer, marchés qui sont en général. très importants, ont été pour ainsi dire monopolisés par quelques grosses maisons qui les achètent aux exploitants et les livrent ensuite aux compagnies.

Nos forêts de France peuvent en fournir en abondance et suffiraient ̀̀ alimenter la consommation.

Il nous en est cependant expédié une certaine quantité de l'étranger ; en revanche, nous en exportons quelques centaines de mille en Belgique.

On débite les traverses, soit dans les cimes des gros arbres, soit, et pour la plus grande partie, dans les arbres de faibles dimensions. 
Nos bois ont perdu en partie leur parure de gros arbres et les géants qu'on y rencontrait autrefois deviennent de plus en plus rares; mais ils sont encore peuplés d'une multitude de jeunes arbres propres à la fabrication des traverses dont la source n'est pas, en conséquence, près de se tarir.

En terminant, signalons à simple titre documentaire qu'une concurrence se dresse déjà aux traverses en bois ; nous voulons parler des traverses en béton armé, dont un certain nombre sont actuellement en essai sur divers points.

Nous ignorons quelsera le résultat obtenu; mais au cas où ces traverses devraient se substituer à leurs rivales, nous ne devrions pas nous en plaindre si cela devait contribuer à diminuer la consommation du bois et a arrêter, d'ailleurs dans une faible mesure seulement, le dépeuplement de nos forêts.

C'est par ce souhait que nous terminérons l'étude de notre sujet.

11. Le Présidext. - Le rapport de M. Georges Rotival ne se termine pas par un veeu. Nous lui avions demandé d'en rédiger un, mais il était très malade et s'est contenté de faire mn historique de la question.

Je ne puis dans ces conditions mettre aux voix. Nous considérerons ce travail comme une simple communication faite à la Section et nous passons à l'ordre du jour qui appelle la discussion du rapport de 11. Paul Coulet sur les Sibvextioxs inurstrielles.

M. Paul Covlet. - Parmi les charges qui incombent aux exploitants de forêts - qu'ils soient à la fois propriétaires et exploitants, ou qu'ils soient simplement acheteurs des coupes - il faut signaler les subventions spéciales pour dégradations extraordinaires des chemins vicinaux, plus simplement et habituellement nommées subventions industrielles.

Ces subventions industrielles apportent une entrave considérable à l'exploitation forestière et, si paradoxal que cela paraisse de prime abord, contribuent à rendre plus difficile le développement forestier en France que nombre d'associations et en premier lieu le Touring-Club de France, s'efforcent de favoriser; en effet, par la gêne que lui causent les subventions industrielles, le propriétaire de forêts n'est qu'incité davantage à se défaire de ses bois et, en tous cas, ne songe pas à repeupler en arbres d'autres terrains. Il apparait donc de prime abord que la suppression des subventions industrielles réclamées aux propriétaires ou aux exploitants de forêts serait une gêne de moins au développement forestier de notre pays.

C'est dans cet esprit qu'est conçu le présent rapport, qui tend à exposer les inconvénients des subventions industrielles et la nécessité de leuı abolition en matière forestière.

Une étude complète de la question dépasserait de beaucoup le cadre de ce travail; nous exposerons donc sommairement ce que sont les subventions industrielles, nous dirons quels abus elles entraînent, et nous formulerons une proposition de loi tendant à leur suppression en ce qui concerne les exploitations forestières.

Les textes en vertu desquels les subventions industrielles peuvent être réclamées sont les suivants : 
"Art. 14. - loutes les fois qu'un chemin entretenu à l'état de viabi- Loi "u g] mai " lité par une commune sera habituellement ou temporairement dégradé " par des exploitations de mines, de carrières, de forêts ou de toute entre" prise industrielle appartenant à des particuliers, à des établissements " publics, à la Couronne ou à l'État, il pourra y avoir lieu à imposer aux " entrepreneurs ou propriétaires, suivant que l'exploitation ou les trans" ports auront lieu pour les uns ou pour les autres, des subventions " spéciales, dont la quotité sera proportionnée à la dégradation extra" ordinaire qui devra être attribuée aux exploitations; ces subventions " pourront, au choix des subventionnaires, être acquittées en argent ou " en prestations en nature, et seront exclusivement affectées à ceux des " chemins qui y auront donné lieu.

"Elles seront réglées annuellement, sur la demande des communes, par " le Conseil de Préfecture, après des expertises contradictoires, et recou" vrées comme en matière de contributions directes.

"ARt. 17.

"Si l'indemnité ne peut être fixée à l'amiable elle sera réglée par le

“ Conseil de Préfecture, sur le rapport d'experts nommés, l'un par le " sous-préfet, l'autre par le propriétaire.

"En cas de désaccord, le tiers expert sera nommé par le Conseil " de Préfecture. "

"Art. 11. - Toutes les fois qu'un chemin rural reconnu, entretenu " à l'état de viabilité, sera habituellement ou temporairement dégradé " par des exploitations de mines, de carrières, de forêts ou de toute autre " entreprise industrielle appartenant à des particuliers, à des établisse" ments publics ou à l' ítat, il pourra y avoir lieu à imposer aux entrepre" neurs ou propriétaires, suivant que l'exploitation ou les transports " auront lieu pour les uns ou pour les autres, des subventions spéciales " dont la quotité sera proportionnée à la dégradation extraordinaire qui " devra être attribuée aux exploitations... "

"Art. 35. - Les adjudicataires des coupes des bois de l'Étal sont " tenus de payer aux communes les subventions spéciales auxquelles " celles-ci ont droit, en exécution de l'article 14 de la loi du 21 mai 1836 " et de l'article 11 de la loi du 20 août 1881, pour dégradations extraordi" naires causées aux chemins vicinaux et chemins ruraux classés, par le "transport des produits desdites coupes..." "

On voit de suite que la principale critique que l'on puisse formuler contre ces textes est que le législateur assimile à tort les exploitations forestières, travail essentiellement agricole, à des exploitations de mines ou de carrières, qui ont un caractère totalement différent puisqu'industriel.

Ce point, sur lequel nous reviendrons d'ailleurs à la fin de notre travail, est capital : il constitue en effet le meilleur argument dont les forestiers puissent se servir pour obtenir la suppression d'une taxe qui leur est si particulièrement préjudiciable. Tout d'abord, qui donc supporte les

Loi din 20 nô̂t 1.ivi.

fahier des rbarges des verilloy de rompes de v'lit. 
subventions? Tous, pourrait-on dire, car la loi s'applique indistinctement à l'exploitant de forêts et au propriétaire : l'un ou l'autre, en effet, en sont frappés. "Suivant, dit l'article 11 de la loi du 20 août 1881, que l'exploitation ou les transports auront lieu pour les uns ou pour les autres ». L'indemnité doit ainsi être réclamée à celui qui est l'auteur du dommage ou pour le compte duquel il se produit, que ce soit ou non le propriétaire de la forêt.

En second lieu, trois conditions sont indispensables pour que des bois transportés donnent lieu à réclamation de subventions industrielles, il faut en effet :

10 Que les transports par chariots aient eu lieu sur un chemin classe comme chemin vicinal;

$2^{\circ}$ Que ce chemin vicinal soit entretenu en bon état de viabilité ;

$3^{\circ}$ Que ce chemin vicinal ait été dégradé d'une façon extraordinaire par le transport des bois.

De ces conditions découle nécessairement cette idée que les subventions industrielles doivent être considérées comme étant la réparation d'un préjudice causé par une fante, c'est-à-dire par l'usure excessive, anormale, extraordinaire, résultant des transports de bois effectués dans des conditions spéciales. Mais nous verrons que cette conception logique n'est pas celle à laquelle s'est rangée l'Administration vicinale quant à l'établissement du préjudice qu'elle doit prouver avoir subi.

Enfin les bases du quantum des subventions industrielles sont déterminées en tenant compte des divers éléments suivants :

10 Tonnage des transports ;

$2^{\mathrm{a}}$ Distances parcourues ;

$3^{0}$ Etat des chemins avant et après les transports̊ ;

$4^{\circ}$ Dépenses faites ou à faire pour remise en état de viabilité;

$5^{\circ}$ Nature des véhicules employés ;

$6^{\circ}$ Circulation générale ;

7o Saisons pendant lesquelles ont eu lieu les transports;

$8^{\circ}$ Quantités de bois transportés.

Nous allons reprendre chacun de ces éléments et indiquer de quelle façon l'Administration procède pour la fixation des subventions industrielles.

10 Tonnage des transports. - Le tonnage des transports est établi par l'Administration d'après les pointages des cantonniers, mais leurs relevés sont bien souvent inexacts et il est très difficile au marchand de bois de faire rectifier leurs erreurs.

$2^{\circ}$ Distances parcourues. - C'est le seul élément sur lequel il ne puisse se produire d'erreurs.

30 Etat des chemins avant et après les transports. - Sur ce point l'Admi. nistration part du principe que des chemins sont présumés entretenus en bon état de viabilité, parce que chaque année elle publie un tableau indiquant les chemins entretenus en état de viabilité. Mlais il arrive souvent que la réalité est loin de concorder avec les affirmations de l'Administration. Si l'exploitant ou le p:opriétaire de forêts, avant de commencer' les transports n'a pas la précaution de prendre counaissance de cet état et de parcourir les chemins qu'il se propose d'employer afin de vérifier leur état de bon entretien, il contestera en vaiu plus tard l'état d'entretien 
des chemins. Il faut done que l'exploitant, s'il constate qu'un chemin n'est pas entretenu en état de viabilité, fasse faire des constatations par un expert nommé à sa diligence par le Conseil de Préfecture.

Quant à l'état des chemins après les transports, la constatation n'est jamais contradictoire. Ce sont les cantonnier's et parfois l'agent-voyer qui relèvent l'étendue et la profondeur des ornières ainsi que leur largeur. Il arrivera souvent que les ornières constatées ne résultent pas de transports de bois, mais de transports agricoles ou industriels. Là encore existe une source d'erreurs et d'abus. Et lorsque, plusieurs années après les transports de bois, les experts se transportent sur place pour examiner l'état du chemin, aucune constatation utile ne peut être faite; les experts alors en sont réduits à examiner les états de dépenses d'entretien et de réparation, et à combiner les chiffres de ces états avec les autres eléments du dossier. Le calcul des subventions est alors inexact et le principe même de la subvention ne peut être justifié.

$4^{\circ}$ Dépenses faites ou à faire pour la remise en étal de viabilité. - L'Administration fournit aux experts un état des dépenses occasionnées arbitrairement établi; aucun contrôle n'est possible de la part de l'industriel.

$5^{\circ}$ Nature des véhicnles employés. - La nature des véhicules employés joue un rôle assez important dans l'usure des chemins. La largeur des "voies " entre les roues, la largeur des bandages des roues, le poids du véhicule, le nombre de bêtes de trait. Là encore, l'Administration se base sur les indications relevées plus ou moins exactement par les cantonniers, nouvelle source d'erreurs.

$6^{0}$ Circulation générale. - L'importance de la circulation générale est très intéressante à connaître, car plus la circulation générale est importante, plus la dégradation des chemins est grave et elle vient en défalcation des dégradations qu'ont pu causer les transports de bois. L'Administration prend encore pour base les pointages des cantonniers et fixe arbitrairement un chiffre, toujours en-dessous de la réalité. Le contrôle est impossible.

70 Saisons pendant lesquelles ont lien les transports. - L'Administration majore d'une ou deux et quelquefois trois unités la taxe de réparation du mètre de chemin lorsque les transports de bois ont été effectués en hiver ou au printemps, à raison de l'état détrempé des chemins qui sont alors plus susceptibles d'être détériorés. L'adoption d'un coefficient de "saison " est régulièrement pratiquée par l'Administration lorsque les transports se placent entre les mois d'octobre et de mai, et cela malgró la sécheresse ou la gelée qui ont pu exister dans cet intervalle. Là encore le contrôle est difficile, sinon impossible.

So Quantités de bois transportés. - Il semblerait que ce point dût ître toujours facilement établi sạs discussion possible. Mais il n'en est rien, et malgré les justifications que les marchands de bois apportent à l'expertise, les chiffres arbitraires portés aux états par le service vicinal sont préférés par les deux experts de l'Administration et du Conseil de Préfecture qui se mettent toujours d'accord pour admettre les évaluations quelquefois considérablement exagérées de l'Administration qui émet la pré. tention de ne jamais se tromper.

Ainsi qu'on le voit, pour la détermination des chiffres des subventions 
industrielles, l'exploitant ou le propriétaire de forêts ne lutte pas à armes égales avec le service vicinal; aussi on peut affirmer que toujours le subventionnaire en est la victime.

Et pourtant, ainsi que nous l'avons vu plus haut, puisque les subventions industrielles sont la réparation d'une dégradation causée aux chemins vicinaux, et par suite d'un préjudice subi parl'Administration, e'est done à elle à établir le principe et le montant de ce préjudice. L'Administration étant demanderesse doit être tenue d'établir sa demande. Le subventionnaire est le défendeur, il n'a done aucune preuve à faire. Malheureusement l'Administration toute-puissante renverse les rôles; elle fait application du principe que voici : du moment où un exploitant de forêts a fait transporter des bois sur un chemin, il est a priori certain pour l'Administration que le chemin a été dégradé extraordinairement, et en conséquence cet exploitant doit payer une subvention calculée en fonction du poids des charrois, de la distance parcourue et de la dépense générale d'entretien.

Bien souvent, le propriétaire ou l'exploitant qui se voit réclamer des sommes minimes, mais sans rapport avec les transports qu'il a effectués, paie, ne voulant pas risquer un procès long et coûteux. S'il fait le procès, il se heurte à la procédure administrative organisée exclusivement en faveur du service vicinal, et il n'est, la plupart du temps, pas écouté par le Conseil de Préfecture. Cependant la loi prévoit le cas où le subventionnaire veut discuter, elle organise une procédure d'expertise dont s'occupe l'article 17 de la loi du 21 mai 1836 et, ainsi que nous l'avons vu plus haut, cette procédure d'expertise est organisée de la manière suivante: l'exploitant nomme un expert, l'Administration en nomme un autre, et le Conseil de Préfecture en nomme un troisième.

Or le subventionnaire peut trouver diffieilement un expert possédant les connaissances spéciales do la matière, eet expert se verra adjoint à deux experts agents-voyers, souvent d'arrond issements voisins, qui auront naturellement tendance tous deux à conclure dans le même sens, le conseil entérinera le rapport des deux agents-voyers sans avoir égard au rapport de l'expert du subventionnaire.

D'autre part, la plupart du temps les demandes de subvention sont produites deux et trois ans après les transports qui y donnent lieu. J،es expertises, dans ce cas, se réduisent à l'examen de documents administratifs savamment préparés, contre lesquels les moyens de critique sont impossibles à trouver. Comment veut-on que l'on puisse arriver à la vérité lorsque la question de savoir si un chemin a été dégradé extraordinairement se pose plusieurs années après les transports?

L'examen du chemin n'est plus possible par suite des modifications qu'il a subies.

Aussi, dès le début de l'application de la loi, les exploitants de forêts se sont élevés contre elle, et ont protesté contre l'erreur que nous avons déjà relevée: l'assimilation des exploitations forestières aux industries proprement dites. En effet, la mise en valeur d'une forêt par le moyen de la coupe des arbres arrivés au moment voulu pour être abattus, ne peut être assimilée à une industrie; c'est un travail agricole et non pas in travail industriel (A. I. I.). C'est la pereeption à époque fixe des revenus de la terre, et de ce que la coupe d'mue forêt ne s'effectue que tous les vingt ou trente ans, il ne faut pas conclure que son caractère agricole disparaisse par là même. Or, les transports des revenus périodiques annuels 
de la terre, tels que les moissons, ne donnent pas lieu à des subventious industrielles.

Ce caractère agricole de l'exploitation forestière résulte encore des différentes lois relatives aux accidents du travail : les accidents survenant dans les exploitations forestières ne sont pas soumis à la loi du 9 avril 1898 sur les accidents industriels.

Tout ce qui concerne les forêts ressortit au Ministère de l'Agriculture.

Par suite, e'est en vertu d'une anomalie de la législation que les exploitations forestières ont été assimilées aux industries proprement dites. Il convient done d'obtenir du législateur la suppression des subventions industrielles pour les exploitations forestières.

D'ailleurs, devançant l'œuvre du législateur, un certain nombre de Conseils généraux ont, en fait, pris des dispositions qui ont amené dans quelques départements la suppression des subventions industrielles. C'est donc dans ces conditions que nous avons l'homneur de proposer au Congrès Forestier International d'adopter le vœu suivant tendant à la suppression des subventions industrielles en matière forestière:

\section{LE Congrès Émet Le VoeU :}

Que les exploitations forestières soient supprimées de la nomenclature portée à l'article 14 de la loi du 21 mai 1836 et à l'article 11 de la loi du 20 août 1881, des industries susceptibles de fournir des subventions pour les chemins vicinaux de grande communication et les chemins ruraux.

M. LE Présinext. - Il y a longtemps que nous travaillans cette question, je pense qu' nous sommes tous d'accord. (1/arque d'assentiment.)

\section{Adopté.}

Nous arrivons au dernies des rapports que nous avons à étudier ce matin, qui est celui de M. René Barbicr, rapport très ducumenté sur la question de la "Coxsenvaton nes bors ", dans lequel il a noté les procédés naturels, les procédés artiliciels, les injections, et tout ce qui constitue la protection du bois.

M. René Barbier. - L'intérêt qu'offre la conservation des bois ne peut manquer de frapper cenx qui s'occupent de la forêt ou de la construction; il faut prévoir le moment où, par suite du déboisement à ontrance, le prix du bois sera devenu tel que cette substance devra être employée avec ménagements. C'est done faire œuvre utile que de tenter la vulgarisation des procédés mis à notre disposition par la science, pour augmenter la durée de vie utile du bois dans ses multiples emplois.

Quel meilleur auxiliaire dans la lutte contre le déboisement que cette vulgarisation dont tout le monde, depuis le propriétaire de la forêt jusqu'au destinataire final, devra tirer profit.

Si, en effet, dans certains de ses emplois, tels que traverses de chemins de fer, pavés, poteaux, ete., on a industrialisé les procédés de conservation, par contre ces procédés ne sont employés qu'exceptionnellement dans une foule de cas ou ils seraient cependant fort utiles, pour lutter contre la pourriture ou l'inflammabilité. 
Car ce sont là les deux grands inconvénients du bois : d'être tòt ou tard, suivant son exposition, attaqué par ses ennemis, champignons ou insectes, ou détruit par le feu.

C'est de ces ennemis ou de cette éventualité qu'il faut chercher i le préserver.

Des ouvrages très documentés, tels que Le Bois, par M. Beaurerie et la Préservation des bois, par. M. Henry, nous ont été d'un appoint important pour la rédaction de ce travail et, aidé par la faible expérience do ce que nous constatons et mettons en ourre chaque jour, nous penson:; donner ici une idée de ce qui a été tenté et industrialisé pour arriver au but que nous nous proposons d'atteindre.

Nous croyons utile d'exposer tout d'abord brièvement les défauts naturels et de définir les ennemis que nous arons à combattre, nous indiquerons ensuite les procédés naturels et artificiels que nous arons à notre disposition pour rendre cette lutte efficace.

Difants et enuemis du bois.

Défauls naturels. - Les défauts du bois proviennent, pour la plupart, d'agents physiques et accidentellement de l'imprévoyance de celui qui l'exploite.

Ses premiers ennemis naturels sont les plantes parasites, tel que le lierre qui, enserrant l'arbre pendant sa croissance, l'étouffe quelquefois jusqu'à le tuer sur pied.

L'époque d'abatage a une intluence considérable sur la durée des bois.

Lors de l'abatage il peut arriver que la chute mal dirigée fait à l'arbre une blessure qui ne tarde pas à devenir un foyer de pourriture.

Les gerçures, gélivures et roulures sont également d'autres foyer's de pourriture. Ces défauts proviennent de l'action du soleil, de la gelée ou du vent sur l'arbre encore debout. Le soleil a aussi une action très néfaste sur les arbres abattus et écorcés; il produit des fentes qui vont jusqu'au coeur et où la pourriture trouve souvent son origine.

Le bois scié a plus ou moins de durée suivant son essence, son exposition à l'abri, à l'humidité ou dans l'eau, ou suivant le milieu plus ou moins nocif auquel il est exposé.

Ennemis du bois. - Les deux grands ennemis du bois sont les champignons et les insectes.

Champignons. - Les champignons se déreloppent surtout farorablement à l'humidité. Leurs filaments pénètrent dans le bois jusqu'au cœur: lui donnent une couleur brune, premier indice de pourriture, et le transforment en une matière légère et poreuse n'ayant plus aucune résistance.

Nous citerons entre autres le Polyporns vaporarius et surtout le Merulius lacrymans, dit champignon des maisuns, dont les méfaits ne se comptent plus.

Ce champignon est d'autant plus dangereux qu'il se répand avec unt rapidité étonnante; tous les bois voisins de la pièce infectée sont attaqués à bref délai. Il se propage principalement dans le bois employé vert et it proximité d'une maçonnerie encore humide.

Les champignons trouvent encore un milieu favorable à leur déreloppement dans les arbres abattus et laissés quelque temps sur un terraiu humide.

Insectes. - Les insectes qui s'attaquent au bois appartiennent à les milliers d'espèces. Ils accomplissent leur curre de destruction en creusant 
en plein bois une quantité de galeries qui enlèvent au bois sa solidité et sont autant de couloirs par où s'infiltre la pourriture.

Parmi les coléoptères, nous citerons les vrillettes, petits insectes dont, on reconnait la présence par les petits trous appelés communément "piqûres de vers" à peine perceptibles.

Les charançons.

Les bostriches, dont les invasions dans les forêts d'épicéa produisent de récls désastres. Il n'y a guère d'autre remède que d'abattre et de brúler les écorces de tous les arbres situés dans la zone attaquée par ce redoutable ennemi.

Les capricornes.

Dans la famille des hyménoptères nous signalerons la fourmi et le sirex, gros insecte ailé que l'on rencontre fréquemment dans les pièces de sapin ou de pin.

Les chenilles de la famille des lépidoptères.

Et enfin parmi les pseudonévroptères, nous citerons les termiles qui se plaisent particulièrement dans les climats chauds.

11 nous faut également parler des ennemis des bois séjournant dans l'eau de mer, soit des crustacés qui les rongent, soit des mollusques tels que le taret contre lequel on cherclse depuis longtemps à lutter sans résultat absolument probant. L'injection d'un antiseptique ne fait que retarder un peu sa présence, le produit injecté ne tardant pas à se dissoudre, et ce n'est guère que par des revêtements de zinc, de cuivre et surtout de ciment que l'on a pu arriver à lutter à peu près efficacement. contre cet ennemi

Quels moyens avons-nous à notre disposition pour atténuer autant que possible tous les défauts que nous avons signalés et pour préserver le bois des ennemis qui le guettent. Il en est de naturels et d'artificiels quenous nous proposons d'exposer brièvement.

Les procédés naturels sont ceux qui, ne changeant pas la composition et l'aspect du bois, ne font intervenir aucun élément étranger.

Le soin à apporter dans les différentes phases de transformation de l'arbre sur pied en sa forme définitive d'emploi est le meilleur procédé naturel de conservation et aussi le plus économique puisqu'il ne coúte qu'un peu d'étude et de prévoyance.

Suivons donc ces phases de transformations.

Tout d'abord le propriétaire prévoyant aura débarrassé ses arbres, au fur et à mesure qu'elles se présentent, des plantes parasites grimpantes ou autres. Il aura par contre laissé les branches, à moins qu'il ne prenne soin d'appliquer sur la coupe fraîche un antiseptique qui la préservera de la pourriture.

Pour protéger l'arbre sur pied de la vermoulure, c'est-à-dire des dégâts causés par les vrillettes, il existe un procédé très efficace décrit par M. Ner, qui consiste à enlever une couronne de l'écorce de l'arbre à une certaine hauteur. Ce procédé est "l'annélation ". ll est à remarquer, en effet, que les vrillettes ne s'attaquent qu'à l'aubier contenant de l'amidon. Cet amidon provenant des feuilles et n'étant transmis à l'aubier que par l'écorce, est arrêté par cet anneau. Tout le pied de l'arbre en est donc préservé. Le résultat est encore amélioré en faisant une double annélation, l'une sous les branches, l'autre plus bas.

Cette opération, pour être utile, doit être effectuée au printemps et, dès

Procetios mastirels pout la prenrervation des bris. 
l'automne suivant, l'amidon s'est considérablement raréfié. Ce procédé a le grave ineonvénient de nuire à la pousse normale des arbres.

On ne saurait trop insister sur l'époque pendant laquelle on doit abattre les arbres. Tout arbre abattu au printemps ou en été, c'est-à-dire aux époques de montée de la sève, est beaucoup plus sujet à la pourriture que s'il est eoupé au moment où ses pores contiennent moins de cet acide néfaste. La fermentation de la sève occasionne l'échauffement et l'amidon contenu dans l'aubier en été est la pâture recherchée des vrillettes.

Signalons, en passant, la vieille coutume empirique qui consiste à ne pas abattre les essences ayant de l'aubier pendant la eroissance de la lune et de profiter du décours pour procéder à cette opération; toujours bien entendu en dehors des mouvements de la sève. Les vieux búcherons assurent, sans qüil soit possible d'ailleurs d'en donner une explication, que les meilleurs résultats ont été acquis par cette pratique.

Sur la blessure de chute d'un arbre, il est prudent d'appliquer une couche d'un antiseptique, tel que le goudron, qui le protrige de la pourriture.

Beaucoup d'exploitants ont coutume d'écorcer les chênes en forêt dès qu'ils ont été abattus. Ceci est une bonne préeaution, car l'arbre qui séjourne quelque temps sur un terrain humide avec son écorce est bientôt attaqué par une quantité de ehampignons et d'insectes. L'écorçage a par contre des inconvénients sérieux si l'arbre est exposé quelques jours seulement à l'action du soleil. Le bois n'étant plus garanti par l'éeorce ne tarde pas à se fendre et les gerçures produites sont nuisibles an produit débité.

Le meilleur moyen, pour éviter l'un ou l'autre de ces inconvénients, est de seier les arbres, en planches ou en plateaux le plus rapidement possible après abatage. Cette méthode est controversée, mais nous estimons que bien des surprises fâcheuses sont ainsi évitées ; certains bois même, tels que le hêtre, particulièrement sujets à l'échauffement doivent être débités avant l'été qqui suit l'abatage.

Le bois étant scié en planches ne doit être employé, dans bien des cas, que dans un état de siceité parfaite. Il est indispensable qu'il ne "travaille" plus, e'est-à-dire que ses pores doivent avoir atteint avant emploi et assemblage leur maximum de retrait.

Cette siccité ne peut être obtenue que par l'élimitation complète de la sève et de son eau.

Un procédé, le flottage, très employé autrefois et dont les résultats étaient d'ailleurs parfaitement satisfaisants, consistait à laisser séjourner les pièces quelque temps dans l'eau courante. L'eau pure, après avoir dissous le tanin, se substituait à la sève et s'évaporait ensuite à l'air libre, beaucoup plus rapidement et súrement que l'eau chargée de sève.

Ce procédé est aujourd'hui presque toujours remplacé par d'autres plus coúteux mais aussi beaucoup plus rapides et basés sur le même principe. Nous voulons parler de l'étuvage.

Etuvage. - Le prineipe des différents systèmes d'étuvage est de remplacer le llottage en eau courante soit par l'immersion dans l'eau chaude, soit par l'exposition, dans une chambre close, à la vapeur d'eau.

Dans ce dernier eas, qui est d'ailleurs le plus efficace, le bois est empilé dans une étuve et soumis pendant une durée variant de 12 heures ì 36 heures, suivant sa dimension, à l'action de la vapeur qui chasse aree la sève une partie des acides pyroligneux hydrophiles et, par sa condensation, remplit d'eau les pores du bois. 
L'amidon est également chassé de l'aubier qui se vivifie par le tanin provenant du bois. L'aubier devient aussi dur et imputrescible que le cour même du bois.

Ce sont là, tout au moins, les résultats que nous arons obtenus par le procédé que nous employons depuis de nombreuses années.

Séchage. - La sève étant ainsi éliminée du bois par l'un ou l'autre procédé, il importe de chasser l'eau qui en a pris la place. Cette opération est celle du séchage.

Le séchage peut être obtenu soit naturellement, soit par chauffage, soit par ventilation.

Le séchage naturel est obtenu à l'air libre. I cet effet les planches de bois flotté, étuvées ou même sans aroir subi de préparation antérieure doivent séjourner à l'air, isolées les unes des autres par des cales ou des lattes. Les piles doivent avoir une pente suffisante pour que l'eau de pluic ne puisse séjourner sur les bois et une courerture doit autant que possible les protéger des intempéries.

Une période de 6 mois à 3 ans, suivant que les bois on tété ou non éturés, doit se passer avant que l'eau contenue dans les pores ne soit complètement éliminée.

Il faut surtout éviter de laisser les planches de bois vert séjourner les unes sur les autres sans lattes pour les isolér car les bois ainsi mis en contact sont rapidement attaqués par les insectes et champignons, causes d'échauffement et de pourriture.

Pour obvier au grave inconvénient d'immobiliser des bois pendant un temps aussi long, il existe plusieurs procédés de séchage artificiel tendant au même résultat dans un court délai. Nlalheureusement aucun de ceux employés jusqu'à présent n'a pu donner une absolue satisfaction; la raison en est facile à comprendre.

Par le séchage lent à l'air libre, non seulement les pores du bois perdent l'eau qu'ils contenaient, mais ils se resserrent graduellement, le bois garde sa contexture primitive et sa solidité en est augmentée.

Par un séchage trop rapide, les pores n'ont pas le temps de se resserrer, la moindre humidité de l'atmosphère les remplit d'eau à nouveau.

D'autres inconvénients, tels que les fentes et gerçures, se produisent également par suite du brusque retrait des couches extérieures du bois.

Nous devons toutefois eiter ces procédés qui, appliqués à des bois demi-secs, ont donné des résultats appréciables.

Tout d'abord par simple chauffage on obtient une élimination plus rapide de' l'eau, mais cette élimination est partielle et irrégulière par suite de la mauvaise répartition de la chaleur.

On obtient de meilleurs résultats par la ventilation. Un courant d'air chaud montant progressivement jusqu'à $80^{\circ}$ est envoyé dans une chambre où sont disposés les bois empilés sur lattes.

Il existe une quantité de procédés tous basés sur ce principe et ne différant que par la façon de les appliquer.

Les procédés artificiels de conservation peuvent être classés en quatre irowidric artificatégories :

$$
\begin{aligned}
& 1^{\circ} \text { Carbonisation. } \\
& 2^{\circ} \text { Badigeonnage. } \\
& 3^{\circ} \text { Immersion. } \\
& 4^{\circ} \text { Injection. }
\end{aligned}
$$

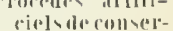
vatiou. 
La carbonisation est le mode le plus ancien et le moins coûteux de préservation du bois contre la pourriture. Son principe consiste à exposer le bois à l'action du feu pendant peu de temps ; la flamme brûle et carbonise la couche extérieure du bois, e'est-à-dire celle qui offre le moins de résistance à la pourriture. Il se forme par suite de cette carbonisation un enduit qui préserve le bois de ses ennemis extérieurs, champignons ou insectes.

On a tenté d'industrialiser ce procédé et M. de Lapparent a imaginé à cet effet un appareil fort ingénieux qui carbonise le bois par un jet de flamme que l'on dirige sur la partie à préserver.

Le risque d'incendie ne permet presque jamais l'application de ce mode de préservation.

Haskin a recommandé la vulcanisation; elle a l'inconvénient de diminuer la résistance du bois que l'on y a soumis.

La fumée n'a donné également que des résultats insuffisants aux inventeurs qui l'ont utilisée sous différentes formes.

Si l'on isole les pores du bois de l'action extérieure d'un milieu nocif ou de l'humidité, il est certain que l'on aura remédié, dan's beaucoup de cas, à l'attraction qu'offre le bois à ses ennemis. C'est là une méthode purement physique et dont l'emploi est tout à fait courant. Quelle pièce de bois ouvré est définitivement laissée en place sans avoir reçu une ou plusieurs couches de peinture.

Pour que cette impression toutefois ait quelque efficacité, il importe que le bois, après avoir été convenablement gratté et raboté pour offrir une surface absolument lisse, ait toutes ses fentes bouchées au mastic, puis par l'application d'une couche d'huile bouillante et de deux couches de pcinture mélangée d'huile, on aura convenablement isolé le bois de l'air.

Le résultat est cependant beaucoup amélioré lorsque, dans certains gros travaux ne nécessitant pas la peinture, on peut employer le goud:on. Ce produit en effet a, outre sa propriété isolatrice, une certaine action antiseptique.

Il en est de même du carbolineum et du carbonyle qui, par simple badigeonnage, protègent très efficacement le bois par suite de leur absorption dans la masse, absorption souvent comparable à celle constatée dans les méthodes d'injection.

Le pétrole a été égalennent utilisé avec succès dans les parquets attaqués par les vers.

Prodults ani- Avant de faire la description des procédés d'injection de produits antiseptiques dans le bois, soit par immersion, soit par pression, il est indispensable d'étudier quels sont les plus employés parmi ces produits, leur's défauts et leurs qualités.

Pour qu'un produit antiseptique soit bon il faut:

10 Que son action soit vraiment efficace;

$2^{\circ}$ (Yu'il n'altère pas la force de résistance du bois en le décomposant;

$3^{\circ}$ Qu'il s'injecte facilement et pénètre rapidement dans le bois en en remplissant tous les pores;

$4^{\circ}$ Il ne faut pas qu'il soit soluble dans l'eau;

$5^{\circ}$ Il ne doit pas augmenter le degré d'inflammabilité des bois;

$6^{\circ}$ Son maniement ne doit pas être dangereux pour les ouvriers qui l'emploient; 
7o Sa composition doit être stable de telle façon que le résultat ì obtenir ne dépende pas d'une bonne ou d'une mauvaise qualité ;

So Il ne doit donner au bois qui en est imprégné ni odeur, ni couleur;

$9^{\circ}$ Son prix doit répondre à l'avantage obtenu.

Toutes ces conditions sont naturellement fort difficiles, sinon impossibles, à réunir dans une même substance.

On peut classer les produits antiseptiques employés en trois grandes catégories :

$$
\begin{aligned}
& 1^{\circ} \text { Goudron et ses dérivés. } \\
& 2^{\circ} \text { Naphtes el résines. } \\
& 3^{\circ} \text { Sels métalliques. }
\end{aligned}
$$

Le goudron de gaz est obtenu lors de la distillation de la houille pour la production du gaz.

C'est un produit noir et épais, d'un emploi assez difficultueux, facilement inflammable et s'épaississant à la moindre baisse de température. Un ne peut guère l'employer que comme enduit et toujours à l'humidité, car sous l'action de la ehaleur il s'amollit et arrive même à fondre; au bout de peu de temps l'enduit se crevasse et laisse pénétrer l'humidité dans les parties profondes du bois qui ne sont plus protégées.

Même appliqué a $50^{\circ}$ on $60^{\circ}$ il pénètre peu.

Le choix judicieux et les dosages des huiles passant durant les phases de la distillation du goudron, donnent les différentes qualités de créosote, carbolineum et carbonyle.

Créosote. - La créosote est une huile lourde d'une odeur violente et peu soluble dans l'eau. Elle contient une faible proportion d'acide phénique dont la propriété intéressante pour la conservation du bois est de coaguler l'albumine, et une certaine quantité de naphtaline qui reste dans les pores du bois et le protège.

La créosote, déposant 20 à $30 \%$ de naplıtaline à la température de $15^{\circ}$, ne peut être employée qu'à chand et le plus sourent par injection sous pression.

Carbolineum. - Il provient surtont des huiles lourdes et eontient sousent encore des goudrons. Il contient moins de produits cristallisables à basse température que la créosote et sa force de pénétration dans le bois en est accrue. C'est un liquide brun et visqueux d'une densité de 1.150 environ. Il renferme de la naphtaline et une assez forte proportion de phénanthrène.

Carbonyle. - Ce produit est obtenu par une rectification et un mélange raisonné des huiles légères, moyennes et lourdes, ce qui lui permet de posséder les qualités des créosotes tout en ayant la possibilité d'application et une grande foree de pénétration dans le bois aux températures ordinaires.

11 est composé de 15 à $20 \%$ de phénols et crésols éminemment antiseptiques, de 75 à 80 \% d'hydroearbures gras, jaunes foncés, qui contiennent à fortes doses les carbures liydrogénés insolubles dans l'eau ou à l'humidité de l'air et ayant la propriété de conserver les matières azotées du bois.

Par sa richesse en produits conservateurs et la facilité de son application, le carbonyle est certainement un des meilleurs produits antiseptiques connus et en usage. 
Saphitas et resines.

sels milalliques.

()n pourrait citor également la paraffine, le tanin, le formol, etc...

Les sels métalliques servant à la conservation des bois sont très nomJoreux, nous nous bornerons à citer les principaux :

Sulfate de cuivre. - Ce sel très fréquemment employé ne peut se fixel (Iaus le bois qu'en lui donnant le temps de s'assimiler à la cellulose.

Chlorture de zinc. - Il donne d'excellents résultats, mais ne doit être appliqué que sur des bois à l'abri. Il est employé avec succès dans le procédé Rütger's, mélangé avec la créosote purifiée qui empêche la dissolulution dans l'eau.

Bichlorure de mercure. - C'est le sublimé corrosif. Cet antiseptique irès puissant offre de grandes difficultés d'emploi par suite de la nocivité de sa manipulation.

Sulfate de fer. - A le grave inconvénient d'altérer les fibres du bois.

Arsenic. - Expérimenté très heureusement par le professeur Duilis.

Tous pourrions également citer les sulfates de magnésie, de zinc, d'alumine, de chaux, de baryte, de soude et les chlorures de magnésium, d'aluminium, de sodium, de calcium, etc.

Ces sels sont employés soit seuls, soit mélangés, soit préparés avec la créosote ou autre produit qui les rend insolubles dans l'eau.

Nous citerons entre autres l'injectol qui est un composé de goudron végétal et minéral auquel sont adjoints certains alcaloïdes facilitant la pénétration dans le bois.

Le microsol, l'antinonnine, l'antigermine, le lysol, etc., sont également employés.

Les produits antiseptiques cités ci-dessus n'ont pas tous la même foree de pénétration dans le bois. Il en est, telle la créosote, qui ne s'inprègnent totalement dans la masse qu'avec l'aide d'une forte pression; dans ce cas il faut une installation très onéreuse. On a donc tenté avec raison d'autres méthodes moins eoûteuses, par simple immersion du bois dans un antiseptique efficace et à pénétration plus rapide.

Immersion à froid. - C'est le procédé le plus simple, mais anssi le plus lent. Il consiste à immerger simplement le bois, aussi sec que possible, lans un bain antiseptique. La préservation n'est que très superficielle que l'on emploie le sulfate de cuivre on même le bichlorure de mercure (procédé líyan).

Le carbolinemm et le carbonyle donnent les meilleurs résultats; les pièces de bois doivent y séjourner, suivant leur essence, deux à trois jours.

Immersion à chaud. - En plongeant le bois dans un antiseptique chauffé à une certaine température, on obtient un résultat bien supérieur de pénétration et dans un temps beaucoup plus court. Il suffit par exemple d'immerger' pendant quelques heures des pièces de bois dans un bain de sulfate de cuivre à $1 \frac{1}{1} \%$ à $70^{\circ}$ et l'on obtient un résultat comparable à l'immersion ì froid pendant plusieurs jours.

Le carbolineum chauffé à $60^{\circ}$ s'injecte avec une rapidité surprenante. Quelqus minutes d'immersion sont suffisantes pour le sapin ou le hêtre secet quelques heures pour le hêtre vert et le chêne.

Différents procédés consistent également à plonger le bois dans un bain à ébullition. On peut par exemple tremper le bois dans de la paraffine chaufféc et maintenue à plus de $100^{\circ}$. 
Injection par refroidissement. - Le principe de cette méthode est de chauffer la pièce de bois avant de l'immerger. Le refroidissement brusque produit un vide partiel qui permet à l'antiseptique de pénétrer.

Ce procédé a le grave inconvénient d'attaquer la substance du bois qui se trouve altérée par la forte chaleur à laquelle elle est soumise.

Un autre procédé existe que nous employons et dont nous avons maintes fois constaté l'efficacité; il supprime l'inconvénient signalé ci-dessus.

Ce procédé consiste d'abord à extraire la sève du bois par l'étuvage à la vapeur d'eau dans une chambre close, puis à immerger le bois avant refroidissement dans une cuve contenant du carbolineum froid. Le phénomène qui se produit est facile à comprendre; la vapeur contenue dans les pores du bois en remplacement de la sève se condense par suite du brusque changement de température et le vide qui s'ensuit aspire le liquide antiseptique et ce d'autant plus facilement que le liquide adopté, le carbolineum, a par lui-même une grande force de pénétration dans le bois. L'ensemble des deux opérations, étuvage et immersion, demande deux à trois jours, suivant l'épaisseur dos pièces à injecter et, leur essence.

On a de cette façon, avec une moindre dépense, des résultats tout à fait comparables et même supérieurs à ceux obtenus par l'injection avec pression.

Le travail du carbolinemm dans le bois n'est d'ailleurs pas terminé dès la sortie du bain, les couches extérieures du bois en sont imprégnées beaucoup plus que le milieu de la pièce, mais le liquide gagne peu à pen pendant une quinzaine de jours jusqu'à ce qu'il soit répandu également dans tous les pores.

Nous avons constaté par ce procédé que le hêtre absorbe environ 200 kilogrammes de carbolineum par mètre cube ; l'aubier de chêne en est complètement saturé et le cœur même du chêne, généralement rebelle à toute injection, en est imprégné.

Les simples procédés d'injection par immersion et badigeonnage ont injection. le grand avantage d'être peu dispendieux et de ne pas nécessiter unẹ installation compliquée, mais leur efficacité n'est pas toujours suffisante ; aussi les grandes usines et les Compagnies de chemin de fer ontelles fait intervenir la pression mécanique qui rend l'imprégnation du liquide plus complète, mais nécessite des appareils cońteux.

Les méthodes employées sont nombreuses, on les classe habituellrment en quatre catégories :

$1^{\circ}$ Méthodes par déplacement de la sève.

$2^{\circ}$ Néthodes par vide et pression.

30 Méthodes par thermo-carbolisation.

$4^{\circ}$ Méthodes par l'électricité.

Méthodes par déplacement de la sève. - Cette méthode due au docteur Boucherie permet d'injecter les arbres sur pied ou récemment abattus. Elle est basée sur ce principe que la montée de la sève peut entrainer le liquide antiseptique.

Cette métliode s'applique à l'arbre venant d'être abattu, c'est-à-dire encore chargé de sève et dont l'écorce n'a pas été enlevée. Le réservoir contenant l'antiseptique doit être placé à une certaine hauteur, pour qu'il y ait une légère pression, et mis en communication arec le gros bout de 
l'arbre coupé. C'est le procédé adopté pour les poteaux télégraphiques avec une solution de sulfate de cuivre à $1 \%$.

L'efficacité de ce procédé est réelle, mais surtout pour les bois facilement pénétrables, tels que le hêtre, le sapin et le pin.

Différents perfectionnements existent qui, pour faciliter l'introduction de l'antiseptique, ont fait intervenir soit le vide (procédé Renard-Perin), soit une pression en vase clos (procédé Lebioda). Ce dernier procédé, dont le seul inconvénient n'était que d'être extrêmement coûteux, a étè heureusement perfectionné par M. Maurice Boucherie.

Méthodes par vide et pression. - Le principe de ces méthodes est de faire pénétrer l'antiseptique par pression et en vase clos.

Le bois doit être sec pour être traité ntilement, car l'eau et la sève contenues dans les pores ne pourraient plus s'échapper par suite de la pression. La compression qui se produirait serait nussible à la structure du bois.

A) Procédé Béthell. - Ce procédé était jusqu'à ces derniers temps le plus souvent employé en France pour l'injection des traverses de chemins de fer.

Les traverses séchées à l'air chaud à $80^{\circ}$ sont placées dans un récipient fermé hermétiquement. On fait le vide pendant une demi-heure environ, puis la créosote à $80^{\circ}$ est introduite et comprimée à une pression de 6 kilogrammes par centimètre carré pendant une heure. Quand la quantité roulue de liquide a été absorbée par le bois, on arrête la compression; $l^{2}$ excédent de créosote est vidé et les traverses retirées.

Généralement les traverses de chêne sont injectées à refus et absorbent 6 à 7 kilogrammes de créosote. On fait absorber aux traverses de hêtre 25 à 30 kilogrammes, quantités reconnues suffisantes pour en assurer l'imputrescibilité pendant 20 ans.

B) Procédé Rï̈tgers. - Est employé principalement en Allemagne, en Autriche et en Russie. La solution antiseptique adoptée est un mélange de créosote et de chlorure de zinc, la créosote empêchant la dissolution du sel métallique par l'eau.

Le bois est tout d'abord étuvé dans un récipient clos, par un courant de vapeur' qui le nettoie de l'eau et de la sève.

Après expulsion de la vapeur et de l'air, la solution antiseptique est envoyée à $65^{\circ}$ et refoulée à travers le bois par une pompe à une pression de 7 almosphères.

C) Procédé Rüping. - Les différents procédés d'injection ont l'inconvénient de laisser perdre beaucoup de liquide; les bois injectés à dose convenue, tel que le hêtre, ne sont pas également imprégnés, il reste presque toujours dans les pores une petite quantité d'eau et de sève qui y est comprimée. Le procédé Rüping tend à remédier à ces inconvénients.

Le principe consiste à injecter le bois à refus et à lui faire rendre immédiatement le superflu, ce qui constitue une économie intércssante de liquide et une meilleure utilisation.

D) Procédé Mcreklen et Chatean, ingénieurs des Chemins de fer de l'État.

E) Procédé Maurice Boncherie. - Ces procédés récents procèdent à l'inverse de Rüping et donnent d'excellents résultats.

Wéthode de thermo-curbolisation. - Cette méthode est due à M. Blythe, alle consiste à faire pénétrer la créosote dans le bois à l'état de vapeur "n l'entrainant par la vapeur d'eau. Le bois étant placé dans une 
chambre close, on introduit la vapeur d'eau et la vapeur carburée que l'on fait circuler par refoulement et aspiration. L'opération est terminée en une demi-heure.

Méthode par électricité. - Cette méthode repose sur le procédé NodonBretonneaul.

Elle est basée sur ce prmeıpe qu'un liquide soumis à un courant électrique a une force d'expansion beaucoup plus grande. On utilise cette force pour faire pénétrer l'antiseptique dans les pores du bois.

Le bois empilé sur une feuille de plomb dans une cuve est recouvert d'une seconde feuille de plomb. La solution antiseptique (sulfate de linc de 25 à $35 \%$ ). est versée dans la cuve et chauffée à $35^{\circ}$ par un serpentin.

Les deux feuilles de plomb étant reliées respectivement aux deux pôles d'une dynamo, on fait passer un courant de 110 volts pendant 15 heures environ à raison de 6 ampères par mètre cube. Ce courant est inversé de temps en temps. Ce procédé appelé eneore sénilisation est appliqué également au séchage rapide des bois; dans ce cas, on emploie une solution de sulfate de magnésie à $20 \%$.

La sénilisation a l'avantage de durcir les bois et d'augmenter leur zésonnance.

Nous arons rapidement exposé les principaux modes de préservation des bois, il est intéressant de voir à quels emplois sont ou pourraient être affectés les bois soumis à ces différents traitements.

Les procédés naturels de conservation, tels que soins d'exploitation, de sciage et d'empilage, l'étuvage, le séchage doivent être généraleınent appliqués à tous les bois de construction, menuiserie et ébénisterie, et en particulier aux bois durs. La quantité de bois déclassé et perdu chaque jour fante de ces quelques soins et précautions élémentaires est difficilement imaginable.

Les procédés artificiels ne peuvent s'appliquer que dans certains cas. En général tous les bois destinés à être exposés à la pluie, dans la terre ou à l'humidité devraient avoir subi auparavant l'une des nombreuses préparations actuellement en usage.

Les traverses, longrines, poteaux télégraphiques, pavës de bois et bois de mine sont déjà presque toujours préservés artificiellement par un antiseptique.

Mais les poutres et poteaux de construction, les lambourdes de chêne, les clôtures et palissades en bois, les bois servant à la construction des wagons et des voitures sont également sujets à la pourriture; il serait à souhaiter de voir se généraliser l'application, dans ces différents cas, des procédés de conservation, immersion ou injection.

Nous avons étudié les différentes façons de préserver les bois de la Ignifugation. pourriture et par conséquent d'augmenter la durée de leur vie utile, mais il existe un risque redoulable et qu'il est intéressant de savoir combattre : c'est le risque d'incendie.

De nombreux procédés ont été proposés et employés pour enlever la faculté qu'ont les bois de s'enflammer rapidement, nous croyons cependant qu'il n'en existe pas de parfait.

Toutefois si l'on ne peut jamais empêcher le bois de prendre feu, certaines préparations retardent cette faculté d'inflammabilité et la rendent 
moins dangereuse, le bois ainsi préparé brúlant avee très peu de flammes ; ce résultat était déjà intéressant à obtenir et l'ignifugation a déjà rendu de nombreux services.

Les substances ignifuges sont employées de différentes façons : par badigeonnage ou revêtement, par immersion ou par injection.

Ces substances sont, en général, des borates, des silicates et des ammoniacaux, ils agissent d'ailleurs différemment.

Les borates et les silicates préservent les fibres du bois du contact de l'air, les sels ammoniacaux ont la faculté, en se volatilisant à la chaleur, de retarder et d'empêcher la combustion des matières organiques.

Les combinaisons entre ces différents sels sont variables à l'infini, il serait impossible de les détailler toutes, nous ne citerons que les plus communément appliquées.

Enduits. - Les enduits ne peuvent préserver le bois que d'une flamme légère et pendant peu de temps; ils s'appliquent au pinceau par badigeonnage de plusieurs couches successives.

Immersion. - La pénétration des substances ignifuges par immersion est encore trop superficielle, nous signalerons cependant le procédé d'Hasselmann qui emploie successivement un bain chaud de sulfate de fer et de sulfate d'alumine, puis le chlorure de calcium et la chaux.

On peut également plonger le bois dans une solution composée ainsi :

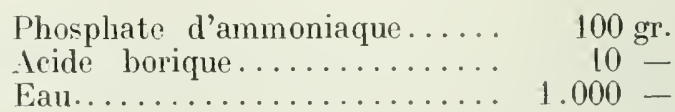

Injection. - L'injection des produits ignifuges se fait en général suivant les mêmes principes que l'injection des produits antiseptiques. Les différents procédés consistent à enlever l'eau e la sève du bois soit par la vapeur d'eau, soit par le vide, et à introduire les substances ignifuges dans les pores par pression. Ces substances sont variées et leur composition en général brevetée, ce sont des mélanges de sulfate de fer ou de cuivre et de chlorure de calcium ou de baryum, des crésylates, des sulfates d'amm oniaque et d'alumine, des silicates de soude et chlorhydrates d'ammoniaque, des combinaisons de phosphates et sulfates d'ammoniaque avec des sulfates de zine ou de magnésie et de l'acide borique, etc.

Le procédé Nodon-Bretonneau que nous avons décrit plus haut emploie avec succès une solution de borate et de sulfate d'ammoniaque.

On peut encore protéger efficacement le bois contre le feu par des revêtements protecteurs. Ce procédé, lorsqu'il est possible de l'employer, donne d'excellents résultats. Il consiste à recouvrir les bois apparents d'une charpente ou d'un plafond d'un enduit de plâtre ou de ciment, cet enduit devant être autant que possible armé par un treillis métallique.

On peut dire en résumé que la plupart des procédés d'ignifugation du bois ont une certaine valeur. Si quelques expériences de laboratoire ont été faites avec plein suecès, les bois ignifugés ne résistent pas en général à un foyer intense d'incendie. La séeurité qu'ils procurent n'est sans doute pas absolument illusoire, mais il est prudent de prendre les mêmes précautions ru'arec l'emploi de bois qui n’ont pas été préparés.

Du long exposé que nous venons de faire, nous devons tirer une leçon et une ronclusion. 
Nous avons parcouru quelques principes naturels et de nombreux procédés artificiels de conservation, quelques-uns sont fréquemment appliqués, d'autres, également efficaces, sont presque totalement méconnus.

Nous n'avons fait qu'en effleurer la description, mais notre but était d'inciter tous ceux qui emploient le bois et qui auront bien voulu constater avec nous la diversité des méthodes à notre portée, à étudier à fond cette question et, partant, à en faire l'application le plus souvent possible.

Chacun aura ainsi contribué à la réalisation du but que nous devons poursuivre : empêcher le déboisement à outrance par la prolongation de la vie industrielle du bois.

Les pouvoirs publics peuvent nous aider dans cette auvre et nous concluerons en émettant deux voux :

I. Que les recherches sur les procédés artificiels de conservation et les découvertes dans cet ordre d'idées soient dotées de primes.

II. Que l'État, partout où il le peut, pour tous les édifices publics et pour certaines constructions privées, exige l'emploi des bois ignifugés.

11. Le Présidext. - Avez-vous, Messieurs, des observations à présenter?

M. Prat. - On a fait ici, à Paris, au Laboratoire Central, des essais. I1 serait à souhaiter que le Laboratoire Central donnât eommunication des résultats qu'il a obtenus.

M. Pelletier de Martres. - On peut réclamer cette communication. mais il y a au Conservatoire des Arts et llétiers toute la documentation utile.

II. Pral. - Ce que je souhaite, e'est que les particuliers puissent profiter de rette leçon.

M Pelletier ne Martres. - On vous doit la communication. Tous trouverez tout ce que rous voudrez à cet égard au Conservatoirer des Arts et Métiers.

Personne ne demandant plus la parole, les roux proposés par to Rapporteur sont successivement adoptés.

La séance rst levée à 10 h. 40 . 


\title{
SEANCE DU 18 JUIN 1913
}

\author{
(MATIN)
}

\section{Présidence de M. POUPINEL, président de Section}

La séance est ouverte à $9 \mathrm{~h} .30$.

M. le Président. - La parole est à M. Simon pour la lecture de son rapport sur les BOIS ITILISES DAXs L'IXILSTRIE DES ALLLMETTES. POLR LE DEBITAGE OL LA CONFECTION DES BOITES.

M. Srmox. - Au point de rue de la nature de leurs tiges, les allumettes se classent en deux catégories : les allumettes en bois et les allumettes en cire.

Les deux variétés se fabriquent à peu près partout. Cependant, on n'utilise guère, dans toute l'Europe centrale et septentrionale, que l'allumette en bois.

En France, notamment, le nombre des allumettes bougies livrées à la consommation n'atteint pas $3 \%$ de la quantité totale des allumettes fabriquées par les manufactures de l'Etat.

Dans la plupart des pays du Nord de l'Europe, l'usage s'est également établi de vendre des allumettes dans des boites confectionnées entièrement en bois.

Toutes les questions relatives à la production du bois présentent donc un intérêt capital pour l'industrie des allumettes.

Bois pour le débitage des tiges d'allumettes. - Les bois pour allumettes doivent être d'un grain fin, homogène et tenace et d'un tissu facilement inflammable; ils doivent encore présenter une élasticité suffisante et être enfin, autant que possible, exempts de nœuds, autres que les nouds superficiels.

On ne peut donc utiliser pour la fabrication des tiges que les résineux et les espèces tendres ou bois blanes.

En général, les usines qui débitent leurs allumettes ne choisissent pas parmi ces essences et emploient ceux de ces bois qu'elles peuvent se procurer le plus facilement et à meilleur compte.

Cependant, le pin, le sapin et l'épicéa ne servent guère qu'à la préparation des tiges rondes ou striées qui ne peuvent être débitées qu'à la filière ou à la fabrication des allumettes les plus communes vendues très bon marché.

On tient beaucoup, en effet, pour flatter l'ail de l'acheteur, à ce que les tiges présentent uno teinte aussi blanche que possible. Les allumettes de 
sûreté, et surtout eelles qui doivent être paraflinées, exigent en outre l'em ploi d'essenees à tissu spongieux.

L'espèce de bois blanc, répondant le mieux à ces deux condions, est certainement le tremble; mais on le remplace très bien par le puplier et même éventuellement par le saule et le bouleau.

Toutefois, e'est le bois du tremble qui se trouve le plus employé pour la fabrieation des allumettes. Cotte essence est d'ailleurs fort abondante dans le Nord-Est de l'Europe où elle eonstitue des massifs entiers à elle seule. Le tremble y est généralement découpé sur place par des usines spécialement établies à proximité des forêts et expédié tout débité aux fabriques qui ne peuvent songer à préparer elles-mêmes leurs tiges, paree qu'elles n'arriveraient pas à se procurer facilement les bois qui leur seraient nécessaires pour cette opération.

En particulier, à l'exeeption des tiges que l'on découpe à Saintines, at des tiges rondes pour tisons, qui sont en résineux, toutes les allumettes blanches qu'emploient les fabriques de l'Etat franȩais proviennent des provinces russes de la Baltique et sont en tremble.

Cès aeliats à l'étranger portent annuellement sur 13 milliards environ de tiges carrées pour allumettes, dites grande section (G. S.) et 25 milliards de tiges de petite section (P. S.), la produetion de la manufacture de Saintines, qui est seule outillée pour le débitage des bois, n'étant que de 7 milliards d'allumettes G. S.

Pour eette fabrieation, l'usine de Saintines n'utilise d'ailleurs que la variété de peuplier dite "peuplier suisse ».

Le tremble est, en effet, peu abondant dans la région; ce bois est, en outre, d'un prix sensiblement plus élevé que le peuplier, quoique d'un 'rendement moins avantagenx. Enfin, le tremble français ne parait pas correspondre comme qualité au bois de même essence d'origine russe, du moins, les quelques essais qui en ont été faits à différentes reprises dans la fabrication des tiges n'ont jamais donné de résultats bien satisfaisants.

Il apparaît, par contre, que l'on pourrait fort bien admettre, pour la préparation des tiges, le peuplier blane, ainsi que la variété dite "Caroline "tandis que le peuplier noir et le peuplier pyranidal doivent être exclus de eette fabrication pour laquelle ils ne sauraient convenir.

Tout le bois de peuplier, débité par la manufacture de Saintines, est tiré des régions avoisinantes et l'approvisionnement de cette usine a pu toujours être assuré, jusqu'à présent, sans diffieultés sérieuses et même dans des conditions satistaisantes.

Mais l'extension de sa fabrication de tiges, si l'on était jamais amené a l'envisager, ne pourrait vraisemblablement être réalisée, qu'à la condition d'étendre le rayon dans lequel s'effeetuent actuellement ses aehats.

Déjà, eet établissement eonsomme annuellement, pour son débitage d'allumettes, près de 4.500 mètres eubes de peuplier de bonne qualité.

Dans ces conditions, le cube de bois nécessaire à la préparation de toutes les tiges employées dans les manufactures de l'Etat doit êtr. évalué à 27.000 mètres eubes.

Bois pour la confection des boîtes. - Les copeaux pour boîtes ne peuvent être obtenus que par déroulage. Les bois à employer pour leur préparation doivent done se prêter faeilement à cette opération. II laut, 
en outre, qu'ils ne se cassent pas lorsqu'on les plie suivant les sillons tracés par les lancettes de la dérouleuse.

Dans ces conditions, on ne peut guère utiliser, pour la fabrication des boîtes, que les espèces de bois blanes déjà citées, le sapin lui-même ne pouvant servir qu'à constituer les fonds des tiroirs.

Comme d'ailleurs la question de couleur ne joue ici aucun rôle, les usines étrangères débitent toujours leurs copeaux dans le peuplier, si elles en disposent, n'ayant recours au tremble que lorsqu'elles y ont avantage.

En France, on n'utilise, au contraire, pour cette fabrication que le bois de tremble.

On n'y fait d'ailleurs en bois que les boîtes pour tisons et les tiroirs des boîtes pour allumettes suédoises.

La manufacture de Saintines, à laquelle incombe également cette fabrication, y consacre annuellement de 500 à 700 mètres cubes de tremble, provenant pour la plus grande partie des forêts de l'Argonne.

On considère, en effet, que le tremble de la région de Compiègne, où il est d'ailleurs plutôt rare, ne se prête pas aussi bien au déroulage.

Quant à la substitution du peuplier suisse au tremble pour la confection des boites, rien ne paraît devoir s'y opposer, s'il le fallait.

Toutefois, puisqu'on peut les remplacer avantageusement par des cartonnages, l'extension de l'emploi des boîtes en bois pour l'emboîtage des allumettes fabriquées dans les usines françaises ne s'impose pas. D'ailleurs, la situation do ces manufactures rendrait généralement difficile, ou du moins fort coúteux, leur approvisionnement en bois en grumes nécessaires à la préparation de leurs copeaux pour boîtes.

M. Le Présidext - Le rapport de M. Simon est surtout une étude de la facen dont on procède ¿̀ la fabrication des allumettes; il n'a pas émis de rou. Estimez-rous que dans ces conditions if suffit de passer à l'ordre du jour, ou quelqu'un d'entre rous a-t-il des observations à présenter?

11. Pelletier de Mlartres - Profitant, puisque l'occasion s'en présente, d'un rapport qui n'a point émis de vou, je proposerai au Congrès de vouloir bien émettre celui-ci :

Le Congrès émet le veru :

Que l'État améliore la qualité et diminue le prix de ses allumettes et que pour arriver utilement et pratiquement à ce but, il accepte la concurrence privée, sons résers'e de l'exercice",

On ne peut pas, en effet, forcer l'tetat qui a racheté assez. cher ioutes les anciennes fabriques d'allumettes, a renoncer à l'achat qu'il a fait jadis, mais on pourrait, it me semble, erée' des fabriques privées a la condition de les exprcer. c'est-it-dire que les fabricants verseraient un iroit à l'État pour pouvoir fabriquer des allumettes. En mettant les fabricants en concurrence avec l'état, je erois que la qualité des allumetles qu'offre l'Etat s'en ressintirait singulièrement et que nour n'aurions point de ces produits qui, en coútant irès cher, ne valent uńnéralement rien. 
M. le Présidext - Il est bien entenclu que le vou présenté par X. Pelletier de Martres n'a aucune relation avee le rapport dr. M. Simon.

11. Simox. - D'autant plus que la qualité des allumettes est pour ainsi dire indépendante de celle du bois, elle ne tient pas du tout au bois.

II. Le Présidext. - Je ne vais pas mettre aux voix la prise en considération du vou, je vais tout simplement mettre le voen aux voix. Si vous l'adoptez, nous indiquerons qu'il a flé voté sur la proposition de .I. Pelletier de Martres, mais qu'il n’a aucun rattachement an rapport de II. Simon.

Le vreu est adopté.

11. Le Présinext. - La parole est à M. Marcel pour la lecture de som rapport SUT LES EMPLOIS DIVERS DU BOIS.

M. Marcel. - "Ne diminuer en rien, angmenter au contraire la production dans la "partie spéciale de l'industrie du bois que nous étudions; chercher à "concilier cette préoccupation essentielle avec l'impérieuse nécessité " de sauvegarder les richesses forestières de la France ", constitue le double but vers lequel vous avez résolu de faire converger vos préoccupations comme vos efforts; nous espérons, pour notre part, ne l'avoir point perdu de vue.

Il est done telle partie du rapport, que nous arons l'avantage de rous présenter, qui se distinguera par de nombreux détails et telle autre qui se caractérisera par la brièveté des préeisions. Il nous aurait, en effet, semblé illogique autant que contraire aux principes mêmes qui vous inspirent d'oublier, par exemple, que l'industrie du bois courbé est fort peu développée dans notre pays, alors que celle des pâtes à papier prend une extension toujours croissante et exige la recherche des moyens propres à éviter sa limitation, ainsi qu'un déboisement intensif préjudiciable aux intérêts nationaux.

Sous le bénéfice de ces observations préliminaires, nous abordons l'étude que vous nous avez fait l'honneur de nous confier.

Ce sont la Suède et la Norvège, très riches en forêts, abondamment pourvues de cours d'eau, qui fournissent la plus grande partie des bois utilisés pour la fabrication de la pâte.

Elles possèdent l'épicea, le bouleau, le tremble qui sont spécialement appréciés en raison de leur résistance et de leur blancheur.

En France, en Suisse, en Allemagne, en Autriche, au Canada et aux Etats-Unis, la consommation est devenue intensive parsuite de la mult iplication et du développement des journaux, des revues, des publications de toute espèce, de la correspondance comme des emballages, et l'exploitation des richesses forestières utilisables s'est très étendue malgré les importations incessantes de bois du Nord.

Il existe deux sortes de pâtes de bois : la pâte de bois mécanique et la pâte de bois chimique.

10 La fabrication de la pâte de bois mécanique s'opère de la façon suivante : 
Les arbres abattus hors sève, en hiver, sont écorcés, tronçonnés en rondins de $0 \mathrm{~m} .30$ de longueur et de $0 \mathrm{~m} .25$ de diamètre environ. On fait subir à ces rondins soit un lessivage dans une eau légèrement alcalinisée, soit un étuvage à la vapeur pour extraire du bois les résines, les gommes, voire même les tanins. Ensuite, a lieu l'opération du défibrage par le moyen ordinairement employé d'une meule de grès dur, verticale, horizontale, tournant à la vitesse de 160 tours par minute, enveloppée dans une gaine métallique et portant, sur le côté, des cases où l'on place les rondins tronçonnés. Cette meule agit comme une râpe et des sabots en fonte exercent une pression incessante en avant vers les rondins; le courant d'eau qui humecte constamment sa surface emporte les fibres et les conduit dans des tambours suecessifs garnis de toiles métalliques de plus en plus serrées et à rotation de plus en plus lente. En dernier lieu, les fibres sont soumises à un dernier tamisage et râpage à l'intérieur d'un moulin raffineur.

Entre autres procédés employés, il en est un qui consiste à ramollir le bois à la vapeur, à le sectionner en rondelles minces, puis à le brover dans un moulin horizontal.

Les diverses espèces de pâtes ainsi obtenues sont le plus souvent mélangées entre elles, suivant les usages auxquels elles sont destinées ; elles sont ou utilisées sur place, l'usine fabriquant le papier, ou mises en balles et exportées.

$2^{\circ}$ La fabrication de la pâte de bois chimique, qui est d'une qualité plus fine que la pâte de bois mécanique, exige l'emploi de bois blancs plus tendres que celle de la pâte de bois, débarrassés de tout nœeud, de toute résine, débités en fragments ou copeaux, juis broyés entre des cylindres cannelés et finalement lessivés au bisulfite de soude.

Le lessivage qui s'effectue durant 14 heures dans un autoclave cylindrique, chauffé à une vapeur de 108 à $130^{\circ}$, aussi sèche que possible, est destiné à extraire de la cellulose toutes les substances tant soit peu résineuses pouvant déprécier sa qualité. Une fois l'opération terminée, la cellulose est retirée sous forme d'une bouillie foncée à laquelle on fait subir un lavage abondant jusqu'à la parfaite clarifica tion de l'eau employée puis un blanchiment au chlorure de chaux ou autre acide.

Certaines pâtes traitées chimiquement d'une façon sommaire sont destinées, en raison de leur couleur brune, à la fabrication des cartons de luxe et des papiers de tenture et d'emballage soigné.

A la réception des balles de pâtes mécaniques et chimiques, le fabricant soumet celles-ci à la trituration, puis à un mélange des unes et des autres dans une proportion adéquate au genre de papier qu'il veut obtenir. Au mélange, il adjoint la "charge ", c'est-à-dire du kaolin. de l'asbestine, de la china clay (talc) et, éventuellement, du savon résineux. Ces substances, dosées suivant des formules très précises, permettent d'obtenir tous les genres de papier.

Le nombre de machines à papier en France, qui était d'environ 580 en 1900, atteignait 620 en 1910 et plus de 640 en 1912.

La constatation de ces chiffres nous induit à en préciser quelques autres :

En France, la production annuelle de papier suit une progression dont il est aisé de se rendre compte ci-après : 


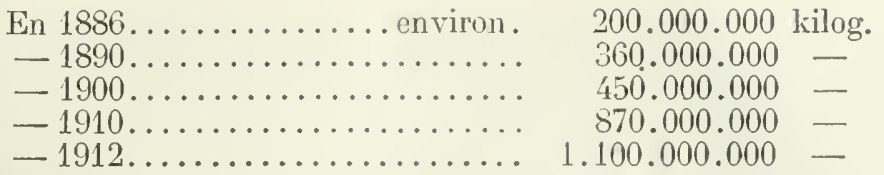

Encore faut-il remarquer, que dans les chiffies de production indiqués ci-dessus, il n'est pas tenu compte des quantités importées de l'étranger, en papiers, cartons, livres, gravures, etc., dont le chiffre dépasse 75.000 .000 francs.

Quant à la consommation mondiale, elle est supérieure à 1 milliard 500 millions de kilogrammes de pâtes de bois, uniquement pour les journaux. En ce qui concerne les usages de la librairie, le chiffre atteint $1 / 2$ milliard. Les autres emplois du papier absorbent 1 milliard de kilogrammes, soit, au total environ 3 milliards de kilogrammes de pâtes de bois que les forêts doivent fournir annuellement pour le monde entier.

De tels chiffres se passent de commentaires.

En ce qui concerne la France seule, l'importation des pâtes de bois s'établit comme suit :

$$
\begin{aligned}
& \text { En } 1910 \ldots \ldots \ldots \ldots \ldots \ldots \ldots \ldots \text {............ } 326.237 .300 \text { kilog. }
\end{aligned}
$$

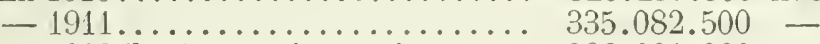

$$
\begin{aligned}
& \text { - } 1912 \text { (les } 11 \text { premiers mois). . ... 386.001.000 - }
\end{aligned}
$$

ce qui indique que pour l'année 1912 entière le chiffre ảe l'importation des pâtes de bois a certainement dépassé 452.000.000 kilogrammes.

Comparativement aux chiffres qui précèdent, la France produit annuellement environ 120.000.000 kilogrammes de pâtes de bois fabriquées soit avec des bois indigènes, soit avec des bois d'importation.

Les statistiques précédentes corroborent done d'une manière péremptoire nos considérations initiales; il est indispensable de prendre des mesures efficaces pour garantir notre sol d'un déboisement supplémentaire en essences, tels que le sapin, le boulcau, le tremble et le peuplier, dont la menace l'accroissement de l'industrie du papier, d'autant qu'il est question de créer en France de nouvelles fabriques; ces mesures consisteront à faciliter par tous les moyens possibles l'importation des pâtes étrangères et des bois appropriés à cette industrie ou produits végétaux coloniaux utilisables. Nous nous permettons d'autant plus de les préconiser qu'avec les bois de pays nos industriels ne produiront jamais assez de pâtes pour satisfaire à la consommation et qu'il ne s'agit point ainsi de protéger une exploitation nationale qui ne dispose sur place que de faibles quantités de matière première.

En premier lieu, nous ferons remarquer que, non seulement les meilleures pâtes sont obtenues avec les chiffons, mais encore avec l'alfa (qui donne un papier très blanc), les fibres du chanvre, du maïs, du lin, du jute, du phormium et du bambou. Ensuite, nous recommanderons l'emploi dı fromager, du musanga, du sterculia dont nos colonies de la Côte d'Ivoire, du Gabon, contiennent des quantités énormes et qui sont des bois très légers, fibreux et par conséquent très propres à la fabrication de la pâte; il faudra, tôt ou tard, avoir recours à ces immenses réserves; sur le terrain économique, comme français, nous pouvons nous en réjouir.

Nous appelons également l'attention des pouvoirs publics sur une 
mesure qui complèterait fort lieureusement celles qui sont spécifiées dans la proposition de loi relative au reboisement des forêts privées et adoptée par le Sénat le 20 décembre 1912.

Nous demanderons que tous les terrains incultes, toutes les dunes de notre litt oral (de la Nanche en particulier) soient plantés de pins ou autres résineux, comme les Landes; certains bouquets de ces arbres qui poussent à l'embouchure de l'Orne croissent dans des conditions qui autorisent les meilleurs espoirs.

Nous désirerions aussi qu'à l'entrée en France des pâtes étrangères, pour éviter aux négociants des discussions et charges préjudiciables, l'Administration des Douanes simplifiât ses opérations en prenant pour base le poids indiqué sur le connaissement avec une tolérance de $10 \%$ en plus ou en moins par tonne, la pâte de bois étant essentiellement lrydrophile et s'imbibant aisément en hiver, alors qu'elle se dessèche très vite en été. L'Administration des Douanes n'a-t-elle point admis un étalon pour le sapin du Nord, le pitchpin et les chênes d'Amérique ou d'Autriche, et ce, à la satisfaction des intéressés?

Il serait enfin très à désirer que les grandes Compagnies de transports maritimes ou terrestres, par l'établissement de tarifs, proportionnés davantage à la valeur de la matièrè, facilitassent l'acheminement des pâtes de bois importées vers les centres de production et de consommation.

Ce produit, d'origine américaine, fit son apparition en France vers 1875 On l'employa tout d'abord à la fabrication des articles de literie, matelas coussins, etc., destinés aux hôpitaux (d'où le nom qu'on lui donna de ( fibre hygiénique »).

Peu à peu, a vec la rareté et l'élévation de prix des fourrages, son emploi se généralisa, prineipalement dans l'emballage. De nos jours, on utilise la fibre de bois dans une quantité d'industries ou de commerces.

En première ligne, pour toutes sortes d'emballages: meubles, quincaillerie, parfumerie, droguerie, fruits, primeurs, denrées alimentaires, etc.

Puis dans la métallurgie, sous forme de cordes pour le noyautage de fonderie.

Dans la tapisserie pour le rembourrage des sièges, coussins, matelas, etc.

La fibre sert encore à la fabrication de quantité d'objets d'usage courant, tels que les paillassons, cordes pour calorifuges, etc.

La fibre de bois (ou laine de bois) est fabriquée, en France, au moyen de bois ronds de 60 à 70 centimètres de longueur et de 10 à 30 centimètres de diamètre.

Les machines à fibre françaises sont composées d'un long bâti de fonte supportant, à l'une de ses extrémités, un arbre sur lequel est fixé un volant également en fonte: ; à l'autre extrémité, une cage à bois qui mesure 70 centimètres delong sur 35 de liant. Un chariot porte-lames passe et repasse devant cette cage, ce mouvement alternatif venant du volant par l'intermédiaire d'une bielle.

On place les bois horizontalement dans la cage, en les superposant, si besoin est, pour atteindre la hauteur de 30 à 35 centimètres. Des contre-poids supérieurs et latéraux les empêchent de bouger. Un chariot d'avancement, progressant sur une vis sans fin commandée par l'arbre du volant, pousse les bois sur le chariot porte-lames, à une vitesse plus ou moins grande suivant l'épaisseur de la fibre que l'on veut obtenir. 
Cette épaisseur varie entre 30 et 8 millimètres.

Le chariot porte-lames détache les copeaux au moyen de deux lames d'acier affilées, placées verticalement et formant un angle plus ou moins ouvert avec le bois. L'une de ces lames est unie, l'autre présente des dents d'une largeur variant entre $1 / 2$ millim. et 2 millim. 1/2. Ces dents donnent la largeur du copeau. Dans certaines machines, la lame dentée est remplacée par un grand nombre de petits couteaux superposés, dont la pointe trace les copeaux que la lame unie détache ensuite.

La production moyenne d'une machine est d'environ 900 à 1.000 kilo. grammes en dix heures.

La fibre est pressée mécaniquement en balles de 20 kilogrammes.

Les qualités varient avec la largeur et l'épaisseur des copeaux. Celles employées actuellement sont au nombre de sept.

Les prix diffèrent, suivant ces qualités, entre 12 fr. 50 et 30 francs les 100 kilogrammes.

La généralisation de l'emploi de la fibre de bois fut rapide.

La maison Falck qui, la première dans notre pays, en commença la fabrication, avec des machines françaises, arrivait péniblement à une production journalière de 2.000 kilogrammes.

Cette production progresse pour arriver:

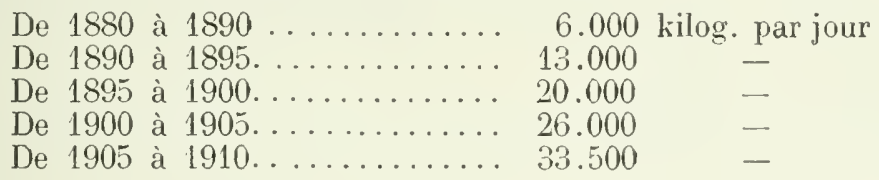

Elle atteint, en 1912, 48.000 kilogrammes pour 21 usines dont 20 sont installées en province et une à Paris, soit un chiffre de 14.400 .000 kilogrammes par année.

A cette production indigène vient s'ajouter l'importation pour les quantités suivantes, dignes d'attention:

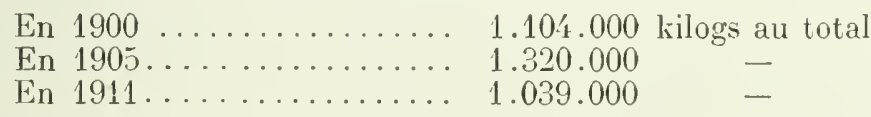

La consommation totale en fibre de bois, tant française qu'étrangèrs, atteignit dans notre pays, pour l'année 1912, le chiffre de 16.320 .000 kilogrammes.

Elle a encore augmenté depuis et il est hors de doute qu'olle poursuivra sa marche ascendante. En effet, l'augmentation du prix des fourrages, causée par les mauvaises récoltes dues, comme leur qualité défectueuse, aux années pluvieuses que nous venons de traverser, leur densité plus élevée, tout tend à une vulgarisation toujours plus grande de la fibre de bois, produit plus souple et plus sain, plus propre aussi, flattant l'œil du client et qui, tout compte fait, n'est pas sensiblement plus cher.

Malheureusement, le développement en France de cette industrie se heurte à des obstacles assez sérieux dont les principaux sont: d'une part, la difficulté do l'approvisionnement en matière première, et, d'autre part, la concurrence étrangère.

L'approvisionnement en matière première. - Le bois le plus communément employé pour la fabrication de la fibre est le sapin. 
Colui qui donne la meilleure qualité, aree le minimum de déchets, est sans contredit le sapin du Nord.

Il est plus blane et n'a pour ainsi dire pas d'odeur, eonséquence de sa faible teneur en résine, c'est ce qui le rend indispensable à la fabrication de la fibre destinée à l'emballage de tous les produits comestibles, entre autres.

L'absence de gros nœuds, son grain plus serré, son fil plus droit, donnent un eopeau plus long, plus résistant. C'est par excellence le bois à fibre.

Le prix en est élevé, et cela en raison principalement des dispositions douanières qui pèsent sur son introduction en France.

Elles figurent aux paragraphes 128 et 133 de la loi douanière du 29 mars 1910, qui stipulent:

$\S 128$. - Bois ronds, bruts, non équarris, avee ou sans éeorce, de longueur queleonque et de circonférence au gros bout supérieur à $0 \mathrm{~m}$. 60 . Tarif minimum, 6 fr. 50 la tonne.

$\S 133$. - Perches, étançons, échalas, bruts de $1 \mathrm{~m} 10$ de longurur et de circonférence atteignant au maximum $0 \mathrm{~m} 60^{\circ}$ au gros bout.

Tarif minimum, 3 franes la tonne.

Les machines à fibre française ne peuvent employer que des longueurs de $0 \mathrm{~m} \mathrm{70.} \mathrm{Or,} \mathrm{il} \mathrm{est} \mathrm{impossible} \mathrm{de} \mathrm{trouver} \mathrm{dans} \mathrm{les} \mathrm{pays} \mathrm{du} \mathrm{Nord} \mathrm{des}$ bois de cette longueur.

Tous les bois à fibre sont done taxés d'après le paragraphe 133, soit à trois francs par tonne, à l'exception de ceux mesurant plus de 0 m 60 dr circonférence au gros bout qui, eux, paient 6 fr. 50 (\$ 12S).

la proportion de ces derniers étant toujours en moyenne de $30 \%$ de la quantité importée, les bois à fibre supportent en réalité, eonséquemment, une taxe d'introduetion de 4 franes par tomne en moyenne.

Or, chacun sait que les bois de papeterie de toutes grosseurs et de $2 \mathrm{~m} 50$ de longueur maxima ne paient que 0 fr. 20 par tonne ( $\$ 135$ bis du tarif).

Pourquoi eette différence de traitement, alors que les bois employés par ces deux industries sont identiquement les mêmes?

Il y a là une anomalie d'autant plus facile à eorriger'que la quantité de bois du Nord nécessaire aux fabriques de fibre est infiniment plus faible que celle employée pour la pâte de bois.

11 suffirait d'ajouter les mots "ou de fibre de bois " à la note qui complète le $\S 135$ bis relatif aux bois à papier ot qui serait ainsi rédigée:

" I charge de justifier de l'arrivée et de la mise en oeuvre dans les "fabriques de pâtes à papier " on de fibres de bois ", sur lesquelles les "bois sont dirigés ".

Cette disposition faciliterait le développement nécessaire d'une industrie dont l'utilité apparaît grandissante, eependant qu'elle aurait une action directe sur la proteetion des forêts françaises où l'on tend à couper les arbres trop jeunes.

La concurrence étrangère. - L'abaissement du droit d'entrée sur les bois aurait encore l'avantage de permettre aux fabriques françaises de lutter plus avantageusement eontre les usines étrangères.

Des fabriques allemandes, notamment, situées à plus de 800 kilomètres de Paris, n'offrent-elles pas leurs produits arec $10 \%$ de rabais sur les prix faits par les fabricants francais, dont les bénéfices sont eependant tres restreints. 
Certaines de leurs forêts contiennent des essences qui, en se rapprochant de la nature des bois russes et scandinaves, leur permettent de coneurrencer la fibre fabriquée en France avec ces dernières essences.

Les importations ont presque doublé en 1912, et elles augmenteront encore si l'on n'y remédie pas.

Les droits de douane, fixés à 5 franes par tonne par l'ancien tarif, avaient été portés à 10 francs par celui de 1910. Les importations fléchirent alor's légèrement pendant deux ans, mais elles reprirent leur marche ascendante causant ainsi le plus grand tort aux fabriques indigènes.

L'industrie française de la fibre de bois traverse, du fait de cette concurrence, une crise que l'on ne pourra enrayer qu'en mettant nos industriels en posture de lutter à armos égales avec leurs voisins.

II serait probablement difficile d'augmenter une fois de plus, en trois ans, les droits d'entrée de la fibre. Aucune raison sérieuse ne s'oppose, néanmoins à faire supporter aux bois à fibre le même règlement qu'aux bois à papier, puisqu'en fait ce sont les mêmes.

La fabrication des sabots s'effectue surtout en forêt: les bois dont elle sahotage. implique l'utilisation sont principalement le hêtre, le boulean, l'aun?, le saule, le noyer et le pin sylvestre.

On prépare les bois en rondins ou en quartiers fendus dans de grozses et moyennes tronces pour en tirer diverses dimensions dont la longueur varie de $0 \mathrm{~m} .20$ à $0 \mathrm{~m} .35$.

Ces bois sont ensuite ébauchés à la hache; on leur donne ainsi la forme grossière d'un sabot; les entailles sont faites ensuite à la vrille, à la cuiller, au boutoir et à la rouanne.

Un mètre cube de hêtre peut donner un rendement de 100 à 120 paires de sabots de dimensions diverses valant 80 francs.

Un mètre cube de bouleau, d'un âge de 40 à 60 ans, peut donner un rendement de 120 à 125 paires de sabots valant de 10 à 12 francs la douzaine. Deux ouvriers fabriquent aisément 20 paires par jour.

Il semble que la fabrication des sabots se heurte à des difficultés de plus en plus grandes, car elle nécessite l'emploi courant du noyer et du hêtre, bois très recherchés par les fabricants de meubles, de voitures, etc.

On peut faire remarquer que la diminution du nombre d'habitants dans les communes rurales entraine une décroissance appréciable dans la consommation. Les petits ouvriers qui travaillent chez eux réussissent proportionnellement beaucoup mieux que les industriels à fabrique mportante; les acheteurs exigent dans le travail un fini que ne peut fournir la machine.

Les cercles se font dans les coupes pendant la période des exploitations, cerelaye. de novembre à fin mars, principalement dans les environs de Paris et en Bourgogne.

Les bois les plus couramment employés sont le châtaignier, le cornouiller, le coudrier, le frêne, le merisier, le bouleau, l'orme, le charme.

L'ontillage se compose d'un bane à fendre et à planer; d'une serpe on forme de faucille, d'uu piochon, d'une plane ou plaine, d'un billard pour cintrer les cercles et d'un parquet pour les tourner.

Les bois coupés hors sève doivent être assez gros pour donner deux. cercles au moins à la fente; ils ont généralement de $0 \mathrm{~m} 10$ à $0 \mathrm{~m} 18$ de tour au gros bout, et de $0 \mathrm{~m} 06$ à $0 \mathrm{~m} 09$ au petit bout. 
Les exploitants vendent de 35 à 55 franes lo $i .000$ de perches en cornouiller et coudrier, et 30 francs le 1.000 de perches en charme.

Les cercles ont 3 mètres de longueur pour les fûts de 250 litres et valent 12 à 30 franes le mille, suivant qu'ils s'appliquent aux feuillettes, pièces ou foudres pour vins et autres boissons.

L'industrie du cerclage a perdu beancoup de son importance depuis que s'est généralisé l'empioides cercles de fer,plus solides, mais protégeant beaucoup moins bien les fúts contre les chocs.

l.e lois conrbi:

L'industrie des meubles en bois courbé fut, pendant de longues années, du domaine presque exclusif de fabricants anstro-hongrois; elle tend ì se développer en Russie et en France, principalement dans les départemints du Doubs, de la Neuse et du Nord.

Le bois de hêtre est employé de préférence à tous les autres pour ce genre de travail et le hêtre de nos pays possède des qualités supérieures à celles de l'essence du même genre qui croît en Autriche-Hongrie ; souple malgré sa résistance et sa dureté, il nous assure ainsi déjà une excellence de fabrication des plus appréciables.

Les pièces choisies sont débitées en lattes carrées de 1 à $6 / 8$ mètres de longueur et de $0 \mathrm{~m} .03$ à $0 \mathrm{~m}$. 06 d'équarrissage, en fil bien droit, et sont ensuite arrondies au tour.

Comme pour le cintrage, on introduit lesdites pièces dans un autoclave où elles sont étuvées, ou cuites sous pression, puis mises dans des moules en métal affectant les formes qu'on désire donner au bois et séchées. Après polissage, elles sont finalement assemblées entre elles au moyen de vis et vernis, cirées ou colorérs, suivant les cas.

Les tarifs de douane sur les importations de meubles ayant été encore élevés l'ammée dernière, l'industrie française se trouve assez bien placée pour lutter contre la concurrence étrangère, d'aut ant que notre bon goút, principalement dans les recherches du "modern style ", lui donne une supériorité immédiate auprès des amateurs intelligents.

C'est donc par des mesures, soit d'ordre forestier intérieur (reboisement), soit d'ordre douanier (abaissement de tarif), destinées à faciliter les approvisionnements de matière première, que l'on assurera d'une manière efficace la protection de cette industrie qui aurait tendanceà se clévelopper fort heureusement dans notre pays.

Les courbes en bois destinées à la carrosserie, au charronnage, à l'aviation, etc., se font surtout en frêne, puis en acacia, en orme, en noyer et en chêne. On les fabrique sous la forme de rayons ou à anse de panier.

En raison de la difficulté de plus en plus grande de trouver de belles grumes de frêne indigène de futaje, les courbes de grandes dimensions s'établissent aujourd'hui en trois pièces avec mortaises. Le frêne de notre pays est une essence incomparable par ses qualités d'élasticité, de souplesse, de dureté. et son emploi ne cesse pas de se développer dans des proportions considérables; sa valeur marchande est done en progression constante.

Le frêne d'Amérique (Etats-Unis)est d'une nature beaucoup plus tendre, il est abondamment offert sur notre marché, mais son trop long séjour sur coupe auquel il faut ajouter la longueur du transport le rendent peu propre au cintrage qui exige des bois frais et nerveux.

Toutes les courbes sont débitées en clrevrons puis rabotées, et enfin 
étuvées pendant une durée d'une heure et demie à deux lieures, suirant l'épaisseur du sciage. C'est ainsi que se préparent les mancherons pour charrues, les panneaux pour eaisses de roitures, les garde-crottes, les cerceaux de capote de voitures et tapissières, etc.

La pièce cintrée est laissée sur son gabarit jusqu'à son complet refroidissement, elle est lattée ensuite pour éviter toute déformation.

Les jantes d'automobiles se font en deux pièces de frêne, d'acaeia ou d'hickory; il faut compter un diamètre double pour obtenir le cintrage désiré.

Les brancards en frêne et en acacia se font à l'aide de ealibres spéciaux permettant de cintrer les pièces à gauche et à droite par paire après avoir été préalablement débitées en chevrons et rabotées. Le cintrage demande une demi-journée; avant d'attacher les brancards par paire on les plane à la dossière pour enlever les éclats.

Dans les campagnes, les charrons cintrent leurs bois en les soumettant à l'aetion d'un feu doux et de la vapeur d'eau, mais pour les pièces soignées il faut recourir aux manufactures spéciales.

L'industrie du tranchage a fait son apparition vers 1850 dans la région parisienne.

Sa réputation s'est étendue jusqu'en Angleterre, en Allemagne, en Espagne, et elle s'impose d'une telle manière que les industriels d'outreManche et d'outre-Rhin font souvent appel aux trancheurs français, tant est indiscutée la perfection du travail de nos usines, et ce malgré les frais de douane et de double transport.

La transformation des grumes en feuilles de 1 à 10 millimètres d'épaisseur s'exécute au moyen de machines de construction exclusivement française, dont l'exeellence est également reconnue partout.

Les bois employés sont, d'ordinaire, des bois de valeur et de fort diamètre, soit indigènes, soit exotiques; néanmoins, on procède également au tranchage des bois de valeur moindre qui sont plaqués sur le panneau formant le cadre même du meuble et recouverts par le placage apparent. Ces placages intermédiaires se dénomment "contre-placages "; ils donnent des panneaux rigides, très résistants et indéformables.

Le tranchage. - Les bois sont amenés à l'usine, soit en grumes, soit en billes; ils sont débités au moyen de seies à grumes avee le minimum de perte et selon les besoins du client. Les quartiers écorcés (sauf ceux d'essences très tendres) sont ensuite placés, suivant leur dureté, dans des chambres de vapeur ou dans des cuves d'eau bouillante; on les y laisse séjourner un temps qui varie afin d'amollir les fibres du bois et donner à celui-ci l'élastieité nécessaire pour la conversion en placage par le moyen de la machine à trancher ou par celui de la dérouleuse, selon les cas.

La machine à trancher à plat se compose d'un bâti rectangulaire dont les deux grands côtés supportent des glissières guidant une partie mobile qui est le chariot porte-couteaux.

Dans le rectangle formé par les côtés du bâti est placé un plateau supporté aux quatre coins par des vis. Des roues dentées placées à la base de ces vis et mues par une cliaîne les reliant entre elles impriment au plateau un mouvement ascendant ou descendant, suivant les besoins.

Le chariot, que l'on peut comparer à une varlope de grandes dimensions, se meut sur les glissières avec un mouvement rythmé d'avancement et de recul. 
A chaque avancement du chariot, le couteau-lame de $0 \mathrm{~m}$. 002 d'épaisseur, placé sur une pièce du chariot nommé porte-lame, et maintenu par un contre-fer, enlève une feuille de placage. Un mécanisme spécial, a vant le nouveau passage du couteau, fait monter le plateau et la pièce à trancher de l'épaisseur de la fenille. A sa sort ie de la machine la feuille de placage est saisie par l'ouvrier et placée sur une table où le quartier ou billon est exactement reconstitué.

Le déroulage. - Le déroulage a pour but d'obtenir des feuilles de grandes dimensions dans des bois d'un diamètre réduit. La pièce à dérouler est fixée par ses extrémités sur l'axe de la machine. lui donnant ainsi l'aspect d'un laminoir.

En tournant, l'axe entraîne la bille et le couteau, à son contact, détache à sa surface une feuille de placage, comme un tourneur tire avec son outil un copeau du bois qu'il façonne.

Dans cette machine le couteau, pendant une révolution entière de la bille, avance d'une façon continue sur le bois de l'épaisseur de la feuille; un trait longitudinal fait dans la bille arant le déroulage interrompt la feuille à chaque révolution. Sans cette coupure le déroulage donnerait une seule feuille de l'écorce ou de son liber, au cour, feuille qui dans une bille de $0 \mathrm{~m} .50$ de diamètre déroulée en épaisseur courante aurait environ 400 mètres de longueur.

Les feuilles tranchées ou déroulées pour placages sont ensuite étalées dans des séchoirs à air libre, sur des claies, jusqu'à ce que leur dessiccation soit complète. Elles sont, en dernier lieu, rassemblées et reconstituées par billes, puis mises en paquets de 30 à 50 feuilles lorsque les parties défectueuses en ont été enlevées.

Le tranchage et le déroulage ont le précieux avantage de donner des feuillets de parfaite qualité, supprimant tout rabotage et procurant une grande économic de matière, de matériel, de temps et de main-d'ouvre.

En 10 heures de travail, une trancheuse peut produire 25 mètres cubes de bois tendres, ou 5.000 mètres carrés de feuillets de 5 millimètres d'épaisseur.

Contre-placage. - Le contre-placage est une industrie toute récente qui rend déjà d"immenses services dans le matériel de chemins de fer, l'ébénisterie, la lutherie, la menuiserie, la carrosserie, la caisserie, l'aviation, etc. Elle a pour but l'assemblage de feuilles de placages posées les unes sur les autres, à contre-fil, c'est-à-dire que le fil du bois est perpendiculaire au fil du placage extérieur.

Cos feuilles ainsi juxtaposées, à fils contrariés, sont collées à l'aide d'une composition spéciale, puis compressées (sinon laminées) de telle façon que l'ensemble des bois contre-plaqués se compose de feuilles absolument homogènes et en épaisseurs variant de 2 à 5 , suivant l'usage auquel ce contre-placage est destiné.

Les qualités principales obtenues par ce procédé si ingénieux, sont: légèreté, flexibilité, solidité. En outre, le contre-placage ne joue pas, nc se gondole pas et peut se cintrer facilement.

Les bois indigènes de gros diamètre, de $0 \mathrm{~m}$. 60 à 1 mètre, sont les plus employés pour les placages, tels que le chêne, le noyer; pour le contreplacage: le hêtre, le peuplier, le grisard, le sycomore, l'aune, le tilleul. D'autre part, les bois exotiques utilisés pour le placage sont: l'acajou, le satiné, le palissandre, le bois violette, le bois de rose, le noyer d'Amérique, ainsi que les plus belles de nos essences coloniales do la Côte d'I voire, 
du Congo et de l'Indo-Chine; pour le contre-placage: le tulipier d'Amérique, l'okoumé du Gabon, le fromager de l'Afrique occidentale, etc., seront intéressants à utiliser.

Dans la carrosserie automobile, les panneaux contre-plaqués ont trouvé une importante application ; ils résistent, en effet, à toutes les vibrations de la route, à la chaleur et à l'humidité.

Le poids moyen de ces panneaux varie de 1 kil.900, pour une épaisseur de $0 \mathrm{~m}$. 003, à 6 kilogrammes, pour une épaisseur de $0 \mathrm{~m}$. 009, avec des dimensions de $0 \mathrm{~m}$. 61 à $4 \mathrm{~m}$. 60, sans raccord ni joint en longueur et hauteur. Il résulte de ces chiffres que le contre-placage pèse six fois moins que le bois massif avec une résistance que l'on peut dire décuplée; un panneau de $0 \mathrm{~m} .005$ offre une solidité équivalente à celle d'une planche de $0 \mathrm{~m} .05$.

L'industrie du bois contre-plaqué est très florissante en Russie où d'immenses forêts renferment les essences les plus recherchées par cette spécialité, tels que le bouleau, le tremble, l'aune, le sapin, dont les dimensions exceptionnelles, la densité légère et le prix très bas permetten t d'obtenir des avantages qui assurent aux producteurs de ce pays une supériorité difficile à concurrencer.

Néanmoins, la France pourrait prendre la place la plus honorable dans ce genre d'industrie si l'emploi du peuplier était adopté d'une façon plus générale par nos fabricants; par son abondance relative et sa reconstitution rapide, cet arbre offre et peut offrir des ressources abondantes : on pourrait aussi recourir aux essences de densité légère dont l'Afrique occidentale française est richement pourvue. Une élévation opportune et raisonnée des tarifs douaniers sur les bois contre-plaqués étrangers permettrait à notre production de soutenir la lutte avec des chances indéniables de succès.

La coloration artificielle des bois s'opère indistinctement sur les grumes, les planches et plateaux, aussi bien que sur les feuilles de placages.

Les essences les plus aptes à ce genre de traitement sont le sycomore, le charme, le hêtre, le tilleul, le poirier' et l'alizier.

Cette industrie spéciale se heurte aux mêmes difficultés que nous avons signalées aux précédents paragraphes de ce rapport: difficultés d'approvisionnement en grumes dont la quantité, la qualité et les dimensions diminuent d'année en année par suite du déboisement intensif de nos réserves : élévation du prix, etc.

Pour colorer le bois, on immerge les débits dans des cuves remplies de teinture, ou bien l'on injecte les grumes selon les procédés employés pour les poteaux télégraphiques, soit même par des moyens électriques; toutes les couleurs peuvent être utilisées : noire, rouge, violacée, bleue, etc.

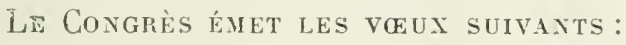

\section{VEUX GÉNÉRAUX}

I. Que toutes les régions qui le permettent soient plantées ou replantées.

II. Que l'importation des bois à ouvrer qui nous font défaut ou dont la rareté nous entraîne à des coupes prématurées soit, dans une certaine mesure facilitée.

Le bois colorè artificiellement. 
III. Que la connaissance de toutes les essences utilisables de nos immenses réserves coloniales soit vulgarisée par tous les moyens, tant pour la mise en valeur de ces réserves que pour conjurer l'appauvrissement des forêts de France.

\section{VEUX SPÉCIAUX}

En ce qui concerne les pâtes à papier :

IV. Que l'importation des pâtes étrangères et des bois dits "à pâtes " soit facilitée par des abaissements de tarifs donanier's qui ne sauraient léser nos industriels, puisque ceux-ci ne produiront jamais assez de pâtes pour satisfaire à la consommation et ne disposent sur place que de faibles quantités de matière première.

V. Que les formalités douanières soient simplifiées en prenant pour base le poids indiqué sur le connaissement avec tolérance de $10 \%$ en plus ou en moins.

VI. Que pour la fabrication de la pâte on fasse emploi en plus grande quantité non senlement de chiffons, mais encore de l'alja, des fibres de chanore, de maïs, de lin, de jute, de phorminm, de bambon, puis de tontes les essences tendres de nos colonies de l'Afrique occidentale française et du Congo.

VII. Que nos dunes du Nord, moins propices à la croissance des pins, soient plantées de graminées à racines étendnes, comme l'orjat; celles de Normandie et de Bretagne, de pins, sapins, etc.

VIII. Que nos montagnes soient plantées de hêtres et de mélèzes et autres arbres.

IX. Que sur les lignes de transport les tarifs soient proportionnés à la valeur de la matière première.

En ce qui concerne la fibre de bois:

X. Que le tanx de la taxe d'introduction des bois à fibre soit abaissée au niveau de celui de la taxe des bois à pâtes à papier.

En ce qui concerne le sabotage, le cerclage, les bois colurbés et cintrés:

$\mathrm{XI}$. Que l'importation des bois employés dans ces industries spéciales soit facilitée par tous les moyens en attendant le reboisement indigène.

En ce qui concerne le contre-placage :

XII. Que l'emploi du peuplier soit généralisé et qu'il soit procédé à des replantations incessantes de cette essence et plus particulièrement le long des rivières et cananx.

XIII. Que l'on ait recours aux bois de densité légère qui se trouvent dans nos colonies.

XIV. Que les droits de donane soient élevés d'une manière raisonnable et opportune sur les bois contreplaqués étrangers.

M. Le Présnext. - M. Marenl a mis plusienus sortes de vocux, d'abord des voux généraux, ensuite des vorux spéciaux. En er qui concerne les 
vœux généraux, M. Marcel propose au Congrès d'émettre les rœux suivants :

" $1^{\circ}$ Que toutes les régions qui le permeltent soient plantées ou replantées $»$.

M. Pelletier ve Mhatres. - Iu lieu de "planlées ou replanlées", je propose de mettre "reboisées ". On procèdo en matière fortstière de trois façons; par la plantation, par la replantation, et par les semis ; mais il y a jun mot qui renferme le tout, e'est le mot "reboisement "; e’est bien l'idée de M. Marcel?

MI. Margel. - Absolument.

Le vœu est adopté avec la substitution du mot "reboisenent".

M. Le Président. - Nous passons au paragraple 2 :

20 Que l'importation des bois à ouvrer qui nous font défaut ou lont la rareté nous entrâne à des coupes prématurées soit dans une certaine mesure facilitée ».

M. Pral. - Je demande qu'on précise en disant qu' les eompagnies des chemins de fer ne mettent pas d'obstacle a l'importation des bois exotiques communs de nos colonies.

M. Hollande. - Je crois qu'il faudrait laisser cette question tout à fait de côté et au contraire s'appuyer sur ceci, c'est que tous les bois de nos colonies devraient profiter d'un tarif tout à fait spécial.

M. Pelletier de Martres. - Les bois venant de nos colonies entrent sans payer de llroits.

M. Hollande. - Je parle au point de vue transport.

M. Marcel. - J'ai voulu généraliser et parler de toutes les essences de bois qui nous font défaut et qui doivent être favorisées à tous les points de vue, sans entrer dans le détail des tarifs.

M. Le Président. - Il n'y a pas d'autres moyens de laciliter l'importation des bois que la douane et les transports ; par conséquent, il faudrait l'abaissement des tarifs douaniers pour faciliter l'importation, d'une part, et d'autre part des tarifs de chemins de fer plus réduits.

M. H. BArbier. - Jr crois que cette question des transports fait l'objet d'une discussion dans une autre section; je crains qu'après une discussion insuffisamment romplète nous votions quelque chose qui soit en contradiction aveé " qu léridera la section voisine. Pour ma part, 
tant qu'il ne s'agit que d'une question d'égalité, je ne fais pas d'objection.

M. Pral. - Je demande qu'on supprime les barrières, je demande l'égalité.

M. le Président. - Voulez-vous, Monsieur Pral, rédiger rotre vou par écrit?

II. Pril. - Voici re vou :

"Que l'importation des bois à centrer qui nous font défant ou dont la rareté nous entraîne à des conpes prématurées soit dans nne certaine mesure facilitée, notamment en taxant le transport des bois exotiques communs de nos colonies, non comme bois précieux comme cela a lien uctullement, mais an même prix que les bois français de même valeur et de même emploi ".

M. Le Président. - I n'y a pas d'opposition?

Le reu mis aux roix est adopté.

II. Le l'Résident. - Nous reprenons la discussion des vrux proposés par II. Marcel.

" $3^{\circ}$ Que la connaissance de toutes les essences utilisables de nos immenses réserves coloniales soit vulgarisée par tous les moyens tant pour la mise en valeur de ces réserves que ponr conjurer l'appanorissement des forêts de France".

Adopté.

M. Miguel Avgel Tobal signale l'importance mondiale de la production de la pâte à papier qui utilise chaque année la production de 3 millions d'hectares de forêts.

Il propose les conclusions suivantes :

$1^{\circ}$ Attirer l'attention de tous les pays du monde sur les funestes conséquences qui menacent l'humanité par la désastution irrationnelle des forêts ayant pour objet la fabrication de la pâte à papier, invitant leurs gouvernements à évoquer l'étude de l'économic industriclle dans relte exploitation.

20 Exhorter les pays qui jouissent des climats subtropicaux a encourager la culture du bambon, plante vivace dont la hauteur de quelques variétés atteint 12 mètres et asec laquclle on prépare une pâte des plus appréciée.

Cette initiative augmenterait considérablement les ressources pubtiques.

$3^{\circ}$ Encourager dans d'autres pays la formation de futaies spéciales formées pur des variétés de plantes choisies, destinéps exclusivement ic cet objet. 
M. Le Président. - Nous passons aux vœux spéeiaux :

En ce qui concerne les pâtes à papier :

" $4^{\circ}$ Que l'importation des pâtes étrangères et des bois dits "à pâtes "soit facilitée par des abuissements de tarifs douaniers qui ne sauraient léser nos industriels, puisque cenx-ci ne produiront jumais assez de pâtes pour satisfaire à la consommation et ne disposent sur place que de faibles quantités de matière première".

M. H. Barbier. - Je vous ferai remarqquer qu'il existe en France des quantités assez considérables de fabriques de pâtes à papier. Au moment de l'établissement du tarif douanier, une discussion s'est élevét, qui a pris une ampleur bien différente de celle qu'elle peut avoir ici. A ce moment-là on a eu deux fils conducteurs de la discussion : $1^{\circ}$ protéger nos bois nationaux, $2^{\circ}$ tenir compte de la main-d'œuvre française. Or, Messieurs, cr vou va directement à l'encontre de ce qui a été fait à la Commission des douanes : si vous demandez un nouvel abaissement des tarifs, vous allez frapper nos usines dr pâtes à papier qui ne sont pas déjà dans une situation très brillante, ainsi que nutre maind'ourre, et derrière elles, la forêt. Je suis donc personnellement très opposé à ce voú.

M. Le Président. - On vous donne la raison de ce va'u, on rous dit qu'on ne peut pas avoir assez de pâtes à papier en France, et qu'il faut trouver le moren d'alimenter nos usines.

M. H. Birbier. - Je vous demande la permission de me faire comprendre. Les pâtes à papier sont fabriquées en France en quantité considérable, e'est un fait acqquis; on n'en fabrique pas assez, c'est un autre fait aequis...

11. Le Présidext. - On ne les fabrique pas exchusivement en France.

11. H. BArBıer. - Je ne dis pas cela, je dis qu'on n'en fabrique pas assez. Quand la discussion de cette question est renue derant la Commission les douanes, on a chiffré la production française; je pense que 11 . le rapporteur va pouvoir nous donner des prérisions sur ce point.

1I. MARCEL. - J'ai dommé tlans mon rapport la consommation qui était faite en pâtes à papier.

M. H. Barbier. - Je n'y ai pas trouvé le chiffr en tonnes de la production française. Nous allons discutrr pendant quelques instants sur dess questiuns de la première gravité, et avec l'autorité qui s'attache à ce Congrès, on va apporter des voux qui ront jeter le disrrédit sur d'autres travaux. Pour ma part, je ne crois pas que nous puissions émettre un veu contre la for̂t française "t contre la main-d'ouvre française. Vous demandez un abaissement des tarifs sur les deruiers droits fixés par le Partement, mais je désirerais voir un tableau annexe que M. le 
rapporteur a sans donte ef qui nous éclairerait sur ce qu'il demande. Vnus connaissez les droits sur les pâtes à papier : on a considéré gưon étail déscendu jusqu'à l'extrême limite à la Commission des dnuanes. Je me résume en rous disant que je vois un gros danger ì l'adoption de ce vou et que personnellement je m'y oppose.

11. HoreAt. - Je regrette de ne pas être tout à fait de l'aris de W. Barbier. On a un peu trop en France l'habitude de vouloir tout demander à la douane. Voici le chiffre que rous demandirz, M. Barbier : en 1912, importation de pâtes de bois, 386.000 tonnes, nt comparativement à ep chiffre, la France produit annuellement environ 120.000 tonnes de pâtes de bois, donc à peine le tires de l'importation. Or, pourquoi drmander toujours à la domaṇ la protection de l'industrie française, an lieu de demander plutòt à l'industrinl de se protéger lui-même "'n fabricant plus? C'esi une question d'ordre général; je l'aurais relevée demain à propos d'un autre vorll du même genre, mais je ne peux pas etre ici demain, et pour l'autre question, elle serait beaucoup plus grave. It crois qu'à force de demander à la douane de protéger l'industrie française on arrior à faire à cette dernière plus de mal que de bien.

M. H. B seprésente devant rous. Je me résume en vous disant: Si la pâte de bois cst produite par des essences trés spécialisées quant a présent, notre pays qui n'en est pas très liche, fournit néanmoins le tiers de la productiom necessaire a ses besnins. Devant la Commission des douanes on a disenté lout cela, if 'n somme, on a surtout dit ce qu'il faut que vous entendiez: cess que, quand l'industrie aura tromse le moyen d'élendre sa spécialisation ì de nowrelles resences, il y a en France un stock énorme de matières lignenses que l'industrie n'emploie pas et ont elle pourra tirer parti.

1. Hollaxte. - - Iu point de vue des droits de douane, je ne suis pas tout a fait de l'avis de 11 . Barbier, of en n'est pas pare que cette question a été disentre dans d'autres sections que nous ne devons pas la discuter. La question est de savoir quel est le prix de la pâte à papier fabriquée con înce ot quel est le prix de la pâtr à papier fabriquée à l'étranger. Si nous pourons prodnire à meillenr marehé, il n'y a aucun inconvénient à ce qu'on abaisse $11 n$ prul les droits de doulane; si, au contraire, la pâte venant de l'étranger rerient à meilleur marché que la nôtre, il fant élever les droits de douane.

11. Lir Il. - II y a dans lo Massif Central, dans la Creuse, la Corrèze, la Hautr-Tienne et le Cantal, des quantités considérables de boulranx dont on he sait que faire el qui seraient très bons pour faire de la pâte à papier.

M. H. Barbier. - de vois que nous sommes, mon cher collègue, M. Hol- 
lande et moi, tout à fait en dehors de la question. Sommes-nous ici pour discuter l'intérêt de la lorêt française ou l'intérêt tle l'industrie ? Discutons-nous, oui ou non, l'intérêt de la forêt française? La question est très délicate. Je ne vais pas vous faire un reproche, mais je ne sais pas, excusez le terme, si vous avez bien dans la peau la forêt française. Vous êtes de brillants industriels de Paris; moi je suis un rural, un forestier, et je trouve qu'en ce momnt nous sortons de la question. Je ne veux faire ici la leron a personne, mais je rrois bien, moi qui ignore tout de votre métirer, que vous ignorez un peu lo mien. 11 existe en France des réserves considérables au point de rue forestie que la science n'a pas encore pu utiliser ; les résineux sont employés pour une part, d'autres rssenees le seront domain ; les bouleaux du Mlassif Central vont entrer en ligne à leur tour, ot l'aulne aussi rertainement. Je connais l'usin qui la traite, et qui précisément ne peut pas lutter contre la pâte ì papier importée ì cause des difficultés qu'elle éprouve à travailler l'aulne. Et pendant que la forêt francaisı se débat contre ces difficultés industrielles et scientifiques, et en mêmr? temps contre les prix relativement bas des pâtes à papier importées, vous allez demander pour la défendre qu'on abaisse ces droits douaniers contre lesquels elle lutte déjà très péniblement! Nous ne sommrs plus dans la question. Nous voulons défendre la forêt française par des moyens appropriés; nous n'avons pas à envisager la situation des industriels qui traitent la pâte à papirr, nous ne sommes pas ici pour cela.

11. Hollande. - Je demande à répondre à $\mathbf{1 1}$. Barbier. II a dit que nous étions ici pour défendre la forêt française, ce qui est l'absolue vérité, et que je n'envisageais pas la question sous le même angle que lui. Je me permets de lui répondre ceci : Je suis, effectivement, importateur do bois exotiques et de bois coloniaux, mais j'ai assez de grandeur d'esprit, lorsqu'il s'agit de défendre la France, pour mettre de còté tous mes intérêts personnels, ot aussi bien mon père que moi nous l'avons souvent prouvé.

Maintenant, Monsieur Barbier, nous entrons dans une rurstion très délicate. Nous sommes ici pour défendre la forêt françaiser, l'rst. vrai, mais nous sommes aussi ici des patriotes et des français pour défendro te commerce français. Or, si aujourd'hui nous ne nous occupons que de la furêt, - ne muttons pas la forêt française, mettons le bois en général, - nous allons peut-être proposer des voux, obtenir des satisfactions qui iront conplètement à l'enrontre des intérêts de nos concitoyens, et un jour ou l'autre, ces concitoyens se lèreront, ils pourront avoir le bras plus long que nous dans les milieux partrnentaires et défaire complètement ce que nous aurons fait, obtenir d'autres ronditions qui seront complètement en désaceord avec les nòtres.

M. I1. Burbier. - M. Hollandre a eu raison au-delis de tout an qui je 
pouvais penser : il a place la question sur son réritable terrain, il l'a pleinement dévoilée. Si nous suivons M. Hollande, nous sommes ici une section qui ra demancler la revision des droits de douane au point de rue de l'importation, du commerce et de l'industrie, mais contre la forêt française. Vous déciderez si vous allez le suivre dans cette voie. Le commerce, j'y appartiens et je m'en lonore, mais je ne suis pas ici pour défendre les commerçants, je suis ici un sylviculteur, r.t c'est sur pe terrain, Messieurs, que je rous demande de rester.

11. Le baron de Belix.r. - Je n'ai pas le chiffres en main, mais je ne rois pas qu'on puisse demander à la forêt française toute la production de pâtes à papier dont l'inclustrie a besoin; je doute qu'elle puisse arriver à la moitié sans compromettre l'avenir des forêts.

II. H. Barbier. -- Nous espérons qu'elle fournira tout un jour.

1I. Hoblaxbe. - Je demante si on peut nous donner le prix de revient de la pâte à papier fabriquée en France et celui de la pâte à papier fabriquée à l'étranger.

M. Le Présidext. - Nous n'avons pas cés chiffres-là. Si personne ne demande plus la parole je mets aux roix lo voru no 4 .

Repoussé.

11. Le P'résident. - Nous passons au veru no 5 :

"50 Que les formulités donanières soient simplifiées en prenant pour base le poids indiqué sur le connuissement as'er tolérance de 10\% en plus on en moins."

Adopté.

11. Le P'résident. - Nous passons au $1^{\circ} 6$ :

- Qne pour la fabrication de la pâle on fasse emploi en plus grande quantité, non senlement de chiffons, mais encore de l'alfa, des fibres de chanore, de muïs, de lin, de jute, de phorminm, de bambon, puis de loutes les essences tendres de nos colonies de l'A frique occidentule française el du Congo. "

1I. Caxon. - Je voudrais simplenent faire remarquer que les produits dont on parle dans le voru, autant que j'ai pu le comprendre, sont les concurrents du bois, et ce sont les bois que nous défendons.

11. Minelin. - Il ne faut pas oublier que re congrès est un congrès inferuational, et qu'en ce moment on se plaint de la destruction des forêts, qui provient de la très grande consommation de la pâte à papiè qui va toujours en augmentant; par conséquent. il sst très logique que, même au point de vur forestier, nous cherchions it remplacer le bois 
par d'autres produits comme l'alfa, le maïs, le lin, le phormium. Ce faisant, nous protégerons, non pas le commerce des bois français, mais la forêt du monde qui est en train, non pas d'être mise au pillage, mais d'aller vers la destruction par la consommation de plus en plus grande, qui se multiplie chaque annér d'une façon formidable, de' la pâte à papier. Il est évident qu'il arrivera un moment où les forêts du monde ne suffiront plus à la fabrication de la pâte ì papier. Eh bien, puisque II. le rapporteur nous offre de l'alfa, du phormium, etc., précipitons-nous sur ces succédanées.

Je me demande cependant à qui ce rueu s'adresse, car je crois que tous les commerecants et tous lés industriels font des travaux considérables pour remplacer le bois par d'autres produits; le jour ou ils auront trouvé le moyen de le faire économiquement, ils emploieront ces autres produits. Je pense que le Congrès, en les encourageant ne fera que les faire persévérer dans la voir où ils sont entrés.

M. Le Président. - Je vais mettre le vou aux voix.

M. H. Barbier. - Je désire répondre à M. Madelin, Il a donné d'une façon bien nette la mentalité de l'Administration forestière française. Il voit avant tout, et e'est le premier de ses devoirs, la perrennité de la forêt, le reste vient après. Et en effet, la pérennité de la forêt sera d'autant plus assurée qu'on lui demandera moins de produits. Eh bien! nous, forestiers français, nous savons que si un tiers de notre production a un débouché large el faeile, la grosse quantité ne trouve plus acheteur; nous savons qu'une masse de bois, les bouleaux du Centre, les hêtres de petite dimension, tout le menu buis, restent invendables; la pâte de bois est là qui peut leur offrir un débouché.

M. Mathieu. - Pourquoi ne s'en sert-on pas? Si on ne les emploie pas, c'est qu'on n'a pas encore trouvé le moyen de les employer; le jour ou vous aurez trouvé ce moyen, alors, je comprends que vous veniez dire qu'on maintienne les droits de douane, mais actuellement, nous n'avons pas l'emploi de ces bois-là. Attendons demain avant de prendre une détermination.

M. H. Barbier. - Les éclaircies des pins de Sologne conviennent à merveille aux pâtes à papier ; on ne les emploie pas à cause do l'entrée à bas prix des pâtes étrangères.

M. Pelletier in Martres. - Je vais vous donner la raison pour laquelle on n'emploie pas certains bois, le bouleau et le tremble, par exemple : c'est parce qu'on n'en tronve pas des quantités suffisantes pour être envoyées à l'usine ; il y en a de trop petites quantités. alors on les laisse.

J'ajoute - et ceci rentre directement dans l'objet du Congrès - qu'à l'heure actuelle, on travaille d'une façon très pertinente sur le hêtre, que la question est pour ainsi dire an point, et que nous touchons an 
moment où on pourra employer le hêtre pour la fabrication de la pâte à papier. J'ai des camarades qui s'occupent comme ingénieurs de la question pour un des plus grands journaux de Paris; elle est presque au point, quand elle le sera complètement, nous pourrons peut-être donner de la valeur à nos taillis de hêtre. Ce ne sera pas long; il ne se passera pas un an avant que la solution soit trouvée, elle est imminente.

M. Le Président. - Je mets aux voix le vou no 6 .

Arlopté.

Nous passons au vou no 7 :

"7o Que nos dunes du Nord, moins propices à la croissance des pins, soient plantées de graminées à racines étendues, comme l'orjat; relles de Tormandie et de Bretagne, de pins, sapins, etc. ".

M. Le Président. - Sous le bénéfice de la suppression du mot "sapins", je mets le vou aux voix.

Adopté.

Nous passons au vou $n^{\circ} 8$ :

" $8^{\circ}$ Que nos montagnes soient plantées de hêtres et de mélèzes et autres arbres $1 . !$

Idopté.

Vheu no 9:

"9o Que, sur les lignes de transport, les tarifs soient proportionnés à la valenr de la matière première. "

M. Pelletier de Martres. - C'est d'ailleurs la valeur de la matière première qui a constitué la base des tarifs.

M. Le Président. - Pas d'opposition? Le vou est adopté.

Nons arrivons à la fibre de bois :

En ce qui concerne la fibre de bois :

"10" Que le tanx de la taxe d'introduction des bois à fibre soit abaissé un nivean de celni de la taxe des bois à pâtes à papier".

M. H. Btrbier. - Mh! jamais de la vie!

M. Mipelin. - Du fait que nous avons refusé de voter le premier vœu, nous serions illogiques en votant celui-ci.

M. Le Présibent. - Le vœu n'est pas pris en considération. Continuons :

En re qui concerne le sabotage, 'le cerclagr, les bois courbés et cintrés : 
" $11^{\circ}$ Que l'importation des bois employés dans ces industries spéciules soit facilitée par tons les moyens en attendant lo reboisement indigène. "

Sur l'intervention de M. H. Barbier, Brion et Pral, le veu est retiré.

1I. Le Président. - Nous arrivons au vou no 12:

En ce qui concerne le contre-placage :

"120 Que l'emploi du peuplier soit généralisé et qu'il soit procédé $\dot{a}$ des replantations incessantes de cette essence et plus particulièrement le long des rivières et cananx. "

Adopté.

"13ํ Qne l'on ait reconrs anx bois de densité légère qui se trouvent dans nos colonies."

\section{Adopté.}

" $14^{\circ}$ Que les droits de donane soient élevés d'une inanière raisonnable et opportune sur les bois contreplaqués étrangers."

M. H. Barbier. - Mh ! cela va mieux! C'est la forêt qui répond! Nous vous lélicitons, Monsieur Marcel!

M. MArgel. - S'il y avait assez de peupliers en France, le vou ne se présenterait pas.

Le vou mis aux roix est adopté.

M. Le Présinext. - La parole est à M. Puteaux pour la lecture de son rapport sur les BOIS DE SCIAGE; OUTLLAGE, DÉBIT, MENUISERIE, PAVÉ.

M. Puteaux. - Une documentation très complète et une étude approfondie de la question permettraient seules de présenter ici une revue de tout ce qui a été créé pour travailler le bois de nos forêts et l'utiliser pour nos innombrables besoins.

Pour rester dans les limites du sommaire à développer, il convient de prendre l'arbre à sa chute, lorsqu'il vient d'être amené, élagué de ses branches, à l'endroit où l'exploitant va avoir à l'examiner pour être débité.

Cet examen fait, la question " outillage » reste entière à étudier suivant un ordre que l'importance de l'outil indique, en tenant compte également des perfectionnements très réels apportés à chacun d'eux depuis leur création.

Forcément un peu d'histoire s'impose pour attester avec plus d'éclat les progrès accomplis dans cette branche de l'activité lummaine.

Et enfin pour compléter et terminer cette énumération commentée de l'outillage du sciage et du travail mécanique des bois, une adresse de félicitations aux précurseurs des appareils de protection destinés à ces 
mêmes outils qui, s'ils forcent notre admiration par la complexité de leur conception, doivent également retenir notre attention pour les accldents, toujours trop nombreux, qu'ils occasionnent aux ouvriers chargés de les conduire.

Tronconnage des grumes.

\section{Ce travail se fait de deux façons :}

1o A la main, à l'aide de la scie à main, ditc "passe-partout ». L'opération, très simple, ne comporte aucune description.

$2^{\circ}$ A la mécanique, par machines fixes et machines mobiles, mues par la vapeur ou l'électricité.

L'électricité, cette force capricieuse, non encore asservie à tous nos besoins, a contribué pour beaucoup à la généralisation de ce système. En effet, beaucoup de nos exploitants utilisent aujourd'hui la " tronçonneuse électrique " et en apprécient la conduite pratique et facile.

Le débit des grumes se fait :

$1^{\circ}$ A la main.

$2^{\circ}$ A la scie circulaire.

$3^{\circ}$ A la scie alternative.

$4^{\circ}$ A la scie à ruban.

Débit à la main. - Il est juste de dire qu'aujourd'hui ce genre de travail, auquel se livraient nos scieurs de long tend à disparaitre. Les moyens de production actuels éliminent peu à peu ce mode de débit, tant sont nombreux les avantages obtenus par l'emploi des machinesoutils.

Débit à la scie circulaire. - La scie circulaire est formée d'un bâti supportant un double palier dans lequel tourne un arbre en acier, aux extrémités duquel sont fixées, d'un côté, les poulies de commande et, de l'autre, la lame.

Cet outil dont la conduite exige quelque expérience est surt out apprécié dans les exploitations forestières.

Débit à la scie alternatice. - Cette machine est composée d'un châssis porte-lame animé d'un mouvement alternatif et coulissant dans les montants d'un bâti en fonte. La grume à débiter y est amenée à l'aide d'un chariot.

Cotte scie, d'un emploi très varié, peut être à plusieurs lames ou à une seule sur le côté; de plus, elle peut être verticale ou horizontale.

La scie alternative à plusieurs lames est destinée au débit en planches ou en plateaux, des bois en grume et des fortes pièces équarries; elle débite un arbre d'un seul coup et sa production est très grande.

L'amenage se fait par cylindres cannelés et par chaînes, par crémaillères et par cylindres cannelés commandés.

La scie alternative à une lame sur le côté jouit d'une grande faveur pour yon travail de précision.

La scie horizontale alternative a une lame à denture spéciale permettant le sciage en allant et en venant.

La scie horizontale alternative à bois montant s'emploie spécialement pour le débit des bois des îles, en feuillets et placage. La perfection de son sciage est absolue.

Ja scie verticale à une ou plusieurs lames peut débiter deux ou une

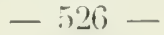


seule pièce à la fois. selon le nombre de lames et de'rouleaux entraineurs.

La scie dite scie à cylindres est recherchée pour les beaux sciages qu'elle donne et la régularité du travail qu'elle assure.

Débit à la scie à ruban. - Avec cette machine, une véritable révolution s'est produite dans le débit des bois, qu'il s'agisse de grume ou de bois équarris.

Longtemps la scie alternative avait été considérée comme l'outil rêvé, le seul possédant les perfectionnements nécessaires au renoncement absolu de l'intervention du scieur de long d'abord, de la seie circulaire ensuite. Cet entrainement automatique et rythmé de l'alternative, c'était l'idéal.

Chimérique illusion; la concurrence, ce stimulant nécessaire à notre activité, devait et pouvait espérer mieux encore.

Cette recherche du mieux fut, en effet, le fait d'un modestr ouvrier menuisier bordelais qui, le premier, eut l'idée de faire travailler une lame de scie sur deux volants superposés.

Le principe de la "lame sans fin " était trouvé et son application, rapidement perfectionnée, donna naissance à la scie à ruban à grumes et à cylindres que nous admirons aujourd'hui dans nos usines.

La scie à ruban à grumes, constituée par un bâti en fonte, porte une poulie à sa partie supérieure et une inférieure.

Sur ces deux poulies tourne une lame en aeier dentée et soudée.

La pièce de bois est amenée contre la lame au moyen d'un chariot à agrafes et à griffes.

Tous nos constructeurs ont rivalisé pour doter cette machine de tous les perfectionnements désirables et nous devons nous réjouir que là encore notre pays tienne la tête avec quelques maisons considérées comme les plus réputées de nos marques françaises dans ce genre de fabrication.

Afin de ne pas prolonger la nomenclature do ces sortes de machines, nous nous en tiendrons done à la description sommair du ruban $\dot{a}$ grumes le plus perfectionné.

Détail à retenir: un seul homme pent conduire cette machine sans avoir à se déranger, tous les appareils de commande se trouvent sur le socle, à portée de la main.

A l'aide de la division automécanique, l'ouvrier n'a qu'à indiquer sur un cadran, au moyen d'une aiguille, la division correspondante à l'épaisseur à obtenir.

La simplicité du mécanisme permet à l'ouvrier, à la fin de chaque trait, de ramasser et de soutenir le bois.

Si l'on ajoute à cela que des appareils de dégagement très ingénieux concourent au fonetionnement faeile et rapide de la machine, on peut en conclure que la main-d'œuvre aidante est totalement supprimée et que la production de cet outil est rendue tout à fait intéressante du fait que la lame travaille utilement dans le bois pendant un temps très appréciable.

Pour ne rien omettre des avantages de cette machine, il convient d'ajouter que les arbres, en acier dur, sont montés sur roulement à billes. Tout danger d'échauffement est ainsi écarté en même tem ps qu'est assurée une économie considérable d'huile et de force motrice.

Bois de sciage. - Le débit des grumes est terminé, les différents sciages exécutés au mieux des intérêts de l'exploitant et de ses besoins, arrivent à la scierie proprement dite, celle chargée d'alimenter une clientèle aussi nombreuse que variée.

L'uutillage mécanique, chargé d'assurer les besoins de notre industrie, 
mérite une description largement commentée où la partie technique doit occuper la première place.

Lames de scie. - La lame de scie, âme de toute machine, appelle tout d'abord notre attention.

Sa préparation, son épaisseur, sa denture, la forme de cette denture, sa profondeur et son écartement, sa tension, la voie qu'il convient de lui donner, les précautions à prendre pour la mettre en mesure de donner de beaux, réguliers et rapides sciages, la façon de la rebraser et de la remettre en état après un accident au cours du trarail, sont autant de points délicats à examiner.

En raison de leur grande longueur et de leur faible épaisseur, du peu de tension qu'on peut leur donner, les lames de scie demandent, pour bien fonctionner, à être usinées dans d'excellentes conditions.

De plus, devant s'enrouler continuellement autour des poulies de la machine et être par conséquent constamment ployées, elles demandent à être de très bonne qualité.

Les lames de scie doivent avoir une épaisseur en rapport avec le diamètre des poulies sur lesquelles elles s'enroulent.

Trop épaisses elles cassent ; trop minces, elles ne sont pas assez rigides.

De $6 / 10$ à $13 / 10$ e pour des variations dans les diamètres des poulies jusqu'à 2 mètres. Telles sont les épaisseurs à observer.

La largeur est déterminée d'après les courbes que l'on veut cxécuter. Employées au débit des bois en grume et au dédoublage des madriers et des plateaux, cette largeur est approximativement de $1 / 18^{\mathrm{e}} \mathrm{du}$ diantètre des poulies.

'Trois dentures sont employées : dents mariées, à gencives, à crochets, selon la nature du bois à débiter.

De la forme de la denture, de son écartement (15 à 30 millimètres) et de la voie, donnée régulièrement et suffisamment (2/3 aux 3/4 de l'épaisseur de la lame), dépend la bonne marche, d'une lame de scie à ruban.

Dans ces dernières années, une denture à grand logement de sciure, avec dents écrasées, a été préconisée et, on peut le dire, employée avec succès dans le débit des grumes, bois rerts ou demi-secs.

Jusqu'à présent, ce système de denture n'a pu se généraliser et s'appli. quer aux bois de sciage secs.

Il est à remarquer toutefois qu'au point de vue travail de la lame, ce système de denture assure un travail régulier de toutes les dents et un dégagement plus intensif de la sciure produite, partant une production plus grande.

L'affûtage d'une lame de scie à ruban, restée longtemps l'apanage d'un petit nombre d'ourriers spécialistes, tout en restant l'opération la plus délicate et la plus sérieuse dans la préparatinn de la lame, a subi une évolution heureuse par l'emploi de la machine à affutter.

Tout d'abord fabriquée pour exécuter l'affútage de la dent à l'aide d'un tiers-point, elle n'est plus guère employée maintenant que montée avec meule artificielle défonçant automatiquement la denture.

Les mouvements réguliers dont la meule est animée assurent un affítage parfait où la main de l'ouvrier n'intervient que pour la mise au point des organes de la machine. Le rôle de l'affûteur, plus effacé que jadis, se révèle encore dans ce quı reste à faire à la lame qưil vient d'enlever, affûtée, de dessus la machine.

La voie, bien que pouvant se donner mécaniquement par cette même 
machine, reste encore, avee le planage, le bagage de tout ouvrier affúteur capable et sérieux.

Exception est faite cependant pour la denture à voie écrasée, pour scies à grumes, pour laquelle deux appareils, très ingénieux et d'une précision remarquable, sont employés.

La rupture d'une lame, qu'elle soit le fait d'une trop grande épaisseur de la lame par rapport au dianètre des poulies, d'un affûtage incomplet du fond des dents ou d'une mauvaise conduite sur la machine, donne lieu au brasage ou suture des extrémités disjointes par les causes précédentes.

Le brasage d'une scie nécessite encore un tour de main spécial pour ne pas risquer de détremper la lame exposée au feu de forge.

Là encore la machine à braser est préconisée et employée avec succès. La brasure au cuivre n'est plus usitée que pour le brasage à la main à l'aide de la forge ; en raison de la température nécessitée pour amener la fusion du cuivre, il est fait usage, avec la machine à braser, de la soudure d'argent.

Pour de multiples raisons, une lame de scie à ruban peut :

a) Se détendre par suite d'un excès de tension dans le travail d'une marche trop longue à une vitesse anormale sans être réaffútée; de la rencontre, et du choc qui en est la conséquence, d'un corps étranger, voire même d'un éclat de bois, dans la lumière do la table du ruban à cylindres; d'un montage ou démontage inexpérimenté sur les poulies porte-lames.

b) Recevoir un "tour de reins", un "gauche".

c) Se creuser au dos et ne pas, pour ces raisons, descendre bien perpendiculairement dans ses guides.

C'est ici que le planage s'impose ; il se fait au marteau, dans des conditions spéciales pour "ramener la lame ".

La machine à tendre les lames intervient également pour 'compléter l'action du marteau, mais le plus souvent lorsqu'il s'agit de lames encore larges, presque neuves, sur lesquelles la pression exercée par les evlindres de la machine à tendre peut se faire partiellement.

Un autre accident peut survenir également à une lame en marehe. Elle peut couper un clou, une pierre, un gravier sertis dans un des morceaux à débiter ou dissimulés dans une gerce; parfois même une balle de chasseur ou de tir.

De ces différentes rencontres, ce qui peut résulter de plus heureux, c'est l'obligation de réaffûter la lame "mouchée " et le pire, c'est le dédentage partiel sur une grande longueur, accompagné d'un gauchissement de la lame.

Le remède apporté à ce genre d'accident, en plus du temps perdu, se traduit par, si cela est possible, car il est des cas où la lame doit être mise hors de service, un réédentage de la lame accidentée. Rebrasée, replanée, elle peut parfois continuer un service normal.

Quelque superflu que puisse paraitre cet exposé de l'utilisation de la lame de scie à ruban, nous n'avons pas cru pouvoir nous en dispenser pour nous aider à formuler des voux auxquels s'associeront sans restriction tous les industriels intéressés.

Cette digression fait ressortir davantage combien est appréciable la lame de scie à ruban bien préparée pour le travail qui peut lui être demandé avec les scies à ruban, à cylindres; actuellement dans nos scieries. 
La scie à rulıan, à colindres, pour n: citer que celle-là, à l'instar de celle à grumes, décrite dans un autre chapitre, procède de la même conception au point de vue de l'esthétique dans la forme et la robustesse dans tous ses organes

Nos maisons françaises lui ont donné l'indélébile marque d'une supériorité que l'étranger copie souvent sans pouroir l'imiter.

Cet outil remarquable, pourvu de la lame de scie qui convient, peut donner une production dépassant l'imagination et cela, sans que l'ouvrier chargé de le conduire éprouve de surmenage; bien au contraire, il est entraìné presque malgré lui à utiliser cette force qu'il a en mains et à lui demander tout ce qu'elle peut donner.

Cette attirance se conçoit très bien d'ailleurs lorsqu'on examine les différents organes de cette machine.

Tendre sa lame, modércr ou accélérer l'allure de l'avancement du bois entraîné par les cylindres, débrayer... tout cela n'est qu'un jeu auquel l'ouvrier s'entraîne de lui-même tant son désir est grand de demeurer malgré tout le maître de sa machine.

Les merveilleux perfectionnements apportés à cet outil dans ces dernières années ont facilité de beaucoup l'éclosion de nombreuses scieries mobiles ou fixes qui toutes concourent à rendre plus rapides nos transactions et à satisfaire les exigences d'une clientèle toujours plus nombreuse.

En nombre restreint d'abord, les scies à ruban'à cylindres, rencontrèrent de fervents adversaires auprès des détenteurs de scies alternatives (décrites plus haut); bien plus, la clientèle, à l'instigation de ces réfractaires au progrès, fit chorus pour repousser l'emploi do cette nouvelle machine à "sabrer le bois".

Aujourd'hui qu'il est reconnu et avéré que la précision et la rapidité peuvent être obtenues avec la "sico à ruban à cylindres ", les détracteurs d'antan sont muets et s'inclinent.

La supériorité incontestable de cet outil est un facteur sérieux de prospérité pour nos exploitations et scieries provinciales ou parisiennes et ce serait nicr l'évidence que de ne pas reconnaître que les bois de sciage, dont en France il so fait un si grand trafic, n'ont pas recueilli quelques profits des perfectionnements apportés à ces machines dans cette partie de notre outillage mécanique.

Menuiserip.

Les bois destinés à la menuiserie, qu'il s'agisse de bois blanc, de sapin ou de bois d'essence, sont façonnés aujourd'hui par une série de machines de la plus ingénieuse conception.

La nomenclature, un peu longue, de ces outils s'impose cependant.

La scie alternative à arc ou à sangle, indispensable aux ébénistes pour les découpages intérieurs.

La scic circulaire à axe fixe ou mobile, permettant d'exécuter une foule d'ouvrages qui se rencontrent fréquemment dans la menuiscrie et l'ébénisterie, notamment les feuillures.

La scic circulaire à table inclinable.

La scie circulaire à amenage automatique par cylindres rerticaux conjugués ou horizontaux, spécialement employée par les scieries travaillant les bois du Nord.

La même scie pour tirer de largeur les frises de parquet de pin vu de chêne. 
La seie eireulaire pour le bouvetage en bout des lames de parquet.

Telles sont les principales scies circulaires à l'aide desquelles certains travaux de menuiserie sont exéeutés en quantités et dans des conditions de rapidité et de fini d'exécution inconcevables.

La raboteuse joue également un très grand rôle dans la menuiserie. Construite pour raboter une, deux, trois ou quatre faces, isolément ou simultanément, elle défie la main-d'œuvre la plus experte.

Combinée avee la toupie, cette machine exécute de véritables merveilles.

La raboteuse quatre faces ou parqueteuse à grande production, d'une construction très complexe, a retenu longtemps les soins de nos constructeurs.

Aujourd'hui, cette machine, chef-d'œuvre de mécanique, donne toute satisfaction.

Les machines à moulures, dites toupies, sont très employées en menuiserie en raison du travail varié qu'elles peuvent donner.

On doit distinguer dans cette catégorie les machines à faire les moulures, sur une seule face, sur trois et quatre faces à la fois. Cette dernière est la plus usitée dans les ateliers de menuiserie de quelque importance.

Quelques autres toupies méritent également d'être signalées; telles sont : celle à table mobile pour les moulures courbes, ne pouvant se travailler sur la table..

La toupie horizontale pouvant recevoir des outils à ses deux extrémités.

La toupie dite machine à défoncer employée par les ébénistes, les menuisiers, les modeleurs, pour défoncer les panneaux, préparer les reliefs de seulpture, faire les refouillements. Elle remplace, dans certains cas, la machine à percer.

Comme tenant une place assez large dans l'outillage mécanique de menuiserie, on doit citer :

La dégauchisseuse remplaçant le varlopeur le plus habile. Nous ne saurions trop recommander, dans tous les cas, de munir cette machine d'un porte-outil circulaire, avec fers minces, système "Rivite ", dont l'application aux raboteuses est très appréeiée.

Tenonneuses et mortaiseuses, ainsi que quantité d'autres petits outils, clôturent la série de ces machines à bois, merveilleuses de préeision et de rapidité.

Dans cette branche de la mécanique, la France tient encore un rang digne d'elle; la compétence de nos ingénieurs ne s'est pas démentie et les notables efforts de nos construeteurs ont puissamment aidé à la notoriété incontestée de notre outillage connu et apprécié du monde entier.

En ce qui concerne la fabrication du pavé de bois, il suffira de dire Pavé. que ce travail est obtenu à l'aide de scies eireulaires à lames multiples placées à l'extrémité inférieure d'un balaneier vertical oseillant automatiquement.

La production de cette machine est considérable et ne comporte aucune description spéciale.

Conclusions. - Avant de terminer ce rapport qui a mis en relief, peutêtre trop amplement, la valeur de notre outillage national, qu'il nous soit permis d'émettre un vœu cher à tous les industriels:

"C'est qu'il soit mis tout en ouvre pour prévenir les accidents pouvant 
survenir aux ourriers chargés de la conduite de ces machines-outils, nos précieux auxiliaires ".

Cette recherche des moyens d'assurer la protection des travailleurs a été l'objet d'études d'autant plus suivies qu'il est plus facile, plus humain et moins coúteux, de prévenir un accident que de le réparer.

C'est dans cette pensée d'humanité d'abord, d'intérêt général ensuite, que l'Association des Industriels de France a contribué à l'organisation, au Conservatoire national des Arts et Métiers, du Musée de prévention des accidents du travail et d'hygiène industrielle.

Aidée en cela par les pouvoirs publics, cette Association a ouvert ses rangs aux sommités industrielles dont les efforts unis aux connaissances professionnelles de nos praticiens ont permis d'augurer le jour prochain où la sécurité absolue du travailleur sera assurée par des appareils réellement utilisables.

Ce résultat obtenu sera tout à la gloire de ces bienfaiteurs du travail.

Comme conséquence de ce travail, la 3 e Section (Technologie forestière) du Congrès Forestier International émet les vœux suivants :

1. Que plus de précautions soient prises pour préserver les arbres en bordure de nos routes, lavoirs et cours d'eau, des clous ou déprédations quelconques ayant le caractère, non pas de malveillance au sens propre du mot, mais d'impardonnable ignorance.

II. Que les stands oul champs de tir soient suffisamment éloignés des parties boisées pour éviter que des balles perdues ne viennent compromettre l'existence de nos plus beaux arbres.

III. Que des appareils de protection, véritablement pratiques, soien't créés pour la conduite, sans danger, des machines-outils.

11. HoredT. - Je crains que vous ne donniez des armes aux inspecteurs du travail sur le dos des industriels. Constamment les inspecteurs du travail rienment nous dire que nos appareils ne sont pas suffisamment pratiques, ne protègent pas assez les ouvriers. Je puis vous citer un exemple: J'ai chez moi - ce n'est pas en France, e'est en Belgique des scies circulaires à scier des fagnts; eh bien! l'inspecteur du travail voudrait que la lame des scies soit enveloppée complètement pour scier des fagots de tous les diamètres!

M. Le Président. - Le vocu paraitt indiquer que tous les procédés actuels ne sont pas pratiques, puisqu'il demande qu'on en crée de véritablement pratiques.

11. Puteaux. - C'est un encouragement aux inventeurs. Le rapporteur estime qu'au musée que vous connaissez, qui se trouve au Conservatoire des arts et métiers, les appareils préconisés par la "Société des inclustriels de France contre les accilents du travail "ne sont pas suflisants pour protéger l'ouvrier, qu'au contraire, certains mêmes sont langereux. L'idée du rapporteur est plutôt une critique des appareils existants. II demande - et c'est plutôt un encouragement aux inventeurs - que des appareils véritablement pratiques soient 
créés pour la conduite sans danger des machines-outils, car nous avons à penser aussi à la sécurité de nos travailleurs.

Les voeux sont adoptés.

M. Le Président. - La parole est it M. Boccquet pour la lecture de son rapport sur les Produtts ACcessolres, léchets de BOIs, UTILISATION DES SCIURES.

M. Bocquet. - Les déchets résultant du travail du bois peuvent être divisés en troi- principaux groupes :

10 Les éclats de bois et déchets de scierie.

$2^{\circ}$ Les sciures.

$3^{0}$ Les copeaux.

Les éclats de bois sont le fait de l'abatage et de l'équarissage à la hache des pièces de charpente en forêt. On ne peut les utiliser que comme combustible.

Les déchets de bois produits par les outils mécaniques, soit à l'exploitation, soit par la suite dans les différentes usines où le bois est travaillé, sont également employés comme combustible.

Les déchets les plus importants sont coupés à longueurs fixes, bottelés et vendus comme bois de chauffage. Les menus déchets, le plus souvent brûlés sur place dans les usines, peuvent aussi être vendus comıne allumefeux pour les usages domestiques.

Les sciures produites par le passage des scies dans le bois se montrent, sciures. au contraire des éclats de bois, susceptibles d'être affectées à beaucoup d'usages.

Il convient donc de les étudier en détail et en raison même de leur utilisation, de les diviser en deux catégories :

Les sciures de boisjvert.

Les sciures sèches.

Sciures de bois vert. - Les premières proviennent du débit des bois en grumes et sont produites en grande quantité dans les exploitations pourvues d'outillage mécanique. En France, ce sont surtout les exploitations de peuplier qui en fournissent la plus grosse partie. Les départements de la Marne et de la Seine-et-Marne envoient cette sciure par milliers de tonnes à Paris où elle est utilisée. La plupart des scieries fixes qui débitent des grumes de bois dur, emploient la sciure comme chauffage, sauf dans la région parisienne où la plupart des sciures vertes trouvent leur emploi.

La grosseur de la sciure, c'est-à-dire la dimension des fibrilles de bois qui la composent est proportionnée à l'épaisseur de la lame de scie qui l'a produite et à l'écartement des dents.

Les sciures produites par les scies circulaires sont les plus grosses, puien décroissant viennent les sciures provenant des scies alternatives et enfin celles des sries à ruban qui sont les plus fines.

La sciure verte de peuplier mélangée avec de la sciure sèche de sapin plus fine est employée pour le bala vage livgiénique des boutiques.

Eclats de tots et déchets de scie. rie. 
magasins, casernes et grands établissements publics. Dans les hôpitaux on y mélange des liquides désinfectants.

On en répand aussi pour ménager les dallages dans certaines boutiques, notamment dans les boucheries.

La plus grosse sciure verte est demandée par l'armée et par d'importants marchands de chevaux pour garnir le sol des manègés.

Les usines à gaz font une grande consommation de sciure verte pour l'épuration des gaz de houille.

Enfin, nous devons signaler que la sciure verte de peuplier calcinée sert à fabriquer le charbon médicinal.

La quantité des sciures vertes utilisées dans l'industrie ou les usages domestiques est bien inférieure à la production; aussi, en dehors de la région parisienne, la plus grande partie est-elle brûlée sur le lieu même de la production. Toutefois, en raison même de la très grande utilisation des sciures sèches, certains marchands ont intérêt à faire sécher les sciures vertes, soit en les répandant et en les plaçant à l'action de l'air, soit en les faisant circuler dans des séchoirs mécaniques.

Deux essences de sciure verte sont inutilisées, ce sont celles du noyer et du sapin.

Avant de terminer ce rapide exposé de l'utilisation des sciures vertes, nous ne manquerons pas de citer cet emploi bien connu des sciures de chêne par les exploitants, qui consiste à en jeter une certaine quantité dans l'eau d'alimentation des chaudières. C'est un excellent désincrustant. Pour qu'il soit parfait, nous conseillons de tamiser la sciure, de n'employer que la plus fine en la mélangeant avec une quantité égale de poudre d'eucalyptus.

Les sciures sèches. - Les sciures sèches trouvent des emplois multiples dans les usages domestiques, dans le commerce et l'industrie. Aussi leur valeur est-elle beaucoup plus grande que celle des sciures vertes.

Il faut encore distinguer dans cette catégorie deux sortes de sciures de valeurs et d'emplois bien différents.

Ce sont les sciures blanches et les sciures de couleur.

Sciures blanches. - Les sciures blanches sont produites par le débit des planches sèches de peuplier, sapin, marronnier, bouleau et de quelques autres essences tendres et de couleur claire.

La sciure de peuplier sans mélange est la plus recherchée. Soigneusement mise à part, elle est transportée dans des bluteries qui la séparent des débris de bois ou copeaux qu'elle peut contenir et la divisent en sept grosseurs différentes pour répondre aux besoins de la clientèle.

La plus grosse sciure et la plus fine sont les plus chères, les sciures intermédiaires étant moins recherchées.

La grosse sciure de peuplier, sèche, est employéc pour le filtrage des huiles animales. Elle est surtout utilisée en grandes quantités pour le polissage et le séchage des pièces argentées, dorées ou nickelées.

Les clouteries et cartoucheries en font une très forte consommation pour le polissage au tonneau des pointes comme des douilles de cartouches.

Nous devons aussi indiquer que les Compagnies de pompes funèbres font une très forte consommation de grosse sciure sèche pour répandre dans les cercueils.

Les sciures de peuplier les plus fines sont utilisées pour le dégraissage 
des pelleteries blanches, on les mélange pour eet emploi aver un corps plus lourd, tel que plâtre on sable fin, qui les entraîne jusqu'à la naissance du poil.

La boulangerie fait une forte consommation de ces sciures fines dénommées fleurage en remplacement de flenrage de son.

On en fait de fortes expéditions en Angleterre et dans l'Amérique du Nord, ces pays ne produisant guère que des sciures blanches résineuses.

On fait rentrer la seiure de moyenne grosseur lans quantités d'agglomérés pour la confection des parquets, on en fait aussi des carrelages m l'additionmant de ciment.

Mélangée avee des poussières de charbon et pressée dans drus moules, on confectionne d'excollentes briquettes qui brûlmut lentement dans les cheminées.

Les sciures de bois résineux agglomérées a vec un excédent de résine liquide et pressées dans des moules font d'excellents allımı-feux.

Nous ne voulons pas oublier de signaler les essais qui ont été tentés de transformer la sciure blanche en pâte à papier.

La pâte ainsi obtenue n'est pas suffisamment fibrexuse, elle est friable et ne peut servir qu'à la eonfection de cartons de qualité très ordinaire.

Enfin, lessciures de moyenne grossenr sont encore emplo vées ponr répandre dans les boutiques, rem ises, ga rages et pourcertains usages domestiques.

Sciures de coulenr. - Les sciures sèches de conlenr proviennent du débit de planehes ou bùches de bois dur.

La plus recherchée et la plus chère est la sciurr de buis. Elle est employée plus spécialement dans la bijouterie pour le polissage des bijoux et leur nettoyage après finition. L'orfèvrerie en fait également une importante consommation, et ces deuxindustries suffisent à absorther toute la production.

La sciure fine de bois dur, talle que cullẹ du chêne, du liêtré, de l'orne, après tamisage, sert pour le dégraissage des fourrures de couleur. Les pelleteries fines sont nettoyées avec des sciures de bois des îles bien séchées, palissandre, acajou, ete., mais la plus recherchée et la plus rare est la seiure d'ébène.

Les sciures d'acajou d'Afrique, d'okoumé, de pitchpin, en raison de leur texture spongieuse, sont livrées en grosses quantités aux fabriques de jouets moulés, tels que bébés, chevaux et animaux divers.

Ces industries malaxent la sciure avee des farines de pulpe, de seigle ou certains autres bas produits organiques, la réduisent en pâte et, après moulage, livrent à la vente de nos bazars et à l'exportation des jouets dits incassables, à très bon marché.

Par le même procédé, en y adjoignant la coloration de la pâte et en opérant par pression dans les moules, on fabrique des objets dits en bois durei, encriers, presse-papiers, socles, ete.

La même pâte colorée rouge brun, et soum ise d̀ une fort pression hydraulique, est employée comme matière isolante dans les industries électriques sous le nom de fibre vulcanisée.

Les grosses seiures de bois dur, surtout celles du chêne et du hêtre, sont employées pour le fumage des salaisons.

les seiures sèches d'essenees diverses mélangées n'ont pour ainsi dire pas de valeur; on ne trouve leur emploi que pour l'emballage des flacons ou brites de conserves, mais faut-il encore qu'en plus de leur parfaite siccité, clles soient inodores. 
Des expériences récentes ont démontré que la sciure, après avoir été soumise à certains traitements de distillation, pent donner une quantité appréciable de sucre.

Ce sucre, nommé succhulose, mélangé avec des mélasses, donnerait un excellent aliment pour le bétail et on en pourrait tirer un alcool d'industrie très utilisable.

Si les expériences ont été concluantes, l'application industrielle de ces procédés 'n'a pas été très heureuse et elle paraît abandonnée pour le moment.

Copenux.

Les copeaux sont produits par le rabotage des bois, soit à la main. soit à'la machine. Les copeaux faits à la main sont longs et sont recherchés par les boulangers pour allumer leurs fours, ils sont utilisés uniquement pour allumer le feu des fourneaux, poêles, forges, etc.

Les copeaux de raboteuses ou de moulurières sont, au contraire, très courts en raison même de la section circulaire des outils tranchants qui les produisent. La plus grande partie sert au chauffage des générateurs des usines où ils sont produits; certaines scieries et parqueteries très importantes en ont même un excédent et les donnent pour en être débarrassées.

Dans certains centres de bois importants, quelques boulangers s'en procurent à bas prix pour le chauffage extérieur des fours.

Les copeanx de raboteuse provenant du façonnage de feuillets de peuplier et de sapin sont secs, minces et forment une excellente litière dans les porcheries où on les emploie mélangés avec des basses sciures. Cette litière économique est changée fréquemment et les animaux demeurent très propres.

Ces mêmes copeaux fins et mœlleux au toucher, absolument débarrassés de sciures, servent à garnir intérieurement des poufs et des tabourets recouverts de cuir ou de moquette.

Enfin, quelques industries, en raison de sa légèreté, emploient le copeau de raboteuse pour l'emballage.

Les repousseurs de métaux brûlent aussi les copeaux de bois dur dans des fours presque complètement fermés en remplacement de mottes de tourbe pour recuire les pièces en cours de fabrication.

Les mêmes copeaux mis en tas et allumés donnent un feu lent et continu qui est employé au désoudage des boîtes de conserve en fer-blanc.

On recueille la soudure ainsi que l'étain qui recouvre le fer-blanc en lavant les cendres, et le fer noir obtenu est revendu aux fabricants d'articles de quincaillerie bon marché (charnières, serrures, ferrures de malles, etc.) et aux fabricants de petits jouets mécaniques. poussières daus les ateliers de scierie meaniyue.
Ainsi que nous venons de le voir, la sciure et les copeaux peuvent être employés à de multiples besoins, mais à une condition essentielle, c'est d'être toujours absolument séparés.

Autant de sciures différentes, soit comme degré de sécheresse, soit comme nature de bois, soit comme grosseur, autant d'emplois différents.

C'est pour cela que nous ne cessons de répéter que l'aspiration des sciures et copeaux dans les ateliers de scierie mécanique par des tambours enveloppant les machines est nuisible à la vente des sous-produits de cette industrie.

Si nous dénontrons que l'aspiration des sciures et copeaux, loin d'être profitable au personnel travaillant aux machines-outils, lui est plutôt 
nuisible; si, enfin, nous faisons votre notre conviction que les ateliers de scierie mécanique proprement dits (où les seuls déchets sont le bois, la sciure et les copeaux) ne sont pas soumis à l'article 6 du décret du 29 novembre 1904, nous aurons rassuré l'industrie et le commerce important des sciures très florissants en France et presque sans concur rence à l'étranger, nous aurons aussi conservé le gagne-pain d'honnêtes travailleurs.

Faisant application de l'article 6 du décret du 29 novembre 1904 , certains inspecteurs du travail ont exigé, dans les ateliers de scierie mécanique de leur ressort, des installations très onéreuses d'aspirateurs de poussières.

Le résultat immédiat a été de mélanger les sciures de toute nature et les copeaux, et de rendre le tout inutilisable en dehors clu chauffage.

C'était là une fausse interprétation des textes et un grave préjudice causé à certains industriels qui ont dû consacrer beaucoup d'emplacement, de force motrice et d'argent à des installations très importantes.

L'article 6 du décret du 29 novembre 1904 dit:

"Les poussières, ainsi que les gaz incommodes, insalubres ou toxiques "seront évacués directement au dehors des locaux au fur et à mesure de "leur production."

Or, les sciures et copeaux ne sont pas de la poussière et ne sont, en outre, ni toxiques, ni nocifs.

Déjà, le 7 avril 1904, le Ministre compétent avait adressé à ce sujet une circulaire aux inspecteurs divisionnaires du travail dans laquelle, d'une part, il leur recommandait une grande circonspection et de l'autre établissait une distinction très nette entre les poussières de bois proprement dites qui doivent être évacuées comme toutes les autres poussières et les sciures et copeaux dont l'évacuation est régie par les prescriptions sur le nettoyage.

Le 16 décembre 1908, M. Viviani, alors Ministre du Travail, a bien voulu nous écrire que ladite circulaire continuait à être la règle de son administration.

Cependant, l'inspection du travail semble être animée d'un esprit différent et, soit par les mises en demeure qu'elle a adressées, dont nous avons eu connaissance, soit par des contraventions qui ont amené des industriels devant les tribunaux, nous avons pu nous rendre compte que pour elle, la distinction de la circulaire ministérielle est lettre morte et que toutes les machines à travailler le bois produisent de la poussière.

La jurisprudence s'affirme chaque jour et nous regrettons de ne pouvoir la commenter dans ce complément d'une brève étude. Nous ne ferons qu'en citer quelques arrêts:

\section{(Tribunal de la Seine, 1er février 1911)}

- Attendu qu'il résulte du rapport de l'expert que les machines-outils employées par les appelants ne produisent pas des poussières au sens du décret de 1904, mais seulement des sciures et copeaux".

\section{(Justice de Paix de Levallois, 7 avril 1910)}

- Que la sciure produite par les appareils du contrevenant ne saurait être considérée comme de la poussière au sens du décret du 29 novembre 1904 ".

Il est évident que dans ces espèces, les inspecteurs du travail n'avaient fait aucune distinction. au point de vue de la production de la poussière, 
entre les machines agissant par voie de pulvérisation et les machines tranchantes produisant des sciures et copeaux.

Enfin, tout dernièrement, par jugement du 31 décembre 1912, le Tribunal d'appel de Paris a confirmé définitivement cette jurisprudence en déchargeant un industriel des contraventions et condamnations qui lui faisaient grief.

Le Tribunal, pour ce faire, entérina le rapport de M. Lecornu, expert, ingénieur en chef des Mines, professeur à l'Ecole Polytechnique.

De ce rapport très documenté et très savant, nous n'extrairons que les parties qui définissent les poussières de bois.

M. Lecornu dit notamment :

"L'article 6 du décret du 19 novembre 1904 ne définit pas avec précision ce qu'il faut entendre par "poussière ". On y trouve néanmoins une indication concernant le genre d'apparils susceptibles d'en produire. Ledit article prévoit, en effet, les " poussières déterminées par les meules, les batteuses, les broyeuses et autres appareils mécaniques». On remarque immédiatement que les scies ne sont pas expressément désignées dans cet te énumération; or, parmi les outils employés dans l'espèce, seules les scies fournissent un produit (la sciure de bois) assez fin pour pouvoir éveiller l'idée de poussière; les autres appareils ne donnent que des copeaux plus on moins volumineux.

* D'après une circulaire ministérielle du 7 avril 1904, le Comité consultatif des Arts et Manufactures a voulu établir une distinction très nette entre les poussières proprement dites et les sciures ou copeaux. On ne saurait, suivant le Comité, considérer comme poussière les paquets de matière projetés par l'outil et retombant à terre sans flotter dans l'air, mais seulement les parcelles menues et légères restant en suspension dans l'air et qui peuvent être respirées par l'ouvrier. Bien que cette in terprétation soit an térieure an décret du 29 novembre 1904, elle a conservé toute sa portée, car l'article 6 du décret reproduit textuellement l'article 6 du décret du 10 mars 1894 qui faisait loi au moment où a été rédigé la circulair et d'ailleurs ancun fait n'est venu, depuis lors, modifier la situation à ce point de rue.

«Ceci posé, j’ai cherché à reconnaitre s'il se produit, à côté de la sciure proprement dite, des "parcelles menues et légères restant en suspension dans l'air ", et j'ai fait à cet égard les constatations suirantes:

" $1^{\circ}$ Quand on regarde de près le travail d'une scie, on voit les menus fagments de bois projetés par l'outil retomber presque immédiatement sur la table ou sur le sol, après s'être élevés tout au plus d'une vingtaine de centimètres. En particulier, les scies à ruban, qui produisent la sciure la plus fine, at taquent le bois de haut en bas, en sorte que la sciure n'a, dans ce cas, aucune tendance à être projetée de bas en haut.

" 2o L'atmosphère de l'atelier demeure, même au voisinage des outils, absolıment transparente.

" $3^{\circ}$ Si l'on prend une poignée de sciure et si, tenant la main à un mètre de hauteur audessus d'une table, on ouvre cette main brusquement, le paquet de sciure tombe en bloc en une demi-seronde environ. Les particules les plus menues demeurent un peu en arrière ; mais au bout de deux ou trois secondes, l'atmosphère reprend toute sa limpidité. Les fragments se trouvent concentrés sur la table, dans un espace circulaire de vingt à trente centimètres de diam itre.

a $40 \mathrm{Si}$ l'on souffle horizontalement sur un petit tas de sciure déposé sur une table, ce tas se déplace sans que ses éléments se mettent en suspension dans l'air.

- 5o Examinée au microscope, la sciure se montre composée de fibrilles de bois assez déchiquetées qui ont une tendance à s'accrocher les unes aux autrés.

"Ces diverses observations montrent nettement que les scies ne produisent pas une poussière capable de flotter dans l'air, suivant la définition adoptée par le Comité con. sultatif.

* Si laissant de côté la définition donnée par le Comité consultatif, on recherche uniquement l'idée à laquelle s'attache, dans le langage courant, le mot de poussière, on trouve qu'il faut entendre par là le produit d'une désagrégation due à l'usure et au frottement. Cette circonstance se rencontre notamment daus les établissements où l'on se livre au ponçag dı bois, par exemple dans les fabriques de meubles; la matière se trouve alors ramenée à un état de division qui la rend en quelque sorte impalpable. Le ponçage se pratique avec des meules en grès qui usent le bois en produisant des grains arrondis. Rien de pareil n'a lieu dans une scierie proprement dite; les scies, avec leur's dents aiguës, travaillent en coupant et hachant le bois, nullement en l'usant par frottements.

a $J$ crois devoir ajouter que la poussière de bois, quand elle existe, doit être bien moins 
dangereuse à respirer que la poussière de pierre ou de métal; car la cellulose qui la constitue ne peut manquer de se résorber rapidement dans l'organisme; elle doit même être moins nocive que la fumée de tabac que tout le monde respire dans un café.

a Quoi qu'il en soit,il ressort pour moi des explications précédentes que l'article 6 du décret du 29 novembre 1904 ne peut être ìnvoqué dans la circonstance. Je dois dire en outre que l'installation de tambours aspirants, placés auprès de chaque scie, serait extrêmement coûteuse en raison du puissant ventilateur qu'elle exigerait, et qu'elle serait sans utilité réelle puisqu'iln'y a rien à aspirer, la sciure tombant spon tanément au-dessous de l'outil à mesure qu'elle prend naissance.

- D'autre part, cette installation créerait des courants d'air locaux, très intenses, qui ne seraient pas sans désagrément, et même sans danger pour les ouvriers. Ceux-ci, in terrogés par moi, m’ont déclaré n'avoir aucunement à se plaindre de l'organisation actuelle: la modification indiquée par l'inspection du travail ne manquerait pas, au contraire, de susciter des réclamations.

En résumé, soucieux de l'hygiène de nos ouvriers, préoccupés des intérêts d'un important commerce, forts de notre droit consacré par les tribunaux d'appel, nous vous proposons d'adopter le vœu suivant:

\section{Le Congrès Forestier International émet le veu :}

Que les aspirateurs de poussières ne soient plus imposés dans les ateliers de sciage mécanique du bois.

11. Le Présnext. - Je demande l'autorisation de faire une observation sur le vou qui termine le rapport. Il est certain que les pouroirs publics et tous ceux à qui seront transmis nos vocux auront surtont ces voux sous les yeux, qüils s'inspireront moins des rapports eux-mêmes; c'est pourquoi la rédaction des voux a assez d'importance pour que nous nous y arrêtions.

II. Horear. - C'est le rou lui-même qui est interessant, pas le rapport...

M. Le Présinext. - Évidemment.

1I. Colbrx. - Je voudrais demander à M. le rapporteur s'il voudrait permettre qu'on fasse une adjonction à son vceu. Dans son rapport très documenté il s'appuie sur des jugements qui ont été rendus, favorables aux industriels qui se sont pourvus contre des décisions de l'Inspection du travail. Je crois qu'on pourrait mettre que, conformément à la jurisprudence, les aspirateurs de poussières ne doivent pas être employés dans les ateliers de sciage mécanique du bois. Je pense qu'en ajoutant ces mots "conformément à la jurisprudence "on n'aurait pas l'air de demander quel que chose de contraire à la loi.

M. LAVıL. - CP qu'il y a de très curieux, c'est que dans certains endroits on ne parait pas comnaitre cette jurisprudence parisienne: à Marseille. nous renons d'être condamnés à mettre des aspirateurs de poussières.

M. Colurx. - Notre collègue et rapporteur, M. Boequet, qui connait très bien la question, pourra rous donner quarlques indications in cet égard. 
M. Boceutet. - J'ai eu un procès que j’ai continué justement pour soutetenir des confrères, et, me basant sur trois jugements déjà rendus, j'en ai obtenu un quatrième qui a été la confirmation absolur de la thèse que je défends. Vous avez pu voir dans mon rapport que je cite une partie du rapport de 11 . Lecornu; je pourrai vous le donner tous entier, il est très intéressant, car il a bien distingué entre la poussière, la sciure et le copeau. Avec les outils tranchants ou arrachants, nout n'arons pas de poussière, il faut bien le spécifier. Tous les outils que nous employons, comme scieurs et comme menuisiers ou charpentiers, ne font pas de puussières. Cela se rapporte absolument à l'instruction ministérielle qui est l'explication que le ministre a cru devoir donner pour les inspecteurs du travail, en disant qu'il fallait bien définir la différence entre poussières et déchets de bois, si nous ne devons pas avoir d'aspirateurs de poussières. J'ai dit : Je ne fais pas de poussières, done, je ne peux pas avoir d'aspirateurs de poussières Malheureusement, je connais un te nos confrères de Lyon qui, après s'être défendu très énergiquement, a fini par accepter de mettre des aspirateurs de poussière. Alors, naturellement, les inspecteurs du travail prennent acte du fait pour venir vous dire : Mais votre confrère l'a fait.

Il m'est arrivé la même: chose; on est venu me dire: M. Colin a mis des aspirateurs de poussières et il en est enchanté. J'ai répondu simplement : Ce n'est pas vrai! - Mais si je n'avais pas su ce qui se passait, M. Colin m'aurait été présenté comme ayant mis des aspirateurs de poussières. Or, M. Colin a installé des éracuateurs, non pas des aspirateur's ; ce n'est pas la même chose.

Les inspecteurs du travail viennent vous dire : Un tel le fait, vous pouvez le faire. Les trois quarts du temps, ce n'est pas vrai. A Paris, en tout cas, nous avons deux jugements du tribunal de simple police et deux autres en appel dans lesquels nous avons eu gain de cause.

M. Laval. - II y a égatement une question incendie. Cela peut paraitre bizarre, mais il y a des appareils qui risquent d'occasionner des incendies par l'accumulation des seiures sur'certains points. Dans le rapport de mon usine de Marseille, je vois qu'il y a eu un commencement d'incendie dú à l'aspirateur de poussières. La sciure entrainée par le cyclont s'est répandue sur la toiture et s'est enflammée.

Un coxgressiste. - C'est un cas exceptionnel.

M. Julliard. - II serait nécessaire, si on veut invoquer la jurisprudence, d'indiquer la jurisprudence de telle ou telle Cour. lee vou tel qu'il est présenté se suffit à lui-même, il est ì toutes fins; il est quelquefois dangereux de laire appel à une jurisprudence qui peut être modifiée.

M. Conx. - I l'heure actuelle, j’ai un dossier complet sur la question: je ne connais pas de jugement d'appel qui nous ait donné tort. II y a bien le jugenent roncernant la puussière de charbon, mais il n'a pas 
pu tenir debout. Lorsque les industriels ont fait défaut en simple police, il y a eu expertise, et jusqu'ici nous arons toujours eu gain de cause. A cette jurisprudence s'ajoute une lettre du Ministre que j'ai recue de M. Viviani, alors Ministre du Travail, au nom de ma Chambre syndicale, et qui nous donne raison, faisant une distinction absolue entre la poussière et les déchets.

Je ne m'oppose pas à ce qu'on adopte le reu du rapporteur tel qu'il est, mais je crois qu'il faudrait $y$ faire une arljonction en parlant de la jurisprudence.

11. Le Président. - Je mets le vou aux voix, avee l'adjonction des mots : "Conformément à la iurisprudence ".

Adopté.

La séance est levée à $11 \mathrm{~h} .10$. 


\title{
SEANCE DL 19 JUIN 1913
}

\author{
(MATIN) \\ Présidence de M. POUPINEL, président de Section
}

La séance est ouverte à 9 h. 35 .

M. Le Président. - L'ordre du jour appelle l'examen du rapport présenté par M. Hirsch sur la question des Bols DE FENTE. BARDEACX, MERRAINS.

M. Hirscit. - Par bois de fente, on comprend les merrains, e'est-àdire les petites planches ou douves servant à la fabrication des tonneaux, muids, cuves, etc., puis les bardeanx, employés pour la couverture des maisons, le revêtement des murs exposés aux fortes intempéries ou pour la fabrication des plafonds, les lattes, pour supporter les tuiles et ardoises, enfin les échalas et piquets pour la vigne.

Les merrains, par leur consommation considérable, représentent la catégorie la plus importante des bois de fente et celle qui présente un intérêt général pour la forêt : la France en est un des plus gros consommateurs, étant producteur de vins, liqueurs, cidres et même bières, mais ces merrains intéressent également les pays producteurs de vins, tels que l'Espagne, l'Italie, l'Algérie, etc., ou de bières, comme l'Allemagne, qui emploie un nombre important de tonneanx. Cependant c'est pour les pays producteurs de vin que la question des merrains offre le plus d'intérêt, car cette hoisson nécessite des récipients fabriqués avec un soin tout particulier.

Les merrains pour tonneaux à vin exigent du chêne fendu de toute première qualité; il faut qu'ils soient sans aubier, sans nceud, fendus suivant le fil du bois ; ils demandent done des bois de droit fil, bien sains, pas trop nerveux, d'une croissance régulière el, afin de réduire les déchets importants déjà par la fabrication même, des bois de fortes dimensions et surtout de gros diamètre.

Jusqu'à ces dernières années le commerce français, et même presque tout le commerce mondial, s'alimentait en Slavonie, en Galicie et en Hongrie; mais l'épuisement des forêts de ces pays ayant entraîné des inesures de protection et, par suite, une hausse surles cours en même temps qu'une pénurie des produits, on s'adresse maintenant à l'Amérique et à la Russie, où des fendeurs hongrois ont été employés et ont formé des ouvriers habiles.

Les bois do France ne fournissent qu'un contingent réduit des matières premières utilisées, et seulement pour les tonneaux de faible dimension, 
à l'exception pourtant des fúts à cognae, en raison des qualités spéciales des bois de pays pour la bonne conservation de cette liqueur.

Jusqu'à présent, depuis de nombreuses années tout au moins, les prix des merrains étaient assez bas pour ne pas présenter un intérêt suffisant dans la production forestière de nos régions, les sciages étant plus rémunérateurs; mais les cours se sont élevés depuis quelques années de telle sorte (les 100 pièces de 34/36 $14 / 6$ sont, en effet, passées de 80 franes en 1909 à 110 franes en 1913) que, même en tenant compte des circonstances exceptionnelles qui ont motivé en 1913 une hausse exagérée, il devient possible d'envisager le moment où la fabrication du merrain deviendra avantageuse pour la forêt française.

$\mathrm{Si}$, dans certaines régions, le chêne de France est trop noueux, trop dur, de fente trop difficile, il y en a cependant de nombreuses, telles que l'Allier, le Poitou, les Charentes, la Touraine, le Perche, la Basse-Normandie, et aussi certaines parties de l'Est et surtout de la Bourgogne, où le chêne possède des qualités de fente pouvant rivaliser avec celles des bois américains.

Il y a donc lieu de proposer au Congrès d'émettre lo vou suivant:

Que les fabricants de futuilles français se préoccupent dès maintenant de prendre des merrains dans les forêts trançaises, et de former des ouoriers capables et habiles à fendre les merrains de grosses et petites dimensions, suivant les exigences des consommateurs; ils créeront ainsi un débouché précienx pour un produït essentiellement national, et en même temps ils s'assureront une partie de leur matière première sans avoir besoin de la chercher an loin, avec toutes les difficultes d'un transport de plus en plus onérenx.

M. Le Présidext. - Personne ne demandant la parole, je mets aux roix le vou.

Le rocu est adopté.

M. Le Présnext. - Passons au seennd rapport de M. Hirsch qui traite

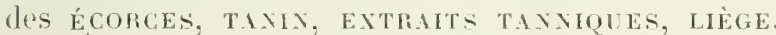

11. Hirscir. - La question des écorees est, à l'hrure actuelle, une de ealles qui touchent le plus les milieux sylvicoles: la erise des écorces influe sur tout lo commerce des petits bois : en effet, outre la rémunération le la rente des écorces, l'écorçage favorise l'écoulement du taillis de chêne, ear la chentèle prise spécialement le pelard comme bois de chauffage, et, pour les étais de mines, pour la petito charpente, le chêne icorés se montre supérieur aux autres bois par ses qualités de conservation, conséquence d'une bonne dessiccation.

11 n'est done pas surprenant que le commerce des bois et les propriétaires forestiers se soient rencontrés pour réclamer des mesures propres à favoriser la vente des écorces de chêtue.

Malheureusement ces efforts n'ont pas produit, jusqu'à présent, l'effet qu'en espéraient leurs auteurs; la crise des écorces, loin de s'atténuer, devient de jour en jour plus aiguë.

Depuis qu'un est arrivé à clarifier et à enrichir, à des conditions de bon marche extraordinaire, les extraits, tanniques, l'industrie to la tannerie 
s'est transformée. C'est qu'en effet le tannage par le procédé ancien. à l'écorce de chêne, présente, au point de vue industriel, certains ennuis qu'il serait chimérique de nier: d'abord ce procédé, par la durée nécessaire aux manipulations, exige des réserves de peaux considérables, d'où immobilisation de capitaux d'autant plus importants que le prix du cuir en poil est élevé, co qui est le cas depuis quelques années. D’autre part, la teneur 'n tanin qui, dans les extraits de qutbracho colorado, atteint $70 \%$ alors que l'écorce de chêne ne tient que de 6.5 à $13 \%$ de tanin, montre quelle peut êtro la disproportion du prix de pevient du kilog de tanin dans les deux cas; cela explique aisément la préférence des industriels qui, cela est compréhensible, cherchent à se procurer la matière première aux meilleures conditions.

Au fur et à mesure que le cour's des peaux s'élevait, la pratique d'un second tannage, par des extraits concentrés, s'est vulgarisée; par cette pratique, los peaux absorbent plus de tanin et prennent plus de poids ce qui st tout à l'avantage du tanneur. Rien de tout cela n'est possible arec l'écorce de chêne, qui ne permet pas de sureharger les cuirs en tanin.

Autre point: les marchés d'écoree ne se font qu'à ane époque déterminée de l'année, où l'approvisionnement doit être prévu avee exactitude pour toute l'année, tandis que les extraits peuvent se fabriquer au fur pt à mesure des besoins.

Enfin est survenue la concurrence du tannage au chrome, qui donne des cuirs spéciaux très appréciés, et notamment le box-calf, fort employé maintenant pour la confection des chaussures.

Sans s'étendre davantage sur une comparaison qui explique aisément les préférences des tanneurs pour les procédés de tannage modernes, il n'est pas inutile de se placer maintenant au point de vue du consnmmateur. Or, le tannage à l'écorce de chêne donne des cuirs de qualité incontestablement supérieure à celle des cuirs obtenus par le tannage rapide aux extraits. Tous les auteurs trchniques sont d'accord pour le reconnaitre, et plusieurs en fournissent des explications théoriques: la dissociation des fibres résultant du gonllement exagéré des peaux, pour faire pénétrer à force le tanin concentré dans les extraits, l'effet de la vapeur chaude, des acides, qui brílent les parties résistantes des cuirs, sont les causes les plus certaines de la mauvaise qualité des cuir's traités aux extraits concentrés et d'action rapide.

Quoiqu'il en soit, il est un fait certain, dont chacun fait la douloureuse expérienee, c'est que maintenant nos chaussures ont une durée infiniment moindre qu'il y a une trentaine d'années. Qui de nous n'a conservé le souvenir, dans notre enfance, des ressemela'ges indéfinis que l'on faisait subir à nos souliers, et quel père oserait maintenir cette saine tradition aux enfants de la génération actuelle? Il n'est pas un marchand de bois, pas un forestier qui, après une simple averse, n'ait regretté l'ancien temps oì l'on pouvait, après une journée entière passée sous la pluie en forêt, rentrer chez soi les pieds bien au sec et chauds, sans crainte de grippe, causée bien souvent aujourd'hui tout simplement par l'emploi de cuirs de fabrication moderne!

Cette fabrication perfectionnée a-t-elle au moins donné au consommateur la consolation de payer moins cher sa chaussure? C'est la question qui l'intéresse avant tout. Or, jamais les cuirs n'ont atteint les cours actuels et ils ne cessent de monter!

Sans doute l'utilisation des cuirs prend une extension de plus en plus 
grande ; l'industrie a besoin de courroies de transmissions plus quau temps jadis; l'accroissement de bien-être a pour conséquence de faire délaisser par les populations rurales les sabots pour les chaussures; l'ameublement est devenu un gros consommateur, toute administration industrielle ou financière qui se respecte tenant à avoir ses bureaux dotés de confortables sièges de cuir; les antidérapants, la carrosserie automobile se sont encore ajoutés aux industries faisant appel au cuir. Tout cela a certainement provoqué un accroissement important de consommation, mais il n'est pas cependant, loin de là, en rapport avec la hausse extraordinaire des prix. $11 \mathrm{y}$ a done une autre cause.

Au moment de l'apparition des cuirs tannés aux extraits ou au chrome, les prix de ces cuirs s'étaient abaissés, mais ils ont vite regagné le chemin perdu! Au fur et à mesure que les nouveaux cuirs ont pris le marché, leur renouvellement rapide, résultant d'usure anormale par suite de la qualité défectueuse, a provoqué un excès de consommation qui a bientôt accentué la pénurie ; aussitôt les cours sont remontés, et nous assistons maintenant à ce spectacle attristant que, plus les cuirs en poils sont chers, plus les fabricants de cuirs et peaux sont tentés de se rattraper sur le tannage, et plus la qualité s'en ressent; alors le cuir dure moins, sa consommation augmente, et les prix se rehaussent. On tourne ainsi dans un cercle vicieux sans aucune issue.

linsi donc, voici la conséquence des méthodes nouvelles de tannage aux extraits : le public paie aussi cher qu'autrefois, toutes proportions gardées, une marchandise de cuualité inférieure, les tanneurs ne roient guère leurs gains accrus parce qu'ils achètent les peaux en poils trop cher, le bon renom des cuirs français se perd et les intérêts du commerce des bois et de la production forestière sont compromis.

Telle est la situation!

Quels sont les remèdes?

La Fédération des syndicats du commerce des bois en France a émis un vou tendant à prendre des mesures utiles et décisives pour que, dans les marchés de l'Etat, les cuirs à livrer après tannage à l'écorce de chêne soient effectivement tannés par ce procédé ; elle a préconisé le contrôle de la fabrication des cuirs sur place, dans les tanneries mêmes, par les agents réceptionnaires des administrations.

I a Société des Agriculteurs de France a émis un vœu analogue en désignant nommément le Ministère de la Guerre, et elle a réclamé l'institution d'une marque légale pour les cuirs tannés exclusivement à l'écorce de chêne. Elle s'appuyait pour cela sur l'exemple fourni par certains tanneurs de Château-Renault, qui emploient le tannage à l'écorce, et qui apposent une marque spéciale sur les produits ayant un séjour minimum garanti dans les fosses à l'écorce. Ces produits sont très recherchés.

Ce système est aussi celui déjà adopté en Amérique.

Ces voeux ont eu pour but commun d'enrayer la fraude et d'empêcher que des cuirs tannés aux extraits puissent être livrés sous la dénomination de cuirs tannés à l'écorce ou vendus pour tels. M. Coste, président de la Société d'Agriculture du Gard, a montré admirablement qu'il est impossible pour l'acheteur (cordonnier et bourrelier notamment), de reconnaître les différentes fabrications des cuirs, et il a mis en lumière les falsifications qui se commettent sur ce produit.

C'est bien de ce côté qu'il convient de rechercher le remède, pour sauvegarder à la fois l'intérêt général du public consommateur (car tout le 
monde est consommateur de cuir, et le Gouvernement a le devoir de protéger un intérêt aussi qénéral) et les intérêts de la production forestière, du commerce des bois, de la tannerie honnête, de la défense nationale, du bon renom des produits francais.

Mais il faut d'abord que le Gouvernement exige formellement, dans tous ses marchés pour les Administrations, des cuirs tannés exclusivement à l'écorce de chêne, et qu'il n'accepte pas, comme l'a fait récemment le Ministère de la Guerre dans son nouveau rahier des charges, l'emploi mêm^ restreint d'acides énergiques, d'extraits et autres matières, à des doses indéterminées, sans aucun contrỏle direct, ce qui laisse la porte ouverte à tous les abus.

Il faut aussi que ce ministère, qui est le plus fort acheteur de cuir, consulte arant l'établissement du cahier des charges tous les groupements intéressés aux fournitures d'équipements militaires. En appelant connme il l'a fait tout récemment à une conférence préparatoire du nouveau cahier des charges, les seuls représentants du Syndicat général des cuirs et peaux, dont les mandants ne sont pas parmi les adjudicataires, et en refusant d'entendre les représentants du commerce des bois, sous prétexte que ce commerce n'est intéressé qu'indirectement aux fournitures militaires, le Ministre ne s'est pas inspiré de l'équité qu'on aurait pu en attendre; pour être logique avec lui-mêmp, il n'ê̂t dû prendre avis que des délégués autorisés des fabricants d'équipements militaires; il ne pouvait connaître la tannerie, à l'exclusion des autres producteurs intéressés - bouchers, exploitants de forêts de chêne, importateurs de matiòres tannantes, etc. - que pour organiser un contrôle sur la préparation des peaux nécessaires ì ses fournitures, ce qu'il n'a pas fait.

Il ne faut pas que de pareils faits puissent se reproduire à l'avenir dans aucune administration consommatrice de cuirs.

Un dernier point doit être examiné ; e'est la question des transports des écorces à tan. Pour favoriser le placement si difficile de ce produit national, il serait désirable d'obtenir des Compagnies de chemins de fer l'application de tarif́s de faveur très bas, d'autant plus qu'il s'agit d'une matière première destinée à assurer la défense nationale.

Pour conclure, nous proposons qur le Congrès forestier international émette les vour suivauls :

1. Que toutes les Idministrations publuques achetant des produits en cuirs et peanx inscrivent dans leur cahicr des charges une clanse à l'efjet de n'accepter que des cuirs et peanx. tannés à l'écorce le chêne pure, à l'exclnsion de tout autre ingrédient tannifère, et prennent des dispositions strictes et sèvères pour surveiller directement l'application de celte claizse.

11. Que les pouvoirs publics, pour réprimer loute fraude et protéger le public consommateur, instituent une marque légale qui sera apposée sur tous les cuirs et peanx tannès à l'écorce de chêne pure.

III. Que les Compagnies de chemins de fer consentent l'application de tarifs le faveur très bas pour le transporl des écorces à tan, et prennent toutes dispositions en vue l'assurer ce transport dans les meilleures conditions.

M. Hrsch. - Je erois utile de vous dommer quelques explications sur les terners des voux que j’ai émis.

las voux que j’ai l'lunnene de vous présentre unt une porló beau- 
coup plus grande que la simple question de l'écorçage de nos furêts, ils se rapportent en effet à une riuestion d'intérêt général. A l'heure actuelle, le public ne peut savoir si un cuir est tanné d'une façon ou d'une autre, s'il est bon ou manvais.

Or, les conditions de tannage ont une importance considérable sur la qualité du cuir. Le Cahier des charges du $2: 3$ aoút 1905 au Ministère de la Guerre était ainsi rédigé :

"Le systène de tannage seul admis est celui des fosses avec le tan provenant de l'écorce de chêne pulvérisée, à l'exclusion de tous autres procédés qui rendent le cuir pesant ou trop souple, et toujours trop hygrométrique et non susceptible d'une bonne conservation".

Depuis, le tannage à l'écorce exigé n'a subi aucune transformation, il est resté ce qu'il était, le tannage honnête donnant du bon cuir, mais un peu coûteux. Ce qui a changé, c'est le Cahier des charges dont voici le nouveau texte:

"Le seul principe de tamnage admis est le système des fosses avec le tan provenant de l'écorce de chêne pulvérisée".

"Est interdit l'emploi d'acides, d'extraits et autres matières à me dose susceptible de produire $m$ gonflement rapide et exagéré des cuirs, de diminuer leur séjour en fosses, et d'activer ainsi leur préparation an détriment de leur qualité..."

On peut être surpris de voir mettre une tlause aussi peu précise "à ane dose susceplible de produire un gonflement rapide et exagéré des cuirs ", par le Ministère de la Guerre, qui, généralement, exige des conditions extrêmement précises pour ses fournitures. L'explication pourrait peut être se trouver dans une lettre-circulaire que le Syndicat Général des Cuirs et Peaux a adressée à ses adhérents ; voici ce qui était dit dans cette circulaire :

"La clause de visite obligatoire des usines nous paraît an contraire toujours très menaçante, et nous venons faire appel à votre esprit confraternel pour signer et faire signer par vos confrères la pétition ci-incluse ".

Nous nous demandons encore comment il se fait que dans la Commission qui a élaboré ce Cahier des charges, on n'ait appelé en consultation qu'un seul syndicat, le Syndicat des Cuirs of P'eaux; car enfin If Syndicat des Cuirs et Peaux n'était pas seul intéressé à la question : la Fédération des Syndicats des marchands de bois avait, elle aussi, demandé a être entendue. On le lui a refusé en donnant comme motif qu'elle était intéressée d'une faron trop indirecte.

Or, justement, dans la circulaire du Syndicat des Cuirs et Peaux, à laquelle je faisais allusion tout à l'heure, j'ai tronvi que dans les objections que l'on lait, on indique que "l'exercice serait injustifie parce que nous sommes pas partie contractante an marché ».

Le Syndieat des Cuirs et Peaux reconnait done que lui-même n'était pas partie contructante an marché. ()ue dire?

Auprès du Syndieat des marehands de bois, les Synticats des propriétaires, les Syndicats des bourhers qui sont intéressís à fournir des 
cuirs, le Syndicat des extraits tanniques avaient leur place toute désignée. Grâce aux indications que nous a donnéesle Syndicat Général des Cuirs et Peaux, et dont nous lui sommes très reconnaissants, nous avons pu aller jusqu'au bout de cette question, et voir comment, par pression politique, on était arrivé à faire modifier les conditions d'application des clauses préparées par les services compétents des bureaux.

C'est aussi, Messieurs, à titre de consommateur que j'ai proposé d'instituer une marque légale pour les cuirs tannés à l'écorce. Il faut que ceux qui se servent de cuir, comme les bourreliers, comme les cordonniers, puissent savoir la qualité réelle de la marchandise qu'on leur vend.

En demandant cette marque, nous n'entendons nullement porter préjudice aux cuirs tannés par d'autres procédés. Si le consommateur en désire, il en trouvera, mais celui qui voudra avoir absolument du cuir tanné à l'écorce de chêne pure, pourra, lui aussi, être certain d'en avoir.

D'ailleurs, en vous soumettant ce voeu, nous sommes tout à fait d'accord avec la masse des groupements, je parle des fabricants de chaussures.

Le 8 arril 1913, la Chambre Syndicale des Fabricants de Chaussures de Paris a demandé l'application aux produits de la tannerie de la Loi sur les fraudes du $1^{\text {er }}$ aoút 1905 qui concerne toutes marchandises. Les fabricants de chaussures se sont plaints au point de vue de la fraude; ils ont considéré que quand on leur livrait du cuir qu'on leur annonçait tanné à l'écorce de chêne pure et qui ne l'était pas, il y avait fraude.

La Chambre Syndicale de la Carrosserie de Paris et des Départements émettait le 2 juin demier le vou qu'un règlement d'administration publique intervint pour déterminer une marque à appliquer aux cuirs tannés à l'écorce de chêne.

La Chambre Syudicale des Bourreliers ef Selliers de Paris, Seine, Seine-et-Oise et Seine-et-Marne, émettait le même vœu.

La Société des Agriculteurs de France, la Fédération des Syndicats du Commerce des Bois en France, les Syndicats Forestiers du Midi, les Sociétés d'Agriculteurs du Gard, de l'Hérault, d'Indre-et-Loire, de la Touraine, du Lot, demandent la marque.

La Chambre Syndicale de l'Ameublement de Paris demande également la marque ; e'est un gros consommateur de cuir, car vous n'ignorez pas que les bureaux qui se respectent ont dans leurs salons des fauteuils de cuir.

La Compagnie des Chemins de fer de l'Ouest-Etat réclame de ses fournisseurs le droit de visite des tanneries et la marque d'origine des produits.

On m'a même cité un fait que je me permets également dle vous rappeler : C'est que les tanneurs espagnols, réunis en Congrès a Sarragosse, le 25 avril dernier, ont émis un vơu tendant à reconnaitre 
aux consommateurs le droit d'exiger des fabricants tanneurs la garantie de pureté de leurs produits ou de pourcentage de la surface.

C'est vous dire, Messieurs, combien il est difficile de reconnaître la qualité du cuir, surtout pour ceux quill'emploient couramment. En adoptant nos voeux, le Congrès protégera la grande masse des consommateurs, les forêts de taillis qui sont déjà si dlépréciées et nos. populations de búcherons si intéressantes et qui méritent à tous égards la protection des Pouvoirs publics.

Lorsque le charbon de bois a été peu à peu remplacé par la houille, les propriétaires forestiers se sont tus, on se tronvait en présence d'un fait économique contre lequel on ne pouvait pas lutter; la masse du public avait besoin d'un combustible bon marché. Mais aujourd'hui la question est différente pour les écorees, nous venons dire : Nous sommes avec le public : nous entendons être respectés au même titre que le public. (A pplandissements.)

M. Gunlot. - Je voudrais faire entendre une note libérale dans l'intérêt de tout le monde aussi bien que dans l'intérêt des producteurs d'écorces, et je proposerais les modilications suivantes :

"10 Que tontes les Administrations publiques achetant des produits en cuirs et peaux inscrivent dans leurs cahiers des charges une cluuse à l'effet de n'accepter que des cuirs et peaux tannés avec les meilleurs produits fournis par nos bois, an besoin couverts par des marques, et réalisant des ronditions de réception suffisamment sévères pour ofirir toutes garanties.

"20 Que les Compagnies de chemins de fer consentent l'application de tarifs de faveur très bas pour le transport des matières premières ligneuses, indigènes, de toutes les matières premières ligneuses indigènes utilisées par l'industrie de la tannerie, et prennent toutes dispositions en vne d'assurer ce transport dans les meilleures conditions".

A Bordeaux, il vient de se former une Société qui a nom Erica, qui extrait le tanin de la menthe, et qui prétend que ce tanin est supérieur à celui du chêne.

M. Plicine Peltereau. - J'ai le devoir et l'honneur de représenter ici les 24 Syndicats du cuir et l'industrie des cuirs toute entière.

Yous savez combien notre industrie a été attaquée par suite le la mévente des écorces de chêne. Vous ne serez done pas surpris de me voir ici venir la défendre. Je dois vous dire tout d'abord qu'en bons patriotes nous déplorons comme vous la crise forestière et la mévento de vos bois et de vos écorees; nous ne sommes pas d'accord sur les moyens de remédier à cette crise, mais nous regrettons avec vous la situation difficile qui vous est faite.

Je remercie II. le rapporteur Hirseh de la forme qu'il a bien voulu donner à son rapport; nous n'avons pas toujours été habitués à la 
forme courtoise ru'il a bien voulu adopter, et je lui en suis reconnaissant au nom des industries du cuir.

Pour rous faire perdre le moins de temps possible. je suirrai les arguments qui ont été développés verbalement par M. Hirsch et je vous parlerai d'abord de la question de la qualité du cuir pour le consommateur, car .1. Hirseh y attache, avec raison, une grande importance. Il est certain, en effet, Messieurs, que tous les consommateurs de cuirs qui sont des industriels savent apprécier d'une façon très súre si le cuir est tanné par tel ou tel procédé; je ne rous apprendrai rien en rous disant par exemple que les fabricants de chaussures, et tous les transformateurs de cuir en général, savent parfaitement distinguer le cuir tanné à l'écorce de chêne pure, le cuir tanné à l'écorce de chêne arec addition d'extrait et le cuir tanné par des procédés rapides.

Vous arez malheureusement la prétention de connaitre notre fabrication beaucoup mieux que nous-mêmes, de diriger la technique d notre industrie. Pourquoi? Parce que, actuellement, vous rendez mal ros écorces de chêne. Eh bien! nous sommes obligés de nous défendr et de vous donner pour cela quelques arguments. Dans tous les cas, il y a un fait qu'il faudrait établir, c'est la qualité supérieure du cuir tanné exclusivement à l'écorce de chêne; car sur ce point, nous sommes en complet désaccord. Nous enseignons, en effet, dans no. écoles professionnelles, que. la science du tanneur moderne est mélange judicieux des différents tanins extraits des ligneux, nous ur partageons done nullement votre manière de voir.

D'autre part, si on vent donner aux consommateurs des facilités d'appréciations pour un produit, il faudrait étendre cette façon de faire à tous les autres produits. Pourquoi ne le feront-on pas pour les draps? Pourquoi ne dirait-on pas au consommateur que le drap de son complet est composé de laine mélangée de coton, ou uniquement de laine? Pourquoi ne le ferait-on pas pour les chapeaux, pour le papier? Il est également important pour le consommateur de savoir comment son drap est fait, et par conséquent, si rous arriviez à demander qu'on donne cette garantie au consommateur pour les euirs, nous demanderions, nous, qu'on la lui donnât également pour tous les articles du vêtement?

M. Hirsch a fait allusion au cahier des eharges de l'Administration de la Guerre, puisque dans une de ses conclusions, il exprime le voru que toutes les Administrations achetant des produits en cuirs et peaux inscrivent dans leur cahier des charges une clause à l'effet de n'accepter que des cuirs et peaux tannés à l'écorce de chêne pure. Je n'ai pas ici à défendre les Administrations de la Guerre et de la Marine, mais je suis étonné véritablement qu'elles soient attaquées, alors qu'elles ont pris tant le soin au contraire à établir toutes sortes de clauses qui les prémunissent coutre l'emploi abusif des pxtraits tanniqurs.

M. H. B.riber. - C'rist une premur.

11. Placide I'Eltereal. - 11. Hirsch a eu l'amabilité de nous lir' un 
passage du cahier des Charges du Ministère de la Cuerre, mais il a perdu de vue toutes les clauses conernant les analyses.

Vous remarquez que dans le texte qui vous a été lu, l'Arministration de la Gulerpe dit :

"Le seul principe de tannage admis est le système des fosses avec le tan provenant de l'écorce de chêne pulvérisée, à l'exclusion de tous autres procèrés."

II. Hirsch se plaint que le Ministère de la Guerre n'ait aucun contrôle au sujet de cette clause, c'est une erreur. 1]. Hirsch n'a probablement pas continué la lecture du cahier des charges, sinon il aurait vu toute une série d'analyses, que prescrit lo Ministère de la Guerre, - et il en use très largement, je vous l'assure et s'entoure de toutes les garanties possibles, au print de rue du tannage.

Je ne sais si vous connaissez, monsieur le Rapporteur, l'organisation du Ministère de la Guerre au point de vue des réceptions; elle est extrêmement sévère, et je puis vous affirmer qu'aucun consommateur civil ne reçoit ses euirs comme le fait lo Ministère de la Guerre. Il y a d'abord une commission de réception, il y a ensuite, pour les litiges entre l'Administration et les fournisseurs, une commission d'appel, et cette commission a le droit de recourir à différents chimistes en dehors des chimistes de l'Mministration, mais c'est toujours le Ministère de la Guerre qui a la dernier mot et qui, par conséquent, sur les analyses faites par les chimistes de l'Administration et les chimistes les plus réputés, a le droit de prentre position. Done; de ce côté-là, vous avez toutes garanties.

En ce qui concerne le Ministère de la Marine, il est dit dans Cahier des Charges:

Les cuirs de bouf um de vache pourront être tannés en fusses avec l'écorce provenant du chène... ".

On a toujours manvaise grâce à parler de soi-même, mais si la clause du tannage en fosses a été ajoutée au cahier des Charges du Ministère de la Marine, c'est grâce a mon intervention. lous royez done que nous ne sommes pas toujours si loin de nous entendre.

En ce qui concerne le Ministère de la Marine, l'analyse vient également suppléer à l'indication d'rxagération d'emploi des extraits.

M. Hirsci. - Je vous demande pardon de vous interrompre. Est-ce qu'il n'y a pas aussi un troit de visite chez les fabricants do cuirs et peaux, qui est préru par l'Administration de la Marine?

11. Pacide Pelteneal. - Non, il n'y en a pas.

Ux Coxgressiste. - - J'appartiens au Ministère de la Marine et je puis rous rire que cela a che introdnit cette année.

11. Plaride Jeztekear. - I'rn suis tris surpris. 
LE PRÉcédext congressiste. - Cela n'a pas encore été fait, mais cela pourrait être fait et la surveillance est possible.

M. Placide P'elteread. - Dans tous les cas, en ce qui concerne le Ministère de la Guerre et le Ministère de la Marine, je dois rous dire que les analyses sont faites également très sérieusement, et permettent de révéler les extraits tanniques qui sont simplement tolérés. 11 est in liqué au cahier des charges du Ministère de la Marine...

"Pour s'assurer qlie le tamage n'a pas été obtenu trop vite...".

Par conséquent, de ce còté encore, les garanties que réclamait 11. Hirseh sont bien obtenues.

M. Hirseh s'est étonné que nous soyons opposés aux visites obligatoires. Véritablement, Messieurs, si vous étiez soumis aux mêmes. obligations pour vos coupes de bois ou vos exploitations forestières, je ne sais si vous trouveriez le procédé agréable.

II. H. Birbier. - Nous y sommes solmis.

M. Placide Peltereat. - Je dois ajouter que si nous avons refusé res visites comme obligatoires, nous nous sommes toujours mis d'accord avec l'Administration de la Guerre pour laisser visiter nos usines; jusqu'à présent, il n'est pas d'exemple qu'une seule tannerie que l'Administration de la Guerr ait voulu visiter, n'ait pas été visitée. L'Administration de la Guerre est en contact permanent avec notre industrie pour tous les renseignements dont elle a besoin, et jusqu’à présent, elle a visité tous les centres importants de tannerie sur sa simple demande. Nous avons seulement demandé que eette visite ne fút pas obligatoire, mais nous n'avons jamais refusé d'ouvrir nos tanneries aux représentants du Ministère de la Guerre et nous continuons, puisque tout dernièrement, j'ai eu l'honneur de voir l'intendant qui s'oceupe de cette question, II. Péria, et j'ai invité le nouveau titulaire à vouloir bien recommencer ses visites.

Vous voyez que de ce còté-là nous avons l'esprit le plus large; nous nous sommes simplement refusés à ce droit d'exercice que nous trouvions exagéré, en ce sens que nous n'étions pas fournisseurs directs.

En ce rui concerne la non représentation de l'industrie du bois à la Commission dont a parlé $\mathrm{M}$. le Rapporteur, cette non représentation n'a pas dépendu de nous. Nous avons demandé à être représentés à cette Commission, nous avons été écoutés, et si j’ai bonne mémoire, votre demande, Monsieur, est venue après que la Commission s'était réunie.

M. H. Barbier. - C'est une erreur.

M. Hirscir. - Le Président du Syndicat vous répondra.

M. H. Barbier. - Oui, monsieur, votre mémoire vous sert mal; j’affirme que la demande a été faite avant la réunion. 
M. Placidr Peltereau. - En ce qui nous eonceme, nous ne voyons aucun inconvénient à ce que d'autres industries, plus ou moins intéressées, soient représentées à ces Commissions. Comme vous le disirz, tout à l'heure, il y aurait lieu d'y admettre les bouchers et également les fabricants d'extraits tanniques.

Quant à la qualité des chaussures, en général, clont se plaint très amèrement $\mathrm{ll}$. le Rapporteur, je n'avais pas pour ma part constaté que les chaussures fussent si mauvaises, $(1 h ! 4 h !)$ mais vous paraisse $z$ tous en être tellement' convaincus que je crains d'être battu à l'avance. Je tiens à vous faire remarquer toutefois que les intermédiaires qui vendent des chaussures, et surtout les grands magasins, les marclıands de chaussures, sont très certainement coupables "n la circoustance. Alors que le cuir brut a subi une hausse considérable pour des raisons diverses et un peu différentes de celles que pensait M. Hirsch, nous avons été obligés tont nalurellement de relever le prix de nos produits fabriqués, puisque la hausse a eu lieu dans des proportions de 30 ì $100 \%$; mais dans bien des cas, les acheteurs de chaussures n'ont pas voulu supporter la hausse du prix du produit fabriqué, de sorte que les fabricants de chaussures, obligés de subir les demandes draconiennes de leurs acheteurs, dans bien des cas ont abaissé la qualité du cuir employé pour la fabrication des chaussures. Il faut done que le consommateur soit assez raisonnable pour payer sa chaussure suivant la hausse des matières premières, s'il veut avoir une chaussure qui lui donne toute satisfaction.

Vous avez cité les voux des diffírents syndicats, vous avez cité le vou de la Chambre syndicale des Fabricants de chaussures de Paris; nous déplorons que la lettre de cette Chambre syndicale n'ait pas été publiée intégralement. L'avez-vous, cette lettre, Monsieur le Rapporteur?

M. Hirsch. - Nous nous expliquerons.

M. Placide Peiterear. - Dans le journal Le Bois, cette lettre n'a pas été publiée intégralement. La Chambre syndicale des Fabricants de chaussures admet l'usage modéré des extraits tanniques; il n’a pas été fait mention du passage te cette lettre.

11. H. Barbier. - Est-ce qu'en dehors de la Chambre syndicale des Fabricants de chaussures, M. le Rapporteur n'a pas parlé de la Chambre syndicale des Bourreliers et Selliers de la Seine? Toudriez-vous nous dire si cette lettre-là est aussi écourtée?

M. Placide Peltereal. - II me serait difficile de vous le dire, parce que nous arons eu seulement communication officielle de la lettre de la Chambre des Syndicats de chaussures, et que nous n'avons pas eu communication des lettres adressées par les autres groupements.

11. H. Birbier. - Nous tenons à faire état que les protestations des 
Chambres syndicales ne se résuneul pas dans relles des chaussures.

II. Placide I'elteread. - Je ne roulrais pas retenir trop longtemps votre attention. Je me permets cependant de revenir sur les trois reux qui sont la conclusion du rapport de 11 . Hirseh.

En ce qui concerne les administrations publiques, tout naturellement nous protestons contre l'usage exclusif de l'écorce de chêne pure ; nous estimons que les cahiers des charges tels qu'ils sont conçus, aver. le contrôle qu'on a ajouté à ròté des termes mêmes qui sont employés. sont équitables et sauvegardent parfaitement les intérêts de l'État.

En ce qui concerne la marque, nous nous rallions an rou modifié de M. Guillot.

En ce qui conceme le second vou : "Que les ponvoirs publics, pour réprimer tonte frande et protéger le public consommuteur, instituent une marque légale qui sera apposée sur tons les cuirs el peanx tannés à l'écorce de chêne pure.", là encorp nos opinions diffèrent puisque nous ne sommes pas d'accord sur le prinripe. Nous prétendons, nous, qur le meilleur cuir n'est pas le cuir tamné "xclusivement à l'écorce de chêne.

Au point dr vue de la clanse de transport, nous sommes d'accord ; nous sommes désireux comme vous, puisque la plupart du temps le prix du transport s'ajoutr au prix d'achat. que cette condition puiss" être améliorée.

En résumé, Yessieurs, nous réclanons pour une grande indistri comme la nôtre le droit de vivere de se drelopper dans un sens beaucoup phs libéral que celui que vous prétendez nous imposer. Nous entendons étudier et discuter librement la technique de notr. fabrication sans être soumis aux obligations que vous voudriez nous imposer dans le but de vendre plus facilament ros érorees de chêne.

M. Coste. - La mévente des écorees de chêne, qui est le résultat de la concurrence des extraits tanniques, est une réritable calamité pour tous les propriétaires dtr taillis de chênes, mais c'est un véritable désastre pour les propriétaires de bois de la région méditerranéenne, puisque dans cettr région qui est celle du chêne vert, l'écorce est, non pas un sous-produit, mais le produit prineipal de cettr essence, et, par conséquent, tant que cetir mérente subsistera, il ne peut être tiré aucun parti de ce bois. Nous arons là 300.000 hectares environ qui sont fatalement appelés à disparaitrr; déjà dans ces régions. depuis 15 ans que rette inévente dure, il y a un certain nombre de propriétaires qui commencent à perdre patience, et qui, quand ils font des coupes, donnent l'order aux ouvriers de faire, comme on dit, sauter le piquet. c'est-à-dire faire sauter la souche. De sorte que ces 300.000 heetares qu'on transforme en pâturage, sont fatalenent destinés à devenir des terrains absolument stériles, fe que nous appelons des garrigues.

Eh bien! dans le Midi, nous avons déjit loup de ces garrigues. Dan- 
nos départements méridionaux, ils représentent $30 \%$ de la surface du sol, dans certains départements eomme les Pyrénées-Orientales, ils représentent $60 \%$; voulez-vous y ajouter 300.000 hectares de plus? C'est vous dire que la question est angoissante pour tous les intérêts nationaux.

Il est donc essentiel de remédier à la mévente des écorces, et lorsque nous nous sommes préoccupés de cette question, en février dernier, à la Snciété des Agriculteurs de France, il nous a paru qu'il y avait un lien étroit entre la méventè des écorces et la question des cuirs. C'est ce qui a motivé un roeu de la Société.

Le cuir, Messieurs, est une des matières premières qui sont, je crois, le plus fraudées; la fraude sur le cuir est - je puis le rappeler dans un congrès international - une fraude internationale. II suffit de se reportẹ à cet égard aux journaux mêmes de l'industrie du cuir ; si je prends, par exemple, la Halle aux Chirs du 16 mars dernier, je vois que dans certains pays, la charge en glucose courante est d'environ $25 \%$; on introduit donc de la matière sucrée dans le cuir pour le faire peser davantage. Dans d'aut res pays, on va jusqu'à $40 \%$. En France, on ne charge peut-être pas en glucose; on a d'autres produits, on charge avec les extraits tanniques; la fraude se commet en surchargeant le cuir d'extraits tanniques, c'est-à-dire en incorporant aux cuirs une quantité surabondante de tannin qui ne sert à rien, qui ne se combine pas avec la peau, et qui n'a qu'un but, celui de faire peser davantage le cuir.

Cette fraude est extrêmement rémunératrice. La vente courante du cuir actuellement est de 5 francs le kilogramme; chaque fois qu'on remplace un kilogramme de cuir par un kilogramme de ces matièreslà, on réalise un bénéfice de 5 francs.

Je tiens à bien préciser ma pensée. Je ne viens pas soutenir ici que c'est une fraude de tanner au moyen des extraits, ce que je soutiens, c'est qu'on se sert des extraits pour commettre des fraudes? C'est la même situation que pour le beurre et la margarine; il est licite de fabriquer et de vendre de la margarine, mais c'est une fraude qu'on a fini par réprimer de mélanger de la margarine au beurre et de vendre le tout comme beurre.

Quand je viens dire que l'usage abusif des extraits est un procédé de charge, j'en apporte des preuves qui sont surabondantes. La chose est indiqué dans tous ses détails par les techniciens de la tannerie, par les journaux de la tannerie. J'ai trouvé, par exemple, un traité tout récent, Traité pratique de la fabrication des cuirs, publié en 1912 par Thuau et Villon, et je vous demande la permission de vous rappeler quelques détails suggestifs qui se trouvent dans cet ouvrage :

"Les cours de la peau en poil, ecrivent MM. Villon et Thuau, page 199, sont devenus si élevés pendant ces dernières années, que le tanneur s'est vu dans la nécessité de cliercher d'une part à diminuer le prix de revient de la fabrication, et, d'autre part de faire un ta unage aussi poussé que possible, 
quand il s'agil des cuirs vendus au poids, et d'augmenter son rendement, pour pouvoir tirer un petit bénéfice de sa fabrication et lutter contre la concurrence.

"L'augmentation de rendement est obtenue soit par des procédés spéciaux de tannage aux extraits, soit par des moyens physiques, soit par l'emploi de tannins que la peau absorbe en plus grande quantité possible ".

L'auteur dit en termes formels que, par ce procédé, on augmente le poids de 10,15 ou $20 \%$.

11 en est de même également pour les matières minérales. Le cuir tanné d'après l'ancien procédé est très pauvre en matières minérales, pt l'auteur nous dit :

"Depuis plusieurs années, la teneur normale en matières minérales s'est fortement accentuée pour les cuirs à semelle : la raison en vient de ce fait que la peau en poil ayant augmenté dans des conditions beaucoup plus grandes que le cuir tanné, le tanneur s'est vu dans l'obligation de chercher à augmenter son rendement pour pouvoir tenir sa place dans la lutte commerciale ".

Non pas pour pouvoir faire un produit de meilleure qualité, mais pour pouvoir tenir sa place dans la lutte commerciale. De même qu'autrefois, en matière de vin, c'était toujour's à qui vendrait le meilleur marché, c’est-à-dire à qui mouillerait le plus sa marchandise.

"Pour augmenter son rendement, le tanneur, ou bien retanne ses cuirs, et pour cela il faut employer des extraits spéciaux, parfaitement décolorés, contenant toujours de 3 à $5 \%$ de matières minérales qui sont absorbées en dose massive par le cuir, ou bien tanne ses cuirs à un haut degré tannique avec des extraits très décolorés qui, par suite, nécessitent un moins grand rinçage, après tannage, ou bien encore utilise des tanins particuliers, pal exemple l'extrait de quebracho qui, employé dans certaines parties du tannage, a la grande propriété de permettre l'augmentation de tannage et, par suite. de rendement. Au sujet de l'emploi si utile de l'extrait de quebracho, rappelons en passant que, pour qu'il soit vraiment utilisable, il faut qu'il soit soluble a froid, ce qui nécessite pour le fabricant d'extrait une quantité de matières. minérales qui ne sera pas à dédaigner lorsqu'on la retrouvera dans le cuir. Comme on le voit par ce qui précède, il est assez difficile d'établir à partir de quel moment un cuir est chargé en matières minérales, c'est-à-dire fraudè : car le tanneur peut, jusqu'à une certaine limite, dire que les matières minéral ss qu'on lui reproche n’ont été employées que pour décolorer le tanin ».

Voilà d'excellents conseils qui seraient certainement utiles devant un juge d'instruction (Applaudissements). Le tanneur auquel on reproche d'avoir chargé son cuir de matières minérales, dira : Ce n'est pas moi qui ai mis ces matières minérales, c'est le résultat d'une addition d'extraits très décolorés, par conséquent très riches en matières ninérales. Cela est-il honnête? Il est impossible de le soutenir.

D'ailleurs, pour prouver cette fraude, nous n'avons pas besoin seulement de cet ouvrage, elle apparaît partout, dans toutes les publications du cuir. Ainsi, dans un journal que j'ai sous les yeux, je tronve cette annonce qui est tout à fait typique, e'est l'annonce d'un fabricant d'extraits de Francfort-sur-le-Mein, où je vois : " J'augmente le rendement du cuir de $10 \%$. Cela fait 50 franes par 100 kilogrammes. Les gens se précipiteront vers cette maisun pour acheter ces précieux extraits qui augmentent le rendement du cuir de $10 \%$. Tous coin- 
prenez très bien que, dans ces conditions, ce cuir, qui est ainsi fraudé, grâce à cet usage frauduleux des extraits, ne peut pas avoir la même qualité que le cuir qui n'est pas chargé du tout. Il n'y a pas besoin pour comprendre cela, d'être chimiste, technicien ou spécialiste, le bon sens suffit.

La consommation s'en est aperçue depuis longtemps, les tanneur's aussi le savent bien. Si vous prenez les journaux de la tannerie, vous voyez toute une série de maisons qui vous offrent le tamnage à l'écorce de chêne pure. Une maison de Limoges dit: Ce que je vends, c'est du cuir tanné à l'écorce de chêne pure. Vous voyez quantité d'autres annonces du même' genre, vous n'en voyez aucune qui dise : Cuir garanti tanné aux extraits (Applaudissements).

Le consommateur recherche le cuir tanné à l'écorce de chêne, vous en avez déjà eı la preuve par les explications qui ont été données par le Rapporteur. En présence des abus auxquels donne lieu l'emploi des extraits tanniques, le consommateur demande le cuir tanné à l'écorce de chêne, parce que, avee l'écorce de chêne, il y a moins d'abus.

Tels sont, Messieurs, les motifs qui ont décidé la Société des Agriculteurs, en février dernier, à déposer un voeu au sujet de la marque des cuirs tannés à l'écorce de chêne.

Lorsque ce vou a été connu dans la région méditerranéenne, et lorsqu'on a su les raisons qui avaient décidé de l'émettre, il y eut un mouvement d'opinion extrêmement puissant; en l'espace de quelques semaines, toutes les sociétés d'agriculteurs se sont prononcées, depuis les Alpes jusqu'à la Méditerranée. Cela indique l'état de inisère dans lequel se trouvent toutes ces populations forestières du midi. Les Conseils Généraux du Gard et de l'Hérault ont spontanément émis des vœux conformes réclamant la marque des cuirs; il y a même des groupements qui, dans une certaine mesure, ne sont pas des groupements économiques, qui ont partagé l'émotion publique, par exemple le vœu de la section du Gard du Comité Républicain du Commerce et de l'Industrie.

Mais, Messieurs, l'émotion a été surtout vive chez les grands propriétaires de bois; chez nous, les grands propriétaires, ce sont les Communes. En l'espace de quelques semaines, j'ai reçu les voux d'une centaine de communes qui toutes protestent contre la fraude du cuir, demandant la répression de cette fraude et, comme sanction, réclamant la marque! Ces communes sont extrêmement malheureuses; par exemple, le maire d'Anial, dans l'Hérault, m'envoyait le compte d'exploitation des bois communaux duquel il résulte que, bon an mal an, les bois communaux lui donnent un déficit variant entre 6.000 et 8.819 francs. Vous figurez-vous ce que c'est dans une commune rurale que 8.000 francs à inscrire en dépenses au budget communal? C'est une véritable contribution de guerre! Combien ne ferait-on pas de choses utiles avec 8.000 francs par an qu'il faut verser ainsi comme rançon de la fraude? (Applaudissements). Vous comprenez l'émotion dans tous 
ces pays ; on a beau habiter dans un pays reculé, on ne peut pas s'empêcher de protester quand on est volé et qu'on sait quel est son voleur!

Je voudrais pouvoir vous lire les lettres indignées de quelques-uns de ces maires, laissez-moi vous en faire connaître seulement quelques lignes...

M. Le Présidext. - Il y a certains mots...

M. Coste. - Je dis que quand frauduleusement on augmente le poids du cuir de 10 ou de $20 \%$, e'est un vol, et je prétends que c'est cette fraude qui cause la mévente.

Je reviens à l'émotion qui s'est manifestée dans le pays, et je vais vous citer quelques lignes d'une lettre que m'écrivait le maire de la commune de Bagad, dans les Cévennes:

"Nos intérèts ne peuvent rester plus longtemps méconnus. C'est un spectacle écœurant que de voir le pays se dépeupler, les maisons tomber en ruines, les jeunes gens obligés de s'expatrier pour essayer de gagner leur vie à la mine ou ailleurs. Voilà le résultat de la fraude. Le gouvernement ne peut laisser ainsi périr des populations fermement attachées à la France et à la République!"

J'ai reçu une centaine de ces lettres en quelques semaines, mais l'impulsion est tellement vive qu'avant deux mois, j'aurai l'opinion des 300 ou 400 communes de cette région, qui se trouvent intéressées par cette question de la mévente des cuirs.

Nous ne nous sommes pas contentés de recueillir les vœux des producteurs, nous avons voulu connaitre la manière de voir des consommateurs de cuir. Le Comité des forêts s'est chargé de ce rôle à Paris; nous, nous l'avons également assumé dans notre région. L'initiative est venue du modeste syndicat agricole de Saint-Sébastien d'Aigrefeuille. Dans cette commune, les 95 propriétaires de la commune ont signé une pétition pour demander la marque et la répression de la fraude du cuir, et le syndicat agricole de la commune a présenté une proposition demandant également la marque des cuirs aux consommateurs de cuir de la grande ville industrielle voisine, la ville d'Alais. Voici le texte de cette proposition :

"Les soussignés marchands de cuir, cordonniers, bourreliers, camionneurs, etc., etc., considérant la mauvaise qualité des cuirs vendus actuellement, demandent l'établissement d'une marque pour les cuirs tannés à l'écorce de chêne pure, et la répression des fraudes sur les cuirs".

Elle porte 200 signatures, parmi lesquelles je relève 33 cordonniers, et 4 marchands de cuirs.

Cet exemple, nous allons le suivre, cette enquête, nous allons la continuer, mais dès à présent, vous avez déjà entendu les arguments de la tannerie qui vient vous dire : "Les cuirs actuels sont très bons." Ce n'est pas l'avis des consommateurs parisiens ni des consommateurs provinciaux.

Je suis obligé de dire un mot du voru des employeurs de cuir pari-

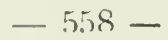


siens, puisque l'on a parlé du voru de la Chambere syndieale dres Chausstres, car e'est à moi-mêm', on effer, qu'a étri adressé le roru de cette Chambre.

La Chambre syndirale nous a adressé un voru qui a étri publié sans y changer une lettre, ef dans lequel elle demande, purement et simplement, l'établissement d'une marque ot un règlement d'adıninistration publique déterminant les conditions d'authenticité de cette marque. Ce voeu était accompagné d'une lettre dans laquelle on indiquait que la Chambre syndicale n'avait pas voulu suivre jusqu'au bout le voru qui arait été émis par la Société centrale d'Agriculteurs du Gard qui demandait en outre la visite des tanneries; mais il n'en rst pas moins vrai que, sans aucune restriction, la Chambre syndicale de la Chaussure a demandé l'stablissement d'un+ marque pour les cuirs tannés à l'écurce de chêne. Il y a eu également des voux extrêmement significatifs qui ont été émis par la earrosserie, par la sellerie, par la bourrellerie, et ces voux ont été acrompagnés do lettres qui sont aussi précises que possible. I'ar exemple, dans la délibération de la Chambre Synkicale des bourreliers-selliers, je lis :

"En ce qui concerne la qualité du cuir, nous déclarons qu'elle est de beancoup supérieure, lorsque la tannerie a employé l'écorce de chène pnre ".

Voila prour le consonmateur. Maintenant, parlons un peu de la tannerie.

Nous nous sommes demandí si nous ne pourrions pas truurer des coneours dans le midi : nous en avons trouvé dans le centre et rlans le midi. Une grande partie de la tannerie souffre, en effet, de la concurrence déloyale qui est faite à son égard par la frande; les tanneries se plaignent, elies sont dlans une situation difficile. Voici, par exemple, ce que mécrivait dernièrement un tanneur du département de l'Hérault :

"Nous comprenons toutes les difficultés que vous aurez à surmonter pour obtenir gain de cause dans la campagne que vous avez entreprise; nombreux sont naturellement les tanneurs qui ne veulent rien entendre, et ce ne sont pas, malheureusement, les moins puissants; néaumoins il ne faut pas désespérer, car il leur est impossible de niel' en totalité que l'équité et la saine raison sont de votre côté. Comment un fabricant tanneur peut-il se refuser à apposer sur les cuirs de sa fabrication une marque légale attestant sous sa responsabilité la loyauté de sa fabrication? Ce refus nous semble bifu difficile à justifier. Nous souhaitons donc vivement votre réussite..."

Enlin, nous avons provoqué une enquêtr de la Chamlire de Commerce de Béziers, qui est un arrondissement du département de l'Hérault oii les tanneurs étaient autrefois nombreux et prospères ct wì la tannerie traverse une rrise extrêmement grave. Nous avons cté entendus par la Chambre de crommerce de Béziers, et à re sujet permettez-moi de vous citer ce détail :

Le Prósident de la Commission était 11. de Crosal, marehand tanneur de la ville de Bezier, viereprésident de la Chambre de Commerce ; 
j'ai trouvé ce llonsieur en parfaite communion d'idées arec moi, et en discutant la question, je lui ai signalé cet argument de nos contradicteurs qui disent : Il est impossible d'accepter un contrôle quelconque sur la tannerie, parce qu'il y a des tours de main dans cette industrie et ces Messieurs ne veulent pas qu'on y mette le nez. Je répondis, en me fondant sur l'ouvrage de Thuau, que je craignais fort que ces prétenduis secrets ne fussent que les secrets de la fraude et des tour's de main plus ou moins honnêtes. Et M. de Crosal ajouta: Sans aucun donte, dans notre métier, il n'y a pas de secrets.

Voilà cette déclaration dont je puis indiquer l'auteur, puisqu'il s'agissait là d'une enquête officielle. D'un jour à l'autre vous aurez un rou de la Chambre de Commerce de Béziers qui viendra appuyer les voux de Lure, de Saint-Omer et d'Auxerre.

Donc, d'un còté, vous avez des tanneurs qui ne demandent qu'à travailler au grand jour, à la condition d'être protégés contre la fraude par la marque. Vous avez ensuite les consommateurs qui se plaignent de la mauvaise qualité des cuirs, et qui se plaignent en tout cas d’être trompés, parce que le fabricant de chaussures ou le bourrelier qui achète le cuir ne peut jamais savoir de quelle façon il a été tanné. Vous avez en outre une vaste région qui est menacée d'une dévastation complète, 300.000 hectares de chêne vert vont disparaître dans quelques années...

Puusieurs rorx. - C'est dans la France entière!

M. Coste. - Enfin, d'un autre còté, vous avez purement et simplement une poignée de fraudeurs. (Très bien!)

Eh bien, je ne comprends pas, que les tanneurs honnêtes puissent s'opposer au contrôle que nous demandons, c'est-à-dire à la marque. Laissez-moi bien préciser ma pensée; nous ne prétendons en aucune façon entraver l'industrie; que les tanneurs qui préfèrent conserver secrets leurs procédés de fabrication, tannent comme bon leur semble, appliquent sur leurs cuirs la marque de leur maison à eux, ils ne seront soumis à aucun contrôle, personne n'aura le droit de voir ce qu'ils font chez eux, et par conséquent leur liberté ne sera atteinte en aucune façon. Le consommateur jugera. S'ils arrivent à faire de bons euirs, il leur donnera la préférence, et vous me permettrez de dire à ce point de vue que très certainement, l'établissement d'une marque sur le cuir tanné à l'écoree de chêne augmentera la qualité du cuir tanné aux extraits. (Rires.) En effet, que voyons-nous? Que, depuis 25 ans que l'on pratique le cuir tanné aux extraits, ce cuir devient de plus en plus mauvais ; or on aurait eu le temps de le perfectionner. Si donc le tannage à l'extrait se trouvait à avoir à lutter avec un cuir portant une marque, il s'efforcerait de son côté de perfectionner son procédé pour le plus grand bien de tout le monde.

Les extraits conserveront leur usage, ear on peut toujours faire des extraits un usage judicieux. Ainsi, quand on a réprimé la fraude 
sur le beurre, est-ce que les fabriques de margarine ont été fermées? Nullement. Depuis 1897 que la loi sur la fraude existe, il y a des fabricants de margarine, ils se multiplient, ils prospèrent. Il y a une clientèle pour la margarine comme il y a une clientèle pour les extraits ; la répression de la fraude a eu pour résultat que le producteur vend son beurre un prix rémunérateur et que tout le monde peut vivre honorablement.

Ux Congressiste. - C'est vrai pour tout.

11. Coste. - Nous ne doutons pas que vous veniez appuyer notre vou, et le vœu que vous émettrez sera pour nous d'ungsecours puissant, mais, je ne me fais pas d'illusion à cet égard, il ne nous donnera pas la victoire, car nous avons affaire à des influences très puissantes qui, jusqu'à présent, ont dominé les pouvoirs publics.

Nous continuerons cependant notre campagne avec énergie, non seulement dans le midi, mais avec le concours des Comités forestier's de toute la France; nous continuerons la campagne dans la France entière, dans toutes les villes, dans toutes lẹs communes, et nous ferons entendre des protestations de plus en plus énergiques. Nous ne nous arrêterons que lorsque nous aurons vaincu la fraude et que nous aurons fait établir la marque. (1 pplandissements.)

Ud Congressiste - M. Placide Peltereau a dit tout à l'heure qu'il était extrêmement facile de distinguer les cuirs tannés à l'écorce de chêne de ceux tannés à l'extrait et qu'il ne s'expliquait pas pourquoi, dans ces conditions, on demandait une marque. Je lui demanderai à mon tour, puisque c'est si facile, comment il explique que les employeurs de cuir, le Syndicat de la Chaussure, le Syndicat des Bourreliers et des Selliers, etc., émettent le même vœu que nous.

Il a dit que le cuir tanné avec un mélange d'écorces et d'extraits était meilleur que 'le cuir tanné a de l'écorce de chêne pure; je lui demanderai encore comment il se fait que ces mêmes employeurs de cuir, les cordonniers et les bourreliers, demandent aussi cette marque pour le tannage du cuir à l'écorce de chêne pure.

Ensuite, M. Placide Peltereau nous a dit qu'il représentait ici tonte la tannerie. 11. Coste a discuté cette question, mais il doit y avoir ici des représentants de la tannerie et j'aurais été très heureux de voir des tanneurs à l'écorce, car il y en a aux environs de Paris, et nous aurions pu nous livrer à une discussion intéressante.

11. Placide Peltereal. - J'en suis un.

Le yêye Coxgressiste. - Il n'en est pas moins vrai que, nous aussi, nous avons interrogé des tanneurs; 11 . Coste a interrogé des tanneurs du midi, nos amis qui habitent le centre ont interrogé des tanneurs du centre, moi j'ai interrogé des tanneurs de l'ouest; or je peux vous affirmer qu'il y a de nombreux tanneurs de l'ouest qui ne s'opposent 
en aucune facon a l'exercice, et qui sont d'aceord avec nous sur la plupart des voeux que nous formulons.

M. Placide Peltereir. - Je voudrais répondre un mot à l'honorable orateur en lui faisant remarquer que je n'ai pas dit que la qualité du cuir pourait être appréciée par le consommateur; j'ai dit qu'un tannage différent pouvait être apprécié par les acheteurs de cuirs tels que les industriels et les marchands de cuirs.

En ce qui concerne les Fabricants de chaussures, je tiens à rous lire, pour en terminer, leur lettre :

" Nous ne croyons pas, en effet, pouvoir vous suivre entièrement dans l'interdiction de j'emploi des extraits tanniques, qui, bien employés, ne sanraient être muisibles...

$$
\text { "Syndicat Général des Cuirs et Peaux de France 》. }
$$

11. Coste. - Seuls les tannems qui réclament la visite seront visités, et ceux-là seuls auront droit à la marque.

M. Hirsch. - J'ai quelques mots à répondre sur les objections formulées par M. Peltereau en particulier. Tout d'abord, je tiens ì dire que si je n'ai pas parlé des cuirs chromés, c'est que les cuirs chromés ne sont pas du tout en question ici; en effet, les cuirs chromés se distinguent des autres cuirs.

J'ai interrogé de nombreux employeur's de cuir, des cordonniers, des bourreliers, j'en ai vu un en particulier dont le père était déjà cordonnier, et je crois qu'il doit déjà commeneer à avoir la pratique du cuir ; or il m'a déclaré qu'il lui était impossible de laire cette distinction.

Au point de vue scientifique, j’ai demandé au Ministère de la Guerre si les dosages qui sont inscrits au eahier des charges étaient une garantie suffisante pour connaître l'origine des cuirs; j’ai été obligé de reconnaitre que ces Messieurs ne sont pas dn tout súrs d'avoir une garantic quelconque. A vrai dire, ils n'en ont aucune. Ce n'est pas parce que l'on lera des analyses qu'on saura si des cuirs sont bons ou manvais. J'ai à cet égard-là un prtit livre de Jacomel qui traite un peu spécialement des analyses des cuirs; il indique $u$ grand nombre de méthodes, et il ajoute :

"Le professeur Propter, dass un travail classique, a indiqué une série de réactions colorées qui aident à fixer l'origine d'un extrait tannique ; mais quelque soit l'intérèt de ces réactions, il convient de dire qu'elles deviennent incertaines dans les cas de mélanges, aujourd'hui très fréquents".

Je vous cite celui-là, jo pourrais vous on citer vingt-rinq. Dans tous les lives, on n'a aucune certitude.

Peut-être MII. Ins Chimistes arriveront-ils i trouver des méthodes meilleures, mais pour l'instant, a cet égard, je m'm rapporte à ce qui m'a éte dit au Mlinistère de la Guerre ; Ies garanties qui sont ici ne signifirnt absolument rien au point de vur de la qualité des enirs. Et je 
m'étonne, puisque le Syndicat des Cuirs et Peaux ne demande qu'à avoir la visite de ces Messieurs, je m'étonne qu'il ait mis tellement d'acharnement à refuser ces visites; car enfin, pour que la visite soit efficace de la part d'une Administration, il ne faut pas cqu'on avertisse. Si on vient prévenir M. Je Président du Syndicat des Cuirs et Peaux en lui disant: "Tel jour, nous irons visiter telle usine ", M. le Président du Syndicat écrira évidemment à cette usine : Je vous avise que vous recevrez la visite d'un contrôleur, recevez-le bien, je ne vous en dis pas davantage ". Je pense que le chef d'usine comprendra à demi-mot - et fera en sorte que la visite ne lui soit pas préjudiciable - ce qui est tout naturel.

M. Placide Peltereaı s'oppose, d'autre part, à ce que nous établissions une marque, et il dit qu'on devrait également la mettre sur les draps. Je dois dire tout d'abord que pour qui a un peu l'habitude du drap, il n'est pas besoin d'être très fort pour en reconnaître la qualité. Il y a des méthodes scientifiques pour arriver à reconnaitre si les draps sont en laine ou non; néammoins, si on voulait une marque pour les draps, nous ne nous y opposerions pas. On a demandé des marques pour la margarine, cela a donné les meilleurs résultats ; nous demandons la même chose et je ne vois pas pourquoi on peut y faire opposition, puisqu'un certain nombre de tanneurs; notamment M. Richard qui a écrit à la Chambre de Commerce d'Auxerre une lettre très caractéristique - déclarent que le tannage à l'écorce de chêne est le seul qui puisse donner de bons résultats.

M. Placide Peltereau a objecté également que la qualité des chaussures actucllement était tout aussi bonne qu'autrefois; je rrois que votre opinion à cet égard est faite. Néanmoins, j'ai cherché de mon côté à savoir ce qu'il y avait de fondé dans l'opinion qui prévaut et qui est celle-ci : on peut dire universellement que les cuirs actuels ne valent pas ceux d'autrefois. J'ai donc demandé au Ministère de la Guerre s'il ne serait pas possible de me donner la statistique de la durée des chaussures d'autrefois, et de celle des chaussures de maintenant. On m'a répondu que ce n'était pas possible parce que les magasins des Corps ont un certain nombre de chaussures qui sont plus ou moins usagées, de sorte que toute statistique établip serait fausse. Dans ces conditions, je ne rois qu'un moyen de solutionner la question, et je pense qu'à ce sujet, M. le P'résident des Syndicats des Cuirs et Peaux s'y ralliera d'une façon complète : Nous pourrions demander au Ministre de la Guerre qu'il veuille bien choisir une unité quelconque et qu'il la chausse du pied droit par exemple avec des chaussures fabriquées en cuir tanné uniquement à l'écorce de chêne, et du pied gauche avec des chaussures fabriquées en cuir tanné uniquement aux extraits. (Rires.) Je suis convaincu que l'expépience sera probante. Nous nous adresserons à un tanneur quelconque pour faire les chaussures du pied droit en cuir tanné à l'écorce de chêne.

H. JaUfFret. - Je demande que les tanneurs veuillent bien nous expli- 
quer pourquoi ils s'opposent à la marque. Si les cuirs tannés aux extraits sont aussi bons que les autres, en quoi la marque les gênera-t-elle?

M. Roy. - Les fabricants d'extraits tanniques vous demandent la permission de rous faire observer que l'extrait tannique contient tout simplement un produit tannant analogue à celui contenu dans l'écorce de chêne, mais de propriété partirulière, parce que le tannin dans l'extrait est dépouillé, chez le fabricant préparateur, des matières colorantes et des matières basiques qui se trouvent dans l'écorce brute - tous impedimenta qui sont cause de l'action pernicieuse de l'écorce sur le cuir, lorsqu'elle est employée en jus fort.

Le tanneur trouve dans l'extrait tannique, comparé à l'écorce, la supériorité que peut présenter un produit industrialisé sur un produit brut, et il tire parti pour le mieux de sa fabrication de quelques réactions adéquates à ce genre de supériorité.

Faut-il ajouter que l'antagonisne entre l'exirait et l'écorce n'existe que dans l'esprit des personnes peu versées dans les questions de tannerie et M. le Rapporteur lui-même vient de reconnaitre qu'il considère comme utile l'adjonction de l'extrait à l'écorce.

Ainsi nous sommes d'accord sur ce fait que les deux matières tannantes se coinplètent dans la technique courante de la tannerie française et l'avenir nous réserve peut-être de revoir un jour les écorces seules dominer la tannerie. Mais ce jour-là - tout est possible - les écorces auront été pour partie à leur tour industrialisées comme matières premières pour la fabrication d'extraits tanniques.

L'industrie des extraits tanniques est d'origine française; elle s'est développée dans lo nonde entier. Elle a permis aux pays non producteurs de chêne et qui étaient tributaires surtout de la France, soit pour le cuir, soit pour l'écorce, de s'affranchir et de fabriquer euxmêmes leurs cuirs.

En résumé, c'est l'industrie des extraits qui a fait universelle l'industrie des cuirs, qui a été le facteur le plus néfaste du commerce d'exportation du cuir de France et qui, enfin, a unifié dans le monde entier, le cours des cuirs fabriqués.

Comme conséquence de cette concurrence mondiale, aujourd'hui le fabricant de cuirs de France n'est plus libre de revenir à la technique onéreuse du tannage à l'écorce pure.

Faut-il ajouter que le tannage mixte à l'écorce et aux extraits, encore généralement pratiqué en France, peut lui-même difficilement résister comme prix de revient au tannage à l'extrait pur pratiqué à l'étranger.

Voici des preuves à l'appui :

Les fabriques de chaussures françaises faisaient un commerce d'exportation en 1880 de 99 millions de franes; elles ont fait en 1912. 10 millions.

Par contre, les fabriques de chaussures étrangères importaient en France en 1880, 880.000 francs, elles ont importé en 1912, 25 millions.

L'anné dernière, la consommation mundiale des extraits tanniques 
a été, en faisant confusion des extraits secs et des extraits liquides, de 360.000 tonnes, en quantité suffisante à tanner son même poids de cuirs.

Ce qui revient à dire qu'il est tanné dans l'univers entier, par le moyen des extraits tanniques - 100.000 kilos de cuir chaque jour.

M. Hirscr. - Je demande si le représentant des Syndicats des Cuirs et Peaux est disposé à accepter ce que j'ai proposé de demander au Ministère de la Guerre?

M. Placide Peltereau. - Je n'ai jamais dit que les cuirs tannés à l'écorce de chêne pure n'étaient pas ineilleurs que les cuirs tannés aux extraits seuls, je n'ai jamais dit cela et je ne le dirai pas ; j'ai dit simplement que nous enseignons dans nos écoles professionnelles un mélange judicieux des différents tanins. Je dis done que si un cuir tanné exclusivement à l'écorce de chêne est incontestablement meilleur que celui tanné exclusivement aux extraits, un cuir tanné avec un mélange judicienx, raisonnable, d'extraits de châtaigniers mélangés et d'écorce de chêne, est aussi bon qu'un cuir tanné à l'écorce de chêne pure. C'est pourquoi nous sommes opposés à la marque de l'écorce de chêne pure.

M. Hirsch. - 11 faudrait tout de même que nous sachions, nous, consommateurs, à quoi nous en tenir? Actuellement, nous n'avons que de mauvaises chaussures, nous demandons à payer le prix el à avoir de bonnes marcliandises. Nous demandons à faire une expérience concluante entre le cuir tanné à l'écorce de chêne pure et le cuir tanné d'une façon mixte, comme vous l'indiquez.

M. Placide Peltereau. - Vous êtes ici deux ou trois cents, si je compte bien, tandis que nous sommes un représentant de l'industrie du cuir, deux journalistes professionnels, et un fabricant d'extraits tanniques.

Un Congressiste. - Et un tanneul.

11. Placide Peltereal. - Nous sommes done ici deux tanneurs; je ne prétends pas faire prendre une décision en ce moment sur une question aussi importante. Je ne pourrai que faire part de votre vœu à l'industrie du cuir et vous faire connaître sa réponse.

M. Dichenrs. - Je suis très frappé de ce que faisait observer tout ì l'heure le Président des Syndicats des Cuirs et Peaux. Il est évident que la mauvaise qualité des cuirs en France provient d'une concurrence et d'une situation économique, mais d'un autre côté, je conçois parfaitement que l'État ait peur pour ses adjudications militaires, et que le consornmateur, qui veut payer cher et avoir quelque chose de bon, puisse exiger une marque. Je pose done simplement cette question à l'honorable représentant des cuirs : Comment, si vous considérez que 
le cuir fait avec un mélange judicieux d'extraits est meilleur que le cuir fait avec l'écorce de chêne pure, comment refusez-vous la marque qui, forcément, n'indiquera la qualité que pour le consommateur qui paiera très cher.

Je conçois qu'un industriel puisse voir avec regret l'introduction d'agents de l'Etat dans son usine, e'est toujours horriblement désagréable, mais d'un autre côté, on doit reconnaitre que lorsque l'analyse ne permet pas de déclarer la qualité d'un cuir, il n'y a qu'un moyen d'avoir un contrôle sérieux, c'est l'exercice.

M. Deveze. - J'ai écouté les différents orateurs qui se sont succédé à cette tribune, et je les ai écoutés au point de vue parlementaire ; je veux vous demander la permission de vous dire à quelle conclusion je suis arrivé. Je pense que cela doit avoir son intérêt, car les questions que vous discutez devront avoir une répercussion au Parlement.

Vous demandez des garanties pour les cuirs qui sont tannés à l'écorce ; ces garanties vous ne les aurez que si le Parlement les ordonne et si le Gouvernement les prescrit. Eh bien, il m'a semblé que l'équivoque n'était pas aussi grande que cela.

M. le président des Syndicats des Tanneurs reconnaissait tout à l'heure que les cuir's qui sont tannés à l'écorce sont supérieurs à ceux qui sont tannés avec des produits chimiques; il ajoutait qu'il ne pouvait pas prendre un engagement quelconque au nom du Syndicat. Mais il est peut-être possible de trouver des conclusions sur lesquelles tout le monde est d'accord. Je ne veux pas discuter sur les statistiques qui ont été apportées ici, je voudrais aller plus loin; en admettant que les cuirs tannés à l'écorce ne valussent pas plus que ceux qui sont tannés d'une autre manière, il reste une question sur laquelle, je crois, tout le monde soit d'accord et qui est celle-ci : Les cuirs qui sont tannés à l'éeorce ont une répercussion dans l'Agriculture, et certes, si on ne peut plus utiliser l'écorce pour cela, ce seront les forêts qui disparaítront. Si vous vous placez à ce point de vue, il ne sera pas possible de trouver d'opposants.

Quand on placera devant la Chambre des Députés l'intérêt doutrux de quelques industriels, puisqu'ils reconnaissent eux-mêmes que le tannage à l'écorce est bien supérieur, quand on placera devant la Chambre, dis-je, l'intérêt douteux de quelques industriels et l'intérêt non douteux des agriculteurs et des forestiers, la Chambre des Députés ne pourra pas hésiter, de même qưelle n'a pas pu hésiter quand on a mis en sa présence les intérêts des industriels de la margarine et les intérêts des paysans qui font le beurre, de même qu'elle ne pourra pas hésiter dans quelque temps d'ici entre les intérêts de quelques industriels qui font de la soie artificielle et les intérêts des éleveurs de vers à soie qui font de la véritable sole avec des vers. Voilà les quelques opinions qui m'ont été suggérées par les arguments qui unt été posés iei.

Eh bien! je vois dans la réunion. quelques-uns de nos collègurs 
qui r'présentent comme unoi des ripconscriptions agricoles forestièms, je suis convaincu que tout leir concours sera apporté au vou qui ra être émis tout à l'heure, car je vois bien quelle est l'opinion de l'Asstmblée, en tout cas, au voeu de ceux qui s’intéressent aux écorces ut par conséquent au maintien de nos forêts dans nos paỵs.

11. Błrener. - C'est la première fois, monsieur Placide l'eltereau. que j’ai l'honn'ur de vous rencontrèr. Nous avons déjà croisé la fel' sans nous connaîtræ; enfin nous voici face à fare ; ce sera, je l'espère, très courtois. Vous avez bien vouh dire que vous aviez l'honneur de représenter ici 22 syndicats de la Tannerie française; j'ai l'honneu de représenter devant vous les 50 et quilques syndicats de la Fédération du Commerce des Bois de France et ses milliers de membres que vous avez décoré du nom de marchands d'écorces. Eh bien oni. nous sommes des marchands d'écorees, marchands de tout ce que produit la forêt; r'est notre honneur, peu souvent notre profit ; mais jarrive à mon sujet.

la Chambere de commerce d'Auxerre, à laquelle j'ai l'honnour l'appartenir, vient d'émettre un voru très considérable, suivant con rela, la déclaration d'un de ses membres les plus distingués, dont le nom est M. Richard, tanneur ¿ Joigny, qui a fait dans la tannerie une carrière des plus honorables et des plus considérables. M. Richart a déclaré que lo tammage aux extraits était particulièrement langereux pour l'acheteur de cuirs, paree que celui-ci, vous l'avez déjà dit, ne sait pas lo reconnaitre.

L'analyse, a dit M. Peltereau, suffit. M. lo Fapporteur a repondu avec des textes: Elle ne suffit pas.

Vous venez discuter la technique de notre métier. Oui, mais nou la discutons avec vos propres arguments et les articles de vos journaux. L'honorable M. Costr, tout a l'heure, a ju faire une partie de son brillant discours par la lecture de La Halle anx Cuirs; j'ai devant moi la Bourse anx: Cuirs de Tournai, journal belge. Ce journal expose qu'on a envoyé à quinze chimistes spécialisés dans l'intustrie du cuir des échantillons de cuir tanné, pris aver un soin remarquable là où i] y a toujours un dosagr assez égal; dix se sont refusés à faire l'analyse; les cinq autres l'ont faitr ot leurs résultats varient avec des érarts de 10 à $50 \%$. Si c'est cutte analyse-là à laquelle vous vous référez, nous la considérons comme nulle et non avenue!

Vous arez dit, Monsieur Placide Peltereau, que la qualité du cuir etait bonne, votre argument avance; si vous l'émettiez dans vingt ans d'ici, pent-être irait-on chereher des textes comme nous venons l'être dans la néressité do le faire; mais nous sommes d'un âge qui nous a permis de connaitre l'ancion et lé nourcau cuir : rous êtes drvant des juges qui ont eu de bonnos chaussures et qui n'en ont plus que de dótestables; vous avez provoqué tout il l'heure leurs manimes protestations.

Jo' vais plus loin, el si je prouonec quelques paroles un pen vives, je 
les retire d'arance; j'estime et je déclare que la hausse formidable du cuir a son origine dans les procédés néfastes de la tannerie; je prétends que ce cuir, gaspillé par les méthodes de fabrication, ce cuir qui ne fait plus qu'un usage de quelques mois, qui est d'une production limitée, ce cuir, vous le gaspillez dans vos usines.

L'ailleurs, les quelques marchands d'écorces que nous sommes, viendront, quand vous voudrez, discuter la question avec vous; mais d'avance, je vous prierai de vous mettre d'accord avec les consommateurs: tous ceux qu'on a cités ici sont contre vous et vous n'avez pas apporté un seul témoignage en votre faveur.

Vous avez dit : "Je voudrais bien voir, Messieurs les Forestiers, s'il était question d'introduire chez vous l'exercice, ce que vous feriez ! " L'exereice chez nous existe : nous fabriquons des poteaux télégraphiques pour le compte de l'État et, de jour et de nuit, à toute heure et sans préavis, on vient vérifier nos chantiers. J'ajoute qu'on a tout à fait raison et qu'aucun État au monde, sauf peat-être la Chine ou la Turquie, n'achète un produit sans le contrôler. Je constate que la visite amiable dont parlait tout à l'heure M. Placide Peltereau, ainsi que l'a relevé M. Hirsch, ne signifie rien, est un trompe-l'œil, une duperie. J'ajoute avee vos textes, que si, avee la loyauté qui vous caractérise, vous venez dire: "Nous n'avons jamais fermé nos usines à la visite ", ceux quisont derrière vous ou qui vous suivent écrivent dans vos journaux que ces visites, même amiables, sont intolérables et qu'il est temps que cela cesse.

J'entends maintenant reprendre l'exposé de la Chambre de Commerce d'Auxerre, disant :

"Enfin, comme après fabrication, les cuirs à l'écorce et les cuirs à l'extrait ne peuvent se distinguer, sauf par l'usage, demandons que les tanneries produisant des cuirs destinés à être fournis aux Ministères de la Guerre et de la Marine, selon les conditions du Cahier des Charges, soient soumises à la visite des agents du contròle de l'État. La tannerie s'élève contre ce qu'elle appelle des mesures rexatoires et se réclane de la liberté. Vaines déclamations...

« La fabrication de toutes les fournitures à livrer à l'État est partout contrôlée dans les usines mèmes. C'est sous ce régime que vivent tous ses fournisseurs qui s’appellent : industries métallurgiques, conserves alimentaires, ciments, draps militaires, poteaux télégraphiques, etc...

"Toutes ces industries trouvent une précieuse référence et une source réelle de crédit, du fait du contròle par l'État. Il ne peut d'ailleurs être question d'exposer ici une industrie à la concurrence étrangère, puisque les cuirs livrés à l'Armée doivent ètre de provenance française. D'ailleurs, la tannerie a-t-elle des droits supérieurs à ceux des autres industries? Va-t-elle prétexter que ses usines sont inviolables, alors que toutes.les autres ouvrent leurs portes au cuntrôle ? Peut-elle, à priori, prétendre à un privilège exclusif? Le peut-elle surtout, étant donné la situation ci-dessus exposée? L'État aurait-il deus poids et deux mesures? Exactitude et bonne gestion d'un côté, abandon et laisser-aller de l'autre?

Ce serait désastreux.

"Ce que l'État exige partout, ce qu'il impose à la Guerre pour toutes ses autres fournitures, pourquoi ne pas l'exiger pour les cuirs? En outre de la défense du budget, il s’agit ici de la Défense nationale."

Et sur ce point, je remercie notre confrère appartenant au Minis- 
tère de la Marine d'avoir bien voulu dire tout à l'heure, en opposition avec M. Peltereau, que la Marine avait devancé la Guerre en imposant la visite des tanneries, affirmant ainsi que l'analyse est inopérante. Nous espérons que la Guerre suivra.

Vous avez dit, Messieurs, qu'il fallait cléfendre la forêt; il faut la défendre it avec elle tous ses auxiliaires, car les quelques milliers de marchands d'écorces que nous sommes ont derrière eux des centaines de mille búcherons, e'est-à-dire des ruraux, des petits cultivateur's, auxquels s'imposera un dur chômage de près de deux mois par an. Si le travail d'écorçage est supprimé, qu'allez-vous leur donner à fair pendant ces deux inois-là? Il faudra leur dire d'aller, oux aussi, à la grande ville. Voilà la solution.

Il est un dernier mot que je tiens à relever, car je crois qu'il n'a été repris par personne ici; M. Placide Peltereau a dit: "Nous ne pouvions pas admettre que l'Administration visitât nos tanneries, parce que nous ne sommes pas parties contractantes ". En un mot, ceux qui livrent le cuir à l'État, ce sont les fournisseurs d'équipements militaires; ils peuvent le produire eux-mêmes, mais généralement ce sont les tanneurs qui le produisent sans fournir lirectement.

L'ubjection n'est que spécieuse et je prends mon exemple dans ]a métallurgie. Les affûts de canons sont composés de métaux différents : acier, laiton, etc. ; les fournisseurs qui amènent l'affút à la réception ne se contentent pas de dire comme M. Placide Peltereau pense que cela suffit : "Voilà les affûts, prenez-les, voyez s'ils sont bons, la partie contractante c'est nous, et cela ne regarde que nous. "Je vous demande pardon ! L'État est allé visiter la fabrication des aciers, des laitons, etc., chez tous ceux qui n'étaient pas parties contractantes et il a tout vérifié avant l'assemblage ; l'État ne doit pas être trompé.

M. Hirsch. - Ce que nous demandons surtout est d'introduire un peu de décision dans les cahiers de charges de l'Administration. Il n'est pas nécessaire de fournir un texte extrêmement large, il faut que nous soyons précis. Nous demandons d'abord de sauver les forêts de taillis, nous sommes en droit de le demander à l'État, et par conséquent, c'est sur ce point là que nous demandons de maintenir le tannage à l'écorce de chêne pure.

La clôture de la discussion, mise aux voix, est adoptée.

M. Le Président. - En ce qui concerne le premier vou, nous sommes saisis d'un amendement de M. Guillot, amendement qui èst ainsi conçu :

"Que toutes les Administrations publiques achetant des produits en cuirs et peaux inscrivent dans leur cahier de charges une clause ì l'effet de n'accepter que des cuirs et peaux. tannés avec les meilleurs prodnits fournis par nos bois, au besoin couverts par des marques et 
réalisunt des conditions de réception suffisumment sévères ponr ofjrir tontes garanties."

Je mets cet amendement aux voix.

L'amendement est repoussé à une grande majorité.

Nous passons au vote sur le premier vocu du Rapporteur :

"Que tontes les Administrations publiques achetant des produits en cuirs et peanx inscrivent dans lenr cahier des charges nne clanse à l'effet de n'accepter que des cnirs et penux tunnés à l'écorce de chêne pure, à l'exclusion de tont antre ingrédient tannifère, et prennent des dispositions strictes et sévères ponr snrveiller dirertement l'applicution de cette clause."

Adopté.

\section{Deuxième vou :}

"Qne les pouvoirs publics, pour réprimer tonte frande et protéger le public consommateur, institnent une marque légale qui sera apposée sur tous les cuirs et peanx tannés à l'écorre de chêne pure. "

Adopté. Deux voix contre.

Troisième vou :

"Qne les Compagnies de chemins de fer consentent l'application de tarifs de fucenr très bus ponr le trunsport des écorces à lan, et prennent toutes dispositions en rne d'assurer ce transport dans les meillenres conditions. "

Amendement de M. Guillot :

"Que les Compagnies de Chemins de fer consentent l'applicution de tarifs de faveur très bas pour le transport des matières premières lignenses indigènes ntilisées par l'industrie de la tamnerie, et prennent toutes les dispositions en vne d'assurer ce transport dans les meillcures conditions."

M. Gilllot. - On ne peut pas refuser aux autres produits de bois [rançais te même traitement que celui qui est fait pour les écorces.

M. Hinsch. - Il ne s'agit pas du tout de refuser des carifs de faveur à une autre branche, il s'agit d'émettre un rou favorable à l'écorce, pour sauvegarder l'écorce. Nous n'avons pas à émettre un rocu qui soit contraire aux intérêts de qui que re soit.

11. Le Présibext. - Je mets aux voix l'amendement de M. Guillot.

Cet amendement est repoussé à une grande majorité.

II. LE l'Résident. - Je mets aux voix le voeu de M. le Rapporteur. Arlopté à l'unanimité.

La séance est levée à 11 h. 35 . 


\title{
SEANCE DU 19 JUIN 1913
}

\author{
(APRÈS-MIDI)
}

\section{Présidence de M. POUPINEL, président de Section}

La séance est ouverte à 2 h. 35 .

11. Le Président. - L'ordre du jour appelle la lecture des rapports de M. Duchemin, sur l'Jxdestrie des résines et la Carbonisation DES BOIS EX VASES cLos. Le premier de ces rapports ne comportent pas de voux, nous prions $\mathrm{M}$. Duchemin de nous donner lecture de son travail sur les deux questions avant de passer à la discussion.

M. Duchemin. - L'industrie des résines en France. - En France, l'industrie des résines est surtout localisée dans les départements de la Gironde, des Landes et du Lot-et-Garonne, où elle traite le pin maritime (Pinus Pinaster).

Elle consiste :

$1^{0}$ A recueillir la gemme qui exude des entailles pratiquées sur les arbres ;

$2^{\circ}$ A purifier cette gemme ;

$3^{0}$ A retirer de la gemme ses différents constituants.

Etudions successivement ces différents stades de la fabrication.

La gemme fournie par les conifères provient des canaux résinifères kiemuaye. logés dans le bois de la tige.

Lorsqu'on pratique une incision (quarre), dont la forme et l'importance varient suivant la nature des arbres, sur un conifère, la gemme afflue sur les bords de l'entaille.

Elle était autrefois recueillie par le procédé au crot. Aujourd'hui le procédé Hugues est presque partout adopté.

L'opération du gemmage donne lieu :

a) Soit au gemmage-épuisement du pin d'éclaircie pratiqué de la $15^{\mathrm{e}}$ jusqu'à la $35^{\mathrm{e}}$ année;

b) Soit au gemmage à vie qui se poursuit pendant 40 à 55 ans ;

c) Soit au gemmage-épuisement préalable à la coupe rase, appliqué de 55 à 60 ans ;

d) Soit au gemmage à mort.

La gemme du pin maritime est liquide et transparente lorsqu'elle rompusition de vient d'être recueillie, mais se trouble et devient laiteuse sous l'influence

la yemme. de l'oxygène de l'air. 
Sa composition moyenne est, la suivante (1):

\begin{tabular}{|c|c|}
\hline ssence & $20 \%$ \\
\hline Produits secs & 70 \\
\hline otés (sables, copeaux, etc.). & 10 \\
\hline oles coneaux etc) & \\
\hline
\end{tabular}

Traitrment des Les gemmes, soumises à l'action de la chaleur dans des chaudières de gemmes formes diverses, se fluidifient et se séparent en plusieurs couches :

A la surface : les impuretés, telles que copeaux, écorces, etc., qui prennent le nom de griches.

Au-dessous: une couche de térébenthine.

Au fond : de l'eau et un dépôt d'impuretés solides (sables, terre, etc.), qu'on désigne sous le nom de grep.

Les résidus ainsi obtenus sont débarrassés des produits résineux qui les imprègnent par chauffage à la vapeur. On peut aussi les traiter dans un four en maçonnerie d'où le goudron, la poix ou brai gras, s'échappent par la partie inférieure.

Traitement de la La térébenthine brute obtenue par la fusion tranquille de la gemme ci-dessus indiquée ou la gemme elle-même est redistillée en vue de :

10 La séparation de l'eau et de l'essence.

$2^{\circ}$ L'obtention d'un produit résiduel qui, par solidification, constitue la colophane ou le brai suivant son degré de coloration.

L'opération se pratique soit à feu nu, soit à la vapeur. C'est la distillation à la vapeur qui est maintenant la plus répandue et l'on rencontre, dans les usines landaises, les principaux systèmes suivants :

10 Appareils Col;

$\begin{array}{lll}2^{\circ} & - & \text { Violette; } \\ 30 & - & \text { Dalbouze; } \\ 40 & - & \text { Germox; } \\ 5^{\circ} & - & \text { Dorian. }\end{array}$

Les produits obtenus par la distillation sont successivement les suivants :

a) Gaz incondensables ;

b) Eau ;

c) Eau et essence;

d) Essence ;

e) Colophane.

L'essence de térébenthine trouve ses principaux emplois dans la fabrication des vernis et la préparation des peintures. Sa consommation comme matière première du camphre artificiel, après avoir été assez importante, a considérablement diminué depuis le jour où la baisse du camphre naturel a rendu impossible la fabrication du produit artificiel.

Les colophanes provenant de la distillation de la gemme sont désignées sous des noms variés suivant leur coloration.

On distingue notamment :

La colophane : jaune pâle.

Le brai clair : jaune.

Le brai noir : brun ou noir.

(1) L'Industrie des Résines, (E. Rabaté Masson et Cie). 
A la sortie des alambics les colophanes sont filtrées, afin d'en séparer les impuretés, puis moulées - soit dans des moules en sable, soit dans des barriques, soit dans des formes en tôle, - avant leur livraison au commerce.

Les colophanes sont principalement utilisées dans la papeterie, la savonnerie et les fabriques de vernis.

Par distillation de la colophane ou du brai, en présence de chaux, on inniles de rísine. obtient successivement :

$10 \%$ de gaz incondensables et de résidus charbonneux.

$5 \%$ de produits acides (acide acétique, etc.).

3 à $5 \%$ d'essence vive.

$60 \%$ d'huiles brunes et blondes.

$20 \%$ d'huiles vertes.

Ces différentes huiles, dont l'emploi est d'ailleurs très réduit, sont clarifiées, désodorisées et neutralisées avant d'être employées au graissage des essieux, à la fabrication des encres typographiques, à l'injec tion des bois, etc.

Les différents stades de la fabrication que nous venons de mentionner brièvement peuvent être résumés comme suit en un tableau :

$$
\text { Gremme brute }\left\{\begin{array} { l } 
{ \text { Essence de térébenthine. } } \\
{ \text { Colophane } } \\
{ \text { Brai } }
\end{array} \left\{\begin{array}{l}
\text { Essence vive. } \\
\text { Huiles brunes et blondes. } \\
\text { Huiles vertes. }
\end{array}\right.\right.
$$

Depuis ces dernières années, on pratique à l'étranger, et en particulier aux Etats-Unis, des distillations ménagées en vue d'en extraire l'essence, sans cependant pousser cette opération jusqu'à la production du charbon de bois.

On retire des appareils du bois dérésinifié qui serait, dit-on, particulièrement propre à la fabrication des meubles en bois blanc.

Nous ne croyons pas que ce procédé ait reçu encore d'applications en France.

En dehors des produits dont nous venons de résumer la fabrication, le pin maritime sert également de matière première à la préparation de goudrons et de charbons de bois.

Cette fabrication, qui met en œuvre des bois d'élagage et des souches, est pratiquée, soit en meules, suivant les procédés connus, soit encore, depuis ces dernières années, dans des cornues mobiles transportées sur le parterre des coupes, en application d'un brevet de M. de Vallandé (1).

Ce procédé permet d'obtenir du charbon de bois, du goudron clair, dit de Suède ainsi que de l'acide pyroligneux et de l'huile de pin extraite au moyen d'un récipient florentin placé à la sortie des produits condensés.

L'appareil de M. de Vallandé se compose de deux cornues placées sur un train de roues, chauffées méthodiquement par un foyer à carneaux échelonnés de façon à obtenir des produits lourds au point bas des cornues

(1) Brevet français no $359.944,29$ novembre 1905. 
et au sommet des vapeurs qui se condensent dans un serpentin et des gaz qui se rendent au foyer.

Ce foyer est disposé pour brûler des brindilles à la mise en train et pour chauffer en même temps une chaudière dont la vapeur sert à produire un chauffage initial et un refroidissement final du contenu de la cornue.

En 1907-1908, il a été traité en forêt, par ce procédé, 16.000 stères de branches.

\section{DOCUMENTS STATISTIQUES}

Nombre des usines: 180.

Surfaces boisées intéressées : environ 1.000 .000 a heetares se répartissant comme suit :

\begin{tabular}{|c|c|c|}
\hline Propriétés de l'État.... & $\begin{array}{l}\text { Cironde....... } \\
\text { Landes....... }\end{array}$ & $\begin{array}{l}29.526 \\
26.537\end{array}$ \\
\hline & Gironde....... & 24.874 \\
\hline Propriétés des communes. & Landes........ & 96.119 \\
\hline & Lot-et-Garonne. & 1.873 \\
\hline & Gironde....... & 307.234 \\
\hline prittés & Landes........ & 440.112 \\
\hline & Lot-et-Garonre. & 74.291 \\
\hline
\end{tabular}

Soit a u total............. 1.000 .566 hectares

\section{TONNAGES FABRIQUÉS}

Essence de térébenthine : 20 a 23.000 kilos.

Brais et colophanes : 75 à 80000.000 kilos.

\section{EXPORTATION}

Essence de térébenthine : environ 10.000 .000 de kilos,

Colophanes thrais : environ 50 à 60.000 .000 de kilos.

COURS HOYEX DE LA TÉRÉBENTIINE DE 1906 A 1913

\begin{tabular}{|c|c|c|c|c|c|c|c|c|}
\hline & 1906 & 1907 & 1908 & 1909 & 1910 & 1911 & 1912 & 1913 \\
\hline $\begin{array}{l}\text { Janvier....... } \\
\text { Juillet....... } \\
\text { Décembre... }\end{array}$ & $\begin{array}{r}116 \mathrm{fl}^{\mathrm{r}} \\
85 \% \\
102 \%\end{array}$ & $\begin{array}{c}107 \mathrm{fr} . \\
96 \\
67 \%\end{array}$ & $\begin{array}{l}70 \mathrm{fr} . \\
60 \% \\
58 \%\end{array}$ & $\begin{array}{l}60 \mathrm{fr} . \\
70 \% \\
87 \%\end{array}$ & $\begin{array}{l}95 \mathrm{fr}^{\circ} \\
100 \% \\
115 \%\end{array}$ & $\begin{array}{c}122 \mathrm{fr} . \\
80 \% \\
80 \%\end{array}$ & $\begin{array}{l}85 \mathrm{fr} . \\
60 \% \\
60 \%\end{array}$ & $65 \mathrm{fr}$. \\
\hline
\end{tabular}

Les brais et les colophanes n'ont pas de marché officiel.

Ces produits ont subi une hausse importante ces dernières années et valent, actuellement, en moyenne de 30 à 40 francs les 100 kilos.

Jo ne rous dirai rien du gemmage et de l'extraction de la résine, de l'industrie des essences, puisque les industriels qui traitent la térébenthine n'ont aucun voru à formuler. Ils sont done satisfaits de l'état do lour industrie désirent sans doute qu'on ne parle pas d'eux. 
Je continuerai done par la lecture de mon rapport sur la Carbovis.TION DES BOIS EN VASES CLOS.

Pour être complète, une étude sur la distillation des bois en vases clos devrait comporter un véritable volume; le comité d'organisation du Congrès ayant exprimé le désir que les rapports fussent brefs et en quelque sorte de simples introductions à la discussion, nous nous proposons, dans ce qui va suirre:

10 De dire ce qu'est l'industrie de la carbonisation des bois en vases clos ;

$2^{\circ}$ D'indiquer, en un tableau, les principaux produits qu'elle fabrique ;

$3^{\circ}$ D'examiner le rôle de cette industrie au point de vue de la richesse forestière française;

$4^{\circ}$ D'exposer rapidement son utilité au point de vue de la défense nationale ;

$5^{\circ}$ De tirer les conclusions de notre étude.

La carbonisation des bois en vases clos a pris naissance en France au commencement du xixe siècle, et elle compte aujourd'hui dans notre pays vingt usines.

Elle consiste à soumettre le bois, dans des cornues en fer, à l'action de la chaleur; à recueillir, par condensation, les produits qui se dégagent et qui constituent l'acide pyroligneux brut; enfin, à retirer de la cornue le résidu de la carbonisation : le charbon de bois.

La distillation du bois est aujourd'hui pratiquée en France, soit dans des cornues mobiles de 3 stères à 10 stères de capacité, soit dans des cornutes fixes de 20 à 40 stères, où le bois est introduit dans des chariots.

Quel que soit le processus adopté par l'industriel, le produit obtenu, l'acide pyroligneux, est un mélange fort complexe et dont on ne saurait faire varier la composition à son gré. Il renferme comme produits principaux : du méthylène acétoné, de l'acide acétique et du goudron.

On ne peut pas fabriquer de méthylène sans acide acétique et goudron et, inversement, les produits acétiques ou le goudron sans méthylène.

De ce fait ressort nne première observation à retenir : pour que les usines de carbonisation de bois aient une existence normale, la valeur totale des produits qu'elles fabriquent doit être constante ou à peu près constante.

Le traitement de l'acide pyroligneux se pratique de façons différentes dans les diverses usines et son exposé nous entraînerait en dehors du champ de cette étude.

Nous nous contenterons done d'indiquer que l'acide pyroligneux, soit simplement dégoudronné et décanté, soit préalablement redistillé afin d'en séparer les flegmes méthyliques, est saturé par la chaux ou par le carbonate de soude. On obtient ainsi le pyrolignite de chaux et le pyrolignite de soude qui servent de point de départ à la fabrication de tous les dérivés acétiques que l'on trouvera dans le tableau que nous donnons plus loin.

Les flegmes méthyliques sont rectifiés à part dans des alambics ad. hoc, afin d'en extraire l'alcool méthylique et l'acétone.

Dans ces dernières années, M. Hirsch, inspecteur des Eaux et Forêts, 
M. Caquet, membre du Conseil supérieur de l'Agriculture, et la Société des Agriculteurs de France se sont préoccupés de la possibilité de pratiquer la carbonisation des bois sur le parterre même des coupes, afin d'assurer l'utilisation des menus bois dont le transport et l'écoulement sont très onéreux.

La réalisation de la carbonisation volante aurait non seulement assuré l'emploi des bourrées, mais aurait ınis à la disposition de l'exploitant de la force motrice par utilisation des gaz incondensables (oxyde de carbone, méthane, etc.) engendrés à côté de l'acide pyroligneux, par la carbonisation du bois.

Des essais ont été pratiqués dans les Landes, sur des bois tendres, par M. de Vallandé, avec comme objectif la production de goudrons et d'essences, mais nous ne croyons pas que, dans l'état actuel de l'industrie du pyroligneux, ils puissent être couronnés de succès pour le traitement des bois feuillus et l'obtention des produits acétiques.

Le problème à résoudre est, en effet, à la fois d'ordre technique et commercial. Il faut tout d'abord assurer la condensation des produits volatils - acide acétique, méthylène et acétone, - ce qui ne peut pas se faire à l'aide d'aéro-condenseurs et nécessite des quantités d'eaus très importantes que, dans la plupart des cas, on ne trouverait pas sur le parterre des coupes. Il faut aussi fabriquer des produits à un état de pureté suffisant pour pouvoir les écouler à un prix rémunérateur.

La solution n'est pas trouvée et il reste un champ à exploiter pour les inventeurs. 
PRODUITS PRINCIPAUX EXTRAITS DU BOIS ET FABRIQUÉS DANS LES USINES DE CARBONISATION DE BOIS

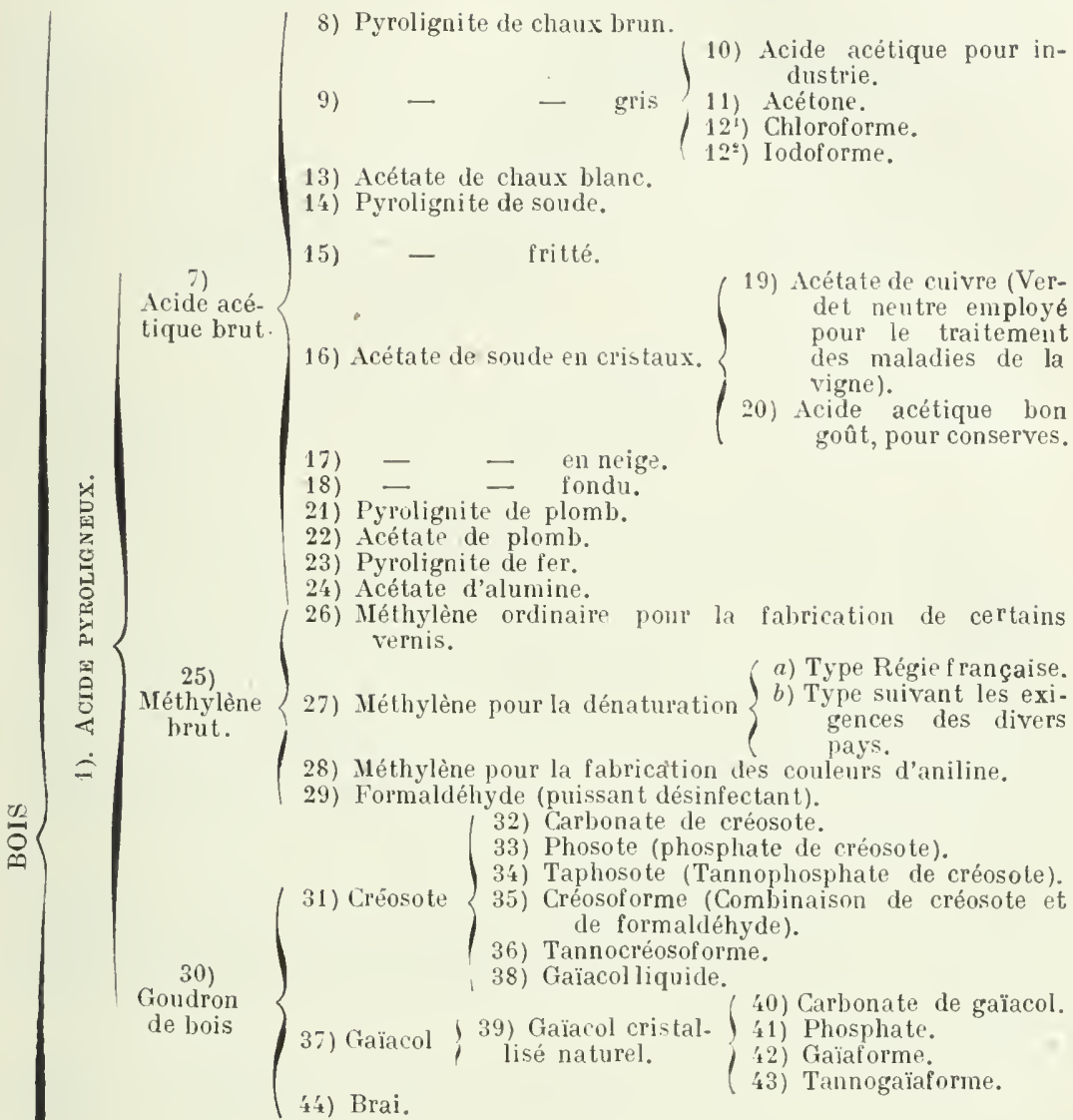

5) Noir de fonderie.

6) Briquettes. 
Tuleur des produits fabriqués. - On distille en France environ 600.000 stères de bois et le total des produits bruts fabriqués peut s'établir comme suit :

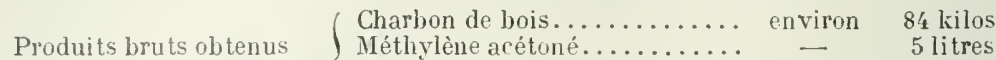

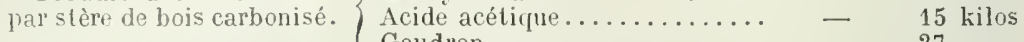

soit, pour 600.000 stères, et en chiffres ronds :

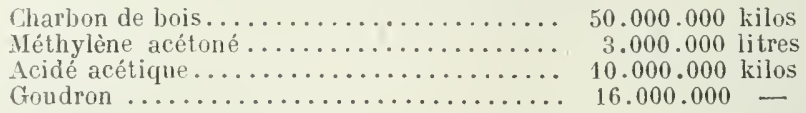

représentant une valeur de :

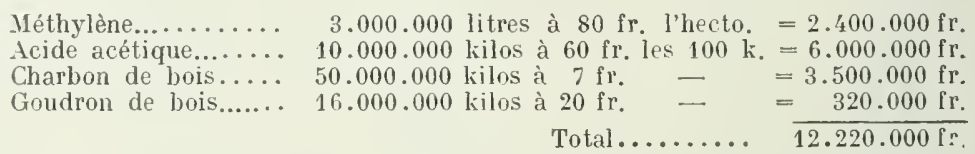

Ce chiffre de 12.220.000 franes est loin de représenter la valeur réelle des produits mis en vente par les usines de carbonisation de bois françaises.

La majeure partie de l'acide acétique, en effet, trouve son écoulement, soit en produits rectifiés, comme l'acide acétique bon gont, soit sous forme d'acétates, comme les sels de chaux, de soude, de plomb, de cuivre, etc.; soit enfin, par transformations et traitements successifs, sous forme d'anhydride acétique, d'acétone, de chloroforme, d'iodoforme, etc., dont les prix de vente font plus que quintupler la valeur de l'acide acétique mis en œuvre.

Si l'on ajoute à cela les créosotes et les gaïacols extraits du goudron de bois, ainsi que les produits pharmaceutiques qui en dérivent, on peut dire, sans crainte d'être taxé d'exagération, que les produits sortant des usines de carbonisation ont une valeur qui atteint, si elle ne les dépasse, 50.000 .000 de franes.

Influence de la carbonisalion des bois sur la prosperive d la sylvicultiile.
Les usines françaises de carbonisation traitent annuellement environ 600.000 stères de bois, représentant une valeur de plus de 4.000 .000 de francs.

Cette consommation de 600.000 stères influe sur les cours des coupes faites dans près de 200.000 hectares de forêts, puisque l'Administration des Eaux et Forêts (A. Milard, Revue des Eaux et Forêts, 1904) admet qu'un hectare de taillis produit annuellement 3 stères de bois de chauffage. Elle intéresse près de 40 départements.

Lorsqu'on sait les difficultés qu'éprouvent les exploitants à carboniser en forêts leurs charbonnettes, quand on connaît la diminution progressive de la valeur des bois de chauffage dont la consommation est battue en brèche par l'emploi des poêles, cheminées mobiles, calorifères ou autres modes de chauffage actuellement en usage, on est en droit de se demander, si, sans la distillation en vases clos, la destruction des taillis ne s'imposerait pas aux forestiers.

La cause du déboisement r'éside - le fait n'est pas niable - dans l'abaissement progressif du revenu des propriétés forestières, tandis que 
les impôts sont restés à des taux exorbitants variant de 20 à $50 \%$ du revenu brut annuel.

Beaucoup de propriétaires, las de voir le plus clair de leurs revenus servir au paiement des impôts, ont, dans un moment de découragement regrettable il est vrai mais excusable, vendu leurs domaines à l'un de ces groupements destructeurs qui ont été dénoncés à la tribune du Parlement.

Il en est résulté ces coupes à blanc si préjudiciables à notre pays puisqu'elles entraînent la destruction du régime des eaux dont nous avons eu ces dernières années de trop nombreux et tristes exemples, le ravinement des gazons, des terres à culture, le bouleversement des conditions climatériques et enfin la disparition de tant de beaux sites qui font la renommée de notre patrie.

Que les forestiers obtiennent, grâce à une modification de l'assiette de l'impôt ou à la revision du cadastre, un dégrèvement leur laissant un revenu plus élevé, et ils trouveront dans les usines de carbonisation un régulateur des cours.

Grâce à une consommation régulière, les propriétaires dont les bois sont à proximité des usines de pyroligneux, divisent leurs forêts en 18 ou 25 secteurs qui sont exploités à tour de rôle. Chaque secteur se trouve ainsi mis en exploitation tous les 18, 25 ans ou même davantage, et reconstitué dans le même laps de temps. Ce sont ces coupes de révolution qui, en assurant un revenu régulier aux exploitants, sont une des meilleures mesures contre le déboisement.

C'est à cette préoccupation d'utiliser les menus bois qu'obéit actuellement le gouvernement austro-hongrois. Il cherche à créer de nouvelles usines de carbonisation de bois, qui lui permettraient de réaliser normalement l'exploitation de ses forêts domaniales, en promettant aux industriels, pour les attirer, l'exemption de l'impôt et l'application de tarifs de transports réduits pour leurs produits fabriqués. Attitude fort compréhensible, du reste, puisque, ainsi que l'a démontré l'honorable M. Gouget, dans un travail présenté à la Société des Agriculleurs de France (1906), si le débouché de la carbonisation des bois venait à manquer aux forêts, celles-ci tomberaient de leur valeur actuelle (750 fr.) à un chiffre ne dépassant pas 150 à 200 francs l'hectare. Il nous sera peut-être objecté que si les usines de carbonisation jouent un rôle prépondérant dans l'exploitation des bois de taillis, leur rôle est moins important dans l'exploitation des futaies.

Mais il ne faut pas oublier que, même si l'on préconisait la reconstitution des futaies de 100 et 150 années, leur exploitation donnerait d'importantes proportions de bois de feu, dont le seul usage étendu resterait la carbonisation.

Comment au surplus demander aux propriétaires, qui souvent, en vue d'une réalisation hâtive, font des coupes dans des taillis de 15 et 16 ans, de laisser à leurs héritiers le soin d'exploiter des forêts dont le revenu est souvent leur seule ressource? On nous en voudrait d'insister, et au surplus, la meilleure des preuves de l'exactitude de notre raisonnement, c'est que partout où sont installées des usines de carbonisation de bois, il n'y a plus de déboisement.

Mais ce n'est pas là la seule influence heurense qu'ont sur la richesse forestière les usines de pyroligneux. Elles retiennent, dans les centres forestiers où elles s'établissent, la main-d'œuvre qui, dans tant de régions, s'en éloigne de plus en plus et dont la disparition a provoqué ce manque 
de bras qui, en aggravant la situation des propriétaires, les a poussés à ces ventes néfastes dont nous avons parlé.

Elles assurent enfin à l'ouvrier et au petit cultivateur un salaire rémunérateur pendant les mois d'hiver où la culture n'a pas besoin de leurs bras.

Les usines de carbonisation de hois et la defense uationale.

Au point de vue de la défense nationale, le développement des usines de carbonisation est d'une nécessité absolue, tant pour la fabrication des poudres de guerre que pour la fabrication des désinfectants.

Poudres. - L'administration de la Guerre emploie aujourd'hui, pour la préparation des poudres et des explosifs, l'alcool amylique et l'éther, alors que la plupart des pays étrangers, et en particulier l'Angleterre, utilisent l'acétone, mais il est probable que bientôt elle sera amenée à compter ce produit au nombre de ses matières premières.

Même s'il n'en était pas ainsi, il est de toute évidence qu'en cas de guerre elle serait forcée, par suite de la consommation effroyable de projectiles, d'utiliser toutes les méthodes de fabrication actuellement existantes. Comme, en outre, l'importation de l'alcool amylique en France (de grandes quantités de ce produit sont de provenance autrichienne) viendrait, dès la déclaration de guerre, à faire défaut, les poudreries devraient faire appel aux usines de carbonisation de bois pour l'acétone ainsi que pour le charbon de bois qui sert à la préparation des poudres noires, dont l'adjuvant ne serait certainement pas à dédaigner.

Tous les pays cherchent d'ailleurs à ne pas être tributaires de l'étranger pour les matières premières nécessaires à leur armement et l'on a vu récemment le gouvernement anglais, qui reçoit l'acétone dont il a besoin de France, d'Allemagne, d'Autriche et des Etats-Unis, et qui conserve toujours en stock dans ses arsenaux 500.000 kilogrammes de ce produit, se préoccuper de développer les rares usines de pyroligneux qui ont pu survivre en Angleterre à l'importation américaine.

A côté de l'acétone et du charbon de bois, il est encore un produit des usines de carbonisation dont l'emploi, en poudrerie, est assez important, c'est l'acide acétique qui sert à la préparation de l'éther acétique (acétate d'éthyle).

Cela fait done déjà trois corps, parmi les plus importants de nos usines, qui sont indispensables à la défense nationale, pour la fabrication des poudres.

Désinfectants. - La guerre russø-japonaise a montré le rôle de l'antisepsie dans la guerre moderne. L'intendance japonaise, acquise aux idées nouvelles en matière de propagation des épidémies, a su éviter à l'armée nippone une mortalité élevée qui, en revanche, s'est manifestée dans les troupes russes.

Elle a organisé un service de désinfection par le formaldéhyde des effets de guerre des soldats, blessés ou non, rappelés dans leurs foyers et les résultats obtenus ont été remarquables.

Elle a remis, en outre, à chaque soldat une boite de pilules de créosote de bois, dont l'usage a éloigné de l'armée japonaise les affections du tube digestif qui, dans toutes les guerres, ont toujours fait de grands ravages.

Rappelons enfin l'emploi de plus en plus répandu de l'iodoforme et du cliloroforme que l'on prépare maintenant en partant de l'acétone.

L'on constate finalement que les principaux produits de la carbonisation des bois en vases clos : l'acide acétique, le méthylène, le formaldéhyde, 
l'acétone, le charbon de bois, la créosote, sont indispensables à la vie nationale, tant au point de vue de la défense du territoire contre une invasion étrangère qu'à celui des mesures prophylactiques à prendre contre les épidémies.

Nous croyons avoir démontré, dans ce qui précède, l'utilité de l'indus- ronclas. wh. ". trie de la carbonisation des bois en vases clos au double point de vue de la conservation de la forêt et de la défense nationale.

Serait-il possible de développer cette industrie et d'y trouver un écoulement eroissant des menus bois?

Le problème est intimement lié à la consommation des produits de la distillation des ligneux. Cette consommation a augmenté ces dernières années et si l'emploi des acétates de cellulose prend le développement qu'on peut espérer, les produits acétiques trouveront dans notre pays un écoulement considérable.

Il n'en resterait pas moins la double nécessité de:

10 Assurer la vente du charbon de bois;

20 Maintenir la consommation du méthỳlène régie.

Charbon de bois. - La prise de vente de ce corps a subi, ces derniers mois, un fléchissement imputable, en grande partie, à la diminution de consommation dans les grandes villes et en particulier dans Paris, par suite de l'emploi du gaz.

Il y a, en effet, en France, peu d'emplois industriels du charbon de bois et son écoulement est intimement lié à la consommation donrestique.

Or, dans la plupart des grandes villes, le charbon de bois paie des taxes d'octroi élevées qui sont sans rapport avec celles appliquées aux combustibles minéraux et qui en entravent la vente.

Méthylène régie. - La France importe environ 30 à $40 \%$ des quantités de méthylène qui lui sont nécessaires et il semble en résulter à première vue que les usines de carbonisation de bois ont un vaste champ d'écoulement pour leurs produits méthyliques.

Il n'en est rien réellemeut, car le marehé des méthylènes est entre les mains des Etats-Unis et des distillateurs allemands de méthylène brut américain. Grâce, en effet, à une législation douanière répondant à la situation économique de leur pays, grâce aussi à une consommation considérable d'alcool méthylique pur, ces derniers peuvent vendre le méthylène acétoné près de $40 \%$ meilleur marché que leurs concurrents français.

Le seul moyen de rétablir l'équilibre rompu au détriment des carbonisateurs de France, serait d'augmenter les droits d'entrée ou d'aceroitre la consommation française par une augmentation d'écoulement de l'alcool industriel que le méthylène sert à dénaturer.

\section{LE Congrès,}

Considérant que les taxes d'octroi sur les charbons de bois sont beaucoup plus élevées que celles frappant les combustibles minéraux;

Considérant que, de ce fait, est entravée la vente des charbons de bois et, partant, l'écoulement d'une partie des produits des coupes de bois ;

Considérant que ces taxes d'octroi, qui frappent un produit destiné à 
Ia consommation ouvrière, élèvent d'une façon exagérée le prix de vente d'une matière de première nécessité;

Considérant, d'autre part, que l'extension de l'industrie de la carbonisation des bois en vases clos rendrait un réel service à la forêt française ;

Considérant enfin que cette extension ne sera possible que le jour où les carbonisateurs pourront être assurés d'écouler leur méthylène à un prix rémunérateur ;

\section{ÉMET LE VOEU :}

I. Que les grandes villes et, en particulier, la ville de Paris, réduisent les droits d'octroi sur les charbons de bois au taux des droits sur les combus. tibles minéranx;

II. Que le Parlement étudie l'élévation des droits de douane, en vue de protéger la production française de méthylène;

III. Qie le Parlement prenne les mesures propres à étendre la consommation de l'alcool industriel que le méthylène sert à dénaturer.

En ce qui concerne, la carbonisation proprement dite, je suis heureux de pouvoir prendre la parole dans ce Congrès, parce qu'on a dit au Touring-Club que nous étions souvent les auteurs du déboisement. Loin d'en être la cause, la carbonisation du bois en vases clos, est une cause de maintien de la forêt.

La carbonisation est peut être aujourd hui la senle industrie qui consomme d'une façon à peu près régulière les produits des coupes, c'est-à-dire la charbonnette et le bois de chauffage.

D'un autre còté, la nature même de l'industrie de la carbonisation, l'obligation pour ses usines de s'assurer des matières premières d'une façon régulière, a eu pour conséquence de faire établir les coupes de révolution plus ou moins longues dans les environs des usines proprement dites. Loin d'être une cause de déboisement, l'établissement de tes coupes est une cause de maintien de la forêt.. .

II. IE LARNAGE. - M. Duchemin a dit que la production de la gomme était localisée dans trois départements. Ceci est inexact. C'était vrai avant 1905. A partir de cette date - où j'ai eu pour la première fois, l'honneur de pratiquer dans le centre de la France, le gemmage de différentes espèces de pins - la tache d'huile s'est agrandie de procht en proche assez pour pouvoir atteindre maintenant 1'́ nouveaux départements français.

Pour cette production, nous nous sommes limites au sylrestre, au pin noir d'Autriche et à l'Alep.

Les propriétaires ne cherchent qu'une chose : la main-d'œurre. Ifs demandent qu'on les aide, comme dans tous les autres domaines, a en trouver. Or, comment trouverons-nous la main-d'ouvre pour le gemmage dans les régions nouvelles? En demandant au gourernement d'introduire par l'école dans toutes les régions où se trouve ce genre de culture, un enseignement sylvicole approprié comme celui qui est

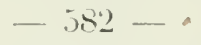


donné dans les écoles de la Gironde et des Landes, par de petites brochures spéciales montrant aux enfants les avantages de cette profession. Cette main-d'œuvre permettra aux ouvriers d'augmenter leurs revenus. Toilà ce que demandent les propriétaires.

C'est une ceuvre d'ordre soeial qui eorrespond à la crise de l'apprentissage dont nous avons à nous plaindre pour toutes les branches de l'industrie française et de l'industrie agricole, peut-être plus que dans toute autre en ce moment. (Applandissements.)

M. H. Barbier. - Je désire au nom du commerce français, au nom de l'exploitation forestière française, m'associer au vøu de M. Duchemin. Son rapport et les explications dont il l'a accompagné sont parfaitement exacts et des plus intéressants. On ne saurait trop protéger l'industrie de la carbonisation.

M. Le Président. - Je donne lecture des roux qui terminent le rapport de $\mathrm{M}$. Duchemin :

$1^{\circ}$ Que les grandes villes, et, en particulier, la ville de Paris, réduisent les droits d'octroi sur les charbons de bois an tanx des droits sur les combustibles minéranx;

Arloplé.

20 Que le Parlement étudie l'élésation des droits de donane, en vue de protéger la production française de méthylène;

Adopté.

$3^{\circ}$ Que le Parlement prenne les mesures propres à étendre la consommation de l'alcool industriel que le méthylène sert à dénaturer.

Adopté.

M. Le Présidext. - L'ordre du jour appelle la lecture d'une communication de M. Cuif sur le gemmage du pin noir d'Autriche et du pin sylvestre en Meurthe-et-Moselle.

M. Curf. - J'ai poursuivi depuis 1907 des études comparées sur le gemmage du pin sylvestre et sur celui du pin noir aux environs de Nancy.

Les gemmages opérés de 1909 à 1912 ont donné 350 grammes en moyenne de gemme pour les pins noirs, et 308 grammes pour le pin sylvestre. (Dans les Landes, la production anmuelle du pin maritime oscille de 1 à 2 litres).

Le rendement en essence de térébenthine a varié entre 13 et 17 pour cent jour le pin noir, et 12 et 18 pour le pin sylvestre. Les colophanes obtenues furent de belle qualité.

Le gemmage n'a eu d'influence appréciable que sur la production ligaeuse des arbres, - on peut l'estimer réduite de 15 pour cent pour les arbres gemmés à vie et de 30 pour cent pour les arbres gemmés à nort.

Le montant du revenu en produits résineux serait - au cours actuel des résines - compris entre le tiers et le quart du montant du revem en bois.

Je conclus, avec calculs à l'appui, qu'à moins de voir réapparaître d'une façon durable les prix atteints pour les produits résineux pendant la guerre de 
Sécession, on peut penser (que le gemmage de ces deux essences ne sera jamais industriellement rémunérateur en Lorraine.

Je vous propose, toutefois, Messieurs, d'émettre le vau suivant :

Que des expériences soient entreprises dans chaque région naturelle peuplée de pins, en vue de déterminer si le gemmage industriel y pourrait être avantagensement pratiqué le cas échéant".

Je suis à l'entière disposition des propriétaires qui, désireux de faire dans leur région des expériences semblables à celle que j’ai poursuivie durant ces derniẻres années, voudraient me consulter.

11. de Lariaget M. Graxd appuient le rou de M. Cuif qui est mis aux voix et adopté.

11. LE P'résinext. - Nous avons maintenant à l'ordre du jour une communication de $\mathbf{~} 1$. Larroquette relative à la Fratde de L'Essexce DE TÉRÉBENTHINE.

Un secrétaire donne lecture du résumé suivant de la communication de II. Larroquette :

Lindustrie résinière constitue un des plus importants éléments de prosnérité pour la région sud-ouest de la France.

Le prix élevé de la térébenthine a déterminé des fraudes de plus en plus nombreuses de ce produit, fraudes consistant à mélanger à l'essence des adultérants les plus variés, soit uormaux, c'est-à-dire pouvant se trouver parmi les produits de distillation des résines, soit anormaux. Le plus répandu de tous est le pétrole blanc ou white spirit.

Ces fraudes pèsent lourdement sur les cours des essences et tendent à déconsidérer les produits résineux français, jusqu'ici universellement prisés.

II. Larroquette expose le ròle du Syndicat des ouvriers gemmeurs, du Syndicat de défense des produits résineux, de la Société des Agriculteurs de France, du Syndicat des Fabricants d'essences dans cette lutte contre la fraude; il aspère que les Pouvoirs publics feront ce qui dépend d'eux pour l'enrayer.

Il conclut :

$1^{\circ}$ A la mécessité de l'extension, à bref délai, à l'essence de térébenthine des dispositions de la loi sur les fraudes (ler août 1905);

$2^{\circ}$ A l'allocation d'encouragements aux chercheurs qui découvriront un procédé simple et pratique de mettre en évidence les fraudes de l'essence. Il siguale à ce sujet les efforts très méritoires du laboratoire de chimie de Bordeaux (dirigé par II. Vège).

Ln projet destiné à définir l'essence de térébenthine et à faciliter la poursuite des fraudes, est actuellement soumis au Conseil d'Etat.

M. Lirropuette. - Messieurs, je rous demande la permission d'ajouter ì ceci quelques courtes observations qui s'étendent à tous les départements qui produisent les mêmes matières que ceux des Landes, de la Gironde, du Lot, de la Garonne et de la Charente.

Cette question de la fraude est de la plus grande gravité pour nos populations. Le grand danger est dans l'emploi du pétrole rectifié qui, par son bon marché, permet à la fabrication de l'essence de térébenthine tout d'abord d'avoir un cours considérable, mais a le gran!

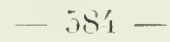


inconvénient d'avilir les prix, et de déprécier à l'étranger notre fabrication qui, jusqu'ici, était estimée.

La situation est fâcheuse et a soulevé de nombreuses protestations, aussi bien des ouvriers que des propriétaires de forêts. Les conseilgénéraux des Landes et de la Gironde ont émis à différentes reprisudes voux énergiques en vue de la répression de la fraude.

Ces doléances ont été exposées au Parlement par nos représentant. Pour mettre fin à l'état de choses, ils ont proposéd'appliquer en France la législation américaine. Les États-Unis sont nos grands concurrents en matière de production d'essence de térébenthine. A còté des 25.000 tonnes que nous produisons, les États-Unis en fournissent 110 a 120.000. La législation américaine n'autorise la vente, sous le nom d'essence de térébenthine, que du produit résultant de la distillation de l'arbre pin. Les pénalités appliquées aux fraudeurs sont très rigonreuses.

Les Pouvoirs publies français ont répondu que la question méritait d'être prise en sérieuse considération et à différentes reprises, le Ministre de l'Agriculture a promis qu'un règlement d'administration publique serait publié pour remédier à celte situation intolérable, à définir exactement, scientifiquement et officiellement l'essen de térébenthine - ce qui n'a pas lieu actuellement et permet justement l'écoulement des produits fraudés.

Un droit de circulation analogue à celui qui frappe tous les alcools serait établi.

Il faudrait également que, sur les récipients et les emballages, l'étiquette "Térébenthine pure "fut appliquée afin que le consommateur fut certain du produit qui lui est rendu.

Jusqu'à présent, on n'a pas abouti à un grand résultat. La frand existe, et on ne peut pas l'imputer à nos procédés d'industrie particulière.

Ce règlement d'administration publique qui mettra fin aux abus, nous l'attendons.

Aussi je vous propose, Messieurs, d'émettre le vou conforme aux desiderata des Conseils Généraux et de nos représentants au Parlement et aux revendications des intéressés. Il pourrait être ainsi conçu :

\section{LE CONGRÈS :}

"Considérant que la fraude sur l'essence de térébenthine est de nuture à porter le plus grand préjudice à la propriété et à l'industrie de la région landaise... "

On pourrait mettre ici "de tontes les régions productrices..."

M. De Larnage. - Parfaitement !

M. Larrogentte. - ... et ì l'industrie de toutes les régions productrices de France. 
EMET LE V(EL :

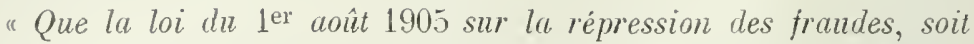
rigoureusement appliquée sur tonte l'étendue du territoire français, et qu'un règlement d'administration publique soit publié sans retard définissant officiellement l'essence de térébenthine et interdisant la vente de tout article qui n'est pas le produit de la distillation de la résine de pin $"$.

II. Graxd. - Loin de combattre votre vœu je veux l'appuyer.

Si les cours tombaient d'une manière définitive, il y aurait dans ce pays, où on fait de la monoculture d'une manière à peu près absolue, une espèce de petite révolution, car cette population se trouverait sans moyens d'existence du jour au lendemain.

M. Larroquette. - C'est très juste.

M. Grand. - Le mal ne vient pas de la concurrence américaine, car, là-bas, les produits de la distillation du bois ne sortent pas du pars. Ceux que nous consommons nous viennent de Russie, de Finlande et de Suèrle. On distille les souches, on obtient ainsi un produit qui est du goudron de mauvaise qualité; on le redistille et on a un produit qui, tout en étant limpide, n'est cependant pas de l'essence et en est si éloigné que des études faites par des savants de ces pays ont démontré qu'il pouvait être néfaste pour la santé publique, que ses vapeurs sont nocives, et que des chiens qui les avaient respirées en étaient morts. Il serait très regrettable de laisser s'établir une confusion alors que la térébenthine, vous le savez, intervient couramment en thérapeutique.

C'est dans ces conditions que je suis heureux de préciser le débat sur la question. La loi de 1905, préroit des décrets définissant tous les produits. Beaucoup de produits ont été définis et réglementés par ces décrets, sauf l'essence...

M. DE LARAAGE. - Ils n'ont pas tous été définis, mais une grande partie le sont.

11. Graxd. - Depuis deux ans, nous réclamons ce décret. Nous avons passé par bien des difficultés et au dernier moment, alors que le décret allait paraitre, et que rien ne pouvait justifter un nouveau retard, de nouvelles difficultés ont surgi.

Nous avons combattu cette essence provenant de la distillation du bois. Nous avons obtenu, en oetobre dernier, un jugement du tribunal de la Seine, portant condamnation et disant que le mot essence de térébenthine était réservé à la distillation de la gemme, de la résine, du suc oléo-résineux, comme il est dit dans les définitions officielles. Nous avons cru qu'il n'y aurait plus de difficultés sur ce point; mais au dernier moment, à la suite d’interventions dont nous n'arons pas 
très bien démêlé l'origine, on prétendit introduire dans le décret qui va paraître, à la suite des mots "L'essence de térébenthine est le produit exclusif des sucs oléaginenx ", les mots "et des bois qui les contiennent", ce qui permettrait de vendre sous le nom d'essence de térébenthine, non plus le produit exclusif de la distillation de la résine. mais le produit de la distillation du bois.

Ceci est inadmissible parce que c'est illégal. Nous connaissons tous la loi sur la répression des fraudes qui a donné au Conseil d'État le droit de préparer des décrets, et au Président de la République, le pouvoir de les signer, réglementant, non pas d'une façon arbitraire. mais d'une façon prévue par la loi, ce qu'il y aurait à en dire, c'està-dire de définir des produits déjà existants. Or, le produit de la distillation du bois en France n'existe pas, et on nous faisait remarquer tout à l'heure que c'est un procédé nouveau. Je ne crois pas qu'il ait été mis sérieusement en application en France et n'a, par suite, pas donné lieu à un courant d'échanges commerciaux sérieux dans notre pays.

II me semble difficile, en droit, que le Conseil d'État puisse définir selon les usages commerciaux un produit qui n'a pas encore été dans le commerce et n'y est pas encore actuellement.

En outre, il parait inadmissible de se servir d'un mot qui désigne un produit bien défini, existant, pour l'appliquer à une production qui n'est pas du tout la même.

C'est pour cela, Messieurs, que je suis très heureux de demander au Cungrès de voter le vou qui vient d'être proposé, mais de le modifier un peu, car notre collègue ne connaissait pas la genèse du décret portant règlement d'administration publique que nous réclamons. On nous a dit, il y a quelques jours, que nous aurions ce décret, mais avec les mots: "distillation de la résine on du bois ". Nous n'en avons pas voulu. Nous avons fait pour cette raison une demande d'audience au Conseil d'État pour être entendus sur la question. Nous confèrerons demain matin sur la question au Conseil d'État. Ce serait une bonne fortune pour nous si nous pouvions nous présenter avec un vosu du Congrès.

Ce vou pourrait être ainsi conçu :

"Que le décret portunt réglement d'administration publique destiné a définir l'essence de térébenthine en vertn de l'article 11 de la Loi dn fer coût 1905, prévoie uniqnement sous ce nom le produit exclusif de la distillation des sucs oléo-résinenx tirés par le gemmage d'arbres résinenx, à l'exclusion de la distillation, même aquense, des bois qui les contiennent."

Ce texte nous donnerait complète satisfaction.

Notre collègue, 11. Larroquette, disait tout à l'heure qu'il demandait l'application rigourense de la Loi de 1905. Je crois que ce n'esi pas nécessaire. La Loi de 190\% s'applique a l'essener de térébenthine, a tel point que nous arons obtenu des condamnations en vertu do 
cette loi. Ce qu'il faut dire, c'est qu'en matière de fraudes, les Parquets sont souvent très mous. Comme l'analyse est difficile, beaucoup de fraudes constatées finissent par passer par les mailles et ne sont pas poursuivies d'une manière définitive. Ce n'est pas la faute de la loi. Il y aurait lieu tout simplement de demander que les prélèvements faits par le service des fraudes sur l'essence de térébenthine soient plus nombreux et plus abondants. En réalité, ils ne le sont pas. Les agents du service des fraudes doivent justifier auprès de leur service des prélèvements qu'ils ont faits. Il est certain qu'ils préfèrent opérer de petits prélèvements qui ne sont pas embarrassants. Pour l'essence de térébenthine, ils doivent prélever quatre échantillons d'un demi-litre chacun, de sorte qu'ils n'aiment pas à faire ces prélèvements. Nous ne pourons pas nous arrêter à des raisons de cet ordre, et c'est pour cela qu'il serait bon de préciser dans un voru notre désir, non pas de voir la loi plus rigoureusement appliquée, mais plutôt de voir prélever des échantillons plus copieux et en plus grand nombre par le service des fraudes.

M. Drсnemix. - Je me demande s`il ne faudrait pas préciser votre va'u, au point de vue de la désignation de la qualité de l'essence. Si demain. par un procédé quelconque, on arrive à extraire par distillation, la térébenthine ayant absolument la même composition que l'essence provenant de la distillation des gemmes - cela peut très bien se produire - la concurrence pourrait vous retomber sur le nez, passezmoi l'expression.

Ne faudrait-il pas demander que la désignation faite par le service des répressions de la fraude, s'applique bien à l'essence de térébenthine telle qu'elle est obtenue par la distillation des gemmes? Sans parler aujourd'hui de la distillation' d'autres choses.

M. Graxo. - Il y aurait danger à le faire, parce qu'il y a un contreprojet qui porte justement ces mots: "la distillation des sucs oléorésineux ou des bois qui les contiennent "mots que nous voulons faire rejeter.

M. Dichemr. - Je crains qu'on vous dise, dans les services techniques des fraudes, qu'il n'est pas impossible d'extraire de l'essence de térébenthine, ayant la même composition, d'autres produits. Cela peut très bien se produire. Ne craindriez-rous pas une confusion?

11. Graxn - - Je crois, Messieurs, qu'il serait abusif que le Conseil d'État entrât dans ces détails. Il doit s'en tenir aux produits existants.

Mi. Drchenis. - Il faut demandes quelque chose qui ne vienne pas it l'encontre d'une jurispruclence acquise.

II. DE LARNAgE. - En ajoutant $u n$ mot, on mettrait tout le monde 
d'accord. Jo roudrais bien, M. le Président, que nos collègues sachent que ce ne sont pas nos intérêts industriels qui nous font agir.

M. le Présinent. - Ou anrait pu ajouter tout simplement: "Et interdisant la vente de tout article qui ne serait pas le produit exclusif de la distillation du bois. "

1I. De LARNige. - Lorsqu'il y a baisse de l'essence de térébenthine, il y a afflux de poteaux de mine, e'est-à-dire des débris de la forêt sur les trois ports d'embarquement de Bayonne, du Boucau et de Bordeanx. S'il y avait diminution considérable des ressources de la gemme, il y aurait forcément déforestation de ces régions qu'on a mis si longtem ps à planter et que nous avons tous intérêt, tant comm" forestiers que comme membres du Touring-Club, à maintenir pour la plus grande utilité des échanges.

II. Le Président. - Nous ponvons unir les deux voeux.

Nous prendrons la première partie du roen de M. Larroquette et nous y joindrons les deux autres parties qui ont fait l'objet de la discussion, c'est-à-dire celle qui est relative à la définition de l'essence de térébenthine et celle qui concerne les prélèvements.

Le Congrès,

Considérant que lu frande sur l'essence de térébenthine est de nature a porter le plus grand préjudice à la propriété et à l'industrie des régions productrices,

Émet le voru :

"Que le décret portunt règlement d"administration publique, destiné à définir l'essence de térébenthine en vertu de l'article 11 de la Loi du

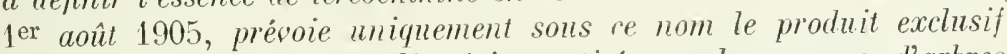
de la distillation des sucs oléo-résineux tirés par le gemmage d'arbres résineux à l'exclusion de la distillation, même aqueuse, des bois qui les contiennent.

"Que le nombre des prélèvements faits par le service des frandes sur l'essence de térébenthine soit augmenté dans de larges proportions.

Ce voru, mis aux voix, est adopté.

II. Le Présinext, - J'ai à vous donner connaissance d'une communication de .1. Chancerel, relative à l'extraction de la résine des tissus des pins dans la fabrication des pâtes à papier'.

11. Chancerel signale l'intérêt qu'il y aurait, an point re vine de la prospérité économique des régions où les forêts résineuses sont abondantes, à trouser un moyen pratique et économique d'utiliser les bois des pins, en les débarrassant de leur résine, pour la fabrication de la pâte à papier. 
Deux un thodes principales se présentent : l'une consiste à dissoudre la résine, l'autre ̀̀ la neutraliser.

Comme dissolvants, M. Chancerel après avoir éliminé, pour des motifs de prix ou des difficultés de manipulation, l'alcool ordinaire, CS2, et CCL'́, retient l'alcool dénaturé.

Pour la neutralisation, après avoir entrainé l'essence de térébenthine par la vapeur d'eau, on neuiralise par une lessive de soude.

Il s'agit là d'une simple communication qui ne demande aucune sanction de notre part.

Nous avons à entendre maintenant la lecture d'une communication d'un de nos collègues japonais ici présent, M. Shozabiro Mnima, délégué japonais.

Ux Coxgressiste. - Je demande à M. le Président de vouloir bien donner lui-même lecture de cette communication.

11. Le Présnuzity - Très volontiers. Toici :

Au sujet de mes expériences sur des produits accessoires importants, des forêts du Japon:

\section{Messieurs,}

Permettez-moi de vous dire ma grande satisfaction d'avoir l'hommenr de parler devant vous.

Je pourrais parler beanconp de la science forestière japonaise; nais je manque de temps. Pour cette raison, je ne vous parlerai que des travalix dont je me suis occupé pendant dix-sept années à l'Institut forestier.

Dans la production accessoire forestière an Japon, le charbon de bois donne le plus grand revenu.

En 1909, on produisit au Japon à peu près un milliard cent millions dt. kilogrammes de charbon pour environ quatre cent cinquante millions de francs.

La méthode de production du charbon de bois est chez nous tout à fait différente de la méthode européenne.

Le fourneau de charbon japonais est stable. Quand on change cette méthode, on peut fabriquer une plus grande quantité de cliarbon de bois avec peu de matériaux.

Après l'achèvement de mes études à l'Université, il y a dix-sept ans, jo commençai l'amendement des fourieaux de charbon. Après plusieurs essais, je réussis, il y a deux ans, à fabriquer un fourneau pratique.

Ce fourneau produit à peu près $10 \%$ de plus que le fourneau ordinaire. C'est une épargne de plus de un milliard sept cent millions de kilogrammes de bois par année, au Japon.

La distillation sèche du bois est pratiquée en petite mesure, chez nous.

Il y a longtemps que j'ai fait des expériences pour obtenir de l'acide pyroligneux du fourneau de charbon japonais et il y a dix ans que mes expériences donnèrent un bon résultat.

Mainternant ils sont réalisés pratiquement. En 1910, dix-huit millions de kilogrammes d'acétale de chaux (calcium acelat) furent produits.

$\mathrm{Si}$ un quart de tons les fourneaux de charbon de bois japonais employiat cette méthode, on gagne rait à peu près vingt millions de kilogrammes d'acétate de chanx par an. 
Le champignon Shutaké (Cortinellus Shutaké P. Henn) le plus important champignon comestible du Japon est, non seulement employé au Japon, nais il est aussi exporté en Chine.

11 y a déjà mille ans que les Japonais cultivaient ce champignon important mais jusqu'en $190^{\prime}$, ils ne connaissaient pas la méthode de l'ensemencement des spores. J'examinai à cette date la qualité des spores et des mrcelium; puis j'employai la méthode de l'ensemencement et obtins un bon résultat, que j'ai publié dans le numéro d'avril du journal périodicue La science forestière japonaise.

Dès lors, ma méthode fut employée en beaucoup de provinces; partont, elle avait toujours un bon résultat. Cela veut dire que, dans les contrées où le champignon Shutaké était cultivé depuis longtemps, et où l'on avait employé ma méthode réformée, on augmentait le profit de $30 \%$.

Dans d'autres contrées où on ne pouvait pas du tout cultiver le Slutaké, on a introduit ma méthode, et l'on a eu de très bons résultats. On peut cultivel' ce champignon comestible toute l'année. Pour cette raison, dans notre pays, nous pouvons toujours manger des champignons frais. Je crois qu'en Europe on peut aussi cultiver le Shutaké sur des branches d'arbres divers.

Feu le professeur Meyer, de l'Université de Munich, a essayé la culture du Shutaké et il a publié ses résultats en 1909.

Le champignon Matsudaké (Cortinellus edodes P. Henn), est, après le Sluutaké du Japon, le champignon le plus important du Japon. Ce champignou croît sur le sol de la forêt de pins rouges.

Ivant moi, on avait essayé la culture du Matsudaké au Japon, mais sans succès. Après avoir achevé la culture du Shutaké, je m'occupai de cultiver le Matsudaké. Je constatai que le Matsudaké est me espèce qui produit le Mrcorhiza octotrophique.. Pour cette raison, je semai les spores du Matsudaki sur les radicelles des pins. J'avais toujour's un bon résultat. J'ai fait un rapport de mes travaux dans l'ammaire de l'Institut de la Science forestière, cahier $n^{0} 7$.

Dans les contrées stériles et pierreuses, la racine de pin aime à croitre à la surface du sol. Pour cela, de telles contrées sont propices à la culture du Matsudaké. On peut dire que la culture du Matsudaké est favorable à la restauration des montagnes.

Malheureusement, je n'ai pas encore vu la forèt francaise. Je ne sais donc si elle a les qualités nécessaires pour la culture du Matsudaké. Pendant mon séjoul à Berlin, je visitais souvent les forèts de pins, et je constatais que le Matsudaké peut y être cultivé facilement. La culture du Matsudaké a l'avantage d'améliorer le sol et d'augmenter le revenu de la forêt de pins.

Le champignon Tremella fuciformis Berk qui est appelé en Chine le "chanpignon d'argent " est aussi bon que la truffe.

Les Chinois aiment le manger ; mais en Chine, on ne connaît pas la culture de ce champignon. En 1910, je fis envoyer le champignon de Chine au Japon. Après des expériences de deux années, je réussis à le cultiver facilement. Il aime à croître sur le bois feuillu mort, spécialement sur des espèces de chènes. et il croît deux fois par an. C'est aussi un précieux produit accessoire de la science forestière.

11 y a trois sortes de camphriers. La première produit beaucoup de camphre et moins d'huile de camphre. La deuxième produit du camphre et de l'huile en égales parties et la troisième seulement de l'huile. Cette huile n'a que la moitié de la valeur du camphre.

On ne pouvait réaliser que de très petits bénéfice par l'exploitation de cette dernière sorte. Aussi cherchai-je le moyen de fabriquer le camphre en utilisant l'huile. En 1910, je réussissais et faisais patenter ma méthode au Japon.

Je fais actuellement des expériences en grand a Formose. Si le résultat rn est bon, ce sera très favorable pour Formose, car la moitié des camphriers de cette île appartiennent à la troisième sorte. 
J'ai encore essayé une méthode d'extermination des insectes du bambou, puis une méthode d'imprégnation du bois, entre autres, j'ai examiné le tanin des arbres japonais.

Les résultats en sont notés dans les cahiers de l'Annuaire de l'Institut de la Science forestière.

Vous trouverez dans cet annuaire les explications exactes de tous les traraux dont j'ai parlé ici.

M. DE LARxige. - Les méthodes de dissémination des spores ont fait des progrès énormes. Un inventeur en a fait l'application. J'arrive moi-même à produire des morilles à volonté. Vous savez que ce champignon est très apprécié, très goúté sur nos marchés, surtout en Angleterre, où il atteint des prix fabuleux.

On a fait des semis de morilles par dissémination des spores sur un substratum préparé en terrain convenable qui donne un rendement de 18 kilogrammes au mètre carré, soit 180.000 kilogrammes à l'hectare.

11. Le Présidext. - Messieurs, les travaux de notre Section sont terminés. Il ne me reste qu'à vous remercier de votre présencen de votre participation à nos travaux et de la patience que vous avez apportée dans nos discussions.

La séance est levée à 4 heures. 


\title{
QUATRIEME SECTION
}

\author{
GRANDS TRAYATX FORESTIERS
}

\section{BUREAU}

Président :

M. Émile Pluchet, ancien président de la Société nationale d'Agriculture, président de la Société des Agriculteurs de France.

Vice-présidents : MM. E. Саврот, conservateur des Eaux et Forêts, secrétaire général de la Société forestière francaise des Amis des Arbres.

LEDDET, conservateur des Eaux et Forêts, chef de bureau à la Direction générale.

Secrétaires :

MM. d'Auber de Peyrelongue, inspecteuradjoint des Eaux et Forêts.

JAGERSCHIDT, inspecteur-adjoint des Eaux et Forêts.

Martin, inspecteur-adjoint des Eaux et Forêts.

Papporteurs: $\quad$ MN. E. CARDot, conservateur des Eaux et Forêts, secrétaire général de la Société forestière française des Amis des libres.

Mougrn, inspecteur des Eaux et Forêts, chef de Section ì la Direction générale. 
RAPPORTEURS : MM. BERAARD, inspecteur des Eaux et Forêts, professeur de mathématiques appliquées à l'École Nationale des Eaux et Forêts.

$\mathrm{Ph}$. Guinier, inspecteur des Eaux et Forêts, chargé du cours de Botanique à l'École Nationale des Eaux et Forêts.

PARDÉ, inspecteur des Eaux et Forêts.

P. Buffatit, inspecteur des Eaux et Forêts. D'Auber de Peyrelongue, inspecteur-adjoint des Eaux et Forêts. 


\title{
SEANCE DU 16 JUIN 1913
}

\begin{abstract}
(MATIN)
Présidence de IM. PLUGHET, président de Section
\end{abstract}

La séance est. ouverte à 11 h. 5 .

M. Le Président. - Messieurs, je suis très touché de l'honneur qui m'a été fait par le Touring-Club de France et par M. Defert, en me demandant de présider cette section. Je leur en suis personnellement très reconnaissant. Je dois d'ailleurs en reporter tout l'honneur à la Société drs Agriculteurs de France que je représente, et qui est particulièrement soucieuse des intérêts forestiers.

Je vous souhaite à tous, Messieurs, très cordialement, la bienvenue et je vous invite à vous mettre immédiatement au travail (Applaudissements).

La parole est à M. Cardot pour la lecture de son rapport sur les Améliorations pastorales.

M. Cardot. - La pâture sauvage. - La pâture sauvage, c'est le sol couvert de sa végétation spontanée et livré aux troupeaux sans que l'homme intervienne pour en améliorer ou même pour en sauvegarder la production.

C'est le mode d'exploitation presque exclusivement en usage chez les peuples primitifs, à l'origine des civilisations. Il suffit à l'alimentation humaine, dans les espaces immenses qui ne sont encore occupés que par de petites tribus, par une population peu nombreuse.

Mais au fur et à mesure que celle-ci se développe, les troupeaux se multiplient et cette végétation spontanée du sol ne tarde pas à s'appauvrir sous l'influence d'un parcours trop intensif ou trop fréquemment renouvelé.

Alors la pelouse gazonnante se troue, se clairière, des dénudations se produisent, le sol se dessèche, la stérilisation s'étend peu à peu.

Et ce n'est pas seulement l'accroissement excessif des troupeaux qui stérilise le pâturage. Celui-ci se transforme peu à peu.

La couche de terre végétale qui couvre sa surface s'enrichit en principes humiques acides produits par la décomposition incomplète des matières herbacées, mais s'appauvrit en matières minérales (chaux, potasse, acide phosphorique, etc.). Les actions nitrifiantes qui entretiennent la fertilité du sol se ralentissent; d'autre part, la flore tend à se 
modifier par une sorte de sélection à rebours qui résulte de l'action du bétail.

Les bonnes espèces végétales incessamment broutées par le troupeau disparaissent pour faire place aux plantes qu'il dédaigne ou qui ne conviennent pas à son alimentation. Le pâturage se couvre de graminées aux chaumes durs, de plantes subligneuses, ligneuses, parfois épineuses.

Le pâturage redevient une steppe infertile ou un maquis improductif.

La pâture nomade. - De la stérilisation progressive des pâturages est née la pâture nomade.

Quand son champ d'action est épuisé, la population pastorale émigre et va chercher sur d'autres territoires les ressources fourragères qui lui font défaut. Les guerres, les grandes invasions des peuples pasteurs n'ont pas d'autre origine que la nécessité pour eux d'étendre toujours plus loin la zone de leurs parcours.

La transhumance. - Des circonstances climatériques spéciales contribuent beaucoup aussi à rendre ce mode d'exploitation du sol aléatoire et intermittent.

Dans les régions froides, sur les montagnes et plateaux élevés, la neige vient recouvrir le sol une partie de l'année; dans les régions chaudes, dans les plaines ensoleillées, la végétation se dessèche pendant l'été; d'où une nouvelle forme de la pâture nomade : la transhumance. Le troupeau est obligé de se déplacer. Il poursuit l'herbe de la montagne à la plaine, de la plaine à la montagne.

Les résultats de la pâture sauvage. - Sous toutes ses formes, la pâture sauvage aboutit fatalement à la ruine du sol.

Toute production naturelle que l'on se borne à récolter sans en assurer le renouvellement s'épuise. Adieu les riches moissons du champ cultivé, si par l'assolement agricole, les labours, les engrais, on ne maintient la fécondité de la terre. Adieu les doux produits du verger, si l'on n'entretient ses arbres par des soins répétés. Adieu la forêt où l'on n'entend que la hache du bûcheron et le bêlement des troupeaux!

Comment de pauvres herbages livrés à toutes les déprédations pastorales et sans aucune protection contre les actions naturelles concurrentes ou nuisibles pourraient-ils maintenir leur production?

Importance dola unestion pastorale.
Et pourtant, le maintien en bon état de production, la conservation de ces terrains pastoraux ont une importance sociale que l'on ne soupçonne guère.

Si l'on voulait bien se rendre compte au moins approximativement de la répartition des différentes formes de culture à la surface du globe, on arriverait à cette conclusion, que les terrains livrés à la pâture sauvage occupent encore aujourd'hui plus de $60 \%$ de la superficie du sol terrestre.

Cette étendue se réduit sans doute un peu chaque année par le développement des cultures; mais d'autre part, elle s'accroît par la destruction des forêts.

Celles-ci sont les premières victimes de la stérilisation des terrains pastoraux et l'on peut dire que dans la plupart des régions du globe, le pâtre et son bétail ont plus fait que le bûcheron pour la destruction de la végétation forestière. Quand le bûcheron est passé, le jeune semis se lève pour remplacer l'arbre disparu, mais le troupeau dévore lo semis, et le pâtre incendie la brousse qui prépare la résurrection de la forêt. 
N'y eût-il que cette seule considération, la question pastorale mériterait déjà la place importante qui lui a été assignée dans le Congrès forestier.

Mais il y a plus : la pâture sauvage s'étend particulièrement dans les régions montagneuses et aussi dans les régions de plaines ou de plateaux qui, par la sécheresse de leur climat ou l'aridité de leur sol, sont peu favorables aux cultures.

Or, dans les montagnes, sur les pentes rapides, l'exercice continu du pâturage provoque rapidement la dénudation, le ravinement du sol et I'on peut dire encore que le pâtre et ses troupeaux ont plus fait que le bûcheron pour la ruine des montagnes et le développement du fléau torrentiel.

Dans les plateaux et les régions de plaines, la pâture sauvage produit fréquemment le désert : ici le désert pierreux où l'eau s'infiltre comme en un crible entraînant avec elle les dernières parcelles de la terre végétale qui couvrait le sol, là le désert de sable dont les éléments mobiles mis en liberté et incessamment remués par les vents n'offrent plus aucune assise à la végétation.

Et ces dénudations, ces formations désertiques ne cessent de s'étendre, non seulement en raison de l'action pastorale toujours agissante, mais encore sous l'influence des modifications climatériques produites par la disparition de la végétation sur de grandes étendues.

L'histoire du passé, l'histoire des peuples pasteurs, dans le grand continent asiatique notamment, l'étude des régions où ils ont étendu leur domination, donne une leçon saisissante sur les résultats de l'exploitation pastorale, dans sa forme primitive : des montagnes sans ombrages, sans verdure, échancrées par les ravins; des rivières au lit pierreux, tantôt desséché, tantôt rempli d'une eau boueuse; des steppes où les troupeaux sont obligés de parcourir des espaces immenses pour trouver leur alimentation; des plaines devenues des déserts, des villes autrefois riches et prospères ensevelies sous les sables et de loin en loin des oasis verdoyantes, des jardins délicieux produits par des courants d'eau amenés à grands frais, formant contraste avec ces régions désolées, et opposant les bienfaits du travail humain à l'œuvre de destruction accomplie par les pasteurs.

Et, résultat plus funeste encore : la mentalité humaine se trouve profondément altérée dans ces pays où la lutte contre la nature, par le travail fécond est remplacé par la lutte contre l'homme, et où un fatalisme inconscient, en se substituant à la Présoyance, continue à préparer avec la ruine du sol, avec la destruction de toute richesse végétale, la misère et la décadence des peuples.

Dans notre grande colonie africaine, l'Algérie et dans les deux pays limitrophes placés sous notre protectorat la Tunisie et le Maroc, le régime de la pâture sanvage appliqué à une très grande partie de leur tertoire a produit les mêmes effets désastreux et compromet les efforts faits pour leur rendre la prospérité d'autrefois. Il serait temps de songer à préserver les richesses forestières, les richesses végétales qui y subsistent encore.

Ainsi que je le faisais remarquer dans une publication précédente (1) il y va de l'a venir et même de la sécurité de nos grandes colonies africaines.

(1) Mémoire de la Société Nationale d'Agriculture de France; sur la restauration des pâturages communaux, Tome CXLII.-1909. 
Liaménagement pastor21.

Mais auparavant, il convient de voir si une nouvelle forme d'exploitation pastorale ne devrait pas être étudiée dans nos pays européens où, en raison de la surface réduite abandonnée aux troupeaux et du développement des idées de progrès, le problème est plus facile à résoudre.

En France, si l'on tient compte des terrains classés comme terrains cultivés ou comme bois et qui actuellement désertés par la culture ou par les exploitations forestières ne sont guère que des terrains pastoraux, c'est à plus de 8 millions d'hectares, soit à environ $15 \%$ de notre territoire (52.857.199 h.) que l'on peut évaluer la surface livrée à la pâture sauvage. Les terrains communaux sont compris dans cette surface pour environ 3 millions d'hectares.

La question de la mise en valeur et de l'exploitation rationnelle de ces terrains a donc une réelle importance. Elle emprunte un intérêt particulier à ce fait bien établi aujourd'hui que le régime exelusif de la stabulation est nuisible à la santé du bétail, et que des pâturages à l'air libre sont indispensables, surtout pour l'élevage des jeunes animaux.

C'est surtout sur les pâturages exploités colleetivement soit principalement sur les pâturages possédés par' les 'communes ou sections de communes qu'il convient de porter son attention.

Le problème de la restauration et de l'entretien de ces pâturages offre beaucoup d'analogie avec celui de la restauration et de l'entretien des forêts appartenant à des collectivités. Pour les uns comme pour les autres, il peut être résolu par l'aménagement.

10 Plan général d'organisation. - L'aménagement pastoral comprend essentiellement un plan général d'organisation du pâturage basé sur le classement des parcelles en différentes catégories suivant le mode d'utilisation qui peut leur être appliqué.

On pourra le plus souvent répartir les parcelles entre les 3 catégories suivantes :

a) Parcelles susceptibles d'être parcourues par des travaux d'améliorations pastorales.

b) Parcelles non susceptibles de travaux, mais qu'il y a lieu de soumettre au parcours réglementé, ou à la mise en défens.

c) Parcelles à reboiser.

20 Plan d'exploitation et de réglementation. - Un plan d'exploitation du pâturage, indiquant pour chaque groupe de parcelles ou eanton: le nombre et la nature des bestiaux qui seront admis à y pâturer.

La possibilité pastorale. - Le nombre sera fixé en se basant sur cette notion de la possibilité bien connue des aménagistes forestiers, c'est-à-dire sur les ressourees fourragères que chaque canton peut fournir. Cette possibilité s'exprime par le nombre moyen de têtes de bétail qui peut être tenu par chaque hectare pour tout ou partie de la saison pastorale.

De la possibilité ainsi établie, on déduira la répartition entre les usagers des droits de jouissance.

Cette répartition peut être établie suivant les droits aequis ou les coutumes locales - soit en se basant sur la surface des domaines ruraux que le pâturage est appelé à desservir - soit par feu, soit par tête d'habitant.

L'affouga pastoral. - Iei eneore on retrouve une notion bien connue en matière forestière : la notion d'affoulage. L'affouage pastoral a la même origine et repose sur les mêmes principes que l'affouage forestier. 
Dans le principe, les habitants des anciennes communautés rurales de la France avaient sur les terres vagues qui entouraient leurs domaines et qui était la propriété souvent contestée, il est vrai, des seigneurs féodaux, des droits de jouissance ou de possession plus ou moins définis en rapport avec l'importance de leurs cultures.

On peut considérer que ces droits étaient des droits réels appartenant à la propriété plutôt qu'à la personne.

Aujourd'hui, depuis que le droit de propriété des communes ou des sections de communes sur ces terrains a été consacré par la législation, on a été amené à envisager le droit d'usage comme un droit personnel appartenant à tous les habitants, et par suite, à considérer que la jouissance de ces terrains devait se répartir par feu ou famille, voire même par tête. Il semble à tous égards que la répartition par feu est celle qui s'harmonise le mieux soit avec les anciennes traditions, soit avec l'organisation rurale.

Mais contrairement à ce qui s'est passé pour les forêts, aucune loi n'a jusqu'ici déterminé le mode de répartition à appliquer à la jouissance des terrains pastoraux.

Il en résulte que cette jouissance est le plus souvent accaparée par un petit nombre de propriétaires, ou par des spéculateurs de bestiaux au détriment de tous les autres habitants, et c'est là certainement l'une des principales causes de la ruine des pâturages.

La réglementation. - Le plan d'exploitation devra nécessairement déterminer aussi toutes les conditions à imposer aux usagers pour l'exercice de leur droit de jouissance : la désignation des chemins à suivre par les bestiaux, l'obligation de confier leur bétail à un pâtre commun désigné ou agréé par l'autorité municipale, les règles à suivre pour assurer l'hygiène ou la sécurité du troupeau, la fixation des périodes de parcours.

Les taxes pastorales. - Il devra également fixer les taxes à percevoir pour chaque nature de bestiaux. Ces taxes ne sont pas seulement nécessaires pour assurer le remboursement à la commune des charges et impositions dont ses pâturages sont grevés; mais contrairement à ce qui se passe presque toujours, elles doivent pourvoir à toutes les dépenses que nécessitent les travaux d'entretien et d'amélioration dont il va être question.

$3^{\circ}$ Plan de travaux. - $1^{\text {re }}$ classe : Travanx concernant la protection du pâturage contre les causes naturelles de dégradation. - On croit souvent qu'une bonne réglementation pourrait suffire à restaurer et maintenir en bon état un pâturage. C'est une profonde erreur. La surcharge de bétail n'est que l'une des causes de détérioration contre lesquelles il convient de se prémunir. Une foule d'actions naturelles viennent en effet s'ajouter à l'action du bétail pour le dégrader ou le stériliser. Dans les régions de montagne, le pâturage est exposé aux avalanches, aux coulées de pierres, aux ravinements et érosions provenant du ruissellement des eaux; aux éboulements que provoquent les infiltrations souterraines, etc. D'où une première classe de travaux concernant la protection du pâturage contre les causes naturelles de dégradation : murs de retenue, barrages rustiques, clayonnages et cmbroussaillements dans les ravins, drainages de consolidation, rideanx ou bandes boisées élablis de façon à s'opposer au ruissellement superficiel des eaux ou à leur concentration, à retenir ou briser les avalanches, à diminuer l'importance des nappes d'infiltration, etc. 
2e classe : Travaux concernant l'organisation et l'outillage de la pâture. - D'autre part, une pâture ne saurait donner grands profits ni s'entretenir en bon état si elle n'a pas une organisation et un outillage bien adaptés à sa destination. Des chemins ou sentiers d'accès et de circulation sont nécessaires pour permettre au bétail d'arriver facilement et sans fatigue à la pâture, pour y transporter les approvisionnements nécessaires aux bergers, le sel pour les animaux, les outils et engrais complémentaires qui peuvent être jugés utiles.

Des abrenvoirs peu éloignés les uns des autres et capables de fournir au bétail de l'eau propre, saine, à une température convenable, doivent être établis.

Il faut également pour les pâtres des baraques-abris au lieu et place de ces gîtes primitifs, réritables tanières où, couchés sur une paille infecte, ils sont obligés de s'abriter pendant la nuit. C'est là certainement l'une des mesures essentielles à prendre pour relever la condition des pasteurs et par suite obtenir d'eux de meilleurs services.

Dans les montagnes pastorales situées à de hautes altitudes, des établesabris sont également indispensables pour protéger le bétail contre les nuits fraîches, les mauvais temps, les chutes de grêle ou de neige et aussi pour assurer aux bêtes malades les soins nécessaires.

Lorsque le pâturage peut être exploité par des vaches et qu'il est trop éloigné des villages, à l'étable abri doit s'annexer une fruitière munie de tous les appareils nécessaires à la fabrication du fromage et du beurre.

On sait l'influence que peuvent avoir ces installations, tant au point de vue de la conservation et de l'amélioration des pâturages qu'à celui du progrès économique dans les régions montagneuses. Elles ont pour résultat de provoquer la substitution dans l'exploitation des montagnes du bétail bovin au troupeau de moutons beaucoup plus destructeurs, et en permettant aux montagnards de tirer bon parti de ses laitages; elles l'incitent à soigner et son troupeau et ses pâturages.

Sous l'inspiration de ces idées préconisées il y a quarante ans par M. Calvet, notre administration forestière a provoqué ou secondé la création d'un assez grand nombre de fruitières dans les Alpes et les Pyrénées. Le succès de cette œuvre est maintenant assuré. Il reste à lui donner un développement large et rapide. Dans la région pyrénéenne notamment, le développement de l'industrie fromagère peut en un petit nombre d'années provoquer une transformation économique aussi heureuse et aussi importante que celle obtenue dans la Charente et le Poitou par l'introduction de l'industrie beurrière.

A l'organisation générale de la pâture se rattachent les travaux d'ensemble d'irrigation et de drainage qui peuvent être exécutés en vue d'une bonne utilisation de ses eaux et aussi la création d'abris-boisés ou de bouquets de bois établis, non plus en vue d'assurer la consolidation du pâturage, mais dans le but d'abriter le bétail contre le vent ou le soleil, de protéger le sol contre le dessèchement et de l'enrichir par ses formations d'humus.

J'ai eu bien souvent l'occasion de développer cette idée que le pré-bois ou le pâturage-boisé serait le salut et la fortune pour la plupart de nos régions montagneuses. C'est la forme idéale qu'il faut étendre et généraliser partout où la pâture nue s'appauvrit et se dégrade.

3 e classe : Travaux de culture pastorale. - A ces deux classes de travaux, il faut ajouter ceux que l'on peut appeler : les travaux de culture pastorale 
et qui ont pour objet de donner aux pelouses les soins d'entretien qu'elles réclament, de les maintenir en bon état de production. Ici je ne ferai qu'une énumération ; les travaux de l'espèce étant, sauf modalités d'exécution, ceux que l'on applique aux pâturages cultivés.

Le nivellement grossier du sol, l'épierrement, l'émottage, l'étaupinage, l'extraction des végétaux nuisibles, les fumures animales, végétales ou minérales, le semis de graines fourragères, enfin la mise en défens temporaire ou l'exploitation temporaire en prairie fanchée afin de remédier à l'appauvrissement des gazons et au tassement du sol.

Il est presque superflu de dire que ces travaux doivent s'appliquer exelusivement aux terrains qui, dans le plan général d'organisation du pâturage, ont été classés dans la première catégorie $(a)$; il convient d'ajouter que ces travaux doivent être exécutés en conformité d'un plan établi d'avance et déterminant non seulement leur nature, mais eneore l'étendue à parcourir chaque année et assurant le retour des travaux sur chaque parcelle dans une période déterminée qui peut varier entre 5 et 15 ans. Les terrains en question seront utilement dans ce but divisés en coupons fixés sur le terrain par des bornes ou des limites naturelles.

Il y aura également intérêt à entourer d'une clôture volante le coupon en restauration. Une mise en défens complète pendant au moins une année est en effet nécessaire. pour assurer la régénération de la pelouse.

Ces travaux de culture pastorale poursuivis d'année en année pourraient avoir pour résultat de eréer dans beaucoup de communes rurales de véritables pares de pâturage où les habitants trouveraient pendant toute la saison d'été une alimentation abondante et presque gratuite pour leurs bestiaux. Appliqués seulement amx meilleures parties de leurs communaux, ils leur procureraient des ressources fourragères très supérieures à celles obtenues jusqu'ici sur les immenses étendues soumises à la pâture sauvage.

Quant aux parcelles de la catégorie (b) où en raison de la nature du sol, de la déclivité des pentes, les travaux de culture pastorale seraient trop coûteux ou insuffisamment rémunérateurs, leur amélioration ne saurait résulter que de l'applieation de bons règlements de parcours. Ici eneore, une subdivision en divers eantons serait utile pour déterminer les rotations à suivre par les troupeaux et éviter que l'un ou l'autre de ees cantons ne soit surchargé ou trop longtemps parcouru.

Cette subdivision permettrait également la mise en réserve d'un ou plusieurs cantons pendant une période déterminée à l'expiration de laquelle les autres eantons seraient à leur tour et successivement mis en défens. Cette mesure si simple, assurant pour chaque canton le retour périodique d'une mise en défens destinée à régénérer les gazons, pourrait avoir un résultat considérable pour la restauration, la eonservation en bon état de production de ces immenses étendues pastorales qu'appauvrissent fatalement un pâturage ininterrompu.

Enfin les terrains de la troisième catégorie envisagés (catégorie c) seraient mis en valeur par le reboisement. Dans les pâturages eommunaux, il existe presque toujours des cantons importants qui, soit en raison de leur situation (éloignement des villages, difficultés d'accès), soit en raison de leur état superficiel (sol rocheux couvert de buissons ou mauvaises plantes) n'offrent pour ainsi dire aucune ressource au bétail et ne sont d'ailleurs susceptibles d'aucune amélioration pastorale.

C'est le cas notamment de ces maquis, garrigues qui, dans les régions 
méridionales et même un peu partout dans nos régions de montagnes et de collines accusent la négligence de leurs habitants. Car si l'on reconstituait peu à peu sur ces terrains improductifs les futaies résineuses ou feuillus qui y existaient autrefois, les communes y trouveraient bien souvent une source de revenus considérable en même temps que leur territoire s'embellirait, devenant plus frais, plus riant et plus recherché des touristes.

Résumé et conclusions.

En résumé, si dans le passé la pâture sauvage a provoqué sur d'immenses étendues la dégradation et la ruine du sol, si au point de vue social, elle a bien souvent déterminé ces exodes guerriers des peuples pasteurs qui, ne trourant plus dans lcurs territoires l'alimentation de leurs troupeaux, se ruaient sur les terres fertiles des plaines et les riches cités et y détruisaient les civilisations les plus florissantes, dans le temps actuel, ce mode d'exploitation primitif ne cesse pas, même dans nos régions européennes, d'exercer une action néfaste. Il contribue à la dégradation des montagnes et des forêts, au développement du fléau des inondations, à la destruction des éléments de richesse et de beauté qui attachent les habitants à leur pays et y attirent les étrangers. On doit donc s'attacher à le refouler peu à peu et finalement à le faire disparaître.

On peut y arriver en appliquant aux pâturages exploités collectivement ce principe de l'aménagement qui a eu d'aussi heureux résultats pour la conservation de nos richesses forestières, en organisant ces pâturages pour une exploitation rationnelle, en les soumettant à des règles de gestion et à des travaux qui les protègent contre toutes les causes naturelles ou humaines de dégradation et en même temps leur assurent un rendement avantageux et soutenu.

Pour cela il est nécessaire que les pouvoirs publics s'intéressent à cette question dont je crois avoir fait ressortir toute l'importance. Une législation pastorale est nécessaire. Le ministre qui en assurera la promulgation et qui prendra cn même temps pour son application toutes mesures administratives et financières utiles, méritera l'éternelle reconnaissance dc nos populations pastorales et $d u$ pays tout entier.

VEU :

Le Congrès émet le vœu qu'une législation pastorale soit édictée et que dies mesures administratives et financières soient prises ou complétées (1) en vue d'assurer aux pâturages communaux ou exploités collectivement le bienfait d'un aménagement rationnel et les travaux nécessaires pour arrêter la dégradation de ces terrains, les remettre en valeur, les entretenir en bon état de production et ainsi rendre aux régions montagneuses les éléments de richesse, de beauté, de prospérité enfin, qui tendent de plus en plus à leur faire défaut et en provoquent la dépopulation.

II. Le Président. - Messieurs, vous venez d'entendre le rapport si complet, si précis, si net de M. Cardot.

Avant de mettre aux roix le rou qui le termine, je demande si l'un de vous a des observations à faire sur ce rapport.

(1) En France, un décret en date du 30 décembre 1897 rendu sur la proposition de M. J. Méline, Président du Conseil, Ministre de l'Agriculture a créé à la Direction Générale des Eaux et Forêts un service des améli orotions pastorales. Ce service est doté actuellement d'un crédit de 145.000 francs. 
M. Lalienaxd. - Japplaudis de tout coeur aux conclusions de M. le rapporteur. Mais je suis président dı Syndicat des propriétaires forestiers en Algérie. Cette question nous intéresse d'une facon particulière, un peu différente de relle qu'a envisagée notre rapporteur.

Chez nous, la question des pàturages̉ est vitale. Nos forèts nous ont été vendues grevées de droits d'usage. Il faudrait que ces droits fussent réglementés. Le nombre des bestiaux augmente avec la population. De plus, certains usagers deviennent commerçant's, prennent des bestiaux de la ville la plus voisine et les font pàturer chez eux. L. nombre augmente donc dans des proportions effroyables en bœufs et en moutons. Il en résulte qu'il n'y a plus de régénération pour ainsi dire. Les plus beaux massifs sont absolument perdus. 11 y a des vieux arbres, qui donnent un mauvais produit. Mais, dans les plus belles parties que nous avions autrefois, il n'y a plus de jeunes sujets. J'ai essayé de mettre en défense certaines régions pendant cinq ou six ans : la forêt était tellement épuisép que rien ne repousse.

Il y a en Algérie une plaje bien plus grande : c'est la chèvre. Le Codp Forestier défend partout le pàturage de la chère. Nous aurions to droit de l'interdire : mais nous aurions le feu immédiatement. Par conséquent, nous sommes pris dans ce dilemme: supporter la chèvre. et e'est la destruction de nos forêts dans un temps difficile à déterminer. peut-être cent ans, ou deux cents ans, ou trois cents ans; ou interdire la chèvre: et c'est la destruction immédiate par lo feu. Alors, entru deux maux nous choisissons le moindre.

Je crois qu'il serait bon, en dehors du vœu proposé par M. le rapporteur, que nous en formions un autre tendant à ce que la question des pàturages fût réglée par une loi. Cela n'existe pas ; je l'ai demandé partout au service forestier en Algérie. Il faudrait aussi que ce fùt l'Etat qui interdit le pâturage de la chèvre. Si c'était l'État, les indigènes se soumettraient.

M. Cardot. - La législation forestière en Algérie renferme déjà, si je ne me trompe, quelques articles concernant les abus pastoraux.

M. Lallemand. - Au point de vue de la chèvre seulement : elle est interdite, c'est tout.

II. Cirdnt. - Je crois qu'il serait nécessaire de compléter ces mesures par une législation pastorale réglementant le nombre des animaux et permettant également, dans certains cas, d'opérer des mises en défens au moins temporaires.

M. LE Président. - Vous voudriez un veu spérial pour l'Algérie.

M. Lallevayo. - Parfaitement.

M. Lecoq. - Le mal dont souffre I'Algerie ne lui est pas exclusif. I suis administrateur d'une société qui exploite des forèts en Espagne. 
Nous avons les mêmes difficultés avec les servitudes de pacage et de pàturage Egalement l’interdiction des chèrres existe; mais, comme vous le dites très bien, si on l'applique, c'est le feu.

Nous avons essayé de nous arranger avec les usagers; il n'y a rien à faire. Au point de vue de la régénération des forêts, une législation serait indispensable; des cantonnements réservés deviaient être spécifiés, pendant un laps de temps déterminé.

Je citerai le fait suivant. Nous avons 2.500 hectares. Dernièrement, nous avons fait une petite construetion de 80 mètres carrés. On nous l'a fait démolir, sous prétexte que cela nuisait aux droits d'usage.

Nous avons demandé de pouvoir réserver certains cantons de un ou deux hectares ; cela nous a été défendu ; nous nuirions à l'elevage du mouton (Exclamations).

I. le baron DE Belinay. - Jai entendu dire qu'une forêt voisine du camp de la Courtine était grevée de droits d'usage dont l'exercice aurait rapidement amené sa destruction. Les propriétaires de la forêt ont obtenu de faire limiter ces droits à une certaine surface. Il y a eu un procès engagé. Le jugement a été basé sur ce principe inscrit dans la loi, que nul n'est tenu de rester dans l'indivision. On a estimé ces droits d'usage et on a accordé un certain cantonnement à chacune des communes qui y participaient. Ce serait la meilleure solution.

M. Lallemaxo. - C'est absolument impossible en Algérie. Le canton- nement y est matériellement impraticable pour les indigènes. Nos forêts ne ressemblent pas à celles de France; elles sont habitées. Sur une forèt de 22.000 hectares, il y a 17 ou 18.000 liabitants, qui sont rassemblés par petits groupes disséminés dans toute la forêt. Si vous voulez dire à un groupe d'un douar quelconque qu'il faut faire pàturer ses troupeaux à deux ou trois kilomètres, e'est absolument impossible ; s'ils les emmenaient à deux ou trois kilomètres, les bestiaux pàtureraient sur tout le parcours.

Ux Congressiste. - Il s’agit de savoir si les droits d'usage ont été concédés originairement à toute la population, ou simplement aux habitants qui se trouvaient là au moment de l'occupation française.

M. Lalleuaxil. - Mon roisin me dit qu'il est propriétaire forestier aux Indes Britanniques. Les forêts y sont grevées de droits d'usage ; mais quand on les a vendues, on a désigné les nouns des usagers et le nombre des bestiaux auxquels ils avaient droit.

M. Le Présunent. - Mais en Algérie, vous êtes en présence d'un état de fait sur lequel il n'y a peut-être pas moyen de revenir.

M. Lalfkuanu. - Non sans doute, mais si on peut établir combien il y avait de bestiaux alor's, - car l'impôt arabe établi sur les bestiaux 
permettrait de le retrouver, - on pourrait voir du moins combien de bestiaux on peut admettre dans une forêt donnée.

M. Maitre. - Le vœu présenté par M. Cardot n'est pas une nouveauté, ear M. Cardot est un précurseur en la matière ; voilà bien vingt ans qu'il demande l'organisation du r'égime pastoral.

Il y a quinze ou seize ans, à la Société forestière de Franche-Comté, à Vesoul, nous en avions parlé, en envisageant notamment un des abus les plus graves, intéressant le plus fortement le tourisme dans les Alpes; ce sont les troupeaux transhumants. Il serait facile de trouver une solution qui, en lésant peu les communes, grèverait de peu l'Etat, le nombre de ces troupeaux transhumants n'étant pas élevé.

Malheureusement, je crois que ce régime recule au lieu d'avancer. Dans l'exposé très intéressant que $\mathrm{M}$. le Ministre, tout à l'heure, a fait des réformes qu'il compte proposer au Parlement, nous avons vu apparaître l'impôt forestier, les travaux d'améliorations artistiques; mais il n'a pas été question du régime pastoral. Si on ne reut pas nous denner le régime pastoral complet, nous devrions au moins demander que certains principes soient posés, qui aideraient à l'établir ultérieurement.

11. Cardot nous dit que la surcharge des pâturages n’est pas la seule cause des dégradations. C'est évident; mais elle en est cependant une des principales et la mise en défens y peut beaucoup. En Dauphiné, dans le vallon de la Celle, il y a un vallon loué par l'Association Dauphinoise des pàturages, depuis cinq ans, et mis en réserve. L'arrêt produit a été des plus heureux, et c'est cet exemple qui a engagé l'Association dauphinoise à persévérer dans cette voie. Je ne suis pas forestier, je parle comme alpiniste. Lorsque je vois la Bérarde, après avoir vu la Suisse, j’en ai mal au cœur. Ce pays pourrait être plus intéressant que la Suisse, parce qu'il y a un plus grand nombre de vallées rayomnantes. Nulle part le touriste ne pourrait faire des journées d'excursions aussi inıtéressantes en rayonnant toujours autour d'un même centre. Malheureusement, il y a là un cercle vicienx. Il est impossible que quelqu'un qui ne passe pas sa journée au-dessus de la limite des neiges, non seulement s'y amuse, mais ne s'y ennuie pas : il n'y a pas un arbre, pas d'eau dans les torrents, pas un lac, rien de ce qui peut plaire à des touristes. Il serait du rôle de l'Administration de dire aux communes : "Vous allez louer tel pâturage pour deux mille franes, trois mille franes; les moutons feront pour cinq mille franes de dégâts. Voilà les trois mille francs. "Il faudrait que les offres soient soumises d'abord à l'Administration forestière qui aurait le droit, non pas d'enchérir', mais de prendre à égalité des sommes relativement peu considérables; on pourrait mettre en défens de grandes surfaces. Il ne s'agirait point d'une mise en défens totale, parce que ce procédé (c'est un des vices de la Loi de 1882), ruine les gens du pays. Il y a des pauvres qui n'ont que les terrains communaux pour faire pàturer 
leurs deux ou trois moutons, lenrs deux ou trois rhèrres. Le bétail qui reste dans les pays de montagne pendant les six mois d'hiver, n'est jamais bien nombreux à cause de la nécessité de loger dans les écuries. Il faut done que les pàturages communaux soient interdits à tout bétail qui n'hiverne pas dans la commune. De cette manière, il n'y aura pas d'opposition de la part des habitants du pays. Aujourd'hui, ce sont des levées de boucliers : maire, conseiller général, député, pour la levée de la mise en défens. L'Administration forestière est considérée comme un gendarme, ou plutôt comme un malfaiteur qui rient $f$ nlever aux habitants leur pàturage ; et on r'aboutit à rien.

Adoptez une solution intcrmédiaire, dites : "Vous êtes obligés de nourrir votre bétail. Je vais louer les pàturages uniquement pour vous les laisser. Et en échange de ce beau cadeau que je vous fais, permettezmoi de les laisser un peu reposer ; je vous les rendrai aussitôt après. ") Jugez de la force que donnerait ce raisonnement à l'Administration forestière auprès des communes, et pour obtenir, au point de vue pàturages printaniers, des petits coins à reboiser. Ce serait le commerce: donnant donnant. Aujourd'hui, quand vous roulez tout prendre, expulser ces moutons, ces chèvres qui font vivre ces malheureux, vous vous mettez tout le monde à dos.

M. Martin. - Malheureusement, je ne crois pas; car, dans mes dix ans de services forestiers, j'ai pu constater que les pàturages de printemps sont ceux qui se dégradent le plus.

\ 1.000 ou 1.200 mètres d'altitude, la neige fond, même en janvier ou février, et le bétail dégrade d'une façon épouvantable.

M. Cardot. - La question est posée depuis quinze ou vingt ans. Un projet de loi qui est maintenant entre les mains de M. le Ministre de l'Agrieulture a été élaboré. Il demande justement d'assurer, tantôt dans une forme facultative, tantôt dans une forme obligatoire, l'organisation, l'aménagement des pâturages communaux.

M. Mirtix. - Comme l'a dit M. Maître, il faut une monnaie d'échange.

M. Dole. - Au point de vue des transhumants, il y a déjà dans les Hautes-Alpes certains endroits où l'administration paye aux communes une redevance annuelle pour qu'elles ne laissent pas venir les transhumants. Le cas existe à Guillestre.

11. CАвиот. - Non seulement à Guillestre, mais à Saint-Christopheen-Oisans et à Revel. La généralisation de cette opération serait un peu coùteuse.

M. Maitre. - Ce n’est rien, à côté de ce qu’on dépense en maçonnerie, en barrages.

M. Le Président. - Messieurs, vous venez d'entendre une commu- 
nication très intéressante concernant plutôt la conservation que l'amélioration pastorale.

M. Martre. - J'estime que la législation à intervenir devra tenir compte de la distinction entre bétail hivernant et bétail non hivernant.

M. Cardot. - C'est un détail de la loi. Il faudrait limiter, comme cela d'ailleurs existait autrefois dans les traditions locales.

UN congRessiste. - Mais si nous nous bornions à garder dans nos châłets uniquement le bétail hivernant dans la commune, nous ne pourrions plus exploiter.

M. Le Présidext. - Nous n'avons pas en ce moment à entrer dans le détail de la législation. Nous pouvons, il me semble, nous borner à voter le vou présenté par M. le rapporteur, en tenant compte des observations qui ont été échangées.

M. Cardot. - Il faudrait ajouter simplement le vœu qu'une législation spéciale soit étudiée pour l'Algérie. Cela donnerait satisfaction aux observations présentées par M. Lallemand.

M. Albert Picard. - Pour les autres questions, c'est l'affaire de la deuxième section.

M. Le Président. - Il n'y a pas d'autre observation?

Par conséquent la quatrième section adopte le rou présenté par M. Cardot, plus une addition en ce qui concerne l’Algérie. Vous voudrez bien faire confiance à votre bureau pour la rédaction de cettu addition. (Assentiment.)

La séance est levée à midi. 


\title{
SEANCE DU 16 JUIN 1913
}

\author{
(APRÈS-MIIDI)
}

\section{Présidence de M. PLUGHET, président de Section}

La séance est ouverte à 2 h. 25.

M. Le Présinent. - S'il y a des délégués étrangers dans la salle, je les prierai de vouloir bien venir prendre place au bureau. Ils nous ont fait l'honneur cl'assister au Congrès, nous serons très heureux de les voir à côté de nous.

M. Dubois prend place au bureau.

M. Bareel. - Monsi ur le Président, je suis délégué étranger, mais j’ai une communication à faire.

Elle ne figure pas en tête de l'ordre dn jour; mais si aucun des auteurs de communications n’est présent, je vous serai reconnaissant de me donner la parole.

Ma communication se rapporte à la question des défrichements.

M. De Peyrelongue. secrétaire. - Si j'ai bien compris votre pensée, le mot "défrichements " est ici synonyme de "mise en valeur ".

M. Bareel. - C'est précisément le sens que je donne au mot réfrichement.

J'ai pensé que cette question pouvait également intéresser, non seulement mon petit pays, la Belgique, mais également la Erance, et mème la plupart des pays où l'on s'occupe du reboisement et de la mise en valeur des landes et bruyères.

M. Le Président. - Le Bureau du Congrès est en possession de votre brochure: UNE NÉCESSITÉ ÉCONOMIQUE : LES DÉFRICHEMENTS, publication du Berenbond Belge, Imprimerie Anneessens-Ninove; nous serons très heureux d'enregistrer toutes les observations supplémentaires que vous aurez à donner à l'appui.

M. Bareel. - Cette question du défrichement a une importance très considérable, surtout pour les pays assez peuplés. Dans ces pays, la consommation ne fait que s'accroitre et on arrive difficilement 
à augmenter, dans une proportion égale, la production, principalement des produits de la terre.

Il est certain que la mise en valeur des terrains incultes, aussi bien que la culture intensive, pourront nous amener à parer à cette crise et à ce malaise áconomique. Mais il $\mathrm{y}$ a des motifs d'un ordre plus positif qui doivent nous amener à accroître notre fortune publique.

Bien que dans la Campine, il ne s'agisse que de 40 à 50.000 hectares de terres incultes qui pourraient être mises en valeur, on prut accroitre simplement la valeur du domaine.

M. Dubors. - Il y en a également dans le Luxembourg, dans le Limbourg et dans le Nord du Brabant.

M. Bareel. - Nous évaluons ces terres à 200 ou 300 franes par hectare. Or, nous pouvons leur faire donner un rendement presque immédiat de 20, 30 et même 90 franes par hectare. Il y a des pàtures qui, après deux on trois ans de mise en culture, rapportent chaque année jusqu’à 90 francs par hertare; ce qui fait, à une rapitalisation de $3 \%$, un accroissement de valeur de 1.500 à 3.000 francs par hectare. Rien que dans la Campine, ce serait donc un accroissement de valeur de plus de cent millions. Je ne vous donne pas ce rhiffre comme parole d'Evangile, je vous demande simplement de retenir ce principe, que, en tout ras, laccroissement de la richesse nationale serait considérable.

Au point de vue social, les résultats sont aussi frappants. On arrive à régulariser le taux des salaires, à diminuer les risques de chòmage, à enrayer l'exode de la population agricole vers les grands centres et à la rendre beaucoup plus apte à sassimiler certaines notions d'agriculture plus modernes.

Le coût des travaux est énorme et ce que nous étudions en ce moment-ci, c'est précisément la possibilité d'arriver à l'exécution de ces travaux à des conditions moins onéreuses.

La Hollande nous a montré la voie. Nos voisins sont arrivés à des résultats extraordinaires; nous avons voulu les imiter et une société de défrichements, e’est-à-dire de mise en valeur, a été constituée en Hollande.

Mais il faut également l'intervention de l'Etat. Cette intervention peut se produire le plus rapidement et le plus facibment quand il s'agit de travaux exécutés par les communes. Je dois signaler, à cet ćgard, la bonne volonté témoignée par le département de l'Agriculture, en Belgique.

Les communes, jusquici, se sont toujours montróes assez réfractaires à la mise en valeur par le boisement et surtout pour l'amélioration agricole. Bien que les communes reçoivent un subside, ce n'est que contraintes et forcées qu'elles se sont mises à l'ouvre.

Des dispositions nouvelles ont été prises, tout récemment, par le Ministère de l'Agriculture tendant à accorder aux communes l'avance 
de fonds nécessaire. L:Etat se fera, en quelque sorte, le banquier des communes qui n’auront plus à contracter d'emprunts. On arrivera, de cette façon, à obtenir que les communes boisent là où les terrains s'y prêtent et aussi qu'elles fassent ailleurs les améliorations agricoles.

M. CARDot. - Quel serait le taux d'intérêt pour les avances consenties par l'Etat?

M. Bireel. - Il avance des fonds à raison de $4 \%$ par an. C'est un peu moins que le taux auquel les communes devraient emprunter.

Le remboursement se fera au gré des communes dans un délai de vingt ans, mais les communes auraient toute latitude pour rembourser au fur et à mesure que les revenus leur rentreraient et qu'elles feraient des rentes, dans des conditions d'ailleur's très réduites, parce qu'en Belgique, on nadmet plus l'accaparement des terres par les gros propriétaires. La loi de 1847 a donné des résultats désastreux; les communes se sont dessaisies de leur domaine au grand détriment des finances communales.

Toici nos conclusions. Il nous parait utile, à un point de vue international, d'instituer immédiatement une commission spéciale pour l'étude de la mise en valeur forestière et agricole des terrains incultes. Nous demandons ensuite la constitution d'un organisme spécial dans le genre de ceux qui ont rendu d'immenses services dans tous'les pays où ils ont été constitués et ayant pour objet tout re qui concerne directement ou indirectement la mise en valeur, l'exécution méthodique et économique de travaux de ce genre.

Nous demandons l'intervention pécuniaire et fiscale des Pouvoirs publics par voie de subsides, exonération d'impòts, etc... Il a été également question, dans certains milieux, d'une taxe spéciale à imposer sur les terrains incultes. On a fait valoir que, dans certains pays, ce sont généralement les grands propriétaires qui possèdent ainsi de vastes domaines qu'ils maintiennent à l'état inculte, soit par luxe pour avoir de grands territoires de chasse, soit par une espèce despéculation essentiellement parasitaire. Ces propriétaires conservent ces terrains sans y faire aucune dépense en profitant cependant de la plus-value des terres environnantes mises en valeur par cle petits cultivateurs, ou par les communes qui tracent des routes, ou par l'Etat qui fait des dépenses pour améliorer les voies de communication, etc., et ainsi, sans aucun travail, res propriétaires arrivent à donner à leur domaine une plus-ralue considérable. Il serait assez juste, puisqu' on a cherché déjà à poursuivre les revenus de pur luxe, de frapper ces terrains incultes d'une taxe assez forte.

Nous demandons également une intervention technique par la spécialisation du rôle des agronomes de l'Etat dans le sens de la mise en valeur des terres : conférences, expériences, directions immédiates et complètes de res agents pour les travaux, bénéfices des subsides 
et exonérations fiscales, organisation et extension des servicen s'occupant de l'assainissement des terres marécageuses.

Nous demandons également une intervention diplomatique par des conférences internationales entre pays limitrophes pour la solution des nombreux conflits relatifs à l'entretien et à l'amélioration des cours d'eau.

Nous demandons la multiplication des voies de communication, des encouragements aux communes par lourerture de chemins agricoles dans les zones à mettre en valeur et l'adoption d'une jurisprudence plus libérale en matière de subsides pour création de routes en dehors des agglomérations et des trafics existants.

Je crois que ces conclusions intéressent la plupart des pays où des défrichements peuvent être exécutés. En tout cas, nous avons déjà, dans notre petite région de la Campine, des espérances qui, je crois, se réaliseront assez tôt, grâce surtout à l'intervention des Pouvoirs publics.

La combinaison imaginée par le département de l'Agriculture, donne déjà lieu à certains projets qui paraissent intéressants. Les améliorations se feront en bloc, d'après un plan d'ensemble qui sera tracé par les services de l'Etat. Nous avons également un service de l'hydranlique agricole extrêmement intéressant.

Enfin, avant même de procéder à l'exécution des travaux. les cornmunes arriveront, par suite de l'intervention de certains groupements, à être certaines de pouvoir louer leurs terres à un prix qui sera des plus rémunérateurs et qui dépassera le taux de l'intérêt que la commune devra payer, et ces locations se feront, d'après les combinaisons qui seront projetées, de telle façon que les locataires soient assurés, d'emblée, de pouvoir faire des frais considérables sans inconvénient. Ils loueront ces terres à très long terme, pour vingt-cinq ou trente ans, et les projets de baux élaborés jusqu'ici donnent à ces petits cultivateurs qui auront loué ces terrains pendant un délai déterminé, le droit d'acheter les terrains qu'ils auront mis en valeur. Ce sera. en quelque sorte, une option d'achat aceordée au locataire.

De cette façon, les communes peuvent immédiatement se mettre à l'œurre; elles sont assurées d'avoir de quoi faire face au service de l'espèce d'emprunt qu'elles contracteront enver's l'Etat, elles ont le droit, après un certain temps, de vendre leurs terres, ce qui leur permettra de rembourser le capital qu'elles auront emprunté, et cess domaines communaux seront ainsi très rapidement mis en raleur, alors qu'il fallait parfois, jusqu'ici, aller jusqu’à l'obligation pour. arriver à faire boiser par ci par là des domaines appartenant aux communes. (Applandissements.)

M. Le Président. - J suis certain, Messieurs, d'être votre interprète en remerciant $\mathbf{~}$. Bareel de la communication si intéressante quil vient de faire et oì nous pourrons puiser dos indications très précieuses. (Applaudissements.) 
M. Mnitre. - 11 serait intéressant de savoir quels seraient les frais de cette mise en raleur. Cirst le noeuil de la question.

M. LE Présluext. - Il faudrait évidemment une approximation.

M. IE Peyreloxgle. - Linitiative communale et privée ne se dérob)rait-elle pas, une fois que la voie aurait été ainsi tracée?

M. BAREeL. - Jusquici ces travaux ont coùté terriblement cher aux particuliers et mème aux communes, ce qui a souvent contribué à décourager ces dernières. Par exemple, pour les défoncements de nos bruyères, nous devons payer jusqu'à 250 et 300 francs l'hectare.

Jusqu'à présent, re travail se fait par petites parcelles, tout se fait à la pelle. Au contraire, si on met des fonds à la disposition des communes, on arrivera à faire un travail d'ensemble parfaitement étudié et organisé méthodiquement qui pourra se faire à la machine. On pourra tracer les voies de communication qui seront nécessaires, faire les écoulements indispensables, arriver à une économie considérable sur les frais de mise en valeur.

M. Mattre. - 300 francs par liectare pour un revenu de 30 francs. c'est encore un revenu de $10 \%$.

M. Bareel. - Je dois ajouter que le prix des bruyères augmente dans des proportions considérables depuis qu'on parle de mise en valeur. Il y a aussi l'emprise des terrains par l'industrie, notamment dans la Campine, par" suite des découvertes de eharbonnages. En tout cas, les chiffres auxquels on arrive par la mise en valeur des bruyères sont réduits considérablement, si le travail est fait méthodiquement, et on arrive à un rendement beaucoup plus rapide.

II. Cardot. - I quelle profondeur faut-il défoncer?

M. Bareel. - Cela dépend des terrains. Tout ce travail doit se faire après des somllages. L'irrégularité des couches est extraordinaire dans la Campine. Il y a des pareelles óù, pour avoir un résultat quelconque, il faut défoncer jusqu’à 80 centimètres : ce sont des parties où il est inutile d'essayer de travailler avec un bénéfice queleonque, elles resteront incultes jusqu'au dernier moment; ce sera le déchet auquel on ne s'attaquera sans donte que lorsque tont le reste sera fait.

M. Martre. - On pourrait les mettre en bois.

M. Bareel. - Lorsque la couche n’a pas ití percée, le bois arrive à dépérir, le sapin ponsse en pommier.

M. Dr bors. - Je dois dire que l'industrie charbonnière s'est précisément installée dans ce plateau campinien et qu'il y arrivera égalerent que res terrains, qui sembleraient destinés par la nature an reboi- 
sement d'une grande étenthe, saront transiormés an cultures et ce ue seront pas des cultures tout à lait splendides. Il y aura du seigle, de la spergule. du sarrazin. de la pomme de terre; on n'arrivera jamais au revenu que pourraient donner des forêts, mais cette production agricole est rendue indispensable par la création des rités ourrières que les charbonnages construisent.

Jajoute que nous avons constaté par expérience, en Campine, qu'il est assez dangereux, quand on pratique des défoncements. de ramener le fond à la superficie. Il y a eu beauroup déchees en Campine quion attribue. sans en avoir la preure immédiate d'ailleurs, à ce fait que, croyant avoir 11 sous-sol d'une richesse plus grande que la superficie, on a ramené à la surface les terrains qui étaient dans la profondrur. Daprès plusieurs forestiers éminents, notamment M. Maas, de Westerloo, beaucoup d'échers, m Campine, seraient dus à cette pratique qui a ramené l'infertilité an-rlessus.

M. Matre. - Il amive parfois que, lorsquon a ramené les couches profondes à la surface et que lo sol parait infertile, au bout de deux ou trois ans, cotte couche, après être restée à l'air, devient très bonne.

M. Bareez. - Cependant le défoncement normal ensiste à laisser la couche infórieure au fond et la couche supérieure en superficie.

M. Dubors. - On revient, en effet, à cette idée de laisses le terrain tel qu'il est.

M. Bareet. - En tout cas, un sondage prialable est indispensable.

M. Dubors. - La Commission de la Campine qui a fonctionné par ordie gouvernemental est plutòt d'aris que le défoncement est une opripation qu'il ne faut faire que quand on y est forcé et que, sourent, on pourrait sen passure et le remplacer par un labour à 25 ou 30 centimètres de profonterus.

M. le baron ne Belixay. - La couche d'alioos est-elle très ipaisse?

II. Debors. - Lalions est extrènement rare; e'est un tuf humide quion a confondusonvent aver l'alioos.

M. Matтre. - Cir qui est imperméable, gest le tuf humide.

M. LE P'résidext. - M. Dubois vient de nous ronner des explications très intrimssantes.

M. Dirbors. - Il s'agrit surtout de la tartique.

M. Le Présibent. - Ce sont des lenseignements sur la tactique fournis par lexpérinter. 11. Dubois est d'aceord avec .11. Bareel sur lopportunití de la mise an valeur de tous ans terrains; la mode de 
procéder peut varier suivant l'expérience de clacun, mais il me semble qu'il y a accord complet sur l'opportunité de cette mise en valeur.

M. Dubois. - L'arenir dira ce qu'il adviendra de la Campint.

M. Garrigot-Lagraxge. - Je tiens d'abord à massocier aux intéressantes observations de MM. Bareel et Dubois. Mais je tiens à signaler qu il y a, pour certains terrains incultes de France, une manière de procéder plus simple et moins coûteuse. Jappelle votre attention tout spécialement sur un vaste plateau, quon appelle le plateau de Milleraches, qui a une assez bonne presse depuis quelque temps t qui en profite dans une certaine mesure.

Après sept ou huit ans rle travaux effectués dans nos congrès de l'Arbre et de l'Eau, nous avons pu élaborer un projet très complet. M. le Ministre de l'Agrieulture a institué au plateau de Millevaches une sorte de service de reboisement, qui commence à fonctionner. Vous savez comment est constitué ce plateau : c'est une suite d'ondulations chauves, où se trouvent les sources d'un grand nombre de cours d'eau du bassin do la Loire et de la Garonne. Ces terrains sont incultes: ils peuvent être très facilement aménagés. Ciest là, je crois, que M. Cardot a fait une partie de ses intéressantes études. Ces terrains ont peu de valeur; ils bénéficient actuellement d'une plusvalue, à raison du bruit fait autour de cette question. On les rendait autrefois à la huchée c'est-à-dire aussi loin que la voix pourait s'étendre. Ils valaient à peine 50 francs l'hectare; ils valent aujourd hui de 100 à 200 francs. Ils sont même montés dernièrement à 400 franes par suite de l'engouement qui s'est produit. En les estimant à 100 francs l'hectare, on est dans la vérité. Nous faisons un travail d'aménagement simple et économique. La plupart des communaux de la Creuse, de la Corrèze et de la Haute-Vienne sont partagés. Les propriétaires qui ont repris leur part se trouvent embarrassés pour l'utiliser. Ils ne demanderaient pas mienx que de se syndiquer. Nous arons organisé de petites associations, sur le modèle de la loi de 1901, associations qui, en principe, ne paraissaient pas très légales, mais qui, d’après la loi nouvelle, peuvent très bien se constituer. La loi Audiffred permet maintenant ces groupements. Je puis indiquer que l'an dernier, arec la somme de 500 francs, nous sommes parvenus à reboiser 30 leectales.

Pour lamélioration pastorale, ce serait encore plus simple; il suffirait d'arriver à faire périr la bruyère. Je crois que le meilleur moyen dans notre pays serait l'irrigation.

M. Mitrre. - Vous arez de l'eau?

M. Gimrigol-Lagraxge. - Nous avoms de leau, en effet. Ciest un trrain siliceux, granitique, surmonté par me couche darène plus ou moins épaisse. Dans tous les vallons, il se produit un suintement; et, comme il y a de la pente - nous sommes dans un pars mame- 
lonné - on peut, à l'aide de rigoles de niveau irriguer de grandes surfaces. Le service de reboisement qui a été institué fait merveille. Malheureusement, on ne peut pas donner en argent de subventions assez importantes. Nous donnons tous les ans ce que nous pouvons en médailles; nous distribuons même un peu d'argent. Seulement, c'est facultatif. Si l'on pouvait au contraire assurer aux propriétaires, au bout de quatre ou cinq ans, une prime, par exemple, de 50 francs par hectare, nous en trouverions autant que nous voudrions. Ne serait-il pas possible d'émettre un vœu pour l'institution de cette. prime?

M. Carnot. - Le département du Finistère a pris l'initiative d’instituer une prime, une fois lonnée, de 25 francs par hectare, alux propriétaires qui reboisent.

M. Garrigot-Lagraxge. - 11 y aurait avantage à domer la prime en l'échelomnant sur plusieurs années, par exemple 25 francs au bout de la deuxième ou de la troisième année, et le reste au bout de dix ans, suivant l'état de conservation du bois.

M. Martre. - Il y a déjà l'expmption d'impôt aceordée par l'État.

M. Garrigou-Lagraxge. - Ciest peu de chose.

M. Martre. - Cela dépend. Il y a des terrains qui, l'après l'ancien cadastre, avaient une valeur appréciable et qui paient un impôt relativent lourd.

M. Bareel. - Pour quel lélai ces terrains sont-ils exemptés?

M. Garrigot-Ligraxge. - Pour trente ans. Cette exemption ne s’applique qu'au reboisement. On a parlé d"améliorations agricoles proprement dites. Je rrois que nous n’avons pas à nous en préoccuper ici. Certains propriétaires ont l'intention d'essayer de faire de la culture industrielle en grand, pommes de terre et topinambours. Pour nous, ce qui nous préoccupe, c'est d'alimenter le bétail ovin sur une surface moindre et de réserver une partie du terrain pour le reboisement.

M. Bareel. - C'est également notre but. Nous nous occupons surtout de la mise en valeur forestière. Seulement, comme il y a des terrains trop bas pour le reboisement, nous les destinons à la crilture et à la pàture du gros bétail, qui réussit admirablement.

M. Maitre. - Que comptez-rons mettre dans ros terrains, Monsieur Garrigou-Lagrange.

II. Garrigoc-Lagraxge. - Des moutons. Nous avons une race très ru-tique, trout à fait arlaptée au climat, que nous roudrions conserver. Naic unus voudrions aussi arriver, comme .V. Carlot le disait dernière- 
ment, à lavoriser l'extrmion dro la race bovine ut à creer des laiteries conprimatives.

II. Carbot remplace 11. Plechet au fauteril de la presidenere.

M. Ciroot, président. - Lïmlustre laitière ponrait cortainement so deretopper sur le plateau de Millevarhes, qui rst très liumide. et où on pourrait aroir de tres belles prairies.

M. Garrigor-Ligrange. - Il est extramdinaire, en rffet, de constater combien, sur re platean. les parties avoisinant lus villages sont verdoyantes ut fertiles, tandis que Ir peste est stirile. Ce sont des oasis dans un désert.

M. le baron to Belinay. - II 11 y a pas de population.

M. Grarigoe-Lighaxge. - La prospériti la rutimdrait ou la ferait même venir.

Un coxgressiste. - Combien y a-t-il "lhectarus?

M. Garrigor-Lagrange. - 100.000 .

M. Cardot, président. - Bien plus. En comptant la Corrèze, la Crense, la Haute-Vienne, le P'uy-rle-Tóme et le Cantal. rela fait plus de 250.000 hect ares.

M. Garmgor-Lagravge. - Il yeu a dejà d'aménagris.

M. Raoul de Chernost. - Dans quelles proportions les communaux ont-ils été partagés?

M. Garrigul-Lariange. - 11 n'en peste certainement jas un dixième qui n’ait été partagré.

M. Raoul de Clemuoxt. - Ciest fàcherux.

M. Le Présthext. - La restauration rommunalu pût éti plus farile. On est obligi maintenant de ronstituer de petites surietes syudieales pour arriver à un résultat.

M. Mntre. - Un syndicat de petits propriétaires fera plus quane commune.

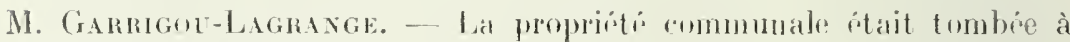
un état lamentable. Certaines pareelles ont quintuple de valene entro Ins mains des particuliers.

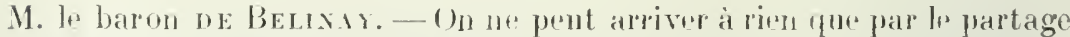
et par les syudieats et les groupemente de syndicats de proprietares.

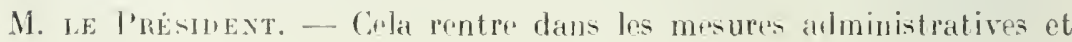


financières. Lu Congrès a déjà émis un voeu re prin “ipe : qu'une législation pastorale soit inlistie pet que des mesures afministratives et linancières soient prises ou complétées.

M. Mitre. - Une fógislation ne pourrait pas sappliquer à une région

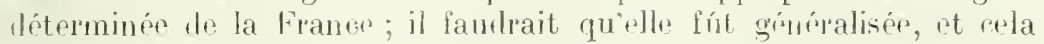
engagerait les finauces publiques dans des proportions que nons ne pourons pas calculer.

M. Raoul oe Cicenuoxt. - Ny aurait-il pas lieu l'rmottre un voeu général, concernant tons frśs dipartements de france et tendant à ce que la partage des communaux soit délinitivement enrayr.

M. Matre. - Il y a le pour ot le contre. Dans la inontagne, par exemple, ce sont de beaucoup les grauds communaux qui sont le plus mattraités.

M. Le Présinext. - Quand jai visité pour la première fois le plateau de .lillevaches, j'ai été lrappé de l'avantage qu'il y avait en à partager certains communaux qui étaient dans les mvirons immédiats du village de La Courtine. Il y avait de véritalurs prairius très belles, entourées d'une laie forestière. J'en ai ronclu qur flans les pnvirons immédiats des villages, oì on peut apporter des engrais, où on peut irriguer, il y a tout intérêt à partager les communaux. Mais s'il s'agit, au contraire, les parties éloignées des villages, où il n'y a pas deau, oir les transports d'ongrais sont dilfiriles, je crois qu'il vaudrait mieux que ces terrains demeurassent communaux et qu'on les mit en valeur par des travaux collectifs, a vec subvention de l'itat. On constituerait ainsi au profit de la commune des propriétés pastorales ou forestières d'une grande valenr, "omme il in existe dans le Jura on en FrancheComtí.

M. Te baron de Belrar. - Jai habité pendaut rincquante ans la Corrèzer, et je suis d'avis que, sans le partage, nous ne serions arrives à rien.

Dans certaines sections, le partage a donné jusqu’à 20 hertares par feu, éest-à-tlire 20 hertares pour 10 à 15 brebis. Vous voyez qu'il y a largement de quoi rebuiser. Je suis d'avis, contrairement à er que dit M. Cardut, le garder le earactère banal à res parties mouillées auxquelles les populations timment pour nourrir les varhes pendant lété; mais quant aux sommets lénulés, qui couvent des milliers Whectares, cest 111 anachronisme, lans ce siècle de travail agriente, de les laisser improductils. Toici des chifferes : les trrese de nos domaines groupées ensemble, prés, pàturages, bois, cte, penvent ître

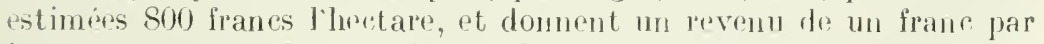
lectare et par an. Lus terrains à reboiser, qui valent de 2 à 300 liranes l'heretare, lomneraient, sils itaient plantés an bois, par excmple, 1 m

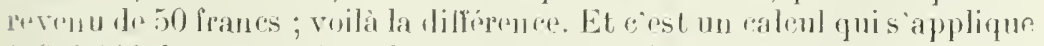

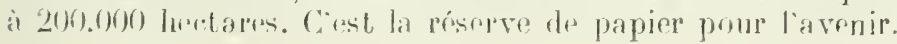


M. Mirtre. - M. le président estime qu'on arriverait plus facilement à améliorer les terrains, s’ils restaient communaux. Il y faudrait une condition préalable: e'est qu'il y ait un régime pastoral. Tant que l'administration n'aura pas les moyens légaux de contraindre les communes à améliorer, celles-ci ne feront rien.

M. Buffurt. - Un article de la loi de finances du 18 atril 1893. réserve un crédit de 100.000 francs pour encourager les communes au reboisement. Ce crédit n’est pas entièrement employé chaque année. Ne pourrait-on pas trouver sur ce crédit de quoi distribuer des primes aux particuliers pour le reboisement?

11. Raoul DE Chermont. - Dans une région que M. le président comnaît très bien pour l'avoir administrée pendant quelque temps, dans les montagnes du Doubs, il y a des communes rlont les communaux ont été si bien aménagés et administrés, que grâce anx revenus forestier's communaux, non seulement les habitants ne paient pas dimpôts, mais ils sont assurés contre la mortalité du bétail, et ils ront chez le percepteur pour toucher de l'argent au lieu d'en domner.

Il serait très désirable de voir cet exemple suivi dans le reste de la France, dans la mesure tu possible. Pour cela, il faudrait enrayer pour l'avenir le partage des communaux, et ensuite soumettre tous les terrains rommunaux à un aménagement sylvo-pastoral régulier.

M. le baron DE BeLinır. - Je sais qu'il y a des communaux qui rapportent beaucoup, parce qu'ilss sont déjà boisés; mais je m’oppose à un vœu général qui s appliquerait à toutes les régions de la France. Je maintiens, d'après l'expérience de ma vie entière de reboiseur, qu on ne peut tirer parti des communaux quen les partageant t'abord et en décidant les propriét aires à reboiser.

M. Maitre. - On ne peut pas, en effet, comparer l'amélioration de ces régions, où tout est stérile, où tout est à faire, arec l'améliuration des communaux de la région du Doubs, où les forêts rapportent énormément. Les communes n'ont pas d'argent, et il est impossible de les décider à consacrer de fortes sommes à améliorer les terrains incultes. Les conseils municipaux, qui sont en exercice pour trois on quatre ans, ne se sourient que de boucler le budget sans mettre te centimes additionnels.

M. Duburs. - Je me permets de confirmer les renseignements qui ont été fournis sur le revenu que peuvent donner les terrains communaux. Je eonnais une commune où le bourgmestre a reboisé 450 hectares par simple semis, qui revenait it 35 francs par hectare, le sol étant constitué par du bon sable jaune. sans tuf, c’est-à-dire un terrain splendide pour le pin sylvestre. C'est 11. Peters qui a commencé à couper les bois qu'il arait smés comme bourgmestre, $\iota_{10}$ ans arant; et rette commune, par suite d'un aménagement autorisé par arrêté 
préfectoral, peut couper tous les ans pour environ 20.000 francs, et cela incléfiniment, à condition'de reboiser. L'aménagement prévoit des coupes de 10 hectares; à 2.000 franes l'hectare, cela fait 20.000 francs. Il y avait plus de 250 hectares du même âge.

"M. Bareel. - Cela prouve que les communes auraient tort de se des: saisir de leurs domaines. Il ne faudrait pas se laisser aller à cette déplorable tentation de permettre aux communes de s'en dessaisir.

M. Dubors. - L'industrie peut créer des besoins nouveaux, et on ne sait pas quelle peut devenir la plus-value de ces terrains.

M. Mattre. - Mais il faut arriver pour cela jà faire un [régime pastoral.

M. Garrigorthagrange. - Qu'il s'agisse de communes ou de particuliers, j'estime qu'il y a lieu d'aider par des primes ceux qui voudront reboiser.

M. Le Présionent. - Nous nous entendons sur la nécessité d’un régime pastoral. Ne conviendrait-il pas de nous en tenir au roeu adopté ce matin, sans entrer dans des détails d'application.

Les observations qui ont été présentées ici figureront au procèsrerbal; je pense que cela suffira.

M. le baron de Belinay: - J'ai là tout un dossier du Cantal et rle la Corrèze. J'ai des demandes de plusieurs conseils municipaux, notamment d'Aurillac. M. Maisonneuve, que vous connaissez de nom certainement, et qui s'occupe beaucoup de reboisement dans le Cantal, ne pouvant pas venir ici, m'a chargé de vous faire tenir les demandes du Cantal. La Corrèze, la Haute-Vienne sont daccord avec le Cantal, et je crois que la Creuse partage également leur aris. Les représentants de cette région demandent, contrairement au désir exprimé par M. le Président, que le Congrès favorise le partage des communaux dans ces départements. Il ne s'agit pas d'une mesure générale. Je parle seulement des départements du centre. C'est une mesure qui leur est particulière; ils demandent spécialement le partage des parties sèches ; on désire généralement, en effet, que les parties mouillées restent bien communal.

11. Raoul de Cleruoxt. - Je tiens à protester de toute mon énergie contre le partage des communaux.

Uy Coxgressiste. - C'est un danger formidable.

11. Raoul de Chernoxt. - C'est un danger national, que nous avons combattu dans tous les congrès jusqu’à présent.

M. Girrigou-Lagraxge. - Il ne faudrait exagérer ni de part, ni d'autre. Ciest une question d'espèce.

M. le baron de Belixay. - D’ailleurs, vous renez de dire que les neuf- 
dixièmes des communaux sont partagís. Vous ne pourez jas pendre aux communes ce qui est partagi.

1I. Le Président. - Ce que je considere comme un mal est fait; il n'y a pas à r revenir. Si rou demandez un rote de principe. je le mettrai aux voix. Toutefois, je tiens à dire que, pour mon compte personnel, je demanderais plutòt qu'on s"oppose au partage des communaux, dont les résultats ont généralement été déplorables.

11. Raoul de Clermont. - On nous parle de la Corréze, de la Creuse, de la Haute-Vienne. Je pourrais vous citer dans la Haute-Vienne des communaux qui ont donné des résultat. mervilleux, par exemple à La Jonchère, que nous avons visitée encemble. Tous rous rappelez cette plantation de pins faite au-dessus de la propriété di. M. Gérardon.

Dans les Pyrénées, je vous citerai une vallie oi les propriétés particulières sont arrivées au prix de 6.000 franes l'hectare, grâce aux communaux. Dans le Doubs, dans les Vosges. il y a des population, extrêmement riches également, gràce à leurs communaux.

11. Martre. - Ce que nous cherchons ici, c'est la meilleure maniẻre de mettre en valeur. Il s'agit de savoir si les communes. dans l'état actuel de la mentalité communale et des mesures administratives, peuvent facilement mettre en valeur.

11. Le Président. - Il y a encore un argument contre le partage des communaux, cest que les communaux, une fois reboisés avec -ubvention de l'État, d'après notre législation française, sont soumis au régime forestier, ce qui fait que la propriété forestière se maintiendra, ce qui n'est pas le cas de la propriété forestière particulière.

M. Raoul de Clermont. - Ne pourrait-on pas domner satisfaction à tout le monde en rédigeant un vou tendant à enrayer le partage des communaux et à soumettre toutes les propriétés communales à un aménagement sylso-pastoral, sous la surveillance de l'administration dez Eaux et Forêts?

M. Maitre. - Nous pourrions dire aussi que ce qui importe, lest d'établir un régime pastoral ; que, faute d'un régime pastoral, on serait obligé, pour la mise en valeur, de partager les communaux, ce qui serait très fâcheux.

11. le baron ne Belinay. - Nos paysans ne veulent pas du régime forestier ; ils refusent d'être sous la coupe do l'Administration des Forêts, ils ne reulent pas de procès-verbaux.

11. Raoul in Chermont. - Comme le propose M. Maître, nous pourrions conclure par un vœu tendant à enrayer le partage des communaux par l'adoption d'un régime d'aménagement sylvo-pastoral. 
II. Le Président. - Pourqui ne pas sen tenir tout simplement an vœu qui prévoit justement l'aménagement pastoral?

M. LE Président. - Je suis saisi du projet de voeu suivant :

"Le Congrès émet le vœu que le partage des communaux: est, en principe, une mesure regrettable qui doil être enrayée, et que toutes les propriétés communales soient soumises at un aménagement syloopastoral obligatoire.

II. le baron DE Belivar. - Jestime quavec ce voeu, vous sacrifiez 250.000 hectares qui' pourraient ètre reboisés. J'ajoute que noh populations n'en tiendront pas compte et que le partage continuera.

M. JaGerschmidt. - Elles n'ont pas tenu compte, pendant trente ans, du régime forestier.

M. Raoul de Chernoxt. - Je demanderai une rédaction plus catégorique encore. Je propose au Congrès de demander que le partuge des communaux soit enrayé et que les communes soient obligées a un aménagement sylvo-pastoral.

II. le baron de Belivar. - Allez-rous demander que les communauz partagés reviennent aux communes?

M. Le Président. - Évidemment non; on ne peut pas reventir sil le passé.

M. Jour. - Il faudrait d'abord proserire le partage de tous les conmunaux déjà boisés. J'ai vu dans la Loire des exemples caractéristiques. Il s'agit de petits bois créés à la suite de la première loi de reboisement de 1860, qui ont été partagés parce qu'ils appartenaient à de petites sections composées de sept ou huit intéressés. Ces copropriétaires ut universi avaient un grand intérêt à se faire reconnaîtr ut singuli, parce qu'on leur offrait une somme déterminée de leur bois. Un propriétaire voisin leur disait : "Vous êtes cinq ou six; je vous offre 30.000 francs, à la condition que vous me fassiez recornaître propriétaire ut singuli. Le tribunal de Rơnne leur a donı́ raison ; chacun d'eux touchait ainsi 5 à 6.000 francs. Cela s'est passé ainsi dans trois communes; c'est très regrettable, parce que ces boir de pins sylvestres avaient été créés de toutes pièces par l'Etat daris I'intérêt général.

Il faut absolument proserire le partage de tous les communaux boisés et de tous les communaux susceptibles de reboisement; il vauf mieux que les propriotés boisées appartiennent à des sections de communes qu’à des propriétaires particuliers.

11. Le Présidext. - On me propose la formule suivante :

"Le Congrès émet le rrou que les terrains communaux suscep- 
tibles de reboisement soient reboisés avec encouragement de l'Etat, mais ne soient pas partagés. ")

M. le baron dE Belixay. - Je propose une autre formule :

"Le Congrès ne conseille le partage dès communaux que dans les départements oì ce partage sera demandé par les conseils généraux. "

(Non, non! sur de nombreux bancs).

Pourquoi, Messieurs? Ils sont linterprète de la volonté de tous les électeurs.

Plesietrs vorx. - Ce n’est pas l'intérèt général.

M. Maitre. - Il y en a beaucoup qui roudraient qu'on supprime le régime forestier.

M. Le Présidext. - Je vais mettre aux roix le rou qui a été exprimé par IIM. de Clermont et Joly :

"Le Congrès exprime le vou que les terrains communaux susceptibles de reboisement et d'amélioration pastorale ne soient pas partagés. ")

Plesiecrs roix. - Ni aliénés.

M. Maitre. - Il faudrait, pour donner satisfaction à M. Joly, ajouter le mot "boisés ".

M. Le Présidext. - Lẹ texte serait ainsi rédigé :

"Le Congrès émet le rou que les terrains communaux boisés ou susceptibles de reboisement ou daménagement pastoral, ne soient pas partagés, et snient reboisés ou aménagés, asec encouragement de lEtut. »)

Ce rou est adopté à l'unanimité moins une roix.

La séance est levée. 


\title{
SEANCE DU 17 JUIN 1913
}

\author{
(MATI) \\ Présidence de M. PLUGHET, président de Section
}

La séance est ouverte à 9 h. 10.

M. Le Président. - Messieurs, M. Dr. Comm. Alberto Geisser, délégué du Touring-Club Italien, a bien voulu déposer sur le bureau, un certain nombre de publications de cette société.

Je prie M. Geisser de transmettre au Touring-Club Italien les remerciements sincères du Congrès, et je lui répète que nous sommes heureux qu'il ait bien voulu le déléguer pour prendre part à nos travaux (Applaudissements).

S`il y a dans la salle des délégués étrangers, je les prie de venir prendre place au bureau pour suivre de très près les discussions qui vont s'ouvrir. Nous sommes ici réunis en un congrès international et nous serons heureux d'être éclairés par ces messieurs sur ce qui se passe dans leur pays et d'en tirer des enseignements pour la France.

M. Jules Rотн, inspecteur des Eaux et Forêts, adjoint à la station centrale de recherches forestières à Selmeczbanya (Hongrie), prend place au bureau.

II. Le Président. - L'ordre du jour appelle la lecture de la discussion du rapport de M. Mougin sur les Grands travadx : Barrages. Dérivations. - Canalisations. - Tunnels. - Restauration des montagnes. - Lutte contre les torrents et les avalanches.

M. Mougin. - Depuis quelques années, les travaux de correction des torrents ont eu le don d'exciter, en France surtout, d'âpres et souvent d'injustes critiques qui ont abouti à un véritable réquisitoire soumis à la fin de 1912 à la Chambre des Députés. (Rapport sur le budget de 1913, Ministère de l'Agriculture par M. Albert Métin).

Les assertions erronées ou hasardées, avancées à ce sujet, ont fait l'objet de restrictions sévères de la part des forestiers étrangers (Journal jorestier Suisse, 1909) aussi bien que de rectifications méritées, tant dans les journaux spéciaux (Revue des Eaux et Forêts 1906, p. 75. Professeur Thierry) qu'à la tribune du Parlement (Séance de la Chambre du 19 novembre 1912, matin). La campagne entreprise ne tendait pas 
à moins qu“ à aflîmmer l'inutilité, bien mieux, la nocuité des travaux de correction.

En France, la loi du 4 avril 1882 en restreignant les travaux de restauration à la plaie et à la lèvre même du torrent, en empêchant dans les bassins de réception l'établissement de massifs forestiers capables d'atténuer le ruissellement, a fatalement amené parfois à employer contre les brusques afllux d'eaux et les érosions qui en sont la conséquence, de plus nombreux ourrages de correction qu'il n'eût été nécessaire dans des conditions normales.

Aucune polémique n'aurait dú naìtre à ce sujet : il suffit de rappeler comment procède l'action torrentielle pour faire apparaître l'opportunité et sourent même la nécessité de ces ouvrages.

Tout filet liquide ayant une vitesse de plus de 3 mètres à la seconde affouille les roches les plus dures comme les granites. Lorsque ce filet roule des sables silicieux, l'action érodante de l'eau s'en trouve singulièrement augmentée; il est clair aussi que la morsure du courant est d'autant plus énergique que la roche est plus tendre, plus soluble, plus friable.

C'est également une banalité de dire que la vitesse d'écoulement est fonction de la pente du lit et du volume des eaux, que le tapis végétal forestier ou herbacé sert de cuirasse au sol, ralentit le ruissellement et absorbe une notable partie des eaux atmosphériques.

Or, le torrent est un cours d'eau à fortes pentes, lancé sur un versant dénudé, souvent constitué par des boues glaciaires, des marnes liasiques, etc., qu'il ronge sans cesse, amenant à chaque crue de nouveaux éboulements des berges, de plus énergiques approfondissements du thalweg. Tous ces matériaux arrachés à la montagne viennent s'étaler dans la vallée en énormes cônes de déjections, envahissant villages et cultures, interrompant les communications et provoquant souvent dans les rivières interceptées de désastreuses débâcles. Parfois même on a à déplorer des pertes de vies humaines.

Pour prévenir ces dégâts, il faudrait diminuer l'importance des crues, supprimer ou réduire le ruissellement, fixer la terre sur les versants : c'est le grand rôle de la forêt dans le drame qui éclate lors de chaque orage en montagne. Mais suivant l'altitude, l'exposition, le sol, il faut 15 ans, 20 ans et plus encore parfois, pour constituer le fourré protecteur. En attendant ce moment, n'y aura-t-il plus de "sac d'eau " capable d'élargir la plaie béante des rives et d'emporter en une lave les berges et les plantations qui les recouvrent? Est-il donc si rare de voir les neiges hivernales amoncelées dans les cirques supérieurs, fondre brusquement sous le souffle brúlant du vent du Sud, du foehn, qu'accompagnent presque toujours de tièdes et diluviennes ondées?

Alors que de vieilles futaies ont été impuissantes à retenir un sol étreint par le réseau de leurs monstrueuses racines, comment de jeunes pins, épicéas ou mélèzes, au maigre chevelu, arriveraient-ils à ravir à la puissance des eaux les pierrailles ou les boues qui les supportent?

Si l'on veut permettre à la végétation de s'installer sur des versants instables, il faut de toute nécessité combattre l'érosion. Il peut suffire d'installer en travers du lit, à son niveau, en divers endroits, une chaîne de pierres qui arrête le surcreusement. Ces "seuils " assurent aux berges qui ont pris leur talus la fixité qui leur faisait défaut, c'est là une correction simple et peu rlispendi use qui peut suffire en beaucoup de cas.

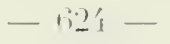


S'agit-il, au contraire, d'un torrent violent qui s'enfonce à chaque crue très profondément, sapant le pied des berges presque verticales dont l'effondrement peut avoir dans le versant ainsi privé de base les plus fâcheuses répercussions.

Il convient alors d'édifier un mnr en pierre sèche, ou en maçonnerie de mortier, ou mixte avec le corps de l'ouvrage en pierre sèche et lo couronnement en maconnerie de mortier, faisant saillie au-dessus du lit. L'atterrissement qui se forme en amont va élever la ligne du thalweg, étayer les berges eroulantes et constituer une plage à pente réduite où les eaux s'étaleront, perdront de leur vitesse, de leur force de propulsion. La curette ménagée au milieu du couronnement dou "barrage "éloignera le courant du pied des rives qui prendront peu à peu leur pente natırelle.

On conçoit d'ailleurs qu'il puisse être établi une série de barrages rapprochés, en gradins, lor'squ'il s'agira de déterminer un atterrissement important et de racheter une forte différence de niveau pour soutenir de puissantes berges menacées.

Ou bien chaque ouvrage se trouve établi à l'extrémité même de l'atterrissement du barrage immédiatement en aval ou à une distance phus considérable encore.

C'est la suppression de l'afforillement par suite de la diminution de la vitesse, due tant à la réduction de la pente qu'à l'augmentation du périmètre mouillé.

Dans cette dernière hypothèse, suivant la pente du lit, la nature du terrain, il peut être ou non nécessaire de fixer le thalweg par la construction de seuils intermédiaires.

Mais il arrive parfois que la pente est trop forte pour qu'on puisse utilement établir des barrages ou des seuils, ou bien que le terrain est tellement peu consistant (éboulis, sable, gypse) que le moindre filet d'eau y produit des érosions. C'est alors que l'on reeourt aux canaux perreyés : on assure au torrent un lit fixe, résistant, imperméable dans toute la région dangereuse. Pourrait-on concevoir autre chose, aussi bien pour protéger le sol que pour prévenir des infiltrations dont les effets, parfois lents à se manifester, sont souvent des plus redoutables?

Tous les moyens qui précèdent s'appliquent lorsque l'affonillement est le seul ennemi à combattre. Le problème devient infiniment plus ardı lorsqu'à l'érosion vient s'ajouter l'instabilité des versants provoquée par des causes autres que le surcreusement du lit. C'est toujours l'eau en excès qui est l'agent du glissement d'une couche superficielle filtrante (souvent un placage glaciaire) sur un substratum argileux ou rocheux imperméable, d'un relief souvent différent de celui de la superficie et plus ou moins incliné.

Le moutonnement de la surface, des déchirures vives, de petites mares sont earactéristiques des glissements qui peuvent atteindre jusqu'à mille hectares et plus encore. Qu'un ruisseau eoule dans le thalweg vers lequel se précipitent les terres, il se transformera en un dangereux torrent et plus il emportera de matériaux, plus la vitesse de descente du versant ira en augmentant.

Il sera toujours utile d'assécher les mares du bassin de réception, de drainer les parties mouilleuses, de faciliter, en un mot, la rapide évacuation des eaux atmosphériques ou de fonte dr neiges, de manière ì créer une eroûte superfieielle solide, formant une enirasse capable de 
maintenir les masses humides sous-jacentes. En certains cas, de tels travaux constitueront à eux seuls toute la correction.

Nais ordinairement il conviendra de les associer à des ouvragos d'autres genres.

Tantôt une digue longitudinale, formant mur de soutènement, le long du cours d'eau de base dont on évitera l'affouillement, suffira à étayer le terrain.

Tantôt cette digue devra être combinée avec des seuils ou des barrages.

On peut aussi, en relevant fortement le lit du torrent au moyen de barrages qui constituent autant d'étais, provoquer de puissants atterrissements servant de cale à la berge mouvante.

Vais tous ces procédés demeurent inefficaces lorsque le torrent, d'un grand débit, est sujet à des crues violentes, soudaines et considérables, que la hauteur et la pente des versants instables sont fortes et que leur mouvement est rapide. Qu'on éloigne alors, si l'on peut, le cours d'eau de la rive dangereuse par une dérivation à ciel ouvert ou en souterrain dans la rive opposée. D'un seul coup, on aura supprimé ou réduit énormément le charriage du torrent, on aura donné à la montagne croulante une place où entasser ses débris et l'appui dont elle a besoin pour retrouver son équilibre et sa stabilité.

Cette solution radicale, qui peut être économique, assure au mieux la sécurité des régions inférieures, des voies de communication, des cultures et des agglomérations dont les populations, quoi qu'on en ait dit, ne se désintéressent pas de la correction des torrents qui les menacent.

Moins chargées de matériaux et, par suite, plus affouillantes, les eaux auront une tendance à remanier leur lit à l'aval de la dérivation : de là l'obligation, pour éviter des surcreusements, de fixer ce lit au moyen d'une série de seuils qui réduiront la pente et partant la vitesse des filets liquides.

Il peut arriver aussi que le torrent dérivé soit jeté dans le lit d'un ruisseau voisin : ici encore, il faudra prendre garde que ce lit d'emprunt ne soit pas érodé par suite de la surchage qu'on va lui imposer. Des ouvrages de protection, de défense de rives serontsans doute nécessaires.

Sur les cônes de déjections enfin, qui portent les plus riches cultures, les vergers, les vignes, aussi bien que les villages, il n'est pas moins important de prérenir la divagation des eaux torrentielles. Autrefois, alors que l'on ne cherchait pas à combattre le mal à son origine, dans ses causes d'ailleurs ignorées, on se bornait à des travaux de protection locaux, le plus souvent des digues, ou des curages de lit. A la première lave, on voyait les digues enlisées, le chenal ouvert à grands frais entièrement comblé, bien heureux encore quand les coulées boueuses ne s'étaient pas frayé un chemin au travers des maisons et des cliamps.

Ce qu'on ne pourait tenter alors avec succès se réalise aujourd'hui après l'achèvement des travaux de correction dont le résultat est la suppression du charriage.

D'ordinaire, on fixe un lit aussi rectiligne que possible, en tenant compte des points de sujétion (ponts, hameaux etc.). Pour empêcher le torrent de sortir, on l'enserre entre deux perrés latéraux parallèles réunis par une cuvette maçonnée continue, ou par des seuils plus ou moins distants, afin d'éviter le creusement du plafond du chenal. Le premier de ces procédés a toutefois l'inconvénient d'amener une usure du parage de 
fond d'autant plus rapide que la pente du còne de déjections qu'il épouse est plus considérable.

Grâce à de telles r'égularisations de lit, on peut rendre à la culture des surfaces parfois fort importantes qui n'étaient occupées que par des graviers ou de la lande; en outre, on garantit contre les crues dont seul le reboisement du bassin de réception du torrent atténuera peu à peu la violence, les propriétés, les routes et les chemins de fer situés dans la vallée principale.

Une autre question se pose, qui a été soulevée récemment en France : faut-il commencer les travaux de correction par la partie inférieure du torrent et aller en remontant on bien adopter la méthode inverse.

Voici ce qu'enseignait M. le professenr Thierry à l'Ecole Nationale des Eaux et Forêts (1).

"Il y a lieu de se demander s'il faut construire les barrages en commençant par le bas ou par le haut du torrent. Chacun de ces systèmes peut se sontenir. On peut commencer par le bas quand on est seulement préoccupé de garantir immédiatement les propriétés inférieures; on ne construit alors un nouveau barrage que lorsque le précédent est complètement atterri, et de cette manière, on retient dans la montagne la totalité ou, au moins, la plus grande partie des gros matériaux.

"Certains reboiseurs pensent, au contraire, qu'il faut d'abord attaquer le torrent à sa source et construire les premiers barrages dans les parties supérieures des gorges. En opérant ainsi, on arrête immédiatement les dévastations dans les parties où les pentes sont les plus fortes; on régularise dans une certaine mesure l'écoulement des eaux et les perturbations inférieures deviennent moins considérables. Il est probable, pour toutes ces raisons, que ce système est plus économique que le précédent, mais il présente sur ce dernier le désavantage de ne pas mettre promptement à l'abri les cultures, les habitations, les routes, les voies ferrées qui sont menacées par le torrent.

"Il existe un troisième procédé qui sert d'intermédiaire entre les deux autres et qui consiste à diviser le torrent en un certain nombre de tronçons séparés par des bandes de terrain inaffouillables (affleurements de roches, veines plus résistantes, portions de lit devenues permanentes, etc.). Ces premiers travaux apporteront une amélioration considérable dans le régime du torrent. Les propriétés inférieures seront garanties promptement, comme dans le premier cas ; et si, pendant la construction de ces ouyrages, on a soin de pousser activement les travaux de reboisement on pourra peut-être, comme dans le deuxième cas, faire une économie sérieuse sur le restant des travaux de consolidation à exécuter. o

Ces considérations pratiques, la liberté du choix, ne trouvent pas grâce devant les partisans de la correction par le bas qui condamnent les autres systèmes au nom du principe de l'érosion régressive des cours d'eau à partir d'un niveau de base et citent, à l'appui de leurs dires, géologues et géographes.

Il ne s'agit pas de nier cette théorie qui s'appuie sur des remarques incontestables mais bien de voir si elle s'applique bien dans la lutte contre l'érosion torrentielle et la formation des laves. En de telles matières, le fait prime tout et s'il est contraire à une théorie, c'est que la théorie ne peut s'étendre au cas observé.

L'érosion torrentielle est provoquée par l'écoulement d'une masse liquide considérable, d'un "sac d'eau " tombé brusquement dans le

(1) Restauration des montagnes, Correction des torrents. Reboisement (Paris, librairie poly technique, Baudry ef $\mathrm{C}^{i \theta}$ éditeurs, Chapitre X, p. 145). 
bassin de réception. On voit aussi en quelques moments tomber 50 , 60 litres d'eau par mètre carré et souvent plus encore. Cette masse s'écoule sur des pentes excessives, sa vitesse s'accroît ( $g$ Sin $x$ ) uniformément et, quand elle a atteint, une valeur suffisante pour attaquer le lit, l'érosion commence. Il ne faut pas oublier que les roches les plus dures sont affouillées dès que l'eau atteint une vitesse de 3 mètres par seconde. Les filets liquides arrachent des matériaux au thalweg, les poussent et bientôt l'abondance des particules solides est telle que ce n'est plus de l'eau, mais un magma où la proportion du liquide est des plus faibles $(1 / 5,1 / 10)$ et qui avance par bonds successifs. Viendra-t-on soutenir que les lois de l'hydraulique régissent encore l'écoulement de la lave?

Alors que la lave emprunte tous ses matériaux aux régions supérieures, peut-on valablement prétendre qu'elle est dıe à l'érosion régressive du cours d'eau?

Ecoutez ce que dit Surell (1) à ce sujet :

"Quand une grande masse d'eau se concentre subitement dans le goulot d'un bassin de réception, lancée sur une pente très rapide et resserrée dans une gorge profonde, cette masse ne s'écoule plus suivant les règles ordinaires de l'hydraulique. Elle monte de suite jusqu'à une très grande hauteur, roule sur elle-même et descend ainsi la gorge avec une vites̉se excessive, bien supérieure à celle du torrent d'eau régulier qui s'écoule de vant elle vers l'aval. Elle doit donc atteindre successivement tous les points de ce courant; elle l'assimile à sa propre masse; elle le balaye et, lorsqu'elle débouche dans la vallée, elle arrive chargée de tout le volume d'eau répandı dans le lit du torrent, depuis sa naissance, jusqu'à sa sortie de la gorge. "

Qu'ajouter à une telle citation?

Mais où l'érosion régressive se fait d'une façon nette, c'est après l'arrèt de la lave. Les matériaux se sont déposés formant une courbe convexe vers le ciel; lorsque les éaux plus claires qui succèdent an phénomène arrivent au contact de cet amas mou, sans cohésion, on les voit se creuser un chenal de plus en plus profond et donner au profil en travers du dépôt la forme d'un M.

C'est à ces faits bien connus de tous ceux qui ont pratiqué les Alpes, qu'on veut opposer la théorie dı creusement par des eaux claires courantes! Alors pourquoi ne pas dire que les lois de l'écoulement des liquides s'appliqueront aux laves.

Où donc est la faute de technique que commettent ceux qui, dans les parties supérieures du torrent, veulent diminuer la vitesse des eaux, augmenter la résistance du lit afin de prévenir l'érosion au point où elle se manifeste?

Surell, auquel il faut encore revenir, disait déjà à ce sujet (2) :

" 11 reste à parler de l'ordre dans lequel il conviendra de pousser les travaux. Cet ordre, loin d'être arbitraire, est une des conditions principales du succès.

"J'ai déjà si souvent fait ressortir dans le cours de ce travail la nécessité d'attaquer les torrents dans leurs sources mêmes, qu'il est inutile d'y revenir encore. Ainsi c'est dans les parties les plus élevées que les travaux seraient d'abord entrepris: ils avanceraient de là vers les parties basses."

Il faut, enfin, ne pas perdre de vue le but que l'on se propose en entreprenant la correction d'un torrent qui est la reconstitution de la forèt

(1) Surdl, Etudes sur les torrents des Hautes-Alpes, Chapltre IX, p, in.

(2) Sitreli, loc. cil. Ch.tp. XXXII, p. 205. 
(t le maintien du sol sur les pentes. Tout ce qui pourra hâter la réalisation de cet objectif ne saurait être négligé.

De là l'obligation de reboiser toutes les parties stables du bassin de réception afin d'atténuer le ruissellement, celle d'entreprendre des ouvrages de correction dans les régions supérieures pour fixer le lit, les berges, empêcher que celles-ci ne s'éboulent et n'entraînent peu à pers ver's les thalwegs les parties les plus voisines.

Dès qu'ils seront stabilisés au moyen de travaux appropriés, les terrains crevassés, ébranlés, qui glissaient, seront plantés. Au fur et à mesure que se développera la végétation ligneuse, le régime du cours d'eau se régularisera et les berges des régions inférieures étant moins menacées, la construction de barrages y sera plus facile et moins onéreuse.

L'érosion régressive est assez lente, c'est une usure du lit; l'érosion torrentielle est soudaine, brutale, puissante : celle-ci agit comme une gouge sur le bois, l'autre, comme du papier de verre. Contre laquelle faut-il lutter d'abord? La réponse ne saurait être douteuse; il faut aller au plus pressé, mais de là à conclure qu'il faille négliger l'érosion régressive, il y a un abîme.

Est-ce à dire encore qu'on ne doive jamais commencer une correction par le bas? Ce serait aussi exagéré que de vouloir l'imposer dans tous les cas. Chaque torrent a ses caractères spécifiques de climat, de sol, de pente, d'exposition, d'altitude, de dénudation. Les travaux à exécuter doivent être décidés en tenant compte de tous ces éléments. Ici encore, il jaut redouter les conceptions purement théoriques dans la recherebe de la solution : c'est l'observation directe des faits qui doit servir de guide et voici les conclusions auxquelles était arrivé Demontzey (1)

"Quant à la marche à suivre dans les travaux, l'expérience à démontré :

" $1^{\circ} \mathrm{Qu}$ 'il importe, avant tout, de corriger tous les ravins supérieurs tributaires d'un torrent donné ;

" $2^{\circ}$ Que, dans le lit principal, on doit procéder de l'amont vers l'aval, en ce qui concerne les différentes sections à traiter ;

" $3^{\circ} \mathrm{Qu}$ 'all contraire, dans les combes, les travaux de l'amont de vant s'appuyer - ur ceux d'aval, il y a lieu de procéder généralement du bas vers le haut, à lexception des combes sèclies où lon doit exclusivement reprendre les travaux par le haut;

" $4^{\circ}$ Que dans le cas de glissement sur les versants du torrent, cliaque section doit être traitée comme une combe ;

" $5^{\circ}$ Que dans chaque section, les travaux secondaires seront toujours menés de l'aval vers l'amont entre deux barrages consécutifs. ?"

Les résultats donnés par cette méthode éclectique n'ont pas été tels qu'il faille y renoncer. Beaucoup de corrections de torrents ont été réussies, qui ont été commencées par le haut. Mais il ne faut pas, une fois les travaux entrepris, les entrecouper, comme cela est malheureusement arrivé, par des intervalles d'inaction qui donnent à l'érosion régressive le temps d'intervenir. Ce sont ces intermittences, non moins que l'étriquement des périmètres, qui ont causé des mécomptes.

Les corrections per descensum se terminent d'ordinaire par l'établissement d'un solide ouvrage de base qui sert alors de couromment a l'édifice au lieu d'en être le point de départ comme dans la méthode per

(1) L'extinction des torrents en France par le reboisement (Paris, Imprimerie Natio. rale 1894, P. 87. 
ascensum. Dans les deux cas, cet ouvrage de base est l'obstacle posé par l'homme à l'action de l'érosion régressive.

En résumé, c'est au technicien à décider de l'opportunité de commencer les travaux de correction d'un torrent par le haut ou par le bas d'après l'examen des circonstances locales et non d'après une formule théorique qui, on vient de le voir, n'envisage qu'une des données du problème.

Les corrections d'avalanches.

Dans les régions montagneuses, en dehors des érosions et des ravages torrentiels, il est d'autres phénomènes qui, chaque année, font des vietimes, arrêtent la circulation et endommagent les propriétés de tous genres : ce sont les avalanches.

Tombées sur les versants dénudés ou non boisés des montagnes, les neiges sont sollicitées sans cesse par l'action de la pesanteur et, bien souvent, avant qu'elles aient pu fondre, elles se précipitent en nappes ou en tourbillons vers la profondeur des vallons. Leurs dégâts sont loin d'être négligeables.

Ainsi de 1900 à 1912, dans les seuls départements de la Savoie, elles ont dévasté 1310 hectares de forêts, renversant, brisant 21.056 mètres cubes de bois; elles ont détruit ou endommagé 134 bâtiments divers, enseveli 128 personnes (dont 27 ont péri) et 203 animaux domestiques de toutes espèces; elles ont barré 569 fois des cours d'eau et 522 fois des voies de communication de terre ou de fer.

Dans la seule commune de Chamonix, par exemple, les avalanches ont créé dans la zone forestière des couloirs qui n'occupent pas moins de :300 hectares ainsi frappés d'une stérilité presque totale, elles empêchent en hiver la circulation des trains en amont de cette importante localité et menacent de ruine de nombreux hameaux.

Ce n'est pas seulement par la destruction des forêts que les avalanches favorisent le développement et les ravages des torrents; en roulant sur les pentes, elles arrachent des rochers, labourent les portions terreuses nues et elles accumulent dans les thalwegs d'énormes quantités de matériaux. Les brusques fontes des neiges ou les "sacs d'eau " de l'été remanient ces dépôts meubles qui augmentent le volume et l'importance des laves torrentielles. D'après les observations faites en Savoie depuis quelques années, on a noté que certaines avalanches de fond ou de glacier pouvaient entrainer jus qu'à 8.000 mètres cubes de blocs, de gravier et de terre!

De tels apports sont donc loin d'être négligeables !

Souvent aussi les avalanches constituent le plus sérieux obstacle au reboisement.

De même que pour les torrents, les montagnards avaient depuis longtemps cherché à se garantir de leur choc par des travaux édifiés à proximité même des points à protéger (tournes, éperons). Ils n'avaient pas été sans remarquer que ces phénomènes ne prenaient pas naissance dans les parties boisées : aussi les cantons situés au-dessus des villages et des hameaux menacés par les neiges avaient-ils, de bonne heure, été placés hors des exploitations pour former des forêts de protection, des bois de ban ou bois bannis.

Naturellement aussi on en vint à conclure que pour arrêter, prévenir les avalanches, il fallait reconstituer les massifs imprudemment détruits ; mais bien vite on s'aperçut que la reforestation n'était possible qu'à 
la condition de retenir les neiges sur les pentes jusqu'à ce que les plantations fussent assez fortes pour jouer leur rôle.

Ici encore les travaux de correction doivent précéder les travaux forestiers ; parfois même, lorsque le bassin de formation de l'avalanehe se trouve à une altitude supérieure à la limite de la végétation forestière, sont-ils les seuls à entreprendre.

C'est en Suisse que les corrections d'avalanches sont les plus nombreuses et les plus importantes; la France et l'Autriche en offrent aussi divers exemples.

Le principe de tous les ourrages de correction est de fixer les neiges sur les pentes.

On y arrive :

10 En ménageant sur les versants des plates-formes horizontales plus ou moins longues, larges de $1 \mathrm{~m}$. 50 au moins, disposées en chicane à des niveaux différents dans la région d'où partent les neiges : ce sont les banquettes. Elles sont, tantôt entièrement en déblai, tantôt partie en déblai partie en remblai; elles permettent de donner de l'assiette aux nappes neigeuses.

$2^{\circ}$ En édifiant sur les pentes des obstacles artificiels munis d'une berme large d'environ 1 mètre, à l'amont, dont la hauteur au-dessus du sol est fonction de l'importance des précipitations neigeuses à l'endroit considéré.

Le choix du procédé se base sur des observations locales : abondance ou rareté de pierres de bonne qualité, présence ou absence de massifs forestiers à proximité, etc. Ces divers moyens peuvent être employés, tantôt séparément, tantôt concurremment. Le type initial peut être modifié suivant les circonstances : à la banquette, on assimile la passerelle à neige faite d'une forte perche placée horizontalement, supportant des rondins ou des branches dont l'autre extrémité repose sur le sol (Schneebrücke).

Le rateau est une sorte de passerelle où les rondins placés presque perpendiculairement au sol et assez distants retiennent de grandes quantités de neige.

Des grillages à larges mailles sont aussi de précieux moyens de rétention.

Au simple mur see, on peut substituer de fortes levées de terre, couvertes de gazon, parfois couronnées d'une rangée de pilots, de manière à accroître le relief de l'ouvrage.

Des murs de soutènement établis à l'amont et à l'aval permettent, sans remuer un trop grand cube de terre, d'édifier de véritables remparts.

Il peut arriver que l'avalanche se détache de parties inaccessibles ou d'un cirque trop étendu : dans ce cas, au moyen de véritables digues ou épis, on se borne à en diriger le cours vers un gouffre, un ravin, où elle ne saurait causer de dommages.

Parfois aussi on en barre la route au moyen de muraillements assez puissants pour en arrêter la marche.

Mais, qu'il s'agisse de la correction d'un torrent ou de celle d'une avalanche, il semble logique de proportionner l'effort au résultat à obtenir. Ce n'est pas un des côtés les moins difficiles de la question. Si l'on peut estimer avee suffisamment de précision la valeur des propriétés à garantir, celle des surfaces à remettre ensuite en production, comment évaluer les interruptions de la circulation? 
S'il s'agit de voies ferrées servant au commerce international, l'arrêt du trafic, les détournements des voyageur's et des marchandises peuvent entraîner des pertes énormes.

Il faut aussi envisager l'intérêt général : comment calculer le préjudice causé au pays par la suspension des communications au moment d'ur: conflit? d'une guerre? Dans quelle mesure des laves torrentielles, des avalanches peuvent-elles agir sur le régime des rivières et des fleuves?

Enfin, lorsque la vie humaine est en jeu, et ce cas n'est malheureusement que trop fréquent, ne devra-t-elle donc compter pour rien?

On a vu plus haut la nécessité d'exécuter des travaux de correction. Il n'y a pas plus de raison de les repousser que d'interdire à un malade une opération chirurgicale.

Que de tels ouvrages soient coûteux, nul ne le nie; que des écolis aient été faites, des fautes commises, il n'en pouvait être autrement er un art si récent où tout était à créer et surtout dans les cas où, sous la pression du public, de ses représentants, l'Administration a eu à intervenir sans délai.

Mais dès que l'on a reconnu l'utilité de traiter un torrent, il faut, sans luxe, exécuter tous les travaux indispensables. A ne faire les choses qu'à demi, on risque de tout voir disparaître dans un retour offens if du torrent ou au moins d'être obligé de revenir exécuter des ouvrages complémentaires et de n'avoir en définitive qu'une correction moins homogène et plus dispensieuse que celle qu'il eût fallu prévoir!

Ce que l'on peut demander raisonnablement, c'est que l'on n'entreprenne la correction d'un torrent qu'après une enquête approfondie sur la nécessité de l'opération et une étude complète des moyens à appliquer pour atteindre le but. Il ne manque heureusement pas de torrents où les corrections ont donmé tout ce qu'on en attendait, où devant les résultats acquis, les populations, jadis les adversaires du Service forestier, en sont levenues les plus précieux auxiliaires et où les faits donnent le plus éclatant démenti aux aflimations erronées et au pessimisme tendancieux de ceux qui nient, de parti pris, l'eflicacité et jusqu'à l'utilité même de la consolidation et de la restauration des terrains en montagnes.

En conséquence, les vœux ci-après semblent pouvoir être accueillis par le Congrès forestier international.

A. Le Congrès forestier international. - Considérant que l'œuvre de la restauration des terrains en montagnes a pour but de prévenir les érosions désastreuses et de rendre au sol la cuirasse végétale qui lui est indispensable ;

Considérant qu'on ne saurait obtenir ce résultat sans avoir au préalable empêché l'érosion et l'écroulement des berges ainsi que les glissement du versant ;

Considérant que seuls des ouvrages appropriés, imposés par les circonstances locales (barrages, seuils, dérivations, épis, drainages) peuvent donner aux terrains instables la fixité nécessaire pour permettre à la végétation de s'installer;

Considérant enfin que l'exécution de ces ouvrages entraine toujours des dépenses assez élevées;

EMET LEVEU:

Qu'il n'y a pas lieu de renoncer aux travaux de correction de torrents, 
mais qu'en raison de leur prix élevé. il convient de n'y recourir qu'après une étude sérieuse basée sur des considérations purement techniques et afin d'éviter dans la mesure du possible leur emploi toujours onéreux, qu'il importe de fa'oriser la création et le développement de massifs forestiers dans les bassins de réception dans la limite oì la lutte contre le ruissellement et le décapage des versants le rendront nécessaire.

B. Le Congrès forestier international. - Considérant que les avalanches de neige contituent un danger pour les populations et pour la sécurité des communications en montagne ;

Considérant, d'autre part, que ces phénomènes contribuent à la dégradation des versants en érodant les couloirs, en détruisant les massifs boisés, soit par choc direct, soit par la violence des courants d'air qu'ils provoquent, et qu'ainsi ils contribuent à l'irrégularité du régime des eaux et fournissent aux torrents des matériaux de charriage;

\section{ÉMET LE veU :}

Que les avalunches soient assimilées anx torrents et que leur correction puisse être égulement déclarée d'utilité publique et dans les mêmes formes.

II. L.F Président. - Tous venez ientendre, Messieurs, le remarquable rapport présenté par $\mathbf{~ H . ~ M o u g i n . ~}$

Sos conclusions aboutissent à drux roeux, l'un relat if à la correction des torrents et au pronisement. l'autre à la eorrection des avalanthes. Avant que je motte crs veux aux voix, M. Roth ne pourrait-il nous dire si des travaux de ente nature, des travalux de enrection ont été faits en Intriche.

M. Rotu. - Nous avons déjà pris, en Hongrie. nu certain nombre de dispositions, mais en ce qui concerne les avalanches seulement, car nous 11 avons pas de torrents; aussi 11 avons-nous pas besoin de faire d'autres travaux que cenx qui concernent le reboisement : pour cres reboisements, nous utilisons surtout le Pinns sylvestris et le Pinns austriaca en mème temps que lacacia et le Juniperus virginiu.

11. Ir Presment. - Ciest là une indication utile pour nous, car l'araria a une végétation rapide et vigoureuse.

11. Rotr. - Et il pousse très bien dans les sols légers ot sers.

11. I e Phésunext. - Personue ne drmande plus la parold ?... Je mets aux voix le premier veu que je pelis:

"Qu'il n'y " pas lien de renoncer aux trasun.r de forrection de torrents, mais qu'en raison de leur prix ćles'é. il consient de niy recouri. quaprès une étude sériense basée sur des considirations purement techniques el afin d'éviter dans la mesure du possible leur emploi toujours onércux, qu'il importe de fus'oriser la création ct le désoloppement de massifs forestiers dans les bassins de réception dans la limite 
où la lutte contre le ruissellement et le décapage des versants le rendront nécessaires.

Ce vœu, mis aux roix, est adopté.

M. Le Présinext. -- Je donne lecture du second vou :

"Que les avalanches soient assimilées aux torrents et que leur correction puisse être également déclarée r'utilité publique et dans les mêmes formes."

Ce rou, mis aux voix, est adopté.

M. Mougin. - Je rous demande la permission, Monsieur le président, l'ajouter quelques mots en dehors de la question qui vient d'être traitée.

Messieurs, depuis quelques années, on a pu lire, sous la plune de nombreux forestiers ou de parlementaires, des assertions du genre de celle-ci : Le reboisement, tel qu'il est pratiqué en France, contribue à la dépopulation des Alpes, parce que les surfaces qu’on reboise sont enlevées aux pàturages et privent ainsi les populations de leurs moyens d'existence. Ce sont là de pures affirmations de la part d'orateurs ou d'écrivains et jamais la démonstration du fait qu'ils avançaient n'a été faite ni même tentée par eux.

L'an dernier, par exemple, me trouvant en tournée dans les BasscaAlpes et dans les Hautes-Alpes, voici l'argument que j'entendais développer : Voilà des terrains que l’on a reboisés; ils sont en très bon état; ils auraient pu donner de l'herbe et permettre l'élevage de troupeaux. Renseignements pris près des services locaux, les terrains dont on parlait n étaient pas du tout des terrains rui avaient été expropriés par l'État; ils nappartenaient même pas à des habitants de la localité; leurs propriétaires habitent, qui Lyon, qui Arles. Ils araient loué ces terrains à des particuliers et ceux-ci en avaient tellement abusé et les araient tellement ruinés, que leurs troupeaux ne trouvaient plus rien à manger. Leurs propriétaires, dans ces conditions. ne trouvaient plus à les louer. Ne sachant que faire de terres qui ne rapportaient même pas de quoi payer limpòt, ces propriétaires sétajent adressés à l'Administration et avaient offert leurs terrains pour qu'on les reboisàt.

Il n'y a done pas eu, dans la circonstance, un acte nuisible de la part le l'Arministration; celle-ci n’a pas entravé l’élevage des troupeaux.

(On dit encore que la reeonstitution de périmètres farorise l'émigration.

J'ai été assez heureux pour trourer des documents caractéristiques qui démontreront d'une façon indéniable que l'émigration est hien antrírieure à la constitution des périmètres de reboisement en Francr.

Le département des Hautes- Jpes comptait, en 1906, 118.000 habitants et, en 18́6, 133.000 habitants. en 1866, il n'y en arait déjà plus 
que 122.000 et en 1913, seulement 105.000. L'émigration a donc commencé après 1846 ; or, les premiers périmètres de correction et de restauration ont été créés dans ce département après 1860.

En ce qui concerne les Basses-Alpes, je n’ai pas les chiffres du début du xixe siècle; en 1846, la population était de 156.675 habitants : c'est exactement à la même époque que l'on constate le commencement de l'exode de la population, à telles enseignes qu'en 1852, après le recensement de 1851, le préfet signale au Conseil général que, pour la première fois, on voit le chiffre de la population diminuer.

Voici ce que dit un rapport de préfet, que j’ai entre les mains :

aI] est certain que le sol productif des Alpes diminue chaque jour avee une effroyable rapidité, emporté qu'il est par le flot sans cesse croissant des torrents. Toutes les montagnes sont aujourd'hui dénudées en totalité or en grande partie; lem sol est brìlé par le soleil et piétiné par les moutons qui, ne tronvant plus à la surface l'herbe nécessaire à leur subsistance, grattent la ter'e pour rechercher les racines qui les nourrissent. Ce sol est périodiquement lavé et entraîné par la fonte des neiges et par les orages. Pas de montagne qui ne possède au moins un torrent : chaque jour il s'en forme de nouveaux; la quantité de sol arable diminue tous les jours... J'en trouve la preuve dans la diminution de la population du pays. En 1852, j’ai dû signaler que la population du département des Basses-Älpes avait diminué de 5.000 habitants. Les maires auxquels j'ai demandé la cause de cette diminntion ont été unanimes pour reconnaître qu'elle provenait de l'émigration des familles de cultivateurs qui ne trouvent plus de moyens d'existence là où leurs pères avaient autrefois !'aisance $n$.

Ceci dit pour les parties les plus dégradées des Alpes françaises, passons aux deux départements les mieux conservés, ceux de la Savoie.

On ne saurait pourtant tirer argument des reboisements effectús en Savoie, puisque les premiers périmètres de restauration n'y furent constitués qu'en 1894.

Au début du Premier Empire, l'ensemble des deux départements actuels de Savoie - je les ai groupés parre que les divisions administratives n'étaient pas les mêmes qu'aujourd'hui et que, sous la Restauration, la division des provinces sardes ne concordait pas arec. les arrondissements actuels - avait une population de 426.000 habitants; en 1824, 501.165; en 1848, 564.137; au moment de l'annexion, 537.099 ; en 1907, 515.000; en 1913, 503.000.

Par conséquent, vous pouvez voir d'après ces thiffres, que le phénomène d'exode est général, aussi bien dans les populations qui étaient. alors sardes que dans les pays qui étaient français, et il ne faut pas roir dans le reboisement la cause do l'émigration. C'est tout ce que je voulais signaler (Applaudissements).

11. Pierre Buffacto - Je demande la permission d'appuyer ep qua dit mon excellent collègue Mougin en citant l'exemple du Briançonnais.

Le Briançonnais se compose de deux parties : la haute vallée de la Durance et du Guil. La dépopulation est très considérable dans la vallée du Guil, dans la région du Queyras. Or, avant la loi concernant. 
Jes périmètres de reboisement, il n'y avait aucun reboisement dans lo Quejras et le Briançonnais. Là encore l'observation montre quil n'y a aucune relation entre la décroissance de la population ef lreboisement. En réalité cette dépopulation tient à des eauses générales. morales : e'est la recherche du mieux être, les difficultés de la vie dans les montagnes.

De même, dans les Basses-Pyrénées, la région llOloron, dont je peux parler parce que je la connais; il n'y a pas de périmètres d. reboisement; cependant la dépopulation y sévit d'une façon considérable.

M. Le Présinext. - Je vous remercie, Messieurs. Cet échange dobservations est de nature à nous éclairer; mais il n'entraine pas de roen comme conclusion?

Liordre du jour appelle la discussion du rapport de MM. Bernard et Guinier sur les Petits travalx.

11. le président, obligé rle se retirer, eède la présidence à M. Leddet. vice-président de Section.

M. Le Président. - La parole est à M. Bernard.

11. Bernard. - J'ai songé à demander à mon camarade et ami, M. Cui. nier, de vouloir bien collaborer avec moi, pour montrer qu'il doit : avoir entre reboiseurs et botanistes un lien intime.

Etat actuel de la unestion de la restauration des montagues

Depuis plus de cinquante ans l'œuvre de la restauration des montagnes est entreprise en France. De nombreux forestiers y ont consacré tous leurs efforts. En présence d'un problème nouveau dont la solution avait, été indiquée dans ses grandes lignes par Surrell, ils se sont trouvés aux prises avec de multiples difficultés; ils sont arrivés à les résoudre pour la plupart. Le résultat est acquis : la restauration des montagnes est un art dont les pratiques sont connues, ont été formulées dans des ouvrages ou se transmettent par tradition. Il semble qu'il ne reste guère ds progrès à faire, ni de connaissances nouvelles à aequérir. Il y a pour. tant eneore matière à de nouvelles recherches.

Tout d'abord, il faut remarquer qu'il existe dans la pratique do la restauration une part de tradition. D'une région à l'autre, d'ur service au service voisin, il y a des différences dans les procédés employés. il y a des sortes d'usages locaux, résultats de l'expérience d'un forestier transmise à ses successeurs. Il serait désirable que ces pratiques fussent publiées, de manière à se diffuser, de telle sorte que l'expérienca des uns pût profiter aux autres. On établirait ainsi l'état actuel des méthodes. On peut regretter à ce sujet que les forestiers ne publient pas plus souvent les faits constatés par eux et ne fassent pas connaître les résultats des travaux qu'ils ont exécutés. Cette critique est particu. lièrement applicable à tout ce qui concerne la divulgation des procédé: relatifs aux petits travaux de correction, aux travaux de reboisement et d'enherbement, lesquels sont précisément l'objet de ce rapport.

De plus, notamment en matière de reboisement et d'enherbement. on peut légitimement espérer perfectionner les méthodes déjà utili- 
sées et leur donner une base plus sûre. La restauration des montagnes est intimement liée à des questions dont l'étude ressort des sciences naturelles, géologie, géographie physique, botanique. Les progrès réalisés dans une science ont leur répercussion sur les arts qui en sont l'application. Les sciences naturelles sont en voie de progrès constant: des faits nouveaux sont établis, des notions nouvelles se font jour, des idées directrices s'imposent. L'art de la restauration des montagnes doit bénéficier de ces acquisitions les sciences naturelles. Partant de là. on peut envisager la découverte de méthodes plus sûres et plus générales, l'établissement d'un corps de doctrines reposant sur des bases scientifiques. C'rst dans cette voie qu'il est désirable de voir les reboiseurs s'engager.

Tout " reboiseur " doit avoir constamment présents à l'esprit les rorrection et reprincipes directeurs suivants :

10 Lorsqu'une surface à très forte pente (plus de $100 \%$ pour fixer les idées) gazonnée ou boisée vient à être subitement privée de toute armature végétale, les organismes végétaux ne peuvent, dans les conditions actuelles de la vie dans les régions qui nous intéressent, s'en emparer à brève échéance, par leurs propres moyens. I la dénudation succède une phase d'érosion.

20 Dans la même hypothèse, il n'est pussible aux organismes végétaux de lutter victorieusement contre les forces naturelles de dégradation que lorsque la pente du sol a pris une valeur plus faible que celle qu'plle avait tout d'abord.

$3^{\circ}$ Un sol de constitution physique et de pente données pourra être cnvahi par la végétation sous un climat défini, alors que cet envahissement aurait déjà eu licu ou serait encore impossible dans d'autres conditions de climat.

$4^{\circ} \mathrm{A}$ toute combinaison donnée de nature physique du sol et de climat correspond une pente superficielle au delà de laquelle toute restauration naturelle du sol est impossible. Cette sorte de pente limite peut être désignée sous le nom de pente de restanration.

Surrell attribuant, à juste titre, aux végétaux ligneux la prépondérance dans le rôle de l'armature végétale, a formulé avee netteté le premier de ces principes en disant que "la destruction d'une forêt livre le sol en proie aux torrents".

Le deuxième principe n'a pas été exprimé sous la forme ci-dessus. Cependant il est contenu implicitement dans tous les travaux publiés sur la restauration des montagnes. Les forestiers l'expriment généralement en affirmant qu'un sol dénudé et dont la pente dépasse une certaine valeur ne peut être reboisé ou gazonné qu'après l'exécution de certains travaux ayant pour but de donner au sol la stabilité qui luj fait défaut. C'est de ce principe qu'ils ont déduit la nécessité d'effectuer la plupart des travaux dits de correction (barrages, clayonnages, fascinages, garnissages, drainages) avant d'entreprendre les travaux dits forestiers (enherbement, reboisement par semis et plantation).

I es deux autres principes paraissent résulter de l'observation des faits. Mais leur exactitude peut être contestée. C'est pour cela qu'íl peut être utile d'appeler l'attention du Congrès sur cette manière d'envisager les liens qui unissent la correction à la réinstallation de la végétation. On est ainsi amené à examiner séparément les petits travaux 
de correction d'une part et les travaux de reboisement et d'enherbement d'autre part.

Petits traraux de correction.
Les petits travaux de correction dont il s'agit ici se répartissent en deux groupes: d'abord les petits travaux de correction proprement dits (façonnage de lit, enrochements, drainages), ensuite les travaux mixtes, c'est à dire ceux qui participent en même temps de la correction et du reboisement (clayonnages, fascinages, garnissages).

Façonnage de lit. Enrochements. - Les matériaux qui, lors des fortes crues avec ou sans lave, s'arrêtent sur les atterrissements des ouvrages construits en travers du lit (grands barrages, barrages rustiques, clayonnages), forment des dépôts convexes vers le ciel, sortes de petits cônes de déjection qui presque toujours détournent les eaux moyennes et les basses eaux et les rejettent contre les berges. Par suite des variations de la force d'entraînement des eaux au cours d'une même crue, ces matériaux sont de dimensions variables. Les plus petits, repris par les eaux moyennes, sont souvent entraînés, mais presque toujours les plus gros demeurent. Certains de ces gros blocs finissent par s'enfoncer dans le lit et par former une sorte de pavage, les autres en saillie peuvent détourner les eaux de l'axe du lit lors des crues ultérieures. Il convient donc de les enlever et de les placer contre les berges. Telle est l'opération du façonnage de lit. Dans cette opération, il faut donc se borner à enlever les gros matériaux, au fur et à mesure qu'ils sont dégagés par l'affouillement provoqué par les eaux claires qui succédent aux eaux des crues.

Le meilleur emploi que l'on puisse faire de ces gros blocs est de les utiliser à la construction de sortes d'enrochements longitudinaux établis à une certaine distance des berges, de chaque côté du lit, dans l'alignement des bords extérieurs des curettes des ouvrages successifs. Ces enrochements longitudinaux en arrière desquels la pente de restanration pourra plus facilement s'établir grâce à l'accunulation des matériaux provenant du déeapage ou de l'érosion des berges, doivent avoir des fondations suffisamment profondes pour qu'en aucun cas ils ne puissent être affouillés et détruits.

Les enrochements et les blocages à établir au pied des barrages pour les protéger contre tout danger d'affouillement ne paraissent pas devoir rentrer dans le cadre de ce rapport.

Irainages. - Nettant à part les grands travaux de consolidation par exhaussement du lit et par dérivation, la stabilisation des glissements a presque toujours été obtenue uniquennent à l'aide de fossés d'assainissement plus ou moins profonds et étroits, à fond pavé, remplis de pierres dont certaines, celles du bas, sont disposées de manière c̀ formel un canal à section triangulaire, rectangulaire ou demi-circulaire. A ces fossés on donne généralement le nom de drains.

Les drains ont le plus souvent donné des résultats excellents, mais ils présentent néanmoins certains inconvénients :

10 D’ordinaire les terrains drainés ne sont pas stabilisés instantanément. Ils continuent à se mouroir, arec une vitesse ralentie, pendant de nombreuses années. Il en résulte que les drains se rompent et cessent de fonctionner normalement. Rien ne décèle l'existence d'une avarie au moment où elle se produit: on ne peut donc la réparer immédiatement. 
20 Lorsque les drains captent des eaux très calcaires, des concrétions peuvent se former qui les obstruent.

30 Les drains nécessitent de grandes quantités de pierres. Ils sont coúteux à établir et à entretenir.

Aussi pourra-t-il être avantageux, dans certains cas, de donner la préférence à l'assainissement par rigoles superficielles.

Ces rigoles ne peuvent, en raison de leur peu de profondeur, exercer une action appréciable d'assèchement direct du sol par drainage latéral des eaux d'infiltration. Nais elles permettent de capter avant leur infiltration une grande partie des eaux de pluie et surtout de fonte des neiges, ces dernières étant de beaucoup les plus dangereuses.

Les rigoles superficielles sont d'une surveillance facile; elles ne peurent être obstruées par les eaux formant des dépôts tuffeux, enfin elles sont d'un établissement peu coûteux.

A dépense égale, le système des rigoles superficielles donnera en général de meilleurs résultats que le système des fossés de drainage.

Il ne paraît pas nécessaire d'appeler d'une manière particulière l'attention du Congrès sur les travaux d'assainissement profond. Ces traraux sont très coûteux et ne peuvent s'appliquer judicieusement qu'à la stabilisation de terrain en mouvement sur un plan de glissement, cas tout à fait exceptionnel.

Clayonnages. Fascinages. - L'expérience semble avoir démontré que la construction de clayonnages et de fascinages transversaux (barrages vivants) sur les atterrissements des grands barrages, dans le but de compléter la correction, au fur et à mesure de la diminution des apports et par suite de l'adoucissement de la pente du lit, ne peut donner que de médiocres résultats. Ces travaux souffrent beaucoup au moment des crues et deviennent difficilement de bons foyers de reboisement. Les elayonnages et fascinages transversaux doivent être réservés pour la correction des petits ravins. Il est prudent toutefois, même dans ce cas, de ne pas leur donner plus de 0 m 60 à 1 mètre de hauteur. Les clayonnages et fascinages trop élevés au-dessus du niveau du lit sont facilement détériorés par la poussée des terres qu'ils retiennent, car les matériaux qui entrent dans leur constitution ne réussissent pas tous, malheureusement, à s'enraciner. Beaucoup de branches entrelacées ou disposées en fascines pourrissent et, par suite, perdent leur résistance au bout de peu de temps.

Les clayonnages et fascinages donnent d'excellents résultats dans la consolidation superficielle des berges nues. Ils sont alors disposés longitudinalement et étagés de manière à constituer dans leur ensemble une série d'escaliers dont les marches prennent facilement la pente de restauration. L'ouvrage de base doit être disposé de manière à être soustrait à tout affouillement latéral. On parviendra à ce résultat en les protégeant à l'aide d'enrochements longitudinaux obtenus en employant les matériaux provenant, comme il a été dit ci-dessus, du façonnage du lit.

La hauteur visible de ces ouvrages ne doit pas, autant que possible, dépasser $0 \mathrm{~m} .40$ ou $0 \mathrm{~m} .60$.

Qu'il s'agisse de clayonnages ou fascinages longitudinaux ou transversaux, on devra choisir avec soin les matériaux à employer à leur construction. Les saules devront appartenir aux espèces à croissance rapide et 
se bouturant facilement (voir ci-après V1). Ils ne devront être mis en œuvre qu'à l'état de branches ou de boutures âgées de 3 ou 4 ans au plus et coupées 'au fur et à mesure des besoins ( 2 à 5 jours au maximum suivant les circonstances atmosphériques du moment).

Garnissages. - On distingue ordinairement les garnissages de lit et les garnissages de berges.

Les premiers sont employés pour obtenir l'élargissement de la section des petits ravins à profils en travers étroits et profonds. Leur base doit être appuyée contre un obstacle solide (seuil ou clayonnage transversal), et les matériaux qui les constituent (branchages de toutes natures) doivent être enchevêtrés les uns dans les autres. Les garnissages mal construits peuvent être entraînés par les crues; celles-ci deviennent alors souvent désastreuses à cause des embâcles qui peuvent se former dans les gorges sinueuses et très étroites. Ne devront d'ailleurs être traités par cette méthode que les petits ravins dont on pourra espérer garnir complètement le lit, de la base au sommet, dans un très court espace de temps. Les garnissages de lit ne doivent d'ailleurs jamais masquer complètement les berges dénudées. Il faut que celles-ei puissent encore fournir des matériaux en quantité suffisante pour combler les vides existants entre les branchages et constituer avec eux un milieu favorable à l'installation naturelle ou artificielle de la végétation. On emploie avec succès dans certaines régions des Basses-Alpes des garnissages tressés qui sont très solides. Il y aurait intérêt à généraliser l'application de ce procédé.

Les berges formées par des dépôts meubles (boues glaciaires, éboulis) sont souvent composées au point de vue topographique par une série de petits bassins fort peu creusés, sortes de petites combes juxtaposées, séparées par des erêtes à peine apparentes. On arrive facilement à fixer le sol en le revêtant de branches de saules enfouies dans le terrain à 15 ou 20 centimètres de profondeur et dont les extrémités seules émergent à la surface, donnant ainsi naissance à une série de boutures solidaires les unes des autres. La partie superficielle du sol nu est ainsi munie d'une armature rigide non apparente et inerte, mais qui se transforme rapidement en une cuirasse vivante et solide. Lorsque l'érosion a donné au relief des formes plus accusées, on peut traiter chaque petite combe comme on le ferait pour un ravin étroit. Les garnissages formés de branchages quelconques, pouvant provenir en particulier d'éclaircies effectuées dans les peuplements créés au roisinage, ne doivent jamais courrir entièrement le sol. Les régions supérieures des flanes des petits bassins doivent être laissées nues : l'érosion s'exerçant sur ces surfaces fournira les matériaux qui combleront les vides du garnissage. Celui-ei pourra ensuite être consolidé faeilement à l'aide de boutures et de plants. Les garnissages de berges comme les garnissages de lits doivent aroir une base solide et, par conséquent, soustraite à l'affouillement par les eaux courantes. On les appuiera donc contre des barrages rustiques, des clayonnages longitudinaux ou des clayonnages transversaux. Les clayonnages pourront être remplacés par des fascinages.

Principes de is réiostallation de la reuetation.
Reboisement el regazonnement. - Restaurer la montagne, c'est rétablir l'état primitif troublé par des actions extérieures et surtout par celle de l'homme. Cela exige nécessairement la connaissance préalable de cet état primitif et le choix des moyens les plus efficaces pour le ramener. 
Si nous laissons de còté les modifications d'ordre topographique el la lutte contre les phénomènes géologiques qui les déterminent, la parti: essentielle du problème consiste à déterminer l'état antérieur de la végétation et la marche à suivre pour revenir à cet état. C'est cette seconde partie de la question qui, pratiquement, a été seule résolue, le plus souvent par tâtonnements; on a installé des végétaux, arbres ou plantes herbacées, qui, d'après ce que l'on pouvait savoir de leurs exigences, paraissaient susceptibles de se développer d'une manière satisfaisante et de couvrir le sol, de constituer une forêt. Bien des essais ont été faits; progressivement on a renoncé à certaines pratiques, les procédés ont gagné en sûreté, mais bien des insuccès ont été enregistrés et, dans des cas difficiles, on se trouve encore pris au dépourvu. La pratique, si précieuse soit-elle, ne suffit, en cette matière, pas plus qu'ailleurs.

Le problème du reboisement et du regazonnement des montagnes, tel que nous l'avons défini, est un problème de botanique appliquée. Les botanistes qui pendant longtemps se sont bornés à étudier les caractères des plantes, à les cataloguer, à noter leur présence dans une localité ont modifié depuis un certain temps leur manière de faire. lls étudient les végétaux, non plus en eux-mêmes, mais clans leurs relations avec le milieu qui les entoure: ils cherchent à se rendre compte des raisons de leur existence dans un endroit donné, ils cherchent à comprendre pourquoi ils se groupent en associations, pourquoi ces associations diffèrent d'une région à l'autre, comment elles se transforment, évoluent. Une section nouvelle de la botanique, la géographie botanique ou phytogéographie est née, qui s'occupe de la répartition des végétaux sur le globe; une branche de cette science, l'écologie, a spécialement pour objet les relations des plantes avec le milieu extérieur. La géographie botanique a pris un rapide essor et elle est maintenant en état de fournir une base solide pour établir définitivement l'art du reboisement.

Le mérite d'avoir montré aux forestiers le parti qu'ils peuvent tirer des données acquises par les botanistes, le mérite de leur avoir ouvert une voie nouvelle revient à II. Flahault. Phytogéographe de haute compétence, il s'est initié à toutes les difficultés du problème du reboisement; il a été le trait d'union entre le monde botanique et le monde forestier qui s'ignoraient, entre la science et l'art qui doit en être l'application. Dans diverses publications, il a exposé les principes directeurs qui doivent guider le reboiseur dans son travail,il a montré comment on peut arriver à résoudre logiquement et súrement le problème posé.

La détermination de l'état primitif d'une région et des méthodes à employer pour le ramener, repose sur une étude botanique, ou plutôt phytogéographique. Dans une région, les plantes qui constituent la population végétale se répartissent le terrain et se groupent en associations suivant leurs exigences. Ces associations qui caractérisent ainsi les diverses stations définies par des conditions de sol, de climat, sont furmées d'un nombre plus ou moins grand d'espèces, parmi lesquelles il en est une ou deux qui sont dominantes, qui impriment à l'association sa physionomie, qui la caractérisent et servent à la dénommer. Le plus souvent. en montagne, ce sont des espèces ligneuses et les associations que l'on rencontre sont essentiellement des forêts caractérisées par une ou deux essences dominantes. On peut arriver par une étude sur le terrain à délimiter ces associations, à faire la description botanique de la région. 
à en dresser la carte botanique marquant les emplacements des diverses associations. Dans une région montagneuse, par exemple, on séparera ainsi et on indiquera sur la carte les limites des associations du pin sylvestre, du chêne rouvre, de l'épicéa. Dès lors si, en un point, l'association s'est trouvée détruite, on pourra sans hésiter savoir quelles sont les essences qui ont le maximum de chances de succès et qui pourront reconstituer l'association. Une pareille étude sera une base solide pour le travail de restauration et il est désirable de voir cette étude précéder tout travail de cette nature : pour chaque périmètre de reboisement devrait exister une carte botanique comme il existe un plan topographique. Un vœu dans ce sens a, du reste, été formulé par la section de sylviculture du Congrès international d'Agriculture de 1903.

Mais cette étude botanique aboutissant à la détermination des associations de végétaux ligneux, des forêts qui occupent ou doivent occuper le sol n'est facile qu'à la condition que l'état primitif ait été peu modifié, qu'il n'existe que des lacunes peu importantes dues à l'établissement de cultures ou de pâturages par exemple; on pourra facilement alors raisonner par analogie et conclure qu'à égalité de conditions la même association doit se développer. La difficulté commence quand les modifications sont plus profondes et que toute trace de la végétation primitive a presque disparu; il existe des ver'sants, des vallées entières, dans lesquelles les forêts ont disparu et ont fait place à des broussailles ou à des pâtu* rages, où rien ne rappelle en apparence l'aspect primitif de la végétation. C'est là le cas pratiquement intéressant; c'est là que le forestier se trouve embarrassé pour le choix des essences et qu'il a le plus besoin d'un guide. La reconstitution de l'état primitif de la végétation est, même alors, possible par une observation de plus en plus minutieuse, et une méthode rigoureuse. M. Flahault en a donné un bel exemple de la plus grande importance pratique en montrant comment on peut tracer dans un pays dénudé la limite primitive des forêts et établir par conséquent jusqu'à quelle hauteur le boisement est possible.

Le rétablissement de la végétation primitiven'est pas toujours possible directement et immédiatement. L'association disparaissant, les conditions de milieu se modifient, le sol s'appauvrit en humus, se dessèche, se ravine, le climat local change. En plantant directement l'essence qui constituait la forêt en ce point et qui doit la rétablir, on s'exposerait à des insuccès puisque l'essence ne trouverait plus le milieu qui lui convient. Par une étude botanique soigneuse, on pourra établir le cycle évolutif des associations, déterminer par quelle marche la station modifiée reprend progressivement sa végétation en même temps que les conditions y changent. On pourra alors choisir parmi les espèces qui s'installent successivement celles à introduire de manière à hâter le plus possible l'évolution naturelle. C'est une méthode depuis longtemps connue des forestiers qui emploient couramment les essences transitoires. La question peut être généralisée et les méthodes à suivre en chaque cas peuvent gagner en sûreté.

Le rétablissement de la végétation primitive doit toujours être considéré comme le moyen le plus sûr, donnant le maximum de chances de réussite. Mais on ne doit pas oublicr que l'établissement des associations végétales n'est pas seulement la conséquence des conditions de milieu. Pour qu'une espèce puisse s'installer dans une station, il ne suffit pas que ses exigences y soient satisfaites; il faut aussi qu'elle ait pu y par- 
venir. Les végétaux ont leurs migrations régies par des circonstances d'ordre topographique et par les variations de climat au cours des périodes géologiques antérieures. C'est la cause des différences existant entre la flore de deux vallées voisines, de deux régions analogues comme sol et climat. Une espèce introduite dans une région où elle n'est pas spontanée peut y trouver des conditions favorables, s'y développer vigoureusement. Cette considération permet d'étendre le cercle des végétaux parmi lesquels le reboiseur fera son choix : il pourra, après une étude comparative soigneuse des conditions de milieu, faire appel à des végétaux de régions voisines. L'emploi et la réussite du cèdre dans les montagnes méditerranéennes, du pin larieio d'Autriche dans la région montagneuse ealcaire, de l'épicéa dans les Pyrénées, sont des exemples probants à cet égard; il y a lieu d'étendre la méthode anx arbustes et aux plantes employés pour le gazonnement. Toutefois le succès ne pourra être proclamé définitif qu'après un laps de temps assez grand : il suffit d'une année exceptionnelle pour faire disparaître une essence non spontanée et rétablir l'ordre naturel que l'on essaie de modifier.

Il y a un point sur lequel l'attention des reboiseurs n'a pas encore été attirée et dont l'importance a été récemment mise en lumière : c'est la question de l'origine des graines à employer. On considère volontiers qu'une espèce botanique est homogène, que tous les individus qui la composent sont identiques comme caractères et exigences, et l'on sème des graines de pin sylvestre, d'épicéa, etc., sans se préoccuper de la localité où ces graines ont été réeoltées. Depuis quelques années des recherches faites, surtout en Autriche, en Suisse, en Allemagne et qui sont la suite d'expériences bien plus anciennes, dues à L. de Vilmorin, ont montré qu'il existe pour une même essence des races plus ou moins différentes par les caractères extéricurs, mais différant aussi par des propriétés physiologiques et manifestant des exigences diverses vis-à-vis des conditions de milieu. La question préoccupe actuellement les sylviculteur's qui cherchent à créer des massifs productifs; elle est d'une grande importance pour les reboiseurs dont le but est, avant tout, de constituer des peuplements solides, composés d'arbres aussi bien adaptés que possible au milieu. Il ne suffit pas de choisir judicieusement une essence, il faut choisir une race déterminée, et la recherche de la race qui convient le mieux est un problème nouveau.

En s'aidant des recherches faites et en s'inspirant des principes qui doivent guider le reboiseur, on peut dire que, d'une façon générale, re sont les races de la région, vivant dans les mêmes conditions de sol, d'altitude, ou les races de régions analogues qui donneront les meilleur's résultats. On évitera ainsi des insuccès. On a établi que l'épicéa présente des races adaptées à des altitudes différentes; bien souvent on a vu des plantations d'épicéa en haute montagne dévastées par la neige, parce que les plants mis en terre provenaient de graines récoltées en basse montagne, avaient une croissance rapide, mais manquaient de résistance. M. Fabre a signalé le mauvais état de reboisements faits dans les Cévennes en sol siliceux, à l'aide de plants de pin sylvestre issus de graines récoltées dans les Causses, en sol calcaire sec. M. d'Alverny a fait ressortir la faute commise en introduisant dans le Massif central le pin sylvestre d'Haguenau, au milieu de peuplements de pin sylvestre d'Auvergne, 
qui se montre supérieur à ce dernier. On a commis des erreurs dommageables en confondant sous le même nom de pin de montagne des formes aussi différentes que le pin à crochets des Pyrénées et des Alpes et le pin rampant des Alpes centrales, et en semant, au milieu de massifs naturels de pins à crochets, des graines de provenance autrichienne qui ont donné des arbres branchus et couchés sur le sol. Actuellement, on achète dans le commerce des graines de provenance quelconque; l'Administration même fait récolter des graines et les distribue au hasard de l'abondance des récoltes, sans tenir compte du lieu de production et du lieu d'emploi. Il importe de renoncer à ces usages; il faut en tout cas connaître l'origine des graines employées et si on veut être sûr du succès, les semer dans des stations où les conditions se rapprochent de celles de la station des arbres semenciers.

Végétanx à utiliser pour l'enherbement $e$ l'embronssail lement.
La réinstallation directe de la végétation forestière dans une station n'étant pas toujour's possible, directement, il faut avoir recours d'abord à des végétaux qui occupent le sol et modifient par leur présence les conditions jusqu'à ce que la forêt puisse se reconstituer. De plus il y a des stations particulièrement intéressantes pour le reboiseur, telles que les éboulis, les terrains en glissement, les atterrissements des torrents, dans lesquels la végétation forestière ne pourra le plus souvent jamais s'installer. C'est aussi le cas de toutes les surfaces situées audessus d'une certaine altitude et comprises dans l'étage alpin, défini par l'absence primitive de toute végétation forestière. Pour garnir le sol, il faut alors avoir recours à des plantes spécialement adaptées. De là le rôle important des végétaux herbacés et des arbrisseaux et la nécessité de travaux d'enherbement et d'embroussaillement.

Jusqu'à présent on s'est borné à utiliser pour l'enherbement un nombre assez restreint d'espèces et l'emploi en est souvent très local. Bien souvent, pour plus de facilités, on emploie des espèces fourragères du commerce : on sème du sainfoin, des graminées fourragères (fenasse). Les résultats sont souvent médiocres ; ces espèces se développent mal et dépérissent rapidement. L'usage des espèces arbustives est aussi trop restreint et demande à être étendu.

C'est encore par l'étude soigneusement faite de la végétation naturelle que l'on arrivera à trouver quelles sont les espèces à utiliser. Dans chaque région, suivant l'altitude et le sol, il existe des plantes qui peuvent rendre des services : chacune d'elles a son mode de vie spécial qu'il faut étudier, afin de la placer exactement dans les conditions qu'elle demande et de mettre à profit ses aptitudes. Les unes occupent les sols dénudés et mobiles, berges en glissements, éboulis, graviers récemment apportés ; ce sont des colonisatrices de places vides qui, grâce à leur enracinement puissant, à leurs tiges souterraines abondamment ramifiées, peuvent sancrer solidement dans ces terrains mouvants, y forment des touffes ou des buissons qui vont en s'étalant et garnissent progressivement le sol. Tels sont l'Argousier (Hippophaæ rhamnoüdes L.), la Corroyère (Coriaria myrtifolia L.) parmi les arbrisseaux; la Bauche (Lasiagrostis Calamagrostis Lk), parmi les graminées. D'autres ne peuvent s'installer que sur un sol plus stable, déjà garni de quelques végétaux; ils relaient en quelque sorte les premiers et caractérisent un nouveau stade de la végétation, tels sont divers arbrisseaux : É pine vinette(Berberis rulgaris L.), Aubépine (Crataegus Monogyna Jacq.), le Bromus erectus 
parmi les graminées, le Dompte-venin (Vincetoxicum officinale L.). Ces végétaux recherchent tous des stations assez ensoleillées et chaudes. Dans les stations plus fraîehes, sur des versants exposés au nord, à de plus fortes altitudes, les éboulis peuvent être garnis de Rumex scutatus L., plus haut d'Avena versicolor Vill. Une catégorie particulièrement intéressante est constituée par ces plantes qui peuvent se développer dans les marnes noires, de propriétés physiques et chimiques si spéciales et dont le gazonnement importe tant pour la restauration de vallées entières : on peut citer la Bugrane (Ononis fruticosa L., le Laserpitium gallicum Scop., etc.

Mais pour que ces espèces que l'on observera aiusi puissent être utilisées pratiquement, il est essentiel que leur propagation soit facile, soit par plants, soit par graines. L'étude de la plante sur place donnera des indications et des essais permettront de conclire. Pour beaucoup de ces espèces qui sont drageonnantes, on aura recours à la plantation d'éclats (Argousier, Corroyère, Bauche). Pour d'autres, il faudra recourir au semis et il sera alors commode d'établir des sortes de pépinières où on pourra récolter facilenent une quantité de graines.

Enfin il y a lieu de remarquer qu'on peut utiliser certaines des espèces d'enherbement et d'embroussaillement, en dehors des vallées où elles sont loealisées pour des raisons autres que les circonstances de milieu. Cette remarque s'applique notamment à la Corroyère et à la Bugrane dont les aires sont restreintes et l'emploi jusqu'à présent localisé.

Parmi les espèces arbustives auxiliaires du reboisement qu'il y a lieu d'étudier davantage, il faut signaler spécialement les Saules. Grâce à leur propriété de croître dans les sols frais et de se multiplier parboutures, on utilise avec succès et avantage les saules pour garnir les fonds de ravins, les atterrissements ; on les utilise beaucoup pour la confection des clayonnages. Trop souvent on a tendance à les utiliser sans discernement en plantant pêle-mêle les diverses espèces que l'on trouve aux environs, sur les délaissés des rivières ou les cônes de déjection, par exemple. Or, les saules ont, suivant les espèces, des exigences différentes et des particularités dans le mode de vie dont il faut tenir compte. Certaines espèces, comme le Saule daphné (Salix daphnoïdes Vill.) supportent des altitudes élevées ; d'autres ne peuvent croitre que dans des régions plus basses, tel le Saule drapé ( $S$. incana Schr.); il en est qui s'enracinent facilement, d'autres reprennent mal de bouture (Saule marsault, Saule à grandes feuilles) ; les uns dounent des rejets vigoureux d'assez fort diamètre, le's autres, comme le Saule pourpre (S. purpurea L.), sont moins avantageux à employer à cause de leurs pousses grêles et de faible longueur. Il est désirable que les divers sanles soient étudiés comparativement et que l'on précise les conditions d'emploi de chaque espèce.

La question de l'origine des graines a été traitée plus haut, mais il est pépinières. un certain nombre d'autres points sur lesquels il parait nécessaire d'appeler l'attention du Congrès :

$1^{\circ}$ Faut-il donner la préférence aux pépinières centrales ou aux pépinières volantes?

$2^{\circ}$ Dans quelle mesure peut-on substituer les engrais chimiques aux engrais naturels?

$3^{\circ}$ Quels sont les meilleurs procédés à employer pour réussir les senis 
de certaines espèces de reboisement ou d'embroussaillement : pin cembro, aune blanc, sorbier des oiseleurs, hippophaæ, aune vert, etc?

$4^{\circ}$ Comment préserver certaines graines dont la germination est lente, comme celle du pin cembro, contre les attaques des oiseaux et des rongeurs?

$5^{\circ}$ Faut-il repiquer les plants?

Semis directs et plantations.

Les questions sur lesquelles l'attention des congressistes mériterait d'être appelée peuvent être groupées comme suit :

$1^{0}$ Essences pouvant être installées par semis direct.

20 Essences devant être installées de préférence par voie de plantation.

$3^{\circ}$ Saisons à choisir pour l'exécution des semis et des plantations.

$4^{\circ}$ Différentes méthodes applicables aux semis directs et aux plantations.

$5^{\circ}$ Dans quelle mesure peut-on favoriser l'essor des jeunes sujets par l'emploi des engrais chimiques.

60 Soins à donner aux jeunes plants. Espacement initial. Eclaircies. Nettoiements.

$7^{\circ}$ Etablissement de tranchées garde-feu, etc.

\section{Le Congrès émet le veu :}

Que les forestiers reboiseurs soient encouragés à faire connaître les moyens pratiques qui leur ont le mieux réussi dans l'exécution des divers travaux de correction et de réinstallation de la végétation.

Que l'attention des reboiseurs soit attirée sur la nécessité d'étudier la végétation naturelle des bassins à reboiser et des régions attenantes, et sur l'intérêt qu'il y aurait à dresser une curle botanique pour servir de base aux travalux de reboisement entrepris.

Que l'on tienne compte des résultats acquis dans la question de l'origine des graines, en semant en tous cas des graines d'origine connue et choisies logiquement.

Que l'on étudie d'une façon rationnelle les végétaux herbacés et les arbrisseanx utilisables pour l'enherbement et l'embroussaillement, et que par des essais on détermine les conditions de leur emploi et de leur multiplication.

Qu'une étude analogue soï faite pour les diverses espèces de saules utilisés pour les travaux de garnissage et de clayonnage.

Permettez-moi, Messieur's, d'ajouter quelques mots :

On ne saurait douter qu'à l'époque où l'homme viut prendre possession des différentes vallées des Alpes, un certain ordre régnait dans la nature.

Sans doute cet ordre, cette harmonie n’étaient pas la manifestation d'un équilibre atteint définitivement, car il 1 `y a pas à proprement parler dans la nature d'équilibre définitif, mais bien plutôt, si nous nous en rapportons à ce que nous pouvons observer aujourdhui, le résultat d'une lutte incessante, dont les phases so sont succédé dans un ordre déterminé, entre divers facteurs antagonistes obéissant d̀ des lois générales et immuables.

Ces facteur' antagonistes sont : 
D'une part, les agents de la géodynamique exterue, dont l'action a son origine à la fois dans l'énergie solaire et dans la gravité, et qui travaillent les uns à la désagrégation de l'écorce terrestre en éléments plus ou moins volumineux, les autres au transport de ces éléments. Par le jeu combiné de ces divers agents, les particules solides du globe se rapprochent d'une situation d'équilibre stable, en mème temps que la surface terrestre tend à acquérir mue forme qui la protège mieux contre toute action ultérieure.

D'autre part, l'armature végétale qui maintient la partie superficielle du sol en l'enserrant dans le réseau de ses organes souterrains, s'oppose ainsi au transport des éléments qui la constituent; en ontre, grâce aux organes aériens, elle protège cette partie superficielle du sol contre l'action des agents atmosphériques.

En réalité, les organismes végétaux contribuent dans une certaine. mesure, nous l'avons vu, et les forestiers le savent, à l'altération et à la désagrégation des roches. Mais si l'on considère que cette action est combinée avec la propriété que les végétaux ont de laisser d̀ la surface ou dans les profondeurs du sol, au moment de la mort de leurs organes aériens ou souterrains, les matières nutritives puisées dans ce sol ou dans l'atmosphère, on constate qu'en somme l'action des organismes végétaux a pour effet de faciliter leur développement immédiat ou de favoriser par la suite l'installation de ceux qui sont appelés à leur succéder dans les phases surcessives de l'évolution du tapis végétal. En sorte que tout se passe comme si les organismes végétaux altéraient, désagrégeaient, et mème décomposaient le sol pour mieux le retenir.

L'étude des phénomènes dont la surface du globe est actuellement le théàtre nous permet de connaitre vers quel but final tendent ces facteurs antagonistes. C'est la substitution au relief primitif d'une pénéplaine, surface telle que toutes les lignes de plus grande pente sont des courbes analogues aux profils d'équilibre des cours d'eau.

Lévolution du relief dans le sens que nous venons d'indiquer est un phénomène de longue haleine. Si les agents de la dynamique interne ne venaient plus jamais modifier les positions relatives des divers éléments de la croúte terrestre, on pourrait presque esquisser à grands traits les caractères essentiels de la pénéplaine qui, dans cette hypothèse, se substituerait peu à peu aux formes actuelles de nos Alpes, bien que cepentlant le soulèvement de celles-ci soit relativement récent et que, toutes choses égales d'ailleurs, le travail de l'érosion y soit encore pen avancé.

Mais si l'on ne peut indiquer l'état géographique final vers lequel tend le relief actuel, on peut affirmer, en tout cas, qu'il est loin d'être définitif et que son évolution serait beaucoup plus rapide si toute végétation en était absente. Cellr-ci exerce un rôle retardateur très puissant, que personne ne méconnait aujourd'hui, et sur lequel est basée l'œurre que l'on a entreprise an faveur de la restauration des montagnes.

Pour le moment, bornons-nous à constater que si l'ordre de choses 
actuel est encore harmonique, comme n’étant pas le résultat du pur hasart, puisqu'il est. ju le répète, le produit du combat des facteurs antagonistes, obéissant tous à des lois définies et immuables, il n’en est pas moins incompatible avec le développement ascensionnel. cest-à-dire dans la voie du progrès tel que nous le concerons, de la civilisation actuelle.

Commint se rétablit aujourdhui l’équilibre détruit?

Dans les régions que l'homme et son industrie ont dù abandonner totalement, rest-à-dire en quelque sorte partout oir se trouvent de grandes surfaces completement lépourrues d'armature régétale, on ansiste à l'évolution rapide des formes du sol rers un terme bien différent de l'état qui existait au moment des son entrée en scéne.

I ref égard, le fait le plus saillant pent-être est le suivant, que looservation la plus superficielle met quotidiennement en évidence lans les pays de montagne en particulier. Si l'on vient à détruire te tapis rigetal existant sur un sol stabto dont la pentedepasse une certaine valeur (au-dessus de 100 pour 100 pour fixer les idlées), on remarque que l'armature végétale protectrice du sol ne se rétablit jamais immétiatement dans l'itat où elle existait auparavant, état qui est encore celui des terrains environnants. Et rependant ces terrains produisent d'innombrables germes qui se développeraient à còté sils y trouvaient des conditions farrorables.

Lis agents dr la dysamilur exteme s'arharnent sur ce sol non abrité rt tendent à lui donner une pente générale inférieure à celle Iu il avait tout d'abord. Ce n'est que lorsine cette pente a prin une valeur voisine de $100 \%$, plus fréquemment inférieure à ce chiffre, que l'on voit les organismes régétaux rhercher à prendre possession du donaine modifié quant à la pente.

Il me semble nécessaire de donner iri quelques indications plus précises sur cette notion de la pente de restumration que j’ai essayé d'introduire dans le rapport.

l'our simplifier notrexamen. smpposons tout d'abord que nous coyions transportés dans une région où les eaux courantes - je dis lus raux courantes - n'interviennent pas comme agents du modelé. Lis matériaux constituant l'écorce terrestre, soumis aux agents de la dynamique exterm", se désagrègent en donnant naissance à des cléments de grosseur variable qui saceumulent directement sur plaee si le relief est peu accentué, ou qui, daus le cas contraire, roulent ou glissent sous l'influence de la pesanteur, à une erertaine distaner du point où ils ont été mis en liberté.

Cette force de propulsion combinée aree les frottements auxquels leur contact rlonne lieu intervient seule dans leur classement méthodique. Dès lors, sont constituées des nappes d'éboulis dont la stabilité est immédiatement définitive et dont la pente superficielle ne dépend plus, en quelque sorte, que de la grosseur des éléments qui les composent. C'est ainsi, par axemple, que les chosen se passent daus lex régions désertiques. 
Les choses se passent tout différemment dans les régions vù les condensations atmosphériques sont assez abondantes pour donnur naissance au ruissellement superficiel et pour permettre à l'action des eaux comrantes — je répète courantes - d'entrer en jeu.

Évidemment, cest encore la pesanteur qui, s'exerçant sur les biéments de tout volume provenant de la désagrégation des roches, provoquera leur collertion en nappes d'éboulis à matériaux grossièrement triés. Nais l'équilibre superficiel de ces nappes se modifiera à la première pluie un peu abondante et tendra à s'établir de telle sorte qu'en chaque point, la résistance du sol soit égale à la puissance d'érosion des paux qui passent par le point comsidéré. Ver's le sommet de la nappe des eaux, n'ayant pas lo temps di se concentrer ou n'ayant formé que de très petits filets liquirles. J'équilibre s'établira sous une pente forte. Vers le bas au contraire, la concentration des eaux aura engenelé de véritables torrents et l'équilibre ne pourra plus s'itablir que sous un pente relativement faible.

Partout, dans les montagnes française's et dans celles des autres pays, on constate que les éboulis de formation récente sont profondément ravinés et qu'en général, lis ravins sont d'autant plus encaissés qu'on se trouve plus loin du sommet de res nappes.

Les ronsidérations qui précèdent font ressortir, je crois, avee évidence, que la pente du sol àu-dessons de laquelle la végétation derient possible à la surface du sol, varie de valeur dans une certaine mesure. suivant la pius ou moins grande ampleur th phénomène tu ruissellement. Aussi constate-t-on aiśment que, toutes rhoses égales d'ailleurs, les formes de relief varient, evoluent tans les sens très différents suivant la plus ou moins grande ampleur du phinomène du ruissellement. La nature des précipitations joue aussi un ròle important dans ces phénomènes.

Il est bien évident que, par exemple, les thutes de grêle sont de nature à activer la marche du modelé, tandis que les chutes de neigu sont favorables au maintien des formes actuelles du sol, à moins toutefois que ces masses de neige ne donnent naissance aux phénomènes glaciaires et aux phénomènes des avalanches. En effet, pendant que le sol rst couvert par la neige, il est soustrait aux alternatives de gel et de dégel, ainsi qu'à l'action mécanique des chutes de pluie ou de grêle. Les eaux arrivent lentenent au sol pendant qu" ilur" la fusion, et l'infiltration se trouvant dès lors facilitée, le ruissellement pst singulièrement amoindri.

Plus longue sera la périofle pendant laquelle la neige eouve le sol, st. moins rapide sera l'évolution du relief, toutes choses restant les mêmes.

De plus, les surfaces enneigées se découvrent d'ordinaire avee lenteur et d'une manière progressive. Si ces surfaces sont nues, la fusion progressive des neiges sera favorable au développement de proche un prochr de la couverture végétale.

De serte quen définilive, on peut, je rosis, formuler le principe suivant : 
Un sol de constitution physique et de pente données pourra être envahi par la végétation sous un climat défini, alors que cet envahissement aurait déjà eu lieu ou serait encore impossible dans d'autres conditions de climat.

Examinons maintenant - j'empiète un peu sur le domaine de mon camarade Guinier, mais il m'en excusera certainement - examinons maintenant comment la nature s'y prend pour établir un tapis régétal sur un sol nu et qui présente des conditions de pente favorables, relativement au climat.

$\triangle$ tu début de cette sorte de restauration, on ne voit que des individus isolés, d'espèces peu nombreuses et bien spécialisées, réussir à s'installer. Beaucoup meurent sans avoir laissé de postérité. Mais les obstacles que certains d'entre eux, mieux armés pour la lutte, opposent aux causes de dégradations, finissent à la longue par réduire la puissance des agents atmosphériques. Ainsi se créent insensiblement de nouvelles conditions qui sont favorables à la multiplication plus abondante des espèces que je viens de signaler et à l'installation de nouvelles espèces, plus difficiles que les premières, par rapport aux conditions offertes par le milieu.

Le résultat final de rette lutte opiniàtre entre la nature vivante et la nature morte est la constitution d'une association végétale, de laquelle sont généralement exclnes les espères qui avaient pris possession du sol an début te la restauration.

Le plus souvent la composition de eette association sera absolument identique à celle de l'association qui caractérise les stations analogues de la zone naturelle de végétation à laquelle appartient le lieu considéré. Mais tel n'est pas toujours le cas. On sait en effet que " les besoins de chaque espèce prise isolément varient dans des limites plus étroites que ceux de lassociation ». Or, le changement dans la forme superficielle du sol aura pu s'accompagner d'une modification importante dans sa nature minéralogique, par exemple si l'érosion a enlevé un terrain de transport qui cowvrait un terrain en place et mis ce dernier à $n u$.

De telle sorte que, même en admettant quaucune modification ne se produise dans les caractères généraux et locaux du climat, on constatera parfois que certains termes de l'association, voire même son principal terme, auront disparu.

En somme, je crois avoir établi les deux autres principes suivants :

10 Lorsqu'une surface à tres forte pente se troure subitement privée de toute armature végétale, les organismes végétaux ne peuvent. dans les conditions actuelles de la vie sur le globe, s'en emparer immédiatement par leurs propres moyens. A la dénudation succède une phase d'érosion.

20 Il n'rst possible aux organismes végétaux dont il s'agit de lutter victorieusement contre les forces naturelles de dégradation que lorsqu la pente du sol a pris une valeur plus faible que celle quelle avait tout d'abord. 
Ces principes ne sont apparus clairement aux yeux des observatenrs rulau cours du siècle dernier.

Surrel, que l'on citt toujours m cette matière, attribuait a juste titre aux vógétaux ligneux, aux arbres en particulier, la prépontérance dans le rôle de l'armature végétale. C'est lui qui, le premier, a exprimé arec vigueur le premier de ces principes en disant que "la destruction d'une forêt laisse le sol en proie aux torrents".

Si le deuxième principe n'a pas été formulé arec autant dr nettré, il n'en est pas moins eontenu implieitement dans tous les travaux publiés sur la restauration des montagnes et la correction des torrents. Les forestiers l'expriment généralement en alfirmant qu'un sol dénudé r.t dont la pente dépasse une rertaine valeur ne peut ètre restauré, c'est-à-dire que son armature végritale ne peut être réinstallée qu après l'exécution de certains travaux ayant pour but de donner au sol la stabilité qui lui fait défaut. Corst ce que M. Mougin disait tout à l'heure.

C'est de ce principe que les forestiers ont déduit la nócessité deffectuer la plupart des travaux de correction : barrages, clayomnages, fascinages, garnissages de lits et de berges, avant d'entreprenfler les travaux forestier's et de reprendre les semis et plantations.

Les réflexions qui précèdent pourraient nous amener à nons poser la question suivante: comment la végétation a-t-elle pu s'emparer des surfaces à très forte pente. alor's que dans les conditions actuelles, elle ne peut plus immédiatements'y réinstaller par ses propres moyens? C'est une question que les botanistes résondront; et je pense qu'ils en trouveront la solution dans l'étude du phénomène glaciaire. C"est probablement à l'époque glaciaire que la végétation s'est installée dans les pays de montagnes.

Le deuxième chapitre de notre rapport traite des petits travaux de eorrection.

Je n'ai pas de choses nouvelles à ajouter au rapport sur ce point, et cela ne conclut à aucun vœu. Je vous demande done de me permettre de passer la parole à M. Guinier.

M. Gunier. - Messieurs, ainsi que M. Bernard l'a dit, il y a dans la question qui nous intéresse en ce moment une part botanique. La restauration des montagnes comporte une grande part de botanique appliquée. Et je tiens tout d'abord à vous faire remarquer que, pour le comprendre, il faut élargir la conception de la botanique qui a étí pendant longtemps universellement admise, et qui demeure encore la seule connue pour beaucoup de personnes étrangères aux progrès de cette science.

Le botaniste, ce n'est pas l'honme qui en se promenant à travers la campagne ramasse des plantes, leur donne des noms, étudie lemrs caractères. Ce n'est pas non plus celui qui dans son laboratoire, an moyen de coupes microseopiques, en étudie les détails de structure. Ce n'est pas davantage et seulement celni qui, dans un laboratuire 
un peu différent, faisant croitre ces plantes dans des milienx dont il règle à sa volonté tous les détails, établit les lois physiologiques de leur fléveloppement. Non, il y a à côté de cela un botaniste plus complet, plus synthétique si vous voulez, d'ordre plus pratique aussi : c'est celui qui, parcourant la campagne, ne se borne pas à constater qu'il y a là une plante présentant tels caractères, mais se? demande pourcuoi elle y vit, dans quelles conditions de milieu elle s'y trouve, quelle est sa signification : en d'autres termes, celui qui se demande quelles sont les propriétés de cette plante et comment on pourrait rn tirer parti pour répondre à un des besoins de l'homme.

C'est ce pas qu'il faut franchir. c'est dans cette voie qu'il faut résolument entrer.

En somme, restaurer les montagnes, c'est rétablir l'état primitif. MII. Nougin et Bernard l'ont éloquemment montré, ce rétablissement comporte une part de lutte contre des phénomènes géologiques. Mais ensuite il faut rétablir sur ce sol la végétation primitive. Il faut done connaitre quelle était cette végétation primitive. Ceci est incontes tablement un problème de botanique appliquée.

Ce problème, les botanistes sont aujourd'hui à mêne de le résoudre. Je dis actuellement, car il y a trente ans ou même vingt ans, la chost n'était pas aussi facile. La botanique a évolué. Et je ne peux pas parler sur ce sujet sans rappeler le nom de celui qui, en France, a contribué le plus à cette évolution st surtout à sps applications pratiques : cist M. Flahault, professeur de botanique à l'Lniversité de Montpellier qui, le premier, a étudié à ce point de rue spécial la flore de nos montagnes méditerrancennes, des Cévennes, d'une partir des Pyrénées, de toutes les Alpes méridionales.

Nous n'entrerons pas dans les détails de ce problème de la détermination de l'état primitif de la végétation : c'est de la botanique. et je ne crois pas nécessaire de m y appesantir. Je me bornerai à faire remarquer une chose : Certainement beaucoup d'entre vous - je parle des forestier's - me feront cette objection; ils diront : "Mais cela exige beaucoup d'etudes botaniques, cela exige une grande connaissance de la flore "l'une région ". C'est bien certain, mais c'est un travail à faire une fois pour toutrs; pt de même, que dans certains cas, on a recours à un spécialiste, je ne vois pas pourquoi les forestiers ne recourraient pas dans ce cas particulier à un spécialiste en botanique.

Le résultat de tous ces travaux serait d’établir une carte botanique do la région à reboiser, pour chaque bassin de réception, pour chaque périmètre, pour employer le terme administratif. Cette carte indiquerait les limites altitudinales et les localisations d'après la nature du sol des différentes essences, ou plutòt des différentes associations végétales. Alors il suflirait de jeter un coup d'oil sur cette carte, fy mettre en place la surface à reboiser, pour savoir immédiatement à quelles essences il faut avoir recours.

Voilà le principe. Je ue nie pas qu'il n'y ait des dillicultés d'appli- 
cation. Mais notre tàche ici est d'émettre des idées générales, de poser des principes; et c'est dans ce sens que tout à l'heure je vous proposerai un rou.

Il y a encore quelque chose à quoi il faut faire attention. Rétablir la végétation primitive, mais est-ce toujours possible? Les forestiers savent bien que non. Instinctivement, de tout temps, quand ils ont à constituer une forêt sur un sol déterminé, ils ont eu recour's à ce qu'on a appelé des essences transitoires, parce qu'ils savent parfaitement que si, par exemple, dans une sapinière complètement détruite. ils veulent planter du sapin, ils s'exposent neuf fois sur dix, et même plus souvent, à éehouer. Mais ils y planteront une essence transitoire, et c'est sous cette essence, le pin sylvestre par exemple, quils verront se reconstituer la forềt.

Cette méthode doit ètre généralisée. Nous ntª devons pas parler seulement d'essences transitoires, mais, d'une faŗon plus générale. de végétaux transitoires, d'ordre quelconque, de toutes dimensions.

D'autre part, une autre notion à retenir est relle-ci : rétablir l'état antérieur est bien, mais il y a des cas où on peut faire mieux. Il ne faut pas oublier ce principe fondamental que, pour qu'une plante se trouve dans un endroit déterminé, il ne suffit pas qu'elle y puisse vivre : il faut aussi quelle ait pu y arriver. Les plantes ont leurs migrations. La population végétale du globe est actuellement le résultat de migrations très lentes. Mais les graines ainsi transportées peurent rencontrer des obstacles. C'est ce que nous royons tous les jours dans les régions de montagnes, lorsque nous passons d'une vallée à une vallée voisine : à égalité de climat ou presque, la végétation change complètement. Ainsi dans les Alpes méridionales, si nous comparons une vallée telle que celle du Var, qui débouche largement sur la plaine méditerranéenne, et une autre vallée, telle que celle dlu Verdon, qui débouche dans la vallée de la Durance, laquelle débouche à son tour, après un parcours encore plus long, dans la vallée du Rhône, nous royons que, dans ces deux vallées de climat semblable, il y a des flores très différentes. Pourquoi? Il est facile de le comprendrè. Un certain nombre de plantes ont pu, partant du rivage méditerranéen, remonter la vallée du Var, tandis que les mêmes plàntes n'ont pu, partant de la plaine du Rhône - où déjà elles n'existent pas d'ailleurs - surmonter tous les obstacles échelonnés sur le parcours qui les mènerait à la vallée du Verdon.

Nous pouvons profiter de cette notion pour provoquer ces migrations de plantes, pour les effectuer nous-mêmes. On a fait cela aussi depuis longtemps : c'est le principe te l'introduction des essences exotiques. Et ce mot peut être généralisé : quand on plante du mélèze en plaine, trélèz" est tout aussi exotique dans cette station que le sapin dr. Douglas l'est en France.

Les reboiseurs eux-mêmes ont largement appliqué ce principe par titonnement. Actuellement, il y a sur pas mal de nos versants calcaires des montagnes méridionales de bearx massifs de pin laricio d Autriche. 
Le cèdre aussi a donné de bons résultats sur certains rersants méditerranéens. Par conséquent, le mot d'essences exotiques ne doit pas nous effrayer. 11 ne faut pas hésiter à faire franchir aux plantes los limites que les circonstances leur ont imposées.

Cela avec toute la prudence nécessaire; car il ne faut pas oublier que si un régétal existe dans un endroit domné, c'est qu'il a pu résister à une très longue série d'années présentant des conditions météorologiques très différentes. Il suffit d'un hiver froid, d'un été excessivement sec, comme on n'en voit que tous les trente ou quarante ans. quelquefois plus, pour faire disparaître certains végétaux et anéantir le fruit d'un travail qui donnait des promesses.

Voilà le premier point sur lequel je désirais attirer votre attention. en vous montrant comment il est temps de substituer à une méthode empirique une méthode plus générale donnant plus de garanties aux reboiseur's et permettant à coup sûr la restauration des montagnes. (Applaudissements.)

Dans ce même domaine de la botanique appliquée, il est d'autres points sur lesquels je désire attirer également votre attention.

A propos des essences de reboisement, il n'y a, je crois, rien à ajouter à ce qui a été dit sur les conditions dans lesquelles il faut introduire chaque essence. Les expériences sont assez nombreuses à présent pour que l'on puisse formuler des règles assez complètes.

Mais il y a un point noureau, d'une importance énorme : c'est la question de l'origine des graines.

Jusquà présent, les forestiers ont volontier's considéré l'espèce botanique comme un bloc immuable. Quand on veut faire un reboinemrnt, on plante ou on sème du pin sylvestre, de l'épicéa, du pin de montagne : on considère que chacune de ces espèces représente un groupe parfaitement homogène. Naturellement, les habitudes commerciales favorisent cette confusion. Les graines achetées peurent renir d'un point quelconque de l'Europe : cela dépend uniquement des cenditions du marché.

Or, depuis un certain nombre d'années, gràce à des expériences poursuivies en Allemagne, en Autriche, en Suisse et qui s'étendent de plus en plus, on a parfaitement établi qu'il existe parmi nos arbres. comme parmi toutes les espèces végétales, une quantité énorme dt races locales. Par conséquent, lorsque vous voulez introduire une essence dans un sol et sous un climat donnés, il est imprudent de s'adresser au commerce et dacheter des graines dont on ne sait pas lorigine. On mettra de son côté le plus grand nombre possible de chances de réussite en faisant récolter les graines de l'essence dans la région même, ou à défaut, dans une région dont les conditions de sol et de climat soient assez voisines.

Voilà la conclusion formelle que lon peut tirer à cet égarel. Et les erreurs extraordinaires commises en négligeant celte précaution ne manquent pas. Tous les jours on peut en observer. Quel est celui qui. en parcourant un reboisement ou un repeuplement artificiel, n’a pas 
observé parfois une essence chétive, malvenante, et ne s'est pas demandé pourquoi, en cet endroit, cette essence ne réussissait pas. Bien souvent, si on laisse de côté certaines conditions toutes particulières de sol, la raison en est dans l'origine des graines.

Par exemple, on confond sous le nom de pin de montagne deux races qui, sans doute, ont en commun certains caractères : les aiguilles, les cônes sont à peu près les mêmes. Nlais pour le forestier, un caractère fondamental est la forme de l'arbre. Or le pin de montagne des Pyrénées ou des Alpes a un fìt rectiligne, des branches peu développées, un port tout à fait pyramidal : c'est par eonséquent un arbre forestier intéressant, susceptible de produire du bois. Tandis que le pin de montagne des $A l p e s$ autrichiennes est un arbuste couché sur le sol, sans fùt, avec de longues branches rampantes, formant des fourrés très denses, incapable de fournir autre chose que du menu bois de chaulfage. Il est évident que ce pin rampant ne rend pas les mêmes services que le pin à crochets des Alpes et des Pyrénées; il sera utile pour former un fourré très dense sur un sol à pente rapide; et inversement dans ce cas, le pin à crochets ne ferait pas l'affaire.

Done il faut se préoccuper de l'origine des graines. Cette question passionne actuellement les forestiers et no pouvait pas les laisser indifférents, parce qu'ils désirent avant tout une forêt solide, et non pas seulement une forêt profluctive. (Applundissements.)

A côté des essences de reboisement, il y a d'autres végétaux qui sont de précieux auxiliaires. Ce sont ceux qui servent à l'enherbement et à l'embroussaillement. L'utilisation de ces végétaux se comprend d'abord parce que, ainsi que je le faisais remarquer tout à l'heure, la réinstallation directe de la végétation primitive n'est pas toujours possible. Puis il y a mieux : il y a des terrains sur lesquels jamais, quoi qu’on fasse, on ine pourra rétablir la lorêt. A certaines altitudes surtout, il y a des terrains à éboulis parexemple, qui sont dans ce cas. Et cependant, ces terrains sont très intéressants pour nous; il faut que nous y unstallions une végétation qui arrête autant que possible les dégradations du sol.

Là encore la question de la recherche et de l'utilisation de ces végétaux est du ressort de la botanique appliquée.

Ainsi nous observons que certains éboulis sont envahis par certains végétaux. Il s'y trouve des graminées, des arbustes. Parmi les graminées, je citerai la plus classique, celle qui a fait ses preuves et est utilisée par nombre de services de reboisement : la bauche (Lasiagrostis Calamagrostis). Parmi les arbustes, celui qui ne manque sur aucune de nos berges des Alpes est l'arbousier (II ippophaae rhamnoü(les).

Si ces végétaux ont fait leurs preuves, il y en a beaucoup d'autres sur lesquels l'attention n'a pas été attirée et qu'il faudrait étudier soigneusement pour bien voir comment ils se développent et quels services ils rendraient. Il faut les étudier à tous les points de vue; leur enracinement, leur faculté de drageonnement, intéressante 
lorsqu'il s'agit de fixer le sol, leur manière de se reproduire par boutures. par graines. Ainsi nous arriverions à dresser une liste qui n'aurait pas besoin d’ètre bien longue, de régétaux qui pourraient devenir nos auxiliaires dans le reboisement.

Seulement la difficulté sera de se procurer en quantité suffisante des graines ou des boutures de ces végetaux. Cela mènera probablement à une nouvelle série d'études et de travaux. Il faudra créer des sortes de pépinières où on pourra les multiplier.

Parmi ces végétaux auxiliaires, il en est un qu'il faut, je crois, placer à part : cest le saule. Tous ceux qui se sont occupés de travaux de reboisement savent combien les saules rendent de services, soit pour garnir le fond du lit des ravins, soit pour servir de matériaux vivants dans les menus travaux de clayonnage et de fascinage.

Jusqu'à présent, on a employé des saules dl une façon générale, sans tenir compte qu'il n'y a pas un saule. mais plusieurs. et que, dans une même région montagneuse, on trouve réparties sur les différents'points du bassin de réception, des variétés qui n’ont pas toutes les mêmes aptitudes. Les unes acceptent volontiers des stations élevées, tandis que d'autres ne peuvent pas dépasser certaines altitudes. Il en est qui produisent des rejets peu longs et très grêles, tandis que d'autres en ont de très vigoureux. Il n'est pas indifférent d'employer l'une ou l'autre de ces rariétés. Actuellement comment procède-t-on?

Trop souvent on fait couper sur les atterrissements des rivières torrentielles, sur les cônes de déjection des torrents, des brassées de saules que l'on emploie pêle-mêle. Ces variétés diverses ne donnent pas une réussite égale, suivant les conditions d'altitude, de fraîcheur ou de sécheresse. Il faudra donc instituer pour les saules en particulier des études analogues à celles dont je vous parlais pour tous les végétaux d'enherbement et d'embroussaillement.

Enfin, je termine en appelant à nouveau votre attention sur le principe dont je parlais en débutant, à savoir qu'il ne faut pas seulement utiliser les végétaux existant localement, mais encore qu'il faut faire effectuer à certains autres des migrations qu'ils n'ont pas pu faire par leurs propres moyens.

Dans les Hautes-Alpes et dans les Basses-Alpes, quand lon arrive dans un périmètre de protection, on voit employer immédiatement et avec un plein succès nne papilionacée à fleurs roses, la bugrane, qui a donné là des résultats superbes. La bugrane existe à l'état spontané dans ces régions, mais elle n'existe pas dans certaines autres parties des Alpes, pas plus qu'elle n’existe dans les Pyrénées ou dans les Cévennes : pourquoi ne pas la transporter? Pourquoi ne pas utiliser ses précieuses facult is?

De même, dans les Alpes-Mlaritimes, il y a une plante qui a donné des résultats tout à fait farorables pour la fixation des berges, la corroyère; elle aussi a une aire très localisée : pourquoi ne pas faire des essais? Pourquei ne pas étendre son emploi à des régions où elle nexiste pas à l'itat spontané? 
Je cite ces exemples, mais il en est eertainement beaueoup d'autres qui pourraient ètre suggérés dans lavenir: ce qu'il y a d'essentiel, éest de bien poser en principe que l'utilisation des végétaux pour l'enherbement et l'embroussaillement doit faire l'objet d'études rationnelles et qu'il y a là une tàche nouvelle qui s`impos'a aux intéressés. Il faut dresser une liste des végétaux utilisables, arec les conditions dans lesquelles on peut les employer. Je erois que ce sera une tàche féconde. permettant de porter à l'apogée, en quelque sorte, l'ourre de la restauration des montagnes (Applandissements).

Je termine, messieurs, en vous soumettant le projet de vœu que vous avez pu lire, à la fin de notre rapport.

La première partie de ce vou résulte de cette constatation qu'il y a des néthodes locales acquises par l'expérience d'un certain nombre de forestiers et dont il y aurait intérêt à provoquer la diffusion. Quant à la fin de ce vœu, il résume les irlées que nous avons développées (Noureaux applaudissements).

M. Tessier. - MM. Pernard et Guinier viennent d'exposer la nécessité. pour les travaux de gazonnement des terrains degradés, d'écarter les graines fourragères du commerce qui, en montagne, donnent des resultats médiocres et dépérissent rapidement. 11 y aurait donc la plus grande utilité, comme ils le disent dans leur rapport, à críer des pépinières pour produire des graines fourragères adaptées, sélectionnées, de manière à donner les meilleures races possibles pour la consolidation des terrains de montagne.

La même observation doit être faite pour les graines fourragères que demandent les améliorations pastorales. Les forestiors des PrrénéesCentrales se préoceupent de cette question et ils ont mis à l'étude, à 1.100 et à 1.600 mètres d'altitude, dans le périmètre de reboisement du Laou d'Eshas, rui protège la belle station thermale de Luchon, la reine incontestée des Pyrénéts, la erration d'une pépinière destinér à la production de graines d'espèces fourragères vivares, prises danla région même et, par suite, parfaitement ataptéeśs.

Dans l'état actuël de la seience agricole, il ne parait pas douteux que si, en montagne, les sujets provenant de graines fourragères du commerce disparaissent le plus souvent au hout d'un petit nombre d'années sans laisser de descendance, il n'en serait pas ainsi aver les graines judicieusement sélectionnées et adaptées. Je eiterai, par exrmple, la houque laineuse qui avait été semée en grande abondance dans les pàturages du Vercors; un an après mon arrivée à Valence. j'ai vainement eherché cette houque : il n'y en avait plus. On arait dépensé en pure perte des sommes importantes pour acheter des graines chez les marchands de Paris et du Nord.

Notre projet de laboratoire du périmètre de Laou d'Esbas répond lone par avance anx paragraphes 3 et 4 du vou si intéressant qui rous est soumis, et j’ai pensé qu'il n’était pas hors de propos d’exposer au Congrès la méthode que nous allons employer. 
Il s'agit, je le répète, de produire en abondance et sur place, aux diverses altitudes, les graines des espèces fourragères les plus aptes en même temps à consolider le sol et à constituer un bon pâturage. Il ne peut donc être question que d'espèces vivaces.

Deux procédés s'offrent à nous pour obtenir un résultat : la sélection directe, ou bien l'obtention de races pures en partant d'une plante unique.

Je prends d'abord la sélection directe, le procédé le plus simple et qui donnera le plus rapidement des résultats pratiques.

Pour chaque espèce ou variété choisie, nous irons extraire dans la montagne même les pieds les plus vigoureux ou en récolter les graines. Nous grouperons les pieds de chaque espèce ainsi obtenus dans un carré de pépinière afin de pouvoir facilement les observer et en recueillir chaque année les graines. Dans ces cultures, on s'appliquera incessamment à éliminer tous les sujets médiocres et à les remplacer par les meilleurs que l'on pourra trouver dans la montagne. Au bout de deux ans, cette méthode commencera à produire des quantités appréciables de graines sélectionnées.

Ce procédé de sélection, diront les agriculteurs, est fort élémentaire : c'est possible ; mais il faut courir au plus pressé et il a l'avantage de donner immédiatement des résultats pratiques.

D'ailleurs, cela ne nous empêchera pas d'utiliser une seconde méthode qui est la suivante : l'obtention de races pures en partant d'une plante unique. Cette méthode est plus parfaite, plus scientifique. mais elle donne des résultats moins immédiats; c'est celle qui est employée par le suédois Nillsun au laboratoire de Svalöf et elle fera de notre pépinière un organisme d'un grade plus élevé auquel nous pourrons donner le nom de laboratoire.

Pour chaque espèce ou variété soumise à la sélection directe, nous choisirons le pied présentant les qualités les plus désirables et, sur ce pied unique, l'on récoltera les graines les mieux conformées. Il faudra donc un examen minutieux et approfondi pour choisir avec discernement ce qui sera la souche future de notre race.

Les cultures ainsi obtenues seront l'objet d'observations attentives ; on y supprimera tous les individus chétif́s ; d'autre part, tous ceux qui présenteront des variations aberrantes et ne reproduiront pas les caractères du pied-mère seront mis à part. Il est entendu que nous aurons conservé en herbier un échantillon de la plante initiale pour que nos successeurs aient des documents leur permettant de suivre l'évolution de la race et ses transformations.

Dès la quatrième année, nous aurons déjà des quantités importantes de graines diune grande valeur pratique pour la consolidation du sol et lamélioration des herbages.

Quant aux individus mis à part comme présentant des variations aberrantes. nous ne les perdrons pas de vue ; nous n' oublierons pas que, dès 1890, les recherches de Braun de Noegard ont déjà établi la constaner des caracteres dans la descendance de certains types aberrants. 
même avec changement de nilieu, et que le savant directeur du laboratoire de Sralöf, M. Nillson, prenant les observations de Braun le Noegard comme base de ses travaux, s’applique à propager les individus aberrants offrant des variations interessantes et réussit ainsi à créer de véritables races remarquables par leur fixité.

Sous le bénéfice le ces observations, je demanderai que te congrès émit le vœu :

"Que le Touring-Club de France venille bien subventionner la création en montagne de laboratoires et pépinières analognes an. célèbre laboratoire de Sualöf en Suède, laboratoires et pépinières dans lesquels on sélectionnerait méthodiquement les espèces fourragères vivaces les plus aptes à consolider le sol tout en fournissant de bons herbages " (Applaudissements).

M. Rотн. - Je m’associe entièrement à la très intéressante communication de MM. Bernard et Guinier, concernant l'origine des graines. Il ne suffit pas, en effet, commo le disait M. Guinier, de connaitre les plantes, on doit encore chercher et connaitre toutes les autres circonstances ; notamment, en ce qui concerne le reboisement des terres nues, il est très nécessaire de regarder la couverture vivace des plantes herbacées pour juger quelles espèces d'arbres nous pouvons planter avec succès. En Hongrie, gràee à cette méthode, nous avons obtenu des résultats excellents sur notre désert de sable.

D'autre part, nous semons, par exemple, au désert sablonnerux, avant le reboisement, la Festuca vaginata, l'Echimops, et nous obtenons de réels succès grâce à une méthode spéciale. La migration des plantes a été très rapide et c'est là un résultat très désirable pour nos déserts de sable; car, après le reboisement, apparait unc végétation qui ne se trouve pas dans les sables, mais seulement dans les forèts ( 1 pplandissements).

M. le baron De BelinaY. - La science et la compétence de M. Guinier m'encouragent à lui signaler un phéuomène qui se passe constamment chez moi : je ne sais pas s'il est général.

J'ai coupé récemment une petite futaie de hêtres : immédiatement après, le sol s'est couvert d'arbrisseaux qui sont inconnus sur le plateau, le sureau à grappe, le framboisier et, en plus, l'épilobe. Comment expliquer cela?

11. Guinier. - Le fait que vous signalez est d'ordre absolument général. Toutes les fois que, dans une forêt, on modifie l'état du peuplement - et la modification la plus profonde est bien la suppression de ce peuplement par la coupe - la végétation change ; un rertain nombre d'espères qui préexistaient sous le couvert, mais d'une façon chétive, se développent immédiatement. Après les graminées qui arrivent au sol deux ans après la coupe, on voit apparaitre d'autres plantes, ot en particulier, celles dont parle .1. le baron de Belinay. Dans 
toutes nos régions de montagne, on voit apparaître, parmi les arbustes, If sureau à grappes, et parmi les plantes herbacées, l'épilobe. Ces plantes exigent, pour se développer, un sol très riche en humus et de la lnnière; elles ne trouvent ces conditions réunies que dans les coupes et elles ne peuvent vivre que là.

Noubliez pas, d'ailleurs, que les plantes dont on a parlé ont des graines très facilement disséminables : le sureau à grappes, le framboisier ont des fruits charnus; absorbées par les oiseaux, les graines peuvent être rejetées à de grandes distances de la plante-mère; d'autre part, l'épilobe est le type le plus parfait de la plante à graine ailée : les graines, très petites et très légères, sont surmontées d'un panache de poils qui permet le transport à des distances considérables.

Ce sont des migrations rapides qui se produisent sous nos yeux.

II. le baron de Belinar. - Nos paysans ont me autre théorie; ils disent que la terre est un bon grenier.

M. Ginner. - Ce n'est pas absolument fanx. On a constaté que, dans les compes, réapparaissent périodiquement certaines espèces dont les graines se conservent dans le sol pendant vingt, trente ans et même davantage.

Ux Coxgressiste. - ] Le fait est particulièrement remarquable en Extrême-Orient pour le bambon.

M. Gunier. - Chez nous, le genêt à balais en est aussi un exemple frappant.

M. Cardot. - Il en est de même pour le fraisier qui couvre le sol des coupes.

1I. Gimner. - Noubliez pas que le fraisier a une multiplication régétative très rapide.

1I. L.emattre. - Et le muguet...

11. Cuinier. - Le muguet se retrouve, mais à un autre stade. Au contraire, pour le genèt à balais, le fait est absolument démontré. les graines se conservent à terre pendant tout le temps qui sépare une coupe de la suivante.

M. Lemaltre. - Quand on met des scories dans un pré où il n’y a jamais eu de légumineuses, trois mois après, c'est un champ de minette et ile trèfle.

II. Guniter. - La végétation se compose en quelque sorte de trois ćléments : les éléments préexistants, puis d'autres éléments introduits, soit du voisinage ou issus de graines conservées dans le sol.

11. le baron de BeLinar. - Je trouve géniale votre idée d'employer 
les plantes pour fixer les terrains de montagne. Cue plante a permis à Brémontier de fixer les dunes; il est exirlent qu'on peut fixer la terre des montagnes de la même facon.

M. Gunnier. - Brémontier n’a fait quappliquer les méthodes que nous demandons d'utiliser en montagne.

M. Le Président. - Je donne lecture du projet de rou présenté par MM. Bernard et Guinier :

"Qne les forestiers reboisenrs soient eneouragés a fair" conmuitre les moyens pratiques qui leur ont le mienx réussi dans l'exécution des divers travanx de correction et de réinstallation de la régétation.

"Que lattention des rehoisenrs soit attirée sur la nécessité d'étndier la végétation naturelle des bassins à reboiser et des régions attenantes. et sur l'intérêt qu'il y anrait à dresser nne curte botanique pont servir de base anx trasanx de reboisement entrepris.

"Que l'on tienne compte des résultuts acquis duns la question de lorigine des graines, en semunt, en tout cus, des graines d'origine connue et choisies logiquement.

"Que l'on étudie d'une façon rutionnelle les végétaux herbacés et les arbrisseaux utilisables pour l'enherbement et l'embroussaillement, et que par des essais on détermine les conditions de leur emploi et dle leur multiplication.

"Qu'une étude analogue soit faite ponr les direrses espèces de saules utilisés pour les travulux de garnissage et de clayonnage."

Les divers paragraphes de ce vóu sont successivement mis aux roix et adoptés à l'unanimité.

M. le Président. - Quant au rœu déposé par M. Tessier, je propose de le formuler ainsi :

"Que soit enconragée la création en montagne de laboratoires et pépinières analogues an célèbre laboratoire de Svalöf en Suède, laboratoires et pépinières dans lesquels on sélectionnerait méthodiquement les espèces fourragères vivaces les plus aptes à consolider le sol tout en produisant de bons herbages. ")

Ce vœu, mis aux voix, est adopté.

La séance est levée à midi moins un quart. 


\title{
SEANCE DU 17 JUIN 1913
}

\author{
(APRÈS-MIDI)
}

\section{Présidence de M. GARDOT, vice-président de Section}

La séance est ouverte à '2 h. 15.

11. Le Président. - Je prie M. Roth, ins̀ pecteur des Eaux et Forêts de Hongrie, dr vouloir bien se joindre à moi pour la présidence de cette séance.

11. Roth prend place au bureau.

M. Le Président. - Je donne la parole à M. Larue, pour sa communication sur LES FACULTÉS DE REBOISEMENT DES DIVERS FACIES GÉOLOGIQQIES.

M. Larue. - Une tendance actuelle est de toujours accuser l'incurie humaine pour expliquer le déboisement, ou mème la lenteur du reboisement. Mais la tàche de l'homme est particulièrement difficile dans certains sols et sous certains climats.

Tous nous contenterons, dans la presente note, d'appeler l'altention sur les différences que présentent en vue Iu reboisement les faciès francais des affleurements des différents étages géologiques.

Deux remarques importantes doivent être faites pour échapper en partie à l'ubjection de n'envisager qu'un côté de la question, et permettre d'abréger dans la suite :

$1^{\circ}$ L in reboisement a d'autant plas de chances de réussir qu'il s'appuie sur un massif forestier:

$2^{\circ}$ La filmpart des terres fertiles rendant plus de bénéfices en culture qu'en bois, il n'y il pas lien de les reboiser, bien que les arbres y poussent très hien.

L'ordre le plus logique consiste à suivre par ordre chronologique les différents afflemrements de notre territoire. Des noyaux granitiques, nous passerons à l'auréole des terrains secondaires qui entourent nos grands bassins, pour achevel par tos rallées d'alluvions.

lioches rrislal

Le "rramit determine des pentes allant jusqu'à m pour un et où la culture est difficile. De plus, les arènes qu'il donne sont pauvres. Fort heurensement, les terrains granitiques occupent ordinairement chez nous des stations élerées (Vosge's, Morran, Massif Central, Pyrénées, Corse) ou des climats humides (Bretague). S'aul fait exerption le massif des Naures et de l'Estérel. Le reboisement des eranits est une opération fréquemuent entreprise, plus rémunératrier que la culture proprement dite, et d'autant plus facile qu'on s'appone le plus solvent sur un massil existant.

l.i grenulite, plus riche en silice, donne parfois des terrains tellement paures 
que le rehoisement en est aléatoile, surtout aax altitudes élevéfs ; les arines profondes qu'elle détermine sont exposées aux intempéries ou aux sécheresses de l'automne. Tel est le plateau de Millevache (Corrèze), stricto sensu. Cependant, quand la forêt est installée, elle y donne de beaux produits, par exemple dans les Vosges, oil les sapins enfoncent leurs racines dans les profondenrs de l'arene.

Par la disposition de ses éléments, le gneiss conduit à des terros plus compactes et plus fertiles. C'est la raison princinale pour laquelle il est moins reboisé. Mais il a l'avantage de pouvoir porter des essences plus prérieuses que le granit. Ainsi dans le Morvan, le gneiss est le domaine du chêne, le granit restant celıi dı hêtre.

Les schistes primaires donnent des terrains fort variables. Sur le dos de leurs plaquettes redressées, la terre es i peu profonde é le reboisement difficile. íans les Alpes et les Pyrénées, on leur réserve les essences à racines tracantes. telles que l'épicéa.

Les grès du trias et du rhétien se prêtent également bien au rehoisıment, d'autant qu'ils se trouvent à des altitudes moyennes dans la Lorraine el la Montagne Noire; mais les gypses et dolomies du Keuper constituent des fonds chimiquement nocils.

Le grès vosgien est à reboiser, non pas à cause de ses aptitudes propres, mais parce que sa rauretí même l'a fait abandonner de toat temps par l'ag:iculture et qu'il est plus facile d'agrandir une forêt que de la créer. Le pin sylvestre y réussit particulièrement bien et prépare le terrain au sapin et aı hếtre. Le chêne $\mathrm{y}$ vient généralement mal el $\mathrm{y}$ est sujet à la gélivure.

Les Marnes du lias resteront le donaine de l'herbe.

Les calcaires fermgineux du bajocien, les banes puissants tle la grandr oolithe du bathonien et les facies coralliens des étages moyens du jurassique sont d'un reboisement moins difficile cule ne parait le comporter le peu de profondeur du sol. Malgré les grosses pierres qui gênent les cult.ures superficielles, l'arbr't finit toujours par atteindre des poches de terre fine particulièrement riche el. où l'humidité se trouve maintenue par la protection móme de la roche. Malheureusement, les arbres d'avenir s'y trouvent clairsemés.

Ces conditions peuvent se trouver moins favorables lorsque les sédimenis sont redressés, dans les plissements alpins par exemple, on bien la roche fondillée verticalement comme sur certains plateaux dı Jura.

Dans les combes des vallées calcaires, la gelée diminue souvent l'avenir de la plantation, bien que le sol y soit phus profond que sur les pentes.

Lorsque ces étages jurassiques présentent des faciès marneux, deux cas peuvent se présenter :

a) Les marnes sont riches en gypses, en sulfures ou en magnésie et situées sous un climat sec à pluies torrentielles. Alors elles s'opposent au reboisement par l'affouillement et l'inaptitude chimique. C'est pourquoi les reboisements des Ilpes de Provence sont les plus difficiles.

b) Si on a affaire à des marnes calcaires sous le clinut tempéré du centre do la France, comme dans les étages oxfordien, et kimméridgien surtout, la forêt pousse vigoureusement, mais les céréales et la vigne également, ce qui a entraîné le morcellenient de la propriété.

Dans ces conditions, mème depuis la crise viticole, le reboisement est difficile, car on ne peut s'appuyer à un massif hoisé. Tne parcelle isolée est exposéé à des aléas de toure nature.

Les plus mauvais terrains dos étages jurassiques sont constitués par les calcaires en plaquettes fréquentes dans les étages bathonien. séquanien et portlandien. La sécheresse de l'automne y améne souvent la mort des jeunes plantations. C'est surtout dans ces terrains que l'on conseille de planter au Nord. J'arbre âgé peut pousser ses racines à une profondeur suffisante.

Il n'en est pas de même si la plaquette est dure, comme sur le pronien plateau du Iura et les Causses truffiers. La forèt n'y peut donner que les 
produits de gros murre. Le taillis de chêne s'y transforme difficilement en futaie. Si le climat $s^{\prime} y$ prète, on peut y tenter la futaie de hètre $J$ ura et Lorraine).

Les marnes du crétacé inférieur du bassin de la Durance se comportent comme celles du jurassique voisin.

Par leur nature et lear situation topographique, les sables et argiles du créracé inferieur de la Champagne humide constituent les terres de prédilection pour les forèts feuillues et en parficulier le chêne. La bande forestière, Cosne, Auxerre, Troyes, Vassy, Sainte-Menehould, Vouziers, s'est longtemps enrichie en fournissant le merrain, le cercle et l'échalas aux vignobles voisins. Depuis la l'eduction de ceux-ci, on laisse vieillir les coupes et l'on y obtient de beaux chênes.

Les terres argileuses ou silicenses, paurres en calcaire, qui constituaient des clairières de l'antique sylve continue, retoument facilement à leur état primitif. On y prépare le chène en plantant du bouleau, ou mème du peuplier en bordure di massif smbsistant. Les cours actuels du blé, du lait, et de la viande enrayent un pro ce monvement en farorisant l'extension des cultures et des pâtures sur les parties drainées.

Les craies marneuses ou glauconieuses sont beaucoup trop fertiles pour ètre hoicées. Les parties trop accidentées on trop humides pour être labourées doment de beaux buis d'industrie : orme, frène, etc.

Les récifs urgoniens de Provence et des Charentes se comportent comme le corallien, e'est-à-dire donnent des terres riches, mais remplies de blocs relatirement favorables à l'arbre, mais non à la forèt, éest-à-dire pouvant porter de beaux arbres dans un massif clairiéré.

La cruie de Champagne roit croitre lentement ses savarts de pin noir d'Autriche. Je boisement $y$ devient d'autant plus facile qu'on est mieux fixé sur l'essence à rhoisir et que l'on possède aujourd'hui des points d'appui. On sait atussi yue l’on ne pent en attendre que des résultats modestes.

Terrains lerliaires.

Fort heureusement, la craie est souvent recouverte du manteau de terrains tertiaires argilo-siliceux, depuis longtemps boisés, à cause de leur paurreté chimique. Il est facile d'agrandir la forèt où le besoin s'en fait sentir.

Quant aux terrains tertiaires récents, ils présentent dans le détail une tell variété que nous ne pouvons les suivre dans nos grands bassins fluviaux.

Ordinairement ils sont situés à de basses altitudes et cultivés.

Seuls les facies arèneux s'offrent aul reboisement et sont effectivenent de plus en plus garnis, tels les sables de Sologne et des Landes. Ils portent egalement nos plus belles futaies feuillues.

Les molasses calcaires sont ordinairement trop fertiles pour qu'on les recouvre de forèts, mais on y cultive avec succès les arbres fruitiers dans l'Agenais, le Dauphiné et la sàvoie.

Terrain: volca- Les laves et basaltes noctupent en France une surface importante que dans niques. le Puy-de-Dôme et le Cantal. Ordinairement fertiles pour l'herbe, ces terrains n'attirent pas le reboiseur. Seules les cheires, (coulées volcaniques) le seraient litilement, mais difficilement ì cause de len' extrême perméabilité.

Quant aux alluvions quaternaires, elles sont occupées presque partout par l'industrie humaine. Souvent parcourues soutermainenent par un courant aquatique, elles constituent la région de prédilection des essences tendres, en particulier du peuplier. Celui-ci pousse dans les graviers les moins fertiles, pourvu qu'il trouve de l'eau courante à quelques pieds de profondeur.

Ce n'est pas l'humidité du sol, mais celle du sous-sol et plutôt enıore lu débit de la rappe, qui détemine la zone favorable au peuplier. C'est commettre une erreur que d'en planter dans les sables argileux si abondants dans lo terfiaire, le crétacé infériemr et lo trias. II y pousse admirablement en pépiniere, mais roit ensuite leancoup) plus lentement que dans les graviers, car 
si l'eau abonde en surface à rause de l'inmerméabilité du sol, wle est pal "cli mème rare dans le sous-sol et absente à l'automne.

C'est pour la même raison que les peupliers réussissent mal dans lestouribieres. La tombe comme l'argile dispute l'ean à la plante.

Si les alluvions ont une grande ejaisseur, tels les cailloutis dil bassin du Rhòne, ils forment des plateaux secs où les reboisements oul peu de cliances d'ètre rémunérateurs. Ils ne peuvent donner que dit bois de rhauffage et servir d'abris : Cran. Confluent de l'Ain.

Les moraines et les cònes torrentiels sont d'autant plus difficiles à rebuiser que la sécheresse du cailloutis s'aggrave de l'instabillité de la masse qui coule sir los pentes lorsque l'e:2u l'imprègne. En plaine, ils sont urdinaimment fertiles et cultives.

En résunté, le reboiseur ne trouve en face de lui que les sols infertiles abandomıés par la charrue. Il ne peut guère réaliser une ouvre rémunératrice que sur les faciès siliceux en climat humide ou moyen, lorsqu'il s'appuie sur des massifs anciens.

Ailleurs l'opéralion est aléatoire, mais si elle n'est pas "rentable "portr lui, elle l'est pour la collectivité. Cela explique l'intervention incessante et nécessaire de l'État dans le clomaine qui nous ocrinne.

Cela explique surtont l'intérêt que tous les gro upuments economiques et intellectmels doivent apporter aux "ceuvres "d'aménagement qui font intervenir la nature et la patience oì le eapital et la main-d'curre ne sauraient trouver utile emploi. Les reboisements sont. en effet, souvent des œuvres sociales et non des affaires.

M. Le Présinext. - Mon expérience le forestier me permet de dire que je suis absolument d'accord sur presque tous les points avec le confirencier. Je relèverai toutefois un peu d'exagération dans sa conclusion, en ce sens que, bien sourent, même dans les sols lés plus ingrats, on trouve une rémunération dans le reboisement.

11. Larue. - Je voulais suntout consoler les reboiseurs des insuccès qu'ils ont pu rencontrer. En 1911, les epiceas ont été désséchés dans presque toutes les forêts des basses altitudes.

M. CAqret. - Jappuie ces observations en ce qui concene l'épicen. Dans le Morvan, dans le Bourbonnais, dans le Cher, la Nièrre, tous les plants sans exception ont péri. Le sapin argenté à résisté assez bien en général; mais l’épicea a complètement disparu de toutes les plantations.

Depuis 120 ans, e’était la première fois que I'épicea se trourait soumis à une pareille épreuve.

M. BERNARD. - Ce n'est pas là une question géologique. L'épicea ct le sapin sont deux essences de montagne qui vivent lans des rondilions de sol et de climat tout à fait spéciales. En utilisant sous un rlimat déterminé une essence qui n'est pas adaptée anx conditions llu milieu, on s'expose toujour's à un insuceès. Cet insureès se ferce attendre 2 ans, 2 ans, 50 ans ; mais inévitablement on aura un insnecès.

M. Martre. - Je ferai remarquer à monsieur l'inspecteur Bernard, quà la fin de rette même année 1911. au bord du lac de Lucerne, j’ai 
constaté, à ma grande surprise, que sur toutes les parties sèchès des pentes du lac de Lucerne, celles de Bürgenstock, du Righi, du Pilate, l'épicea arait óté grillé comme en hiver.

M. Bervard. - C'est que là aussi l'epicea n’était pas chez lui. Il fait partie de ce que MM. Flahault et Guinier appellent la zone alpine Ce n'est qu'au-dessus de $1.300,1.400,1.500$ mètres qu'il est vraiment dans sa patrie. Au-dessus de cette zone, il y a d'autres essences, comme le mélèze, le pin à crochet, qui sont dans leur patrie, et puis enfin l'admirable pin cembro. N'essayez pas de l'introduire dans nos pares, vous courreriez aussi à des insuccès. L'épicea, en Savoie, a une tendance manifeste à envahir les forèts de basse montagne, étant donné les conditions de climatologie actuelles. Mais survienne un accident, comme la sécheresse de 1911, il y a bien des chances pour qu'il disparaisse à son tour des sols qu'il a indùment conquis. Les autres essences, le pin sylvestre, les chênes, finiront par l'emporter sur lui.

M. LARue. - J'ai traité la question à un point de vue spécialement géologique. Ce n'était pas mon ròle d'indiquer les essences qui convenaient, et qu'on connait d'ailleurs.

M. Le Présinext. - La section est bien d'accord pour demander que le travail si intéressant de M. Larue soit imprimé in extenso? (Assentiment nnanime).

M. Le Présinext. - La parole est donnée à M. Descombes, pour la lecture de la communication de M. le comte de Roquette-Buisson, sur La Question syluo-pastorale.

M. Descoubes. - Dans les siècles passés, tant que l'harmonie entre les diverses parties de la montagne n'avait pas été rompue, on n’avait eu aucune raison de se préoccuper du ròle de la forèt.

Les bois étaient insuflisants, tant au point de vue de leur utilisation immédiate, construction, entretien des bàtiments, chauffage, fabrication des outils, abri pour les animaux pendant les grandes intempéries, nourriture des bestiaux avec leurs feuilles et leurs brindilles, dans les saisons trop rigoureuses - qu'à celui de la protection contre les avalanches, de leur artion bienfaisante pour le bon entretien des pâturages.

Pour chercher à se rendre compte d'un organisme qui fonctionnait normalement, répondant aux besoins auxquels il devait pourvoir, il eìt fallu un esprit de curiosité presque inquiète, prévoyant l'avenir. Esprit étranger au tempérament montagnard, dont la caractéristique est un mélange d'énergie calme et de nonchalance contemplative.

Ce fut seulement vers le milieu du xvile siècle que l’on commença à se préoccuper de la nécessité de conserver les forêts; on s'en préoccupa uniquement, à ce moment, au point de vue do la marine, puis vers le milieu du xvine siècle pour assurer le chanffage des habitants, l'entretien des forges (1).

Un peu plus tard, vers 1778 , les habitants des plaines songèrent aux forèts de la montagne pour empècher les inondations, les ensablements des rivières, des coltrs d'eau.

(1) Comte be Roquette-Buisson, Le déboisement des Pyrénées. 
On trouve daus le mémoire de Poyederant en 1778 sur l'action utile des bois, ume page qu'aurail pu signer l'ingénieur Surrel, dont pas un forestirł. de nos jours ne saurait contester l'exactitude absoluc (1).

Après avoir proposé les moyens les plus propres, d'apròs lui, pour arrêter les défrichements, il continue en ces termes:

En adoptant le parti proposé, il y aurait lieu de se flatter qua les débordements des rivières qu'on ne saurait empècher, seront moins prejuliciables qu'ils ne le sont depuis quelques années. Les endroits élevés, les coteaux, les penchants de montagues dans lesquels la culture serait interdite, se courriraient bientòt de bois, d'arbustes ou de gazons qui en lieraient et, so stiendraierit les terres, de manière à prévenir les debordements; les eaux seraint d'ailleurs retenues par les obstacles que les arhustes et les herbages mettraient à leur prompt écoulement, et les reiges se trouvant moins uxposées à l'action directe du soleil, elles se fondraient avec plus de lenteur; nos rivières recevraient d'ailleurs beaucoum moins de matieres par les ravins et les torrents qui y affluent; en sorte que tout concourrail a renfre les inondations moins fortes et à dimimuer les atlerrissements et à empècher dans les campagnes les irruptions qui les dévastent.

Maluré ces avertissements, que Poyedevant ne ful pas seil a domner, mais qu'il a rédigés arec phus de précision, de nettetó que les autres, rieu ne pit arrêter la dévastafion commencée; les idits, les roglements ne produisirent aucun résultat. N'en est-on pas an mème point anjolin(llui, et malgré les rmelles leçons de l'expérience, ne s'enlize-t-on pas dans les errements semblables, en se bornant à faire des lois inefficaces?

Pent-ètre cela tient-il à ce que les ilès des Poyedevant, des Surrel, des Demontzey, en ce qui concerue l'utilité des forèts, sont encore trop peu conuues du grand public.

l.'idée de cette utilité, pour tout ce qui lonche alu régine des eanx, n'est pas nouvelle, et en 1751, d'Etigny émettait an sujet de la néressité de conserver les forêts de Bagnères-de-Bigorre, dans l'intérôt des sources themales (2), une opinion pleinement justifice aujomethui par la suience.

On peut dire qu'en Franee, il u'y a jamais tu de politique forestiere ; Colbert, nous l'avons vi, l'avait créé ; après lui, ell n'a plus existi. L'étut semble avoir oublié completement la necessiti de sanvegamer les forèts. Jusqu’à la Révolution il les a, nalgré l'ordonnance de 1669 , laissées dans les Pyrérées à la merci de tout le monde (3).

Après la Rérolution, l'Administration forestière s'occupa des hiens domaniaux; mais après avoir exercé ses revendications légitimes vis-à-vis des communes, dle s'aliéna, à plusieurs reprises, des forêts nationales. Plusieurs même ne drent d'être conservées que faute d'acquereurs. On a soumis en bloc au régime forestier, en 1827, les buis communanx, mais de nombreuses distractions en ont été et sont faites chaque jour. La plus importante à été celle (jui, de 1851 à 1854 , a enleré daus la nontagne t'nviron 'o0.000 hectares à ce régime protecteur.

Depuis, on a fait des lois dont l'effet cùt été ntile, si, presque immédiatement après, des décrets n'étaient venus entraver tout le bien qu'on pouviait en atlendre

On a décidé la création de fierinètres te roboisement, dont benucoun n'existent que sur le papier, et en méme temps on a négligé les occasions les plıs favorables t'acujérir des forils de la plus grande utilité puur la régime des

(1) Poyedevant, Mémoires (Op. cit., tome II). Je cite ce passage particulièrement intéressant parce que Poyedevant, né à Pau en 1750, d'origine basque, avant de devenir premier secrétaire de l'intendant du Roussillon Lebon, avait été commis de l'intendant à Pau, et était, par suite, très au comrant des choses des Pyrénées.

(2) Comte DE Roquette-Buisson, le déboisement des P'yrénées, p. 57.

(3) Dralet, Deseriphion des lyrénés. 3e parlie, chapilres iv et V.

Incohiremce de la politinue forestivere. 
eaux, d'éviter dess disastres qu'on est ensuite obligé de répaler à très chers deniers.

Il me parait intéressant de donner à ce sujet les détails des péripéties de la vente de la forèt de Gazost, située ldans les Hautes-Pyrénées (1). Témoin des faits qui se sont passés, j’en puis certifier l'absolue exactitude.

La forêt de Gazost, d'une contenance de 400 hectares, fait partie d'un domaine de 1.137. hectares qui, en plus de la forèt, est composé de 737 hectares de pacages. Située sur le versant nord du Mont-tigu, elle est bornée au Sud par une crête de laquelle se détachent plusieurs sommets, entre autres ceux du Nont tigu et du Pic d'Eihères de 1.800 à 2.000 mètres.

En étudiant le plan de ce domaine, on est tout d'ahord frappé de voir que tout ce qui est porté comme bons pâturages est attenant aux parties boisées.

On constate en outre que les principaux ruisseaux, l'Hountage, le Pla de la Per.nr, et tous ceux moins importants qui y aboutissent, sont abondants, soltent les uis comme les a.ıtres des régions boisées. On peut regarder cette propriété comme le modèle type de la propriété en montagne : mélange dans les proportions les pilus heureuses des forèts et des pâturages, $1 / 3$ bois, 2,3 pacages ; elle pourrait, bien soignée, constituer la meilleure des leçons de choses pour la manière d'aménager les montagnes des Pyrénées.

Acheté au Crédit Foncier par M. Imbert pour 80.000 francs, le domaine fut, en 1905, offert à l'État pour 50.000 franes. L'exploitation de M. Imbert avait été intensive; mais les forêts étaieni en bon état.

Sul le refus de l'Étal, qui ne vollut pas dépasser le prix de 34.000 francs, la proprieté fut alors acquise par M. Ricard nour 40.000 francs.

Après avoir, en exploitant tous les sapins yli'il pouvait atteindre', en coupant à blanc étoc les massifs de hêtres, "réalisé de súrieux bénéfices, il a dù cesser toute exploitation de la forêt. Si elle est protégée, elle se repeuplera rapidement.

En achetant ce domaine, qu'il eût payé à laison de trente-cinq francs dixhuit centimes l'hectare, l'Etat enit fait une excellente opération financière; il serait, en moins de quarante dns, non stulement rentré dans tous ses débours, mais aurait eu des revenus, et surtout il eut presque sans frais, on peui le dire, conservé une forêt des plus utiles pour le régime des eaux de cette région.

Mais il eût fallu pour cela une politique forestière sérieusement suivie, et l'Etat, n'en a pas. Il n'a pu mème jusqu'ici en avoir, trop d'intérêt.s privès très mal compris en lutte, sur ces questions, avec l'intérêt général, venant paralyser sa bonne volonté.

() n comprend qu'er présence du rôle encore discuté de la forèt, les législateurs aient hésité sur les nusures à prendre. Il leur eut fallu une conviction frofonde, et une énergie très grande pour risquer de compromettre leur popularité en imposant à des populations pastorales, devenues inconsciemment lostiles à la forêr, des mesures dont elles ne comprenaient plus la nécessité.

La loriet et les pitturages
I ès l'origine, toute la vie montagnarde a dépendu des pâturages. Hauts paciages d'été, pacages d'automne et de printemps, prairies cultivées pour récolter le fourrage nécessaire à la nourriture des animaux, ont été la constante préoccupation des habitants des vallées pyrénéennes.

Bornages, arbitrages, procès sur les droits respectifs dans les montagnes, sont les documents les plus nombreux des archives pyrénéennes, en ce qui concerne la vip écononique.

L'importanee accordée dans les coutumes des communautés, dans leurs règlements, dlans les chartes spigneuriales, à cette question des pàturages, témoigne hautement combien elle leur tenait à cour.

11 ne pouvait en être autrement; de toute antiquité, à travers les milliers de sièclu's coulués, conme ne nos jours encore, l'industrie pastorale a été la seule ressource, l'unique richesse des populations des montagnes.

Je suis absolument convincu que si les Pyrénées se sont jusqu'ici conser-

(1) Gazost, village du canton de Lourdes. 
vées en meilleur etat que les Mpes, si les ravinements dans les pentes, la dénudaticu des rochers y sont bien moins grands, elles le doivent à leur heureuse situation géngraphique, mais plus encore à la sagesse, à la prévoyance des vieux usages, des vieux règlements. G'est lepuis qu'ils sont, pour les raisons nombreuses exposées dans le cour's de cette étude, tombés peu à peu en désuétude, que la montagne a connu des désastres de plus en plus nombreux, que les rochers se sont dénudés. Il n'y a pas encore cinquante ans, le sommet de la montagne de Pouryaspe, qui domine le village de Sasos dans la vallèe de Barèges, était couvert de bois ; aujourd'hui, il est entièrement dépouillé de toute terre végétale et ne montre plus que la roche lisse. La conséquence immédiate a été la diminution de la fertilité des pacages. 'Tant que la torét a existé, snn influence combinée avec l'exposition du midi des pâturages, permettait anx habitants de ponvoir, pres d'un mois avant les autres villages de la vallée, vendre, grâte atu parfait état dés pàturages tu printemus, les élèves de leurs troupeaux. Aijourd'hui, ils ne punvent p]us réaliser ce bénéfice ; leur pacage est comme les autres. Ils ont, en mème temps qu'ils laissaient détruire la forêt, abandonné les prescriptions du vieux règlement communal défendant, comme dans la coutume du Baigorry, de garder pendint l'été aucun animal dans les pacages, et obligeant à les envoyer dans les hautes montagnes de Gavarnie. Cet exemple justifie d'une maniere frappante l'opinion que je viens d'émettr't.

Cette relation étroite entre la forèt et les pacages ne semble pas avoir eté remarquée; les deux choses paraissent incompatibles, comme l'avaient dit les Etats du Béarn en 1775.

Nul ne songeail à l'hureuse harmonie des proportions qui, durant tant is siècles, avait assuré lat prospérité des montagnes comme celle des plaines. Avant d'arriver à envisager la question à ce point de vue, les idées les plus extraordinaires avaient été émises, même celle d'exproprier en masse les populations pastorales pour reboiser à tout prix les montagnes et sauver les plaines. Ce n'est que depuis quelques années que la question a été nettement posét par les travaux de MI. Demontzey, Briot et Cardot. De lents remiarquables études est sortie l'éclatante vérité de la dépendance étroite de la forèt et du bon entretien des nacages.

M. Paul Descombes, président de l'Assuciation centrale de l'Aménagement des montagnes, est venu, après eux, confirmer par ses lecons de choses sur le terrain, la parfaite justesse de leurs observations. Amené pár la lecture de ces ouvrages, le récit de ces travaux, à étudier l'application de leurs idéns dans la chaine des Pyrénées, j’ai pu constater combien elles etaient vraies et la statistique de la propriété communale dans la zone montagneuse des Pyrénées m'a conduit à formuler le résultat de mes recherches dans les turines suivants :

\section{Plus une région est boiste, plus elle nourril d'animaux.}

La lecture du tablean qui suit montrera l'xactitude de cette loi. I'our arriver à l'étahlir rl'une manière sérieuse, j'ai dû longtemps chercher l'explication d'anomalies qui, brusquement, venaient interrompre la progression régulièr" entre le taux de boisement et le nombre d'animanx.

Mais peu à peu la question s'est éclaircie ; ce qui, a:ı début, praraissait être dnomalie, est devenu justification de la loi, répondant aux justes objections qui m’avaient été faites.

C'est ainsi que j'ai été conduit a diviser les vallées pyrénéennes en rallées supérieures et vallées infériemres, les premières étant celles dans l'altitude moyenne, c'est-à-dire la plus grande partie des pâturages étant superieurt à 1.000 mètres - - les secondes étant celles où ils sont au-dessous d+1.000 metres.

Lobjection tirée de la supériorité des pacages sitvés dans les terrains plas fertiles les uns que les antres, se tronvait ains i résolut, fes proportions dans lrs denx catégories de vallées rupenaient leur régulariti.

Cette première classification faite, des irrógularités dans la plogression rigur 
lière de la proportion subsistaient encore. Elles étaient moins nombreuses, et se sont expliquées par la différence entre les climats océanien et inéditerranéen.

La possibilité des pâturages suit une marche absolumcnt égale à la transition qui se fait presque irisensiblement entre les deux climats, de son maximum dans le Béarn et la Bigorre, elle arrive à son minimum dans le Roussillon.

Le Lez, le Sarlat, l' Iriège sont la prenve indiscutable de cette progression.

Une autre difficulté, en apparence la plus malaisée à résoudre, apparaissait brusquement dans toutes les régions, déroutant tous les calculs. Dès quon arrivait à une proportion boisée dépassant $30 \%$, aucune règle ne pouvait plus ètre établie.

Après de longues recherches pour découvrir la raison de cette anomalie, j'en suis arrivé à conclure yu'au delà de ce taux de boisement de $30 \%$, la diminution du sol restant libre pour le pacage n'était plus compensée pau l'action bienfaisante de la forèt, et que l'harmonie entre les forêts et les pàturages était rompue au détrinrent de ces demiers.

Vous omettez, me disait-on encore, dans vos calculs, de tenir compte du nombre des animaux étrangers introduits dans les divers bassins, ce qui forcément peut augmenter la possibilité, puisque vos calculs reposent sur la statistique du Ministère de l'Agriculture, ne comprenant que des arrimaux vivant toute l'année dans les communes.

Cette objection n'avait pour moi aucune portée, l'enquête très minutieuse a laquelle je me suis livré pour établir mes statistiques de la propriété communale dans la zone montagneuse m'ayant pleinement démontré que, eu égard à la superficie des territoires de chaque bassin, le nombre d'animaux étrangers qui y étaient annuellement introduits était partout très sensiblement le mème, et prouvé en mème temps que dans les montagnes, depuis quelques années, ce nombre tend partout constamment à décroître.

Après ces explications, il me reste deux observations importantes à fair pour que la lecture du tableau soit facile et claire.

A taux de boisement égal, la possibilité entre bassins des mèmes régions, est parfois différente. En parcourant l'état des forèts, on se rendra compte yut cette différence provient toujours de la proportion des bois soumis. Plus celleci, eu égard à la superficie des bois non soumis est élevée, plus la possibilité est graude. I e bon état des forêts non soumises y exerce quelquefois une légèr inlluence; mais la faible étendue des parcelles de bois particuliers permet de la regarder généralement comme absolument négligeable.

Les hassins d'Ossau, et des Neste, d'Ame et du Louron, sont notamment uis exemple de ce fait.

Enfin, j’ai pu parfois grouper ensemble certains bassins contigus. Cela s'est produit six fois. Fn voici les raisons :

Le Bastant et le Gave supérieur de Pau parcourent la vallée de Barèges, dont 33.611 hectares formant les $3 / 4$ de la superficie lotale appartiennent collectivement aux seize communes réparties dans toute la vallée.

Les communes des bassins de l'Ouzom, des gaves d'Arrens, Bun, Cauterets, sont tellement encherêtrées entre ces divers bassins, grevées les unes au profit des autres de tels droits d'usage, de pacage, d'indivision, qu'il est absolument impossible de faire la classification par bassirs isolés.

Il en est de même pour les bassins des Neste, d'Aure et dı Louron ; des gaves d'Aspe, et du Vert des nives d'Arneguy, de Behobie, de Lauribar ; «u gave de Pau inférieur et de l'Echezz.

Chacune de ces régions ainsi composées forme des massifs montagneux aux limites communales chevauchant sur les divers versants, aux droits de pacage, d'usage, d'indivision à peu près inextricables. Au point de vue de l'industrie pastorale, chacune constitue dans son ensemble une région nettement déterminée.

Enfin, me conformant à la vieille et immémoriale tradition de toute la chaine des.s Pyrénées, j’ai pris pour base de tous mes ealculs la barcade, qui a toujours 
été l'unité des troupeaux de montagne, assimilant pour les droits, pour toutes les redevances, une vache à dix montons; j'a i trad ıit la possibilité cles pâturages par le nombre d'ares nécessaires à la nourriture d'un mouton.

RELATION ENTRE LE TAUX DE BOLSEMENT ET LE NOMBRE DANIMAUX

\begin{tabular}{|c|c|c|c|c|}
\hline \multirow{2}{*}{$\begin{array}{c}\text { TAcx } \\
\text { de } \\
\text { boisement } \\
\text { pour cent } \\
\text { de la } \\
\text { superfieie } \\
\text { totale } \\
\text { des bassins }\end{array}$} & \multirow{2}{*}{$\begin{array}{l}\text { Youbke } \\
\text { d'ares } \\
\text { néeessaires } \\
\text { pour } \\
\text { la } \\
\text { nourriture } \\
\text { d'un } \\
\text { mouton }\end{array}$} & \multicolumn{3}{|c|}{ NOMS DES BASSIN } \\
\hline & & Pyrénées Occidentales & Pyrénées Centrales & Pyrénées Orientales \\
\hline \multicolumn{5}{|c|}{ Vallées supérieures } \\
\hline 49 & 68 & $\begin{array}{l}\text { Le Bastan, Gave } \\
\text { de Pau supé- } \\
\text { rieur. } \\
\text { L'Ouzom, Gaves } \\
\text { d'Arrens, Bun, } \\
\text { Cauterets. }\end{array}$ & $\cdot$. & \\
\hline $\begin{array}{l}19 \\
22\end{array}$ & $\begin{array}{l}83 \\
47\end{array}$ & Gave d'Ossau. & $\ldots \ldots \ldots \ldots$ & La Têt. \\
\hline 22 & 46 & $\ldots \ldots \ldots \ldots \ldots$ & $\begin{array}{l}\text { Nestes d'Aure ef } \\
\text { du Louron. }\end{array}$ & \\
\hline 25 & 45 & $\begin{array}{l}\text { Gave d'Aspe et le } \\
\text { Vert. }\end{array}$ & & \\
\hline 25 & 79 & & $\ldots \ldots \ldots$ & La Sègre. \\
\hline $\begin{array}{l}27 \\
29\end{array}$ & $\begin{array}{l}22 \\
21\end{array}$ & $\begin{array}{l}\text { L'Adour'. } \\
\text { Le Saison. }\end{array}$ & & \\
\hline \multicolumn{5}{|c|}{ V'allées inférieures } \\
\hline 111 & 64 & $\cdots$ & Vicdessos. & \\
\hline 19 & 30 & $\begin{array}{l}\text { Nives d'Arneguy, } \\
\text { de Béobie, Lau- } \\
\text { ribar. }\end{array}$ & & \\
\hline 20 & 29 & $\begin{array}{l}\text { Gave de Pau partie } \\
\text { infér.. l'Échez. }\end{array}$ & & \\
\hline 22 & 70 & & & Le Tech. \\
\hline 23 & 24 & L'Arros. & & \\
\hline 25 & 31 & $\ldots \ldots \ldots$ & Le Le'z. & \\
\hline $\begin{array}{l}26 \\
26\end{array}$ & $\begin{array}{l}33 \\
46\end{array}$ & $\begin{array}{c} \\
\ldots \ldots \\
\ldots \ldots\end{array}$ & $\begin{array}{l}\text { Le Salat. } \\
\text { LiAriège. }\end{array}$ & \\
\hline \multicolumn{5}{|c|}{ Vallées dont le taux de boisemement dépasse 3100} \\
\hline 31 & 75 & $\ldots \ldots \ldots \ldots \ldots{ }^{\prime}$ & & L'Aude. \\
\hline $3 i$ & 31 & & La Neste. & \\
\hline 34 & 49 & & La Pirpue. & \\
\hline 35 & 39 & $\ldots \ldots$ & Lourse. & \\
\hline 38 & 48 & $\ldots \ldots \ldots \ldots \ldots$ & & Le Rebenty. \\
\hline $\begin{array}{l}11 \\
43\end{array}$ & $\begin{array}{l}31 \\
39\end{array}$ & & $\begin{array}{l}\text { Le Gers. } \\
\text { La Garonne, jus- }\end{array}$ & \\
\hline 46 & 31 & & $\begin{array}{l}\text { qu'a Hontréjeau } \\
\text { Le Nistos. }\end{array}$ & \\
\hline
\end{tabular}


Ie suis persuadé qu'après avoir attentivement. lu ce tableau, tout le monde serd d'accord pour reconnaître que la forêt est la protectrice nécessaire, indispensable ì l'industrie prstorale, l'aide sans laquelle celle industrie est appelée d dépérir rapidement el à disparaître même complètement.

M. LE Présidext. - Je serai certainement, messieurs, votre interprète à tous, en remerciant M. le comte de Roquette-Buisson, auteur du mémoire dont notre collègue vient de clonner lecture. Notre collègur est bien conmu de tous ceux qui ont parcouru la région pyrénéenne; il a fait des publications très intéressantes sur les questions pastorales et forestières. Nous prions M. Descombes de remercier M. de RoquetteBuisson, au nom de la section.

II. Desconbes. - Je serai très lutureux d'être rotre interprète auprès de M. Roquette-Buisson.

II. Descombes dit ensuite quelques mots de l'Association pour l'Aménagement des Montagnes et des Associations scolaires forestières créces par ses soins.

M. Le Présinent. - Je remercie en rotre nom, M. Descombes de sa communication et donne la parole à II. Maitre. qui a une communication intéressante à nous faire sur la question de la transhumance.

V. Mantre. - Tout le monde est d'accord pour la création d'un code pastoral impatiemment attendu, et tout le monde est d'accord aussi qu'il se heurte a des difficultés, par suite d'intérèts confradictoires qui sont en présence. C'est pourquoi j'ai pensé que la meilleure nunière de faire aboutir le code pastoral serait de le réaliser en détail, c'est-à-dire de faire aboutir d'abord les parties qui paraissent les plus urgentes at les plus efficaces. L ne fois qu'on aurait construit quelques piliers isolés, pour ainsi dire llu code jrastoral, il serait relativement facile de les relier, de les codifer, comme on a fait, par exemple, pour les lois concernant le travail.

Le point sur lequel l'accord semble être fait. parce que ciest celui pour lequel les abus sont le plus grands, c'est l'abus du pàturage daus les communaux. D'autre part, c'est sur les pàturages communaux qu'on a le plus d'action. puisque l'Etat est le tulemr maturel des communes. Te remande donc an Congrès d'émettre le vou quion commence immédiatement, sans attendr. l'établicsement d'un code pastrual, par s'attaquer à er léfant de réglementation des pâturages communaux el yuon mette entre les mains de l"Adninistration forestièie, si dérouée, si à mène d'en user, une arme sérieuse, lui permettent d'effectuer de réelles améliorations à cet égard, et rermettant igillement à l'État de ne pas travailler pour le roi dr. Prusse et de tirel protil to ce qui aura été réalisé.

1). là un enbryon de cole que je veux soumettre à l'appréciation du Congrès. Toiri les articles que je proposerais :

"()'il soit proct́dé au plus tôt à l'organisation d'un régime pastoral général, assurant la conservation et l'amélioration des pâturages de montagne. comme le régime forestier le fail pour les bois communaux;

(n'en attendaut, et dès maintcuant, dans les communes recerant actuellement des moutons transhumants ou étrangers, l'Etat prenne à sa charge le pri.e moyen de location de ces pâturages affectés au petit bétail, par application de l'article 5 de la loi de 1882 et par prélèvement sur les crédits mis à la disposition des services de reboisement.

Celle suborntion serait continuée aux communes pendant un nombre 
d'années à fixer, et, en outre, les pâturages leur seraient restitués après un court temps de repos, sous la double condition:

$1^{o}$ D'interdire absolument l'admission de moutons ou de cheores non hivernées dans la commune:

"2o De limiter" à lin nombre déterminé de tétes, 5 ou 6, par exemple, par famille, l'effectif du petit bétuil qui pourre dorrtavant être introduit gratuitement ou à bas prix duus les terraius communaux, aussi bien sur ces pâturage remis à la disposition des habitants que sur les pentes inférieures servant de pâturages printaniers.

"Liberté complète étant, d'ailleurs, laisisée actuellement uu pâturage du gros bétail.

En somme, au moment où les commines vont mettre en location 1.000, 2.00 hectares, je denande que l'État leur tienne ce langage : "Voici un terrain que vous louez 1.000 franes par exemple. Je me réserve de le prendre pour cette somme de 1.000 francs, avec cet avantage pour vous, que je vous le rendrai amélioré, et que d'ailleurs, mème pendant le temys où j’en iserai, ajrès un certain repos toutefois, je laisserai le pâturage aq bétail livelnant dans la commune. Seulement, je veux être rémunéré des sacrifices que je ferai sur ce terrain : je vous laisse à vous tous les bénéfices, jusqu'à concurrence du double de la valeur initiale, et je ne prendrai pour moi cque ce qui dépasse le double de cette valeur. Quant à cette plis-value, je l'affecterai à des améliorations pastorales on sylvicoles dans la conmune.

Évidemment, cette mesure serait encore peil de close dans l'usemble dn cole pastoral; mais elle aurait l'avantage d'ètre efficace et immédiatement applicable, et d'ailleurs, dans cette matiere plus qu'en tout autre, ce sont les petits ruisselets qui font les ruisseaux et les rivières. Ce texte ne soulèverait ancune objection de la part des habitants des commmes, puisqu'il réserve toujours le pâturage du gros et du petit bétail ajpartenant aux habitants dè la commune, jusqu'à concurrence du nombre de bêtes hiv̌ernées. J'ajoute yu'il faudrait absolument qu'un état des lieux soit fait au délıut du contrat, de manière que les améliorations introduites par l'État puissent être nettement constatées. Lorsque nous aurions réalisé quinze ou vingt petites lois comme celle-là, nous pourrions alors commencer à les codifier, et réaliser ce code pastoral que nous attendons depuis si longtemps ( 1 pplaudissements).

M. LE Président. - Je remercie en votre nom M. Maitre de sa communication. Il me semble quelle implique une conclusion. Il y aurait lien, pour donner satisfartion aux idées si justes qu’il a émises, d'émettre un voeu. Il fandrait notamment que les locations faites pal les communes à des trompeaux étrangers, et particulièrement d̀ des troupeaux transhumants, soient contròlées par le pouroir administratif; en vertu de la loi de 1884, les communes actuellement ont le droit de louer, toutes les fois que le bail ne lepasse pas 18 ans; il $n$ y a aucune espèce de contròle sur la location. Pour mpêcher Jabus lu parcours, il serait rxtrêmement intéressant qu"une disposition lógislative permit aux ponvoirs puhlics dr eontrôler les locations faites par les commmnes. Dautre part, il serait tres arantageux que l. Etat put participer à res locations.

Pour donmer satisfartion à re doulse desideratum, il y amrait peutitre lien pour la section, demettre mn reen qui pourrait ètre ainsi (1) 1 ç'11 :

\section{"Le Congrès émet le copu quien uttendaint qui une legistation pastorale}


soit promulguée, on adopte tout diabord des dispositions législatives en vue d'assurer le contrôle des locations faites par les communes et de faciliter à l'Etat la location de ces mêmes terrains. ")

11. Lirre. - Nous pourrions dire : En assurant à l'Etat la clansc du jermier améliorateur."

I. Le Présinent. - Le vou pourrait être ainsi coneu :

"Le Congrès émet le vœu qu'en attendant qu'une législation pastorale soit promulguée, on adopte d'abord des dispositions législatives en sue d'assurer un contrôle des locations faites par les communes, et de permettre à l'Etat d'exercer un droit doption sur ces locations, avec facnlté d'insérer dans le bail la clause du fermier améliorateur. "

Cette rédaction, mise aux voix, est adoptée.

M. le baron DE Belixas. - Je tiens à déclarer que je nai pu voter ce texte. Je ne suis pas partisan, en effet, de l'intervention de l'Etat dans les affaires des communes.

M. Le Président. - La parole est à M. Roth, pour une communication SUR UN NOUVEAU FORET POLR LA PLANTATION EN MOTTE.

M. Rотн. - Il у a quelque temps, un monvement partait de la France, lequel avait comme devise : Retournons à la Nature! " et qui tentait de s'opposẹr aux raffinements exagérés et à leurs conséquences pernicienses qui faisaient dis mrogrès de plus en plus grands dans le domaine de l'agriculture et de la sylviculture; ce mourement tendait à s'appuyer, de plus en plus, dans less exploitations, sur les moyens naturels.

Rien ne prouve mieux l'importance et la nécessité de ce mouvement, gulu sou développement rapide qui se fait remarquer partout, notamment aussi dans l'exploitation des forêts. La sylviculture devait, en effet, participer la première à re moavement, puisque c'était justement dans son domaine qu'on avait commis des fautes graves contre la nature.

11 est inutile de mentionner que l'exploitation par coupe unique et la régénṕration artificiclle ne correspondent pas du tout aux lois de la nature et que les jeunes forêts, créées ainsi, doivent végéter dans des conditions tout autr's que celles qui provienuent de la régénération naturelle. Il suffira de nous en rafporter à notre litterature techniqu qui exige avec énergie le reiour à l'installation naturelle de nos forêts et à leur éducation conforme à la nature, et de nous rappeler que la pratique revient de plus en plus à colte forme primitive de la régénération.

Arec la régénération naturelle, la plantation en motte acquiert une plus grande importance, puisque c'est imiquenent la plantation en motte qui place fes jeunes plants en terre, sans heurt et daus la même position qu'ils avicient avant.

Jo n’ai yas l'intention de répéter inatilement ici les grands avantages de la plantation en motte, romus fle tout homme dil métier. Tout le monde sait que cette plantation - jugér au point de vue de la sylviculture - est la meilleure et la seule qui soit conforme à la nature. C est surtout dans la régénération naturelle qu'elle peut ètre utilisée avee le plus grand succès parię que son seul dísavantage - le transport compliqué et coûteux - est réduil à soll minimunt.

Dams la régénération naturelle, il s'agit de regarnir des trouées mampluées; 
pour cela nous prenons les plants situés à proximité dans les groupes trop) serrés. Ces plants conviemuent le mieux puisqu'ils ont poussé dans les mêmes conditions que les roisins. Mais ce matériel qui convient le mieux, ne peut être utilisé que par la plantation en motte.

La plus ancienne forme de forèt n'a pu se propager, bien qu'clle ait été adoptée chez nous, en Hongrie, dans les emblèmes allégoriques forestiers. Cela tient sans doute à ce que ce foret convenail très bien pour enlever les plants, mais qu il était très difficile te sortir la motle du foret; il fallait pousser li motte avec la main; ce travail était sale et difficile. II camsait somvent des blessures aix mains. De plus, la motte s'émiettait.

On a fait un grand progres en employant des forets avec cylindre divisu ait moyen duquel la motte peut ètre levée rapidement et facilement. Nais cet avantage amenait do nouveau un grand inconvénient : la construction était compliquée et la solidité très affaiblie par suite de la division du cylindre. Les forets de ce systeme tonctionnent encore assez bieu dans un sol menble et léger, mais ils ne peuvent servir dans un sol dur, notamment lorsifu'il est pierreux ou traversé par des racines.

Pour remédier à ces inconvémients, j’ai constmit un foret qui rémnit les avantages des deux systemes sans avoil lears incouvénients.

Je suis revenu an cylindre fermé, e est-à-dire se composant d'mue senle pièce, parce que cette forme garantit la plas grande solidite. A ce cylindre sont attachées denx tiges de fer; pour rémnir la légèreté et la force de résistance, je me suis servi de fers un $\mathrm{T}$ qui sont joints entre eux, solidement, à trois endroits (voir Ia figure 1 , $a$ et $b$ ). La tige supérienre de jonction entre daus le manche massif en bois.

L'arrangement pour sortir des mottes est tont à fait nouveau, de construction originale, en mème temps que l'une simplicité étonnante.

Entre les denx tiges, il se ment un rail qui porte, attaché à deux tiges de fer, un anneau plat, lequel peut monter et descendre librement, avec le rail, entre de certaines limites. En posant le cylindre sur la plante et en l'enfonçant dans la terre - on fait alors agir sur le foret tout le poids du corps - lanneau se lève. Vu la solidité de l'instrument, on peut emplover une grande force en enfoncan' le foret; prisque le cylindre est tout à fait lisse à l'intérieur et à l'extériear, on peut le tourner facilement autour de son axe longiludinal, ce qui, avec son bord tranchant ondulé, facilite beaucorp son entrée dans la terre. Ceci esí un grand avantage vis-à-vis de tous les autres systèmes, qui sont divisés et possèdent à l'intérieur du cylindre des conteanx oà des saillants qui empèchent le mouvement tournant; én mème temps, la motte est bien formée ef bien lissée par suite de ce mouvement tournant.

Nous nous servons des jambes pour sortir la motte, sachant que les jambes peuvent développer une force beaucoup plus grande que les bras. Lorsque le foret est enfoncé assez profondément dans la terre, nous l'inclinons un pen pour détacher la motte par le bas. Iprès l'avoir sorlie de terre, nous mettons le pied sur la traverse de l'annean; une pression (en tenant le manche aven les deux mains) fait sortir du foret la motte, avec une forme irréprochable.

Ce forêt a un autre avantage (qu'ducun des systèmes actuels ne possède : c'est que la plante peut être transportée dans le foret mème isans sortir li motte) jusqu'à l'endroit de la plantation, el plantés directement du forrt en terre, ce qui simplifie beaucoun le travail, lorsqu'il s'agit de petites distauces. Surtout avec un sol meuble et une terre sèche où les mottes s'émiettent facilement, en anéantissant ainsi l'avantage principal de la plantation en motte, ceci est un avantage essentiel. Le foret, avec la molte el la plante, est placé dans le trou qu’on avait creusé auparavant. Puis le foret est sorti, l'anneau sur lequel on presse avec le pied maintenant la motu dans lo trom de plantation.

En résumé, ce nouvel appareil pour la plantation en motte pẹt stre utilisi avec le meilleur sucees partont où l'on peut travaitler aver des plants. en notle. 
Avantages. - La plus grande solidité arec une construction simple.

Durée illimitée: lés réparations qui pourraient être nécessaires peuvent être exécutées par chaque sermier on forgeron de village, vu la simplicité de la construction.

Le cylindre est tout à fait lisse à l'intérieur et à l'extérieur' il est massif et construit d'une seule piece si bien que le foret pent être enfoncé - au moven d'un mouvement tournant - dans un sol compact, traversé par des racines, même contenant des pierres. Le mourement toirnant facilite l'entrée dans le sol: il forme et lisse la motte.

La motte peut facilement et intégralement être sortie dir fer.

La levée de la motte et sa sortie dn fer se lont automatiquement, par une pression du pied, sans que la mottte soit touchée par la main.

On peut aussi transporter la motte dirertement rers le trou de plantation et la planter sans la sortir du foret.

Le travail est rapide sans être fatigant, puisqu'il uat réparti sur les bras ef sur les jambes (Applaudissements).

M. Le Présinext. - Je remercie M. Roth de son intéressante communication qui sera insérée dans le compte-rendu du Congrès, (Assentiment).

La séance est levée à 4 h. 10 . 


\section{SEANCE DU 18 JUIN 1913}

\section{(MATIN)}

\section{Présidence de M. LEDDET, vice-président de Section}

La séance est ouverte à 9 h. 1/4.

Sur l'invitation de 11. le Président, M. Joaquim Ferreira Borges, chef du Bureau des Forêts aux Travaux publics à Lisbonne, prenk place au bureau.

M. Le Président. - La parole est à M. Pardé pour la lecture de son rapport sur les Tourbières ét Marécages.

M. PARDÉ. - Les tourbières et marécages occupent sur la terre des surfaces importantes.

Ces surfaces, dans les différents pays, sont, le plus souvent, assez mal connues, faute de statistiques sérieuses à ce sujet. Tel est le cas, notamment, pour la France où on estime, d'une façon très approximative, que les tourbières et marécages couvrent environ 300.000 hectares.

Tous ces terrains marécageux et tourbeux sont, en grande partie, improductifs.

I] semble possible de les utiliser.

Sans doute, un certain nombre de tourbières, celles qui ne sont pas trop éloignées des habitations, peurent être mises en valeur par la culture agricole et, surtout, par la culture pastorale qui peut y prospérer et, lorsqu'elles se trouvent à proximité des villes, par la culture maraîchère qui, généralement, y réussit.

Pour toutes les autres, c'est certainement le reboisement qui permettrait d'en tirer le meilleur parti.

Et, au moment où tout le monde s'accorde pour réclamer une élévation du taux de boisement, tant pour suppléer à l'insuffisance de plus en plus grande de la production ligneuse, que pour régulariser le régime des eaux, améliorer le climat et augmenter la salubrité, il devient de plus en plus utile, nécessaire même, d'étudier sérieusement cette important question de la mise en valeur, par la culture forestière, des terrains marécageux et tourbeux.

L'opération est-elle possible? Quels sont les meilleurs movens à em. ployer pour y procéder? Tel est lobjet de ce rapport.

Tout d'abord, il y a lieu de considérer que les tourbières ne sont pas toutes de même nature. 
On distingue les tourbières supraaquatiques, appelées tourbières hautes, tourbières de montagne, tourbières moussues - en allemand "hochmoor" - qui doivent leur origine aux eaux de pluie et sont earactérisées surtout par la présence de mousses appartenant au genre sphagnum, de linaigrettes, de myrtilles, de bruyères; - et les tourbières infraaquatiques, nommées encore tourbières basses, tourbières de vallée, tourbières vertes - en allemand "flachmoor", "niedermoor" - qui sont dues aux eaux des rivières ou des lacs et sont caractérisées par la présence de roseaux, de earex, de jones, de graminées et de mousses du genre hypnum. Entre ces deux types, existent les tourbières intermédiaires ou de transition - en allemand "ebergangsmoor" - à la formation desquelles participent à la fois les eaux météoriques et les eaux telluriques et où l'on reneontre également des espèces végétales caractéristiques des tourbières hautes et des tourbières basses.

Cette distinction est, pratiquement, très importante. D’une façon générale, les tourbières hautes, dues à des eaux météoriques très paurres, sont beaucoup moins riches en prineipes nutritifs que les tourbières basses qui doivent leur origine à des eaux telluriques plus ou moins chargées de matières minérales et qui reçoivent fréquemment, a n moment des crues, des apports de substances fertilisantes.

Notamment, pour ce qui concerne la mise en valeur par la culture forestière, le reboisement est, en général, une opération beancoup plus difficile dans les tourbières hautes que dans les tourbières basses.

Il est donc nécessaire, avant d'entreprendre tout travail dans une tourbière, de déterminer bien exactement la nature de cette tourbière.

Qu'ii s'agisse de tourbières hautes ou de tourbières basses, les procédés fir employer pour installer la végétation forestière sont les mêmes.

Tout d'abord, il y a lieu de faire une étude générale complète de la tourbière, d'en lever le plan, avec nivellement, de se renseigner le pius exactement possible sur la composition chimique du sol, sur l'épaisseur de la couche de tourbe, enfin sur le niveau de l'eau en de nombreux endroits, aux différentes saisons de l'année.

Dans tous les cas, il y a lieu de prévoir deux catégories de travaux : les travaux de préparation du terrain et les travaux de boisement proprement dits.

En premier lieu, toute tourbière que l'on se propose de reboiser doit être préalablement asséchée, assainie. Les végétaux ligneux ont généralement des racines qui s'enfoncent plus ou moins profondément dans le sol; il est nécessaire que ces racines, qui ne pourraient vivre dans une terre non aérée, constamment baignée par des eaux plus ou moins stagnantes, trouvent toujours, pour se développer, une épaisseur suffisante de tourbe assainie, au-dessus du plan d'eau.

Abaisser le plan d'eau à un niveau convenable est donc la premièrt opération à faire. Et cette opération - tous les auteurs sont entièrement d'aceord sur ce point - est absolument indispensable.

Jusqu'à quelle profondeur faut-il abaisser Je plan d'eau? M. le professeur Tacke (1), de Brême, déclare que la hauteur d'un peuplement forestier est en rapport direet avec l'épaisseur du sol de la tourbière utilisable par

(1) Tacke. - Die Bewirthschafung der im Wald gelegenen Grünlands-und Hochmoore. - . Keitschrift für Forst-und Jagdwesen, 1900, page 38. 
les racines. Et il admet que le bon développement des végétaux ligneux sera certainement obtenu, lorsque cette épaisseur dépassera 1 mèłre.

On doit donc chercher à abaisser le plan d'eau à 1 mètre, et même davantage, si on le peut, au-dessous de la surface du sol. Mais, cela est souvent difficile à obtenir, quelquefois même impossible, par exemple, dans les tourbières basses, quand le niveau de l'eau dans la rivière ou le lac voisin est à une distance de la surface du sol inféricure à celle que l'on désire obtenir, pour le plan d'eau, dans la tourbière.

Certains auteurs conseillent d'obtenir cet abaissement du plan d'eau progressivement, au fur et à mesure que les racines des arbres se développent. 11 convient en effet de faire observer que le sol de la tourbière assainie et reboisée se tasse et s'affaisse peu à peu.

Comment obtenir l'abaissement du plan d'eau? Des drains courraient le risque d'être plus ou moins endommagés ou même détruits par les racines des arbres ou, simplement, par suite de l'affaissement du sol. Il est donc préférable d'obtenir l'assainissement de la tourbière au moyen de fossés à ciel ouvert, dont les terres, rejetées sur le sol, viennent en augmenter l'épaisseur.

Ces fossés peuvent être entretenus facilement.

Ils présentent, en outre, l'avantage de pouvoir, au moyen de barrages de retenue construits à cet effet, permettre d'irriguer la tourbière, ce qui peut ètre très utile durant les périodes de sécheresse.

Suivant les conditions, les fossés d'assainissement sont espacés de 3 à 6 mètres et même davantage; ils peuvent mesurer de $0 \mathrm{~m} .60$ à $1 \mathrm{~m} .20$ de largeur à la guenle, de $0 \mathrm{~m} .30$ à $0 \mathrm{~m} .50$ de largeur au fond et de $0 \mathrm{~m} .20$ a $0 . \mathrm{m} .50$ de profondeur, et même plus, suivant que la tourbière est plus ou moins humide et qu'il s'agit de fossés bordiers, de fossés principaux ou de fossés secondaires.

Le sol de la tourbière une fois assaini, il est ordinairement utile, et même souvent nécessaire, de l'enrichir au moyen d'apport d'engrais.

En aucun cas, écrit M. le professeur comte dé Leiningen (1), de Vienne, on ne peut se dispenser d'apporter des engrais, car, au moins pendant la première révolution du peuplement forestier installé sur la tourbière, le sol n'est pas assez riche pour nourrir les arbres.

D'apr'ès ce qu'a été dit plus haut, cet apport d'engrais est surtout nécessaire, lorsqu'il s'agit d'une tourbière haute.

Les substances qu'il y a lieu d'apporter sont, en général, l'acide phosphorique, la potasse, et, exceptionnellement, l'azote. Une application de chaux est également très utile, au moins dans les tourbières hautes, et surtout si cette application est faite avant les plantations, car la chaux provoque une décomposition plus rapide de la tourbière (2).

Les engrais doivent être apportés sous des formes et en des proportions convenables. Ordinairement, on apporte l'acide phosphorique à l'état de superphosphates ou de scories de déphosphoration; la potasse, sous la forme de chlorire de potassium, de sulfate de potasse ou de kainite; l'azote, à l'état de nitrate de soude ou de sulfate d'ammoniaque; la chaux, sous la forme de marne, de chaux ou d'écumes de défécation.

(1) Wilh. de Leiningen. - Die 11 aldvegetation prealpiner bayerischer Hoore, page 67. Munich, 1907.

(2) Wilh, de Leiningen. - Même ousrage, page 66. 
Les scories de déphosphoration et les phosphates Thomas, qui apportent en même temps de l'acide phosphorique et de la chaux, sont, généralement, les engrais à appliquer de prélérence.

II. le professeur baron von Tubeuf (1), de Munich, a étudié scientifiquement l'action des diver's engrais sur les pins, dans les tourbières hautes. Il résulte de ses expériences que l'acide phosphorique, appliqué seul ou en mélange, dome toujours de bon résultats, tandis que les autres engrais, qu'ils soient donnés seuls ou en mélange, sont presque sans effet, si on ne leur adjoint pas l'acide phosphorique. En outre, l'acide phosphorique serait assimilé plus facilement et plus rapidement à l'état de biphosphate de soude que sous la forme de scories Thomas. Mais, le biphosphate de soude coûte très cher et il n'est pas facile de se le procurer dans le commerce.

M. Yinspecteur Schnyder à Neureville, un des forestiers suisses qui connaissent le mieux la question du reboisement des tourbières, a employé arec succès les scories de déphosphoration et la kainite. Et son collègue, M. Liechti, inspecteur à Morat, recommande l'apport de scories contenant $18 \%$ d'acide phosphorique et de kainite renfermant $12 \%$ de potasse.

D'après MII. Gully et Baumann, les débris de démolition des maisons, qui renferment en moyenne $0,50 \%$ d'acide phosphorique, $0,50 \%$ d'azote et $0,75 \%$ de potasse, peuvent être avantageusement utilisés, lorsque les frais de transport ne sont pas trop élevés. Mais, il n'est pas douteux que ces matériaux agissent davantage par leurs propriétés phyques et par leur teneur en chaux, que par les faibles quantités d'acide phosphorique, d'azote et de potasse qu'ils contiennent.

II. le professeur comte de Leiningen (2) signale aussi l'emploi des terres des routes qui renferment de l'acide phosphorique, de l'azote, de la chaux et un peu de potasse.

Graebner conseille éventuellement la culture du lupin, comme engrais vert, dans les tourbières, - dans les tourbières hautes, sans doute.

A quelle époque doivent être appliqués les engrais? A l'automne qui précède les travaux de boisement proprement dits, répond M. l'inspecteur Liechti.

Une autre opération qui pourrait être utilement faite, avant les plantations, consisterait à détruire, aussi complètement que possible, les régétaux herbacés qui absorbent une partie des substances nutritives contenues dans le sol et sont susceptibles d'entraver le développement des jeunes plants forestiers.

Mais cette opération, pour être pratiquée avec succès, nécessite des labours convenablement exécutés et, par suite, difficiles et coûteux; et elle doit avoir, pour complément, l'engazonnement du sol.

Peut-être, serait-il possible d'y procéder plus facilementet plus économiquement, en employant des solutions chimiques judicieusement choisies et appliquées.

Le terrain de la tourbière étant ainsi préparé, quels sont les travaux de boisement proprement dits et comment y procéder?

(1) Von Tubeuf. - Düngungssersuch zu Kiefern anf Hoochmoor. - Naturwissen-

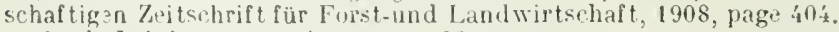

(2) 13 I, oining?n, op. citat., page $6 \%$ 
Tout d'abord, il convient de ne commeneer les semis ou plantations que un ou deux ans - on attend deux ans dans l'Hertogenwald belge après la fin des travaux indispensables d'assainissement; il est en effet nécessaire de laisser le sol de la tourbière s'assècher et se tasser convenablement.

Doit-on procéder au boisement par semis ou par plantation?

Sauf dans certains eas particuliers, le semis n'est pas à eonseiller dans les tourbières, à cause des froids et des gelées qui $\mathrm{r}$ sévissent souvent, de la sécheresse des eouches superfieielles pendant l'été, des herbes qui menacent d'étouffer les jeunes plants les végétaux ligneux résistent d'autant mieux aux gelées de l'automne et du printemps, comme aussi à l'envahissement des herbes, qu'ils sont de taille plus élevée.

Done, très généralement, la plantation est préférable et, en fait, e'est le mode de boisement le plus employé, de beaneoup, dans les terrains maréeageux et tourbeux.

Il convient d'employer de forts plants, repiqués, ear ils résistent mieux au froid et à la séeheresse et peuvent mieux lutter contre la végétation herbacée.

A quelle époque faut-il planter de préférence? Sans vouloir formuler de prineipe absolu à ee sujet, on peut dire que le printemps est, en général, la saison la plus favorable pour installer des plants forestiers dans lé tourbières qui sont ordinairement des "trous à gelée ». Tel est aussi l'avis de M. l'inspecteur Liechti.

Comment procéder aux travaux de plantation?

Le plus souvent, la plantation s'effectue partrous qu'il convient d ouvris dans l'automne qui précède la mise à demeure, afin que la terre puisse se déliter et s'aérer.

Les trous sont disposés en quineonce, à des intervalles plus ou moins éloignés, sur des lignes plus ou moins espacées et avee des dimensions en largeur et en profondeur plus ou moins grandes, suivant la nature et la taille des plants.

On augmente avantageusement l'épaisseur de la conehe de terre assainie, en rejetant la terre des fossés sur les bandes à cultiver et, lorsque cela est possible, sans frais trop élevés, en apportant sur ces bandes de la bonne terre provenant du sous-sol ou d'ailleurs.

Lorsque le terrain est très humide ou que le plan d'eau est à une faible profondeur, on peut, dans le même but, comme eela a lieu dans l'Hertogenwald belge et eomme l'a fait M. Liechti sur certains points, installer les plants sur des buttes ou, eneore, sur des mottes engazonnées qui, souvent, peuvent être fournies par l'ouverture des fossés.

Dans les parties bien assainies, M. Liechti a eu de bons résultats en plantant sur les ados obtenus, l'année précédente, par le labour à la eharrue de deux sillous contigus.

Enfin, toutes les fois que eela est possible sans augmenter par trop la dépense, il est excellent d'apporter, au pied des plants, des pierres ou. défaut, du sable; cet apport entretient un peu de fraicheur, empeche le déchaussement et maintient la terre au contart des raeines.

Quelles sont maintenant les essences qu'il convient de planter de préférence dans les terrains tourbeux?

D'une façon générale, les tourbières étant ordinairement très exposés 
aux gelées, il faut choisir des arbres particulièrement résistants à ce point de vue.

Dans les tourbières basses, les essences qui réussissent ordinairement le mieux, abstraction faite des peupliers, des saules osiers et des arbres fruitiers, sont, parmi les espèces feuillues : l'Aune glutineux (Alnus glutinosa Gaerter) qui convient parfaitement, si on ne tient pas à avoir des bois de fortes dimensions (1); l'Aune blane (Alnus incana Willd), qui, d'après M. Liechti, a, sur le précédent, l'avantage de drageonner, ce qui rend les plantations complémentaires moins nombreuses, et d'être moins attaqué par le charançon de l'aune (Cryptorhynchus Lapathi L.); les Bouleaux bubescent (Betula pubescens Ehrh.) et verruqueux ( $B$. verrucosa Ehrh.) qui fournissent de bons rendements en bois de feu; le Frêne commun (Fraxinus excelsior L.) qui s'accommode bien de parties assez humides et donne un bois supérieur en dimensions et en qualités à ceux des espèces précédentes - et, accessoirement, les érables, les chênes, les tilleuls; parmi les espèces résineuses : le Pin sylvestre (Pinus sylvestris L.) et l'Epicéa élevé (Picea excelsa Link).

Les peupliers peuvent également réussir dans les tourbières basses tt y donner alors de beaux revenus.

Les saules, cultivés pour la production des osiers, sont également susceptibles de fournir de bons rendements dans les tourbières. Pour cette culture, M. Wilhelm Bersch (2) conseille de bien assainir le terrain, de détruire la végétation spontanée, de retourner le sol, en évitant de le labourer au delà de $0 \mathrm{~m} .20$ à $0 \mathrm{~m}$. 25 de profondeur, et d'introduire les saules, de préférence au printemps, au moyen de boutures espacées de $0 \mathrm{~m} .10$ à $0 \mathrm{~m}$. 15, sur des lignes distantes de $0 \mathrm{~m} .50$ à $0 \mathrm{~m}$. 75. D'après II. Reppin, les boutures ne doivent pas avoir plus de $0 \mathrm{~m}$. 20 à $0 \mathrm{~m} .25$ de longueur, et elles doivent être complètement enfoncées dans la tourbe, sauf lorsqu'on a fait un apport de sable, auquel cas elles sont plantées dans la couche de sable sur une longueur de $0 \mathrm{~m} .10$ et dans le sol de la tourbière pour le surplus. Les meilleures espèces de saule pour la production des osiers sont: Salix purpurea L., S. triandra L., S. alba L. var. vitellina, S. fragilis L., S. viminalis L. M. Wein déclare que le rendement peut être augmenté considérablement par l'emploi des fumures artificielles.

Les arbres fruitiers, notamment les pommiers à cidre, paraissent aussi devoir réussir dans les tourbières basses.

Dans les tourbières hautes, on peut introduire, parmi les espèces fevillues : les bouleaux qui s'accommodent des parties les plus sèches, et, parmi les espèces résineuses : l'Epicea élevé (Picea excelsa Link) qui, d'après M. Liechti, peut se maintenir jusqu'à l'âge où cette essence fournit des poteaux de télégraphe, et qui, dans certaines régions, est avantageuse à cultiver, d'après M. Bersch, pour la production d'arbres de Noël; le Pin de montagne (Pinus montana Mill.), "la meilleure espèce pour le reboisement des tourbières hautes ", déclare M. le professeur comte de Leiningen (3); le Pin sylvestre qui, dit M. Liechti, est susceptible de bien venir, mais qui, le plus souvent, prend une forme très étalée et ne présente qu'un fût très court. D'après M. Liechti, le Sapin pectiné (Abies pectinata D. C.) pourrait être introduit après les preniers boise-

(1) de Leiningen, op. cit., page 75.

(2) Wilhelm Bersch. - Handbuch der Moorkultur. Chapitre VI. $2^{2}$ édition. - Vienne et Loipzig. 1912.

(3) de Leiningen, ap, cit., page 75. 
ments. Enfin, le Pin Cembro (Pinus Cembra L.) a réussi dans quelques tourbières de montagne.

Les essences exotiques peuvent-elles rendre des services pour le boisement des terrains tourbeux? Bien que certaines, parmi elles, aient été déjà expérimentées assez anciennement - W W Bühler (1), en 1831, parle d'expériences de ce genre, qu'il qualifie de jeu - il n'est pas encore possible de se prononcer nettement sur ce point.

En tout cas, il serait certainement exagéré de formuler dès maintenant une réponse négative.

Déjà, le Pin Weymouth (Pinus Strobus L.) a donné de bons résultats en plusieurs endroits et M. l'inspecteur forestier Womacka signale sa belle venue, jusqu'à présent, dans les essais qu'il poursuit, depuis l'année 1900, dans une tourbière de transition, située en Bohême.

De même, l'Epicea de Menziès (Picea sitkaensis Carr.) a réussi sur certains points, notamment dans l'Hertogenwald belge.

En revanche, l'Epicea piquant (Picea pungens Engelm.) a échoué dans les quelques essais dont il a été l'objet jusqu'à ce jour.

En définitive, certaines espèces, déjà expérimentées, ne l'ont pas encore été suffisamment, et d'autres, qui paraissent intéressantes, n'ont pas été essayées jusqu'à présent.

Dans ces conditions, il n'est pas possible, actuellement, de prendre une conclusion, en ce qui concerne l'opportunité d'introduire des essences exotiques dans les terrains tourbeux.

La question reste à étudier. Et, dans cette étude, il conviendra de ne pas oublier que les résultats peuvent varier suivant la nature de la tourbière, la composition chimique du sol, l'épaisseur de la couche de tourbe et le niveau du plan d'eau. Les essais devront être faits dans tous les cas différents.

Lorsque la végétation forestière aura été installée sur une tourbière, il sera nécessaire, au moins au début, de prendre certains soins pour la maintenir.

Tout d'abord, il est indispensable d'entretenir en bon état les fossés d'assainissement, et cela aussi souvent qu'il devient utile de le faire. Cet entretien s'impose d'autant plus que le sol de la tourbière assainie et reboisée tend à se tasser progressivement, à s'affaisser.

Les jeunes plants peuvent être exposés au déchaussement; on y remédie par l'apport de pierres ou de sable et, au besoin, en tassant la terre, à leur pied, au moyen d'un pilon.

Cette dernière opération peut être également utile, durant les périodes de sécheresse, pour ramener, au contact des racines, la terre devenue sans consistance.

Jusqu'à ce que les plants soient assez forts pour se défendre contre les végétaux herbacés, il est nécessaire de les protéger contre ces derniers ; pour cela, il convient, durant l'été, de couper les herbes qui sont dans le voisinage des plants, puis, à l'automne, de procéder à un fauchage général de la végétation spontanée.

Enfin, lorsque cela est possible. il est excellent, pendant les périodes de sécheresse, d'utiliser les fossés d'assainissement pour irriguer la tourbière.

(1) W. Bühler. - Die Versumptung der Wälder mit und olne Torfbildung und die Wiederbestockung derselben mit besonderer Hinsicht auf den Scwarawald. Tübingen. 1831. 
On voit, d'après ce qui précède, que le reboisement d'une tourbière, surtout lorsqu'il s'agit d'une tourbière haute, est une opération le plus souvent difficile, presque toujours très coúteuse et qui, faute de données encore bien certaines sur les moyens d'y procéder, comporte ordinairement beaucoup d'aléas.

Aussi, est-ce aux collectivités qui disposent des fonds nécessaires et peurent attendre les résultats, notamment à l'État, aux départements, aux communes - et aussi, aux sociétés - qu'il appartient surtout d'entreprendre ces travaux.

Si l'opération est difficile, il ne semble pas qu'elle soit impossible.

On peut citer des cas assez nombreux de réussite.

En Belgique, les forestiers sont parrenus à reboiser avec succès les hautes fagnes de la région de Spa (1). Dans cette région, l'assainissement est obtenu par l'ouverture de fossés distants de 3 à 6 mètres, d'axe en axe, suivant le degré d'humidité du terrain. Les plantations ont lieu deux ans plus tard. Elles sont faites en buttes, et, dans les parties les plus humides, sur des mottes de gazon provenant en partie des fossés. Comme essence, on emploie surtout des epiceas âgés de 4 ans, dont 2 ans de repiquage, que l'on plante en quinconce, à $1 \mathrm{~m}$. 50 d'intervalle, sur des ignes espacées de 2 ou 3 mètres ; soit un total de 2.200 ou 3.300 sujets à l'hectare. Chaque plant reçoit environ 25 grammes de phosphate basique que l'on mélange intimement à la terre du trou représentant en moyenne 1 décimètre cube.

En Suisse, M. Liechti, inspecteur forestier à Morat, a reboisé arec succès une partie des tourbières basses étendues qui avoisinent le lac de Neufchâtel (2). Par suite des travaux d'assainissement, le plan d'eau s'est trouvé abaissé à $1 \mathrm{~m}$. 50-2 mètres, au-tessous de la surface du sol, du moins au début, car depuis, la tourbière s'est tassée et affaissée. Les plantations, qui eurent lieu 1 ou 2 ans après l'assèchement, ont été effectuées sur les ados obtenus par le labour de deux sillons contigus ou, dans les parties insuffisamment assainies, sur des buttes de terre. Les essences employées ont été, parmi les espèces feuillues : le bouleau, l'aune, le frène, et, parmi les espèces résineuses : l'epicea et le pin Weymouth; le pin sylvestre a médiocrement réussi. On a planté aussi des peupliers et des saules.

Les travaux, commencés en 1879, ont donné de très bons résultats, tant au point de vue forestier qu'au point de vue de l'amélioration du climat. Les parties peuplées de feuillus, traitées en taillis sous futaie, ont été déjà exploitées trois fois. La quantité et la qualité des produits réalisés ont été satisfaisantes. Mais, chaque exploitation doit être suivie de plantations complémentaires, car un certain nombre de souches ne repoussent pas.

En Allemagne, les travaux de reboisement de tourbières ont été assez. nombreux et quelques-uns sont déjà assez anciens.

II. If professeur comte de Leiningen cite, d'après Sendtner, ceux qui

(1) Bulletin de la Société centrale forestière de Belgique, années 1896 et 1900. - E. Nélis. Les hautes fagnes de l'Hertogenaald. Bulletin de la Société centrale forestière de Belgique, anvier et février 1908. - Progiamme du V'Ie Congrès de l'Union internationale des stations de recherches forestières. Bruxelles, 1900.

(2) Liechti, Beobachtungen auf dem Gebietc der Moosaufforstungen. - Schwcizerische Zeitschrift für Forstwesen, mai 1906. 
ont été effectuées par le forestier de Larosée dans les tourbières hautes situées près de Rosenlıeim, en Bavière, où 650 arpents furent mis en valeur, par la culture forestière, de 1822 à 1850 (1). Les fossés d'assainissement furent ouverts dlans des conditions particulièrement favorables. Les essences employées furent le bouleau de l'épieéa.

II. de Leiningen signale encore; d'après un rapport du forestier $K$. L. Pfob, les reboisements exécutés dans la tourbière de la vallée de Joachim (2). L'assainissement fut opéré vers le milieu du siècle dernier. Les plantations furent faites en buttes, à 2 mètres d'intervalle. L'essence utilisée a été l'epicea. Malgré les gelées tardives, très fréquentes en cet endroit, les jeunes sujets ligneux se sont bien développés.

En ce qui concerne l'Allemagne du Nord, on trouve, dans les compterendus des travaux de la Commission centrale des tourbières, années 1876-1879, page 33, un rapport sur les cultures forestières, commencées en 1855, dans les tourbières hautes du haut Venn, où 5.000 arpents, sur 30.000 , furent plantés avec succès en épicéas.

M. Liechti cite aussi les reboisements en epiceas, effectués dans les environs de Brême.

En Autriche, N. W. Bersch signale les beanx résultats obtenus avec Pinus montana rotundata dans le domaine du prince de Schwartzenberg, en Bohême (3).

Des travaux de reboisement importants ont aussi été entrepris dans les terrains marécageux et tourbeux qui aroisinent le lac de Chiem, en Bavière. Mais, les plantations anciennes occupent des surfaces trop restreintes et les dernières exécutées sont trop récentes, pour qu'on puisse tirer des conclusions définitives.

En France, il faut l'avouer, on s'est fort peu préoccupé, jusqu'à présent, du reboisement des tourbières et il a très pen été écrit sur le sujet.

Sans doute, il existe cà et là, dans des vallées à sol plus ou moins tourbeux, de belles plantations de peuplier. Et les essais que poursuit à Andryes, dans le département de l'Yonne, II. Schribaux, professeur à l'Institut national agronomique, semblent démontrer que l'on peut obtenir de très bons résultats, en employant des peupliers de 3 ans, plantés au printemps, dans des trous ouverts, à l'automne précédent, sur $0 \mathrm{~m} .80$ en tous sens, et en mélangeant intimement, à la terre provenant de chaque trou, 2 kilogrammes de scories de déphosphoration et 1 kilogramme de chlorure de potassium.

Sans doute, on rencontre aussi, dans quelques fonds tourbeux, des cultures rémunératrices de saules osiers.

Mais, de boisements forestiers proprement dits, effectués sur des tourbières, il n'en existe pas d'anciens, à ma connaissance du moins. Et les essais entrepris dans ces derniers temps sont encore bien peu nombreux.

Je ne puis signaler que ceux qui ont été exécutés dans les tourbières de Frasne (Doubs) et ceux qui ont lieu actuellement dans les marais de Bresles (Oise).

En 1901, la commune de Frusne entreprit de reboiser une partie des

(1) de Leiningen, op. cit., page 68.

(2) de Leiningen, op cit., page 71 .

(3) W. Bersch. - Handbuch der Monkultur. Chagitire VI. 2e édition - Vienne et Leipzig, 1912. 
importantes tourbières hautes qu'elle possède dans l'arrondissement de Pontarlier (1). Le terrain dont il s'agit est traversé par une sorte de canal ou l'eau s'écoule assez mal, faute d'une pente suffisante. Il ne fut pas ouvert d'autres fossés d'assainissement. Aucun engrais ne fut apporté,

Au printemps de 1901, des sujets des essences suivantes furent plantés: Alnus cortada Desf. (500), Betula papyracea $\Lambda$ it. (500 qui furent remplacés à l'automne suivant), Betula lenta 1. (500 qui durent être remplacés à l'automne), Alnus incana Willd. (200 dont 25 furent remplacés à l'automne), Fraxinus americana L. (100 dont 10 furent remplacés à l'automne), Liquidambar slyraciflua L. (200 dont 180 furent remplacés à l'automne), Liriodendron tulipifera L. (100), Chamaecyparis Lawsonianá Parl. (500, dont 100 furent remplacés à l'automne), Chamaecyparis nutkaensis Spach. (500 dont 300 furent remplacés à l'automne), Thuya gigantea Nutt.) (500 dont 350 furent remplacés à l'automne), Pinus syluestris L., var. rigensis (500 dont 100 furent remplacés à l'automne), Pinus Banksiana Lamb.) (500 dont 40 furent remplacés à l'automne), Pinns ponderosa Dougl. (500 dont 40 furent remplacés à l'automne), Pinns Strobus L. (200), Pins divers (80), Epicéa de Norvège (500), Larix sibirica Ledeb. (500 qui furent remplacés à l'automne), Larix leptolepis Murr. (500 qui furent remplacés à l'automne), Picea sitkaensis Carr. (500 dont 135 furent remplacés à l'automne), Sapin de Russir (500 dont 130 furent remplacés à l'automne); en outre, il fut planté, à l'automne de la même année 1901 : 100 Prunus serotina Ehrh., 100 Taxodium distichum Rich. et 100 Abies grandis Lindl.

De toutes ces plantations, il ne restait plus guère, à l'automne de 1903 , que quelques pins sylvestres de Riga et quelques pins de Banks.

Le terrain fut alors clôturé el divisé en 14 carrés.

Aux printemps des années 1904, 1905 et 1907, on y planta : 800 Alnus glutinosa Gaertner, 3.200 Alnus incana Willd., 270 Betula papyracea Ait., 200 Betula lenta L., 300 Betula lutea L., 100 Juglans nigra L., 200 Tsuga Mertensiana Carr., 50 Abies grandis Lindl. qui furent remplacés, 250 Picea alba Link, 600 Picea pungens Engelm, dont 400 furent remplacés, 310 Picea sitkaensis Carr., 500 Pinus sylvestris L., 600 Pinus Laricio Poir., var. austriaca, 570 Pinus Banksiana Lamb., 610 Pinus rigida Mill. dont 270 furent remplacés, 200 Pinus Strobus L., qui furent remplacés, 300 Pinus Cembra L., 100 Taxodium distichum Rich. et 300 Thuya occidentalis L. dont 220 furent remplacés.

Toutes ces plantations furent effectuées en potets, à l'exception de 170 Pinus Banksiana qui furent plantés sur buttes légères, au printemps de 1907.

En juillet 1912, il ne restait plus, de toutes les plantations exécutées, que quelques pins sylvestres et quelques pins de Banks.

D'après ce qui a été dit plus haut, cet insuccès ne doit pas surprendre, étant donné qu'il s'agit d'une tourbière haute, qu'il n'a pas été fait de travaux d'assainissenent et qu'il n'a été apporté aucun engrais. Il semble aussi qu'on ait employé un trop grand nombre de plants d'essences exotiques non encore suffisamment expérimentées, surtout dans ces conditions très spéciales, et qu'on n'ait pas fait une place assez impor-

(1) Ronseignements domnes trar M. Cuif, Inspecteur des Faux et Forêts, attaché i la station des recherches forestières de Vancy. 
tante aux espèces indigènes mieux connues, notamment à l'epicea élevé qui paraît l'arbre le plus indiqué dans ces stations.

Il serait certainement très intéressant de reprendre ces expériences, en tenant compte de ces observations et, en particulier, après assainissement du terrain et avec apport d'engrais.

Nalheureusement, la commune de Frasne, découragée par cet insuccès - on pourrait l'être à moins, - semble actuellement peu disposée à entreprendre de nouveaux travaux.

A Bresles (Oise), M. Schribaux et moi procédons depuis 1908, avec des crédits mis à notre disposition par la Commission des Etudes scientifiques, à des essais méthodiques de boisement, dans un champ d'expériences concédé gracieusement par la commune dans les marais tourbeux qui lui appartiennent.

Le champ d'expériences forestières de Bresles, d'une surface de 1 hectare 25 ares, est situé en terrain presque complètement plat, à l'altitude de 60 mètres environ; il est limité à l'Ouest par le ruisseau de Trye, affluent de la rivière Thérain; au Nord et à l'Est, par une fausse rivière qui aboutit à la Trye, dans l'angle Nord-Ouest du terrain.

La tourbière de Bresles est une tourbière basse.

La couche de tourbe, dont la partie utilisable a été exploitée, a une épaisseur moyenne de 2 mètres ; elle repose sur un sable profond.

Les travaux de préparation du terrain ont été les suivants : ouverture, en 1908, d'un fossé bordier de $1 \mathrm{~m} .50$ de largeur et $0 \mathrm{~m} .60$ de profondeur, pour limiter le champ d'expériences au Sud, et creusement, sur $2 \mathrm{~m}$. 80 de largeur et $0 \mathrm{~m} .80$ de profondeur, d'une partie de la fausse rivière située à l'Est ; ouverture, la même année, sur toute la surface à l'exception de deux bandes de terrain, l'une de 15 mètres de largeur à l'Est et l'autre de 12 mètres de largeur au Sud, laissées intentionnellement pour servir de témoins - avec une pente de 25 millimètres par mètre, de fossés d'assainissement distants de 5 mètres, d'axe en axe, et mesurant $0 \mathrm{~m}$. 40 de largeur à la base, $0 \mathrm{~m}$. 80 au sommet et $0 \mathrm{~m}$. 70 de profondeur; ouverture, également en 1908, des trous destinés à recevoir les plants, savoir 430 grands trous de 1 mètre carré de surface et $0 \mathrm{~m} .70$ de profondeur, placés à des intervalles de 6 mètres, pour les peupliers et les pommiers, et 1548 petits trous de $0 \mathrm{~m} .50$ de superficie et $0 \mathrm{~m} .35$ de profondeur, éloignés de 3 mètres, pour les saules osiers et les plants forestiers; enfin, construction, en 1908-1909, sur le ruisseau de Trye, en aval du champ d'expériences, d'un barrage à aiguilles pouvant permettre, avec les fossés, d'irriguer le terrain pendant les périodes de sécheresse et de relever ainsi le plan d'eau suivant les besoins.

D'après les constatations faites dans les trous préparés pour recevoir les plants et dans ceux qui ont été ouverts spécialement dans ce but, la distance du plan d'eau à la surface du sol varierait actuellement, suivant les endroits, de $0 \mathrm{~m}$. 30 à $0 \mathrm{~m} .70$ pendant l'hiver et de $0 \mathrm{~m} .55$ à $0 \mathrm{~m} .95$ durant l'été. Et il semble difficile d'obtenir davantage, à cause du niveau des eaux dans la rivière qui borde le champ d'expériences. La couche de tourbe assainie atteint donc bien rarement, à Bresles, l'épaisseur de 1 mètre, que Tacke indique comme le desideratụn à réaliser.

Les plantations ont été effectuées, à l'automne de 1909, sur les bandes délimitées par les fossés dont les terres ont été rejetées sur ces bandes. Chaque bande, d'une largeur de $4 \mathrm{~m}$. 20, renferme trois lignes de plants ; 
la ligne du milieu a été reservée aux peupliers et aux pommiers qui ont été plantés dans les grands trous, ourerts à 6 mètres d'intervalle : les deux lignes latérales, situées à $1 \mathrm{~m}$. 50 de la ligne du milieu et à $0 \mathrm{~m} .60 \mathrm{du}$ bord des fossés, ont été destinées aux saules osiers et aux arbres forestiers qui ont été plantés dans les petits trous, ouverts à l'espacement de 3 mètres.

Les essences suivantes ont été introduites :

a) Des pommiers à cidre de six variétés, savoir : Belle-Cauchoise, lieine-des-Pommes. Pomme-du-Temple, Peau-de-Vache-nouvelle, GriseDieppoise et Pomme-Hauchecorne, chacune de ces 6 variétés étant représentée par 5 sujets.

b) Des peupliers de 10 espèces ou variétés. savoir : peuplier demiblane du pays, peuplier blanc du pays, peuplier d'Eugène (Populus Eugenei Simon-Louis), peuplier suisse blanc eucalyptus (Sarcé), peuplier robuste (Populus robusta Simon-Louis), peuplier suisse régénéré (Barbier), peuplier de la Caroline (Populus angulata Aiton), peuplier blanc type, Ypréau ou blanc de Hollande (Populıs alba L.), peuplier du Canada (Populus canadensis Monch) et peuplier de Virginie (Populus monilifera Aiton), chacune de ces 10 espèces ou variétés étant représentée par 40 individus, dont 20 plants enracinés, 8 sujets enracinés dont les racines furent coupées au moment de la plantation et 12 boutures ou plançons.

A l'automne de 1912, 20 peupliers d'Eugène et 15 peupliers de la Caroline, morts ou très dépérissants, ont été remplacés par 35 peupliers blanes.

c) Des saules osiers de trois espèces ou variétés, savoir : saule pourpre (Salix purpurea L.), saule blanc var. vitelline,(Salix alba L. var. vitellina) et saule viminal (Salix viminalis L.), représentés, les deux premier's par 9 sujets chacun et le troisième par 18 individus.

A l'automne de 1912, 9 saules pourpres et 2 saules blanes noureaux ont été plantés dans les intervalles des précédents.

d) Des essences forestières de 29 espèces, dont 6 européennes, considérées comme essences principales ou essences de reboisement proprement dites, savoir, parmi les espèces feuillues : le bouleau commun (Betula alba L.), représenté par 311 sujets, le frène commun (Fraxinus excelsior L.), représenté par 120 plants, l'aune ghutineux (Alnus glntinosa Gaertner), représenté par 72 individus et le tilleul d'Europe (Tilia europea L.), représenté par 48 sujets : parmi les espèces résineuses : le pin sylvestre (Pinus sylvestris L.), représenté par 3'1 plants et l'épicéa élevé (Picea excelsa link), représenté par 200 individus, et 23 espèces indigènes ou exotiques, considérées comme essences secondaires, essences de remplissage ou essences d'essai, savoir, parmi les espèces feuillues : le charme commun (Carpinus Betûlus L.), le prunier tardif (Prunus serotina Ehrh.), l'aune cordiforme (Alnns corlata Desf.), le bouleau à papier (Betula papyracea Aiton), le robinier faux-acacia (Robinia psendo-acacia L.), le chêne rouge d'Amérique (Quercus rubra L.), le clıêne pérlonculé (Quercus pedunculata Ehrh.), le chêne des marais (Quercus pulustris Duroi), le frêne blanc d'Amérique (Fraxinus americana L.), le copalme d'Amérique (Liquidambar styraciflua L.), représentées chacune par 20 sujets repartis également sur 4 bandes consécutives, et le eatalpa Chavanon (Catalpa speciosa Warder) dont il n'a été planté que 5 individus, sur une seule ligne; parmi les espèces résineuses : le sapin concolore (Albies concolor Lind. et Gord.), le mélize du Japon (Larix leptolepis Murr.). Ie sapin de 
Douglas (Pseudotsuga Douglasii Carr.), le thuya géant (Thuya gigantea Nutt.), le genévrier de Virginie (Jnniperns virginiana L.), le tsuga du Canada (Tsuga canadensis Carr.), le pin à feuilles rigides (Pinus rigida Mill.), l'épicéa de Menziès (Picea sitkuensis Carr.), le pin Weymouth (Pinus Strobus L.), l'épicéa piquant (Picea pungens Engelm.), représentées ehacune par 20 individus également répartis sur 4 bandes eonsécutives, le cyprès de Lawson (Chamaecyparis Lar'soniana Parl.) dont il a été planté 10 sujets sur 2 lignes, et le eyprès clıauve (Taxodinm distichum Rich.), dont il n'a été introrluit, en 1909, que 5 exemplaires, sur une seule ligne.

A l'automne de 1910, parmi les plants morts ou très dépérissants, 22 bouleaux furent remplacés par 19 aunes glutineux et 3 frènes eommuns; 60 pins sylvestres, par 2 aunes glutineux et 58 frènes eommuns; 9 epiceas élevés, par 9 aunes glutineux.

En outre, à l'automne de 1912, on a introduit 15 ormes ehampêtres (Ulmus campestris L.), en remplacement de 15 aunes cordiformes morts ou très dépérissants et 1'́1 pins de Banks (Pinus Banksiana Lamb.), à la place de 14 pins à feuilles rigides disparus. Et, 7 noureaux exemplaires du Taxodium distichum ont été intercalés entre les pommier's de la ligne du milieu de la première bande.

L'azote et la clıaux ayant été reconnus exister en quantités suffisantes, les essais d'engrais ont porté uniquement sur l'aeide phosphorique et la potasse.

On a employé, comme engrais phosphaté, les seories de déphosphoration (Phosphates Thomas "Etoile "), à raison de $1 \mathrm{~kg} 500$ par grand trou et $0 \mathrm{~kg} 750$ par petit trou, et comme engrais potassique, le elılorure de potassium, puis, en 1910 seulement, le sulfate de potasse, à raison de $0 \mathrm{~kg} 300$ par grand trou et de $0 \mathrm{~kg} 500$ par petits trous.

A l'exception des 30 pommiers, des 47 saules osiers, des 12 eyprès ehauves, des 10 eyprès de Lawson et des 5 catalpa Chavanon, qui, oeeupant les trois premières bandes situées au nord du champ d'expériences. ont reçu, de même que tous les sujets des essenees principales plantés dans ees trois bandes, l'engrais eomplet, tous les autres végétaux ligneux introduits ont été répartis en 10 groupes, comprenant chacun 4 bandes conséeutives, dont la première a reçu l'engrais eomplet; la seconde, l'engrais phosphaté seul; la troisième, l'engrais potassique seul; la quatrième bande de chacun des 10 groupes restant sans engrais, pour servir de témoin.

Chaque année, depuis 1909, il a été proeédé aux travaux d'entretien suivants : tassement du sol au pied des jeunes plants pour empêcher' leur déehaussement et, pendant les périodes de séelieresse, pour ramener la terre, devenue sans consistance, au eontaet des racines ; enlévement, durant l'été, dans le voisinage immédiat des plants, des végétaux herbacés qui menacent de gêner les jeunes sujets ligneux dans leur croissanee. toutes les autres herbes étant eonservées jusqu'à l'automne, pour protéger les plants eontre les eoups de soleil et leur proeurer un peu d'humidité par les condensations de rosée qu'elles provoquent ; faucliage général de la végétation spontanée, à l'automne; enfin, remplacement de tous les plants morts ou dépérissants, chaque sujet nouveau étant, à part les quelques exceptions signalées plus haut, de même essence que celui remplacé, el lraité, an point de vue de l'application des engrais, absolument eomme l'avait été ee dernier. 
Les essais sont encore de date trop récente pour qu'on puisse tirer des conclusions' eertaines des résultats obtenus jusqu'à ce jour.

Ces résultats, actuellement, sont les suivants (1) :

En ce qui concerne les différentes essences introduites :

Les pommiers à cidre des six variétés expérimentées ont tous très bien repris et, bien que la plupart aient eu leur écoree plus ou moins rongéè, aı pied, par les rats d'eau, ils sont en très bon état de végétation; ils ont commencé à donner des fruits.

Les saules osiers des trois variétés essayées subsistent tous; ils ont été recépés en 1912 ; les sujets se sont produits très vigoureux; le saule pourpre paraît devoir donner les meilleurs résultats.

Parmi les peupliers, ceux qui ont été introduits au moyen de sujets déjà un peu âgés et suffisamment forts, comme les peupliers demi-blancs et blanes du pays, ont généralement beaucoup mieux réussi que ceux qui, comme les peupliers d'Eugène, de la Caroline, du Canada et de la Virginie, ont été plantés en exemplaires jeunes et de petites dimensions, ce qui tient sans doute à ce que ces derniers ont davantage souffert des gelées. Toutefois, le peuplier blanc type, Ypréau ou blane de Hollande, a très bien résisté, quoiqu'il ait été introduit au moyen de sujets de petite taille.

ll est, dès maintenant, impossible de distinguer les individus qui ont été plantés avec leurs racines de ceux dont les racines ont été coupées, au moment de la mise à demeure, et de ceux qui sont issus de boutures ou plançons. 11 y a lieu de retenir seulement que, parmi les sujets morts ou dépérissants qui ont dû être remplacés, la proportion la plus forte a été fournie par les peupliers nés de boutures, et la plus faible, par ceux dont les racines ont été enlevées lors de la plantation.

De toutes les essences forestières principales, le frène commun est celle qui, jusqu’à présent, a donné les meilleurs résultats ; l'aune glutineux et le tilleul d'Europe ont aussi une végétation assez satisfaisante; au contraire, un assez grand nombre de bouleaux sont morts et ceux qui subsistent ne sont pas aussi bien venants que nous l'avions espéré; des deux espèces résineuses, le pin sylvestre et l'epicea, beaucoup de plants ont disparu, mais ceux qui restent sont en assez bon état de végétation.

Parmi les essences secondaires, le frène blanc d'Amérique, le chêne rouge d'Amérique et le catalpa Chavanon, parmi les espèces feuillues, le genévrier de Virginie, le eyprès de Lawson et le sapin concolore, parmi les espèces résineuses, sont celles qui, jusqu'à ce jour, donnent les meilleures espérances ; le charme commun, le chêne pédonculé et le mélèze du Japon ont une assez bonne végétation; le chêne des marais, qui s'était très bien comporté durant les trois premières années, a souffert en 1912 ; le bouleau à papier, le prunier tardif et le robinier faux-acacia, très vigoureux au début, présentent actuellement un ralentissement dans leur croissance; l'aune cordiforme a été très endommagé par les gelées; le copalme d'Amérique, le tsuga du Canada, l'epicea de Menziès, l'epicea piquant, le cyprès chauve et le pin Weymouth - ce dernier planté sans doute, comme également les autres espèces, en sujets trop jeunes -

(1) Voir Pardé - Rapports annuels manuscrits sur les travaux effectués et les résultats obtenus dans le champ d'expériences forestières de Bresles - Années 1908 à 1912. 
poussent médiocrement; le sapin de Douglas, le pin à feuilles rigides et le thuya géant viennent mal.

En ce qui concerne les applications d'engrais (1), il y a tout d'abord lieu de retenir que la proportion des plants morts ou dépérissants qui ont dú être remplacés, au cours des trois dernières années, a été à peu près la même dans les bandes qui ont reçu l'engrais phosphaté que dans celles laissées sans engrais, et qu'elle a été, au contraire, très sensiblement plus élevée dans celles qui ont reçu l'engrais potassique, seul ou en mélange avec les scories.

Au point de vue de la croissance et de l'état de végétation, les plants qui ont reçu seulement l'engrais phosphaté sont visiblement plus forts et mieux venants que ceux qui ont été laissés sans engrais; il en est à peu près de même pour ceux auxquels l'engrais complet a été appliqué : au contraire, ceux qui ont reçu seulement l'engrais potassique sont moins forts et moins bien venants que les sujets auxquels aucun engrais n'a été administré.

Les conclusions à tirer des résultats obtenus jusqu'à présent, relativement aux essais sur les engrais, seraient done les suivantes : l'engrais phosphaté, qu'il ait été appliqué seul ou en mélange avec l'engrais potassique, a eu une action nettement satisfaisante; au contraire, l'engrais potassique, lorsqu'il a été administré seul, ne semble pas avoir eu d'effet utile. Mais, il est peut-être encore trop tôt pour pouvoir admettre ces conclusions comme définitives.

Les essais entrepris dans le champ d'expériences forestières de Bresles vont être continuées.

II. Schribaux et moi avons l'intention de les complèter comme suit:

De nouvelles essences seront expérimentées. Déjà, comme il a été dit plus haut, l'orme champêtre et le pin de Banks ont été introduits en 1912.

Un engrais purement phosphaté et un engrais calcique seront appliqués séparément, afin de pouvoir se rendre compte de l'action respective de chacun d'eux.

On recherchera s'il ne serait pas possible d'obtenir économiquement, au moyen de solutions chimiques judicieusement choisies et administrées, la destruction de la végétation spontanée.

Les plantations ayant été faites, jusqu'à présent, à l'automne, à cause de la facilité plus grande d'avoir des ouvriers à cette époque de l'année, on expérimentera les plantations de printemps, qui, dans cet endroit très exposé aux gelées, paraissent devoir donner de meilleurs résultats que celles d'automne.

On expérimentera également les plantations faites sur buttes et les plantations faites sur mottes engazonnées, qui ont, les unes et les autres, l'avantage d'augmenter la couche de terre située au-dessus du plan d'eau.

Enfin, on apportera des pierres ou du sable au pied des jeunes plants, ce dépôt devant avoir pour effet d'empêcher le déchaussement, de maintenir la terre au contact des racines et d'entretenir un peu de fraîcheur.

Nous espérons que, bons ou maurais, les résultats, soigneusement contrôlés, des essais entrepris ou restant à entreprendre dans le champ

(1) Voir Pardé - Rapports annuels manuscrits sur les travaux effectués et les résul tats obtenus dans le champ d'expériences forestières de Bresles. - Années 1908 à 1912. 
d'expériences forestières de Bresles fourniront des renseignements qui contribueront à résoudre, au moins dans les tourbières basses, analogues à celle de Bresles, l'importante question de la mise en valeur, par la culture forestière, des terrains marécageux et tourbeux.

En résumé, au moins dans certains états, en France notamment, il n'a pas été dressé une statistique sérieuse des tourbières.

Et, jusqu'à présent, les essais de boisement dans les terrains marécageux et tourbeux sont à peine commencés dans quelques pays, en France, par exemple, et encore incomplets ou insuffisants dans d'autres. En particulier, certaines essences, qui paraissent susceptibles de réussir, n'ont pas encore été expérimentées ou ne l'ont pas été suffisamment, et l'action des divers engrais n'a pas encore été très nettement établie.

En conséquence, nous proposons les vœux suivants :

1. Qu'il soit dressé, dans les divers États. une statistique très complète et très sérieuse des tourbières de différentes natures qui y existent.

II. Qu'il soit créé, dans les tourbières des diverses catégories, en plaine et en montagne, des champs d'expériences où seront étudiés très méthodiquement les procédés d'assainissement, les modes de boisement, les époques les plus favorables pour les plantations, les différentes essences indigènes et exotiques, l'action des divers engrais, les soins à donner anx plants.

III. Et que les résultats, bons ou manvais, de toutes ces expériences soient portẹ́s à la connaissance du prblic.

M. PArdé ájoute : En résumé, au moins dans certains Etats, en Franeł notamment, il n'a pas été dressé une statistique sérieuse des tourbières. Jusqu’à présent, les essais de boisement dans les terrains marécageux et tourbeux sont à peine commeneés aussi bien en France que dans les autres pays.

Certaines essences qui paraissent susceptibles de réussir, n’ont pas encore été expérimentées, ou ne l’ont pas été suffisamment, et l'action des divers engrais n’a pas encore été nettement établie.

M. HАтт. - Je pourrai vous citer une expérience faite aux environs d'Epinal, il y a environ cinquante ans, sur des espaces dissémincís dans la montagne, à une altitude variant entre 300 et 500 mètrés. Les agents forestiers qui, à ce moment-là, opéraient aux environs d'Epinal, ont relevé soigneusement toutes les parties qui étaient marécageuses, humides, et on trouve encore sur les plans actuels, en pointillé, la limite de ces parties tourbeuses ou marécageuses, qui sont sur lo grès vosgien ou le grès bigarré. Le sol est généralement tout à fait spongieux, couvert de mousses et de stagnum. Je demanderai, entre parenthèses, si le nom de faigne, employé dans les Vosges, ne pourrait pas etre rapproché du mot latin stagnum.

M. Pırdé. - De même que les "hautes fagnes " de la région de spa. 
11. Hatr. - Ces fagnes ont été reboisées méthodiquement. En même temps que le pin weymouth, on a introduit dautres essences. On était à ce moment-là au même point que vous ètes maintenant, "II ce qui conceme les tourbières de Frasnes. On y a introduit de l'épicea, du pin weymouth. II semble qu'on l'ait introduit dans l'espoir de réussite complète. Il y a vingt ans, dans une description de ces parcelles que les aménagistes de l'époque araient faite, ces parcelles ítaient appelées "res taillis de bonleaux, entremèlés de perchis, "'épicéas et de pins weymouth ». Le weymouth est une essence à ramure extêmement légère; c’est un arbre de pare très apprécié dans la région. Il était encore à l'état de peuplement naissant. Ce n'est que depuis vingt ans qu'il a pris l'importance que nous lui voyons aujourd'hui. Dans ces parcelles, nous avons, depuis ces vingt dernières années, un accroissement moyen vraiment étonnant. A ma connaissance, il n'existe pas d'accroissement semblable dans aucune autre essence connue, du moins de celles qui peuplent les Vosges : Nous avons trouvé, à l'àge de 45 ans, des weymouth qui avaient 60 centimètres de diamètre, et ce n'était pas l'exception. La moyenne était de 40 à 45 centimètres de diamètre. Je vous laisse à penser qu'il n'y a pas à chercher d'autres essences que celle qui, en 4.5 ans, donne un accroissement moyen annuel de plus diun centimètre de diamètre. Cela parait digne d'ètre notí. C'est done une expérience qui remonte à très loin, et dont les résultats ont lépassé toutes les espérances.

Jo complèterai ces renseignements en vous disant que ces reboisements ont été faits, comme le disait M. Pardé, après l'assainissement du sol, et qu'on trouve encore aujourd'hui trace des fossis d'assainissement qui ont été creusés à environ 50 ou 60 centimètres et qui aujourd'hui sont obstrués.

La question se pose actuellement de savoir ce que nous ferons de ces peuplements de weymouth. Ils sont mùrs, en ce sens que, sétant accrus très rapidement, il semble que leur àge d'exploit abilité ne puisse pas être considéré comme celui du sapin, par exemple. Ce sont des peuplements qui donnent des signes de maturité; en particulier, ils sont attaqués, partiellement au moins, par un champignon, le peridermium pini, exactement le peridermium strobi, puisque cest la variété qui pousse sur le weymouth, et nous avons dì envisager leur réalisation. J'avoue que j'ai eu beancoup de mal à imposer une méthode qui me paraissait tout indiquée; cutte méthorle, je laai empruntée aux forestiers allemands. C'est la première fois que dans les Vosges nous avons fait une eoupe rase. Nous avons délimitó sur ces parcelles les parties qui itaient destinées à être coupées à blanc, et nous avons divisé les peuplements en bancs alternés, les uns derant rester dobout pour produire les semences, les autres devant être abattus. Ces exploitations ont en lien lamnée dernière. Ivant-hier encore jétais là-bas, et je me promenais daus la parcelle exploitée : J'ai pu me rendre compte que les semis de weymouth itaient déjà 
suftisamment abondants pour qu’on puisse considérer la régénération comme réussie dès maintenant.

Il suffira, à mon avis, de curer les fossés, qui ne l'ont pas été depuistrès longtemps, depuis le moment où on a fait la plantation, e'està-dire il $\mathrm{y}$ a cinquante ans. Ils sont encore apparents; mais les eaux ne s'écoulent pas convenablement. L'assèchement était fait par les racines de weymouth, qui pompent l'eau avee une abondance extrême. Si nous curons les fosses, lo peuplement pourra renaitre, et reproduir un rolume semblable, c'est-à-dire de 250 à 300 mètres cubes, en l'espace de quarante-cinq ans.

Je dois ajouter que le mètre cube de pin weymouth se rend à raison de 18 franes, sur pied, dans le pays. C'est une essence appréciéc des marchands de bois. D'après un calcul que j'ai fait, et qui a éti reproduit dans la Revue Forestière. il y a quelques mois, en tenant compte d'une production de 250 à 300 mètres cubes à l'hectare, à raison de 18 franes le mètre cube, en romptant comme frais d'établissement les frais de plantation, de curage des fossés, d'acquisition du terrain. on peut évaluer le taux de ce placement à $7 \%$. A còté de res pareelles. et royant que l'Administration forestière avait si bien réussi. des propriétaires ont fait des plantations de weymouth; mais ils n'ont pas songé à draîner le terrain, et cela n'a rien donné. II suffit de faire de l'assainissement, sans ajouter d'engrais. J'estime que dans ces régions, le sol est tellement fertile, par suite de l'accumulation des détritus qui sont venus s'entasser dans le fond des vallées, qu“il n'est pas nécessaire d'y ajouter de l'engrais. Je dirai mème que c'est une illusion qu'on se fait lorsqu'on ajoute de l'engrais à de pareils terrains pour les améliorer. Ces terrains. en effet, sont extrêmement riches, et parfois presque trop riehes. (Applandissements.)

11. Flahict. - La communication que vient de faire M. Hatt est des plus intéressantes, et je me rappelle aroir lu avec un intérèt tout particulier l'article dù à la plume de notre collègue et paru il y a quelques mois dans La Revue forestière.

Certes, il est interessant que, dans les vastes tourbières des losge.. situées entre 800 et 500 mètres d'altitude, le pin Weymouth réussisse, mais j'estime qu'il faut considérer rela comme un fait particulier : en matière d'utilisation de tourbières et surtout de reboisement. l'on devait toujours mettre en première ligne la question de climat.

Pour moi. rett" question a été placée hier sur son véritable terrain par .11. Guinier. ut il n'y a pas à sortir de là ; ce sont arant tout dequestions de geographie botanique. Je citerai à l'appui de cet te opinion un fait qque M. Pardé connait ; il a pu roir, dans les hautes Céremms des penplements de pin Veymouth plantés en applieation de la loi de Istor, lejà anciens, par conséquent, et qui nont donné aurun résultat séririx : les fùts ont at teint quarante centimètres de diamètre, mais les cimes itaient eonstamment endommagées par la neige. On 
avait bien du repeuplement, mais, en réalité, c’étaient là des forêts sans avenir dans nos climats du midi, mème en haute montagne.

En ce qui coneerne la richesse du sol, je ne doute point que, dans les tourbières de l'Est, comme dans la plupart des tourbières, les engrais proprement dits soient le plus souvent inutiles; rependant j'estime que lamendement par la chaux est toujours nécessaire et il y a tout avantage à reporter les économirs faites du còté des phosphates et de la potasse vers la chaux qui permet une meilleure utilisation des richesses tu sol.

Arrivant à un autre point, je demanderai à men ami M. Pardé de vouloir bien introduire dans le texte définitif de son rapport trois lignes pour indiquer que l'assainissement des tourbières n'est pas toujours une opération qui s'impose. En effet, si cot assainissement des tourbières était indiqué comme une mesure nécessaire, il pourrait arriver que les agents fussent conduits, par des décisions impératives de l'administration centrale, à assainir des tourbières dans des conditions où cette opération serait désastreuse.

Nous avons, dans les hautes Cévennes, de vastes étendues de tourbières qui sont des éponges, au même titre que les tourbières dle Russie: si, en application de la loi de 1860 , on les assainit au moyen de tranchées profondes, on aura bien abaissé le plan d'eau, mais on aura alimenté d'autant et d'une manière d'autant plus irrégulière les torrents qui en naissent. Il y a tonc lieu de faire des réserres a sujet de l'assainissement des tourbières qui, en certains points des Pyrénées et des Alpes, peuvent être des sources permanentes.

Vous vous rappelez, Monsieur Pardé, avoir vu ces quelques centaines d'hectares de tourbières de montagne : il serait évidemment fàcheux, aujourd'hui, que lardministration, conduite par une idéc excellentr en soi, voulùt transformer ees tourbières où nous essayons de retenir les eaux en réservoirs de torrents (Applandissements).

M. Pardé. - Le cas que vous signalez n’est pas isolé. A Spa, par exemplr: l'administration des eaux a protesté contre un assainissement qui tarirait ses sources.

En qualité de rapporteur, je me rallie complètement aux observations que M. Flahault vient de présenter (A pplaudissements).

M. Flandlet. - Vous voyez mon intention, e'est d'attirer l'attention sur un ròté de la question qui échappe généralıment à la première observation. II. Halt, par exemple, serait nommé aujonrd'hui, ce que je lui souhaite très vivement, inspecteur général des hantes Cóvennes. qu'il arriverait avec l'intention d'assainir tontes nos tourbières...

I. HАтт. - Je demande la permission de rous contredire un peu. Nous avous, dans les Vosges, dles forèts à une altitude rolativement élevée: par prinripe, les tourbieres n’ont pas été reboisées paree qu'elles constituent des souries utiles pour l'alimentation des nombreuses usines installies dans les vallies. 
11. Fumarte - Chez nous, il s'agit plus modestement de torrents à morterer.

11. Debors. - Je drmande la permission d'apporter au Congrès l'opinion des forestiers ardennais belges, au point de vue de la valeur du Weymouth : vest une opinion qui n’a pas étí publiée. mais elte a cour: (hez les agents des forêts.

Dans les Ardennes belges, on utilise te pin sylvestre jusqu'à 400 mètres, et l'epicea au-dessus, parce qu'au delà de 400 mètres, le pin sydrestre se dójette, n'a pas de fùt et prend des formes tortueuses.

Len bons résultats obtenus arec l'epicea dans tes terrains de fagnes ont incite les particuliers et les communes à adopter ret te essence qui a etri plantée dans les terrains ardennais, schisteux, et dans certaines parties peut-ètre un peu spéciales, olle donne un revenu qui atteint jusqu à 100 franes à l'heetare.

Nos forestiers avaient anssi pense au pin Weymouth: Eh bien, il y a me opinion courante chez eux, e'est que le pin Weymouth est tellement attaqué par la rouille, qu'il y a une tendance générale à y renoncer. Il attrape la rouille diune façon seandaleuse (Rires). En sorte qu'après avoir roulu l'utiliser, non pour faire eoncurrence à lepicea. mais comme adjurant à cette essence, il y a maintenant une temlance assez forte à y renoncer (Applandissements).

11. Flinult. - Etant presque bełge moi-même, j’ai un grand respect pour les forêts des Ardemnes et je les connais fort bien. Là romme ailleurs, la question de géographie botanique s'impose et elle a attiré, nous renons de le voir, lattention de nos voisins. Il n'est pas douteux que le pin Weymoutl, dans la rhaine des Ardemnes, ne doive donnel les résultats plus médiocres que l'epicea et que lo pin sylvestre. Il se déjette, il ne se déreloppe pas au-dessus d'une certaine altitude: en réalité, vous vous plapez clans les mêmes conditions où se placent les Suédois et les Norrégiens dans leur's efforts de peuplement de leurs furèts septentrionales : les forêis rles Ardennes ressemblent d'une manière pemarquable aux forèts du nord de la Suède que je connais bien.

Jen reviens encore à mon idée. On peut faire des expériences très intéressantes, on trouvera pent-être des espères ayant un intérêt majeur pour un pays donné ; mais, toujours, nous sommes bien d'accord sur ce point, les expériences doivent se faire pour un pays donné.

Jexperimente, en re moment, dans les hautes Cerennes l'epicea pungens : il semble donner de bons résultats à de liautes altitudes. 11. Hatt l'a-t-il wsayé dans les Vosges?

M. HIT\%. - Non: mais je sais que M. Dubois, en Belgique, paraît aroir der risultats meillents avere leppicen sitka.

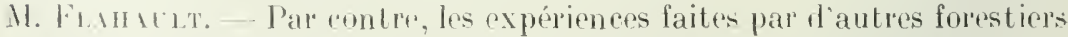
avere l'epiren plungens dans d'autres régions nont pas réussi. 
En fait, il faut tonjours en revenir à cette question de géngraphie botanique. Le sitka ne m'a pas donné de résultats appréciables dans les hautes Cévennes, tandis que le pungens donne des résultats analogues à eeux que lion trouve en Suisse où il atteint 1.845 mètres dans les forèts qui environnent le lac de Saint-Moritz; lepicea pousse si bien dans ce pays que toutes les communes de l'Engadine accordent une large place dans leui's pépinières à cette essence.

L'epicea pungens parait done favorable pour le peuplement des marais en haute montagne, et le sitka, au contraire, parait inférieur.

II. Dubors. - Il faut toujours parler du pays et ne pas généraliser.

II. Flanatlt. - Il faut tenir compte du climat, des conditions spéciales de température, d'humidit́ atmosphérique, ete...

11. Breton-Boxmard. - Messieur's, je ne me placerai pas au point de vue mondial auquel se sont placés les prócédents orateurs, mais jo vous parlerai de la Somme où jai opéré, depuis quarante ans, beaucoup de reboisements.

On a parlé tout à l'heure les engrais potassiques, phosphoriques. De tous les engrais que j’ai employés, la eraie seule n’a donné de bons résultats. Dans une plantation, les arbres que nous gamissons de craie à la base dépassent de beancoup les autres.

Dans nos tourbières, nous avons essayé aussi le pin weymouth et l'épicea; mais je voudrais attirer votre attention sur la disparition le l'aulne. Nous avions des aulnes admirables autrelois, vous pouvez m'en croire, car j'ai été marchand de bois pendant trente-cinq ans : aujourd'hui, on a beau reboiser, on n'arrive à rien : l'aulne ne pousse plus. Pour quelles raisons? Nous l'ignorons.

Ce qui chez nous donne un gros revenu, c'est le peuplier, qui produit toujours et, au moins au nord de Paris, le peuplier doit toujours itre choisi de préférence au pin weymouth qui ne pousse pas.

Un autre fait intéressant est le suivant. On dit que lo mélèze est un arbre de montagne : un propriétaire en a planté une cinquantaine dans son pare et ils ont donné des résultats phénoménaux...

M. Hotgin. - Ils mourront!

II. Breton-Bonnard. - C'est certain, mais mfin, ils sont dans leur vingt-cinquième année, et je serais curieux de savoir quel bois ils donneront.

11. Auguste Barbey. -- M. Pardé, dans son remarquable rapport, a parlé de la Suisse; permettez-moi de vous présenter quelques remarques que me suggèrent les travaux faits aux environs du lac de Neuchatel.

Dans les tourbières situées mutre ce lac rt le lac de Bienne, on a planté au commencement des résineux, en nnélange intime, épieca, sapin blanc, pin sylvestre et weymouth. Ces plantations ne datent 
que de 35 à 40 ans, mais le weymouth jusqu'ici donne de très bons résultats.

J'ai fait des plantations dans les marais de l'Orb, dans les mêmes conditions qu'à Neuchatel, dans un marais bas, qui reçoit les alluvions d'une rivière, et mes constatations sont celles-ci.

Nous faisons une faute quand nous plantons en automne, parce que les jeunes plants sont déchaussés par la gelée tardive de printemps: notre règle, c'est la plantation au printemps. Plus nous nous éloignons de la rivière, source de limon, plus nous sommes dans la tourbe pure, plus nos plantations ont peine à reprendre. A cette altitude de 480 mètres, malgré ce qu'en disent les auteurs allemands, le stika nous a donné de bons résultats; encore faut-il réunir certaines conditions et surtout lui procurer un abri latéral.

11. Debors. - Nous essayous le sitka surtout dans la plaine.

M. Auguste Barber. - Une essence à recommander est le frêne d'Amérique qui supporte mieux la gelée tardive que le frêne ordinaire et donne un bois de qualité supérieure.

Le grand ennemi contre lequel nous avons à lutter dans les plantations de marais en Suisse, c'est l'incendie : dans nos marais du Seeland, on en a tellement peur que dans les peuplements d'épiceas, à partir de l'état de perchis, on scie toutes les branches à deux mètres de hauteur. Et ceci m'amène à prendre les mesures suivantes : c'ust que dans les marais bas, il faut arriver le plus tôt possible à tuer la végétation herbacée, et pour cela, une essence de transition, comme un mélange intime d'aulne et de frène donnera les meilleurs résultats : là-dessus nous pourrons installer dans la suite les résineux. (Applan(issements.)

11. Herrgott. - J'ai pensé que je pourrais profiter de la discussion du rapport de notre collègue $\mathbf{M}$. Pardé, pour vous dire les essais que jai faits en Lorraine et plus particulièrement dans l'arrondissement de Toul en faveur du reboisement en général et plus particulièrement du reboisement des friches communales.

11. Le Présidext. - Je vous demande la permission d'en finir d'abord avec les travaux de reboisement des tourbières.

I. HenRGoTT. - Très volontiers.

M. le Présidext, - Messicurs, je donme lecture des projets de vюux :

"10 Qu'il soit dressé, duns les divers Etats, une statistique très complète et très sériense des tourbières de différentes natures qui y existent.

"20 Qu'il soit créé, dans les tourbières des diverses cutégories, en 
plaine et en montagne, des champs diexpériences oì seront étudiés très méthodiquement les procédés d'ussainissement, les modes de hoisement, les époques les plus farorables pour les plantations, les différentes essences indigènes et exotiques, l'action des divers engrais, les soins ì donner anx plunts. "

" $3^{\circ}$ Et que les" résultats, bons on manvais, de toutes ces expériences soient portés à la connaissance du public. "

Ces trois voeux sont mis successivement aux voix et adoptés.

11. Le Présinent. - Il me reste à soumettre à rotre approbation un quatrième vou, présenté par M. Bauchery, sylriculteur à Crony (Loir-et-Cher).

" $4^{\circ}$ Les membres de la quatrième Section, considérant la grande documentation et les précieux renseignements renfermés dans l'étude. ci-dessus, émettent le veu que ce rapport soit ulressé gratnitement, par les soins du Winistère de l'Agriculture, aux Sociétés forestières proprement dites ainsi qu'aux groupements scolaires forestiers. "

Ce vœu, Meģsieurs, est très bien dans son esprit, mais it ne faut pas oublier que nous sommes dans un Congrès international où le Ministère de l'Agriculture de France n'a rien à voir.

Je vous propose donc, en conséquence, de modifier comme suit le vou de M. Bauchery :

Que, eu égard anx précienx renseignements pratiques contenus dans le rapport ci-dessus, ce document soit adressé gratuitement anx collectivités ainsi qu' aux sociétés et groupements forestiers que la qnestion peut intéresser. "

Ce vœu, mis aux voix, est adopté.

M. Herrgott. J'ai eik l'idée d'envoyer, en 1909, un questionnaire aux 119 communes de l'arrondissement de 'Toul pour leur demander' :

$10 \mathrm{Si}$ depuis 1990 la commune avait reboisé pour son compte, et combien d'hectares :

$2^{\circ} \mathrm{Si}$ depuis la même époque, des particuliers avaient égạlement reboisé, et le nombre approximatif d'hectares;

$3^{\circ}$ Quelles étaient les essences les plus généralement emplovée ;

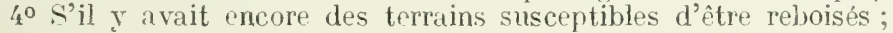

$5^{\circ}$ Enfin si des déboisements ou des exploitations intensives, réalisant tort le matériel arbre de la forêt, avaient en lien.

Des chiffres obtenus et contrôlés de diverses matières, il résultait que si. depuis 1900, ur millier d'hectares avaient été rehoisés, il on restait bien 2.400 environ qui pourraient l'être utilement et zratiquement.

Après avcir examiné très attentivement les résultats de cette enquète, j'écrivis ofliciellement aux maires des communes où se tronvaient des terrains susceptibles d'êtr reboisés; j’invitais les Conseils municipaux à délibérer et je leur disais une l'Administration forestière serait à leur disposition pour leur donner, le cas érhéant, toutes indications utiles rotamment M. l'inspecteur des Forêts Boppe et M. le garde général des Forêts Coulaux, à Voviant. 
Voici, à la date du ler mai 1913 , les rés:1? tats de la campagne inenée en faveur du reboisement dans l'arrondissement de Toul :

51 communes ont répondu à l'appel qui leur avait été fait et les crédits qu'elles ont rotés s'élèvent à ume somme globale de près de 30.000 francs; c'est ainsi que la très grande majoritè des terraus incultes appartenant aux commerces ont été reboisés. Je n'ai pu encore savoir le nombre exact ou approximatif d'hectares, mais j'espère le savoir dans quelque temps

1 I m'est donc particulièrement agréable de rendre hommage, une fois de plus, aux maires de ces communes et aussi aux irstituteurs qui nous ont secondé et surtout à ceux qui dirigent et ont créé des sociétés scolaires forestières.

De 8 (fu'elles étaient en 1906, elles sont, en 1913, au nombre de 16.

Toutes ont fait d'intéressants travaux, quelques-unes notamment, en créant Jes pépinières familiales. Ils sont résumés dans une brochure que j’ai fait naraitre et qui a été honorée d'une souscription du Ministère do l'Instruction publique.

J'ai l'honneur de déposer cette brochure sur le bureau. C'est un relation des résultats obtenus dans l'ouve que j'ai entreprise depuis plus de six ans, en vue de favoriser et de propager le reboisement.

Daus un but d'enseignentent véritable pour tous, j’’ ai groupé les comptesrendus des travaux de reboisement déjà exécutés par les sociétés scolaires forestières de l'arroudissement et par les vrincipaux reboiseurs du Toulois.

Ces comptes-rendus traitent des différentes espèces de plants à employer selon la nature du terrain, des diverses manières de reboiser et sont ainsi aufant de leçons de rhoses devant servir de guide indispensable aux reboiseurs qui veulent éviter les mécomptes d'une plantation mal conditionnée.

J'y indique aussi les grands avantages des peupliers ; je reproduis un très interessant cours de sylviculture fait par un instituteur de l'arrondissement à l'usage de ses jeunes élèves; puis, parlant du grave problème de la dépopulation des campagnes, je démontre avec des documents officiels à l'appui que si l'on se remet à reboiser dans les communes rurales, on atténuera par une remise en valeur des terrains, les effets de leur abandon.

Ai-je besoin d'ajouter, en terminant, que les maires des communes rurales, dont les revenus diminuent chaque année, alors que les dépenses augmentent, seront heareux de trouver un jour des ressources nouvelles qui leur permettront d'équilibrer leur budget communal et de faice de nouvelles améliorations dans leurs communes?

Ayant reboisé leurs terrains incultes ou friches communales, ils auront fait de bonne administration et avec raison on pourra leur dire : "Reboiser c'es l prévoir ; reboiser c'est aussi aroir la richesse. „) (Applaudissements.)

1I. Le Présunext. - Je pemereje M. Herrogott de sa très intéressante communication.

11. Le Présinent. - La parole est à M. Pardé poul donner lecture de la communication de M. Vallet sur la Culture oE L’osier.

En voici les priuripaux passages :

Lar culture de l'osier senble indiquee pour tous les terrains humides, et. appliquee d'une facon rationnelle, elle donne de fort beaux rapports.

l.es rlifféres ts modes de plantation les plus propices à ce genre de terrains sont : $1^{\circ}$ par boutures assez blevées au-dessus du sol poar se défendre contr les ma.rvises herhes; 20 par la greffe d'osier sur peuplier, qui aura une très grande durée et une végétation hien supérieure aux usiers les plas vivaces. Eludions done les feax procedés :

10 la plantation s' faisant par boutures, diviser les ter rains en plates-bandes 1. 1 m. 50 à 2 mères, séparées par des fossés dits d'assainissement, se déversanl dans un fosse principal. Issainir le terrain et rohausser la terre régétale. 
Sur ces plates-bandes ainsi préparées, planter les boutures de 0 m. 50 de longueur, les enfoncer verticalement de $0 \mathrm{~m}$. 30 , de façon à former la souche en dehors des nnauvaises lerbes; cette mime plantation, en terrain moins humide, peut se faire avee les houtures de $0 \mathrm{~m}$. 30 de longueur; les enfoncer verticalement et au ras dusol, aux intervalles de $0 \mathrm{~m}$. 50 à 1 mètre de distance, suivant la qualité du terrain.

20 Plantation par l'osier greffé sur peuplier. Ce genre de plantation est le plus pratique et celui qui donne le plus de revenu, tout en supprimant bien des frais.

11. Tallet a greffè du Salix viminalis sur le peuphier blane de llollande (Populus alba). Il nous a fait voir dewx greffages faits au printemps qui ont parfitement réussi; nous avons d'autre part constaté, près de la gare d. Cormeilles-en-Parisis, un greffage semblable datant de 1910. Les pousses de l'année vrésentaicnt une superbe végétation.

D’aures greffages identiques ont été tentés avec succès par M. Vallet.

Cet osiériculteur a employé la greffe eu fente ordinaire; le greffage s'est fait ou au niveau du sol, ou à 5 ou 6 centimètres du sol.

De ces constatations, il résultr clairement que le greffage de losier sur le peruplier est absolument pratique.

Ces premières expériences faites par M. Vallet peuvent avoir une très grande importance au point de vue osiéricole.

$1^{\circ}$ Le choix du sujet porte-greffe. II y aurait lieu alors de faire des recherches avec les variétés suivantes : Populus alba ou Blane de Hollande, Populus italica ou peuplier d'Italie, Populus nivea ou peuplier neige, Populus virginiana ou peuplier suisso régénéré;

2o L'adaptation du greffon an sajet : sur du Blanc de Iollande va-t-on greffer, par exemple, d: Salix viminalis ou d!ı Salix Purpurea ou du Rubra, ete.;

$3^{\circ}$ L'adaptation à la fois du sujet et du greffon à la composition chimique du sol, d'une part, à l'altitude et à la latitude d'autre part;

$4^{\circ}$ I Le mode de greffage à employer : le greffage en courome sur des peupliers plus âgés donnera peut-être de meilleurs résultats que le greffage en fente.

Q.ıiqu'il en soit, ce greflage étant pratique, peut transformer avantageusement la culture de l'osier de la manière suivante :

a) Dans certains terrains trop humides, comme les champs d'épandage de la vill. de Paris, ou dans les terrains ou l'eau est plus ou moins stagnante, cerrains dans losquels le peuplier réussit très bien et l'osier très mal, on pourro se livrer à la culture des osiel's el greffant ceux-ci sur peupliers. Nous avons vu, à tehères, à Méry-sur-Oise, à Saint-Germain, à Pontoise, ete, des peupliers superbes dans des sols presque incultes; le greffage des osiers semblì là tout indiqué.

Combien n'y a-t-il pas en Frarce, de terrains semblables?

b) Le greffage des osiers à 1 mètr ou à $1 \mathrm{~m}$. 50 du sol, pourrait permertre de se livrẹ à une culture rationnelle, en têtards, calture qui, jasquı à présent, constitue une très rare exception.

Ia culiure en têtards, sur une souche solide formée par le peuplier, supprimerait on diminuerait dans une très grande proportion les frais de binage et de Sirclage; or, clacun sait que ces frais sont ceux qui grèvent le phis la culture de l'osier'.

Totis ne pensons pas que la rulture en tètards donnera en général des produits aussi abondants fue la culture actuelle, mais elle est appelée à rendre les plus grands services dans une foule de cas, en mettant en valeur de maurais sols.

De plus, par ce genre de greffage ue l'osier, il est nue yaestion tros imporlante concernant les osiers de vannerie fine qui, jus fu'à ce jour, ont eu beaucoup de difficultés à se développer, la nature du terrain empèchant en grande parti le développement et détoarnant le propriétaire de plantations susceptibles de lui assurer du succès. L'osier constitue la matière première sprvant ì fabriquer la vannerie de ménage, indispensable à tous, la cannerie d'emballage pour 
laquelle on ne saurait le remplacer, étant donné sa légèreté qui diminue les frais de transport pour le produit réel, la vannerie fine ou de fantaisie qui se fabrique géréralement dans le nord et dans l'est de la France.

Ce genre de greffage est également désigné pour reproduire avec grande facilité toute la collection d'osiers exotiques or: d'ornement qui ont disparu pour la plupart, faute de régétation sous notre climat. Pař le greffage de l'osier sir pemplier, le rapport est plus important que celui de la plantation d'osien ordinaire et d'une grande durée.

De plus, la plancation d'osier's fournit un couvert à gibier apprécié de toutes les personnes s'occupant de chasse; on a en ontre la faculté par la taille de chaque année, de former le couvert à la hauteur désirée et à l'emplacement roulu, ce qui est très avantageux.

On s'en sert également pour la fabrication de la pâte à papier.

Comme on le voit, l'osierest me des matières premieres textiles qui s'utilisent dais toutes les régions de la France.

L'établissement d'une plantation l'osiers ne peut dépasser '́ à 500 franes l'her tre pour le labo: ${ }^{\prime}$, les boutures et binage dans les deux premières années.

la récolte de première année est inutilisable. A partir de la deuxième année, l'hectare d'osier peut rapporter er: moyenne 200 francs, et cela en augmentant, jasqu’à dix ans, où il peut arriver à produire de 5 à 600 francs. La durée de plantation est d'environ 15 à 20 ans, selon les terrains et selon les variétés appropriées à chaque genre de culture.

La plantation se fai i de novembre à avril ; il est préférable de ne pas dépasser le 15 mars. L'osier cst très hâtif. Un autre genre de plantation se fait aussi par semis de 1 on 2 ans. Ce dernier donne moins de rapport et demande beaucoup plus d'années à former ure plantation convenable en terre plus humide et plus maigre, mais toujours par plates-bandes.

la culture de l'osier est donc très rémunératrice. Par les différents genres de plantation, elle donne du rapport, ou couvert à gibier appréciable. Flle assuỉ en mème temps le reboisement, l'assainissement du terrain principalement en bordure des coms d'eau où elle ariète la perte de terrain qui se fait journellement par le déversement des eaux sur la propriété.

Il y a lone liea de recommander, de développer par tous les moyens, la culture de l'osier qui, nieux comprise, peut et doit devenir une richesse nationale, en utilisant quantité de non-valeurs.

Dans une exploitation agricole bien comprise, a dit La Blanchère, il ne dois pas "I asoir un pouce de terrain perdu."

II. Le Préstnext. - Lordre du jour appelle la discussion du rapport de 11. Pierre Buffault sur: Les DLNEs. - LEUR Fixation. Letr

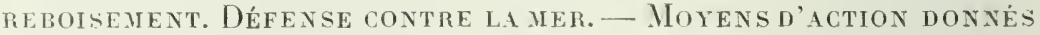
l. Ar la législation actuelle. Mesures léglslatives a prendre.

Technique travaux.

II. Pierre Buffault. - I. Les dunes sont des amoncellements de sable d'origine éolienne, soit littoraux, soit continentaux.

Les dunes françaises sont littorales, sauf quelques exceptions négligeables. Les plus importantes sont celles de Gascogne, puis celles de Saintonge, de Vendée et des îles voisines, enfin celles du Pas-de-Calais, de Bretagne et du Languedoc.

A l'étranger, en Europe et hors d'Europe, il y a des dunes considérables, littorales et continentales.

1I. En France, toutes les dunes, un peu importantes et dangereuses par leur mobilité sont depuis longtemps fixées et boisées. On n’a plus à $\mathrm{y}$ faire que des regarnis et petits travanx particls. 
La fixation et le boisement des sables ont été obtenus par des semis de graines de pin maritime, d'ajone et de genêt (30 à 20 kilos par hectare), faits à la volée sous ou sur une couverture de branchages (1.000 fagots de 15 à 20 kilogs par hectare); quelquefois, ces branchages étant rares, on a remplacé la couverture protectrice par des aigrettes (rameaux piqués verticalement dans le sable), ou des cordons de fascines se recoupant. Ces deux procédés ne valent pas celui de la couverture. (Dans le Nord, le pin maritime a été employé avec le pin sylvestre et même en proportion prédominante).

Sur les sables trop près de la mer pour que le pin y végète, on a obtenu et on entretient encore leur fixation par des plantations de touffes plus ou moins espacées de gourbet ou oyat (psamma arenaria).

Le boisement s'obtient donc concurremment avec la fixation; et, dans les vieux peuplements exploités. l'ensemencement naturel suffit aujourd'hui d'ordinaire à assurer la régénération, sauf les cas de pâturage ou de mauvaise exploitation.

Hors de France les procédés de fixation sont à peu de chose près les mêmes qu'en France, soit que la fixation des dunes y ait été commencée en même temps (Danemark, Hollande, Prusse), soit qu'on se soit inspiré des procédés français.

III. En France, pour protéger les surfaces qu'on ensemençait ou allait ensemencer dès l'arrivée de nouveaux sables, soit que l'on fût au milieu de dunes mouvantes, soit que l'on fût au bord de la mer, on établissait une palissade de planches ou un clayonnage, renforcé d'une plantation de gourbets du côté de l'arrivée des sables mobiles, et qu'on exhaus sait au fur et à mesure que les sables le couronnaient. On édifiait ainsi, par l'effet du vent, une sorte de parapet ou de digue, qui empêchait l'ensablement des semis et donnait à ceux-ci le temps de grandir et de se développer jusqu'à ce que les sal)les mobiles de l'Ouest fussent eux-mêmes fixés. ou maîtrisés.

Généralisée et uniformiséc tout le long de la côte maritime, cette digue artificielle est devenue la "dune littorale " des forestiers. Son but est, non d'arrêter les sables venant de la mer, mais :

10 de diminuer la violence du vent de mer et de favoriser ainsi la végétation herbacée, arbustive, puis arborescente de la zone littorale située derrière $; 2^{\circ}$ de diminuer la quantité des sables que le vent prend à son pied parmi ceux laissés par le flux et de modérer leur transport éolien dans la zone littorale pour que l'exhaussement du sol y soit lent et ne dépasse pas l'exhaussement parallèle de la végétation.

La régularité de la dune littorale et l'uniformité de son profil en long et de son profil en travers (trapézoïdal) sont nécessaires pour offrir moins de prise aux attaques des vents et des hautes mers et réduire les travaux d'entretien. (En moyenne : hauteur 10 mètres, pente Ouest, 20\%, plateforme de 5 mètres).!

IV. La dune littorale ne peut rien contre l'érosion marine. Lorsque les forestiers ont à lutter contre celle-ci, ils ont recours d'abord à des ouvrages offrant aux lames une résistance flexible ou relative, plutôt qu'absolue, et favorisant l'amoncellement du sable : fascinages, clayonnages, groupes de pieux (à espacements variables, en tenailles, etc.). Ce n'est qu'exceptionnellement et dans des cas spéciaux (courant de 
Mimizan) que l'on recourt à des ouvrages comportant plus ou moins de maçonnerie dont la résistance cherche à ètre absolue (digues, brise-lames, épis, etc.).

Il a été essayé, ces années dernières, à Soulac (Gironde), divers systèmes de revêtement protecteur sur le talus ouest de dunes littorales érodées : le système Decauville, nappe souple de briques en ciment juxtaposées et soutenues par des fils métalliques suspendus à des piquets fichés dans le haut de la dune; le système Delpech, nappe de briques creuses rendue rigide par des joints en ciments; le système de Muralt, formé de poutres et de panneaux en ciment armé d'un seul tenant. De tous ces systèmes, dont le troisième est le plus résistant, mais aussi le plus coûteux (100 francs le mètre carré), et d'autres analogues (travaux de défense de Soulac de 1912) on peut dire qu'ils n'ont de valeur qu'à condition de comporter des fondations ou des digues de base empêchant l'affouillement par les lames et surtout assez étanches pour que l'eau ne vienne pas en-dessous délayer le sable et le faire foirer.

V. Conclusion. Il nous paraît n'y avoir aucune innovation à apporter dans la technique des travaux de fixation des dunes et de défense contre la mer.

Moyens daction artuels et mesures à prenIre.
I. a). Quant aux moyens d'action domnés par la législation actuelle en vue de la fixation des dunes, il faut distinguer.

S'il s'agit de dunes soumises au régime forestier (à l'Etat, aux communes et aux établissements publics), les moyens d'action sont suffisants. L'Etat est libre daus son domaine privé; il peut très largement subventionner les travaux de reboisement sur terrains communaux soumis (ou à soumettre), d'après la loi de finances du 18 avril 1893.

S'il s'agit de terrains non soumis au régime forestier (particulier's et communes), c'est le cas intéressant ici - les moyens d'action sont à peu près nuls actuellement. Dans les départements maritimes autres que la Gironde et les Landes, le décret du 14 décembre 1810 donne bien à l'Etat, notamment par son article 5, le pouvoir de suppléer au propriétaire défaillant. Mais un récent avis du Conseil d'Etat (3 mai 1911), s'opposant à l'application des dispositions de ce décret comme " trop anciennes et peu conformes aux tendances actuelles de l'Administration ", tend à rendre cette législation désuète et à paralyser complètement les pouvoirs publics. Dans la Gironde et les Landes, le décret de 1810 , non fait pour ces deux départements, est inapplicable et l'on n'y a même pas les ressources de principe qu'il pourrait offrir.

En fait, maintenant, l'Administration ne peut plus guère intervenir nulle part pour la fixation des dunes non soumises au régime forestier.

$A$ l'égard des propriétaires de dunes actuellement boisées et non soumises (particuliers et communes), les pouvoirs publics sont également désarmés dans le cas où des exploitations abusives seraient faites et pourraient compromettre soit la fixité des sables, soit le rôle protecteur des rideaux boisés du littoral. Ce n'est qu'au cas très rare d'un défrichement caractérisé (direct ou indirect) que l'Administration pourrait intervenir en faveur de l'in térêt général menacé.

Les forêts communales des dumes ne peuvent être soumises au régime forestier que sous les réserves inscrites à l'article 90 du Code forestier. Aussi plusieurs échappent-elles à la tutelle bienfaisante de l'Etat. 
b.) En ce qui regarde les travaux de défense à la mer, dans toute la France, l'Etat ne peut rien non plus, légalement, en dehors des forêt,s domaniales du littoral.

L'Administration des Ponts et Chaussées (service maritime) ne tr'availle que dans l'intérêt public, pour les ports (ainsi les travaux de la Pointe de Grave sont faits uniquement dans l'intérêt dı port de Bhrdeaux). Elle ne s'occupe nullement de la protection des intérêts privés. Les agents le font parfois, mais c'est à titre d'ingénienrs ou d'architectes privés, movennant honoraires et les dépenses étant intégralement payees par les particuliers ou les collectivit és qui ont recours à eux. Les propriétaires particulier's sont done livrés à eux-mêmes, à leur fantaisie ou à leur impuissance, sans autre lien ni aide possible que leur association en syndicats, ce qui n'est pas toujours réalisable.

Cependant rien ne s'oppose, ce semble, dans l'état de la législation actuelle, à ce que, en deliors des terrains soumis au régime forestier, les particuliers (individuellement ou associés), qui ont à se défendre des attaques de la mer, fassent appel au service des améliorations agricoles, comme le font déjà ceux qui, à l'intérieur, ont à se défendre des incursions des fleuves et cours d'eau.

Et cela paraît suffisant. Toutefois, il faudrait que l'Etat puisse imposer l'exécution de travaux de défense nécessaires lorsque le ou les propriétaires du littoral s'y refuseraient, et puisse contrôler ceux que ces propriéaires exécutent d'eux-mêmes.

II. Nous conclurons donc d'après les considérations qui précèdent, en proposant le vœu suivant:

Qu'une législation nouvelle, applicable à tous les départements maritimes, relative à la fixation des dunes et anx travanx de défense contre la mer et destinée notamment à remplacer le déeret du 14 décembre 1810, soit mise à l'élude et promulgalée dans le plus bref délai possible.

M. Pierre Buffallt. - Au sujet des revêtements protecteurs des dumes, je dirai qu'il est arrivé à Soulac que la ville a demandé aux Ponts et Chaussées de faire des travaux très coùteux qui, cependant, se sont effondrés au bout de trois ou quatre mois, à cause de l'affouillement par les lames. Ce fait paraît provenir de ce que la mer a érodé la plage qui s'est abaissée dr beauroup an-dessous de son nivean primitif. Lieau venant par-dessous a évidé le revêtement de ciment, qui ña plus eu de base et s'est effondré sous l'action des lames.

M. Le Présinent. - Vous avez parlé des terrains eommunanx soumis ou à soumettre au régime forestier. Ils peuvent y être soumis in effet, du fait que les communes recoivent des subventions de l'Etat.

M. Pierre Buffavte - If est arrivi eependant que l'Etat a subventionné un terrain communal sans le sommettre au régimu forestier. C'est arrivé à Soulac en $18950 u 1896$.

C'est pour cela que j’ai distingué entre les terrains soumis ou à soumettre et les terrains non soumis au régime forestier. 
Au sujet des exploitations abusives des dunes boisées, je citerai cet exemple. $11 \mathrm{y}$ a deux ou trois ans, les forêts particulières qui courrent les dunes du Verclon, sur une étendue assez grande, ont été vendues par le propriétaire. On a fait une coupe rase. Les communes voisines du Verdon et de Soulac, protégées du vent d'Ouest par cette étendue boisée, ont demandé à l'atministration d'interdire ces coupes. L'autorité préfectorale s'est émue et a écrit an Conservateur. L'Administration s'est trouvée désarmée. Il pourrait être utile de donner à l'Administration le moyen d'empêcher de pareilles coupes d'être trop absolues.

Dans la partie domaniale de cette forêt du Verdon et de Soulac qui tourhe à la mer, l'Administration a demandé aux communes de molifier l'aménagement et de supprimer l'exploitation dans une bande formant un rideau protectrur. Il serait bon de pouvoir appliquer le même précaution aux bois particuliers.

J'ai parlé des travaux de téfense à exécuter par l'Etat lorsque les propriétaires du littoral s’y refuseraient. Voici ce qui m’amène à proposer cela.

Dans un ouvrage publié pour l'Exposition de 1900 sur les traraux de défense à la mer, MII. Lafon et Guilbaut citent le cas de la rivière de l'Auzance qu'il s'agissait de protéger. Le propriétaire s'opposait à ce que l'Administration travaillât sur son terrain.

On ne peut trouver de solution actuellement que par des échanges de terrains. C'est une solution assez longue et pas toujours facile. 1l serait bon, si l'on a besoin de faire des travaux de défense dans l'intérêt général, que les propriétaires puissent être obligés de les supporter moyennant indemnité.,

M. Le Président. - Je remercie de sa très intéressante communication M. Buffault, dont on connait la compétence particulière en matière de lunes.

M. Flahaute - Je suis trop heureux de féliciter notre confrère de son très intéressant rapport: Mais je voudrais seulement faire observer qu'il y aurait lieu de donner au roeu un caractère un peu plus formel, en lisant :

"Les forêts des dunes penvent être considérées comme forêts protertrices et truities romme telles.")

11 est évident que tous les pays d'Europe anjourd hui tendent à suirre ladmirable exemple de la démorratie suisse qui a sacrifié ses intêrêts particuliers à l'intérèt général en déerétant que toute forêt protectrice ne peut être exploitée sans un avis favorable du service foresticr.

M. le Présinext. - Je urois devoir faire remarquer que cette question des forêts protmotriês est traitée à la leuxième Commission. 
Iei il s`agit spécialement de la fixation de la dune et non de l'exulortation des forêts déjà constituées.

M. Jagerschutt. - Voici le texte que je propose :

" $1^{\circ}$ Que dans tans les pays où le besoin s'en fuit sentir, une législation relative à la fixation des dnnes et anx travanx de défense contre la mer soit mise à l'étude et promulguée dans le plus bref délai possible. "

" $2^{\circ}$ Que les forêts des dunes soient classées comme forêts de protection."

Le vœu, ainsi amendé, est adopté à l'unanimité.

M. de Peyrelongue donne lecture des communications de M. Lippens, ingénieur, membre du Conseil supérieur des Forêts en Belgique.

Les dunes du littoral belge ont éfé longtemps considérées comme cunatituant des terrains improductifs. C'est seulement rers 1880 que quelques propriétaires pensèrent à les mettre en valeur par le boisement.

L'essence la plus appropriée, nous dit l'auteur du rapport, est le piu maritime. Il convient, non pas de le semer sur place, mais de le transplanter après repiquage dans les pépinières.

Le terrain à planter est divisé en bandes de $0 \mathrm{~m}$. 50 de largeur, séparées par. un intervalle de terrain inculte égal à la longueur des bandes. Les arbustes et les herbes qui croissent ainsi tout aatour, abritent les jeunes sujets contre les vents violents du large.

Dans les bas-fonds, on laisse se développer des taillis de saules, de peupliers et de bouleaux

Le boisement de ces dunes a été entrepris, il y a trelte ans, par M. le sénate:ur Auguste Lippens, et continué par ses fils, MM. Philippe-Auguste Lippens, membre du Conseil supérienr de l'. Igriculture, et Hippolyte Lippens, sénateur.

H. Le Présluent. - Nous passons, Messieurs, à la suite de l'ordre du jour.

La parole est à M. Jagerschmitt au sujet d'une communication de II. Ricardo Codorniu.

M. Jagerschuttr. - M. Ricardo Corlorniu présente une itude fort intéressante sur le service hydrologico-forestier de l'Etat en Espague Fixation et rebolsement des dunes; Correction des torrents ET RESTALRATION DES MONTAGNES.

L'auteur du mèmoire esl entré dans ce service à sa création. dès 1887. Snccessivement ingénieur de section, thef de division et enfin inspecteur général, il était particulierement qualitié pour exposer a!k Congrès les résultats obtemus gràce aux travaux exécutés par l'Etat depuis vingt-cing ans dans les dunes et les montagnes espagnoles.

Les difficultes a vaincre etaint d'autant plas granules que, sur le rersant méditerranéfn de la péninsule, où ont été exécutés lit plupart de cés lravarux, lus pluies sont particulierement rires.

Les travaux de fixation de dunes ont alé pxérntés lans le golfe de Rosas, à Gilaradamar é à Elche, sur la côte de la Méliterranée, à Vejer, à Sintir Maria et linta et à la pointe Cä̈man, sur la côte de l'r Jién. l. fisg hectares sont irtuellement fixés. Sir ce total, 817 hectares sont boisés. 
Les travanx de lestauration des montagnes ont été exécutés dans les bassins des affuents de l'Ebre, du Jucar, du Guadalentin, du Guadalquivir et du Tage.

Lt's projets de correction ont porté sur près de 300.000 hectares. 18.278 hectares ont été reboisés dans les périmètres. Plus de 15.000 hectares ont été mis en défense.

La longue expérience đe 11. Ricardu Codorniu lui a permis, en terminant son étude, de soumettre au Congrès quelques conclusions pratiques qui peuvent se résamer ains :

$1^{0}$ Les résultats obtenus sont satisfidisants ot plus complets que ne l'espéraient les forestiers eix-mèmes.

$2^{\circ}$ Les travaux de fixation des dumes ef de restauration des montagnes sont conteux et ne doivent ètre entrepris que lorsgu'on peut disposer des moyens indispensables à leur prompte exécution.

$3^{\circ}$ L'Ftat doit acquérir les terrains où il tratvaille.

$4^{\circ}$ Des crédits sullisants doivent ètre consacrés à ces travaux pour quon puisse les pousser avec activité, sans quoi, les prix d'unités augmentent dans ane large mesure.

$5^{\circ}$ Il convient de n'entreprendre les travanx de correction proprement dits gue dans les endroits où ils sont indispensables et urgents.

60 Les lravaux doivent ètre compris dans molu plan d'ensemble bien étudié.

70 La sécheresse fui sévit sur la plus grande partie de l'Espagne, n’est pas in ulstacle insurmontalile.

$8^{\circ}$ : In doit s'efforcer, quand les conditions sont défavorables, de couvrir le sol aree des essences puru exigcantes, auxquelles on pourra substituer plus tard des espèces ayant plus de ialeur.

yo bans les terrains sees et stériles, le reboisement est facilité par la création de lignes on de bonquets d'arbres lorsque le reboisement en massif est inpossible.

110 o 11 est inatile de cherrher a obtenir un repeuplement artificiel complet de la surface à rebuiser. La natur! se chargera de complóter l'marre entreprise.

$11^{\circ}$ L'économie dans l'ensemble des travaux est palticulierement recommandée. Mais il ne faut lésiner, ni pour la profondeur du labour, ni pour les dimensions des potets, la quantite des semences, les abris des jeumes plants, les engrais ou les arrosages. Car c'est encore l'insuccès qui coite le plus cher.

120 En ce qui concern. lus voles de communication, il ne fant créer que les sentiers absolument nécessaires à la surveillance et à l'exécation des travaux.

M. Le Présinext. - Messieurs, lordre du jour est épuisé. Nous ne -iegeons lonn pas wet après-midi.

La seance ast lovio a 11 11. 1 1'. 


\section{SEANCE DU 19 JUIN 1913}

La séance est vureptè à 9 h. 20.

La parole est donnée à M. d Iuber de Peyrelongur pour la lecture

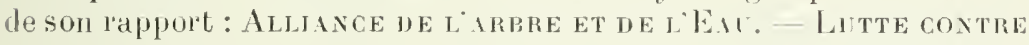
LES INONIATIOXS. )

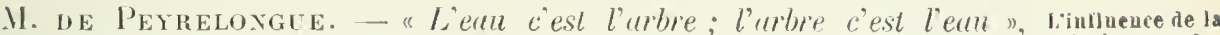
bit M. Onésime Peelus, dans son Manuel de lEau. "In precle indissoluble lie l'éternellement fuyunte ì l'éternellement immobile " et il est procorêt sur les inondatione. dable que cette allianee, contractée dès les promières hrures de l'existence du globe, a été conclue pour toujours.

Quel est son effet sur le régime des conrs d'eau?

Dans quelle mesure pouvons-nous l'utiliser pour lutter contre les inondations et, si son aetion est insuffisante, comment devons-nous y suppléer? Autant de questions auxquelles nous allons essayer de répondre.

La forêt influe : $1^{\circ}$ sur la quantité d'eau plıviale qui parvient au sol; $2^{\circ}$ sur la proportion de eette eau qui arrive dans les thalwegs par le ruissellement.

Par là, elle doit agir sur l'alimentation et le débit des courśs d'eau. L'eau que reçuit le sol boisé provient : de la pluie, de la condensation, à la surface des feuilles et des tiges, d'me partie de la vapeur d'eau atmosphérique et de la condensation d'une autre partie de cette vapeur au contact de la couverture.

La quantité d'eau provenant de la contensation est insignifiante, comparée à celle que fournit la pluie.

Celle-ci a fait l'objet des expérieners classiques de Mathieu qui ont démontré que, même en tenant compte de la retenue non négligeable des cimes, le sul boisé est plus abondamment arrosé que le sol agricole. Le fait, ajoute 1I. Hüffel (1), est certain pour les forêts feuillues, sans doute aussi pour les pineraies et les mélézaies, probable pour les pessières malgré le couvert très épais de l'ŕpieña.

Les forêts tendraient ainsi à envoyer aux rivières, surtout en hiver, plus d'eau que les terrains agricoles, ce qui leur assignrrait un ròle plutôt nuisible qu'utile au point de rue des inondations.

(1) Economie forestière, Hüflel. 
Mais cette eau s'évapore, en partie, sur place; en partic, imbibe la couverture morte, pénetre dans le sol, soit pour être absorbée par les racines des arbres, soit pour alimenter les nappes souterraines.

Une fraction seulement du volume total ruisselle à la surface; c'est elle qui, en temps de crue, profite immédiatement aux cours d'eau.

Il suffit donc de savoir comment la forêt agit sur le ruissellement pour pouvoir dire comment elle influe sur les crues. A cet effet, on choisit deux bassins qui, toutes les autres conditions étant identiques, diffèrent par le taux du boisement.

On mesure pour chacun d'eux : la quantité de pluie tombée en un temps donné, sur les versants; et la fraction de ce volume qui arrive au thalweg.

La comparaison des deux séries d'observations indique l'influence de l'état boisé.

Supposons en effet, pour fixer les idées, que nous ayons trouvé les nombres suivants, correspondant, pour les deux bassins, au même intervalle. de temps:

Bascin boisé ..............

Hauteur de pluie
moyenne en
millimètres
nillimètres

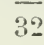

29
Accroissenient du volume
d'eau du cours d'eau en metres cubes

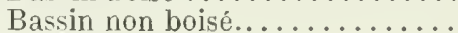

1 m. 28

$1 \mathrm{~m} .74$

Le calcul nous montre que 1 millimètre de pluie envoie dans le cours d'eau :

Pour le bassin boisê.............. 0 mc 0 't

Pour le bassin non boisé............. $0 \mathrm{mc} 06$

Les quantités d'eau de ruissellement sont donc dans le rapport de de 4 à 6 ou de 2 à 3 . Nous en conclurons que la présence du massif boisé sur les versants considérés, diminue, toutes choses étant égales d'ailleurs, l'intensité du ruissellement du tiers de sa valeur.

Tout revient, en définitive à déterminer, pour chaque bassin :

to La hauteur d'eau pluviale.

$2^{\circ}$ La portion de cette eau qui arrive au thalweg.

La première est déduite des mensurations pluviométriques et nous n'y insisterons pas.

Quant à la deuxième, elle est exprimée, suivant les stations de recherches, de deux manières différentes: soit en fonction de la surélération du niveau des eaux dans le cours d'eau, soit en fonction du débit.

De là deux méthodes d'opération distinctes basées, l'une, sur' la mesure de la hauteur des eaux, l'autre sur celle du débit.

Voyons à quels résultats a conduit leur application :

Méthode basée sur la hesure de la haUteur des eaux (Observations de M. Willis L. Morre (1). (Bassin de l'Ohio). - M. Willis Moore, chef du U. S. Weather Bureau, a mesuré la hauteur des précipitations atmosphériques dans le bassin de l'Ohio, à North Le wisburg. Portsmouth, Confluence et Franklin, et les hauteurs d'eau fluviale qui leur' correspondaient, sur l'Ohio lui-même à Cincinnati : ses expériences

(1) A report on the influence of forests on climate and on floods. By Willis L. Ioore LL. D. S. C. D. Cheef of U. S. Weather Bureau Washington 1910. House of representatives. 
ont duré de 1871 à 1908, soit 37 ans, et lui ont donné les résultats suivants :

\begin{tabular}{|c|c|c|c|c|c|}
\hline \multirow{2}{*}{ PÉRIODES } & \multicolumn{5}{|c|}{ HAUTEUR DE LA TRANCHE D'EAU ANNUELLE (en pOUces) } \\
\hline & North-Lewisburg & Portsmouth & Confluence & Franklin & Pour toutle bassin \\
\hline $1871-1889$ & 39.8 & 41.1 & 41.5 & 42.7 & 41.3 \\
\hline \multirow[t]{2}{*}{$1890-1908$} & 38.1 & 40.9 & 46.0 & 42.3 & 41.8 \\
\hline & NIVEAL MOY & EN DE L'OH & A CINCINN. & (en pieds & \\
\hline 1871-1889 & 17.3 & & & & \\
\hline $1890-1908$ & 17.6 & & & & \\
\hline
\end{tabular}

Il en résulte que, durant la période totale de 1871 à 1908 , ni la hauteur des précipitations, ni celle de l'eau pluviale n'ont cliangé. Comme, dit M. Willis Moore, la déforestation doit avoir été aussi considérable dans le bassin de l'Ohio que partout ailleurs, il y a lieu de conclure que les forêts n'ont qu'une influence des plus minimes sur les précipitations et sur le régime des cours d'eau.

Mais M. Willis Moore reconnaît que les précipitations n'ont pas été mesuréeş d'une façon bien précise.

La précipitation moyenne pour le bassin n'est pas aussi facilement obtenue (que la hauteur des eaux). 》.

"C'est seulement dans des cas exceptionnels que des mensurations continues de précipitations, sont susceptibles de servir à des études comparatives.

Les chiffres officiels, dans les grands centres, sont fournis par des repères dont l'entourage immédiat a fréquemment changé dans le cours d'une longue série d'années, et c'est pour cela que les repérages des pluies de Cincinnati et Pittsburg n'ont pas été connus. Les points choisis sont les meilleur's et les seuls où des observations aient pu être utilement effectuées pendant une longue période."

Acceptons cependant, sans les discuter, les chiffres de M. Willis et admettons qu'en effet, ni les précipitations, ni l'écoulement fluvial n'aient changé depuis 1871. Encore nous faudrait-il, pour pouvoir en conclure que les forêts n'ont exercé aucune influence, démontrer que le taux de boisement du bassin a varié. Or, précisément, M. Willis l'ignore.

"Je ne sais pas, dit-il, quelle étendue a été déboiscée dans la vallée, durant les 38 années considérées ; mais, quelle qu'elle soit, il semble évident qu'un tel changement dans le rapport de la surface boiscée à la surface cullivée n'a pas eu d’effet appréciable sur le régime de l'Ohio.»

\section{Et plus loin, comme conclusion:}

"Je crois que le lecteur reconnaitra que j’ai démontré, dans les paragraphes précédents, que l'écoulement de l'Ohio, où je présume que la déforestation a été aussi grande que dans n'importe quelle autre partie du pays, dans les temps récents, n'a: pendant une píriode de 38 ans, subi d'autres changements que ceux qu’ont apportés les précipitations.» 
11 parail done y avoir. dans les expériences de .II. Willis, une lacune qui fail perdre à ses conclusions une grande partie de leur valeur.

Observalions du Col. Burr (Bassin du Merrimac). - Le rapport dans lequel le Col. Burr, du cor'ps des Ingénieur's, relate ses observations, se trouve dans le U.S. Senate Doenment $n^{\circ} 9$ of the $62 d$. Congress.

Il est résumé et commenté dans la revue Engineering Nerrs $\left(n^{\circ}\right.$ du 27 juillet 1911), sous le titre: The influence of forests on Stream flow in the Merrimac river basin. Nerv Hampshire and Massachussets.

La Nature ( $n^{\circ}$ du 23 novembre 1912) en reproduit los conclusions :

"Depuis les premiers settlements jusque vers 1860-1870, le déboisement du bassin dı fleuve Merrimac a été constamment en augmentant. Pıis, à partir de cette époque, la surface boisće s'est accrue, dans tout le bassin, de plus de $25 \%$.

"I] n'a été observé ni diminution dans la hauteur d'eau tombée sur le bassin par suite des déboisements, ni augmentation à la suite des reboisements de plus de $25 \%$ de la surface de ce mềme bassin.

"La durée des crues et leur débit ne sont aucunement influencés par le reboisement ou le déboisement. "

11 serait trop long d'entrer dans le détail des observations du Col. Burr, basées, comme celles de M. Willis Moore, sur la comparaison de la hauteur des caux fluviales avec celle des précipitations atmosphériques.

Nous nous contenterons de faire observer quo ces observations - très intéressantes d'ailleurs - ne nous paraissent pas concluantes pour les raisons qui suivent :

10 Les terrains que le Col. Burr considère comme boisés ont tout l'air d'être seulement couverts de quelques bouquets de vieux arbres disséminés, dans des peuplements d'âges très divers, mais pour la plupart très jeunes et dont l'effet sur le ruissellement ne saurait être bien considérable.

"Le New-Hampshire, ditl'auteur (1), renferme en quelques rares endroits des arbres de plus de 80 ans et, ailleurs, des sujets plus jeunes, de tons les âges.

"Près des anciens settlements, particulièrement au sud-est de l'État, la plupart des bois ont étẻ coupés deux ou trois fois el les jeunes peuplements y sont plus nombreux qu'ailleurs. "

M. Edgecomb, à propos du New-Hampshire, fait observer que la surface boisée s'est beaucoup étendue par le fait que des terres agricoles ont été délaissées. Depuis $1880,800.000$ acres de terrains se trouvent dans ces conditions et " une grande partie (de cette surface) n'est pas encore bien couverte d'arbres *

Même remarque pour l'étal des Massachussets qui, d'après M. Edgecomb, renferme "des bois de plus de 30 ans, des bois de moins de 30 ans, de la broussaille et ailleurs des forêts parcourues par des incendies nais dont la destruction a été rarement totale ».

20 La série des observations relalives aux précipitations atmosphériques renferme des lacunes.

Dans la partie du bassin du Merrimac (qui appartient aux Mlassachussets, d s mensurations ontété faites partout, mais "elles sont relativement peu nombreuses dans le New-IIampshire (2) et aucunr n'a été faite

(1) Cf. "Engineering News ", 27 July 1911.

(2) Enginerring News, loc, cil. 
dans la partie du bassin - mosurant 900 miles carrés - qui rst située au-dessus. de Plymouth ni dans la large zone qui s'étend, sur les pentes onest du bassin, antere Peterboro el Gaften».

L'auten ajoute, il est rrai, que d'autros obsrrvations "le romete durre " ont élé nites qu quon a pu ainsi arriver è obtenir des indications générales satisfaisantes. Mais ces obsprvations n’ont pas le même poids que celles qui s'étendent sur une longue sérix d'amníes et par suite ne nous somblent pas combler suffisamment la lacume, pour permettre au Col. Burr de conclure sans restrictions.

Observations' de II. Lokhtine (Bassin du Volga). - M. Lokhtine les a rulatées clans le rapport qu'il a présnnté en 1905 au Congrès international de navigation de Milan (1). Elles ont duré 22 années (de 1878 à 1900), pendant lesquelles on a mesuré la hauteur des eaux de la somra, de la Bieleia et du Volga.

"Un déboisement considérable " pfrelué dans lo bassin rle la Soura an 1852, a provoqué un abaissement du nivrau d'éliage dans la période comprise entre les années 1889 et 1900.

Les mensurations effectuées, pour la Bipleia, à la station l'Oufa (située dans une partie cléboisée) et à celle de Gouzderka (située dans une partie moins dénudée), ont accusé uno baisse plus accentuée au premier poste qu'au second.

Obserations de M. Ponti (Bassin de l'Adra). - Elles font l'objet du rapport de M. Ponti, au Congrès de Milan en 1905 (2). De 1821 à 1900, on a relevé le nombre des crues de l'Adcla et, pour chaque erur, la hauteur des eaux sur le signal de garde - limite marquée sur les hydromètres à partir de laquelle les ingénieurs surveillent la crue d'une façon toute spéciale - la durée du séjour de l'eau au-dessus du signal, l'accroissement lioraire en centimètres et la durée de cet accroissement; on a constaté que le 1831 à 1890, l'aecroissement horaire a augmenté et sa dırée a diminué.

De 1890 à I900, l'accroissement horaire a diminué et la hauteur des crues a été moindre.

Done, lans la première période, le régime du lleuve a perdu de sa régularilé et dans la deuxième, il s'est régularisé. Or. de 1855 à IS65, d'importants déboisements ont été pratiqués dans le bassin et à partir de 1883 , on a procédé à des reboisements.

L'inlluence des uns et des autres est manifeste.

Observations de I/ II. Mall et IVash (3) (Cours d'eau des Ippalaches.) MM. Hall el Wash, ont étudié les variations, dans un intervalle de 20 ou 30 années, du régime des cours d'eau qui descendent des montagnes des Appalaches. Ils en ont conclu à une augmentation sensible du nombre et de la durée des inondations.

Deux d'entre ces cours d'eau sont particulièrement intéressants : Le Cumberland et le lied River.

Dans le bassin du Cumberland, d'importants déboisements ont été effectués. Ils avaient atteint, en 1890, les 21/100 de la superficie totale et s'étendaient, en 1908, sur les $32 / 100$.

Le bassin du Red River, an eontraire, a été reboisé.

(1) Influence de la destruction dus furôts rt du dessèrhement des marais sur le légime et le débit des rivières (Rapport. de If. Irokhtine).

(2) Intluence de la destruction dis forêts et du dessecliement des marais sur le régime et le déluit des rivières (Rapport de $\mathbf{I 1}$. Ponti).

(3) Surfare Conditions and Strom flow; by Hall and Wash (Jorest Cirrular 176 ). 
Son taux de boisement qui était de $14 \%$ en 1900, s'élevait à $40 \%$ en 1908 .

On a relevé en même temps dans les deux bassins, les hauteurs de pluie et dans les deux cours d'eau la hauteur des eaux et l'on a obtenu les chiffres suivants :

\begin{tabular}{|c|c|c|c|c|c|c|c|c|}
\hline \multirow{2}{*}{$\begin{array}{c}\text { NOM } \\
\text { du cours d'eaul }\end{array}$} & \multirow{2}{*}{$\begin{array}{c}\text { ETENDUE } \\
\mathrm{du} \\
\text { bassin }\end{array}$} & \multirow[b]{2}{*}{ PERIODES } & \multicolumn{2}{|c|}{ CRUES } & \multicolumn{2}{|c|}{ BASSES EAUX } & \multicolumn{2}{|c|}{ PR ECIPITATIONS } \\
\hline & & & $\begin{array}{l}\text { Sombre } \\
\text { de crues }\end{array}$ & $\begin{array}{c}\text { Sombre dejoars } \\
\text { de erues }\end{array}$ & $\begin{array}{l}\text { Sombre de } \\
\text { basses eaux }\end{array}$ & $\begin{array}{l}\text { Yombre dejours } \\
\text { de basses eatux }\end{array}$ & $\begin{array}{l}\text { Nombre } \\
\text { de stations }\end{array}$ & $\begin{array}{c}\text { Hoyeone do } \\
\text { precipitatioos } \\
\text { (e) pouces) }\end{array}$ \\
\hline \multirow{4}{*}{$\begin{array}{l}\text { Cumberland } \\
\text { Red River. . }\end{array}$} & \multirow{2}{*}{$\begin{array}{c}\text { mètres carrés } \\
3.739\end{array}$} & \multirow{4}{*}{$\begin{array}{l}1890-1898 \\
1899-1907 \\
1892-1899 \\
1900-1907\end{array}$} & 32 & 89 & 61 & 61 & 3 & 7 \\
\hline & & & 43 & 102 & 65 & 1.576 & 3 & 41,42 \\
\hline & & & 19 & 87 & 49 & 826 & 5 & 31,80 \\
\hline & 40.200 & & 16 & 60 & 8 & 208 & 5 & 29,86 \\
\hline
\end{tabular}

Ce qui démontre que :

Dans le Cumberland, il y a eu 13 jours de crues et 315 jours de basses eaux de plus dans la deuxième période que dans la première. Quant aux précipitations atmosphériques, elles ont diminué de 4,85 pouces en moyenne.

Dans le Red River, il y a eu 27 jours de crues et 618 jours de basses eaux de moins dans la deuxième période que dans la première. Les précipitations atmosphériques n'ont diminué que de 1,94 pouces.

En d'autres termes, le régime du premier bassin est derenu moins régulier; le second s'est, au contraire, régularisé.

Observations de $\mathbf{1 I}$. Leighton (1). (Bassin de l'Ohio.). - Elles ont permis de constater une augmentation du nombre et de la hauteur des crues, en particulier, dans les bassins de l'Ohio, de l'Allegheny, du Monogahela et de l'Youghiogheny. Or, depuis 30 ans, ces bassins subissent d'importants déboisements qui, entrepris d'abord dans celui de l'Allegheny, se sont poursuivis dans ceux du Monogahela et de l'Youghiogheny.

MÉthode basée sur la Mesure du débit. - Cette méthode nous semble plus parfaite que la précédente, la quantité d'eau qui s'écoule dans une rivière étant exprimée, non pas par la hauteur de son niveau, mais par le débit (produit de la vitesse moyenne par la section mouillée). Elle a été appliquée en France par Belgrand, puis par trois gardes généraux des Eaux et Forêts: Jeandel, Cantegril et Belland.

Mais leurs observations, trop connues pour que nous nous y arrêtions présentaient le grave défaut de porter sur des bassins d'étendues très différentes et d'amener par suite à des résultats peu comparables. Parmi les nouvelles recherches dirigées dans ce sens, nous citerons celles que M. Lauda, directeur du bureau central d'hydrographie de Vienne, a relatées dans son remarquable rapport au Congrès international de navigation à Milan, en 1905 .

(1) Report of the National Conservation Commission (Leighton, Washington 60 th. Congress 2 session). 


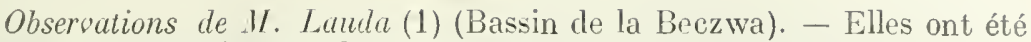
faites sur la Bistritzka et la Seniza, affluents de la Beczwa.

La superficie et l'altitude des deux bassins sont les suivantes:

Bistritzka, altitude $912 \mathrm{~m}$., superficie 63,50 Kmq.

Seniza, altitude $923 \mathrm{~m}$., superficie 74,80 Kmq.

La vallée de la Bistritzka est orientée est-ouest, celle de la Seniza, Nord-sud.

La hauteur annuelle de pluie est sensiblement la même pour les deux ; la constitution géologique semble peu différente de l'une à l'autre, mais le taux de boisement est près de deux fois plus élevé pour le bassin de la Bistritzka que pour celui de la Seniza.

En 1903 et 1904, on a mesuré à diverses reprises :

$1^{\circ}$ La hauteur des précipitations atmosphériques.

$2^{\circ}$ Le débit correspondant des deux cour's d'eau par la méthode du déversoir.

$3^{0}$ La rétention - c'est-à-dire la quantité d'eau retenue par les versants - différence entre la quantité de pluie tombée et la quantité de cette eau débitée par la rivière. On en a déduit le coefficient d'écoulement pour chacun des deux bassins, c'est-à-dire le rapport entre le volume de l'eau parvenu au thalweg et le volume des précipitations.

II. Lauda est ainsi arrivé aux conclusions suivantes :

"La forèt exerce une influence sur l'écoulement des eaux.

"La rétention des eaux de précipitation est, dans une certaine mesure, plus importante dans le bassin le plus boisé que dans le bassin le moins riche en forêts.

"Pour des averses dont l'importance dépasse certaines limites - ainsi, par exemple, en temps de crues - la rétention devient moins intense dans le bassin le plus boisé que dans le bassin le moins riche en terrains forestiers.

"Après une période de sécheresse, l’influence des averses se manifeste plus rapidement et d'une façon plus progressive dans le bassin le moins riche en forèts, tandis que l'inverse se produit dans le bassin à plus grande étendue forestière. "

Il s'ensuivrait done que les forêts cessent de jouer un ròle utile sur le ruissellement, dès que les pluies acquièrent une certaine persistance et dépassent un certain degré d'intensité. Résultat surprenant, à coup sûr. Dans l'article "Le Problème de la Forêt sur les inondations au Congrès de Milan " paru en 1908, dans la Revue des Eaux et Forêts, M. Tessier expose les raisons pour lesquelles il ne nous est pas possible de suivre M. Lauda jusqu'au bout de ses conclusions. Nous nous bornerons à la remarque personnelle suivante : les observations de M. Lauda ont été faites dans les mois de juin à novembre; durant cette cette période, il tombe en moyenne, d'après les chif̂res mêmes relevés dans le rapport, près de 4 millions de inètres cubes d'eau pluviale de moins dans le bassin de la Seniza que dans celui de la Bistritzka. En outre, le taux de boisement de ce bassin étant près de 2 fois moindre (exactement 1,8 fois) que celui de la Bistritzka, le sol évapore beaucoup plus, surtout en été.

Pour cette double raison, il n'est pas étonnant que les expériences aient pu laisser croire à un pouvoir rétentionnel plus grand, pour le bassin de la Seniza, déboisé, que pour celui de la Bistriłzka, courert de forêts.

(1) Influence de la destruction des forêts et de l'assèchement des marais sur le régime des rivières (Rapport de $\mathbf{M}$. Lauda). 
En résumé, des observations que nous arons relatées. quelques-unes n'autorisent pas à conclure d'une faŗon absolue, faute de données suffisamment précises; la plupart témoignent de l'influence bienfaisante de de la forêt sur le ruissellement.

La forêt agit encore d'une autre manière sur le régime des cours d'eau.

Grâce au manteau protecteur dont elle courre le sol, celui-ci échappe, dans une large mesure à l'aetion des agents atmosphériques, et par suite, est moins sujet à l'affouillement. Par là, elle exerce une influence des plus certaines sur le charriage et diminue ainsi l'importance des crues torrentielles.

Nous arons donc un double motif de maintenir ou de créer l'état boisé partout où nous avons à lutter contre les dangers de l'érosion et les envahissements des fleuves, des rivières ou des torrents.

liourre de la forêt complétée par tie travande ré gularisation.

Mais quelque indispensable que soit la forêt, surtout dans les parties hautes des bassins, sa présence ne suffit pas pour supprimer les inondations. Il faut lui adjoindre des ouvrages de régularisation ayant pour objet, les uns de remédier aux effets des crues (ce sont les redressements de lit, les travaux de défense des rives, les endiguements), les autres, de restreindre leur cause. c'est-à-dire l'afflux brusque des eaux dans les thalwegs; ce sont les puits absorbants et les barrages-réservoirs.

Voyons quels sont ceux auxquels nous pourrons le plus utilement avoir recours et dans quelle mesure nous derrons en faire usage.

Redressements de lit. - Ils ont pour but de faciliter l'écoulement des eaux en remplargant par des lignes aussi droites que possible les sinuosités du lit.

Remarquons cependant que le trajet sinusoïdal des cours d'eau naturels, à fond mobile et présentant une succession de mouilles et de maigres, est une courbe d'équilibre résultant de l'équivalence entre la puissance d'affouillement des eaux et la résistance du lit. Vers cette forme, que lui ont imposée les circonstances extérieures et la nature du terrain sur lequel il coule, le cours d'eau tendra toujours et si on lui fait violence pour l'en écarter, on suseitera, dans son régine, des désordres dont l'intensité peut être considérable.

En admettant que les ouvrages résistent, leurs effets restent incertains. Quelquefois même, on en obtiendra des résultats opposés à ceux que l'on cherchait. Le redressement sera suivi d'un exhaussement du lit avec diminution de la vitesse du courant au lieu de provoquer un approfondissement du chenal avec écoulement plus rapide.

On voit donc qu'il faut agir avee circonspection; ne rectifier le lit que par places bien choisies et éviter l'abus de la ligne droite. Encore se pourra-t-il que les dangers, conjurés au point primitivement menacé, soient transportés en aval et rendus plus redoutables.

Travaux de défense des rives. - Le trajet sinueux qui suit le cours d'eau naturel comprend une série d anses concaves et de parties convexes. Or, il est bien connu que celles-ei sont formées aux dépens de celles-là. Les eaux suivent les bords concaves qu'elles affouillent et s'écartent des bords convexes contre lesquels elles déposent. Le courant est rejeté d'une rive à l'autre en même temps que, tantôt à droite, tantòt à gauche. s'effectuent les dépôts.

On conçoit done que, si l'on arrive, au moyen d'ourrages spéciaux, à fixer l'anse concave, on diminue le dépôt sur le burd convexe et on 
régularise, dans une certaine mesure, le lit du cours d eau. Mais dans un' certaine mesure seulement, car il est certain que l'affouillement ne devient jamais nul et par suite la forme d'équilibre jamais stable.

Les ouvrages de défense des rives consistent en blocages, enrochements, perrés, fascinages qui assurent au lit mineur une certaine fixité. Mais ils doivent être exécutés avec mesure, sans avoir pour objet d'obtenir, au moyen de redressements trop brusques, une augmentation du mouil. lage que l'on risquerait d'acheter au prix d'inconvénients d'une extrême gravité.

Endiguements. - L'endiguement diminue, en la resserrant, la section libre du cours d'eau. Mais il serait faux de croire qu'il doit en résulter partout et toujours un approfondissement du lit et un plus fort débit et que, dès lors, ce moyen suffit pour mettre les terres riveraines à l'abri des inondations.

En amont de l'endiguement, la vitesse de l'eau est augmentée du fait du resserrement de la section: d'où, affouillement et par suite approfondissement du lit. En aval, au contraire, la section s'élargissant, la vitesse diminue et un dépôt se forme qui relève le fond. L'approfondissement en amont et le relèvement en aval diminuent la pente moyenne de la partie endiguée et ont pour conséquence l'exhaussement du lit.

C'est ainsi que l'Isère, endiguée sur une grande partie de son cours, entre Albertville et Montmélian coule maintenant à un niveau supérieur à celui de la plaine, et des infiltrations se produisent sur les terrains avoisinants. Quant à l'affouillement d'amont, s'il n'est pas aussi prononcé qu'il pourrait l'être, c'est que l'Arly qui se jette, près d'Albertville, dans l'Isère, apporte à celle-ci une partie de ses graviers.

La Garonne est resserrée entre la limite du département de la Girond et Langoiran "par des rives artificielles auxquelles on a généralement donné un écartement à peu près uniforme, moindre que la largeur naturelle (1) ". Entre la limite du département et Portets, nous dit II. Fargue, l'étiage s'est abaissé, en moins de 40 ans, de $1 \mathrm{~m}$. 30 en moyenne. A Barie et à Caudrot, les eaux d'étiage ont été, en 1870 , à $1 \mathrm{~m}$. 85 en contrebas du niveau auquel elles coulaient en 1832. En aval, au contraire, et jusqu'à Bordeaux, le fond s'est exhaussé.

Cet effet de l'endiguement se fait plus ou moins sentir suirant que les digues sont plus ou moins rapprochées; suivant, surtout, qu'elles sont ou non insubmersibles.

Le resserrement du cours d'eau entre des digues insubmersibles, amène un exhaussement du fond du lit, qui, en général, ne va qu'en s'accentuant, de sorte que les digues deviennent insuffisantes et dangereuses. Insuffisantes, parce qu'il faut les surélever toujours davantage si l'on veut maintenir le cours d'eau dans le lit qu'on lui a tracé. Nous sarons, pat Comoy, que "dans-les temps anciens, on avait réglé la liauteur des digues de la Loire, à 15 pieds au-dessus des basses eaux (2). "Après lix crue de 1906, les eaux s'étant élevées en certains points à 18 pieds; 1 ia hauteur des digues fut portée à 21 . On 1846 , on a surélevé ces digues qui ont encore été insuffisantes.

On les surmonta alors d'une banquette de 1 mètre de haut ur. La crue

(1) Etude sur la largeur moyenne de la Garonne (Fargue, in Flamant, loc. cit.).

(2) Mémoire sur les ouvrages de défense contre les inonlations (Comoy). 
de 1865, ajoute Comoy, est venue démontrer que cette surélévation était encore insuffisante.

Le Pò, qu'il a fallu endiguer pour protéger les nombreuses villes disséminées dans la plaine qu'il arrose, exhausse constamment son lit.

Graëff cite l'exemple de l'Aar, en Suisse "littéralement suspendue sur les terrains environnants $\%$.

Les dangers d'une pareille situation sont évidents.

Les remous qui se produisent dans la partie endiguée peuvent surmonter les digues ou les rompre et occasionner alors des dégâts dont l'étendue est impossible à préroir.

Est-ce à dire qu'on doive proscrire, d'une façon absolue, l'emploi des digues insubmersibles. Non certes. Il est au contraire tout indiqué en certains points et dans certains cas. En plaine, par exemple, quand il s'agit de mettre à l'abri des crues des agglomérations, les digues insubmersibles produiront d'excellents effets pourvu que l'on combatte, par des dragages, l'exhaussement du lit. Leur emploi sera surtout indiqué dans la région des grands bassins voisins de la mer. Le niveau des eaux, même en temps d'inondation, y varie peu, la grosseur des matériaux charriés y est faible; il est donc possible, au moyen de digues peu élevées et assez espacées pour ne pas occasionner au lit de rétrécissement nuisible, de procurer aux terres avoisinantes un abri protecteur.

II. Flamant ajoute même que telles digues insubmersibles constituent pour ces terrains "la défense la plus naturelle et la plus efficace (1)".

Quant aux digues submersibles, placées à une distance telle de l'axe du cours d'eau qu'elles en fixent, sans trop de contrainte, le lit mineur, elles peuvent rendre de précieux services, en permettant d'abriter, des crues ordinaires, les cultures les plus délicates et en laissant en arrière en cas de forte crue, un champ d'inondation assez vaste pour que s'effectue sans remous - surtout si l'on appuie sur leurs bords des chaussées transversales - le dépôt des limons.

Tous les travaux précités combattent les effets des inondations et n'exercent qu'une action locale.

Il en est d'autres qui s'attaquent à la cause principale des crues, c'est-àdire à l'afflux subit des eaux, et dont l'influence peut se faire sentir sur toute l'étendue du cours d'eau. Nous voulons parler des puits absorbants et des barrages-léservoirs.

Puits absorbants. - Leur but est d'emmagasiner les eaux de ruissellement dans le sol, comme le ferait un réservoir d'où elles s'écouleraient ensuite d'elles-mêmes sans causer de dégâts. Théoriquement il suffit de forer des puits d'une profondeur et d'une section telles qu'ils ne s'emplissent jamais.

En fait, la question est beaucoup moins simple.

Le puits est alimenté surtout par les eaux d'infiltration Or, quelque perméable que soit le sol, son pouvoir absorbant n'est pas illimité et la quantité d'eau maximum dont l'emmagasinement est possible, est presque toujours bien inférieure à celle ru'il faudrait enlever au cours d'eau pour agir d'une façon sensible sur les crues.

On peut, il est vrai, quelquefois, choisir un endroit d'où l'on atteigne une nappe d'eau profonde où iront se perdre les eaux de surface.

Mais il y a de fortes chances que cette nappe soit alimentée par les

(1) Hydraulique, 1909 (Flamant). 
eaux du même bassin fluvial et quand les pluies des régions supérieures seront assez abondantes, elles surélèveront le niveau de la nappe et refouleront celle-ci dans le puits. Il se peut même que le refoulement ait assez de puissance pour transformer le puits absorbant en un puits jaillissant.

M. Bergeron, dans le rapport qu'il a présenté en 1910 à la Commission des Inondations (1), cite deux exemples de cette inversion.

"Dans la vallée de la Loire, existent de nombreuses mardelles ou puits naturels ; l'une d'elles, dite de Montauban, dans le val d'Orléans, est en communication avec la Loire en amont de cette ville.

"En période d'etiage, c'est un véritable puits absorbant, mais en temps de crue, les eaux s'y élèvent à une cote supérieure à celle de la berge de la Loire, et alors elles débordent en inondant la région de Saint-Hilaire-Saint-Mesmin...

"Le second exemple est fourni par certains égouts de la ville de Paris; antérieurement et même pendant une partie de la période d'inondation, les bouches d'égout ont fonctionné, conformément au rôle qui leur est normalement attribué, comme de véritables puits absorbants; mais du jour où les égouts ont été en communication directe avec la Seine, dont la cote est supérieure à celle des bouches, celles-ci se sont transformées en véritables puits jaillissants.”

Le forage de puits absorbants peut encore présenter des dangers d'un autre ordre.

Bien qu'il soit très difficile de prévoir le point de résurgence des eaux ainsi emmagasinées, étant donné que l'hydrographie souterraine est indépendante du relief superficiel, on peut dire que ces eaux auront tendance à suivre les conduits souterrains déjà existants ; par suite, elles pourront augmenter brusquement le débit de certaines sources et provoquer des inondations en des points où celles-ci seront d'autant plus dangereuses qu'elles auront été moins prévues et qu'aucun ouvrage n'aura été établi pour s'en garantir.

De plus, les eaux recueillies dans un bassin ressortiront le plus souvent en un point aval du même bassin, mais avec un certain retard. Ce retard peut-être tel qu'il amène l'afflux de ces eaux à coïncider avec une crue secondaire du cours d'eau, d'où accroissement du danger comme le fait s'est produit en janvier 1910, où une crue secondaire de l'Yonne a coïncidé avec la crue de la Marne (2).

Enfin, les eaux absorbées peuvent fort bien, dans certains cas, contaminer une nappe d'eau d'alimentation, ce qui rend alors le remède certainement pire que le mal.

L'emploi des puits absorbants ne semble donc pas indiqué en France.

Notons cependant que, dans certains pays, où les conditions ne sont plus les mêmes, il en a été fait parfois un usage fort judicieux.

Barrages-réservoirs. - Le barrage-réservoir a pour objet de retenir une plus ou moins grande proportion des eaux de ruissellement de manière à diminuer la hauteur de la crue; et une fois celle-ci passée, de laisser le surplus s'écouler peu à peu.

Il va sans dire que le barrage-réservoir doit être établi sur terrain imperméable et en un point tel, qu'avec des dimensions admissibles, il retienne un volume d'eau assez considérable pour produire un effet utile.

(1) Les pujts absorbants (Bergeron, président de la Sociêté des Ingénieurs civils de France).

(2) Cf. Bergeron, loc. cit. 
C'est dans les parties hautes du bassin que ces cunditions seront le plus souvent réalisées. Car, c'est là qu'il y a le plus de chances de trouver un sol imperméable et résistant, comme de rencontrer un étranglement rocheux où l'on puisse épauler le barrage et en arrière duquel l'écartement des berges augmente, à dimensions égales, la retenue du réservoir.

là, enfin, les terres ayant en général peu de valeur, la crue occasionnée par le barrage, en arrière, devient relativement peu dommageable.

Nais un barrage ne retient que les eaux venant de l'amont, et son eflet, très sensible sur la région voisine d'aval, s'amoindrit au fur et à mesure qu'on s'en éloigne pour devenir à peu près nul à une certaine distance. Cela, à vrai dire, n'aurait pas lieu de nous préoccuper beaucoup, puisque le niveau de la crue va lui-même en diminuant de l'amont vers l'aval, à la condition, bien entendu, de ne pas rencontrer d'affluent.

Or, en général, tout cours d'eau reçoit un plus ou moins grand nombre d'aftluents.

Il est alors nécessaire, pour régulariser l'ensemble du bassin, de construire des barrages, non seulement sur le cours d'eau principal, mais encore sur ses principaux tributaires. Cette multiplicité d'ouvrages complique beaucoup la question.

L'effet d'un barrage unique est certain sur la région voisine en aval et peut être presque mathématiquement calculé.-Il demeure encore certain, dans le cas de plusieur's barrages placés sur le même cours d'eau. Mais son évaluation est d'autant plus difficile que le nombre des barrages est plus grand. Elle devient incertaine quand les ouvrages sont situés sur des cours d'eau différents. La crue d'un affluent quelconque arrive, en général, au confluent avant ou après celle du cours d'eau principal. Le retard oceasionné par les barrages, peut amener ces deux crues à coïncider. Il convient cependant de remarquer qu'il devient de plus en plus facile de parer à de telles éventualités.

Comme le fait très judicieusement observer M. Lévy Salvador (1):

" ... Il existe, au moins en principe, pour chacun de nos principaux bassins un service d'annonce des crues, chargẻ de faire connaître aux riverains des grands cours d'eau le niveaı que l'eau d'une crue paraît devoir atteindre dans un délai rapproché. Supposons que, dans l’un de ces bassins, il ait été établi une série de réservoirs disséminés dans la partie supérieure du fleuve et de ses affluents, on pourrait mettre en communication les barragistes avec le bureau de l'ingénieur en chef du service d'annonce des crues au moyen de postes de télégraphie sans fil, par exemple : l'ingénieur en chef, prévenu d'une baisse des eaux dans la partie moyenne d'une rivière commandẻe par un de ces barrages, expédierait l'ordre de vider la re tenue correspondante. Ce chef de service aurait pour ainsi dire, sous la main, une sorte de table d'enclanchements dont chaque levier correspondrait à une retenue, et il lui serait loisible de combiner, sous sa responsabilité, la vidange successive ou simultanée des retenues pour en tirer le meilleur parti possible."

Quant à l'objection basée sur la dépense que nécessiterait l'établissement de ces barrages-réservoirs, elle a beaucoup perdu de sa valeur, maintenant qu'il est démontré que ces ouvrages peuvent, non seulement servir à la régularisation des rivières, mais encore, au moyen d'un aménagement spécial, retenir assez d'eau pour subvenir aux besoins re l'agriculture et de l'industrie.

(1) La Régularisation du régime des cours d'eau (P. Lèry-Salvador, ingénieur des constructions civiles, 1911). 
Nous sommes donc amenés à conclure:

10 Que la forêt exerce, ì n'en pas douter, une inlluence regulatrice sur l'alimentation et le débit des rours d'ean, en diminuant le ruissellement et en n'envoyant dans les thalwegs que des eaux claires.

Mais il serait utile de savoir exactement dans quelle mesure s'exerce cette inlluence, les expériences faites à ce jour. pour intéressantes qu'elles soient, ne nous ayant pas donné, ¿̀ ce sujet, de réponse précise.

$2^{\circ}$ Qu'un grand bassin hydrographigue constitue un tout dont le cours d'eau principal est l'expression. Pour donner à celle-ci plus de régularité, de simples retouchés ne suffisent pas. Il faut un traitement d'ensemble comportant :

a) Des travaux forestiers en premier lieu, le reboisement des parties déclives du bassin ; jusqu'ì présent. il était laissé à l'initiative des propriétaires tant que leurs terrains n'étaient pas menacés de dangers " nés et actuels ", mais l'Etat sera en mesure d'y pourvoir lui-même dès que sera voté le projet de loi de . I. Fernand David, tendant à modifier la loi du 4 avril 1s82. sur la restauration et la ennservation des terrains en montagne (1).

b) Des currages de régularisation, les uns d'utilité générale, tels, par exemple, que les barrages réservoirs dans les régions élevées du lit; les autres de défense locale, tels que redressements de lit, élévations de digues, ete., dans les régions basses.

Les travaux, dont l'ensemble constitue notre programme, ressortissent : en partie au Ministère de l'Agriculture, en partie à celui des Travaux publies.

Il est nécessairr, pum donner aux efforts plus de cohésion et de suite, que les projets en soient élaborés en commun, par des fonctionnaires appartenant ì l'une et à l'autr' de ces administrations.

En conséquence. le Congres Forestier international émot le vou :

$1^{\circ}$ Qu'il soit procédé, en France, comme il l'est à l'étranger, à des obseruations suivies et méthodiques, ayant pour biut de déterminer l'influence de la forét sur le régime et le débit des conrs d'ean.

20 Que la loi dont le projet a été présenté par. IV. Fernand bavid, et qui a pour objet la modification de la loi du 4 auril 1882 sur la Restauration et la Conservation des terrains en montagne, soit votée dès que possible (1).

$3^{\circ}$ One les trasaux de régularisution des cours d'ean soient l'objet, par bassins hydrographiques, d'études d'ensemble, concerlées entre les divers services appelés à en rssurer l'exécution.

II. ue Peyreqoxgue. - Messieurs, laallianer de l'Arbre de l'Eau ast un des faits les plus anciennement et les plus universellement recomuls. Cette association du bois et de la soure de are qui reste et de re qui s'en va, de l'itrenellement fuyante avec l'riternellement immobile, n'a pas manqui de frapper les esprits de toms les trmps et d'inspires" les mythes, les alligories ef les lignurles, romme de notre temps le piuceau de nos peintres ut la plume de nos poètes. Gloire a l'ran comme

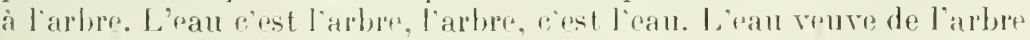

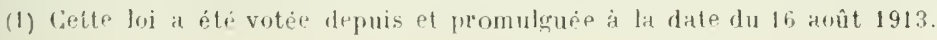


meurt; l'arbre serré de l'eau se refuse à virre... Litanies que rous reconnaissez. n'est-ce pas? C'est en brodant sur ce thème pendant quelques centaines de pages, arec la richesse de forme, la beauté de style, de bonheur dexpression dont il a le secret, que M. Onésime Reclus nous a donné cet ourrage original qui s'appelle Le Hamel de l Ean et qui complète si heureusement lo Hannel de l'Arbre, livre qui nous est très cher, à nous les forestiers, et qui. en quelques images peintes dans un style sobre et pur, illustre une de ces rérités dont la démonstration n'est plus à faire. mais qu'il est bon de dire et de répéter sans cesse, parce qu il est essentiel à un pays qui ne reut pas aller à la ruine, de ne l'oublier jamais (Très bien! Très bien! Applandissements).

Comment cette rérité se manifeste-t-elle à nous? Comment lá eréation, le maintien ou le développement de l'état boisé d'une région ou au contraire son déboisement influent-ils sur son système hydrographique. Ou. si vous le préférez. comment deux cours deau appartenant à deux régions identiques sous tous les rapports, sauf sous celui de leur taux de boisement, se différencieront-ils au point de vue de leur profil, de leur régime et de leur débit? Telle est la question que le Touring-Club de France a tenu à mettre à l'ordre du jour du Congrès Forestier international.

M. Le Présidext. - Messieurs, arant de mettre aux roix les roux qui sont la conclusion du rapport de M. de Peyrelongue, je rous prip de bien vouloir prisenter vos observations.

M. DE LirXige. - Je voudrais, sans entrer dans de plus amples détails, que nous ajoutions aux conclusions de . II. le rapporteur une considération qui né lésera en rien le tourisme et ne méritera pas d'alarmer la Commission des Sites. Nous noublions pas que nous sommes au Touring-Club qui a tant et si justement fait pour l'accroissement et le progrès du tourisme. Je demande quion insère cette phrase, qui n’a l'air de rien, et qui pourrait exercer une grande influence sur la discussion ultérieure qui va se poursuive devant le Sénat:

"Que le décret du 1er août 1905 soit complété de munière à ne pas entraver les dérivations de cours dean non navigables ni flottables, en faisant juges de la protection des sites. II. Le Ministre de l'A griculture et celni des Beanx-Arts, sans exiger nn décret rendu en Conseil. d'Etat."

I. Le Président. - Afin de procéder par ordre, nous derrions, ju crois, mettre aux voix d'abord les voux proposés par M. de Peyrelongue, et multe rotre proposition dni constitue une ardition.

11. Molgix. - Il conviendrait de modifier la forme des voux pour ne pas leur laissor un caractère particulariste et national : étant donné

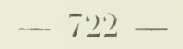


que nous sommes dans un congrès international, il faut que les roux puissent s'appliquer à toutes les nations représentées.

M. Le Présidext. - Il faudrait modifier le texte ainsi :

" $1^{\circ}$ Qu'il soit procédé, en France comme à I'étranger', ì des obsercations snivies et méthodiques, ayant pour but de déterminer l'infuence de la forêt sur le régime et le débit des cour's d'eau. "

M. Le Rapporteur. - J'accepte la modification.

II. Le Président. - Je mets aux voix le premiel vou ainsi rédigé.

Le premier voeu est adopté à l'unanimité.

" $2^{\circ}$ Que la loi dont le projet a été présenté par H. Fernand David, et qui a pour objet la modification de la loi du 4 asril 1882 sur la restauration et la conservation des terrains en montagne, soit cotée lès que possible."

Ciest encore un vou national.

M. of Lariage. - Je demande à nos collègues s'ils ne trourent pas plus régulier d'aljoindre mon observation à ce même paragraphe.

M. Cardot. - Mais cela n'a guère de rapport avec la loi Fernand David. C'est un vœu d'ordre différent.

M. de Larnage. - Non, paree que nous craignons qu'on apporte une entrave aux grands travaux.

M. de Peyrelongue. - Il semble que tout le secret de la réglementation réside dans le reboisement des bassins supérieurs et dans les barrages.

M. De Larnage. - Le projet Fernand David est distinct, c'est entendu; mais son application se trouvera gênée par les dispositions de la loi de finances.

M. Carnot. - Vous pourriez en faire un vœu distinct.

M. De Larnage: - J'en ferais plutôt un corollaire du vou proposé par II. Is rapporteur :

"Qne le décret du ler août 1905 soit complété de manière à ne pas entraver les dérivations des cours d'ean non navigables ni flotiables, en faisant juges de lu protection des sites le .Iinistre de l'Agriculture et celui des Beaux-Arts, suns exiger un décret rendu en Conseil d' Etat. ")

M. Muret. - C'est le commentair que je voudrais voir supprimer. Les conclusions, j'y souseris bien volontiers; mais il me semble qu'il y a 
une critique de la protection des paysages, par le fait que ces entraves cont mises dans l'intérêt des sites.

1I. De Lariage. - Au contraire, en faisant juges de la protection des sites les ministres compétents, qui sont leurs protecteurs naturels, je montre que je ne désire pas porter atteinte aux intérèts du tourisme.

II. Мс Rеt. - Je crains que l'on ne voie une critique dans la forme ; car, à l'heure actuelle, le danger n'est pas douteux : c'est celui de l'industrialisation à outrance.

11. de Lariage. - Je ne peux pas admettre ce mot. En particulier, dans le Dauphiné, l'industrie a été absolument respectueuse des beautés naturelles.

Vous avez vu que, en dehors du Guil et de Château-Quegras...

II. Carbot. - C'est cela qui a motivé les protestations.

M. DE LARnage. - Ce projet de créer au Guil un réservoir naturel je ne juge pas le projet en lui-même - pouvait très bien être défendu et être exécuté de façon à ne pas nuire à la beauté du paysage.

M. Carnot. - Mais on s'est ému surtout de l'épuisement de la rivière sur une certaine longueur.

M. Mougrx. - C'est un cours d'eau qui n'est pas fourni par des glaciers ; il a un étiage en été. C'est pendant cette période que tout le Guil serait passé dans les tubes.

M. Carvot. - Et cette gorge magnifique aurait un torrent à sec. Le paysage serait gâté par ce lit pierreux.

11. DE LARXAGE. - II n'y a pas de société industrielle, à ma connaissance, qui ait demandé un travail d'art de ce genre.

M. Muret. - Tous venez de voler la Crense!

11. DE LARAAGE. - Le Loiret en sait quelque those. on vous apporte des 35.000 volts.

Je le répète, je demande le respect des garanties actuellement exigées, mais qu'on n’en ajoute pas de nouvelles qui seraient prohibitives.

H. LE L'RÉsID Ext. - II n'y a pas dautre observation?...

Je mets aux roix le deuxieme roeu, aree la disposition additionnelle proposée par M. de Larnage.

Le roeu ainsi complété est adopté.

"3o Que les travaux de régularisation des cours d'eau soient l'objet, 
par bassins hydrographiques, d'études d'ensemble, concertées entre. les divers services appelés à en assurer l'exécution."

M. DE LARnage. - Je tiens comme riverain de la Loire, habitant d'une région intéressée, à donner mon plein assentiment aux considérations que vous avez présentées.

Le troisième vou mis aux voix est adopté à l'unanimité.

II. Le Président. - Nous avions encore à notre ordre du jour deux communications, l'une de M. de Rouvray. I'autre de M. Crand-d'Enon. Ces messieurs sont absents.

I. Cardot. - J'ai là un résumé fait par notre serrétaire de leupo crommunications.

LES PLANTATIONS DE PINS SYLVESTRES DANS LA CHAMPAGNE POULLEUSE

(Communication de M. Grand-d'Esnon).

II. Grand-d'Esnon appelle l'attention du Congrès sur l'avenir des plantations de pin sylvestre dans la Champagne Pouilleuse.

Ces plantations dévastées de 1892 à 1895 par la chenille du Lasiocampa pini, ont éprouvé de tels dommages que les propriétaires se sont hàtés de couper et de rendre tous leurs bois de pins sylvestres non encore détruits et ont abandonné le sol à lui-même, comptant sur les semis naturels pour le recouvrir de bois.

Or, actuellement, ces terrains portent des fourrés de pins trop serrés pour produire du bois marchand. D'autre part, il n'est pas possible de les éclaircir sans dépenser beaucoup, les fagots produits par les éclaircies ne trouvant pas d'acquéreur. La situation est done critique et il serait utile de tronver un moven d'y remédier.

ALLIANCE DE L'ARBRE ET DE L'EAU. LITTE CONTRE LES INONDATIOYS

(Communication de M. de Rourray).

M. de Rouvray, estimant qu'il est utile de protéger l'arbre aussi bien en plaine quilen montagne, propose d'émettre le vou suivant :

"Les nouveaux articles 671,672 et 673 du code Civil, depuis leur modificalion par la loi du 20 aồt 1881, contribuant dans une importante mesure à la déforestation générale, ainsi qu'à la diminution dans la production de certaines espèces de bois en ce qu'ils ne respectert plus les anciens usages et ne permettent, par suite, plus le remplacement des nombreux arbres qui existaient tout en bordure des prairies et des champs,

Le Congrès émet le væu :

Que ces articles subissent une nouvelle modification en vue de permettre, comme autrefois, avant 1881, le remplacement des arbres de bordure suivant les usages constants et reconnus.

Après cette lecture, la séance est levée à $11 \mathrm{~h} .1 / 4$. 



\title{
CINQUIEME SECTION
}

\author{
DE LA FORETT DANS LE DEVTELOPIEVENT DU TOURISME
}

\section{ET L'ÉDUGATION ESTHÉTIQUE DES PLUPLES}

\section{BUREAU}

Président:

Vice-Président :

Secrétaires :

RAPPORTEURS : MM. G. Géneau, conservateur des Eaux et Forèt. Anselme Changeur, secrétaire général de la Société pour la protection des paysages de France.

Flahault, directeur de l'Institut botanique de l'Université de Montpellier.

Sinturel, inspecteur-adjoint des Eaux et Forêts. 
RAPPORTEURS: MII. Benrquer, président de la Société pour la protection des paysages de France.

Dupuicir, docteur en droit, arocat à la Cour

dappel de Paris, membre du Comité de Contentieux du Touring-Club.

Thiollier, inspecteur des Eaux et Forêts.

Goullly, garde-général des Eaux et Forêts.

A. Mather, conservateur des Eaux et Forêts. 


\section{SEANCE DU 16 JUIN 1913}

\section{(MATIN)}

\section{Présidence de M. AUSGHER, vice-président de section}

La séance est ouverte à onze heures. M. Auscher, rice-président, en l'absence de 17. Chaix, président do la section, empêchí, prononce l'allocution suivante :

Messieur's, notre cinquième section, est celle qui s'oceupe de la forèt et de son influence dans le développement du tourisme, relle dont les liens sont les plus ítroits avec la besogne journalière que nous accomplissons, mes collègues du comiti de tourisme en montagne et moi, au Touring-Club.

Il est évident que l'un des objets principaux, je dirai pent-être la tàche la plus belle l'un congrès comme celui-ci, consiste dans l'union des efforts faits pour agrandir le domaine forestier, d'un còté, pour lo maintenir ot le conserver, de l'autre. C'est l'union de ces efforts qui doit rendre la forêt plus belle, et favoriser le succès de l'aménagement de notre domaine forestier.

Dans notre pays de France, la forêt présente malheureusement cet inconvénient d'être un peu considépée comme "un mur derrière lequel il se passe quelque chose n: On la voit, on l'admire de loin. on en fait le tour, mais on n'y pénètre pas!

Et pourquoi? Parre que vous arez pu vous-mêmes lí constatrè à maintes reprises, il part certaines rógions privilégiées comme quelques coins des Vosges, des Alpes on du Massif central, il y a très peu de forêts aménagies en pays de: montagne, an point de vne des facilités d'aceès et de circulation.

C'est l'étude de ces travaux d'aménagement qui retiendra une partie de l'artivité de nos séances; elle présente un très grand intérêt et elle a fait l'objet de plusieurs rapports, très documentés dont, au nom du président de cette section, je remercie très vivement les auteurs. J'espère qu'ils voudront bien nous aider do lour précieuse collaboration daus la discussion des textes que nous avons à adopter et je vous prie, Messienrs, en díclarant cette première séance ouverte, de bien vouloir exenser celui qui la préside de la prisider si imparfaitement. (Applundissements.) 
Notre ordre du jour appelle l'étude et la discussion du rapport de M. Géneau, conserrateur des Eaux et Forèts.

M. Géxeau donne lecture de son rapport sur l'Énucation Forestière DU PUblic:

1I. GÉNEAU.- En France, le public ignore à peu près tout des choses forestières, et cette ignorance ne s'atténue pas, tant s'en faut, à mesure qu'on s'élève dans l'échelle sociale. Les hommes les plus instruits, les esprits les plus cultivés, se font du traitement des forêts et du rôle de l'Administration, une idée qui stupéfie les hommes du métier. Magistrats, professeurs, industriels, publicistes, tous, on peut le dire, sont logés à la même enseigne et un simple bûcheron en sait plus long qu'un législateur. Cette ignorance a passé inaperçue aussi longtemps que le public s'est désintéressé des questions de cet ordre et s'en est remis du soin de les résoudre au service public qui en a la charge. Mais depuis quelques années la situation n'est plus la même; de nombreuses publications ont fait naître un mouvement d'opinion marqué en faveur du reboisement et éveillé la sympathie du public pour tout ce qui touche aux forêts. Cette sympathie est précieuse à beaucoup d'égards, elle témoigne d'un progrès considérable, mais elle ne peut produire d'effets vraiment utiles qu'à la condition d'être éclairée. L'homme qu'on a intéressé sans l'instruire a, en effet, une tendance inévitable à critiquer et à contrarier l'action du professionnel dont la raison lui échappe. II y a là un danger qu'il importe d'éviter. C'est un métier d'être forestier, métier qu'il faut apprendre comme les autres et qu'on ne peut confier à tout le monde. Si toutes les bonnes volontés qui s'empressent n'avaient pour guide que leur seule inspiration, la condition de nos forêts, loin de s'améliorer, irait sans cesse en périclitant; des lois mal faites, des règlements inefficaces, des mesures prises de travers, tel serait le résultat le plus clair d'un zèle qui ne connaîtrait pas de règle.

Il faut donc instruire le public et, tout d'abord, lui montrer ses erreurs qui sont énormes. On peut ramener à deux propositions essentielles les idées généralement reçues en matière d'économie forestière.

Lapremière, c'est que "le bois pousse tout seul ». La forêt est un genre de propriété à part qui n'exige aucun travail cultural; la nature se charge de tout et l'homme n'a qu'à laisser faire. Rien n'est plus faux. La production forestière obéit exactement aux mêmes lois que tout autre production industrielle ou agricole. Dans aucune branche de son activité matérielle, l'homme ne produit rien par lui-même; c'est toujours la nature qui produit, mais elle ne produit utilement que si l'homme intervient pour diriger les forces par lesquelles elle se manifeste. C'est l'orientation donnée par l'homme aux agents naturels, chaleur, pesanteur, électricité, actions chimiques ou biologiques, qui détermine la valeur économique de la production. Si les forces physiques qui concourent à la végétation des arbres restaient entièrement liviées à elles-mêmes, on aurait bien une production forestière, mais cette production répondrait fort mal aux besoins de la société, car elle ne fournirait à la consommation que des produits imparfaits ou vicieux, en quantité insuffisante; elle aurait à peu près la valeur qu'a, dans l'alimentation, la cueillette des plantes et des fruits sanvages. Ce qui trompe le public, ce qui 
le porte à méconnaitre la nécessité de l'intervention de l'homme, lorsqu'il s'agit de la forêt, c'est qu'il n'aperçoit pas les effets de cette intervention. La vie des arbres est si longue que, seul, le forestier peut saisir la trace des influences qui l'ont affectée. En agriculture, le labourage, les semailles et la moisson se renouvellent chaque année; ce tableau parle à tous les yeux et rend manifeste l'action du cultivateur dans la production. Mais le chêne de nos forêts ne peut dire au passant le nom des hommes qui, depuis deux cents ans, l'ont aidé à édifier sa magnificence.

Il est des gens que la vue d'un arbre abattu transporte d'indignation comme une sorte de sacrilège. Pour eux, toute exploitation est condamnable, "toute coupe d'arbres est un déboisement ", et c'est là la deuxième maxime de la sagesse des foules.

On pourrait citer de nombreux exemples de cette manière.de voir.

$\mathrm{Au}$ cours de la discussion du dernier budget, on a entendu un député, des mieux intentionnés d'ailleurs, se plaindre que le "Ministre de l'Agriculture saccage les forêts de l'Etat ": "Il s'est laissé dire que, dans le courant de 1912 notamment, on a coupé pour des millions et des millions de francs de gros arbres, d'arbres en pleine prospérité, appartenant aux forêts domaniales. Il ne sait jusqu'à quel point le fait est exact et il serait heureux qu'on donnât à la Chambre des chiffres précis un jour prochain ".

La presse, loin de combattre ces erreurs, croit servir l'intérêt général en les propageant. A tous moments, les forestiers sont accusés dans les journaux de détruire les forêts, de faire oeuvre de vandales.

Ici encore ce qu'on voit fait illusion sur ce qu'on ne voit pas. Ce qu'on voit, c'est le fait brutal de l'abatage d'un arbre, fait à la vérité pénible et qui retentit douloureusement en chacun de nous. Ce qu'on ne voit pas, c'est que la suppression de cet arbre procède d'une cause utile, d'une idée raisonnable. Une coupe de bois, faite à son heure et comme il convient, n'est pas autre chose qu'une récolte, acte en soi des plus légitimes. Et presque toujours la coupe est quelque chose de plus : c'est l'opération culturale par excellence, celle par laquelle l'homme du métier entre en collaboration avec la nature, soit pour régénérer la forêt et assurer sa perpétuité, soit pour améliorer ses conditions de végétation. Dans ce dernier cas, la récolte n'est même qu'un accessoire, et elle est souvent onéreuse. Ainsi un acte qui, de prime abord, apparaît comme le symbole du massacre et de la destruction devient, pour un homme averti, une mesure de conservation au premier chef. Mais tout cela exige une démonstration que personne ne fait.

Si le public savait réfléchir, il se rendrait compte que la suppression des coupes dans les forêts ferait disparaître toutes les industries du bois et priverait la société d'une matière indispensable. On est positivement accablé lorsqu'on lit dans le Journal officiel des phrases comme celle-ci : "Les mauvaises langues affirment que c'est là au fond (il s'agit de la vente des coupes) une façon détournée par l'Etat de faire de l'argent... Il serait, en effet, extraordinaire de constater que l'on réclame aux domaines de l'Etat une somme représentant une grande partie des 56 millions du budget de l'Agriculture ». Ce qui est plutôt extraordinaire, e'est qu'un législateur puisse, en toute bonne foi, dénoncer l'exploitation des forêts domaniales comme une sorte d'attentat contre la chose publique et qu'il ne se trouve personne pour lui répondre.

Le principe de non-intervention, qui est un véritable non sens économique n'est pas moins faux, si l'on envisage la forêt au point de vue esthé- 
1,ique. C'est même dans cet ordre d'idées qu'il est le plus dangereux, car' il vevêt les allures d'une doctrine d'art qu'on proclame incompatible avec la technique des forestiers. Les partisans de cette doctrine professent que toute exploitation tend à détruire la beauté de la forêt, qu'il faut laisser la nature agir seule, qu'en un mot, l'idéal c'est la forêt vierge.

Assurément la forêt vierge a son genre de beauté; son existence peut se justifier, voire être désirable, dans certaines circonstances particulières. La science y trouvera des éléments de comparaison précieux et le touriste un attrait de curiosité peu banal. Il ne faut donc pas la condamner d'une façon absolue. Mais poser en axiome que la forêt vierge sera en tous lieux la plus belle, qu'il faut amener à cet état toutes nos grandes forêts de promenade, c'est véritablement tomber dans l'absurde et tourner le dos à la beauté aussi bien qu'à la nature. La beauté ne va guère sans la santé et la forêt abandonnée à elle-même est une forêt qui souffre et qui dépérit ; c'est une société qui regorge d'éclopés et d'infirmes, une cité sans règle où l'élite est opprimée par le vulgaire, où les vivants sont étouffés par les morts. Ubi solitudinem faciunt, ibi naturam appellant, pourrait-on dire de ceux qui prônent la beauté désertique. Mais la nature n'a pas voulu partout des déserts ; on oublie qu'elle a placé l'homme à côté de la forêt et qu'elle les a destinés à vivre et à prospérer ensemble. Qu'on se garde de détruire une telle association; c'est de l'harmonie de la forêt avec tout son milieu que naîtra la véritable beauté.

Comment répandre ces notions générales? Il ne semble pas qu'on doive attendre de grands résultats d'un enseignement didactique. A première vue, il peut paraître séduisant d'instituer des cours, d'ouvrir des chaires dans les facultés ou dans les établissements d'instruction secondaire. On pourrait être tènté de suivre l'exemple de la Belgique où il existe des cours "volants " de sylviculture professés par des agents forestiers et comportant une vingtaine ou une trentaine de leçons avec des examens et la délivrance d'un diplôme en fin d'études. Ces cours sont sans doute excellents, mais ils s'adressent à des personnes pour lesquelles la forêt représente un intérêt direct et personnel, élèves-gardes, régisseurs, propriétaires désireux de mettre en valeur des terres incultes par le boisement. Un enseignement de cet ordre manquera toujours du rayonnement nécessaire pour atteindre le public que nous visons ici, public qui n'est, à aucun degré, professionnel, qui n'a ni le goût, ni le loisir de revenir à l'école et qui, pourtant, fait l'opinion. On n'agira sur ce public qu'à la condition de lui offrir une science aimable et facile au-devant de laquelle il aille de lui-même par délassement et par curiosité.

Cette instruction familière, nous pourrons la donner à la manière des Grees, en nous promenant sous les embrages. La "conférence-promenade " en forêt remplacera l'amphithéâtre.

Dans les grands massifs forestiers fréquentés par les touristes, tels que les forêts de Fontainebleau ou de Compiègne, l'Estérel, la Coubre, pour ne citer que quelques exemples, les agents des Eaux et Forêts organiseraient des excursions analogues aux tournées d'herborisation ou de minéralogie que dirigent les professeur's de l'Université. Des avis dans la presse locale, au besoin quelques affiches, annonceraient au public que tel jour, à partir de telle heure, M. X..., inspecteur, ou M. Y..., gardegénéral, fera une conférence-promenade dans la forêt de..., en suivant tel ou tel itinéraire. Tous ceux qui se présenteraient seraient les bienvemus. 
Au cours de la promenade, l'agent forestier ferait halte aux points les plus intéressants et donnerait aux personnes qui l'accompagnent quelques explications sur le coin de forêt qu'elles ont sous' les yeux; les essences, leur adaptation au sol et au climat, le mélange de ees essences entre elles, l'âge des arbres les plus remarquables, le régime adopté et le but poursuivi par l'aménagement. Si l'on traversait une coupe de taillis sous futaie, le conférencier apprendrait à distinguer un taillis d'une futaie, il montrerait ce qu'on entend par baliveau, moderne ou ancien, comment on choisit ces arbres, comment on débite les bois abattus, à quels emplois on les destine, ete. Quelques aperçus sur la géologie, la flore ou la faune de la forêt; quelques détails historiques, toujours très goûtés des anateurs, complèteraient au besoin ces renseignements dépourvus de tout pédantisme. L'agent forestier ferait, en somme, à ses auditeurs les honneurs de sa forêt : tel un grand propriétaire qui fait visiter son domaine, ou un ingénieur qui explique le fonetionnement de son usine à des étrangers. Le promeneur de bonne volonté, qui aurait fait le petit effort d'écouter, trouverait bientôt dans les exeursions en forêt un élément d'intérêt entièrement nouveau pour lui. Actuellement la forêt représente pour le touriste un monde inconnu, un mystère qu'il ne peut pénétrer ; il en perçoit sans doute la beauté, mais cette beauté demeure pour lui inexpressive et muette. Il l'aimerait plus eneore le jour où il saurait la comprendre et discerner sous les aspeets changeants des feuillages le jeu divers des forces de la nature.

Le Touring-Club paraît tout désigné pour assurer le suecès de ces conférences-promenades, en leur prêtant l'appui de sa large publicité, en collaborant à leur organisation, et en entraînant ses nombreux adhérents sur les pas des conférenciers.

Un second moyen d'instruire le public nous est offert par la presse. Nombre de grands journaux publient périodiquement sous des titres divers : Chronique agricole, la Vie rustique, des articles de vulgarisation d'une lecture agréable dont les sujets sont empruntés à l'agrieulture, à la chasse ou à la pêche. Quelques spécialistes sont passés maîtres en ce genre de littérature. Rien de semblable pour les choses forestières ; on trouvera dans nos grands quotidiens de faciles lamentations sur le déboisement, des appels retentissants pour sauver des forêts qui n'ont jamais couru aueun risque, mais aucun d'eux n'a jamais offert à ses lecteurs une causerie écrite par un homme connaissant la forêt et sachant dire ce qui s'y fait. Il y a là une lacune évidente. Encore une fois, il ne s'agit pas d'ouvrir les colomnes des journanx à des articles techniques ; la elientèle du Matin ou du Figaro n'est pas celle de la Revue des Eanx et Forêts. Ce qu'il faut donner au public, ce sont des chroniques légères, égayées d'un brin de fantaisie, et qui fassent passer la leçon avee la peinture des ehoses. Pour brosser ces simples pochades de la vie forestière, qu'on fasse appel aux hommes du métier. Les bonnes plumes ne manquent pas dans l'Administration des Eaux et Forêts et il est à croire que la presse n'aurait pas à regretter leur' collaboration. Quant à l'Administration, elle ne peut que gagner à encourager son personnel dans cette voie et à prendre de plus en plus contact avee le public. C'est l'insuffisance de ce contact, il faut bien le reeonnaître, qui a perpétué l'état d'ignorance dont nous souffrons aujourd'hui.

Le Touring-Club pourrait s'associer à ce mode d'enseignement en insérant dans sa Revue des articles de tourisme consacrés ì des régions 
boisées, et dans lesquels les auteurs insisteraient sur les particularités forestières les plus intéressantes.

Enfin, le Touring-Club pourrait publier sur les régions forestières les plus fréquentées des monographies sous forme de notices, qui seraient comme le résumé des explications données au cours des conférencespromenades. Ces notices, accompagnées autant que possible d'un plan, feraient connaître tout ce qui peut intéresser le tourisme : la géographie physique et administrative de la forêt, les grandes lignes de l'aménagement, les voies de communication, les sites et les peuplements les plus remarquables, les travaux dignes d'attention, etc. Ces notices seraient en quelque sorte le Baedeker ou le guide Joanne de la forêt.

En résumé, nous avons l'honneur de proposer au Congrès l'adoption des vœux suivants :

I. Que l'administration des Eaux et Forêts organise, avec le concours du Touring-Club, dans les régions forestières fréquentées par les touristes, des conférences-promenades accessibles à tous, en vue de donner au public des notions exactes sur la constitution des forêts et les diverses opérations de la sylviculture.

II. Que la Presse sollicite et que l'Administration encourage la collaboration des agents des Eaux et Forêts pour instruire le public au moyen d'articles de vulgarisation.

III. Que le Touring-Club contribue à la diffusion de cet enseignement écrit par des articles insérés dans sa Revue et des notices monographiques rédigées, sous ses auspices, par des agents des Eaux et Forêts.

La lecture du rapport de M. Génean est accueillie par de vifs applaudissements.

M. Le Président. - Les applaudissements qui viennent d'accueillir le très intéressant rapport de M. Géneau prouvent combien il a touché juste et su envisager, sous ses angles les plus curieux, la question qu'il étudie.

M. Benuquer propose d'ajouter les professeurs de botanique des Facultés aux personnes chargées de faire les conférences-promenades.

M. Flihallt, directeur de l'Institut botanique de l'Université de Montpellier, appuie l'observation de M. Beauquier et demande que le vœu de M. Géneau soit légèrement étendu et qu’au lien d’indiquer simplement les agents forestiers, on ajoute: "ou toutes autres personnes compétentes ").

1I. Le Président. - Je crois que vous serez tous d'accord arece M. Flahault, Messieurs, pour aclmettre cette légère addition au texte du voeu de M. Géneau.

Je mets aux voix les voux du rapport de M. Géneau.

Le premier de ces voux, avec l'addition qu'on a proposce, est ainsi colnẹ : 
"Que l'administration des Eanx et Forêts organise, uvec le concours du Touring-Club, des professeur's de botanique ou toutes antres personnes compétentes, dans les régions forestières fréquentées par les touristes, des conférences promenades accessibles à tous, en vue de Ionner an public des notions exactes sur la constitution des forêts et'les diverses opérations de la sylviculture ».

Ce vœu, mis aux voix, est adopté.

M. Le Président. - Voici le vou no 2 du rapport de M. Créneau :

"Que la Presse sollicite et que l'Administration enconrage la collaboration des agents des Eaux et Forêts pour instruire le public au moyen d'articles de vulgarisation ".

M. D’Alueida expose qu'un moyen très pratique de vulgarisation employé au Portugal consiste, dans tous les pares nationaux, à faire étiqueter les arbres avec une notice très courte résumant la nature, l'espèce, la production.

II. Flahadlt souligne que son ami M. Henriquez a emprunté ce procédé au Jardin botanique de MontpeHier pour l'appliquer au Portugal, mais insiste à son tour sur le succès d'un tel moyen d'éducation.

M. Le Président fait remarquer que les observations de MII. d'Almeida et Flahault se rapportent plutòt à la question des arboretums, jardins alpins et pares nationaux qui sera diseutée ultérienrement et met aux voix le vou de M. Génear.

Ce vœu est adopté.

M. Le Présinextr. - Voici le dernier vou du rapport de M. Géneau :

"Que le Touring-Club contribue à la diffusion de cet enseignement écrit par des articles insérés dans sa Revne et des notices monographiques rédigées, sous ses unspices, par des agents des Eanx et Forêts \%.

Ce vou, mis aux voix, est arlopté.

M. Drerckx indique encore comme procédé de vulgarisation la création de Sociétés des amis de la forêt, telle celle de Soignes, en Belgique, qui auraient pour mission diorganiser, plusieurs fois par an, des conférences -promenades.

M. le Présinent. - Nous pourrions relier les observations qui viennent l'être présentées avee les conclusions principales de la communication de M. Delville. (Assentiment.)

La parole est à M. Delville pour une communication relative à "LA FORÉT DANS LE DÉVELOPPEMENT WU TOI RISME ET L'EDrCATION ESTHÉTIQUE DES PEUPIES ". 
II. Delville. - Le monde intellectuel semble s'enthousiasmer de plus en plus pour la forêt et les beautés naturelles.

Déjà au Congrès international d'agriculture temu à Vienne en 1907, la protection des paysages et la conservation des sites a fait l'objet de plusieurs rapports et donné lieu à des discussions fort intéressantes ainsi qu'à l'adoption de voux dont un certain nombre ont reçu une exécution pratique.

Le Touring-Club de France rui, avec d'autres organisations similaires, poursuit une active propagande en favenu des idées de protection et d'embellis sement des forêts, en mettant au programme de la cinquième section " uA FORÉT DANS LE DÉVELOPPEYENT DE TOLRISHE ET L'ÉNLCATIUY ESTHÉTIUI E DES PEUPLES „) a mérité la reconnaissance de tous cenx qui, devant la splendeur, l'immensité, la sauvagerie ou simplement le pitturesque d'un paysage. éprouvent autant d'émotions fortes et doures que devant les plus grands tableaux des maitres.

Nous devons le prorlamer bien haut, la foret una jas nuiguement pour but la production du bois. Elle est un laboratoire merveileux. dans lequel il est exécuté des travaux qu'ancune puissance humaine ne saurait entreprendre ou imiter, elle remplit des fonctions climatériques el hygiéuiques extrèmement importantes et elle contribue grandement aux agrements de la vie.

Elle embellit la contrée et y exerce une influence bienfaisante par sa beauté, son charme et la salisfation qu'elle procure ainsi que par les auvres qu'elle inspire. Les coutrées où il $n^{\prime} \mathrm{y}$ a pas de végétation arborescente paraissent désertes et monotones. Ies champs chargés des plus plantureuses récoltes, ne peuvent remplacer la forèt dans l'aspect tu paysige et, lorsque l'hiver la neige a recouvert de son blanc et iuniforme linceul la contrée dépourvue d'arbustes et d'arbres, l'effet en est désespérant et force à la mélancolie.

I celui qui est amant de la belle nature, elle offe a tout iustanl une nouvelle jouissance, une pensée grandiose et un donx plaisir (1).

La forêt parle aux yeux, à l'esprit, à l'imagination et au corur...

Elle laisse découvrir à charue pas de nouvelles beautés, de nouveaux agréments, elle porte aux nobles sentiments et ses mille bruits composent une harmonie plus poétique que les sons diffus de la eivilisation.

Ln philosophe pä̈en, Sénèrue, voyait dans la forit, la preuve de l'existence d'un Etre suprène.

Gaint Bernard re Clairvanx a avout ru’il u’avait le plus souvent pas eu d'autres maîtres que les hètres et les chênes, tandis que l'admirable auteur de l'Imitation a inserit sous son portrait : "Je chercluais la tranquillité et je ne la trouvais que dans les bois et les livres ".

Dans les temps plus rapprochés, le célèbre ornithologiste américain Wilson a dit "qu'il avait pénétré des milliers de fois avec une extase approchant de l'adoration da'is les forèts, ees grandes volières de la nature. "

Que de musiciens, Weber, Menilelssolm, Mozart, IJaydn, ont reçu dans les forèts. l'inspiration le mélorlies aujourd'hui célèbres.

I a peinture du paysagt doit égalemenl sa renaissance à l'étude apprufondie des forèts. l'artiste, en elfet, épure son gont et l'iléalise dans la contemplation des arbres.

Enfin, n'est-re pas la futaie de luetres, aver la colonuade de ses trones élancés, les arêtes formées par ses branches et sa voìte de leuillage qui a été le type de l'art gothique, qui règne avee tant de majesté dans les temples chrétiens.

Voyons là une fois de plus que la nature est maîtresse en toute chose chaque fois qu'elle n'a pas été contrariée par la maiu des hommes.

Daus tous les pays, ou a protégé les animaux sauvages par des lois et règlements sur la pêche, la chasse et li tenderie. Dans certaines régions, on a pris la défense des plantes (l'édelweiss en dutriche et en Suisse, la flore des montagnes en France, en Bavière, en Italie, en Espagne, en Écosse, en Damemark et en Vorvège). Partont on garde jalousement les mounments de l'art et de

(1) Koltz. I'n peu de tout à propos de forêt. 
l'histuire, mais il nous manque sumvent des moyens de comserver les sites. les paysages, les forêts, ces momments naturels remarquahles.

Ainsi que nous le disions dans un rapport adressé au Congres de Vienue, nous pensons que la loi doit intervenir, mais nun comme un instrument de coërcition pouvant amener des révoltes individuelles, notamment dans les pays on le droit de propriété ne supporte que de raps atteintes et seulement dans des cas exceptionnels.

C'est par l'éducation esthétique les masses que l'on résoudla, avec le moins de secousses, la question qui doil préoccuper toutes les nations : la conserva tion rles beautés naturelles.

Cette éducation doit ètre commencée à l'école primaire (1). C'est l'école qui doit préparer à la vie, et vivre, a dit un philosuphe, esest a la fois sentir et connaître, penser et agir. L'art doit laire partie intégrante de tout système complet d'éducation, mais il doit ètre enseigné en respectant les individualités, en atteignant l'intelligence par les sens, afm de ne pas dommer un jour à la société des hommes qui ne soient que la servile copie d'aulrui.

L'instituteur, qui recerra dans ce but une culture spéciale pl me préparation sérieuse dans les écoles normales, profitera des excursions scolaires pon attire l'attention des élèves sur la splendenr des spectacles de la nature et l'mposante majesté des momments natulels. Il évitera de lenl' présenter l'appréciation du maitre, mais leur laissera te robe actif. Eux-mêmes, doivent voir, regarler, observer, explorer, analyser, comparer, guidés discrètemenl par ts professeur, qui aura l'air te discuter, d'óluclier le sujet comme ses disciples, mais qui mettra toute son âme d'anliste et tout son talent d'éducateur ì coll faire jaillio tour a toul toutes les parcelles dre beauté, de telle snrte que rharum, les ayant vues et senties sans qu'm les lui ait annoncées, croira les avoir découvertes.

Ce qu'il faut a l'école prinaire, cest éveiller le sentiment latent du luan, c'est rendre les enfants conseients de leurs preférences, de lenrs jugements. de leurs goùts. en matière d'esthétique champêtre.

Dans cet ordre d'idées, l'enseignement forestier primaire. r'est-à-dire celui qui tend à inculquer les premières notions forestieres sams purtée seiertifique mais dans un but pratique el éducatif, mérite d'être encouragé.

Pour répandre dans les masses les premières notions de sylviculture, donf la connaissance olfre tant d'inférêt dans les pays forestiers, on a songé, en France, à l'instituteur public. C'est à lui, le premier éducateur de l'enfance, que revient le soin d'enseigner dans son école primaire, surtout par des leçns de choses, les principes élémentaires sur lesquels repose la gestion forestière. On a créé, dans ce but, des conrs de sylviculture dans les écoles normales des principales régions boisées. Ces cours sont professés par des agents des eaux et forêts désignés de commun accord par les administrations intèressées.

Cos instituteurs, pénétrés de l'utilité des forèts et de leur róle daus la vie, s'appliquent à l'éeole primaire, par quelyues notions el quelques leçons donmées sur le terrain, à faire aime les arbres et les forêts par les enfants dout l'éducation leur est confice. Ils deviennent ainsi des collaborateurs utiles pour lia protection et l'administration des forèts et pour la mise en valeur des terrains incultes, par le boisement.

L'enseignement lorestir primaire est poursuivi par l'institution de suciétés scolaires forestieres, reposant sur la collaboration volontaire du personuel des eaux et forêts, avec les membres de l'euseignement primaire.

Le Mamuel de l'Arbre, publié en 1907, grace à l'initiative du Touring-cilub de France et complété ensuite par un tableau mural, fut pour les institutensis un premier guide précieux, leur fournissant le moyen d'éveiller de bunne lenre l'attention de l'enfunt sur los bienfaits de la lorèt, de lui inspirer l'anour

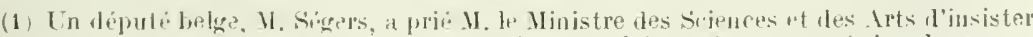

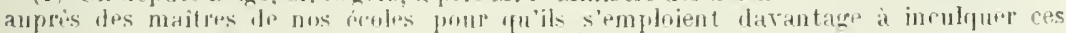
principes it lentrs cheves. 
de l'arbre et de faire ressortir l'utilité et le ròle essentiel que les sociétés végétales jouent dans la nature.

Le Manuel de l'Eau est venu mettre aux mains des plofessenrs une nouvelle arme de salut public.

Nous soulignons avec plaisir la réaction qui se manifeste en France contre le déboisement intense qui sévit et expose ce beau pays aux conséquences désastreuses résultant de ce que, d'un mot typique, on appelle la "déforestation $)$.

En présence de l'esprit mercantile qui fait sacrifier l'avenir au présent égoïste, c'est sur la jeunesse, c'est sur la nouvelle génération éduquée dans ce sens, que l'on doit compter aujourd'hui, pour maintenir le taux de boisement dont la réduction ne peut être envisagée sans crainte.

D'ailleurs l'amour des forêts s'allie à l'amour du sol natal.

Au plus profond des bois, la Patrie a son cœur,

T'n peuple sans forêts est un peuple qui meurt.

Le rrai patriote, dit Koltz, est heureux et fier d'avoir vu le jour dans un pays où les beautés naturelles sont relevées par l'architecture grandiose des plantes ligneuses. Tous ses souvenirs sont liés à l'existence des massifs forestiers.

Si vous parvenez à respecter les fleurs et les arbres, ajouterons-nous avec Emile Verhaeren, vous finirez par aimer la terre qui les porte, la lumière qui les baigne, l'eau qui les nourrit; vous aimerez le site entier qui les encadre ; en un mot, vous aimerez le coin du sol où vous êtes né; vous aimerez votre pays.

Le Congrès d'art public a tenu, en 1910, une de ses séances au milieu des merveilleux cadre de la forêt de Soignes, aux portes de Bruxelles et, au pied d'un grand hêtre, tour à tour, M. Buls, président des "Amis des Arbres", M. Bourgeois, sénateur et ancien président de la Chambre française, M. Cavens et d'autres, redirent avec émotion que nous devons aimer la forêt pour ellemême, pour son histoire, pour le repos et la consolation qu'elle nous procure, pour son intense poésie, pour l'inspiration qu'elle fait naître chez l'artiste, pour les enseignements variés qu'elle nous donne, etc.

G'est très bien. Mais quel résultat fécond faut-il attendre de cette éloquence sil'on se borne à "prêcher des convertis"?

Ne serait-il pas rationnel de commencer par semer les germes de l'intelligence esthétique dans l'âme et le cœur de l'enfant, de cultiver l'amour du Beau, encore maladroit et imparfait chez lui, en faisant en même temps connaître et aimer la forèt?

En Allemagne, la plupart des grandes villes possèdent des $\mathscr{H}$ aldschulen, des écoles dans les bois.

La ville de Charlottenbourg a même organisé officiellement l'école buissonnière; les enfants vont au bois avec leurs maîtres et ceux-ci entre deux parties de jeux, leur apprennent à lire lans le livre de la nature, éveillent la saine curiosité latente et font apprécier et respecter la forêt, source de vie et de jouissances innombrables.

La question de l'éducation esthétique à l'école primaire sera donc fort utilement exposée dans les écoles nornales et daus les cours de racances qui sont organisés à l'intention des inspecteurs cantonaux et nous signalons ici la collaboration précieuse que peuvent apporter les forestiers dans la réalisatiou de l'ceuvre de l'éducation esthétique des enfants.

T)ans plusieurs pays des fètes de l'arbre sont organisées avec le concour's des élèves des écoles qui se livrent à des travaux de plochage, semis, plantation, élagage, etc. Ces fètes, dit M. Changenr, créent un lien entre l'enfant et l'arbuste et font qu'une fraterinité se développe entre le sange t la sève, qui tirent leur force d'un mème snl. 
Dans certaines régions, on conserve le caractère primitil des forêts et on érige des parcs nationaux (Bohmerwald, Yellowstone, Iosemite, suisse).

Tout en évitant de tomber dans l'exagération et de conclure, avec certains esprits exaltés, qu'il faut aimer d'abord les arbres, puis les bêtes, puis les hommes, nous pensons que ces idées méritent de retenir l'attention des pouvoirs publics.

Non pas, à l'encontre de certains philosophes, qu'il puisse entrel dans notre esprit de substituer une vague religion de l'art et de la nature à la religion traditionnelle. Elle ne saurait satisfaire aux aspirations de l'individu vers l'infini et brùler quelques grains d'encens à la be auté ne suffirait pas à combler le vide des cours.

Mais là où la forèt parle dans toute sa splendide majesté à l'imagination et au cœur de l'homme, elle ne peut manquer d'exercer me influence puissante sur le développement progressil de l'esprit et du caractère. Car la forêt laisse une impression profonde à toute époque de l'existence. La jeunesse y séjourne avec bonheur, l'âge mur y trouve une distraction ainsi que l'oubli des soucis et des peines, tandis que la viejllesse s'y retrempe dans le souvenir du temps passé.

Quels sont les résultats que procurent les excursions scolaires, faites sous la direction du maître?

D'abord, une promenade hygiénique, amusante, intéressante et instructive. Les enfants sont tout étonnés de constater que l'on peut parcourir les bois d'une façon très récréative, sans se faire dénicheur ou dévastateur, et leur mentalité change à mesure que l'horizon de leur's connaissances s'élargit. Ils apprennent à respecter les jeunes plants, le brin de chène, les essences à feuillage ornemental, l'oiseau et, lorsqu'ils respertent les biens de la collectivité, ils sont bien près de considérer comme sacrée la propriété individuelle.

Ensuite, elles montrent anx enfants que la forêt est toujours belle, qu'elle a sur la mer et sur la montagne, ces deux autres grandes sublimités de la Nature, l'avantage d'être plus humaine, plus accessible en toute saison.

En outre, et nous insistons sur ce point, une excursion forestière, la visite d'un arboretum, d'une pépinière, tout en constituant une promenade instructive et récréative, est l'occasion d'une narration, d'un devoil de style, d'une lecon de géographie, d'histoire naturelle, d'un exercice de mathématiques, ete.

Enfin les promenades en forèt ouvrent l'esprit aux impressions du beau, et par là même disposent au bieı, suivant le mot de Schiller. De plus, l'esprit d'observation des élèves se développe et ce point est de la plus grande importance, car il n'est presque pas de profession où il ne soit utile de bien voir.

On donne aussi de la délicatesse au gout par la contemplation des vastes paysages et l'examen minutieux des petits coins de la nature. Les élèves contractent l'heureuse habitude de parler de ce qui les entoure, de ce qu'ils ont vu et ainsi se relève le niveau de leurs conversations.

Et c'est une bien noble tâche que la culture de cet instinct qui attire l'enfant vers le beau, afiu de l'arracher à l'indifférence, de le garder du scepticisme stérile, malheureuseınent si fréquent, et de le doter d'une âme vibrante pour laquelle la nature, la forêt, soient plus tard la consolation des heures moroses, la source intarissable de fines et vives jouissances.

E'n Batgique, les pouvoirs publies se sont aussi préoccupés de maintenir. dans leur grandeur sauvage et leur àpre beauté, les régions forestières ët d'ouvrir les âmes enlantines anx saines émotions du Beaı.

Il existe en Belgique une sertion des sites annexés à la Commission royale des Monuments, qui poursuil sa tàche avec une activité et me conscience lonables.

Elle est vaillanment secondée par la Soeiété centrale forestière et par son "Bulletin" qui défend aver tant le tact et d'espril pratique la cause des arbres, des massils et des parsages.

La société centrale forestière avait constitué dans son seiı, un Comité des Amis des frbres et, a l'intervention re celui-ri, la protection des plantalions 
a ete inscrite an froglamme de l'enseignement theorique et pratique des notions l'agriculture. Ionne par l'instituteur. Personne ne contestera que les arbres sont un lement important du paysage et comptent parmi les plus belles choses de la nature. L'imposante majesté des arbres impressionnait déjà nos ancètres ganlois et les colosses de nos forêts étaient l'objet de leur venération.

I'antres associutions, telles le Touring-elub de Belgique et la Société namuroise pour la protection des sites, airlent puissamment ì l'éducation esthétique du public.

Lat section des sites. T'accord aver le Muste des Irts décoratifs et le Toung-Club, a fait-relevel par des artistes photographes, en un inventaire qui sera prérieux: les paysages les plus caractéristiques des neuf provinces helges.

De son cité, l’Adnuinistration forestière, prépondérante dans les régions pittoresqnes, a déployé les plus intelligents efionts - on s'esi plu à le reconnaître - pun empècher la profanation des sites boisés intéressants.

Elle a fait proveder an recensentent des arbres remarquables au point de vue de la légende, de l'histoire, sions.

Elle convertif certains buis n boquetean bien placés en bois d'agréments et les approprie comme tels, creant anside réritables pares forestiers toujours aressibles anx promeneurs.

Elle pncourage, par l'allocation de subsides, le reboisement des carrières émistes un abandonneses. les tranchées et remblais démmdés.

Elle manifesta également toute sa sollicitude pour la création de massifs de verume sur les places publinues. les exrédents de chemins, les abords des gares, etr.

Des écrivains le mérite à l'àne éprise lle poésie champêtre, ont fondé la Ligue des Amis des flures, comptant de nombreux adhérents, et ont imaginé les fètes des arbres, quni rappellënt la vieille coutone nationale du "Meyboom ".

bautre part, le gouveruement achète. pour les incorporel au domaine national, les lorèts menacés de lestruction.

Mais ce niest pas lont.

La voix te $n 0$ s missant poetes sinst faite donce pour parler aux enfants el len dire tute les arbres sont beanx: qu ils sont indispensables à la vie de notre planete ; qu'ils domment à l'Inmanité des lecons de la plus haute sagesse ; qu'il laut les aimer. les resperter et les protéger (1).

Cn exemple jorecrenx a été clomé au pays lorsque Léopold II fit dun à la Nation des lomaines qüil a réés on angundis, a Laeken, à Tervueren, à Ostende, ¿ Ciergnon. i lrelenne. Il stipula comme condition que ces bois, qui constituent mo nervilleuse reserve de beautis pittoresunes. ne pourraient jamais etre aliénés ni transformés et fue. sous aucun prétexte, on ne poura en riminue la valen esthétique.

Tne Ini, votée en 1911, impose aujourllui a lout exploitant l'obligation de repare le dommage causé à la beanté du paysage, notamment en laisant les plantations necessanes: pn convanl l'un mantean de verdure les excavations, cléblais on remblais, lestinés a subsister d'une manière permanenle.

In projet de loi sur les pxpropriations. déposé en 19013 par le Hinistre des finauces et des Travanx publics met expressement le principe dexpropriation an service de l’intéret esthetique el, d'autre part. le Conseil supérieur des forêts a mis a l'étude la question de la conservalion. dans leur état naturel, de certinins cantons hises on incultes ponr assurer le maintien donne flore ou d'une fevme intiosiante.

Signalons anssi l'hempuse intiative fu'a ene le tomite de lexposition de Gand en reant un jarlin gente "alpestre qui est lome incontestable beanté en tant qu'initalion de citos natmins, ainsi que la constitution a Bruxelles

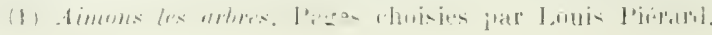


d'une suciété nouvelle sous le titre Li nouveau jardin pittoresque \#. Les fondateurs ont pour but de populariser en Belgique le type du " jardin naturel ", ce que les Anglais appellent le "Wald Garden! , avec, en plus, une note l'art apportée par l'amenagement de scènes pitoresques.

Enfin, il s'est formé en Belgique comme en France, en Allemagne et en suisse les comités régionaux composés de personnes pouvant, par leur prestige, leur talent, leur autorité ou leur popularité, exercer une influence bienfaisante sur les masses et ainsi répandre dans toutes les classes de la société, le respect les beautés naturelles.

Vous en connaissons iqui, par des confélences atrec projections lumineuses, ont assume la tiche ele popularispr le sentiment du beau et du pittoresque.

Et II. Delville cite l'exemple du Comiti des sites et Promenades de Bouillon (Belgique) dont le programme se jisume en lenx mots : CONSERVER- INÉLIOHER.

Conserver tonl le pittoreqque naturel des sites; aneliorer l'accés des points culminants, des endroits sauvages et agrestes, des calmes retraites, de fraîche veldure où, sans ètre lérangé, le promeneur peut. suivant l'expression du mete, "junir du chant des oiseaux, du bruissement des feuilles, du souftle it la brise et des parfums de la foret

De telles initiatives méritent d'être virement encoul'agées.

I la protection des forets et anx vertus éducatives que l'on doil reconnaitre a l'eurre que nons défendons, se lie dans notre esprit, d'une façon intime, la protection des ilres ailes yui les pemplent, les animent et les égaient et nous croyous devon signaler ici le mouvement qui s'accentue en laveur de l'oiseau.

L'admipistration forestiere et les administrations communales de phusieurs grandes villes font placer des nids artificiels dans les arbres qui entomrent les maisons des gardes et dans les parcs publies. A Bruxelles, des pâtées et des graines sont distribuées en hiver. I stavelot, les petits oiseaux sont recmeillis et soignés pendant la saison des frimas ot làehes aux premiers jours du printemps. lilleurs, on organise des concours de nichoirs entre les élèves des écoles.

En Amérique, pass des innovalions et des excentricilés, on wrdonne anx instifuteurs de laire prèter, à la rentrée des classes, ce serment à tous les écoliers : Je jure de ne détruire ni les arbres, ni les Heurs; de protéger les petits oiseaux; de respecter la propriété d'autrui, afin ffu'on respecte la mienne, etc.

Et ainsi, lentement, mais surennent, lon prépare la génération de demain a aprécier toute l'importance des ceuvres de la natuure et les saines et innombrables jonissances que celle-ci procure à cenx qui savent la romprendre et l'aimer.

Les nations sont les depositaires, et non les proprietaires, des renvres et des richesses naturelles et il importe, non seulement a l'etal, mais a tous los habitants, de veiller i la protection de la nature et specialement des forêts, dont l'existence est un nécessite matérielle et inorale pour les peuples.

1 ce point le vue, la générafion actuelle porfe vis-à-vis des générations futures une responsabilite qu'il importe de mettre en ividence.

Pirtant du principe rue la conservation, le développement et l'embellissement des forets duivoll late t'objet dime collaboration des pouvoirs publics

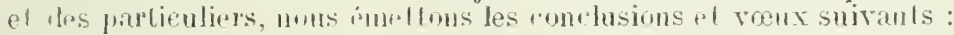

10 Inesser dans lous les pans un inventare des regions boisées ou non

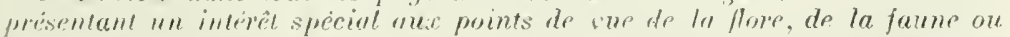

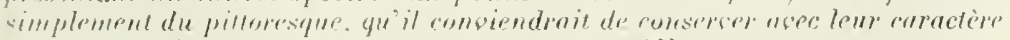

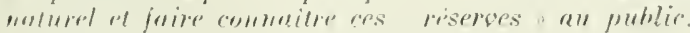

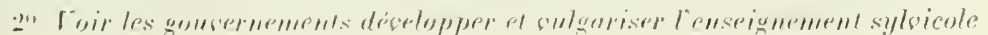


sous la forme la plus simple, répandant par tous les moyens possibles les notions forestières élémentaires et en organisant des excursions scolaires.

$3^{\circ}$ Faire l'éducation esthétique du public :

a) En inculquant à l'enfance et à l'adolescence dans les écoles, collèges, athénées, lycées, le sentiment et le respect du Beau.

b) En propageant par la photographie et les conférences avec projections iumineuses le culte, c'est-à-dire l'admiration des beautés naturelles et notamment des arbres.

c) En multipliant les fêtes de l'arbre.

d) En formant des comités régionaux qui ont pour but de veiller à la conservation des sites les plus intéressants, de les faire connaître au public par des liorets-guides et des plans d'un prix minime et de faciliter l'accès ou la contemplation des endroits sauvages et agrestes encore peu connus des promeneurs.

e) En intervenant judicieusement par la voie de la Presse.

$4^{\circ}$ Inviter les gouvernements à acquérir, principalement dans les régions industrielles, les propriétés forestières dont la conservation est d'intérêt général aux points de vue de l'hygiène et du pittoresque et à les aménager en tenant largement compte des considérations esthétiques.

$5^{\circ}$ Intervenir par voie de conseils auprès des administrations publiques et des particuliers à l'occasion des travaux qui peusent porter atteinte aux: paysages.

$6^{\circ}$ Placer entre les mains des gousernements, une arme légale adoptée aux mœurs du pays et au tempérament national.

Messieurs, je le déclare pour terminer, je suis venu au Congrès moins pour donner des avis et des conseils que pour prendre des leçons et je me résume en ces quelques mots: Unir nos efforts pour faire connaitre les forêts et les autres beautés naturelles ; car les connaître c'est les aimer, et les aimer, c'est les conserver et les respecter. (Applaudissements.)

M. Le Président. - Quelqu'un a-t-il des observations à présenter au sujet de ces vocux?

M. GÉxEAL. - Le premier vou touche à la question des pares nationaux

M. Le Présinext. - La rlemière phrase lui donne, en effet, un caractère un peu spécial, et je serais d'avis de la supprimer; mais le commencement est excellent.

M. Delville. - Il s'agit de dresser le cadastre du Beau. Si vous voulez supprimer les mots : "faire connaître ces réserves au public " je ne ferai pas d'objection; je parle naturellement des réserves de beauté en général.

M. le Président. - Je rous propose done, Messieurs, d'adopter le premier vœu ainsi rédigé :

" $1^{\circ}$ Dresser dans tous les pays un inventuire des régions boisées ou non présentant un intérêt spécial au point de sue de la flore, de la 
faune on simplement du pittoresque, qu`il conviendrait de conserser avec leur curactère naturel $\%$.

Ce vou, mis aux voix, est adopté.

M. le Président. - Voici les voux suivants :

"20 Voir les gouvernements développer et vulgariser l'enseignement sylvicole sous la forme la plus simple en répandant par tous les moyens possibles les notions forestières élémentaires et en organisant des excursions scolaires ".

Adopté.

" $3^{\circ}$ Faire l'éducution esthétique elu public:

a) En inculquant à l'enfance et à l'adolescence duns les écoles, collèges, athénées, lycées, le sentiment et le respect du Beau.

b) En propageant par la photographie et les conférences asec pro-

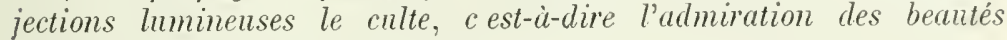
naturelles et notumment des arbres.

c) En multipliant les fêtes de l'arbre.

d) En formant des Comités régionanx qui ont pour but de veiller ¿i la conservation des sites les plus intéressants, de les faire connaître an public par des liorets-guides et des plans d'un prix minime et de faciliter l'accès ou la contemplation des endroits sanvages et agrestes encore pen connus des promeneurs.

e) En intervenant judiciensement par la voie de la presse".

Adopté.

" $4^{0}$ Inviter les gonvernements à acquérir principalement dans les régions industrielles, les propriétés forestières dont la conservation est d'intérêt général aux points de vne de l'hygiène et du pittoresque et à les aménager en tenant largement compte des considérations esthétiques $»$.

Adopté.

$5^{\circ}$ Intervenir par foie de conseils anprès des administrations publiques et des particuliers il l'occasion des trasunx qui pensent porter atteinte anx paysages $»$.

Adopté.

"60 Placer entre les mains des goucremements une arme légale adaptée anx mours du pays et an tempérument national ». Adopté.

M. Dierckx. - On n'a pas statuésur le rou relatif aux encouragements à donner aux Soriétés des amis des arbres.

M. Le Présidext. - Si votre vœu n'est pas rédigé, nous ne pouvons Padupter. Nous n'y sommes pas opposés en prineipe; mais il y a à arrêter une question de rédaction. Voulez-rous done en rédiger les 
tormes et a voir lobligeances de nous lo présenter an début do la sianec de ret après-mili.

11. Inselme Cunger la - Je vous demanderai la permission, Monsieur lo président, avant de lever la séance, de lire mon rapport. II nesouleve aucune observation particuliere.

M. Le P’résnext. - Pas doopposition? La parole est à M. Changeur.

M. Cungetr donne lerture de son rapport sur la "Bente ue pars PAR LI FORETT ".

Il semble que la Nature ait voulu, en quelque sorte, parer de beauté sa puissance, associer la grâce ou la majesté au jeu des organes par quoi s'exercent ses fonctions ritales : sources, lleuves, mers, bois, forêts.

Car la forêt n'est point inférieure en splendeur à l'élément immense. l'Océan. Ello évorgu des sensations égales de puissance et de orandeur. Les voix de la forêt ont un registre aussi étendu que celles de la mer, ế le grand soufle dont elle s'anime sous les caresses de la brise ou les morsures de la tempête l'apparente aux flots tantôt chantants, tantôt hurlants. Et l'on conçoit sans peine que la forêt fût le pregaier temple des hommes et qu'ils aient attribué un carartère sacré aux géants sylvestres, vivants emblemes de force et de duree.

Comme la mer, elle est toujonrs en beaulé. Chaque saison tient it honneur de la pares. L'hiver même, le dur hiver qui la dépouille, n* l'arilit ni ne l'enlaidit: ce n'est pas un attrait moindre, c'est un attrait antre qu'il lui donne. Nors le peuple noir des arbros, éclairé par places du fít marmoréen dos bouleaux blanes, développe sans voiles sa musculature puissante, veloutce de mousse, festonnée de lierre on ponctuée des touffes vives du gui. La solennelle beauté des bois silencieux s'affirm aussi émouranté qu'aux éporques où des frissements d'ailes et des trilles d'oiscaux ribrent sous les frondaisons épaisses. Et l'été n'oftre pas de spectacle plus magnifique que le ciel rouge des crépuseules d'hiver flamboyant en lueurs de vitraux sprtis de l'étain des pamures dénudées.

Mais la forêt n'est point que beauté, clle est aussi force. Réserroir d'énergies, dispensatrice de vie, vivante elle-même, c'est d'elle que le fleuve tient le cours large et régulier qui, né en torrent ou en ruisseau, s'enfle en avançant, s'aceroit des rubans d'argent de mille afluents et traverse les plaines en répandant la fécondité dans les campagnes, la prospérité dans les villes. La forêt a su capter, puis retenir la force qui voguait aux flanes des nuages; puis, la défendant des ardeurs du soleil ou des rigueurs de la gelée, la distribuer avec mesure. Aussi un pays ne saurait-il être beau et fort - les deux terues sont ici synonymes - sil ne possède ent élément essentinl : la forêt.

La vigne aux longs enlacements sert de parure aux arbres, la grappe rubiconde aux vignes, le taureau mugissant au troupeau, la moisson blonde aux eampagnes, a dit le poètr des Bucoliques, et la forêt aux nations, peut-on ajouter.

Un pays est incomplet, pour ainsi dire, si eu ses plaines ne s'étale l'épais tapis aux senteurs vivifiantes de la forêt, si l'épaule de ses colliñs ou de ses monts m se diape du large manteau, aux nuances cliangeantes au gré des saisons, de la forêt profonde. 
La douce terre de France joint re prestige il beaucoup d'autres. Son sol aimé des dienx, son sol hospitalier aux arłres comme aux hommes, présente les plus riches spécimens de toutes les essences depuis l'orme, l'arbre national au point de porter en maint endroit le nom du plus populaire de's ministres lrancais, Sully, jusqu'au cèdre dont les larges rameaux horizontaux étendent autour d'eux une bénédietion de patriarche venu des régions libliques.

Les Vosges, les Ardennes, l'Esterel, les forêts du Jura, de l'Auvergne, du Morvan, des Landes, des Pyrénées, pour ne citer que les plus notables, sont autant de joyaux dont alle peut s'enorgueillir. Chaque province possède un fleuron du diadine national, berceau de races fières, svmbole des vertus loeales, car une sorte de fraternité unit l'arbre et l'homme, les marque presque d'un sceau commun.

C'est là une incomparable beauté, c'est lì une richesse qu'il importe de défendre jalousement, de conserver et d'augmenter sans cesse.

Il faut ajouter que ja forêt no peut être élément de beauté que si elle est belle elle-même. Et la première condition pour qu'elle soit belle est qu'aucune exploitation abusive ou irraisonnée n'en altère le caractère originel, nous dirions même volontirrs "aueune exploitation " tout court, si nous ne eraignions de heurter des convictions profondes, mais inspirées de principes plutôt utilitaires qu'esthétiques.

Il faut, en un mot, que la plus large liberté soit laissée à l'auvre de la nature, que l'homme y mette le moins possible la main - sinon le pied - et que, sauf les routes et les sentiers indispensables à la traversée de la forêt, nulle note " humaine "n'en diminue le charme intégral.

Il est assez délicat de fixer avec précision quelles régions seraient, plus que d'autres, susceptibles de reçvoir cetélément de leauté. D'une manière générale, la forêt semble s'adapter plus spécialement aux endroits d'une certaine altitude, collines ou montagnes, tant au point de vue esthétique qu'au point de vue utile, étant admis la relation étroite de la forêt avec l'atmosphère et son rôle d'agent de transmission et de liffusion de l'humidité aérienne. Elle constitue le courunnement naturel des cimes.

Mais ce qu'il est nécessaire de répéter, en conclusion de ces observations, c'est que la forêt, où qu'elle se trouve, apporte une contribution essentielle, indispensable à la beauté du pays, et que nul pays n'est absolument.beau qui ne la possède.

En conséquence, nous avons l'honneur de proposer les vocux suivants aul Congrès Forestier:

1. Qu'aucun moyen ne soil épargnè d'abord pour conserver les foréts existantes, ensuite pour en accroûtre l'étentne th le nombre, soit par les soins de l'Élat, soit par des encouragements aux iniliatives privées.

11. Qize dans l'exploitation des forêts acturlles et fulures il soit tenu compte dans la plus large mesure possible de l'intérét esthétique que ces forêts peusient présenter.

M. LE Prisinext. - Je rois que ans resux sont de remx qui doivent reunil l'unanimité.

Je les mets aux roix.

Cese recux sont aldphtes.

La síanee est levin: it midi. 


\title{
SEANCE DU 16 JUIN 1913
}

\author{
(APRES-MIDI)
}

\section{Présidence de M. GHAIX, président de Section}

La séance est ouverte à deux heures.

M. Le l'résident. - M. Flahault a la parole pour la lecture de soz rapport et l'exposé de ses idées sur les Jarmixs alpins et les Arbo. RETUMS.

L'attention a été appelée dès longtemps sur l'opportunité de créer en montagne des jardins comme centres d'étude des problèmes intéressant la biologie des végétaux propres aux zones élevées et l'économie des montagnes. Les efforts tentés en Autriche et en Suisse par de savants économistes, de 1835 à 1875, n'eurent pourtant qu'un succès éphémère, en dépit de l'autorité des hommes qui en avaient pris l'initiative.

Les jardins dits alpins sont assez nombreux aujourd'hui dans les pays d'Europe entre lesquels se partagent les Alpes. Tous les établissements de ce genre ne sont pourtant pas aux Alpes. Il en existe au moins un dans les Pyrénées centrales françaises ; quelques-uns sont situés dans les basses montagnes de l'Europe occidentale et centrale. Le Danemark en possède un au Groënland.

Un certain nombre de jardins ont été eréés, puis ont disparu. Pendant quelques années, le but à atteindre ne paraissait pas assez précis. Certains furent établis sans que leurs créateurs eussent les ressources nécessaires pour en assurer l'entretien; l'inexpérience et l'imprévoyance ont compromis des tentatives louables. L'histoire de ces essais a été écrite et publiée (1).

Il existe aussi quelques arboretums, colleetions d'arbres étrangers au pays où elles sont établies. Ces arboretums ont été créés surtout dans le but de discemer des espèces présentant des avantages forestiers. Certains d'entre eux sont devenus des centres importants pour l'étude des problèmes forestiers (Suisse, Autriche, Bavière). En outre, les services forestiers ont multiplié en certains pays les places d'essais qui rendent de grands services, notamment en Autriche et en Suisse. Ces places d'essais

(1) J. Ivolas, Les Jardins alpins : broch. in- $8^{\circ}, 100$ p. P. Klincksieck, Paris, 1908. 
sont au nombre de 500 environ sur le seul territoire de la monarchie austro-hongroise; on y poursuit des expériences sur tous les problèmeg de la culture forestière.

Deux Congrès spéciaux ont réuni en Suisse (1904 et 1907) un certain nombre de personnes s'intéressant aux questions de botanique et d'économie alpestres. On y a précisé les problèmes à résoudre et tracé un programme de recherches. Un troisième Congrès paraissait désirable; diverses circonstances majeures en ont empêché la réunion.

En attendant, on travaille. Plusieurs des jardins actuels sont devenus des centres actifs de recherches; le moment semble venu de formuler de légitimes désirs relativement au rôle des jardins de montagne, arboretums, places d'essais dans les études relatives à l'économie des montagnes sous les latitudes moyennes.

Enoncés de principes. - 1. Le elimat détermine les possibilités de l'économie biologique et du peuplement des montagnes; or, la végétation est le miroir fidèle du climat; elle en traduit les moindres nuances de la façon la plus précise. La connaissance de la végétation est, par suite, la condition fondamentale, la base de toute étude sur l'économie biologique et sur l'exploitation biologique intensive des montagnes.

2. C'est la végétation qui nourrit et qui peuple. La plante domine tous les autres facteurs de la production agricole; la géographie des plantes joue done un rôle prépondérant dans l'économie biologique rationnelle du sol. Te botaniste a donc le devoir d'étudier la végétation dans ses rapports avec l'économie biologique du sol, d'où dépend le peuplement rumain.

3. La plupart des montagnes de l'Europe ne sont pas aussi peuplées qu'elles pourraient, qu'elles devraient l'être, si l'on tient compte des possibilités naturelles. Les montagnes de France sont, à cet égard, en mauvaise situation. Nous trouvons des modèles à imiter, particulièrement en Suisse.

4. Ménager, produire et utiliser au maximum la végétation la plus conforme aux possibilités d'un lieu déterminé, c'est préparer la place à un nombre maximum de vies humaines; c'est tendre vers la densité maximum de peuplement pour ce lieu. Etendre cette cuvre à tout espace habitable avec la même préoccupation, c'est favoriser l'expansion de l'humanité. La culture du sol ne saurait a voir de but plus élevé.

5. Données scienlifiques et économiques. Programme d'études. - Le cultivateur ne modifie pas le climat; il le subit. Le elimat détermine, par l'intermédiaire de la végétation, les possibilités du peuplement et le mode de vie des hommes.

En conséquence, il y a lieu, à la faveur des centres d'étude créés en montagne d'établir la climatologie locale, en ce qu'elle a de plus essentiel pour la vie végétale : températures de l'air et du sol, gelées; précipitations atmosphériques, enseignement, nébulosité, luminosité ; il faut noter les températures maxima et minima de ehaque jour et ne pas se contenter de moyennes journalières.

6. Dans les pays tempérés, le elimat impose une distinction fondamentale du territoire en trois eat égories économiques primordiales, déterminant les rapports essentiels de l'homme avee les produits vivants du sol. On reconnait, en effet, des terres de vocation agricole, de vocation forestière, de vocation pastorale. Ces distinctions sont ordinairement faciles dans les régions niontagneuses sous les latitudes moyennes; elles 
se révèlent avant tout par l'étude détaillee de la régétation spontanée aux différents étages des montagnes.

En conséquence, la connaissance des associations végétales naturelles devant être la base des travaux d'économie rationnelle du sol, il y a lieu : 10 de faire la statistique aussi complète que possible du domaine occupé par les jardins, arboretums, etc.; $2^{\circ}$ de décrire exactement les associations végétales spontanées dans leurs rapports avec les stations qui les portent On se préoccupera en particulier des champignons et des parasites contribuant à limiter l'extension des végétaux cultivés et des es pèces ligneuses $; 3^{\circ}$ de faire des observations phénologiques de la base au sommet des montagnes, au moins sur les espèces dominantes et les plus répandues. Les observations porteront principalement sur les premières manifestations de la vie au printemps, la feuillaison et la défeuillaison des espèces ligneuses les plus répandues, là floraison des espèces printanières, la limite à laquelle diverses espèces mûrissent leurs fruits et leurs graines, les floraisons tardives, l'arrêt automnal manifeste de la végétation aérienne, les phénomènes biologiques déterninés par des accidents climatiques exceptionnels.

7. La culture assure aux terres de vocation agricole le rendement maximum qu'on en puisse attendre; elle y permet la densité de peuplement la plus grande qu'on en puišse espérer. Il faut done la développer, l'encourager et la perlectionner. Ces terres de vocation agricole pénètrent bien avant dans les vallées, s'effilent dans les vallons, s'y égrènent. Il faut en respecter la vocation, y maintenir l'homme, protéger ces poussières d'humanité.

En conséquence, il y a lieu de rechercher avec d'autant plus de soin qu'il s'agit de sites plus élevés, les terres de vocation forestière, vocation déterminée éventuellement par le climat local, l'exposition, la situation géographique. Il y a lieu de compléter cette élude par l'analyse des sols, par la détermination des possibilités d'irrigation, le sol et l'cau pouvant accroître ou diminuer les possibilités agricoles dépendant du climat.

La main-d'œuvre ayant une importance majeure en montagne, il convient d'étudier aussi tout ce qui contribue à la maintenir et à la développer, conditions du travail, forme des contrats de travail, etc., questions liées aux possibililés de l'agriculture en montagne.

8. C'est par l'exploitation des forêts que les territoires de vocation forestière atteignent leur rendement maximum. Il faut donc y dévelop. per autant que possible l'exploitation du bois. Les limites normales des terres de vocation forestière sont le plus souvent indécises; les travaux de reboisement ne tiennent pas toujours assez compte des limites rationnelles dans lesquelles il faut les effectuer.

En conséquence, il y a lieu : $1^{0}$ de recueillir des notes précises sur la biologie des espèces ligneuses, au moins les plus répandues, considérées surtout au voisinage de leurs limites; établir leurs limites extrêmes et les causes diverses, climatiques ou autres qui les déterminent ; $2^{\circ}$ de dresser des cartes détaillées de la répartition spontanée des végétaux ligneux dans les vallées de montagne et les massif́s montagneux, cartes appelées à fournir une base solide à tous les travaux de restauration et d'exploitation économique des montagnes. Des travaux de ce genre, poursuivis en Suisse depuis 1900 , ont donné déjà des résultats de première importance et fourni des règles aux forestiers reboiseurs.

9. Les territoires de vocation pastorale fournissent, par l'exploitation

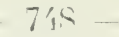


des plantes herbacées en vue de l'élevage du betail, le rendement maxi. mum qu'on en puisse espérer. Dans les limites où aucun autre mode d'exploitation n'est plus favorable, il convient de développer l'exploitotion pastorale et de lui assurer le caractère le plus extensif.

En conséquence, il y a lieu de reconnaître les territoires où l'exploitation pastorale est seule possible, de rechercher tous les moyens de la rendre aussi intensive que possible, de déterminer les amélioralions pastorales de toute sorte, capables d'accroître le rendement par unité de surface, de permettre l'augmentation du cheptel en montagne et l'aceroissement corrélatif du peuplement humain. La Suisse nous offre encore des modèles à cet égard.

10. Indépendamment de la vocacion imposée à la terre par le climat, des convenances multiples peuvent déterminer des habitants avisés à utiliser de diverses manières le sol des montagnes. Des circonstances particulières, souvent locales (débouchés, etc.) déterminent ces convenances; elles n'infirment pas la valeur de la distinction primordiale établie par le climat.

Cette considération conduit à l'étude des moyens de suppléer à l'insuffi. sance des ressources principales par des ressources annexes.

L'Agriculture insuffisante trouve des compléments nécessaires dans l'exploitation forestière ou pastorale, dans les industries dérivées, dans les petites industries familiales, dans l'utilisation des petits produits du sol, voire même dans les industries minières, dans l'industrie hôtelière. Le but suprême de l'économiste, en ce qui concerne la montagne, étant de la voir peuplée et productrice au maximum, aucune de ces questions n'est indigne de ses préoccupations. Pourquoi des habitations sont-elles délaissées ? Cet abandon est-il rationnel, nécessaire, imposé par le climat ou la pauvreté du sol ? S'il n'est pas nécessaire, il est infiniment regrettable. Il y a donc lieu d'étudier ce côté de la question par l'étude très attentive des fourrages et des moyens de les améliorer, par l'étude de la possibilité des cultures maraîchères et des améliorations de l'hygiène alimentaire. La montagne ne peut être prospère qu'à la condition d'être habitée par une population en rapport avec les possibilités naturelles sagement mises en valeur.

S'il s'agit de places ou de stations d'essais, dépourvues de personnel scientifiquement préparé, on se contentera d'un programme restreint ; des études spéciales y seront entreprises d'après la situation, les nécessités locales ou momentanées, par exemple, sur les meilleures races des espèces forestières indigènes, sur l'importance des engrais dans les pépinières forestières, sur la valeur des graines de différentes provenances, sur les adaptations des essences forestières à des sols différents, sur les maladies qui menacent les essences forestières dans le pays.

Le programme pourra s'élargir d'autant plus que le personnel sera scientifiquement mieux préparé, qu'il aura une plus grande expérience du pays et de plus grandes ressources matérielles. Les arboretums rendront d'autant plus de services qu'ils seront confiés à des techniciens ou à des savants plus expérimentés. Les jardins botaniques de montagne, sous la direction d'hommes préparés de longue main, seront pourvus de laboratoires où l'on puisse séjourner, où tous les problèmes spéciaux à l'économie des montagnes puissent être abordés par des spécialistes.

Quels que soient les objets soumis à l'étude, on n'oubliera pas que s'il s'agit de la solution de graves problèmes techniques, il s'agit aussi du rôle 
social de la montagne, étroitement lié à son exploitation économique la plus rationnelle et la plus prévoyante.

\section{Le Congrìs Émet Le veU :}

Que les jardins de montagne, arboretums, stations ou places d'essais soient établis comme centres d'études non seulement pour les questions de sylviculture, mais poúr tons les objets intéressant l'économie des montagnes comme foyers de vie humaine.

Messieurs. - Il y a $u$ instant, j'entendais un de nos confrères jeter ces mots en passant derant la porte : "Ici, c’est l'esthétique ".

Permettez-moi de rous dire qu’à mes yeux, ici ce n’est pas l'esthétique. J'ai accepté très volontiers de faire ce rapport sur les Jardins alpins et sur les Arboretums et je déelare que ce n'est pas du tout, à mes yeux, une question d'es thétique. Comme l'a dit ce matin M. le Ministre, e'est la question de la vie humaine, c'est la question de la vie sociale qui est en jeu.

Je crois en effet que la préoccupation essentielle des sylviculteurs profescionnels comme des hommes de science s intéressant aux sciences biologiques, doit être de mettre chaque chose à sa place dans la nature, et que la restanration, - pour employer cette expression au sens archéologique du mot, - la restauration de notre monde ne peut venir que de la mise de chaque chose à sa place. Voilà pourquoi, à mon sens, il faut qu'il y ait des arboretums, des jardins alpins.

Il y a des principes qui permettent d'établir immédiatement le bienfondé de cette affirmation. D’abord, la végétation est le miroir du climat. La végétation exprime le climat avec une netteté et une présision infiniment plus grandes que tous les observatoires météorologiques. Eìt-on vingt observatoires météorologiques dans un même massif montagneux, la végétation exprimr le climat avec plus de netteté que ces vingt observatoires. Sur le versant d'une montagne, il y a des différences de niveau de quelques mètres qui suffisent souvent à introduire des différences dans la végétation. On ne s'est pas assez préoccupé de ces choses qui ont une importance capitale.

En second lieu, je ne saurai jamais asez le répéter, c’est la végétation qui nourrit et qui peuple. Il y a quelques semaines, j'étais au dísert du sud tunisien : là où on crée des oasis, on crée la vie. Dans la montagne, là où on crée la forêt, on crée la vie : il n'y a pas un point du monde où on peut nourrir un enfantsi on n'a pae de bois pour faire du feu. Partout oì on a déboiś, comme dans les Pyrénées, à plus de 1.000 mètres, il est impossible de nourrir un enfant à cette altitude. Si on réussit à créer la forêt, comme la suisse l'a "réée. jusqu’à 1.800 mètres, on porte les possibilités de la vie humaine à cette même altitude.

Voilà los principes fondamentaux sur lesquels nous. biologi̊tes et forestiers, nous devons nous appuyer. Si nous faisons le calcul des terrains vaeante ef les landes sans rappert qui se trowvent actuel- 
lement dans les six départements méditerranéens des Pyrénées-Orientales, de l'Aude, de l'Hérault, du Gard, des Bouches-du-Rhòne et des Alpes-Maritimes; nous derons considérer qu'il y a de ce fait un déficit de 585.000 vies humaines, 585.000 vies humaines exclues du pays par le fait du désordre introduit dans la nature par l'existence de ces landes improductives. Je dis que ce manque de vies humaines pèse comme une responsabilité majeure sur notre pays et qu'il est du devoir, non pas seulement des forestiers, mais de tout citoyen, d'y remédier par un effort constant. Or, aménager, produire et utiliser au maximum la végétation la plus conforme aux possibilités d'un lieu déterminé, c'est préparer la place à un nombre maximum de vies humaines.

Vous voyez que nous dépassons de beaucoup la portée d'une section considérée comme s'occupant d'esthétique. C'est, en réalité, de la population de notre pays que nous nous occupons, c'est de cette France qui s'appauvrit en hommes que nous nous occupons. Puisque le cultivateur ne modifie pas le climat et qu'il le subit, nous devons, nous, hommes instruits, instruire les gens du peuple.

Je connais des hameaux où on ne sait pas qu'il existe des écoles où on peut apprendre l'agriculture et la sylviculture.

Dans les pays tempérés que nous habitons, le climat à lui seul, indépendamment de toute autre condition, impose une division du sol en trois catégories : terres de vocation agricole, terres de vocation forestière, terres de vocation pastorale. Et lorsque nos camarades forestiers déterminent des périmètres de reboisement, ils doivent déterminer des périmètres basés exclusivement sur la vocation des terres.

J'évoque ici le souvenir d'un nom que je respecte entre tous, celui de mon ami et maitre Georges Fabre. Si Georges Fabre reste, - et il restera, - le premier sylviculteur de France, c'est parce qu'il a reconnu, en botaniste qu'il était, cette question des rocations et que jamais il n'a consenti à faire entrer dans un périmètre, un champ qui puit produire davantage par l'agriculture.que par la forêt.

Ciest donc avant tout une question de géographie botanique, de géographie biologique. Nous devons pousser la forêt aussi loin quelle peut être poussée, mais il est inutile, il est nuisible, de vouloir la pousser au delà de ses limites naturelles : on n'y ferait que des sottises.

Nous entendons parfois, - j'en ai entendu, je vous le dis un peu bas, - de jeunes forestiers de 23 ou 24 ans nous dire : "Dans les Alpes, je plante jus qu'à 2.600 mètres. "Il m'arrive de leur répondre : "Permettez-moi de vous dire qu'il vaudrait peut-être mieux que l'Etat conservât son budget. Aucun arbre ne peut vivre chez nous à 2.600 mètres. " A 2.600 mètres, en effet, on a dépassé les limites des possibilités. Il y a donc une question scientifique, une question pour laquelle nous avons besoin de bases scientifiquement très précises. Ces bases scientifiquement très précises, c'est dans les arboretums et les jardins alpins qu'on peut les trouver. Permettez-moi de vous rappeler ce que j'ai dit au commencement de mon rapport : II y a, sur le territoire de la monarchie austro-hongroise, cinq cents places 
d'essais ou arboretums ou jardins botaniques. Que ceux d'entre vous qui sont au courant de cette question reuillent bien se demander combien il y en a en France. Je ne réponds pas moi-même.

Il serait intéressant qu'il y eùt en France des places d'essais, des arboretums ou jardins botaniques, dans les différents massifs et dans les diverses conditions naturelles qu'offre notre pays, - et aussi que les surfaces consacrées à l'expérience soient observées pour le massif en rue duquel elles seraient établies, car, ainsi que je le disais tout à l'heure, il y a des nuances qui ne se marquent que par des différences de quelques mètres d'altitude, de telles sorte que les données ne peuventservir que pour un groupe déterminé.

Je puis donner des conseils autorisés sur quelques points du massif central, je ne me permets pas, sans y aller voir, de donner des avis sur d'autres parties, car je ne mappuie précisément que sur des connaissances précises, absolument nécessaires.

La main-d œuvre a une importance majeure en montagne et il faut absolument l'y retenir, ou l'y amener. Pour cela, il faut que les jardins, arboretums, places d'essais soient des centres d'études et d'observations aussi précisee que possible sur toutes les possibilités économiques du territoire où l'on est établi. Il faut qu'on s'y occupe, non seulement de sylviculture, mais d'amélioration pastorale, qu'on y cultive des légumes, qu'on montre aux habitants du pays que l'on peut y obtenir une alimentation variée, qu'on leur fasse voir qu'il est possible à l'occasion d'y, avoir des fruits, qu'on leur montre aussi qu'ils peuvent mettre un peu d'agrément autour de leur maison.

Ces places d'essais, ces arboretums ou jardins alpins doivent done être des centres d'étude de géographie biologique appliquée à toutes les questions biologiques.

Vous avons en mêne temps uı autre devoir : C'est celui d'essayer de combiner les multiples ressources sylvicoles, agricoles et pastorales de manière que les peuples montagnards en tirent le plus grand profit. J'arrive maintenant à la conclusion :

Le programme pourra s'élargir d'autant plus que le personnel sera scientifiquement mieux préparé, qu'il aura une plus grande expérience du pays et de plus grandes ressources matérielles.

Les arboretums rendront d'autant plus de services qu'ils seront "onfiés à des techniciens ou à des savants plus expérimentés.

Les jardins botaniques de montagne, sous la direction d'hommes iléparís de longue main, seront pourvus de laboratoires où l'on pourra réjourner, ou tous les problèmes spéciaux à l’économie des montagnes pourront ètre abordés.

Il fant que nous fassions appel à toutes les bonnes rolontés. Les forestiers sont les premiers désignés pour s'occuper de cette question, mais il y a aujourd'hui, - et c'est là précisément le grand mérite du Touring-Club, - a còté de larministration, des bonnes volontés colletives qui ont fait naitre des bonnes volontés individuelles. Si 11. X... 011 . I... porsinant quelques hertares de terrain au roin 
d'une vallée ou à l'orée d'un vallon olfre un bout de vallon comme champ d'expériences, arceptons-le : plus ils seront multipliés, mieux rela vautra.

Vuici, Messeurn, le voru que jai pris la liberte de formuler sur cette yuestion :

"Qne les jurdins de montugne, arborctnms, stutions on plures d" essais soient itublis comme centres d'études non senlement ponr les 'questions de sylviculture, muis pont tons les objets intiressant liconomie des montagnes comme foygers de ries humaines \#. (1pplandissements.)

11. Le P'uśbuext. - V'ou: venez d'entendre la rommunication véritablement remarquable ef exeptionelle que M. lilahault vient de nous faire. Il y expose le ròle de l'arboretum et celui du jarlin alpin dans les flues lions économiques tonchant au développement le la rare humaine et au repeuplement de nos montagues. Cette rlunière ques. tion est particulièrement interessante, maintenant oì nous royons nos montagnes onvahies par l'industrie qui, certainement, n'est pas toujours lamie des plantes.

Je vais ouvrir la discussion sur le rapport dr $1 \mathrm{l}$. Flahault et sur les idées quil vient d'imettre.

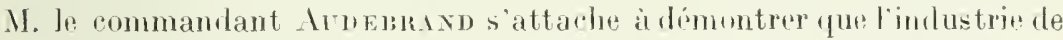
la houille blanche retient au costraire l'ouvejer à la montagne.

Je voudrais, dit-jl, arriver à détruire l'arrjère-pensée d'une influence nocive de lindustro hydro-ihetrique sur la beautí de la montagne.

Jaa des amis très chers a ver lesquels je suis en perpétuelle contradiction à re sujet. Ce sout de tres lraves gens, mais quand ils roient un tuyau qui amène de l'eau quelque part, ils sont navrís pt diclarent: "Ces abominables ingriveurs ont abime rompletement notre montagne \%. Je vouluais quon arrice à comprendre que si quelquefois des incunsiquenes ont puse produire par le fait de errtains employés maladroits ou de certains ingenieurs inattentifs, re ne sont jamais que des expeptions malleweuses, choquantes, je lo reconnais, mais ct he sont que des exceptions. Et romme dans les questions qui, nous intéressent : industrie, agrieulture, sylviculture, emploi pastoral de la montagne. il $31^{\circ} \mathrm{y}$ a pas antagnisme, il doit y avoir moyen de trouver

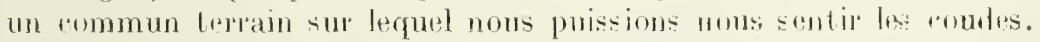

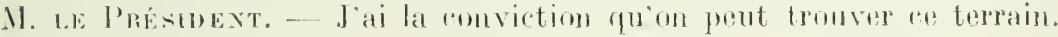

11. le commandant de oebrisu. H sultit que noss y mettions fos une et les autres de la bonne volonte. Yous nous offorene de ne pat lioisser vos sentiments es thétiques, qunique cela nesoit pas toujours aisi, mais il faut que vous arriviez a considerer les ingénieurs commo itant des gens qui travaillent aver vous. I a petite socirte que jai l'hnneur de presider ce la Chambres yodieale des fores hydraulirues favorisent par

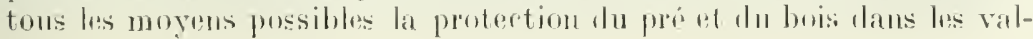


lées quis ont au-dessus des vallées industrielles. 11 y a donc là un terrain commun sur lequel nous pourons collaborer. Je tenais à rous demander d'aroir pour ces misérables ingénieurs un peu de commisération.

M. Flahilt. - Je ris dans la montagne et je rois par conséquent lindustrie hydraulique aux prises arec les conditions du pays. Il est bien certain que l'industrie hydraulique est un moyen d'empêcher l'émigration. D'autre part, il faut bien reconnaître aussi que la montagne est comme la forêt et que nous ne pourrions pas adopter cette formule un peu naïre d'un membre du parlement qu'on nous signalait ce matin et qui ne voulait pas qu' on coupàt un arbre de la forêt. La forèt est faite pour être exploitée et notre pays doit produire; c'est à cette condition seule que nous arriverons à produire des hommes. Tous sommes done d'accord : l'industrie hydraulique établie dans la montagne y retient des populations, mais justement nous devons compter sur la bienveillance. sur le goût, sur les préoccupations sociales de nos confrères les ingénieurs de la montagne pour mettre le plus de bien-être poscible dans la maison de leurs agents et assurer à ces agents, - je reviens maintenant à l'esthétique. - l'esthétique de leur demeure, de façon à ce que. en attendant que les lois permettent de mettre la France à l'abri de l'alcoolisme, nous arrivions tout au moins, en mettant de l'agrément dans la maison familiale, à lutter contre l'alcoolisme et le cabaret. (Tifs applaudissements.)

11. Le P'résinext. - Je vois que les divers éléments sont tout à fait d'accord. Je voudrais dire un mot du ròle du Touring-Club sur cette quertion qui est éminemment délicate, puisque deux éléments se trouvent en face l’un de l'autre. Yous arons pu, dans le demier numéro de la Rerue du Touring-Club, indiquer de la manière la plus nette la. position que nous désirions prendre. Nous estimons en effet aree II. le commandant Lebrun. qu'il faut trouver un terrain de conciliation. Il faut que nons cherchions àsauver le pittoresque de nos montagnes, et d'autre part, il serait inarmissible que nous puissions empêcher le developpement industriel de la France. Ce terrain d'entente, nous sommes surs quion peut le trourer.

\section{1. le Commandant Atdebraxd. - Quand on roudra!}

II. Le Présidext. - Ce que je disais tout à l'heure au sujet du tort que certaines industries. - je ne dis pas exclusivement la houille blanche, - pouraient causer à la régétation, était inspiré par des exemples que jai constatés à plusieurs reprises dans des tournées alpestres. Certaines industries émettent des vapeurs, des fumées qui proluisent des effets terribles sur la régétation. Nous avons pu roir, dans le courant d'air de la vallée dans laquelle ces fumées sont entrainées, qu il n" $\mathrm{y}$ a plus une seule feuille aux arbres dans un rayon de quatre 
kilomètres. Il en est ainsi dans la Romanrhe, à Moutiers, à Notre-Dame de Briançon, dlans la Haute-Maurienne. Il y a là un problème très intéressant à étudier an point de vue forestier. La production industrielle peut aroir. par certaines émanations, certaines vapeurs, un effet déplorable sur la végétation ; c’est une question locale à étudier, je crois qu'il y a des moyens d'enrayer le mal par des dispositions de bâtiments industriels qui permettraient d'empêcher le développement de res fumées et de ces vapeurs, et par conséquent qui protégeraient la régétation dans les environs de l'usine.

M. Je Commandant Audebrand. - Je urois qu'il faut dans toutes ces questions ne point se lenrrer d'es poirs irréalisables; je erains bien que vous n'ayez jamais la pureté d'air que vous réclamez et que, pour mon compte, je désirerais également. Permettez-moi une remarque. Il y a deux espèces d'industries électriques qui peuvent se rencontrer dans la montagne : l'une ne nous gêne nullement, elle ne gêne que le coup d'œil quelquefois, e'est le transport de force : on produit à un certain endroit, dans la valjée, une certaine énergie et on la transporte à 250, 300, 400 et même 500 kilomètres. Pour celle-là, on pourrait s'entendre assez farilement, car on peut arriver à discimuler Ie réseau de conducteurs et à le placer de façon que ce ne soit pas inesthétique. Les réseaux pourraient même parfois servir à l'ornemnt de la montagne (rires); jai l'air de faire un paradoxe, mais je pourrais vous en montrer des exemples.

Il y a, par contre, d'autres industries extrêmement intéressantes, mais qui ne peuvent se produire qu'au pied de la chute : ce sont les industries de l'électro-chimie et de l'électro-métallurgie. C'est là je crois, qu'il est nécessaire que vous, Touring-Club, arec votre hante autorité, disiez aux partisans de l'air pur, des belles perspectives et de l'agrément de la montagne, qu'il y a une petite concession à faire. Je ne crois pas, en effet, qu'on puisse arriver à faire des réactions chimiques qui n'envoient pas dans l'atmosphère les fumées désagréables.

M. le Présidext. - On pent capter ces fumóes, prendre certaines dis-. positions de bâtiments qui empêchent le dégagement excessif de ces fumées.

M. le commandant Audebrand. - Il est nécessaire qu'on s'ingénie à le faire. Mais il faudrait que Messieurs les amants de la nature fassent de petites concessions. C'est celà que je demande.

M. de Clenmont parle de l'intérêt qu'il y aurait à eréer des jardins alpins, au-dessus de la région des forêts, afin d'étudier si ces graminées de la plaine, telles que la houlque laineuse, pourraient être acclimatées dans la montagne.

M. Flahault. - Je prends la liberté de dire à notre confrère qui vient de parler des plantes pastorales de haute altitude que. d'un manière 
gemérale, nous ne réussissous pas à modilier les plantes des plaines lorsque nous les cultivons en hant. Mais, comme je le disais il y a un instant, les placer d'essais aboutissent, - et c'est là un point de vue extrêmement in téressant, - lorsqu'elles sont établies dans les hauteurs, à la sélection des planteri de hauteur et à l'amélioration pastorale de ces plantes. Les places descaie, jardins botaniques alpins, arboretums, ptc., etc. ne peuvent être établis que dans des circonstances données et res circonstances, on ne peut pas, dans tel ou tel massif, les réunir pour des raisons souvent matérielles, parce que la montagne manque d'altitude, par exemple, mais, dans tous les cas, c'est par des études faites sur place qu'on peut connaitre les améliorations réalisables. C.est ainsi par exemple, - je ne sais pas si j'ai l'honneur d'être entendu ici par quelques confrères suisses, - c'est ainsi que mes amis MII. Stedler et Schroeder ont établi il y a longtemps, dans les Grisons. au Furstenalp, un champ d'expériences que j’ai visité. Ce champ d'expériences pastorales est établi à 1.845 mètres environ, et on y fait, - ur les plantes qui vivent à ce niveau, des efforts de sélection qui aboutissent. J’ai fait moi-même des expériences de cette sorte à 1.550 mètres d'altitude, - je ne puis aller plus haut, dans les hautes Cévennes, faute de montagnes. Ce sont là des préoccupations que plusieurs hotanistes ont aujourd'hui et que plusieurs forestiers ont également.

Il y a là beaucoup à faire. Il faut avant tout que ces places soient nombreuses et qu'elles s'occupent de toutes les possibilités réalisables dans le massif oì le champ d'expériences est établi.

M. Henry MaIge. - Plusieurs de mes collègues ont dit que les rmanations industrielles étaient néfastes au point de vue de la forêt. C'est. si vrai que, dans beaucoup de régions des. llpes, les industriels paient Les indemnités considérables aux riverains. Il y a des procès énormes qui sont encore en cours.

M. Le Présinent. - Je vais proposer à votre adoption le voeu qui termine le rapport de M. Flahault.

Ce vou est ainsi conçu :

"Que les jardins de montagne, arboretums, stutions ou places liessais soient établis comme centres d'études, non seulement pour les questions de sylviculture, mais pour tous les objets intéressant l'économie des montagnes comme foyers de vie humaine ".

Le voeu est adopté à l'unanimiti.

M. Le Présıdent. - Ce matiı M. Dierkx, délégué belge, a exposé l'intérêt qu'il peut y aroir à créer des Sociétés des amis de la forêt et il a proposé un rocu sur ce point. L'assemblée a demandé à M. Dierkx de vouloir bien rédiger son voeu. Le voici :

"Que le Touring-Club soccupe de créer des Ligues locales des 
IXEMNITIONIL 191:)

amis des arbres on do lu forèt dans toutes les villes on lncalités impor tantes.

Li Congressiste. - Cela existe déjà.

1. le Président. - Oui, mais on demande de généralizer la méthode. de développer les associations déjà existantes. Il np peut y avoir là rien que de très intérersant.

Le voeu de M. Dierkx, mis aux voix. pet adepte.

11. Le Président. - La parole est à MI. Sinturel pour la lecture de $k$ on rapportsur la Bewté des Routes.

M. Sixturel. - Au même titre que les massil's forestiers les piantations en bordure de routes ajoutent à la richesse esthétique d'un pays. La monotonie d'un sol dépouillé de sites disparait devant l'ornement ef le pittoresque de longs cortèges d'arbres piqués dans la plaine. Le sentiment, inné d'ailleurs, qui nous porte en quête de la beauté, dirige toujours de préférence le touriste, le promeneur, vers ces larges avenues riches d'un cadre de verdure et où l'agrément sourd plus du spectacle offert que de l'abri ménagé. Nul ne saurait rester indifférent au charme d'une rcute qui glisse sous une ogive de feuillage et que de faibles rais de lumière, filtrant parmi les feuilles qui tremblent, éclairent timidement pour ne point en troubler le mystère et le calme. Dans le désordre des branches qui s'entrecroisent ou se frôlent, la nature du reste se pique de coquetterie à ménager à chaque pas les hasards charmants d'un art tout fait des expressions de mille physionomies diverses.

Chaque arbre, en effet, a sa physionomie, celle d'une forme vivante -qu'animent les caprices de l'heure, des saisons et des âges.

Le matin, il se dore sous les feux du soleil; la lumière du jour le montre avec toute sa puissance ou toutes les tristesses de sa végétation. Au soir, il frissonne et pendant la nuit, la bise qui arrivait muette, court dans sa ramure, s'éparpille dans les cimes voisines, agite les feuilles et reste une note de vie obstinée dans le silence toujours lugubre des campagnes endormies.

Avec chaque saison, la route ombragée retrouve encore un attrait toujours nouveau. Le printemps y charrie des parfums de fleur et des odeurs de sève. L'été, épanouissant les frondaisons, tamise la clarté d'une lumière trop crue qui tue les paysages. Aux jours d'automne, rien n'y égale le charme d'une flânerie alors que les feuilles se teintent de blond, de jaune rouille et de pourpre et tourbillonnent follement dars l'air vif qui passe. L'hiver paillette les branches de ses cristaux de givre, les enveloppe d'une toison de neige et révèle les plus délicates harmonies.

Il n'est pas jusqu'aux âges divers des plantations de routes qui n'éveillent également toute une gamme d'impressions. Les végétations qui se succèdent se distinguent à la manière d'êtres qui naissent, se développent et meurent. Chaque étape de croissance accuse leur vigueur, leurs souffrances, modifie leur parure. Et l'enfant qui les vit à leur premier effort retrouve, très tard dans sa vie à considérer ses fidèles amis vieillis à garder la route de son village, un peu des souvenirs de son passé, car "la configuration d'une chose n'est pas seulement l'image de sa nature, c'est, le 
mot de sa destinée et de son histoire". Regarder ces témoins d'un premier âge c'est éroquer toute la vie qu'ils abritèrent, toute la distance parcourue, s'attarder aux enseignements de toute une époque. Et ainsi à une harmonie naturelle, les pensées ajoutent une harmonie morale.

Une bordure d'arbres vaut encore par tout le pittoresque vivant qu'elle apporte. C'est autour de toutes les cîmes des tourbillons d'ailes menues, une vie grouillante de bestioles, des sautillements d'oiseaux, des bruits de mille chantres qui arrivent avec leurs ballades, leurs refrains, préparer leurs nids ou chercher un refuge dans les jours de tempête. Et le voyageur qui va, palpite avec ces chants, se réjouit avec cette symphonie.

Ces considérations toutes subjectives ne sont pas pour faire oublier le rôle utilitaire des plantations en bordure de route. Longtemps on a cru que ces plantations entraînaient une humidité trop considérable, nuisible à l'entretien des chaussées. Il est reconnu aujourd'hui que la présence d'arbres aide souvent, au contraire, à la viabilité des routes, notamment dans les terrains secs, en y maintenant la dose d'humidité qui permet la cohésion des matériaux. D'ailleurs, même dans les sols compacts, sous un climat humide, quelques essences donnant peu d'ombre et suffisamment espacées peuvent encore rendre d'appréciables services. Seules les parties abritées, traversées de forêts par exemple, dispensent de plantations.

L'un autre côté, des rideaux d'arbres jalonnant les routes, lors des neiges abondantes ou de brouillards intenses, servent d'abri contre les pluies et le vent, diminuent les chances d'accident dans les sites escarpés, protègent contre le soleil et la poussière.

Et par les produits qu'ils procurent ils valent encore un revenu appréciable au propriétaire. Si nous supposons, en effet, les seules routes nationales de France, soit un réseau de 38.192 kilomètres, toutes bordées d'arbres espacés de 10 mètres les uns les autres, nous obtenons * une somme de 7.638 .400 tiges correspondant, à raison de 400 pieds à l'hectare, à un peuplement normal d'une étendue de 19.096 hectares de forêt, soit près de 1/50 de la superficie totale des forêts domaniales. Et ce revenu nouveau demeure d'autant plus appréciable qu'il dérive d'un sol appelé par sa première destination à ne donner aucune rente.

Indépendamment de ces avantages se rapportant à la route elle-même, les plantations entrainent d'autres profits pour les riverains.

L'abri donné aux champs voisins contre le vent, la sécheresse, compense largement tous les inconvénients à résulter d'un envahissement par les racines, ou d'une ombre trop loin portée. Toutes les familles d'oiseaux qu'il retient aident à préserver les cultures contre les insectes, et le plus souvent prétendre à une dépréciation d'un fond parcouru par des lignes d'arbres reste une raison sans valeur, le mauvais calcul d'une routine ignorante.

Le prix du champ, la valeur de l'héritage furent d'ailleurs étảblis après acceptation de toutes servitudes, et nul ne saurait se prévaloir pour supprimer une bordure d'arbres d'un mauvais prétexte de pertes imprévues (1).

(1) A. Umbdenstock : Les arbres, parure utile des routes. 
nous résumons les règles à observer pour le elioix dis essenees et la, conditions de plantations.

$1^{0}$ Les arbres ne doivent pas gêner la eireulation; ils seront done à cimes élevées, à fùts non branchus. Les résineux, qui à l'état isolé développent des branches jusqu'à la base, seront écartés; d'ailleurs leur trop sombre feuillage laisse trop de mystère et de mélancolie.

$2^{\circ}$ Les frondaisons seront abondantes à l'effet de foumir un ombrage suffisant.

$3^{0}$ Les essences devront donner du bois de bonne qualité marehande.

$4^{\circ}$ Elles seront à eroissance rapide et très résistante aux intempéries, aux attaques d'insectes, aux blessures diverses, toutes qualités qui supposent d'ailleurs une adaptation parfaite aux conditions de sol, de climat, et d'exposition.

$5^{\circ}$ De tous les abords des agglomérations, seront enfin bannies les essences, tels que les peupliers ou les platanes dont les fruits valent certains jours une pluie de duvet ou flocons fort désagréable, même dangereuse.

D'autre part, la cireulaire du Ministère des Travaux publics du 20 avril 1897 nous renseigne sur les dispositions générales à suivre dans la technique des plantations. Ainsi, à l'exception des routes trop sèches ou se développant en pays de montagne, il convient de ne planter en bordure que celles dont la largeur de la voie est d'au moins 10 mètres. Si les routes ont plus de 16 mètres de large, deux lignes d'arbres formant contre-allée trouveront place sur un même accotement, mais l'intervalle entre ces deux rangées sera au moins de 3 mètres et les arbres devront être disposés en earré et non en quinconce pour ne pas entraver l'aceès des propriétés riveraines. Les rangées d'arbres seront parallèles à l'axe de la route. On évitera de les établir sur l'arête des fossés ou des talus ou trop près de eette arête, à l'effet de leur donmer une assiette plus solide et d'empêcher les racines de se répandre dans ces fossés et sur ces talus. "La distance d'un aubre à l'autre variera suivant le déve. loppement probable des sujets, le degré de siccité de la route et la nature des cultures des ehamps traversés ". Dans une plantation trop serrée, les branches 'et les racines s'atteignent trop vite, les arbres se génent, luttent pour la vie, et les plus faibles sueeombent.

Une même ligne ne comprendra que des espèces de nature et de régétation semblables. On ne saurait interealer des espèces à végétation lente, tels les chênes, les ormes, entre des espèces à végétation rapide (peupliers par exemple) sans placer les premières dans les plus mauvaises conditions de bonne venue. Un palliatif reste cependant à cette situation celui de disposer les espèces à végétation lente à des distances plus grandes que la normale et de leur ménager ainsi suffisamment de so! et de lumière.

Quant aux essences à employer, ce seront sous les climats non atteints par des extrêmes de température et dans tous les sols, à l'exception des sols tourbeux ou légers et trop sees, des ormes (ormes champêtres, ormes de montagne et plus spécialement la variété à larges feuilles dite de Hollande, ormes diffus); dans les sols argileux ou de consistance moyenne, des chênes (chênes pédonculés, chênes rouvres, chênes ehevelus, chênes rouges); dans les sols argilo-caleaires, argilo-siliceux ou légers et humides, des érables (érables sycomores, érables planes), des platanes (platanes d'Orient et d'Occident, magnifiques espèces d'une longévité remarquable 
et d'une croissance extrêmement rapide), des tilleuls (à grandes et $\dot{a}$ petites feuilles : tilleuls de Hollande, tilleuls argentés), des marronniers. des rernis du Japon, des robiniers faux-acacia, des peupliers (peuplier blane de Hollande, peuplier grisaille, peuplier noir pyramidal ou d'Italie. peuplier du Canada).

Jans les terrains meubles et frais, le frêne commun croitra et résistera a la violence des plus grands vents.

Le châtaignier végétera dans les terrains siliceux.

Dans les sols humides ou tourberix, on pourra employer des aulne: (aulnes glutinenx et cordiformes).

Sous les climats de montagne, les bouleanx pubescents et le sorbier des oiseleur's ne souffriront pas des plus grands froids.

Dans les régions méridionales, enfin, on plantera des mûriers, des acacias, des eucalyptus, des dattiers, des chênes tauzins, des micocouliers. des pins maritimes, des pins d'Alep.

Les plantations d'arbres fruitiers entreprises sur plusieurs points ne semblent pas encore avoir produit des résultats tellement intéressants que l'on soit porté à trop les recommander. La plantation routière d'Offenbach-sur-Nein, célèbre en Allemagne, et donnée comme modèle de culture d'espèces fruitières, reste jusqu'à ce jour une exception... (Il peut paraitre cruel de disputer aux chemineaux une récolte du chemin).

Nous ne disons rien des travanx de premier établissement et d'entretien des plantations, question d'ordre cultural d'un intérêt trop restreint dans l'étude que nous poursuivons; nous n'argumentons pas sur les suites fâcheuses l'élagages inconsidérés et sur l'horreur des "chicots ", mais dans un souei d'esthétique, nous nous arrêtons à considérer l'exploitation des arbres d'alignements.

Par une circulaire récente, M. le Ministre des Travaux Publies insiste d'ailleurs sur les conditions de cette exploitation :

"Les plantations ne seront jamais sacrifiées sur la réclamation des riverains qui se plaignent des dommages cansés aux champs voisins \#. L'intérêt général prime les intérêts privés.

Seuls devront être réalisés les arbres morts ou ceux qui, eommençant à dépérir, pourraient devenir une cause de danger's sérieux pour la circulation. On évitera de proposer l'abatage de toute une file d'arbres de même essence et de même âge, les sujets plantés à une même date u'arrivaut pas à la même heure au même état de dépérissement. "On ne saurait assimiler les plantations des routes à des exploitations forestières où l'arbre est élevé pour sa valeur marchande et abattu au moment précis où il doit être du meilleur rapport ".

Par l'observation de ces règles, un paysage pittoresque de toutes ces longues routes courant sous des masses de verdure ne lisquera plus de s'enlaidir brutalement au lendemain d'une exploitation déréglée. La hache glissera prudemment, presque honteuse. De nouveaux venus remplaceront sans retard les disparus. Et ainsi le royageur continuera à rrerer dans l'intimité de mille familles d'arbres et ne souffrira pas du spectacle d'une nature diminuée.

Lia conclusion de ce rapport nous porte ámettre le rou :

Que chaque Elat poursuive et encourage l'établissement de plantations en bordure des rontes et veille. pour des raisons d'ordre esthétique et ulitita ire. is en réglementer sévèrement l'exploitation. 
11. Ginis. - Qne pen=e\%-vons dusorbier rommun?

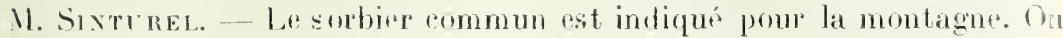
la resayé notamment dane le rentre, pròs du platean de Gergovie..

11. LE Presmext. - I a rote samvage do Ruanne à Tarares est plantro de sorbiels.

11. SINT REL. Cos usais nont pas donme de manvais resultate. Cepentdant il y a lieu do lro limiter a la montagne.

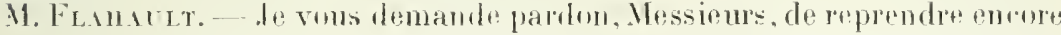
la parole an risque de vons impatienter. Jo voudrais simplement dire d̀ M. Sinturel, ainsi qu’à vous fous, que "est rnoore là une question de: géographie botaniqur.

11. LE Presinext, - Pardaitrment.

11. Flemiret. - Je me rappelle avoir vu, lorsque jallai au fond de la baltique, les boulrvards des villes de la baltique bordés de sorbier des oiselents. lotuellement, à 1.300 mètros, je plante des avenues de sorbiers des oiseleurs. Mais si je les plantais à 100 mètres plus has, ils ne pousferaient pas. alors que nous aurioms de belles avonups de chàtaigniers et, plu: bas encore. de belles avenues de peupliers. Je de ripète, rest une question dr grographie hotaniqur. Je demande en conséquence quon ne laisse pas aux agents-voyers, pas nême aux

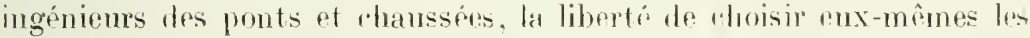
resences, mais qu'on fasse appel pour cola a des gens compétents. (.tpprobation dans lassemblée.) Chaque chosu doit être à sa place.

Je vis en plein massil forestier. Le long dime route qui est dans lo périmètre de reboisement, jo vois planter des acacias, des robinia, pseudo acacias, à me altitude wì lo: garde gónéral des forêts qui opère là - et qui a permis à lagent-voyer de faire des plantations -ait très bien que cela ne poussera pas. Cest pour cette raison que je -mis d'avis que lion ronfie res plantations à des lommes rompetents. Une rifference de 50 mètres d'altiture st extrêmement importante ut il n'y a pas un point de la France, même daus nos montagnes du midi nì on puisse utilement planter des ararias à plus de 1.000 mètres l'altiturle, et il n'y a pas, dans nos montagnes du midi, un point oi on puisse planter des sorhiers à une altitude inforrour à 1.000 mètres.

Tout reta demande à cotro iturtió de très près.

11. Manie. - Jappelle votre atention, Mesienss, sur l'utilisation, en bordure des routes, larbos à rendoment, comme les arbres liuitiers. Hs nous domnent leme omlorage ot leurs fruits. Pronons par exemple la vallés du Cósivaudan, sur la rive droite, en allaut à Grenoble

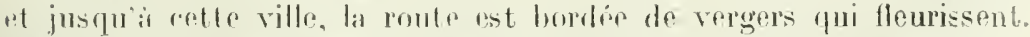

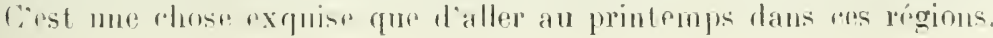


M. Sixtrefer. - Le moment critique pour les plantations fruitières est relui oủ l'on ra cueillix les fruits. Les passants cassent des branches ; au bout de peu d'années l'arbre est mort.

M. ne Villemerefil. - Je connais la route dont parle M. Maige, celle du Grésivaudan. Il me semble me souvenir que les arbres ne sont pas sur la route elle-mème? L’inconvénient des arbres fruitiers comme arbres de route, ceest d'être trop bas.

M. Mige. - Je pourrais rous eiter plusieurs routes plantées d'arbres fruitiers - sur certaines on trouve de fort beaux pommiers - qui n'ont pas souffert du tout des mauvais traitements des passants.

M. oe Villeneretil. - En Allemagne où le public est plus discipliné, la chose serait plus facile.

Ux Coxgressiste. - M. Sinturel a condamné dans son rapport tous les résineux, il en est rependant qui pourraient très bien convenir.

M. Flahaclt. - Liabies concolor vient très bien en montagne. J'en ai planté de très beaux exemplaires qui sont bien venus à 1.400 mètres. Cest un arbre qui dépasse 250 ans dans les montagnes rocheuses et qui, étant donné sa hauteur qui peut atteindre 60 mètres, a très peu de branches basses. Cet arbre atteint l’àge adulte à 150 ans. Il produit un fut très long arant de fournir des branches. En tous cas, je crois quil ne faut pas exclure les résineux. Dans le midi, par exemple, le pin d'Alep rend de très grands services.

Uy Coygressiste. - Pas sur les routes.

M. Flahaclt. - Mais si. Le pin d'Alep vient dans les endroits les plus stririles, là où on ne pourrait pas planter autre chose. On pourrait consulter arec intérêt les techniciens du pays.

J'ajoute qu'il n'y a pas d'inconvénient à ce qu'on plante des arbres fruitiers. Dans le Mirli ou l'indiscipline est ase grande, nous avons des routes nationales hordées damandiers qui donnent en janvier et en février un clarme énorme à nos routes, et au moment où les fruits múrissent, personne ne songe à les cueillir. Dans le Midi, des routes sont plantées d'arbres fruitiers depuis Napoléon III.

Ce sont des plantations complètes, sans lacunes. Ce qui prouve que si des enfants ont arraché de temps en temps une branche pour prendre les fruits, l'arbre n’a pas péri pour cela.

Ly Coxgressiste. - ( ) a dù abandonner les plantations fruitières paree que les arbres fruitiers s'étalent trop.

M. LE Présuext. - Ju roulais pricisiment attirer rotre attention

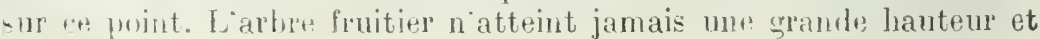


reste relativement bas. C"et un arbre dont les branches s'étalent beaucoup. Je crois qu'il est phutòt intéressant d'aroir sur les routes un arbre assez élevé d'abord, parce qu'il projette son ombre sur le milieu de la route, et puis parce que l'air circule mieux entre le sol et les premières branches. Lombre maintenue sur les routes est destructrice. Nous en avons, M. Flahault, dans le Midi, un exemple frappant dans les plantations de platanes dont les branches se réuniscent audessus de la route et sont relativement peu éle rées. Le sol, constamment à l'ombre et à l'humidité subit des modifications. Il faut de l'ombre sur la route, mais il y faut aussi une circulation d'air afin que le sol puisse sécher.

M. Hermaxs. - J'ai lu dans le rapport de II. Sinturel qu'il préeonise les plantations d'ormes. En Belgique, l'Arministration des Ponts et Chaussées proscrit absolument ces essences.

On proscrit aussi le peuplier. Ce qu il faut chercher dans une plantation routière, ce n'est pas simplement le rapport', mais, à côté de cela, la décoration, l'ormementation de la route. Au point de ve de l'esthétique, le peuplier ne me parait pas à conseiller.

Il y a un autre inconvénient. D'après l'expérience que j'en ai faite dlans les Ponts et Chaussées, le peuplier isolé lors qu'il atteint l'àge de 40 à 50 ans, - le cas n'est pas le même dans les plantations serrées a une tendance à se pencher et cela est dù à son enracintment peu profond, superficiel et non pivotant. Je suppose que c'est là la cause de cette tendance à s'infléchir. Il n'y a rien de plus lairl, le long d'une route, que ces arbres penchés, qui paraissent toujours prêts à tomber.

Quant aux ormes, nous derons aussi les proscrire à cause de leur voracité qui provoque les plaintes des riverains; leurs racines tracent en effet, beaucoup et causent un réel tort aux cultures roisines. L'Administration des Ponts et Cliaussées belge a été saisie de tant de réclamations de riverains que force a été de proscrire cette essence des plantations routières.

Ux Congressiste. - Une enquête a été faite à un moment donné dano les Vosges afin de savoir quelles essences il fallait planter le long des routes. On avait adopté, me semble-t-il, le cerisier.

M. Le Présidextt. - C'est une question de géngraphie botanique, comme nous l'a fort bien explique' M. Flahault.

Un altre Coxgressiste. - Palmi les résineux, il y a le milèze. Danles pays du Nord, dans les contrées montagneuses. le mélèze peut donner au point de vue esthétique de beaux résultats. surtout en automne, arec ses feuilles jaumes et dorées. Ciest tres beau.

On doit employer de préférence au mélèze ruropien le mélèze d. Sibérie parce que sa lige est droite alors que celle du premier est tores. La première esmere est mplogée en Ruscie. 
M. Flahalet. Theviens sur point que tous les détails quon reut bien nous donner contirment re que jai dit tout à l'heure, à savoir que tout rela se résume en une question de géographie botanique.

In th nos confrères, qui est des Vosges, nous parle du cerisier comme d'une essence très propre au reboisement dans sa région. Notre autre amfrère qui vient de prendre la parole et qui est Russe sans doute. nous a parlé lu mélèze de Sibérie, comme étant propre aux plantations routières en Russie. Qu'il me permette de faire des réserve: en c"s qui concerne le même mélèze dans nos montagnes de France. Le mélèze de Sibérie reste, chez nous, un petit arbre; mais je recommande d'une manière toute particulière le mélèze du Japon qui a plude souplese que celui de Sibérie et celui des Alpes, par exemple.

En tont cas, je crois qu il y a un point de vue auquel nous devonnons en tenir. Il s'agit d'une question de géographie pour laquelle il est essentiel que les ingénieurs des Ponts et Chauscées et les agentsvoyer's consultent les gens compétents.

Je suis né à 50 mètres de la frontière belge. Je comnais le pays et - es peupliers. Je suis d'accord avec vous pour dire que l'enracinement du peulier est trop faible; mais d'un autre côté, au bont lo 40 ans, un peuplier doit être réaliś et remplacé par un autre.

Considérons la route comme devant être esthétique. mais aussi commedevant produire. Quand vous plantez des chênes rouge: d:Amérique le long de ros routes nationales - vous voyez que je connais le sujet - vous poursuivez un but es thétique, mais rous ne négligez pas, je l'espère, la haute valeur de l'arbre. Quand vous les exploiterez, l'heure venue, rous éviterez les dommages rausós anx riverains et vous donnerezsatisfaction à tout le monde en assurant à l'administration et aux communes nu revenu résultant de cette exploitation.

M. Heruass. - Il no faut pas les remplacer trop souvent. In chêu: donne de l'ornementation pendant 50 et même 100 ans.

M. Flandet. - Il n’atteint sa pleine maturité quà làge de 150 années.

M. Henuxs. - In peuplier ornemente pendant quinze ans. II we laut pas négliger la différence au point de vue du rapport.

M. Flanacte - In peuplier en France rapporte un franc par au. Iu bout de:30 ans rela fait :30 franes. Mais rette essence ne peut ètro employé en pays humide, ainsi que tans le midi. On ne peut l'utiliser se long des canaux, ear il a linconvínient, un jour de grande tourmente, de se deraciner parfoir arre son bloe de racinps at de terre. th de faire une fissure dans la berge du eanal.

On pent remédier à est inconvinient en plantant des perupliere melanges aver d antres escuces, un peuplies sur quatre autres arbres. Tout wala est une question de doigte et llapplication au pays. Quand

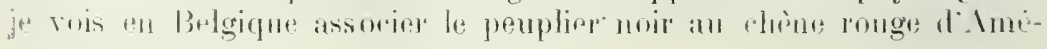


rique, je me réjouis parce que je me dis : voila des peuplier's réalin in dins 30 ans et des ehênes qui seront alors très beaux et qui ront domm immédiatement de belles tiges.

M. IIERMaxs. - Ils souffrent de la présence du pemplier qui prend le dessus. Nous sommes revenus de ce système!

II. Franult. - Oni, mais enfin ce n’est là qu'une question de loigté, de combinais on.

Lx Congressiste. - On ne remplace pas les peuplier tous ensemble; il y a un roulement à établir.

M. le Prísinext. - Nous tenons à ne pas attendre l'ombre trop Iongtemps; le peuplier pousse vite...

II. Henuas. - Le tilleul rous domerait plus vite de l'ombre que le peuplier..

M. Le Présnext, - Ce n’est pas sùr; pent-ètre en Belgique, mais pas en France; nous en revenons toujours à une question de géographie botanique.

11. Flandelt. - A Paris, au Luxembourg, les tilleuls perdent en genriral leurs feuilles à lin juin parce que l'atmosphère st trop sèehe. Dans notre Vidi les tilleuls perdent leurs feuilles dès le 15 ou le 20 juin.

11. Le Présinext. - Il y a d'abord une question de primeipe sur laquelle nous derons nous prononcer, celle de l'intérêt que présente la plantation des routes. Nous nons oceuperons ensuite du ehoir des essences; en nous arrètant plus particulièrement sur l'emploi des arbres fruitiers qui a éte jobjet d'une discussion approfondie. Enfin la proposition faito par 1I. Flahault relative à la nécessité pour les services chargés de la plantation des routes de consulter des spécialistes pour le choix des essences devra ître examinée.

Une demière question est celle de l'exploitation, sur laquelle je serais heureux d'avoir rotre avis, car notre service des routes m'a pric de vous en parler.

Nous avons justement parmi nous le representant de loffice national du tourisme. M. Lorieux, qui est en rommunication constante a vec notre ministère des travaux publics ot plus specialement aree notre direction des routes.

Il arrive souvent, Messieurs, que lorsque certains arbres d'une route commencent à hépérir, l'ingínieur qui est chargé de l'entretien de la route, técrète la coupe totale, au lieu de la restreindre anx seuls sujets atteints. Si on replantait, il n’y aurait que demi-mal, mais ce quilil y a de déplorable, és qu'après une coupe totale, on oublie presque

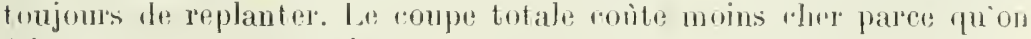
lait tont an une uperation. 
Il serait donc intéressant que nous demandions que des coupes rases ne soient jamais faites dans les plantations bordant les routes, et que les sujets soient enlevés seulement au fur et à mesure de leur dépérissement.

Nous sommes saisis de cette question par M. le Directeur des routes nationales au Ministère des Travaux Publics. Il est assailli de demandes d’ingénieur's des ponts et chaussées à qui les municipalités et les membres du Parlement, pour des raisons d'intérêt local, réclament la suppression des plantations routières.

M. Lorievx. - Je ne puis qu'appuyer votre proposition et rous dire que rous avez raison de dire que les ingénieurs sont assaillis de demandes tendant à la suppression des arbres des routes.

J'ai fait vingt ans de service dans les routes nationales. J'ai dù défendre bien des plantations contre les plaintes dont elles étaient l'objet, surtout de la part des cultivateurs en rase campagne.

En général, aux abords des villes, lor'sque les arbres ne sont pas trop rapprochés des maisons, on en accepte très bien l'ombrage et même on désire qu'on les maintienne le plus possible.

Je ne partage pas entièrement votre manière de voir au sujet des aggiesements des ingénieurs qui suppriment tous les arbres aussitôt qu' un ou deux commencent à dépérir. La plupart des ingénieurs sont, au contraire, des amis des arbres et défendent les plantations.

J'aborde le point le plus délicat de la question. Du moment qu'on a enlevé une plantation, il faut la remplacer. Je suis le premier à recomaitre que cela ne se fait pas souvent. Au fond, voici le secret de l'histoire.

11 y a malheureusement dans notre atministration deux caisses : la caise des Domaineś et la caisse des Travanx publics. La caisse des Domaines encaisse le produit de l'adjudication des arbres et c'est la caise des Travaux publics qui paye les plantations neuves. Nous nous trourons done en présence d'une caisse qui est obérée par les soins que nécessite l'entretien des chaussées; nour ne pouvons pas, dans ces conditions critiquer l'ingénieur et le conductenr qui, ayant besoin de cailloux pour réparer la route défoncée, préfèrent en acheter que l'artheter des arbres.

Jirai plus loin. Le peu de goût que temoignent certains conducteurs pour les plantations, résulte de ce fait qu'ils n'ont pas dans leur sprvice un intérèt immédiat au développement de ces plantations.

Si un trouvait le moyen d'affecter au budget des routes le produit des plantations, on intéresserait énormément le personnel. On rëeupèrerait d'un còté une somme certainement plus forte que celle qui serait nimssaire au renourellement de la plantation.

N. Le Présunent. - L'État levrait gérer son bien en bun père de famille. Il supprime son capital; il devrait bien Ie remplacer par quitlques chose et prendre sur l'argent qu'il touche la somme néces:aire 
pour remplacer les plantations supprimées. Son devoir est aussi d'intéresser les agents chargés de la surveillance des routes au bon développement des plantations.

Malheureusement il n'est pas possible de porter actuellement remède au mal signalé par M. Lorieux; car il faudrait procéder pour y remédier à une transformation profonde de l'administration et de la comptabilité publiques. Je ne crois pas quon y puisse toucher pour le moment.

Je crois que le vou de M. Sinturel répond assez à l'idée exprimée, quand il dit :

Que chaque Etat poursuive et encourage l'établissement de plantations en bordure des routes et reille, pour des ruisons d'ordre esthétique et utilitaire, à en réglementer sévèrement l'exploitation,

Je crois, en ellet, qu'une réglementation sévère empèchera la coupe totale et nous permettra de garder les sujets encore pleins de vie.

M. Flailault. - Pourquoi n'y aurait-il pas, comme en matière forestière, la contrepartie d'une exploitation? Pourquoi à la suite d'une coupe naffecterait-on pas une partie du revenu réalisé au remplacement, au renouvellement des sujets enlevés?

M. Le Président. - L'idée est juste.

Ux Coxgressiste. - C'est entendu, mais on nous a dit que ce n était pas la même caisse qui encaissait les revenus et payait les remplacements des arbres.

UN AUtre congressiste. - Qu'on impose alors une charge sur les coupes. Vous rendez une coupe à condition qu'on verse une somme déterminée pour le remplacement...

M. Le Président. - Est-ce possible en matière d exploitation de routes? il y a des règles établies contre lesquelles il est difficile de s'élever. Le service des forêts a admis le système qu'on nous propose. mais celui des routes l'arlmettra-t-il? C'est là la question délicate.

M. Lorieux. - 11 faut établir une différence entre les routes: les routes forestières dépendant d'une administration, et les routes ordinaires dépendant d'une autre. Les routes nationales dépendent du Ministère des Travaux publics, et leur exploitation dépend du Ministère des Finances.

M. Ilermaxs. - La situation dépeinte par M. Lorieux est la mème en Belgique en ce qui concerne le comblement des vides, ou plutòt elle a été la mème il y a dix ans, mais depuis cette époque, une circulaire ministrielle oblige les services intéresses à combler les vides immerdiatement. Aussin`y en a-t-il pas en Belgique dans les plantations. 
Lue circulaire ministérielle proscrit aussi tout abatage d'arbre; on $n$ abat que dans des cas tout a fait exceptionnels.

Ux Congressiste. - Pourquoi ne pas obliger l'adjudicataire de la coupe à remplacer les arbres sous la direction de l'Administration?

Ux mtre Coxgressiste. - Cela existe dans ladministration forestière.

IT. LE PrÉsidext, - Je crois que nous pouvons dès maintenant adopter le roeu présenté par M. Sinturel et qui embrasse dans son ensemble les idees émises aujould'hui. Demain je vous soumettrai unt rédaction touchant le choix des essences et le mode d'exploitation. C'est en sadressant à l'Administration des Eaux et forèts que les ingénieurs trouveront les compétences qui les dirigeront. Lidrministration pourrait établir un petit tableau indiquant les essences à employer suivant la région, le climat, les conditions atmosphériques labituelles, et nous pourrions à ce sujet nettre ntilement a contribution la science géngraphique botanique de M. Flahaull.

M. Flum Lt. - Je propose qu'on ajonte une ligne an rou dans le sens que rous indiquez. Si le Touring-('lub me charge de faire un rapport sur les possibilités de plantations dans telle ou telle riggion, je m'efforcerai de faire valoir ce que j’ai appris depuis quarante années de la Baltique au Sahara; mon travail comprendra toutes les régions de la France.

11. LE P'Rishnext. - Je vous remereic ot nous sommes tous assurés quavec votre érudition vous nous domerez des renseignements de tout premier orilre.

11. be Vilengereut. - Je roudrais ajouter une idée à celles déjà smises dans to but de compléter le vou, qui me parait indispensable, et je regrette que le Commandant Lehrum ne soit pas là pour la disruter. Je veux faire allusion à la pose des conducteurs d'électricité de toute nature le long des routes ot spécialement des faisceaux de fils de transport de force. Messieurs les ingénieurs établissent souvent ces lignes sans se préoceuper des conditions de l'esthétique. Ceux qui feront l'exeursion des Mpes en auront la preuve. Dans la vallée de l'Oisans où les transports de force sont extrèmement nombreux, il y a de véritables toiles d'araignée. Dans les rommunes de Livet et (i) Gavet, vous pourriez voir des arbres saceagés; des sycomores ont étí roupes en denx pour faire passer la ligne...

11. Le Pnésionxt. - Ces arbres sont la propriatí de l'Etat. Qu'a dit lingínieur le jour où il a constaté les régìts?

II. He Vilemerent. I Ientrée du village de livet on a coupré la 
tête des arbres pour fair passer la ligue de transport de foree. Ces abus sont intolérables. Je demande quion ajoute au vou quelques mots pour demander que des mesures soient prises contre ces agissements.

M. Le Présinext. - Votre observation sera ronsignée au procès-verbal et nous saisirons l'Administration des ponts at chaussées.

M. Delahiye. - Ne serait-il pas possible de faire pour les plantations routières ce qu'on fait pour les forèts? C'est-à-dire d'établir une alternance de deux àges dans les plantations faites en bordure de routes?

Ux Congressiste. - Ny aurait-il pas lieu d'examiner l'influence du goudronnage des routes sur la conservation des plantations?

M. Le Président. - Le gondronnage des routes se fait, dans l'ensemble, sur une petite échelle, sur des parcours très limitís.

Ladministration des Ponts et Chaussées se préoreupe de la façon la plus sérieuse de la transformation du sol de nos routes. M. Lorieux vous dira, puisqu'il est spécialement ehargé de ce service, qu'on réalise maintenant des sols de routes suflisamment durs pour qu'on n'ait pas besoin de goudronner par dessus. Ce traitement d'épiderme, si je puis dire, ne sauve pas la route et il a des inconvénients.

Votre observation, mon Cher Collègue, sera inscrite au procès-rerbal et il en sera tenu compte.

M. Flaindut. - 11 fant que les forèts vivent, que les arbres vivent, mais il faut aussi que la vie continue à évoluer. Nous sommes obligés de faire la part de l'industrie, comme aussi du gondronnage et de la viabiliti des routes. Il y a des ennemis avec lesquels il fant vivre. On crée des ennemis surtout par lintensité de la vie, et si nous n'arlmettons pas cette intensite, nous revenons aux temps barbares...

M. de Villemereetl. - Vous pourrez voir dans l'excursion de l'Oisans. sur la route no 91 , de Grenoble à Briançon, que le mal causć par les conducteurs de force était évitable et que ces conducteurs auraient parfaitement pu être posés à còté, dans des terrains vagues.

- Ux Coxgressiste. - On pourrait peut-être demandèr à Mdministration des Ponts et Chaussées de ne pas goudronner les routes aux endroits nù se trouvent de vieux arbres vénérables lignes d'être conservés.

M. LE Préstonext. - C'est un point sur lequel nous pourrons attirer l'attention de l'Adminis tration.

M. Flahact. - Les diverses observations qui ont été présentées trou- 
vent, je crois, leur réponse, dans la formule même proposée par M. Sinturel. Si on demande à l'Administration d'être sévère dans l'exploitation, on répond à toutes les objections.

M. Le Presinent. - Je partage votre manière de voir.

J'ai cru comprendre, Messieurs, qu'une opinion ne s'était pas formée sur la question des plantations d'arbres fruitiers. Certains d'entre vous ont exprimé le vœu que ces plantations se multiplient; d'autres au contraire, ont estimé que ces plantations ne valaient pas celles d'arbres forestiers. Il est nécessaire que la section se prononce sur cette question.

Je crois qu'un rapport a été présenté à la troisième Section sur la question des plantations d'arbres fruitiers; ce rapport conclut, je ne dis pas d'une manière défavorable, mais fait certaines restrictions sur l'emploi des arbres fruitiers sur les routes. Il serait nécessaire que nous connaissions les conclusions adoptées par cette Section pour que les vœux émis de part et d'autre ne soient pas en opposition.

M. MAIGe. - Je n'ai pas voulu parler tout à l'heure de l'emploi exclusif des arbres fruitiers comme plantations routières. La question est tout à fait subordonnée à des conditions de terrain, de climat, d'altitude.

M. le baron be Segonzac. - Messieurs, au Conseil général de l'Oise nous avons étudié cela très soigneusement. Chaque pays a sa manière. Dans des terrains très riches, les plantations des routes ont beaucoup d'importance pour les cultivateure. Si on y place des arbres de haute futaie, c'est autant de terrain de perdu.

M. Le Président. - Nous sommes au milieu de la route et non pas de l'autre còté. (Rires.)

M. le baron De Segonzac. - Avec des arbres de haute futaie, la route est toujours remplie d'eau et est d'un entretien difficile. Avec les arbres fruitiers, la route est toujours sèche et on a de l'ombre. C'est un avantage considérable.

Dans ma région, toutes les routes, sans exception, sont plantées de pruniers et de poiriers. Et cela rapporte trois ou quatre fois plus qu’avant.

M. Le Président. - Je vous rappelle, Messieurs, le titre du rapport de 1I. Sinturel : La Beauté de la Route...

M. le baron DE SEgonzac. - C'est bien, mais ce n'est pas tout.

M. Le Présidext. - Là doit se borner notre discussion. L arbre fruitier a sa beauté, surtout lorsqu'il est en fleurs. Quand il est chargé de fruits et qu'il n’a pas été abimé, il a son utilité. Vous parliez de l'ombre 
du piéton, mais celui qui est au milieu, le charretier, par exemple et son attelage?

M. le baron DE Segonzac. - Tous les gens qui travaillent à la campagne ne travaillent pas à l'ombre...

M. Le Président. - C'est entendu, mais quand ils peuvent avoir de l'ombre, ils la prennent.

M. Flahault. - On pourrait modifier légèrement le vœu de M. Sinturel en y indiquant qu'il est bou d'employer des essences diverses, notamment des arbres fruitiers, si les conditions voulues sont réunies.

M. Le Président. - C'est entendu.

Un Congressiste. - J'appelle votre attention sur ce fait qu'il y a parfois intérêt à ne planter des arbres que sur un côté de la route.

M. LE Président. - Votre observation sera signalée et étudiée. Messieurs, jo ne soumets pas aujourd'hui à votre approbation le vou de M. Sinturel. Nous l'adopterons demain avec les adjonctions que nous venons de décider.

La séance est levée à $4 \mathrm{~h}$. 1/4. 


\section{SEANCE DU 17 JUIN 1913}

\section{(MATIN)}

\section{Présidence de M. GHAIX, président de Section}

La séance est ouverte à dix heures.

M. LE J'résIDExt. - Messieurs, avant d'entamer la discussion du rapport de M. Beauquier sur la Beauté des Paysages, je donne la parole ¿ M. le docteur Alberto Geisser, qui l'a demandée pour nous faire une communication au nom du Touring-Club italien.

11. le doctevr Alberto Geisser, déléguŕ du Touring-Club italien.

Messieur's, au nom du Touring-tilub d'l talie, j'ai l'honneur de vous soumettre une très brève communication. Permettez-moi, tout d'abord, de faire une remarque d'ordre général : la France et l'Italie sont des pays que la nature et l'homme ont, au cours de l'histoire, le plus largement dotées de beautés ; la France et l'Italie sont, à mon sens du moins, les pays où de tout temps, les hommes ont le plus cherché à propager au-delà des frontières de leur pays les idées de force et de lumière.

L'ltalie a été le théâtre d'une civilisation trois fois millénaire; mais la France est le sol d'où sont jaillies toutes les idées généreuses que ses fils ont répandues par toute la terre; aussi tout ce que la France entreprend pour la défense de son patrimoine artistique, pour la protection de ses monuments, de ses paysages, intéresse-t-il tout particulièrement les Italiens. C'est donc a vee un très vif plaisir que nous a vons pris connaissance des rapports présentés à ia cinquième section de votre Congrès international, et notamment du rapport de M. Beauquier où l'on trouve une indication, de ce qui a été fait dans l'ordre didées qui forme le thème d'études de votre section.

Peut-être serez-vous, Hessieurs, heureux d'avoir à ce sujet des détails complémentaires : le Touring-Club italien, qui compte 110.000 sociétaires, a suivi de quelques innées le Touring-Chub de France et, suivant les traces de son aîné, il a fait tout son possible pour faire miẹx connaitre et par conséquent mieux aimer les beautés de notre pays. Toutefois le Touring-Club italien a cru devoir insister particulièrement sur le problème forestier, parce qu'il touche spécialement à l'intérêt industriel du pays, par l'aménagement des incutagnes, bois, etc., en harmonje avec ce qu'un homme d'État a appelé la conscience forestière ", c'est-à-dite la conviction raisonnée que ce problème forestier présente pour le pays un intéêt de premier ordre. Dans cet ordre d'ilées, le Touring-cilub italien a rassemblé tuus le's moyens qui permettent le tro iver ane solation da problème dans rne série de piblications analognes à celles que le Touring-Club de France a répandues, telles yue le Manuel de l'A trere pt le Manuel de l'Eau.

Hais, landis yue ces deux publications du Touring-cilub français, yui sont 
trés appréciées chez nous, s'adressent plus particulièrement à la jeunesse des écoles, les publications du Touring-Club italien s'adressent à tout le monde "n général. Ces publications ont été tirées à cent mille exemplaires et je tiens it en faire l'hommage d'un certain nombre aux nembres de la cinquième stetion.

Je me hâte maintenant de vous donner quelques indications sur la défense des monuments et des paysages en Italie. Tout d'abord on s'est préoccupé des monuments. Cela n'a pas été sans difficultó, parce que notre paýs a dî tout d'abord refaire son outillage économique et ce r'est qu'après de longtues discussions que le Parlement a sanctionné, il y a quatre ans, nu e loi pour la protection des nonuments historiques. On n'a pas inclus la protection des vaysages dans cette loi: mais comme il $y$ a aussi en Italie des difenseurs très convaincus de nos sites, je dois signaler que, dis 1905, lo Ministre de l'Instruction publique avait obtenu du Parlement une loi spéciale pour léfendre contre toute destruction la vaste forêt de Ravenne qui a jadis inspiré au Dante sun magnifique poème du Paradis. Puis, en 1910 a eté voté une loi que M. Beauquier mentionne dans son rapport, assurant la protection et la conservation des villas et jardins. Tous n'êtes pas, Messieurs, sans savoil que les villes historiques constituent un des ormements principaux dans toutes les régions d'Italie. Malheureusement, il s'est présenté en pratique des cas qui démontrent l'insuffisance de cette loi : ainsi, à liome, la villa Bonaparte, qui aurait dû être visée par cette loi, n'est pas protégée et risque de disparaître pour laisser la place à des terrains à bâtir. Aussi, le Touring-Club italien a-t-il réuni, il y a trois mois, un congrès à Milan, où sont intervenus les représentants des Ministères et du Parlement, à côté d'associations privées, telles que le "Chub-Alpin "; ce congrès a été illustré yar un discours de l'ancien Ministre de l'Instruction publique de 1905 dont je vous parlais tout à l'heure, M. Ravera; on y a élaboré tout un programme, très complexe pour la défense des paysages et des monuments historiques; je ne vous en rntretiendrai pas ici, car il se trouve imprimé en annexe à la publication que je vous ai fait remuttre. Permettez-moi seulement de terminer par un vou sincère et ardent : Le président du Touring-Club de France, dans la séance d'inanguration lu Congrès, a exprimé hier l'espoir qu'il sortirait de ce Congrès quelque chuse de durable, et il a affirmé l'union nécessaire de toutes les nations dans l'étude de la défense des intérêts de la forêt. Ion voen personnel serait qu'un Comité central international fut créé pour la défense des parsages; ce comité pourrait aroir son siège à Paris; nous avons créé des comités centraux pour la protection de la propriété littéraire et artistique, pour la protection des brevets d'invention et pour bien d'antres objets; presque tous ces comités ont actuellement leur siège à Berne. Nous pourrions organiser un bureau international analogue en retle matière : je n'ai pas à insister sur les a vantages qu'il offrirait et sur l'essor' qu'il pourrait donner en vue de mesures ultériemres pour la protection des paysages. (Vifs applaudissements).

11. LE Présnext. Jp vous remercie vivement de votre intéressante communication et jo rous cache pas qu'il miest personnellement agréable de roir que le Touring-Club italiense montre le frère ardent et zílo du Touring-Club de France (Très bien! très bien!)

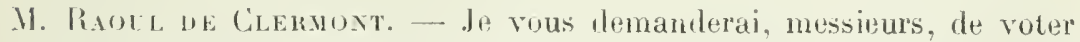
des félicitations particulières à l'Italie qui, en 1902, a ronné un bel *xemple: en effet, à rette date. les enfants des reoles de Rome ont

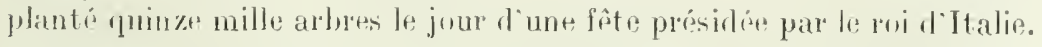

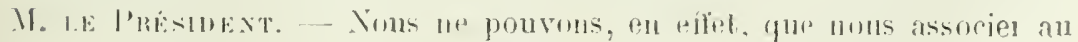


vœu formulé par M. de Clermont; tous ici, nous sommes d'accord avec lui. (Approbation unanime).

En ce qui concerne la création d'un office international, je répondrai à M. Alberto Geisser que nous avons l'intention de constituer, immédiatement après notre Congrès et comme conclusion à ses travaux, un comité central international, à l'image de celui qui a été créé après le Congrès de la route.

Nous avons encore à discuter, arant d'aborder l'étude du rapport de M. Beauquier, qui fait l'objet principal de notre séance de ce matin, le vœu émis par M. Sinturel, relatif aux plantations le long des routes et au choix des essences.

La troisième section discute sur cette même question un rapport de M. Artus, ce matin même, rapport qui est absolument défavorable à la plantation d'arbres fruitiers le long des routes; il convient de bien nous mettre daccord pour ne pas émettre ici un vœu contraire à celui qui aurait été adopté dans une autre section. Le rou de M. Artus exclut les arbres fruitiers.

J'ai demandé aux membres de la section de M. Artus pourquoi on avait prononcé cette exclusion d'une manière aussi formelle. On m`a répondu que l'emploi des arbres fruitiers pouvait, sans doute, présenter un certain intérêt, mais qu'il est une question qui doit prédominer : c'est celle du bois d'ouvre qui, petit à petit, se raréfie. Cette disparition du bois d'œurre est tout à fait inquiétante et, puisque l'État possède un territoire considérable, celui des routes, il conviendrait que ce territoire fùt, de préférence, employé à la plantation de bois d'œuvre plutôt qu'à celle d'arbres fruitiers qui ne présentent pas le même intérêt général. Telles sont les raisons pour lesquelles le rapport de M. Arthus conclut à l'exclusion des arbres fruitiers.

M. Beavquer. - On pourrait ajouter encore une raison pour justifier cette exclusion : c'est que généralement les arbres fruitiers sont mutilés par les passants et principalement par les enfants, bien que leur production soit insignifiante. tandis quil ne vient à l’idée de personne de casser des branches ou de mutiler des arbres non fruitiers.

Dans le département du Doubs on a complètement renoncé à la plantation des arbres fruitiers.

M. Le Président. - Notre section n’a pas émis un vou formel; nous arons dit que la plantation des arbres fruitiers devait être considérée comme étant du domaine de la géographie botanique; il y a dono intérèt, nous sommes bien d'accord sur ce point. à s inspirer de considérations qui peuvent varier suivant telle ou telle région.

M. FlahAUlt. - Je demande à ajouter un mot encore sur cette question. II. Artus conclut que le peuplier est un arbre national; il ne saurait convenir cependant dans tuute la région méditerranéenne. où le climat 
est trop sec; ne posons donc point de règle générale : si nous avons un terrain siliceux, plantons des chàtaigniers; si nous sommes dans le Midi, multiplions les mûriers; si nous sommes en Normandie ou en Picardie, plantons des pommiers; si ailleurs nous pourons planter des arbres de futaie, eh bien! plantons-les!

M. Le Président. - Je crois, Messieurs, qu'après ces observations nous pouvons procéder au vote sur le vou de M. Sinturel. Je vous en donne lecture :

"Que chaque État poursuive et encourage l'établissement de plantations en bordure des routes, et veille, ponr des raisons d'ordre esthétique et utilitaire, à en réglementer sésèrement la protection et l'exploitation \%.

Nous avons ajouté les mots : "la protection " à la suite de la liscussion qui s'est produite hier :

"Que pour chaque plantation, l'administration compétente soit consultée sur le choix des essences, choix qui est surtout du lomaine de la géographie botanique.

Que chaqne exploitation soit suivie, anssitót que possible, d'une nouvelle plantation ».

Je crois que ce vou résume exactement en ses trois parties toutes les idées qui ont été émises hier. Je vous propose donc de l'adopter.

Ce voeu, mis aux voix, est adopté.

M. le Président. - La parole est à M. Beatquier pour la lecture de soll rapport sur la Beauté des Paysages.

M. Beauquier. - Les arbres isolés ou réunis en massifs plus ou moins étendus constituent un des éléments essentiels de la beauté des paysages. C'est pourquoi, indépendamment de leur utilité au point de vue de l'hygiène, de l'assainissement de l'atmosphère, indépendamment de leur action régulatrice sur l'écoulement des eaux, les forêts réclament impérieusement la protection des lois.

C'est depuis quelques années seulement qu'on s'est préoccupé de sauvegarder les beautés de la nature. Il est vrai qu'autrefois elles n'étaient pas menacées aussi souvent qu'elles le sont aujourd'hui : le développement extraordinaire de l'industrie en quête de forces nouvelles, la multiplicité des routes, des voies ferrées, sont la cause principale de la destruction continue de nos sites les plus pittoresques.

Les Français, admirateurs des beaux paysages, n'ont pas été les premiers à réclamer leur conservation. Dès la fin du siècle dernier, l'Allemagne instituait un office ou bureau central, chargé d'étudier les mesures à prendre pour sauver les beautés naturelles menacées par le vandalisme industriel. Le professeur Conwentz était nommé président de ce bureau, et à l'heure actuelle, une douzaine de comités provinciaux et de districts ainsi que des comités locaux ont la mission de reiller à

Yesures prises pour la protection des paysages. 
la sauvegarde des monuments de: la natum (Naturdenkmäler). C'est le bureau central qui csl chargé de mettre en mourenent l'action gouvernementale et celle des grandes administrations lorsqu'il s'agit de prendre des mesures de protection.

De nombreuses assoeiations poursuivent le même but. Telle est par exemple l'association fondée en Saxe en 1908, sons le nom de Sarhsisten Heimatschuz.

Une loi saxonne de 1909 protège les paysages urbains et ruraux : elle interdit notammont les affiches de nature à enlaidir les rues, les squares, ote.

Le grand duché de Hesse, dès 1902, a promulgué une loi sur la protection des paysages et sur la limitation du droit d'afficher.

Tout dernièrement, la Chambre des députés de Prusse, le Landtagr (11 décembre 1912), a discuté un projet de résolution ainsi conçu : "Le Gouvernement royạl est invité à présenter un projet en vue de lá protection des monuments naturels situés sur l'étendue de la monarchie prussienne ».

Nous ajouterons qu'en Allemagne, comme en d'autres pays, on discute avec passion la création de pares nationaux à l'imitation de ceux des Etats-Unis.

En résumé, nous constaterons un mouvement d'opinion public Lrès prononcé en Allemagne en faveur de la protection de la nature.

I'Angleterre, au point de vue qui nous occupe, est demeurée fort en arrière. Cependant au cours de ces dernières années, il convient de signaler des ordonnances réglementant l'affichage et attribuant un pouvoir diserélionnaire aux autorités loeales en cette matière. Notons également certains articles de la loi de 1909 sur les habitations ouvrières, articles relatifs aux plans d'extension des villes, et oi se font remarquer de louables préoccupations esthétiques.

I. a Belgique, où l'on peut signaler un fort courant d'opinion en faveur de la protection des beautés naturelies, n'est encore entrée dans la voie des réalisations qu'en un point. Nous voulons parler de la loi récente du 12 aoút 1911 qui oblige tous les exploitants de mines ou de carrières, leurs travaux terminés, à rétablir autant que possible l'aspect du sol au moyen du reboisement.

Il convient de mentionner, également en Belgique, des circulaires ministérielles en rue de sauvegarder les vieux arbres des forêts domaniales.

En Autriche, la ville de Vienne a voté l'acquisition d'un vaste territoire de prairies et de forêts formant une ceinture esthétique et hygiénique à la capitale. Cinquante-cinq millions de franes seront consacrés à cette acquisition.

En Italie, un mouvement assez prononcé pour la protection des paysages commence à se manifester. En 1905 et 1909, diverses propositions cL projets de résolution, dans ce sens, ont été discutés à la Chambre des députés et ont abouti en 1910 au vote d'une loi assurant "la protection ct la conservation des villas, jardins et autres propriétés foncières qui se rattachent à l'histoire ou à la littérature ou qui offrent un intérêt public à raison de leur beauté naturelle particulière n.

Il semblerail que la Suisse, cet incomparable musée de chefs-d'œuvre de la Nature, dút figurer en tête de toutes les nations qui ont eu souci de protéger les beaux paysages. 
I] n'en a rien été. Ce pays des torrents, des laes, des cimes neigeuses en est encore à désirer ume législation protectrice. On n'y a guère jusqu'à présent légiléré que sur les excès d'affichage (canton de Vaud) et sur la destruction de l'édelweiss et autres plantes alpestres menacées de disparaitre. En revanche et il convient d'applaudir ì cette idée, il est question de créer en diverses régions des pares nationaux. Déjà certaines vallées saurages de l'Engadine et la monlagne du Boudry, entre le lae de Neuchâtel et le val Travers, ont reçu cette affectation qui les garantit rontre le randalisme industriel on commereial.

En Vor'ège, à part quelques réserves boisérs établies par la loi sous le nom de forêts de défense, nous ne sachions pas qu'aueun texte légal s'oppose à l'exploitation dévastatrice de la houille blanche. Cette exploitation est si intense que ce pays, un des plus pittoresques du monde, ne sera bientôt plus visité que par des marchands de bois.

La Suède, la Russie, l'Espagne, lo Porlugal, en Europe, ne paraissent pas encore s'être préocempés dr la sauvegarde de leur patrimoine national de beautés naturelles.

Pour terminer cette revue forément teourtée, des pays qui ont le snuci de conserver les beaux aspects de la Nature, nous citerons à l'étranger : les Etats-Unis dont les fameux pares nationaux sont connus dans le inonde entier; le Canada qui a promulgué des lois contre le déboisement; le Japon qui possède tonte une législation protectriee ders forêts; la Nonselle-Zélunde qui a classé el mis à l'abri des mutilatious 27.000 hectarns boisés à raison de leur beauté pittoresque...

Si nous considérons maintenant notre pays, la France, nous constatons avee satisfaction que nous sommes entrés depuis quelque temps dans un roie qui, selon toute apparence, nous conduira it une protection efficace de nos plus beaux sites

Yous devons toutefois recomnaitre que la lui que nous avons fait voter par le Parlement en 1906 et qui permet aux départements et aux communes de poursuive l'expropriation des beaux sites, des sites classés, n’a pas donné les résultats qu'on en ispérait. Les départements el les communes n'étant jas en mesure d'indemniser les propriétaires expropriés. la loi est demeurée let tre morte. Pour remérler à cette situation nous avons déposé dernièrement sur le bureau de la Chambre une nouvelle proposition de loi complétant la première et frappant d'une servitude tous les sites classés par la Commission départrmentale qu'a instituée la loi de 1906.

Comme conséquence de l'exposé que nous renons de faire de la législation élrangère en matière de protection des paysages, le: Congrès, estimant que la France ne doit pas rester en arrière d'autres pays, úmet les roux suivants :

1. Que lu législation. sur les occupalions lemporaires soi modifiée duns le sens d'une proposition de loi dẹà déposée en 1909. loi d'uprès laquelle uncune-occupation temporaire ne pourra ctre aulorises anx ensirons des siles el paysages classés, dans un périmiètre qui sera fixé dans chaqne département par la commission des siles.

11. Que toul reploitunt qui modifiera laspere visible du sol seru lenu, anssilôl ses truvuni acherés, wh si possible à mesure do lenr achèement, de. 
réparer le dommage causé à la beauté du site, notamment cn faisant les plantations nécessaires pour couvrir d'un manteau de verdure les excavations, déblais on remblais résultant des travaux.

III. Que tant an point de vne de la beanté que de l'hyoiène, dans un rayon de 80 kilomètres autour de Paris, dans les forêts de l'Etat, de nombrenses réserves artistiques soient établies auxquelles sera imposé un régime d'aménagement spécial; les commissions des sites détermineront l'emplacement de ces réserves.

IV. Que les commissions départementales des sites (loi de 1906) soient toujours consultées sur tout projet de déboisement ou de travaux publics, routes, chemins de fer, cananx, etc.

Y. Que la Caisse pour l'achat des paysages forestiers et autres, votée par la Chambre dans sa dernière session, soit largement dotée par l'Etat.

VI. Que les plus beanx paysages de France soient déclarés réserves nationales et mis ainsi à l'abri de toute mutilation.

VII. Qu une légistation uniforme sur les cours d'eau du domaine public et privé ne permette aucune emprise sur les eaux, sans l'autorisation expresse du. Gouvernement et après avis de la Commission des sites des départements intéressés.

1I. le commandant AcDEBRaxd s'élève contre la mention faite dans ce rapport d'une proposition de Loi qui frapperait d'une servitude tous les sites classés par la Commission départementale instituée par la Loi de 1906 .

I. Coliet-DAige proteste à son tour contre pareille atteinte à la propriété privée.

Il ne faut pas parler, dit-il, de servitude et d'obligation de conserver à des gens qui sont propriétaires chez eux. Nous sommes les premiers narrés quand nous sommez obligés de couper des arbres; je représente des propriétaires forestiers qui payent cent pour cent d'impôts ; jai moi-même payé en dix ans 9.200 francs alors qu'il n’est pas tombé dans ma poche plus de 2.400 franes nets. Je n'admets pas qu'on emploie le mot de servitude et qu'on empêche les propriétaires d'être maîtres chez eux. (Applaudissements.)

M. Le Présidext. - Je répondrai quaucun rou ne rous est soumis sur la question soulevée. M. Beauquier vous dira lui-même que dans le rapport qu'il avait présenté en première ligne, il n’avait pas hésité à émettre un rou sur ce point : mais nous avons estimé qu'un tel vœu dépassait la limite de ce que le Touring-Club devait soumettre au Congrès, parce que nous considérions, comme M. le commandant Audebrand, qu'il y avait danger, au point de vue du droit de propriété que nous entendons respecter, à entrer dans la voie préconisée par notre rapporteur. C'est alors que, d'accord avec nous, M. Beauquier a modifié la rédaction des voux qu`il rous présente, tout en mainte- 
nant les termes de son exposé. Par conséquent, le vœu que vous voterez, en lui-même, ne touche en rien au droit de propriété.

M. Flahault. - Je prends la liberté de demander à M. le Rapporteur une petite explication au sujet de trois lignes seulement de son rapport: "Il semblerait, dit-il, que la Suisse, cet incomparable musée de chefsd'œuvre de la Nature, dût figurer en tête de toutes les nations qui ont eu souci de protéger les beaux paysages. 11 n'en a rien été..."

M. Beavquier. - Je ne sache pas que, dans la législation suisse, il y ait une loi qui protège les paysages.

M. Frainult. - Il n’y a pas de lois fédírales, mais il existe des lois cantonales.

M. Beavquier. - Je ne displpas que la Suisse se refuse à protéger les paysages, je dis qu'étant donné sa richesse, elle n'a pas fait ce qu'elle aurait dû faire.

M. Flahatlt. - Je suis un des membres les plus actifs de la "Société suisse de protection de la nature ") et nous sommes arrivés à soustraire deux mille kilomètres carrés à toute exploitation; c'est quelque chose dans un petit pays comme la Suisse que d'arracher à toute espèce de ravages une telle étendue de terrains, - y compris les ravages de la chasse, - et ce, avec le seul appui de lois cantonales; car la Suisse est une fédération de petites républiques, la Confédération n'a pas à intervenir par une loi. C'est ce qui m’a été dit, voici deux ans, dans une réunion où je fus admis, - réunion à laquelle ascistaient 40 forestiers autrichiens. Mais si la Confédération ne saurait intervenir, les cantons, au contraire, ne méconnaissent pas leur devoir, et quand on voit un canton de montagnards, un canton démocratique comme celui des Grisons abandonner les bénéfices de ses pàturages pendant une durée de cent ans, avec promesse de vente définitive au bout de ces cents années, quand on voit un canton tout entier intervenir par des lois pour protéger des vallées entières, on ne saurait dire que la Suisse n'a rien fait. Une telle initiative, au contraire, mérite d'être placée en toute première ligne.

M. Beavquer. - Jesuis très heureux de vos explicatione et je reconnais très volontiers que j’avais été mal reenseigné.

M. Flahault. - Je serais reconnaissant au Congrès, si le rapport de M. Beauquier était réimprimé, de vouloir bien signaler les efforts de la "Société suisse de protection de la nuture " ainsi que ceux de la "Société helvétique des sciences naturelles". I a Suisse est un pays qui a la bonne fortune de ne pas posséder d'acarlemies (rires), pardonnezmoi cette sortie.

Cette "Société helvétique des sciences nnturelles ", dès la promiòre 
année deson existence, a su trouver cent mille francs pour réaliser ses rues et nous arons acheté, - non pas définitivement, mais pour cent ans, - des propriétés sur ce capital qui nous a été ainsi attribué.

11. Le Présloext. - Je crois, Messieur's, que nous pouvons clore la discussion générale (Assentiment.)

Nous allons maintenant prendre les voux un à un et ouvrir la diseussion sur chacun.

1I. Brtaxi demande l'adoption d'un vœu supplémentaire ayant pour' objet de modifier la Loi du 19 juillet 1906 relative à l'abaissement les pénalités en matière forestière.

II. LE Présinent. - Ivez-vous formulé votre voll?

II. Brtaxd. - Je l'ai ainsi rédigé :

"Que les modifications apporties par la loi du 19 juillet 1906, en ce qui concerne les pénalités édictées par le Code forestier, soient rapportées ».

Le vou de M. Bruand, mis aux voix, est adopté.

M. Le Président. - Nous abordons le premier des voux présentés par M. Beauquier.

J'en donne lecture:

"Que la législation sur les occupations temporaires soit modifiée dans le sens d'une proposition de Loi déjù déposée en 1909, loi d'après laquelle ancune occupation temporaire ne pourra être autorisée aux environs des sites et paysages classés, dans un périmètre qui sera fixé dans chaque département par la Commission des sites ».

M. Colmet-DaAge. - Qu'entend-on par occupation temporaire?

M. Beavquier. - C'est le droit conféré à tout entrepreneur de travaux de s'installer dans une propriété privée pour extraire les matériaux qui lui sont nécessaires : ainsi un entrepreneur pourra s'installer dans une forêt, si cela lui convient; il pourra couper les arbres, faire des trous pour extraire la pierre, puis s'en aller en laissant ces trous énormes et horribles.

M. LORIEUx. - Je suis d'accord avec vous, mais il y a des intérêts qui sont en jeu st qu'il convient de ménager. Sous cette forme un peu impérieuse, le vœu me paraît dangereux. Il faut des matériaux pour faire nos travaux; l'intérêt public est en jeu. Je comprendrai qu'on consultàt une Commission compétente sur l'ocrupation temporaire, mais de là à dire qu'aucune occupation temporaire ne pourra être autorisée dans un périmètre fixé par la Commission des sites, il y a une marge. 
INTERNATIONAL 1913

M. le Président. - Ce ri est pas la Commission qui donne l'autorisation ; elle fournit un avis au préfet.

M. Lorieux. - Une Commission des sites sera toujours dis posée à classer tout son territoire.

M. Le Président. - On pourrait peut-être rédiger ainsi le vou : " dans un périmètre qui sera proposé à l'approbation dn Préfet par la Commission. des sites."

M. Lorieux. - Parfaitement.

M. BeAuquier. - La même observation pouruait alors être faite à propos du classement : le public croit que lorsque la Commission des sites a classé un paysage, celui-ci est définitivement classé ; c'est une erreur ; elle se borne simplement à proposer le classement : c'est toujours l'Administration qui classe.

M. Berr ie Turique. - C'est le Ministère des Beaux-Irts qui classp.

M. Le Président. - Il faudra que la proposition de la Commission temporaire s'applique à un terrain qui sera aux environs de sites classés : voilà qui restreint déjà l'influence de la Commission, parce que des sites, des paysages classés, il n'y en a pas partout, et étant donné les difficultés de ces classements, je ne crois pas qu'ils puissent s'étendre rapidement; il y a donc là une première restriction à l'ingínrence de la Commission de classement. De plus, si nous disons que le périmètre sera proposé par la Commission des sites à l'Administration, nous plaçons cette Commission dans son véritable ròle qui est celui d'un Comité consultatif, et l'Administration verra si elle doit admettre la proposition.

M. le commandant Audebrand. - Ne craignez-vous pas que, lorsque quelqu'un se sera vu une première fois refuser une autorisation, cela ne crée un précédent fâcheux et qu'un autre entrepreneur ne se voie systématiquement refuser toute demande d'occupation temporaire?

M. Le Président. - Nous sommes un Congrès de protection des paysages pour défendre la nature contre toute exploitation outrancière. L'Administration qui aura l'avis de la Commission des sites pourra apprécier si cet avis est sérieux.

M. le commandant AUdebrand. - C'est entendu pour une première demande; mais cela ne va-t-il pas, ipso facto, créer un précédent pour une demande ultérieure?

M. Le Présidentr. - Non, car l'avis s'applique pour un cas d'espèce.

M. le commandant Audebrand. - Nous sommes d'accord. 
M. Le Président. - S'il n'y a pas d'autre obsərvation, je vous propose, Messieurs, d'adopter ce vœu.

Le vou, mis aux voix, est adopté.

M. Le Président. - Je passe au vou no 2 :

"Que tout exploitant qui modifiera l'aspect visible du sol sera tenu, aussitôt ses travaux achevés, et si possible, à mesure de leur achèvement, de réparer le dommage causé à la beauté du site, notamment en faisant les plantations nécessaires pour couvrir d'un manteau de verdure les excavations, déblais ou remblais résultant des travanx».

M. Beauquier. - Ce rou implique l'obligation pour n'importe quel exploitant, pour n'importe quelle occupation temporaire - et que le site soit classé ou non, qu'il se trouve ou non dans un périmètre de site classé, - il implique, dis-je, l'obligation pour n'importe quel entrepreneur qui aura modifié l'aspect du sol d'une façon désagréable au point de vue du paysage, de réparer le dommage fait à sa beauté, comme on répare un accroc fait à une robe.

Je parle là de l'accroc fait à la robe verte de la nature : gazon ou forêt!

Vous vous êtes rendu compte, au cours de vos royages, de l'aspect désagréable de ces plaies, de ces taches, de ces accrocs au flanc des montagnes...

M. Gabiat. - De ces éventrements !

M. Beauquer. - Le carrier qui vient de faire un trou pour l'exploitation du sable s’en va et laisse à la nature le soin de réparer le désastre. Cela peut durer longtemps, alors qu'en jetant quelques graines ou en faisant des plantations, il pourrait souvent hàter la réparation.

Dans un récent article, paru dans le journal la Nature, M. Martel s'occupe de cette question et formule des observations très intéressantes. Je me permettrai de rous lire quelques lignes seulement de son article, parce qu'elles viennent précisément à l'appui du vœu que je soumets en ce moment à votre approbation.

Voici ce qu'écrit M. Martel :

"En dépit de tous réglements et circulaires administratifs, les travaux sont presque toujours commencés avant l'achèvement des enquètes, et quand celles ci sont défavorables, on se trouve en présence du fait accompli, du barrage édifié, du viaduc construit, du remblai achevé, de la montagne éventrée, du cours d'cau asséché !

"Il est trop tard! le forfait est perpétré !

Aux entrepreneurs surtout on laisse trop d'initiative et d'indépendance, principalement quand il s'agit de se procurer des matériaux à l'usage des remblais et soutenements; alors ils n ont nul soucid'enlaidir un paysage par l'ouverture, à portée commode pour eux, d'une carrière ou d'une tranchée qui pourrait, avec plus de discernement, ètre exécutée à une autre place ". 
M. Colmet-Dahge et M. le commandant Atdebraxd consentent bien à accepter le vœu de M. Beauquier, mais sous condition qu'il soit complété par une formule réservant le droit de propriété.

Le vœu ainsi complété, mis aux roix, est adopté :

"Que tout exploitant qui modifiera l'aspect visible du sol sera tenu, aussitôt ses travaux achevés, et si possible à mesure de leur achèvement, de réparer le dommage causé à la beauté du site, sans qu'il soit porté atteinte à son droit de propriété, notamment en faisant les plantations nécessaires pour convrir d'un mantean de verdure les excavations, déblais ou remblais résultant des travaux ».

M. Le Président. - M. Beauquier s'oppose à l'addition qui a été votée avee le vœu; nous ne pouvons, naturellement, qu'enregistrer sa protestation.

Nous arrivons au vou $n^{0} 3$ dont roici le texte :

"Que tant an point de vue de la beauté que de l'hygiène, dans un rayon de 80 kilomètres autour de Paris, dans les forêts de l'Etat, de nombreuses réserves artistiques soient établies auxquelles sera imposé 1 n régime d'aménagement spécial; les Commissions des sites détermineront l'emplacement de ces réser'es ».

La parole est à M. Bruand.

M. Bruand. - Je trouve le rayon de 80 kilomètres beaucoup trop court, surtout avec la facilité actuelle des moyens de communication; la population parisienne, de nos jours, n'hésite pas à s'éloigner de la capitale et à excursionner dans un rayon de 90 et 100 kilomètres : il me suffira de citer la forêt de Compiègne qui est distante de Paris de 84 kilomètres, où les Parisiens font cependant de fréquentes excursions.

On pourrait done, sans inconvénient, augmenter le rayon et le porter, par exemple à 100 kilomètres.

J'ai une seconde proposition à présenter : je roudrais qu' on ajoutât,

- à la suite du vou, les mots :

" et qu’à l'avenir, tontes propositions quels qu'en soient les auteurs, tendant à restreindre l'étendue de ces forêts soient absolument écartées ».

Dans ma pratique forestière jai été témoin de choses extraordinaires : c'est en vain que les pouvoirs publics proclament la nécessité de maintenir intégralement notre admirable domaine forestier; toujours au lendemain d'une semblable déclaration, un accroc formidable au principe est donné. En voulez-vous un exemple? Prenez la forêt de Saint-Germain; je l'ai vue successivement sillonnée par deux voies de chemins de fer, deux lignes pour le camp, encombrée d'un champ de tir, d'un champ de courses, et par-dessus tout, réduite de 400 hectares, à Achères, pour l'installation d'un champ d'épandage dont on a fait un centre pestilentiel! Les forestiers ont eu beau lutter, ils ont 
¿́té abandonnés par leurs chefs. Et le plus souvent le déboisement s'est produit pour satisfaire des intérêts tout à fait mesquins : c'est ainsi que l'ancienne Compagnie de l'Ouest a fait sa ligne de chemin de fer uniquement pour faire concurrence aux voituriers de MaisonsLaffitte et profitel" du trafic.

Au champ de tir de cette dernière localité, une cause de perte énorme réside dans ce fait que nombre de balles qui manquent les cibles vont occasionner des dégàts considérables en forêt; quand on fait des coupes à cet endroit, à tout instant on troure des arbres mutilés par les balles.

Le champ d'épandage dont je parlais tout à l'heure est, dans cet ordre d'idées, un exemple rraiment homérique : là, les ingénieurs ont éridemment induit en erreur les populations. Il conviendrait que les grands corps de l'Etat ne perdissent jamais de rue l’intérêt général en semblable matière.

M. Le Présinent. - Le Ministre a parlé hier de cette question et il crée en ce moment-ci une Commission pour indiquer les emplacements de toutes les réserves artistiques.

II. BrunxD. - I'aj entendu bien des paroles de ministres dans ma carrière et jaai toujours constaté qu’à la suite des beaux discours que j’avais applaudis, une influence quelconque était venue faire apporter une dérogation au principe affirmé la veille.

1I. Le Président. - Quand le Ministre peut se retrancher derrière une Commission officielle, il est beaucoup plus fort.

11. BRUху1. - Vous connaissez peut-ètre le fait qui s'est produit, il y a quelques années, à Embrun : un enfant de cette localité, qui avait fait fortune à Marseille, léguait ses biens à sa ville natale...

II. Le Présinent. - C'est l'histoire de la forêt de Gadarache.

11. Britnd. - Vous la connaissez! alors, je n’insiste pas.

M. Le Présunent. - Nous avous suivi, au Touring-Club, cette question de très près et nous sommes intervenus, très heureusement et avec succès. Nous connaissons par conséquent toute l'histoire de cette forèt qui ne pouvait entrer dans le clomaine national d'Embrun qu'à la condition d'en sortir.

11. BRuAND. - Eh bien! je suis très heureux que le Touring-Club ait réussi dans son intervention, car c'est moi qui avais attaché le grelot.

M. Le Président. - Vous royez que le résultat a été très beau.

M. DE. Clenxont. - Je voudrais vous proposer comme conclusion à notre discussion, ladoption' d'un vou qui a dójà ité adopté par le 
"Congrès de l'Alliance thygiène sociule ", qui s"est tenu à Roubaix en octobre 1911, vou qui concerne cette même question. Il est ainsi r’élligé :

"Le Congrès insite $\mathrm{M}$. C'harles Benuquier a ajonter it su proposition de loi tendunt ir créer des réserves nutionules boisées en vur de lhygiène et de la conservation de la beauté des sites un article étendant le bénéfice de l'aménugement forestier spécial hygiénique ot psthétique it tons les départements.

"Il insite le Parlement à soter dorgence rette proposition ainsi modifiée m.

II. Le P'résinext. - C'est dans l'esprit du Ministre actuel : il veut créer dans l'ensemble de la France une série de réserves artistiques qui seront soumises à un régime spérial d'exploitation. C’est le but ip la Commission dont le Ministre a parlé hier.

Je crois que nous serons ilaccord avee. II. Beanquier ; il ne demande qu'une chose : cost qu'on multiplie les réserves artistiques et la meilleure preuve, e'est que son veu no 6 dit ceci :

"Que les plus beunx prysuges de France soient déclurés réserves nationales et mis ainsi it labri de tonte mutilation ".

Pour revenir à la proposition de M. Bruand sur laquelle nous n’ avons pas encore statué, je vous demanderai de supprimer purenent et simplement la phrase: "dans un rayon de so filomitres antour de J'aris ".

M. Hicket. - Je voudrais demander à M. Beauquier ve que dans sa pensée, signifient les mots "aménagement spécial".

11. Le Présninext. - Cost un aménagement pour lis friserves altistiques.

11. Hickel. - M. Flahault vous expliquerait aver beauroup plus dt: talent que moi que les coupes sont une succession détats diffirents. dans la vie de la forêt. Prenez le train te Paris a Versailles. vous rencontrerez, après des portions le bois à l'aspert morne et triste. du fait de l'épais tapis de feuilles mortes qu'on loule aux pieds, de véritables rhamps de digitales que les promeneu's sont lienreux de rapporter à pleines brassées.

Je crois done que toute modification à laminagement artuel de res forêts irait à lencontre de l'esthrique et des drisirs, probablement inconscients des promencurs. Je n’ai janass orcupi liuspretion de Versailles, mais je puis vous dire cependant quavant mème que lidministration prescrivit la róserve des arbres remartuabless. les inspertenrs ont toujours lien rempli leur dexom.

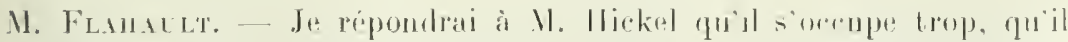
sinquiete trep surtout de la valeur de res mots " amemagement spés- 
cial s et en lui disant cela. je pense à Fontainebleau. Quand il aura vécu aussi longtemps que moi, il comprendra quen quarante ans de vie de naturaliste on peut voir le sens d'un substant if et d'un adjectif se modifier profondément. Heureusement pour nous, M. l'inspecteur Bruand ou .I. I'inspecteur X... ou Y... n'interprèteront peut-être pas l'aménagement de la même manière. de sorte qu'ils aideront la nature à recouvrer ses droits et par là même. feront.ce que nous souhaitons.

M. de Clermont. - En ce qui concerne les environs de Paris, jestime qu'il n'y a qu'à maintenir le statı quo, parce que personne, mieux que l'Administration des forêts et la Conservation de Paris, ne saurait apporter plus de soins à l'esthétique des forêts.

M. Beatquier. - La "Société pour lu protection des paysages » comprend un grand nombre de forestiers, notamment le Directeur général des Eaux et Forêts, qui marche toujours d'accord arec nous. Nous sommes heureux de lui rendre hommage.

M. Le Président. - De toutes les obserrations qui précèdent, il ressort que nous sommes tous d'accord; par conséquent je n'ai plus qu’à vous proposer l'adoption du vou dont je vais vous donner une nouvelle lecture, en le complétant par l'addition proposée par M. Bruand, en supprimant d'autre part la phrase relative au rayon de 80 kilomètres autour de Paris ainsi que la partie finale relative aux Commissions des sites, puisque, comme je rous le disais tout à l'heure, ce sera la Commission instituée par le Ministre qui aura à déterminer l'emplacement des réserves.

Voici ce rœu :

"Que tant an point de sue de la beanté que de l'hygiène, dans les forêts de l'Etat, de nombrenses réserves artistiques soient établies auxquelles sera imposé un régime d’aménagement spéciul. et qu’à lavenir toutes propositions quels qu'en soient les unteurs, tendant à restreindre l'étendue de ces forêts soient absolument écartées».

Ce roeu, mis aux roix, est adopté.

M. Le Présidext. - Je donne lecture du rœu no 4 :

"Que les Commissions départementales des sites (Loi du 21 avril 1906) soient toujours consultées sur tout projet de déboisement on de travaux publics, routes, chemins de fer. canaux. etc.".

M. Colmet-DaAge. - Il faudrait mettre: "en matière de travanx publics" et non pas "ou de travaux publics". Ciest absolument différent.

II. de Cleruoxt. - Je demanderai qu'on ajoute après les mots : "les Commissions des sites " ceux-ci "réunies à la Commission départementale d'hygiene ». Ces denx Commissions s’éclaireront l'une l'autre. 
M. Le Président. - Je ne rerrai pas, quant à moi, d'inconvénient à cette addition.

M. DE Segonzac. - La question est assez sérieuse. On nous dit : " en France, il ne faut pas déboiser \%. Celà est vrai ; mais c'est là une charge nouvelle qu'on impose aux propriétaires, charge très lourde et dans ces conditions nous, les propriét iires fonciers, nous estimons que si on veut nous obliger à garder les forêts, il faut nous indemniser.

M. Le Président. - Le principe de l'indemnité a été discuté dans une autre section.

M. Beauquier. - D'ailleur's, on ne demande qu'un avis.

M. Le Président. - Vous en tiendrez compte ou non.

M. Beauquier. - On n'entrave en rien votre liberté : on fera simplement appel à vos sentiments artistiques, le cas échéant.

M. Le Président. - La Commission émettra un avis qui n'aura qu'une valeur purement morale.

Il est arrivé que, sur des observations présentées, soit par le préfet au nom de la Commission, suit par certains organismes d'Etat, on a pu enrayer certains défrichements fàcheux.

M. Beauquier. - Très souvent, quand la Commission écrit à un propriétaire qui veut déboiser et fait appel à ses sentiments artistiques, celui-ci consent à ne pas couper ses bois. Laissez-nous donc cette ressource d'agir moralement.

M. Le Président. - Si ce vou portait un préjudice queleonque au droit de propriété nous ne vous l'aurions pas présenté.

M. DE Segonzac. - Je ne le vois pas comme vous. J'estime que si vous laissez passer le petit cloigt dans l'engrenage, la tête et tout le corps y passeront ensuite.

Un Congressiste. - Je suis d'avis qu'il convient d'éviter autant que possible l'intervention de l'Etat. (Marques nombreuses d'approbation.) Il n'a absolument rien à voir, ni dans les sites, ni dans les paysages.

M. Beauquier. - Il ne s'agit pas de l'Etat, mais d'une Commission départementale élue.

M. Flahault. - Il me semble que nous mettrions le vou en harmonie avec l'opinion rqui parait dominer chez un certain nombre de congressistes qui partagent l'avis de M. de Segonzac, en mettant tout simplement, comme le propose M. Colmet-Daâge "en matière de travaux publics ». En réalité, la propriété privée est protégée par d'autres articles de lois; il s’agit ici d'un cas spécial. 
1. Vax de Poll. Je représente ici le Touring-Club de Hollande. Permettez-moi de vous dire que nous avons, dans notre pays, organisé des Sociétés qui se sont donné pour mission d'acheter des sites pour les préserver des dangers qui peuvent les menacer. Nous avions tout d'abord songé à faire intervenir l'Etat, mais celui-ci n'a rien fait. Heureusement le Touring-Club s'est adonné à cette tâche et il a réussi a faire racheter des sites intéressants. Nous avons depuis longtemps des Sociétés pour la préservation des monuments de la nature, analogues aux "Naturdenkmäler " qui existent en Allemagne. L'une de ces Sociétés pour la préservation des monuments de la nature a racheté un lac, ou plutôt une espèce de marais aux environs d'Amsterdam, qu'on avait voulu combler pour y mettre les déblais de la ville. Ce marais présente un intérêt esthétique par sa forme curieuse; nous l'avons done acheté ainsi qu'un bois immense, - le bois de Haguenau, pour un million de florins. C'est un bois qui se trouve entre le diluvium et l'alluvium.

Je terminerai par cette remarque que chez nous on pratique la politique de la porte ouverte en ce sens que tout le monde peut voir les belles propriétés, alors que celles-ci en France sont, la plupart lu temps, entourées de clôtures qui ne permettent pas d'en contempler la beauté.

Ne croiriez-vous pas qu'il y aurait pour vous un intérêt à constituer des Sociétés analogues à celles dont je viens de vous parler et qui, en Hollande, emploient l'argent qu'elles recueillent sans donner d'intérêt.

M. Le Président. - C'est très difficile à réaliser : on peut cepundant trouver de ce côté des concours précieux.

¿n Congressiste. - Ces bois rapportent; si vous les faites améllager par un forestier qui connaisse son métier, vous pouvez en tirer, pour la Société tout au moins, la rente qui l'aidera en partie dans la tâche qu'elle a entreprise.

M. Le Président. - Nous avons en France des Sociétés commp celle des "Amis de l'Arbre " qui ont fait beaucoup de bien.

Le Même Congressiste. - Ce que je voudrais simplement, e'est qu'au lieu de faire intervenir l'Etat, on s'adressât à ces Sociétés.

M. le Président. - On peut avoir les efforts réunis des particuliers et de l'Etat et à ce point de vue, le Touring-Club a tracé la voie; il a exercé son action sur les pouvoirs publics en même temps que sur les particuliers. Nous serions très heureux de voir des Soriétés spéciales se créer dans les différentes régions.

M. De Clermont. - Au sujet des observations présentées par M. le délégué du Touring-Club de Hollande, je dois signaler qu'un nouvel article du code bernois et un autre du code zurichois commissionnent 
des Sociétés particulières pour la protection des sites et pour la protection des forêts, lorsqu'elles offrent des garanties suffisantes.

M. Le Président. - Je mets aux voix, car je crois que personne n'a plus d'observations à présenter sur cette question, le voeu no 4 modifié dans le sens qui a été indiqué tout à l'heure par M. Colmet-Daâge et M. Flahault.

Voici la rédaction que nous vous proposons :

“Que les Commissions départementales des sites, -.. Loi de 1906 soient toujours consultées en matière de travaux publics, sur tout projet de déboisement, de travaux, routes, chemins de fer, canaux. etc. ").

Ce vou est adopté.

M. Le Président. - Vœu no 5.

"Que la Caisse pour l'achat des paysages forestiers et autres, v'itee par la Chambre dans sa dernière session, soit largement dotée par l'Etat ».

Ce vœu, mis aux voix, est adopte.

M. Le Présidext. - Vœu no 6.

"Que les plus beaux paysages de France soient déclarés réserves nationales et mis ainsi à l'abri de toute mutilation ».

Nous sommes tous d'accord sur cette question. Le jour où l'on clas sera, il faudra bien indemniser; on ne peut classer que moyennant indemnité.

Ce vœu, mis aux roix, est adopté.

M. Le Présidext. - Voiri notre dęrnier vœu :

"Qu'une législation uniforme sur les cours d'eau. du domaine public et privé ne permette aucune emprise sur les eunx sans l'autorisation expresse du gouvernement et après avis do la Commission des sites des départements intéressés ».

La parole est à Il. Beauquier.

M. Beatquert. - Ce vou soulève, Messieur', une très grosses question. Il s'agit de l'utilisation des cours d'eau non navigables ni flottables.

Il y a déjà, sur ce point, une Loi de 1898 qui décide qu'en matière d'utilisation des cour's d'eau, l'autorisation de l'Etat est nécessaire. Il y a quatre ou rinq ans une grande Comnission a été nommée pour étudier le régime des eaux; elle comprenait des ingénienr's en grande quantité et toutes les sommités de l'Administration.

J'avais demandé à en faire partie, malgré mon incompétence, pour présenter un article relatif à la protection des paysages. A l'unanimité, mon article a été adopté : l'autorisation du gonvernement deve- 
nait nécessaire en cas d'utilisation des eaux, soit au point de vue de l'irrigation, soit au point de vue de l'alimentation, soit au point de vue de la protection des paysages. Cette Commission, après avoir tenu de longues séances, n'a pas abouti.

Le Ministre en a reconstitué une nouvelle où il m'a appelé à collaborer. Naturellement je me propose de faire prévaloir mes idées pour introduire dans la Loi la protection des paysages. Je suis sûr, étant donné les sentiments dont le Ministre est animé et qu'il a manifestés hier, que ma proposition passera puisqu'elle a passé déjà au sein d'une Commission composée en majorité d’ingénieurs.

Nous pourrions émettre sur cette question le vou que je vous présente; certainement son adoption aurait une grande valeur.

M. le Président. - Vous avez demandé que la question fût soumise au Congrès puisque vous en avez fait l'objet d'un vœu de votre rapport. Il est naturel que la section qui en est saisie discute ce vœu et émette une opinion pour pouvoir dire si elle admet ce vou ou si elle le repousse.

La discussion est done ouverte.

M. le commandant Audebraxd. - Cette question est extrêmement grave et, comme la plupart des questions qui ont été soulevées aujourd'hui, elle s'étend beaucoup plus loin que la protection des paysagés Elle touche à une richesse nouvelle en France : l'industrie de la houille blanche. Si vous voulez bien me le permettre, je reprendrai la question ab ovo.

Une loi de 1898 a réglé un certain nombre de points litigieux au sujet des cours d'eau qui ne sont ni navigables ni flottables.

Il y a, au point de rue légal, deux catégories de cours deau : ceux qui ne sont ni navigables ni flottables et où l'eau est res nullius, et les cours d'eau navigables et flottables.

Sur les premiers on peut statuer par voie d'autorisation administrative, suivant une procédure compliquée; sur les seconds, on peut avoir des concessions toujours révocables ad nutum.

L'Etat octroie la permission d'installer une usine à grands frais ; sans donner aucune compensation, il peut vous obliger à partir.

Si j'ai bien compris votre idée, il serait question, à l'heure actuelle, d'étendre ce régime des cours d'eau navigables à la généralité des cours d'eau et vous légitimeriez cette mainmise générale sur nos rivières par des considérations d'esthétique.

Prenez garde! Réfléchissez bien ! c’est là une mesure très grave : c'est une dépossession presque complète et la rupture de contrats en cours à l'heure actuelle; c'est une expropriation générale de notre richesse. A l'heure actuelle, nous sommes obligés d'importer tous les ans environ un tiers de la houille qui est nécessaire à notre industrie, car nous n'extrayons pas de notre sol la totalité de combustible dont nous avons besoin ; nous sommes donc, dans la lutte économique, à ce 
point de vue, dans un état d'infériorité; mais il se trouve que, grâce au cours d'eau, nous pourons lutter économiquement avec les autres nations; ce n’est donc pas le moment de nous déposséder de tout ce que nous avons. La rais on esthétique que vous invoquez est certainement très respectable ; mais il est très difficile aussi de définir les limites de l'esthétique en pareille matière.

M. Beauquier. - L'Etat, la collectivité sera juge de l'autorisation à donner ou à refuser. Evidemment, il résèrvera sou autorisation pour les beaux sites. Par exemple, voici la source de la Loue dont l'expropriation est poursuivie devant le Sénat après avoir été admise à la 'Chambre : nous avons demandé que l'Etat achète la source de la Loue pour empêcher une emprise sur ce site admirable; il est évident que si la loi autorisant l'Etat à empêcher l'usinier de s'établir à cet endroit avait été votée, il n'aurait pas donné cette autorisation.

Nous demandons que, dans un beau site, un industriel ne puisse avoir le droit de changer complètement l'aspect du paysage sans l'autorisation du gouvernement. Qu'il place son usine ailleurs!

M. le commandant AUdeBrand. - Il ne le peut pas.

M. Beauquier. - Eh bien ! je prétends qu'il y a dans la conservation de ce beau site un intérêt général supérieur à l'intérèt de cet industriel.

M. le commandant Audebrand. - Très bien pour la source de la Loue! Là, l'Etat est dans son droit, mais je vais vous dire comme M. de Segonzac tout à l'heure : quand on met le petit doigt dans l'engrenage, tout le corps passe. Demain une autre personne trouvera une chute d'eau aussi esthétique que la Loue et alors, nouvelle interdiction? Où s'arrêtera-t-on alors dans cette voie?

M. Beavquier. - Mais tant mieux ! si ces cours d'eau sont intéressants à ce point! c'est ce que nous demandons.

M. Flahault. - J'insiste avec M. le commandant Audebrand sur les raisons qu'il a fait valoir pour défendre les cours d'eau non navigables.

Cette question touche de très près à celles qui ont été posées tout à l'heure par M. de Segonzac; elle touche aux intérêts sacrés de la propriété que je ne place pas au-dessus de l'intérêt général, mais qui peuvent s'exercer in minimis, sans attendre les décisions de l'Etat.

M. Beauquier. - Il ne s'agit que des beaux paysages.

M. Tribot-Laspière. - Il ne faut pas confondre les deux questions : domaine public et domaine privé. Dans le domaine privé, au point de vue esthétique, l'Etat n'a rien à faire; autant il a le droit dc légiférer pour le domaine public, autant il doit s'abstenir pour le domaine privé. Sous prétexte d'esthétique, ce sera une intervention permanente. 
NI. DE SEgoxzac. - J'ai le regrat, à mon tour, de ne pas ètre d'accord avec. II. Beauquier. Evidemment, il est animé, je le sais. des meilleures intentions, et si nous n'avions affaire qu’à lui, cela irait tout seul. Mais il sagit de demandes qui peurent se multiplier sur tout le territoire et dans toute la France surgiront mille petites tracasseries continuelles.

Si, à chaque prise d'eau, il faut s"inquiéter le savoir si le site est phus ou moins esthétique, nous n"en finirons pas; "ela durera deux ans, trois ans. quatre ans. Je suis bien convaincu, je le répète, quavec 11. Beauquier, cela irait tout seul, mais il ne se rond pas compte de l'ennui considérable qu'il nous occasionnerait aver sa proposition.

Ux Congressiste. - Dautant plus qu'il est extrêmenent difficile de Ionner un rritérium de l'esthétique d'un site.

M. he Présinext. - 11 ñy a qu’un moyen ! est le classement !

M. Tribot-Laspière. - Je vous demande la permission d'élever un peu le débat et de vous indiquer pourquoi à mon sens, il convient de repousser ce vou : c’est que le premier devoir d'un gourernement est de favoriser l'aménagement des chutes d'eau, parce que toute la puissance que nous pouvons en tirer se traduira par des iconomies pour l'industrie : il ne faut pas oublier, en effet, qu'à l'heure actuelle, nous importons pour 470 millions de francs de houlle : ce n'est done pas le moment de compliquer les formalités pour lachat d'mn rours d'eau quelconque.

M. Le Présibext. - Il faut tirer le maximum de rendement de la houille blanche.

N. Tribot-Laspière. - Il faut se pénétrer de cette idée que tous ces cours d'eau représentent de l'argent et qu'il serait très dangereux daugnenter les formalités, si nombreuses déjà, 'qui détourneraient l'industrie de leur utilisation.

M. uE Seguxzic. - II randrait mieux certainement que M. Beauquier retiràt son yœu.

M. MAIGE. - Ce n'est pas mon avis. Je ne erois pas ru'il faille retirer le roeu; sans doute les cours d'eau sont pour l'industrie une grande source de richesse; mais la beauté des sites est également une cause de. profits pour toute une région. Nous devons défendre les montagnes ut empercher l'installation d'usines dans tel ou tel endroit dont la beautí attire une foule de touristes et d'étrangers. 11. le rapporteur a donc ité très bien inspiré en tenant compte de cet íment principal: "l'esthétique " que "ertains industriels affectent de par trop négliger.

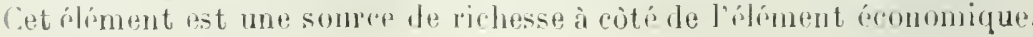


11. 'Tunot-1, spiène. - Mais cela rapporte-t-il les 5010 millione quo nous ronte l'ntilisation incomplète de nos cours d'rau?

11. Nalge. - Je vous citerai le cas d'un petit village, où rien ne se serait fait, où les gens étaient flans la misère et y seraient restés ioute leur existence si le "Club-Alpin " et le "Syndicat dinitiatice de Saroie. n’en avaient révélé les beautés naturelles. Dès lors, les touristes sont arrivés et tous ces malheureux ont pu se donner un peu do hien-être; ils ont vu petit à petit s'accoitre leurs ressources; eh bien! jamais $u$ industriel ne serait venu là.

Nous ne devons done pas repousser le vou de M. Beanquier, rar il tient compte de l’intérêt gínéral re la France et c’est re qui nous guide quand nous demandons que soit conservée la beauté d'un paysagt:

II. Framult. Je ne mopposerai pas à ce que le voeu soit adoptí en tant que rou ; mais it me semble qu'il y aurait lieu, si . II. Beanquier y consentait, le supprimer ces deux mots : "et privé " de façon à ne laisser subsister le vou qur pour les cours d'eau du domaine public. Ainsi disparaitraient toutes les difficultés, toutes les tracasseries auxquelles on a fait allusion.

11. Le Présinext. - Si vous supprimez les mots "et privée " vous retonlbez dans la situation actuelle. Arec la législation présente, vous ètes toujours oblige de lemander une autorisation en ce qui concerne les eaux du domaine public ; et comme le disait très hien M. le commanrlant Audebrand, cette autorisation est révocable "ad nutum ". Le vou ne fait que consacrer la situation actuelle si nous supprimons ces deux mots "el pris'é » et par conséquent il n'offre plus d'intérêt.

M. Loneux. - Il y a un mot qui, peut-pitre, effraye les membres de cotte section : e'est l'expression "législation uniforme". 11 me parait difficile, en effet. d'associer dans une mème législation des comrs d'eau si différents: il est évident que le petit torrent des Alpes ne saurait jouer le même rôle que tel autre cours d'ean, au débit calme et lent. Il conviendrait donc de tronver une formule qui ne consarre pas rette injustice. Voilà un premier point. 11 en est un autre : j’ai entendu dire tout à l'heure que les cours d’eau non navigables n’étaient pas sou. la tutelle rb gouremenent. Il y a là une erreur : on ne peut rien fare sur nu cours d'eau sans l'intervention du gouvernement, qui se manifeste, non pas par laction ministérielle, du moins par celle de la préfecture. C’est déjà une garantie considérable : on ne peut, par exemple, atablir de barrage sans autorisation; il y a là pour lo public une garantie sérieuse.

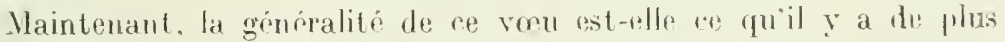
inquiétant? Comme l'a dit 11. Beauquier - et il a mille fois raison. il faut défendre les beaux sites ; par conséquent, si le voen do Il. lirauruier vous semble un pen large, il ronvient de rechercher me formule 
qui concilie les opinions qui se sont fait jour; cela ne parait pas impossible.

M. LE Présidext. - M. Lorieux vous invite à trouver une formule qui donnerait satisfaction à le fois au désir de M. Beauquier de conserver les sites si particulièrement beaux de nos montagnes et le désir des industriels qui veulent jouir d'une liberté suffisante pour pouvoir exploiter. Cette idée est dans l'esprit de tout le monde. Il nous faut done chercher une rédaction moins large que celle de 11. Beauquier qui affirme une espèce d'emprise du gouvernement sur tous les cours d'eau de France. Nous ne pouvons pas improviser un texte; il est nécessaire de rédiger une formule qui serait soumise au vote de la section. Quelqu'un a-t-il un texte à présenter?

M. de Clemiont. - Nous pourrions nous mettre d'accord et restreindre la généralité du voeu en l'appliquant uniquement aux sites qui ont été proposés pour le elassement par la Commission instituée par la Loi de 1906.

M. Le Présidext. - Nous sommes, après cette longue discussion, plus éclairés sur les idées respectives qui ont toutes été nettement émises. Etes-vous d'avis de clore la rliscussion et de mettre aux roix le texte de M. Beauquier, étant entendu que, s'il est repoussé, nous nous réservons de vous proposer un texte transactionnel? (Adhésion.)

Sous la réserve que je viens d'indiquer. je mets done aux voix le texte du vœu de M. Beauquier tel qu'il vous en a été donné lecture.

Ce texte n'est pas adopté.

M. Le Président. - Il convient maintenant de trouver un texte transactionnel.

11. Gabiat. - Voici la rédaction que je proposerai : au terme «législation uniforme" substituer les mots "législation appropriée " et terminer le vœu après les mots "emprise sur les eaux " par ceux-ci : "dans les sites proposés pour le classement".

M. Tribot-LAspière. - Et si les sites ne sont pas proposés dans un délai acceptable? Quand une Commission est en jeu, sa décision peut se faire attendre plusieurs années. Pendant ce temps, l'industrie attend.

M. Le Présidext. - Sils ne le sont pas, vous avez votre liberté.

II. Tribot-Laspière. - Comment seront limités les sites à protéger? C'est un nouvel élément d"incertitude.

II. Gibiat. - Ce sera une question d'espèce et de fait.

M. Le Présidext. - Cette rédaction nous permet de ménager, je crois, 
les intérêts en présence : je comprends très bien que vous défendiez avec énergie des intérêts personnels qui sont aussi des intérêts nationaux, cela est indiscutable, mais vous comprendrez aussi que le Touring-Club défende les intérêts du tourisme et s'efforce d'aménager et de protéger la montagne.

J'estime que la proposition nouvelle qui nous est faite peut ménager tous ces intérêts. Par conséquent, je vous demande, Messieurs, de vouloir bien voter la proposition transactionnelle de M. Gabiat, dont je vais vous donner lecture :

"Qu'une législation appropriée sur les cours d'eau du domaine public et privé ne permette aucune emprise sur les eaux dans les sites proposés pour le classement $»$.

$\mathrm{Ce}$ vou, mis aux voix, est adopté.

La séance est levée à 12 h. 1/4. 


\title{
SEANCE DU 18 JUIN 1913
}

\author{
(MATIN) \\ Présidence de M. CHAIX, président de Section
}

La serance ast wuverte it 9 h. 14

M. le Présinext. - Messieurs, arant daborder la discussion des trois rapports inscrits ce matin à notre ordre du jour, je vais vous donner lecture d'une communication qui m'a été transmise par .H. Horter, représentant de la Commission départementale des sites et monuments naturels de caractère artistique des Basses-P'yrénées. Cette communication traite dr l'IfFICHIGE DANS LES FORÊTS. - MEscres A PRENHRE.

A l'uccasion de la mise en application de la loi du 12 juillet 1912, relative à la publicité par panneaux léclame, les commissions départementales des Sites et Monuments raturels de caractère artistique, ont été consultées sur diverses questions. Leur examen et la discussion ont amené l'une d'elles à émetire un vou qui a été transmis à M. le sous-secrétaire d'État des BeauxArts et a II. le llinistre de l'Agriculture.

La commission avait été frappée dn silence du Code forestier relativement à la publicité en général, silence qui favorise les abus de la réclame, alors que celle-ci pourrait ètre lacilement interdite dans le plus grand nombre de nos sites pittoresques, soumis pour la plupart an régime forestier.

Arisce, an cours de la mème séance de la réunion du Congrès, la Commission en y souscrivant, a compté sur l'un de ses membres pour' reprendre ce vou, le présenter et proposer au Congrès forestier international, d'en soutenir le principe, dans la forme qui paraîtra préférable.

Le Congrès, examinunt les inesures à prendre pour la protection des proysrages au point de sue de l'affichage, observe que le Code forestier est mupt relativement à la publirité dans les forêts soumises à son régime. Il eimet le veu que les ponvoirs compétents étudient et poursuivent l'insertion Inns le Code forestier d'un article additionnel réglementant l'affichage et la publicité dnus toute l'étendue des régions soumises an régime forestier.

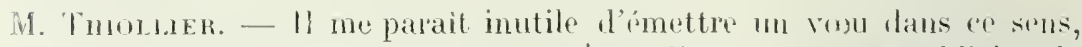
stant domin que nous sommes maitres d'écarter toute publiciti de Jus forêts. Si des abus se produisaient, nous pomprons demander à

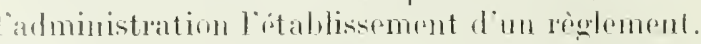

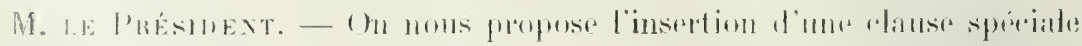


dans le Code forestier, ce qui empêcherait, en eflet, les abus: 11its c'est au Parlement seul qu'il appartient de compléter le Code forestier.

M. Drpucn. - Nos codes ont pour utilité de poser de grands principes. Si vous y insériez des dispositions de tétail, peut-être les résultats excéderaient-ils ros désirs!

M. Le Présidentr. - Nous demanderons que le Ministrir venille bien rappeler aux chefs de service, par circulaire, quon ne doit tolerer ancun affichage abusif dans l'étendue du domaine forestier.

si vous acceptez l’ilće émise, nous présenterons votre temande au Ministre et nous la considérerons comme un vaun.

Ir même, au point de vue international, le Congrès pout ímettre dans ce sens m veu qui sera transmis par chacun des représentants les pays étranger's à son administraltion forestière nationale.

M. Vax ne Pol.t. - En Hollande, nous nien avons pas; mais nous sommes tont disposés à nous associer ì toutes les mesures destinces à empêcher l'affichage dans les forêts.

M. le Président. - Nous pourrions modifier le texte de la faron suirante:

"LE Concirès,

"Examinant les mesures à prendre pour la protection des paysages, all point de vue de l'affichage,

"ËVET LE VEU que les pouvoirs compétents étudient et poursuivent l'application de dispositions interdisant l'affichage et la publicité dans tonte l'étendue des régions soumises an régime forestier. „)

Le virll, mis au voix, est adopté.

M. Le Président. - La parole est à M. Oupuen. purr la lecture de son rapport sur la Bentté Des Col'ss D’ext.

II. Dupuich. - L'arbre sur la montagne, c'est l'ean dans la rivière. Tout ce qu'un rideau de sveltes peupliers ou de saules trapus ajoute à la rivière de grâce et de beauté, il n'est pas besoin de le díre; cela se voit, cela se sent. Ce qu'on sait moins ou ce qu'on oublie, e'est que l'existence des bois est pour les cours d'eau plus qu'un charme, une primiordiale nécessité. Non pas seulement parce que l'arbre proche consolide les berges et combat l'évaporation de la nappe liquirle, mais parce que la forêt, si lointaine qu'elle soit, travaille, depuis la source du fleuve, ¿t en alimenter et à en régulariser le cours.

Quand, en 1827, on jugea nécessairo de doter la France d'un Code forestier, le gouvernement, par la plume rle $\mathbf{H}$. de Martignac, écrivait un tête de son exposé des motifs : Ce n’est pas seulement par les richesses qu'offre l'exploitation des forêts qu'il faut juger de leur utilité: leur existence même est un bienfait inappréciable pour les pays qui les possrident. soit 
qu'elles protègent et alimentent les sources et les rivières, soit qu'elles soutiennent et raffernissent le sol des montagnes \%. On ne peut mieux marquer l'intime lien qui fait des "eaux et forêts " un tout harmonieux. "L'eau vient de l'arbre, dit Onésime Reclus, et l'arbre vient de l'eau."

L'eau vient de l'arbre.

La rivière, dit-on, naît de la source. Mais qu'est-ce que la source? Rien qu'un relai dans le cycle ininterrompu que la goutte d'eau parcourt éternellement. Par la source, la terre rend l'eau qu'elle a reçue du ciel. La souree, e'est l'épargne de la pluie, de la pluie qui serait du bien perdu si la terre n'en avait fait provision et réserve. Qu'un orage, soudain et violent, éclate au-dessus d'un sol dénudé : il se forme cent petits torrents fous qui s'égarent et se dispersent et qui sèchent en peu d'instants. Mais si la pluie tombée longuement, doucement, trouve pour la recueillir cette éponge d'humus que l'arbre entretient par les débris de ses feuilles mortes, voilà les gouttes de pluie qui s'infiltrent dans ce sol perméable ; à travers mille canaux souterrains, elles se glissent dans les sables, s'effondrent dans les failles, et s'en vont former, au hasard du sous-sol, un réservoir caché qui, à son affleurement, devient source.

Or, qu'est-ce qui fait l'ondée longue et douce, au lieu de l'averse brusque et brutale? C'est la forêt, dont l'influence régulatrice est décisive sur le régime des pluies. "Les principaux effets du déboisement, disait M. Legrand, ancien Directeur général de l'Administration des Eaux et Forêts sont une violence plus grande et plus instantanée des pluies et des vents et le tarissement des sources ". Donc, si l'on veut ménager des sources, il faut préserver les forêts.

Eparpillée par les branches et les feuilles, l'ondée s'égoutte lentement ; le bois pleure eneore longtemps après qu'il ne pleut plus. Humée par les racines pour gagner les ramures, une part de l'eau tombée retourne à l'atmosphère et l'imprègne d'une humidité que le premier fraîchissement va condenser et résoudre en une ondée nouvelle. Humée par les gazons et s'instillant en terre, le trop plein des gouttes s'en va reeonstituer les réserves souterraines.

I'arbre a fait la pluie ; la pluie a fait la source; la source a fait le ruisseau, et la rivière fille du ruisseau, et le fleuve fils de la rivière. Tous les fleuves, toutes les rivières, comptent parmi leurs sources toutes les fontaines dont ils boivent les eaux; un fleuve n'a pas une source, il en a des milliers ( 0 . Reclus), et les milliers de sourees, ce sont les millions d'arbres, qui les font.

Si l'eau vient de l'arbre, elle ne vient pas que de l'arbre. Tel fleuve, comme la Seine, a des sources pluviales; tel autre, comme le Rhône, a des sources glaciaires. Au soleil de l'été, la fonte des glaciers et la fonte des neiges déversent d'énormes masses d'eau dans les vallées alpines. Rivières bienfaisantes ou torrents redoutables? Richesse ou fléau? C'est de l'arbre que cela dépend pour beaucoup. Il y a plus d'un demisiècle que Surrel en a fait l'éclatante démonstration. Ingénieur chargé de dompter dans les Alpes les torrents et les avalanches, e'est l'art du forestier qu'il a appelé à son secours, en proclamant ce principe devenu axiome: "La végétation est le meilleur moyen de défense contre les torrents $n$.

Aussi haut que l'arbre puisse vivre, établir des barrages pour entraver les éboulements; reboiser ce sol encore meuble et ineonsistant, mais qui, d'année en année, prendra plus d'assiette, ear c'est un fait d'expé- 
rience que l'arbre consolide les versants les plus escarpés; par ce fourré forestier, étreindre les torrenticules avant qu'ils aient pu se grouper en torrents; canaliser l'eau folle en ruisselets d'eau sage, pour l'empêcher de se ruer en avalanche liquide; voilà la manouvre au bout de laquelle est la victoire, et dont l'arbre est le pivot.

En attendre la disparition complète et définitive de tous les méfaits des torrents, on n'y saurait songer car il faut toujours compter avec les colères de la nature ; mais e'est raison que d'appeler la nature à l'aide contre elle-même, pour discipliner ses furies, provoquées trop souvent par les imprudents déboisements de l'homme. "Sans doute, la neige continuera chaque année de charger les sommets; sans doute, elle fondra en été, mais sa masse rompue ne ferait pas de torrents si l'antique forêt qui était là eût été respectée, si la hache avait eraint de détruire la barrière vivante qu'ont si longtemps honorée nos aieux" (Michelet).

Or, en assagissant ainsi les sources neigeuses et glaciaires, on ne protège pas seulement les flanes de la montagne, e'est la vallée et ensuite la plaine qui vont trouver là le salut, car ce sont les torrents, rongeurs des hautes terres, qui font, dans le plat pays, les fleures torrentiels, les fleuves ensablés, les fleuves inondants. Privé de la consolidation forestière, le sol montagneux s'effrite en détritus qui, lentement mais sans répit, glissent jusqu'au lit des cours d'eau et l'obstruent. Et alors, pour peu que survienne un excès de pluviosité, l'afflux liquide ne trouve plus entre les rives du fleuve un canal suffisant pour le contenir et le g'uider à la mer ; c'est le débordement, l'inondation et la dévastation pour la campagne. On ne saurait dire combien, en entretenant ses forêts, le montagnard des Cévennes épargnerait de désastres, cent cinquante lieues plus loin, aux riverains de la Loire angevine:

Ainsi, de quelque point de vue qu'on la regarde, là réservoir, ici barrage, la forêt apparaît toujours indispensable à la rivière. C'est encore Onésime Reclus qui l'a dit, dans sa prose de poète: "L'eau et l'arbre sont deux époux, dont le divorce est la calamité suprême».

\section{Le Congrès É Met I.E VEU :}

Que les pouvoirs publics votent des crédits suffisants pour permettre à l'Administration forestière de pousser plus activement ses trasanx de reboisement.

Que, partout oì cela sera reconnu nécessaire et possible, l'Administration forestière, en dehors des périmètres de reboisement, encourage les propriètaires de terrains en montagne, communes, collectivités ou simples particuliers à faire des plantations sur ces terrains en vue d'éviter l'envasement des rivières et d'assurer la limpidité de leurs eaux.

M. Le Présidext. - Le rapport de M. Dupuich est remarquable. Vous avez pu constater aver quelle élégance et quel charme ce travail a été établi. Le foml est aussi intéressant que la forme, et je ne doute pas que rous arepptiez les propusitions de notre collègue à qui vous serez l'avis, je pense, d'allessipl nos plus sincères félicitations Très bien! Très bien!)

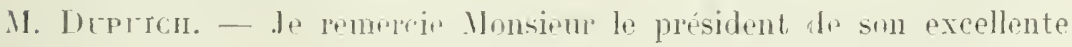




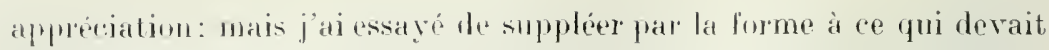
manquer at fond.

Vous arez pu rinir, par lo titre de mon rapport, "Beauté des Cour's d'ean " L'arbre sur la montagne. c'est l'eau dans la rivière » qu'en somme, ce travait se rapportait très ilirectement à une question terehnique, celle du reboisement, qui est etudiée dans le plus grand letail à la quatrième section. sur le programme de laquelle nous 1'avons pas à empirter.

Le Comitr a pensé qu'il y avait ntilité à ce que rette question lît discutée aussi à la cinquième section. Si le torrent est quetrue chose de drivasteur, c'est anssi quelque chose de terriblement laid, au point de vue absolu; et nous qui umos preoreupons du côti tompistique, Hous semmes tout naturellement portés a emettre des vorux tendant a la suppression de tout ce qui peut angmenter la laideur du paysage of an developpement de tout re qui peut en développer la beanté.

11 uous a parn que ar que mons penvions faire surtout, r'était de steconder, en temps que touristes. les flesirs des techniciens, en émettant le rour rue leurs ellorts en vur du reboisement des montagnes, fussent comronnes de succès et appurís par la Gouvernement.

Tol est le voru qu'en ronsépuence je vous propose d'adopter :

"Que les poncoirs pullies cotent des rededits suffisunts pour permettre

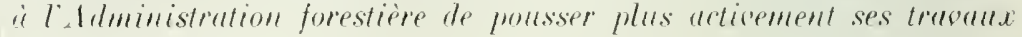
de reboisement.

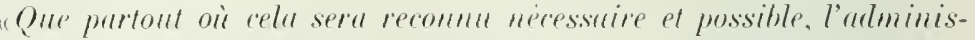
lintion forestiere, en dehors des périmètres de rehoisement, encourage les proprictuires de lerruins en montugnes, communes, collectivités ou simples purtiontiers a fuire des pluntutions sur ces terruins en

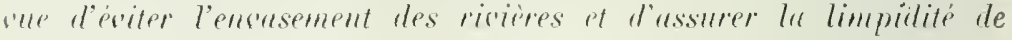
leurs e(turit).

Vous vorez qu'il y a derux puints dans le veru: d’aborl que l’Ardministration fasse, dans la mesure le ses ressources, le nécessaire pour whises, et que, d'autre part, etle promage le plus possible ceux qui ne sont pas de I Idministration is suive son exemple.

Le voru so termine par quelques mots rappelant qüil s'agit l'óviter lenvasement des rivières ot la limpidite de leurs caux. Il se pattaede. ainsi à la question générale du regime des raux.

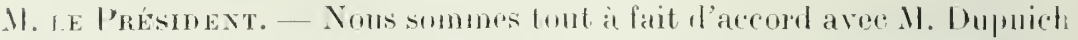
sur la dernière plurase du texte qu'il nums propose. Si nous pivitons fenvasement des livières, nons amrons parrí all ravinement de la montagne, puisque rest par la protertion du haut que nous assurerons la liberti du bas. Dès lors, les caux u'blant phus chargées de matières roui les mondent opaques of ípaisses, l'mvasement ne se produira jlis.

Ir rolis la premiere partio du vonu. 


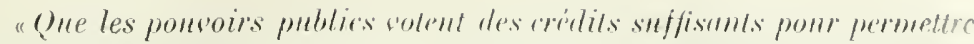
"l'Administration foresticre de pousser plns acticement ses truvun de reboisement.

"Qne, partout où cela seru reconnu nécessatre et possible, l' I dministrution forestière, en dehors des périmètres de poloisement, enconrage les propriélaires de terrnins en montagne, rommunes, collectivités ou simples parliculiers a faire des plantations sur ces terrains, on vne

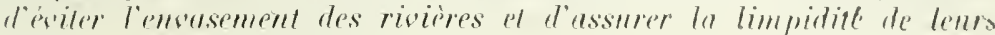
eanx."

11. Ir comte Clary. - Ce vou a un caractère nniquenent national. La question est de savoir si, en notre qualiti do Congrès international, noms devons le génópaliser.

11. Inplacur. - C'est l'esprit même du Congrès. Tous les vorux, sauf clanse contraire, doivent être interpretés dans un sens international.

M. I. l'résurext. - II ist ívident que toutes les opinions qui sont émises ici prennent toujours un pen le caractère national, fitant donné les connaissances particulières des persomues qui les exprosent, en ce sens fu'on parte de ce qu'on romnail te mienx, des exemples quon a eus sums les reux a parfois de l'ouvre qu'on a arcomplie personuellement; mais il est bim entendu cur nous attribuons i l'ensemble de nos propositions un alactère international. Il no s'agit pas ici de laire th particularisme.

J.r vou, mis aux roix, est adoptr.

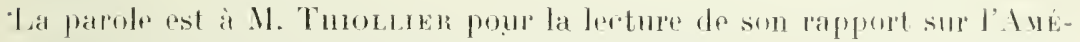
NAGEMEXT DE FORETS EX VUE DI TOIRISUE.

M. Thiollier. - Ce n'est point à un Congrès comme celui-ci qu'il est nécessaire de démontrer l'importance du ròle esthétique de la forêt. Aucun parmi nous ne l'ignore et nous avons tous, à maintes reprises, étudié les moyens de concilier les exigences du propriétaire de la forêt considérée comme "usine à bois " et les désirs du promeneur ou de l'artiste.

On ne peut nier que les agents des Eaux et Forêts tiennent le plus souvent compte de ce point de vue dans la gestion dı domaine qui leur est confié ; plusieurs sont même passés maîtres dans cet art, mais il reste beaucoup à faire et il n'est pas inutile de préciser les desiderata des touristes en forêt.

Viabilité. - Pour qu'un massif boisé rende les services esthétiques et hygiéniques que l'on attend de lui, il faut d'abord qu'il soit accessible et percé de bonnes routes. Le trafic sur les routes forestières est très irrégnlier ̀̀ cause de la mobilité des exploitations, mais il atteint aux environs des coupes une intensité très grande et les chaussées ont à supporter parfois des poids extrêmement forts. Seul le cylindraģe mécanique peut leur douner la résistance suffisante.

Sur les plateaux du Jura où la pierpe est mauvaise, l'eau rare, et où les 
énormes sapins sont extraits sans tronçonnage, donnant parfois par essieu des charges de 10 tonnes, des routes empierrées au rouleau à vapeur ont vu, malgré ces conditions déplorables, leur viabilité devenir presque parfaite.

On peut donc, sans hésiter, demander que le cylindrage mécanique soit appliqué partout aux principales voies de vidange des forêts.

La dépense est un peu plus élevée que par les procédés anciens, mais elle est largement compensée par la plus-value des bois et il suffit d'augmenter légèrement les sommes mises en charge sur les coupes en les portant, par exemple, à $5 \%$ de la valeur des produits ligneux.

Sentiers. - La viabilité des grandes voies assurée, il faut faciliter au touriste l'accès des points de vue, sources, arbres ou groupes d'arbres remarquables.

Toutes ces curiosités sont connues du personnel forestier, mais il en garde parfois trop jalousement la jouissance pour lui-même et on ne saurait trop lui recommander d'ouvrir, s'il y a lieu, des sentiers pour les touristes et de les jalonner par de plaques indicatrices.

Le tracé de ces sentiers est une opération très délicate mais fort intéressante pour qui a quelque sentiment artistique; en plaine, on devra étudier soigneusement les parcelles à traverser et faire passer le sentier auprès de toutes les curiosités que 'l'on rencontrera; en recherchant les groupes de beaux arbres et même les arbres isolés de forme artistique, les rochers, etc., ou donnera au sentier un intérêt bien plus grand.

En montagne, la question est encore bien plus compliquée, mais un chemin bien tracé avec des pentes convenables est une œuvre dont l'intérêt ne devrait jamais être perdu de vue par les administrateurs du domaine forestier.

Conservation des arbres remarquables. - Il faut enfin que l'Administration non seulement autorise les forestiers à créer ou conserver des arbres ou groupes d'arbres remarquables, mais même le leur prescrive.

Il n'est, en effet, pas possible de créer des séries artistiques dans toutes les futaies qui offrent des vieux massifs de belle allure, mais la conservation d'un arbre remarquable, ou mieux d'un groupe d'arbres, ne diminue pas la production ligneuse d'une façon sensible et constitue pour les touristes et les artistes un attrait réel.

De même, pourquoi ne pas transformer, dans l'insipide taillis sous futaie, les sommières et les lignes en allées et sentiers ombragés par une ligne ininterrompue de réserves.

Les carrefours, eux aussi, devraient être à ce point de vue particulièrement soignés : on doit les entourer d'un cercle de beaux arbres, mais le diamètre de ce cercle doit être assez grand pour que les véhicules modernes puissent voir à temps les croisements des routes.

Facilités de parcours. - L'Etat réduit au minimum les entraves apportées à la circulation des promeneurs en forêt, il ne peut eependant toujours sacrifier les gros. revenus que lui procure la location des chasses et on lie peut que demander que les intérêts des promeneurs soient lésés le moins possible.

Quant aux forêts particulières olles, sont parfois l'oljet de prohibitions injustifiées et il faut que les associations de touristes agissent par leurs délégués. auprès des propriétaires des massifs pour qu'ils se montrent aussi tolérants que possible. 
INTERNATIONAL 1913

\section{Le CONGRès ÉMET LES VEuX SUIVANTS:}

Les agents forestiers, et autant que possible les particuliers, ne perdront pas de vue l'aménagement des forêts au point de vue esthétique.

Les grandes voies seront empierrées mécaniquement.

Les curiosités forestières, les sources remarquables, les ruines, les rochers et les points de vue situés en forêt, etc, seront rendus accessibles par des sentiers munis de plaques indicatrices.

L'Etat et les particuliers entraveront le moins possible la circulation des promeneurs en forêt.

Il sera conservé lors des exploitations tous les arbres ou groupes d'arbres remarquables et même des bouquets de vieilles futaies lors de la réalisation. des vieux peuplements.

Les sommières, lignes et sentiers seront transformés en allées ombreuses par la réserve, lors des exploitations, des arbres qui les bordent.

Les carrefours seront encerclés d'arbres de futaie, mais à une distance assez grande du croisement des routes.

M. Le Présınext. - Je demande à Xl. Thiollier de vouduir bien expliquar les motifs pour lesquels il a présenté les voux qui terminent sun rapport.

M. Throller explique que l'arcès des curiosités forestières, sumpes, ruines, etc., a besoin d'être farilité par des rontes, des sentiers, munis de plaques indicatrices.

Le premier paragraphe :

"Les agents forestiers, el antant que possible les partimliers. ne perdront pas de ane l'uminugement des forêts, an point de vue esthétique."

mis aux voix est admptr.

M. le Présidext, - Nous passons au denxième paraglaphr.

"Les groundes roies seront empierrées méeuniquement."

11. Corlox fait ressortir l'insuffisance des crédits d'entretion des proutes forestières, en raison to la circulation intense des automobiles. si préjudiciable à la bomn conservation et demande que ces routes eonservent un peu plus leur première destination. rar l'Artministration forestière a avant tout son sepvice ì assurer.

M. LE Présinext. - J rous demande pardon. Lei, nuus ne summes plus du tout dans l'esprit du rapport.

Nous nous placons au point de vore touristirgur, puisque le rapport a pour titre "Aménagement de forêts an vu" du tumrisme ". On

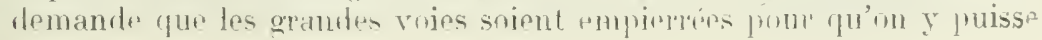




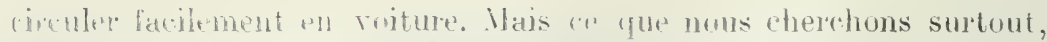
cest rempe les forêt- arersibles facilement) à la masse du publie, et ce qur num vouluns. aree le Parlement et l'Administration, cost favoriser. sul lus rutes forestières, la cireulation du tourisme. lid meillen' prove. "Ast que nous étudions on es moment, à l'Office National du Tourisme, un projet dr lni que nuus allons présenter frochainement an P'ulement dans le but d'établir un certain nombre ditineraires de poutes do fourisme. Nous allons dasser dans une ratégorie spreciale ot sous un régine spécial un certain nombre de joutes qui recevront des affectations particulières pour leur entretien.

L’idée ent fone tout it fait au développement de la circulation avee des voies de courisme sur l'ensemble du riseau routier français. Nous avons l"intention de favoriser les routes forestières, parce que nous savons très bien que l' Idministration considère ses ehemins uniquement comme instruments de travail, of non pas comme instruments d'agrément. Ce que nous roulons, cest permettre à ces instruments de travail d'être à la fois mpilleurs an point de vue de l'Administration forestière, ot possibles an point do vur de la circulation de fourisme. Ce que nous voulons. fest puscre la question de unincipre.

Si le Comgrès rote la proposition de M. Thiollier, voyez quel argument nous aurons lorsque nous proposerons au Parlement un projet de loi pour l'entretien des routes de tourisme, at que nous demanderons des crédits spéciaux, si nous pouvons dire: "Le Congrès a demandé que les grandes voies forestières et celles dont la circulation intéresse le tourisme soient "mpierrés. "C'est un argument de plus pour venir au secoms do l'Administration des forêts, qui a besoin de crédits pour entretenir ees roies.

Mais conme ce Congrès söintéresse à la lois à la comservation des forêts et à leur mise is la disposition du grand public pt du tourisme, comme instrument d'agrément national et même international, nous pourous admettro difficilement que l'Administration déclare: "Mes joules sont à inoi, je m’en ser's pour mes besoins, le reste ne mintéresse pas. "Ce que nous devons rerhoreler, c'ost le grompenent des deux intérits; vous savez d'ailleurs que l'Administration forestière envisage ce groupemment des deux intérets de la manière la plus bienveillante. de vais vous en tonner un exemple extrêmement typique; c est la route du Désert de la Grande-Chartreuse, qui est vicinale entre Saint-l aurent-du-P'ont ef Fourvoirie, et route forestière après Fourvoirie. Il est indispensable que tous ces éléments soient joints dans les memes crédits dentretien, at qu’il y ait councidence entre les charges qui ront incomber a la virinalité pour lentretien de son troncon, et à l'Idministration forestière pour l'pntretien du sien. Autrement, il y aturait dans cos jonctions des parlies très mauvaises

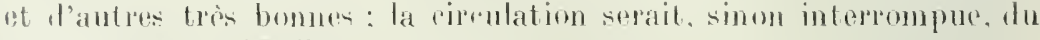
morins pendue dillicile.

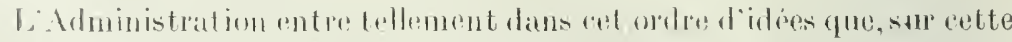
partio de la route du brisit, nous avous obtenu du dipartement que 
le truncen qui était vienal et qui in avait pas -ullisanment de uredits Hentretren. fôt incorporé dans le réseau départemental: l'Administration forestière y a lait cette année des réparations considérables, yui se chithrent par une cinquantaine de mille franes; mais l'effort s cos portí en même temps sur la partie forestière et la partie départementale de la route.

Par conséquent. wh ven qui demande l'mepierrenent des grantes voies, e'est-à-dire di- voies qui servent à la rirculation boutistique, me semble rentrer absolunent dans libjet de notre Congres et aussi dans nos ilées.

M. Cot Lox. - Il hat alors ajonter que des redits spéciaux seront alfectén a lentretien de res routes.

M. I.E L'RÉLIUENT. Celat Va de soti.

Que fait aujourd hui I' trministration forestiere pour les voies qui fui servent exclusivement? On pent dire qu'elle ne les entretient pas on ì peu près pas. Pourquoi? parce qu’elle n`a pas de crédits. Il en est ainsi dans la forêt de Lente. El hien, nous demanderons, pour les voies de tourisme, une affectation spéciale de crédits, et si l'Administration, sur ses rédits personnels. vent forep un peu les sommes affectées à tel tronçon de route aux dépens de tel autre moins intéressant, jo ne rois pas ce qui pourrait l'en empecher.

M. Henry Maige. -.. On ne peut pas dire que les lorestiers ne font rien pour leur route, quand .I. Thiollier vient de nous dire equ'il avait obtenu dans le Jura dexcellent résultats aver des moyrens pelativement restreints.

M. Le Préshent. - Césunt des eas it especo, particuliers à certaines régions et à certaines exploitations.

En tout cas, sur la question de savoir si les grandes rontes de tourisme duivent ètre empierrées, je trois que la discussion est close.

Si personne ne demande la parole. je vais mettre aux voix le deuxièma vou, ainsi concu :

\section{"Les grandes roies seront pmpierries ménniqurment".}

Ce reu esh mis aux voix et adeptí.

M. Le Preshext, Co Nols passons au troisieme paragraphe :

"Les curiusités foresticres, les sources remarquables, les ruines,

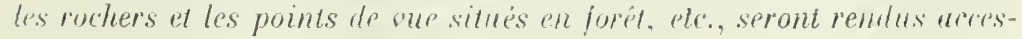
sibles par des sentiers munis de pluques indicutrices".

M. J. Confor. de demande quin ajoule a l'enumeration du taxte in ascates naturelles. du moine les plus importantes. II sn produit

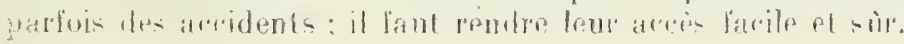


M. Dupuich. - Il se. peut qu'il y ait des dérivations, et les cascades finissent par ne plus ètre naturelles.

M. Le Présinent. - Si elles sont jolies à voir! (Très bien! drès bien!)

M. D'Orlye. - Nous ne demandons pas qu’on les détruise, nous demandons quion nous permette de les aller voir.

M. Le Présinent. - Nous ajoutons à l'énumération du voeu les "cascades ».

La parole est à M. van de Poll.

M. VAx de Poll. - Je veux rous mentionner une autre manière de favoriser la circulation des promeneurs en forêt. C'est le sentier de piétons ou cyclable, très économique à construire et qui permet d'accéder facilement à de grands bois, à d'immenses bruyères, à de belles forèts, auxquels, jusque-là, on ne pouvait arriver.

Evidemment cette solution ne peut intervenir que quand le sol s y prête. Il serait infiniment coùteux d'établir des sentiers cyclables dans le roc, et d'une façon générale en montagne. Il est vrai que chez nous l'intérêt de ces accès est général, car, le pays étant plat, tout le mondes fait de la bicyclette. Je ne sais si, en France, on y tronverait le même intérêt.

M. Le Président. - Au contraire ; nous faisons beaucoup de tourisme à bicyclette en montagne.

M. Gabiat. - M. Ballif fait étudier spécialement cette question.

M. Le Présidext. - La communication est diautant plus intresesante que venant d'un Délégıé dn Tomring-Clnb hollandais, elle est adressée au Touring-Chul, de France qui s'ocerupe activement de la circulation veliste.

L'observation sera inscrite au procès-rerbal. Xuus pourons mêmo laire une addition an texte; nous y insćrerions, après le mot sentiers. les mots piétons on cyclables (Très hien! Très bien!)

Le veru serait done ainsi ródigé :

"Les curiosités forestières. les sonrces remarquables, les ruines, les rochers, les points de we et les tuscades sitnés en forêt. elc.. seront rendus accessibles pur des sentiers de piétons on rydubles munis de plaques indicatrires."

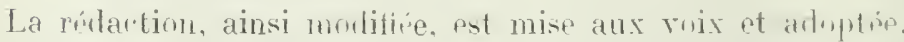

M. 1. Prémext. - Nons arrivons an quatrième paragraphe:

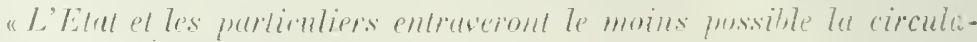
lion des promenems en forit."

Le vou, mis atux roix, est adoptr. 
M. Le Phésidext. - Restent encore trois verux, qui sans doute seront arloptés sans discussion. Les ruici :

"Il sera consercé. lors des exploitations, tous les arbres ou groupes d'urbres remuryulules, et même des bouquets de vieilles futuies, lors de la réalisation des vieux peuplements.

"Les sommières, lignes et sentiers seront transformés en allées ombreuses par la réserce, lors des èxploitations, des arbres qui les bordent.

"Les currefours seront encerclés d'arbres de futuie, muis ì une distunce ussez grande du croisement des rontes."

Les trois derniers voux sont mis aux roix et adoptés.

M. le Présinext. - Messieurs, si rous êtes d’accord sur le détail de ces sept roux, vous le serez aussi sur l'ensemble.

Liensemble est mis aux roix et adopté.

M. Le l'Résinext. - La parole est à M. Gouilly, pour la lecture de son

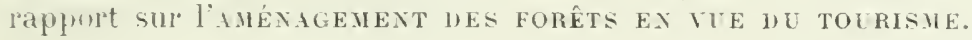

M. Gotillr. - Aménager une forêt au sens spécial du not que nous lui attribuons, c'est l'adapter aux exigences du tourisme.

C'est, d'une part, en rendre l'accès et la visite faciles, c'est aussi en faire valoir les beautés naturelles. C'est la rendre hospitalière et attrayante. N'est-ce pas par voie de conséquence le moyen de la faire aimer?

Une forêt aménagée pour le tourisme devra done posséder, en premier lieu, un réseau de routes complet et en bon état (cette question a été traitée dans un précédent rapport) et différents dispositifs à l'usage exclusif du touriste qui font l'objet de la présente étude.

Chacun sait combien il est souvent malaisé de s'orienter sous bois. L'histoire militaire elle-même ne nous en fournit-elle pas de nombreux et saisissants exemples?

Aussi les excursions en forêt sont-elles presque tonjours limitées aux abords même des massifs dont les beautés les plus parfaites restent sourent ignoréps.

Pour rngager le touriste à pénétrer au coeur de la forêt, il est indispensable de lui fournir les moyens pratiques de se diriger vers les points les plus intéressants par les voies les plus directes, les plus faciles d'accès Gu les plus pittoresques.

Or, en dehors de quelques forêts privilégiées dont le Touring-Club s'èst oceupé, ces indieations font totalement défaut dans la plupart des bois sounis an régime forestier, qui sont les seuls réellement ouverts au tourisme.

Est-ce à dire qu'aucun point de l'epère n'existe dans ces forêts? Assurement non. Mlais les seules indications qui s'offrent aux yeux sont d'ordre administratif pur. Numéros de coupes ou de séries, lettres de parcelles, noms de maisons forestières. Si ces renseignements sont suffisants pour la grestion du domaine, il ne saurait en être de même pour le voyageur qui ne connaît pas la forêt ou qui ne possède pas une des cartes dressées par le service forestier et qui reproduisent le parcellaire. 


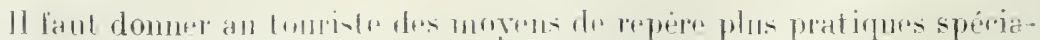
lement adaptés ì sill usalgon.

C'est le rôle des plarmes. pulerant or sisnes indicateurs.

Plaques el po teanx.

vignada avelis vents.

Bancy. - Abris.

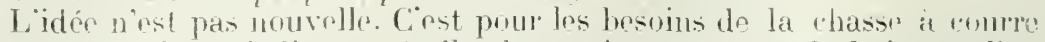
que Purnt parris jadis aux etoiles les anciens poteaux de bois que linn reneontre cnomp dans los forêts qui dépendaient du domaine de la Conronne, potraux de elenen iquaris a plusirurs pans suivant lo nomber de ravons de leteile.

On divise en gíneral les signaux de la poule en doux grompes : Ies indicaleurs et los aserlisisers.

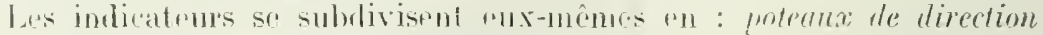
at en poleun d'inlérél exclusivement louristique.

Les uns ef les autres aturont leur plare en forêt.

Les poleanr de direction, sur toutes les routes qui sillomment la forêt, ì l'origine de ces routes, aux rarrefours et aux ronds-points. Ils porteront comme indications. d'une part, le nom de la route, et d'autre part, le $n$ om des maisons forcestieres un des localités les plus roisines de la forêt qu ils desserivint.

C'est le canevas général.

Les poleaux d'inlérét touristique, plus spécialement signaleront les curiosités naturelles de la forêt (sites, points de rue, arbres remarquables). Ils mentionnerout aussi des renseignements d'une réslle ulitilé pour lo rovageur (postes de serours, abris, gares, efe.)

1 côti de ces poteaux nous mentionnerons les sigues indicaleurs.

C'est le Club Ilpin. le premier, qui prit l'initiative de faire placer 'n pays de montagne des lacés d'itinérains, con couleur. Ce procidé demanderait a ôtre gŕnéralisé un forôt. "ar il est à la fois simple, pratique et pers onéreux.

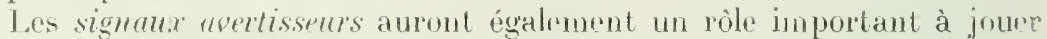
en forêt, ear les routre forestipes, dont lir traré n'a été étudié qu'en vue de la vidange des ioupes, présentent souvent des pentes rapides ou dris viraces brusquen. On amra recours, ln cas échéant, au systeme de signaux convintionnels artopté dans la Conférener internationale du fer décembur logs pour désigner les obstackes usuels (rassis, virages, passages à niveau. (roinements).

1 ròté des putudux avel lissentrs des dangers de la route, il faut ranger

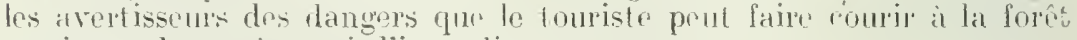
par imprudener. at savoir l'incendie.

The recommandation d'un autre ordre d'ides is faire an visiteur : "ugager à respecter la forêt en ne mutilant pas les arbes par les inscriplions, on en ne la déshonorant pas par l'ahandon do papiers ou de reliefs di. déjeuners champêtres.

Signalons on passant qun les planues adoptions par lo T C. F. sont rn

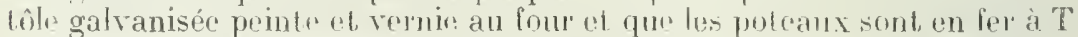
ou ia double T. Les plaques reviennent is 8 tranes, le potwan i mm plaque à $2 \mathrm{fr}$. 55 ot le poteau ì doux plaques a $3 \mathrm{fr}$. 10 .

Nous déconseillons la pose de plaquess directmurnt sul lis allores a

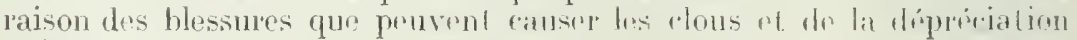
qui peut en résulter.

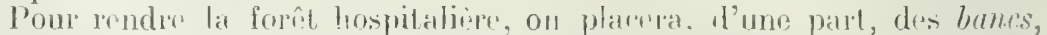
et il sera ádifie, l'antre part, des abris contm los intempéries.

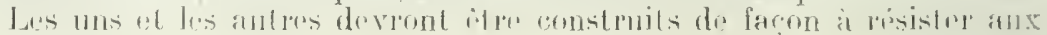




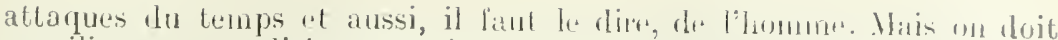
concilier cette condition essentielle de solidit aveo l'ubligation de ne pas commettre de faute contre le gout en rompant l'harmonis du carle environnant. Suivant une henreuse exprussion, hanes of abris devront être construits par les moyens i du bord".

Iprés un concours ouvert entro les priposic forestiers des enviruns de J'aris en 1911, le Touring-Club a adopté un I ype de bane dit "forestiep" qui répond à ces différentsdrsiderata. Son prix de revient est de 15 franes. Les banes seront disséminés en forêt, plarés de préférence amx endroits "sui offrent un intérêt partirulier.

In contraire, ce ne sera qu'en des points isolés, bluignés de tunle habitalion que seront édifiés des refuges momentanés contre l'orage mi l'ondée.

Par contre, les banes auront une place toute indiquée aux abords des sites ronarquables ou des points de rue.

La réation des poinls de vue est essentiellement du domaine de l'ané- poinrs de var. nagiste, qui, en lant qu'architecte paysariste, doit mettro en valeur lis brautés nalurelles.

L'aménagenent d'un point de vue romprend, d'une part, la création d'un champ visuel étendı en "xploitant los bois qui masquent la rue à la manière des tirés, el, d'autre part, l'établissement d'une terrasse limitée par un.' balustrade rustique.

Signalons l'utilité pratique de res points de vue pour la snrveillance des incendies.

L'idée des points dr vue est inséparable de celle des lables d'orientation.

Jusqu'à présınt, ees tables d'orientation n'ont été placées qu'aux abords des sites remarquables, en pays de montagne principalement. 56 tables ont été posées par le Touring-Cilub.

A mesure que des points de rue seront eréés dans les massifs forestier's importants, de nouvelles tables derront êlre installées. Les tables ılu T. C. F. sont en lave de Volvic énaillée. Comme pour tout autre disporsitil d'intérêt touristique, les soeles de support seront mis en hamonio avee le cadre environnant.

Cos différunts aménagements terminés, ou d'autres d'uns utilité moins immédiate, tols que lourne-brides, eaptage des sources, ete., l'ocuve de l'aménagiste n'isl pas teminée.

Le moment est venu de iresser mue carle à grande échelle (au 1/10.000 par cxemple) oil figureront par des signes enrentionnels appropriés les curiosités naturelles et toutes choses crées it l'uscigr du louriste.

Ciss rartes s'inspireron! nécessairement des plans du Servió forestier sur lusquels stules sont indiques les rontes forestierus d'expluitation qui sillomnent, la lorêt. Jais il sera inutils, pour en faciliter la hecture, l.' reproduire le parcellaine.

Cons frons une seule réserve il r. sujel. Il serait désirable, dans la \%ont frontière, lo ne pas liver a la publicité les renseignements que donnent les cartes du service forestier, dans l'intérêt de la défense nationale.

Nons vondrions voir annexer à celte carle, à la manière de cerlariss guides do lomismo, m lived de quelques feuillets qui compléterail lus

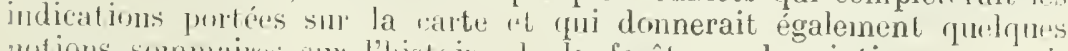

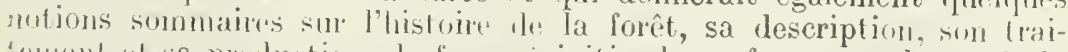

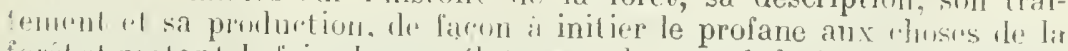

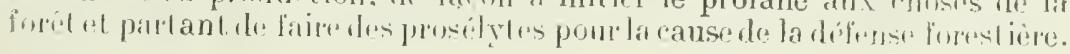

Tables dinienralion. fins, - Jin reisgluides. 
L'Administration des Eaux et Forêts a d'ailleurs compris tout le parti qu'on pouvait tirer du touriste en lui faisant aimer la forêt.

Ca ta log a $\theta$ des arbres remarquables.

L'intérêt qu'elle attache à la conservation des arbres remarquables, "témoins d'un lointain passé auxquels se rattachent sourent des souvenirs historicques ou légendaires ou qui imposent l'admiration par la majesté de leur port ou leurs dimensions remarquables ", n'en est-elle pas une preuve frappante?

Un inventaire détaillé de ces arlores a été dressé et ils ne peuvent être exploités que par décision spéciale.

Le Touring-Club qui a été le premier à s'occuper de l'aménagement touristique des forêts a d'ailleurs rencontré auprès de l'Administration un bienveillant accueil dès l'origine. Son premier soin fut de donner au touriste le moyen pratique de se diriger sous bois.

Aménagements exécutés par le T.C.F. - Des poteaux indicateurs d'intérêt touristique furent placés à cet effet dans les forêts de Fontainebleau, de Marly, de Compiègne, de Roumare, de Lente, du Tercors, de l'Estérel, et dans celles dépendant des conservations de Gap, de Mâcon, de Valence, de Vesoul, etc. De ce fait, au moment du Congrès International de la Route, le T. C. F. arait engagé une dépense de 18.000 francs (en 1908$)$.

Mais ce ne fut qu'en 1911 qu'il entreprit l'aménagement touristique complet d'une forêt.

La forêt de Meudon fut choisie conme champ d'expériences.

Cet essai, auquel nous avons collaboré, a été couronné d'un plein succès. On peut dire que la forêt de Neudon réalise le type le plus parfait de la forêt ouverte au touriste.

Des sentiers pour piétons et des pistes cyclables ont été ouvertes; des ponts rustiques ont été jetés sur les fossés d'assainissement, des routes forestières ont été améliorées; 250 bancs ont été placés. Des tournebrides ont été installés à certains carrefours. Un point de vue a été créé et un kiosque-abri édifié.

De nombreux poteaux de direction et avertisseurs de toute sorte sillonnent la forêt.

Après la forêt de Meudon, ce fut la forêt de Marly que le TouringClub aménagea dans les mêmes conditions. Puis viendra le tour de la forêt de Rambouillet.

D'autres associations ont suivi la voie que le Touring-Club leur avait tracée. Signalons ici le Syndicat d'Initiative de Versailles qui aménagea les forêts de Satory et de Fausses-Reposes.

D'autres initiatives continueront l'ouvre commencée, telle l'Association centrale pour l'aménagement des Montagnes qui s'attache à faciliter le tourisme dans la région où elle organise des leçons de choses sur ses territoires affermés, en publiant à cet effet des plans de ses territoires et en munissant ces derniers de poteaux indicateurs.

Cas initiatives contribueront ainsi à l'organisation générale de la défensı' forestière, cet élément indispensable de la beauté, de la richesse et ro la sécurité du pays.

\section{LE CONGRÈS ÉMET LE VEU :}

Que l'accès ct la visite des forèts de promenade soient facilités par l'amélioration des chemins, la création de sentiers, la pose de plaques 
indicatrices ayant un caractère rustique, l'établissement de bancs ou d'abris pour les promeneurs, le dégagement des points de vıle;

Que, sur les cartes déià publiées et sur celles affichées dans les postes forestiers, les arbres, les peuplements ou les sites remarquables, les points de vue et les curiosités naturelles existant dans chaque forêt soient repérés.

M. Goully. - Lans le vorn qui termine mon rapport, j’ai visé surtout les forêts de promenardo; il y a aussi d'antres forêts qui ne se trouvent pas aux environs des granles villes et dans lesquelles le touriste peut être amené.

Je vous propose donc, arant de diseuter ce vou, de demander:

Que les indications d'ordre administratif qui existent ou sont susceplibles d'exister en forêt et qui peuvent être d'un intérêt quelconque pour le tourisme, soient placées d'une façon apparente.

(Tive approbation.)

M. Henry Marge. - J'entends dire près de moi que, dans certaines forêts où de telles indications existent, elles sont très sommaires : un chiffre sur un arhre, ou même sur une pierre. Pourquoi ne pas chercher à ubtenir l'átablissement d'une carte forestière?

M. Le P’RÉ-HUExt. - Nous allons étudier ce qu'il est possible de faire pour la proposition de M. Maige au sujet des cartes forestières. Jusru’à présent, l'Adninistration n'est pas entrée dans cette voie qui consiste à mettre à la disposition du public des rlocuments de ce genre et il est assez difficile, dans certains eas, de se les procurer. Ouand nous avons poursuivi le but que le Touring-Club entend réaliser le plus tôt possible, c'est-à-dire de mettre à la disposition du public des rartes permettant de circuler facilement, nous avons cherché à établir des cartes à grande ichelle pom les environs de Paris, contenant l'indication de tous les sentiers et de tontes les directions, pour que le touriste puisse se promener en forêt sans rainte de se perdre...

M. J. Cocnux: - Ceci existe puur crutaines forêts, comme celle d'Aixles-Bains, par exemple.

M. Le Président. - Nuus avons voulu établir ces cartes d'après des documents officiels de l'Administration des forêts. Cette administration s'est mise à notre disposition avec beaucoup de grâce, et nous a fourni les documents que nous lui demandions, mais elle ne consent pas à les mettre à la disposition du public. Nons examinerons s'il n'est pas prissible d'arriver à faire bénéficier le public de ces documents, - je ne dis pas avec l'autorisation de l'Administration des forêts, - mais au moyen d'une entente avec un éditeur. lıe mode d'exéculion est à itudier, mais le principe est intéressant.

Nous pourrions demander à l'Administration des forêts de permettre au public, par les moyens qu'elle aura choisis elle-même, de profiter 


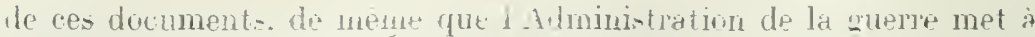
la disposition de tout le monde ses carte- aux dirones echelles, 50. 60 et 200 millièmes. Je no pense pas qu'on fasse do diffienltín prut rela.

11. Thiolier. - Mon, cela ne soulevera ammur diffirulté.

1). Lonieux. - Je roudrais faire une proprosition qui m'a été suggrérép par une aventure arrivée à notre exrollont ami et prénirlont, M. Rausrhet, qui, vous le savez. aime beaucoup le tourisme et les forêts.

l. orsqu'on consulte une carte quelconque, on remarqur hien des teintes vertes qui indiquent les forêts. mais on ne sait jamais si ces forêts sont accessibles au public ou si elles ne le sont pas. On peut done organiser une promenade dans n'importe riulle région do la Fiance et tomber sur un parc plus ou moins en clôtur sur un bien particulier et se voir interdire l'entrée de ce par. ou n̂̂me s'en voir exclure, 'omme cela est arrivé a $\mathrm{M}$. Bauschet. Il serait utile de demander aux éditeurs de cartes, d'étudier le moyen d'indiquer par une teinte spécial les forêts appartenant à l'État, aux communes ou à des collectivités, celles qui sont accessibles au public. Ce n'est pas une question administrative, e'est une question d'édition. Il y a là dẹs renseignements utiles à connaitre et qu'il est facile de se procurer.

11. le comte Clary. - Le Touring-Club semble tout indiqui, dans unf certaine mesure au moins, pour prendre l'initiative d'un mouvement au point de vue de la confection d'une carte. Ne pourrait-il pas, par exemple, se mettre en rapport avee les Syndicats d'initiative départementaux qui ont déjà fait beaucoup pour le tourisme, dans nombre do départements el qui entreraient peut-être dans cette voie, en prenant à leur charge une partie des frais de confection des cartes. Il y aurait là une doubte initiative qui pourrait rendre de très grands services:

M. LE L'RÉIDEXT. - Le Tuaring-Chul, envisage tous les aspects de son rôle avec le plus grand intérêt. II est cependant nécessaire de faire certaines restrictions sur le rôle qu’il peut jour sur des entreprises qui peurent derenir une sorte d'exploitation commerciale. Nous ne pouvons pas - et nous ne voulons pas, c’est un principe que nous avons étahli de la manière la plus formelle - faire concurrence à une branche quelconque du commere. Nous roulons laisser les coudées franches aux éditeurs de cartes et de livres, ct à toutes les industries. II ne faut pas qu'on puisse dir" qu'arec les moyens que mous avons a notre disposition. nous laisons concurrence it telle ou telle partie du conmerce ou de l'industric. Mais nous pumvons très bien faciliter aux éditeurs la recherche do documents pum l'ćtablissoment de leurs wartes. Vuila nì notre pôle vă s'aftirmer d'un manière particulière.

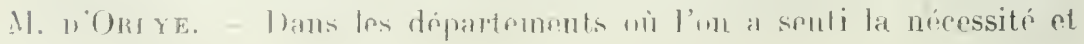




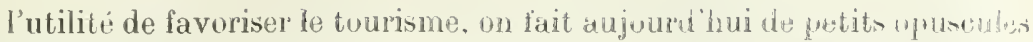
dans lesquels sont indiqués la situation de tontes les forêto, et les tracés de tous les sentiers. Le Syndirat d'initiatioe du Club alpin eb la Société des Amis des Arbres se sont entendus pour l'établissement, l'opuscules de ce genre, où les chemins sont très exactement tracés. Les touristes n'ont qu'à demander ces opuseules au Syndicat d'initiative, qui les leur remettra gratuitement et aver beaucoup de bonne grâce.

Si le Touring-Club voulait faire quelque chose daus cet vrdre d'idées, je lui demanderai d'aider les Syndicats d'initiative qui. généralement, ne sont pas très riches.

11. re Président. - C'est entrer dans des détails qui nous mèneraient trop loin. Je crois que nous pourrions émettre un voen ainsi conçu :

Que, dans tous les pays, les administrations et les vocietes fompiétentes veuillent bien faciliter l'établissement et la mise à la disposition dn pnblic de cartes forestières.

11. Gabiat. - Il serait à désirer que ces cartes fussent ṕtablips sur un type unique.

M. le Président. - Il appartiendra ḋ.la Commission de réalisation. les voeux d'étudier l'échelle qui sera la plus favorable pour l'établis. sement de ces cartes. Cette commission émettra un avis que chaque État adoptera ou n’adoptera pas, car il faut laisser ì chapun toute sa liberté.

M. LoRieux. - Je vous demande de vouloir bien insérer dans le veu la motion que j’ai déposée demandant que les forêts accessiblos ans public soient indiquées d'une manière très claire.

M. Le Président. - On pourrait en effet ajouter dans le vou que, sur ces cartes, les voies mises à la disposition du public soient indiquées par une teinte ou un signe spécial.

M. Dupurcu. - L’idée est certainement interessante, parce qu'on aura plus de renseignements qu'on n'en a à l'heure actuelle, mais il y a quelque chose qui est plus fâcheux encore que l'absence de renseignements, c'est le renseignement inexact. Or', je crains qu'on n'arrive pas facilement à avoir des renseignements certains sur les points en question. Quand il s'agit de connaître un renseignement administratif, comme par exemple le caractère domanial, communal ou autre d'une forêt, c'est une chose ferme, facile à déterminer, mais lor'squ'il s'agit de savoir si l'accès de telle ou telle forêt est permis au public, c'est un renseignement qui peut ître très variahle.

M. Le Président. - Quand les hois appartienuent an Inomaine national, l'accès en ast tonjours antorisí pour le publir, mais, comme nous 
émettons un veru international, nous pulvons ajouter dans ce vou les mots dans la mesure du possible. Nous savons que l'Administration francaise possède ces documents. mais il se peut que d'autres administrations ne les possèdent pas.

M. VAx de Poll. - II serait évidemment difficile de préroir tous les cas qui penvent se produire. Ainsi, en Hollande, oì j’ai été garde géneral, il existe des routes qui ne sont ourertes au public que temporairement. Il ell est ainsi notamment dans une forêt qui appartient à la Reine. 11 y a aussi des routes qui ne sont pas accessibles aux automobiles : il faut, pour y circuler, une autorisation spéciale. Il n'est pas possible d'entrer dans tous ces détails dans un røeu qui swit être général.

M. Du MEsNiL. - Pour eviter toute confusion, il serait bon de convenir qu'il n'y aurait que denx teintes différentes ou deux signes conventionnels différents, l'un pour les bois particuliers, l'autre pour les forêts nationales ou communales. Il n'est pas besoin de deux signes différents - pour ces deux dernières.

M. Le Présinent. - Il s'agit en effet de distinguer simplement les bois particuliers des autres. Ce n'est pas un droit que nous signalons sur les cartes, e'est simplement l'indication qu'on peut habituellement se promener dans telle ou telle forêt.

Voici la rédaction que nous vous proposons :

"Que les Administrations et les Sociétés compétentes veuillent bien faciliter l'́rtablissement et la mise à la disposition du public de cartes forestières.

"Que sur les cartes touristiques à établir, les bois habituellement onverts an public soient indiqués d'une façon précise".

M. Lorieix. - Pourquoi parler des " cartes touristiques "seulement. La distinction s'impose pour toutes les cartes d'une manière générale.

M. le Présinent. - Il s'agit d'un renseignement d'ordre général, je ne vois pas pourquoi nous ne demanderions pas que ce renseignement figure sur toutes les cartes. Pour mettre tout le monde d'accord, nous pourrions rédiger le vou de la façon suivante :

"Que les Administrations et les Sociétés compétentes v'euillent bien faciliter l'établissement et la mise à la disposition du public de curtes forestières;

"Que, sur les cartes, les bois habituellement ouverts à la circulation touristique soient indiqués d'une manière précise ".

Le vœu, mis aux voix, est adopté.

M. Dumesnil. - Vous avez dit tout à l'heure qu'il etait désirahle que 
toutes les cartes soient uniformes. Cette unifornite ne peut exister que par pays : car il ne faut pas oublier une nous sommen un Congres international.

M. le Présinent. - Nous avons dit qu'il serait in téressant que, daus l'ensemble des cartes qui seront publiées dans tous les pays, une échelle uniforme soit adoptée, mais nous ne pourons pas en faire l'objet d'un rou. Chacun est libre d’agir selon ses facilités et son bon plaisir. La Commission qui va poursuivre la réalisation des roeux établira un projet qui sera soumis aux différents gouvernements en leur disant: "Nous serions heureux de voir ce rou exécuté de telle ou telle manière.

Nous allons maintenant soumettre à votre approbation le vou présenté par M. Gouilly comme conclusion de son rapport.

M. Gingly. - Ce voeu est le suivant:

"Que laccès et la visite de forêts de promenade soient facilités par lamélioration des chemins, la création de sentiers, la pose de plaques indicatrices ayant un caractère rustique, l'établissement de bancs on t'abris pour les promeneurs, le dégagement des points de vae;

"Que, sur les cartes déjà publiées et sur celles affichées dans les postes forestiers, les arbres, les penplements oul les sites remarquables, les points de vue et les curiosités naturelles existant dans chaque forêt soient repérés ».

M. J. Cochox. - Je vous propose d'ajouter également les fontaines dans cette énumération.

UN Coxgressiste. - Et les sources.

M. Le Président. - Les fontaines sont une chose toujours très intéresisante en forêt. Nous pourrions rédiger le vou ainsi: "oules sites remarquables, les sources, les fontaines, les points de stze. etc. ".

M. le comte Charr. - Pour renforcer le vou que nous arons émis tout à l'heure lors de la discussion du rapport de M. Thiollier nous pourrions également, dans le vœu actuel, puisqu'il y est question de la création de sentiers, indiquer " sentiers de piétons ou cyclables".

11. Le Président. - Nous dirions done: "lamélioration des chemins, lu création de sentiers de piétons ou cyclables, la pose, etc. ".

Je mets aux voix le vœu de M. Gouilly, modifié par les deux adjonetions qui viennent d’ètre proposées.

Le rou est adopté.

M. Le Présinext. - La seconde partie du roeu de M. Gouilly a trait aux cartes. Si rous le voulez bien, nous y ajouterons le veu que nous avons 
émis dejà pour l'établissement et la mise à la disposition du public de cartes forestières.

Adopté.

M. ie Présidext. - Il nous reste enfin à statuer sur le you que M. Gouilly a proposé au début de la discussion de son rapport et qui est ainsi ronçu :

"Que les indications d'ordre administratif qui existent ou qui sont susceptibles diexister en forêt et qui peuvent être d'un intérét quelconque pour le tourisme soient placées d'une façon très apparente et toujours entretennes en bon état ".

Le roeu est arloptr.

M. Coulox se plaint que l'Administration forestière se trouve complètement désarmée pour poursuivre les entrepreneurs qui déchargent des gravier's ou conduisent des détritus en forêt.

Et la section arlopte le vou présenté par M. le comte Clar :

"Le Congrès émet le vœu que certuines sunctions rendues nécessaires pour la protection des sites, la créution de pares nationaux, etc., dans les forêts sonmises an régime forestier, soient présnes et ajoutées an Code forestier \%.

La spance est levée à 11 heures. 
SEANCE DU 19 JUT 191:3

$(M \times T I)$

Présidence de M. CHAIX, président de Section

La séance est ouverte a 9 h. 20.

II. Le Pressuext. - Liordre du jour appelle la discussion du rapport de . M. Nathey sur les pares nationanx. La question des pares nationaux est nne question vitale pour tout re qui nous intéresse et nous aurions ite tres heureux de voir notre iminent collegue venir defendre arec lónergie qui hui est cuntunière les idées qu’il a émises dans son rapport. Cependant, comme il n est pas possible de remettre ce débat,

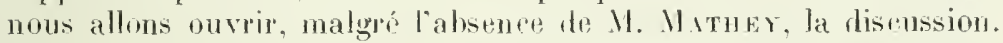

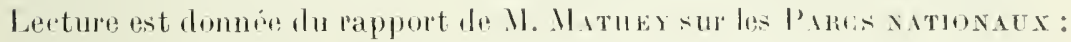

Rapponte ne M. A. Matrey. - L'industrialisme poussé jusqu'à ses dernières limites, la cupidité hmmaine ne respectant plus rien, pas même les impressionnantes beautés naturelles, le viol permanent des sites les phus vantés érigé à la hauteur d'une institution d'Ltat, l'appanvrissement incessant de la flore spontanée, la disparition de nombreuses et inoffensives espèces animales ont fini par provoquer ehez tous les peuples un réveil de la conscience nationale. De là, est née l'idée de la constitution de pares nationanx, e'est-i-dire de la mise a ban de rastes territoires a tout jamais sonstraits à l'entreprise des hommes et dans lesquels animauxet plantes revivront en paix les premiers âges de l'humanité, domnant ainsi l'attrayant et instruetif spectacle d'un monde qui évolue librement rers des destins inconnus.

Et, tout d'abord, je dois faire remarquer que, si l'appellation est relati- mrịines. vement nonvelle, en revanche l'idée est fort ancienne of, comme torjour's, 'd'origine francaise. Vers 18:30, tonte me bite de jeunes gens aux longs longs cheveux of aux harbes de fleuve vint s'installer à Barbizon, an sud de la forêt de Fontainebleau, séduite par la sauvagerie relative de ses virilles futaies et de ses piltoresques empilements de grès. Les artistes aiment le bruit. La colonie do Barbizon ne tarda pas a faire parler d'elle. La foret étant son atelier, olle se dematidia quelle farce elle pourrait birn jouer aux plilistius qui s'armgeajent des droits sur un terrain qu'elle avait décrété siru. Elle frouva le motif de rethe linee dans les exploitations forestières. Elı quai! on ositit toncher at des arbers qui inspiraient de si 
belles curres! N”était-ce pas là le comble de l'iconoclasme! En vain les barbares vonlurent tenir tête à l'orage; en vain prétextèrent-ils que le bien de la forêt exigeait l'enlèvement des arbres morts et mourants, les petits rapins têtus et bien servis par leur sens artistique ne voulurent rien savoir; ils rugirent: Vous ne toucherez rien ; l'art s'inspire aussi bien des œuvres de mort que des œuvres de vie. Passez votre chemin, ô féroces contempteurs de la nature librement épanouie, nous voulons pouvoir peindre la jeunesse et l'amour, le printem ps et l'hiver, la vieillesse et son long cortège de misères et de deuils ; nous voulons montrer à l'humanité que la vie est un perpétuel combat et que rien n'est éternel en dehors des œurres de génie $)$.

Et ils firent tant, les petits rapins têtus, ils agitèrent si fort leurs longs cheveux, ils promenèrent si bien leurs barbes de fleuve dans les bureaux de rédaction des grands quotidiens, qu'ils obtinrent satisfaction. En 1861, on finit par ériger en séries artistiques, où la hache ne devait plus pénétrer, rertaines parties de la forêt de Fontainebleau. Telle est la genèse des parcs nationaux. Est-il besoin d'ajouter que la constitution des séries artistiques eût les plus heureuses conséquences pour les bourgades entourant la forêt de Fontainebleau. Barbizon et Marlotte, en particulier, durent à cette institution leur célébrité, leur vogue et leur embellissement. Tant il est vrai que les beautés naturelles sont une source prolongée de richesse pour ceux qui savent les conserver! Il faut reconmaitre qu'en dehors de sa proximité de Paris et de ses beaux massifs forestiers, la forêt de Fontainebleau n'était rien moins qu'indiquée pour la constitution de séries artistiques. C'est, en effet, une forêt sèche et silencieuse par excellence. De fréquents et calamiteux incendies en altèrent périodiquement la physionomie. Aucun oiseau n'y gazouille, aucun ruisseau n'y murmure, et ses mares, illustrées par le pinceau de peintres fameux, et légèrement creusées dans la table de grès, ne renferment que quelques gouttes d'eau,

- à peine suffisantes pour étancher la soif des chevreuils, des cerfs et des sangliers qui hantent ses fourrés.

Aux séries artistiques de Fontainebleau, j'aurais voulu ajouter celle du Couvent de la Grande-Chartreuse. Longtemps soustraite aux exploitations, la végétation forestière y avait acquis une force incomparable et une majesté impressionnante. Des coupes récentes ont malheureusement jeté bas les beaux épicéas de Casalibus et fait, de ce site merveilleux, un type banal de forêt éventrée. N'est-ce pas le cas de répéter avec le poète: Sunt lacrymæ rerum! Il est question de rendre cette partic de la forèt domaniale de la Chartreuse à sa destination primitive. Ce sera sage ; mais de tels peuplements demandent un siècle pour retrouver leur splendeur détruite.

Les pares natio nanx chez les différents peu ples.
Nous venons de voir que nous devons à une pensée esthétique la constitution des premières réserves artistiques forestières. Nous allons maintenant suivre cette institution chez les différents peuples et montrer comment l'idée a grandi, évoluant d'abord dans une direction scientifique, puis poussant enfin ses racines jusqu'au plus profond de l'âme populaire.

En 1805, un trappeur américain du nom de Coulter s'engagea, avec Lewis et Clarke dans les terres inconnues de l'Arkansas et revint ébloui des merveilles qui s'étaient offertes à ses yeux. Ses récits, s'ajoutant aux légendes indiennes, firent longtemps l'objet de l'incrédulité générale. Ce qu'on appelait "l'enfer de Coulter " passa pour une légende et l'on fût de longues années encore à ignorer "ce pays de la glace et du feu, 
de l'eau et de la poix bouillante, de la fumée tomnante, pays dont n'osaient approcher les Peaux-Rouges qui le eroyaient hanté par le mauvais esprit ». Plus tard, en 1869, les inspecteurs Cook et Folson visitèrent le Yellowstone et remontèrent jusqu'au lac. Enfin le géologue Hayden en fit l'exploration détaillée en 1871 et publia un rapport sur ses merveilles. Le Yellowstone fut alors déelaré parc national par une loi du Congrès, promulguée le $1^{\text {er }}$ mars 1872 , sur la proposition d'Hayden. Voici le texte de la loi organique :

" Ce territoire est érigé en pare public ou jardin d'agrément pour l'avan" tage et la jouissance de la nation; quiconque s'y établira ou en occupera " une partie, sauf dans les cas prévus par les règlements, sera considéré " comme eontrevenant et immédiatement expulsé. Les règlements ont " pour but de préserver de tous dommages et spoliation et de conserver " dans leur état naturel les forêts, les dépòts minéraux, les curiosités " naturelles et les merveilles que renferme le Pare ".

Le Parc national du Yellowstone forme un quadrilatère d'environ 80 à 100 kilomètres de côté ; son étendue est done de 800.000 hectares. C'est avant tout une contréc volcanique, où l'on trouve tous les accidents plutoniques possibles, et, en particulier, c'est le pays des Geysers. Les 49 sources chaudes de l'Arkansas y sont englobées avec leur débit quotidien de 45.000 mètres cubes d'eaux thermales. Sous le rapport des phénomènes geysériens, dit Leclereq, l'Islande elle-même n'est cqu'une pâle réduetion du Yellowstone.

Si l'on se reporte au texte de la loi organique, on voit que c'est bien une pensée scientifique qui a dicté les actes du Congrès de Washington. D'une part, les Américains ont voulu eonserver leurs richesses minéralogiques; d'autre part, ils ont compris qu'il ne fallait point toucher au cadre forestier qui ajoutait sa splendeur à la magnificence des phénomènes dont est le théâtre cette terre privilégiée. A ces préoccupations d'ordre scientifique et esthétique se mêlèrent également le souci de l'éducation des masses, pour lesquelles le respeet des arbres était comme un évangile nouveau, et le désir très légitime de créer, par le tourisme, une nouvelle source de richesse pour les Etats-Unis. Le Parc national du Yellowstone devint la "Great attraction " de l'Ouest américain. A peine décrété, on s'évertua à le faire connaître et à l'aménager. Tout d'abord, on ehercha à reconstituer, sur cet immense territoire interdit aux chasseurs, la faune de l'Amérique du Nord. On y introduisit les espèces en voie de déclin ou de disparition. Et ce n'est pas un des moindres étonnements que de voir jeter en pâture à la curiosité des visiteurs, à côté des ours bruns apprivoisés et venant, sur les tas d'ordures, manger les restes des hôtels, les derniers représentants de la race autochtone, de cette race qui préféra s'ensevelir vivante dans son cercıeil plutôt que de se plier aux lois de ses vainqueurs.

J'ajoute, pour être complet, que les Amérieains ont aussi érigé en parc national un espace plus petit de terrain dans le Mariposa, où croissent des sequoias géants.

Cet exemple des États-Unis ne tarda pas à être imité par presque lous les États de la vieille Europe. En 190', sur l'initiative de l'illustre explorateur Nordenskjold, le Parlement suédois mit en dehor's de toute exploitation un territoire de 18.000 heetares autour des laes de Laponie, dans 
le but de protéger toute vie animale et régétale ét de voir comment se comportait la forêt à l'état vierge. Plus tard furent créés d'autres parcs de la nature tendant toujours à la protection des sites, de la faune et de la flore.

En 1905, furent décrétés les premières réscrves norvégiennes et le premier parc national autrichien englobant 1.748 hectares de forêt vierge en Bosnie. A la même époque et grâce à l'ardente campragne menǵe par le professeur Couwentes, l'Allemagne protégeait contre toute ingérence humaine de nombreux cantons forestiers situés dans les plaines du Nord et dans les basses montagnes.

L'Angleterre possède la réserve royale de chasse du New-Forest, en Hampshire, créée par Gruillaume de Normandie au $\mathrm{xl}^{\mathrm{e}}$ siècle; elle montre en outre avec un légitime orgueil un grand nombre de parcs appartenant à d'anciennes familles qui les gardent depuis plusieurs siècles à l'état de nature. Ces pares, dont l'étendue dépasse sóuvent 1.000 hectares, sont peuplés d'arbres superbes et très vieux; ils sont de plus soigneusement clos, de façon à pouvoir conserver des cerfs, des daims et le bétail blane indigène qui n'existe pas en d'autres pays et qui fait la gloire d'Albion.

Malgré toutes ces richesses, le Royaume-Uni n'a pas voulu rester en dehors du mouvement qui pousse tous les peuples à communier dans l'amour de la nature. Et la société "National trust for places of historic interest or natural beauty " a acheté, entre autres et vers 1906, le Bradlehow-Park, dans le Cumberland, pour le prix de 150.000 francs. C'est une forêt vierge de 50 hectares, qui est conservée à titre de propriété nationale. La somme requise a été récoltée par souscription, en cinq mois.

A ce propos, je ne puis m'empêcher de gémir sur la disparition de plus en plus grande des parcs privés de France. Les derniers auront bientôt vécu. Et la fiscalité qui s'acharne après eux tend tout simplement à appauvir le patrimoine esthétique de notre pass. D'une part, on édicte des lois pour la protection des sites el, d'autre part, par des menaces d'impôts exagérés, on décrète la mort sans phrase de véritables monuinents naturels, car ce sont bien des monuments que ces vieilles futaies et que ces vieux arbres, témoins de nos gloires séculaires, de nos vietoires et de nos défaites, de nos luttes et de nos passions, dont ils gardent le souvenir gravé sur leurs écorces. Comprenne qui pourra! J'arrive maintenant au dernier acte de ce long historique. C'est au plus petit Etat d'Europe, à la Suisse, qu'il appartenait de grouper en un faisceau compact tout ce que l'art, la science, l'amour de la patrie ont accumulé de motifs en faveur de la protection des œuvres de la nature. Une véritable croisade a été entreprise pour sauver du vandalisme les derniers vestiges du passé. Et cette ligue a recruté des adhérents nombreux dans toutes les classes de la société. A la tête des croisés, nous sommes heureux de trouver la Société des Forestiers suisses, à laquelle revient lo très grand honneur d'avoir, la première, mis à l'étude l'établissement de réserves forestières. Voicidu reste le texte exact de la motion présentée par MM. H. Badoux et R. Glutz à la réunion annuelle do 1906 du Congrès forestier, motion qui a été votée d'enthousiasme.

\section{Considérant :}

10 Qu'il est du plus haut intérêt pour la sylviculture, la botanique et la géographic botanique de conserver en permanence quelques mas de forêts à l'état vierge; 
20 Que l'institution de pareilles réserves deviendra toujours plus diffieile eu égard au rapide développement de la culture forestière.

$3^{\circ}$ Que dans d'autres pays, on a, dès longtemps, décrété le maintien de. réserves forestières.

\section{Les soussignés déposent le vou suivant:}

Est-il désirable et possible de choisir en Suisse quelques mas de forêts (d'environ 20 à 100 hectares), lesquels seraient soustraits à toute action de l'homme, abandonnés ainsi à la nature et conservés pour toujours à l'état vierge?

Cette motion eut le don de réveiller toules les énergies qui sommeillaient. La Ligue pour la Conservation de la Suisse pittoresque, la Ligue nationale pour la Protection de la nature virent tout le parti qu'elles pouvaient tirer de ce mouvement d'opinion, et elles offrirent immédiatement leur puissant concours aux forestier's suisses. Enfin, les sections scientifiques d'histoire naturelle, alarmées par le préjudice considérable causé à la faune et à la flore par l'extension des cultures, l'industrialisation des forces naturelles et... le tourisme, se mirent en campagne à leur tour. Elles instituèrent dus commissions pour la protection des monuments naturels, leur donnant pour mission de préserver dans la mesure du possible ce qui serait encore de la faune et de la flore, ce qui demeure toujours des blocs erratiques et des documents préhistoriques, qui ont été légués à travers les âges aux générations actuelles et qui font partie du patrimoine esthétique et intellectuel de tous ceux qui aiment leur pays.

De ce concours puissant de bonnes volontés sont nées des ordonnances cantonales pour la protection de la flore, ordonnances qui ont été consacrées par un vote quasi-unanime des populations consultées. J'ajoute que depuis longtemps la faune est largement protégée en Suisse, car il existe, dans presque tous les cantons, de nombreux distriets - qualifiés de refuges - entièrement fermés à la chasse.

Ces refuges ont été institués par l'artiele 15 des lois du 17 septembre 1875 et du 24 juin 1904 sur la chasse et la protection des oiseaux. En voici le texte: "Il sera réservé un district où la chasse du gibier de montagne " sera prohibée dans chacun des cantons d"Appenzell, de Saint-Gall, de " Glaris, d'Uri, de Schwyz, d'Unterwald, de Lucerne, de Fribourg et de "Vaud; deux districts dans chacun des cantons de Berne et du Tessin, " et trois dans ceux du Valais et des Grisons. Ces districts devront " être d'une étendue suffisante; ils sont placés sous la haute surveil" lance de la Confédération. Un règlement spécial du Conseil fédéral " fixera les limites exactes de ces districts (sans avoir égard aux fron" tières cantonales et ordonnera une surveillance sévère sur le gibier; ce "règlement contiendra les dispositions nécessaires pour la protection " et la conservition du gibier de montagne, suivant les circonstances of "la situation de's lieux.

"La délimitation de ces districts francs sera modifiée autant que pos" sible tous les cinq ans.

"La Confédération cherchera à acclimater des bouquetins dans res " districts".

A l'heure actuelle, ces districts fermés couvrent une étenduc de 171.200 hectares, représentant les $4 / 100$ du terriloire de la Suisse. On évalue la population animale de ces refuges à 6.000 chamois et 700 chevreuils.

Quand on pénètre plus avant dans les détails de la législation suisse 
sur la chasse, toute d'humanité et de protection, et qu'on la compare avec la nôtre, toute de sauvagerie et de destruction, on constate avec honte que nous avons reculé d'un siècle dans la voie du progrès. Le gibier de l'Ouganda est mieux protégé que celui de France contre la cupidité barbare et areugle des chasseurs-destructeurs. N'est-il pas temps de réveiller la pitié des masses pour tant de gentes bêtes qui disparaissent de notre doux pays et qui emportent avec elles ce renom d'hommes au cœur généreux et tendre sous lequel furent connus nos ancêtres? N'est-il pas temps aussi de fonder une ligue pour la protection de la faune française? Protéger ies sites, c'est assurément très bien; mais protéger la vie de créatures inoffensives et belies, qui attestent la variété et la puissance de la nature, n'est-ce pas mieux encore? Allons donc hardiment de l'avant, imitons la Suisse; nous aurons avec nous toutes les femmes de France, heureuses de jeter dans la balance, en faveur de pauvres victimes, leurs cœeurs de mère, d'śpouse ou de fille!

La fondation de cette Ligue pour le beau et pour le bien est d'autant plus nécessaire qu'il est promptement apparu aux forestiers et aux naturalistes suisses que les mesures restrictives, prises par les gouvernements cantonaux, ne pouvaient protéger d'une manière absolue ni la faune ni la flore. En France, ce serait pis. 11 suffit que l'autorité commande pour que le peuple se révolte. Quand on lui dit: "Protège ", il tue ou il détruit ; quand on lui ordonne de détruire, il passe indifférent ou mème il s'amuse à protéger, pour " embêter " l'autorité et le voisin. Certes, vous vous êtes arrêtés bien des fois devant de grandes affiches blanches ordonnant le hannetonnage, l'échenillage, l'échardonnage, la destruction du houblon sauvage, de l'épine-vinette, que sais-je encore ? Mais je ne rrois pas que vous ayiez jamais vu dresser une seule contravention aux contrevenants à ces arrêtés, qui sont légion, qui sont messieurs "Tout le monde ". A peine a-t-il quitté son biberon que le Français apprend à se moquer des règlements et des lois. 11 est vrai que les règlements et les lois ne soni pas toujours d'line application commode. Et je me suis toujours demandé comment je pourrai bien arriver à détruire les hannetons sur ume profondeur de 50 mètres au long de mes forêts. Toute une brigade réunie au pied d'un chêne centenaire ne parviendrait pas, quels que soient ses efforts, à imprimer à la cime l'oseillation nécessaire pour faire tomber à terre le ou les hannetons qui dérorent son feuillage. Ce que je dis des forestiers s'applique aussi bien aux cantonniers.

L'impossibilité l'obtenir, même en Suisse, des résultats positifs par la voie des circulaires et des affiches étant bien et dument constatée, nos voisins en revinrent à la conception des enceintes fermées, dans lesquelles plantes et bêtes jouiraient d'un' entière liberté à l'abri des interventions humaines. Ils furent ainsi conduits à créer des asiles intangibles dans des régions soigneusement choisins, asiles où les végétaux et les animaux. pourraient se développer suivant les lois naturelles, évoluer avec le milieu, former enfin dans le cours des ans des sociétés semblables à celles qui existaient avant l'oceupation de l'homme.

Toutes les volontés agissantes de la Suisse se fundirent alors en une société unique, dite de protection pour la nature ", dont est membre toute personne versant une cotisation annuelle de 1 frane ou, un versement définitif de 20 franes.

A sa naissance, cette société comptait 5.000 membres disposant d'un fonds social de 20.000 francs. C'était en 1909. Depuis, le nombre des 
membres a plus que doublé. I Paques 1911, M. In docteur Schröter. l'infatigable apôtre de la Ligue, m'écrivait que cette dernière ralliait 10.000 adhérents, que ses revenus annuels étaient de 15.000 franes et que son capital inaliénable atteignait 30.000 franes. Un subside annuel de 30.000 franes est accordé par le Conseil fédéral di la société.

Celle-ci n'est pas restée inactive. Nanile de ces ressources, plle a immédiatement eréé dans la Basse-Lngadine, sur le territoire de la commune de Zernez, au sud du coule formé par l'Inn, le premier Parc national suisse. Les débuis ont été modestes. Le noyau central formé par le Val Cluoza ne renfermait de prime abord que 2.560 hectares; mais, autour de ce noyau, sont déjà venus cristalliser de nombreux cantons qui ont élevé à 5.000 hectares la superficie du Pare. Ce n'est pas tout. Chaque année voit grandir cette contenance qui sera bientòt de 21.000 hectares. Telle est, en effet, la puissance de l'attraction moléculaire, que toutes les communes avoisinant le Val Cluoza veulent ajouter un nouveau fleuron à la couronne tressée au front des Alpes par les amis de la nature. Et si l'on songe que le projet a été soumis à la votation populaire du canton des Grisons, qui l'a adopté à la presque unanimité, on pent dire que le Parc national suisse est dú à une magnifique et touchant explosion d'amour pour le pays natal.

Quelles sont les raisons qui ont fait choisir le Val Cluoza pour l'emplacement du Parc national ? Le docteur Jaceard va nous los dire : "Grâce " à son accès diflicile, le Yal Cluoza a conservé un cachet de sauvagerie " et de virginité qu'on ne rencontre guère ailleurs en Suisse au même " degré. Le domaine forestier de l'Ofeu, auquel il se rattache, présente un " intérêt exceptionnel, spécialement à cause de ses remarcquables forêts "de pins de montagne, qui sont les plus grandes de la suisse, auxquelles "s'ajoutent de belles forêts à peu près pures d'aroles, do magnifiques "peuplements mélangés d'épicéas et de mélèzes, et où se rencontrent "diverses formes particulières de torehr-pins et de pins sylv'stres (Pinns " sylvestris, d. var. engadineusis Heer; Pinus montann sar. mughus), a yant " un réel caractère botanique. Grâce à la grande diversité orographique et " pétrographique de ce territoire, la llore ainsi que la faune d'ailleurs y" " sont d'une grande richesse; de nombreuses espèces orientales et méri"dionales s'y rencontrent qui n'existent nulle part ailleurs en Suisse. "Le territoire de l'Ofeu est enfin le dernier refuge de l'ours en Suisse, et, " s'il n'y a aucune raison sérieuse pour propager d'une façon générale " cet intéressant plantigrad", lequel est parfaitement inoffensif pour "l'homme, il est, par contro, des plus désirable d'empêcher sa dispari" tion complète, de même que colle du bouquetin aui, jadis, peuplait " nos Alpes méridionales".

Non contents d'avoir créé leur Parc national, les forestirs suisses ont énergiquement poursuivi leur idée première, qui était la conservation de forêts à l'état vierge. L'n auteur forestiẹ de grand mérite, M. Dimilz, après avoir visité la forêt vierge de: la Bosnie, s'écrie enthousiasmé : "Flle est la preuve vivante que la nature est le meilleur architectr. de la forêt; si nous voulons l'imiter, nous ne pouvons que copier son cuvre». Mais, comme le fait si justement remarquer notre collègue 11. H. Badoux, où peut-on étudier et imiter l'exemple de la nature, puisque toute forêt vierge a disparu? Et cependant, c'est bien dans la seule forêt vierge qu'on pent apprécier avec súreté les exigences de nos ussences quant à la station; après une lutte plusieurs fois séculaire pour 
l'existence, olle ont pu faire lon choix; cette lutte, tout an moins entre les individus adultes, est anriver it son terme ( $\mathrm{D}^{\mathrm{r}}$. Mavr).

D'une part. les aménagements et les riploitations, les caprices et les fantaisies, ont hrisé partout ln eycle de l'cohution naturelte des massifau point que nous ignorons absolument si le recul ou l'avancenent de ceptaines essences est le fait du climat ou do l'homme. C'est ce que ne mandait dernièrement II. Charles fiahot. I peine eneore sommes-nomrenseignés sur les zones conlestéps. r'est-id-dire sur les points où les diffépentes essences entrent en rontact, et qui wst rependant un des ehapitres les phus instructifs et les phos curioux dr l'histoire do monde régétal. Et ces associations lignemses ef herbacées, que nous nous plaisons sonrent à donner comme une rraction du sol et du climat, ne sont trop souvint qu'un moment éphémèr of lugace di: la vie dos peuplements. C'est ainsi que l'on décrit à chaque instant l'association du chêne rourre, alors que ce chêne n'est parfois qu'un áchelon très bàs l'une association beauconl plus élrvée, dont nous arons brisél'évolution. D'autre part, nous n'arons, pour ainsi dire, aucune donnée sur les transformations économiques de nos peuplements. Les forestiers eux-mêmes ne sont pas d'accord sur ce qu. l'on peut demander aux différents sols. Ici on rous dit sans rire : "Les taillis de chêne meurent à 25 ans ": ailleurs, on proclame que "les taillido hêtr ne prospèrent plus à partir de 40 ans ". Cos crreurs se propagent vite et s'enracinent dans l'ane porulaire. Comment les combattre d'unt façon péremptoire, si ce n'est en montrant que la for'́t est éternelle?

Oui, elle est éternello la forêt que l'hommen n’a point torturée, n'a point modelée au gré de sus changeants caprioes, n’a puint déflorée, en un mot. et ceux qui manifestent des eraintes pusillanimes sur le danger que ferairnt courir aux peuplements abandonnés it eux-mêmes les insecteet les champignons, peuvent se rassurer. Tons ceux do nus camarades qui ont visité des forêts rierges peurent aitrster qu'ellos présentent unc. végétation subúrante et une vitalité tout a fait remarquable. I ceux qui savent voir, il apjoarait nettemnt quw ce sont surtout les apports étranwers et la rulture qui développent les malaties et les domnages causes par les insectes. Dans nos bois des allurions, la vigne saurage se rit du

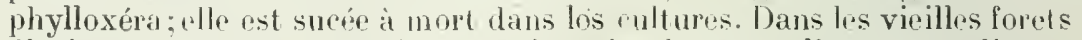
d'épicéa, hr Trametes radiciperda wxiste simplement it l'état sporadique: il décine, par contre, les peuplements crés de main d'homme. Et. pour se préservor des insectes at des champignons. lo dernier mot de la sciener "st de laissir le mélange des ressences sopérer an gré de la nature.

Les réserves forestières, qui se concilient si bion avec la protection desites et de la flor.. sollicitent donc. au même titre que les pares nationanx, dont ils sont une image affaiblie, toute l'attention des amis do la nature, des savants et des pouvoirs publics. Celui qui, sans rlles, voudrail ingre l'histoire dre la terpe mesemblerail a wt historiographe qui s'efforwrail d'éroque le passé d'un pays sans palimpsestes, sans manuscrits.

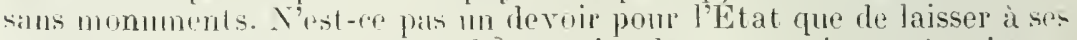
penseur's, it ses chereheurs. quelques coins de nature vierge ni puissent

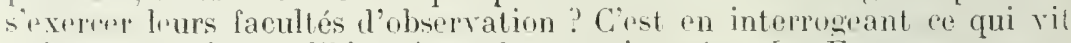
guion reconstituera l'historique de ren quij a rexu. La France est assez.

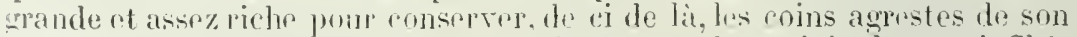
terpitoire. fou donneront is chaque region son rarher original et rai. Chê-

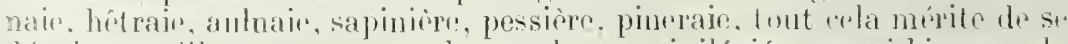

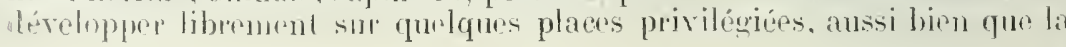


lande of le guépet, la garrigue of le maquis, la buxprate el la tourbiere. Tu libr jeu de ees associations jaillira un enseignement fécond, destiné it "xpliquer le passí et à élairer l'avenir. Pour trouver la nature recueillin ot vierge, point ne sera hesoin l'aller en Bosnie, en Nllemagne, en Norrège, en Suisse; la France, qui synthétise tous les climals de l'Europe, pourra offrir à ses enfants un champ d'éturles pour ainsi dire illimité.

Et maintenant que je viens d'esquisser à grands traits le magnifique courant d'opinion qui se dessine ehe\% les peuples voisins et qui les pousse irrésistiblement à reconstituer lo berceau de l'humanité, tout en respectant les curres grandioses de la nature, ll me reste a indiquer ce qui a sté fait en France, w plutôt ce que l'on projette de faire et comment il faut le faire.

Les séries artistiques, que nous avous vu éelore en 1861 dans la forêt de Fontainchleau et qui existaient de tont temps en Clartresuse, ont cédé devant l'espril de fiscalité outrée qui a sonfllé en tempête sur la France a la suite de nos désastres. Jusqu'à ees dernières annés, on peut dire que les particuliers, comme l'Etat a vaient honte de leur's richesses. Et, rlu passé d'épargne, des fastes de notre listoire, des monuments qui rappellent notre splendeur et notre richesse, chaque jour en emporte un lambeau.

Après arnir sorti du tombeau de l'oubli la grande figur de Surell, je me suis adressé à ceux qui m'avaient suivi dans cette entreprise. Et, de même que c'est à Grenoble que l'ourre de Surell a été magnifiée. c'est à Grenoble encore que la "Société forestière de Francle-Comté et Belfort " a voté une motion, la première. en faveur de la eréation des Pares nationaux en France. J'arais, en effet, insisté pour qu'on traitât en assemblée générale cotte question, dont j’avais précédemment exposé les premier linéanents dans une eauserie an Bio-Club.

L'annonee était à peine faite que je recus me lettre chammante de mon excellent maître et ami, M. le docteur Flahault, mo demandant de lui passer la parole. Avee un tel concours, l'issur. Im: pouvait être douteuse. La motion fut votée d'enthousiasme.

Mais il y a sourent loin do la coupe aux lères, ut il ne suflit pas de voter des motions pour en voir s'eflectucr la réalisation. Le problème était posé. Allait-on pouvoir le résoudre? Après avoir rappelé les résult ats obtenus dans les autres pays, M. Flahault s'écriait: "V Vila bien des exemples a suivre. La France le peut-elle? Des pessimistes diront que non! Les difficultés sont grandes et je ne m'illusionne pas à ce sujet».

Oui, les difficultés étaient grandes, mais avec la foi nous les arons vaincues.

Tout d'abord, il s'agissait de trouver l'emplacement du pare national. Chacun avait son idèe là-dessus. Les uns le voulalent dans l'Estérel, les autres en Chartreuse; d'aucuns le plaçaient dans le Queyras et d'autres dans Belledonne. Et cette diversité d'opinions tenait à ce que l'on n'était point du tout faniliarisé arec la conception du pare national, impliquant l'abandon de la nature à olle-même. L'Estérel ne convenait en rien parce qur, d'une part, il appartient à une région maritime to chaude, parce que, d'autre part, ses peuplenents ont été profondément modifiés par l'lomme et que de désastreux incendies s'y observent tous les ans. La Chartreuse n'avait pas dr glacier's, et l'on ne pouvait vraiment, pour des motifs économiques impérienx, suspendre les exploitations tan ce massif. C'était vouer les populat ions r.r la région is une véritable ruiu11 Y a minux it faire en Chardeuse, of nous y travaillons: cist de rémin? 
en une seule masse forestière tous les pâturages des hospices. Le jour oì cette acquisition sera réalisée, la Chartreusé sera un incomparable asile pour la faune et pour la flore des Préalpes. Nous y réintroduirons, le 20 juin prochain, le cerf, le chevreuil et le grand tétras. Le Queyras était loin, difficilement abordable. Enfin Belledonne était déjà défloré par l'industrie; des robinets avaient été mis à ses lacs; ses glaciers étaient petits, et l'on me demandait des sommes fabuleuses pour la région voisine du Glandon.

De prime abord, j'avais songé à Saint-Christophe-en-Oisans et plus spécialement à la Bérarde. La paurreté du pays, la faible densité de la population, un abord relativement facile, une nature impressionnante par sa sauvage grandeur, des cimes admirables, des glaciers éblouissants, une vallée étroite, fermée, facile à verrouiller, la présence d'une faune alpine encore riche, tout me portait à persévérer dans mes desseins. Les critiques ne manquèrent cependant pas. On objecta tout d'abord qu'il aurait fallu prendre un massif homogène, entier, et ne point se borner à quelques versants, à quelques fonds de vallées. L'objection était mesquine. car l'emplacemeni choisi permet justement l'extension presqu'indéfinie du Parc sur le territoire de communes ainsi paurres, aussi étendues, aussi déshéritées et aussi intéressantes que Saint-Christophe. Dans un avenir très peu éloigné, le Pelvoux constituera le plus beau pare du monde entier. Et il est tout entier francais, francais dans son noyau, français dans son pourtour, ce qui n'est le cas ni de la Vanoise, ni du Mont Blanc, les deux seules régions de nos Alpes qui offrent un déploiement de. glaciers et de lautes cimes égal ou supérieur.

On fit ensuite valoir que le Pare national ne comprendrait pas de forêt et que sa flore était particulièrement paurre et monotone. En ce qui concerne les forêts, il est rrai qu'elles ne sont pas très bien représentées. Il existe cependant au-dessus du Plan du Carrelet un massif important de pins de montagne, jadis mélangé de cembros, et merveilleusement situé et agencé pour servir de refuge à la faune du pays et à celle qu'on se propose de réinstaller.

Cette relique a un intérêt considérable, car, de son extension ou de son rétrécissement, on pourra tirer argument définitif pour ou contre la dégradation du climat alpin. Les derniers arbres sont actuellement situés vers 2.450 mètres d'altitude. On aura à repérer soigneusement cette limite supérieure, comme on le fait d'ailleurs pour le front changeant des glaciers.

Il est incōntestable que ce lambeau de forêt est le débris d'un massif beaucoup plus étendu, qui couvrait jadis tout l'espace dévolu actuellement aux pâturages. Et il n'est pas rare de trouver au milieu de ceux-ci des souches de pin attestant le recul de la végétation forestière qui s'est élevée jusqu'à 2.700 mètres environ. Les cembros du sommet ont disparu sous la dent des troupeaux, comme les mélèzes du bas sous la hache des cultivateurs. Un seul exemplaire d'arole existe encore dans le fond du rirque de la Bérarde, non loin du glacier de la Piłate, et le dernier mélèze, qui marquait l'emplacement du pont jeté sur' le Vénéon, a été coupé il y a quelque dix ans. Par derrière les cimes de l'Oisans, sur les versants de la Vallouise, qui tôt ou tard seront réunis au Parc national, la forêt a conservé plıs d'empire, et nombreux sont les massifs de mélèzes et de ceml.ros qui pourraient ceindre d'une verte couromne le front blanc du Pelvoux. Ce ne sont done pas les arbres qui manqueront i notre Pare nationat. 
Au surplus, si nous nous interdisons de construire des hôtels, de travailler la terre et de planter dans les limites du territoire réservé, nous nous ménageons la possibilité de reconstituer la flore locale, en confiant au sein fécond de la nature les semences d'espèces qui, comme je viens de le montrer, ont paré à une époque relativement récente les flancs de ces montagnes. Je dis à une époque relativement récente, car les archives communales de l'Oisans permettent de déchirer facilement le voile du passé et de reconstituer, sur des bases solides et précieuses, l'historique forestier de la région. S'il est un pays déboisé, c'est bien celui qui s'étend autour du massil des Rousses, et les pauvres chalets égrenés au milieu des pâturages en sont réduits, pour se chauffer, à brûler la bouse de vache séchée contre les murailles des habitations ou contre les rochers qui émergent de la verdure. Or, les premiers déboisements, effectués sur le territoire de la commune de Beye, remontent à 1340, et c'est seulement pendant la nuit du 15 août 1540 que le feu fut mis à l'immense forêt de Mélèze qui, de l'entonnoir de la Salsse, s'étendait vraisemblablement sur tout le plateau d'Emparès. Et, dans les ruines de ce qui furent de gras et riches pâturages, on retrouve encore quelques souches épargnées par le temps. Or, il y a de fortes raisons de penser que la nature est capable à elle seule de guérir les plaies ainsi creusées en son flanc par les hommes. Elle y mettra sans doute le temps ; elle passera sûrement par bien des transformations, par bien des étapes; mais chacune de ces transformations, chacune de ces étapes constitueront un précieux et inimitable enseignement.

Le cirque de la Bérarde se composant d'un noyau de protogyne massive, sur lequel s'appuie de tous côtés une épaisse écorce de gneiss déchirés et fracturés, il est certain que la flore, essentiellement silicicole, n'offrira pas la richesse des terrains calcaires et liasiques. A ce point de vue spécial, nous sommes un peu moins bien partagés que la Suisse. Cependant, des lambeaux de terrains secondaires paraissent subsister dans les replis du gneiss (Ch. Lory), et l'inventaire floristique de cette vaste région doit ménager bien des surprises à ceux qui auront le devoir et la mission de le dresser. Le glacier du Chardon, exploré par l'abbé Ravaud, renferme une flore variée et qui est loin d'être sans intérêt. Ce qui doit au surplus attirer les savants, c'est moins encore l'étude de quelques types peu communs que les rapports inconnus qui s'établissent entre les végétaux et les animaux abandonnés à l'état de nature. Les biologistes trouveront là une mine d'observations inépuisable.

Dans une goutte d'infusion de foin, on voit se succéder, rapidement et dans un ordre déterminé, tout un monde d'infiniment petits. Une prairie est de même dans une perpétuelle rénovation, mais l'évolution se poursuit si lentement qu'on la soupçonne à peine. Reconstituer les phases de cette lutte, montrer comment se forment, s'enchaînent et se détruisent les associations du monde végétal, tel est un des problèmes qui retiendra longtemps encore l'attention des observateurs et qui offre beaucoup d'intérêt, mềne au point de vue pratique. Chacun sait que la composition floristique d'un pâturage brouté diffère profondément de celle d'un alpage fauché, et la composition du foin sauvage n'est pas cell.t. du foin récolté sur des prairies que visite la faulx. Même entre deux alpages. dont l'un est fauché tous les ans rt dont l'autre ne l'est qu'à des inter-, valles plus ou moins éloignés, la dissemblance est profonde. Mais la lutie ne se confinera pas toujours entre les herbes qui composent le tapis végétal. Tout un monde de végétaux plus puissants, artrisseaux, arbustes, 
mortes, "litreront "n lice is lenr tuur, suivant lenr alfinité, leur trmperament et leurs exigences, et viendront donner un nouvel intérêt ì cecombats dont l'hist.oire nst encore si mal connue. Cest toute une noisson de fails ì récolter'.

En plaçant le noyau du Parc national à la Berarcle, éélail aussi st réserver la possibilité d'étendre l'aire de ce parc, en y englobant toutes les régions désertes du Pelvoux. Par là, on réalisera l'union de denx climats, de deux cieux, de deux Alpes: la verte et la sèche; par là encore, on aura la diversité des terrains et, par suite, aussi de la flore. Abords saurages, cimes majestueuses, glaciers étincelants, nature mourante, mais seulement de ses blessures, et qui cache encore en son sein des trésors de force ut de vigueur, susceptibles de la faire revivre dans un cadre de superbe verdure, rien ne manquera au Parc national franęais pour en faire un site 'nchanteur pour le touriste, l'artiste et le sarant.

D'autres raisons encore militaient puissamment en faveur du choix dr la Bérarde. La commune de Saint-Christophe ayant loué ses pâturages à l'Etat et à un groupe de sociétés, parmi lesquelles je citerai le Syndicat des lorces hydrauliques des Alpes, le Club Alpin, la Société des Touristes du Dauphiné, l'Association dauphinoise pour l'aménagement des znontagnes, il ćtait évident que la constitution d'un territoire réservé dans ces parages ne pouvait gêner beaueoup la population. L'étendue considérable de la commune (26.000 heetares) se prêtait également bien à un démembrement en faveur de l'intérêt particulier et général du pays. Enfin, l'accès de la Bérarde est facile, même pour les petites bourses.

Ce n'est pas tout. Cette région du Pelvoux est, par ses glaciers, une unine, très riche de houille blanche. Or, les glaciers, malgré les osci]lations dont ils sont le théâtre. rrculent singulièrement vite dans leur ensemble, et cela d'autant plus que l'on descend davantage vers le sud. On explique ce recul par la sécheresse de plus en plus accentuée du climat. Mais cette sécheresse n'est-elle pas due, pour une forte part, au déboisement ? Il est scientifiquement établi que les forêts favorisent les précipitations. L'homme n'a donc qu'un moyen et un seul d'entretenir cette source de richesse, et ce moyen consiste à entourer les bassins de houille blanche d'une eouronne épaisse de forêts. Soustraites aux entreprises humaines, ces forêts finiront par replacer la nature dans son cadre primitif et ménageron à nos descendants de puissantes sources d'énergie.

Si les glaciers sont une source d'énergie, ils constituent aussi des agents singulièrement aetifs d'érosion, d'accumnlation et de transport des matériaux arrachés aux flanes de la montagne. Ces amas de matériaux sont partieulièrement abondants dans la vallée rénudée et déboisée du Vénéon. Il y a longtemps qu'un ingénieur extrêmement distingué des Ponts et Chaussées, digne émule de Surell, M. Philippe Breton, a dénoncé de peril que font courir à la plaine du Bourg-d'Oisans les formidables apports du Vénéon. Ces apports finiront par combler le canal de la Romanche et par rendre illusoire la protection des digues. La plage de Buclet, longue de 3 kilomètres, occupe nue superficie de 263 hectares. Sur ces 263 hectares, 195 sont couverts par les déjections du Vúnéon. On a ealculé que celte plage s'exhaussait de 24 millimètres par an. C'es। done environ 45.000 mètres rubes de maténiaux détritiques que vomit munuellement le cirque de la Bérarde. On voit par là de quelle importance ust la stabilisation des 12 i 15.000 hecures qui forment le haut hassin du Véncion. Or, j’ai la conviction profonde que cette stabilisation peut être 
obtenue simplement, sans frais, sous les seules forces de la nature, pd le reboisement et le gazonnement. La prenve matérielle en est fourni, par une mise en défends de 5 années seulement, qui a suffi pour faire reverdir les montagnes de Saint-Christophe. Le changement apporté par cett: mesure frappe les esprits les moins prévenus. Et, si l'on mei en regard des laibles sommes qui ont été versées à la commune pour la location de ses pâturages, les dépenses formidables et jamais arrêtées qu'entraine la correction de nos torrents alpins (500.000 francs pour Chantelarde, 418.000 franes pour Entraigues, 315.000 francs pour le Périer, $205.000 \mathrm{fr}$. pour le Roissard, 200.000 pour Valjouffrey, 153.000 pour Tréminis, 143.000 pour Pellafol, 137.000 Iranes pour l'achat de Saint-Maurice-enTrièves, 130.000 franes pour la Proize-de-Voreppe, 126.000 francs au Manival, 113.500 franes a Biviers, 113.500 francs anx Gorgettes, $70.000 \mathrm{fr}$. sur le minuseule torrent du Malhyver sur Claix, ete.), on recomnaitri que le Pare national est vraiment digne d'intérêt pour les résultats qu'il permet d'entrevoir, pour les enseignements qu'il no manquera pas de procurer.

Mais ce n'était pas tout que de trouver l'emplacement dı Parc national, il fallait encore faire partager ma foi d'apôtre aux populations intéressérs, il fallait les amener au sacrifice temporaire dont la conséquence immédiate sera la riehesse du pays. Coûte que cuûte, en effet, il importe de retenir dans l'Oisans la population robuste et saine, qui cherche à s'en ivader. Et il n'existe guère de moyen plus rapide et plus sûr que celui de créer, on cette région, un centre d'attraction artistique, touristique et scientifique. L'exemple de Chamonix et de Zermatt est là pour en témoigner.

La tâehe était d'autant plus dure qu'il Pallait aller vite et dommer a l'œuvre d'inébranlables fondations. L'achat par l'État de ce qui doit constituer le noyau du Pare nationals'imposait done. Après bien des pourparlers, apres bien des heures angoissantes d'espoir ol de déeouragenucut, la munieipalité de Saint-Christophe consentit enfin à vendre à l'État, pour un prineipal de 100.000 francs, 4.248 heetares formant le fond du cirque de la Bérarde et eompris entre le glacier dı Chardon et le ravin de Bonme-Pierre. Elle fit mieux encore ; elle lona à nouveau le parcour's sur 8.714 hectares, en y ajoutant le droit de chasse. A l'heure actuelle, on peut done dire que le Pare national de Saint-Christophe renferme une étendue de 12.962 heetares, ce qui le classe parmi les plus grands et les plus beaux de l'Europe. Ionneur donc à la bonne et vaillante municipalité de Saint-Christophe! Honneur aux habitants de la Bérarde ! Et is ce propos cqu'il me soit permis de rapporter co mot du jeune et intelligent maire de Saint-Christophe, M. Casinir Gaspard, disant au moment de signer la délibération qui consacrait l'acquisition des terrains : "Less Lorrains d'Arracourl viennent de faire leur devoir onvers la patrie en se rendant d'un cueur joyeux à l'appel de la mobilisallion ; a nous maintenant d'aceomplir vis-i-vis de la France notre devoir de bons Dauphinoi- " Je voudrais que ces mots fussent gravés dans la pierre à l'entrée du Pare national et qu'ils aient un écho, ın long écho, dans tout le Dauphiné el dans foute la France. Less cœur's généreux sauront recommaître, j'en suis sirr, le bean geste du maire et du conseil municipal de Saint-Christophe.

Ét main lenant que voili l'ocuver laneée, il faut la complétoren étendant nus conquêles, un annénageant lo. Pare, e'est-à-dire en y construinant les. sontirrs et les luttes nécristaires, en y réintroduisant les esperess anmalis 
et végétales qui ont disparu. Il nous fant de l'argent pour payer des gardiens, pour acheter bouquins, grands tétras et graines à confier à l'alma mater. Allons-nous nous en remettre à l'État-Providence du soin de tout cela? Pas du tout, et c'est ici qu'apparaît le rôle des grandes sociétés touristiques, comme le Touring-Club de France, le rôle des sociétés alpines et scientifiques. L'État nous a fait un cadeau princier, qui donne à l'entreprise son caractère national. Nous ne lui demanderons pour l'instant que de louer pour 1 franc par an, à la Société des Parcs nationaux de France, que nous allons immédiatement fonder, si vous le voulez bien, l'acquisition qu'il va faire à la Bérarde. Et, pour donner à cette "Ligne» le caractère patriotique et populaire, qui doit en faire la force et la grandeur, nous ne demanderons aux adhérents qu'une cotisation annuelle de 1 franc ou, une fois payée, de 5 franes. Bien entendu, nous ne refuserons pas les dons généreux des favorisés de la fortune qui voudront bien s'associer de façon plus complète à cette œuvre si française, qui est à la fois une œuvre scientifique, une œuvre économique et une cuvre de haute éducation sociale. Comment fonctionnera cette Ligue? Oh! le plus simplement du monde. A sa tête, un comité central qui comprendra des représentants de toutes les sociétés scientifiques et alpines parisiennes, de façon à coordonner les efforts de la province; puis des comités régionaux, formés des mêmes éléments et qui, eux, feront vivre les pares nationaux. Pour que ces créations puissent, en effet, vivre et se développer, il faut qu'elles aient leurs racines dans le pays même, fier de son ouvre, conscient de ses devoirs, intéressé à maintenir l'épanouissement du beau et du bien. Et je demande que, dans ces comités une place d'honneur soit réservée à l'Administration des Eaux et Forêts et à la Société forestière de Franche-Comté et Belfort qui ont été les véritables promoteurs de l'entreprise et qui en ont rendu l'application immédiatement possible dans les Alpes. C'est nécessaire, car je ne vois que les forestiers qui puissent assurer l'exécution des décisions prises par les comités central et régionaux.

La création du Pare national en Dauphiné est d'ailleurs indépendante de celle de réserves forestières et autres, qui m'apparaissent comme des œuvres essentiellement locales, pouvant et devant être réalisées par des groupements régionaux, à défaut de l'intiative de l'État. Évidemment, la Ligue coordonnera tous les efforts, subventionnera au fur et à mesure du développement de ses ressources toutes les initiatives ayant pour but de protéger la faune, la flore et les documents préhistoriques du pays. Nais ce sera aux comités locanx de dresser l'inventaire de ces richesses naturelles, d'en préparer l'acquisition dans de bonnes conditions. Ici, nous créerons un parc à gibier pour nous affranchir du lourd tribu payé aux nations voisines; là, nous acquerrons un bloc erratique, débris infine mais singulièrement suggest if d'une époque disparue; plus loin, nous nous approprierons une caverne, sur les murs de laquelle nos primitifs ancêtres ont tracé d'une main gauche et hósitante les premières ébauches de l'art ; ailleurs, nous achèterons un coin de rochers, une tourbière, derniers asiles de plantes méridionales ou septentrionales, qui éroquent des climats plus doux ou plus âpres, des mondes et des civilisations disparus.

Et quand l'homme des champs, allant accomplir' son dur labeur, verra ressusciter sous ses yeux l'histoire de la terre, il comprendra qu'il y arait ici-bas quelque chose avant lui et qu'il doit laisser quelque chose après lui. Peut-être alors son cour s'ourrira-t-il à la pitié pour les bêtes 
qui embellissent et adoucissent son existence, et son âme percevra-t-elle la plainte de la nature qui expire sous ses coups?

Ah! certes, l'œuvre à accomplir est aussi grande que noble; mais il faut se hâter. Demain, il sera trop tard; demain, le poulpe aux mille bras qui s'appelle la cupidité humaine aura, pour un peu d'or, défloré toutes nos montagnes, anéanti tous les souvenirs qui nous rattachent au passé et qui font de la Patrie la terre à jamais bénie, à jamais aimée et pour laquelle sont doux tous les sacrifices!

II. Le Président. - Je vais, si vous voulez me le permettre, commenter en quelques mots, les grandes lignes de ce rapport.

Il vise trois points principaux : le premier est la définition de ce. qu'est un pare national ; le second est l'exposé historique du développement de la question dans les divers pays ; le troisième est l'exposé de l'initiative personnelle accomplie par 11. Nathey pour la constitution d'un pare national en France.

Je crois que, dans un Congrès international comme le nòtre, il peut ètre intéressant d'indiquer les effor'is particuliers qui ont été accomplis. mais, cependant, je suis d'avis qu'il faut laisser ces efforts au second plan et envisager surtout le problème au point de vue général et international.

M. Flahault m’a clit qu'il serait heureux de résumer le rapport de M. Nathey et de nous exposer en même temps ses idées personnelles sur la question. M. Flahault est une lumière en ces matières et il est placé mieux que quiconque pour nous intéresser. Je lui donne done la parole.

M. Flathlt - Je n'ai pas besoin, messieur, de vous redire combien il est regrettable de ne pas pouvoir entenrtre M. Mathey qui a toujours été un défenseur extrêmement ardent et éloquent des idées qưil préconise.

Je laisserai de còté ce qui concerne l'historique pour mocenper des derniers évènements qui se sont produits en Europe sur le point qui nous intéresse. Je passe ilone l'histoire du parc de Yellowstone qui a été notre point de départ et nous a servi d'exemple, mais je prends cependant la permission de vous rappeler les efforts réalisés depuis quelques années par les Suisses.

Les Suisses sont des pnaturalistes excessivement affinés et des amateur's de la nature sous toutes ses formes. Or, ils ont été extrèmement frappés des dégradations subies par la nature du fait de l'homme. Les chemins do fer n'ont pas en effet besoin d'être à crémaillère pour introduire dans la vie les perturbations les plus profondes. La bouteille lancée par un voyageur contribue à molifier la llore do la prairie danlaquelle elle tombe. De plus une, foule d'animaux disparaissent d'un pays par le seul fait du siffet des locomotives. Il y a six semaines. je mo trouvais dans le golfo de Tunis : dans cette rigion on ne voit plus guère de flamants depuis le jour où le sifflet du chemin de fer est vernu les elfrayer! 
Cinsi lone le geste du malotru qui jelte une bouteille par la portière H. Le sifflet pourtant passager des locomotives suffisent à troubler la faune et la llore d'un pays. Cela vous montre quelle est laetion consriente et inconsciente do l'homme lorsquil eherche à tirer un profit immédiat de la nature autour de lui. Nous ne voyons ordinairement dans nos exploilations - je fais exception pour les forestiers que le bénéfice; quand noussemons du blé, nous demandons que ce blé se transformo en argent te plus tòt possible. Evidemment nous whtenons souvent de la terre un rendement superieur, mais il n'en est pas moine certain que nous portons, en agissant ainsi, une atteinte ponstante à lorde do la nature et "est ce trouble qui, de fil en aiguille, arrive à allírep les "enditions génirales posées par la nature: il les altère en modifiant les climats, en morlifiant le sol et en morlitiant la couverture virante du même sol. Ine quantité consirléralile de plautes ont disparu. II. Matley, dans son rapport, nous en cite un exemple très intéressant : il sagit de lasisuciation du chène. Or, ce chêne n'est qưun érment très lointain $n$ répondant plus du tout a létat primitif de lassoriation qui, en ríalite, itait tout à fait différente.

Aujourd'hui les geologues commencent avee un intorèt extrême àsaisir dans le passé les modifieations des groupres biologiques d'espéces; ils eommencent a petpouver au-delà des tumps glapiaires, jusque dans la periorle tertiaire. les groupenents les êtres notre eux et lharmonie do res groupements. Cost rettre harmonir que nous voulons voir respecter par l'homme. L'homme fait partic des assoriations vivantes: il un ost un bement si ussentiel ot si puissant que, tout naturellement, il sost imagino être le maiter dr la nature. ()r. il n'an est pas aiusi. Lorsqual a commis des artions impertentes sous ante impulsion du bonelier immerliat que je signalais a l'instant, il a dielanche reptaines lorers; an compant des forèts, il a mis an branle des forrents et formi

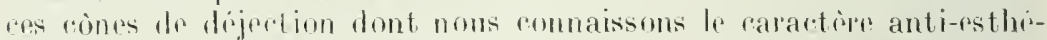
tiqur. Il en est de mêmr par ailleurs. Je suis convaincu que M. SainteClaire Deville est d'aceord ave moi et ne me contredira pas lorsque je dirai qu'il suflit de penelser tans une forè frour pouvoir déclarer

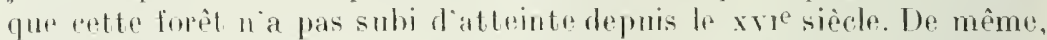
nous summer rapables de dire que telle atutre forêt a ót malarlooitement administrér, quelle a perdu son caractere et quelle nost plus dans lorde de la nature.

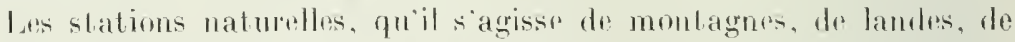
dunes, de lalaises, oi la vie présente a nos yeux un rarartère tout à fat mormal et ordomné, sont exressivement rares. I part le fond de la Hongrie et aussi quelques forêts du Nordland sumbois que jai an le:

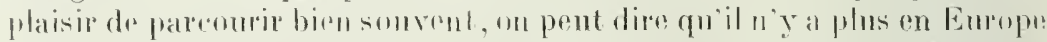

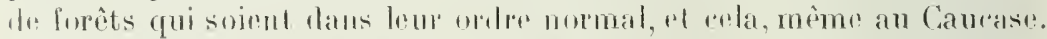
Lussi nous venons demandere, au nom de la sciener future, que notre.

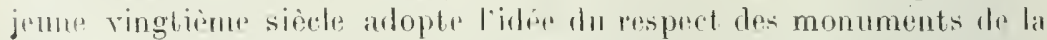

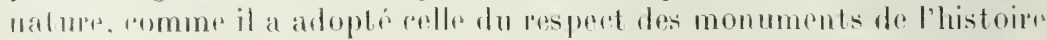

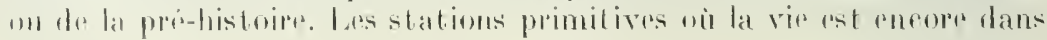


son équilibre normal, valent autant que Notre-Dame ou les Pyramides d'Egypte! Nous demandons done qu'elles soient considérées comme sacrées. Chaque pays doit porter tous ses efforts à la conservation des monuments et permettre l'évolution de la nature dans toute sa régularité et sa simplicité, lni laissant ainsi son libre jeu en certains points. Nos successeur's ne pourront point ainsi nous accuser d'avoir fait de notre planète une terre inhabitable.

Il ne faut pas oublier qu'aujourd'hui la destruction des espèces se poursuit arec un acharnement extraordinaire. Les autruches ont disparu de la Tunisie et cependant dans mon dernier voyage, j'ai trouvé dans le désert, des traces certaines de lenr présence antérieure dans cette contrée. Vous savez ce que deviement les derniers ours de nos Pyrénées : on les voit traînés par des tziganes et dansant au son du tambour de basque dans nos villages pour faire tomber des sous dans le chapean crasseux des Romanichels! II est pourtant infiniment intéressant qu'il y ait encore des ours virants, et qu'un jour nous puissions comparer nos ours quaternaires à reux que nous pourrons voir antour de nous. Il faut que nos descendants puissent se rencontrer arec les ours dans les bois et que pour eux cet animal ne soit pas un mythe! Il est également essentiel que les castors, qui sont un des souvenirs les plus intéressants de notre histoire humaine primitive, soient protégés, non pas seulement par un arrèté départemental du préfet du Garl, mais encore par la société, non pas pour la France, mais pour le mond 11 en est eneore de mème pour le flamant rose de notre Camargue.

J'en dirai encore autant de l'aigle. Lorsque la Suisso a liecidé de faire un pare national dans l'Engadine an Val Cluosa, nous arons déclaré que la suciété tronverait sur son capital les fonds nécessairez pour rémunérer, à la suite d'expertises, les persounes qui auraient à se plaindre des dégàts. C'est un sacrifice qu'il fallait faire, parce que quand l'aigle royal aura disparu, il y aura lieu de le regretter. En dépit du mouton qu'il emporte quelquefois, nous avons intérêt à le défendre, car nous ne savons pas dans quelle limite il est bon ou maurais, nou. ne savons pas quelle est sa place dans le jeu de la nature.

Je passe, depuis longtemps, tout mon temps disponible dans les Cérennes. Dans cette région, il y a quelques années, nous étions infestés de viperes. Or. mes deux jeunes enfants ne rencontrent plus jamais aujourd'hui de ces reptiles. Il n'en est pas moins certain pourtant que nous sommes impuissants à empêcher la reproduction de ces animaux. Savez-vous à quoi nous attribuons la disparition des vipères? A la multiplicité des sangliers. Les sangliers sont d'artifs chasseurs de vipères. Voilà done denx animaux considérés tous les deux comme nuisibles qui établissent, l'un au regard de l'autre, un équilibre que nous ne sommes pas maîtres de modifier.

II. Sainte-Claire Deville pousse plus loin la même constatation et délare qu'il y a une quantite d'insectes qui ont leur place dans la nature et qui demandent à être protégés. Les êtres vivants demandent 
cette protection les uns contre les autres, si nous voulons connattre l'ordre de la nature.

Lidée maitresse que nous défendons en Suisse et en France avec M. Mathey, c'est celle de la conservation des espèces dans leurs rapports relatifs. Notre but est de faire cesser le travail de destruction méthodique qui résulte de la recherche d'un gain immédiat, afin do permettre à tous les êtres de retrouver leur équilibre, et de nous éclairer sur une quantité de points fondamentaux, comme la question de l'altération des climats au sujet de laquelle nous avons tous des convictions faites, mais sans avoir aucune preuve scientifique.

Les climats s`altèrent. Ils ont été altérés, nous en sommes certains, par les excès du déboisement en montagne, mais nous n'avons pas la preuve absolument scientifique de la chose. Le jour où à Val Cluoza ou au Pelvoux, on aura pu constater le retonr naturel de la forêt vers les sommets, nous avons tout lieu de croire que la preuve se fera évidente de ce qui est la conviction de tous les hommes qui se préoccupent de l'avenir de notre planète, à savoir que l'homme, dans sa gestion de la terre, doit, avant tout, respecter les lois de la nature.

Voilà pourquoi nous demandons qu'il y ait quelque part des réserves intangibles à tous, intangblies à l'amateur de chasse, comme au cultivateur, comme au braconnier et que, dans ces réserves, la vie se développe dans le but de fournir à la science des données positives sur le jeu libre de la nature. Ce que I'Amérique a fait dans le Yellowstone, nous demandons qu'on le fasse chez nous. C'est un fait accompli au Pelvoux. Nous le demandons également pour une quantité de choses d'importance topographique ou géographique beaucoup moindre, pour de très petits coins, exactement comme les archéologues déclarent intangibles un dolmen, un menhir, ou un rocher sur lequel les préhistoires ont gravé quelques animaux qui n'existent plus dans nos pays. De mème qu'on l'a fait pour un bloc ematique, perdu très loin de son lieu d'origine, nous demandons qu'on le fasse pour un coin de forêt où vivent quelques insectes, comme le cirque de Gavarnie par exemple.

Voilà ce que M. Mathey aurait voulu vous dire en concluant. Il vous l'aurait fait aree plus d'éloquence que moi, mais il ne l'aurait pas dit avec plus de conviction.

Voulez-vous me permettre encore de, vous demander que nous nous engagions moralement ici, à être tous des membres fondateurs de la Société des Parcs nationanx de France. Nous domnerons ainsi l'exemple d'un groupe s'intéressant à la fois à l'esthétique de notre pays et à ces choses plus profondes anxquelles se ramènent toutes les discussions, e'est-à-dire la recherche des grandes lois de la nature. Il s’agit ici d'une ouvre mondiale qui est l'honneur de l'humanité puisqu'elle Iui apporte l'espoir. Ne faut-il pas d'ailleurs que l'humanité ne sache pas faire que détruire et qu'elle sache montrer également qu'elle sait protéger ce que la nature a créé. 
M. Le Président. - Je ne saurais dire combien nous sommes touchés de la manière si éloquente et si convaincue dont M. Flahault vient de nous exposer et ses idées et le rapport de M. Mathey sur la fondation des pares nationaux. Avee son érudition profonde, il a envisagé aussi bien le rôle du pare national au point de vue de la protection des espèces qu'au point de vue de l'action que celles-ci peuvent avoir sur la conservation de notre terre et l'évolution de l'humanité. Nous voyons ainsi que le parc national est une des choses les plus essentielles et que, par conséquent, l'objet de notre délibération d'aujourd'hui a une portée considérable. Je remercie M. Flahault de la communication qu'il vient de nous faire et qui s'ajoute à toutes celles que vous avez entendues depuis le commencement de nos délibérations. Nous avons trouvé en lui un collaborateur remarquable et, puisque dès demain il va reprendre la route du midi, permettez-moi, au nom de la section, de le remercier de tout ce qu’il a fait pour elle.

M. Flahault rous a signalé la demande faite par M. Mathey de constituer la Société des parcs nationdux de Frunce. Au Comité exécutif, nous avons envisagé cette idée de la manière la plus favorable. Nous sommes disposés à la pousser le plus possible pour lui donner son maximum de développement. Notre président, M. Defert, lors de la conférence de M. Thays que je suis heureux de saluer parmi nous, a l'intention de faire une communication relative à la création de cotte société et de demander une participation au Congrès. Il me serait particulièrement heureux, lorsque cette annonce sera faite, de pouvoir dire que notre section est déjà inscrite. Aussi, je vous demande à l'issue de notre séance, de vouloir bien vous inscrire sur une liste que je remettrai à notre Président.

Je vais continuer la discussion du rapport de M. Mathey.

A mon avis, il est regrettable que M. Mathey n'ait pas cru devoir conclure son rapport par un voeu nettement formulé. Les questions que nous agitons sont tellement importantes qu’il est nécessaire d'émettre un roeu. M. Mlathey s'est contenté de demander la constitution d'une Socítŕ en France. Or, ce n'est pas là notre but unique; nous poursuivons quelque chose de beaucoup plus général. Aussi, après la discussion, je rous proposerai le vote d'un roeu. J'ai reçu une proposition en ce sens de ll. le comte Clary; j'en ai formulé une moi-même, car j'avais senti la nécessité d'arriver à une formule concrète. Nous assemblerons ces diverses réflactions de manière à en faire un tout.

M. MAIGE. - Le mieux n'est-il pas de conchure, ainsi que l'a fait M. Mathey, par une réalité, an lien d'un voun?

M. Le Présidext. - M. Nathey no conclut qu'au point de vur français, au point de rue de l'ourpe it areomplir sur notre territoire. Or, dans un Congrès international, nous derons imettre un desir qui puisse 
s'étendr à tous les pays. Nous ne derons done préconiser que des idées susceptibles dêtre mises en pratique partout.

M. le comte Chıry. - Dans l'exposé très lumineux de II. Flahault, il y a un programme très vaste de ce qu'on pourrait appeler la gestion de la nature par l'homme. Pour le point précis qui nous intéresse aujourd'hui, je rois deux choses absolument distinctes. L'une concerne le programme des réserves artistiques et touristiques. l'autre les réserves naturelles. II y a là deux choses entièrement distinctes.

M. le Présinext. - A ce point de vie, je vons demande la permission de vous éclairer sur les travaux de notre section. Nous arons déjà emis un rou sur les réserves artistiques. Nous estimons que cre n’est pas la même chose que la question du parc national.

M. le comte Crafr. - M. Flahault disait qu il fallait classer des portions le notie territuire, si minuscules fussent-elles. II y a là quelque chose de différent de l'idé d’un par national. Awx Etats- T'nis, il y a une quinzaine de pares nationaux qui comprennent 3 ou 't millions d'hectares réservés. Les pares du Jellowstone et de l'Arizona sont, non seulement des réserves au point de rue des animanx, mais encore des centres touristiques, puisque les gens peurent $y$ aller passer 8 ou 15 jours pour y laire, soit une enre, soit un séjonr d'agrément, soit une étude scientifique. En France, nous nous trourons actuellement vis-à-vis d'un parc qui répond à ce double but. C'est indiqué dans le rapport de M. Nather. Ne dit-il pas en effet, qüil faut créer me réserve, un centre d'attraction artistique, touristique et scientifique. Par conséquent, le pare national de Saint-Christophe qui va être organisé, repond a ce double programme. Ce n'est pas exactement le parc natio. nal tol que nous le concevions, tel qu’il a ité constiture en Suisse, en Suède ou en Argentine. Je crois malgrí tout que c'est un eommencement et, dans le veru que nous allons adopter, nous pourrions peut-être indiquer que le Congrès désire voir se constituer des parcs nationanx m peu différents de celui en urganisation actuellement. Celui-ci ne serait qu'un premier jalon.

M. Flahatr. - La distinctinn me me parait pas anssi nécessaire que :ela. Il n'y a actuellement aucune distinction entre lo pare national "onsideré au point de voue de la prutection de la vie et an point de vue de l'art. Lorsque les Suisses ont, prur la première fois, retenu mu bloc "rratique, ils l'unt fait au point de rue scientifique et igalement au point de voe artislique. Ce bloe qui est anx envions de Bâle, sup)-

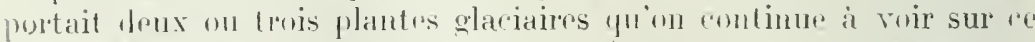
rocher. Mais ce rouher vaut a la fois au puint de vole ant istique comme au point de vue scientifique. de ne vois pas qu'il y ait lien dr distinguer. Le pare lu lal Cluoza prend toute sa valeur esthrítipe de la vie qu'il protègre. 
MII. le comte Clary et Flairatot insistent sur la héressilé de limiter la circulation dans les pares nationaux et do: u'en permettre l'accès qu'aux amateurs scientifiques.

M. VAx DE P'OLL. - Je voudrais vous dire ce que mous arons fait en II ollande. II st bien certain qu'on re pourrait pas toliper l'invasion du public faisant du bruit.

Nous avons un granl marais qui ust très intéressant au point de vü te la conservation de certains riseaux rares, comme les spatules. 11 y a une grande Sociétŕ qui a été fondée. Les personnes, membres de cette Socirté, unt le droit de visiter lo marais. Nais à l'époque où les spatules font leur nid, un ne domne qu'un nombre très restreint do permissions et l'un n'accorde pas le droit d'aller voir les oiseanx si l'on n'est pas muni d'une carte signie du secrétaire. la règlement ent très sévère.

M. Sante-Cline Dethle. - Je roudrais rulus signaler une autre -whution qui serait de s'en remettre aux etablissmments scientifiques punr la gestion de ces réserves. I Fontainebleau, il y a une statiun de biolugie vígítale qui est ouverte toute l'année et ou des savants peuvent renir s'installer. Wes établissements de cet tr nature pourraient, lì où ils existent, être employés à la surveillance des réserves. Il y allra d'ailleurs antant de modes de gestion que de ras particuliers.

M. Le Pliésuext. - Ce serait parfait si ces Sociétés voulaient lien prêter leur concours pour la garde. Nais il nous faut choisir un mode d'appliratiun.

M. Thays. - Je désirerais faire connatre co qui se lait en Argentine. J.e gourernement argentin a projeté, il y a dix ans, la formation de deux pares, l'un dans le nord et l'autre lans lo surl. Le prenier est taillis dans une forêt complètement vierge le cent mille hectares. 11 sera lui-même limité à 25.000 hectares. Jusqu’ici les difficultés d'expropriation ont empeché la réalisation de ce pare, mais elles vont s'aplanir.

Au sur, il y a un lac immense entouri de montagnes qui appartiennent presque toutes a l'Etat. II y a dix ans, lors de l'itablissement de la ligne frontière entre lo Chili et l'Argentine, lo gouvernement donna 10.000 feretares a . I. Moreno qui avait ité expert dans l'allaire. 11. Noreno a immódiatement offert an gourroment ces 10.000 tertares qui servent de noyau a la formation du pare national.

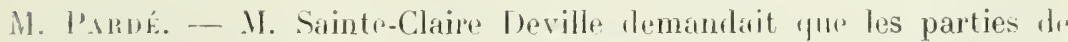

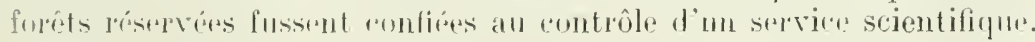

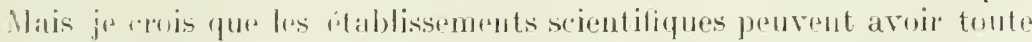

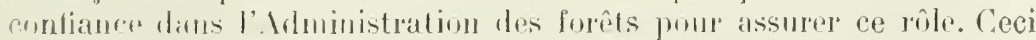

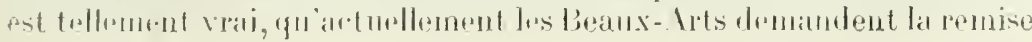


à l'Administration de certaines parties de forêts détachées dans un but artistique.

11. de Chermoxt. - Il serait nécessaire de rattacher toutes les séries artistiques à l'Administration des forêts.

11. Flahault. - M. Sainte-Claire Deville est parfaitement d'accord avec nous sur ce point lorsque je dis que les serviteurs des services scientifiques ne sont pas des agents assermentés. Ils ont des services intérieurs qui leur interdisent toute chose extérieure. Dans tous les cas, la situation des gardes forestiers est telle qu'ils peurent remplir ces fonctions.

M. Sainte-Claire Dèville. - Je m'associe à l'observation qui vient d'être présentée.

11. Le Présidext. - Si on veut faire des zones protégées, il faut les faire surveiller.

M. vax de Poll. - Le mourement pour la préservation des pares nationaux en Hollande est assez récent. L'Etat n'a encore fait que très peu de chose à cet égard. Il s'est formé une grande Société pour cet objet. Elle a dressé un catalogue de tous les monuments intéressants a cet égard, puis elle a pris en main leur aménagement. Elle a essayé, pour parrenir à son but, d'acquérir tous ces monuments : c'est le point primordial, car lor'squ'on est-propriétaire, on est maitre, et l'on peut faire tout ce que l'on veut.

M. le Présidext. - C’est un très bel exemple au point de vue du désintéressement.

11. vax de Poll. - Le Touring-Club des Pays-Bas a pris sa part dans rette charge, et cela d'une farcon importante. C'est un exemple que le Touring-Club de France snivra sans doute.

M. Le Présnext. - Le Touring-Club de France n'a jamais hésité en pareille matière.

II. VAx IE POLL. - J'ai apporté quelques photographies du marais d'Oisterwijk très intéressant au point de rue ornithologique. Il produit en outre beancoup de roseaux ; or ces roseaux servent à la couverture destoits. Cela lui permet de rapporter quelque argent.

M. Ie Présidext. - Nuus rous remerecions de rotre communication qui est fort intéressante.

M. Je comte Charx. - Dans le rapjort de M. Mathey, on ne parle pas de la protection nécessaire des pares nationaux. 
M. Le Président. - J'ai eu la même idée que rous et le vou que rous prosentez correspond à celui que j’ai rédigé de mon côté.

II. Julien Morel. - En tant que Suisse, je voudrais intervenir dans le débat très brièvement, et vous faire part de notre expérience.

Lorsque la Société pour la protection de la nature s'est créée, on a applaudi surtout ce qui concernait l'organisation d'un pare national. Elle a loué des territoires assez considérables. Tout allait pour le mieux; l'argent affluait; les cantons, puis la Confédération s'y sont intéressés et la Confédération désire maintenant prendre la chose en main. Nalheureusement la Société pour la protection de la nature a cru devoir intervenir dans une multitude de questions secondaires. Elle s'est opposée à la construction d'un chemin de fer à tel endroit sous prétexte que cette construction était un acte de vandalisme; ailleurs, elle a empêché la construction d'un hôtel. Aussi maintenant on entend dire un peu partont que la Société est excellente lor'squ'elle s'oceupe du pare national, mais qu'il est regrettable qu'elle intervienne continuellement pour parler de la protection de la nature. Il faudrait done distinguer soigneusement les deux choses : d'une part, le pare national exclusivement, d'autre part tout le reste! Il ne faut pas ínerver, ou agacer les populations.

M. Le Président. - C'est l'esprit du rapport de M. Mathey. Sa conclusion est de constituer une Société des parcs nationaux de France. Nous avons des associations de tourisme, des sociétés d'amis des arbres, des comités locaux qui s'occupent de la protection générale des richesses touristiques et artistiques. La société dont il est question dans le rapport de M. Mathey est une société uniquement fondée pour la création d'un parc national : son but en est done strictement limité.

M. Julien Morel. - C'est ainsi qu'il faut faire, car il ne faut pas se laisser déborder.

M. de Clermont. - A côté des pares nationaux, qui sont de grandes réserves, il y aurait lieu de constituer des réserves spéciales. Cela serait intéressant au point de vue zoologique pour le développement de certaines espèces d'animaux en voie de disparition. Par exemple, il $\mathrm{y}$ a en France deux endroits où l'on peut eonstater la présence, malheureusement rare, du bouquetin. Il serait intéressant de pouvoir assurer à cet animal son développement et le défendre contre les braconniers. On pourrait peut-être ne pas aller dans ce cas jusqu'à la création d'un pare national, mais on pourrait créer une réserve semblable à celle qui existe en Amérique pour la consurvation du pélican. II. le comte Clary connait certainement cette réserve, qui ne comprend que deux hectares. Elle a permis de samver le pélican en voie de disparition. Il y a igalement d'autres points stratígiques pour les oiseaux migrateurs : ils oreupent une tres petite surface, sur laquello 
ces oisfaux viennent se poser. Ces points peuvent ètre réservés sarns de lourds sacrifices.

11. Le Présinext. - Vous demandez, de même qu’on a créé des siric: artistiques. quon préenise l'établissement de séries scientifiques qui permettraient de conserver le développement de cretains insectes et oiseaux. La question ne rentre pas absolument dans celle du parc national. Ciest là une question d'espere qui se rattarhe à celle dr la réstrve artistique.

M. MAIGE. - Je mois que re sera le ròle des pares nationaux d'interdire la chasse aux bourquetins et aux autres animaux rares.

M. Le l'resinext. - Dans la définition du pare, nous avons parli de la flore et de la faune. Mlais $\mathrm{M}$. de Clermont demande qu'on réserve certains endroits pour la protection de certains niseaux rares on migrateurs. Il ne s'agit plus là d'un pare national. Ce dont il s'agit en ce moment, cost la mise en lihertó de la nature à tous lis points de vาเ

M. ne Clenuoxt. - Nous devous nous occuper également de la fame.

11. Le Présnnext. - Votre observation sera mentionnée an procèverbal et nous en tiendrons compte.

M. le comte Chars. - Il y a deux choses d distinguer, le programme des riverves artistiques et celui des pares nationaux. Quand on veut protéger un site ou un paysage, on classe ce site on ce paysage comme un monument historique auquel on ne peut plus toucher que sous eertaines conditions. Au point de vue du pare national, la condition sera la mème. On créé une sorte de musée de la vie.

Nais le jour où ce musée de la nature sera organisé, il faudra mettre sur pied me législation spéciale qui sera protectrice d'une façon absolue. Il est nécessaire en effet que ces musées soient la propriété de l'État et soient protégés par lui. 11 y aura lieu d'examiner s'il ne faudra pas ajouter des articles au Code forestier et établir des sanctions particulières. Je suis persuadé en olfet qu'il faut toute une lógislation speciale pour assurer la vie à ces pares nationaux.

II. de Clermont parlait de róserves pour le bouquetin. La première rhose à faire serait d'instituer en parr national certaines forêts : il strait nocessaire de classer plusieurs massifs de montagnes. On veut acelimater le bouquetin rans foisans. Cet animal vient de la grande ríserve du roi d'Italie: il traverse la frontiòre et entre en France. Sil existait un massil sperial où il soit eantomni, on pourrait demandere a létat de vouloir birn l'uriger en l'eserve. S'il n'est pas possible de le faire dans l'état actuel des chosps, on pourrait peut-ètre y arriver an moren d'une législation spóciale. Ciest ainsi qu'on pourait idicter l'interdiction de tirer lo bouquetin en France. 
M. Parné. - En attendant qu'uno fígislation nouvelle soit édictée pour la protection des pares nationaus, on pourrait sans doute obtenir une certaino protection en les faisant classer comme monuments.

11. Le Présinext. - Le dassement ast unt dhose particulierement difficile en ce sens qu'il est nécessaire d'avoir le consentement du propriétaire. Cest pour cela que nous voulons aller plus loin et crier les pares nationam.

II. 1E CLendont, - Je vais vous eiter à litre de curissite une loi qui va très certainement un peu toin. Cisst l'artichs 75 du Code civil de Berrıe; il est ainsi conçu :

"IL A UTURISE LE CONSEL EXECUTIF"A PRENURE PAR VOLE D'ORDONXAXCE LES MESURES VÉCESSAIRES, A EUICTER DES PEINES POUR LA PROTECTION DES MUNUMETS NATLRELS, DES PLANTES RARES, POUR PLOTÉGER CONTRE TOUTE ALTERATION DES SITES, L'ASPECT DES LOGALITÉS ET LES POINTS DE VUE; SI LE CONTELL EXÉCUTIF DÉCLARE YE PAS VOULOIR FAIRE LSAGE DE CETTE AUTORISATION, LA COMMUNE POURHA EXERCER LE DROIT QUI EN EST L'OBJET ; L'ÉCAT ET LES COMMUNES PEUVENT PROCEDEL PAR IOIE D'EXPROPRIATION ET PAR L'ÉTARLISSEMENT DE SERVITLDES PUBLIOIES ATX EAUROITS OI SE TROUVENT CLS MONIMEXTS NATIRELS, SITES, ASPECTS ET POIATS DE VIE; 1L LEUR EST LOISIBLE INE DÉLÉGUER CE DROIT A DES ASSOCIATIONS ET FONAATIOXS D'ITILTÉ PEBLIQUE. „

Ciest l'article qui va le plus loin parni tous cenx que je connais.

1I. Le Présinext. - Vous vous eontentez de le signaler?

M. de Cheruont. - Parfaitement.

Ux Cuxgressiste. - 11 y aurait lieu de alistingner entre le pare national et les zones de protection. Le pare national suppose nue propriéte acquise qui sera ensuite réservée et gardie, ce qui entrainera des dipenses considérables. Trouvera-t-on facilement des fonds? L'État rous donnera-t-il des sommes suffisantes? Il faudra de nombreuses années pour parvenir à la réalisation complète d'une telle entreprise. En attendant, ne pourrait-on pas instituer, pour la protection de telle ou telle chose, plante ou animal, des zones de protection? Cela permettrait de mettre à l'abri la llore et la faune, et ceserait un acheminement vers la ríalisation des pares nationaux.

M. LE Présinext. - Il y a là une question des plus intrirtsinates dans cotte ide de la zone de protection en vue de preparer l'oeure du paro national. Il fant eflectuer d'une maniore pratique la protection. Il faut done qu'un règlement soit fait pour etablir rette zome de protection. Toute la charge consiste dans la garde et la délenss ste la zone. Or, dans l'établissement d'un par national, la plupart du temps les terrains sont abandomins a des prix extrêmement has par les eommunes. Je rains done que si noms rommençons par

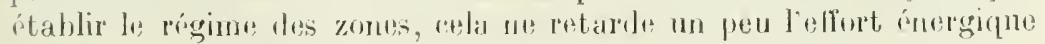


fait en vue de l'établissement du parc national. Vous redoutez un laps de temps trop long. C'est possible! Mais remarquez cependant que M. Mathey est parrenu à obtenir un résultat très rapidement dans le massif de l'Oisans.

De plus, lorsque l'on aura établi des zones de protection englobant des terrains privés. il y aura superposition du garde forestier chargé de la surveillance de la zone et du garde particulier : ne craignez-vous pas qu'il puisse s’élever des difficultés entre ces deux gardes? Je ne dis pas que votre idée ne soit pas bonne, mais je dis que l'application en sera peut-être difficile.

M. de Cleruont désirerait voir appliquer le bénéfice du classement comme curiosités naturelles aux animaux en voie de disparition.

M. Le Président. - Nous pouvons demander que chaque pays protège les espèces rares et intéressantes dans la mesure où il le jugerait nécessaire. Nous ne pourons pas aller plus loin.

Il nous faut maintenir notre programme dans ses limites. Revenons donc au pare national qui, dans son enceinte, protégera la flore et la faune. Je vais vous donner lecture du projet de vœu qui m’a été remis par M. le comte Clary au nom de la principauté de Monaco :

"Considérant que les pares nationaux constituent d'immenses réserves destinées à empêcher la disparition de la faune indigène, à protéger les espèces sédentaires, permettre les tentatives d'acclimatation d'espèces nouvelles et à favoriser le repeuplement en leur permettant de vivre et de se reproduire en toute sécurité;

"Considérant que les parcs nationaux constituent en même temps d'admirables réserves forestières;

Le Congrès émet le vœu :

"Que, dans les pays où il n'en existe pas encore, les gonvernements érigent en parcs nationaux certaines forêts domaniales, que particulièrement dans les régions de montagnes certains massifs soient classés comme grandes iéserves nationales et que, dans ces sanctuaires de la nature, une légistation spéciale suffisamment sérère y assure la protection de la faune indigène. "

Je vais vous donner maintenant lerture du projet que j'ai rédigé de mon côté :

"Le Congrès estime quill y a lieu de constituer des réserves de grande étendue dans lesquelles la nature rendue à elle-même et mise à labri de toute intervention humaine puisse laisser évoluer librement sa flore et sa faune, préconise dans ce but la création on l'installation dans chaque pays de parcs nationaux, déclare quine stricte surveitlance et de très sévères sanctions devront être prévnes pous leur défense et protection, que leur emplacement devra être choisi de préférence dans les parties les plus piltoresques du territoires. ") 
Voilà les deux projets qui vous sont soumis. Nous allons pouvoir prendre dans chacun ce qui vous paraitra le mieux convenir.

M. le comte Clary. - Je me rallierai entièrement au vou de M. le président qui est le même que le mien, sauf pour le dernier paragraphe où j'aurais préféré ne pas parler de réserve pittoresque. J'aurais préféré laisser cela à la série artistique et touristique. Je demande en outre que ce soient de grandes forêts domaniales qui soient érigées en pares nationaux ainsi que certains massifs de montagnes, parce que ce sont les deux choses qui ont le plus besoin d'être protégées.

M. Flahault. - Je suis d'accord pour cette question du-pittoresque avec M. le comte Clary. Il peut se faire en effet qu’on soit amené dans tel ou tel pays à considérer comme pare national une steppe plate : il pourra en être ainsi en Russie au point de vue de la faune. Or, une steppe plate n'a rien de pittoresque. Je crois donc que cette notion peut être éliminée ici. Bien qu'elle soit presque toujours incluse dans l’idée même de parc national, elle doit pouvoir en ètre séparée.

M. le Président. - La notion du pittoresque entrait dans le programme du Touring organisateur de ce Congrès. C'est pourquoi j'avais pensé qu'il était intéressant de la noter. Il est utile que les pares nationaux soient des endroits spécialement choisis pour leur beauté et pour l'impression qu'ils peuvent produire sur l'esprit des visiteurs. J'ai d'ailleurs mis dans ma rédaction ces mots : "Desront être choisis de préférence... ") Certes, si au point de vue de la conservation de la flore ou de la faune, il est utile qu'on organise en parc national une steppe, qui n'est pas pittoresque, on n’hésitera pas à le faire. Mlais si l'on peut allier à la fois les mesures de protection et la beauté, il me semble qu'on devrait le faire. Telle est la raison pour laquelle j'ai indiqué que l'endroit devrait être choisi de préférence dans un site pittoresque. J'arais d'ailleur's mis en tête une sorte de définition du pare national.

"Estime qu'il y a lien de constituer des réserves de grande étendue où la nature rendue à elle-même, mise à l'abri de toute intercention humaine, puisse laisser éroluer librement sa flore et su fanne. ")

Je crois que c’est bien l'idée qui a été développée par M. Flahault.

11. Flahault. - Il me semble que le voeu exprimi sous cette forme est parfaitement clair et répond à tous les desiderata qui ont été discutés ce matin. Je pense done que M. le Président pourrait le mettre aux roix.

M. le comte Charr. - Je vous demande d'insírer dans ce vou le mot de forêt, parce que j'aurais été henrenx que certaines forêts qui ne sont pas actuellement louées pour la cliasse, soient immédiatement transformées en pares nationaux. Ces forêts ont un revenu insignifiant. Il en est ainsi de la forêt de l'Aigoual. 
I. Flahil LT. - J'ai loné cette forét et je l'habite!

II. Le Présinext. - La constitution d'un pare national nécessite l'acquisition des terrains. Je sais bien que lorsqu'il s'agit d'une forêt de l'Etat, celui-ci en est déjà le propriétaire, mais le parc national prévoit la liberté de la nature et par conséquence, l'absence de toute exploitation. Lorsque nous demanderons à l'Etat de diminuer son revenu forestier. il nous fera grise mine!

11. le comte Curux. - Le ministre arait fait cette réserve à propos du classement.

11. le P'résunxt. - Nüs sommes d'arcord sur les réserves artistiquer.

11. le comte Chary. - I'un côté, il y a l'esthétique et de l'antre, le Trésor.

II. Le Présidext. - Le jour ou noun viendrons derant l'Etat, j’ai peur que nous ne trouvions le Trésor en première ligne!

Nous allons nous heurter à des difficultés de réalisation et sortir de l'idée du parc national. Ce que nous voulons faire surtout, ce sont le grandes réserves. La forêt rentre dans le domaine artistique. Or il faut laisser à notre vou le caractère très étendu de protection géne rale. Je crains qu'en parlant de forêt, nous n'arrivions à restreindre ce que nous cherchons.

I. Saxte-Claire Deville. - Je suis absolument d'accord atee vous sur la question de la forêt domaniale. On n'admettra pas facilement la transformation d'une forêt domaniale en parc national.

En dehors de la réserve artistique, la réserve scientifique a une importance considérable qui pourrait peut-être faire l'objet d'un voeu annexp. II y aurait lieu de se réserver la possibilité de demander a l'Administration un sacrifice moins considérable, à savoir la mise en réserve d'une petite parcelle pour un hut spécialement defini, soit entomolngique, soit biologique.

I. de Chermoxt. - On pourrait mettre les mots: "la serie artistique ot. scientifique ».

11. Frairault. - 11 y a lieu de distinguer les drux choses. Nous reviendrons d'ailleurs dans un instant sur la questionı des réserves artistiqur's et scientifigues. Nous pouvons d'abord roter sur lo vou de lf. le l'risident.

11. LE Présinfit. - Jo rous donne un nouvelle lecture dn premim paragraphe :

"Le Congrès rstime qu'il y a lieu de constituer des réserves de grande étendur dans lesquelles lo nature rendue à clle-méme et mise 
INTERNATIONAL 1913

à l'abri de toute intervention humaine puisse laisser évoluer libremp̀ sa flore et sa faune $).$

Je le mets aux voix.

Le premier paragraphe est adopté.

M. Le Président. - Voici le second paragraphe :

"... préconise, dans ce but, la création on l'installation dans chuqu? pays de parcs nationaux $)$.

Je mets aux voix ce second paragraphe.

Le second paragraphe est adopté.

M. Le Présidext. - Voici maintenant la rédaction do I. le romtf Clary :

"... Dans ces sanctuaires de la nature, une législution spéciule suffisamment sévère y assure lu protection de la fanne indigène...

Nous y ajouterons la flore. Voici ensuite ma propre rédartion :

"... Une stricte surveillance et de très sévères sanctions drsont étre présues pour leur défense et protection.".

Ces denx rédactions disent done la même chose.

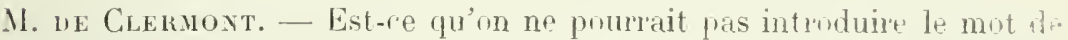
réglementation?

Ux Congressiste. - Vous avez raison.

1I. ne Clernoxt. - Nous pourrions mettre l'expression de "législation et réglementation ».

Lf. Coxgressiste. - Ne faites pas intervenir le pouroir légiclatif.

II. Le Présinext. - Le mot de réglementation comprend tout. De plus la législation peut être indispensable en France et ne pas l'être à l'étranger. Le terme de réglementation s'applique lone à tout.

Ux autre Coxgressiste. - On peut aussi bien procéder par un décret que par une loi.

II. van de Polı. - En Hollande, on a voté une loi pour la protection des oiseaux.

II. le comte Clary. - J'estime qu'en France, s'il n'y a pas de loi spéciale pour les pares nationaux, il est utile d'en créer. La loi de 1844 est totalement insuffisante pour assuser en effet leur protection. C'est pour cela que j'avais mis lans mon vœu les mots "législation suffisamment sévère. ». 
M. Le Président. - Dans la rédaction du veeu, cette question ne peut pas intervenir parce que nons devons nous placer uniquement au point de vue international. Chaque pays fera intervenir le pouvoir légis. latif s'il le juge nécessaire. Votre idée est sans doute très bonne, mais c'est à notre Commission de réalisation des vœux qu’il appartiendra de l'examiner. Votre observation sera d'ailleurs nutée au procèsverbal et nous en tiendrons compte à la Commission; nous agirons auprès des pouvoirs publics en ce sens. Chacun agira de son côté auprès de l'autorité compétente pour établir la réglementation qui lui semblera indispensable. Le mot de réglementation suffit donc, quitte à examiner ensuite dans quelles conditions cette réglementation aura lieu. Mais il nous faudrait ajouter un qualificatif à ce mot de réglementation.

M. Berr de Tírique. - On pourait mettre réglementation uppropriée.

M. le Président. - On aurait done le texte suivant:

"... L'ne réglementation appropriée et de très sévères sanctions desront être préunes pour leur défense et leur protection ».

Je le mets aux voix.

Le: texte est adopté.

M. Le Présidext. - Il reste le quatrième paragraphe qui concerne la question de la situation pittoresque. Je vous ai montré qu’il pouvait etre intéressant d'allier l"intérêt artistique et l'intérêt de la protection. Je vons mopose le texte suivant:

"Déclure que les emplacements devront être choisis de préférence dans les parties les plus pittoresques du territoire ".

Je le mets aux ruix.

Le paragraphe est adeptí.

11. Flinatet. - Je prends la liberté de ramener la discussion sur un point de détail, e'est-ci-dire sur la notion des réserves scientifiques introduites par M. Sainte-Claire Deville qui va avoir la bonté de nous dire quelques mots à cet ígard.

M. Sainte-Claire Deville. - Le vou amnexe qui ra rous être soumis était destiné à servir de conclusion à un rapport qui n’a pas été imprimé en temps utile et dont la lecture est inutile, car tout ce qu'il contenait de bou a été exposé par M. Flahault.

Je dois dire cependant quelques mots pour montrer dans quelles cunditions j’ai cté amené à le proposer. Le texte même du vou a été rédigí par un inspercteur des forôts. M. Panl de Peyerimhoff, président de la "Société d’histoire nuturelle del'.1 frique dn . Tord 》. Il a été adressé 
au Gourerneur de l’Algérie il y a 15 mois pour être applicable par décret dans nos colonies.

L'intérêt de ce rou est exclusirement scientifique. Nous savons très hien que nous ne pourons pas créer partout des pares nationaux pour conserver nombre d'espèces qui sont en train de reculer devant la civilisation, et qui auront bientôt complètement disparu. Il est donc urgent de prendre des mesures tout au moins modestes, à savoir la rréation de petites réserves qui arriveraient an but désiré.

M. le Présidext. - Vous renez d'entendre la proposition de notre collègue. Nous allons pouroir la joindre à celle que l'un de nous a faite tout à l'heure dans le même sens. On vous demandait d'établir des zones de protection, comme mesure transitoire; la proposition de II. Sainte-Claire Deville est. elle, permanente. Voici le texte que je vous propose :

"Que chaque gous'rnement poursuive l'établissement de réserves scientifiques destinées à protéger on à conserver certaines espèces et qu'en attendunt lu création des parcs nationaux, il procède à l'étublissement de zones de protection de la faune et de la flore".

Le vou est adopté.

M. Le Présidext. - Personne ne demande plus la parole.

M. le comte Clarr. - Je regrette que rous n'ayez pas cru deroir indiquer que l'affectation d'un domaine forestier aux parcs nationaux eut été souhaitable. Au point de rue forestier, il eut été naturel qu'un domaine national servit de parc national. Tous allez alors créer un pare là où il n'y a rien. Mais alors comment conserver les animaux? Comment protéger la faune? Yous n'aurez pas de pare comparable à ceux de la Suisse, de l'Autriche, des Etats-Unis ou de l'Argentine. Dans ces pays, on a pris des massifs forestiers déjà existants, ce qui a permis d'obtenir immédiatement de beaux pares nationaux. Il serait très facile de iaire classer comme pares certaines forêts. On dépense bien assez d'argent par ailleurs pour pouroir renoncer à un revenu nettement déterminé tous les ans. S'il n'en est pas ainsi, votre vou restera platonique et ce ne sera que dans bien des années qu'on pourra constituer de réritables parcs nationaux. En Angleterre on a choisi comme pare un endroit où se trouvent des arbres déjà séculaires. C'est pour cela que dans mon rou j'arais lemandé qu'on classât certaines forêts domaniales. Je crois qu'on pourrait l'obtenir. Le jour où vous aurez acheté le grand massif de l’Oisans, combien vous faudra-t-il de millions pour reboiser? Or, si l'Etat accepte cette donation, il sera bien obligí d'y consacrer l'argent nécessaire à l'entretien. Ce qu'il donnera d'un côté, il aurait pu facilement le mettre de l'autre. Il eut été plus simple dans ces conditions d'employer et d'utiliser ce qui existait déjà, à saroir une forêt. 
11. LE Présidext. - Votre ubservation est extrêmement intéressante. Mais je me permets de vous faire remarquer que, dans le vou qui vient d'être adopté, rien n'empêche l'Etat de constituer une forêt en par national si tel est son bon plaisir. Nous avons demandé yue des pares de grande étendue fussent constituis où la flore et la fame fussent protignées : cela ne met aucune barrière à rotre désir.

II. le romte Chary. - 11 eut áté du rôle du Congrès d'émettre ce vou.

M. Le Président. - Il raut mienx ì mon avis adopter des conchusionextrêmement générates qui permettent tuutes les applications sans spécifier de solutions particulières. De la sorte, nous pouvons réaliser le programme du Congrès dans les limites les plus larges. Nous avuns toute liberté pour agir en vue de l'affectation de la forêt de Fontaine. bleau ou d'une autre en pare national.

M. Iutex Morel. - On a raison de ne pas parler de furêts tomaniades, car il $\mathrm{y}$ a des états qui n’en possèdent pas.

M. Le Présidext - Comme le fait remarruer notre collègue suisse, il y a des Etats qui n'ont pas de forêts: notre roru doit être rédigi en voue de son application internationale.

Messieurs, nous voiei arrivés à la fin des travanx de notre section. Permettez-moi, an nom du Toming-Club de France, de vous remercier de la collaboration si artive et si constante que roms lui avez apportíe dans l'accomplissement de son anvre. l'adresserai tous nus remerciements aux délégués étrangers qui. avee leur connaissance si parfaite de la langue francaise, unt bien voulu nous donner des renseignements très intéressants sur re qui se passe dans lours différents payss.

11. le Président informe les Congressistes ifue M. Thays, directeur des Promenades publiques et du Jardin Botanique de Buenus-Aires, délégué au Congrès par la Société forestière argentine, frra dans laprès-midi une conférence sur les Projets de Pares Nationaux el les Forêts Natureltes de la Rípublique Argentine. Il les invite à y venir nombreux.

La séance est levée à 11 l. 25. 


\section{LES FORETS TITTRELLES}

\section{IL LA REPURLIOTE ARGENTIAE}

\section{PROJETS DE PARCS NATIONAUX}

Sous er titre, M. Charles Thays, directeur des Promenades publiques et du Jardin botanique de Buenos-Aires, vice-président de la Société Forestière Irgentine, a fait aux membres du Congrès une conférence extrêmement intéressante, accompagnée de deux cents clichés raractéristiques de l'importance et de la beaute des forêts argentines.

M. Henry Defert a remercié en res termes le conlérencier :

\section{Mesdames, Messieurs,}

te ne veux pas lever la séance sans remercier $\mathbf{I I}$. Charles Thays de la très intéressante et très agréable conférence qu'il vient de nous faire. II a fait passer sous nos yeux une série de tableaux aussi artistiques qu'instructifs, dont nous autres, Français, pourrons tirer le plus grand profit. L Gourernement argentin nous montre la voie que nous devons suive pour la création en France de Pares nationaux el nous pourrons utilement nous inspirer des exemples que nous donne la République anie.

Si notre flore ot notre faune ne nous permettent pas de rivaliser aves elle, nous pourrons du moins l'imiter de loin el constituer, à notre tour, ces róserves territoriales, ces grands pares de la Nature, aussi intéressants pour les savants qu'attrayants pour les touristes.

Au nom du Touring-Club, j'exprime à notre empatriot" notre sincère reconnaissance pour la tres suggestive lecon de choses qu'il a bien voulu nous domner. 



\section{SÉANCE DE CLÔTURE}

\section{DU VENDREDI 20 JUIN 1913}

\section{Présidence de M. DABAT, Directeur général des Eaux et Forêts}

La séance est ouverte à 2 h. 35 .

M. Le Présidext. - La parole est à M. Ballif, Président du TouringClub.

M. Ballif. - Messieurs, appelé par un devoir auquel je ne saurais me soustraire et qui m'oblige à partir dans quelques instants, je me vois contraint de vous adresser dès l'ouverture de cette séance-quelques paroles qui, peut-être, auraient trouvé mieux leur place à la fin. Je rous prie de m'en excuser.

En qualité de président du Touring-Club de France, organisateur de ce Congrès, j'ai l'agréable mission de vous remercier du précienx servie que vous venez de rendre à la cause forestière, de vous féliciter en même temps de l'empressement avec lequel" vous arez suivi les travaux de ce Congrès, de l'ardeur même - le mot n'est pas trop fort - avec larquelle vous avez pris part aux discussions.

De. l'avis unanime, peu de congrès ont été aussi laborieux, aussi vivants que celui-ci.

Cet cmpressement, cette ardeur sont significatifs; ils nontrent combien cette manifestation répondait à un besoin, rombien elle est arrivée à son heure, quels heureux résultats on est autorisé à m attendre.

Dois-je dire "attendre ", et n'arons-nous pas déjà des résultats? 
Daus la séance inaugurale. M. It2. Hinistr ne nousen a-t-il pas apporté déjà, et des plus prérieux?

Au nom du Congrès. jadresse à . M. le Ministre l'expression de notre profonde gratitude pour les paroles qu'il nous a dites, les encoura. gements qu'il nous a donnés. les promesses qu'il nous a faites, les résultats qu'il nous a apportés; la forêt compte en lui un défenseur et un ami. (Applaudissements.)

An nom dı Touring-Club en particulier, je le remercie également de la haute distinction qu'il a bien roulu annoncer en faveur de nos collaborateurs : le président de ce Congrès, M. Ilenry. Defert. et le secrétaire général, M. Chaplain.

Tous deux ont été l'âme et le bras de cette manifestation; c'est à lęur zèle et à leur dérouement inlassables qu'est dû son sucrès. (Applaudissements.)

Je prie M. Dabat, notre éminent collaborateur, de rouloir bier présenter à M. le Ministre l'expression de ces remerciements, et je lui demande en rotre nom, Nessieurs, de rouloir bien en prendre pour lui-même une bonne part. (Applaudissements.)

1I. Le Présuext. - C'est une mission très agréable que rous me donnez, mon cher Président, et je ne manquerai pas de m’en acquitter auprès du Ministre; je lui ferai part de ros éloges et de ros remerciements.

Je vous remercie dès maintenant des félicitations que vous avez bien voulu m'adresser, à moi et à toute mon administration qui a. tenu à donner son concours le plus complet à cette belle maniferiation du Congrès Forestier organisé par le Toming-Clul de France. (Applaudissements.)

Je vais maintenant donner la parole it chacun des présidents de section, pour qu'ils présentent les roenx de leurs sections.

La parole est à M. Cyprien Girerd, président de la première section.

M. Cyprien Girerd donne lecture des roeux de la première section :

\section{VEUX PRINGIPAUX :}

"Qne leśs éléments de l'enseignement inrestier. spécialisé selon les besoins de la région. mi il est donné, soient inscrits dans les programmes des écoles primaires.

"Qu'une entente s'étuhlisse entre le Ministère de l'Agriculture et celui de l'Instruction publique, "fin que les inspecteurs d'Académie et les agents de l'Admimistration des Eanx et Forêts soient invités à aider, de tontes manières, la ronstitution de sociétés scolaires forestières, à en favoriser le plus possible le développement, ì en assurer le bon fonctionnement et la pérennité, et propagent. lı Fête de l'A rhre. 
"Que, dans les concours nationaux on généraux, le Winistre de l'Igriculture fas'se à lu sylviculture une place correspondant à son importance :

"Par l'attribution de primes d'honneur anx meillenrs aménugements, à cenx qui anront le mienx tem compte du climat, du sol, des essences, des besoins locunx:

"Par la distribution de snbuentions, de récompenses, de prix aux meilleurs profédés d'exploitation des bois, à l'ntilisution de leurs produits et sons-produits et ì l'introduction d'essences nouvelles, de même qu'aux plantations dans les landes et autres terres incultes,

"Par l'organisation de concours destinés is stimuler toutes les initiatives entre savants, indnstriels et prodnctenes pour la recherche de nouvenux produits ot la construction des appareils propres it les extraire :

"I'ar l'attribution de récompenses an personnel i gages qui sp" sera signalé par les travaux forestiers ci-dessus et aura coopéré aver zèle à des trasanx de reboisement on d'améliorations pustorales.

"Qne l'introduction d'essences pxotiynes dans les plantations ot les reboisements forestiers soit enconragée :

"Par des subventions en nuture ot en argent:

"Par des récompenses et des primes distribnées duns les concours régionulux.

"Que les résineux soient introdnits, duns la plus large mesure, dans les taillis médiocres pour élever lenr rendement, et que l'intruduction en soit favorisée sur tons les points oì les feuillus ne sont pas susceptibles de fonrnir en quantité importante du bois d'anore de bonne qualité.

"Que les propriétaires soient cngagés pur tous les moyens, soit à prolonger l'âge d'exploitation, soit ì entreprendre immédiatement la conversion de leurs taillis on taillis sous-futuie en futaie pleine, par bonquets, assurés de compenser ainsi les sacrifices momentunés résultunt de l'opération par une augmentation de revenus certuine et durable dans l'avenir.

"Qu'à cet effet les gonvernements intéressés orgunisent des conférences faites par les forestiers de l'Etat dans les régions forestières. importantes, d'où les propriétaires partinliers puissent tirer tonte. les explications nécessaires ot intéressuntes à l'opérotion pmposép.

"Qn'il snit établi des primes à la replantation et, plus lard, nux. châtuigneraies domant les produits les meillenrs.

"Qu'il soit établi des primes ì la replantation des noygers.

"Que la station des recherches dr Vuncy concentre les résultrats ohtenus pratiquement, swit ì l'étranger. sonit par l. Irlministration fores- 
tière, soit par les sociétés d'agriculture régionales et locales, et les publie dans les bulletins dont elle dispose.

"Qu'il soit créé uu .Ministère des Colonies un burean spécial chargé :

"Du contróle supérieur du domaine forestier colonial,

"De l'élaboration d'un programme d'action uniforme pour toutes les colonies, en ce qui concerne l'unénagement progressif des forêts dans chaque colonie et lu constitution de réserves forestières.

"Que, dans le plus bref délai possible. soit déterminé dans quelle mesure le service forestier et le service de la météorologie agricole. doivent collaborer en vue de l'intérêt générul.

\section{Y'EUX SECONDAIRES :}

"Que le diplôme d'ingénieur forestier soit décerné anx élèves de l'Ecole nationale des Eanx et Forêts de Nancy qui en seront jugés dignes.

"Que l" mention "sylviculture " soit portée sur les diplômes d'ingénieur agronome et dingénienr agricole, déliorés anx élèves de l'Institut national agronomique et des écoles nationales d'agriculture qui se seront particulièrement distingués dans cette branche.

"Que des notions les plus indispensables de sylviculture et d'aménagements sylvo-pastoranx soient données dans les écoles pratiques d'agriculture et lans les fermes-écoles.

"Que lenseignement théorique et pratique de la sylviculture soit donné dans les écoles normales d'instituteurs par un agent des Eaux ot Forêts on jar tout ingénieur agronome ou agricole ayant sur son diplôme la mention "sylviculture ".

"Que la mention. "sylvionlture " soit portée sur le certificat de fin d'études nomales' des muitres qui en seront jugés dignes.

"Qu'en général, l'enseignement ì tous les degrés comprenne l'étude sommire et méthorlique des notions les plus indispensables d'économie forestière et sylvo-pastorale.

"Que les agents de T"Administration des Eanx et Forêts, les professeurs d'agriculture, les ingénieurs agronomes on agricoles pourvis du diplôme avec mention "sylviculture ", les membres des syndicats forestiers tt des sociétés sylvicoles soient délégués, snivant un proGramme fixé anmuellement, pour faire des conférences forestières et sylon-pastorules de vulgarisution duns les écoles et partout où cotte propagunde punrait être utile.

"Oue les Associntions touristiques. les Antomobile-Clubs, les Syndicats d'Initiative. les Sociétés d'Agriculture encouragent l'enseignement forestier et sylor-pastoral et conconrent à linrganisation de fêtes de l'Arbre. 
"Oue l'attention des botunistes et forestiers soit attirée sur l'étude des végétunx ligneux de la flore françuise en particulier, an point de vne de leur répartition géographique et de leurs relations avec les conditions de milien.!

"Que les faits observés duns chaque région. quclle que soit leur importance, soient publiés sous forme de notes ou de mémoires; qu'il soit dressé, le plus possible, des curtes régionales indiquant la répartition des essences on de préjérence la répartition des associations qu'elles caractérisent, en s'inspirant des principes posés par.1\%. Flahanlt.

"Que des études d'ensemble soient organisées par la station de recherches de l'Ecole nationale des Eaux et Forêts avec le concours de tous les agents des Eunx et Forêts.

"Que les parcs forestiers dans lesquels auront été faites des plantutions de végétanx exotiques, pouvant servir d'étude à l'emploi de ces essences duns les grands reboisements forestiers, snient exonérés pendant 10 ou 20 ans de tont impôt foncier, ì la condition qu'ils soient ouverts aux professenrs d'agriculture, aux ugents forestiers on aux autres personnes officiellement accréditées, en sue d'études dendrologiques, botaniques et forestières.

"Qne l'Etut entre dans la voic des essais de culture des essences exotiques!!

"Qu'on favorise, par tous les moyens, l'élaboration d'études ayant pour but de jaire connaître anx propriétaires, en citant des exemples judicieusement choisis, les espèces les mienx appropriées anx facteurs de la production et anx conditions économiques locales.

"Que dans les coupes de taillis, soumises au régime forestier, les résineux soient réservés, en principe; que. seuls, soient exploités les sujets surannés, dépérissants ou surabondants, martelés en délivrance par les agents forestiers.

"Que les propriétuires soient invités à profiter des avantages et lois existantes ou projetées pour soumettre leurs forêts à la gestion des services publics, en vne de réaliser plus sûrement et plus rapidement l'amélioration de leurs forêts dans le sens indiqué.

"Qu'en raison de l'intérêt général de la conservation et de l'amélioration des forêts, des primes, comme pour d'autres cultures, à titre d'encouragement et de compensation de la perte de revenus momentanée subie par les propriétaires intéressés, soient instituées par l'Etat en javeur des forêts améliorées, soit par l'allongement indispensable de lenrs révolutions successives, soit pur leur conversion directe en jutaie pleine par bouquets.

"Que l'Administration centrale des Eunx et Forêts fasse immédirtement l'application, à titre d'essai, dans les forêts domaniales traitées en taillis sous futaie, de la méthode préconisée et à l'étude par l'Ecole de Nancy, sous le nom de futaie pleine par bontyets.. ress essuis seraient tentés dans les jorêts proprices et dans diverses régirns: les résultuts du traitement seraient produits au prochain Congrès. 
"Qu'il soit constitué des taillis at des jutures d'aracius comme mode éennomique de boisement, particnlièrement sur les terrains propices à bresses altitudes.

"Que les terrains imprombrtifs, dont le sol, la région et le climat sont properes un châtuignier, soient remis en v'ulenr par la reconstitution de moncelles rhâtaigneraies.

"Que les châtuigneraies solent exploitées suns enlèvement de frnilles qui constiturnt la conserture morte; qu'elles soient chtretenues par un jurlinuge judicienx et par des repenplements en sujets grefjés ot soiunenssement sélectionnés.

"Qn'il sorit rréé des pépinièros destinées ì fonmir des porte-groffes. on des plants areffés dont lu délivence ponrmit se faire on gratuitement on iो prix il'argent.

"Que la loi dégrevant de tout impoit foncier pendant trente ans les terains remis an nature de bois soit étendue anx châtaigneraies nonvelles lorsqu'elles sont nécessaires an maintien des terrains instables.

"One la loi sur le défrichement des bois purticuliers soit étendue anx rhâtaigneraies, partont oil les châtaigniers ocrnpent des versants susceptibles de se dégrader, on des régions duns lesquelles ils contribuent ì régnluriser le régime des enu.r.?

"Que des coniérences destinées i instmire nos multivatenrs soipnt "rganatlisérs.

"Qne des pépinières destinées i fomrnir uratuitement, an moyennamt.

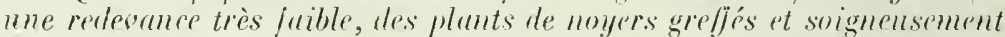
sélectionnés à tons renx qui ventent efjectuer des replantutions soient créées soms lu diretion des professeurs d'agriculture.

"Que M.le IInistre de lu Guere fasse procéder, dès à présent, à des expériences en vize de tronver un surcédané dn noyer pour la fabrication des crosses de iusils.

"One les bulletins olfirids of de renseignements ugricoles des dicerses nutions solliritent de's expériences de la part des sylviculteness : qu'ils recueillent et publient les observations communniquées et les résultats obtenus, afin que lu presse générule 't spéciule puisse s'en inspirer pour la s'ulgarisution des procédés employés.

"One le hurenn spócial du Ministère des Colonies soit churgé également de contraliser les yuestions générales d'intérêt forestier concernant tontes les wolonie's.

" (ule le rerutement des ugents forestiers à destination des pays de proterforat et des colnnies ait lien, partiellement an moins, dans le cadre des agents de la métropole, ot soit réglementé par dérets mis d"accord entre les ministeres intérossés (1 griculture, Iffaires étrangères, Colonies).

"One les Administrations" forestières de France et de l'étrunger soimt insités i prosonuer tous les renseignements des syloirulteurs mondiaux sur la croissance des arbres forestiers; que les bulletins. 
officiels of de renseignements agficoles des aliverses nutions soifnt invités à les centruliser et à les publier, ufin d'érlniver définitivement l'opinton publique égarée par les écrits d'antenrs qui, an lien de prendere ponr huse des donnés scientifiques on expérimentales, se sont latssés guider par des tendaness personnclles on par ane imagination trop fucile.

"Qne res mênes renseignements soient communtiqués ì la presse. afin yn'elle puisse s'en servir ponte la sulesurisation de cette ynestion, aII plus gratud profit de l'ensergnement public.

"Que la météorologie forestière premme un monvel essor af s'uttuche notamment à déterminer les conditions rlimatériques ot la sone mutnrelle des principales essences.

"Qne les antenrs tespmsubles des incendies dus ì lu malveillanep soient recherchés activentent, at que les ponsonirs publics lenr uppliquent. dans toute leur riguenr, les sametions prérues pur la lai.

"Que l'attention des Ponnors publics soit appelée sul la nécessité d'interdire dans les jêtes publiques on pricées le lanrement des mongolfières, en raison des dungers qu'elles présentent an point de sur iles incendies de forêt.s.

"Que, dums l'enseignrment sylvicole, des leçms suient frites sur le rôle réciproque de la forêt et de l'oisean, l'un ensers l'untre : l'oisean protégeant la jorêt conlie l'insecte, la jurêt offraut le rejuge ì l'oispan.

"Que, dans les réserves forestières et les pares nationaux, des mesures soient prises pour la multiplicution des oisenux ntiles on des espèces rares en voie de aisparition.'

"Qn'une dassification, basée sur les trusand de la Commission" instituée par $\mathrm{I}$. le Ministere de l'Igriculture, sonil étublie le plus trit possible ponr déterminer les oisenn ntiles on nuisibles.

"Qne l'Administration fusse rechercher s'il ur spait pas possible d'employer la jenille on l'écorce des lrunches du mûrier pour fabriguer de la pâte ì papier concurremment arec lu fibe de bois et les chiffons."

Tous ees vous sont arloptés sans observations.

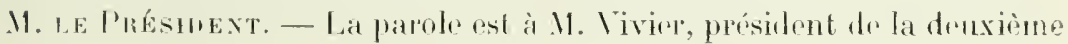
secion.

11. Vivere domme lecture des varma de la denxiemo soction:

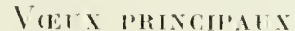

Le Comgrès. comsidérant que la conservation des forêts existant duns les régions élevées ot daus les dunes nécessite des mesures exorptimmelles et que la législution répressioe an défrichement ne suflyit pas pour assurer le maintion de res forêts,

Est d'uvis qu' une législution spéciale des forêts de protection atars les régions élevées et duns les dumes est seule aupuble de présenir les 
dangers qui résultent de leur disparition, législation préventive qui doit tenir compte de la situation économique et de l'organisation admimistrative des divers pays, étant entendu tontejois que les servitudes qui en résultent pour les propriétaires forestiers doivent être compensées pur des avantuges équivalents, tels que exemptions d'impôt, subventions et, au besoin, faculté pour les propriétaires 'intéressés de requérir l'expropriation.

Le Congrès, considérant que les droits de jonissanfe et de disposition des propriétaires forestiers sont anssi respectubles que cenx des propriétaires de tons antres immenbles : que ces propriétaires doivent avoir la liberté de jonir de leurs forêts comme ils l'entendent, sans être sonmis à une intervention administrative; qu'une telle intervention ne peut se justifier qu'en cas de dunger public et non sous le simple prétexte d'utilité publique.

Est davis que, sous réserve des mesures de conserwation qui penvent être prises contre le défrichement et pour la protection des terrains en montagne et iles dunes, les purticuliers soient libres d'asseoir dans leurs forêts telles coupes qu'ils jugent convenubles, de réaliser quand ils l'estiment opportun le matériel sur pied résultant de leurs économies, suns être astreints à aucune décluration ni antorisation préalable;

Mais attendu que, dans la crise économique intense que subit en ce mument lu propriété forestière privée, l'Ëtat a le devoir de venir en airle aux particuliers détenteurs de forêts, qui sont pour la plupurt de petits propriétaires, suivant les principes de l'égalité et de la soli. durité sociule;

Le. Congrès est d'uvis :

" $1^{\circ}$ Que lu sullicitude de l'Étut peut se manifester très efficacement, sans ancune mesure coercitive, notnmment par une répression plus effucare des délits, par des molérulions d'impôts, pur la faculté donnée anx particuliers d'ntiliser le personnel de l'Administrution des Eanx t forêts qu'il convient d'orienter en one des services commereianx qu'il prut rendre, an moins antant que dans le sens des applications techniques; par des mesures ì prendre pour arrêter la dépréciation de certains froduits lignenx (bois de chanffage, charbons de bois, éror(es); pur des institutions de crédit facilitant anx particuliers la créution oul lu reconstitution de leurs forêts;

"20 Qu'en France, la loi Andiffred soit appliquée dans un esprit do bienseillante collaboration entre l'Administration forestière et les propriótuires particuliers.

"Que, druns t'mut systène fiscul, lu buse d'ínuluation du revemu foresLier soit le produit net de la coupe normule correspondant un plan d'exploitution udoptó: nsuellement dans la région si l'impôt est réel: pur le propriétuire si l'impût est persomnel.

"Que le revem lotul annuel des forêts soit évalué anmme l'annuité reproduisunu la valent de lu roupe normale dans le nombre d'unnérs 
INTERYATIONAL 1913

compris entre deux conpes snccessives, les coupes étunt supposées régulièrement réparties sur la durée de la résolution.

"Que, excepté un cas d'un impôt unique sur le revenu, l'évaluatior. du revenu imposable des bois et jorêts soit fuite d'après les principes suivants :

"Le revenu des bois et forêts est formé de deux éléments: $1^{\circ}$ le revenu du sol; $2^{\circ}$ le revenu de l'épargne accumulée dans les arbres de futaie et les coupes en croissunce:

"Le revenu du sol est égal à l'annuité reproduisunt lu valeur de la coupe d'un peuplement (taillis, semis ou pluntution) exploité à l'àge minimum auyuel il peut fournir des produits de valeur marchande dans la région;

"Le revenu de l'épargne est la différence entre le revenu total et le revenu du sol.

"Que le revenu de l'épargne ne supporte en ancun cus l'impôt foncier, ni les impôts ou tuxes assimilés.

"Que, dans l'impôt sur la plus-oglue ou l'enrichissement, ne soient pas consilérés comme un accroissement de vuleur des forêts ì coupes non annuelles les revènus dont la perception est différée et qui restent accumulés dans les coupes en croissance en attendant l'époque de lear réalisation.

"Qu'en France le dégrèsement de lu propriété unn búlie soit onté le plus tôt possible pur le Purlement, mais, qu'en attendant, les propriétuires particuliers snient admis légalement à bénéficier immédiatement des dispositions de l'Ordonnance du 3 octobre 1821.

|"Que, pour l'impôt sur les successions, l'évaluation des forêts en capital soit basúe non sur le rendement moyen des dernières exploitations, muis sur le revenu total annuel què peut donner la forêt dans l'état où elle sp trouve ì l'oncerture de la succession.

"Que, duns les ventes de forêts en fonds et superficie, les jurdins et parcs exceptés, la oaleur du fonds soit seule imporsée aux droits sur les ventes immobilières, la valeur de la superficie étant imposée unx droits de transmission des caleurs mobilières ou an plus anx droits sur les ventes mobilières.

"Que le règlement d'alministration mublique roncernunt l'pxécution de lu loi Audiffred soit établi el publié duns.s le plus bref délui.

"Qu'à l'avenir un crédit soit inscril chuque année au lmulget des Euux et Forêts pour urquisition sur l'ensemble du territnire de forêts panyubles pur annuités.

"Que le Gouvernement de la République jrunçaise prenne l'initiative de la création ì l'aris d'an office forestirr international nuto- 
nome, dont lemplacement serait junmi par la France, et dont le budget serait alimenté par les contributions de tons les Etuts intéressés.

"(Jue les turijs des rhemins de jer soient révisés d'urgence duns un sens favorable ì la prodnction et an commerce des bois français et les colonies françuises.

\section{VIETY SECONHAHES}

"Qu'il soit accordé des dégrèvements temporaires ponr les bois rninés par des incendies, des invasions d'insectes ou des muladies cryptogumiques, dont la reconstitution par semis on pluntutions anra été reconmue indispensuble an maintien de l'état boisé.

"Que des procédés rationnels ot équitubles, basés sur les principes et les méthodes admis d'une façon générale en matière de sylviculture et d'aménagement, soient adoptés pour l'assurance des forêts et des pluntutions contre l'incendie.

"Qu'en ce qui concerne spéciulement les forêts françaises, ces principes et ces méthodes, ainsi que des modèles d'assurance et de règlement de sinistre, soient transmis anx compagnies d'assurunces on unx unions de ces compagnies par les syndicats de propriétuires forestiers on pur les fédérulions de cos syndicuts en one d'établir nne entente sur de telles bases, sans préjudice, partout où les circonstances le permettront, dn développement des assurances mutnelles bénéficiant de tous les avontages yue l'Etat accorde on accorderu anx mutnulités.

"Qne des cuntons on purcelles bien choisis des forêts de l'Etat, duns le voisinuge des grundes willes, en des prints pittoresques et fucilement accessibles, soient distraits du cudre des aménagements ordimaires, traités spéridement an point de sue de l'ornement et disposés ponr l'agrément des promeneurs at des tonristes, partunt où les circons. tances économiquess ne s'y opposeront pas.

"Que la taxe de main-morte sur les bois al forêts actunis nur les étublissements publics on d'ntilité publique ne soit pas supérieure à celle frappant les biens des communes et des itablissements publirs de bienfaisunce on d'ussistunce.

"Que les terrains reboisés on nousellement boisés pur somis on plantations soient exonérés de tont impôt:

"Pendant trente ans pour ceux situés sur le's sommets et les versants des montagnes, sur les dunes, dans les landes et les terrains marécegents:

"Pendant vingt ans pour tous les antres terraius.

"Le Congrès, rendant instice anx efforts jaits par les syndicalistes de tons les payss, les engage ì continuer de développer lenr urtion syndiscale,

"Préconise lu formation de conpératives de propriétés, complètes. ì circonseription restreinte et anies par des fédérations,

"Sonhaite que les associutions ugrionles adident de leur expérience

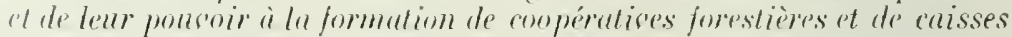
de créslit forestier, 


\section{El émet le serre:}

"Que les législations des difiérents pays sonient adaptées ì la foruntion de syndicats et de coopératives forestières ct que les Étuts fuporisent ces associations par des subventions, par des exemptions T'impôts graduées pur laide de leurs agents forestiers, et par l'organisution du crédit jorestier.

"Qne le Sénut mette le plus tît possible en lisanssion le projet de Ini Fernand Darid portant modification de la Loi du 5 asril 1882.

"Ou'ì l'égaral des massifs d'une v'aleur trop grande pour être uchetés à l'uide du crérlit ci-dessus mentionné, les Ministres de l'a gri- nlture et des Finances soient autorisés à conclure des contrats d'acquisition sons la condition suspensive de la ratification parlementuire, et qu'en eas d'insuffisance des disponibilités budgétaires le paiement en soit assuré par un emprunt amortissable, me par me arance de fonds le la Caisse des dépôts et consignations.

"Subsidiairement, yn'an cas où des ruisons funancières ne permettraient pas un de ces deux modes de réalisation des achats de grands massifs, les Ministères de l'Agriculture et des Finances aient le droit de saisir des projets la Caisse des dépôts et consignations chargée de la gestion de la Caisse nutionale de retraites en sue de l'application de iarticle 15 § ́ de la loi dn 5 arril 1910.

"Que les droits de mutution ì tilre oncreux soient réduits en cas d"ucquisition de jorêts par des commmnes ou établissements publics et même, s'il est possihle, par les associutions reconnues d'utilité publique : caisses dépurgne, caisses de retruites et sociétés de secours mutuels upprousées, ainsi que par les sociétés ronstituées on one du relioisement et de l'acquisition des jorêts:'

"Que les décrets antorisunt les conmmunes on étublissements publics i accepter des legs de propriétés forestières n'imposent l'obligation de "endre ces immenthles qu'en cas de volonté formelle du testateur."

"Que M. le I inistre de l'Intéricur invite les préfets à faroriser les opérutions qui cousistcruient ponr les communes et établissements pmblics ì transformer dans des conditions usantagenses en placements forestiers leurs valeurs mobilières et leurs domaines ugricoles.

"One le paragraphe '́ de l'article 15 de la loi dn 5 avril 1910 soit molifié pur l'élésution à 1/100 de la portion de l'ruoir que les caisses de retrailes pourrout employer en achats de bois ot de terrains i boiser.

"Que dans tons les puys, at spéciulement en Firance, l'amétroration les stations de recherches jorestières fasse l'objet de lu sollicitude purticulière de l'Administrution forestière.

"One loffiere forestier international dont lu créntion a éé préone

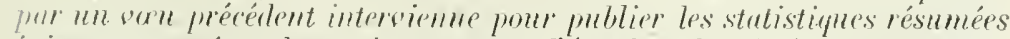
frisumt commutrer duns rhaque pays l'étendue des forêts exploitables,

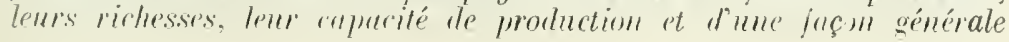


les ressources qu'elles sont susceptibles de fournir all commerce du monde entier.

Tous ces voux sont adoptés sans observations.

"Que lors de la prochaine révision des tarifs douaniers, il ne soit apporté aucune modification anx droits actuellement en vigueur sur les bois.

M. Le Président: - Permettez-moi de vous arrêter. Sur ce vou nous avons été saisis d'une lettre de M. de Nicolay, président du Syndicat des propriétaires forestiers de la Sarthe, demandant que ce vœu ne soit pas adopté.

M. de Nicolay. - Parfaitement.

M. Le Président. - En Assemblée générale, nous ne pouvons pas discuter une question an fond, nous devons accepter ou rejeter le veu proposé. Si rous le rejetez, il sera repris par la Commission permanente et pourra être représenté à un prochain Congrès, mais il faut qu'un vceu, pour être présenté en Assemblée générale, ait été discuté dans une section.

Vous avez donc à vous prononcer en l'aceeptant ou le rejetant.

Le roeu est repoussé.

11. Le Présidext. - - Le vocu étant rejeté, la question sera renvoyée à l'étude du prochain Congrès.

M. Vivier (continuant la lecture des veeux) :

"Que la proposition de loi déposée pur $1 \%$. Pasqual, député du Vord, tendant à angmenter les droits de donane sur les bois contreplaqués, soit adoptée le plus tôt possible.

"Qu'il soit établi un droit sur l'entrée du bois de quabracho en France.

"Qne les propriétaires forestiers et les négociants appartenant au commerce des bois et produits accessoires soient largement représentés, savoir:

a) An Comité consultatif des Arts et IIanufactures.

b) A la Commission permanente des Valeurs en donane.

"Que. les propriétuires forestiers et les négociants appartenant un commerce des bois et produits accesso ires soient représentés lurgement i) la section permanente du Comité consultatif des chemins de fer.

M. LE Wr VIUAL. - Je ne sais si ju ne trompe, mais jo n'ai pas entendu parler l'un veu sur les voies de communication et chemins forestiers lans la région des Maures, adopté par la deuxième section. 
M. Vivier. - Parce que la section ef le Congrès ont pensé que ceitait un appel à l'attention de l'Administration, mais que ce n'était pas à proprement parler un vou.

11. LE Dr VIDAL. - Je demande que dans vutre rapport, qui est si bien fait, vous vouliez bien attirer l'attention de l'Administration sur cette question.

M. Tivier. - Ce sera le rôle de la Commission permanente du Congrès. La Commission attirera l'attention des Pouvoirs publics sur ce point. Celle de l'Administration des forêts a déjà été appelée, puisqu'il y a au Sénat une proposition de loi sur la question que vous indiquez. Tous aurez done toute satisfaction.

II. Voelckel. - Il n'y a qu'à l'inscrire comme voeu. (Approbation générale.)

M. Le Président. - Si tel est l'avis de l'Assemblée générale?... Personne ne fait d'objection?

Eh bien, le vœu que vient d'indiquer M. Vidal, et qui avait cité accepté par la section, sera considéré comme adopté.

Il est ainsi conçu :

"Le Congrès, considérant que dans la région des Haures les voies de communication sont notoirement insuffisantes.

\section{ÉMET LE VOU :}

"Qu'il soit mis, à bref délai, un terme à cette situation dont on ne trouve pas un autre exemple sur tout le territoire françuis.

11. LE Dr Vidu. - Je vous remercie, au nom de ces malheureux propriétaires qui voient brûler leurs héritages depuis 300 à 400 ans et nepeuvent pas exploiter leurs bois. (Applaudissements.)

M. Le Président. - La parole est à M. Poupinel, président de la troisième section.

M. Pouptel (lisani) :

\section{VEUX PRINCIPAUX}

"Que l'Étut incite les particuliers et les communes ì constitucr des massifs de futuies partout oì la qualité dn sol le permet; pour ce faire, non seulement ces massijs seraient, comme les plantations it les semis, exonérés d'impóts pendant trente ans, mais cnorre des primes pourraient leur être attribnées.

"Oue la Tille de l'aris abaisse sensiblement les droits doctroi qu'elle perçoit actucllement sur le churbon de bois, ot gu'elle mette ces druits e'n harmonie avec ceux anxquels sont tuxés les autres combustilles. (Bravo!) 
"Que l'État jusse jaire ì lu station forestière spéciale de Vancy et duns tons les étullissements scientifigues dont it dispose des recherches scientifuques sur la meilleure utilisution chimique ot mécanique des taillis et des menus bois.

"Qu'il accorde de larges subventions i toutes les initiatives privées : syndicuts, sociétés et savants qui se lioreront à des truvaux sérienx sur cette question.

"Qu'il fonle un prix l'une importunte valeur pour récompenser les savants on les inventeurs qui auront trousé une on plusieurs solutions économiquement pratiques de cet importunt problème de l'utilisution chimique et mécanique des taillis et des memns bois. (Applaudissements.)

"Que l'État, les lépartements pt les commures plantent indistinctement toutes les routes de France en essences appropriées ai la nutnre du sol, i l'exclusion des arbres fruitiers.

"Que les exploitutions jorestières soient supprimées de la nomonclature portée à l'article 1'i de la loi du 21 mai 1836 et à larticle 11 de lu loi du 20 aôt 1880, des indnstries susceptibles de fonrnir des subrentions pour les chemins vicinanx. de grande communication et les chemins rurumx. (Très bien!)

"Qne tontes les administrutions publiques achetunt des prouluits en onir et pean inscrivent duns leur cahier des churges une planse à l'efïet de n'uccepter que des rnirs et peanx tumnés à l'écorce de chêne pur, ì lexthsion de tont autre ingrédient tannifère, et prennent des dispositions strictes et sévères pont snrepiller diretement l'appliation de rette clunse. (Applaudissements.)

"Qne les Ponvorirs publies, ponr réprimer tonte froude et pour protéger le publir consommatenr, instituent une murque légale qui sera apposée sur tons les cnirs et peunx tunnés à l'écorce de chêne mir. (Applaudissements.)

"Qne rertuins cunanx solent améliorés, notumment que les trusunx commencés depuis de nombrenses années sur le canal du Vivernais, qui dessert une région essentiellement forestière. soient poussés utisemient, de façon ì permettre le passuge des buteunx de 38 mètres, er qui dimimueruit notublement les fruis de transport.

\section{ViEIX SECOXHARES}

"Que les Compagnies de chemins de fer consentent lapplicution

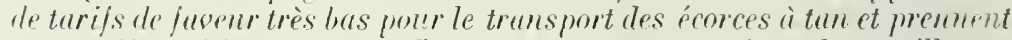
tontes dispositions en sue dissurer le transport duns les meilleures enditions.

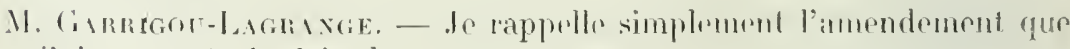
jai prepense. de fais des réserves. 
INTERNATIONAL 191:3

11. Potpisel (lisant) :

"Que l'impôt foncier que les forêts particulières ont à acquitter soit diminué par la réforme de la Loi dn 3 frimaire an VII, ou par l'application du nouvean régime de lu propriété non bâtie.

"Que. duns le domaine du gros outillage, il soit établi nne machine is abatre le taillis, d'une utilisation réellement pratique.

"Que les transformationss du prtit ontillase de munutention et dubatage se produisent en s’inspirunt des progrès déjii réalisés, uutant en France qu'ì l'étranger, et en tenant compte des amélioration.s obtenues pur le perfectionuement du mutériel sersunt unx grandes exploitutions.

"Que lemploi des transports antomobiles soit fuvorisé de tontes manières, notumment par l'améliorution des chemins forestiers an point de sue de leur solidité.

"Que TÉtut soit invité à fuire le plus de réserves possibles, de façou i produire, dans un avenir enerore lointuin. plus de futaies et moins de tuillis.

"Qu'on enconruge les particuliers ì faire les mêtures réserves. en les" indemmisant de lenrs sucrifices, an moyen de la suppression totule on partiplle des impôts yui arèvent la propriété forestière. (Applaudissements.)

"Que l’Étut, suns s'occuppr des nécessités bulgétuires, angmente la durée de seś aménugements ut encourage les purticuliris et les communes it suire son expmple.

"Que" la législution fucilite lurression ci la propriété jorestière de propriétniress dits "impérissubless "qui, senls, ont intérêt à l'aménugement de coupes de longue durée.

"Que de très sérienx enconuragements soient arovelés anx cherchenrs pour les annener a tronver l'utilisution industrielle dn petit bois.

"One l'industrie bonlangère soit incitée à utiliser le bois pont la cuisson the pain.

"Qne le Service dess ports, si éronomique pour le commerce des bois, snit maintemu dans sonn intégralité, et étendu. antant que faire se' pourru, anx gares situées dans les limites des cantonnements des gardes-prorts.

"Que. dinne munière générale, les marchands de bois exploitant. fassent lendre contes les bûches de charme dont la grossente atteint ane dépassir l'́ centimetres de diumètre.

"Que les propriétuires forestiers soient invités ì angmenter lri durée des uménagements des conpes, de fuçon ì les porter, chanue foris que la qualité due sol le permettra. à 35 on in ans.

"Oue les bois destinés ì la carbonisution aient an moinss $0 \mathrm{~m} .1125$ de diumetre an petit bout. 
"Que les distillatents de bois en r'ase clos soient inc'ités à n'utiliser que la charbonnette exclusivement.

"Que le décret portunt règlement d'administration publique destiné à définir l'essence de térébenthine, en vertu de l'article 11 de la Loi du ler août 1905, prévoie uniquement sous ce nom le produit exclusif de la distillution des sucs oléo-résineux tirés pur le germmage d'arbres résineux, à l'exclusion de la distillation même aqueuse des bois qui les contiennent.

"Que le nombre des prélèvements faits pur le Service des frundes sur l'essence de térébenthine soit augmenté dans de larges proportions.

"Que de très réels encourugements soient uccordés anx chercheurs, soit par voie de concours, soit par tout autre moyen, pour les amener ì tronver des procédés scientifiques permottunt l'emploi indnstriel du charbon de bois.

"Que des tarifs spéciuux soient accordés an trunsport dn charbon de bois destiné à l'exportation.

"Que les bois de mines destinés à lexportation jonissent d"un régime de faveur particulièrement pour les transports à longue distunce:

"Qne les Compagnies de chomin de fer soient invitées ì ne faire ancune distinction pour le coût et le transport des bois de mines entre cenx ayant moins de $5 \mathrm{~m} .40$ qui voyagent à la série $E$ èt cenx de plus de $5 \mathrm{~m} .10$ qui voyagent à la $6^{\mathrm{e}}$ série.

"Que l'Étut français amélinre la qualité et diminne le prix de $\overline{\text { ses }}$ allumettes; que pour urriver utilement et pratiquement à ce but, il accepte la concurrence privée. sous réserve de l'exercice. (Applaudissements.)

"Que les terrains incultes les plus susceptibles de reboisement soient plantés, avee exonération dimpôt pour les propriétaires, an delà même des trente ans préous par la loi.

"Que des produits antiseptiques ayunt fait leurs preuves soient utilisés ì l'effet dungmenter le roefficiont de résistunce et de durée des lnois soumis it leur traitement.

"Ou'une impulsion sigoureuse et pratique ì tous égards soit donnée ì l'importation de nos essences roloniales qui peuvent, en matière de poteanx télégruphiques comme en bien d'anties, purcr an déficit menaçant de la production nationale.

"Que les recherches sur les procédés urtificiels de conservation des bois et les découvertes dans cet ordre d'idées soicnt dotées de primes.

"Qne l'État, partont oì il le peut, ponr tous les édifices publics et pour certaines constructions privées, exige l'emploi de bois ignifugés.

"Que toutes les régions uni le permettent soient reboisées. 


\section{INTERNATIONAL 1913}

"Que l'importution des bois à ceuverer qui nous font défaut, ou dont la rareté nous entrâue à des coupes prématurées, soit duns une certaine mesure facilitée, notamment en taxant les transports des bois exotiques communs de uos colonies, non comme bois précieux, comme cela a lieu actuellement, muis au même prix que les bois français de même valeur et de même emploi.

"Qne la connaissance de toutes les essences utilisables de nos immenses réservés coloniales soit vulgarisée par tous les moyens, tant pour la mise en valeur de ces réserves que pour conjurer l'appan. vrissement des forêts de France.

"Qne les formalités donanières soient simplifiées en prenant pour base le poids indiqué sur le connaissement, avec tolérance de $10 \%$ en plus ou en moins.

"Que pour la fabrication de la pâte, on fasse emploi en plus grande quantité, non seulement de chiffons, mais encore de l'alfa, des fibres de chanore, de maïs, de lin, de jute, de phormium, de bambou, puis de tontes les essences tendres de nos colonies de l'Afrique occidentale française et dn Congo.

"Que nos dunes du Vord, moins propices à la croissunce des pins, soient plantées de graminérs à racines étendues, comme l'orgeat: celles de Normandie et de Bretagne, de pins, etc.

"Que nos montagnes soient plantées de hêtres et de mélèzes et untres arbres.

"Que, sur les lignes de transport, les tarijs soient proportionnés ì la valeur de la matière première.

"Que l'emploi du peuplier soit générulisé et yu'il soit procédé à des replantutions incessantes de cette essence et plus particulièrement le long des rivières et canaux.

"One l'on ait recours unx bois de densité légère qui se trouvent dans nos colonies.

"Que les droits de donune soicnt élevés d'mue munière raisonnable et opportune sur les bois étrangers contre-plaqués.

"Que plus de précuntions soient prises pour préserver les arbres en bordure de nos routes, lavoirs et cours d'eun, des clous et déprédutions quelconques ayant le curactère, non pas de malveillunce an sens propre du mot, mais d'impartonnable ignorance.

"Que les stunds on chanps de tir soient suffisamment élrignés des parties boisées pour éviter que des balles perdues ne viennent. compromettre l'existence de nos plus beanx arbres.

"Que des appareils de protection véribblement pratiques soient créés pour lu conduite, sans danger, des machines-ontils.

"Pue, conformément ì la jurisprudence, les aspirateurs de ponas- 
sières un soient plus imposés duns les uteliers de sciage mécrnique du bois.

"Que les fabricunts de futailles frunçais se préoccupent, dès maintenant, de prendre des merrains dans les forêts françuises, et de former des ouvriers cupables et habiles à fendre les merrains de grosses et petites dimensions, suivant les exigences des consommateurs: ils créeront ainsi un lébouché précieux pour un produit essentiellement national et, en même temps, ils s'assureront une partie de leurs matières premières sans aroir besoin de la chercher an loin, avec toutes les difficultés d'un transport de plus en plus onéreux.

"Que les grandes villes, et en purticulier lu ville de l'aris, rérluisent les droits doctroi sur le churbon de bois an taux des droits sur les combustibles minéramx. »

"Que le Parlement étudie l'élévation des droits de doune en sue de protéger la production française de méthylène.

"Que le Parlement prenne les mesures propres ì étendre la consommation de l'alcool industriel que le méthylène sert ì dénaturer." (Applaudissements.)

Tous ces voux sont adoptés.

11. te Présuent. - Le président de la fe seetion, M. Plueluet, n'ayan pu venir, je demande a M. Cardot de nous donner lecture des vorux.

M. Caruot (Jisant).

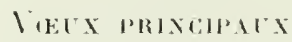

"Que dans les diflérents payss une législation pustornle snit édictée et que des mesures administratives et financières sonient prises on complélées, en s'lle d'assurer anx pâturngess communumx ou exploités rollestivement le bienfait a'un. aménugement rationnel of les travanis nécessuires pour urrêter la dégradution de cess terrains, les remettre en saleur, les entretenir en bon état de production ot ansisi rendre anx régions montagnenses les éléments de richesse, de beauté, de prospérité enfin, qui lendenu, de plus an plus. ì lentr fuire défunt et ì en proinquer la dépopulation.

"Que des mesures législations soient prises on rue de réglementer lexercice des droits de pruturage pll .lgérie.

"Qu'il n'y a pas lien de renoncer anx lravanx de correction de torrents, mais qu'en raison de lemr prix élevé. il convient de niy reconrir qu'après une élude sérieuse basée sur des considérations purement lechniques et, "fin d'éviter, dans la mesure du possible. leur emploi toujours onéreux, qui il importe de favoriser la réation ot le décoloppement de missifs forestiers dans les bassins de réception, dans la limite oi la lutte contre le ruissellement al le dérupage des versants le rendiont nécessuires. 
"Que les aralunches soient ussimilées anx torrents pt que leur correction puisse êture également déclurée d'utilité publiqur et dans les ur̂ômes formes.

"Qu'il soit dressé, duns les divers étuts, nne'stutislique lè̀s complete "t tès sériruse des tourbières de difiemntes natures qui y existem.

"On'il soit créé, duns les tonrbières des diverses ratégories, en plaine et en montugne, des chanips d'expériences oi seront étudiés très métho. diquement les procédés d'ussuinissement. les modes de boiscment. les "poques les plus favorubles pour les plantutiouls, les différentes esstrnces indigènes el exoliques, l'action des divers engrais. les soins à donner unx plants,

"Et que les résultals, bons on mausais, de toutes ces expériences sontent portés à la comminssumer du public.

"Que, dans tous les pays où le besoin s'en fait sentir, une législution relutive ì la fixatiou des dunes el aux lravanx de défense contre la mer snit mise à l'élude "t promulguée dans le plus bref délai possible.

"Qne les forêts des dunes soient clussées commur fortêts de frrotertion.

"Qu'il soit procédé, en Firance comme à l'étranger, à des olssercations diverses et méthodiques, ayant pour but de déterminer l'inflnente de la forêt sur le régime et le débit des rour's d'eau.

"Qu'en France, lu loi dont le projet "été présenté pur. W. Fermund Javid, et qui a pour objet la modificution de la Loi du 4 avril 1882 sur la restauration et la couservalion des terrains en montagne, soit sotée dès que possible. (1)

"Que les travanx de régularisution des cours d"eun soient l'objet, pur bassins hydrographiques, d'étndes d'cusemble, concertées entre less divers services appelés à en assurer l'exérntion.

"Qh'il suit institué des primes un reloisement.

"Que les lerruius communanx boisés ou susceptibles de boisement on d'untéliorutions pustorales ne soient ui purtagés ni aliénés. "

M. De Berixay, - Ja demande la parole.

la fuestion des rommunaux n'a pas etir tration aren l'ampleur qu'elle romporte.

Nous avons 250.000 heectares de bruyeres an Plateau central qui un prevent produre que par lo reboisenent. L'Thministration nous

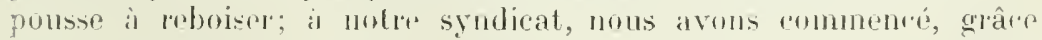
an parlage des communam, à pousser an reboisenent : si vous arrôtry Jo partage, vous arrêtry lin reboisement.

Je sais que la questim li ist pas la même dans foute la france, mais

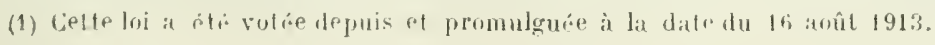


pourcquoi ne pas ajouter à ce roru que le partage spra autorisé quand les intérêts du département le demanderont?

M. Le Présinext. - Nous ne pouvons pas modifier le rou, mais ros obserrations seront consignées au procès-rerbal.

M. Cirnot. - Ce vou a été voté à l'unanimité par la rection, moins

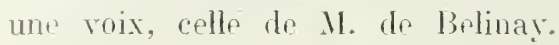

\section{VEEX SECONDAIRES}

"Que les forestiers reboiseurs soient encouragés à faire connaitre les moyens pratiques qui ont le mienx réussi dans les divers trubunx de correction et de réinstallation de la ségétation.

"Que l'attention des reboisenes soit uttirée sur lu néressité d'étudier la régétation naturelle des bassins à reboiser et des régions attenuntes, et sur l'intérêt qu'il y aurait à dresser une carte botanique ponr servir de base anx travanx de reboisement entrepris.

"Que l'on tienne compte des résultuts arquis dans la ynestion de l'origine des graines, en semant, en tons cas, des graines d'origine conmue et choisies logiquement.

"Que l'on étudie, dinne fuçon rutionnelle, les végétanx herbucés et les arhrisseat x utilisubles pour l'enherbement et l'embroussuillement, et une, pur des essais, on détermine les conditions de lenr emploi et de leur multiplicution.

"Qu'une étade analogue soit jaite pour les liverses espèces de saules utilisés pour les travanx de gamissuge et de clayonnage.

"Que soit encouragée la création de laboratoires et pépinières anulogues à ceux de Soulof, en Suède, laboratoires at pépinières dans lesquels on sélectionnera máthodiquement les espèces fonrragères vivaces les plus aptes à consolider le sol et à formir de bons herbages.

"Qu'eu égaid anx précienx renseignements prutiques contenus duns le rapport de $1 \%$. I'urdé, ce document soit adressé gratuitement anx collectivités, ainsi qu'anx snciétés et groupements forestiers que la question pent intéresser.

"Qu'en attendant la promulgation d'une législation pastorale, on arlopte tout d'abord des dispositions législatives en vue dissurer le contrôle des locations faites pur les communes at de permettre à l'Etat d'exercer un droit d'option sur ces locutions aser faculté d'inséret dans le bail la clanse du fermier amétiorateur.

"Que le décret du 1er an̂t 1905 swit complété de manière ì ne pas entraver les dérivations des rours d'ean non navigables ni flottubles, en faisant jugess de la prolection des sites le . Hinistère de l'Agriculture et celui iles Berux-1rts, sans exiger un décret rendu en Conseil "Etut." 
M. Le Présilext. - I a-t-il des observations sur l'ensemble de ces voeux?

lis snnt adoptés.

La parole est à M. Chaix, président de la 5 e section.

M. Chaix (lisant).

\section{VEUT PRINCIPAUX}

"Le Congrès, considérant qu'il'y a lien de constituer des réserees de grande étendue, dans lesquelles la nature rendue à elle-même et mise ì l'ubri de tonte intervention humaine, puisse luisser évoluer librement la flore et la faune,

"Préconise, dans ce but, la création on l'extension, dans chaque pays, des pares nationanx;

"Ëmet le vou qu'une réglementation appropriée, nne stricte surveillance et de très sévères sanctions soient prévnes pour leur défenes et lenr protection;

"Que lenr emplacement soit choisi de prélérence dans les parties les plus pittoresques du territoire.

"Que les jardins de montagne, arboretums, stations on places d'essuis, soient étublis comme centre d'études, non seulement pour les questions de sylviculture, mais pour tous les objets intéressant l'économie des montagnes comme foyers de rie humaine.

"Que les modifications upportées par la Lni de 1906 aux pénalités édirtées par te Code forestier soient rupportées.

"Que la législation sur les occupations temporaires soit modifiée duns le sens d'une proposition de loi défic déposée en 1909, loi d'après lupuelle ancune occupation temporaire ne ponra être antorisée aux environs des sites et paysuges classés duns un périmètre qui sera proposé à l'Administration dans channe département par la Commission des sites.

"Que tout exploitunt yui modifiera l'aspect visible dn sol sera tenn, unssitôt les travanx urhevés, at si possible à mesure de leur achèvement, de réparer le dommage causé à la beanté du site et suns qu'il soit portŕ atteinte anx droits de propriété, notumment en faisunt les plunlutions nécessuires pour couvrir d'un munlean de verdnre les cxcuations, déblais et remblais résnltant des truranx.

"Que, tant au point de vue de la beunté yue de l'hygiène, duns les forêts de l'Étut, de nombrenses réserves urtistiqurs soiemt étublies, uncyuelles sera imposé un régime d'aménagement. spécial, et qu'à l'uscmir tonte demunde. (quels yn'pn soient les anteurs) tendunt it restreindre l'étendue de res forêts soit ubsolument érortép. 
"Oue la Caisse pour lachut des paysauses jorestiers of autres, volée par la Chambe dums su demière session, soit hargement dolée par IÉlal.

"Qu'ulumu moyen ne soit épargné. qubord pour consereer les jurêts existuntes, ensuite pour en accroâtre l'élendue et le nombrere, suit pur les soins de l'Elut, soil pur des encomragements anx initiatives príées.

"Que dhaque Etul poursuice et encourage l'étublissement de plunlutions en bordure des routes et reille, pour des ruisons d'ordre esthélique et ulilitaire. à en réglementer sévèrement la planlation el l'exploitation et à en assurer d'une façon efficace la protection.

"Que, pour shaque plantation, I'administralion" compétente soil consultée sur le choix des essences, choix qui est surtout du domaine de la géographie botanique.

"Que chaque exploitution soil surive, anssitôt que possible, d'une nowoelle plantalion".

Ux Coxgressiste. - Ju vondrais baire observer que la troisième section a émis un vorn où on proserivait la plantation d'arbres fruitiers : an

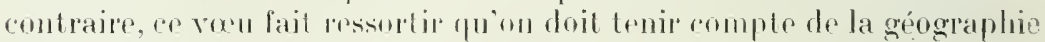
botalisqur...

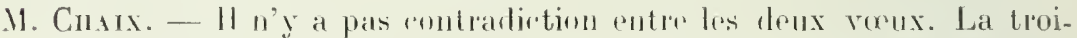
sième section a demandé l'exchusion des arbres fruitier's, estimant qu'au point de vue du reudement il est phus intéressant d'avoir du

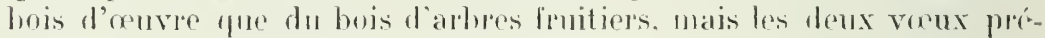
sentés ne so rontredisent pas : je rovis qu'mu pent les adopter l'un et l'autre. ( Ilargues d'approbution.)

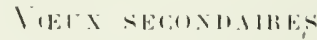

"Que rhuque gousernement poursuice el étende l'élublissement de réserses scienlifiques destinées ì motéuer corlatues espèces menurées

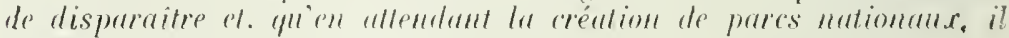
éublisse des zones de protertion de la jaune et de la flore.

"Que le Touring-Club s'orrupe de réé des ligues locules des

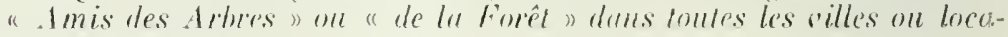
lités importanlos.

"Que les Commuissions dépurlementules des siles (loi de lonnt) soient loujours consultées en maliere de lraraux publics sur lout projeb

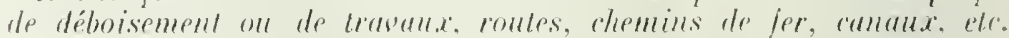

"Que bes plus beanx paysasess de firance soimt dédarés réserves nationales at mis ainsi it Pabri de loule mulilation. 


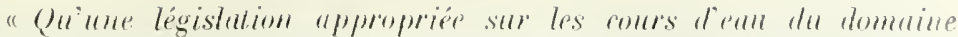

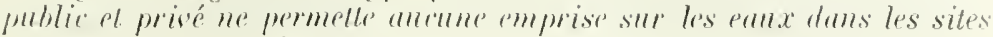
proposés pour le rlassement.

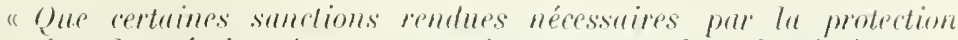

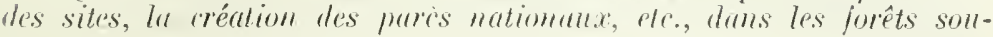
misps an régime jorestier, soimt prévnes ot ajontées an Cole jorestier.

"Que duns l'exploilation des forêts actuelles et futures, il soit lenu romple, dans la plus large mesner possiblole. de rintérêt esthétique que cess forêts penvent présenter.

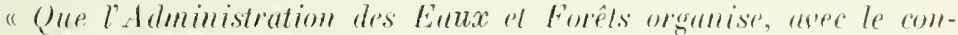

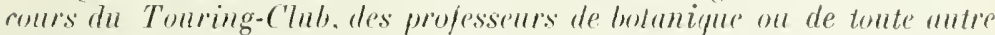
personme rompétente, duns les régions forestières fréquentées par les tomristes, des conférences-promenudes, acressibles it lous, en wlle de donner an publir des notions exactes stur la conslitulion des forêts et les diverses opérations de la sylvirnlture.

"Que la presse sollicite al que Thlministration encomrage la rolluborution des agents des Eanx et Forêts poul instrnire le public an moyen d'articles de oulgarisulion.

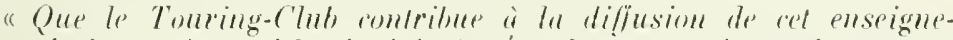
ment érrit par des articles insérés danśs sa hevau, et des notices momographiques rédigées, sous ses auspices, par des agenls des linux ot Forîts.

"Qne les poncoirs publics sotent des ádits sulfismats pour permetre it ladministation forestiere de pousser plas nclivement ses travam de reboisement.

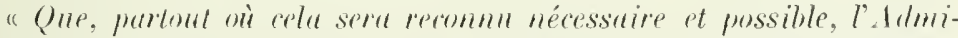
mistralion jorrestière, en dehors des périmètres de reboisement, entom-

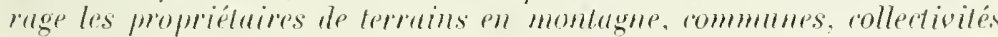

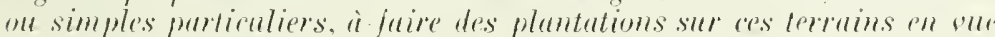

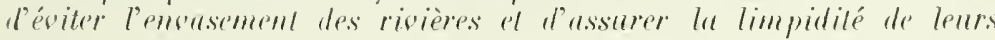
pratlx.

"Que les indicutions deretre abministralif qui aristent on qui sont susceptibles d'existur en jorêl, et qui peusent être d'un intérêt quel-

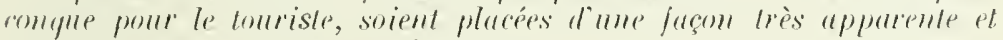
tonjours's plretemues en bon élut.

"Oue l'arès et la visite des forêts ale promenade soimt facilités par l'amélionation des chemins, la réation de sentives de prétons:

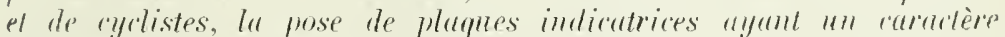

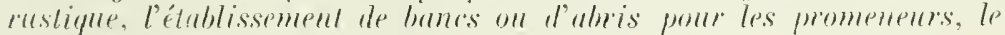
déguement des poinls de vile.

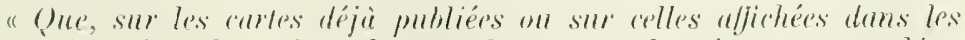
postes forestiers, les arbres, les penplements on les sites remarymbles,

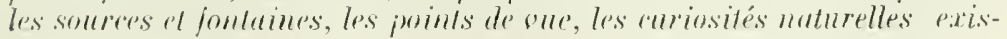

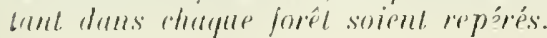


"Que les udministrutions et les sociétés compétentes venillent bien fuciliter l'étublissement et la mise à lu disposition du public de cartes forestières: yue, sur ces curtes, les voies habitnellement onvertes an public soient indiquées de façon précise.

Que les agents forestiers, et antant que possible les particuliers, ue perdent pas de vale l'aménagement des forêts an point de one estlétique.

"One les grandes voies snient tmpierrées mécaniquement.

"Que les curiosités forestières, les sonrces remarquables, les ruines, les rochers et les points de vne situés en forêt, etc., soient rendns accessibles pur des sentiers munis de plaques indicutrices.

"Que l'Etat et les partialiers entravent le moins possible la cirrulution des promenenrs en jorêt.

"Qu'il soit conservé; lor's des exploitutions, tons les urbrès ou gronpes d'urbres remurquables ot même des bonquets de vicilles jutuies, lors de la réalisation des vieux peuplements.

"Que les sommicres, lignes et sentiers soient transformés en allées ombrenses par la réserre, lors des exploitations, des arbres qui les bordent.

"Que les carrefours soient encerclés d'arbres de futaie, mais à une listume assez grande du roisement des routes \#.

Tous ces vocux sont adopiés.

M. Le Présidext. - L'ensemble de tous les vorux a été arlopté. Je vais donner la parole i VI. Defert, pour vous fournir des renseignements sur l'organisation de la Commission permanente, dont il rous a entretenus à la première séance.

M. Defert. - La proposition relative à la constitution de la Commission permanente internationale a reneontré auprès de vous un acrueil des plus favorables.

M. Inton Ilolub, prísident de l'T Tnion forestière tchèque de l'rague, a déposé entre mes mains la proposition suivante:

"Le soussigné Anton Holub, président de l'Union forestière "Jednota ceskych lesnilan zemi koruny Cèslié ", it Prague, émet le vœu que le Congrès décide la constitution. d'un OfFice rorestier INTERNATIONAL représenté par une Commission permanente siégeant à Paris, dans laquelle les diverses sociétés forestières étrangères seraient représentées par des délégués. Cet office international, qui pourrait s'appeler Ligue forestière, aurait pour mission d'organiser des congrès dans les divers pays et de traiter de tontes les questions forestières on s'en rapprochant an point de vue forestier proprement dit, comme au point de vne social." 
Messieurs, au nom du Comité exécutif du Congrès, je vous propose de constituer la Commission permanente internationale sur les bases suivantes :

A la différence des commissions analogues, instituées dans d'autres Congrès, conme le Congrès de la Route, le Congrès de la Chasse, rette Commission permanente ne demanderait à ses membres aucune cotisation. Le Touring-Chub de France lui oflre l'hospitalité de sou hôtel de l'avenue de la Grande-Irmée. (Applandissements).

Il se chargera des dípenses, des cnuvocations, do la correspondanee, ete.

J'ai, ce qui est plus important, à vous faire connaitre et la mission U. cette commission at sa composition.

La Commission permanente internationale aurait pour mission de suive la réalisation des voux du Congrès forestier international tenu à Paris en juin 1913, et de provoquer, au besoin, l'organisation de congrès foresilers internationaux, lorsque des questions nouvelles, intéressant la forêt, lui en feront apparaitre l'opportunité. (Marques dapprobation)

Toiei maintenant la composition que nous vous proposons:

Comme memhres de cete Commission : tous les délégués des Etats étrangers reprósentés an Congrès de 1913 (Applandissements), à raison de un déligué par Etai, sous réserve, bien entendu, de la ratification de leur désignation par le gourermement de chaque pays cqui l'rstimerait nécessaire.

A ces délégués étrangers, nous adjnignons tous les membres du Comité exécutif du Congrès de 1913, dont vous avez la liste sul les imprimés du Congrès, et les présidents des cinq sections du Congrès, plus qualifiés que personne pour suire l'ouvre du Congrès qu'ils ont présidé daus chacune de leur section respretive.

Je vous propose de leur adjoinde:

M. de Nicolay, en qualité de président du Comité des forêts.

Et M. Barbier, en qualité de président de la Fédération des syndicats du tommerce des bois de France. (Applaudissements.)

$A$ la têie de cette Commission permanente ainsi composée, il y aurait 111 Comité exécutif, comme pour le Congrès actuel, lequel serait ronstitué pitr le Directeur général des Eaux et Forêís de France... Je ne dis pas II. Dabat, je dis : le Directeur général, p ésident. (Approbation.)

Je suis obligé de me nommex : M. Henry Defert, président du Connité d'organisation du Congrès de 1913, vice-président du Touring-Club de France, comme vice-président... (.1 pplutulissements.)

11. Chaplain, enmme soerétaire général. (Appluudissements.)

Si vous adopiez ces propositions, Ie Comité exécutif fera le nécessaire aupròs des États etrangers pour régulariser les désignations de leurs délégués. 
11. on Sébille. - Si je me leve esest pour félieiter le Comité exécutif de notre Congrès de l'initiative qu'il vient de prendre.

Appelé à l'honnenr de présider, ì Gand, la cinquième section dr: Congrès intemational l'agriculime, où nous étions un peu comme la Cendrillon de la maison - la plus grande partie des personnes ignoraient qu il y avait un Congrès de sylviculture, - j'ai compris fu'il ne fallait pas toujours demeurer modestement en arrière; je tiens done à vous exprimer le désir que nous avons, en Belgique, de voir fonder un Comité organisateur des Congrès dans l'arenir, tel que vient te le définir l'honorable vice-président du Touring-Club de France.

Je saisis cefie ncrasion pour remercier le Comité exécutif de la façon amable dont il a reģ nos délégués. ei pour lui exprimer toute notre rermmaissanee. (Applaudissements.)

1I. DE SEgoxzac. - Je crois être l'interprètr de touies les personnes qui ont assisté à ce Congrès pour remercier particulièrement les présidents de sections qui ont bien voulu nous écouter, surtout que beaucoup d'entre nous - ei je suis du nombre - ont quelque peu: abusé de la parole. (Rires.)

M. Ifarchal. - Jי suis de ceux qui sp félicitent de la teme du Congrès, et des sections, et des vorux.

Je demande simplement à faire une observation pour prier la Coinmission futuro f́ventuelle, déjà décidée en principe, de ne pas commettre l'omission qui me paraît avoir été faite au sein du Congrès. Il y a un ilément considérable dont on a à peine parlé, l'élément Nord-Afri"ain. La forêt du norl de l'Afrique - Algérie et Tunisie - comporte des millions d'heetares smpérieurs au nombre d'hectares que l'Etai francais possède sur son territoire continental.

Jr demandr que cel élément ne soii pas oublié désormais.

II. I. Présmext. - Lobservation figurera an procès-verbal et la Comminsion permanente en tiendra compte.

11. Le conte Chars. - Puisqu'on consitue un Commission premaliente internationale, je demande s'il ny aurait pas lim de penser à la périodicité des eongrès. On a parlé de constiture une Commission qui comprendrait un certain nombre d'étrangers. Si unte Commission esi à Paris, il ne laudrait pas empêcher les gouvernements étrangers d'organiser des congrès internationaux. Il faudrait gue la Commission internationale permanentr française, composero de représentants étrangers, puisse faire, pour ces congrès élrangers, re que font les autres commissions internationales permanentes, c'est-à-dire qu'elle puisse passer la main on soumettani un programme ot en indiquant los parties qui pourraient otpe traitées dans les congros futurs.

11. DeFert. - La réponse est dans la delinition de la mission de la Conmission : 
"...provoquer un besoin l'orgunisution de congrès forestiers inter". nationaux lorsque des questions nouselles intéressant la forêt lui en. " feront apparaître l'opportunité."

Cela répond ì tout. Il n'est pas besoin de poser le principe de la périodicité. Un congrès international qui aurait lieu périodiquement, lous les deux ans par exemple, pourrait être sans intérêt, sans objet; il vaut mieux s'inspirer des circonstances et laisser à la Commissior permanente le soin de choisir le moment opportun. Peut-être sera-t-elle provoquée elle-même par des propositions fui lui seront faites et qu'elle retiendra. Mais je crois inutile de poser, dès maintenant, le prineipe de la périodicité des Congrès forestiers.

11. Hıckel. - J'ai assisté an Congrès de Gand, et je tiens à rentlre hommage à M. de Sébille pour la courtoisie avee laquell, il a présidé $n$ nos débats.

Je voudrais vous parler des congrès de sylviculture. Je ne remonterai fras au delà du Cougrès de 1900. 11. de Sébille vous a dit "qu'à Gand nous avions constaté que le Congrès forestier ótait des plus réduits. Depuis 1900, j’ai assisté à tous les congrès d'agriculture internationaux. c'est-à-dire : Rome, Vienne, Madrid, Gand. Dans tous ces congrès - à l'exception de Vienne, où les forestiers étaient venus en nombre d'Allemagne et d'Autriche, - on a fait la constatation faite à Gand, c'est-à-dire que les forestiers étaient en très petit nombre, la Frane" en comptait 30 ou 40 au maximun.

Dans ces conditions, je soumets cette idée à vos réflexions: N'y a-t-il pas lieu d'aller un peu plus loin que le projet qui nous est soumis, rt de reprendre la liherté entière qu'avaient les congrès forestiers jusqu'en 1900? D'où seission d'avee les congrès internationaux d'agriculture. Conme l'a fort bien dit II. de Séhille tout à l'heure, nous sommes les Condrillons de ces congrès.

M. le Présinext. - Nous avons des congrès d'agriculture qui ont des sertions do sylviculture ; nous pouvons lemr permettre de continuer a vivre. Ces seetions seront peut-être moins importantes maintenant; mais ce ne 'serait pas bien de notre part, parce que nous voyons que nous sommes en nombre, d'aller dire à ces congrès d'agriculture, qui ont cru bien faire et qui ont bien fait en owrrant une section de sylviculture : séparons-nous. Laissons-les continuer leur section de sylviculture; si elle ne prend pas de développement, elle mourra de sa belle mort.

Je remereie $\mathbf{N}$. Hickel dre sa bonne intention: Illais je crois qu'il vaut mieux ne pas y donner suite.

Il n'y a pas d'autres observations?

Alurs la Commission, telle que l'a indiquée M. Defert, est adoptée. Je donne à nouveau la parole à M. Defert. 
M. Defert. - Messieurs, rous renez de voter la création de pares nationaux. Le Touring-Club voudrait, en ce qui concerne la France, faire passer immédiatement ce rou dans le domaine des faits. Avec l'aide de l'Administration des forèts, nous arons d'ores et déjà le moyen de le faire aboutir, et dans ce but, nous nous proposons de fonder une association pour laquelle nous faisons appel à votre concours.

Cette association - je ne fais qu'en indiquer les grandes lignes aura pour objets la création et l'entretien, sous la dénomination commune de Parcs nationaux de France,

Soit des réserves territoriales de grande étendue, choisies parmi les régions les plus pittoresques, à l'effet d'y laisser évoluer librement la flore et la faune en les défendant contre toutes les atteintes, individuelles on collectives, de l'homme, et de constituer ainsi, en même temps qur des laboratoires d'études, des centres de régénération riaturelle,

Soit des pares proprement dits pour la protection de la faune et de la flore qui s'y trouvent et la sauvegarde des beautés naturelles qu'on y rencontre.

L'assoriation comprendra des membres fondateurs à deux cents francs, donateurs à vingt francs, titulaires à dix francs, souscripteurs à cinq franes et adhérents à un franc.

Il faut qu'une ourre que nous considérons comme d'intérêt général ot de salut public sorte d'un mourement populaire; e'est pour elle une garantie de sucrès, et nous entendons la mettre à la portée de toutes les bourses. (Applandissements.)

M. Le Pfésinext. - Les travaux du Congrès forestier international sont terminés. Les 700 membres de cefte réunion ont, sans relâche pendant quatre jour's, donné l'exemple de l'activité la plus féconde. Les disrussions, empreinies de la plus grande courtoisie et de la plus dimable cordialité. ont mis en relief le savoir et la compétence de reux qui y ont pris part. Iucune question n'a été laissée dans l'ombre. Libre cours a été donné à l'expression des opinions les plus diverses, sır les abondantes natières qui ont ité soumises à ros délibérations.

C'nst du choc des idées que nait la lumière ; celle que vous avez fait jaillir éclairera désormais la voje que suivent les forestiers et les -ylvicultelurs. Ainsi l'irurre du Congrès se continuera, même après que sen nembres auront íté dispersés; lenr collaboration n'aura pas seulement la durér des quelpues heures trop courtes qu’il nons a été Ionni de visre avee vous; voire action sera de tous les jours, puisque naintenant fos matériaux anenés par vous ì pied d'ceuve vont pouvoir êt pe utilisés.

Et quels importants matériaux! Les rapports si documentés, si fournis de substance, si complets, si divers, si élégants souvent dans leur forme, qui ont été produits, les communications nombreuses et spontanées qui ont été envoýrs an Congrès ont étŕ mis en valunr 
grâce à l'heureuse distribution du programme. La division en cinc sections, dont chacune avait sa caractéristique, a permis le groupement des, matières de même ordre et leur ensemble a formé une synthèse les plus harmonieuses.

Les discours et les discussions que nous conserve la sténographie composeront un volume qui ne manquera pas - en France comme à l'étranger - d'être souvent et fructueusement consulté. Ilistoriquement il fera date, car il marquera pour l'avenir, de façon très nette, quelle est, an commencement du $x^{\mathrm{e}}$ siècle, la conception que les esprits éclairés se font du rôle de la forêt, te son utilité, et des méthodes à employer pour l'amener à rendre tout ce qu'elle est capable de produire. (Appluudissements.)

A ce titre, les voux que vous venez d'émettre à l'instant constituent une manifestation des plus significatives.

Pour ceux de ces voux cui s'arlressent aux pouvoirs publics, je vous donne la ferme assurance qu'ils seront étudiés avec le vif désir de les faire entrer dans le domaine de la réalisation. (Applaudissements.) Ils pèseront d'un grand poids dans les déterminations à prendre. Cenx qui concement mon Administration recevpont d'elle, vous n'en doutez pas, un accueil d'autant plus favorable qu'ils sont l'émanation des eonceptions et des travaux de l'élite forestière de ce pays. (V ifs applandissements.)

11 me reste à remplir un devoir très agréable en remerciant, au nom du Ministre de l'Agriculture, tous ceux qui ont rontribué à l'éelat sans précédent de ce grand Congrès. Sa réussite a lépassé les espérances mêmes de cenx qui l'ont organise. Je tims ì les en féliciter.

Ces remerciments, je les dois d'abord au Touring-Club de France dont le eoncours est toujours acquis aux entreprises d'intérêt général et qui. dans la circonstance, a pris l'initiative de ce grand mourement de la façon la plus désintéressée et même la plus généreuse. (Appluudissements.) Il n'est pas d'ceuvre à laquelle il a participé qui n'ait été couronnée de suceès: il a rendu ainsi an pays des servires considérables. Défenseur des beautés de notre France, il a pensé qu il lui appartenait de s'attacher particulièrement à la protection de nos forêts, ce manteau splendide, eette parure naturelle de notre sol national. (Applandissements.) Et ainsi il a acquis un droit de plus à la gratitude de nos compatriotes.

Le nom de son éminent président, I. Ballif, est trop populaire dans toutes nos provinces auxquelles son incessante action a donné une vie nouvelle, il est trop souvent prononeé sur toutes les routes de France, autrefois attristées et désertes, aujourd'hui animées par le développement de plus en plus acru du tourisme, pour que les félicitations que je lui apporte ajontent quoi que ce soit à sa réputation. (A pplaudissements.) Mais c'est pour moi une satisfaction de joindre ma voix ¿) toutes celles qui le célèbrent et l'aeclament.

Nous lui restons particulièrement reconnaissants d'avoir couvert de son antorité la propagande faite dans la Revne du Touring-Club 
en faveur du Congrès. Toutes les foress de rette belle Association - et elles sont eonsilérahles — ont été mises a la disposition de reette (1'urre si utile et si interessante. (Applandissements.)

Il men romdrait de ne pas assucier inmediatement à son nom relni de .11. Tefert (Applandissements) qui dirige depuis tant d'annéele Comite des Polouses of Forêls du Touring-Club. C"est à lui que nous sommes en grande partie redevables le te que l'opinion s'est tommée aver faveu vers les problèmes forestiers. Quel plus magnilique couronmenent pourait-il rêver. aus études pomsuivies par le Comité qu'il préside, qur ce Comgrès à l'organisation duquel il a consacré son activité et anssi son brillant talent de parole. (.1pplondissements.) Il aura été, on peut fr dire, le Pirre l'Emite de recte pacilique cruisarte. (Applaudissements.) Qu'il en soil ici remercié et qu'il me permette d'applaudir des deux mains a la hante distinction que . I. Clémentel lui a annoncrón dans la séaner d'ourerture. (.1pplandissements.)

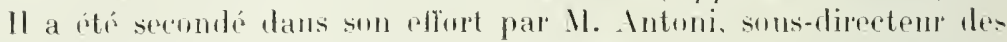
Eaux of Forêts. vice-président du Comité pxéentif (Applomdissements). par des lientenants qui égalaient leur chef en ardem, MII. Auscher ef Famechon qui méritent tous les compliments pour la manière dont ils ont préparé les séances du Congrès ef les excursions qui ront les suive. (Applandissements.)

11. Chaplain faisait ses déluts comme suerétaire géméral du Congrès. Il a pleinement réussi el s'est dévoilé un parfait organisateur : il sest montré a la hauteur des maitres gue je viens do riter. (1 pplandissements.)

La composition mêne des bureaux des sections dans lespluels ligurent tous les hommes les mieux qualitiés pour la tâche qui leur élait confiée ralait tout un programme. Dans la première section, nous avons salué areé respeet, son président 11 . Cirerd. II nous apportait, après mo rarrièr déja longue, toute l'ardenr ot tonte la jeunesse dont était animé le sous-sectrétaire d'Etat de J87T, relui-lì même qui rut le premirr a conduire l'Administration forestière tans une nomrelle voie, après qu'elle ent éti séparés du Vinistère des Finaners. (Applum(issements.)

Je tiens à le renercier tout partienlièrenent.

La seconde section était présitée par un de nos plus brillanis conservateurs, M. Vivier. (lifs applandissements.) Tuss unt aulmiré l'antrití, la distinetion of le tact avee lesquels il a conduit les discussions souvent ardentes, même parfois passionnées. (.1 pplundissements.) 11 a su faire profiter sa sertion, lans me lrès large mesure, de ses capacités de juriste pui le font tant appréciel pal mui a l'Idoninistration centrale où nons avous le bonheur de le pusséder. (.tpplandissements.

11. Poupinel, en présidant la troisième sertion, a valu au Congres le concours du commere des buis dont il est l'une des personnalités les plus hantes of les plus estimées. (.I pplandissements.) Sa prudence. sa rompétence ont éti largement appróciess de lous les rongressister.

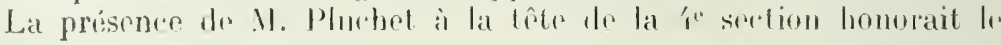




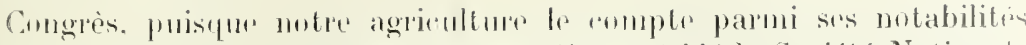
les plus en vue. (Applandissements.) Il a présidé la Socitió Nationate d'Agrienlture, il préside les Agrenlteurs de France. Ses comseils ut sa dimefion staient done l'mo plus grande importance pour un seetion appelée di se promoncer sur les questions do relooisement ot d'amélionations pastorales qui ont dr si ctroits rapports aver l'agriculture. (A pplumlissements.)

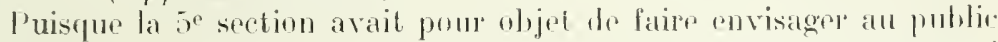
l'interef yui s'atfarhe an developprument du tompismo l'orestier, nul n'ótait miens à mêne que M. Chaix de conduire ses déliberations. Il stait ulile que fût rappele lo rôle ensiderable que doit joner la forêt, pour la branté des sites, attrait des fouristes. Le président du Comiti lu tourisure de l'Antonobile-Club de France, pui tiont une place si importanie a l'Ollice national dı tomismon, avait la me mission digme le sit hante valeur. (Applumdissements.)

Inx lóliciations que j’adresse aux presidents des rimy seretions du Congres, s'en ajoutrot l'autres pour leurs vice-presidents dout plusirums appartimment is mon Arministration.

La plus grande part les remoreienents doit aller aux rapportentr.

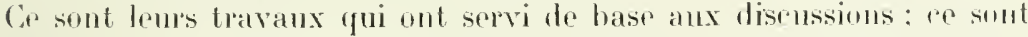
enx qui ont apporte la charpente qui a servi à hâtir les édifices. Les rapports sont au nombre de plus de 50 ; ils représentent un ellort romsielerable et mos somme de travail importante. Tous ont und valeu! réelle et, malgné lour romeision obligatoire (d'après le mot d'ordre donne par le burrau du Congres), ils contiennent mo docmmentation des plus remarquables. Je erois être votre interprite en lour adressant uos plus vifs conpulinents. (Applondissements.)

Jo tiens a adresser des remereipments fout partiruliers à la presse farisienne qui nous a prêté son romenums le plus eflicace ol, avant comme promlant le Congrès, a si largenent contribué i renseigner

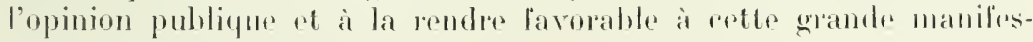
lation. (.1pplemdissements.)

Jo dois anssi des remereiements aux dillérents ministères qui so sont fait lepprosenter ir.i; anx sociétes lorestières et des Amis des Mures: aux associations agrienles qui sont représentés au Congrès : aux propriétaires, anx forestiers qui ont apporte rlacun lem experiene.

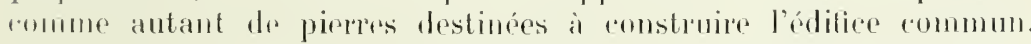

Ir les dois enfin, ers pomereiements, am délégues des pays étrangers tout la présence ajoute 101 lustre de phus i res grandes assises

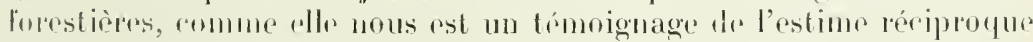

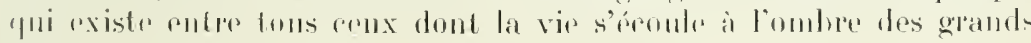
luis.

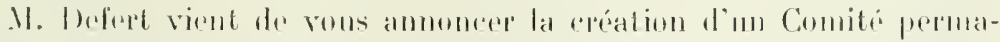

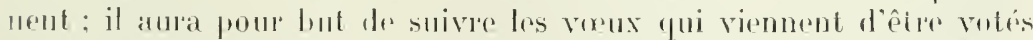

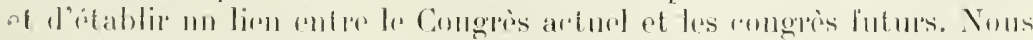

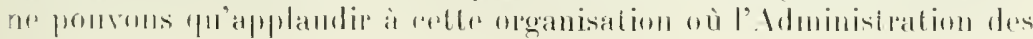


Eaux et Forêts se troure représentée, et je dois dire quelle a recue l'approbation de M. le Ministre de l'Agriculture. (Bravo!)

Et maintenant, Messieurs, je ne prends pas définitivenent congé de rous. Après le travail des commissions et des sections, vous allez visiter ces forêts dont il a été tant question dans cette enceinte é nous resterous encore en contact pendant quelques jours.

J'ai done la satisfaction de ne prononcer aucune parole de séparation définitive en déclarant clos le Congrès forestier international de 1913. (I'ifs applaadissements.)

La séance est levée à 4 h. 25. 
IYTER NATIOYAL 1913

\section{ANNEXE A}

\section{LA CAMPINE BELGE}

SA TRANSSORMATION EY RÉGION INDUETRIELLE - COYSÉQUENCES AU POINT DE VLE FORESTIER

PAR

\section{DUBOIS}

Sinus-Inspecieur des Eaux el Forêts de I Élas belge

La campine belge est une vaste plaine sablonneuse de 500.0001 hectares, d'une altitude de 10 à 100 mètres, située dans les provinces d'Anvers, de Limbourg et de Brabant, avec la rivière du Démer comme limite méridionale.

- Elle est caractérisée (1) par la pauvreté de son sol, ses grandés étendues de pineraies - en géneral malvenantes et de landes couvertes de bruyères et de marécages.

- Mais la campine n'offre plus partout l'image d'une terre desheritée. On y trouve - de magnifiques propriétés, snit qu'il s’agisse de sols de meilleure qualité, soit que les " terrains aient eté méliorés, au cours des siècles, souvent par des travaux divers et - l'apport de matières fertilisantes. Les villages son tentourés de productives campagnes et - de belles prairies bordées, les unes et les autres de larges haies d'essences forestières

- et d'arbres feuillus, donnant parfois l'impression d'une contrée riche en matériel - ligneux.

"Dans ces derniers temps surtout, les progrès réalisés dans le domaine de la science " agricole ont rendu possibles des transformations tellement rapides et surprenantes

" qu'il est enfin permis d'espérer que, si l's moyens dont nous disposons ne viennent "pas à nous manquer un jour, la lande sera vaincue."

Depuis ce rapport de 1904 , le sylviculteur possède un guide fidèle qui lui permet d'analyser chaque cas en particulier et de lui appliquer le mode de mise en valeur rémuúrateur et économique qu'il comprorte.

Les anciens procédés routiniers y sunt caractérisés de facon convenable et sont en géuéral abandonnés partout.

L'assainissement n'est pratiqué que pour l'enlèvement et l'écoulement vers les émissaires naturels des eamx nuisibles et surabondantes. II n'y a aucune utilité à rigoler les sables secs et cette opération est souvent indifférente et parlois franchement nuisible. Lorsqu'un degré d'assainissement suffisant ne peut pas être obtenu par le sys-

(1) Rapport de la Commission chargée de l'ètude de la eampine au point de vue forestier (31 décembre 1904), aurjuel nous fajsons également d'autres emprunts dans la suite du présent. 
tème de fossés habituellement en nsage, il faut aviser et étudier si le terrain ne peut recevoir une autre destination. La création d'étangs, l'installation de sociétès de "wate. ringues». combinées avec le curage rationnel des cours d'eau publics rendent aussi parfois de réels services. surtout si le service d'hydraulique agricole fonctionnait en campine comme il fonctionne en ardenne.

Le défoncement est une opération coûteuse qu'il ne faut pratiquer qu'à bon escient, en tant qu'il s'agit du travail profond du sol; il existe en campine un abus du défoncement, contre lequel il y a lieu de réagir, d'autant plus uque dans la plupart des cas il peut être avantageusement remplacé par un travail superficiel, toujours utile et reconmandable, après extraction des souches à la machine dans les parcelles exploitées ou après arrachage complet des pins lirrés à l'exploitation.

* C'est au labour complet (1), a une profondeur de $0 \mathrm{~m} .20,0 \mathrm{~m} .25$, qu'il faut donner - la préférence. Par ce travail, on assure l'aération du sol et la pénétration de l'eau, - et l'on favorise l'action des microbes. En enterrant à nne profondeur de $0 \mathrm{~m} .20$ - environ la couche tourbeuse superficielle munie de sa garniture de courte bruyère, non

- seulement on fait disparaître une plan te qui prélève sa part de nourriture et d'eau, et l'on liminue donc la perte de celle-ci par transpiration, mais on jrovoque la dícomposition - des matières organiques et les divers phénomenes qui ont pour effet de rendre les " substances nutritives assimilables par la végétation.

* Nous avons déjà dit ailleurs (1) que nombre de sylviculteurs campinois avaient - espéré rencontrer dans la profondeur du sous-sol une force le production qu'ils avaient * vainement réclamée au sol même de leurs terrains, surtout lorsque ce sol avait été - épuisé par une première production. Presque toujours ils ont été tout à fait désillu- sionnés. Nous ne reviendrions pas sur ce point si nous n'arions a constater ici que

* l'enfouissement profond des matières organiques de la surface, ayant pour effet de les

- mettre à l'abri de l'action de l'air, rend leur décomposition impossible et que, long-

- temps après, on les retrouve à peu de chose près dans le même état. llest même arrivé

- qu'un défoncement opéré dans ces conditions, en culbutant dans le fond de la tran-

- chée de gros blocs de la surface garnis de bruyère, avait eu pour résultat de rendre le

- terrain trop poreux, trop perméable et à peu près stérile. Pour procéder d'ıne facon

- rationnelle, il faut donc bien se garder de rejeter dans le fond du sillon la couche

" superficielle plus ou moins tourbeuse et pourvıe de sa végétation de bruyère. Il faut

- se borner à la recouvrir d'une légère couche de terre sous laquelle elle se décomposera

- le mieux, ou bien, après un labour ordinaire, la laisser s'effriter et s'ameublir sous

- l'action des agents atmosphériques, avant d'en entreprendre le défoncement.

"Ise tuf, le tuf ferrugineux surtout, devra être ramené à la surface. Il s'v délitera - et certains de ses éléments serviront à la nourriture des plantes: tand is que, laisse dans

- le sol, il restelait inerte et pourrait se reconstituer a l'étát de couche dure imperméable,

- sous l'influence persistante des causes auxquelles cette couche doit sa formation.

"Il est mauvais de ramener à la surface le sal le boulant ou driftzand, parce qu'alors

- les plantes se déchaussent, par l'effet de la gelée surtout.

"De même, lorsqu'il y a de l'argile dans le sous-sol, il ne faut pas la ramener à la

suriace, mais la mélanger au sol dans une mesure raisonnable, quand c'est possible. .

Tous les terrains de la campine sornt pauvres surtout en acide phosphorique et en chaux, il estindispensable de les fertiliser avant de les boiser et surtout de les reboiser.

On y arrive par divers procédés :

$1^{\circ}$ La culture agricole pendant une certaine période, dans les situations où les terrains trouvent preneurs à de bonnes conditions. Cette méthode, lorsqu'elle peut être pratiquét économiquement. est la meilleure de toutes, celle qui fournit partout et toujours de t.eaux pins, le sol recevant à la fois des préparations répétées et nne fumure suffisante pour les besoins de la culture forestière.

$2^{\circ}$ L'épandage direct d'engrais phosphatés et potassiques sur labour superficiel. mèthode péu cốteuse et produisant de fort bons résultats dans les bruyères vierges ayant conservé une certaine lertilité naturelle.

$3^{\circ}$ L'emploi des boues de ville aux environs des canaux et des grandes voies de communication, du moment que leur prise de revient ne dépasse pas trop sensiblement la valeur de l'engrais minéral qu'elles contiennent; la valeur des matières organiques ne doit pas entrer en ligne de compte, d'autres moỵens plus éronomiques existant pour donner au sol les matières organiques faisant rléfaut.

40 On puise l'azote et les matières organiques à l'aide du lupin jaune, on ajoute des engrais minéraux et un rentre dans une grande partie des avancesfaites par la culture unique ou répétée du seigle "at de l'avinine. C"as ne s'emploie que pour des sables peu f r rliles ou lorsqu'il s'agit de restaurer lws fomls epuisi's par une ou deux productions ligneuses et pour les abus dus smutrage.

(1) Rapport précité. 
INTERNATIONAL 191:;

Système applique et recommandé par le $\mathrm{M}$. Dr Nuets, président de la Commissiou de la campine :

$1^{\mathrm{rc}}$ année. - Sur sol travaillé l'année précédente et ayant reçu à l'automne 1.000 kilo grammes de phosphate basique, qu'on recouvre par un coup de herse (et 200,300 kilo grammes de kaïnite, si on le juge à propos), semaille all printemps, en avril-mai, de 80 à 100 kilogrammes de graine de lupin par hectare. Enfouissement de la récolte vers la fin de la tloraison.

$2^{e}$ année. - Nouvelle culture de lupin, sans engrais : enfonissement, semaille de seigle avec 1.000 kilogrammes de phosphate basique.

$3^{e}$ année. - Récolte hu seigle. Labour du terrain.

$4^{\text {e }}$ innée. - Troisième culture de lupin, sans engrais ; enlouissement en septembreoctobre. Ensuite, seigle avec 1.000 kilogrammes de phosphate basique, 500 kilogrammea de kainite et, au printenus, 150 kilogrammes de nitrate rle soude.

$5^{e}$ année. - Femaille de lupin dans le seigle. Enfouissement du lupin.

Le terrain est alors suffisamment préparé. Il peut recevoir an printemps suivant une plantation forestièr ou être affecté à la production agricole régulière.

Si l'on fait abstraction du con̂t du défoncement éventuel dans certaines situations, ce coût est même couvert par la vente des souches, les frais occasionnés par la fertilisation sont comprensés par le produit des récoltes de seigle.

Lorsque les terres sont assez fraîches, on peut aussi reconrir à la culture de l'avoine. La pomme de terre peut également entrer dans l'assolement.

Nous ne nous étendrons pas plus longtemps sur ce sujet: les assolements sont cri. demment fort variahles et dépendent des conditions dans lesquelles on opère, mais l.s principes fondamentaux en sont les mêmes.

Le terrain, ainsi travaillé et amendé, est plan té en pin sylvestre, auquel on associe un quart ou un cinquième de pin laricio le Corse. La venue de cet arbre est belle «n général, sa tige droite el verticale, ses faibles branches latérales en font un arbre pré. cieux, surtout sur les bords des peuplements. On peut espérer qu'il sera rustique, malgré son origine méridionale, par suite de l'abri que lui procure le mélange et surtout si l'on emploie de préférence la graine des sujets âgés, qui existent chez nous ei dont plisieurs sont centenaires. Culture d'essai toujours, mais qu'on peut espérer voir réussis en majeure partie dans l'avenir.

Dans quelque endroits spéciaux on introduit le mélèze du Japon, l'épicéa de Sitka, le pin Weymouth, le sapin de Douglas; parfois aussi les pins de Banket rigide, auxquel cependant on paraìt avoir renoncé depuis quelques années. mais ce ne sont là que des essais de yetite envergure et il ne s'agit pas d'essences de boisement proprement dites. La commune de Genck et autres se trouvent fort bien de regarnir les plantations de pin sylvestre, en sol de nature médiocre, quoique amélioré avant le boisement, à l'aide d'un semis de pin maritime, excellente essence, qu'on a en le tort de condamner d'une façon complète après les désastres occasionnés par les getées hivernales de 1879-1880 1891-1892 et autres. Il n'est pas rare de rencontrer, à l'heure actuelle, dans les peuplements de 35 à 40 ans des pieds isolés de cette essence, toujours de meilleure végétation que le pin sylvestre, et il existe actuellement encore des pins maritimes qui ont dépassé la centaine. Le semis en mélange pour le pin maritime et la plantation on le semis en mélange pour le pin laricio de Corse parajsent être les facteurs primordiaux et essentiels de leur réussite dans les sables campiniens; si la première n'est jamais destinée qu'à rester une espèce de deuxième ordre en matière de boisement, à appliquer surtout dans les terrains de moindre cualité, la seconde paraît être appelée, en cas d succès des essais entrepris, à être classée comme essence princinale et à augmenter dans une assez forte proportion les revenus en matière et en argent le nos peuplements.

La densité des plantations varie avec la nature $d u s o l$, les conditions économiques et la valeur des sous-produits : cette méthode est très ratjonnelle. "(In peut admettre (1) que, pour satisfaire aux diverses exigences de la nature du sol et de l'essence envi" sagée, le nombre des plants nourra varier de 10.000 it 20,000 par hectare au grand "maxinum."

Suivant los conditions économiques pt la valeur des sous-produils. on dépasse sourvent ces chiffres en pratique, "au point de vue forestier (1), nous ne pouvons que con" damner la méthode des plantations trop serrées, car elle a été la cause de bien des * désastres, en campine surtout, où les dégagements frop négligés ont compronis li

" végétation des massil's et favorisi ainsi la multiplication exagirée des insertes rava"geurs.

"En rialite, dans la pratique, il y a plutôt nne question do routine et, dans la majo" rité des cas, le nombre de 20.000 sujets doit déji être ronsidrire conme excessif, " même en tenant compte dés rirconstances économiques."

(1) Rapport précité. 
Les icartements les plus fréquents sont pour les pins:

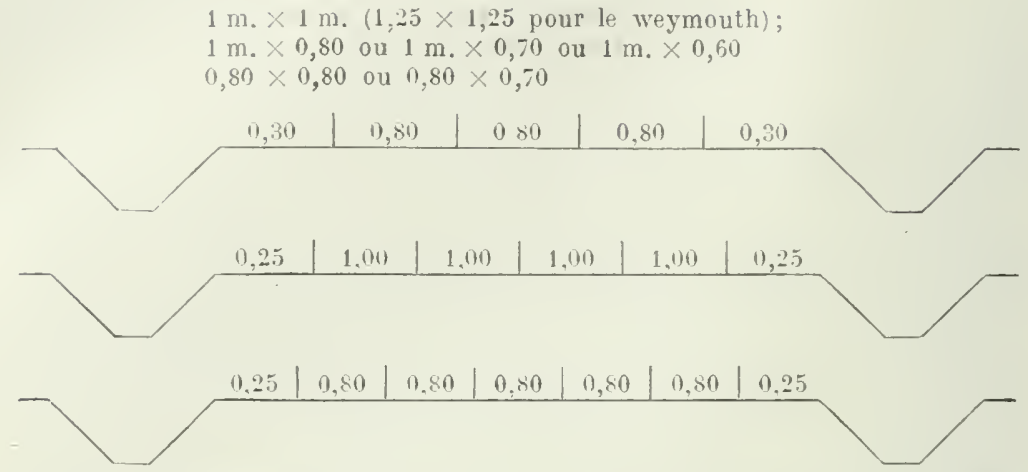

En terrain non rigolé, on réserve tous les 4.5 mètres une bande de 1 à $1 \mathrm{~m}$. 20 de largeur; soit pour y établir plus tard une rigole, soit pour y trouver la terre nécessaire au recouvrement des aiguilles, avec ou sans épandage d'engrais; cela facilite l'exécution des premiers nettoiements et l'enlèvement des produits.

Bien.que la nature du terrain des bruyères campiniennes se prête mieux à la culture des esssences résineuses, on ne néglige pas, lorsque la chose est possible, d'établir des cordons feuillus et même des peuplements mélangés d'essences feuillues. Comme à l'henre actuelle l'industrie, la culture herbagère et agricole, la spéculation se ruent d'une facon ardente et systénatique à la conquête des bruyères encore existantes, la sylviculture de l'avenir aura à sa disposition encore beaucoup moins de bons terrains que par le passé, ce qui fait perdre encore de l'importance aux peuplements feuillus mélangés. Relativement à ces deux points, je m'en réfère tout simplement au rapport de la Commission forestière de la campine.

Le boisement des dunes terrestres est aussi soumis à des règles précises : travail par bandes du sol, avec engrais et fixation des parties mouvantes à l'aide de bruyères fauchées et fixées par une motte de terre. Plantation du pin sylvestre, du pin laricio de Corse, semis du pin maritime. Ce système donne de bons résultats.

La campine est une région calme, pacifique, agreste, d'une sauvagerie naturelle très appréciée; la lande fait encore des taches trop étendues sur la carte, mais le paysan est tenace, tient à ses aises et à ses habitudes, il n'a pas toujours l'aisance nécessaire nour renoncer à son système irraisonné de culture et apporter les modifications néces. saires à la construction de ses étables. La situation n'est pas bonne cependant au point de vue de la conservation des litières et la culture du pin $\in \mathrm{n}$ campine revêt le caractère d'une culture réellement spoliatrice, au point qu'on voit les produits diminuer et décroître après chaque génération et qu'on se voit forcé de faire la restauration complète et à replanter.

La question de l'enlèvement $d \cdot s$ souches dans les pineraies exploités ne préoccupe pas trop le sylviculteur; dans beaucoup de stations, ces produits acquièrent une valeur fort appréciable et ailleurs les souchures à bras de la région parviennent à les faire disparaitre sans trop de frais.

Tout ira en s'améliorant et eli tenant compte dę divers intérêts en présence ; il faut d'ailleurs que l'amélioration soit progressive et suive une marche adéquate avec l'augmentation de la population et la création de nouveaux débouclsés. Le domaine inculte communal doit être ainsi progressivement transforme suivant des règles fixes et une ligne de conduite bien arrêtée.

L'Etat achètera et boisera les bruyères dont les communes ne sont pas à même d'entreprendre la conversion (domaines d'Exel, de Raevels, de Heiwich (op. grimby); les communes de leur côté, encouragées par les subsides de l'Etat et éventuellement de la Provid nce, boisent d'une façon normale et régulière. Des aliénations sont consenties pour l'agrandissement rationnel des cultures et l'arrondissement du patrimoine familial chez les petits cultivateurs. La population est essentiellement agricole et l'on espère que ses idées concernant l'utilité des litières dans les bois se morlifieront avantageusement, au point que la pineraie campinienne finira par jouer l' grand rôle d'amélioration du sol, qu'on lui reconnaît dans les pays limitrophes.

Les amateurs de la nature agreste et primitive pourront venir longtemps encnre fixer 
sur la toile les endroits les plus captivants t les plus pitturesques de Genck et des enri. rons. Tous ceux qui aiment la vie champètre et l'air vif, pur, embaumé par l'odeur if la résine, pourront renir longtemps encore se reposer et letrouver leurs forces perdues,

Tout est pour le mieux dans la meilleure des campines, la roie est tracée, les moyens sont connus.

Dès fin 1908 et commencement 1909, plusieurs sociétés anonymes de charbonnages furent autorisées à acheter de gré à gré des blocs assez importants de bruyères et de boi communaux, pour être affectés : $1^{\circ}$ aux installations requises par l'exploitation des mines de houille dont la société a obtenu la concession et par les opérations que le combustible extrait peut être appeli à subir en vue d'en assurer ou d'en faciliter l'écoulement : $2^{\circ}$ à l'érection d'habitations pour le personnel le l'exploitation.

A l'heure actuelle, la vaste plaine de la campine est en pleine fièvre, les sièges des exploitations charbonnières dressent dans l'air, leurs hautes cheminées, leur's bâtiments et s'apprêtent à construire de grandes cités ouvrières. On ouvre de nouveaux chemins de fer, de nourelles routes, de noureaux canaux. La main-d'cuvre est rare et augnente de prix dans des proportions fabuleuses.

Des idées nouvelles surgissent : une Commission des sites tâche de conserver l'exis. tence de plusieurs curiosités naturelles.

Une Commission gouvernementale fonctionne et étudie l'orientation nouvelle à donner à la mise en valeur des terres incultes. La forêt risque fort de se voir considérer comme une spéculation trop lente et devoir se contenter des terrains dédaignés pal l'industrie, la bâtisse et la culture agricole ou herbagère ; on pourrait cependan t réserver à l'industrie tous les terrains les moins fertiles, point sans importance pour elle. La cause du maintien et de l'existence des massifs forestiers se pose donc et il est à espére que si les bois viennent à diminuer dans la région charbonnière proprement dite, il pourra y avoir compensation par la création de nouveaux massifs dans le restant de la campine. Il ne faut pas perdre de vue, en effet, la grande consommation de produits forestiers nécessitée par l'extraction de la houille. Une situation nouvelle est donc créée dans cette campine, toujours si pauvre et qui est appelée à un essort économique si grave!

Le forestier, d'autre part, a dû étudier d'une façon toute spéciale la question d'organiser son outilage économique et de diminuer la prise de revient des opérations forestières.

Un premier progrès avait déjà été réalisé par le labourage des terrains à l'aide de tracteurs à vapeur et la firme Sneets et fils, d'Exel, s'est acıuise une spécialité en cette matière. Elle livre un travail fort bon à un prix de revient rémunérateur; de 50 à 60 francs l'hectare pour un labour de $0 \mathrm{~m} .20$ à $0 \mathrm{~m} .25$ de profondeur, $\mathbf{2} 25$ francs et plus pour les défoncements proprements dits.

Ces tracteurs risquent fort d'avoir une concurrence fort sérieuse, dans l'avenir, de lid part des noto-charrues dont une, la moto-charrue "Stock" - usines de la Kôpenicker strasse, 49, à Berlin, et de Niederschœneweide - a déjà labouré une dizaine d'hectares à Eysden (Limbourg belge), pour la société des charbonnages des Limbourg-Meuse et est occupée à labourer 40 hectares de bruyères, que la commune de Mechelensur-Meuse (Limbourg belge) est autorisée à boiser.

Il n'est pas possible à l'heu re actuelle de prendre parti pour l'un des systèmes en présence. Nous n'en retiendrons que l'idée maîtresse, cherchant un système de labourage aussi rapide, aussi écononnique que possible, avec suppression presque absolue de maind'œuvre. Ia maison "Stock " ne possède pas seulement des moto-charrues pour le labourage superficiel, mais est outillée également pour le défoncement des bruyèrts aux profondeurs et suirant le système adopté par la pratique.

Dans le même ordre d'idées, il a été institué en 1912, à Lanaeken (Limbourg), un concours entre les dessoucheuses et les déracineuses par' la Société centrale forestière de Belgique; un concours des mêmes appareils dans des blanes étocs et peuplements de bois resineux en sols argileux sera organisé en 1913. Il convient que le forestier ait à sa disposition non seulement un appareil pratique propre à arracher les souches des pins, mais aussi une machine arrachant les arbres des blancs étocs. On est déjà arrivé á des résultats très satisfaisants au concours de Lanaeken, les dessoucheuses Dehez, à Grand-Halleux et Hubrechts, de Grintrode, fournissant un travail économique et fort bien exécuté pour les scuches et pour les arbres. Nul doute que le concours de 1913 ne marque un nouveau progrès dans la construction de ces appareils si in téressants.

Si le forestier campinien a à sa disposition une bonne dlessoucheuse, une bonne déracineuse, une moto-charrue pratique, il lui sera toujours possible, même dans une région industrialisée à l'excès, de créer rationnellement et économiquement des bois, pour le plus grand profit de notre prospérité nationale.

Il faut aussi signaler, en terminant, qu'un organisme nouveau, une société coopérative vient de s. funder le 22 mars 1913 à louvain, sous le nou de "Société des bruyères de 
Belgique ", ressemblant à plus d’un titre à la Société néerlandaise du même nom, et dont le but avéré est de hâter dans une forte proportion la mise en valeur du domaine

inculte de la campine.
On roit donc que la rampine belge est en pleine effervescence et que le tous côtés ,n se rue vers sa conquête, chacun poursuivant des buts plus ou moins contradictoiles :

a) Etablissements charbonniers et industriels;

b) Cités ouvrières, hâtisses et agglomérations nouvelles ;

r) Voies de communication : chemins, voies ferrées, canaux;

d) Cultures et prairies ;

e) Bois.

Il est à espérer que tous ces buts divers pourront recevoir satisfaction et que la rause des bois, si nécessaires à l'extraction de la houille, ne sera pas négligée. 


\title{
INNEXE B
}

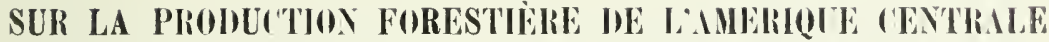

\author{
PIK
}

\section{Désiré PECTOR}

Délègué ofticiel du Honturas

Jo crois que pour ce qui a trait à la smperficie boisée des divers Etats et de ceux d'Amérijue ne figurent pas, par suite sans foute d'une omission involontaire, les cinq Etats da l'Amerique Centrale. Or ceux-ci, sur le compte desquels mon ouvrage les Richesses de $l$ tmérique Centrale a donní des précisions détaillées, onl, d'aprés les rensejgnements ell mon pouroir, le chiffre respectable de 47.300 .000 hectares boisés.

Je décomposerai ce chiffre, d'après l'ordre géographique du nord an sul :

Le Guatemala, qui a une superficie totale d'environ 11.500 .000 hectares, peut avoir une superficie boisée d'environ 7.000 .000 hectares, surtout à la côte de l'Océan Atlantique et dans la région du l'etenl.

Le Salvador qui a environ une superficie totale de 3.400 .000 luetares, n'a qu'environ 1.000 .000 d'hectares boisés. Cette particulariti provient de la grande culture agricole de ce pays, qui est à la fois le plus pelit et le plus peuplé des Etats d'Amérique.

Le Honduras a un minimum de 13.000 .000 hectares lotaux sur lesquels on pent compter 9.500 .000 hectares boisés, surtout à la côte de l'Atlantique, dans la région de Caratasca, les' lépartements de Cortes, d'Mtlauticla, d'Olancho, ot aussi dans les lépartements de Santa-Rosa, Gracias, Clioluteca, etr.

Le Nicaragua. Ce pays compte environ 1'.000.000 de suprefficie totale, tont environ \$.000.000 boisés, surtoint a la côte Atlantique et dans les départemenls de Matagalpa, Chontales, Carazo, ete.

Le Cosia-Rica. Ce pays a une superficie fotale de 5.400 .000 hertares dont environ 3.000 .000 boisés, surturit à la cóte Atlantique, la Talamane'a, ete.

Ces richesses lorestières consistent en tous bois exotiques de teinture, éhénisterie et d'usages à plarmacopée, et surtout rn acajou, chêne, palissandre, pitchijin, etc. 11 est à regretter que les capitax français ne se portent que très peu vers l'exploitation fores-

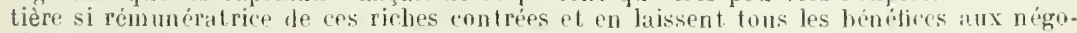
ciants des Etats. Tnis, plus avisés.

J'ajouterai que le Honduras a, Jepris tes annés, institué lat fête des drlmes qui lui permet de propager dans les andes du pays les ćloments primordianx le l'exploitation rationnelle? forestière. 


\title{
ANNEXE C
}

\section{LES RESSOURCES FORESTIÈRES DE L'AUSTRALIE OUEST}

PAB

\author{
Lieut.-Col. the Honorable Sir Newton MOORE K. C. M. C.
}

Igent général de l'Australie Ouesl

Quoique la superficie de l'Australie ouest soit d'environ 253 millions d"hectares. la partie boisée n'en occupe guère que '́t millions. Cette estimation fut faite par moimême en 189 ' et la carte ci-annexée donne une idée très exacte des parties où dominent les essences principales. Il est bien entendu que dans chaque localité il n'y a pas d'essence dominante, mais les teintes de repère montrent les emplacements oì celles-ci se rencontrent en plus grand nombre. Sur la carke ont été reportée plus spécialement les bois de valeur marchande et les limites de zones peuvent être considérées exactes.

La surface correspondant aux essences marchandes peut se résumer comme suit:

$$
\begin{aligned}
& \text { Le Jarrah ou Euculyptus marginato.) } \\
& \text { Le Blarkbult _- patens. } 3.237 .369 \text { hectares. } \\
& \text { Le Red ium _calophylla. } \\
& \text { Le Fiari _ diversiolor. } \\
& \text { Le Twart _- sumphorephala. } \\
& \text { Le } \mathbb{I}^{r} \text { andoo } \quad \text { - rerlunca. } \\
& \text { Le York Gium _. lacophleba. } \\
& \text { Le late cornuta. } \\
& \text { Le Bois de Santil ou Santalum cygnorum. } \\
& \text { Leacia on icacia reuminata. } \\
& 485.605 \\
& \text { 80. } 934 \\
& \text { 2. } 832.697 \\
& 1.618 .68 \%
\end{aligned}
$$

Sur tout le restant de la superficie boinée (à part toulefois ruelques exceptions) les essences sont en général de classe inférieure et à peine utilisables, ailleurs que sur place ou alors dans des régions pen accessibles, tout an moins pour le moment.

\section{Répartition}

La zone réellement forestière de l'Australie est plutôt maritime, c'est-à-dire que le portions les plus touffues occupent les somınets montagıeux, lesquels, en général, contournentla cóle di petite distance, également les plateaux et pentes. Tout fois lorsque les chaines deviennent très colières, lelles que celles de Darling (Iustralip ouest), la cein ture furestiere gagne en profondeur el la démarealion se fait sentir par line plus grande abondance de pluie el par un climal plus temperi. Ainsi dans l' Dustralip onest, la grande 
ceinture de bois de Jarrah, qui a 560 kilomètres de longueur et qui, partant des chaine. Darling, pour se diriger vers l'est, comprend une étroite bande de bois de Tuart entr. elle et la mer.

A l'intérieur de cette ceinture de Jarrah et vers le sud-ouest se trouve celle où le bois Karri domine, allant du cap Hamelin à Torbay et situee entre les 115 et 118 degrés longtude est; 34 et 35 latitude sud. Ges régions où dominent le Jarrah, le Karri, le Tuart, le Blackbutt et le Gommier rouge, on t une pluviosité annuelle de 88 cen timètres à 1 mètre. Dans la proportion relativement plus sèche. qui s'ètend à l'est de la ceinture de Jarrah, existe une bande assez large de Gommier blanc englobant une autre bande plus étroite de gommier York, laquelle par ses extrémités nord et sud constitue pour ainsi dire une continuation de la région du Jarrah. Vers l'est ou la pluviosité annuelle est de 35 centimètres au plus, la forêt s'éclaircit et l'on n'y trouve plus que du Gommier blanc et, dans les régions aurifères, du Gommier vrille ou saumon, ainsi que quelques ceintures de pins.

\section{Entretien des Forêts}

Dans tous les pays où la question forestière a été étudiée aeve soin, plusienrs systèmes ont été élaborés offrant les uns on les autres certains avantages suivant leur application laquelle peut varier en raison de circonstances locales ; toutelois la méthode généralement employée icj est celle usitée en France des coupes divisées; c'est-à-dire en opérant l'abatage des grands arbres isolément, conservant ceux qui n'ont pas atteint leur pleine croissance. Cette méthode est également suivie en Amérique où ne sont abattus que les arbres au-dela d'une certaine dimension.

l] résulte de ce système que la forêt a toujours un aspect assez diver's au point de vue de la croissance, les arlores adultes étant abattus et enlevés, permettant ainsi à la nature de reprendre ses droits par reproduction des espèces suivant l'ensemencage naturel.

De la sorte la zone forestière s'entretient d'elle-même, ainsi que cela se produit dans les forêts vierges où le feu, les orages et la pourriture, en clégageant naturellement de. étendues de terrains, permettent avec le temps de reconstituer les especes disparues et de porter remède aux dégâts.

Les dimensions-types auxquelles est soumis l'abatage des espèces ci-dessous sont, mesuré à 90 centimètres au-dessus di] sol et écorce comprise :

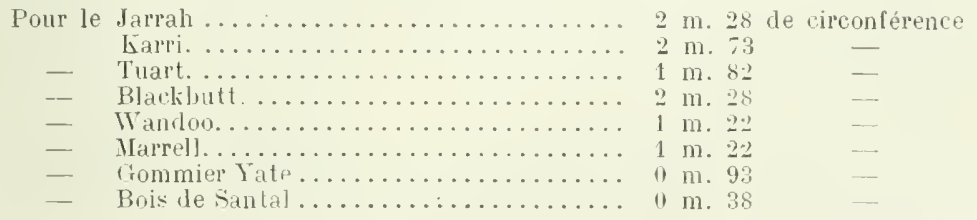

D’après ce (qui précède, l'on voit que les chiffres sont plutôt élevés et que par conséquent un pourcentage important reste en valeur pour les coupes suivantes.

\section{Reconstitution des plants}

Lo système eurupeen de reconstitution naturelle par semailles directes des arlores adultes est le soul pratique poul le moment en Australie.

Le repiquage ou bouture a été reconnu impraticable en raiscn de son prix élevé.

Avec cesystème, la reconstitution s'opère normalement dens toute l'étendue forestière par suile de l'abatage des arbres adultes de dimension convenable, de ceux avariés ou de pousse défectueuse, de l'enlèvement des sauvageons ou de ceux qui, par un défaut de croissance, risquent de ne donner' qu'un résultat négatif d'utilisation.

Ce moyen n'est que copié des forêts vierges où lorşu'vn arbre meurt de vieillesse ou toute autre cause, une éclaircie se produit dans la froudaison et les graines provenant des arbres ainés peuvent germer et les jeunes pousses se développer à l'abri des anciens. Ainsila forêt vierge se reconstitue d'elle-mème avec le temps. Ce procédé est naturellement un peu lent, attendu que les jeunes pousses ne peuvent grandir que si laair ct lit lumière leur parviennent en quantitésuffisante et cela par sujte de la mort ou de la chute des vieux arbres. Aussi en s5lvin!ture aide-t-on artificiellement par l'abatage des arbres de dimension marchande".

Il est bon toutefois d’ajouter 'pue, vu les dèpenses énormes nécessitées par les grande étendues a parcourir, ce système n est pour le noment utilisé que sur une échelle relativement restreinte.

Les bois indigenes del 'Australie mest ont une puissance de reproduction formidable la constatation a pu =e faire souvent Jor'sque l'on s"es l trouré en présence de coupes de 
for èt exigérées, par exempje, ou lorsqu un emplacement, jadis habité, avait élé abandonné ('nncien scierie, dépôt de troncs, chantiers d'équarissağe).

En fait, weu de forêts au monde, arec l'aide de la nature, sont à même de se reconstituer aussi rapidement que les nôtres et je crois devoir dire que si le système préconisé pouvajt s'étendre, toutes les forêts de l'Australie pourrajent être conservées et donner un meilleur rendement comme qualité et quantité ; un gros pourcentage des pertes actuelles. provenant de ce que le bois est plus que mûr et aurait dû être abattu depuis longtemps.

En mêne temps que l'exploitation commerciale forestière était encouragée, la question le reconstitution n`a pas été oubliée. Toutes nos essences de bois dur son tsusceptibles fe reconstitution naturelle et, avec un peu d'aide. lon peut dire que nos ressources sont inépuisables. Toutefois le gouvernement a considéré comne indispensable de créer des réserves perpétuelles, et de vastes espaces ont été conservés dans re but.

Lindustrie forestière est aujourd'hui une tes principales du gouvernement. constitwant un enploi pour plus de 6.000 individus, et représente comme salaire une summe annuelle de 18 millions. La valeur totale du bois dur' exporté pendant l'année expirant au 30 juin 1910 ótait de 22.346 .000 franes dont seulement 7.587 .000 francs pour les pays orientaux.

Le tableau ci-dessous domnant le chiffe des exportations indique bien la valenr universellement recomnue des essences australiennes:

PAYS D'EXPORTATIOY

Bois en srume

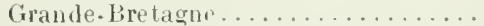

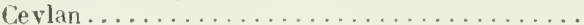

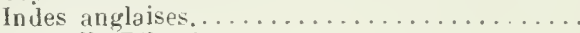

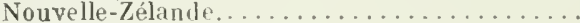

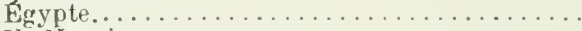

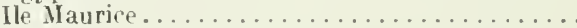

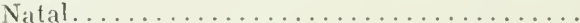

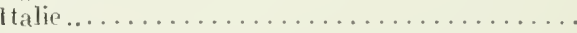

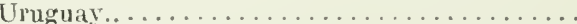

Iles Philippines....................

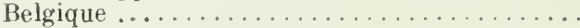

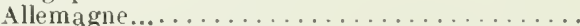

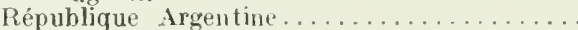

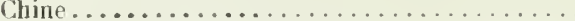

Colonies portugaises d'Airique............

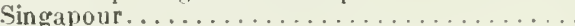

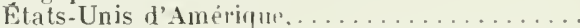

Hong-Kong. . . . . . . . . . . . . . . . .

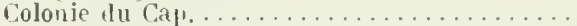

\begin{tabular}{|c|c|}
\hline QUAXTités & VAIETR \\
\hline Hètres carrés & Fr. \\
\hline $\begin{array}{r}113.417 \\
36.603\end{array}$ & 1.350 .025 \\
\hline 2.599 .229 & 2.126 .600 \\
\hline 873.996 & 1.493 .800 \\
\hline 1.668 .343 & 2.990 .150 \\
\hline $21+.620$ & 38.525 \\
\hline 719.588 & 1.222 .075 \\
\hline 2.627 & 1.875 \\
\hline 319.013 & 572.375 \\
\hline 260.892 & $\$ 68.050$ \\
\hline $30 \% .417$ & 546.475 \\
\hline $1.52 i$ & 20.700 \\
\hline 59.888 & 125.375 \\
\hline 32.70 ' & 57.400 \\
\hline+39.656 & 78.925 \\
\hline 1.632 & 2.950 \\
\hline 31 & 75 \\
\hline 2.230 & 4.050 \\
\hline $45 \div .554$ & 804.90 \\
\hline 2.185 & 3.92 \\
\hline
\end{tabular}

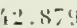

3.149

1. 2.21

17.970

8.185 .979
400

70.175

6.175

1.900

32.250

12.758 .425

Total.

Alors que l'Australie ouest a été faroriste par la nature avec une telle richesse en forêts, il est bon de noter que heaucoup d'essences exetirgues peuvent y pousser, le terrain et le climat de la vortion sud-ouest de la province se prêtent merveilleusement a la venue de ces bois. Quoique la généralité des essences soient le bois duss, les hois tendres s'y rencontrent quoique rarement, et l'on n'y trouve aucune essence pouvant remplacer les bois très tendres du commerce.

Actuellement l'on cherche le moyen d'utiliser les bois de rebut, lesquels sont gén'iritlement brîlés. Les diverses compagnies forestières se rendent parfaitement comptr de l'utilité de diminuer lo déchet; malheureusement, comme jusulu'a ('t) jour cette valeur markhande est presque mulle il semble difficile de l'éviter. 
Jarrah (Euculypus Warginat $)$. - Il n'est pas rare de trouver des qroupes d'arbres avant de 27 a 37 mètres de hauteur, s'élevant parfaitement droits, et de 0 m. 90 $1 \mathrm{~m} .50$, le liamètre, les premières branches à 15 à 18 mètres du sol, Toutefois comm movenine, l'on peut considérel qu'un arbre de 27 à 30 mètres, avec $0 \mathrm{~m} .75$ à $1 \mathrm{~m}$. 05 de iliametre à la base, est bon pour l'abatage. Certains spécimens ont été rencontrés ayant des dimensions supérieures à celles données. Le jarrah a une densité d'enivron 1.I2 fraiset $0.96 \mathrm{sec}$, le bois d'me couleur rougeâtre, très dur et très serré, généra. lement très droit comme fibres et peu d'aubier. L'acajou rouge de la Nouvelle-Galles du Sud a souvent été confontu, par erreur, aver le jarrah.

Karri (Eucalyptus dicersiculor). - Cet arbre est l'un des plus beaux et des plus gracieux " $\mathrm{t}$ Iustralie. A l'état alulte et lor'sque de grandes dimensions, son aspect est imposant. 1 a hauteur moyenne est de 46 mètres, son diamètre de près de $1 \mathrm{~m} .80$ à 1 m. 41, à 1 111. 20 du sol èt ses basses branches à 30 à 35 mètres de nauteur. Dans le réginn ae la Warren River, il n'est pas rare de rencontrer des spécimens de 90 mètres de hauteur. les hasses branches etant à 55 mètres du sol et ayant de 6 à 9 mètres de circonférence à la base. Son bois a une densité de 1.00 à l'état sec; de couleur rouge, lourd. rude et serré, assez élastique, ressemble braucoup au jarrah.

Tuart (Eucalyptus gomphocephala). - Atteint une hauteur de 16 mètres, avec $6 \mathrm{~m} .70$ de circonférence, - con diamètre moyen est d'environ $0 \mathrm{~m}$. 90. En général, il est très branchu, avec un tronc le 12 mètres aux premières. Le bois esi de couleur crème, très dur, à grain croisé et, pour cette raison, généralenent considéré comme le plus fort et le plus résistant du continent. Il est égale ment l'un des plus lourds, ayant 1.12 de densité à sec. Est très de mandé pour les constructions spéciales où la résistance est de première néces sité; malheureusement son débit restreint n'en permet pas un usage courant.

Blackbutt (Eucalyptus patens). - Ce bois ne se tronve pas en groupes compacts, mais se rencontre parmi le jarrah et le karri, Il peut atteindre me hauteur de 36 mètres aver un diamètre de $1 \mathrm{~m}$, 80. Sa couleur est claire. il est dur et serré et tellement résistant que l'élatement ne se produit jamais. Très usité pour emplois souterrains.

Wandos (Eucalyptus redunca). - Cette esprèce, plutôt connue sous le nom de gommier blanc, est très répandıe. Les arbres atteignent de 18 à 2'. mètres de hauteur, avec un diamètre de $0 \mathrm{~m}$. 60 à $0 \mathrm{~m}$. 90 ; rroit en général sur les terrains découverts. Le bois est brun-ronge, très dur et très serré. Sa densiti. même bien sec, ne descend pas au-dessous de 1.15 .

York Gum (Eucalyplus loxophleła. - Ye délasse pas comme hauteur 25 mètres, arec un diamètre de $0 \mathrm{~m}$. 90 , le tronc en général assez rugueux. Le bois est rougeâlre, très dur et très serré. Densité, pnviron 1.08, même très sec.

Red Gum (Eucalyptus colophylla). - Très répandu et de belle apparence, atteint une hauteur de 30 mètres, arec un diamètre de $0 \mathrm{~m}$. 90. Le bois est jaune-rouge, phus léger que les autres vąriétés d'encalyptıs quoique assez serré et dur; éclate facilement. Etant assez resineux, ne convient plas à tous les genres de fonstructions. Sa risine a une grande valeur médicinale et sert śgalement au tannage.

\section{Erportation}

Le commerce d'exportation a pris, ces dernières années, une extension considérable surtout ponr les essences de jarrah et karri employées principalement comme traverses ou pour le pavage. Ces bois ont égitlement été fort demanulés pour pilotis ou pour le bstiment.

La valeur totale des bois exportés de 1895 à fin 1912 est de près de 262.500 .000 frincs hors do l'Australie.

\section{Emphis ironomiques des bois australiens.}

l'emploi bcononique des buis peut se résumer comme suit ;

Jarrah. - Pour les chemins de fer comme traverses, dans les clantiers de coms. tructions, les usines, le bâtiment et convient particulièrement unx usages souterrains oul lorsqu'il doit être au contact de l'air et de l'eau.

Comme durée, ce bois est certainement celui qu i remplit le mienx le but proposé de toutes les essences, aussi est-il presufuc exchisivement employi dans les themins de per pour les traverses, pilotis nu longrines le ponts, aussi bifn pour les travaux aérifus que pour ceux souterrains.

Parmi ces emplois, l'on pent citer la ronstmetion des wagns pour les chemins de 
fer anglais et les compagnies australiennes avec un resultat satisfaisant pour le pavage; le Lloy lui accorde la première place pour la construction maritime et seulement comparalble au bois de fer parmi les bois durs australiens, très recherché également pour les poteaux télégraphiques et téléphoniques.

Karri. - Ce bois est très employé par le gouvernement ainsi que par les compagnies privées des chemins de fer, pour longrines et supports de wagons, les ponts, parquetages, bras mobiles de signaux, charronnage et caisses à primeurs. Il jouit d'une réputation méritée pour le pavage, étant même considéré comme supérieur au jarrah. Toutefois il ne convient nullement aux travaux de mines ou exposé à l'humidité.

Tuart. - S'emploie pour les cadres de wagons, tampons, bâtis de machines, barreautage, bordés de ponts, arbres et objets de charronnage, principalement pour les roues des chèvres de transport oủ il a la préférence sur le fer. Il est surtout préconisé lorsque la force et la dureté sont qualités indispensables, et Laslett affirme qu'il a l'avantage sur tous les bois comme résistance transversale on longitudinale.

Blackbutt. - Surtout employé sur place dans les usages fermiers: haies de séparations, entourages, roues, etc., peut convenir également comme traverses et parés ainsi que pour pilotis. Pour la construction des wagons, de grandes quantités ont été demandées par des compagnies de chemins de fer à l'étranger.

Wandoo. - Comme traverses, il est considéré l'égal du jarrah; est également employé comme pilotis. Pour les travaux de charronnage, sa dureté, surtout lorsqu'il est bien sec, lui donne la première place.

Généralités. - Le bois de jarrah comme usage dans le bâtiment n'a pas son égal. La surface parfaitement homogène et résistante en font un auxiliaire précieux pour le hois de plancher, surtout lorsque celui-ci est soumis à un trafic important, comne dans les magasins, entrepôts ou stations de chemin de fer; pour le parquetage suigné, tel que pour maisons particulièrs ou salles de danses, etc. son grain uni susceptible d'un très beau poli lui donne une place prépondérante.

La plupart des bois australiens conviennent également à la menuiserie et l'ameublement par suite de leur diversité de couleur variant du jaune au rouge-brun, płssan même jusqu'au noir ; plusieur sont un grain moucheté ou moiré ; certains même possèdent un léger parfum.

\section{Séchage}

Toutes les catégories de bois gagnent par le séchage. I a pratique suivie est, en génèral, de les garder en grume douze mois avant de les débiter. Celle qui consiste á débiter de suite les traverses et longrines jour les laisser sécher ensuite est considérée comme très préjudiciable à la durée du bois et si la première solution représente une déjense plus élevée, celle-ri est largement compensée par la longérité.

\section{Tin-inflammávililé}

En Ingleterre, le comité de surveillance łles incendies a fait, il y a quelques années; des expériences en vue de se rendre compte de la force de résistancè à la propagation du feu des bois de jarrah et de karri, et celles-ci ont donné des résultats surprenants, surtout avec les poutres et plancher's.

Les traverses employées dans le chemin de fer métropolitain de Londres sont entièrtment faites au jarrah.

En ce qui concerne l'usage dans la construction mécanique, il est indispensable de connaitre les caractéristiques des essences employées et. quoirue le jarrah australien soit parmi les bois recommandés, l'on manquait de données à son égard.

Il y a quelques années, agissant comme ministre des forêts, j'ai eu l'occasion de demander qu'une enquête très sérieuse fût faite à ce sujet. Celle-ci. conduite par II. G. A. Julius, B. Se. M. E.. s'est portée sur une série d'essais, dont les résultats sont condensés dans un rapport que j'ai le plaisir de vous transmettre (ci-annexé) avec l'espoir que ces renseignements aideront au développement de l'industrie forestiere du gouvernement.

En terminant ce bref exposé des ressources australiennes, j'exprime le très grand plaisir que j'éprouve à prendre part à une conférence tuuchaut une les questions les: plus importantes du monde civilisé. C'est un inmense privilège de pouroir discuter un tel problème économique en présence d'hommes aussi éminents et lont les noms sunt un garant certain de la valeur de la réunion.

Je regrette que mon manque de connaissance de votre langue ne me permette pas de prendre une part plus active aux délibérations, aussi ai-je pris la liberté de vous transmettre par up rapport l'ensemble des renseignements sur les ressources forestières de l'fitat dont i’ai l'honneur l'ôtre le représentant en Grande-Bretagne. 
INTERNATIONAL 1913

\section{ANNEXE D}

\section{LES RESSOURCES FORESTIÈRES DE L'ÉTAT DE VICTORIA}

P.AR

\section{Peter Mc BRIDE}

Ageul gèndral de Victoria-Australic

L'Etat de Victoria, qui est situé entre la rivière Murray et l'Océan du sud, forme la partie sud-est de l'Australie. Sa surface comprend 56 millions $1 / 4$ d'arpents, et de cette surface 1.2 millions environ d'arpents sont couverts de forêts, dont 7 millions sont de vraies forêts de charpente; on y trouve de grands eucalyptus et autres arbres utiles.

Il y a plus de vingt espèces principales, et de la famille de l'eucalyptus il y a dix espèces qui fournissent le bois le plus précieux.

Voici une courte description démontrant leurs qualités et leur emploi :

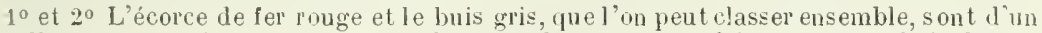
excellent usage, mis en contact avec la terre. Les traverses faites avec ces bois durent de 25 à 30 ans, et les pilotis de ponts ou de jetées durent encore plus longtemps. lls sont durs, pesants, épais, avec des fibres très serrées. On les emploie aussi beaucoup à faire des poutres, des traverses pour rails et des poteaux télégraphiques.

$3^{\circ}$ Le gommier rouge, que l'on trouve en abondance sur les bords de nos fleuves et rivières, est un grand arbre aux branches étendues, ayant de 50 jusqu'à 60 pieds de hauteur et le tronc une circonférence de 12 à 19 pieds. Quelques-uns des plus grands arbres fournissent de 8.000 à 10.000 pieds de bois de charpente, qui eșt fort estimé dans les régions où le sol est en général marécageux. Le bois de ces arbres est d'une couleur rouge-foncé et dure longtemps en contact avec la terre. On l'emploie souvent à faire des traverses, des pilotis, des ponts, de petites poutres, et pour la construction de fosses et de canaux, ainsi que pour les bordures en bois des jetées, les fondations et les encadrements des maisons. Les traverses faites avec ce bois durent de 20 à 25 ans et les pilotis de ponts de 30 à 40 ans.

$4^{\circ}$ Le gommier bleu est un arbre qui atteint une hauteur de 150 à 200 pieds. Le bois est d'une couleur janne-paille et d'une grande dureté. On l'emploie à faire les poutres de ponts, des pilotis, des planches et planchers de navires, pour la cunstruction de roitures et aussi pour la fabrication des manches d'outils. Quoiqu'il soit un peu plus luurd que le chêne le frêne et le noyer blanc, sa force spécifique est beaucoup plus grande.

$5^{\circ}$ Le commensal (Messmatte). - Bois d'une couleur brun-clair et d'une grande valeur. Il est employé pour la construction des maisons, y compris les encadrements, les platsbords, les parquets et les intérieurs.

f.o Frêne de la montagne ou frêne blanc. - Bois d'une couleur gris-clair, d'une force et d'une légèreté considérable. On l'emploie pour la construction dés maisons el depuis 
yuelyue temps pour la fabrication des meubles. Celuj-ci est le géant des forêts australiennes On trouve dans le Victoria du surl et de l'est des arbres de cet.te espèce quj ont une hauteur de 350 à 380 pieds. tandis qu il y en a d’autres quj ont à leur base une circonférence movenne, mais d"une hauteur remarquable, domnent quelquefois de 8.000 a 10.000 palissades, longues de 6 pieds, évaluées à 115 livres sterling. Des zones couvertes de frênes propres a l'alimentation des scieries donnent de la charpente d'une valeur de 100 à 200 livres sterling par arpent

-o Frêne rouge. - Bois léger, dur, à grain long, de couleurs nuancées de gris-blanc à rose-clair. On l'emploie pour la construction des maisons ( $y$ compris les parquets et les panneaux), ]ả carrosserie et l'ébénisterie en général. Les meubles fabriques de ce bois, qu'ils soient polis d'un vernis de cire légère ou traités de la même manière que le chêné fumé, sont torjours d'un beau fini ; il est employé de plus en plus dans l'Etat ite Victoria pour la fabrication de chambres à coucher et salles à manger complètes.

gn L'érorce jaune fibreuse (Yellow Stringybark). - Bois très fort et très durable, fort estimé pour la construction des pilotis, poutres et traverses. II est d'une couleur lrun-clair tirant sur le jaune et les bâtiments et palissades construits avee ce bois. all début de la formation del'Etat, sont en parfajte condition depuis plus de fio ans.

g' Lécouce blanclıe fibreuse. - Bois durable servant aux mêmes usages que le précédent, ainsi que pour la construction des maisons. Dans la partie orientale de l'Etat, il y a une immense région couverte deces arbres — région ulont l’étendue est estimée à plus diun million d'arpents.

$10^{\circ}$ L'écorce de fer à faite d'arsent. - Bois d'un brun-clair, fort estimé pour la construction des maisons et lic fabrication des parquets, voitures, brancards et les timons des "bogrogies". Très dur et élastiupe, ce buis se trouve en abondance dansle Virtorja de l'est.

Bois noir. - Le bois de cet arbre, de la famille des acacias, est léger, fort et dur, dune couleur bun-foncé, ayant un beangrain onduleux ou nuageux, d'un ton brun-rloré (on appelle ce grain-là dós de siolun et cril doiseans. On l'emploie surtout à la fabricatiun des meuliles destyle de toutes sortes et les pianos, aussi bien que pour les panneaux, les jamlirissages, les vajtures (y compris les rayons et les jantes). les meubles de bureaux, les crosses de fusil, etc. Ce bois d un beau grain est d'une excellente qualité. est évalué maintenant dans l'Etat à $6 \mathrm{~d}$. par pied superficiel ou même davantage.

11 y a l'autres arbres d'un grain fin dans le centre des forêts; ritons, par exemple. le hêtre tomjum's vert, le mrrte, le mus:, le sassafra, le buis le satin, le bois de crayon. etc., quj sont utilisés à la fabrication de panneaux et de fenilles ponr placage, étant d’une couleur t d'un grain trés beaux, d'aspect tout à fait agréable après le poliscage.

L'Etat de Virturia na dans ses !orts naturelles qu un arbre de valeur, le pin de Civpre, qui porte des cone: Cet arbrese tromve seulenent dans les plaines de pierre calcajre ou dans la région salilonneuse et onduleuse le l'arrondissement du nord-est, qui s’appelle le "Mallêe". Cel arlure, qui appartient à la même famille que le sandarac et le callitris le l'Mgerie. donne une chalpente très durable, bien adajtée à la ronstruction les maisons et à la fabrication des palissarles et les poteaux télégraphiques. C"est un hois anque] ne sattaument ni les termites ni les fomrmis blanches.

\section{CONSERIATION ET ADMINISTRATIOY}

Prndant les cing dernières années, beaucoup de progrès ont été faits dans l'adminis. tration rles forêts qui a lonné comme résultat un contıóle et une surveillance plus stijete sur l'ahatage et l'enlèvement des arbres lans les forêts. Dans les régions de hautes forêts, le travail des sijelies est soigneusement réglé, et on a réussi à réduire de heauroup le asulille ge d'une lartie des arbres. Kes forêts sont divisées en quartiers et compartiments. qui sant distribues pu lots et le propriétaire d'un lot doit enlever tous les arbres qui sont propres à être emploves avant de commencer le travail sur un autre lot. la reproduction naturelle des semences dormantes dans le telles régions est bien grande. Jans les zones des jeunes forêts, près des villes où il y a des mines, se trouvent des taillis réglés sous un système molèle. On abat les arbres de rualité inférieure à ras de terp et on les emploie à faire des supports pur les mines el aussi pour la conulustion, taudis que tous les arbres droits rt siniss sont lassés debout comme etalons ponr nue jotation mins longue. Dans tous les faillis et les régions de hautes forêts. ril les pilutis et les poteaux télćcraphiques sont necessaires, les abres avant d'etre aliattus sont tous matrqus jar un furestier officiel; cette marque donne la permission de les abattre. Le revenu anmuel donne par la forêt de l'Etat est maintenant d'envirun so.0on lives storling. Envirm 1:2 le cette somme sont druensés wour l'adninistration et l'blevage des jeunes arbres dans les péminières de l'Elat. Ia diffrence (ruviron 27.000 livres) est utilisép. avec l'apunolution du Parlement. "a l'amelination des jemes forêts naturelles et a la plan-

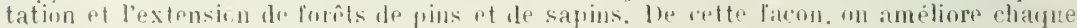


IXTERNITIONAL 191:

année de 12.000 à 15.000 alpents de jempes eucalyptus et on ulante environ 3.000 alpent3 d'arbres exotiques th bois dur. C'est ce dernier travail que je vais expliquer maintenan plus an long.

\section{PLANTATHONS}

Il y a, dans l'Etat de Victoria de grandes aires qui s'étendent le long du littoral et qui consistent principalement en vallées de pierre calcaire et de zone de composition sablon. neuse où les pluies sont ahondantes : ces régions de leur nature propre, bien adaptées à la production d'arbres portant des cônes. Sur les ver'sants de la chaîne de montagnes centrales divisant en deux l'Etat il y a aussi des régions dépouillées près des vieux placers, où croissent ces arbres. Il y a environ 25 ans que l'on fit de petits enclos s'étendant sur quelques centaines d'arpents pour la culture des pins et dans quelques-uns de ces enclos les arbres (ayant une circonférence de 2 pieds) sont maintenant prêts à être convertis en bois de charpente. Le département des forêts, après avoir un complet abatage des arbres, a gagné environ 90 livres sterling par arpent sur la vente de la charnente.

Le rendement annuel des trois pépinières dépasse actuellement 6 millions d'arbres, et quand nn pourra pleinement utiliser la capacité des pépinières, le rendement total sera de plus de 10 millions de pieds d'arbres par an. A l'heure actuelle, la plus grande difficulté rencontrée par les administrateurs du département des forêts est de recruter pendan l'hiver un nombre suffisant d'ouvriers experts pour entreprendre la plantation des jeunes arbres. La superficie tatale de toutes les plantations variées est d'envirun 20.000 arpents. Les arbres à cones, qui croissent rapidement et promettent de donner comme charpente le meilleur rapport pécuniaire sont : le pin Monterey, le pin de Corse, le sapin Douglas, le pin des Iles Canaries, le pin rouge Japonais, le pin Bouf ou Jaune, le pin cle Sucre des Etats-Unis, le sapin Manzies ou Sitka, le bois rouge de Galifornie et l'arbre Mammouth.

Le pin IIonterey donne dans la région de Victoria une grande quan lité de bois de char. pente de deuxième rlasse; le bcis de cet arbre étant dur, fort et léger. On l'emuloie de plus en plus pour les parquets, les maisons, les intérieurs et les planches ainsi que pour les boîtes et caisses. Les luùches de ce bois, d'une largeur' de 6 punces on davantage sont de vente facile.

On a soigneusement éprouvé cette charpente à Melbourne, Adelaïde et syduer et on l'a trouvé propre à la fabrication des parquets, des lambris, de panneanx de plafonds et d'encadrement. Les rapports financiers de ce pin par arpent, d'une croissance si rapile, varient de 80 à 150 livres sterling pour les arbres de 25 à 30 ans.

\section{PREPARATION DU BOIS DUR}

Afin d'éprouver à fond nos bois durs naturels, nous avons bâti à Jelbourne des usines d'assaisonnement d'Etat où les frênes blanes et rouges sont chauffés au feu au moren "l'un procédè à la vapeur'. Le travail est limité à présent à la charpente destinée à la fabrication des parquets et de l'ébénisterie. Ce procédé a eu un grand succès de sorte que d'autres charpentes, y compris le bois noir, destinées à la fabrication de l'ébénisteria seront traités bientôt de la même facon.

\section{JECOLE FORESTIERE}

On a établi à Greswick, ville située sur le penchant de la chaine de unontagnes centra le à environ 85 milles au nord-est de Melbourne, une école forestière de théorie et de pra. lique. On n'y admet que des élèves a yant réussi à passer l'examen de compétence d'en trée Les sujets traités sont les suivan.ts : l'anglais, les ma thématiques, la botanique, la géologie , la chimie, la physique, l'inspection forestière et théolique. On emploie tous les moyerns pour assurer la complète instruction pratique dans les pépinières et dans les plantations, afin qu'elle soit aussi étendue que possible.

Le cours de l'instruction comprend une période de trois ans, et les élèves réussissant à passer l'examen indispensable à la fin des cours sont en rôlés comme cadets dans le service des Forêts de l'Etat.

J'ai joint à cet article un appendice traitant les plantations démontrant dans 11 s forme sy puotique la croissance des arbres à cônes en Grande-Pretagne et à Victoria resper. tivement. Dans cette table, on verra que par suite, du climat plus doux de Victoria, lix croissance de presque tous les arbres mentionnés est plus rapide que dans les lles Britan. niques. Il 'st évident que cela doit avoir pour résultat uu retour pícuniaire aussi plus rapide de la vente des pins $\mathrm{ft}$ des sapins de l'Australip du Sud. 
Crotssance des arbres portant des cónes en Grande-Bretagne et en Victoria

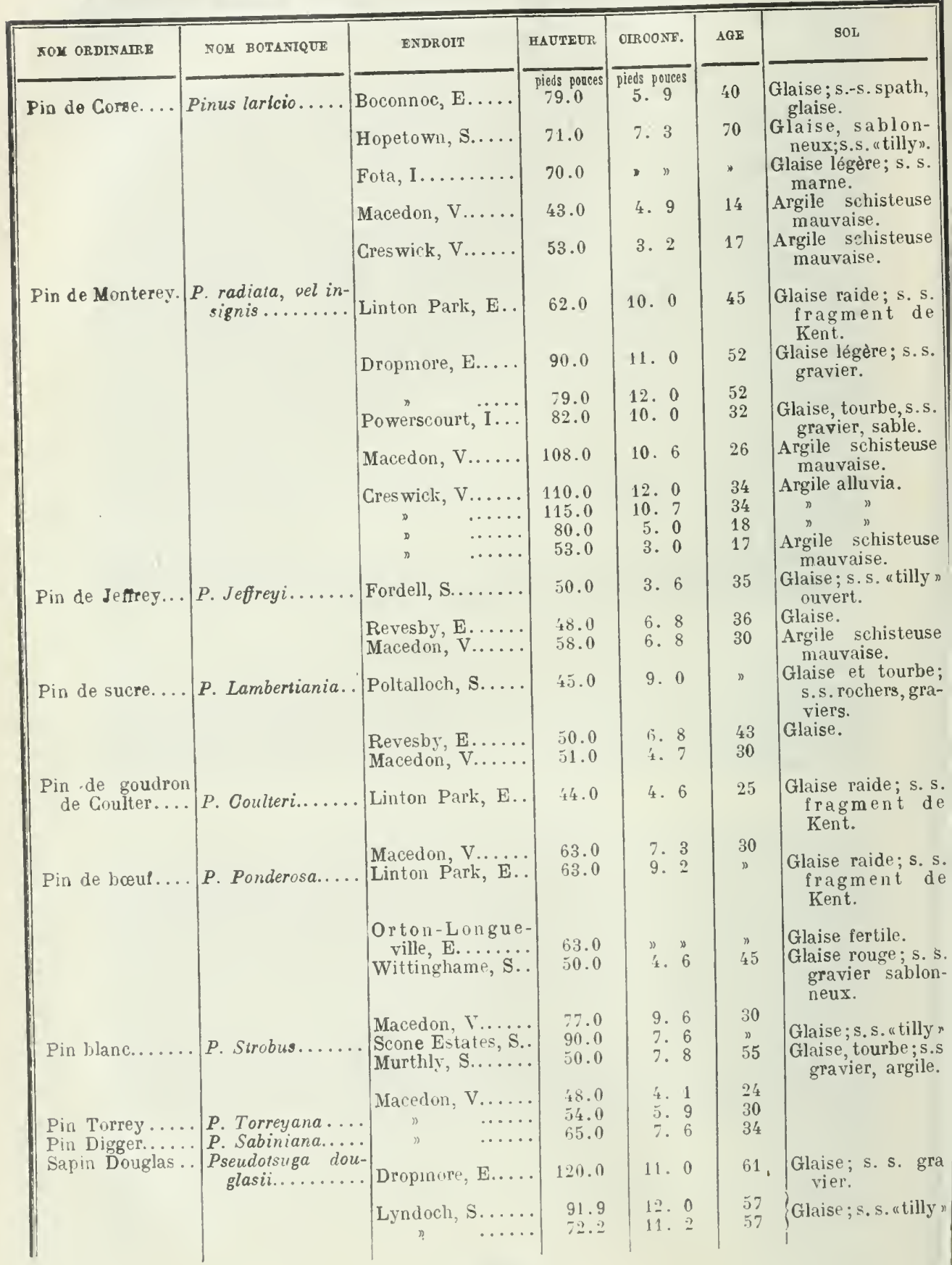




\title{
TRANSPORT DES PHODLITS FORESTIERS
}

\author{
COMMUICATION DE H. P. LETURQUE

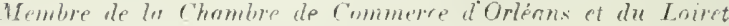

Le Congres foreslier international, en se domanl la thehe de rechercher " les amélio"rations a apporter dans lutilisation des produits forestiers, les réformes législatives " ou administratives de nature à assurel la conservation et l'amélioration des forêts " lomaniales et particulières ", met, par là même, dans son programme, l'étude des conditions de transport des produits forestiers.

Une grande partie de ces produits, bois de tous usages, charbons de bois, écorces à tan, ne penvent, aujourd"hui, être utilisés sur place et doivent f̂tre transportés, souvent, à des distances considérables, la plupart du temps, par voie ferrée.

Or, en France, le rail, qui est notre grand transporteur, — en attendant que les voies a avigables puissent hui aider. - impose aux uroduits forestiers rles tarifs écrasants, et hors de jroportion aver la valent du bois.

Cette injuste rétribution du transporleur entre, pour me grosse part, dans' l'amoindrissement du revenu du propriétaire lorestier, qui, bien flus fulatrefois, doit se servir iu rail pour écouler ses produits.

Quelques exemples :

Expéditions du charbon de bois d lun rrand rentre de production, la Nièvre, par exemple, en Beauce : J'Inphy átampes. 24.5 kilomètres $=19 \mathrm{fr}$. 90 le la tonne, soit \& centimes $1 / 2$ de la tonne kilomètre. C'est-a-dire 1 f'. 21 du sac de charbon qui rapporte a peine 1 franc au propriélaire du bois.

Voici un stère de toois le sipin destin: an chanflage les fours de boulangers. Il part de Sologne pour arriver à Paris. On l'a payé $2 \mathrm{fr} .50$ sur pied au propriétaire du bojs. Après l'abalage et les divers travanx d'exploitation, il esl, en gare de départ, transformé en cotrets.

Or, son côt de transport sur rail jusqu’à Paris est de $2 \mathrm{fr}$. jo.

Pour les écorces a titn, snil silr lon kilometres. de Châtillon-siur-Loire à Meungr-sur-

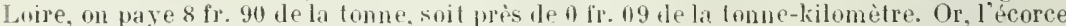
à tan ne rapporle presque rien al propritaire forestier.

A ce propos, je désire appeler l’attenlion du Congrès sur une des clauses du Cahjer dos eharuzes du Winistère de la finerre imposant à ses fomrnissent's des cuirs tannés de jicion.t.

Les écores a tan doivenl done être partimlièenent protruces, et litvorisées, - en

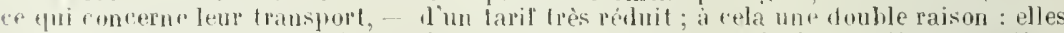
sont un ormluit fe notre sol formtien: de plus, plles font partie les matières premièes lestineses is assurer la défense nationale.

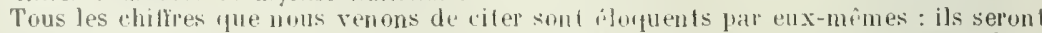

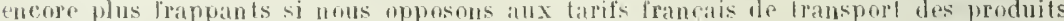
forestiers, les latrifs étringers. 
L étude que nous avons faite des prix de trarspurt des buis en Belgifue, Italie, Iutrithe -L Lllemagne, nous autorise à affirmer qu"ils sont très inférieurs aux prix de transport "xigés par nos chemins de fer francais.

Dans les pays que je viens de citer, le prix de la tome-kilomètre sétablit, pour les bois, chirbons de bois, écorces à tan, etc., entre 2 centimes 12 et $t_{t}$ centimes $1 / 2$ avec des tarifs décroissants selon les distances.

Wone, en écartant quelques tarifs spéciaux exceptionnels, on peut affirmer que les tarifs généraux de nos chemins de fer français grèvent les produits forestiers nationaıx I'un prix de transport an moins double de celui de nus voisins.

Cie fait, à lui senl, place notre propriété forestière en élat d'infériorité grave vis-à-vis le la propriété lorestière étrangère, gêne nos transactions intérieures et cause un uréjudice grave au commerce des bois et anx industries qui utilisent ses produits.

Il y aurait donc urgence, pour favoriser la creation et la conservation de la for $\hat{\imath} l$, dapporler anx produils forestiers nationaux cette efficace protection d'une réduction importante des tarifs de transport, au moins égale à ce qui se pritique chez nos voisins les phus firvorisés de ret égard.

liette ríluction devrait ître d"au moins to or pour les expedilions par wagons isolés,

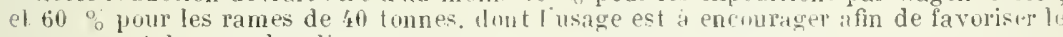
groupement des marchandises.

Vous terminons par dleux petits lableaux où nous avous roulu prisenter de façon plus atsissante les exagerations des tarifs de themins de fer frauçais.

\section{Honographie diun sar de charbon de bois:}

1.e sac de charbou de bois, parti, sur wagon romplet, d'Inphy pour Etampes 245 kiloIuritres).

All'il jilyé :

WE LA CUEPE I LA GARE 1 ARRIVÉ

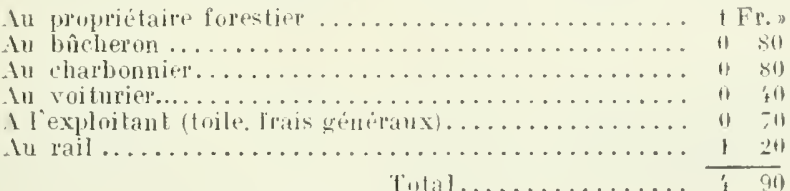

Proluits forestiers transpurtes sur mit: I'UTR CENT FRANCS

Les compagnies de chenius de fer lrançais transportent:

A 100 kilomertes...................... 1t. $1000 \mathrm{kil}$.

Les compranies de ehemins de lee ètrangers transprortent:

I 1001 kilomètres................... 24.0100 kil.

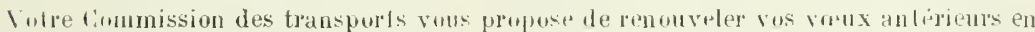
Hrenant la déliberation suivante:

L.a Chambre de commerce d'Orléans et du Leviret,

Considérant, dune part, la crise actuelle du commerce des bois provenunt de lu dípréciutiun des produits forestiers, bois de chaufjage, charbons de bois, écorre à tan, ete. ;

D’autre part, le prix de transport élesé que les turifs actuels imposent à ees produits :

Estimant qu'il est indispensable de remédier ì cet état de choses, autant pour fasoriser le commerce et lindustrie que pour empêcher la propriété forestière de subir une absolue dépréciation;

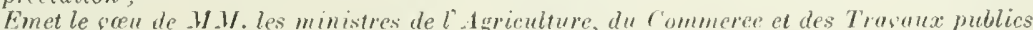
se concertent pour obtenir des compagnies de ehemin de fer une réduction des tarifs actuels applicables aux products forestiers, réduction qui, pour être efficuse, derrait être un moins de 40 o pour les wagons isolés et te 60 o pour des rames de 40 tonnes:

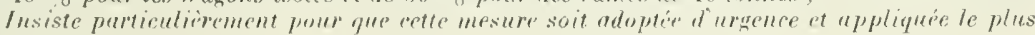
tît possible.

le raplorl, mis aux voix, esl adopté à l'unanimité.

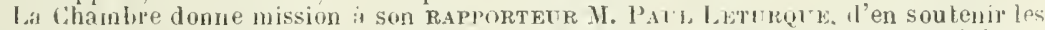

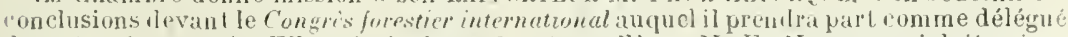
le notre Compaguir. Elle prie igalenent notre collegne II. I1. Hadre, qui doit suive le Congrès en sid qualité de prósilent du syndicat du commeree des bois du I coirel, de

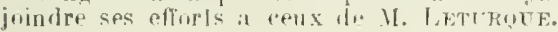




\section{ANNEXES AU PAPPORT}

DE M. VILLAME

\section{SUR LES DROITS DE DOCANE}

TABLEAU DES mPORTATIONS ET DES EXPORTATIONS DE MERRAIN

\begin{tabular}{|c|c|c|c|c|}
\hline & \multicolumn{2}{|c|}{ IMPORTATIOSS EX FRAYCE } & \multicolumn{2}{|c|}{ EXPORTATIONS DE FRAXCE } \\
\hline & toune: & francs & tonnes & francs \\
\hline $1900 \ldots \ldots \ldots \ldots \ldots \ldots$ & $160.838^{*}$ & $r$ & 5.866 & ” \\
\hline $1901 \ldots \ldots \ldots \ldots \ldots \ldots \ldots$ & $188.99 i$ & 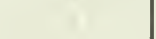 & " & 2) \\
\hline $1902 \ldots \ldots \ldots \ldots \ldots \ldots$ & $159.86 f$ & 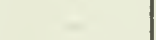 & - & ” \\
\hline $1903 \ldots \ldots \ldots \ldots \ldots \ldots \ldots \ldots \ldots \ldots \ldots$ & 141.747 & - & 8.925 & , \\
\hline $190{ }^{\prime} \ldots \ldots \ldots \ldots \ldots \ldots$ & $139.00 \%$ & 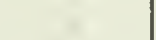 & 8.762 & $"$ \\
\hline $1905 \ldots \ldots \ldots \ldots \ldots \ldots$ & 146.999 & (s) & 7.625 & r. \\
\hline $1906 \ldots \ldots \ldots \ldots \ldots \ldots$ & $134.92 \div$ & - & 8.190 & , \\
\hline $1907 \ldots \ldots \ldots \ldots \ldots \ldots \ldots \ldots$ & $1: 3.13 \%$ & $=$ & 10.384 & " \\
\hline $1908 \ldots \ldots \ldots \ldots \ldots \ldots \ldots$ & 143.500 & 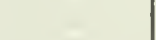 & 10.012 & " \\
\hline $1909 \ldots \ldots \ldots \ldots \ldots \ldots$ & 150.270 & 32.000 .000 & 7.672 & 1.550 .000 \\
\hline 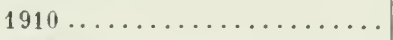 & 176.8511 & 15.000 .000 & 7.612 & 1.481 .000 \\
\hline $1911 \ldots \ldots \ldots \ldots \ldots \ldots \ldots$ & 180.000 & 17.000 .000 & 6.378 & 1.315 .000 \\
\hline
\end{tabular}


TABLEAC DES EXPORTATIOSS HT DES IMPORTATIOS DE TRIVERAES ES BOIS PEXDAXT LES DERNIERES AYNEES (fonnes ef franes)

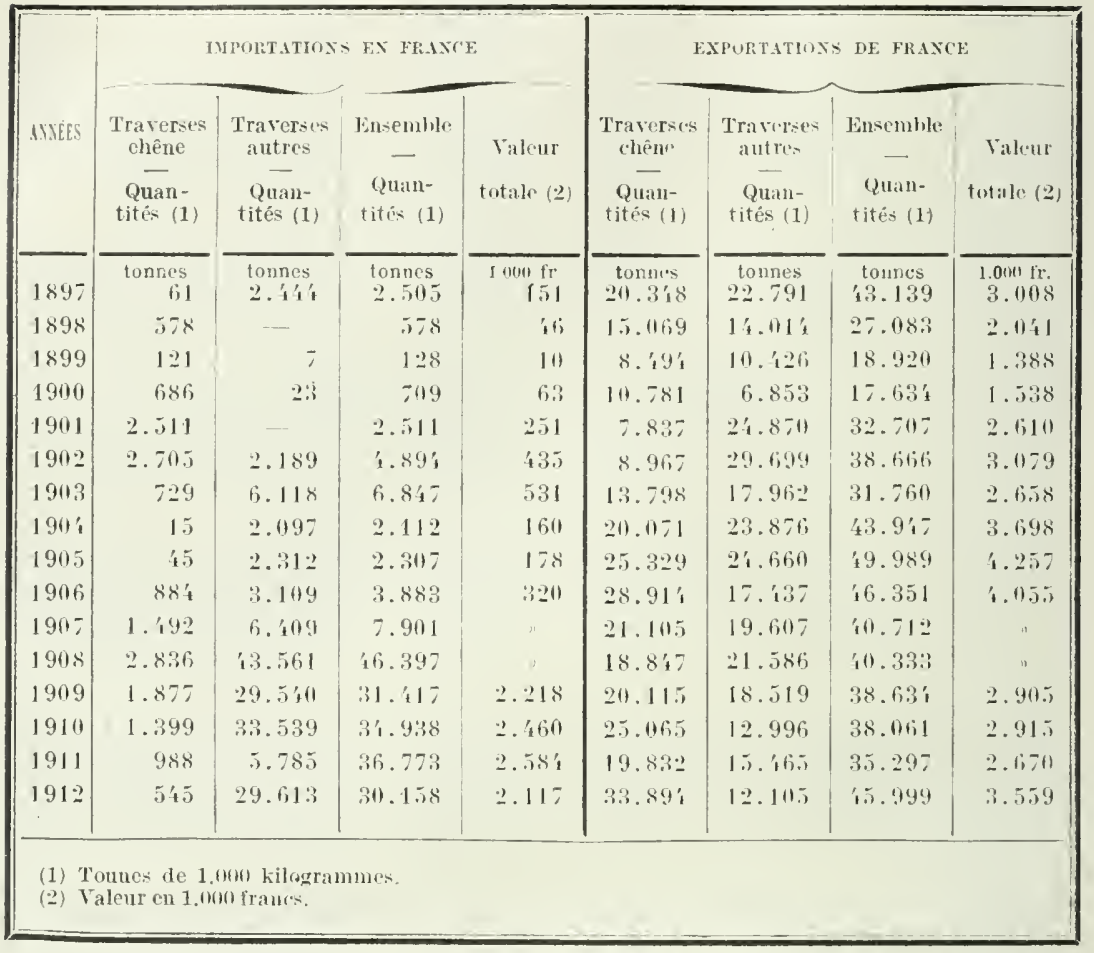

TARLEAC JES IMPORTATIONA ET DES EXPORTATIONS DES BOIS DE CONSTRICTION CHEYE PENDANT LES DERNIERES INNÉES (tonnes de 1.000 kilogrammes)

\begin{tabular}{|c|c|c|c|c|c|c|}
\hline \multirow[b]{2}{*}{1} & \multicolumn{3}{|c|}{ IMPOLTATIOXS EN FRAXCE. } & \multicolumn{3}{|c|}{ FXPORTAIOXS DE FRAXCE } \\
\hline & 1909 & 1910 & $19: 11$ & 1909 & 1910 & 1911 \\
\hline Bois ronds bruts... . . . . & $\begin{array}{c}\text { tonnes } \\
1.54 .1\end{array}$ & $\begin{array}{l}\text { tonnes } \\
2.220\end{array}$ & $\begin{array}{l}\text { tonnes } \\
1 . \text {. }\end{array}$ & $\begin{array}{l}\text { tonnes } \\
211.637\end{array}$ & $\begin{array}{c}\text { tonnes } \\
21.639\end{array}$ & $\begin{array}{r}\text { tonnes } \\
28.535\end{array}$ \\
\hline Traverses.............. & 1.877 & 1.399 & 988 & 211.115 & 25.06 .5 & 19.832 \\
\hline Autres Jois tiguarris... & S.9if & 9.921 & $\overline{3} .17$ & 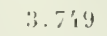 & 3.811 & - .560 \\
\hline Bois épuarris de 80 à $25 \mathrm{~m} / \mathrm{m}$ & $\mid 3.601$ & 12.125 & 12.329 & 3.727 & 3.681 & 1. $11 . \overline{0}$ \\
\hline Boissoies :3.) m/et au-rles. & 22.618 & 20.782 & 19.502 & 1. 9.3 .5 & 1.928 & 2.512 \\
\hline Tulaux (1)..... & $: 8.587$ & if. 797 & 39.103 & 56.163 & 56.132 & 56.581 \\
\hline
\end{tabular}




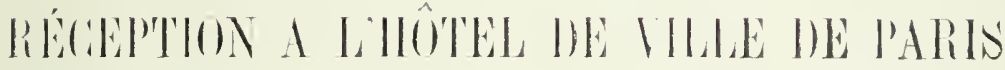

\section{LE VENDREDI 20 JUIN 1913}

A l'issue de la stance de eloture, te Conscil Munieipal de la Ville de Paris a recu, à l'Hòtel de Ville, les múnbres dn Congrès Forestier International de 1913.

A rete reception, les discours smivants ont ete prononues :

\section{Discours de M. Chussaigni-Coyon, président du. Conseil municipal}

\author{
Monsieur le président. \\ Mes dames,
}

Iessieurs,

Nous devions an Touring-Clul de mieux connaitre les parsage chamants, lts sitrs grandioses de notre France et voici qu'il nous a conviés à un Congrès de véritable détense nationale.

Vulle institution n'était plus qualifiée pour prendre l'initiative de cette patriotique crois ade pour les alut de la Forêt française, l'un des plus beaux fleurons de notre couronne champêtre, et la mener à bien.

Jusqu'a c'es dénières annéfs, l'importance de lo queztion forc lière n'avait pas été

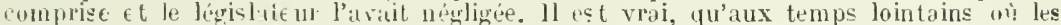
lutaies séculaires comvraient le sol, le fait de les léfricher était considéré comme un service rendu à la collectivité.

I.e droit ancien, le droit romain, n’ont pas songé à les protéger et les quelques textes ¿'Ulpien que l'on pourrait citer défendent les droits du propriétaire et non ses arbres.

L'ordnnnance d'aôtt 1669 et l'arrêté du Directoire exécutif du 28 floréal an IV, ne visaient guère que les arbres cn bordure des ruutcs. Le code forestic r ne s'applique, d'une manière générale, qu'aux forêts appartenant à des collectivités et les lois des 28 juillet 1860 ot 8 juin 1864 , relatives, la première au reboisement, et la seconde au gazonnement des montagnes, tendent bien à la conservation it à lá restauration des forêts, mais n'ont aucunement paré aux dangers du défrichement.

Je ne veux pas vous entritner, Messieurs, dans l'expuse' comple d'une r'églementation plutôt tonffine, si j'use m'exprimer ainsi. Je me bornerai à vous mapele $\mathrm{r}$ que les premiers germes d'une légiclation r'épressive de l'abus du cléfichement se recnontrent dans le decret de l'Assemblée nationale du 11 décembre 1789 "roncernant la répression des délits qui se commettent dlans les forêts et bois". Seule des texte postérieurs, la Loi du 4 avril 1882 a établi un régime de protection des plus énergiques pour la restauration

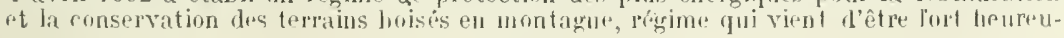


sement compléıé yrar l'^doption toute récente de la proposition de l'honorable M!. Audiffred, qui permettra d'étendre à nombre de forêts les règles de la sylviculture.

Nous possédons d'admirables futaies qu'il uous faut défendre contre le terrible déboisement de ces quarantes dernières années. Sans vouloir passer une revue complète des mesures proposées pour arriver à ce résultat et examiner ici toutes les questions qui ont été magistralement traitées dans des rapports remarquables et très pratiquement discutées et résolues au cours des séances de rotre Congrès, je ne signalerai que les plus importants des veux adoptés par vous.

Vous êtes unanimes à demander la dininution des impôts, des charges pesant sur la forêt, qui encouragerait ses propriétaires à la conserver et à l'agrandir. Elle deviendrait alor's une source de revenus certains et rémunérateurs. Les landes incultes n'ont. elles pas dû la richesse à leurs pins résineux?

M. Defert, le très distingué président đu Connité de ce Congrès, préconise judicieuse. ment un système de réserves forestières, indivises, assurées de perpétuité, et dont le stock permanent servirait de régulateurs au marclié national. Les communes, les grandes associations reconnues d'utilité publique, toutes les collectivités jouissant de la personnalité civile paraissent désignées pour procéder à la reconstitution de ces réserves fores. tières.

L'État, de son côté, doterait largement la caisse destinée aux achats des paysages forestiers, comme M. le Ministre de l'. giriculture a bien voulu nous le faire espérer dans son remarquable discours d'ouverture du Congrèz, et les Conımissions des sites déter mineraient l $\mathrm{f}_{\mathrm{s}}$ beautés naturelles qui méritent d'être conservées.

Il faut à tout prix sauver nos arbres, sentinelles avancées contre les eaux montantes, ils opposent aux torrents et aux avalanches la meilleure des digues. Le fléau de l'inondation, nouveau Macbeth, sera vaincu par la forêt.

Je vous parlais tout à l'heure, MIessieurs, de défense nationale et ma pensée ne s'arrê. tait pas seulement à l'inondation menaçante.

Déraciner nos arbres séculaires, e’est arracher les pages de uotre histoire. Nos chênes géants ont abrité le berceau de la Gaule ; le gui dé leurs vieux troncs était la fleur symbolique de la Patrie, la parure de nos aïeules, déjà coquettes et adulées, quand il était tombé sous la faucille d'or. Nos ancêtres, Mesdames, araient le respect. le culte de li femme et lui donnaient, près de leurs druides, une place d'honneur, sans même lui demander d'être ves tale.

Quand, plus tard, l'âme francaise éprise de mysticisne, de gràce et de beauté commença à se dégager de la brume médiévale, c'est à la Forêt qu'un peu nairement nus artistes demandèrent leur inspiration pour élever ces prestigieıses cathédrales rqui. de Rouen à Strasbourg, émerveillent encore le monde.

C'est dans les futaies des Arvernes que s'organisa la défense nationale au temps de Vercingétorix et, dans notre histoire contemporaine, la forêt d'Orléans n'a-t-elle pas, de ses troncsenlacés, retardé en 1870 l'invasion triomphante?

Conservons jalousement les témoins de notre passé et nlantons - même à notre àge de jeunes et vigoureux rameaux. Que toujours le voyageur retrouve sur notre terre cette collection unique d'essences rariés : depuis le saule charmant qui a vu fuir les nrmphes, jusqu'à l'olivier d'argent, parure de la mel' blene. Conservons nos sapins, à la verdure éternelle, nos frênes, nos bouleaux. nos charmes, aussi beaux dans leur parure printaniêre qu'en leur automne loré, nos châtaigneraies, sous lesquelles se joue la lumière, et nos trembles frissonnants.

Conservons la Forêt, cette réserve de santé et de joie. Elle offre aux pauvres souffrants ses trésors inépuisables d'oxygène, aux regards fatigués le vert reposant de ses frondaisons, aux découragés, l'asile de ses futaies, aux poètes amoureux, ses cliarmilles ombreuses.

La Forêt! Mais n'est-elle pas le temple de noire vieille gaìté nationale? Janais faunes et nymphes, que je sache, ne fureut jamais neurasthéniques !

Laissons à la gravité de l'hidalgo, au fatalisme de l'Arabe, leurs sierras désolées et leurs déserts brûlants. Sous la feuillée doit retentir le rire gaulois.

Joyeusement, je lève inon verre en l'honneur des représentants éminents des nations étrangères qui ont bien voulu prendre part au Congrès intemational forestier, et je leur souhaite, au nom de la Ville de Paris, la plus chaleureuse, la plus cordiale bienvenue dans notre Hôtel de Ville. Je bois au Touring.Club de France dont l'importance et la renommée ne cessent de croître, à son très distingué président, II. Ballif, à l'actif et dévoué président du Congrès, M. Defert, à tous ses menbres enfin

Je vous remercie, Mesdames, d'avoir bien voulu animer et embellir de votre charme et de votre grâce cette réception qui, sans rous, eut été un peu austère et je vous lemando la permission de porter respectuensement votre santé. (.1pplaudissements). 


\section{Discours de II. Aubanel, Secrétaire général de la Préfecture de la Seine}

Messieurs,

L'Administration parisienne que j'ai l'homneur de représenter est heureuse de se joindre à M. le Président du Conseil municipal et à M. le Président du Conseil général de la Seine, pour vous présenter ses souhaits de bienvenue.

Elle a été vivement intéressée par les questions inscrites à l'ordre du jour de vos séances, et dont certaines font l'objet de ses propres préoccupations, et c'est avec la certitude d'en retirer d'utiles enseignements qu'elle a prêté à vos travaux une scrupuleuse attention.

Interprète fidèle de $M$. le Préfet de la Seine, qui $n^{\prime}$ a $p u$, à son vif regret, venir vous recevoir personnellement, mes compliments s'adressent tout d'abord à la grande et populaire Association qui a pris l'initiative de votre réunion. Le Touring-Club de France est depuis de nombreuses années pour les Pouvoirs publics un auxiliaire précieux dans la sauvegarde des beautés et des richesses naturelles de notre pays, dans l'amélioration de ses routes ct la fréquentation de ses sites. A son école, nos jeunes générations ont pris le goût du tourisme et des exercices de plein air également favorables au développement des forces physiques et de la santé morale.

Aujourd'hui, c'est un titre nouveau à la reconnaissance publique qu'il s'est créé en proposant à vos délibérations l'étude des questions intimement liées à la salubrité, à la sécurité et à la prospérité économique de nos provinces.

L'importance et l'attrait de ce programme ne sauraient être mieux attestés que par le nombre et la qualité des adhésions qui on trépondu à son appel.

Le Touring-Club de France pent à bon droit se féliciter d'avoir groupé pour la défense de la Forêt plus de 700 congressistes appartenant à 25 nationalités différentes.

Vos rapports, que j'ai eu plaisir à parcourir, ont traité avec un égal succès de sujets très variés; il nous a été particulièrement agréable de relever au bas d'une notable partie d'entre eux, la signature de fonctionnairs de l'Administration forestière qui forment dans nos grands services publics une administration d'élite, $\in t$ ont, en ce tte circonstance, justifié une fois de plus leur réputation de compétence et de savoir. (Applaudissements).

Mais auprès de nos nationaux, nous avons hâte d'adresser un déférent hommage aux congressistes de nationalité étrangère, qui ont bien voulu nous apporter le précieux appoint de leurs connaissances.

Dans cette maison commune où se formulent les voux de la Cité, je les prie d'agréer l'expression de la sympathie de nos concitoyens qui, avec nous, leur sont reconnaissants de leur collaboration à une couvre d'intérêt international et s'estimeront heureux s'il a pu s'en dégager, en même temps qu'un avantage matériel, un sentiment de concordo et de solidarité humaine. (Applaudissements),

\section{Discours de 11. Laurent, Secrétaire général de la Préfecture de Police, représentant $\boldsymbol{M}$. le Préfet de Police}

\section{Mesdames,}

Messieurs,

1I. le Préfet de police éprouve le vif regret de ne pouvoir venir vous complimenter personnellement, en raison de l'obligation où il se trouve de se consacrer, pendant tout cet après-midi, aux débats d'une question qui est du plus pressant intérêt pour son administration.

Il m'a donné l'agréable délégation de vous saluer en son nom et de vous assurep de l'attention avec laquclle il a suivi les travaux de votre congrès international, aussi bien que de ses souhaits de voir aboutir les avertissements et I s ruseignements qui se dégagent de vos délibérations, et les projets de résolutions que vous recomnand. à la sanction des gouvernements.

Nous avons accueilli avec une grande satisfaction l'initiative du Touring. Chub d* France qui a été le grand patron de votre réunion. Nous lui devons, en qu Iqu.s annés.s d'existence, beaucoup de bienfaits. Il á aidé puissamme nt à faire la rout nuie ux entre-

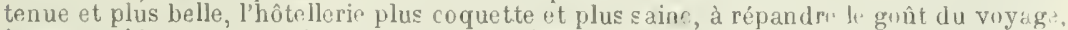
à nous guider vers des sites que nous ne visitions pas assez, parce qu'ils étaient p'ut être tout près de nous, et à donner à notre pays, pour le plaisir d $\mathrm{s}$ yeux $t \mathrm{t}$ par l'entrafile- 
nuent des forces physiques de ses enfants, la connaissance de lui-même, avéc un sentiment raisonné de confiance.

De tous les points du globe, rous vous êtes groupés pour étudier en commun une question qui est d'un intérêt vital pour la terre.

L'arbre qui, selon les heureuses expressions de M. le Ministre de l'Agriculture, enrichit, assainit et embellit, ne créé pas seulement le charme des narsages; il est, dans le groupement du domaine lorestier, la meilleure digue contre les torrents, les avalanches et les inondations.

Vous vous étes justement préoccupés de sa conservation et, par des vœux qui doi. rent avoir pour conséquence des mesures législatives d'un urgent intérêt, vous avez mis en garde les gouvernements et les administrations contre des défrichements mal combinés ou des destructions coupables.

Vos leçons seront retenues dans une nation dont le tiers à pe ine du domaine forestier est possédé, comme l'on dit, par des "propriétaires impérissables ". Le Gouvernement vous a prouré qu'il ne laissait échapper aucune occasion de faire œuvre d'intervention utile four la préservation des forêts.

La même pensé a trouvé le même écho dans toutes vos nations. Paris qui aime les arbres et qui en a fait sa parure, ne peut que s'y associer sans réservt.

Nous irons encore longtemps " au bois ", $\epsilon t$, si des lauriere y sont coupés, ce ne sera que pour fêter le succès de votre propagande, et en célébrer les mérites.

Je porte, $\mathbf{M}$ ssic urs, très cordialement, le toast de $\mathbf{M}$. le préfet de police à la santé de chacun des membres du Congrès international forestier, et des dames qui nnt donné à ros travaux l'intérêt et l'attrait do leur on muragement (.1 pplandissements).

\section{Discours de M. Billard. Fice-président dn Conseil Général}

Mesdames.

Messieurs:

Après le discours si complet et si plein de poésie de notre excellent président, M. Chas. saigne-Goyon, après les deux discours que vous venez d'€ntendre, de la part de MI. le représentant du Préfe $t$ de la St ine et de M. le représentant du Préfet de police, j'aurais ḋ la vérité, mauvais€ grâce à abuser longt $\mathrm{mps}$ d€ votre bienveillante attention.

Permettez-moi simplement de vous apporter le très vif regret du président du Conseil général, mon excellent ami, Maurice Quentin, qui, retenu par des occupations impérieuses, n'a pas vu venir au milieu de vous.

Je sais ce que vous avez fait par ce que j'en ai entendu dire. J'ai été délégué un peu à la de rnière heure pour vous parler $\epsilon t$, comme $j \in$ ne veux pas $r \in t \in n i r$ une attention qui serait beaucoup trop bienveillante, je rous demande purement et simplement, $\in \mathrm{n}$ me résumant, la permission de boir: à l'heureux résultat di votre Congrès $\epsilon$ t de porter votre santé (Applaudissements).

\section{Discours de M. Defert, Président du Congrès}

Monsieur le Président du Conseil municipal,

Messieurs les Secrétaires généraux, des Préfectures de la Seine et'de Polire.

Monsieur le Vice-président du Conseil général,

Mesdames,

Messieurs,

J'ai le très grand honneur de vous présenter les compliments du Congrès forestier international qui vient de terminer ses travaux et de faire, je crois, de la bonne besogne.

La question forestière est devenue, vous le savez, Massieurs, une question mondiale. 1 ceux qui pourraient en douter, il suffira de citer les sept cents congressistes accourus a l'appel du Touring-Club de France, et les ringt-cinq États étrangers qui se sont fait officiellement représenter dans ces grandes assises des amis des arbres et du reboisement.

Jamais Congrès forestie ' n'a réuni, $\in \mathrm{n}$ aucun pays du monde, un pareil nombre d'adhérents. G'est, en même temps qu'un succès considérable pour là cause forestière, un 
honneur pour la ville de Paris, d'en avoir éte le siège et dr voir une fuis de plus son nom attaché a une de ces grandes manif sstations de solidaritú humaine dont elle est coutumière. (Applaudissements.)

Dans les voux émis par ce grand Congres, et dont tous les intéresses pourunt fairt leur profit, dans tous les pays du monde, il en est deux qui intéressent particulierement la Ville de Paris, ce sont ceux relatifs au reboisement en montagne et is l'aménagement des bois et forêts de promenade autour des grandes citées.

Paris est, entre beaucoup d'autres capitales, exposé anx inoniations, et cette menace trop souvent réalisée, tient pour une grande partie a l'insulfisance des boisements existant dans les parties élevées du bassin de la Seine. On a beau dirt et répéter que cu bassin est un des plus boisés qui soit en France, son taux de boisement n'atteint qu $24 \%$, alors qu'il devrait être de 33 an moins. Et mis. il est loin d'être boisé comme il devrait l'être. Les masses forestières du bassin de la st ine sont presulue exclusivement constituées par des feuillus ef, dans cette masse mêne, il existe de nombrux vides. I: y a longtemps qu'un des ingénieurs les plus éminents, M. Belgrand, a signalé la nécessité d'y boiser 30 à 40.000 hectares en résineux, avec indication des emplacements à donner à ces plantations. Un moment, on a pu espérer que les terribles inoudations de 1910 feraient faire un pas vers une solution, mais l'étude des moyens d'empêcher le retour du fléau a pris bien tôt une orientation différente et les choses en son t toujours au même point. L'élévation du taux de boisement serait cependant bien utile; flle vie In lrait heureustment compléter le système de défense constitué par les puits absorbant: actuellement à l'essai, car si la méthode absorbante constitue un moyen efficace, les grunds massif. forcstiers sont eux aussi des absorbants des eaux pluviales, arec cet avantage en plu= qu'ils évaporent $\mathrm{\epsilon} t$ que, par le ur évaporation, ils entretienennt dans les hautes régions: de l'air, un état hygrométrique qui constitue, lui encore, une protection contre ces chutes d'eau anormales, que nous voyons dégénérer en cataclysmes. C'est le r ropr en $\in$ fiet, des régions dénudées ou insuffisamment boisées, d'aspirer les gros nuages du large, de les faire accumuler sur certains points et de les faire s'abattre en cyclones et cataractes désastreuses, comme celles qui viennent, ces jours derniers, de ravager plu. sieurs contrées de la Champagne et de l'Ile-de-France, et votre concours nous ser: précieux pour hâter l'heure des reboisements indispensables à la défense de votre ville.

L'autre vœu que je signale à votre attention évoque des idées plus souriantes, mais non moins intéressante. Le Congrès a proclamé la nécessité d'aménager autour dè grandes agglomérations, des bois et des forêts pour la promenade, le délassement et la récréation physique et morale des populations laborieuses. L'agglomération parisienne a, plus qu'aucune autre, besoin de cette couronne de verdure, d'ombrage et de beautis. à une époque où les espaces libres dans l'intérie ur de la ville vont diminuant sans cesst, puisqu'ils se réduisent à $41 / 2 \%$ à Paris, contre $15 \%$ à-Londres, et $10 \%$ à Berlin. A une époque où les jardins disparaissent avec leurs arbres, pour faire place au moellou, et où les bois de Boulogne et de Vincennes sont devenus vraiment trop étroits pout tous les assoiffés de fraícheur $\epsilon t$ d'air fur, le Touring-Club de France a déjà, dans cut ordre d'idées, devancé le but du Congrès en aménageant les bois de Meudon, de Verrièrt’n de Fausses-Reposes et la forêt de Marly. Son initiative se trouve encouragée et vous ne doutez pas qu'il poursuivra de plus belle l'ceuvre si bien commencée.

Je m'arrête, Messieurs, pour remo rcier au nom du Congrès, la Ville de Paris et ses représentants, de leu» aimable réception. La visite dı Palais municipal, que vous voulez bien offrir aux Congressistes français et étrangers, leur donnera une idée de nos beautés artistiqut:s. Ce sera pour eux la préface des beautés naturelles que nous allons leur faire admirer dans leurs excursions à travers la forêt domaniale de Lyons, et nos Alpes Dauphinoises.

Au seuil de cette visite, permettez-moi, M. le Président, de lever' à mon tour non verra à lia prospérité de la Ville de Paris, préservée dı fléau des inondations et parée de la couroune forestière qui sied au front d'une grande citó.

\title{
Discours de M. de Sébille, Représentant de Belgique
}

\author{
Wessieurs,
}

Il est toujours agréable a un Belge d'exprimer à ses voisus, les frauçais, ses sentiment: de gratitude pour l'accueil si affactueux, si cordial qu'ils lui réservent en toutes circons. tances et tout particulier m.nt aux édiles de la grande et belle capitale qui nous reçoivent aujourd'hui. 
Nous n'oublierons jamais que c'est grâce au concours des armées françaises que notre Indépendance a été assurée. Nous devons aussi à la France notre première reine qui a laissé parmi nous d'impérissables souvenirs de beauté et de générosité.

Nos deux grands fleuves, l'Escaut et la Meuse prennent leur source en France, de sorte que nos eaux couleront éternellement chez nous de l'Ouєst au Nord et du Sud à l'Est. De même la poussée française, quoiqu'on puisse faire, aura une éternelle influence sur la mentalité belge.

Les liens de la reconnaissance qui nous font aimer et estimer votre pays et souhaiter que nos relations soient de plus en plus cordiales vous assurent de las incérité des vøux que je forme pour la France et en particulier pour la Ville de Paris, qui nous fait le grand honneur de nous recevoir à l'occasion de ce Congrès.

Je lève mon verre à la prospérité de la Ville de Paris et à la gloire de la France.

Une visite de l'Hôtel-de-Ville a été ensuite effectuée sous la conduite du Président du Conseil Municipal. 


\title{
EXCURSION
}

\section{DANS LA FORÊT DOHANIALE DE LYONS}

\author{
le Samedi 21 Juin 1913
}

Le samedi, 21 juin, le Congrès a fait une visite aux sonptueuses futaies de hêtre de Lyons-la-Forêt, en Normandie, sous la direction de M. Pintiau, inspecteur des Eaux et Forêts, délégué du Touring-Glub de France à Lyons-la-Forêt et Gouilly, garde général des Eaux e Forêts à Rouen.

La forêt de Lyons se compose d'une série de massifs séparés les uns des autres par de verdoyants pâturages et des vergers chargés de fruits : véritable damier dont la masse sombre des bois figure les cases noires et les prairies, les blanches.

Le hêtre en est l'essence dominante. Il s'est taillé là un royaume, et quel royaume! peuplé de sujets magnifiques dont quelques-uns, hor's de pair, ont fait l'admiration de tous les congressites. Leur enthousiasme ne connut plus de bornes quand, après avoir traversé de superbes hêtraies, la caravane arriva aux antiques futaies du Catelier, que l'administration for'estière a récemment constituées en réserve ornementale et qui forment un trésor désormais intangible.

Un sentier a été aménagé à travers ce monde de géants plusieurs fois centenaires et bientôt, sous la voûte majestueuse de leur feuillage, grâce au Touring-Club, s'élèvera, à l'intention des promeneurs, un kiosque rustique qui sera connme un reposoir érigé par la pitié des fidèles all culte des beaux arbres.

Dirai-je le déjeuner champêtre, au cœur de la forêt, à l'un de ses plus beaux carrefours, avec accompagnement de fanfares de cor's de chasse dans le lointain des bois et de toasts enflammés à la Gloire de la Forêt, du T. C. F. et du Congrès? Cela n'est intéressant que pour ceux qui ont pris part à ces agapes forestières, et pas n'est besoin pour ceux-là d'en évoquer le souvenir. Mais ce que je tiens à dire et ce qu'il faut dire, pour rendre hommage à la vérité autant que par reconnaissance, c'est que Lyons n'est pas seulement le pays des grands bois; c'est aussi celui de la bonne chère, le tout agrémenté de l'hospitalité la plus avenante dans ce frais village nnrmand si joliment tapi dans l'écrin vert de ses forèts où les excursionnistes ont été l'objet d'une réception triomphale. 
Dut pris part à lexeursion: .I., Mme et Mlle Defert, MI. Boullenger, ChaJlain, Umbdenstock, Bacon de la Vergne, Badu, Baquedano, Barbet, Barbier Etienne, Barbier Honoré, Barbier de la Serre, de Bazelaire de Lesseux, de la Benodière, Bertrand, Blondeau, Blondel, M. et Mme Bommer, MM. Bonnet, Bouisset, Boulanger, Bouvet, Boppe, M. et Mme Broussais, MM. Paul Camus, Carbonnier, Caldot, Carraz, Caubert, Chancerel, Chaudey, Dr Cost, Delaye, Delville, Deroye, Dole, Dubois, Ducamp, Duparc, Dupont Paulin, Duras Chastellus, Baron d'Encausse, Eymieu, Gazin, Geisser, Giraud, Gouget, Gouilly, M. et Mme Goureau, MM. Graffin, Comte de Grancey, Gréa, Guillemin, Guillot, Guillou, Guyot, Henriquet, Hermans, John Hill, Hubault, Imbart de La Tour, Jobez, Jolain, Jousset, Kern, Krarup, Ladam, Lahaussois, Laval, M. et Mime Jules Lecoq, MM. Lefébure, Le Mire, Leroy-Moulin, Lescouzères, Capitaine Lombard, Maire, Marciguey, Margaine, Martin André, Martin Paul, Mendes d'Almeida, Menget, Mimura, Nouguier, d'Orlye, Otin, Pardé, Pascal, Pierronue, Pintiau, Poisson, Polako, M. et Mme Poussard, Roser, Rousselet, Roux, Roy, de Sailly, Schæffer, de Sébille, Mme Simon, MM. Sinturel, Sutherland, Tanassesco, Thays, Thil, Thiollier, Thivel, Thomas, Tortel, Touchalaume, Tourtel, de Toytot (Albert), de Toytot (Auguste), Tripier, Trutat, Van de Poll, de Villemereuil, Wahl, Welsch, Woolsey. 


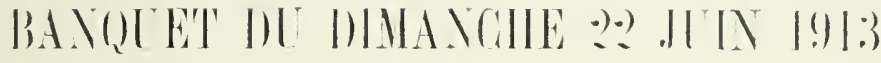

Le dinanche 22 juin, les congressistes se sont reunis dans un banquet servi dans les salons du l'alais d'Orsay.

11. L. Dabat, Directeur général des Eaux et Forêts, présirlait. A ses còtés avaient pris place : MIM. Abel Ballif, président du Touring-Club de France; Henry Defert, prisident du Comité d'organisation ; Antony, vice-président du Comité d'organisation; Chaplain, secrétaire général du Comité d'organisation; Feret du Longbois, directeur du Contrôle au Ministère des Finances: Julien berr de Turique, inspecteur général des Monuments historiques; Guillaume Capus, délégué de I'Indo-Chine à l'Oflice colonial: Ducamp, directeur du Service forestier de l'IndoChine; Dr Narcet Briant, membre du Conseil du Touring-Club de France : Jaeques Ballif, secrétaire géniral du Touring-Club de France; De Lagorsse, secrétaire général de la Socitte d'Encouragement; J. Berthelot, trésorier du Comité d'organisation ; A. Tmbrlenstock, secrétaire administratif du Comite dorganisation : Desire Partor. consul géneral de Honduras: Prefro E. Valdez, consul de JÉquatem; Enrique Dorn. y de Alsua, chargé d'affaires de l'Equateur ; Dr $A$. Nenours, ministra d'Haiti; Julin Llanos, Miguel F. Cazares, lálégurs de la République Argentine: Baron de Hennet, délégué d'Autriche-Hongrie; Peter llace Bride, déprour de Victoria (Australie); Mme et Mlle Bride; MII. Eil. Hermans, délégué de l'Administration des lonts at Chaussées de Belgique : De Sibille. Blondeau, Bubois, délégués du royaume de Belgiqur: Krarup, dólegur du Danmarck: Woolsey, dilegui des Etats-Cnis ; Forbes, Augustin Henry, délégués d'Irlande : Shozaburo Mimura. délégué du Japon: Badu, délígué du Grand Inethé de Luxembourg. Tony

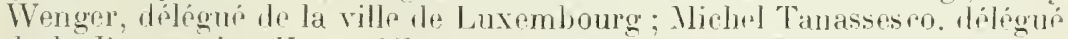
de la Roumanie: Kern, délégué de Russie: Comte Clary, délégué de la Principautri de Monaro, etc.: Honoré Audifired, sénaterur; Challamel, députí, frésident du Groupr foresties de la Chambre des Députís: E. Cardot, Édouard Vivier. Pienre Leddet, Pierre llougin, Baron de Belinay, Ilirseh. Jules Gal, P. de Laflott", Comte de Togué, Pierres

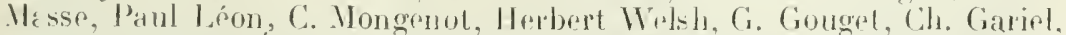
R. Tolmerangw, Edonard Martin, Charles Delahaye, C. Comean, Andró

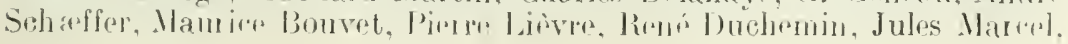


A. Arnould, Paul Gouilly, J. Demorlaine, Paul Dupuich, Paul Coulet, Émery, J. de Peyrelongue, Maurice Mangin, Joseph Thiollier, Gustave de Veyssière, Gyprien Girerd, Ch. Guyot, J. Madelin, Fernand Deroye, André Jousset, Michel, Léon Pardé, H. Barbier, Brally, Eugène Poisson, Sauvage, de Sébille, Caquet, capitaine Lombard, Van de Pool, de Larnage, de Nicolay, Anselme Changeur, Rivé, Maître Jean, comte Imbart de La Tour, Margaine, de Monchy, Vivier, Deroye, Sinturel, Carbonnier, etc., etc...,

Les principaux journaux étaient représentés.

La musique du $104^{\mathrm{e}}$ régiment d'infanterie, sous la direction de M. H. Vivet, s'est fait entendre pendant la durée du banquet.

Au dessert, les discours suivants ont été prononcés :

\section{Discours de M. Ballif, président du Touring-Club de France}

Messieurs,

J'ai l'honneur de vous proposer la santé de M. le Président de la République française, ainsi que des Chefs des États qui ont pris part à ce Congrès. (Applaudissements.)

Monsieur le Directeur général,

Messieurs,

Au cours de ce magnifique Congrès de la forêt, il a été dit beaucoup de choses et de bonnes choses, et cela m'a inspiré une certaine réflexion, dont je vous demande la permission de vous faire part. On a beaucoup parlé des intérêts économiques en jeu, du rendement de la forêt, des meilleurs modes d'exploitation, des charges sous lesquelles elle succombe. On a parlé de tout cela et j'y applaudis des deux mains, mais c'est l'idée d'utilité, et c'est à peine si l'idée de beauté a trouvé quelques défenseurs.

Et cenendant, Messieurs, n'est-ce pas le plus important? Je dirais volontiers que cela seul est important (Braco!). Rien sur la terre n'existe que par la beauté. C'est la beauté répandue dans toute la nature qui est pour nous la source des joies les plus élevées ee les plus pures. (Applaudissements.)

Elle nous est aussi nécessaire que l'air que nous respirons, que les aliments qui nous restaurent. J'en veux prendre un exemple ici même. Je vous le demande, Messieurs qu'est-ce qui a constitué le charme de ce repas? Sans vouloir médire en aucune sortt de la cuisine, n'est-ce pas plutôt le décor, la lumière, les fleurs, la musique, tout ce qui en un mot, est la beauté.

La beauté, de tout temps, a régné sur l'univers. En France, plus que partout ailleurs, on ne saurait l'oublier, et pour ma nart, je saluerais avec joie la création d'un ministère de la Beanté publique. (Applaudissements.) Et je lui donnerais le pas sur tous les autres. (Applaudissements.) Je pense bien que cela ne sera pas offert à un autre qu'au Soussecrétariat des Beaux-Arts, qui, du coup, se verrait passer le premier des ministères.

Or, la forêt - et c'est à cela que je veux venir - la forêt est la beauté de la terre. C'est elle sa belle parure. Bravo pour ceux qui veulent en tirer toute l'utilité possible et désirable, c'est tout à fait légitime, mais hourra cent fois pour ceux qui veulent la voir toujours belle, toujour's parée de son bel habit vert. C'est à ceux-ci, c'est-à-dire à vous tous, qui êtes ses amis etses admirateurs, que je lève mon verre, ainsi qu'à la forêt, beauté de la terre, à la forêt toujours belle! (Applaudissements.)

\section{Discours de M. Defert}

Monsieur le Directeur général, Messieurs,

Si le Touring-Club a, dans le cours de ses diverses entreprises, rencontré quelque succès, je ne crois pas qu'il en aitj amais obtenu de supérieur à celui de ce Congrès. L'idée était dans l'air. Certains même avaient songé à l'organiser, mais ils se sont loyalement 
ralliés sous le drapeau du Touring, et c'est par la quantité, par le nombre comme par la qualité, que le Congrès forestier international de 1913 aura droit à une place d'honneur dans les Annales forestières pour les résultats pratiques qu'il est permis d'en attendre.

Ces résultats, Messieurs, je voudrais les résumer en quelques mots qui vous retraceront les grandes lignes du Congrès et qui en dégageront l'essentiel. Ces résultats sont au nombre de quatre.

C'est d'abord la condamnation sans appel de l'impôt forts tier, tel qu'il grève actuelle. ment la propriété forestière. (Hourras.) A cet égard, il y a eu unanimité. C'est la première réforme à faire si l'on veut sauver la propriété forestière privée et les six millions d'hectares qu'elle représente, c'ect-à-dire les deux tiers de la superficie boisée de la France, et c'est une réforme qui ne peut plus attendre. (Très bient).

Le Congrès aura eu ce résultat de rallier toutes les troupes, et il n'y a plus maintenant qu'à monter à l'assant d'une législation inique — ce n'est pas moi qui l'ai dit, c'est le Ministre de l'Agriculture - pour substituer à cet impôt spoliateur, qui grève la forêt d'aujourd'hui, l'impôt raisonnable, l'impôt modéré, l'impôt adapté ì la sylviculture privée, et qui, dans tous les pays du monde, - le Congrès en a jeté les bases - assurera l'avenir de la propriété fores tière. (Applaudissements.)

A ce premier résultat, un autre s'ajoute, qui est de grande importance, et j'insiste sur ce point parce que j'en vois les conséquences non seulement lointaines mais presque immédiates, c'est l'union scellée, définitivement scellée entre tons les intéressés de la forêt, entre ceux qui en vivent, ceux qui la possèdent, ceux qui l'exploitent, ceux qui en transforment les produits et ceux aussi pour qui elle est une source de joie, d'air pur et de beauté. (Applaudissements.)

Le Congrès a eu ce mérite de rapprocher tous les intéressés de la forêt les uns des autres. Des discussions ouvertes dans les sections, des conversations qui ont suivi, des propos même échangés à table est déjà né, et s'affirmera encore avec le temps, un désir de colla. boration à l'œuvre commune. C'est une excellente préparation à l'application prochaine de la loi Audiffred, qui permet aux propriétaires de faire appel an concours de l'Adminis. tration forestière pour la gestion et la surveillance de leurs bois.

Ainsi tomberont bien des préjugés, bien des préventions, si bien qu'entre gens égale. ment animés d'un esprit nouveau les uns vis-à-vis des autres, esprit d'entente cordiale et de mutuel appui, il n'existera plus de barrieres, mais seulement une union durable et féconde qui sera le meilleur ouvrier de la conservation et du développement de nos richesses forestières. (Applaudissements.)

Si ce dernier résultat touche plus spécialement notre pays, il en est deux autres qui intéressent tous les peuples. Je veux parler de la constitution d'importantes réserves forestières et de la défense des sites et paysages qui a occupé une large place dans les délibérations du Congrès. (Applaudissements.)

La superbe promenade qu'ont faite avec moi les excursionnis tes d'hier dans les magnifiques futaies domaniales de la forêt de Lyons, donne bien l'impression que la formation de pareilles réserves, qui est l'œuvre des siècles, ne peut être assurée que par ce qui dure et que, tout en encourageant les propriétaires à augmenter leurs réserves pour leurs arrières-petits-enfants, c'est $s$ ur des personnes impérissables, Ettat, communes, départements, établissements publics, qu'il faut surtout et avant tout compter pour en assurer la pérennité. D'autres nations sont entrées dans cette voie. Il est temps que nous nous y engagions nous-mêmes. Le million annuel qui va être inscrit an budget de l'agriculture pour l'acquisition, de compte à demi avec les communes et les départements, de forêts ruinées, va déclancher le mouvement, et l'on $\epsilon$ st en droit d'espérer que ce grand réservoir de capitaux qui s'appelle la Caisse des Dépôts et Consignations, nos Caisses d'Épargne, nos sociétés de Secours mutuels, nos Caisses de retraites pour la vieillesse, nos Caisses de retraites ouvrières, sans parler de tous les établissements reconnus d'utilité publique, viendront peu à peu au placement forestier à long $t \in r m e$ qui es $t$ une avance non remboursable, mais que seuls ils sont capables de faire, des générations présentes à celles de l'avenir. (Applaudissements.)

J'ai gardé pour la fin le dernier résultat du Congrès, bien qu'il intéresse plus spécialement le Touring-Club de France, et qu'à ce titrs il nous soit particulièrement cher. C'est la protection des sites et paysages, l'aménagement de quelques belles parties de forêts judicieusement choisies en séries artistiques ou en promenades. Cette protection ira s'organisant et se fortifiant de plus en plus dans tous les pays dı monde, parce qu'elle est la condition même de l'industrie du voyage, de son développement et de sa prospérité, dont nous commençons seulement en France à ressentir les heureux efret.j. Au surplus, l'intérêt du tourisme n'est pas un intérêt égoïste, pas plus que celui des amis des beaux arbres, artistes ou poètes, ou celui des promeneurs.

Cet intérêt ne se confond-il pas avec l'intérêt même de la forêt proprement dite? Que cherchent en effet le touriste, le rêveur, le poète, le promeneur? Le bon La Fontaine l'a dit depuis longtemps dans un langage d'une poésie imagée qui touche au lyrisme. Co que veut le tonriste, le promeneur, le llâneur qu'il était, mais 
.... C'est la douceur des buis,

Le tapis vert des prés, et l'argent des fontaines.

Les trois hémistiches contiemnent tout le programme forestier ;

Pâturages, que parcourent d'énormes troupeaux,

Grands bois solitaires, où va rêver le poète,

Rivières aux eaux claires et limpides, qui sont à la fois une force et une source do brauté. (Très bien!)

Pour donner à cet ensemble de résultats toute l'ampleur qu'il comporte, nous avons deux forces à notre disposition. Nous avons d'abord la Commission internationale permanente, que vous avez eu la sagesse de constitıer; mais elle n'est pas encore formée, il nous faut faire appel aux gouvernements étrangers. Dès qu'elle sera constituée, son action, n'en doutez pas, se fera utilement sentir. En attendant, nous avons la Presse, et c'est à la Presse que j'adresse ce dernier appel.

Elle nous fut précieuse pour la préparation de ce Congrès, et nons la remercions une lois de plus du concours et de la collaboration dévouée que tous les journaux de Paris et de Province ont bien voulu nous apporter dans cette circonstance. Mais la Presse a aujourd'hui un rôle bien plus considérable et bien plus utile à jouer.

Après sa campagne commencée depuis huit ans, le Touring-Club de France a préparé l'opinion publique et c'est cette préparation qui a fait le succès même du Congrès. Il a mis cette opinion pour ainsi dire en état de réceptivité.

Eh bien, semez la bonne parole, jetez dans cette opinion les germes qui doivent produire les résultats que nous attendons : vous ferez ainsi de la bonne besogne et de la besogne patriotique. Il y a longtemps qu'un grand poète l'a dit:

* An plus profond des bois la Patrie a son cœur ! (Applaudissements.)

Travaillez, Messieurs, travaillez avec nons à cette grande ourre, faites-vous les auxiliaires du Touring-Club de France, servez de véhicule à sa nensée et faites qu'elle pénètre jusque dans les coins les plus reculés du pays pour qu'un jou ou puisse dire —et ce sera la meilleure récomplense de ses efforts : - le Touring a frappé du pied la terre et il en est sorti des forêts. (Applaudissements.)

Je m'arrête, Messieurs, et sans rouvrir ici un palmarès de remerciements, de félicitations et d'élogrs, embrassant tons nos collaborateurs dans une formule commune, je lève mon verre à nos Congressistes d'hier, à nos collaborateurs de demain. (Applau dissements.)

\section{Discours de 1 . Berr de Turique, inspectenr général des Monuments histo- riques, représentant $M$. le Sons-Secrétaire d'Etat des Beanx-Arts}

\section{Monsieur le Directeur genéral,}

Messienrs

M. le Sous-secrétaire d'État des Beaux-Arts, appelé à l'improviste dans son départe. ment, s'est vu obligé de renoncer au très vif plaisir qu'il se promettait de venir présider votre banquet.

11 eût aimé à venir et il vous eûi dit, avec l'autorité qui s'attache à s a personne $t$ t avec la tournure d'expression qui lui est propre, combien il porte d'intérêt aux choses qui vous sont chères.

Aursi, cn me déléguant cour le représenter parmi vous, m'a-t-il non seulement chargé de rous faire agréer ses sincères regrets, mais encore de vous donner la formelle assurance de toute sa sympatlie agissance.

Comment, d'ailleurs, pourrier-vons douter de la pleine adhécion du Ministre des Beaux-Arts, alor: cue la loi de 1887 l'a in:titué gardien suprême de nos richesses monumentales, et celle de 19196 , gardien suprême de 110 s richesses pittoręques, des parures zssentielles dont s'orne aver une égale fierté notre sol national! (Apploudissements.)

\section{Messieurs,}

La collicitude de M. Léon Bérard pour ce qui touche à la défense des paysages ne date pas d'aujourd'hui. Dé'à, l'année dernière, il déléguait un fonctionnaire de son adminis tration a" Congrès international de Stuttgart pour établir le contact entre la législation Iran paise et la législation étrangère en ce qui concerne la protection des sites.

Fn désignant re même fonctionnaire pour suivro vos discussions, il a tenu surtout à 
mnntıer sa ferme intention de réunir en un seul faisceau ces divers éléments d'études atin d'être mieux à même d'en tirer parti et pouvoir, le cas écliéant, traduire vos vaux nn langage administratif ou législatif, seule manière pour cux de recevoir la vie.

Mescieurs,

J'ai déjà dit à M. le sous-Secrétrire d'État tout l'interêt qui s'attache a ros travaix notamment à ceux de la cinquième section. qui regarde plus spécialement l'Administralion des Beaux-Atrs.

Jo dois avouer, cependant, qu'en venant y prendre part, je n'etais pas sans une cer. taine appréhension. L.es individualités, les collectivitès surtout, dans le ur ardeur à marcher à la conquête des progrès qu'elles réclament, vont souvent droit devant elles sans trop s'inquiéter des barrières rencontiéfe sur leu: chemin. Or, en matière de protection des sites, ces barrières sont parfois celles de la propriété privée, et les pouvoirs publics $s$ ont obligés d'€n tenir compte. Me faudrait-il donc, presque à chaque pas, vous arrêter dans votre élan et vous montrer l'orstacle? Mais, contrairement à mes crain tes, grâce à votre sens profond des réalités, grâce à lo science juridique de l'éminent président de votre Congrès, grâce au tact et à l'autorité du Président dr: la cinquième section, je Il'ai pas eu pour ćinsi rire à intervenir. A peins l'ol jection se présentait-elle à mon esprit que l'un de vous la formulait en termes excellents, et vous l'acceptiez d'autant plus volontiers qu'elle émanait d'un des vitres, d'un des congressistes et non pas d'une personne un peu suspecte, de M. le Bureau. (Rires.)

Aussi votre Congrès n’a-t-il pas été seulement une grande assemblée dans laquelle de hautes et bienfaisantes paroles furent prononcées, mais encore une sorte de laboratoire dont sont sorties des formules pratiques.

Au nom de M. le Sous-Secrétaire d'État des Beaux-Arts, je vous convie à lever nos verres en l'honneur de M. Ballif, Plésident du Touring.Club de France; de M. Defert, jrésident du Congrès ; de M. Chaix, président de la cinquième section, le tous les hôtes étrangers, et à boira à l'intangibilité des plus beaux paysages du monde. (Apploudissements.)

\section{Discours de $\mathbf{1}$. le docteur Auguste Nemours Ministre de la République de Hấti}

Messieurs,

Au num du gouvernement d'Haiti, qui m’a fait l'honneur de le représenter ici, à ce Congrès, j’adresse mes remerciements les plus sincères à M. le Président du TouringClub de France et à messieurs les organisateurs de ce Congrès.

Je les remercie du bon accueil qu'ils ont fait, non seulement à moj-même, mais à tous les représentants étrangers, de la bienveillance et de la cordialité qu'ils ont montrées toutes les fois que nous avons $e$ u becoin de renseignements, renseignements que je me suis donné le plaisir de demander, jusqu'à la fin de ce banquet.

Mais, messieurs, ma gratitude vá encore plus loin, car ce ne sont pas seulement des renseignements que j'ai pri ici. Ces renseignements vous ont suffi, à vous qui êtes au courant de ces graves et nombreuses questions, mais j'y ai puisé autre chose : c'est un enseignement complet.

Je crois que je ne dirai rien qui choque personne dans cette Assemblét, en affirnant que les choses de la forêt sont un peu spéciales et que tout le monde n'est pas au courant des intéressantes questions que vous avez développées.

Je suis du nombre de ceux dont l'ignorance est presque complète sur cette matière, mais je me plais à dire que, non seulement j'ai appris beaucoup dans votre compagni et en lisant les rapports si importants qui nous ont été distribués, mais que j’ai pris un tel plaisir à entendre ce qui a été dit, a lire ce qui a été écrit, que j'ai été pris comm vous, d'une grande passion pour les choses de la forêt.

Je ne puis mieux terminer ce que j'ai l'honneur de dire devant vous, qu'pn décharant que j'apporterai ces enseignements à mon Gouvernement, que je tâcherai d'olitenir de lui, au moins un commencement, un embryon d'organisation d'administration forestière, de manière à ce qu'il marche un jour daus la voie qur vour lui av» si brillummen tracée. (Applaudissements prolongés. Un ban est battu.)

Je ne puis que vous remercier à nouveau de cette nowvello marque do gratitude. 


\section{Discours de M. Chalamel, député, président du Groupe forestier de la Chambre}

Monsieur le Directeur général, Messieurs,

Je ne veux pas retarder par un long discours, celui que vous attendez tous, celui du distingué directeur général des Eaux et Forêts, M. Dabat, qui nous a déjà donné des marques si nombreuses de gratitude et de sympathie, je veux simplement remercier lo Touring-Club de France, en la personne de son distingué président, M. Ballif, en la personne du Président du Comité d'organisation du Congrès, M. Defert, d'avoir bien voulu m'inviter à ce banquet. Je veux aussi les féliciter de l'imposante manifestation forestière le cette semaine, manifestation qui a été si excellemment organisée par mon ami Cha. plain, que je suis heureux d'avoir aujourd'hui à mon côté, et qui a donné à cette cuvre toute son activité et tout son cœur (Applaudissements.)

Je suis certain que, dans cette invitation, vous avez mis la pensée de demander la collaboration du groupe parlementaire des forêts, que j'ai le très grand honneur de présider, pour que vos voux puissent devenir le plus rapidement possible des réalités légales (Très bien!)

Permettez-moi de vous dire que vous avez eu raison, que vous n'aurez pas frappé inutilement à notre porte et que notre concours vous est pleinement acquis. (Applaudissements.)

Mais, messieurs, votre Congrès n'aura pas seulement des effets matériels, il aura aussi un effet moral, que je considère pour ma part comme extrêmement utile. Il met d'abord l'idée fores tière à la place de choix qui lui convient; il montre que nous ne nous occupons pas seulement ici de questions d'ordre secondaire, mais qu'il s'agit véritablement d'une question d'intérêt national.

D'autres pourront chercher daccroittre les forces vives de ce pays par le développement du commerce, de l'industrie; nous, nous nous contenterons, et ce sera une noble tâche, croyez-le bien, de servir la Patrie, en exploitant l'idée forestière. Nous montrerons à nos laborieuses et intéressantes populations des montagnes, que pour elles aussi, peut s'ouvrir une èré insoupconnée de richesse et de prospérité. Nous montrerons aux populations de la plaine qu'elles sont solidaires de celles de la montagne et que la prospérité de la mon. tagne domine nécessairement la prospérité de la plaine.

Là où ne régnait que la tristesse et que le deuil, là où u'exis tait que la lande morne et désolée, nous saurons faire surgir de nouvelles richesses, nous saurons faire surgir la gatté et la joie des pâturages, l'arg’nt des clairs ruisseaux, comme vous disiez, tout à l'heure, M. Defert, nous saurons faire surgir l'ombre protectrice, l'ombre bienfaisante de la forêt et nous montrerons enfin que, dans toutes les montagnes françaises, nous pouvons faire disparaître l'ère des torrents.

C'est à cette cuvre de prospérité nationale et de rénovation sociale que je lève mon verre, en v associant les noms de M. Ballif, de M. Defert et le nom aimé et vénéré de notre très distingué Directeur général des Eaux et Forêts, MI. Dabat. (Applaudissements.)

\section{Discours de M. le baron de Hennet, délégué permanent du Ministère} autrichien de l'Agriculture

Monsiour l. Lirecteur général,

Messieur.

Je vous prie de bien vouloir exenser mon petit discours. Je sais qu'en France, on $\in \mathrm{s}$ très indulg’at pour les étranger:.

Comme délégué du Ministere de J'Agriculture d'Iutriche, et au-si comme propriétaire forestier, je dois tout d'abor remercier le Touring-Club de France de l'heureuse initiative qu'il a prise d'org iniser ce Congrès et le féliciter du succès qu'il a remporté nous sommrs tous d'accordsur ce point - succès qui a été peut-être plus grand encore que ses org xnisateurs eux-mêmes pouvaient le penser.

UI's r'merci ments respectueux s'adressent encore au Grouveruement de la République, qui a bi 'n vonlu transmettre à mon gouvernement l'invitation à " Congrès.

Je félicite la France du concours que les Forestiers ont trouvé dans l'Administration de l'Agriculture. 


\section{Messieurs,}

Les poètes affirment que les fleur's ont leur langage et que ceux qui les aiment et qui veulent les comprendre les comprennent.

Je rrois que nos arbres, les grands arbres, les pins, les sapins, les chênes, les hêtres ont aussi leur langage. (Applaudissements) et, quand nous sommes seuls dans nos forêts, soit qu'un vent léger remue les branches, soit qu'une tempête fasse gémir les vieux troncs, et même dans le silence, nous nous entendons avec nos arbres comme avec quelqu'un avec lequel il n'est pas besoin d'échanger des paroles pour se comprendre. (Applaudissements.)

Si ces arbres pouvaient parler, s'ils pouvaient nous raconter l'histoire de leurs ancêtres, l'histoire de leurs espèces, je crois qu'ils nous diraient que, parmi les hommes, ils ont toujours trouvé plus d'ennemis que d'amis. (Applaudissements.)

Tout d'abord l'homme a défriché les forêts afin de se créer des champs pour vivre. C'était nécessaire, c'était excusable. Puis, il a commencé à dévaster ; il a dévasté pour avoir du bois de chauffage, pour construire des bateaux et, pendant logtemps, pendant des siècles, il n'a pas pensé à replanter.

Il cultive ses champs chaque année, parce qu'il sait que l'année suivante il aura une récolte, mais il a cru que la nature se chargerait seule de la forêt. C'était une grave erreur, et nous en souffrons tous.

Il n'y a pas longtemps que la sylviculture s'est développée. Elle est la sœur de l'Agriculture, sa sœur cadette, mais je dirai qu'elle est l'expression d'une plus haute civilisation. En effet, nous voyons des peuples sauvages cultiver leurs champs, parfois d'une manière primitive, mais jamais nous n'avons vil un peuple sauvage faire de la sylviculture. (Applaudissements.)

L'homme - il en est malheureusement presque toujours ainsi - n'apprécie que ce qu'il est sur le point de perdre et il connait la valeur que des objets qui lui échappent. C'est pour cette raison que, dans ces derniers temps, le développement des idées fores. tières a pris un si grand essor, et cela a été le mérite du Touring-Club de France, de réunir tous les efforts et de rassembler tous les Amis de la Forêt, dans quelque pays qu'ils se trouvent. Je crois que l'Autriche n'est pas indigne de prendre place parmi eux, puisque, parmi les pays de l'Europe centrale, de l'Europe de l'Onest et de l'Europe du Sud, elle est presque seule - je dis, presque - à avoir plus que ce qui lui est nécessairo et à pouvoir encore exporter.

Notre Congrès - je peux dire aussi; notre - a pu mettre en lumière certaines idées, il a pu nous réunir pour établir des bases que nous avons fixées dans un accord presque complet. On a dit que les forêts constituaient une richesse nationale, économique et financière. Elle est plus que cela, et vous l'avez entendu dire par des personnes plus compétentes que moi; c'est une richesse dont prennent leur part toutes les classes de la population, qui retrouvent, après le travail dans les villes et dans les usines, non pas la nature flétrie et dévastée, mais la nature soignée et dirigée par l'homme.

Aussi, quand nous rentrerons dank nos forêts, nous pourrons raconter aux arbres qu'ici, à Paris, qui, comme l'a dit Victor Hugo "donne un manteau de lumière aux idées "se sont réunis des amis des arbres.

Je félicite encore le Touring-Club de France de l'initiative qu'il a prise, en nous donnant encore l'occasion de nous retrouver, ce qui nous permettra de ne pas voir se clore, après un seul effort, tous les travaux que nous avons accomplis ces jours derniers.

Je lève mon verre en l'honneur de la culture forestière de la France, dont je salue ici l'élite des représentants dévoués et vaillants.

Mes hommages vont à leur patrie, à la France, à laquelle ils rendent les plus grands services, services qui seront peut-être appréciés plus tard à leur juste valeur, mais qui. sont de la plus grande utilité, non seulkment pour la France, mais pour l'Europe et pour l'humanité. (Applaudissements.) 


\section{Discontrs de .1. Bonnet, président de la Socisti forestiere de Franche-Comté et Belfort}

Monsieur le Direcleur général, Messieurs,

Ma qualité de I'résident de la Socirté Forestière de Frunche-Comté el Belfort m impose le klevoir de prendre ici la parole pour lraduire la joje profonde, le sentiment de légitime fierté qui remplit aujourd'hui le cenur de nos 1.500 sociétaires.

Parni ces sociétaires, nous sommes heureux de compter des Suisses, des Belges, des Anglais, des Italiens, des Canadiens, des Américains, des Roumains, des Bulgares.

Comment n'aurions-nous pas un peu de satisfaction si nous portons nos regards en arrière. Que de chemin parcouru, en effet, depuis le jour où, en 1891, sous l'égide de inon regretté prédécesseur, M. Armand Veillard, député de Belfort, nous jetions à Besançon les bases de la première société forestière mixte qui soit née sous le ciel de France.

Les premiers, nous élargissions le cercle et nous appelions à nous tous les hommes ayant lil Foret et ses produits comme point de contact, pour les faire bénéficier des avantages d'me association libre.

Notre but était de faire apprécier et aimer la forêt qui est la principale richesse dı pays, Ce but qui n'était que régional, nous avons la satisfaction de voir qu'il est devenu national et international.

Nous n'étions que cent au début, mais déjà notre vaillante phalange étudiait avec soin le tarif des droits de douane sur les bois, et grâce à l'appui de notre compatriote M. Viette, alors député du Doubs et ministre de l'Agriculurure, elle réussissait à faire etablir des droits compensateurs qui, après vingt ans d'application, réunissent encore liunanimité des suffrages.

Notre nombre augmentait rapidement. Dans le Jura naissait la première sociétíscolaire forestière et sous notre impulsion, ces utiles sociétés se proprageaient en FrancheComté et sur d'autres points.

Des sociétés søurs de la notre se fondaient à lix. à Nice, au Mans, à Linoges. ailleurs; la Société des Amis des Arbres sorganisait à Paris et sur divers points du territoire. Le Touring-Club à son tour šintèıssait aux arbres et aux forêts, et il faisait connaître à tous les dangers du déboisement, en provoquant l'apparition du bel ouvrage de mon ami Cardot, le Manuel de l'Arbre, et en l'adressant à toutes les ícoles publiques. (.t pplaudissements.)

['n grand mouvement d'opinion était créé en faveur des forêts, el il nes'arrêtera plus. Entre temps, notre Soriété croissait toujours, redoublait "l'arıleur au travail. Son bulletin trimestriel. ses congrès annuels posaient et résolvaient les questions lorestières les plus graves : l'assurance des hois, la protection des lorêts, l'impót lorestier faisaient l'objet de rapports et d'études de la plus haute valeur', qui ont servi de base à plusieurs des voux que vous avez votés.

Quel ne doit pas être le mérite et l'orơueil légitime des lommes qui, pendant près d'in juarl de siècle, ont fait preuve d'une initiative aussi féconde et ont fourni un labeur aussi opiniâtre! lls ont aujourd'hui l'immense satisfaction de voir aboutir - ou près d'aboutir - les urandes améliorations qu ils on t rêvées, étudiées, préparées, pour le plus grand bien de la France et de la forêt française. Et cette satisfaction, à qui la doivent-ils?

A la grande et puissante Société du Touring-Club de France, aux hommes éminents iqui la dirgent et qui savent faire aboutir tout ce à quoi ils s intéressent. (Applaudissements.)

Aussi, la Société furestière de Franche-Comlé et belfort ne leur a-t-elle pas marchandé son concours et a-t-elle été heureuse de s'assorier à ses travaux en venant assister au Congrès forestier.

An nom de nos 1.500 sociétaires, je remercie M. Ballif. M. Defert et leurs eollaboritteurs d"a voir provoqué ces grands jours forestiers. Je les félicite de l'organisation parfaite qui en a assuré l'incomparable succès. Grâce à eux s ouvre une ère nouvelle qui verra Je Parlement défendre énergiquement les intérêts forestiers. Grâce à eux, nous pouvons cspérer une diminution des charges qui écrasent les forêts francaises, car celles-ci, contrairement à ce que beaucoup croient, n’appartiennent pas exclusivement à quelques grands propriétaires, mais surtout à des milliers de petits propriétaires.

Girâce au Touring-Club, mes anciens camarades des Forêts verront revenia il eux la laveur publique et il faut espérer que le Parlement saura, par de larges rrédits, recounaîlre la valeur et l'utilité d'une administration d'élite qui sauvegarde et augurmento: la richesse du pays et fait honneur all nom trançais. (Applaudissements.)

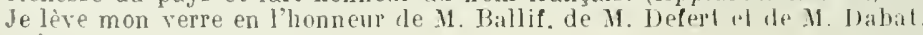
Qu ils vivent longuement! 


\section{Discours de 11 . de Sébille, membre du Conseil supérieur des forêts du royaume de Belgique}

Monsient le Directenr général, Messieurs,

Oblige de rentrer en Belgique, je ne puis partir sans vous exprimer ma gratitude pour les attentions et les prévenances que vous nous avez temoignées, et vous fúliciter clidleureusement pour la parfaite organisation du Consrès.

Avant tout, Messieur's les membres du Comité organisateur, vous avez rivalise de zèle et de dévouement pour mener à bien la tâche que vous aviez assumèe. Vous avez la satisfaction du devoir arcompli et le succès a couronné vos efforts.

Je conserve linoubliable vision de l'admirahle forêt que nous avons parconntu hier. Jamais je n’ai vu un pareil matéicl aussi dense et aussi bien aménagé ; on n’y trouve ni clairière inculte, ni arbre dominé. Ciela fait le plus grand honneul' à l'Administrítion des Eaux et Forêts de France, qui, à juste titre, a une réputation mondiale

Je conserverai l'inaltérable sourenir des guelques jours passés an milien de vons,

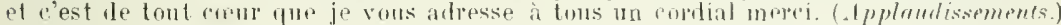

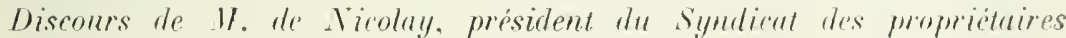 forestiers de la Sarthe}

Munsieur le Directeur général.

Messieurs,

Je ne saurais laisser se clore les brillantes manifestations organisées el thrigées yar le Touring-Club de France, sans proclamer quelles espérances il va naitre dans les cours de tous les intéressés, les propriétaires forestiers.

I'ar l'initiative qu'il a prise, frar la charge qu'il a assumét, le 'fouring-Club a ajouté in titre de plus à tous ceux qui lui donnent droit déjà à la reconnaissance du public. (Aplaudissements.)

M. le Président du Touring-Club disait tout à l'heure que sa principale préoccupation, que la notre devrait être de recouvrir le sol francais d'un large mantean de verdure. Hélas! l'réoccupés trop souvent par des réalités, nous sommes obligés de penser que la forêt est une sonrce de richesse et que, comme telle, elle est sujette aux lois économiques qui régissent les échangres. Aussi pensons-nous que c'est par l'amélioration de la pronuction, par la régularisation que nous pouvons le plus fucilement et le plus utilement travailler pour sa propagation et pour sa conservation. (Applaudissements.)

C'est, Messieurs, la tâche que s'est donnée le Comité des Forêts, que j’ai l'homnenr de présider. Il doit séféliciter d'avoir trouvé dans l'organisation du Touring-linh l'orcasion exceptionnelle de sentir quel appui il pent trouver, tant parmi ce personnel de l'Aintinistration des Eunx el Forêts qui doit être pour les jpopriétaires mu guide et un soutien (Applaudissements) yu auprès de celte association superbe du Touring-Chul, de lrance, "ui, war la larke inlluence dont elle jonit, qui, par les nombrenses branches qu'elle a su deja donner a son artivilio, exere dans ce pays une artion hienfaisante. (Applandissements.)

l'est à cptle lssurialion. Messieurs, c'est à son l'rósident dévoné, que je vous demande de lever avee moi volte verre. (.Ipplandissements.)

\section{Discomrs de 11 . de Larnuge, président du Symblint forestier de Sologne}

Messieurs,

Après le Président du Comité des Forêts, qui est mon P'résident et dınt je ne suis que l'humble collaboratem', je devrais me taire. Il mexusera si je parle après lui. Lil diffi culté n’en sera gur plus grande, mais j’ai le duvoir de parler au nom des propritaires,

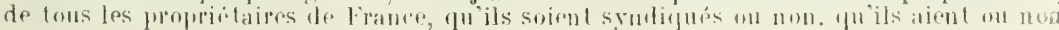


pris part à ce Congrès, soit par eux-mêmes, soit par la replésentation de leurs associations. de ces propriétaires qui ne peuvent manquer d'applaudir à l'effort énorme qui s'est produit, et aux résultats considérables que l'on peut attendre de cette initiative qui est due - nul de vous ne l'ignore, on l'a déjà dit. vous ne vous lasserez pas de m'entendre le dire - qui est due à cette organisation si judicieuse, si accueillante, si merveilleuse en un mot, faite par le Touring-Club de France, du premier Congrès forestier internationals

\section{Messieurs,}

De ce Congrès ressort pour nous, propriétaires, une donnée qui domine toutes les autres: C'est la première fois que nous avons pris, uous propriétaires de la forêt, contact avec tous ceux qui en sont les auxiliaires indispensables, que ces auxiliaires appartiennent à la technique ou à l'exploitation forestière, toutes associations similaires dont les efforts doivent être convergents et dont les intérêts sont les siens. Ce serait banal que de répéter ce que nous pouvons attendre de fructuellx de cette force et de cette association. Je me bornerai donc à dire également merci au Touring-Club de France pour la consécration définitive de nos efforts, car il a voulu rendre permanents nos résultats en instituant cet office forestier international qui nous permettra, d'un pays à l'autre, de mieux nous connaître, de sonder nos besoins, de partager et de faire converger, nous aussi, nos efforts.

Nous avons en présence de nous des nations si nombreuses et si bien représentées, tant par la parole que par les travaux, que nous devons nous féliciter de cette collaboration qui a fait régner, pendant jours trop courts. au milieu de nous, une atmosphère de paix et de fraternité dont la continuation se fera par l'Office forestier international. (Applaudissements.)

Nous ne devons pas oublier de rappeler ceux qui nous ont devancés. Nous devons être reconnaissants des efforts de ceux qui, dans notre pays, se sont faits les pionniers de l'cuvre d'association, et je ne veux vous en citer qu'un exemple, en la personne de M. Roulleau, secrétaire général du Comité des Forêts de France. M. Roulleau est un homme de cour et d'action. C'était oeuvre de justice de l'en remercier.

En terminant, je n'ai plus à ajouter à mes remerciements au Touring-Club que l'expression de notre profonde gratitude pour la Ville qui a abrité ce premier Congrès. pour la Ville de Paris. (Applaudissements.)

Parler de Paris, c'est parler de la France, puisque quand on évoque son nom, on sent battre le cœur de la France, ce cœur généreux, ouvert à tous ceux qui, de tous les coins du monde, viennent faire cause commune avec elle quand il s'agit des intérêts de l'humanité. (Applaudissements.)

C'est un intérêt essentiellement humanitaire que celui de la Forêt, car elle est non seulement cette source de richesse dont on a tant parlé dans notre Congrès, mais en même temps, le domaine mondial, la propriété mondiale de la beauté souveraine.

J'aurais voulu dire l'autre jour, à la Ville de Paris, en quelques mots rappelant l'arbre tt l'eau, ce que nous pensons de Paris :

\section{A LA VILLE DE PARIS}

\section{LA FORÊT}

Que ta nef, o Paris! toute entière tressaille

tux pas renus vers toi, de la forêt profonde

Dì s'amassent en paix, en réserve féconde,

L'arbre et l'eau. Quels trésors! Est-il rien qui les vaille!

Nas-tu pas fait venir des quatre vents du monde Les hois de ta membrure, et ceux de ta muraille, Abri sûr, quel que soit l'ouragran qui l'assaille:

Notre chêne ne craint rien du vent ni de l'onde!

Le pin venu du Nord, pour tes mâts élancés.

Aribore fièrement les trois couleurs de France

Aux tissus d'Orient, par le vent balancés.

Tu tires ta beauté, le luxe et l'élégance,

De ces bois précieux par le sud amassés

Et par toi "la Forêt "vers le progrès s'avance.

An Touring-Clul de France!

A lá Ville de Paris!

(.1 pplaudissements.)

(Ip plaudissements.) 


\section{Discours de M. Changeur, secrétaire général de la Société pour la protection des paysages de France}

Monsieur le Président, Messieurs,

Quelques mots.

Je n'aurais pas la hardiesse de prendre la parole, si ce n'était au nom de M. Charles Beauquier, Président de la Société pour la protection des Paysages de France, auteur de la Loi, qui me prie d'exprimer son très vif regret de ne pas être des vôtres aujourd'hui.

J'ai de plus le devoir d'exprimer les félicitations de la Société pour la Protection des paysages de France aux organisateurs de l'importante manifestation qui vient de prendre fin, et ses remerciements aux autorités qui ont, une fois de plus, témoigné du précieux intérêt qu'elles portent au reboisement du sol français.

Je n'ai pas à revenir sur la valeur es thétique de la Forêt. Les forestiers qui m'entourent sont des artistes par destination et ils savent mieux que moi que la Forêt constitue le décor le plus grandiose du paysage et qu'elle y apporte l'élément le plus majestueux. Il n'est pas, avec la mer, de source plus féconde d'inspiration, non seulement pour l'art en tous ses domaines, mais en général, pour la pensée humaine, et c'est fort justement qu'on a nommé la Forêt le Musée de la Nature.

Aussi, la question fores tière est-elle in timement unie à celle de la protection du paysage, et beaucoup de personnalités présentes se souviennent de la place qu'occupa cette ques tion au premier Congrès international pour la protection des paysages, qui eut lieu en octobre 1900.

Faut-il en outre rappeler que depuis juillet 1908 la Chambre des Députés est saisi d'un projet de Loi déposé par M. Potié, tendant à créer une l'éserve nationale en vue de l'hygiène et de la conservation de la beauté dı sol?

La Loi Audiffred vient de consacrer un article de ce projet. Nul doute que le Congrès forestier n'aide puissamment, par les vœux autorisés qu'il vient d'émettre, à l'adoption définitive des mesures réclamées par tous ceux qui ont souci à divers titres de conserver et d'accroître les trésor's forestiers de la France. C'est dire quelle gratitude l'on doit au Touring-Club de France, qui, de façon si éclatante, a pris en main cette noble cause.

A nos remerciements, je voudrais joindre une proposition. Peut-être en̂t-elle dû êtr émise au cours d'une séance de travail. Je ne déplore pas trop ce retard, convaincu qu'un état de digestion heureuse ne saura nuire à son adoption.

Ce Congrès a donné une confirmation à deux adages fameux :

L'union fait la force.

De la discussion jaillit la lumière.

Les échanges de vues, si féconds, ne devraient-ils pas être moins lares? Ils devraient, à mon avis, être non pas occasionnels, mais permanents en quelque sorte, et c'est là que je veux en venir. Nous souhaiterions qu'un Office international forestier fût institué qui centraliserait jour par jour tous les rensieignements, tous les documents capables de servir une cause universellement reconnue comme belle et utile.

Si le Touring-Club voulait bien apporter à la réalisation de cette idée la puissance de son organisation, ce serait là un sûr garant de son suecès.

Je termine sur cette prière, en levant mon verre à vous tous, Iessieurs, pèlerins passionnés de la Forêt. (Applaudissements.)

\section{Discours de M. Tanassesco, délégué de la Roumanie}

Messieurs,

Jamais un Congrès forestier, même international, n'a été si grand, si impurtant, soit par le nounbre immense de ses adhérente, soit par les questions de si grand intérêt qui ont été mises à l'ordre du jour des délibérations des congreșistes.

Souhaitons que la mise en application des voux adoptés par le Congrès, et qui sont d'une si grande importance pour la protection de la forêt si nécessaire à la vie de l'homme, et pour lis propriétaires de forêts, se fasse aussi vite que possible.

Comme délégué d'un petit pays latin situé aux bouches du Danube, loin, très loin de la France, comme délégué de la Roumanie, je prends l'engagement d'exposer la question des forêts au gouvernement de mon pavs arec l'ardeur que j'apporte dans l'accomplissement de mon métier de forestier. 
Nous qui sommes toujuurs en contact arec la forêt, nous l'aimons plus que les autrés et nous la comprenons mieux qu'eux.

Je lève mon verre en l'honneur des organisateurs grands et petits, de ce Congrès forestier international, en l'honneur de l'École forestière de Tancy, mère intellectuelle ite plusieurs écoles forestières étrangères (applaudissements) comme relle de la Rouin anje. et de tant de forestiers éminents qu'elle a donnés à la France. (Applaudissements.)

\title{
Discours de U. Krarup, délegué du Danemark
}

En ma unalité de rejrésentant du Danemark, je désire, monsieur le Président, et messieurs les memhres du Conité du Congrès forestier international, vous remercier d'avoir fourni à mon gouvernement l'occasion de se faire représenter', J'adresse en outre à tous les forestiers français les salutations de leurs confrères danois.

Les relations entre forestiers français et danois ont été rares, mais rela tient, je crois, d̀ ce que nous avons eu pentant phus d'un siècle in quart, une école forestière supérieure et que nous n'avons yas eu besoin d'aller à l'étranger pour étudier la sylviculture.

Je rois ponvoir dire que c'est un de vos plus grands forestiers, l'illustre Duhamel du Monceail, qui a inspiré le plus grand de nos forestiers danois, le comte Reventlow, ninistre d'État. urand propriétaire de forêts, qui a étudié dans sa jemnesse, en France, en Allemagne. in ingleterre et dans d'autres pays.

C'est le connte Reventlow qui nous a donné les enseignementr, que nous avons ut ilisés rhez nous, de n'ivoir tue de hautes futaies, des ensemencements et des plantations intensives.

de desire, mes cher's confrères francais, porter mon toast en l'honneur des succuseurs nt des héritiers de Duhamel du Monceau, et je pense que vous pouvez accepter mon toast. J'espère qu'il y aura tougiours en France des héritiers de Dubamul du Monceau, qui, comme mon compatriote. a dit

- Il Paut tomjours travailler dans la vraie science forestiere! (Applondissemenis.)

\section{Fiscour's als .H. Dabat, Directeur général des Eaux pt Forêts}

\author{
Messieur's,
}

Je vous remercie de m'avoir prié de présider volre binquet. Je regrette pour vous que ce ne soit pas MI. Bérard, le Sous-Secrétaire d'État des Beaux-Arts, comme vous l'aviez espéré, parce que je ne puis égaler son talent, et que je suis d'aillenrs beaucoup moins qualifié que lui ponr vous enfretenir, comme il l'aurait fait, des ressources de beauté que rè̀le la forêt. Je rrains surtout, vous ayant parlé vendredi, de tomber dans les redites.

Mais n'est-il pas des circonstances où ce n'est pas se répéter que de dire denx fois la mêrne chose: Ce ne sera donc pas me répeter que de rous láliciter "de rous remercier d'avoir mené à bien, d'avoir réalisé an deli de toute espérance. l. Inurd programme que vous vous étiez lraré.

Le forestier, le propriétaire ont toujours rultivé leur forêt avec anour : ils s'y sout attachés, comme à un être cher, parce qu'elle parle à leur intelligence et souvent, par tout ce qu'elle leur rappelle, à leurs souvenirs et à leur cœur. Elle leur représente l'émanation du sol natal; ils la contemplent sepuis longtemps, tel le clocher du village prochain. Mais, quel que soit leur attachement, les hommes de litheur et de bonne volonté, pour. suivint un travail obscur $\mathrm{t} t \mathrm{~s}$ ans gloire, épronvent le besoin de sentir que leurs efforts ne sont pas stériles, qu'ils ne sont pas des incompris, que leur activité est encouragice.

Cet encouragement, ce réconfort, vous les leur avez apportés. Vous leur avez dit : Vous êtes les artisans d'une reurre considérable. Vous n'êtes pas seulement les gestionnaires d'un domaine important, cherchant à faire rendre au sol des produite rénımérateurs; vous ne travaillez pas exchsivement pour le présent. Vous faites plus et mieux. Ces bois, rui lentement sortent de terre, et dont ceux qui les voient naitre ne verront pas la fin, vous les préparéz your l'avenir. Vos vues s'étendent bien au delà de lix vie humaine; les générations de demain, les enfants de vos enfants, vous devront ef res ombrages jeins de serénité et de majesté, et la perpétuité de des forếts que nous voulons 
de plus en plus denses, parce qu'elles répondent ì un besuin d'utilité générale, qu'elles sont comme l'un des contreforts du pays, contreforts dont la destruction et la ruine entraîneraient destruction et ruine pour le pays lui-même. (Applaudissements).

Oui, il faut de la forêt, pour que les matériaux de la montagne ne descendent pas dans la plaine, semant désastres et inondations. Il faut de la forêt, pour que le torrent soit dompté et assagi, pour que la mer s'arrête docile au vied du rivage eq que le sable reste immobile sur la dune. Il faut de la forêt pour que les cours d'eau ne soient pas desséchés, que les fontaines ne soient pas taries, pour que la source continue à sourdre toujours égale à elle-meême, assurant la fraîcheur de nos pâturages. La forêt fait l'air salubre et purifié. Elle eft la beauté de nos paysages, la coquelterie de nos sites, la splendeur de nos monts, la grâce de nos collines, la fertilité de nos plaines, le charme des promenemrs, l'agrément des touristes. Elle donne asile à l'viseau, si utile à notre agriculture. Elle sert aussi à la stratégie, à la guerre; clle est l'obstacle à l'envahissement. Il faut de la forêt encore pour les cuvres de paix, pour que l'ouvrier des eampagnes ait du travail dans le rude hiver, pour qu'il ne déserte pas le village et ne s'ach mine pas vers les villes. (Applaudissements.)

Un de nos plus charmants poètes contemporains a dit justement;

Au plus profond des bois la patrie a son cour.

Un peuple sans forêt est un peuple qui menrt.

Les forêts ne sont-elles pas, en effet, comme les joumons de notresol? Tels les poumons, elles aspirent l'air et l'expirent afin de lui rendre son ardeur et sal pureté. Grâce à cette épuration, les artères de notre vie physique, les fleuves, les rivières, les ruisseaux, fécondent et transforment la terre, la belle terre de notre pays qui est un pen comme sa chair vivante.

Vivante, elle l'est vraiment, $\epsilon$ t d'une éternelle jeunesse, puisqu'elle a ses amoureux et ses poètes; ille a été chantée par toutes les lyres et dans tous les siècles. Elle a été la grande inspiratrice, non pas seulement des artistes, mais aussi des hérns qui, $n$ tombant pour qu'elle reste intangible, ont écrit avec le ursang le plus beau de ces poèmes. (Applaudissements).

C'est vers cette terre de France, dont lui-même tst épris, que le Touring-Club cherche, depuis bientôt un quart de siècle, à attirer les regards; elle ne doit pas être la princess lointaine dont les citadine ont entendu parler, mais qu ils ne visitent jamais; elle a droit à ce que ses enfants viennent lui rendre hommage. Elle n'est pas isolée dans je ne sais quelle inaccessible tour d'iroire; tlle $t s l$ all contraire partout où nous pourons contempler les splendeurs des a belle nature et plus particulièrement dans ces forêts où nos pères dressaient des autels à la divinité.

Beauté de notre sol et de nos bois, richesse de notre production fortstière, protection de nos arbres contre l'exploitation mal comprise et la destruction irraisonnée, amélioration dans les procédés de culture, accroissement du champ d'action sylvicole par le reboisement et aussi par la création de parcs nationaux où la nature pourra prendre la plus libre expansion et la forêt croître dans le calme et le repos.

Tels sont, messieurs, les objets que votre Congrès a mis en relief.

Encore une fois, je vous en remercie, et je lève mon verre bien liaut a la prospérité de la grande Association qui nous a valư ces belles fêtes, à l'avenir de la forêt française, à tous ceux qui, travaillant d'mn même cœur à la rendre plus magnifique, collahorent ainsi it la grandeur de la patrie. (.1pplaudissements.) 



\title{
EXGURSION
}

\section{A GREYOBLE ET ACX ALPES DAUPHIYOISES}

\author{
du 22 au 29 Juin 1913
}

Le Dimanche 22 Juin, le Congrès s'est agréablement clôturé par le départ pour une excursion à Grenoble et aux Alpes Dauphinoises.

Partis de Paris par train spécial, les congressistes, sous la direction de MM. Auscher, Famechon membres du Comité exécutif ; Mathey, conservateur des Eaux et Forêts, président du Comité local d'organisation ont visité la Bérarde et le Massif de la Chartreuse.

Cette grande semaine d'excursions aux Alpes dauphinoises fut très réussie et féconde en heureuses impressions.

Sous la direction toujours bien inspirée de M. Mathey, conservateur des Eaux et Forêts à Grenoble, cinquante congressistes, dont une dizaine de forestiers étrangers, Belges, Norvégiens, Suédois, Portugais, Hongrois, Irlandais, Japonais, ont, sept jours durant, vécu en contact avec les les beautés naturelles les plus justement renommées de nos Alpes, et aussi les plus disparates, le Lantaret avec sa ceinture le neiges et de glaciers, l'Oisans avec la nappe verdoyante de sa plaine fertile, la Bérarde avec sa robe de pierres et de rochers stériles, semée ça et là de quelques oasis de verdure, derniers vestiges d'une végétation disparue; le massif de la Chartreuse enfin avec son odorant mantean de forêts résineuses.

Après une randonnée pittoresque en cars alpins, en carrioles, à dos de mulets ou à pied dans la hauto vallée du Vénéon, le long du lit de ce torrent que grossissent par endroits d'admirables cascades, la caravane atteint, à la tombée du jour, le hamean de la Bérarde, but de la première excursion.

La Bérarle! C'est, dans le cerele de plus en plus resserré des montagnes qui nous entourent, un nouvel horizon 'pui s'ouve devant nous; car nous voici au seuil de ce qui doit être, de ce qui est le premier "Parc national français $m$.

C'est là en effet, parmi ces monts ruinés, ces vallées aux versants dénudés, ces gorges désertiques, dans le domaine de la désolation et de la mort, que le Parc national va ramener la vie et préparer pour 
l'arenir de la richesse et de la beauté. Dans leux ans, ceux qui viendront à la Bérarde y arriveront, s'ils le voulent, en automobile, par me bonne route tracée dans lo plus magnifique décor qu'on puisse rêver... Dans dix ans, l'arbre et les arbrisseanx monteront à l'assaut des pentes anjourd'hui dépouillées de rerdure... Dans ringt ans, la régétation revenue dans ce paysage macabre y aura déjà fait aux neiges et aux glaciers qui courrent les sommets, un superbe piédestal de pâturages et de forêts, où jamais plus la hache. ni la faux, ni la dent du bétail domestique ne viendront exercer leur's larages. - wi la flore et la faune se perpétueront selon leurs propres lois, - où l'homme enfin ne pénétrera plus pour détruire, mais pour apprendre, pour admirer et pour airner!

L'onvre de régénération conçue par M. Mathey, adoptée par le Touring-Club, est en en roie de réalisation, et son avenir sera assuré par la Soriété des Parés nationaux de France, dont le Congrès forestier a posé les bases et qui compte déjà de nombreux adhérents. Saluons bien bas cette premièr création qui inangure une ère nouvelle pour la défense de nos montagnes et lo dévoloppenent des beautés naturelles de notre pays.

Le massif de la Chartreuse! Changement de tableau. Après la disette d'arbres et de verdure c'est une orgie de furêts, de prís-bois, de verdoyantes pelouses imaillées do fleur's multicolore dont les botanistes de lescursion ont fait l'amples cueillettes. Et cest encore, après la visite du monastère - paurre grand torps salls âme - une excursion ¿ travers bois sous de magnifiques sapins, an col de la Charmette aver" restour par le sentier des Sangles: c'est enfin l’ascension du grand Som avere inauguration deme table d’orientatjon par notre atlègure. 11. Léon

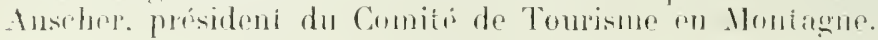

\section{La fête fut exrquise et fort bien ordonnée.}

Ellı: so déroulia à 2.033 mètres d'altitude an milien d'un grand concours de populations accommes de tons lés points de la région, wt re ne fut pas un spertacle banal que celui de cette foule d'alpinistes de fous âges et de tous sexes où tous les groupements locaux se trouraient représentés, Syndirat d'initiative de Grenoble et du Dauphiné, Société des Touristes du Dauphiné, Section dauphinoise du Club alpin, Syndicats d'initiative de Saint-Pierre de Chartreuse ef des rillages environnants, arclamant is l'envi le Touring-Club, communiant avec hi dans l'amour les grands horizons qui élève l'âme of là pensíe et funalement fraternisant, sous son pavillon ami, autour de la table dressée par les foretiers, an col du liovinant, - un petit chef-d'ouvre de décoration forestière, cetfe table improvisée ! - pour sceller une fois de plus, le verre en main, l'union de tous les défensenr's de la Montagne et de la Forêt.

C'est dans eet esprit ru'après le hanquet de rlôture à Saint-Pierre, la raravane se distoqua, "hatenn emportant, avee le souvenir d'agréables jounées pássées en bonne eompagnie, la conviction profonde que, quand les intéressés se seront donné la peine de mettre en valeur les

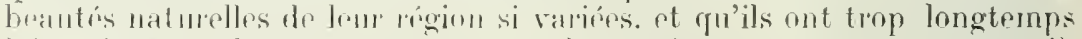

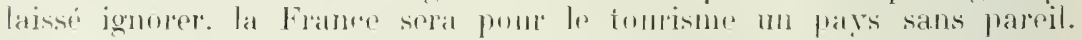

' Hut pris part à l'excursion : MII. Dabat, Heury Defert, Auscher, Famechon, 
Chaplain, Mmes Altmann, Auscher, MM. Berthelot, Blondean. M. et Yue Bomner, MM. Paul Bory, F. Bouisset, Carbonnier, Chabrand, G. Combéléran. Dannin, Mme et Mlle Defert. M. Defert fils, MII. Constant Delville. Francis Doé, Dubois, Ch. Dupont, Comte Gazeau, Henry Jauflret, Andre Kalkir. Fréderik Krarup, Dr Le Ber, M. 1.t Mne Lescouzères, MII. Lombard, Mathey,

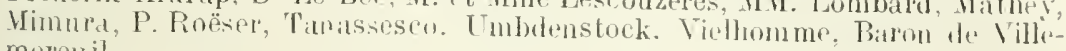
mereuil 



\title{
BIBLIOGRAPHIE
}

\author{
PREMIERE SEGTION
}

\section{ENSEIGNEMENT}

La bibtiographie sylvo-pastorale comprend des publicalious de tout premier ordre, dues à des auteurs d'une compétence incontestable et d'une autorité reconnue, parmi lesquels nous citerons Surell, Cézanne, Demontzey, Broilliard, A. Mathieu; IM. Boppe, Jolyet, Briot, D. Cannon, Ch. Guyot, Huiffel, Ilathey. Nous n'indiquons ici que les ouvrages susceptibles de s'adapter ă l'enseignement primaire.

Tounici-Cueb de fraxce : Manuel de l'Arbre, par E. Cardot. conservatenr des Eaux pt Forêts.

Manuel de l'Eau, par Onésime Reclus.

Le déboisement, la restauration et la mise en valeur des terrains en montagne, texte de conférence de propagande acrompagné de 39 clichés de projertion. par P. Mouan, conservateur de Eaux et Forêts.

Sucrété Forestrère de Fraxche-Comté ét Bellort : Aide-mémoire du furestier : fer fascicule: Sciences nuturelles, par L. Pardé, inspecteur des Eaux et Forêts: $2^{\mathrm{e}} \quad$ - Sciences mathématiques, par A. A..., inspecteur des Eaux et Forêts; $3^{e} \quad$ - Sciences juridiques, par 1:. Denove, conservateur des Eaux of Forêts.

Lige De Reborsemext de L'Algérie: Manuel du planteur d'arbres en Algérie.

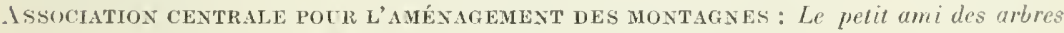
el des polouses, par William Gas, recuêil de dictées.

Less arbres de la mutualité el leurs ancêtres, par Théophile Jaxvrars. - Librairie do la Ilutualité, Bordraux.

Forêts, paturages et prés-bois, par A. Fnox, inspecteur des Eaux et l'olêts, professeur à l'Lcole forestière des Barres (Encyclopédie agricole pratique). - Lilirairie Hachette et Cie, 79. loulevard Saint-Germain. 
Quelques hotions: forestirres à l'usage des écoles, par C. RABгTTE, inspecterr des Eaux et Forêts. - Librairie Livoir-Hennuy, Vouziers.

Hanuel de sylviculture et uméliorations pastorales à l'usage des instituteurs, par F. CARdot, inspecteur des Eaux et Forêts, et C. Frrmas, inspecteur primaire. - Félix Alcan: érliteur, 108, boulevard Saint-Germain, Paris.

Petit manuel sur les forêts et les améliorations pastorales, à l'usage des écoles pri. maires du département du Far, par J. SALVADor, insperteur des Eaux et Forêts. Paul Tissot, fiditeur à Toulon.

P'etit manuel sur les forêls el les ameliorutions pastorales. il l'usage des inslituteurs

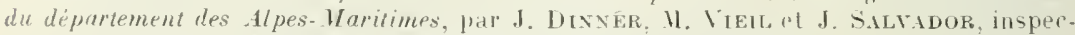
teurs des Eaux el Forêts. - Imprimerie J. Ventre, à Vice.

Petil manuel à l'usage des saciétés scoluires pastorales farestières de Franche-Comté, par E. Cardot, conservateur des Eaux pl Forêts. - Imprimerie P. Jaçuin, Besançon.

Les essences forestieres (essences feuilhes, essences résineuses), deux volumes, par IIenri Lovbré, secrétairé de la Bibliothèque et des Archives de la Société des Agriculteurs de France (Encyclopédie scientifique des aide-mémoire). - Masson et cie. éditeurs, 120. boulevard Saint-Grmain; Gauthier-Villars et fils, imprineurs-éditeur: 55, ruai des Granıls. Augustins.

Enseignement sylva-pastural (précis d'histuire forestière — utilité des forêts _botanique - notions élémentaires de sylviculture - pépinières - pâtarages et prés. bois - précis de législation forestière), par A. UnBDenstock, secrétaire de la Commistion des Pelouses el Forêts du Touring-Club. - Journal des Instituteurs, 1, rue Dante.

Terres incultes, mise en craleur par les amélinations pastorales et par le reboise-

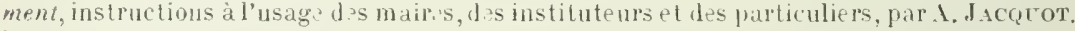
inspecteur des Eaux et Forêts. - Imprimerie Cavaniol, à Chammont.

Sylviculture, manuel pratique à l'usage des propriétaires fonciers, les régissenrs: de donaines forestiers, des reboiseurs el des élèves des écoles d'agriculture, par A. Jacucot, inspecteur des Eanx et Forêts. - Berger-Levrault, éditeur, 5 , rue de: Beallx-Arts, Paris.

Le reboisement dans l'arrondissement de Toul, par P. HERRotot, sous-préfet. Lihrailir Mar Imhaus of lie, io, rue de soine, Paris.

\section{RÉPARTITIOY DES VËGÉTAUX LIGNELX EN FRANCE}

\section{OUVRAGES RENFERHANT DES INDICATIONS GENERALEK SUR LA REPARTITION DES ESSENCES EN FRANCE}

Mathier. - Flore forestière, ie élition, revie par Fliche (1897).

BOPPE. - Traité de sylviculture (1889).

BOpPE et JoLYet. - Les forêts (1900).

Frox. - Sylviculture.

Desuxtzex. - Traité pratique du rebuisement el du gazonnement des muntagnes (1882). D) EScomBEs. - La défense forestière et pastorale.

Statistique forestiere. Administration des forêts (1878), ch. VIII, 1). 6,j-102.

20 QUELQUES TRAVAUX RECENTS RENFERUANT DES DONNEES NOUVELLES SUR LA REPARTITION DES ESSENCES ET I A METHODE A EIILOYER POUR L'FTLUIER

FrallaUlT, - Projet de carte bolanique forestiere et agricole de la France (" Bulletin de la suciete botanique de France p, tome Xl.l (1894). 
INTERNATIONAL I91:;

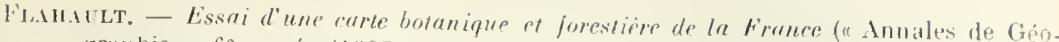
graphie n; 6e année (1897).

Tessier, - La forêt eommunale de l/âcot (Tarentaise) ("Revue des Eaux of Forêts p. tome XIIV (1905).

S.ALVADuR. - Introduction à une étude sur la distribution des principales essences foreslieres dans les Alpes-1/aritimes (. Revue des thax et Forêts"), tome XIAX (1910).

S.ILvador. - Observations sur le climat, le sol et les essences foresticres de la ane miditerranópnne des .llpes-Ifaritimes ("IRevue des Eawx pt Forêts", lome LI (1912).

30 TRAVAUA ETRANGERS SUP LA REPARTITION DES ESSENCES

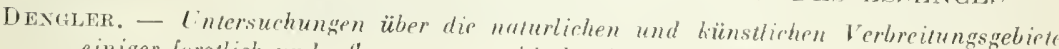
einiger forstlich und planzengeographisch wirhtigen Holzartenein Word-und Hitiel. dertschlond.

I. Die Horizontatrerbreitung aler Kefefer (Pinus Silvestris L.) (190i).

11. Die Horizontaiverhreitung der Fichte (Picea excelsa Lk.) (1912). 111. Die Horizontalverimeitung der Weistanne (Abies peetinata D(j.)
(1912).

COAz rt SCHRoter. - Amweisung zur Erforsehung der Verbreiung de wildwashsenden IVolzarten in der Sehweiz (1902). - Recherches sur la répartition des plantes ligncuse.: croissant spontancment en Snisse, élahorées et publicées par ordre du déplortement fédéral de l'Intérieur. Livraison Ire. Territodre fu canton de Genève.

Ricklr. - Die free in der Schweis (190y).

\section{ALLONGEMENT IDES RÉVOLUTIONS DES TAILLIS ET TALLIS SOUS FUTAIE}

Baddruldrt. - Dictionnaire de's Eaux et fiorêts. Anenagement.

II CFFEL, - Economie forestiere, tome III, Paris, laveur (1907),

\begin{tabular}{c|l} 
Resue & Année 1895, Novembre, lidge 510. \\
des & Annce 1896, Nai, page 218.
\end{tabular}

Euux et Forêts \ Année 1898, Février, page io1.

Bulletin de la Année 1905 No 1, page 38.

Sopiétri foresticr

de Franche-Comté Innée 1908, No 7, page 632.

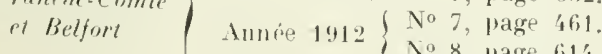

Die Forsten und Holzungen

im deutschen Reich,

nach der Erhebung des Jahres 1900 ,

barbitet in kaisertichen statischen Amt.

Berlin

Virlag. von Püttkamel

and Miihtbrecht

1903.

La Production et la Consommotion des bois d'cusre en suisse, publite, au nom de l'Inspection fédérale des Forêts, gar M. Decoppet, professeur de l'bole Ponytechuique

(to Zurich $(1312)$.

\section{AMELIORATION IES TAILLIS A FAIBLE RENHEMENT}

\section{REVUE DES EALX ET FORETS}

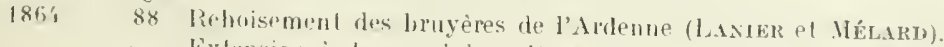

Extrasion à domer da la culture du sapuin perfine : 
295 BROILLIARD

1847 t0 Contersion d"un taillis en sapiniere (Brolliard).

14012609 Jême sujet (Brollutard).

\section{BEILETIN DE LA SOCIETE FORESTI ÈRE DE FR.INCHE-COMTÉ ET BELFORT}

1896 '28 Conférence de H. Cardot.

1899 155 Confépence de M. Rexarher.

1 Jémoira de U. MArre.

$1901-190283$ Utilitédel'introduction dusapin ef le l'épicéa dans les taillis médiocres de la région jurassienne (M. Bouvet).

372 Introduction des résineux dans les taillis ( М. (raz.Ix).

569 Mémoire RUxACHER.!

1903-190' 192 La propagation des sapins lans les feuillus (II. GraDiL).

1905-1906 565 Conférence de M. Grexier.

1907-1908 653 Conférence de M. ALGAx.

1909-1910 12 Taillis de montagne (Brotlli.trD).

1910703 Conférence de M. Chatder.

713 Conférence de M. Thioliter.

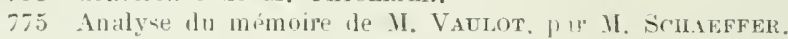

\section{DITERA}

Règfement général des Commissair s du mi dépulés par lettres patentes du 14 norembra 172' pour la réformation des Eaux ef Forêts do la proviure du Dauphiné.

Traitement des bois en France ì l'usage des particuliers (BROILLIARD).

Compte-rendu du Congres international de Sylviculture de 1300 (Rapporl de

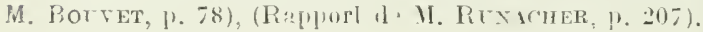

\section{TALLIS IDATACIA}

CH. BALTET. - De l'.1etion du froid sur les végélaux pendant l'hiser 1879-1880 (extrait du

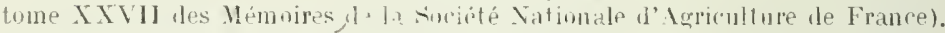

BeIssxer. - Handbuch der Nadcholz hunde, 2e édition (Bertin, 1909 ; imp. P. Parey).

Сн. Bommer. - L' Arboretum de Terweren (Bruxelles, 1905 ; imp. F. et L. Ternen).

Ch. Broilliard. - Le Traitement des bois en France (Paris el Nincy, 189 ' : édit. BergerLevanlt et Cie).

Pierre Biffault. - Elude sur la côte el les dunes du Médoc (Souvigny, 1897 ; imp. Jehl.)

F. Caquet.- Les Reboisements par l'acacia (1887), journal La France Forestirre, de 1883 à 1887 (Mémoire présenté à la Société des Agriculteurs de France en 1910).

A. Frox. - Sylsiculture (1'aris. 1903 ; édit. J.-B. Baillière et fils).

Ir K. Gayer. - Der Waldbau, édition (Berlin, 1898 ; imp. P. Parey).

D) J. HANx. - Allas der Meteorologie (Gotha, 1887 ; édit. J. Perthes).

Il ARTIc. - Traité des maladies des arbres, traduetion par J. Gerschet el. E. Ilenry (Paris et Nancy, 1891 ; édit. Berger-levrault el Cie).

Matriey. - Traité d'erploitation commerciale des bois (I'aris, 1 yo6 ; élit. L. Laveur).

A. Mathiet. - Flore forestière, '́t élition revue par P. Fliche (Paris. 1897: édit. I.- B. Baillière et fils). 
P. Mounlefert. - Trailé de sylviculture (Paris, 1yó ; élit. Félix Alran).

CH. A. SARGEXT. - Sixtecn maps accompanying report on forest trees of North America, carte 15 (édit. Department of the Interior, (ensus Office).

CH. S. Sariant. - The Silva of North America, volume YII, page 90 (Boston et NewYork, 1948; édil. lloughtun, Mifllin et Cie).

Sevrre. - Elude sur le robinier, publiée par la Société forestière de Franche-Comté et. Belfort (Bullelin du $1^{\text {er }}$ mars 1911, tome XI, no 1).

THÉLd. - Volice sur les étnis de mines en France (Paris, 1878: Imprimerie Nationale).

E. VADAs. - L'Importance du robinier dans la foresterie hongroise, traduction par E. Hen ry (Annales de la Srience agronomique française et étrangère, 1911, page 92).

Vauzot. - Le Robinier faux-acacia, histoire, emplois, végétation, traiternent (Paris, Laveur, édit.)

Comte A. Visart et Ch. Bomer. - Rapport sur l'introduction des essences exotiques en Belgique (Bruxulles, 1909 ; imp. (ih. Bulens). 


\section{DEUXIE.ME SECTION}

\section{ASSURANCES CONTRE LIYCENIDE}

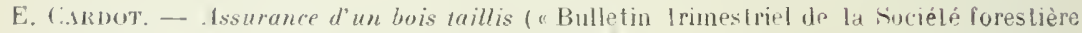
française des Amis des Arbres n; no 7ł, 1911).

F. DAVID. - Les Incendies de forêts (Journal "Le Bois ", du 18 mai 1911).

F. Lerove. - Issurance des forêts contre l'incendie, arec commentaires, lar R. Roulleau (26 p.) (Le Mans, Benderitter, 1911).

F. DERoYE - Assurance des plantations résinenses contre l'incendie, 12 11. (Besançon, Jacgues et Demontrond. 1912).

P. Lesconaes. - La Défense forestire el pastorale, tome XV, l'a p. (l'aris, GaullierVillars. 1911).

I'. Desconbes. - Relevement de la sylvirulture privée, 15 p. (Bordeanx, Gounonilhou, 1913).

1. JACQuot. - Assurance des foréts eontre l'incendie ("Bulletin trimestriel de l'Office forestier du Centre el de l'Ouest ", novembre 1909 (Le Nans, R. Roulleau, édit.).

11. Lécurle. - Assurance des bois sur pied "Bulletin trimesl riel de la Société forestière

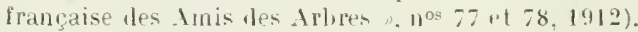

F. MARre. - L'Assurmee conture les incendies de forêts (Jumrnal l'"Eclair" dı 16 juillet 1912).

X... - Assurance contre l'incendie des forêts en Allemagne (Journal "Le Bois" du 23 mal 1912).

M. PeRrot. - L'dssurance forestiere officielle ("Revue forestière ile France ", 1911, [). 11 ).

\section{IMPOT' FORESTIER}

\section{FRANCE}

Arxot:ds. - L'Evaluation du resenu imposable des foréts, 191 8 (l'aris, Laveur).

Gotglit. - Les eharges qui pèsent sur la propriété forestiére (Grenolile, Édouard Vallier).

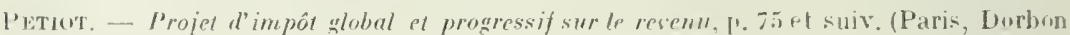
ainé). 
Rotldeat el Arsoldd. - Revision de l'impôt forestier (Cruide pratique prur les propriélaires de bois, P'aris, Laveur, 1910).

Année Pages

\section{REVUE L'ECONONIE POLITIQLE}

1910 5it et suiv., 581 et suiv. Durarcox. - Le Fise el les Forêts.

\section{REVIE DES EALA ET FORETS}

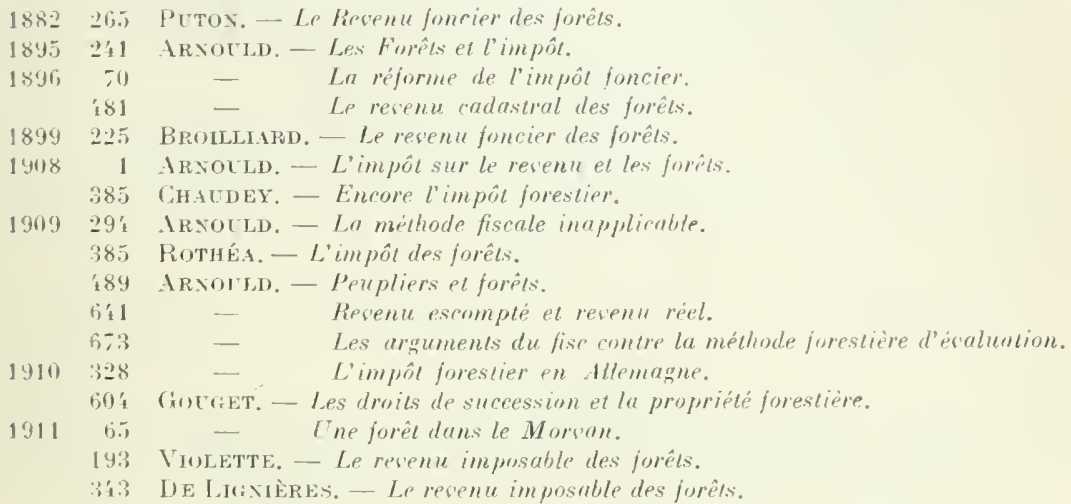

Années Hois 1909 décembre $1911 \mathrm{mai}$

\section{REVUE POLITIQUE ET PAREEIENTAIRE}

\author{
D. ZouLA. - Chronique des questions agricoles.
}

Dutirços. - La loi.jrançaise el les questions forestieres.

\section{BULIETIN DE LOFFICE FORESTIER DU CENTRE ET DE LOUEST}

Anuées Pages

1908 85 RotlleAt. — L'impôt forestier.

1909283 BRoILLIARD. - La jeuille ou revenu foncier.

337 ARvotLd. - L'évalumion du resenu forestier.

378 - Revenu forestier dì à l'aménagement.

ي19:3 Rouldwit. - Revision de l'impôt forestier.

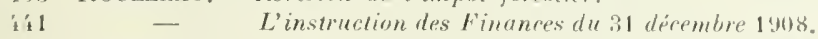

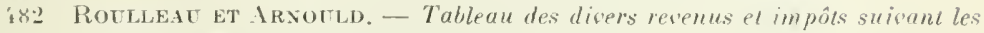
dicers procédés d'ésalnation.

†il2 IrvothD. - L'avis officiel de l' 1dministration des contributions directes.

fi2) Roclleat. - In coup de Jarnac lu fisc à propos de l'impấ forpstier.

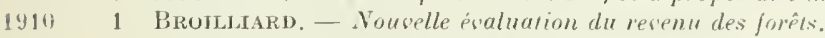

19 La circulaire des Finances du 17 septembre 1909.

17.2 RoublaAu. - Distinction du resenu forestipr en deur parties: foncier, copiunl. bois.

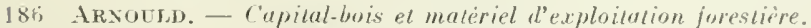

132 Roullbau. - Les droits de succession sur les forêts.

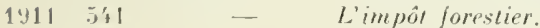

tíg - Limpôt forestier.

\section{BUILLTIN DE A A SOCIÉTÉ DES IGRICULTEURA IOE FRANCW}

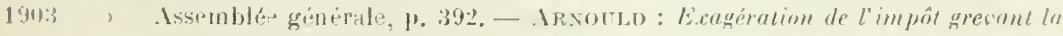
propriélé forpstivire.

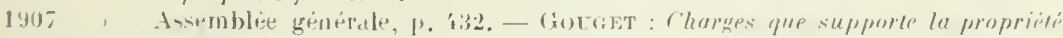
jorestivie. 
Aunées Pages

1908 " Assemblée générale, I'p. 161 et 511. - Arvotud : T'ceu sur l'écaluntion du resenu foresticr.

710-717 Documcnts sur les charges de la propriété forestière.

1910 "Assemblèe générale, P. 113. - Arvould : Distinrtion des deux res'enus forestiers; le revenu foncier et lc resenu du capital-bois.

175 ARNOULD : Réponse aux arguments du fisc.

184 HrRsCH : L'instruction sur l'éraluation des propriétés non bâties.

1911 " Assemblép générale, 1. 602. - Communications relatives à la nouvelle évaluation de la propriété non bâtie pour les terrains classés comme bois.

¿zo) Gouget : Droits de mutation par décès sur les forêts.

\section{BULLETIN DE LA SOCIETÉ NATIONALE D'AGRICULTURE}

1909906 D'Arbots De Jubanville. - Eraluation des resenus de la propriétéboisée. 1910 280-352 Le Riesenu imposuble des forêts.

1913110 IMBART DE IA TOUR. - La surcharge de l'impôt forestier.

\section{BULLETIN DE IA SOCIETTÉ FRANGAISE DES AMIS DES ARBRES}

Aunées

19]1) no 72 E. Cardot. - L'impôt forestier.

19]1 n०73 - Encore l'impôt forestier.

1912 no79 E. Chatelaix. - Les Bois du Morvan et l'impór forestier.

\section{REVUE DU TOURING-CLUB}

Années Mois

1910 octobre H. DEFERT. - Ceci tuera rela,

\section{BULLETIN DE LA SOCIFTEE FORESTI ERE DE FRA YCIIE-COMTÉ ET BELFORT}

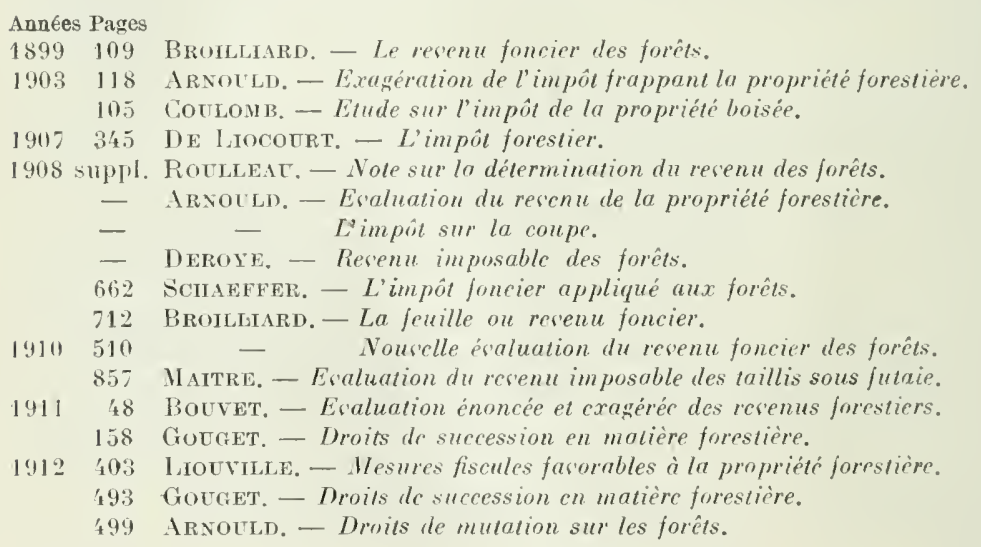

\section{PRESSE QUOTIIIEN VE}

Les Débats : 20 novembre 1909. - Les forêts et le fisc.

20 décembre 1909, 5 février 1910,7 février 1911. - Les forêts et le fisc.

Le Watin : 11 décembre 1909. - Le fisc tue nos forêts.

Paris-Centre: 8 septembre 1910. - Droits de succession en maticre foresticre.

Le Temps : 5 janvier 1910. - La déformation el l’impố foncier de la propriété boiséc. Journal du Loiret : 28 l'évrier, 5 avril 1910. 
IOURNAL "LE BOIS"

Nombreux articles, voir notamment: 31 a0ût 1907, 4 janvier 1908, 22 février 1908 , 31 mars 1910.

\author{
JOURNAL OFFICIEL
}

1907 Chambre, Joc. parl. A. E., no 1352, p. 416. Proposition de loi de $\%$. Fernand David (exposé des molifs).

1908 Chambre, débats S. O., p. 613. - II. Renard, M. Cuillaux.

- doc. parl.S. O., n 1385, P.618. - Rupport de M. Iigouroux.

1909 - débats S. O., p. '37. - .I. Perroche, W. Caillanx

- - S. E., p. 2998. - M. Bonnesal.

Sénat, doc. parl. S. O., no 185, D. \$45. - Rapport de .11. Alediffred.

1910 Sénat, débats S. O., p. 287. - M. Aueliffred.

Sénat, débats S. O., P. '09. - W. Ruau.

1911 Chambre, débals S. O., 1. 1843. - M. Maurire Dutreil.

\title{
LOPINION
}

30 netolnte 1909. - Le fiser et le bûcherom.

\section{ALLEMAGNE}

ENDres. - Handbuch der Forstpolitil (1905, Berlin, chez Springer).

WÉBER. - Die Besteuerung des Waldes (1909, Francfort, chez Saıerländer).

BERICHT UBER DIE V. HAUPTVERSAMMLUNG DES DEUTSCHEN FORSTVEREINS ZU EISENACH 190' (CONGRES FORESTIER D'EISENACH)

ENDRES, P. 105. - Graner, P. 129. - WhMexaUer, j. 136.

\section{HLLGEUEIVE FORST. LVD JAGDZEITUNG}

$1895 \quad 219$ WIMMENAUER.

189838 Erdmann. - Die Besteuerung der Forsten.

1900208 WIMMENAUER.

1906 Is' FREY. - Zur Frage der I'aldbesteuerung.

DEUTSCIIE FORSTZEITUNG

1902 901 Fricke; 1). 982, Gonbesser.

HALBIONATSSCHRIFT FUR POIITISCHE BILDLNA

$1 \$ 11 n^{08} 15.16$ Wener. - Das Problem der J Valdbesteuerung.

MONATSSCHRIFT FUR DAS FORST. UND JAGDWESEN

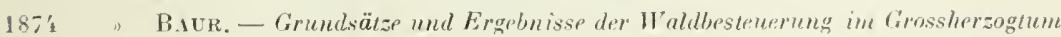
Hessen.

\section{SIIVI}

1911 5 Trebeldahr. - Zur Waldsteuerfrage.

$n^{\circ}$ 10 GARTNER. - Zur Waldbestenemugfrage.

\section{TIIARANDTER FORSTLICHES JAHRBUCII}

Vol. 27 1. 71 JudeICI. - Die Bestenerung der Waldwirtsehaft.

Vol. 38 I. 95 JuDEICI, - Die Auwendung der Einkommenstener anf die Waldvirtschaft.

\section{FORSTWIRTCHAFTICHES ZENTRALBIATT}

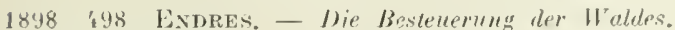

1900539 Uniril. - Dir Besteurmug der Waldungen. 
Anné ss Pages

1901539 ENwRE4. - Die Besteuerung des H'aldes.

1901 " WEBER, - I ber die Bestenerung des Italdes.

1901559 WIMmSACR. - Zur Waldbestewerung.

1906 9 HATSRATH.

\section{AUTRICHE}

ZENTRALBIATT FUP DAS GESAMTE FORSTWESEN

1895 195 RiEBeL. - C Cer die Besteuerung der Wälder.

293 Hufsige. - Zur Frage der Besteuerung der Wälder.

19119

BACER. - Steuerfiragen der Forstwirchaft.. 


\section{()LTTHEME SEGTION}

\section{PETITS TRAVAUX}

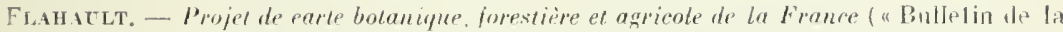
Société botanique Je France n, tome XILI, 1894.)

Finhatlt. - Rapport sur les herborisations de la Soriétr botunique de France dans la callie de l'Tbaye (Ibid. tome XIIV, 1897).

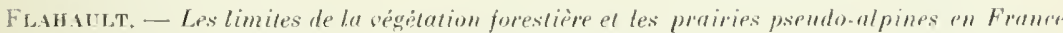
("Revue des Eatux " Forêts tome XI, 1901).

\section{TOURBIÈIRES - NARÉCAFES}

W. BüHLER, - Die V'ersumpfung der Wälder mil und ohne Torfbildung umd die ITieder. bestopkung derselben mil besonderer Hinsicht auf den Srhwarswatd (Tühngen, 1831).

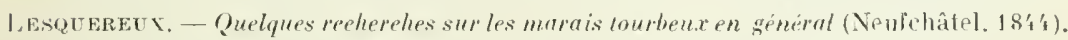

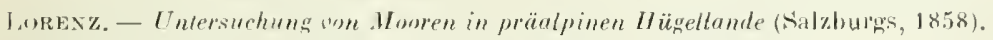

SENDTNER. - Die legetalionsserhälmisse des bayrichen II aldes ( 18660 ).

Bourue.tT. - Les Tourbires du Jura (Joligny, 1885).

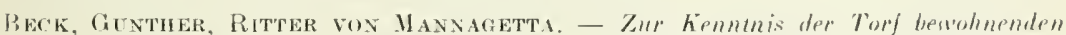
Föhren Viederösterieirls (Vienne, 1888).

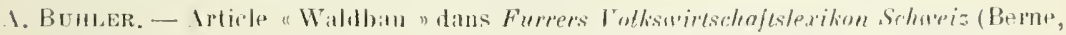
$1890)$.

12rint. - Empliehll sirh der Forsllimllur auf Horhmooren (Milteilıngen, 1891).

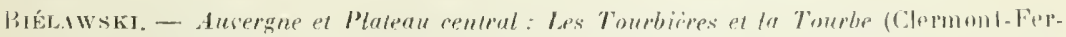
l'and, 1892).

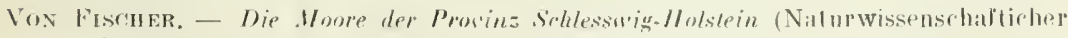
Verein, IIambourer, 1891).

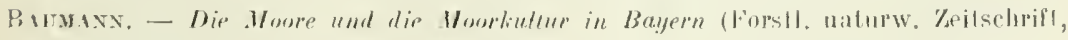
$189 ;-1898)$.

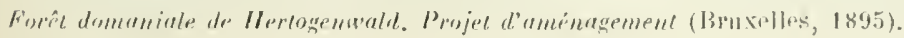


Rabaxx. - Wald und Woor in den russichen Ostseeprosinzen (Furst- und Jagdwesen, (Berlin, 1895).

Maviel - Die Moore des Eragebirges (ForstI. naturw. Zeitschrift, Munich, 1896).

Bulletin de la Société centrale forestiere de Belgique (1895 et 1900).

REPps. - Ueber die Kulur der forbweide auf Voorboden (Mitteilungen, 1900).

TACKE. - Die Bewirthschaftung der im Wald gelegenen Grünlands- und Hochmoore (Zeitschrift für Forst- und Jagdwesen, 1900).

Kr.HMER, - MitteiImgen (1902 et 1908).

Wouncis. - Zeitschrif für Moorkulur und Torfversertung (1903).

QuLLY. - Morflora und chemische Zuzammensptzung der Böden (1904).

FruH et Schroter, - Die Morre der Schweiz (1) (Beme, 190').

PFoB. - Zur Aufforstung der Hoehmoorflärhen (Zeitschrift für Moorkuftur und Torfver, wertung, 190\%).

QULLY et PAlL. - Botanische und chemische Beschofenheil verschiedener Hoorflächen (1905).

MuLLER, - Beitrag zur Bodenkunde im Chiemgau (1906).

Liechti, - Beobachtungen auf dem Gebiele der Moosauforstungen (Schweizerische Zeitschrift für Forstwesen, mai 1906).

PAUL. - Die Schwartzerlen Bestände des südliehen Chiemseemoores (Naturw. Zeitschrift für Land- unif Forstwirtschaft, 1906).

Z1 LeINIncex. - Die llaldvesetation präalpiner bayerischer Moore, insbesondere der südlirlien Chiemseemoore (Munich, 1907).

l’oxnsoki. - Erfahrungen auf dem Gebiete der Korba'eidensuch (Berlin, 1907).

Vus Tubeuf. - bürgungsversuch zu Kiefern auf Horkmoor (Naturw. Zeitschrift für Forst. und Iandwirtschaft, 1908).

Vúlis, - Les Hautes Fagnes de l'Hertogenwald (Bulletin de la Suciété centrale forestière de Belgique, janvier el février 1908).

Рғов. - Ueber die Kullur der Korbreide auf Horboden (Mitteilungen, 1909).

Chancerel. - Action des engrais sur les s'ésétaux ligneux (Paris, 1909).

Programme du VI: Congrès de l'Union internutionule des stations de recherches forestières (Brixelles, 1910).

Berscn. - Handluch der Moorliulur, chap. VI (Vienne et Leipzig, 1912).

Schribatx. - Cours d' Igriculuure générale professé à l'Instilut national agronomique, (1912).

PARDÉ. - Rapports annuels sur les tracuur pxécutés el les résultals obienus dans le champ d'expériences forestiorres de liresles (1968 à 191?)

\section{IULYES}

\section{WUNES DE FRANCE - GEOLOGIE ET GÉVEPALITÉ}

If enki Antigue. - le l'cnsahissement par la mer des vobtes de France entre Bayonne et Royan (Artes Soc. Imnéenne de Bordeanx, t. XXIX).

BAT URIMONT. - Etude des différents sals du départrment de la Gironde (Bordeaux, Croumonilhou, 187i).

(1) Cet olvage contient un index bibliographique tris conplet concernant les tourbière: 
B.AUDRIMOxT et DELBOs. - Examen comparatif de lu composition chimique du sable des dunes ct de celle des cendres des végétaux qui rroissent à leur surface (Congrès de l'Association française pour' l'avancement des sciences, 1872).

Cin. Béstro, - V'ariations de la Conbre (" la Géographie ", 1905).

BrÉMontier. - Mémoire sur les dunes et particulièrement sur celles qui se trouvent entre bayonnc et la Pointe de Grave (Paris, thermislor an V (1797); Wémoire ('e) relatif aux dunes de la Manche et de la Mer du Nord (20 pluviôse an XII (1803).

Pierre Buffidut, - Etude sur la côte ct les dunes du Hédoc (Souvigny, Jehl, 1897); Les Crands étangs littoraux de Gascogne (Bulletin lle Géographie historique pt descriptive, 1906); Le Littoral de Grscoune (Congrès des Sociétés françaisps de Géographie, Bordeaux, 1907); Dunes intérieures de Gascogne (Revue de Géographic commerciale, Bordeaux, 1912 ).

,H. Cildérax. - Vote sur une formation d'eau douce an lieux-soulac (Actes Sor. linnéenne de Borleaux, t. XXV).

Cinarlevoix de Villers. - Mémoires (5.5) sur l'établissement d'un port à Arcarhon, 1778. 1781, Mss (Bibliothèque municipale de Bordeaux el Archives, 29e Conservation des Eaux et Forêts).

DE CHOLNoKY.- Lois du transport des sables mourants (analyse par Achirmer dans la "Géographie " du 15 avril 1903).

R. CHUdeAt. - Remarques sur les dunes ( La Géographie ", 1911).

Eт. Clouzot. - Variations de la Combre ("La Géographie ", 1907).

DALIGNOx-DESGR.inges. - Emersion sur le littoral de Gascogne (Actes Sor. liuneenne de Bordeaux, I. XXXI): Les dunes de Gascogne, le bassin d' trcachon el lo baron de rillers, 1890 ).

E. Delfortrie. - Emersion des fonds de la mer sur les côtes de Gascogne (Actes Soc. linnéenne de Bordeaux, 1. XXVII); Empiètement de la mer sur la plage d' 1rcachon (Ilsidem, t. XXIX, 1874); Notes supplémentoires sur l'afjaissement des côtes de Gascogne (Ibidem); Noureaux documents sur l'affaissement des côtes de Gascogne. (1)irlem, t. XXXI); Les dunes littorales du Golfe de Gascogne (Ibidem, 1879).

DTFF.ıRT. - Le bassin d'Arcachon (Congrès des śociétés françaises le Géographie, Bordeaux, 1895$)$ : Les anciennes baies de la côte de Gascogne, de la Gironde à l' Adour (Bullelin de lic Société de Géographie, Bordeaux, 1896); Les embouchures et les lits de l'Adour avamt le $\mathrm{xvI}^{\mathrm{e}}$ siècle (Ibiden, 1897); Distribution góengraphique des dunes continentales de Gascogne (Ibidem, I898); Carte de Masso (1bidem, 1898); Réponse à M. Saint-Jours sur l’âge des dunes et des étangs (Ibidem, 1901); Lacs d'Hourtinet de Lacanau (Ihidem, 1901); La carte de Claude Masse (Bulletin the Géographie historique et desrriptive, 1903); Les formations éoliennes du platenu landais (Ibilem, 1899 et 1905$)$; Iariations du cap Ferret et de la passe d'Arcachon. (Ibidem, 1908); Origine marine des lacs littoraux gascons (Ibidem, 1910); Les dunes continentales de Morct-sur-Loing (Ibidem).

Duffotr-BAzix. - Monographie agricole du département des Landes (Bulletin du Ministère de l'Agriculture, 1899).

Dufourcet. - Formation du sol du départemcut des Landes (Balletin de la Fociéló le Borila, Dax, 1897 et 1898 ).

DTRÈGxE. - Les anciennes forêts du littoral et la spontanćité du pin maritime dans les dunes de Gascogne (Journal d'Histoje naturelle de Bordeanx et du Sud-Ouest, 1888); Dunes anciennes do Gorsogne (Artes Soc. linnéenne, tome LXVI] (1890), tomes LXXVI, XLVl et LXXXVI (1895 et 1896); Sur la destruction de deux áges dons la formation des dunes de Grascogne (Comptes rendus de l'Acartém ie des sciencer. $1890)$; Sur le mode de formation des dunes primaires de Gaseognc (1billeur, 1897); Dunes primitives et forêts antiques de la côte de Gascogne (Bordeaux, Counouilhols.

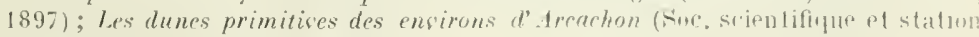
zoologingur al'Arearion 1896-1897). 
DUtrait, - De mutationibus oræ lluvialis el maritime in peninsula medulorum (Thèse. Bordeanx, Vve Cardorel, 1895).

La Girande Eneyclopédie. - Articles: Gironde et Landes.

L.-A. FABRE, - Les ensablements du littoral gascon (Comptes rendus de l'Académie des Sriences, 1900); Le courant et le littoral des Landes (Ibidem, 1902); Les plateaux. des Hautes-Pyrénées et les dunes de Gascogne (Comptes rendus du Congrès internalional de Géologie de 1900); L'Adour et le plateau landais (Bullelin Géographique historique et descriptif, 1901); La magnétite pyrénéenne et les sables gascons (Ibidem, 1902): Les Galets des pluges gasconnes, ln Pérnéplaine landaise (Ibidem. 1903 ) : Le sol de la Gascogne (La Géographie, 1905).

FALLoT, - Les régions naturelles de la Gironde (Congrès national des Sociétés francaisen de Géographie. Bordeaux, 1895); Sur une carte géologique des environs de Bordeaıx (Bulletin de la Société de Géographie commerciale de Bordeaux. 1896): Esquisse géalngique d" département de la Girnnde ("Feuille des jeunes naturitlistes ", 1889).

Fleury, - Projet d'amélioration pour une partie du for arrólissement de Bordeaux. pri. senté au Consail dudit arrondissemenl le 26 messidor de l'an VIII (1800).

Paul Girardix, - Les Dunes de Frunce (Annales de Géographie, 1901).

E. HaRí.́. - Dunes parallèles au cent sur la côte de Gascogne (Comptes rendus sommaires: de la Societŕ géologique de France, 19 février 1912).

II ITG. - Traité de Géologie (Armand Colin, Paris, 1907).

Ilautreux. - Sables el pases de la Gironde (Bulletin de la Societé des Sciences de Bor. deanx, 1886): Cötes des Lundes et bassin d'Alcaehon (Congrès lles Sociélés Trancaises de Géographie, Bordeanx, 1905); La carle de Masse (Bulletin de la Société de Géographie commerciale de Borleaux ", 1896):

E. JaCuUot, - De la recherche des eaux jaillissantes dans les landes de Gasmgne (Artes Soc. linnéenne de Borleanx, tome XXIV).

E. IACQUOT et V. RAtLIN. - Statistique minéralogique, géologique el agronomique du département des Landes (1877).

LABAT, - Les dunes maritimes et les sables littoraux (Bulletin de la société géologinue de France, Paris, 1899-1880); Forme des dunes en Europe et spécialement en France (łbirlem, 1890).

L.AFuxt. - Empiètements de la mer sur la plage d'Arcachan, réponse à M. Delforlrie (Actes Soc. linnéenne de Bordeaux, tone XXIX); Nouselles notes (Ibidem).

LALAxinE. - Constitution géologique du littoral océanique du Bas-.l/édoc (Bulletin de la Société de Géographie rommerciale de Bordeaux, 1910).

L.Aval. - Vémoire sur les dunes du Golfe de Gascogne (Annales des Ponts et Chaussées, 18:7).

l.INDER, - Etude sur les terrains de transport du départememt de la Gironde (Arles Soc. linnésnne de Borleaux, tome XXVI).

Méraud. - Mémoire sur les dépôt littoraux observès de Vantes à Bordeaux (Actes Sor. linnéenne re Bordeaux, tome XXI1).

De Paxidita, - Les landes de Gascogne et les delus de la Gironde (Bulletin de la Société de Géographie commerciale de Bordeaux, 1906).

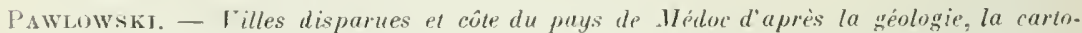
graphie et l'histoire (Bulletin de Géoglilphie historique el descriptive, 1903); Lt Pays d'Arert et de l'aur. (Ibidem, 190'); L'lle d'Oléron ì trasers les âges (Ibidem. 1905 ): Pays de Didonne, Talmondais, Larragnois (Ibidem, 1906); L'He th Yeu à travers les âges (Ibideın, 1910).

Pork maritimes de la France, lome VI, 2e partit (Ministem des Travaux publics, Inprimerir Vationitle, 1887 ). 


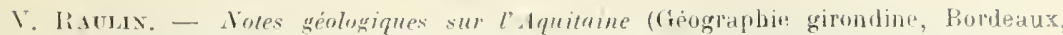
Chaumss, 1859).

E. Rechos. - Elude sur los dumes (Revile des Deux-Mondes, novembre 1863 , et Bulletin de la Sociéti de Géographic, 1865).

SArvage. - Dunes de Normandie (Bulletin de la Suciété gralogique de France Paris, 1880$)$.

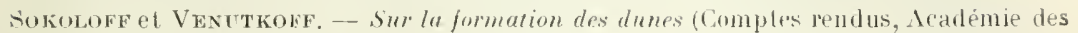
scitences, 1885$)$.

1. Thouset, - Le bassin d' freachon (Revue Ies Deux-Mondes, 1893 ).

Vissiblère. - Los dunes girondines (F̂tule agricole, Porleäux, Firel, 1889 ).

J. Werscil. - Fenille de In Ruchelle, Poitou (Bulletin de Ja Carte géologique de Frantee, comptes reodus des collaborateurs, lomes XX et XXI, mai 1910, juin 1911 et mai 1912): La lourbe litlorale du Croisie (Bullelin de la société des Srienrea naturelles de l'ouest de la France, Nantes).

\section{DLNES DE FRANCE. - HISTOIRE ET GENERILITEX DENELOPPEMENT ECONUMIQTE}

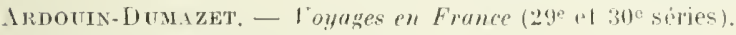

B.urain. - Tariélés bordeloises (Borleaux, 1784-1786).

G. BEAURAIX. - Quelques fuits relatifs à la jormution du lithoral des landes de Grascogne (Revue de Géngraphie, 1891 ).

1. Bert. - Note sur les dunes de Ginsogne (Ministère de l'Agrienllure, Imprimeria Vationale, Paris, $190(1)$.

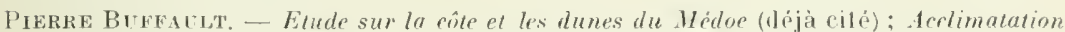
de dicers régétaux dans les dunes du llédoc (Revul: des lianx et Foròls, 189z); Les Carde-fen et leur utilisation (Ibidem, 1901); Pour nourrir du bétail dans les dunes (Revue agricole illustrée, Bordeaux, 1905); Arbres pt cultures sur les sables de Gascogne (Bordeawx, Pech, 1908); Les déluts de lu fixation des dunes; les essais de Brémontier ot I'eyjehan; la Commission des dunes (Revne philomilique le Bordenux el du Sul-0uest, 1904-1905); La marche ensahissante des

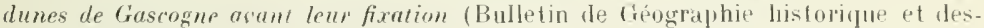
('ipiptive, 1905$)$.

Cilambrelext. - Les landes de Gascogne (Paris, Bandry, 1897) : Sul l'étal acluel des dunes du golfe de Biscaye (Comples reudus de l'Aradémie des Sciences, 1892 );

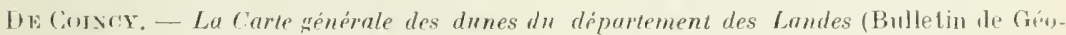
graphit histurique et deseriptive, 1908); Note sur les Ateliers de semis des dunes de la Gironde (Ibinem, 1909); Nole sur les ateliers de semis des dunes du dépurtement des Landes (Congrès lles Sociétés savantes, 1910 , Sciences).

Cuzıco. - Les grandes landes de Gaspognt (Bayoune, Lamaignière, 1893).

P.-H. Dorgar. - Histoire politique, religieuse el lithraire des Landes depuis les temps les plus reculés jusqu'd nos jours (Auch, Foix, 1846).

Duristas. - La Grande montasne de la Teste-de-Buch (Annuaire du Cluh-Alpin-Françis, 1903).

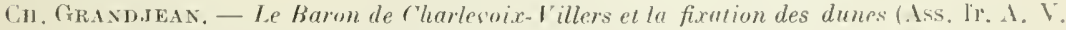
Sejences, 1895) ; les landes el dunes de Gascogne (1'aris, Rolhschild, 1897).

Baron D'HAlssez. — Etules administratives sur les landes (Bordeaux, (iassinl, 1826)

Dr ПАМ в.1т. - Quelques aperçus historiques el toposraphiques sur lo Teste-rle-liurle et ses environs (Actes de l'Aradénie de Bordeaux, 18il).

P. JoINNE. - Dirtionnaire géngraphique el administralif de la France (Tountes III et IV. $189 \%-1896)$. 
L.IFOND. - Les paysages des dunes, les travaux de défense contre l'Océan, I'endée et Cha. rente.Inférieure (Imprimerie Nationale, 1900).

A. DE I.A.JONKaIRE. Mémoires sur la mise en culture des terres ragues dans le département des Landes (Le Havre, Lemesle, 1856).

Dr A. laLESQUE. - Coup d'aeil rétrospectif sur les dunes mobiles du golfe de Gascogne et leur immobilisation dans les temps anciens et modernes (Bordeaux, Gounouilhou, $1884)$.

Matrice Martin. - La Cồte d'Argent (Bordeaux, Gomouithon, 1907).

Masse. - Mémoires sur les carrés d'Aunis, Snintonge, Bas-Poitou, Bas.Védoe, etc. (Mss., 1705-1721, Ministère de la Guerre).

Nezcret, - Notre-Dame de Soulae (Lesparre. 1865).

DE SAINT-AMANS. - Joyage dans une partie des Landes (Agen et Paris 1818).

Sarnt-Jours. - Port d'Albret; l'Adour ancien et le littoral des Landes (Perpignan, Lu. Irobe, 1900); Etat ancien du littoral gascon (Borleaux, 1901); Les Fleuves fôticr: de Gascogne (Bordeaux, 1902).

Thore. - Promenade sur la côte du golfe de Gásogne $(1810)$.

Tríndu. - Dunes du. Nord (Amiens, Jeunet, 1879).

\section{IJ. DUNES DE FRANCE. - TRAVAUX}

Pierre Buffault, - Etude sur la côte et les dunes du llédoc (déjà cité).

C. Granjean. - La dune lithorate (Revue des Eaux et Forêts, 1886).

Goursatd - Les landes et les dunes de Gascogne (Revue des Eaux et Forêts, 1879-1880).

LAFOND. - Les paysages des dunes et les trasuru de défense contre l'Océan (déjà cité).

De Vasselot de Régné. - La dune littorale (Revue des Ealix et Forêts, 1875); Le dunes de la Conbre (Imprimerie Nationale, 1878).

VIoLETTE. - Entretien de la dune littorale des Landes, trataux de défense contre la mer (Mont-de-Mlarsan, Dupeyron, 1899).

\section{DUNES DE FRANCE, - QUESTIONS JURIDIQUES}

J. BERT. - Note sur les dunes de Gascogne (déjà cité).

Pinrre Buffault. - Etude historique sur la propriété des dunes de Gascogne (Bordeaux. Gounouilhou, 1905): Questions de propriété, les dunes du littoral atlantique (Revue des Eaux et Forêts, 1910); Les Dunes ide Gascogne et la possession de l'Etat (IJ)idem, 1910).

Сн. Guуoт. - Cours de droit forestier (Vo Dunes et Revue des Eaux et Forêts, 1910).

DE L APAsse. - La police des dunes dans le département des Landes au début du Xixe sircle (Revie des Eaux at Forêts, 1905).

\section{DUNES IIORS DE FRANCE}

F. Ilbert. - Dunes du Chili (La Géographie, 1902).

Comte Batdissin. - Bericht über die Dünen der Inscl Sylt (Flensburg, 1865).

Becrusns. - Bericht über die Wittel, welche in Flandern und Holland angevendet werden, um dir Dünen zu, erhalten und zu serstärken (Hannoverischer Magazin, 1712).

BERENDT. - Geologic des Kurisches Haffes, Königsberg, Korh (18699).

BERandus. - Das Jünengebirt längs der Ostsee im Stettiner Rrgierungsbezirk (Das Muslitni, 1880$)$. 
SORFx BroRx. - Ueber die beste Art der allmähligen Versandung der Mehrung durch Dühnenbau und Bepflanzung Vorzubeugen, Sammlung Nützlicher aufsätze und Nachrichten die Baukunst betreffend (Berlin, 1798): Uebersicht der sortheilhaftesten Behandlung der Weidenarten (Dantzig, 1804): Ueber die vortheilhafteste Behandlungs-Methode bei Besammung und Bepflansung der hiefern auf sandigen Boden und Sanddünen (Dantzig, 1S07); Bemerliungen über die ormahlige und gegenwärlige Lage der preussisehen und Dantziger sudbältisehen Ufer (DanLig, 1808).

BuAxc. - Nole sur la formation des dunes sahariennes (Comptes rendus de la Société le Géographie, Paris, 1890).

Bu.ACFORD. - On the physical geography of the Great Indian Desert, and on the origin and mode of formation of the sand hills (Journal R. Society of Bengal, 1876).

Blesson. - Bemerkungen über Land und Dünen (Sluttgart, 1828).

Pierre Buffatrt. - Les Dunes maritimes allemundes (Rev゙ue des Eaux et Furêts, 1901, et Bılle lin de la Sociélé de Géographie commerciale de Bordeanx, 190's).

Cotris. - L'Mumidite du sol, principale cause des amoncellements de sable dans le Saharu (Comptes rendus de la Sociélé de Géographie, Paris, 1890).

DEHORs, - Voygge à Rubal (dunes du Médoc) (Bullelin de la Sociélé de Géograplupr d'Alger, 1904).

Doss. - Ueber Dünen der Umgegend son Riga, horrespondensblatt der Naturforschervereins (Riga, 1896).

Forsyth. - On the buried cities in the shifting sands of the Great Desert of Gobi (R. Gengraphical Sociely, London, 1876-1877).

Foste, W. Kixe U. A. - Dunes de l'Inde (Memoirs of the geologieal survey of India,

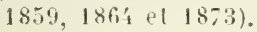

PATL Gerhardt. - Uferdeckungen durch Binsen, Rohr, Schilf und Weiden. Zeitschrif für Banresen (Berlin, 1897): Handbuch des deulches Dünenbanes (Berlin, Paul Parey, 1900 (riche bibliographie surlout allemande).

Augader. - Latle contre lensahissement des sables dans disers pays (Bultetin do la Direction de l’Agriculture et du Commerce, Tunis, 1901).

Tríon. IIARTre. - Ueber Bildung und Befestigung der Dünen (Berlin, 1830).

Ḧ̈ BBE. - Der Dünenbau der Königl. Preussischen Regierung (Berlin, Wilgand1. HempeI und Parey, 1879).

Karsten. - Leber die Warnemünder Düneapflanzung. Venen Annalen der Meelilenb. Landwirthschafls-Gesell (Rostock, 1817) : Mein letzles IVort übre die Warnemünder Dünen-Brpflünsung (Ihidem, 1820 ).

Кенцаск. - Vie Wanderdünen Hinterpommerns (Promethens, 1893).

KraUse. - Der Düncnban auf den Ostseeküsten West-P'rensens (Berlin, 1850).

LinMER. - Der erste Aufang einer regelrechten Dïnenhefestigung an der preussischen Ostseekï̈tc und die Sören Biörnsche Deuksehrift (Berlin, Ernst und Sohn, 189ti).

lonrá. - Contribution à la géologie des Pays-Bas (T. Les dunes intérieures, archires lu Musée Teyler); Binnenduiren en bodenberegingen (Jémoires de la soriélí belge de Géologie et IIyalrologrie, 1893).

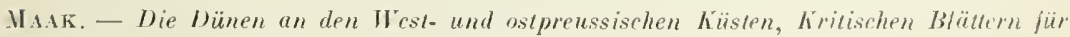
Forst- und Jagdwissenschaft (1865).

MeIEr. - Beschreibung des Tidwilder Flugsanddistriktes auf Seclamd, Faterland-W'ald. berichten (Altona, 1820).

Mudrer. - Beschreibung der hurischen Nehrung, Die fünfte Versummlung des PreussForstvereins (Wehlan, 1872; Königsberg, 1882).

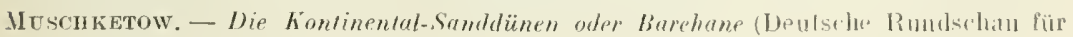
Groger. und Slatist., 1890$)$. 
Vox P.xxewrz. - Anlriung zum Anbau der Sandfäshen im Bimnenlande und auf den Strand-Dünen (Marifnwerder, 1832).

P.ARRAx. - Observations sur les dunes littorales en Algérie et en Tunisie (Bulletin de 1 a Sorciété géolngique de France, Paris, 1889-1890).

R.ızEBrR:. - Die Sandgewäehse der pommeruhen Küste (185;).

Risтот. - Les dunes mouvantes d'Aïn-Sefra (Paris, Baillière et fils. 1890).

Foldixn. - Sur les grandes dunes de sable du Sahara (Bulletin de la Société géologique de France, Paris, 1881-1882): Hydrographie et Orographie du Sahara algérien (1bidem, 1885): Grólogic du Sahara algérien (Paris, 1890).

SABвAL, - Die Dünen der südwestlichen Heide Hecklenburgs (Rostock, 1897 ).

Simsox scribser. - Land-Binding Grasses, Vearbook of the U. S. Department of Agric. (Washington, 1899).

SHALER. - Róle des dunes montre la puissance d'érosion de la mer (Bulletin of reological Siociely of America, $\left.1899^{\prime}\right)$.

SIEMsSEx. - Ueber die sicherste Befrstigung und nuzbarsle Bepflanzung der Dülen zu IVamemünde. Tersammlung der Naunrior. Gesellschaffi. (Rostock, 1803).

Sokorow. - Die Dïnen (Traduction allemante du professeur Arzruni. Berlin, Springer, 189'): Bibliographir des annes de Russie.

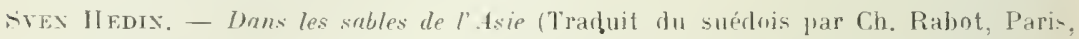
F. Juven).

Tellier. - Totes sur la fixalion des dunes et la proteetion des oasis dans le sud de la régrnre de Tunis (Bulletin de la Direction de l'Agriculture et du Commerre, Tuni-, $1901)$.

Tiтiss. - Mémoire à la Soriété des spiences naturelles de bantzig sur les moyens de firer los dunes (Lojpigig. 1768).

VIBora. - Beschreibung der Sondgerrächse und ihrer Ancendung auf der hüste son Jutland (Kopanhagen, 1789).

WEsselY. - Der Eumpäische Flugsand und seine Kultur (Wien. 1873).

Wilckoms. - Die Dünen Jütlands, Zeitehrift für. 1llg. (Erdkunde. 1863).

ZER_NECKE. - Der Dïnendurshorueh bei Veufahr in der frischen Velurung (hönigsherif, $18+0)$.

X... - Fixation de sables mousonts en Russie (Publication du Ministère impérial russ. la l'Agriculture. traduite en allemand par M. Knüpfferet analysée par G. Itiiffel dans la "Revue des Eamx et Forêts ", Paris, 190 ').

X... - La Esenela de Guardas (Fixation des dunes du .Mexique) (Revista forectal mexirana, marzi de 1910). 


\section{TABLE DES MATTERES}

Comité d'Honnenr...................... Pages

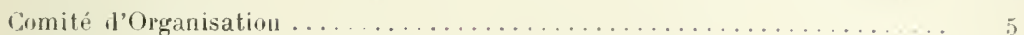

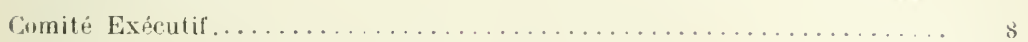

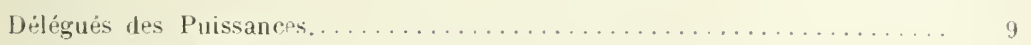

Délégués des Ministères............................ 12

Meinbres du Congrès............................... 13

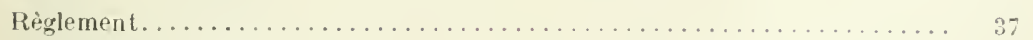

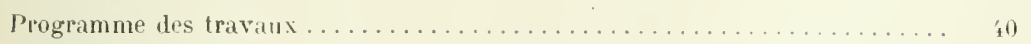

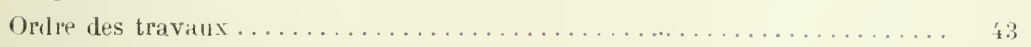

Limu des séances. . . . . . . . . . .

BUREAUX ET RAPPORTELRS :

Première section : Techuique Porestière ou sylvicultu!......... j.j

Denxième section : Eornomir et législation forestières.......... 197

Troisième sertion : Terhnolugie forestière. Commeree et industrip du bois......................

Quatrieme section : Grands travaux forestier. ............ 593

Cinquième section : De la forêt dans le développement: du fourisme tol l'érlucation asthétique des peuplés...................27

\section{(OMPTES REXDUS DES SEANCLS}

Sisture généralo alouverture du Congrès:

Discours de V. Batlif, Président du Turring-cilub le Fran. . . . . . is.

Discours to 11 . Clementel, Ministre le l'Agriculture.......... is

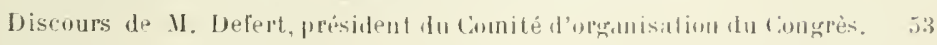

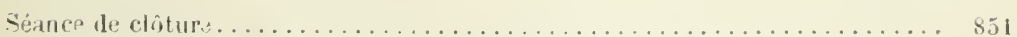

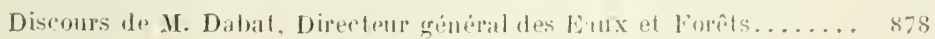





\section{TABLE ANALITIQUE}

A

Abris (voir : Tourisme (Aménagement de forêts en vue du).

Acacia (Les taillis d'). - Rapuort de M. Jolyet. .

Discussion : MIM. Banchery, Borgès, Caquet, Delahaye, Guillot, llickel,

Larue, de Lesseux, Mangin, Monnin, de Pottel'é, de Segonzac,

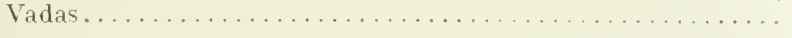

Acacia dans la foresterie hongroise (Importance de l'). - Communication de

II. Vadas. . . . . . . . . . . . . . . . . . . . . .

Affichage dans les forêts. Mesures à prendre. - Communication de M. Hoerter. - Discussion : MM. Chaix, Dupuich, Thiollier, Van te Poll .........

Affouage pastoral (voir: Améliorations pastorales).

Alliance de l'Arbre et de l'Eau. Lutte contre les inondations. - Ratuort de II. d'Auber de Peyrelongue . . . . . . . . . . . . . . . . . Discussion : MM. d'Auber de Peyrelongue, Carrlot, de Iarinage, Lefduet, Hongin, IIuret............................ Résumé d'une communication te II, de Rouvray sur le même sujet...

Allumettes (Bois utilisés dans l'industrie des) pour le débitage et la confection des boites. - Rapport de M. Simon . . . . . . . . . . . . . . . . . Discussion : MI. Pelletier de Martres, Poupinel, Simon...........

Améliorations pastorales. Création, restauration, entretien des fâturages. Amínagement et réglementation des pâturages appartenant à des commun unes ou collectivités. Affouage pastoral. Troupreanx transhumants. I chèvre.

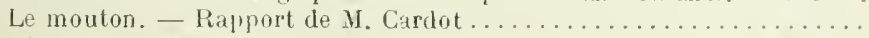
Discussion : MW. de Bélinay, Cardot, Dôle, Lallemand, Ieroq, Maitre,

Lartin, Picard, Pluchet .................... 602.607

Aménagement de forêts en vue du tourisme (voir : Tourisme).

Amérique Centrale (Production forestière de l'). - Communication de .1]. I) ésiré

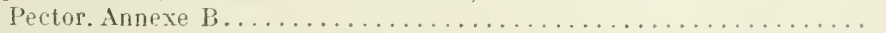

Arboretums (roir: Jardins alpins).

Arbres remarquables (roir: Tourisme (Aménagement de forêls on sue du).

Argentine (Les forêts naturelles de la République). - (ionféren fe dr. M. Charles

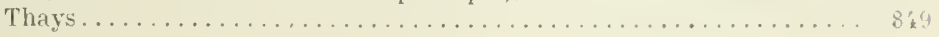


Associations d'utilité publique (voir : Etat. T'tilité de l'arquisition de. forêts).

Assurances contre l'incendie. - Rapport de MI. F. Deroye............ 197-201 Discussion : MII. Delahaye, Deroye, Descombes. de Mentque, Roul-

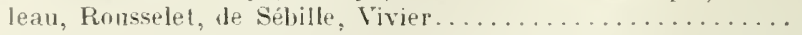

Australie-Ouest (Ressources forestières de l'). - Communication de sir Newton Iloore. Annexe C........................... $890-89$.

Avalanches (voir: Grands trasaux).

Bancs (voir: Tourisme (Aménagement de forêts en sue dlu).

Bardeau (voil : Bois de tente).

Barrages (voir : tirands travaux).

Beauté des cours deau (voir : rours d'enu).

Beauté des paysages (vuil : Paysages).

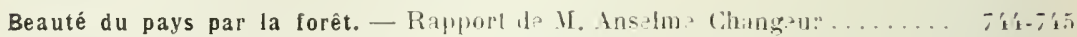
Beauté des routes (voir: Romtess).

Bois bruts (voir : L'tilisation des bois).

Bois colorés artificiellement (voir : Emplois divers du bois).

Bois courbé (voil' : Emplois divers du bris).

Bois équarris. Poutres, charpentes, traverses, - Rapport I. I. G. Rolival.. '

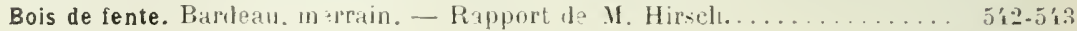

Bois plaqué (voir : Empluis disers du bois).

Bois de sciage (voir: Sciane).

Bois sur pied (La connaissane des). Un nouveau demdromètre. - Communiration de II. Cuif . . . . . . . . . . . . . . . . . . . .

Boites d'allumettes (voir: Allumetles).

\section{C}

Caisses de crédit forestier (voir: Liturues).

Calcium dans la végétation forestière et son action sur les jeunes plants ligneux (La role du). - Communication de II. Chancerel...............

Camping belge (L) . - Communication de U. Dubois. Annexe A........ 883-888

Canalisation (voir : firands trasaux).

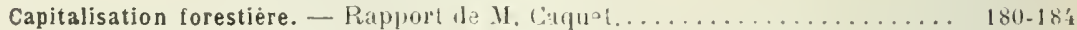

Carbonisation des bois en vases dos. - Rupporl de M. Duchemin . . . . . . . 575-582 Discussion : M.M. II. Barbier, de Larnag?. Poupinel. . . . . . . . . 58:-583 Cerclage (voir : Emplois divers du bois).

Champagne pouilleuse (Plantations dn pin sylvestle dans la). - Communicalion de II. Grand d'Enon ........................... 
Charbons (voir : Ltilisution des bris).

Charpente (voir: Bois équarris).

Châtaigneraie française it sa destruction systématique (laa). Mesure à adopter. - Communication de M. P. Camus........................

Châtaignier (Le). Sa disparition. Moyens d'y remédier. Nécpssité de donner une nouvelle extension à sa culture. - Rapport de M. Mangin. - Commu-

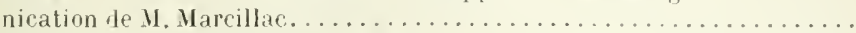
Discussion du rapport de M. Mangin et des communiealions relatives au châtaignier : MM. Camus, Coste, Emery, Garrigoul-Lagrange: Guillot, Hickel, Hirsch, Mangin, Roy, de Sogonzac . . . . . . . .

Châtaignier en Lozere (Le). - Communication de II. Pellequer .

Chauffage (voir : Utilisation des bois).

Chemins forestiers (voir: Tourisme (.Iménagement de forĉts en she du).

Clayonnage (voir: Petils travaux).

Collectivités (voir : Etat (L'tilité de l'acquisition de forêts pat l).

Colonies (voir : Forêts coloniales).

Commission forestière permanente internationale.

Communes (voir: Etat (Utilité de l'acquisition de forêts par l').

Conservation des bois. P'rocédés naturels, procédés artificipls (enduits, injurtions, immersion, ignifugation). - Rapport de XI. Reni Birbie . ...... Discussion : MN. Pellelier de Martres, Poupinel, Pral . . . . . . . . . . .

Cours d'eau (Beauté des), L'arbu sur la mon tagne, r'est l'eau daus la rivière. -

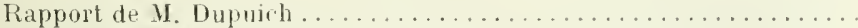

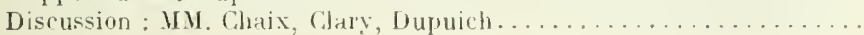

\section{D}

Déboisement (Consideration sur le). - Communicalion dt M. Wurand.......

Déchets du bois (voil : Produits accessoires).

Défrichements. - Communication de M. Barell. Discussion : $\mathbf{H} \mathrm{M}$. Barell, de Bélinay, Cardot, de Clermont, Dubois, Crar. rigou-Lagrange, Naitre, de Peyrelongue, Pluchet ...........

Denđromètre (Un nouvean) (voir : Bris sur pied).

Dérivations (voir : Grands trasaux).

Douane (Droits de). - Riapport de M. Villame ................... Discussion: MM. Bouvet, Delahaye, Grand, Guyot, Hollande, du I'ré de Saint-Maur, Raisin, Sébastien, de Sébille. Siłgrfrifl, Villame

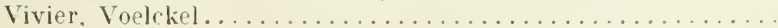

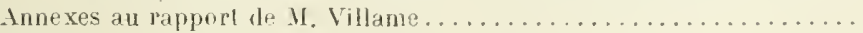

Drainage (voir : 'Petits trataux).

Dunes (Les). Leur fixation. Jemr phoisement. Delense contre la mer. Huvents I'action donnés par la législation actuelle. Mesures lérislatives à prendpe. - Rapport de M. P'ierre Buffault....................... Discussion : МM. Bulfault, Flahault, Jagerschmidt, Leddel . . . . . . 
Danes (Fixation et reboisement des). Correction des torrents et restauration des montagnes, en Espagne. - Communication de M. Ricardo Codor-

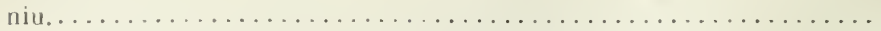

Dunes du littoral belge (Les). - Communication de II. Lippens........ 707

\section{$\mathbf{E}$}

Ecorces, tam nin, extraits tanniques, liège. - Rapport de M. Hirsch......... Discussion : MM. Barbier, Coste, Devèze, Duchemin, Guillot, Hirsch,

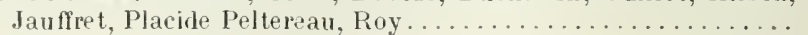

Education forestière du public. - Rapport de I. Géneau............ 730-73't Discussion : MM. d'Almeida, Auscher, Beauquier, Dierckx, Flahault. . 734-735

Education esthétique des peuples. - Comnunication de M. Delville....... 736-742 -Discussion : MH. Auscluer, Delville, Gémeau .............. 742-743

Emplois divers du bois. Fabrication dı papier, laine de bois, sabotage, cerclage, lois courbé, bois plaqué, bois coloré ‘artificiellement. - Rapport de

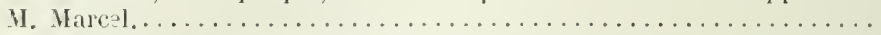
Discussion : MM. II. Barbier, de Bélinay, Cannon, IIollande, Horean, Laval, Madelin, Marcel, Mathien, Pelletier de Martres, Poupinel,

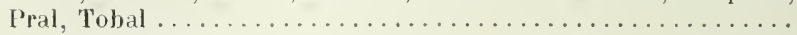

Encouragements et récompenses à lasylviculture (voir : Enseignement sylvicole et sylvo-pastoral).

Enduits (voir: Conservation des bois).

Engrais chimiques en sylviculture (Les). - Rapport de M. Caquet.........

Engrais en pépinière (Influence des). - Communication de M. Cuil ........ Discussion: M.M. Caquet, Chancerel, Cyprien Girerd, Guillot, de Lesseux. (Voir : Culcium).

Enherbement (voir : Pelits travallx).

Enrochement (voir: Pelits travaux).

Enseignement sylvicole et sylvo-pastoral. Propagande en faveur de l'arbre et de l'eau. Saciétés scolaires forestières. Fêtes de l'A rbre. Encouragements et récompenses à la sylviculture. - Papport de M. A. Umbdenstock. . Discussion : MM. de Bazelaire de Lesseux, Cyprien Girerd, Ch. Guyot, Hickel, de Larnage, Lecocq, de Nicolay, Désiré Pector, Roux, de Saguzac, Umbdenstock, Watier................

Espagne (voir: Dunes et Fêle de l'Arbre).

Essences exotiques et naturalisées. - Rapport de M. Hickel............. Discussion : MI. Alberto Gaisser, Cyprien Girerd, Gujllot, Guinier,

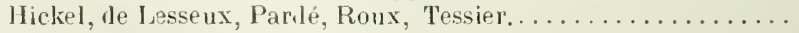

Essence de térébenthine (voir : Fraule de $l$ ).

Etablissements d'utilité publique (voir ci-après : Etul).

Etais de mines (voir : Utilisation des bois).

Etat (Utilité de l'acquisition par l'), les communes et autres collectivités publicues, les établissements ou associations d'utilité publique, de lorêts ou terrains à reboiser. Nesures législatives, administratives et financières à prenilre pour faciliter cette acquisition. - Rapport de

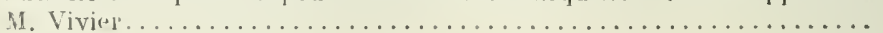


Communicalion de $y$ blonclean sur lit yuestiona . .

Communication de M. G. Marlio sur la question. . . . . . . . . . . 348-349

Discussion : MM. Blondean, Bouvet, Desconlues, Girerd, Tandssesco,

Vivier............................ 349-354

Etat (Rôle forestier de l') (voir : Législation comparée et Intersention de l'Etat dans la gestion des bois particuliers).

Exploitation des bois. - Rapport de M. Rachet ............... 427.432

Extraits tanniques (voir: Ecorces).

Façonnage de lits de torrents (voir : P'etits trasaux).

Fascinage (voir : Petits trasaux).

Fêtes de l'Arbre (voir : Enseignement sylvicole et sylso-pastoral).

Fête de l'Arbre en Espagne (La). - Communication de M. Ricarion Codorniu..

Foret pour plantation en motte (Un nouveau). - Communication de M. Poth.

Forêts coloniales. - Rapport de MII. Chaplain et A. Umbdenstork......... Discussion : MI. Cannon, Capus, Chaplain, Ducamp, Emery, Umbdenstock............................. $1622-166$

Forêts de protection (Etablissement de). - Rapport de II. Ch. Guyot........ Discussion : MII. Amould, Chalamel, Delahaye, Deroye, Descombes, lmbart de la Tour, Ch. Guyot, Marchal, de Nicolay, Vidal,

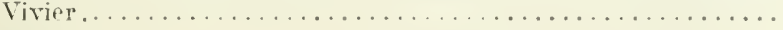

Fraude de l'essence de térébenthine. - Communication de II. Larroquelte.. 584 Discussion : MM. Duchemin, Grand, de Larnage, Larroquette, Poupinel. 584-589

\section{G}

Gemmage (voir : liésines (Industrie des).

Gemmage du pin noir d'Autriche et du pïn sylvestre en Meurlle-pl-Moselle. Communication de M. Cuif...........................

Gestion des bois particuliers (voir: Intcrsention de l'Etat dats la).

Grands travaux forestiers. Barrages. Dérivations, canalisations. Tunnels. Res. tanration des montagnes. Lutte contre les torrents et les avalanches, Rapport de M. Mougin .............................. Discussion : MII. P. Buffault, Mougin, l’uchet, Roth...........

$\left.\begin{array}{l}\text { Ignifugation } \\ \text { Immersion }\end{array}\right\}$ (voir: Consersation des bois).

Impôt forestier. - Rapport de M. Arnould.

Discussion : MII. Amould, Bancherean, Barloier, de Barluat, lBouret,

Chancerel, Coste, Descombes, Gazin, Gouget, Hirsih, de larnage, Larroquette, Leroy, de Nicolay, Pelletier de llartres, Roul-

leau, de Sébille, Tanassesco, Vessiol, Vivier.......... 26.8-303

Communication de M. Pallier sur la question............... 26s 
Incendies. Région des Maures et de l'Estérel. Nécossité de modifier la loi de

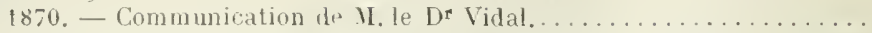
(Projet de dispositions légales et de police pour la conservation des lonis confre les). - Communication de II. A. Rousset............ (Mosures tendant à diminuer les risques l'). - Communication de

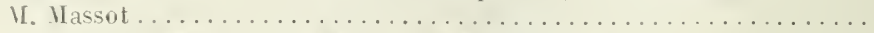
Liscussion : MMF. Locoq, Marcillac, Michaud................. Les incendies en forêts. - Communication de II. Girarı........... (Voir : Plantations ignifuges et Assurances contre l'incendie).

Pages

$206-208$

$17:$

$175-176$

176.177

$177-179$

Injections (voir : Conservation des bois).

Inondations (Lutte contre les) (roir : Alliance de l'-1rbre el de l'Eau).

Intervention de l'Etat dans la gastion des bois particuliers. Législations diverses reglant cette intervention. - Rapports de Mn. Ch. Guyot et

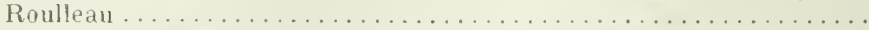

Discussion : MI. Banchereau, Bouvet, Carbonniel. Challamel. Coste. Delahaye. Dascombes, Grand, Guyot, lmbart le la Tour, Jauffret, Laroquette, Margaine, Hoyat, de Vicolas, du Pré de SaintMaur, de tailly, de Sébille, Tanassesco, Vivier............

Italie (Les problèmes forestiers en). (Euvre du Touring-Club italien. - Com-

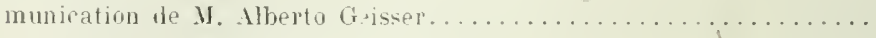

\section{$\mathbf{J}$}

Japon (Plouluits acressoires des forêts llu). - Communication de M. Shozaburo

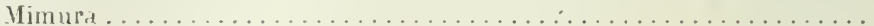

Jardins Alpins. Arboretunis. - Papport le II. Flahault............. 746-750

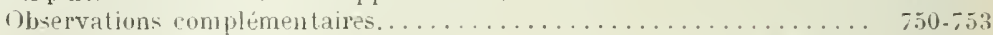
Discussiuns : HH. Aulebraud, Auscher, de Clermont, Flahault, Iaige.

\section{L}

Laine de bois (roir : Emplois divers du bois).

Législation forestière comparée. Lo rôle forastier de l'Etat. Comparaison entre les differents pays. - Rapproft de II. Huffel. . . . . . . . . . . . Discussion : Illl. Banchereau, Delahaye, Descombss, Guyot, Vivier..

Liège (roir : Ecorces).

Ligues, Syndicats et Caisses de crédit forestier. - Rapwort de .I. Margajne... Discussion : HII. Banchereau, Descombes, Gazin, Guyot, de Larnage, Margaine, sintt Elliot, Thivel, Vivier..............

Livrets-guides (Voir : Tourisme (.1mónagement de jorêtś en sue du).

Marécages (vuil': Tourbières)

Menuiserie (voir : Sriuge (Bois de).

Menus bois (voir: ('ilisation des menus bois).

Merrain (velil : Lesis de jente). 
Météorologie agricole (Lid collaburalion des forestiel's all strvice de la). -

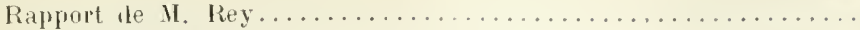
Discussion : MII. Caypet, Cuil, Emery, Lecoq, lieutenant-ivilutel l'and

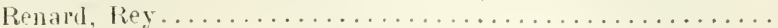

Météorologie comparée, agricole et forestière. - Communication de M. Ciil.

Mûrier (Le). Une disparition qui commence. - Communication de M. Iar-

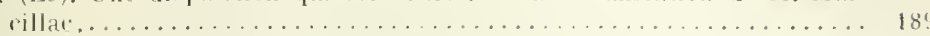

\section{$\mathbf{N}$}

Noyer (Le). Sa disparition. Joyens d'y remédier. Nécessité de donntr mne nouvolle extension à sa culture. - Rapport le M. Mangin . . . . . . . . . . biscussion: MII. Caquet, Cyprien Girerl, Hickel, Mangin, de Siegunzal.

\section{O}

Office forestier international (Utilité puor les syndicats de propricidides at (réer un). Stations de recherches, d'expériences et de renseignemonts. Rapport de II. de Nicolay . . . . . . . . . . . . . . . . . . . Discussion : MII. Cuif, Delahaye, Ch. Gugot, de Henmet, de hamag,

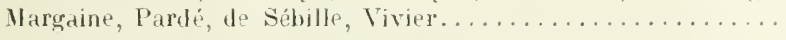

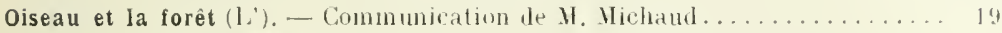
Discussion: MII. Poux, de Fiogonzac, Villatte des Prugries......... 190-193

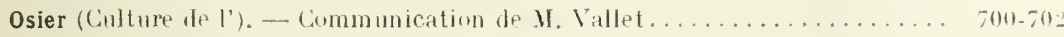

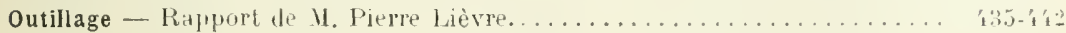

\section{P}

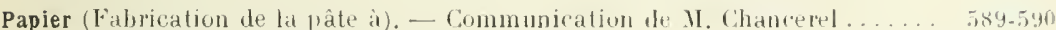
(Voir : Emplois divers du bois).

Pares nationaux. Réserves et séries artistiques. - Rapjort de M. Matley... Discussion : HII. Berr de Turique, Chaix, Clary, de Clermont, Flabault, Maige, J. Morel, Fardé, Sainte-Claire-Deville, Thays, lin de

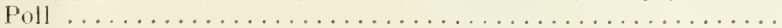

Pares nationaux de France (Societé des) .................... sz

Pâturages (voil : Améliorations pastorales).

Pavé de bois (voir: Scinge (Bois de).

Paysages (Beauté des). Mesures prises dans les difiem ts pays pour leur prutection. Nouvelles mesures à prendre. - Rapjort de M. Beanquicr... Discussion : IIM. Aulebrand, Auscher, Beauquier, Brrr de Turique, Bruant, de Glernont, Colmet-d'Aage, llahault, Gabiat, Ilickel, Maige, lonpux, Je Sognanar, Tribot-laspière, lan de Holl...

Pépinières (voir : Petits lrasaurx).

Petits travaux forestiers. Fascindge, ratyondge, laconndge de lits, enloclllment, drainage, inhorboment, raboisement, somis pl plantations, pssences à employer, graines, pépinières. - Rapport du MII. Burnard et Guinier.................................. 
Observations complènentailé. . . . . . . . . . . . . . . . 646-65-

Discussion: MI. re Bélinay, Cardot, Guinier, Lerldet, Lemaitre, Roth, Tessuel ............................. 6...67

Peuplier (roir : Taillis).

Pin noir d'Aurtiche (voil' : Gemmage du).

Pin sylvestre (voir : Gemmage et Champagne pauilleuse).

Plans de forêts (roir : Tourisme (tménagement de forêts en vue du).

Plantations ignifuges. -- Communication de M. Majehal.............. Discussion : MM. Descombes, Emery, Marchal, le IIontmorancy-

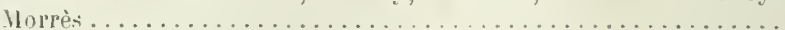

Plaques (voir : Tourisme (Aménagement de forêts ên sue du).

Points de vue (Vuir: Tourisme (Aménagement de forêts en cue du).

Poteaux (voir : Tourisme (Aménagement de forêts en vue du.).

Poteaux télégraphiques. - Rapport de M. Pelletier de Martres........... Discussion : M. Arlus, H. Barbier, Brion, Marlelin, Pelletier de Uartres, Poupinel, Pral

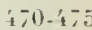
$: \div 5-: 80$

Poutres (voir : Bois équarris).

Production forestière dans les livers pays du globe. - Rapport de M. Madelin. 369-38: Discussion : M. Ch. Guyot, Marlelin, Viviel. . . . . . . . . . . 383-38.

Produits accessoires, déchots de bois, utilisation des sciures. - Rapport de II. Bocquet .............................. Discussion : MII. Bucquet, Colin, Horeau, Juilliard, Laval, Poupinel. .

Propagande en faveur de l'Arbre et de l'Eau (voir : Enseignement sylvieole et syloo-prstoral.

Q

Question sylvo-pastorale (la). - Communicalion de II, le conte de Rorquette-

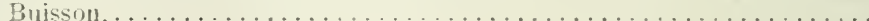

$666-6=2$

\section{$\mathbf{R}$}

Reboisement (voil : Petits travmux).

Facultés de reboisement des divers faciès gé logiques. - Communication de II. Larue . . . . . . . . . . . . . . . . . . . . . . . Discussion : MIM. Bemaru, Caquet, Cardot, Larue, Maitre.........

$662-665$ $665-666$

Répartition des végétaux ligneux en France. - Papport de M. Guinier..... $7 x-80$

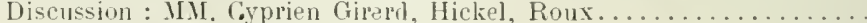

Réserves artistiques (voir : Pares nationaux).

Résines (Industrie des). - Rapport de M. Duchemin ............. 571-57'

Restauration des montagnes (voir : Grands tracaux).

Robinier (roil : Acaciu)

Routes (Plantations des). - Rapunel de II. Gustave Irtu ..........

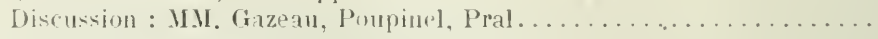

Routes (Bo:uté d’s). Plantations lo long des routes. lazurs avantaues. Choix

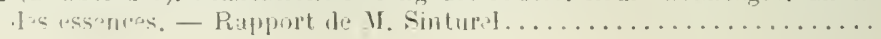


Discussion : Mil. Auscher, Hahault, Cabiat, Hermans, Lorienx, Maige. de Sagonzac, Sinturel, de Villemereuil............. $761-771$

Routes forestières (voir : Tourisme. (Aménagement de forîts on sur du).

Sabotage (voir : Emplois divers d" bois).

Sciage (Bois de). Outillage, débit, menuiserie, pavé. - Rapport ıe U. Puteanx. 525-5ł2

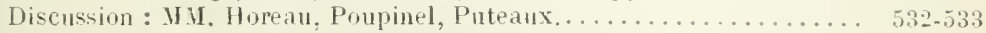

Sciures (Utilisation lles) (voir : Produits accessoires).

Sentiers forestiers (voir : Tourisme (Aménagement de forêts en vue du).

Séries artistiques (voir : Parcs nationaux).

Signes indicateurs (voir : Tourisme (.tménagement de forêts en v'ue du).

Sociétés scolaires forestières (voir : Enseignement sylvicole et sylvo-pastoral).

Stations de recherches, I'expériences et de renseignements voir : Office forpstier international).

Stations de recherches forestières. - Communication de II. (uif........... 366 -368 Discussion : MII. Guyot et Vivier................... 36.

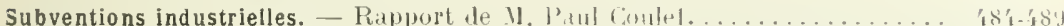

Syndicats forestiers (voir : Liglues).

\section{$\mathbf{T}$}

Tables d'orientation (voir: Tourisme (Aménagement de fortsts en vue du).

Taillis à faible rendement situés en plaine ou en montagne. Imélioration pas l'introduction de résineux. — Rapport de $\mathrm{V}$. Schaeffer...........

Discussion : MII. Caquet, Cuil, schaeffer..................

Taillis et taillis sous futaie. Allongement des revolutions. Diminution de la proportion las bois de patite dimension. Conversion des taillis pt taillis sous futaie en futaie. - Rapport de $\mathbf{H}$. Demorlaine............. Communication de M. Cnif sur la question, et discussion : MII. Carpupt. Cuif, de Larnagre, le lesseux, Iaitre, Mangiı.............

Taillis (Introluction du peuplier dans les). - Commanication il M. Ravel-

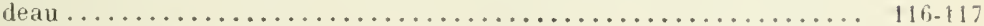
Discussion : MM. Baurloux, Barbpy, Ir Sognnzar............ 117-118

Tanin (voir : Ecorces).

Terres incultes (voir : Campine belye).

Torrents (voir : Grands travaux, Dunes, Correction des torrents).

Tourbières. Marécages. leul' assèchement et lem mise en valeul' par lan reboi. sement. Essences id amployer. Mode de plantation. - Rapport de

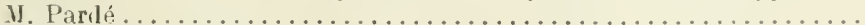

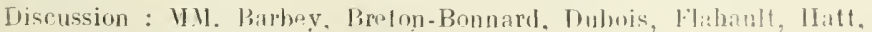

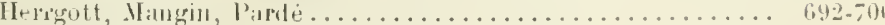

Touring-Club italien (voil : Ilalie (les problimes forestiers ell) 
Tourisme (Aménageneut de forêts en vue (lı). Création. Anélioration des l'ultes et chemins. Sentiers forestiers. - Rapport de M. Thiollier..... Disrussion : MI. Chaix, Cochon, Coulon, Dupuirh, Gabiat, d'Orlyé,

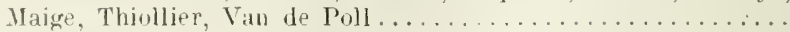
Plaques, poteaux, signes indicateurs, abris, banes, points de vue, lables d'orientation, etc. Livrets-guides on plans de forêts à l'usage des touristes. Catalogues des arbres remaryuahles, - Rapport de II. Gouilly. Discussion : MM. Chaix, Clary, Cochon, Coulon, Dumesnil, Dupuich, Gabiat, Cruilly, Lorieux, Maige, d'Orlyé, Thiollier, Van de Poll.

Pages $801-803$ $803-807$ $807-811$ $811-816$

Transhumance. - Communication de M. Maîlre... . (i) 72.673 Discussion : MII. de Bélinay, Cardot, Larue . . . . . . . . . . . . . . 673-674 (Voir : Améliorations pastorales).

Transport des bois. - Rapport de M. Villame.................... Discussion : MM. Hollande, du Pré de Saint-Maur, Raisin, Villanne,

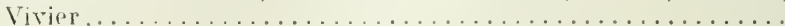

Transport des produits forestiers. Anmexe E. - Communicalion de M. P.

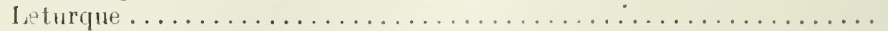

Traverses (voil : Bois équarris).

Tunnels (roir : Grands trasaux).

\section{$\mathbf{U}$}

Utilisation des bois. Bois bruts. "haullage, charloon, étais de mines. - Ray. port de M. Edouard Riziel........................ Discussion : M. Gaquel, Duchemin, Poupinel, Tortel...........

Utilisation des menus bois par les nouveaux procédés chimiques et mécaniques. — Rapport de M. Ciaquel......................... Diseusion : MM. Caquel, Poupinel, Raisin, Sebastien, de Segonzar...

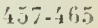
$1,5-466$

\section{V}

Victoria (Ressoures forestieres de l'Etal de). Annexe D. - Communication de Ir Peler Mr Bride.......................................

\section{Vœux adoptés par le Congrès}

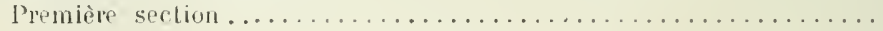

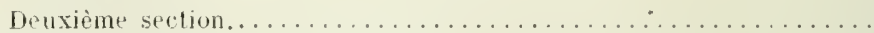

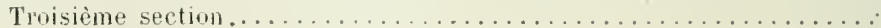

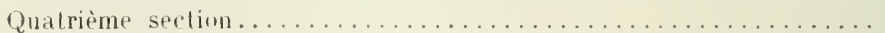

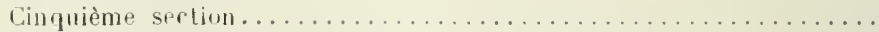

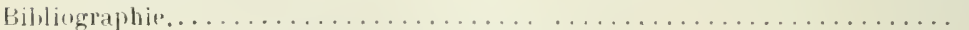

852.857 857.853 $863-868$ $868-871$ $871-874$ $931-9: 8$

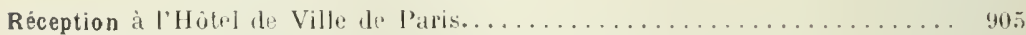

Discours de M. Chatssaigne-Goyon. P'résident du Conseil municipal. . 905-906

Discours de M. Aubamel, Serrétaire général de la l'rélecture de la Seine............................. $90^{-}$ 
Discours de II. Lanrent, Secrétaire général de la Préferture de Pulice.

Discours de II. Billari, Vice-président du Conseil géníral. . . . . . . .

Discours de .. befert, Président du Congrès .............. 908-90y

Discour's de II. tw Sébille, Représentant de Betgique.......... 969-910)

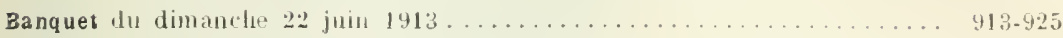

Discours de M. Ballil, Président du Touring-Club de Franc....... 91't

Discours de M. Defert, Président dus Congrè. . . . . . . . . . . . 91' 916

Discours de M. Berre de Turique, Inspecteur gimeral drs Monuments

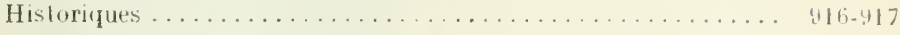

Discours de M. Le Dr Auguste Nemomrs, Ministre de la Riepublique de

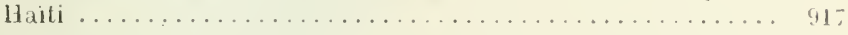

Discours de M. Chalamel, député, Président du gronpe fortestier de la Cliambre............................ 918

Discours de M. le baron de Hennel, Détégué permanent du Ministère autrichien de l'Agriculture . . . . . . . . . . . . . . .

Discours de M. Bouvet, Président de la Societé forestière de Francle-

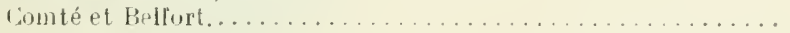

Discours de M. de Sébille, Représentant de Belgique, memlore du Conseil supérieur des lorêts du royaume de Belgiqum.........

Discours do W. de Vicolay, Président du Syndicat des propriélaires iorestiers the la Sarth .................... 92

Discours de M. le Litrnage, Président du Symalial forestier de

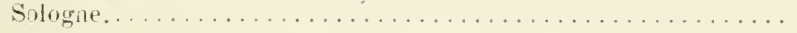

Discours de M. Changeur, Secrétaire général de lat Succiété pour lit protection des paysages de France................. 923

Discours de M. Tanassesco, Délégué de la Roumanic.......... . .23.42't

Discours de H. Kramp, Délégué du Danemark.............. y2't

Discours dr I. Dabat, Directenr général des Eaux ot Forêts..... 92:-925

Excursion dans la forêt domaniale de tyons................. \$11-912

Excursion à Grenoble et atux Alpes Damphinoises ( 11222 an 29 juin 1913) . . 92:

Talble des Matières. . . . . . . . . . . . . . . . . . . . . 

P’Ras, - Imp L. Pocur, 52, me du châtean. - 1518-13

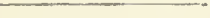






UNIVERSITY OF BRITISH COLUMBIA LIGRARY

DATE DUE

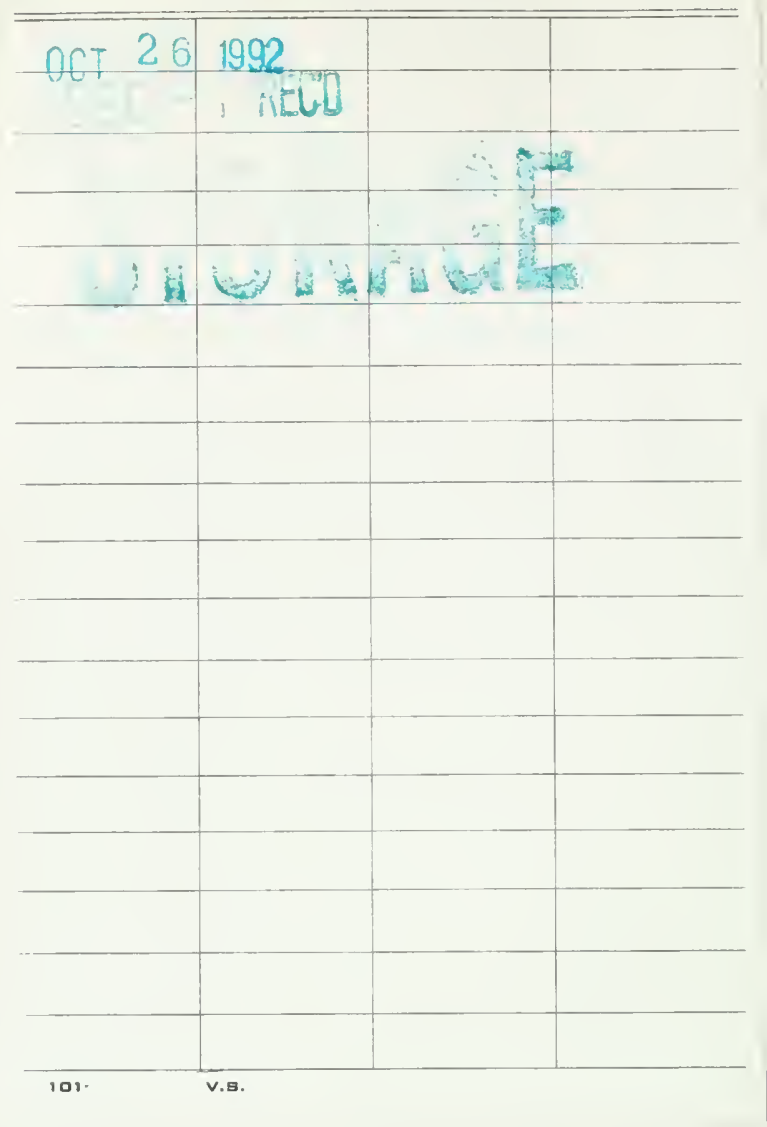




\section{LIBRARY}

C 68

191

SD118 C68 1913

Longrès forestier international, Paris, 1913.

Library of The University of British Columbia

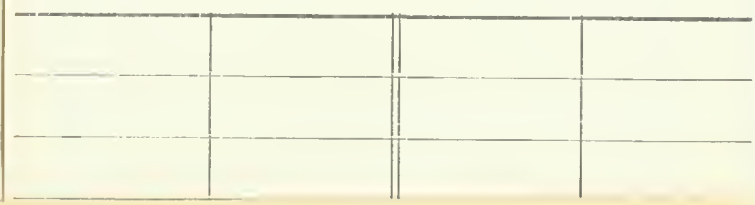



(1)

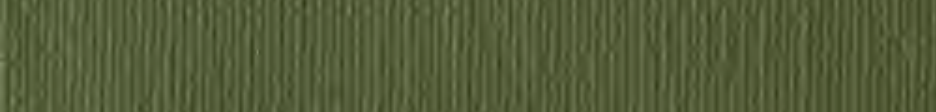

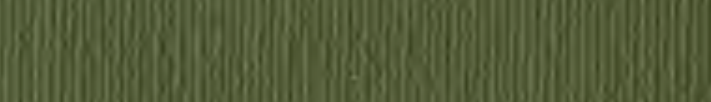

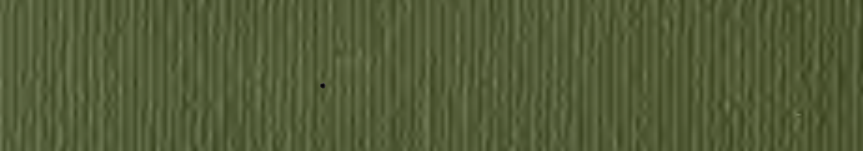

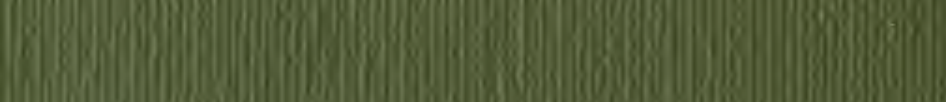

(1)

(3)

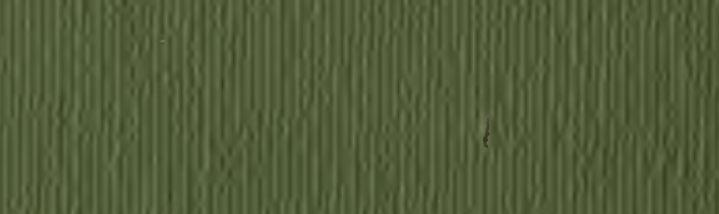

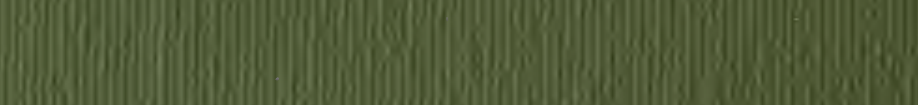

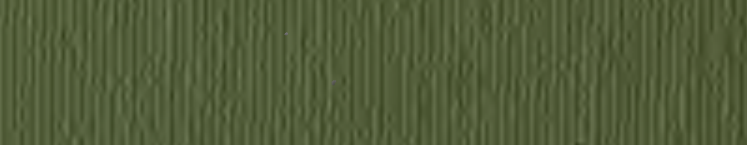

In.

(6)

s, 